Final Report

FHWA/IN/JTRP-2004/24

\title{
JOINTLESS AND SMOOTHER BRIDGES: BEHAVIOR AND DESIGN OF PILES
}

\author{
By \\ Robert J. Frosch \\ Principal Investigator \\ Professor of Civil Engineering \\ and \\ Voraniti Chovichien \\ Katrinna Durbin \\ David Fedroff \\ Graduate Research Assistants \\ School of Civil Engineering \\ Purdue University \\ Joint Transportation Research Program \\ Project No. C-36-56XX \\ File No. 7-4-49 \\ SPR-2393 \\ Conducted in Cooperation with the \\ Indiana Department of Transportation \\ and the Federal Highway Administration
}

The contents of this report reflect the views of the authors, who are responsible for the facts and the accuracy of the data presented herein. The contents do not necessarily reflect the official views or policies of the Indiana Department of Transportation or the Federal Highway Administration at the time of Publication. This report does not constitute a standard, specification, or regulation.

\author{
Purdue University \\ West Lafayette, IN 47907 \\ January 2006
}




\section{TECHNICAL Summary}

INDOT Research

Technology Transfer and Project Implementation Information

TRB Subject Code: 25-1 Bridges

Publication No.: FHWA/IN/JTRP-2004/24

January 2006

Final Report

\section{Jointless and Smoother Bridges: Behavior and Design of Piles}

\section{Introduction}

Integral abutment bridges have been used in the United States for decades. These structures eliminate expensive expansion joints by utilizing the end bent to accommodate the total thermal movement of the bridge. Due to their complexity of response, these bridges are designed based upon experience, and a rational design specification has not been developed. Furthermore, the interaction of the abutment, pile, and soil remains uncertain. A better understanding regarding the behavior of this system is needed. The objective of this research is to evaluate the behavior of the integral abutment-pile system and evaluate any limitations of its use. A goal of the research is to develop minimum design and detailing recommendations. Two phases were conducted: a field investigation and an experimental investigation. In both phases, analytical and parametric studies were performed to further understand the behavior of this structural system. Based on the research performed here, design recommendations are provided regarding the design of the pile system as well as limitations on the overall length for this structural type.

\section{Findings}

Based on the results of the field, experimental, and analytical studies, the following recommendations are provided. In general, these recommendations are directed towards the pile behavior.

1. Piles sizes should be selected to provide adequate axial capacity while minimizing their bending resistance along the longitudinal axis of the bridge. This selection provides for maximum ductility response while minimizing stresses at the abutment-pile connection.

2. Piles should be oriented about their weak axis. This orientation provides for maximum ductility response while minimizing stresses at the abutment-pile connection.

3. Axial load should be limited to $0.25 f_{y} A_{s}$ for $H$ piles and $0.25 f_{y} A_{s}+0.4 f_{c}^{\prime} A_{c}$ for CFT piles. This axial load level which is currently stipulated by AASHTO based on pile driving stresses provides adequate displacement response and ductility. Higher stress levels demonstrate a lower ductility capacity.
4. The minimum embedment length of 15 in. often specified for pile embedment should be increased and/or confinement steel should be provided. Additional research in this regard is needed to quantify the effect, but it is recommended that a minimum of $24 \mathrm{in}$. be provided at this time. Significant deterioration of the pile-abutment connection occurred for the larger pile sections that can limit the response and behavior of the pile-abutment system.

5. A minimum pile length below ground is required to prevent displacement at the pile base. The minimum length depends on pile size as well as soil type and is provided as follows:

Table 8.1: Minimum Pile Length

\begin{tabular}{|l|c|c|}
\hline \multirow{2}{*}{ Pile Size } & \multicolumn{2}{|c|}{ Minimum Depth (ft) } \\
\cline { 2 - 3 } & Clay & Sand \\
\hline HP10 & 30 & 25 \\
\hline HP12 & 35 & 25 \\
\hline HP14 & 40 & 30 \\
\hline CFT14 & 50 & 35 \\
\hline
\end{tabular}


6. Bridges designed considering the above recommendations can be constructed up to a maximum total length of $500 \mathrm{ft}$ for both steel and concrete superstructures. This recommendation is based on consideration of structures with skews less than 30 degrees. The length limit was selected to limit local pile buckling and provide for a bridge life of 100 years. Lengths longer than this limit are possible if the bridge deck casting which provides continuity for the integral bridge is conducted at temperatures less than $60^{\circ}$ $\mathrm{F}$. For temperatures in the range of $40-50^{\circ} \mathrm{F}$, the bridge length can be extended to $770 \mathrm{ft}$. Casting at moderate temperatures should be encouraged.

\section{Implementation}

The recommendations provided through this study can be easily implemented to improve the performance of integral abutment bridges and extend the benefits of integral and jointless design to a larger number of structures. Implementation should proceed primarily through the INDOT Design Division through changes in design requirements provided in the design manual.

There are many benefits from the use of jointless, integral bridges. The elimination of joints and bearings reduces maintenance costs as well as results in a smoother pavement. Smoother bridges result in a reduction in live load impact, improved riding quality, and reduced snowplow damage. Experience in Indiana as well as other states has demonstrated that integral bridges result in an increased service life and a substantial savings to INDOT in construction as well as lifecycle costs. This improved performance and resulting cost savings can now be extended to a larger number of structures.

\section{Contacts}

For more information:

Prof. Robert J. Frosch

Principal Investigator

Purdue University School of Civil Engineering

West Lafayette IN 47907

Phone: (765) 494-5904

Fax: (765) 496-1105

E-mail: frosch@ecn.purdue.edu

\author{
Indiana Department of Transportation \\ Division of Research \\ 1205 Montgomery Street \\ P.O. Box 2279 \\ West Lafayette, IN 47906 \\ Phone: (765) 463-1521 \\ Fax: (765) 497-1665
}

\section{Purdue University}

Joint Transportation Research Program

School of Civil Engineering

West Lafayette, IN 47907-1284

Phone: (765) 494-9310

Fax: (765) 496-7996

E-mail: jtrp@ecn.purdue.edu

http://www.purdue.edu/jtrp 


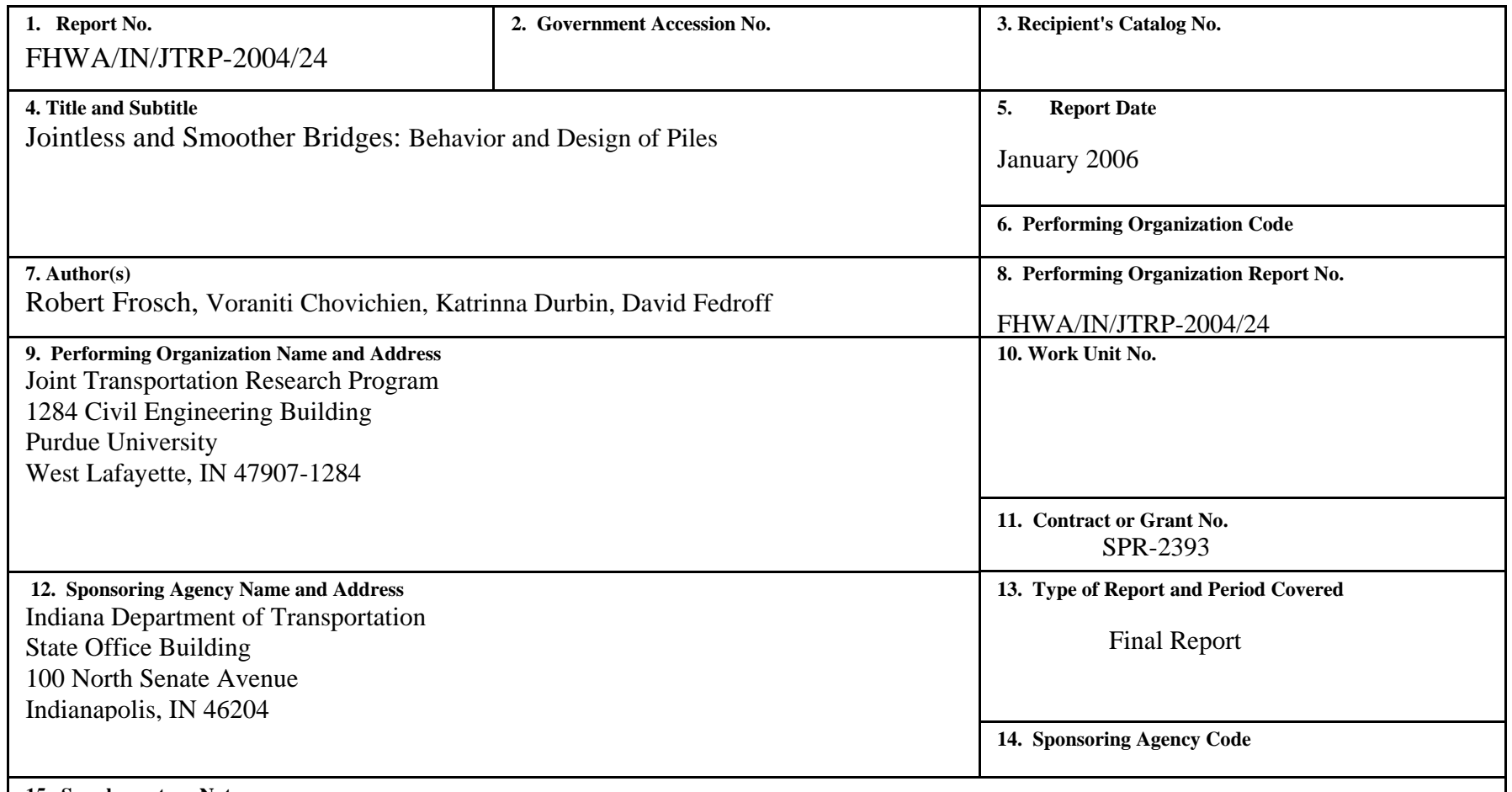

15. Supplementary Notes

Prepared in cooperation with the Indiana Department of Transportation and Federal Highway Administration.

\section{Abstract}

Integral abutment bridges have been used in the United States for decades. By eliminating expensive expansion joints, the piles supporting the end bent accommodate the total thermal movement of the bridge. Currently, integral bridges are designed based upon experience, and a rational design specification has not been developed. Furthermore, the interaction of the abutment, pile, and soil remains uncertain. A better understanding regarding the behavior of this system is needed. The objective of this research is to evaluate the behavior of the integral abutment-pile system and evaluate any limitations of its use. To achieve this objective, two phases of research were conducted. The first phase was a field study that investigated the in-service pile behavior of four integral abutment bridges. The second phase was an experimental study that was used to evaluate the capability of piles typically used in integral abutment bridges. Nine low-cycle, large amplitude lateral displacement pile tests were conducted. Throughout both phases, analytical investigations were also conducted. To develop simplified modeling techniques that sufficiently account for soil-pile interaction, the piles supporting abutments were analytically modeled and calibrated based on the field and experimental results. A parametric study was also performed with variables including pile type, pile orientation, axial load, pile length, and soil type. The results of these phases were evaluated and design recommendations were developed based on these results. Overall, the design recommendations provide for an extension in the length limits often used for integral bridges. The extension of these limits can result in a reduction in bridge construction and maintenance costs for a large number of structures that cannot currently be built using this structural system.

17. Key Words
Bridge, Bridge Design, Integral Abutment, Jointless, Piles

19. Security Classif. (of this report)

\footnotetext{
Unclassified
}

\section{Distribution Statement}

No restrictions. This document is available to the public through the National Technical Information Service, Springfield, VA 22161

20. Security Classif. (of this page)
Unclassified

21. No. of Pages
534




\section{ACKNOWLEDGEMENTS}

This work was supported by the Joint Transportation Research Program (JTRP) administered by the Indiana Department of Transportation (INDOT) and Purdue University through contract SPR-2393. The support of the Indiana Department of Transportation (INDOT) and the Federal Highway Administration (FHWA) are thankfully recognized. The authors would like to thank to Dr. Tommy Nantung from the INDOT Division of Research for his support throughout the project. Thanks are extended to members of the Study Advisory Committee for their participation and helpful comments throughout the project. These members include Naveed Burki, Khalil Dughaish, Jaffar Golkhajeh, Keith Hoernshemeyer, Jim Karr, Randy Strain, and Mike Wenning. Finally, thanks are extended to Stephen Weintraut, Scott Newbolds, Jerry D. Ritchie, and Dan Clark for providing information and thoughtful comments throughout this project. 


\section{TABLE OF CONTENTS}

Page

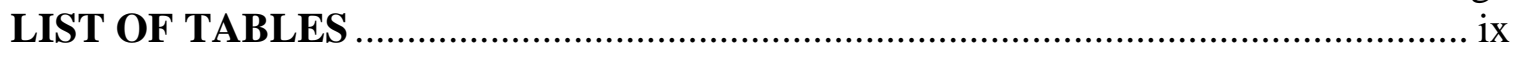

LIST OF FIGURES ……............................................................................. xii

CHAPTER 1: INTRODUCTION AND LITERATURE REVIEW .............................

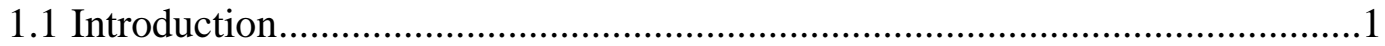

1.2 Overview of Integral Abutment Bridges ..........................................................2

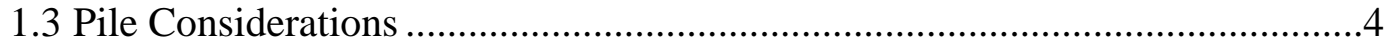

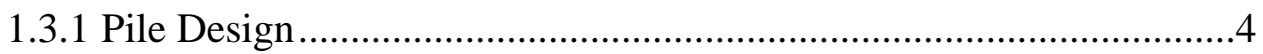

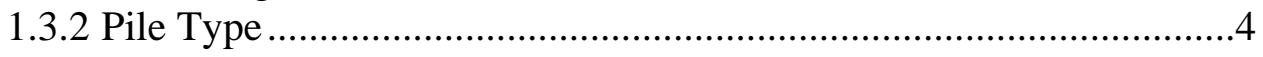

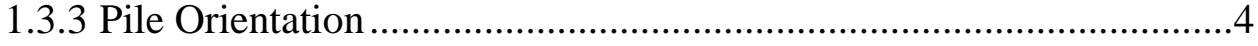

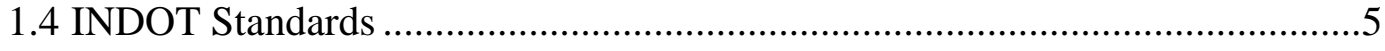

1.5 Objectives and Scope...................................................................................

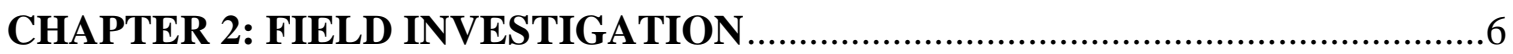

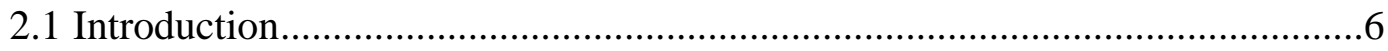

2.2 SR249 over US12 Bridge ................................................................................

2.2.1 End Bent/Pile Design.......................................................................9

2.2.1.1 End Bent ............................................................................

2.2.1.2 Pile Design ...........................................................................

2.2.1.3 Pile Borings........................................................................11

2.2.2 Structural Materials.........................................................................15

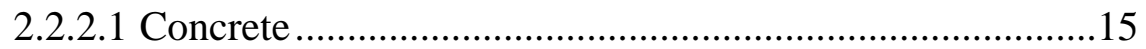

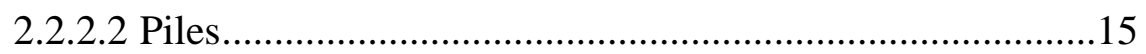

2.2.3 Instrumentation Design...................................................................15

2.2.3.1 Bent Instrumentation......................................................15

2.2.3.2 Pile Instrumentation.....................................................16

2.2.3.3 Pier Instrumentation......................................................17

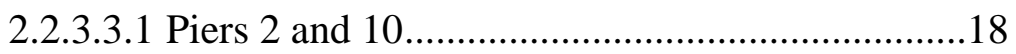

2.2.3.3.2 Piers 3, 4, and 5................................................19

2.2.4 Data Acquisition ...........................................................................21

2.2.4.1 Problems ......................................................................21

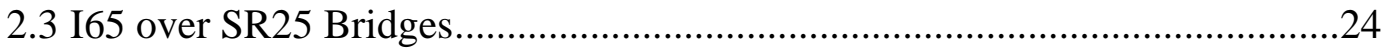

2.3.1 End Bent/Pile Design........................................................................25

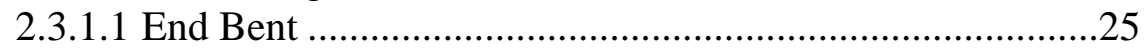

2.3.1.2 Pile Design .......................................................................26

2.3.1.3 Soil Borings ........................................................................2.

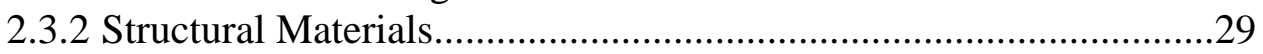

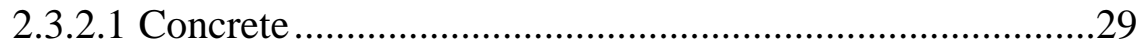

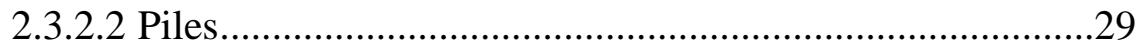


Page

2.3.3 Instrumentation Design.......................................................................29

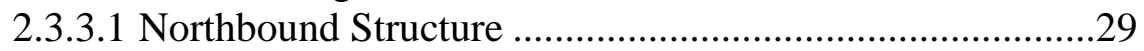

2.3.3.2 Southbound Structure .......................................................31

2.3.4 Data Acquisition ............................................................................34

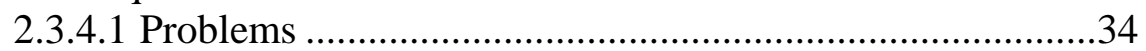

2.4 SR18 over Mississinewa River Bridge ..............................................................34

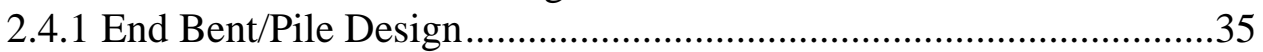

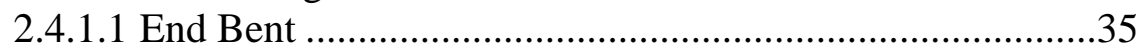

2.4.1.2 Pile Design ...........................................................................37

2.4.1.3 Soil Borings .........................................................................

2.4.2 Structural Materials.........................................................................40

2.4.2.1 Concrete ...................................................................... 40

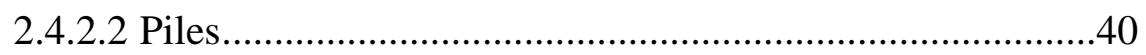

2.4.3 Instrumentation Design......................................................................40

2.4.3.1 Bent Instrumentation..........................................................40

2.4.3.2 Pile Instrumentation...........................................................43

2.4.4 Data Acquisition ..............................................................................46

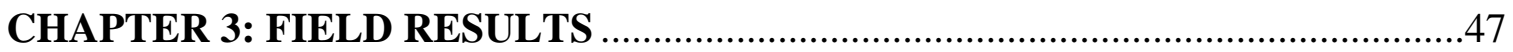

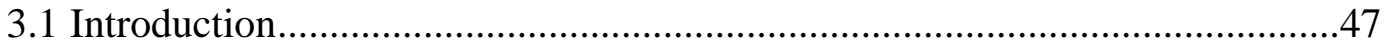

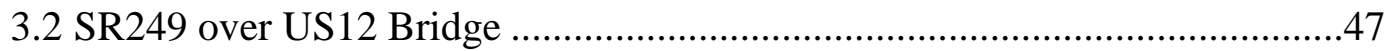

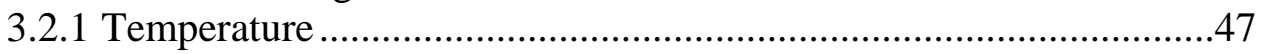

3.2.2 Rotations of the Abutment ...............................................................48

3.2.3 Relative Displacement ....................................................................51

3.2.4 Pier Strains..............................................................................54

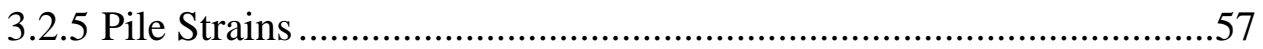

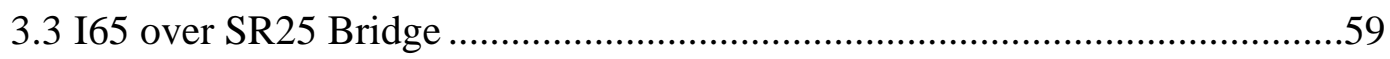

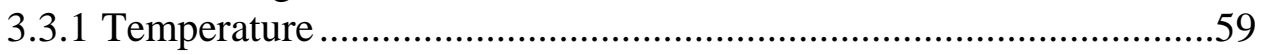

3.3.2 Abutment Movement .....................................................................60

3.3.3 Pile Strains .....................................................................................63

3.4 SR18 over Mississinewa River Bridge .........................................................66

3.4.1 Temperature ................................................................................66

3.4.2 Rotations of the Abutment ...............................................................66

3.4.3 Abutment Movement .....................................................................67

3.4.4 Pile Strains ...................................................................................

3.5 Analysis of End Bent and Pile Movement....................................................76

3.5.1 SR249 over US12 Bridge .................................................................76

3.5.1.1 Pier Cross Section ..............................................................76

3.5.1.2 Pier Movement...................................................................78

3.5.1.3 Abutment Movement .........................................................79

3.5.2 I65 over SR25 Bridge ......................................................................

3.5.3 SR18 over Mississinewa River Bridge ...............................................85

3.5.3.1 Stresses and Strains along the Pile Length .........................86

3.5.3.2 Deflection of Pile 6 6.........................................................90 
CHAPTER 4: ANLYSIS OF FIELD RESULTS

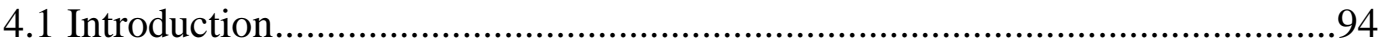

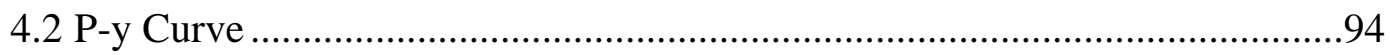

4.2.1 Clay Model ..................................................................................96

4.2.2 Sand Model ...................................................................................99

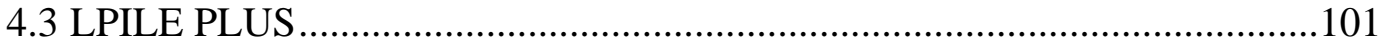

4.3.1 Soil Models (LPILE PLUS) ..........................................................102

4.3.1.1 Clay Model ....................................................................102

4.3.1.2 Sand Model ....................................................................102

4.3.2 Equivalent Diameter .....................................................................102

4.3.3 Transformed Section.....................................................................103

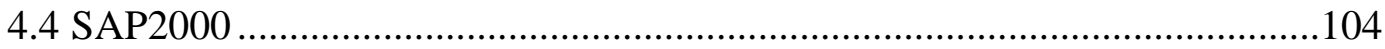

4.4.1 Elastic Soil Spring Method.............................................................104

4.4.2 Soil Models (SAP2000) ...................................................................106

4.4.2.1 Clay Model .........................................................................106

4.4.2.2 Sand Model .................................................................106

4.4.3 Transformed Section.......................................................................106

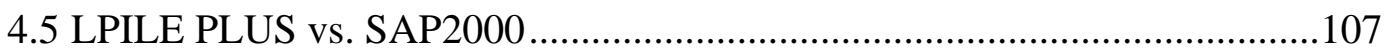

4.6 Analytical Bridge Models .............................................................................107

4.6.1 SR249 over US12 Bridge .............................................................107

4.6.1.1 Pile Model..............................................................107

4.6.1.2 Soil Model......................................................................110

4.6.1.3 Results..........................................................................111

4.6.1.3.1 Deflected Shapes...............................................111

4.6.1.3.2 Moment vs. Depth ............................................112

4.6.2 I65 over SR25 Bridges............................................................116

4.6.2.1 Pile Model.............................................................116

4.6.2.2 Soil Model..................................................................118

4.6.2.3 Results.............................................................................119

4.6.2.3.1 Deflected Shapes...............................................119

4.6.2.3.2 Moment vs. Depth ...............................................121

4.6.3 SR18 over Mississinewa River Bridge ...........................................123

4.6.3.1 Pile Model.....................................................................123

4.6.3.2 Soil Model.................................................................124

4.6.3.3 Results........................................................................125

4.6.3.3.1 Deflected Shapes................................................125

4.6.3.3.2 Moment vs. Depth ...........................................127

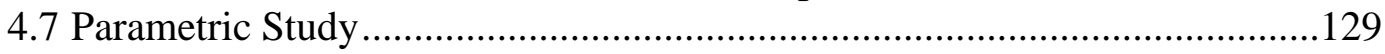

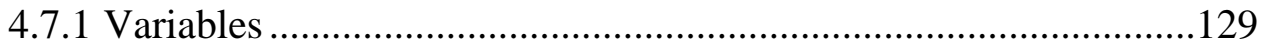

4.7.1.1 Lateral Displacement ........................................................129

4.7.1.2 Axial Load ..............................................................130

4.7.1.3 Pile Length.....................................................................130

4.7.1.4 Pile Type ………………………………....................130

4.7.1.5 Pile Orientation .................................................................131 
Page

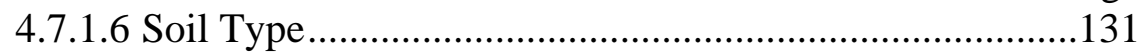

4.7.2 Results of Parametric Study..........................................................132

4.7.2.1 Effect of Axial Load .....................................................132

4.7.2.2 Effect of Pile Length..........................................................134

4.7.2.3 Depth of Inflection Point .................................................137

4.7.2.4 The Final Zero Deflection and Zero Moment Depths .....139

4.8 Conclusion

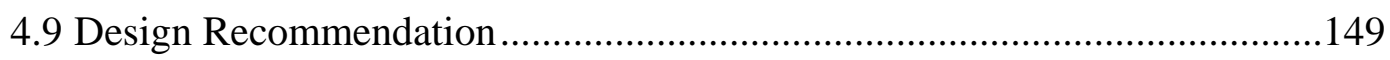

CHAPTER 5: EXPERIMENTAL INVESTIGATION ……….............................150

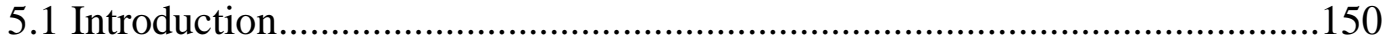

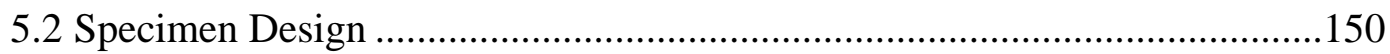

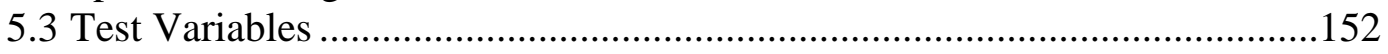

5.3.1 Pile Type ………………………………………...................152

5.3.2 Pile Orientation ............................................................................153

5.3.3 Axial Load Level ........................................................................153

5.3.4 Embedment Length........................................................................154

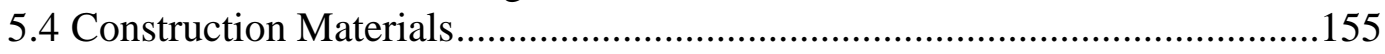

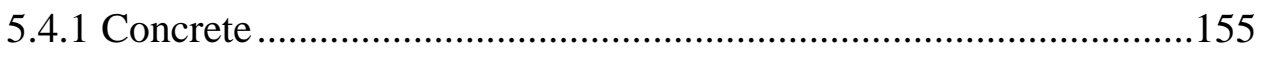

5.4.2 Reinforcing Steel .....................................................................158

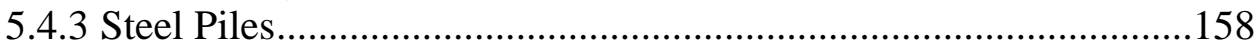

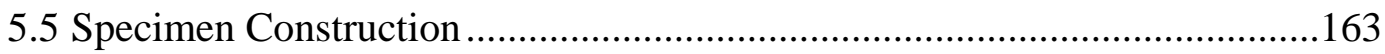

5.5.1 Specimen Support Block …………………………........................163

5.5.2 Concrete Abutment Construction ………………………….............165

5.5.3 Steel Pile-Abutment Connection ....................................................169

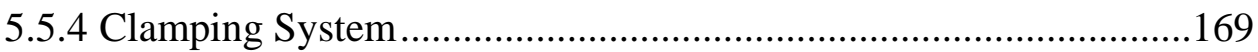

5.5.5 Self-Equilibrating Load System.....................................................171

5.5.6 Casting and Curing ......................................................................173

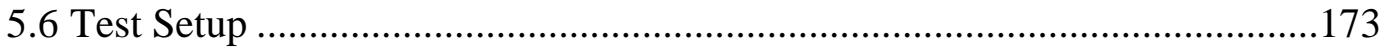

5.7 Test Instrumentation .............................................................................175

5.7.1 Displacement .............................................................................175

5.7.2 Strain Gages..........................................................................176

5.7.3 Test Procedure ..........................................................................178

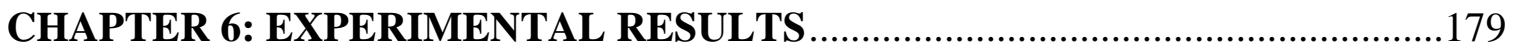

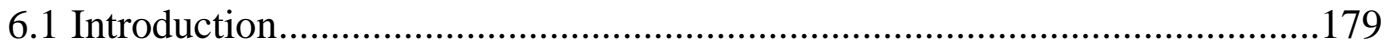

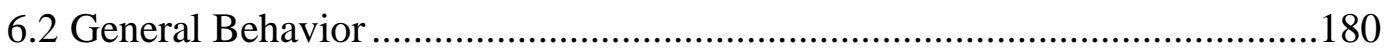

6.3 Experimental Results ..................................................................................197

6.3.1 Specimen 1 (HP8x36, Weak Axis, 9 ksi) .......................................197

6.3.2 Specimen 2 (HP8x36, Strong Axis, 9 ksi) ......................................201

6.3.3 Specimen 3 (HP8x36, 45 Axis, 9 ksi) ..........................................206

6.3.4 Specimen 4 (HP8x36, Weak Axis, 18 ksi) …………………..........212

6.3.5 Specimen 5 (HP10x42, Weak Axis, 9 ksi) .....................................215

6.3.6 Specimen 6 (HP12x53, Weak Axis, 9 ksi) …………………….....217 


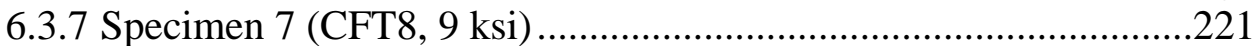

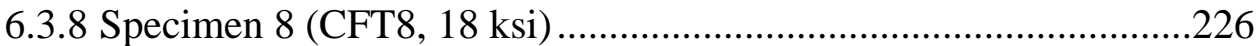

6.3.9 Specimen 9 (CFT10, 9 ksi) .....................................................231

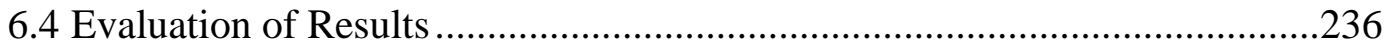

6.4.1 Effect of Pile Size …………………………………...................236

6.4.2 Effect of Axial Load ...................................................................240

6.4.3 Effect of Pile Orientation............................................................245

6.5 Conclusions from Experimental Results.....................................................247

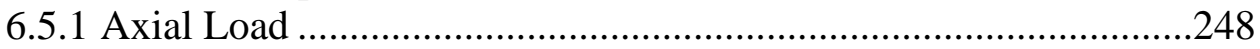

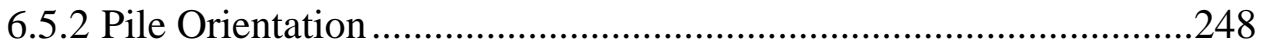

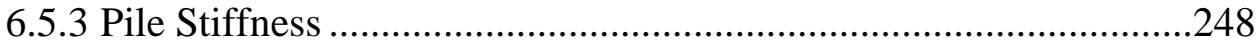

6.5.4 Abutment-Pile Connection ............................................................249

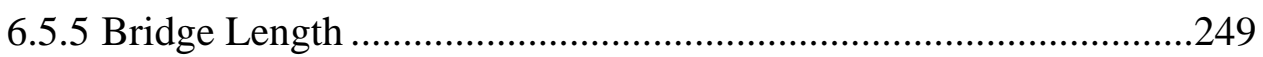

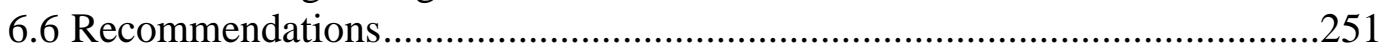

Page

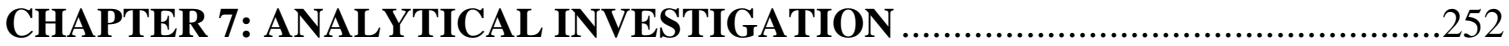

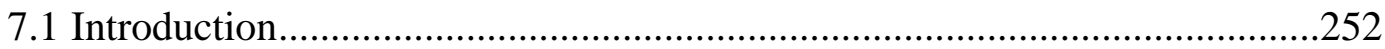

7.2 Material Modeling of Steel Strength and Failure Criteria ...............................252

7.2.1 Steel Model for H Piles.....................................................................253

7.2.2 Steel Model for Steel Shell of CFT Piles..........................................254

7.3 Material Modeling of Concrete Strength and Failure Criteria.........................258

7.3.1 Modified Hognestad Model (Hognestad, 1951) ..............................258

7.3.2 Kent and Park Model (Kent and Park, 1971) ..................................260

7.3.3 Modified Mander et al. Model (Elremaily and Azizinamini,

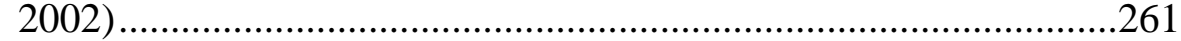

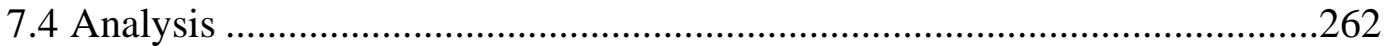

7.4.1 Moment-Curvature Analysis..........................................................262

7.4.2 Load-Deflection Relationship .....................................................264

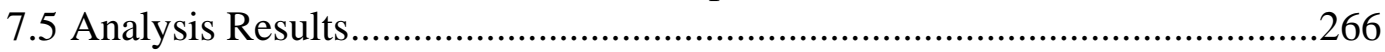

7.5.1 H Piles .....................................................................................266

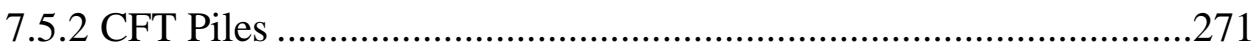

7.5.3 Ductility Ratio............................................................................274

7.5.3.1 Effect of Pile Size on Ductility Ratio ...............................2275

7.5.3.2 Effect of Axial Load Level on Ductility Ratio .................276

7.5.3.3 Effect of Pile Orientation on Ductility Ratio ....................276

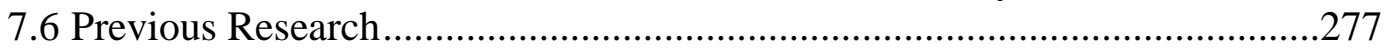

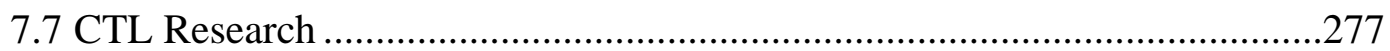

7.7.1 Test Setup (CTL Specimen) ..........................................................2.278

7.7.2 Experimental Results (CTL Specimen) ……………………….......279

7.7.3 Pile Model (CTL Specimen)...........................................................279

7.7.4 Analytical Results (CTL Specimen) ...............................................281

7.7.5 Comparison between Test Results...................................................281

7.7.6 Comparison of Abendroth et al. (1989) and Buckling Strain

Analysis Model 
7.8 Recommended Pile

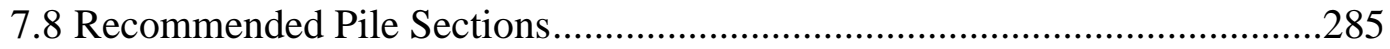

7.8.1 H Sections .................................................................................285

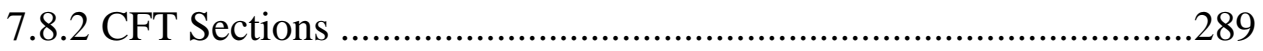

7.9 Calculated and Measured Movements .....................................................293

7.10 Recommended Bridge Length .........................................................295

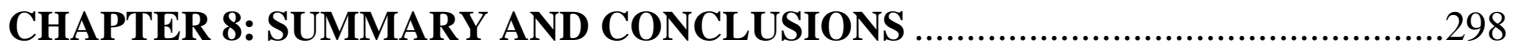

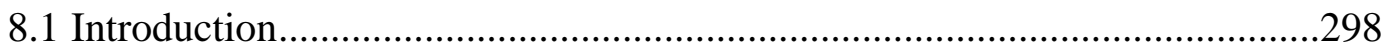

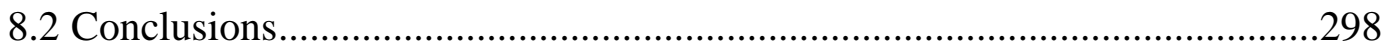

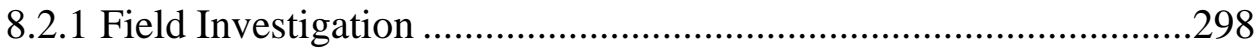

8.2.2 Analysis of Field Investigation ...............................................299

8.2.3 Experimental Investigation .......................................................300

8.2.4 Analysis of Experimental Investigation......................................301

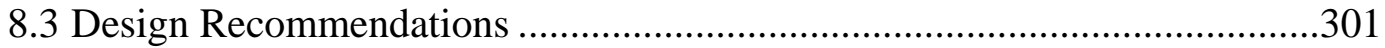

8.4 Recommendations for Further Research...................................................303

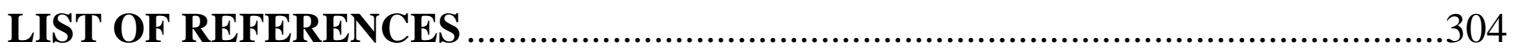

\section{APPENDICES}

APPENDIX A: INDOT Bridge Design Memorandums...................................310

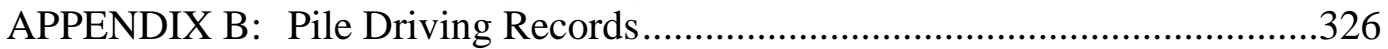

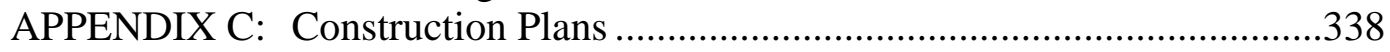

APPENDIX D: Construction Sequences .........................................................345

APPENDIX E: Computation of Deflected Shape of Pile 6 (SR18) ...................356

APPENDIX F: LPILE Soil Model................................................................359

APPENDIX G: Soil Spring Stiffness Values .................................................364

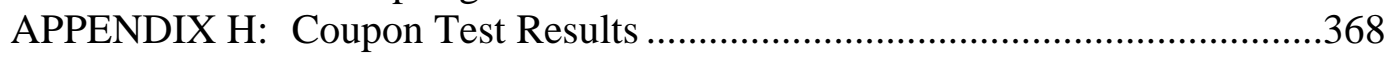

APPENDIX I: Experimental Results ...........................................................382

APPENDIX J: Moment-Curvature Analysis and Load-Deflection Analysis ...481 


\section{LIST OF TABLES}

Table

$2.1 \quad$ General Details of the Bridges..........................................................................6

2.2 Soil Boring Data from TB-1 for Bent 1 (SR249 over US12) ................................12

2.3 Soil Boring Data from TB-10 for Bent 11 (SR249 over US12) .............................13

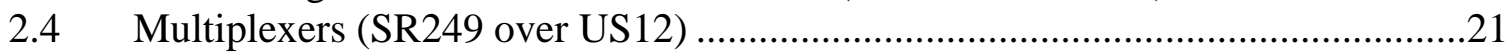

$2.5 \quad$ Instrumentation Problem (SR249 over US12) .....................................................22

2.6 Soil Boring Log Data from TB-1 (I65 over SR25)...............................................27

2.7 Soil Boring Log Data from TB-2 (I65 over SR25)..............................................28

2.8 Soil Boring Log Data from TB-3 (I65 over SR25)...............................................28

2.9 Soil Boring Log Data from TB-4 (I65 over SR25) ................................................28

2.10 Soil Boring Data (TB-1) on Bent 1 (SR18) ..........................................................38

2.11 Soil Boring Data (TB-2) on Bent 6 (SR18) .......................................................38

2.12 Zeroed/Started Reading (SR18) ....................................................................

$3.1 \quad$ Construction Temperature (SR249 over US12).....................................................49

3.2 Air Temperature (SR249 over US12) …………...............................................49

$3.3 \quad$ Air Temperature (I65 over SR25) .....................................................................60

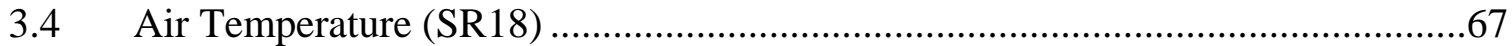

3.5 Abutment Movement (SR18)..........................................................................

3.6 Simplified Pier Cross Section Details (SR249 over US12) ………………….........78

3.7 Comparison between Extrapolated and Calculated Movements (in.)......................85

3.8 Temperature Change Range (SR18) ..................................................................8

4.1 Undrained Shear Strength and Soil Modulus Parameter for Clays.........................98

4.2 Terzaghi's Values of $\mathrm{k}$ for Submerged Sand (Terzaghi, 1955) .............................101

4.3 Recommended Values of $\mathrm{k}\left(\mathrm{lb} / \mathrm{in} .^{3}\right.$ ) (Reese et al., 1974)......................................101

4.4 Input for LPILE Program (SR249 over US12) .....................................................110

$4.5 \quad$ HP14x89 Cross Section Properties ……………................................................110

4.6 Soil Properties on Bents 1 and 11 (SR249 over US12) ......................................111

$4.7 \quad$ Inflection Point (SR249 over US12)...........................................................114

4.8 Depth of Zero Lateral Displacement (SR249 over US12) ....................................114

$4.9 \quad$ Moments at Ground Level (SR249 over US12) …………………………….......116

4.10 Summary of Pile Properties for LPILE (SR249 over US12) ...............................118

4.11 Cross Section Properties of HP12x53..............................................................118

4.12 Cross Section Properties for CFT14.5x0.25 ………….....................................118

4.13 Soil Properties (I65 over SR25) ................................................................119

4.14 Inflection Point (I65 over SR25).......................................................................121

4.15 Depth of Zero Lateral Displacement (I65 over SR25)..........................................121

4.16 The Depth of Zero Rotation (I65 over SR25) …………........................................123

4.17 Moments at Ground Level (I65 over SR25) ………............................................123

4.18 Cross Section Properties of CFT14 ..................................................................124

4.19 Soil Properties (SR18) ………………………............................................125

4.20 Inflection Point (SR18) ................................................................................127 


\begin{tabular}{|c|c|}
\hline Table & Page \\
\hline 4.21 & Moment at Ground Level (SR18). \\
\hline 22 & Section Properties in Parametric Study. \\
\hline 23 & Soil Properties in Parametric Study.. \\
\hline 24 & The Minimum Pile Length (ft). \\
\hline 25 & Minimum Design Pile Length (ft). \\
\hline & Soil Properties for LPILE Model... \\
\hline 2 & Summary of Test Variables ....... \\
\hline 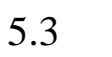 & Mix Design................................. \\
\hline 4 & Casting Sequence..... \\
\hline 5 & Average Concrete Compressive Strength and Modulus of Elasticity............. \\
\hline 6 & The Coupon Test Results....... \\
\hline 7 & Nominal Cross-Sectional Properties of Steel H Piles...... \\
\hline 8 & Dimensions of CFT Piles.... \\
\hline 9 & Transformed Section Properties of CFT Piles ... \\
\hline 10 & History of Testing..... \\
\hline 1 & Numbers of Cycles.... \\
\hline 2 & n 1 - Test Sum \\
\hline 3 & n 2 - Test Summary .. \\
\hline 4 & 3 - Test Summary ... \\
\hline 5 & Specimen 4 - Test Summary .. \\
\hline 6 & 5 - Test Summary .... \\
\hline .7 & Specimen 6 - Test Summary . \\
\hline 8 & 7 - Test Summary . \\
\hline 9.9 & 8 - Test Summary .. \\
\hline 10 & Specimen 9 - Test Sumn \\
\hline 11 & 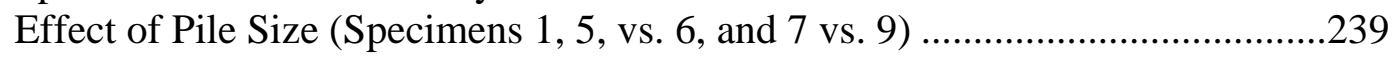 \\
\hline 12 & 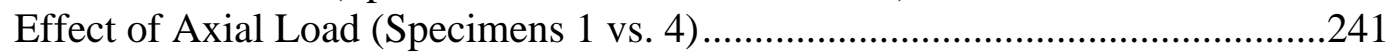 \\
\hline 13 & 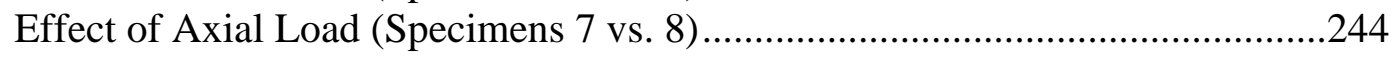 \\
\hline 14 & 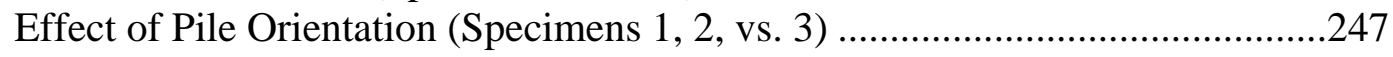 \\
\hline 15 & 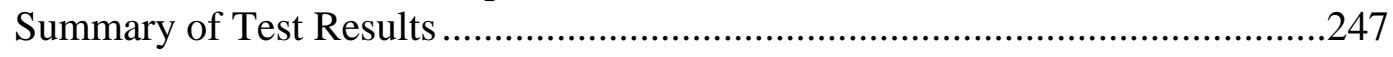 \\
\hline 16 & H Piles vs. CFT Piles. \\
\hline 7.1 & d at Failure of the H Specimens ........................... \\
\hline 2 & at First Buckling and at Failure of the CFT Specimens....................... \\
\hline .3 & 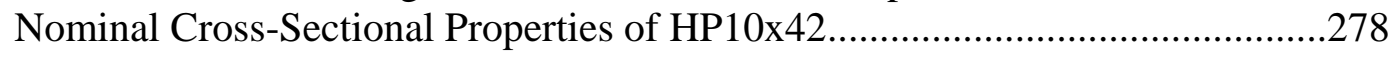 \\
\hline .4 & 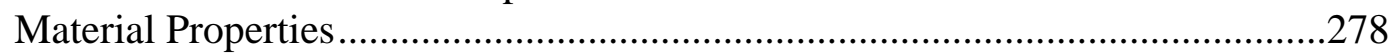 \\
\hline .5 & son of the Theoretical Displacement at Buckling ...............................284 \\
\hline .6 & .............................. \\
\hline 7.7 & Length of the H Piles Based on LPILE PLUS..... \\
\hline .8 & 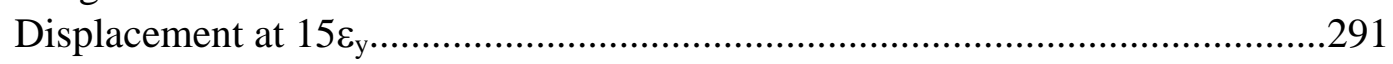 \\
\hline 7.9 & 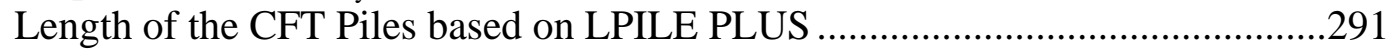 \\
\hline .10 & Length of the Piles Embedded in Very Stiff Clay and Dense Sand....................292 \\
\hline & 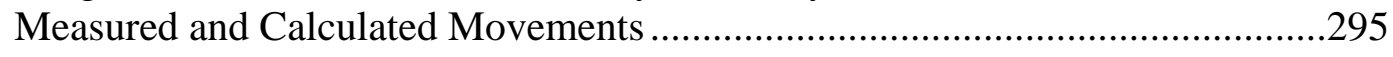 \\
\hline .12 & 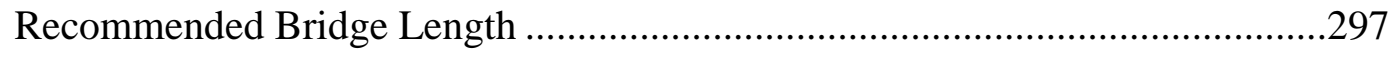 \\
\hline & Minimum Pile Length ........... \\
\hline
\end{tabular}




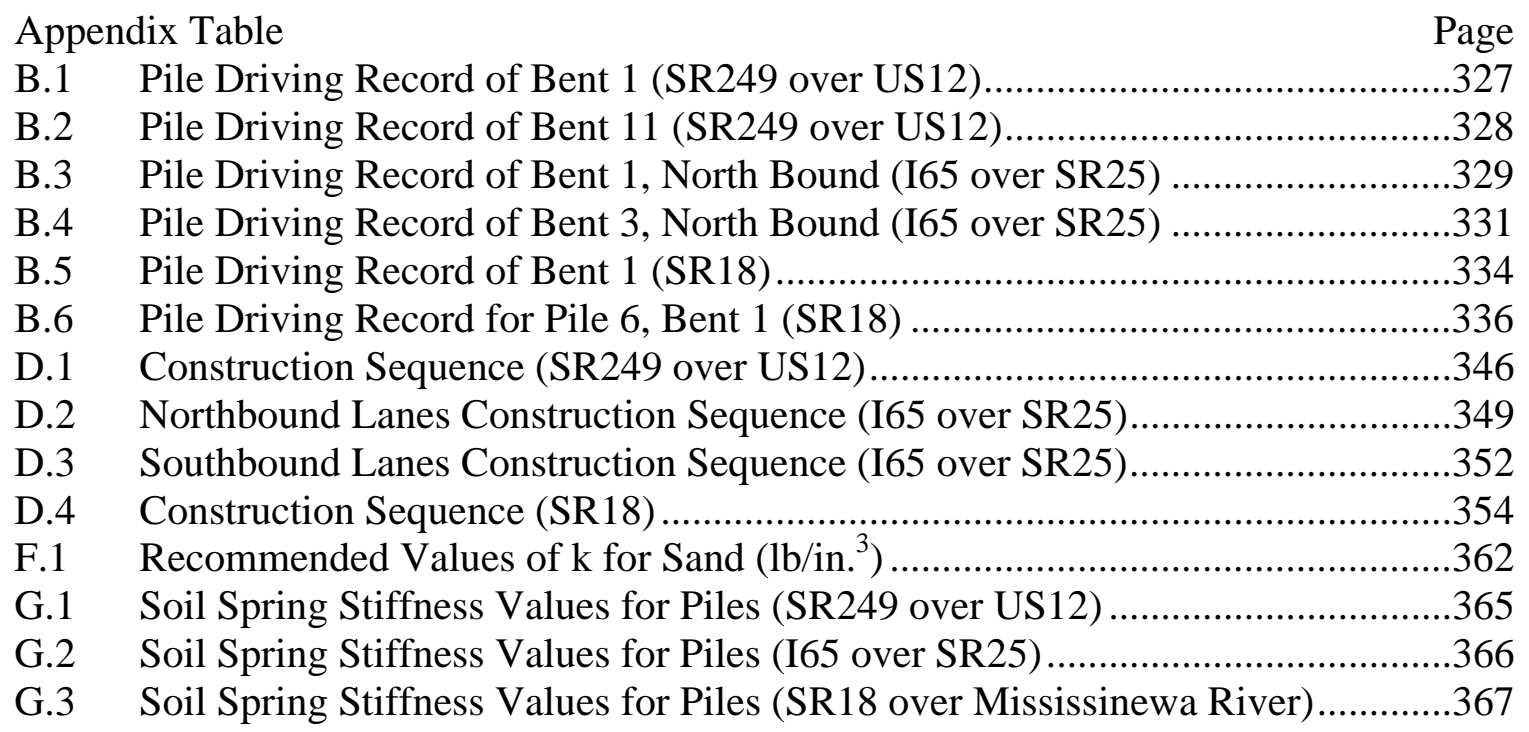




\section{LIST OF FIGURES}

\begin{tabular}{|c|c|}
\hline Figure & Page \\
\hline 1.1 & oss-Section of a Typical Integral End Bent (Durbin, 2001) .... \\
\hline 2.1 & SR249 over US12 Bridge..... \\
\hline .2 & Plan View (SR249 over US12). \\
\hline 2.3 & Typical Cross Section (Section A-A of Figure 2.2) (SR249 over US12)..... \\
\hline 4 & Bents 1 and 11 Plan Views (SR249 over US12) \\
\hline 2.5 & 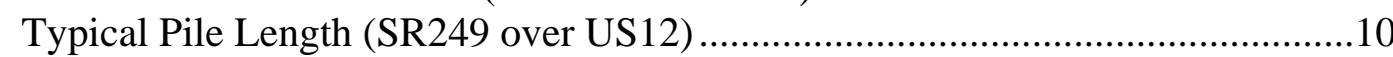 \\
\hline 6 & Expanded Polystyrene (SR249 over US12). \\
\hline 2.7 & Soil Boring Plan (SR249 over US12) ... \\
\hline 2.8 & Soil Profile (SR249 over US12) \\
\hline 2.9 & End Bent Instrumentation (SR249 over US12) \\
\hline .10 & Crackmeter and Tiltmeter Locations on Bent 1 (SR249 over US12). \\
\hline 2.11 & Pile Instrumentation (SR249 over US12) \\
\hline 12 & 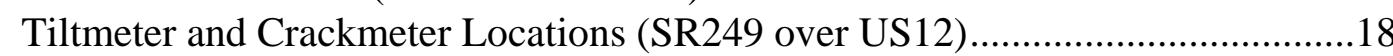 \\
\hline .13 & 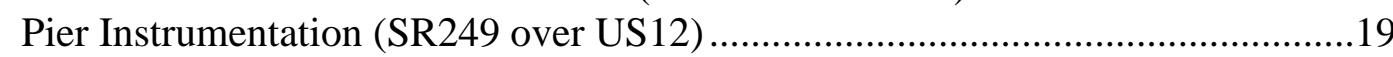 \\
\hline .14 & $\begin{array}{l}\text { Strain Gages and Tiltmeter Locations (Section A-A of Figure 2.13) (SR249 over } \\
\text { US12) }\end{array}$ \\
\hline 2.15 & Bridge Instrumentation (SR249 over US12)................ \\
\hline 2.16 & Malfunct \\
\hline .17 & hbound Stru \\
\hline 2.18 & Plar \\
\hline 19 & Profile View \\
\hline .20 & 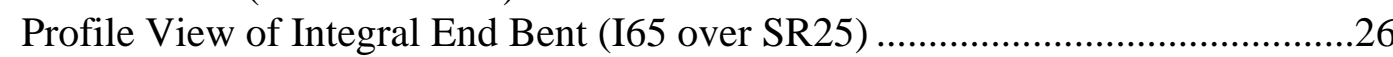 \\
\hline .21 & Soil Boring Plan (I65 over SR25) \\
\hline 22 & $\begin{array}{l}\text { Strain Gage and Thermocouple Locations on Northbound Structure (I65 over } \\
\text { SR25) }\end{array}$ \\
\hline 23 & Strain Gage Location on Pile on Northbound Structure (I65 over SR25) ....... \\
\hline 24 & ations on Southbound Structure (I65 over \\
\hline .25 & cture (I65 over SR25).... \\
\hline .26 & und Structure (I65 over SR25)........ \\
\hline 2.27 & 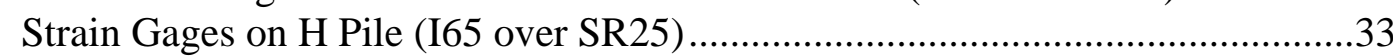 \\
\hline .28 & ter Protected with Conduit (I65 over SR25).................... \\
\hline 2.29 & 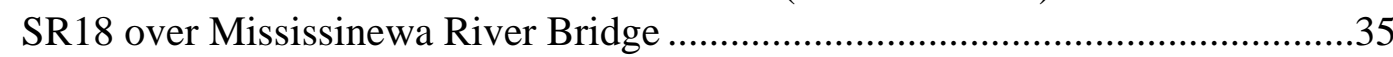 \\
\hline 2.30 & Plan View (SR18). \\
\hline 2.31 & Тур \\
\hline 2.32 & Soil Bori \\
\hline 2.33 & les on Bents 1 and \\
\hline 2.34 & Tiltmeter Location (SR18)....... \\
\hline .35 & Convergence Meter (SR18) . \\
\hline .36 & End Bent Instrumentation (SR18)... \\
\hline
\end{tabular}


Figure Page

2.37 Pile Instrumentation (SR18) …………………................................................43

2.38 Strain Gages along the Pile Length (SR18) .......................................................4

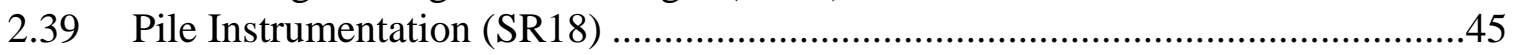

2.40 Variation of the Pile Length - Bent 1 (SR18) ………..............................................45

2.41 Piles before Cut Off - Bent 1 (SR18) ..................................................................46

$3.1 \quad$ Air Temperature (SR249 over US12) ……………………………………….....48

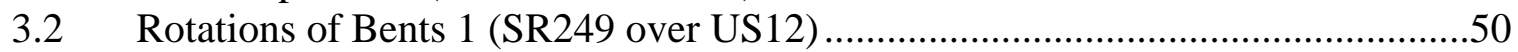

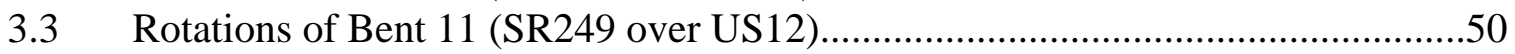

3.4 Sign Convention for Tiltmeter (SR249 over US12) ..............................................51

3.5 Sign Convention for Crackmeter (SR249 over US12) ………................................52

3.6 Relative Displacement on Bents 1 and 11 (SR249 over US12).............................52

3.7 Relative Displacement on Piers 2 and 10 (SR249 over US12)..............................53

3.8 Spalling of Concrete at Pier 10 Cap (SR249 over US12)......................................53

3.9 Strains and Stresses at the Base of Pier 2 (SR249 over US12)...............................54

3.10 Strains and Stresses at the Base of Pier 3 (SR249 over US12)...............................55

3.11 Strains and Stresses at the Base of Pier 4 (SR249 over US12)...............................55

3.12 Strains and Stresses at the Base of Pier 5 (SR249 over US12).............................56

3.13 Strains and Stresses at the Base of Pier 10 (SR249 over US12).............................56

3.14 Contraction Phase (SR249 over US12)...............................................................57

3.15 Stresses and Strains on Piles Supporting Bents 1 and 11 (SR249 over US12)......58

3.16 Air Temperature (I65 over SR25) ..................................................................59

3.17 Longitudinal Movement (I65 over SR25).............................................................61

3.18 Initial Longitudinal Movement (I65 over SR25) ....................................................61

3.19 Transverse Movement (I65 over SR25)..............................................................62

3.20 Initial Transverse Movement (I65 over SR25) ....................................................62

3.21 Strain Gage Locations on Piles 6 and 9 (Bent 1, Southbound Structure of I65 over

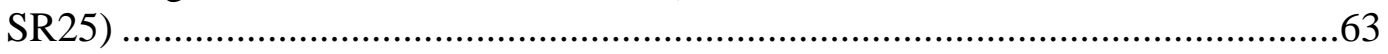

3.22 Strain at NW and NE Locations on Pile 6 (Bent 1, Southbound Structure of I65 over SR25)

3.23 Strain at SW and SE Locations on Pile 6 (Bent 1, Southbound Structure of I65 over SR25)

3.24 Strain on the North and South Locations on Pile 7 (Bent 1, Northbound Structure of I65 over SR25).............................................................................................65

3.25 Air Temperature (SR18) …………………………………………………...67

3.26 Rotations of the Abutment (SR18) …………...................................................68

3.27 Abutment Movement (SR18)...........................................................................69

3.28 Adjusted Longitudinal Movement (SR18).............................................................69

3.29 Calculated vs. Measured Movements (SR18) .........................................................70

3.30 Strain at the East Locations on Pile 6, Bent 1 (SR18) ............................................71

3.31 Strain at the West Locations on Pile 6, Bent 1 (SR18) ............................................72

3.32 Strain at the South Locations on Pile 6, Bent 1 (SR18)...........................................73

3.33 Pile Strains, East Face, Bent 1 (SR18)................................................................74

3.34 Pile Strains, West Face, Bent 1 (SR18) …………..............................................74

3.35 Pile Strains, East Face, Bent 6 (SR18).................................................................75 
Figure Page

3.36 Pile Strains, West Face, Bent 6 (SR18) ……………...........................................75

3.37 Pier Cross Section (SR249 over US12) .............................................................76

3.38 Simplified Pier Cross Section (SR249 over US12) ...............................................77

3.39 Moment-Curvature Relationship of Pier Cross Section (SR249 over US12)........77

3.40 Pier Model (SR249 over US12) .........................................................................80

3.41 Extrapolation of Bent 1 Movement (SR249 over US12) ........................................82

3.42 Extrapolation of Bent 11 Movement (SR249 over US12)......................................82

3.43 Average Daily Air Temperature (SR249 over US12)............................................83

3.44 Extrapolated and Calculated Movement of Bent 1 (SR249 over US12) ................84

3.45 Extrapolated and Calculated Movement of Bent 11 (SR249 over US12) ..............84

3.46 Comparison of Measured and Calculated Movements (I65 over SR25) ................86

3.47 Stresses and Strains on Pile 6 on East Face (SR18)...............................................87

3.48 Stresses and Strains on Pile 6 on West Face (SR18) ..........................................87

3.49 Stresses and Strains on Pile 6 on South Face (SR18) .............................................8

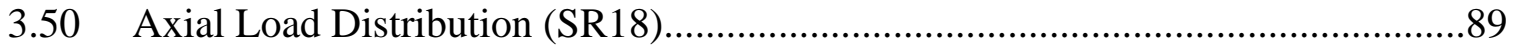

3.51 Assumption of Pile Movement .......................................................................

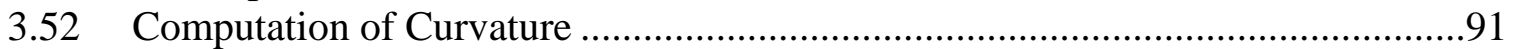

3.53 Curvature on Pile 6 over Various Changes in Temperature (SR18).......................91

3.54 Deflection of Pile 6 over Various Changes in Temperature (SR18) ......................92

3.55 Deflection at the Top of Pile 6 (SR18) ............................................................93

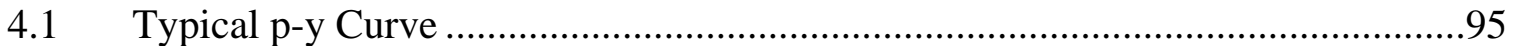

4.2 Set of p-y Curves (Reese et al., 1974) .................................................................96

4.3 The Definition of the Width, B .......................................................................98

$4.4 \quad$ Typical p-y Curve for Soft Clay and Stiff Clay .....................................................98

4.5 Typical p-y Curve for Very Stiff Clay ...................................................................99

4.6 The Computation of Equivalent Diameter and Equivalent Area ...........................103

4.7 Transformed Concrete-Filled Steel Section........................................................104

4.8 Initial Soil Stiffness and Soil Spring Stiffness.......................................................106

4.9 Pile Length for Piles of Bents 1 and 11 (SR249 over US12)..............................108

4.10 Pile Models for Bents 1 and 11 (SR249 over US12) ..........................................109

4.11 Deflected Shape of the Pile of Bent 1 (SR249 over US12) ................................113

4.12 Deflected Shape of the Pile of Bent 11 (SR249 over US12) …..........................113

4.13 Moment vs. Depth of the Pile of Bent 1 (SR249 over US12)...............................115

4.14 Moment vs. Depth of the Pile of Bent 11 (SR249 over US12).............................115

4.15 Pile Model (I65 over SR25) ...........................................................................117

4.16 Deflected Shape of the H Pile (I65 over SR25) ...............................................120

4.17 Deflected Shape of the CFT Pile (I65 over SR25) ..............................................120

4.18 Moment vs. Depth of the H Pile (I65 over SR25) ………………........................122

4.19 Moment vs. Depth of the CFT Pile (I65 over SR25) ...........................................122

4.20 Pile Model (SR18) .....................................................................................124

4.21 Deflected Shape of the Pile surrounding in Dry Medium Sand (SR18) ..............126

4.22 Deflected Shape of the Pile surrounding in Dry Stiff Clay (SR18) ......................126

4.23 Moment vs. Depth of the Pile in Dry Medium Sand (SR18)...............................128

4.24 Moment vs. Depth of the Pile in Dry Stiff Clay (SR18)......................................128 
Figure Page

4.25 Effect of Axial Load on Lateral Deflection (SR249 over US12) ..........................133

4.26 Effect of Axial Load on Bending Moment (SR249 over US12) ………...............133

4.27 Effect of Axial Load on Lateral Deflection (SR18)..............................................135

4.28 Effect of Axial Load on Bending Moment (SR18)...............................................135

4.29 Deflected Shape of the Pile with Various Pile Lengths .........................................136

4.30 Moment of the Pile with Various Pile Lengths.....................................................136

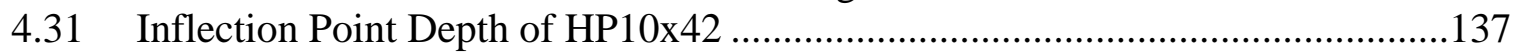

4.32 Inflection Point Depth of HP12x53 ............................................................138

4.33 Inflection Point Depth of HP14x89 ....................................................................138

4.34 Inflection Point Depth of CFT14 ………..........................................................138

4.35 Zero Deflection Depth of HP10x42 ..............................................................140

4.36 Zero Deflection Depth of HP12x53 …………..................................................141

4.37 Zero Deflection Depth of HP14x89 …………..................................................142

4.38 Zero Deflection Depth of CFT14 .....................................................................143

4.39 Zero Moment Depth of HP10x42 ....................................................................144

4.40 Zero Moment Depth of HP12x53 .....................................................................145

4.41 Zero Moment Depth of HP14x89 ……………...............................................146

4.42 Zero Moment Depth of CFT14 ………………................................................147

5.1 Test Design ……………………………………………………………….....151

5.2 Example of Bending Moment versus Depth from LPILE Program .....................151

5.3 Abutment Concrete Compressive Strength Gain...................................................156

5.4 Compressive Strength Gain of Concrete in CFT Piles ........................................157

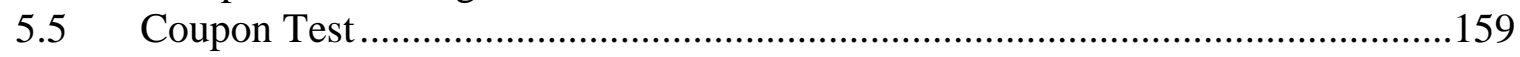

5.6 Rectangular Tension Test Specimens ...............................................................159

$5.7 \quad$ Tubular Tension Test Specimens ......................................................................160

5.8 Coupon Specimens.......................................................................................160

5.9 Initial Stress-Strain Relationship of Specimens 7, 8, and 9.................................162

5.10 Support Block Details ..........................................................................................163

5.11 Support Block Formwork ………………………..............................................164

5.12 Single Flared Loops for Support Block Formwork ……………….......................164

5.13 Support Block .....................................................................................................165

5.14 Concrete Abutment Cross Section .......................................................................166

5.15 Concrete Abutment Details..................................................................................166

5.16 Wale and Tie System for Concrete Abutment Form ……………….....................167

5.17 Flared Loop for Concrete Abutment Form ..........................................................167

5.18 Concrete Abutment Form ...............................................................................168

5.19 Concrete Abutment after Casting........................................................................168

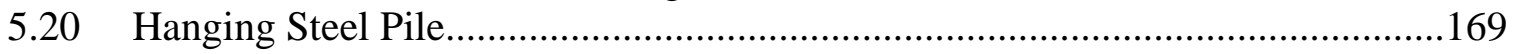

5.21 Pile Braced by Steel Angles.............................................................................170

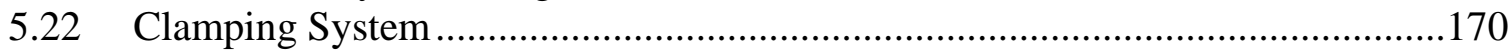

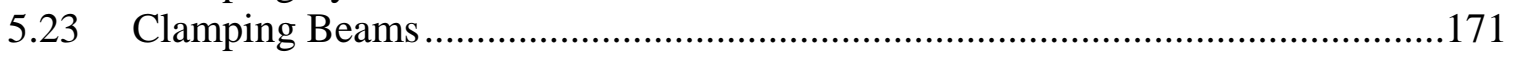

5.24 Axial Beam behind Concrete Abutment (BA1)...................................................172

5.25 Axial Beam at the Pile Tip (BA2).................................................................172

5.26 Scheme of Test Setup......................................................................................173 
Figure Page

5.27 Test Setup in the Laboratory ........................................................................174

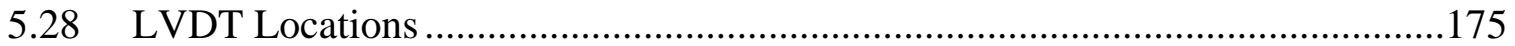

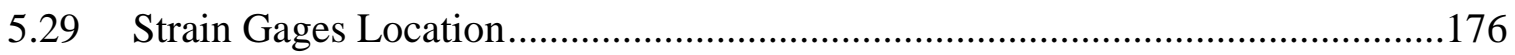

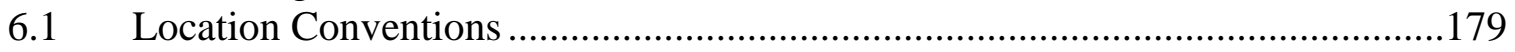

6.2 Specimen 5 - Load-Deflection Response ( \pm 0.25 in. Range).................................181

6.3 Specimen 5 - Load-Deflection Response $( \pm 0.50$ in. Range ...................................182

6.4 Specimen 5 - Load-Deflection Response ( \pm 0.75 in. Range).................................183

6.5 Specimen 5 - Spalling of Concrete at the NE Flange.............................................184

6.6 Specimen 5 - Load-Deflection Response ( \pm 1.00 in. Range).................................185

6.7 Specimen 5 - Load-Deflection Response ( \pm 1.25 in. Range).................................186

6.8 Specimen 5 - Load-Deflection Response ( \pm 1.50 in. Range)................................187

$6.9 \quad$ Specimen 5 - Load-Deflection Response ( \pm 1.75 in. Range)................................188

6.10 Specimen 5 - Load-Deflection Response ( \pm 2.00 in. Range).................................189

6.11 Specimen 5 - Crack Propagation........................................................................190

6.12 Specimen 5 - Web Yielding at the Bottom of the Web.........................................192

6.13 Specimen 5 - Spalling of Concrete.....................................................................193

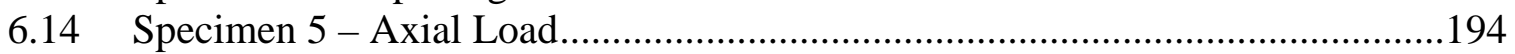

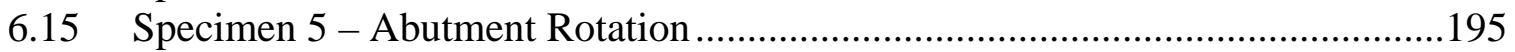

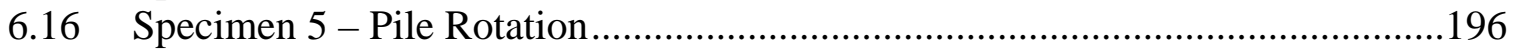

6.17 Specimen 1 - Pile Buckling ............................................................................197

6.18 Specimen 1 - Flange Cracking ..........................................................................198

6.19 Specimen 1 - Load-Deflection Response ( \pm 3.00 in. Range) ………………….....199

6.20 Specimen 1 - Overall Load-Deflection Response ...................................................199

6.21 Specimen 2 - Flange Buckling on the East Side ..................................................201

6.22 Specimen 2 -Abutment-Pile Connection Damage (West Side) ............................202

6.23 Specimen 2 -Abutment-Pile Connection Damage (East Side)...............................203

6.24 Specimen 2 - Load-Deflection Response ( \pm 1.75 in. Range) .................................203

6.25 Specimen 2 - Overall Load-Deflection Response ................................................204

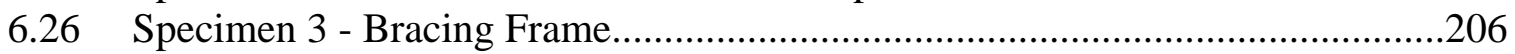

6.27 Specimen 3 - Cracks in Concrete ...................................................................208

6.28 Specimen 3 - Fracture of the North Flange .........................................................209

6.29 Specimen 3 - Web Yielding ………………….................................................209

6.30 Specimen 3 - Load-Deflection Response ( \pm 2.00 in. Range)...............................210

6.31 Specimen 3 - Overall Load-Deflection Response ................................................210

6.32 Specimen 4 - Web Yielding (2.50 in., 66th Cycle) ..............................................212

6.33 Specimen 4 - Load-Deflection Response ( \pm 2.50 in. Range)................................213

6.34 Specimen 4 - Overall Load-Deflection Response ...................................................213

6.35 Specimen 5 - Overall Load-Deflection Response ............................................215

6.36 Specimen 6 - The NW and NE Flange Buckling ...............................................217

6.37 Specimen 6 - Flange Fracture (NE Flange)........................................................218

6.38 Specimen 6 - Deterioration at the Abutment Pile Connection ..............................218

6.39 Specimen 6 - Load-Deflection Response ( \pm 1.75 in. Range)..............................219

6.40 Specimen 6 - Overall Load-Deflection Response .................................................219 
Figure Page

6.41 Specimen 7 - Pile at Failure (1.75 in., 33rd Cycle) ...........................................222

6.42 Specimen 7 -Load-Deflection Response ( \pm 1.75 in. Range)..............................223

6.43 Specimen 7 - Overall Load-Deflection Response .............................................223

6.44 Specimen 7 -Deterioration at the Abutment-Pile Connection.............................224

6.45 Specimen 8 - Steel Shell Fracture at the Bottom of the Pile ...............................227

6.46 Specimen 8 -Deterioration at the Abutment-Pile Connection.............................228

6.47 Specimen 8 - Load-Deflection Response ( \pm 1.50 and \pm 1.75 in. Range)..............228

6.48 Specimen 8 - Overall Load-Deflection Response ............................................229

6.49 Specimen 9 - Crack on the Pile $\left( \pm 2.00\right.$ in. Range, $100^{\text {th }}$ Cycle) .........................232

6.50 Specimen 9 - Deterioration of the Abutment-Pile Connection ...........................233

6.51 Specimen 9 - Load-Deflection Response ( \pm 2.00 in. Range)..............................233

6.52 Specimen 9 - Overall Load-Deflection Response ...........................................234

6.53 Lateral Load-Deflection Responses for H Piles..............................................237

6.54 Lateral Load-Deflection Responses for CFT Piles ............................................238

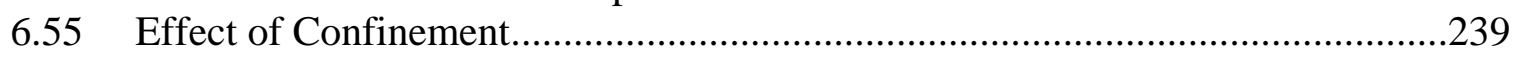

6.56 Load-Deflection Responses in HP8x36 under Different Axial Stresses .............240

6.57 Web Yielding of HP8x36 Bending about Weak Axis .......................................241

6.58 Load-deflection Responses in CFT8 Piles under Different Axial Stress.............243

6.59 Abutment-Pile Connection of CFT8 Piles under Different Axial Stress .............244

6.60 Lateral Load-Deflection Responses in HP8x36................................................246

6.61 Inflection Point Depth of the HP12x53 on I65 over SR25 ...............................250

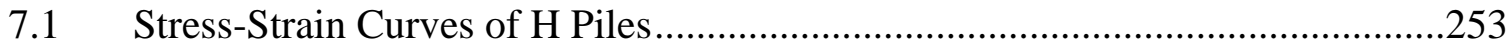

7.2 Specimen 5 - Stress-Strain Curve of Steel .......................................................254

7.3 Specimen 5 - Complete Stress-Strain Curve .......................................................255

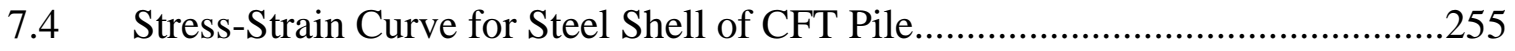

7.5 Specimen 7 - Stress-Strain Curve of Steel Shell ...............................................256

7.6 Specimen 8 - Stress-Strain Curve of Steel Shell ..............................................257

7.7 Specimen 9 - Stress-Strain Curve of Steel Shell .................................................257

7.8 Modified Hognestad Model ...............................................................................259

7.9 Kent and Park Model (Kent and Park, 1971)..................................................260

7.10 Modified Mander et al. Model (Elremaily and Azizinamini, 2002) ....................261

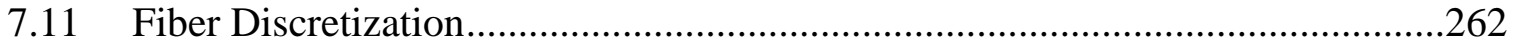

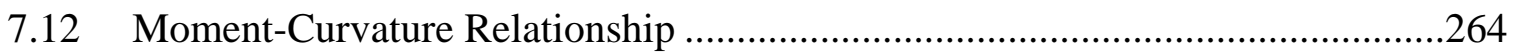

7.13 Cantilever Beam with Axial Load .....................................................................265

7.14 Specimen 1 - Load-Deflection Curve............................................................268

7.15 Specimen 2 - Load-Deflection Curve............................................................268

7.16 Specimen 3 - Load-Deflection Curve............................................................269

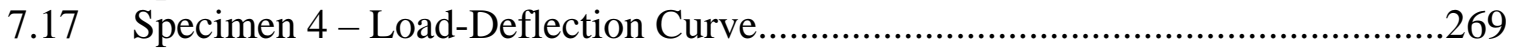

7.18 Specimen 5 - Load-Deflection Curve...........................................................270

7.19 Specimen 6 - Load-Deflection Curve.............................................................270

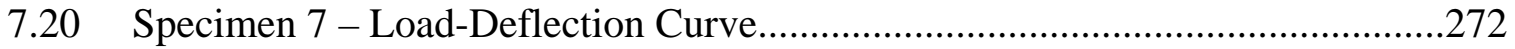

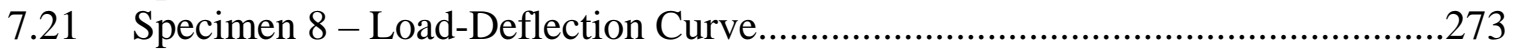

7.22 Specimen 9 - Load-Deflection Curve...........................................................273

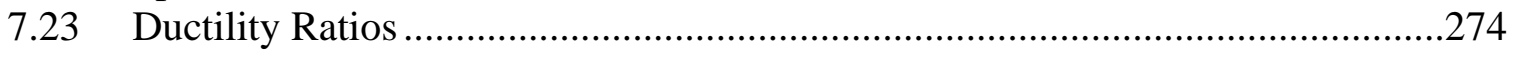


Figure Page

7.24 Clamping Beams ........................................................................................275

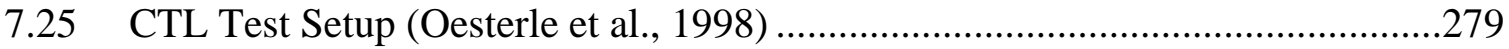

7.26 Cracks on Concrete Abutment (1.2 in. Cycle)...................................................2.280

7.27 Buckling at the Bottom of the Flanges (2.4 in. Cycle) ........................................280

7.28 Load-Deflection Curves for CTL Specimen.......................................................282

7.29 Load-Deflection Curves for Specimen 5 (HP10x42)..........................................282

7.30 Equivalent Cantilever Pile ................................................................................284

7.31 Moment-Curvature Relationships of All H Piles...........................................286

7.32 Load-Deflection Relationships of All H Piles ......................................................286

7.33 Displacement at $20 \varepsilon_{\mathrm{y}}$ Based on the Inflection Point using LPILE ......................288

7.34 Moment-Curvature Relationships of CFT14 Piles ............................................290

7.35 Load-Deflection Relationships of CFT14 Piles ...................................................291

7.36 Displacement at $15 \varepsilon_{y}$ Based on the Inflection Point using LPILE .......................292

7.37 Load-Deflection Curves for Piles on I65 ..........................................................294

7.38 Load-Deflection Curves for Piles on SR18 ……...........................................294

$7.39 \quad$ Expected Total Bridge Length ...........................................................................296 
Appendix Figure $\quad$ Page

C.1 End Bent Details of Bent 1 (SR249 over US12)..................................................339

C.2 Plan and Elevation Views of Bent 1 (SR249 over US12) ...................................340

C.3 End Bent Details of Bent 1 (I65 over US25) .........................................................341

C.4 Plan and Elevation Views of Bent 1 (I65 over US25) ............................................342

C.5 End Bent Details of Bent 1 (SR18 over Mississinewa River) ...............................343

C.6 Plan and Elevation Views of Bent 1 (SR18 over Mississinewa River)................344

E.1 Curvature of Pile 6 on Bent 1 (SR18) at $\Delta \mathrm{T}=-60^{\circ} \mathrm{F}$........................................358

E.2 Deflected Shape at $\Delta \mathrm{T}=-60^{\circ} \mathrm{F}$...................................................................358

F.1 Characteristic Shape of a Family of p-y Curves for Static and Cyclic Loading in Sand (Reese et al., 1974)..............................................................................361

F.2 Values of Coefficients $A_{s}$ and $A_{c}$ (Reese et al., 1974)........................................361

F.3 Values of Coefficients $B_{s}$ and $B_{c}$ (Reese et al., 1974) ........................................362

H.1 Specimen 1 - Coupons....................................................................................369

H.2 Specimen 2 - Coupons..................................................................................369

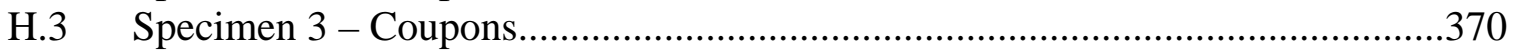

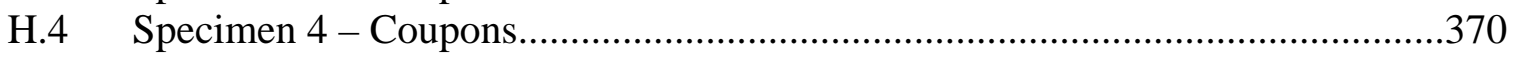

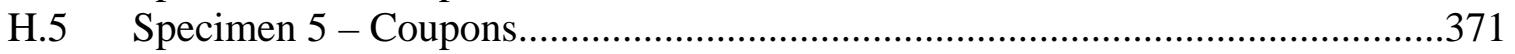

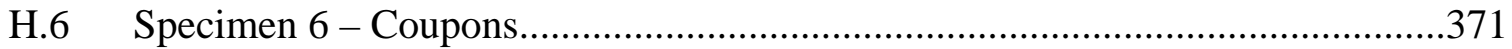

H.7 Specimen 7 - Coupon .....................................................................................372

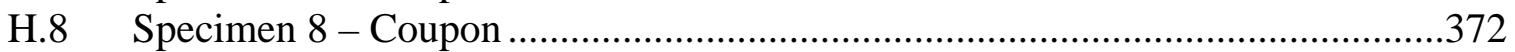

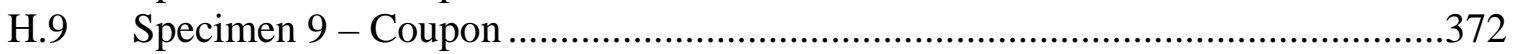

H.10 Specimen 1 - Stress-Strain Relationship ..............................................................373

H.11 Specimen 2 - Stress-Strain Relationship ...........................................................374

H.12 Specimen 3 - Stress-Strain Relationship ...........................................................375

H.13 Specimen 4 - Stress-Strain Relationship .............................................................376

H.14 Specimen 5 - Stress-Strain Relationship .............................................................377

H.15 Specimen 6 - Stress-Strain Relationship ............................................................378

H.16 Specimen 7 - Stress-Strain Relationship ........................................................379

H.17 Specimen 8 - Stress-Strain Relationship ..........................................................380

H.18 Specimen 9 - Stress-Strain Relationship .......................................................381

I.1 Specimen 1 - Yielding (3.00 in., $80^{\text {th }}$ Cycle)......................................................383

I.2 Specimen 1 - Flange Buckling (3.00 in., $80^{\text {th }}$ Cycle) ..........................................384

I.3 Specimen 1 - Crack on Steel Pile (3.00 in., $80^{\text {th }}$ Cycle)......................................385

I.4 Specimen 1 - Crack on Concrete Abutment (Overall) ............................................387

I.5 Specimen 1 - Crack on Concrete Abutment (Front View)......................................388

I.6 Specimen 1 - Summary of Lateral Load-Deflection Curves...................................388

I.7 Specimen 1 - Lateral Load-Deflection Response $( \pm 0.25$ in.)................................389

I.8 Specimen 1 - Lateral Load-Deflection Response $( \pm 0.50$ in.)................................389

I.9 Specimen 1 - Lateral Load-Deflection Response ( \pm 0.75 in.).................................390

I.10 Specimen 1 - Lateral Load-Deflection Response ( \pm 1.00 in.).................................390

I.11 Specimen 1 - Lateral Load-Deflection Response $( \pm 1.50$ in.).................................391

I.12 Specimen 1 - Lateral Load-Deflection Response $( \pm 2.00$ in.)...............................391

I.13 Specimen 1 - Lateral Load-Deflection Response ( \pm 2.25 in.)................................392

I.14 Specimen 1 - Lateral Load-Deflection Response ( \pm 2.50 in.)................................392 
Appendix Figures Page

I.15 Specimen 1 - Lateral Load-Deflection Response ( \pm 2.75 in.).................................393

I.16 Specimen 1 - Lateral Load-Deflection Response $( \pm 3.00$ in.)..............................393

I.17 Specimen 2 - Cracking (1.75 in., $100^{\text {th }}$ Cycle) ...................................................394

I.18 Specimen 2 - Deterioration at the Abutment-Pile Connection (1.75 in., $100^{\text {th }}$

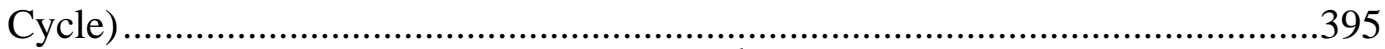

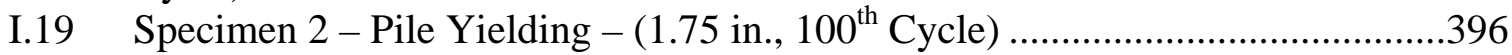

I.20 Specimen 2 - Crack on Concrete Abutment (Overall)............................................397

I.21 Specimen 2 - Crack on Concrete Abutment (Top View)......................................398

I.22 Specimen 2 - Crack on Concrete Abutment (Front View)....................................398

I.23 Specimen 2 - Crack on Concrete Abutment (West View) .....................................399

I.24 Specimen 2 - Crack on Concrete Abutment (East View).......................................399

I.25 Specimen 2 - Summary of Lateral Load-Deflection Curves ..................................400

I.26 Specimen 2 - Lateral Load-Deflection Response $( \pm 0.25$ in.)................................401

I.27 Specimen 2 - Lateral Load-Deflection Response ( \pm 0.50 in.)................................401

I.28 Specimen 2 - Lateral Load-Deflection Response ( \pm 0.75 in.)................................402

I.29 Specimen 2 - Lateral Load-Deflection Response $( \pm 1.00$ in.)..............................402

I.30 Specimen 2 - Lateral Load-Deflection Response $( \pm 1.50$ in.)................................403

I.31 Specimen 2 - Lateral Load-Deflection Response ( \pm 1.75 in.)................................403

I.32 Specimen 3 - Cracking (2.00 in., $100^{\text {th }}$ Cycle) ……….........................................404

I.33 Specimen 3 - Pile Yielding (2.00 in., $100^{\text {th }}$ Cycle) …………..............................406

I.34 Specimen 3 - Flange Buckling and Web Yielding (2.00 in., $100^{\text {th }}$ Cycle)..........407

I.35 Specimen 3 - Flange Buckling along with Crack on Pile (2.00 in., $100^{\text {th }}$

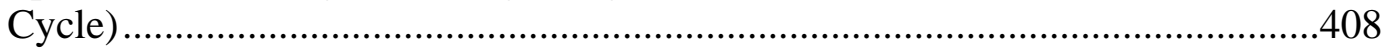

I.36 Specimen 3 - Crack on Concrete Abutment (Overall) ...........................................409

I.37 Specimen 3 - Crack on Concrete Abutment (Top View).....................................410

I.38 Specimen 3 - Crack on Concrete Abutment (Front View).....................................410

I.39 Specimen 3 - Crack on Concrete Abutment (West View) ......................................411

I.40 Specimen 3 - Crack on Concrete Abutment (East View).......................................411

I.41 Specimen 3 - Lateral Load-Deflection Curves......................................................412

I.42 Specimen 3 - Lateral Load-Deflection Response $( \pm 0.25$ in.).................................412

I.43 Specimen 3 - Lateral Load-Deflection Response ( \pm 0.50 in.)................................413

I.44 Specimen 3 - Lateral Load-Deflection Response ( \pm 0.75 in.)................................413

I.45 Specimen 3 - Lateral Load-Deflection Response $( \pm 1.00$ in.)..............................414

I.46 Specimen 3 - Lateral Load-Deflection Response ( \pm 1.25 in.)................................414

I.47 Specimen 3 - Lateral Load-Deflection Response ( \pm 1.50 in.)................................415

I.48 Specimen 3 - Lateral Load-Deflection Response ( \pm 1.75 in.)................................415

I.49 Specimen 3 - Lateral Load-Deflection Response ( \pm 2.00 in.)..............................416

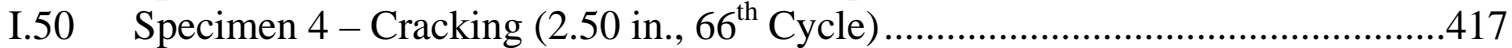

I.51 Specimen 4 - Yielding (2.50 in., $66^{\text {th }}$ Cycle)......................................................418

I.52 Specimen 4 - Flange Buckling and Web Yielding (2.50 in., $66^{\text {th }}$ Cycle).............419

I.53 Specimen 4 - Crack on Concrete Abutment (Overall) ………………………........420

I.54 Specimen 4 - Crack on Concrete Abutment (Front View)......................................421

I.55 Specimen 4 - Summary of Lateral Load-Deflection Curves ..................................421 
Appendix Figure Page

I.56 Specimen 4 - Lateral Load-Deflection Response ( \pm 0.25 in.)...........................422

I.57 Specimen 4 - Lateral Load-Deflection Response $( \pm 0.50$ in.).............................422

I.58 Specimen 4 - Lateral Load-Deflection Response ( \pm 0.75 in.)............................423

I.59 Specimen 4 - Lateral Load-Deflection Response $( \pm 1.00$ in.)............................423

I.60 Specimen 4 - Lateral Load-Deflection Response $( \pm 1.25$ in.).............................424

I.61 Specimen 4 - Lateral Load-Deflection Response ( \pm 1.50 in.)............................424

I.62 Specimen 4 - Lateral Load-Deflection Response $( \pm 1.75$ in.)..............................425

I.63 Specimen 4 - Lateral Load-Deflection Response ( \pm 2.00 in.).............................425

I.64 Specimen 4 - Lateral Load-Deflection Response ( \pm 2.25 in.)............................426

I.65 Specimen 4 - Lateral Load-Deflection Response ( \pm 2.50 in.)............................426

I.66 Specimen 5 - Cracking (2.00 in., 50 ${ }^{\text {th }}$ Cycle) ..................................................427

I.67 Specimen 5 - Pile Yielding (2.00 in., $50^{\text {th }}$ Cycle) ............................................428

I.68 Specimen 5 - Pile Flange Buckling and Web Yielding (2.00 in., 50 ${ }^{\text {th }}$ Cycle) ....429

I.69 Specimen 5 - Crack on Steel Pile (2.00 in., 50 ${ }^{\text {th }}$ Cycle) ....................................430

I.70 Specimen 5 - Crack on Concrete Abutment (Overall) .......................................432

I.71 Specimen 5 - Crack on Concrete Abutment (Front View) .................................433

I.72 Specimen 5 - Summary of Lateral Load-Deflection Curves...............................433

I.73 Specimen 5 - Lateral Load-Deflection Response $( \pm 0.25$ in.)............................434

I.74 Specimen 5 - Lateral Load-Deflection Response $( \pm 0.50$ in.)..............................434

I.75 Specimen 5 - Lateral Load-Deflection Response $( \pm 0.75$ in.).............................435

I.76 Specimen 5 - Lateral Load-Deflection Response $( \pm 1.00$ in. $)$.............................435

I.77 Specimen 5 - Lateral Load-Deflection Response $( \pm 1.25$ in.)............................436

I.78 Specimen 5 - Lateral Load-Deflection Response $( \pm 1.50$ in.)............................436

I.79 Specimen 5 - Lateral Load-Deflection Response $( \pm 1.75$ in.)............................437

I.80 Specimen 5 - Lateral Load-Deflection Response $( \pm 2.00$ in.).............................437

I.81 Specimen 6 - Cracking (1.75 in., $70^{\text {th }}$ Cycle) .................................................438

I.82 Specimen 6 - Pile Yielding (1.75 in., $70^{\text {th }}$ Cycle) ...........................................439

I.83 Specimen 6 - Pile Flange Buckling (1.75 in., $70^{\text {th }}$ Cycle) .................................440

I.84 Specimen 6 - Crack on Steel Pile (1.75 in., $70^{\text {th }}$ Cycle) .....................................441

I.85 Specimen 6 - Crack on Concrete Abutment (Overall) .......................................443

I.86 Specimen 6 - Crack on Concrete Abutment (Top View) ....................................444

I.87 Specimen 6 - Crack on Concrete Abutment (Front View) ..................................444

I.88 Specimen 6 - Crack on Concrete Abutment (West View) ..................................445

I.89 Specimen 6 - Crack on Concrete Abutment (East View) ...................................445

I.90 Specimen 6 - Summary of Lateral Load-Deflection Curves...............................446

I.91 Specimen 6 - Lateral Load-Deflection Response $( \pm 0.25$ in.)...........................446

I.92 Specimen 6 - Lateral Load-Deflection Response $( \pm 0.50$ in.)............................447

I.93 Specimen 6 - Lateral Load-Deflection Response $( \pm 0.75$ in.)............................447

I.94 Specimen 6 - Lateral Load-Deflection Response $( \pm 1.00$ in.)............................448

I.95 Specimen 6 - Lateral Load-Deflection Response $( \pm 1.25$ in. $)$..............................448

I.96 Specimen 6 - Lateral Load-Deflection Response ( \pm 1.50 in.)............................449

I.97 Specimen 6 - Lateral Load-Deflection Response $( \pm 1.75$ in. $)$..............................449

I.98 Specimen 7 - Cracking (1.75 in., $33^{\text {rd }}$ Cycle)................................................450 
Appendix Figure

I.99 Specimen 7 - Pile Yielding (1.75 in., $33^{\text {rd }}$ Cycle) .................................................451

I.100 Specimen 7 - Crack on Concrete Abutment (Overall) ...........................................453

I.101 Specimen 7 - Crack on Concrete Abutment (Front View).....................................454

I.102 Specimen 7 - Summary of Lateral Load-Deflection Curves..................................454

I.103 Specimen 7 - Lateral Load-Deflection Response $( \pm 0.25$ in.)...............................455

I.104 Specimen 7 - Lateral Load-Deflection Response ( \pm 0.50 in.)...............................455

I.105 Specimen 7 - Lateral Load-Deflection Response ( \pm 0.75 in.)................................456

I.106 Specimen 7 - Lateral Load-Deflection Response ( \pm 1.00 in.)................................456

I.107 Specimen 7 - Lateral Load-Deflection Response ( \pm 1.25 in.)................................457

I.108 Specimen 7 - Lateral Load-Deflection Response ( \pm 1.50 in.)................................457

I.109 Specimen 7 - Lateral Load-Deflection Response ( \pm 1.75 in.)................................458

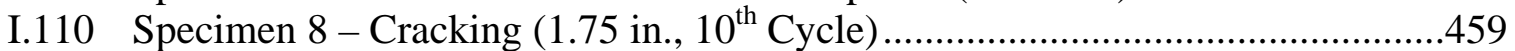

I.111 Specimen 8 - Pile Yielding (1.75 in., $10^{\text {th }}$ Cycle) ..............................................460

I.112 Specimen 8 - Crack on Concrete Abutment (Overall) ............................................462

I.113 Specimen 8 - Crack on Concrete Abutment (Top View) .......................................463

I.114 Specimen 8 - Crack on Concrete Abutment (Front View).....................................463

I.115 Specimen 8 - Crack on Concrete Abutment (West View) ......................................464

I.116 Specimen 8 - Crack on Concrete Abutment (East View)........................................464

I.117 Specimen 8 - Summary of Lateral Load-Deflection Curves...................................465

I.118 Specimen 8 - Lateral Load-Deflection Response ( \pm 0.25 in.)................................465

I.119 Specimen 8 - Lateral Load-Deflection Response $( \pm 0.50$ in.)...............................466

I.120 Specimen 8 - Lateral Load-Deflection Response $( \pm 0.75$ in.)................................466

I.121 Specimen 8 - Lateral Load-Deflection Response $( \pm 1.00$ in.)................................467

I.122 Specimen 8 - Lateral Load-Deflection Response $( \pm 1.25$ in.)...............................467

I.123 Specimen 8 - Lateral Load-Deflection Response $( \pm 1.50$ in.)................................468

I.124 Specimen 8 - Lateral Load-Deflection Response ( \pm 1.75 in.)................................468

I.125 Specimen 9 - Cracking (2.00 in., $100^{\text {th }}$ Cycle) ...................................................469

I.126 Specimen 9 - Cracking on Concrete Abutment (2.00 in., $100^{\text {th }}$ Cycle) ...............470

I.127 Specimen 9 - Pile Yielding (2.00 in., $100^{\text {th }}$ Cycle) ............................................471

I.128 Specimen 9 - Crack on Concrete Abutment (Overall) ...........................................473

I.129 Specimen 9 - Crack on Concrete Abutment (Top View) ........................................474

I.130 Specimen 9 - Crack on Concrete Abutment (Front View).....................................474

I.131 Specimen 9 - Crack on Concrete Abutment (West View) …………………..........475

I.132 Specimen 9 - Crack on Concrete Abutment (East View)......................................475

I.133 Specimen 9 - Summary of Lateral Load-Deflection Curves.................................476

I.134 Specimen 9 - Lateral Load-Deflection Response ( \pm 0.25 in.)................................476

I.135 Specimen 9 - Lateral Load-Deflection Response $( \pm 0.50$ in.)...............................477

I.136 Specimen 9 - Lateral Load-Deflection Response $( \pm 0.75$ in.)...............................477

I.137 Specimen 9 - Lateral Load-Deflection Response $( \pm 1.00$ in.)...............................478

I.138 Specimen 9 - Lateral Load-Deflection Response ( \pm 1.25 in.).................................478

I.139 Specimen 9 - Lateral Load-Deflection Response ( \pm 1.50 in.).................................479

I.140 Specimen 9 - Lateral Load-Deflection Response ( \pm 1.75 in.)................................479

I.141 Specimen 9 - Lateral Load-Deflection Response $( \pm 2.00$ in. $)$...............................480 
Appendix Figure Page

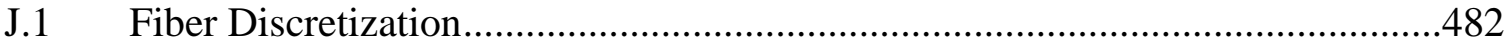

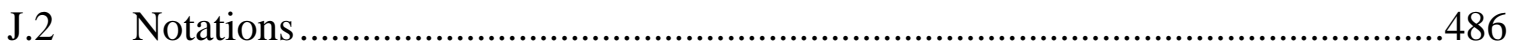

J.3 Curvature Interpolation ................................................................................48

J.4 Deflection Calculation Example .....................................................................488 


\section{CHAPTER 1: INTRODUCTION}

\subsection{Introduction}

In traditional bridge construction, expansion and bearing joints are installed at selected locations along the bridge. These joints are often costly to purchase, install, maintain, and repair. In addition, corrosion damage to the joint can occur from salt, moisture, and accumulated dirt. Snow plows often damage or loosen the joint hardware (Wasserman, 1996). Due to these problems, elimination of joints is desirable. A jointless structure can be achieved using an integral abutment bridge. This bridge type uses short stub type abutments that are rigidly connected to the bridge deck without joints. A typical integral abutment is illustrated in Figure 1.1.

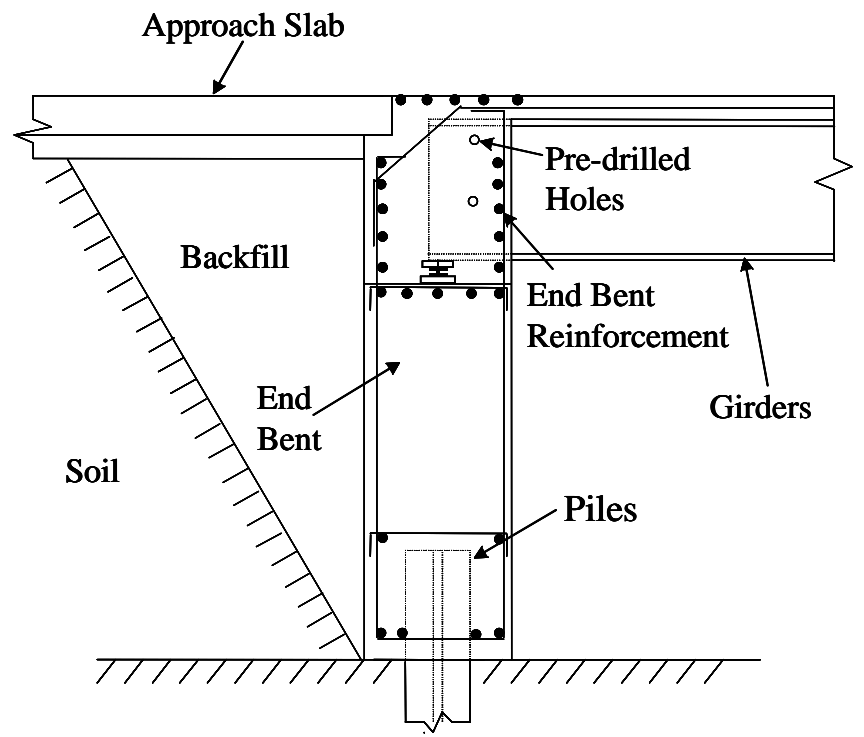

Figure 1.1: Cross-Section of a Typical Integral End Bent (Durbin, 2001) 


\subsection{Overview of Integral Abutment Bridges}

Integral abutment bridges have several advantages over traditional bridges including:

- Integral abutment bridges are more economical because of the elimination of expensive expansion joints and the reduction in maintenance costs (Steel Bridges, 1993).

- Integral abutment bridges improve riding quality because of the elimination of joints.

- The construction of integral abutment bridges is more rapid than that of traditional bridges because of the use of only a single row of vertical (not battered) piles. Fewer piles and less forming are typically required.

- As reported by Burke (1993), integral abutment bridges are simple to design and time-efficient to analyze. A continuous superstructure including girders is simplified as a continuous horizontal frame member. Also, the piles and piers can be represented by vertical members.

- Integral abutments provide for improved seismic performance.

Even though integral abutment bridges have many advantages, a number of issues should be considered. By eliminating joints, the end abutments must accommodate the total thermal movement of the bridge. This movement can be estimated by Equation 1-1.

$$
\Delta \mathrm{L}=\alpha(\Delta \mathrm{T}) \mathrm{L}
$$

where:

$\Delta \mathrm{L} \quad=$ change in bridge length due to temperature change, in.

$\alpha \quad=$ material coefficient of thermal expansion, $1{ }^{\circ} \mathrm{F}$

$\Delta \mathrm{T} \quad=$ change in temperature, ${ }^{\circ} \mathrm{F}$

$\mathrm{L} \quad=$ total bridge length, in. 
While the abutments and piles resist longitudinal movement of the superstructure, additional stresses or secondary stresses due to shrinkage, creep, settlement, temperature, and earth pressure can occur in the girders and piles. Problems occurring in integral abutment bridges can be briefly summarized as follows:

- Differential support settlements induce additional shears and moments in the deck, girders, and piles.

- Temperature-induced movement of the abutment can cause settlement of the approach slab (Arsoy, 1999).

- Daily temperature change causes bending moments in the bridge girders.

- High passive earth pressures behind the abutment can damage the bridge abutments while resisting movement.

- Pile stresses in the abutment can reach or exceed yield, induce plastic hinging, and consequently reduce the axial capacity of the pile.

As reported by Russell (1994), the interaction of abutment, soil, and superstructure still remains unknown. The soil-pile relationship under cyclic bridge movement is also uncertain. Moreover, there are no available methods for estimating the magnitude and distribution of passive pressure forces. Better understanding regarding the behavior of pile and soil should be investigated.

Due to concerns regarding secondary effects, a Technical Advisory of the Federal Highway Administration (FHWA, 1980) suggested length limits for integral abutment bridges in 1980. The limits were set as follows: 300-ft for steel bridges, 500-ft for castin-place concrete bridges, and 600-ft for prestressed concrete bridges. However, as reported by Burdette, et al. (2002), the Tennessee Department of Transportation (TDOT) has used longer lengths for integral abutment bridges. Wasserman provides several recommendations about pile configuration, pile orientation, anchorage of beam to pile cap, and backfill (Wasserman, 1996). These recommendations are provided based on field experience. Piles, for example, are recommended to be driven vertically and in only one row to achieve the highest extent of flexibility to accommodate cyclic thermal movements. As reported by Wasserman, there is disagreement regarding pile orientations; fifteen states orient the pile for strong-axis bending, while thirteen states 
orient the pile for weak-axis bending. To reduce pile stresses, the piles may be driven through a pre-bored hole approximately twice the diameter of the pile. The pre-bored hole is recommended to be 8-ft in depth below the abutment beam and backfilled with loose sand (Wasserman, 1996). As noted, there are a variety of recommendations that are based solely on field experience. In addition, these recommendations often vary considerable with diametrically opposed recommendations provided from state to state.

\section{$\underline{1.3 \quad \text { Pile Considerations }}$}

\subsubsection{Pile Design}

Pile design for integral abutment bridges is based on a variety of assumptions and is often specified by state standards or guidelines. In general, the following methods are used:

1. Pile design considers only axial loads.

2. Pile design accounts for bending stresses due to temperature effects, but ignores backfill resistance.

3. Pile design incorporates soil-pile interaction based on results from specified computer programs such as LPILE (Reese, 2000).

\subsubsection{Pile Type}

Some states specify steel H piles (HP); other states specify concrete-filled steel tube piles (CFT), while others use prestressed concrete piles.

\subsubsection{Pile Orientation}

Besides design considerations and pile types, pile orientations vary from state to state. Orienting the $\mathrm{H}$ piling for weak-axis bending offers the least resistance and facilitates pile-head bending for fixed head conditions. However, due to the potential for flange buckling, the total lateral displacement is more limited than when the piling is oriented in strong-axis bending. 


\section{$1.4 \quad$ INDOT Standards}

In Indiana, according to Bridge Design Memorandum \#233 and \#243 (INDOT, 1992a and INDOT 1992b), bridge lengths are limited to 250-ft for steel bridges and 300$\mathrm{ft}$ for prestressed concrete bridges with a maximum skew angle of $30^{\circ}$. For reinforced concrete integral bridges, the maximum bridge length is 200-ft regardless of the skew. Only steel H piles or 14-in. diameter concrete-filled steel tube piles are permitted for use in integral abutment bridges. Steel $\mathrm{H}$ piles are recommended to be oriented in weak-axis bending to minimize pile bending stresses. Furthermore, the axial stress on the pile should be no more than 9 ksi. The Bridge Design Memorandums are provided in Appendix A. INDOT also allows jointless bridges up to a 454 degree skew as long as the bridge length doesn't exceed $150 \mathrm{ft}$ (45 m).

\subsection{Objectives and Scope}

There is interest in extending the length limitations for integral abutment bridges in Indiana to take advantage of the benefits of integral construction for an increased number of structures. Therefore, the objective of this research is to develop minimum design and detailing recommendations to allow extension of the current length limitations. Integral bridges are in general considered limited by the capability of the piles to accommodate thermal movements. To achieve this objective, this study will:

1. Investigate the in-service pile behavior of integral abutment bridges.

2. Develop simplified modeling techniques that sufficiently account for soil-pile interaction. Soil-pile interaction will be based on measured in-field response.

3. Evaluate the capability of the pile types used in Indiana to support axial load while subject to low-cycle, large-amplitude lateral displacements. 


\section{CHAPTER 2: FIELD INVESTIGATION}

\section{$2.1 \quad$ Introduction}

Four bridges were instrumented to observe the in-service behavior of integral abutment bridges as well as the behavior of the piles supporting these structures. Structures instrumented as part of the research include the SR249 over US12 bridge, two I65 over SR25 bridges, and the SR18 over Mississinewa River bridge. General details of the bridges are tabulated in Table 2.1. This chapter discusses both the instrumentation scheme and the response of the piles.

Table 2.1: General Details of the Bridges

\begin{tabular}{|l|c|c|c|}
\hline & SR249 over US 12 & I65 over SR25 & $\begin{array}{c}\text { SR18 over } \\
\text { Mississinewa River }\end{array}$ \\
\hline Total Length (ft) & 990 & 152 & 367 \\
\hline Skew Angle (degrees) & 13 & 25 & 8 \\
\hline Number of Spans & 10 & 2 & 5 \\
\hline Span Length (ft) & $\begin{array}{c}86.6,3 @ 98.4,114.8 \\
4 @ 101.7,86.6\end{array}$ & $2 @ 76$ & $62,3 @ 81,62$ \\
\hline Number of Girders & 4 & 7 & 5 \\
\hline Girder Type & $\begin{array}{c}\text { Prestressed Concrete } \\
\text { Bulb Tee }\end{array}$ & W36x150 Steel & Prestressed Concrete \\
Bulb Tee
\end{tabular}




\section{$2.2 \quad$ SR249 over US12 Bridge}

The first integral abutment bridge instrumented is located on SR249 over US12 in Portage Township, Indiana (Figure 2.1). The bridge (Structure \#12-64-2673) is located near I65, 1.51 miles to the South of US30 and is a continuous, composite, prestressed concrete, bulb-tee bridge with ten spans. The bridge has a skew angle of $13^{\circ} 11^{\prime}$ $\left(13.183^{\circ}\right)$ relative to the abutments and has a total bridge length of $990 \mathrm{ft}$. A plan view of the bridge is presented in Figure 2.2. This bridge was selected because its total bridge length exceeded the INDOT length limitation of $300 \mathrm{ft}$ for a prestressed concrete, integral abutment bridge. The bridge consists of varying span dimensions that include: $86.6 \mathrm{ft}$ (26.4 m),3@98.4ft (3@30.0 m), 114.8ft (35.0 m),4@101.7ft (4@31.0 m), and 86.6ft $(26.4 \mathrm{~m})$. A typical cross section of the bridge is shown in Figure 2.3. It should be noted that this structure was designed using metric dimensions, hence, the irregular U.S. customary units.

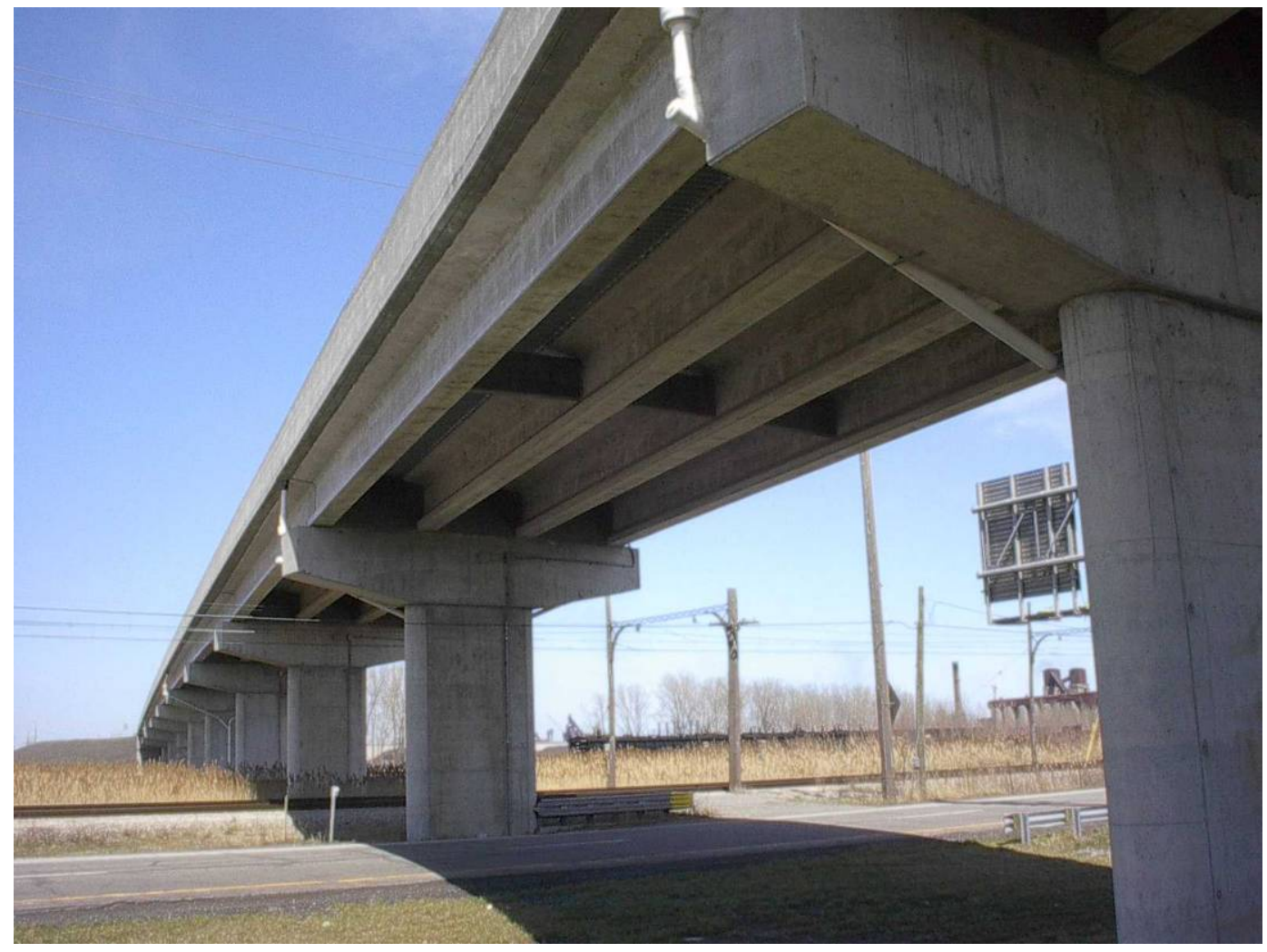

Figure 2.1: SR249 over US12 Bridge 


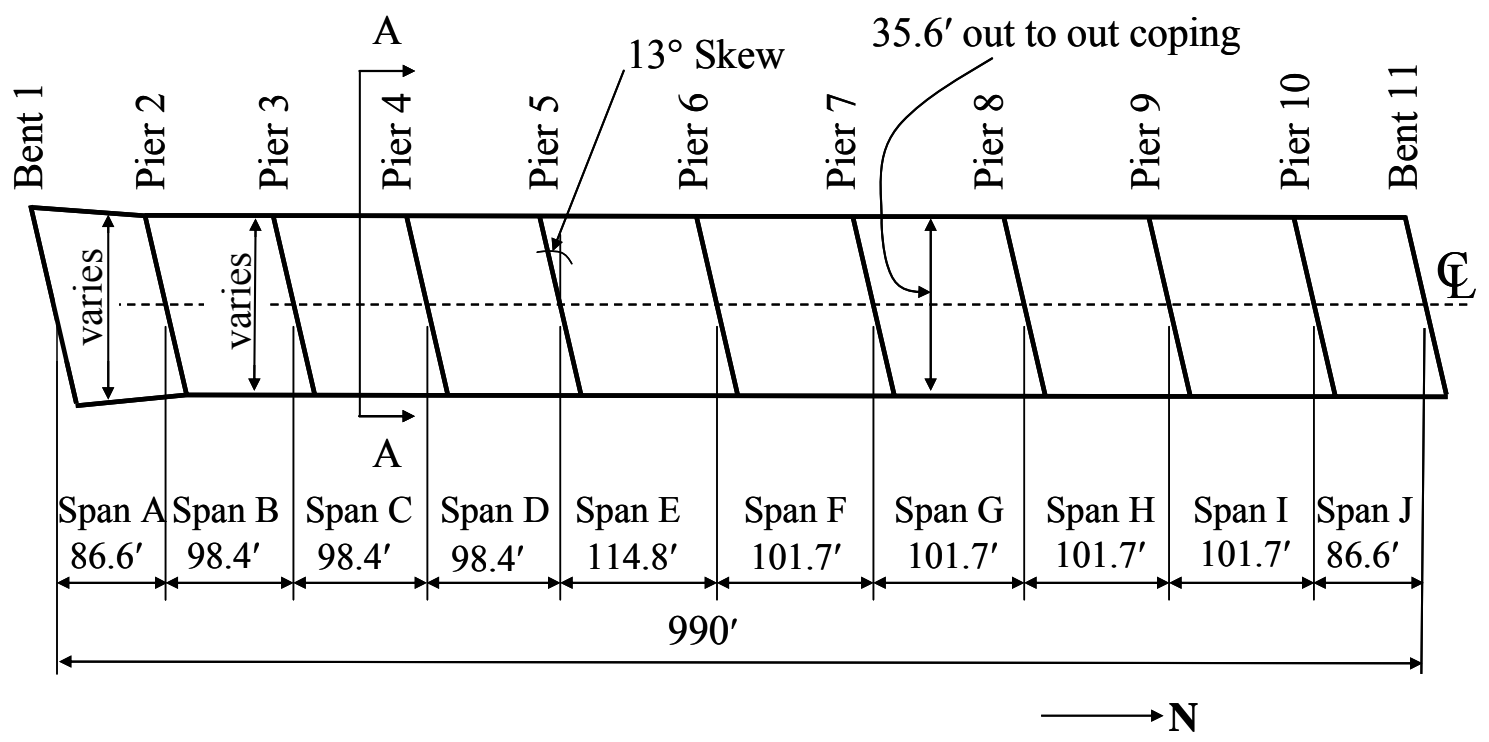

Figure 2.2: Plan View (SR249 over US12)

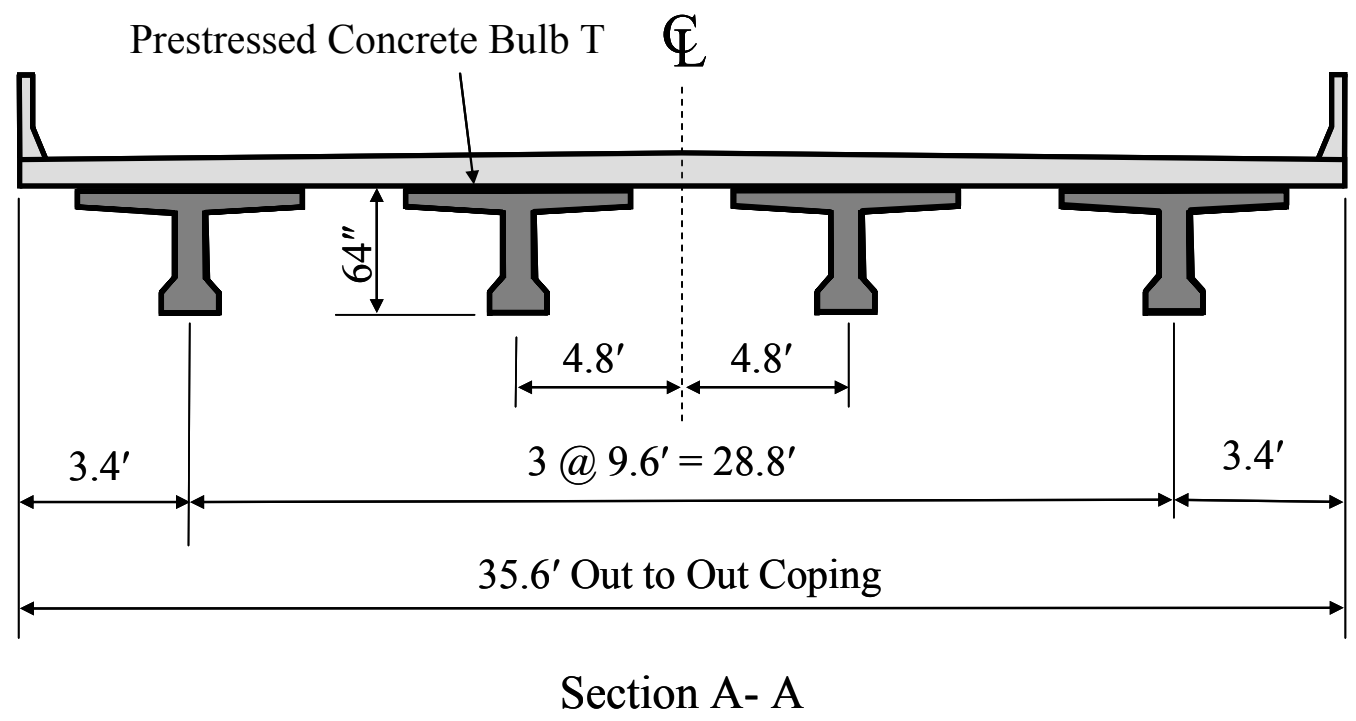

Figure 2.3: Typical Cross Section (Section A-A of Figure 2.2) (SR249 over US12) 


\subsubsection{End Bent/Pile Design}

\subsubsection{End Bent}

The end bents are supported on steel HP14x89 (HP360x132-SI) piles embedded 18 in. $(450 \mathrm{~mm})$ into the end bent pile cap. A single row of six piles supports Bent 1, and a single row of five piles supports Bent 11 as shown in Figure 2.4. Piles were oriented to provide strong axis bending with respect to the longitudinal axis of the bridge. The total pile length is approximately $131 \mathrm{ft}(40 \mathrm{~m})$ for piles on Bent 1, and all piles were driven to a bearing capacity of 245 tons $(2182 \mathrm{kN})$ according to the INDOT pile driving record provided in Appendix B. The total pile length is approximately $164 \mathrm{ft}(50 \mathrm{~m})$ for piles on Bent 11, and all piles were driven to a bearing capacity of 240 tons $(2143 \mathrm{kN})$. Figure 2.5 illustrates the piles included in Bents 1 and 11. The piles are embedded $1.5 \mathrm{ft}$ in the abutment. The pile length below ground is approximately $113 \mathrm{ft}$ and $143 \mathrm{ft}$ for piles on Bents 1 and 11, respectively. An expanded polystyrene (EPS) was placed behind the end bents (Figure 2.6). The EPS fill was used to eliminate the effect of passive earth pressure on the end bents. Consequently, the piles are unsupported above ground. End bent details of the bridge are included in Appendix C.

\subsubsection{Pile Design}

All piles were designed considering both the vertical loads and the horizontal thermal movement. The axial load consisted of the dead load of the abutment, bridge deck, girder, and live load. The live load was based on HS20-44 truck and Michigan Truck Train loading No. 5 with distribution in accordance with the $16^{\text {th }}$ Edition of the AASHTO Standard Specifications (1996). H piles bending about their strong axis were selected because of the greater allowable stress permitted by the AASHTO specifications for this bending direction. The piles had $0.5 \mathrm{in}$. $(13 \mathrm{~mm})$ thick by $1 \mathrm{ft}(300 \mathrm{~mm})$ high expanded polystyrene placed around the pile in the abutment to simulate a pinned connection. 


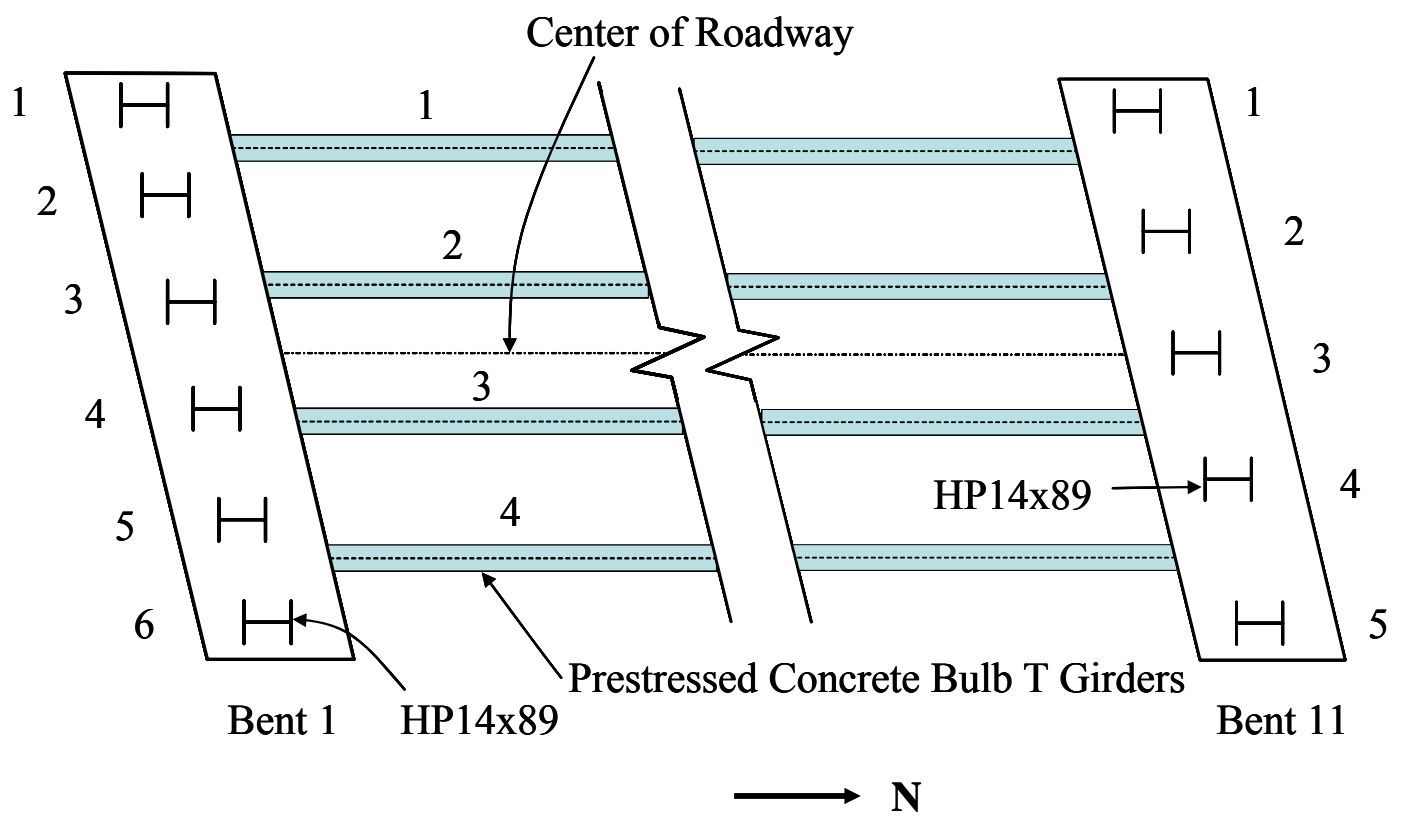

Figure 2.4: Bents 1 and 11 Plan Views (SR249 over US12)

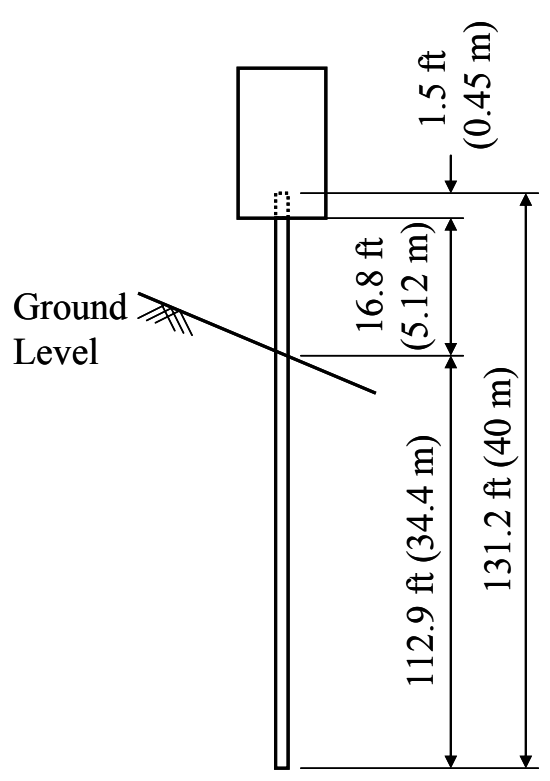

Bent 1

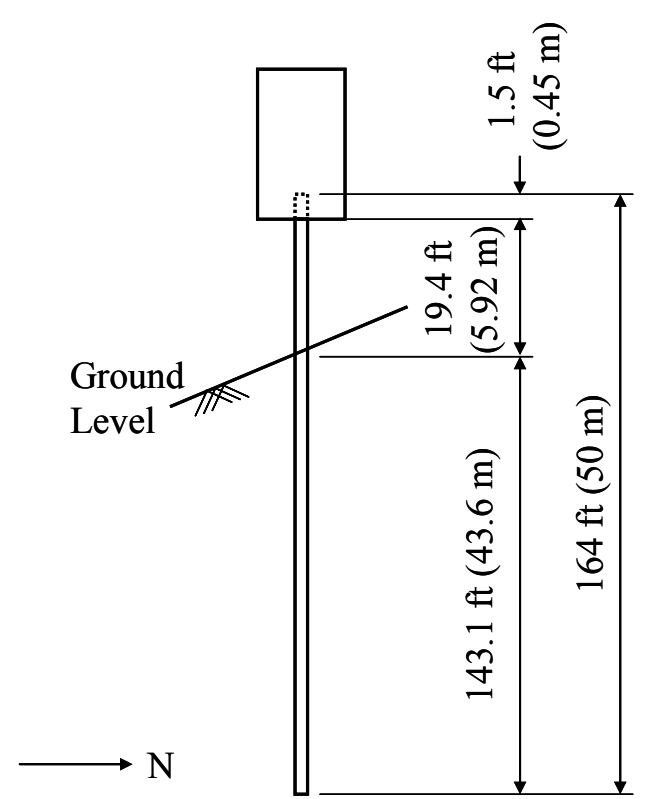

Bent 11

Figure 2.5: Typical Pile Length (SR249 over US12) 


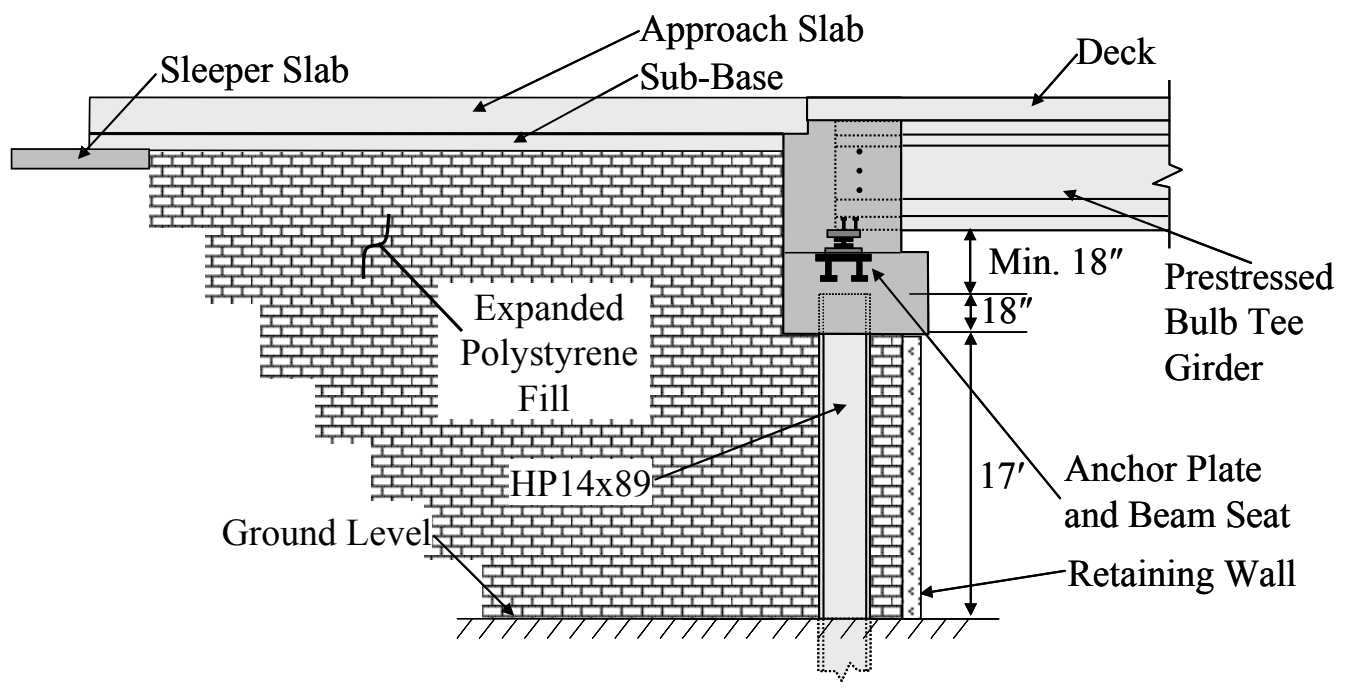

Figure 2.6: Expanded Polystyrene (SR249 over US12)

\subsubsection{Soil Borings}

The soil boring plan is provided in Figure 2.7. Soil boring No. 1 and 10 (TB-1 and TB-10) are representative of soils at Bents 1 and 11 as tabulated in Tables 2.2 and 2.3 , respectively. The value of $\mathrm{N}$ from the Standard Penetration Test (SPT) indicates the average number of blows required to drive a 1.375 in. inner diameter (I.D.), 2 in. outer diameter (O.D.) split spoon sampler $12 \mathrm{in.} \mathrm{by} \mathrm{means} \mathrm{of} \mathrm{a} 140 \mathrm{lb}$ weight falling $30 \mathrm{in}$. The ground water table was measured $4.2 \mathrm{ft}$ from ground level for Bent 1, while it was $5.9 \mathrm{ft}$ from ground level for Bent 11. Soil profiles for Bents 1 and 11 are shown in Figure 2.8.

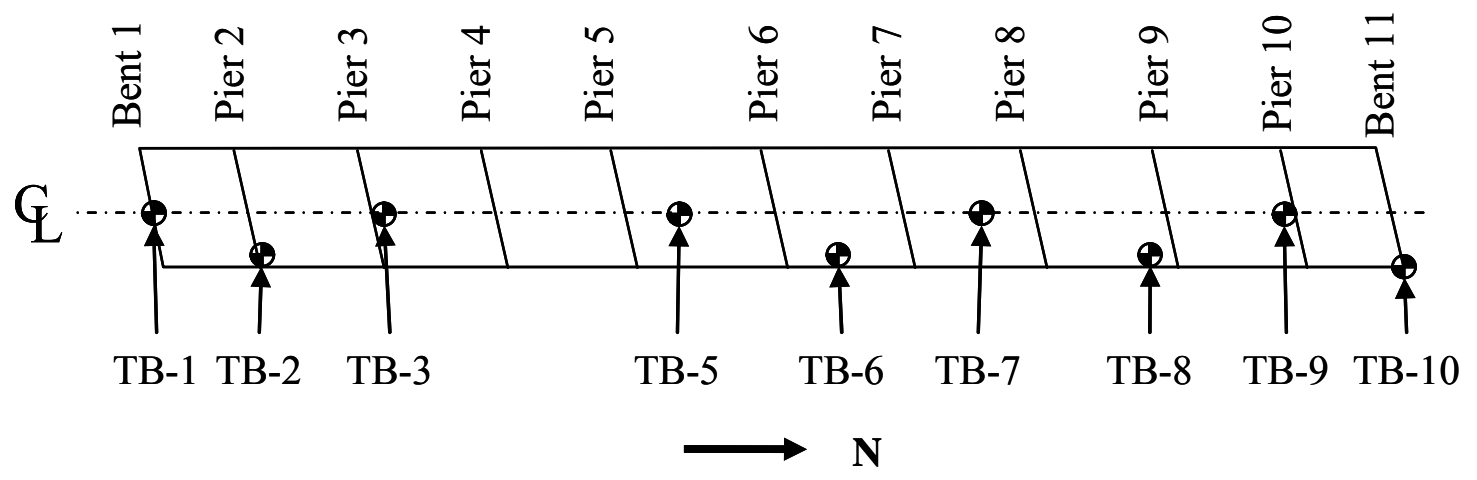

Figure 2.7: Soil Boring Plan (SR249 over US12) 
Table 2.2: Soil Boring Data from TB-1 for Bent 1 (SR249 over US12)

\begin{tabular}{|c|c|c|l|}
\hline $\begin{array}{c}\text { Depth from } \\
\text { Ground } \\
\text { Level (ft) }\end{array}$ & $\mathbf{N}$ & \\
\hline 0 & 3 & - & Gravelly sand, dark brown (visual) \\
\hline 2.5 & 10 & 18 & $\begin{array}{l}\text { SAND, medium dense, moist to wet after } 4.6 \mathrm{ft}, \text { brown to gray after } \\
6.9 \mathrm{ft}\end{array}$ \\
\hline 10 & 15 & 2 & PEAT, moist, black with occasional sand seams (visual) \\
\hline 15 & 20 & 0 & MARL, moist, dark gray \\
\hline 20 & 35 & 14 & SAND, medium dense to loose, wet, gray \\
\hline 35 & 45 & 2 & MARL, moist, dark gray \\
\hline 45 & 60 & 19 & $\begin{array}{l}\text { SAND, medium dense, wet, gray, with occasional thin silty clay } \\
\text { seams (visual) }\end{array}$ \\
\hline 60 & 65 & 21 & SILTY LOAM, very stiff wet, gray \\
\hline 65 & 75 & 36 & SAND, dense, wet, gray \\
\hline 75 & 80 & 13 & SILTY LOAM, medium dense, wet, gray \\
\hline 80 & 100 & 47 & $\begin{array}{l}\text { SAND, dense to very dense, wet, gray, occasional thin silty clay } \\
\text { seams. }\end{array}$ \\
\hline 100 & 110 & 14 & CLAY, hard to stiff, moist, gray \\
\hline 110 & 115 & - & SAND, very dense, wet, gray (visual) \\
\hline 115 & 130 & 56 & SILTY LOAM, hard, moist, gray \\
\hline
\end{tabular}


Table 2.3: Soil Boring Data from TB-10 for Bent 11 (SR249 over US12)

\begin{tabular}{|c|c|c|l|}
\hline $\begin{array}{c}\text { Depth from } \\
\text { Ground } \\
\text { Level (ft) }\end{array}$ & N & \\
\hline 0 & 10 & 11 & $\begin{array}{l}\text { SAND, medium dense to very loose, moist to wet, brown, } \\
\text { occasional thin peat seams from 3.6 ft to 7.9 ft }\end{array}$ \\
\hline 10 & 15 & - & MARL, moist, dark gray (visual) \\
\hline 15 & 35 & 19 & SAND, medium dense, wet, gray \\
\hline 35 & 40 & - & PEAT, moist, black (visual) \\
\hline 40 & 45 & 4 & MARL, moist, dark gray \\
\hline 45 & 55 & 14 & SAND, medium dense, wet, gray \\
\hline 55 & 60 & 8 & SILTY LOAM, loose, wet, gray \\
\hline 60 & 85 & 36 & $\begin{array}{l}\text { SAND, medium dense to very dense, wet, gray, occasional thin silty } \\
\text { loam seams }\end{array}$ \\
\hline 85 & 100 & 19 & $\begin{array}{l}\text { SILTY CLAY, very stiff to medium stiff, moist, gray, occasional } \\
\text { thin to interbedded fine sand and silt seams }\end{array}$ \\
\hline 100 & 115 & 18 & SILTY LOAM, very stiff, moist, gray, occasional thin sand seams \\
\hline 115 & 120 & 32 & SAND, dense, wet, gray \\
\hline 120 & 140 & 39 & SILTY LOAM, hard, moist, gray, occasional thin sand seams \\
\hline
\end{tabular}




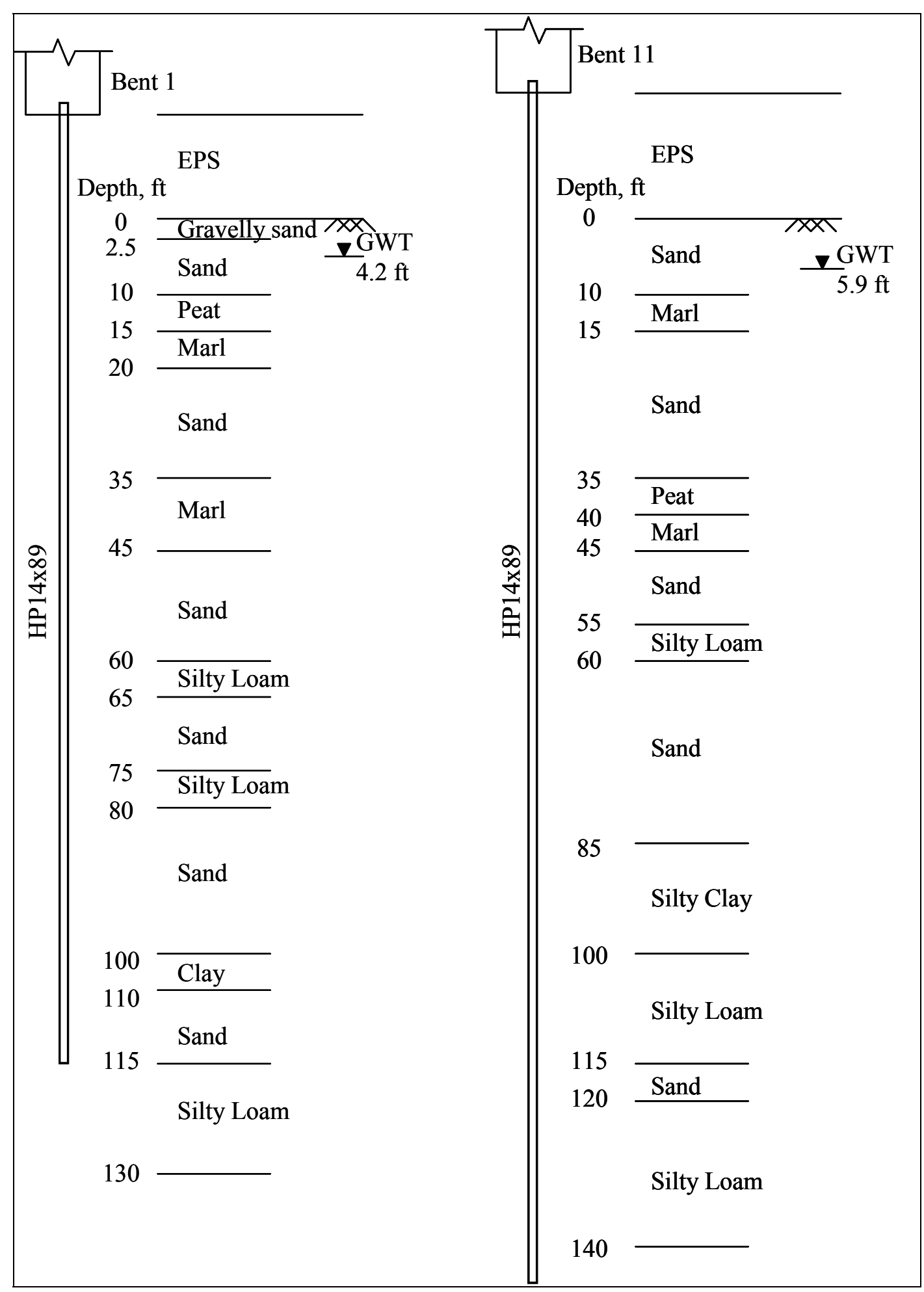

Figure 2.8: Soil Profile (SR249 over US12) 


\subsubsection{Structural Materials}

\subsubsection{Concrete}

According to Bridge Design Memorandum \#246 (INDOT, 1992c), the superstructure shall be Class $\mathrm{C}$ concrete with a 28-day design compressive strength $\left(\mathrm{f}_{\mathrm{c}}^{\prime}\right)$ of 4,000 psi. However, for the SR249 over US12 bridge, INDOT Class C concrete was used for both the superstructure and the substructure for Bents 1 and 11. Structural concrete for piers excluding footings was INDOT Class A $\left(\mathrm{f}_{\mathrm{c}}^{\prime}=3,500 \mathrm{psi}\right.$.), while INDOT Class B concrete $\left(\mathrm{f}_{\mathrm{c}}^{\prime}=3,000 \mathrm{psi}\right)$ was used for footings. The bridge deck was cast in phases which began on September 16, 1999 and finished on October 11, 1999. The complete construction sequence is provided in Appendix D.

\subsubsection{Piles}

The HP14x89 piles were supplied in accordance with AASHTO M 183 (INDOT Standard Specifications, 1999).

\subsubsection{Instrumentation Design}

The objective of the bridge instrumentation was to investigate the behavior of the end bents and piles. Since direct movement of the end bent displacement was not possible, these displacements will be extrapolated from data obtained in combination from instrumentation provided on the end bents as well as instrumentation of adjacent piers. Details of the instrumentation scheme provided across the bridge including the bents, piles, and piers are discussed.

\subsubsection{Bent Instrumentation}

Bents 1 and 11 were instrumented similarly, and the instrumentation scheme for these end bents is shown in Figure 2.9. All instruments were manufactured by Geokon, Inc. A tiltmeter (Model 6350) was used to measure the rotation of the abutment and was located at the center of the abutment, 20 in. below the bottom of Girder 3 (Figure 2.10). A tiltmeter was located on the north side of Bent 1 and on the south side of Bent 11. In 
addition, a crackmeter (Model 4420) with a capacity of 6 in. and a gage length of 27 in. was used to measure the displacement of the girder relative to the abutment. The crackmeter was connected at the bottom of Girder 3 and the abutment (Figure 2.10). All instruments incorporate thermistors that enable temperatures to be monitored along with the gages.

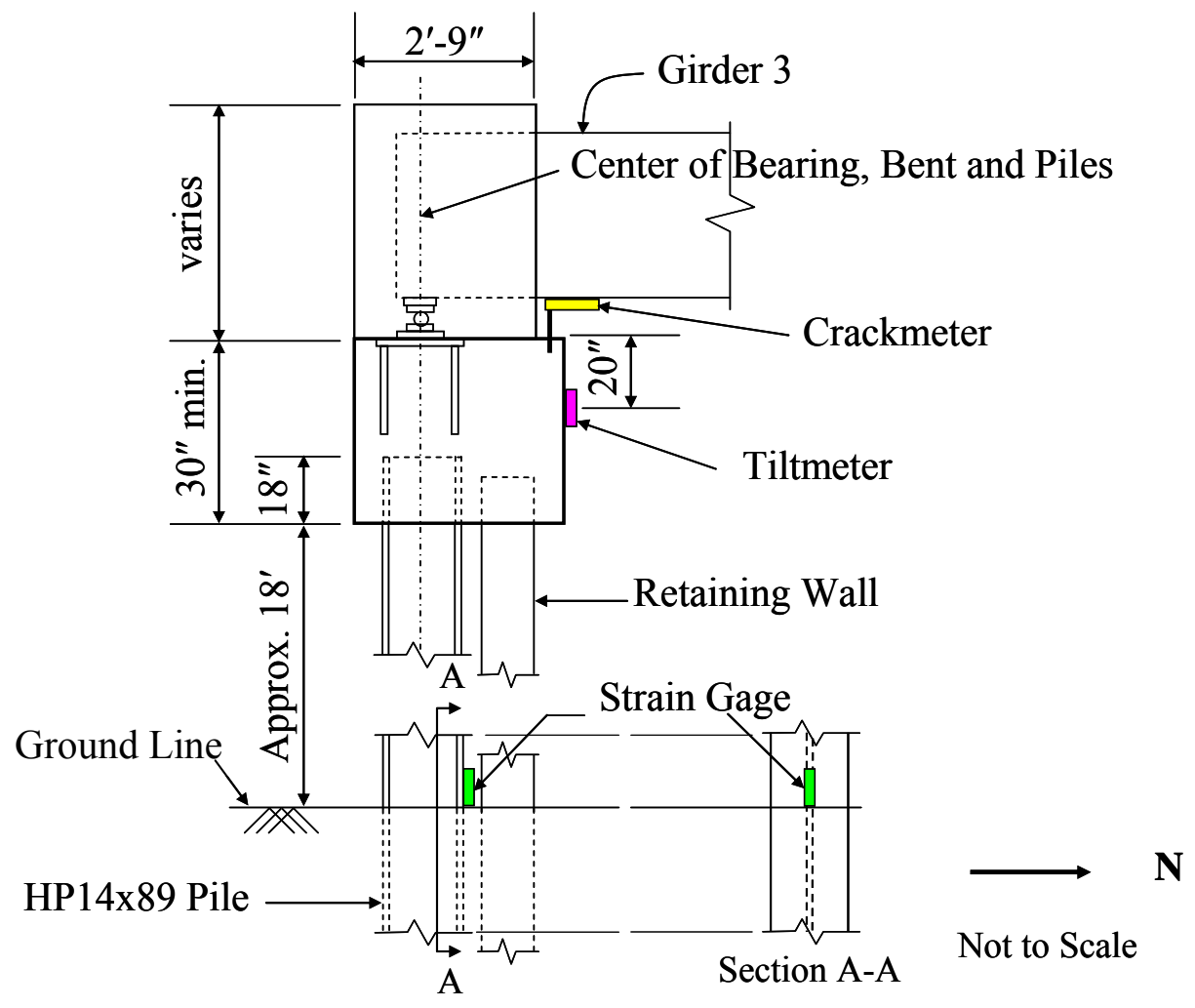

Figure 2.9: End Bent Instrumentation (SR249 over US12)

\subsubsection{Pile Instrumentation}

The behavior of the piles supporting the integral abutment was of particular interest. To investigate the behavior of the piles, strain gages (Model VK-4100) were installed on the piles of each end bent at ground level (at the bottom of the expanded polystyrene (EPS) fill level) as shown in Figure 2.11. Strain gages were spot welded at the center of the pile flange on the north face of the flange on Bent 1 and on the south face of the flange on Bent 11 as illustrated in Section A-A in Figure 2.9. 


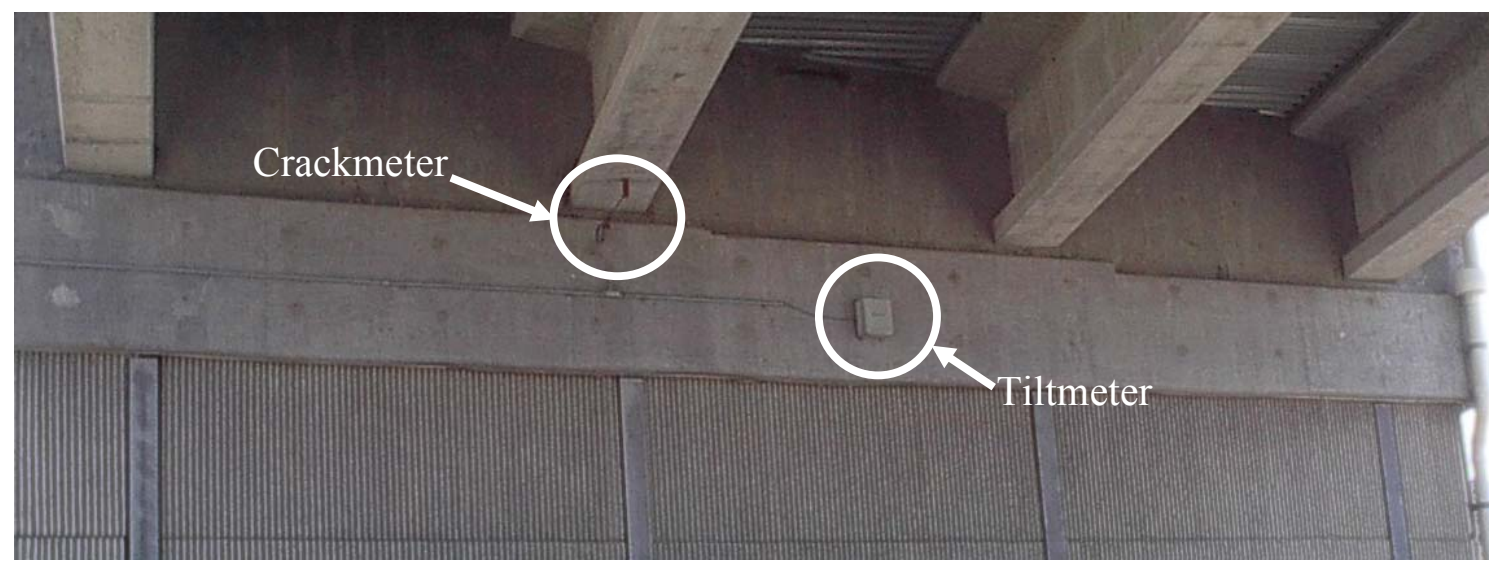

Figure 2.10: Crackmeter and Tiltmeter Locations on Bent 1 (SR249 over US12)

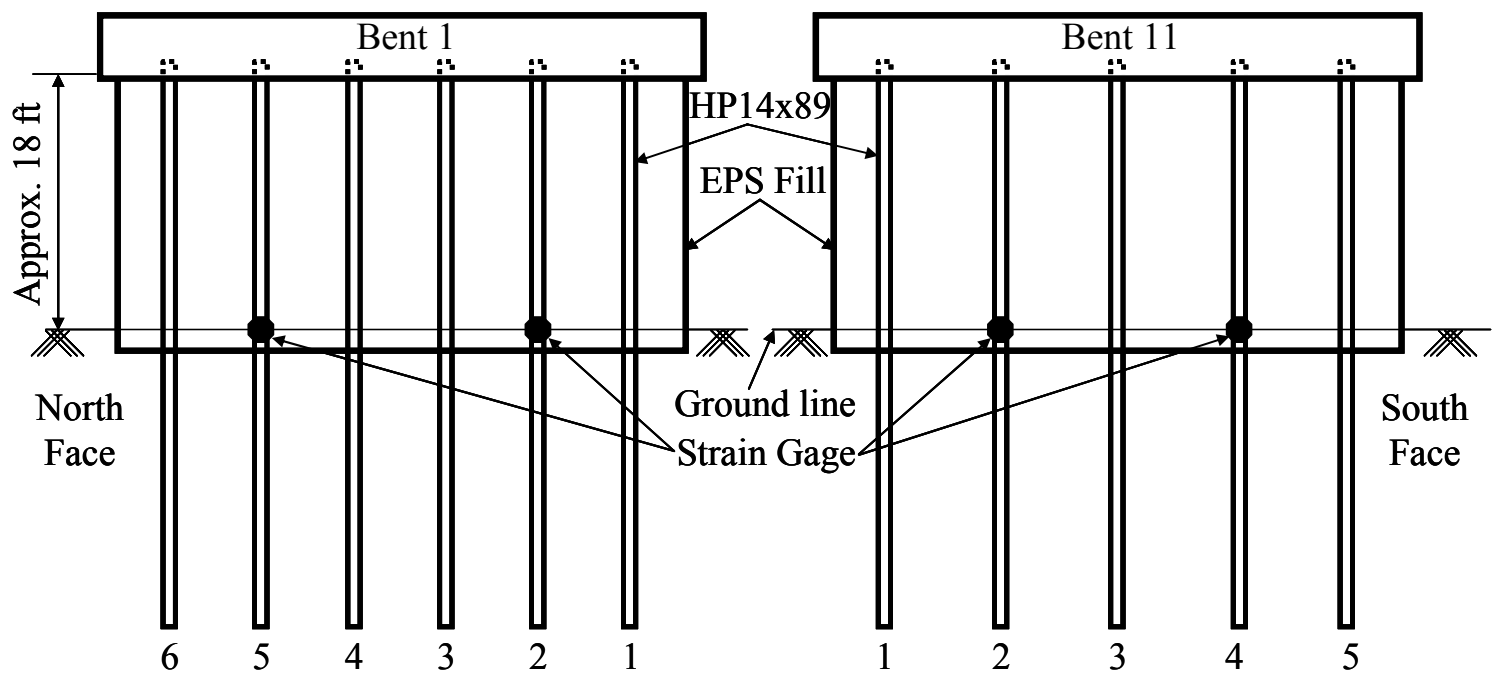

Figure 2.11: Pile Instrumentation (SR249 over US12)

\subsubsection{Pier Instrumentation}

Several of the piers were selected for instrumentation to evaluate movement of the piers as well as to enable estimation of the end bent movement. Rebar strain gages, crackmeters, and tiltmeters were used to determine movement at the top of the pier. Figure 2.12 shows the locations of tiltmeters and crackmeters on Pier 2. End bent movements were extrapolated from the calculated pier movements. 


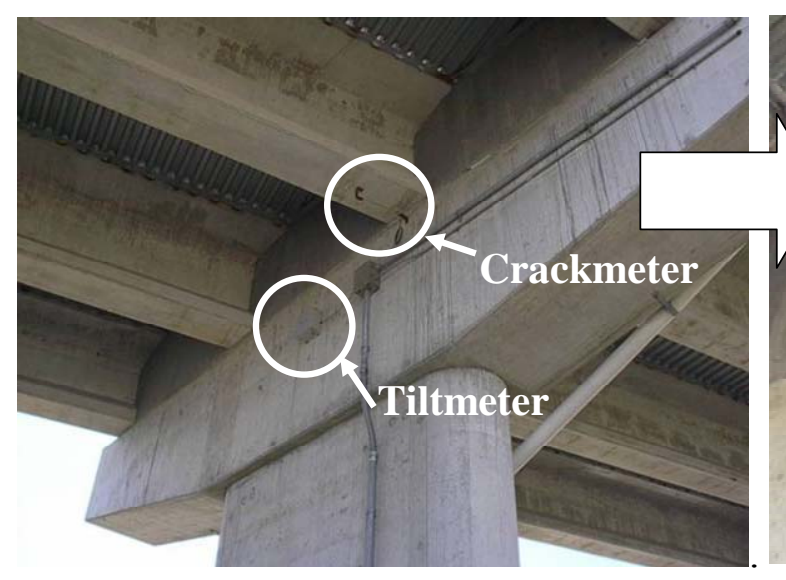

(a) Top of Pier 2

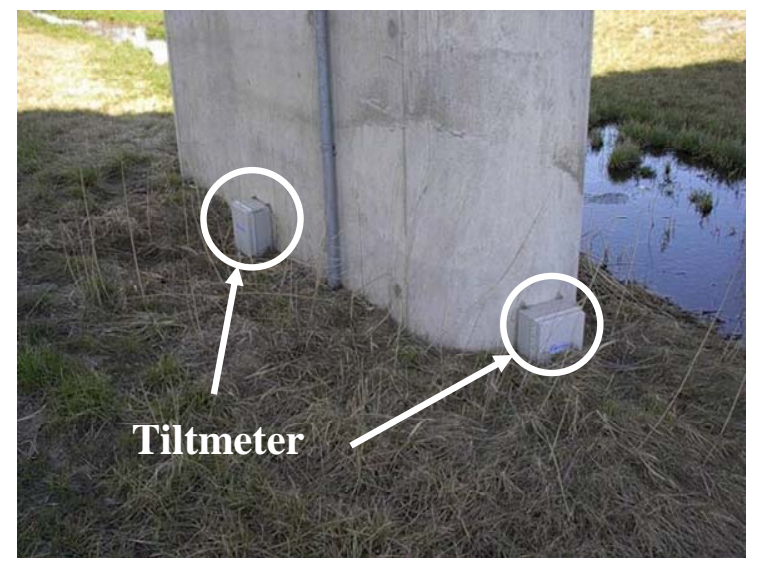

(c) Bottom of Pier 2

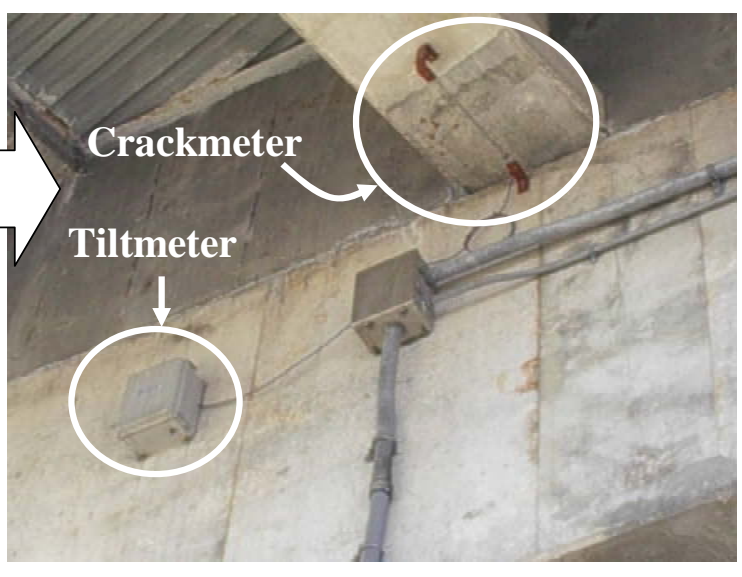

(b) Top of Pier 2

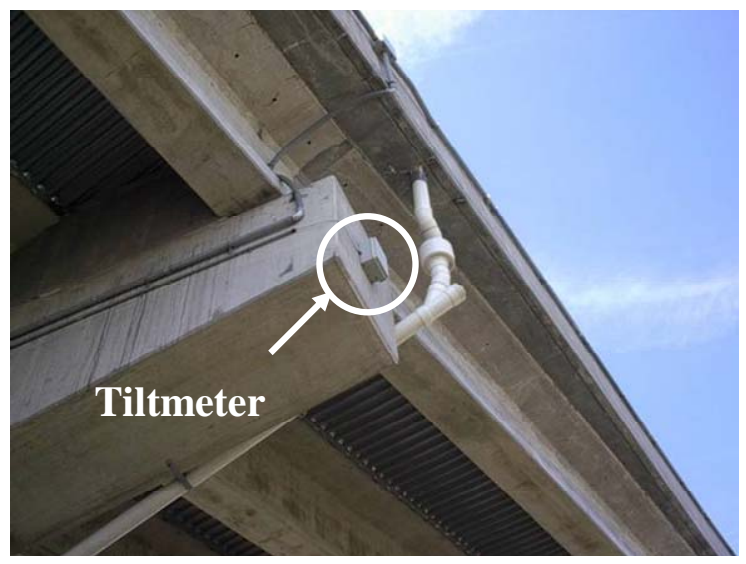

(d) Top of Pier 2 (East Side)

Figure 2.12: Tiltmeter and Crackmeter Locations (SR249 over US12)

\subsection{Piers 2 and 10}

Piers 2 and 10 were instrumented identically (Figure 2.13). A crackmeter was used to measure the displacement of Girder 3 relative to the pier to evaluate relative movement between the pier and the girder as well as to enable an estimate of the movement of the end bents. Rotations were measured by the tiltmeters at the base and pier top. These gages were used to evaluate footing rotations and pier top rotations such that the deflection of the pier could be estimated based on calculations. Tiltmeters on both Piers 2 and 10 were mounted on the south and east faces (Figure 2.13) to measure rotations about both axes of the pier to enable evaluation of the effect of bridge skew. 
In addition, six rebar strain gages (Model 4911) were provided around the perimeter of the base of the pier to determine the magnitude of axial and bending forces resisted by the pier (Figure 2.14). These gages were installed at sister bars adjacent to the actual rebar. The combination of these gages was used to determine the forces experienced by the piers as well as their deflections.

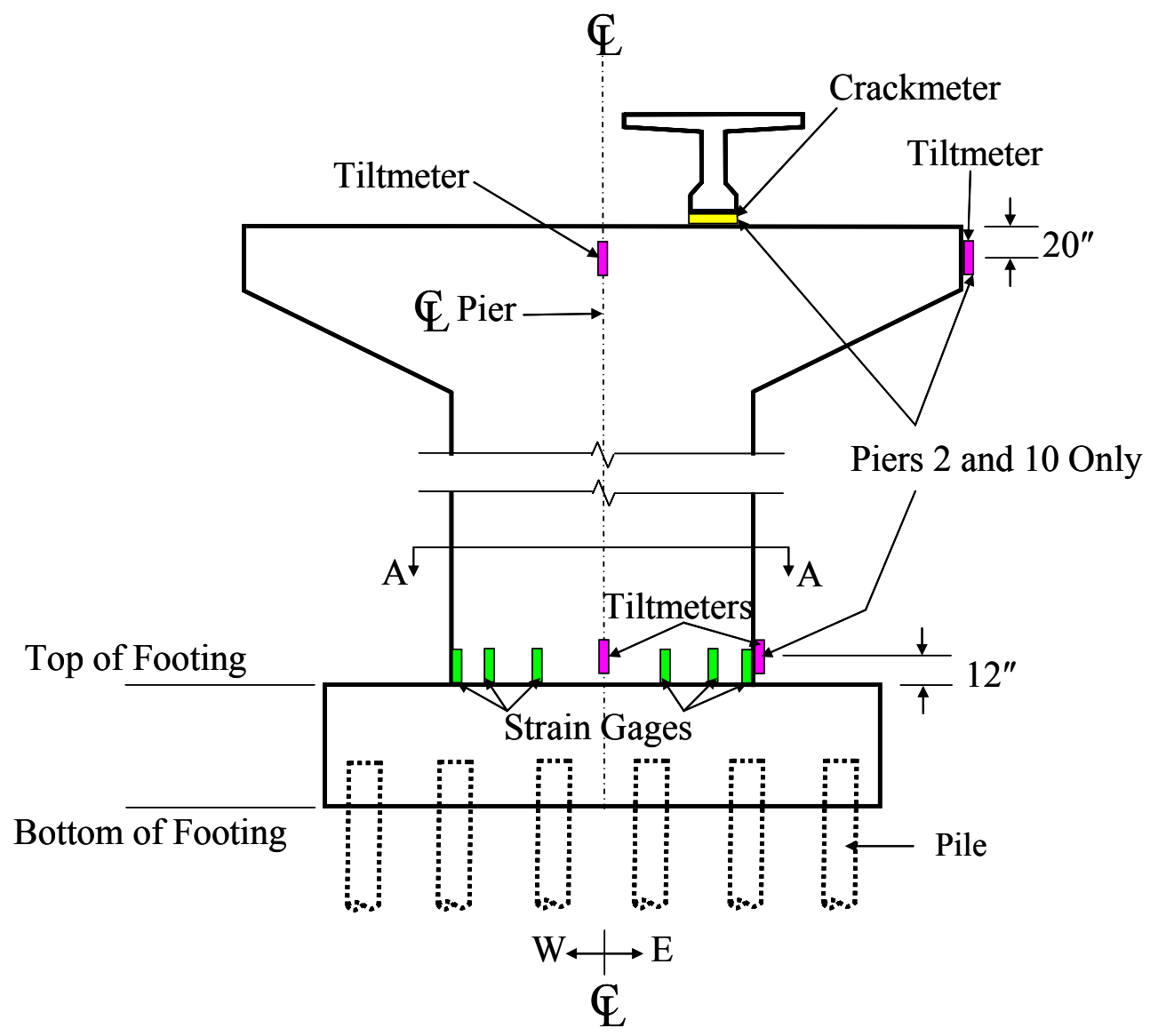

Figure 2.13: Pier Instrumentation (SR249 over US12)

\subsection{Piers 3, 4, and 5}

Piers 3, 4, and 5 were instrumented identically. Tiltmeters were located at the top and bottom on the south face (Figure 2.13). Furthermore, rebar strain gages were located at the base similar to Piers 2 and 10, with the exception that gages were not located on the east and west faces (Figure 2.14). The instrumentation of the SR 249 over US 12 bridge is summarized in Figure 2.15. 


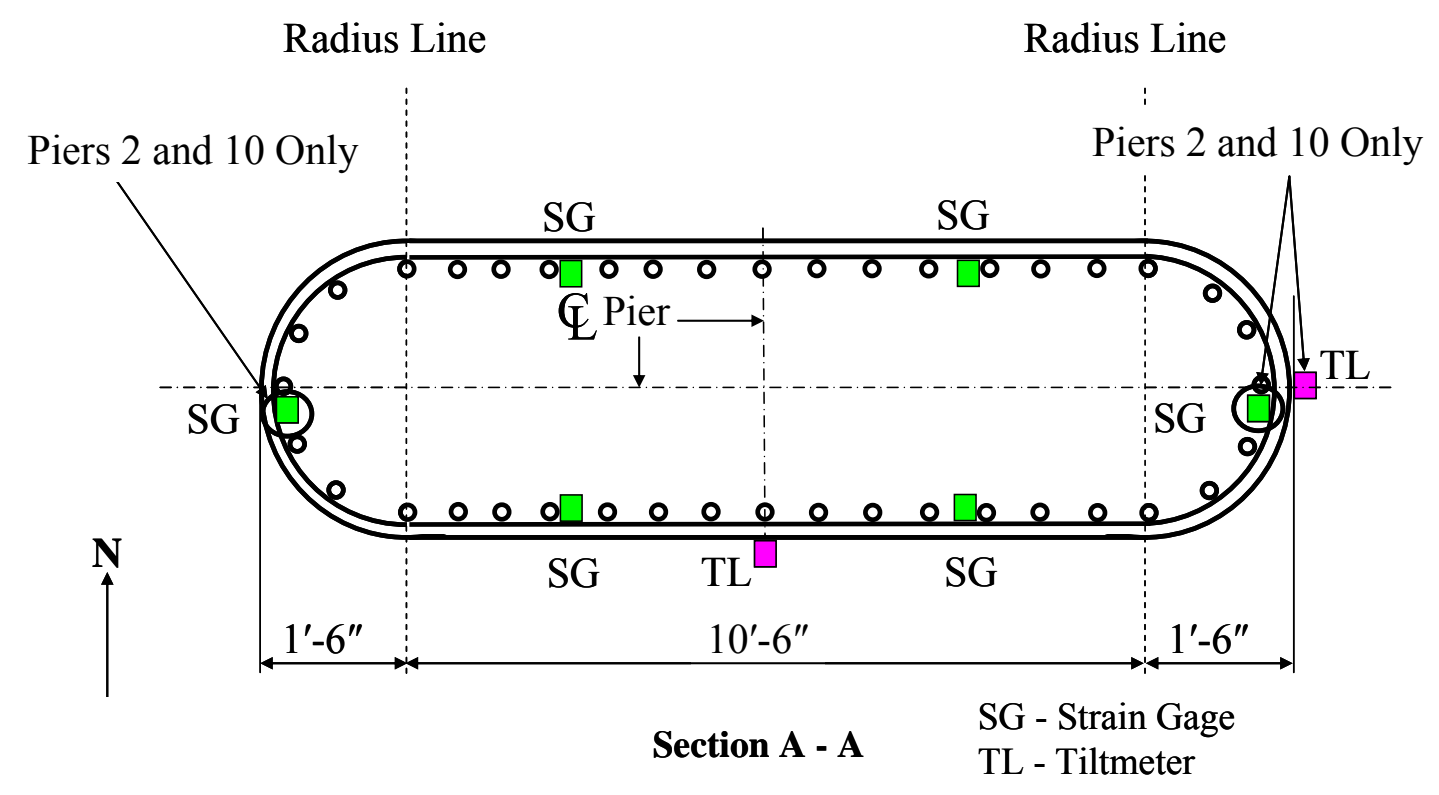

Figure 2.14: Strain Gages and Tiltmeter Locations (Section A-A of Figure 2.13) (SR249 over US12)

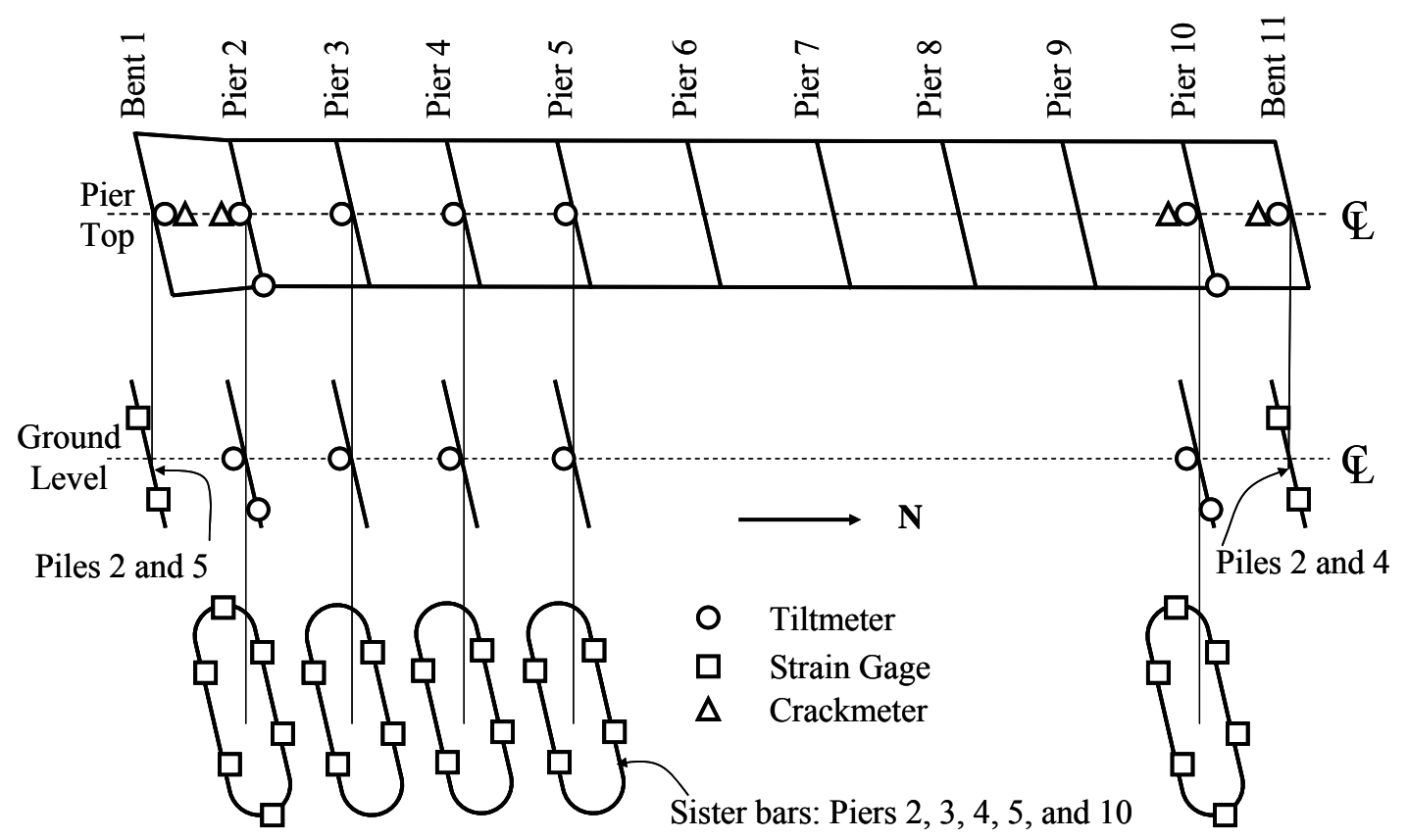

Figure 2.15: Bridge Instrumentation (SR249 over US12) 


\subsubsection{Data Acquisition}

A Model 8020 MICRO-10 Datalogger and four Model 8032 Multiplexers provided by Geokon Inc. were required to record the data from the instruments previously discussed. It should be noted that tiltmeters and crackmeters were installed after the bridge was cast, while strain gages were installed before casting. The initial reading date of each multiplexer is shown in Table 2.4. All gages were zeroed at the initial reading date and read hourly. Therefore, the values recorded from all gages are relative to the day that gages started reading.

Table 2.4: Multiplexers (SR249 over US12)

\begin{tabular}{|c|l|c|}
\hline Multiplexer & \multicolumn{1}{|c|}{ Gages } & Initial Reading Date \\
\hline 1 & - All tiltmeters & May 17, 2000 at 11:00AM \\
\hline 2 & - Rebar strain gages on Piers 2, 3, and 10 & June 7, 2000 at 9:00AM \\
\hline 3 & $\begin{array}{l}\text { - Rebar strain gages on Piers 4 and 5 } \\
- \text { All crackmeters }\end{array}$ & June 7, 2000 at 9:00AM \\
\hline 4 & $\begin{array}{l}\text { - Pile strain gages on Bents 1 and 11 } \\
- \text { Temperature gages }\end{array}$ & June 7, 2000 at 9:00AM \\
\hline
\end{tabular}

\subsubsection{Problems}

Problems with the instrumentation system for the SR249 over US12 bridge began on August 18, 2000 as summarized in Table 2.5. The system was reinstalled and failed on July 23, 2001. Figure 2.16 provides a summary of the inoperable gage locations. Solid shapes indicate that the gage has been malfunctioning since July 23, 2001.

Rebar strain gages started reading on June 7, 2000 and a large number of gages (Figure 2.16) failed on July 23, 2001. Recorded data beyond July 23, 2001 is not considered reliable; therefore, only data from June 7, 2000 to July 23, 2001 will be considered in this research. 
Table 2.5: Instrumentation Problem (SR249 over US12)

\begin{tabular}{|l|l|}
\hline \multicolumn{1}{|c|}{ Date } & \multicolumn{1}{|c|}{ Event } \\
\hline May 17, 2000 & All tiltmeters were zeroed and started reading. \\
\hline June 7, 2000 & $\begin{array}{l}\text { All rebar strain gages, all pile strain gages, and all crackmeters } \\
\text { were zeroed and started reading. All temperature gages started } \\
\text { reading. }\end{array}$ \\
\hline August 18,2000 & $\begin{array}{l}\text { A modem was installed incorrectly causing all gages to } \\
\text { malfunction. All gages read off-scale. }\end{array}$ \\
\hline December 8, 2000 & The system was back on-line and functioning properly. \\
\hline July 23, 2001 & $\begin{array}{l}\text { All gages read off-scale due to a problem with a multiplexer } \\
\text { board. The datalogger was subsequently removed from the bridge } \\
\text { and repaired by INDOT. }\end{array}$ \\
\hline April 10,2002 & $\begin{array}{l}\text { The system was repaired and Multiplexers 1, 2, and 3 were } \\
\text { operational. However, the data obtained from the bridge was very } \\
\text { sporadic. }\end{array}$ \\
\hline April 20,2002 & The complete system failed. \\
\hline April 25,2002 & Multiplexers 1 and 2 became operational. \\
\hline May 9, 2002 & $\begin{array}{l}\text { Multplexers 3 and 4 became operational. Although all } \\
\text { multiplexers were operational, several gages were out-of-range } \\
\text { due to damage to the recharging system. }\end{array}$ \\
\hline The multiplexers were removed and repaired by INDOT. \\
\hline May 13, 2002 & $\begin{array}{l}\text { The datalogger was removed and sent to Campbell Scientific for } \\
\text { repair. }\end{array}$ \\
\hline May 29, 2002 & $\begin{array}{l}\text { The datalogger was reinstalled with a reconfigured charging } \\
\text { system. Unfortunately, only Multiplexer 1 was operable and only } \\
\text { the thermistors in the tiltmeters provided reliable data. Some } \\
\text { tiltmeter data were out-of-range. The boards in Multiplexers 2, 3, } \\
\text { and 4 had electrical damage. Lightning was suspected. }\end{array}$ \\
\hline July 2, 2002 18,2002 & $\begin{array}{l}\text { All crackmeters and seven tiltmeters on the bridge were } \\
\text { malfunctioning. All temperature gages were no longer in-service. } \\
\text { Five rebar strain gages failed. }\end{array}$ \\
\hline
\end{tabular}




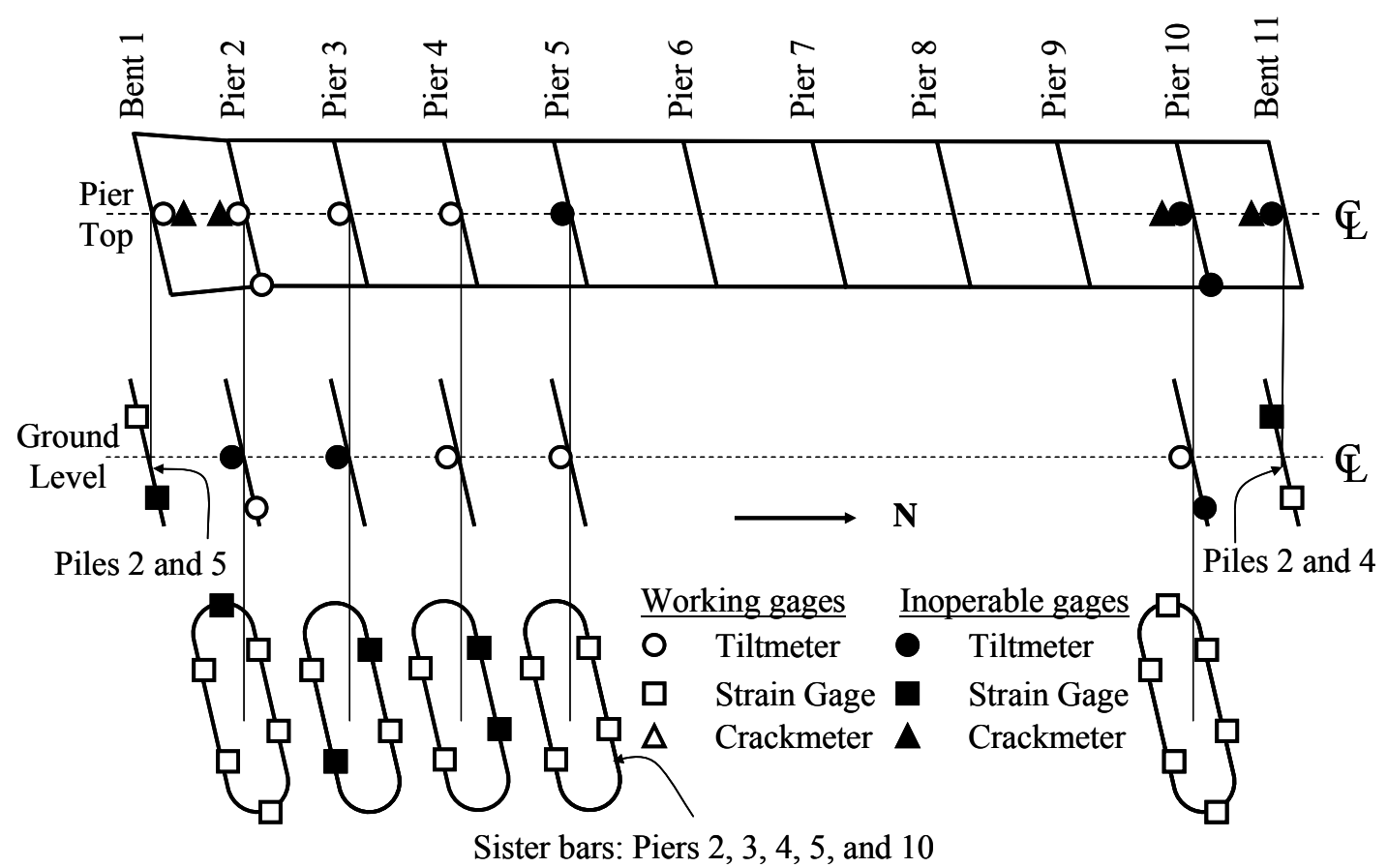

Figure 2.16: Malfunctioning Gage Locations (SR 249 over US12) 


\section{$2.3 \quad$ I65 over SR25 Bridges}

Due to the number of malfunctioning gages on the SR249 over US12 bridge, INDOT Bridges \#I-65-176-5543C (I65 over SR25) in Tippecanoe County were selected to investigate the general behavior of an integral abutment bridge. These bridges were chosen for study because they are considered typical integral bridges and their length and skew met current INDOT limitations.

Two identical bridges, one northbound and one southbound structures were instrumented. These bridges are located approximately 15 miles from Purdue University in Lafayette, Indiana. The bridges are two-span continuous, with seven-W36x150 steel girders supporting the concrete deck (Figure 2.17). The bridges have a total length of $152 \mathrm{ft}$ and a skew angle of $25^{\circ}$ relative to the abutments (Figure 2.18). An elevation view of the bridge is shown in Figure 2.19.

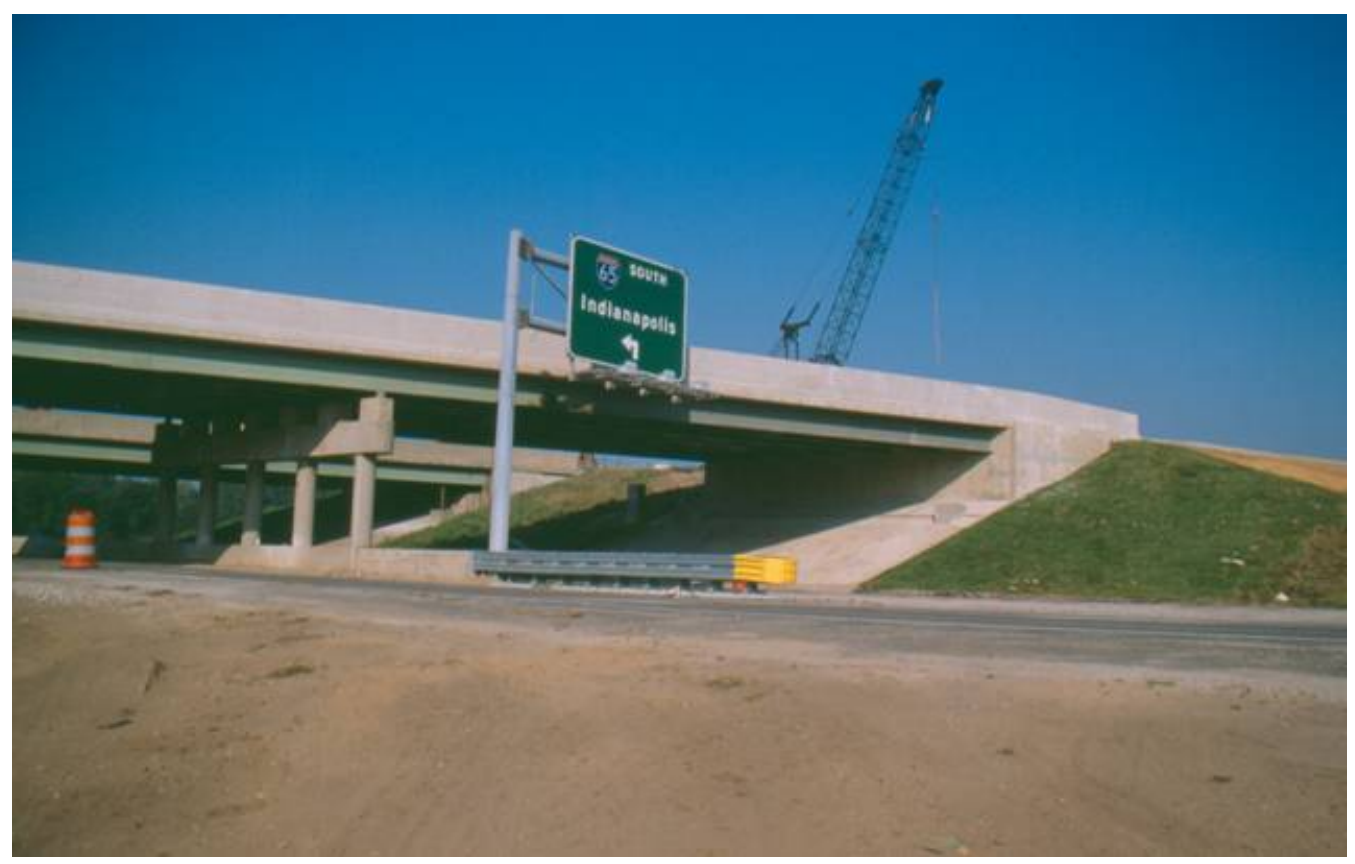

Figure 2.17: I65 over SR25 Northbound Structure 


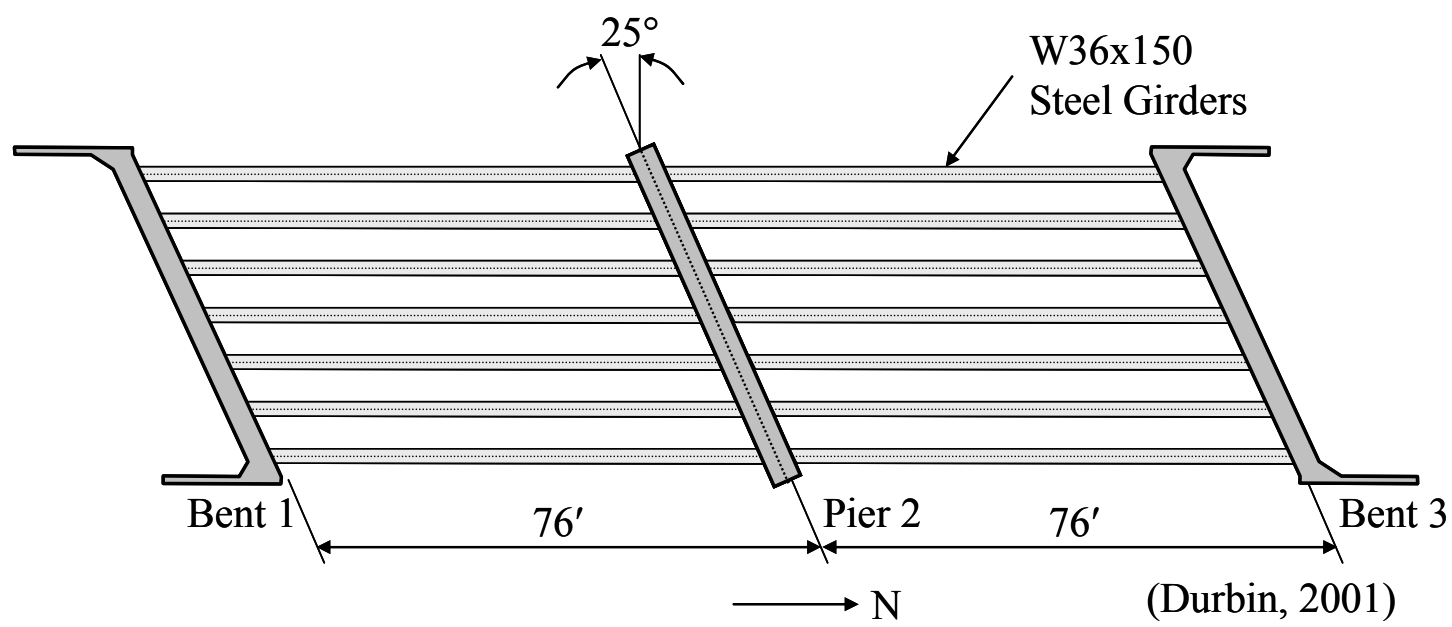

Figure 2.18: Plan View (I65 over SR25)

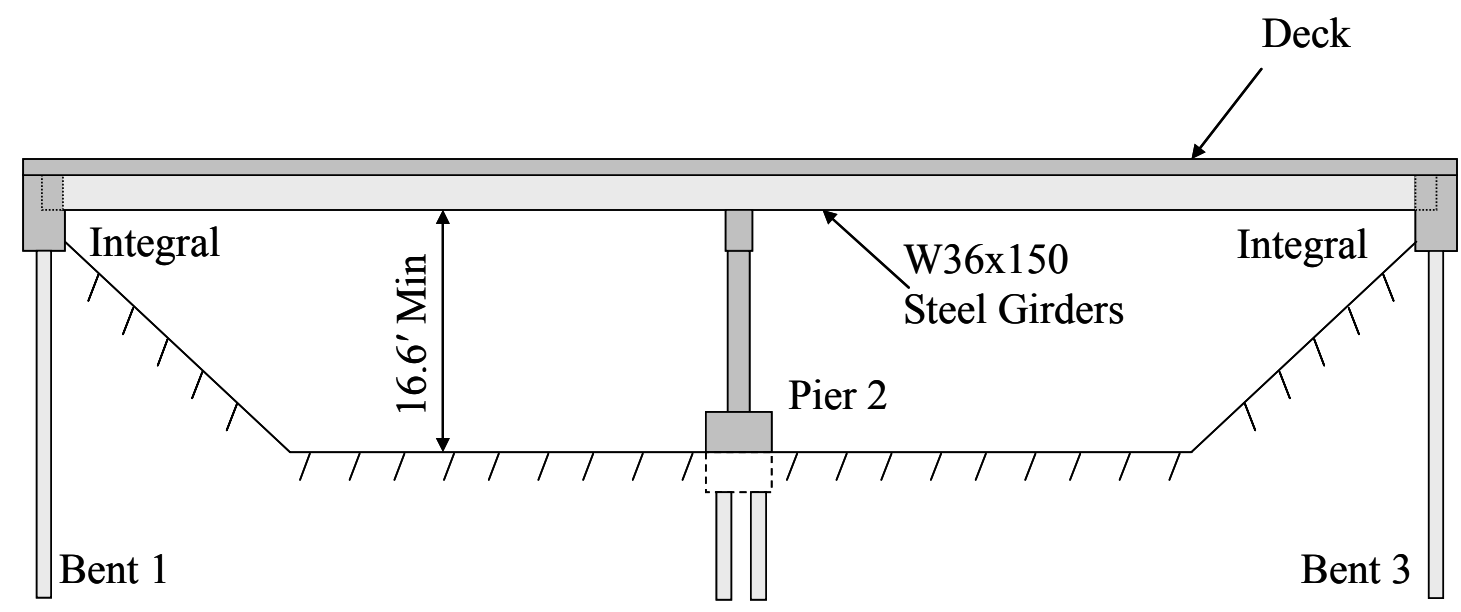

Figure 2.19: Profile View (I65 over SR25)

\subsubsection{End Bent/Pile Design}

\subsubsection{End Bent}

A single row of ten piles supports each abutment. Six HP12x53 steel piles bending about their weak axis and four $14 \frac{1}{2}$ in. diameter concrete-filled steel tube piles with a wall thickness of $1 / 4$ in. (CFT14.5x0.25) support each end bent. Because this project was a rehabitation, the four CFT piles were reused from the existing construction and the six $\mathrm{H}$ piles were added. The total pile length was approximately $42 \mathrm{ft}$, and the 
piles were driven to a bearing capacity of 100 tons according to the INDOT Pile Driving Record provided in Appendix B. The piles were embedded $2 \mathrm{ft}$ into the abutment as shown in Figure 2.20. Therefore, the pile length below ground level was approximately $40 \mathrm{ft}$. End bent details of the bridge are included in Appendix C.

\subsubsection{Pile Design}

All piles were designed for axial load only. The axial load consisted of the dead load of the abutment, bridge deck, girder, and wingwall. The live load was based on HS20-44 truck loading in accordance with the $16^{\text {th }}$ Edition of the AASHTO Standard Specifications (1996).

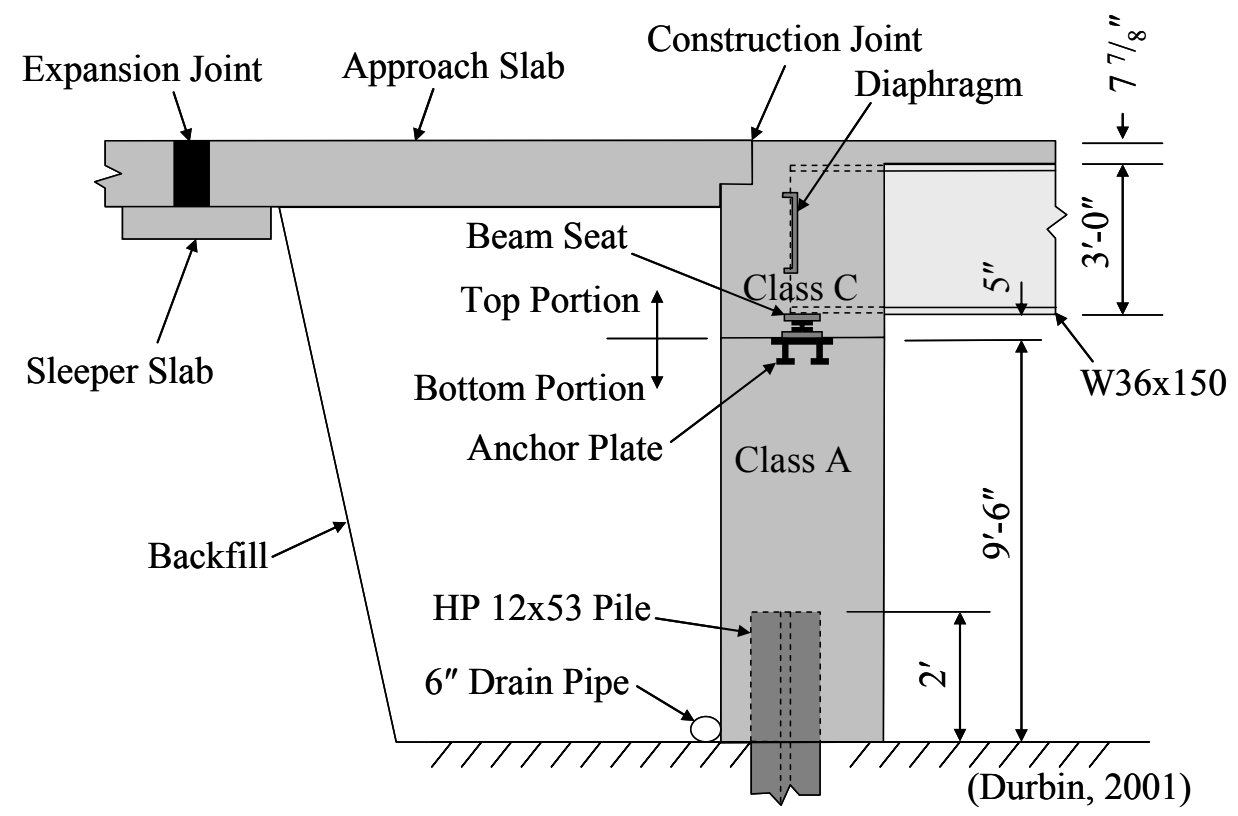

Figure 2.20: Profile View of Integral End Bent (I65 over SR25) 


\subsubsection{Soil Borings}

Soil borings were located at Bent 1 and Pier 2 for the southbound structure as well as at Pier 2 and Bent 3 for the northbound structure. Soil boring plans are provided in Figure 2.21. The soil boring logs are summarized in Tables 2.6 - 2.9. The SPT values are also provided. Soil borings No. 1 and 4 (TB-1 and TB-4) were considered as a representative soil profile for the southbound and northbound structures, respectively.
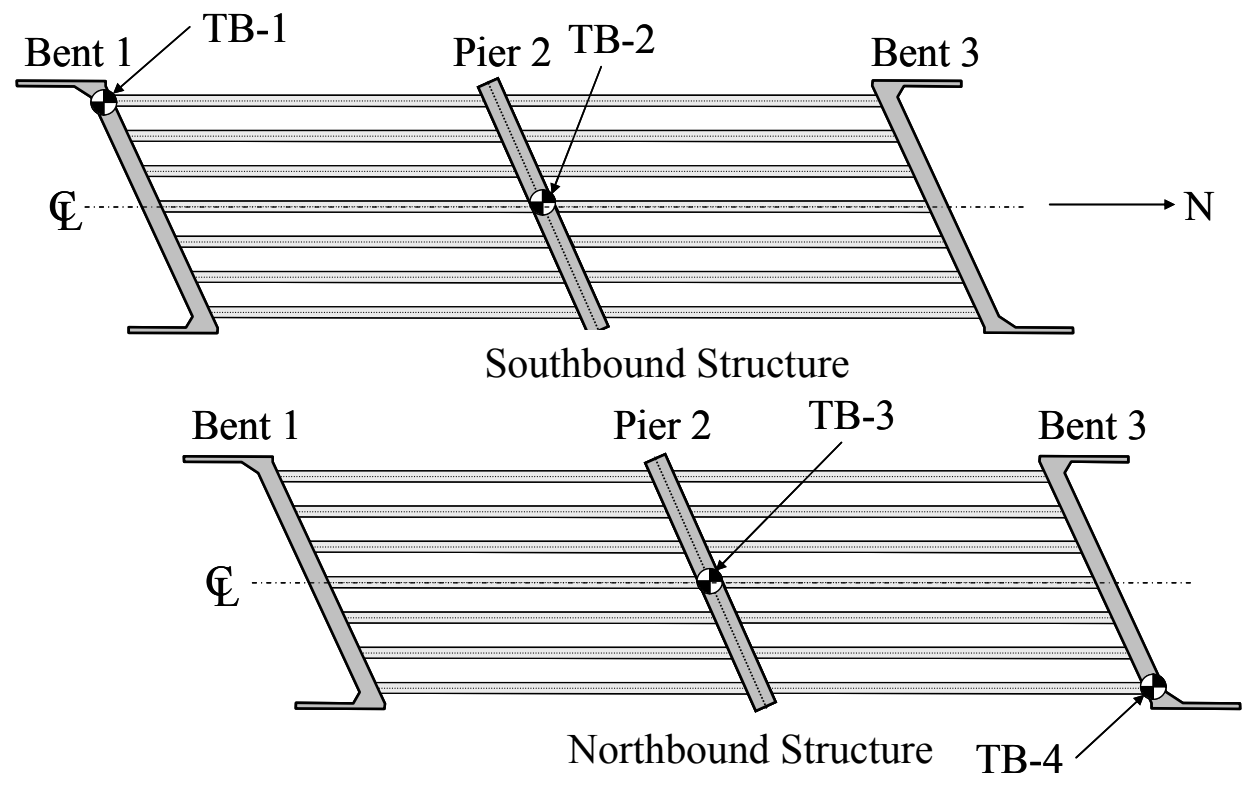

Figure 2.21: Soil Boring Plan (I65 over SR25)

Table 2.6: Soil Boring Log Data from TB-1 (I65 over SR25)

\begin{tabular}{|c|c|c|l|}
\hline $\begin{array}{c}\text { Depth from } \\
\text { Ground } \\
\text { Level (ft) }\end{array}$ & N & \\
\hline 0.0 & 1.0 & 5 & Gray moist soft sandy clay, trace of organic material \\
\hline 1.0 & 5.5 & 6 & Brown loose fine to medium sand \\
\hline 5.5 & 22.5 & 27 & $\begin{array}{l}\text { Brown medium dense fine to medium gravel with some fine to } \\
\text { medium sand, large gravel noted }\end{array}$ \\
\hline 22.5 & 26.5 & $*$ & Gray dense fine to medium sand, thin layers of silty clay \\
\hline 26.5 & 30.0 & 29 & Gray very hard clay loam, trace of fine sand and gravel \\
\hline
\end{tabular}

* Cored boulder

Note: Ground water table was $6.5 \mathrm{ft}$ below ground level 
Table 2.7: Soil Boring Log Data from TB-2 (I65 over SR25)

\begin{tabular}{|c|c|c|l|}
\hline $\begin{array}{c}\text { Depth from } \\
\text { Ground } \\
\text { Level (ft) }\end{array}$ & $\mathbf{N}$ & \multicolumn{1}{|c|}{ Soil Type } \\
\hline 0 & 8 & 26 & $\begin{array}{l}\text { Brown moist medium dense sand and gravel - Fill } \\
\text { Top soil noted at 8 feet }\end{array}$ \\
\hline 8 & 16 & 15 & Brown medium dense medium sand, a little clay \\
\hline 16 & 22 & 2 & Brown loose medium sand \\
\hline 22 & 32.5 & 27 & Brown medium dense coarse sand and gravel. \\
\hline 32.5 & 34 & $99 *$ & Gray moist very hard clay loam, trace of small gravel \\
\hline
\end{tabular}

$* 4$ in. Penetration

Note: Ground water table was $22.5 \mathrm{ft}$ below ground level

Table 2.8: Soil Boring Log Data from TB-3 (I65 over SR25)

\begin{tabular}{|c|c|c|l|}
\hline $\begin{array}{c}\text { Depth from } \\
\text { Ground } \\
\text { Level (ft) }\end{array}$ & N & \\
\hline 0 & 7.5 & 35 & Brown moist medium dense sand and gravel - Fill \\
\hline 7.5 & 8 & - & Topsoil \\
\hline 8 & 17 & 6 & Brown loose mediumsand, a little clay \\
\hline 17 & 28 & 28 & Brown medium dense, medium to coarse sand and small gravel \\
\hline 28 & 45 & 99 & $\begin{array}{l}\text { Gray moist very hard clay loam, trace of small gravel, seam of } \\
\text { sand and gravel at } 38 \mathrm{ft}\end{array}$ \\
\hline
\end{tabular}

Note: Ground water table was $8.5 \mathrm{ft}$ below ground level

Table 2.9: Soil Boring Log Data from TB-4 (I65 over SR25)

\begin{tabular}{|c|c|c|l|}
\hline $\begin{array}{c}\text { Depth from } \\
\text { Ground } \\
\text { Level (ft) }\end{array}$ & N & \\
\hline 0 & 1 & - & Top soil \\
\hline 1 & 8 & 6 & Brown moist loose medium sand, a little clay \\
\hline 8 & 22 & 25 & Brown medium dense coarse sand and small to medium gravel \\
\hline 22 & 30 & 99 & Gray moist very hard clay loam, trace of small gravel \\
\hline
\end{tabular}

Note: Ground water table was $10 \mathrm{ft}$ below ground level 


\subsubsection{Structural Materials}

\subsubsection{Concrete}

INDOT Class A concrete $\left(f_{c}^{\prime}=3,500\right.$ psi) was used for the substructure for the bottom portion of the abutment. Structural concrete for the superstructure which consisted of the top portion of the abutment and the bridge deck was INDOT Class C $\left(\mathrm{f}_{\mathrm{c}}^{\prime}=4,000 \mathrm{psi}\right)$.

The deck of the northbound structure was poured on August 15, 2000 from 7:00AM to 2:00PM, while the deck of the southbound structure was poured on October 18, 2000 from 7:30AM to 1:30PM. The construction sequence of this bridge is provided in Appendix D.

\subsubsection{Piles}

According to INDOT Standard Specifications (1999), all HP12x53 piles were supplied in accordance with AASHTO M 183. Material data for the existing CFT14.5x0.25 piles was not available. It is estimated based on typical practice that the piles were ASTM A252, Grade 2 or 3.

\subsubsection{Instrumentation Design}

Both the northbound and southbound structures were instrumented to investigate the end abutment and pile response.

\subsubsection{Northbound Structure}

On the northbound structure, Micro-Measurements 1/4" foil strain gages (CEA-06250UN-350) were installed on the piles as shown in Figure 2.22 to evaluate the pile behavior. On Bent 1, gages were attached to Piles 2, 6, and 7 while gages were installed on Piles 2, 4, and 6 on Bent 3. All gages were installed at ground level (Figure 2.23) as the maximum stress was expected to occur at this location. Omega Type T 24 AWG solid thermocouple wire was installed on Girder 7 at midspan as illustrated in Figure 2.22 to provide ambient air temperature measurements. 


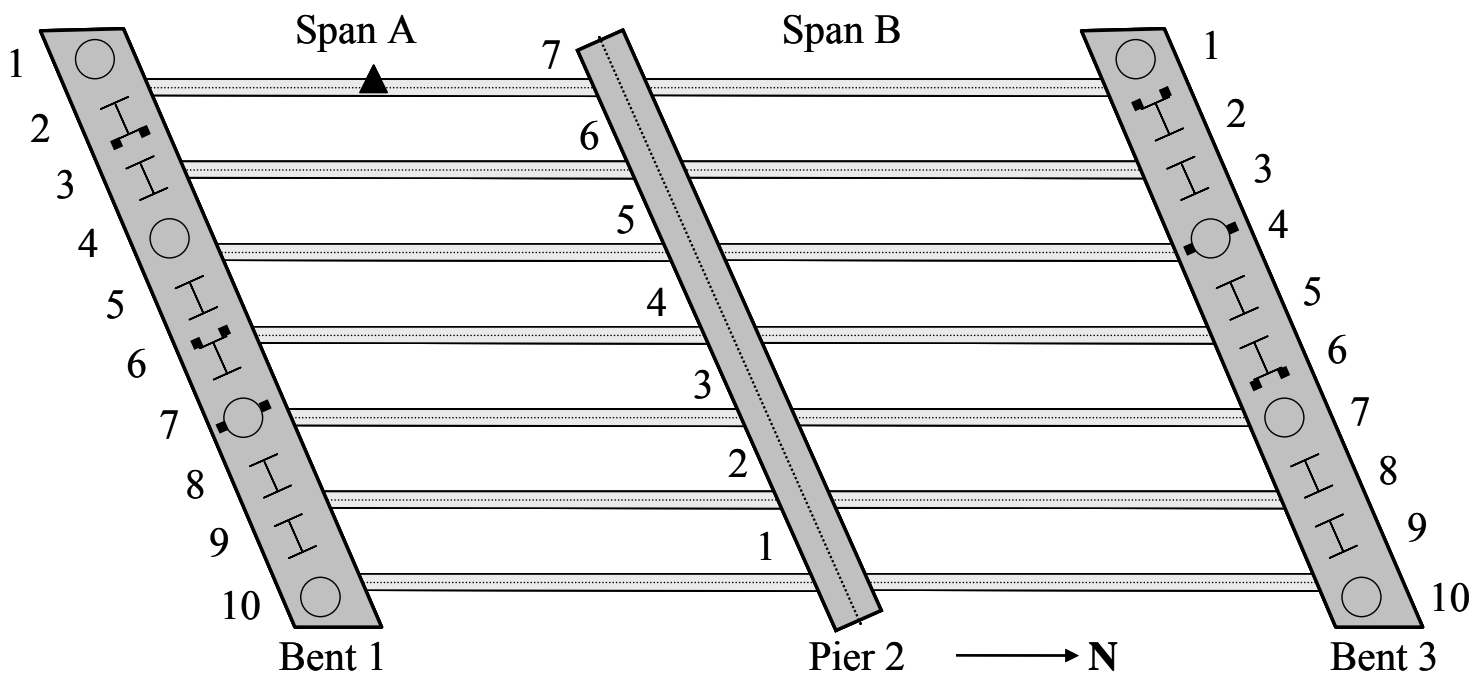

- Strain Gage

$\Delta$ Thermocouple

(Durbin, 2001)

Figure 2.22: Strain Gage and Thermocouple Locations on Northbound Structure (I65 over SR25)

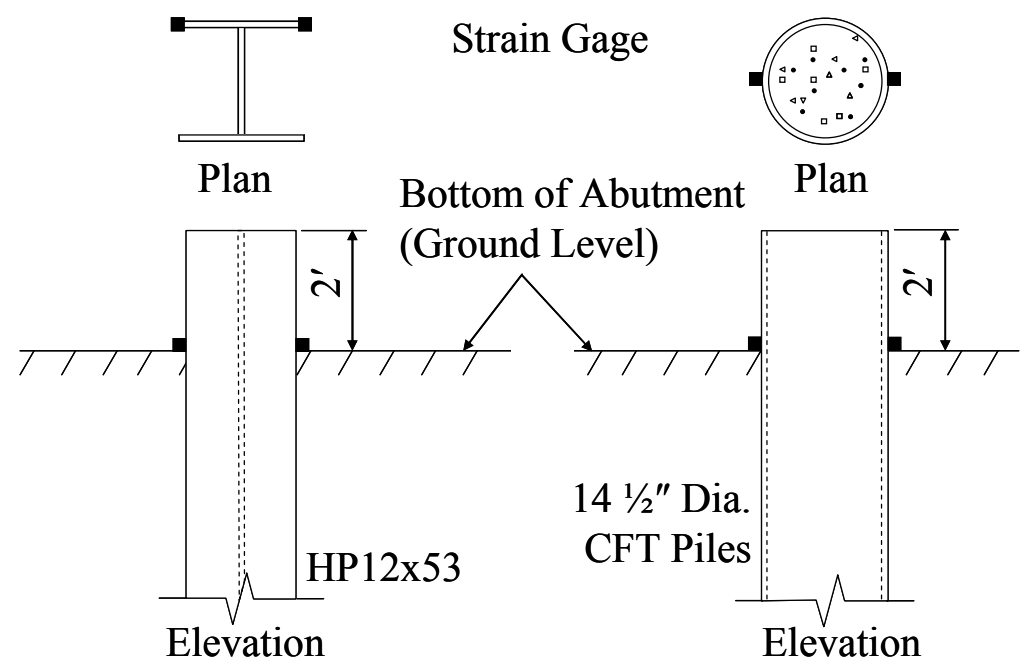

Figure 2.23: Strain Gage Location on Pile on Northbound Structure (I65 over SR25) 


\subsubsection{Southbound Structure}

The southbound structure was instrumented to determine the longitudinal and transverse movement of the abutment as well as the response of the piles. In general, the instrumentation of this structure concentrated on the movement of the end bent. The locations of strain gages and potentiometers incorporated into the structure are shown in Figure 2.24. Micro-Measurements $1 / 4$ " foil strain gages (CEA-06-250UN-350) were installed on the edge of each flange of two HP12x53 piles (Piles 6 and 9) at the bottom of the abutment to measure biaxial bending of the piles. Figure 2.25 shows an elevation view of the end bent instrumentation. The strain gages were installed at the bottom of the abutment (Figures 2.26 and 2.27) where maximum pile stresses were expected.

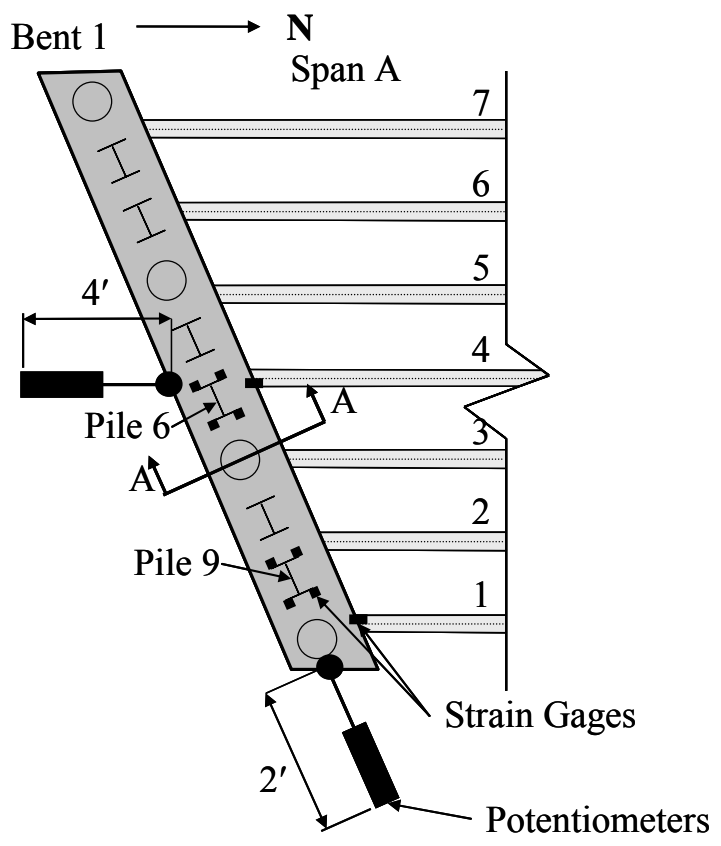

(Durbin, 2001)

\section{Figure 2.24: Strain Gage and Potentiometer Locations on Southbound Structure (I65 over SR25)}

In addition, two linear motion potentiometers (Maurey Instrument Corp. \#M13263-103) were installed to measure the movement of the abutment (Figure 2.24). These potentiometers have a displacement capacity of 3 in. The longitudinal motion 
potentiometer was placed approximately $4 \mathrm{ft}$ behind the south face of the abutment (Figure 2.28) and the transverse motion potentiometer was placed approximately $2 \mathrm{ft}$ east of the abutment. Only Bent 1 for the southbound structure was instrumented.

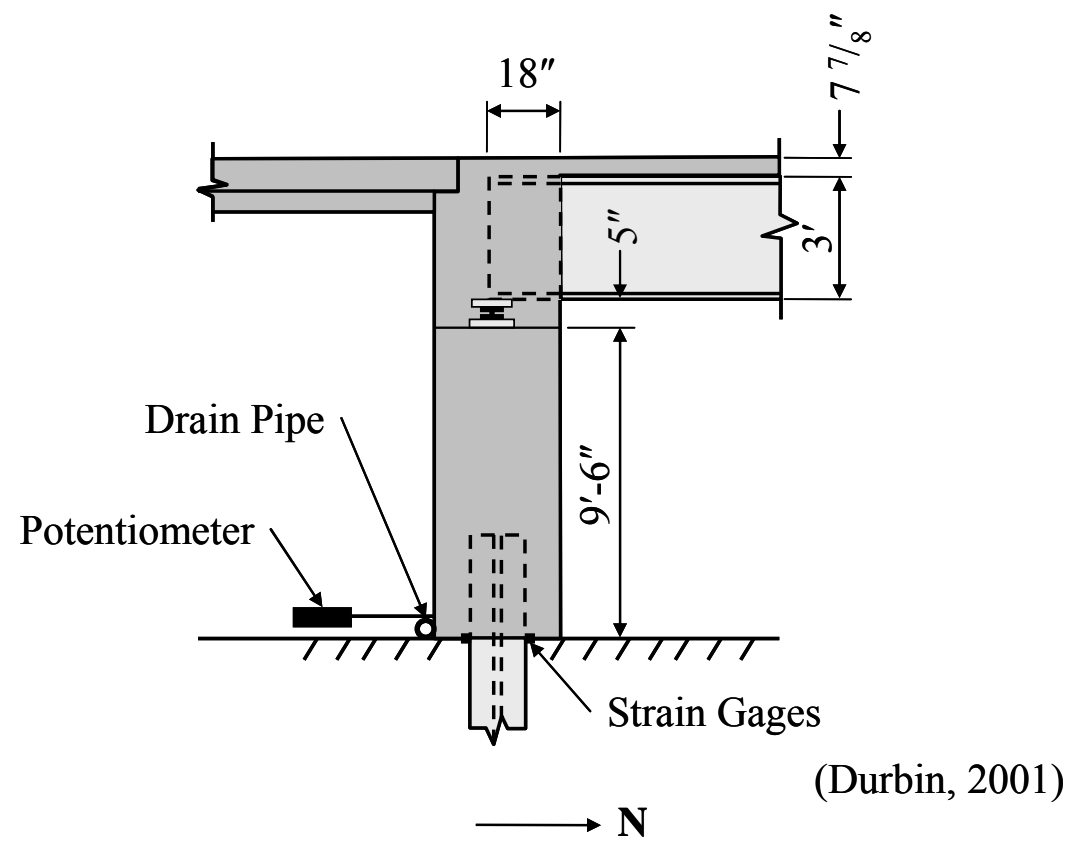

Figure 2.25: End Bent Elevation View on Southbound Structure (I65 over SR25)

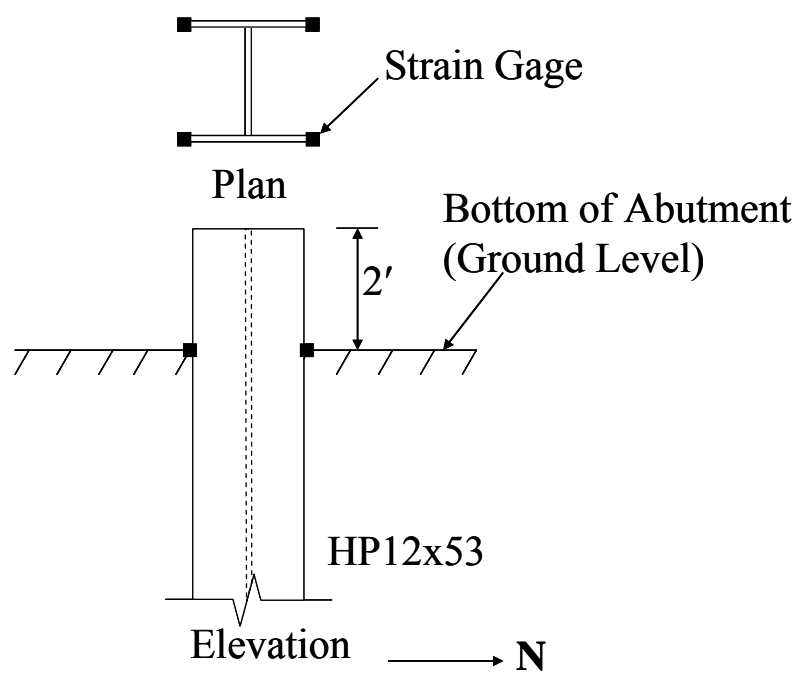

Figure 2.26: Pile Strain Gage Locations on Southbound Structure (I65 over SR25) 


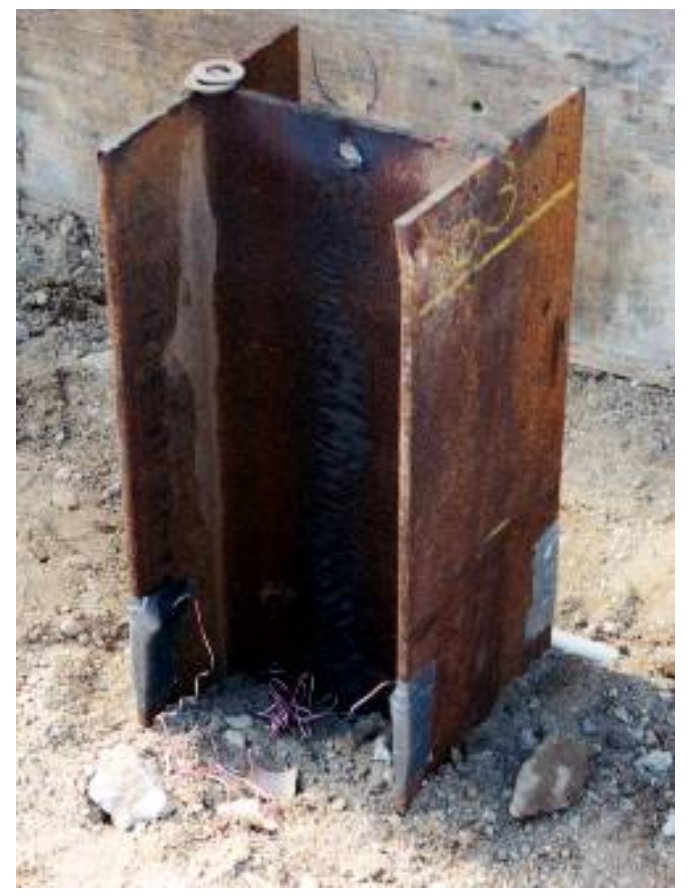

Figure 2.27: Strain Gages on H Pile (I65 over SR25)

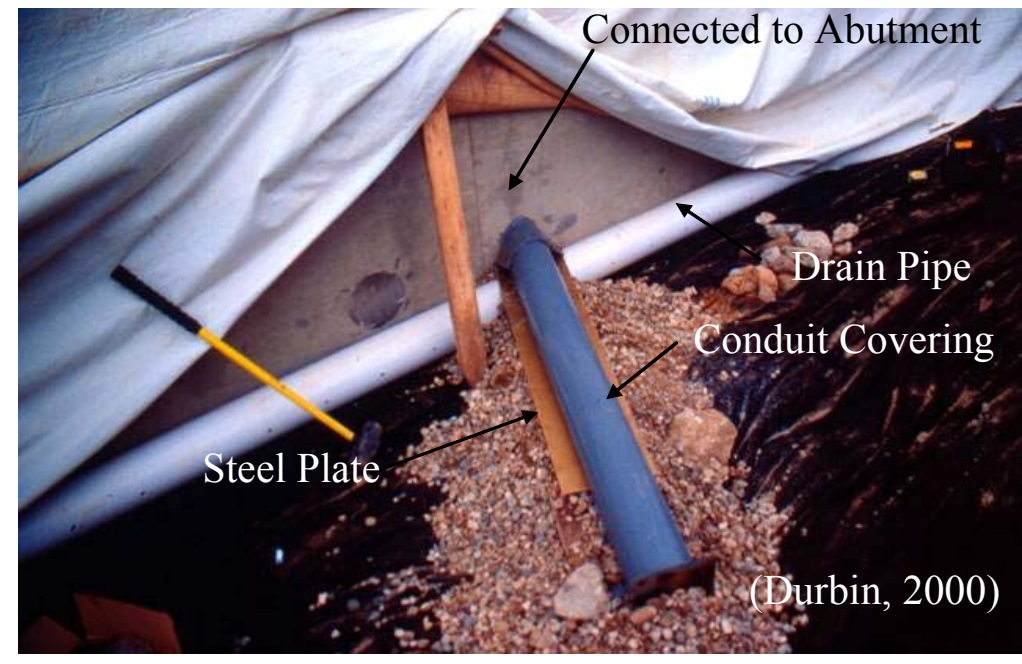

Figure 2.28: Linear Potentiometer Protected with Conduit (I65 over SR25) 


\subsubsection{Data Acquisition}

To monitor the strain gages, thermocouples, and potentiometers on the bridge, a Campbell Scientific datalogger system (CR10X) with AM416 multiplexers was selected.

On the northbound structure, all gages were zeroed and began reading every 15 minutes on August 14, 2000, the day before deck casting. On January 17, 2001, the time interval was changed to hourly.

On the southbound structure, all gages were read hourly. The initial readings for various gages were taken at various times. The longitudinal potentiometer was zeroed on September 24, 2000, strain gages were zeroed on October 6, 2000, and the transverse potentiometer was zeroed on October 18, 2000.

\subsubsection{Problems}

Data from the southbound structure between May 13, 2002 and July 30, 2002 were not available because of a battery failure. All initial zero readings were unable to be recovered; therefore, beyond this date, the initial reading was estimated based on thermal response and historical data.

\subsection{SR18 over Mississinewa River Bridge}

As previously discussed, extensive problems with the SR249 over US12 bridge led to incomplete data for that structure. To make up for this deficiency, the SR18 over Mississinewa River Bridge (Figure 2.29) was also selected for instrumentation. There are several reasons for selecting this structure.

1. The bridge was designed and constructed according to typical integral abutment details.

2. The bridge exceeded the length limitation of INDOT and could provide much needed data regarding bridge length.

3. The skew of the structure was small. Therefore the research could focus on the effects of bridge length. 


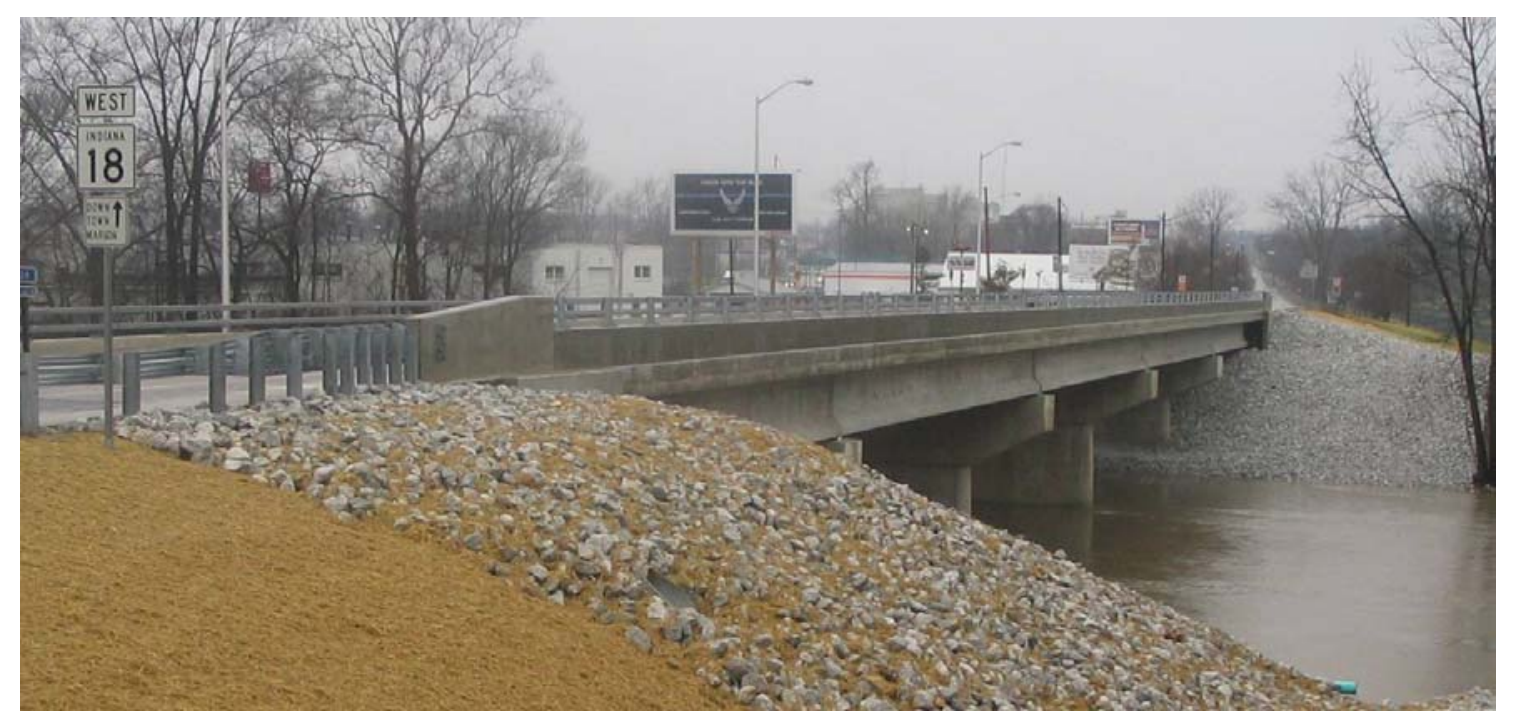

Figure 2.29: SR18 over Mississinewa River Bridge

To better understand the soil-pile-abutment-system, the five-span, continuous prestressed, concrete bulb-tee integral bridge was instrumented. The construction and instrumentation were part of Project No. STP/132-5 which was a bridge rehabilitation of Structure 18-27-4518D. This bridge is located east of the city of Marion in Grant County, Indiana on the westbound lanes of State Road 18 crossing the Mississinewa River. The total bridge length is $367 \mathrm{ft}$ (Figure 2.30) with a skew angle of $8^{\circ}$. A typical cross section is presented in Figure 2.31.

\subsubsection{End Bent/Pile Design}

\subsubsection{End Bent}

Each abutment is supported by ten 14-in. diameter concrete-filled steel tube piles with a wall thickness of 0.312 in. (CFT14.0x0.312). The average pile length for Bent 1 was $20.8 \mathrm{ft}$ with all piles driven to a bearing capacity of 112.5 tons. For Bent 6 , the average pile length was $27 \mathrm{ft}$ with the piles driven to 100 tons according to INDOT Pile Driving Record provided in Appendix B. The piles are embedded $1.25 \mathrm{ft}$ in the abutment. End bent details of the bridge are included in Appendix C. 


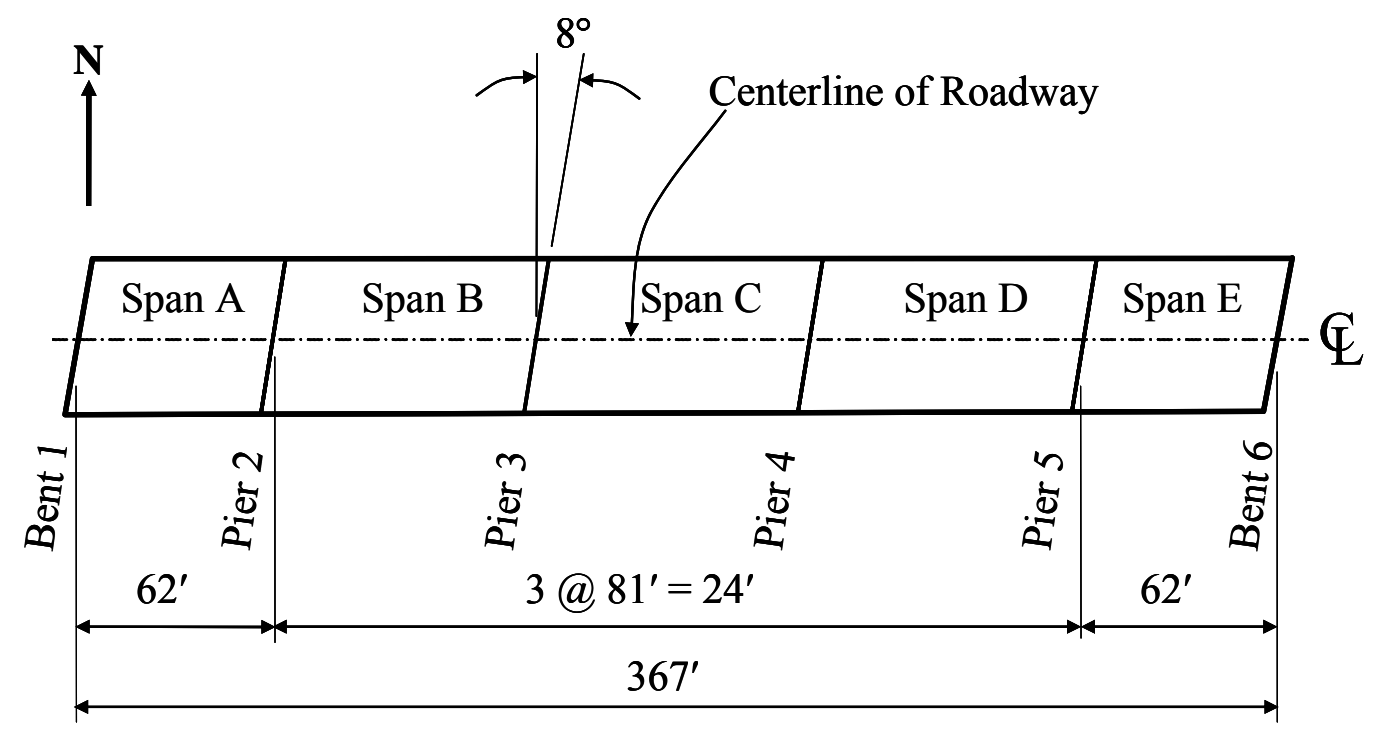

Figure 2.30: Plan View (SR18)

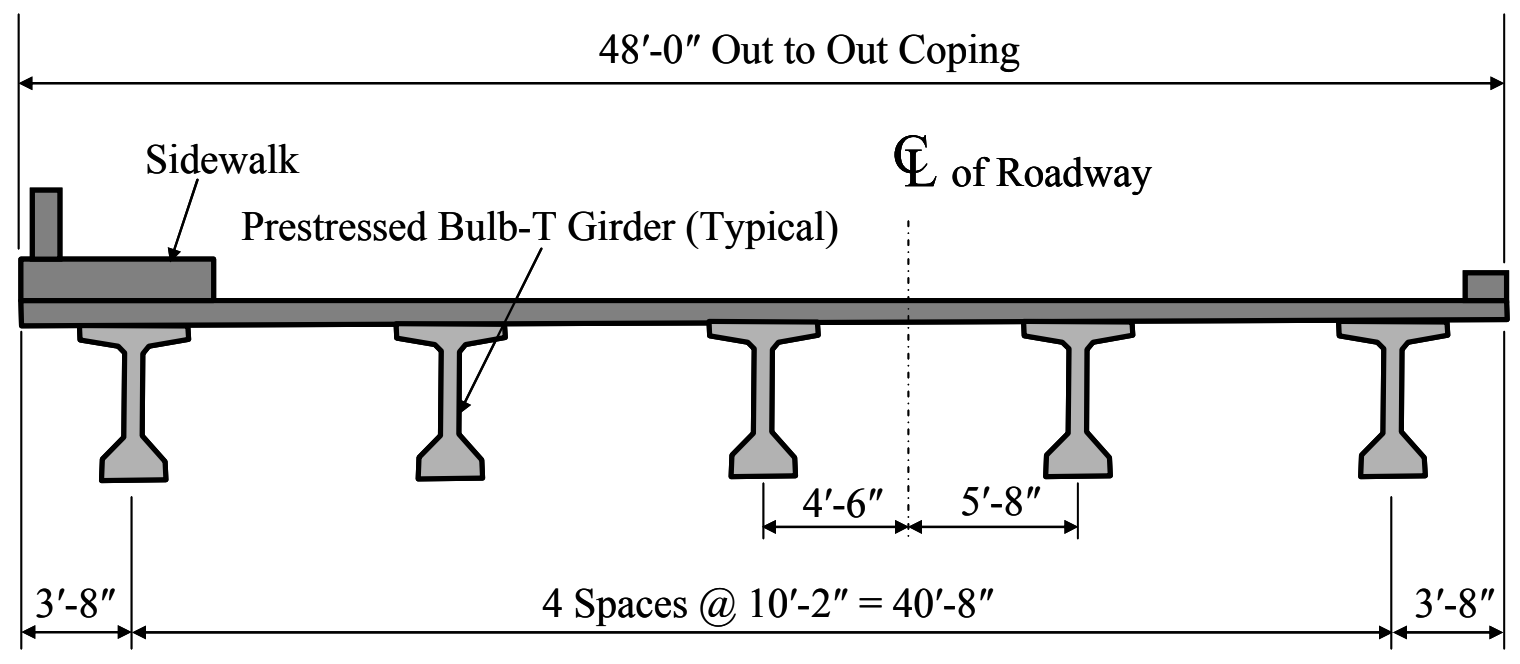

Figure 2.31: Typical Cross Section (SR18) 


\subsubsection{Pile Design}

All piles were designed for axial load only. Axial loads consisted of dead loads from the abutment, bridge deck, girder, and diaphragm as well as live loads. Live load was based on HS20-44 loading with impact load (including consideration of lane load) based on $16^{\text {th }}$ Edition of the AASHTO Standard Specification.

\subsubsection{Soil Borings}

Soil borings were located near each end bent as illustrated in Figure 2.32. Soil boring logs for Bents 1 and 6 are summarized in Tables 2.10 and 2.11. The ground water table was located $33.5 \mathrm{ft}$ below ground level at Bent 1. At Bent 6 , the ground water table was not observed at the maximum boring depth of $35 \mathrm{ft}$. The soil profiles for Bents 1 and 11 are presented in Figure 2.33 compared to Pile 6, which is approximately $23.5 \mathrm{ft}$ long and are embedded $1.25 \mathrm{ft}$ in the abutment; therefore, the pile length below ground level is approximately $22.25 \mathrm{ft}$

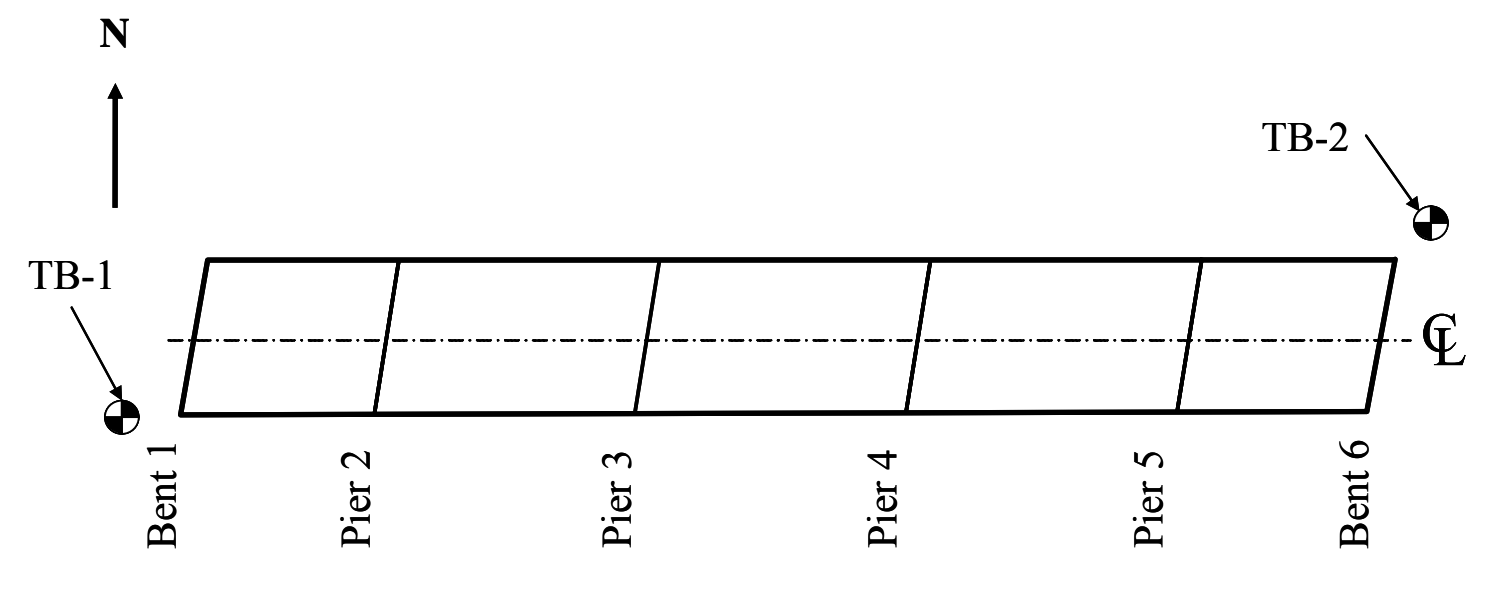

Figure 2.32: Soil Boring Plan (SR18) 
Table 2.10: Soil Boring Data (TB-1) on Bent 1 (SR18)

\begin{tabular}{|c|c|c|l|}
\hline $\begin{array}{c}\text { Depth from } \\
\text { Ground } \\
\text { Level (ft) }\end{array}$ & N & \\
\hline 0.0 & 0.5 & - & Asphalt \\
\hline 0.5 & 1.4 & - & Concrete \\
\hline 1.4 & 2.9 & 17 & SILTY LOAM, Slightly Moist, Stiff, Tan \\
\hline 2.9 & 5.0 & 23 & SILTY CLAY LOAM, Stiff, Slightly Moist, Gray \\
\hline 5.0 & 10.0 & 20 & $\begin{array}{l}\text { SILTY LOAM + some sand + gravel, Stiff, Slightly Moist, } \\
\text { Brown }\end{array}$ \\
\hline 10.0 & 15.0 & 21 & SILTY LOAM, Stiff, Slightly Moist, Tan \\
\hline 15.0 & 20.0 & 16 & $\begin{array}{l}\text { SILTY CLAY LOAM, Stiff, Slightly Moist, Grayish Brown, } \\
\text { Medium }\end{array}$ \\
\hline 20.0 & 25.0 & 15 & SILTY LOAM,Medium stiff, Slightly Moist, Gray \\
\hline 25.0 & 30.0 & 6 & SILTY LOAM, Soft, Moist, Gray, \\
\hline 30.0 & 35.0 & 47 & SILTY LOAM, Soft, Gray \\
\hline 35.0 & 45.0 & 78 & SILTY LOAM, Hard, Dry, Gray \\
\hline
\end{tabular}

Table 2.11: Soil Boring Data (TB-2) on Bent 6 (SR18)

\begin{tabular}{|c|c|c|l|}
\hline $\begin{array}{c}\text { Depth from } \\
\text { Ground } \\
\text { Level (ft) }\end{array}$ & N & \\
\hline 0.0 & 0.6 & - & Asphalt \\
\hline 0.6 & 1.2 & - & Concrete \\
\hline 1.2 & 2.7 & 19 & SILTY LOAM, Stiff, Slightly Moist, Brown \\
\hline 2.7 & 8.0 & 28 & SANDY LOAM, Medium Dense, Slightly Moist, Gray \\
\hline 8.0 & 10.0 & 16 & SILTY LOAM, Medium Stiff, Slightly Moist, Brown \\
\hline 10.0 & 15.0 & 8 & SANDY LOAM, Loose, Slightly Moist, Brown \\
\hline 15.0 & 20.0 & 12 & SAND, Loose, Slightly Moist, Tan \\
\hline 20.0 & 25.0 & 19 & SAND + some gravel, Medium Dense, Moist, Brown \\
\hline 25.0 & 30.0 & 63 & SILTY LOAM, Hard, Slightly Moist, Gray \\
\hline 30.0 & 35.0 & 112 & SILTY CLAY LOAM + Gravel, Hard, Dry, Gray \\
\hline
\end{tabular}




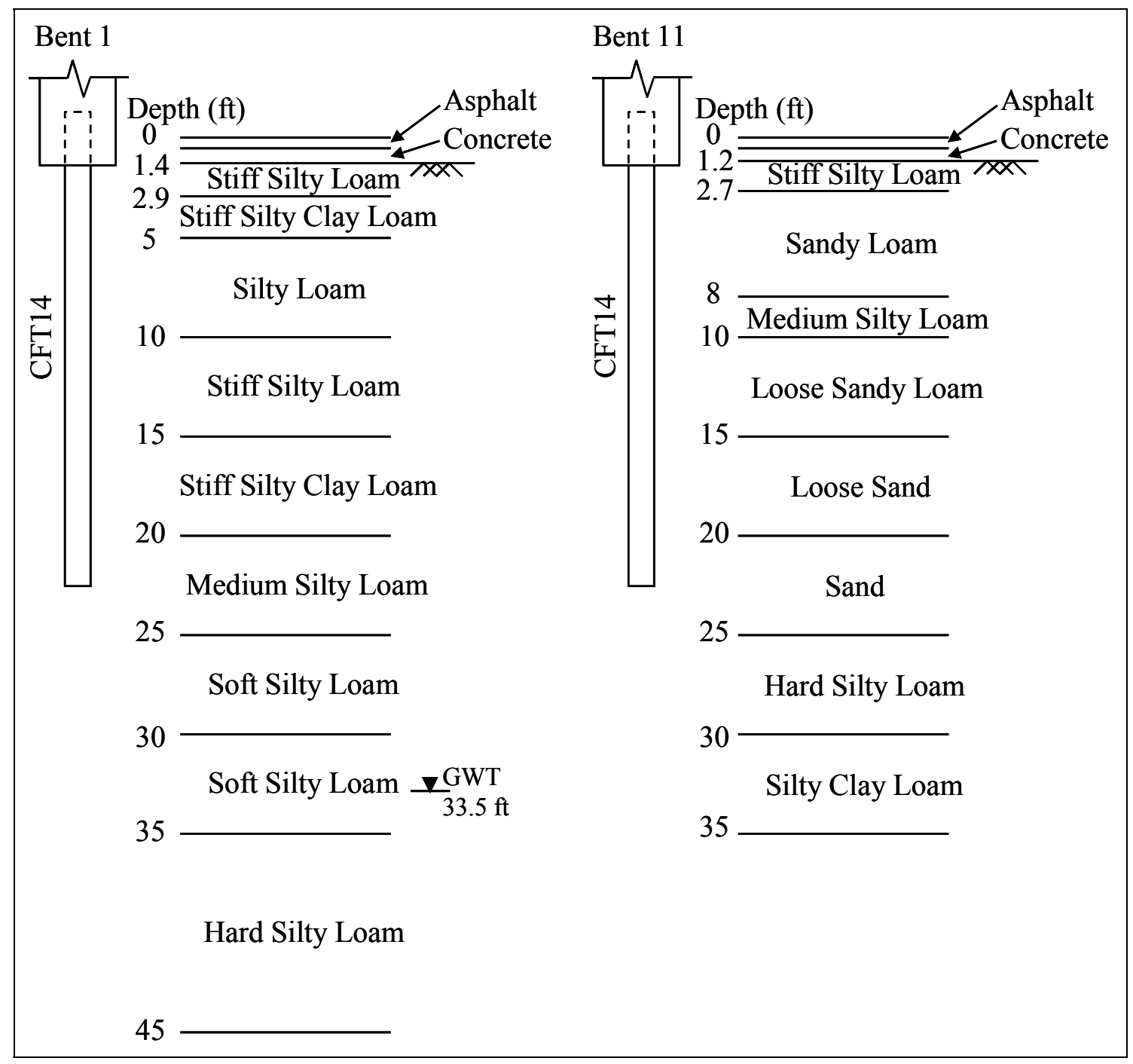

Figure 2.33: Soil Profiles on Bents 1 and 6 (SR18) 


\subsubsection{Structural Materials}

\subsubsection{Concrete}

INDOT Class A concrete $\left(\mathrm{f}_{\mathrm{c}}^{\prime}=3,500 \mathrm{psi}\right)$ was used in all bents and piers while INDOT Class $\mathrm{C}$ concrete $\left(\mathrm{f}_{\mathrm{c}}^{\prime}=4,000 \mathrm{psi}\right)$ was used in the superstructure. INDOT Class B concrete $\left(\mathrm{f}_{\mathrm{c}}^{\prime}=3,000 \mathrm{psi}\right)$ was used for the footings. The bridge deck was cast on September 26, 2003 and opened to traffic on November 25, 2003. The construction sequence for this bridge is provided in Appendix D.

\subsubsection{Piles}

According to INDOT Standard Specifications (1999), the CFT14 rounded steel pipe shells were supplied in accordance with ASTM A252, Grade 2.

\subsubsection{Instrumentation Design}

\subsubsection{Bent Instrumentation}

To evaluate the abutment movement, tiltmeters and convergence meters were provided on Bents 1 and 6. All instruments were manufactured by Geokon Inc. A tiltmeter (Model 6350) was installed vertically on the face of end bent located 18 in. from the bottom at the center of the abutment (Figure 2.34).

To evaluate the longitudinal abutment movement, a convergence meter or displacement meter (Model 4425) was installed behind the abutment (Figure 2.35). The transducer end of the convergence meter was attached to a reference pile using an eye bolt. The rod end of the convergence meter was attached to the back of the end bent using an eye bolt anchored into the concrete. The convergence meter was oriented horizontally and operated perpendicular to the abutment. The convergence meter was used to measure the relative displacement between the end bent and the reference pile to determine the longitudinal abutment movement. The locations of the convergence meters, tiltmeters, and pile strain gages are shown in Figures 2.35 and 2.36. 


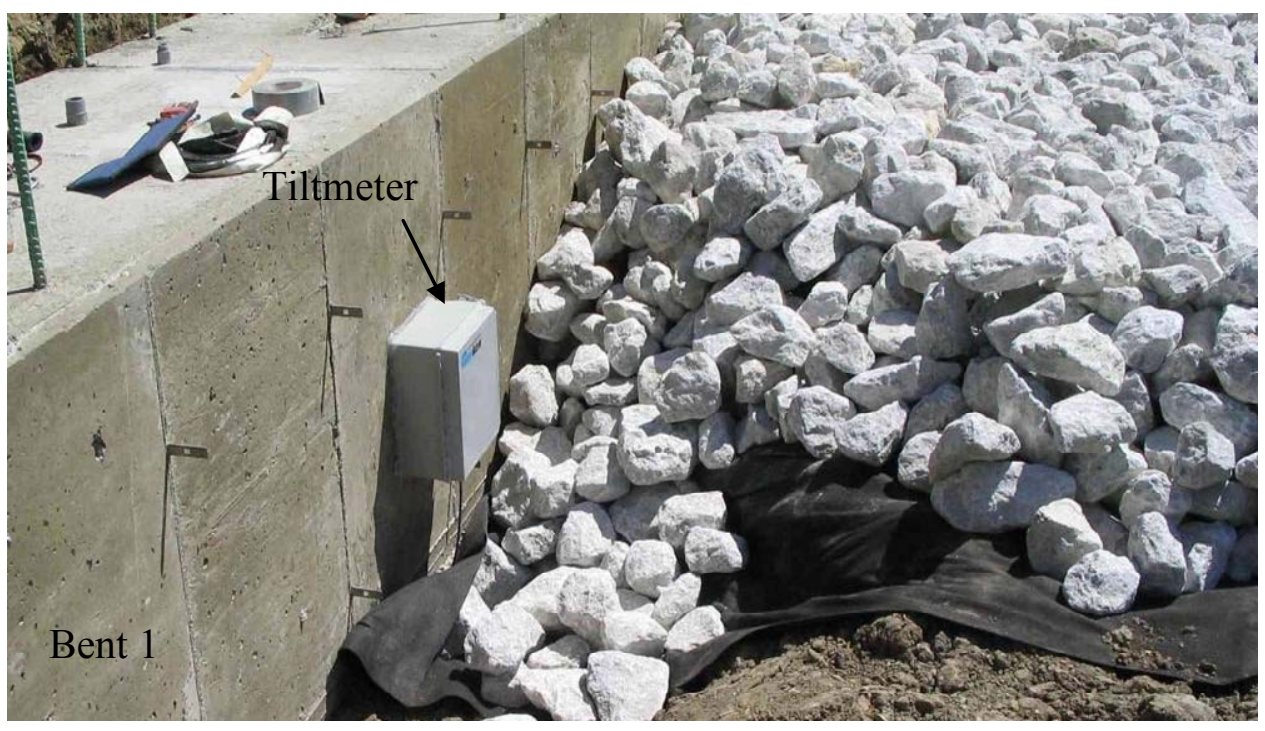

Figure 2.34: Tiltmeter Location (SR18)

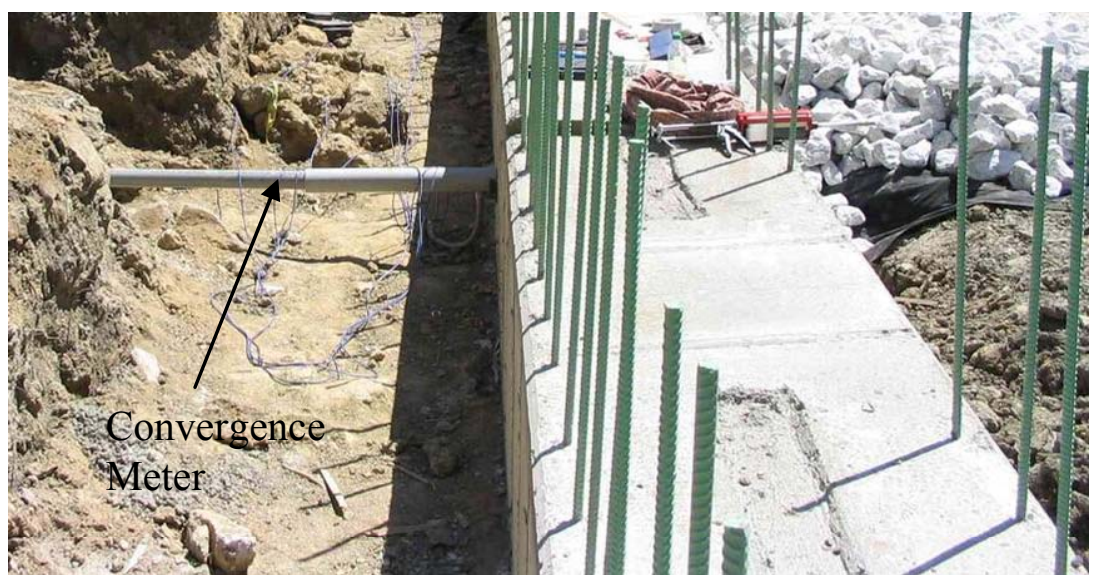

Figure 2.35: Convergence Meter (SR18) 


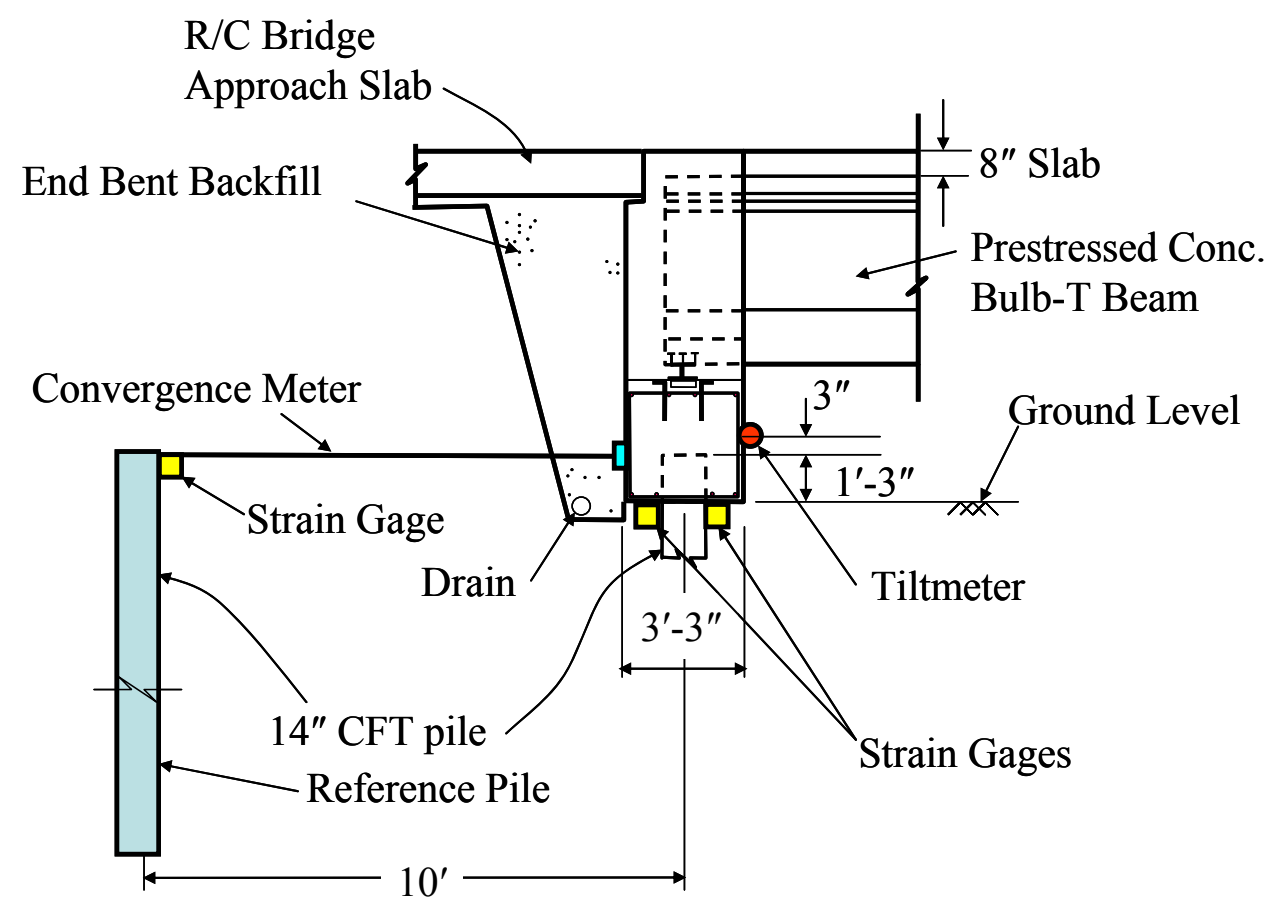

Figure 2.36: End Bent Instrumentation (SR18)

To measure the air temperature, three temperature gages (Model 4700) were installed on the bridge. One temperature gage was located at the mid-height of the concrete bridge deck between Bent 1 and Pier 2. Another gage located between Pier 5 and Bent 6 was also installed between the bottom of the deck and the bottom of the girder to prevent exposure to direct sunlight. The girder temperature gage was used to measure ambient temperature while the deck temperature gages were used to determine the rate at which the structure responded to air temperature changes. 


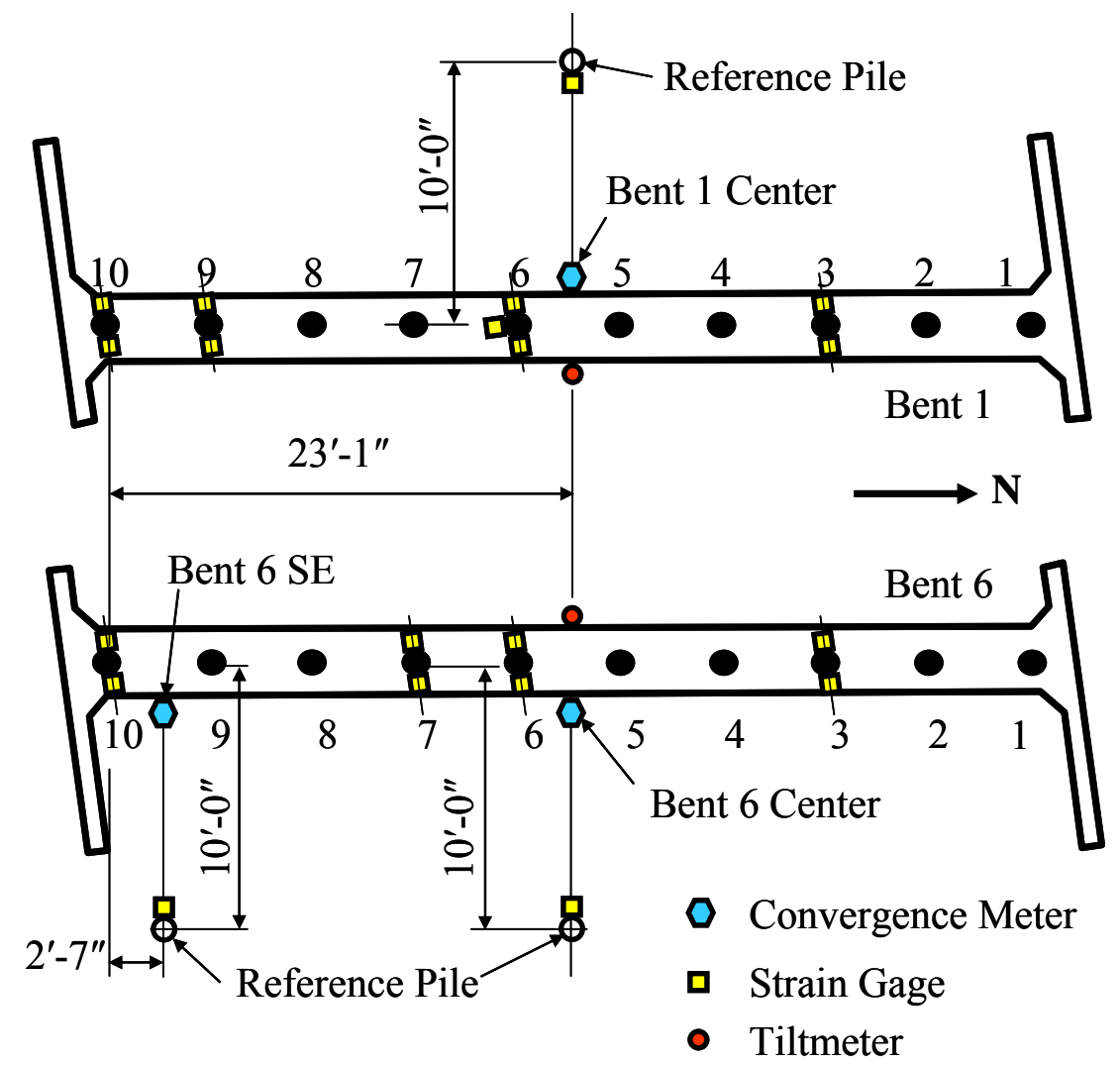

Figure 2.37: Pile Instrumentation (SR18)

\subsubsection{Pile Instrumentation}

Vibrating wire strain gages (Model VK-4100) were installed on piles, not only at ground level but also along the length of Pile 6 on Bent 1 (Figure 2.37), to evaluate the in-service, soil-structure response and to determine the response of the entire pile rather than only at the base of the abutment. Strain gages on Piles 3, 9, and 10 on Bent 1 as well as Piles 3, 6, 7, and 10 on Bent 6 were located on both the east and west faces at ground level to evaluate the pile behavior at the abutment-pile connection.

Strain gages on Pile 6 of Bent 1 were located at and below ground level as shown in Figure 2.38. All strain gages were attached to the pile by spot welding and were protected by steel angles (Figure 2.39). All strain gages except the ones at ground level were installed prior to pile driving to provide the strain profile along the length of the pile enabling investigation of the overall pile behavior. The strain gages at ground level were 
installed after driving. These gages on Pile 6 allow calculation of pile bending down the length of the pile and estimate of the deflected shape. Strain gages on the south face were installed to provide redundancy, locate the neutral axis, and evaluate out-of-plane movement of the pile.

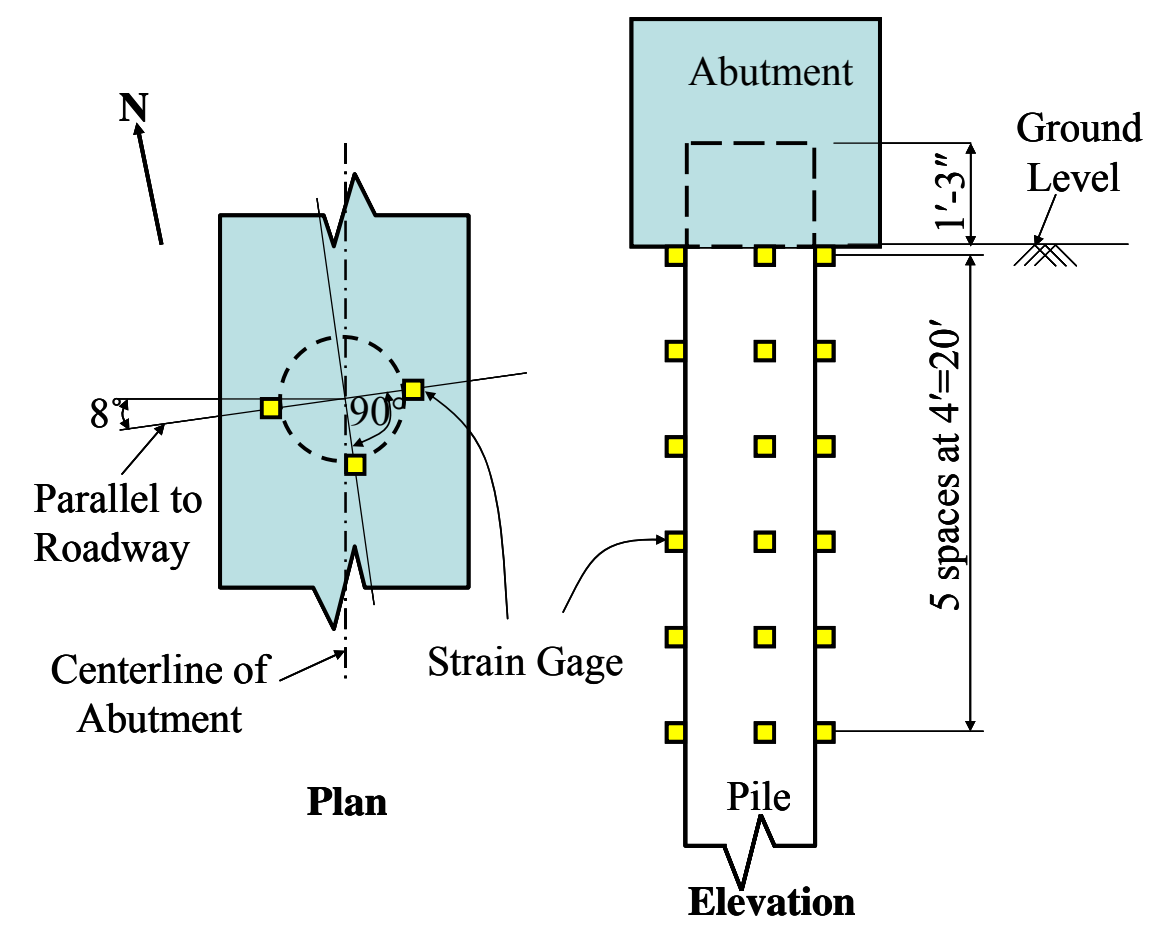

Figure 2.38: Strain Gages along the Pile Length (SR18)

To ensure that the gages on Pile 6 were installed at the correct depth, the other nine piles for that bent were driven first. While significant variation in pile length to achieve adequate bearing were observed, a reasonable estimate was obtained. Figure 2.40 shows the variation of the pile length that occurred for Bent 1 . The pile prior to cutoff are shown in Figure 2.41. The pile was cut to the designed length so that the gages were properly located. The final instrumented pile length was $23.5 \mathrm{ft}$ with $15 \mathrm{in}$. embedded in the abutment. 


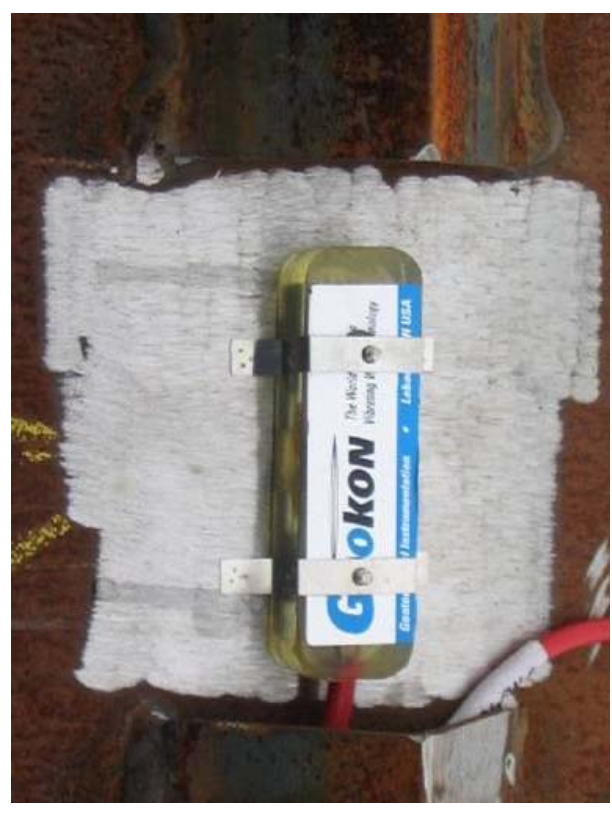

(a) Pile Strain Gage

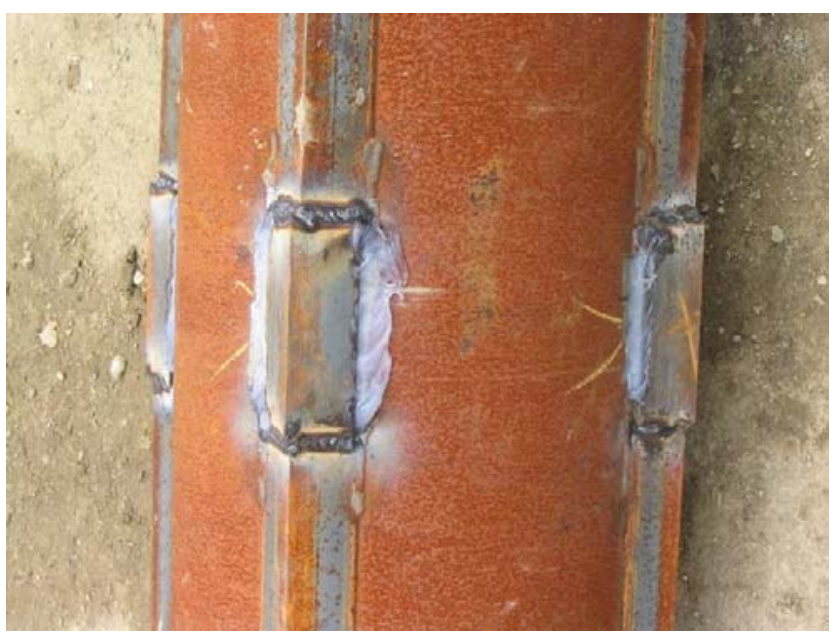

(b) Spot Welding

Figure 2.39: Pile Instrumentation (SR18)

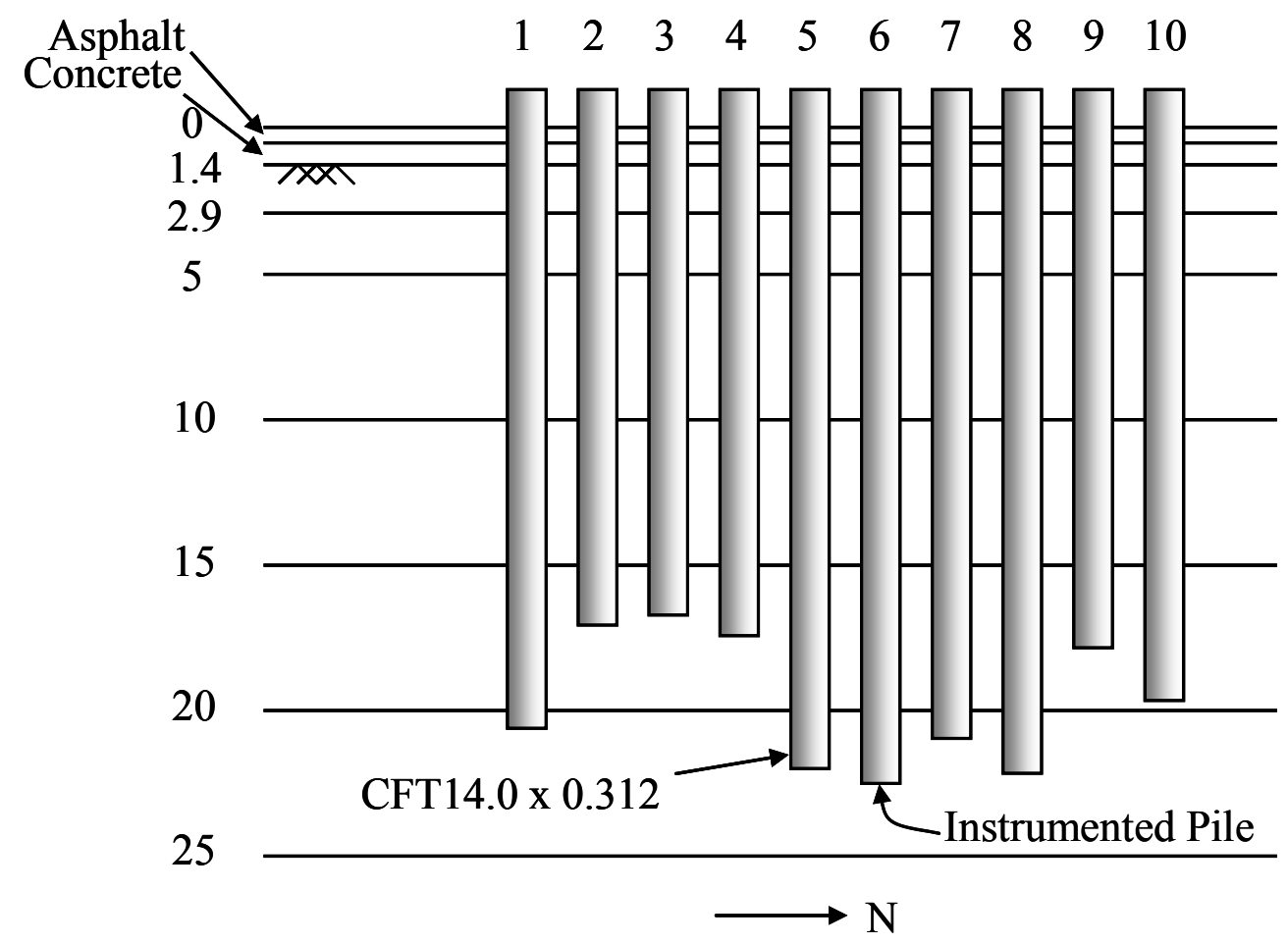

Figure 2.40: Variation of the Pile Length - Bent 1 (SR18) 


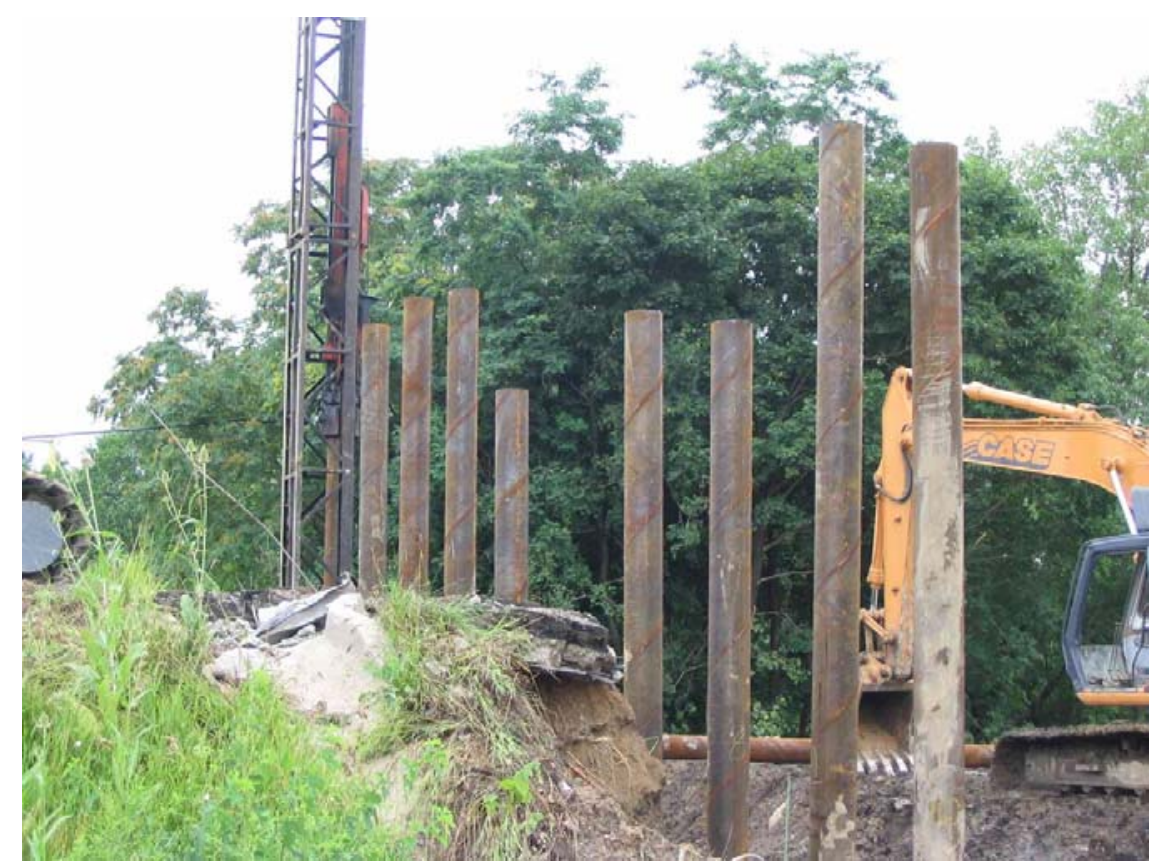

Figure 2.41: Piles before Cut Off - Bent 1 (SR18)

\subsubsection{Data Acquisition}

All data was recording using a Geokon datalogger (Model 8020 Micro-10) along with several multiplexers (Model 8032). The gages on both end bents were zeroed and started reading hourly as listed in Table 2.12. To provide increased lightning protection, lightning arrestor boards (LAB-3) were also installed between the sensors and the multiplexers.

Table 2.12: Zeroed/Started Reading (SR18)

\begin{tabular}{|l|c|c|}
\hline \multirow{2}{*}{\multicolumn{1}{|c|}{ Gages }} & \multicolumn{2}{c|}{ Zeroed/Started Reading } \\
\cline { 2 - 3 } & Bent 1 & Bent 6 \\
\hline Pile Strain Gage & July 17, 2003 & June 18, 2003 \\
\hline Convergence Meter & July 22, 2003 & June 20, 2003 \\
\hline Tiltmeter & July 22, 2003 & June 20, 2003 \\
\hline
\end{tabular}




\section{CHAPTER 3: FIELD RESULTS}

\subsection{Introduction}

To evaluate the pile and abutment behavior of the four bridges discussed in Chapter 2, the field results were analyzed. Data recorded by the bent, pile, and pier instrumentation were used to estimate bent movements, determine deflected shapes of pile, and better understand the pile and abutment behavior of those bridges. In addition, the piles supporting abutments were analytically modeled, and the results from these analyses were calibrated with the field results.

\subsection{SR249 over US12 Bridge}

Due to problems with the datalogger system, data from most of the instruments are reliable only until July 23, 2001. Beyond this date, only temperature data is available. Therefore, data provided by tiltmeters, strain gages, and crackmeters will be considered only from June 7, 2000 to July 23, 2001.

\subsubsection{Temperature}

Air temperature was monitored by several thermistors across the structure. All thermistors read approximately the same value; therefore, the temperature from the tiltmeter on Bent 1 is considered as the representative ambient temperature. The temperature over time is shown in Figure 3.1. As noted, the breaks in the data are due to problems with the datalogger system. Since temperature data provided by the instruments began reading from June 7, 2000 after the bridge was cast, the construction temperature was obtained from data reported during construction. The construction 
temperature was calculated from the daily low and high temperature throughout the casting period as provided in Table 3.1. Also tabulated in Table 3.2, are the construction as well as the maximum, and minimum temperatures over the time of the study. The average daily low and high construction temperatures were $45^{\circ}$ and $68^{\circ} \mathrm{F}$; however, the construction temperature was assumed to be equal to $60^{\circ} \mathrm{F}$ for simplicity as the exact temperature distribution over the construction sequence was not available.

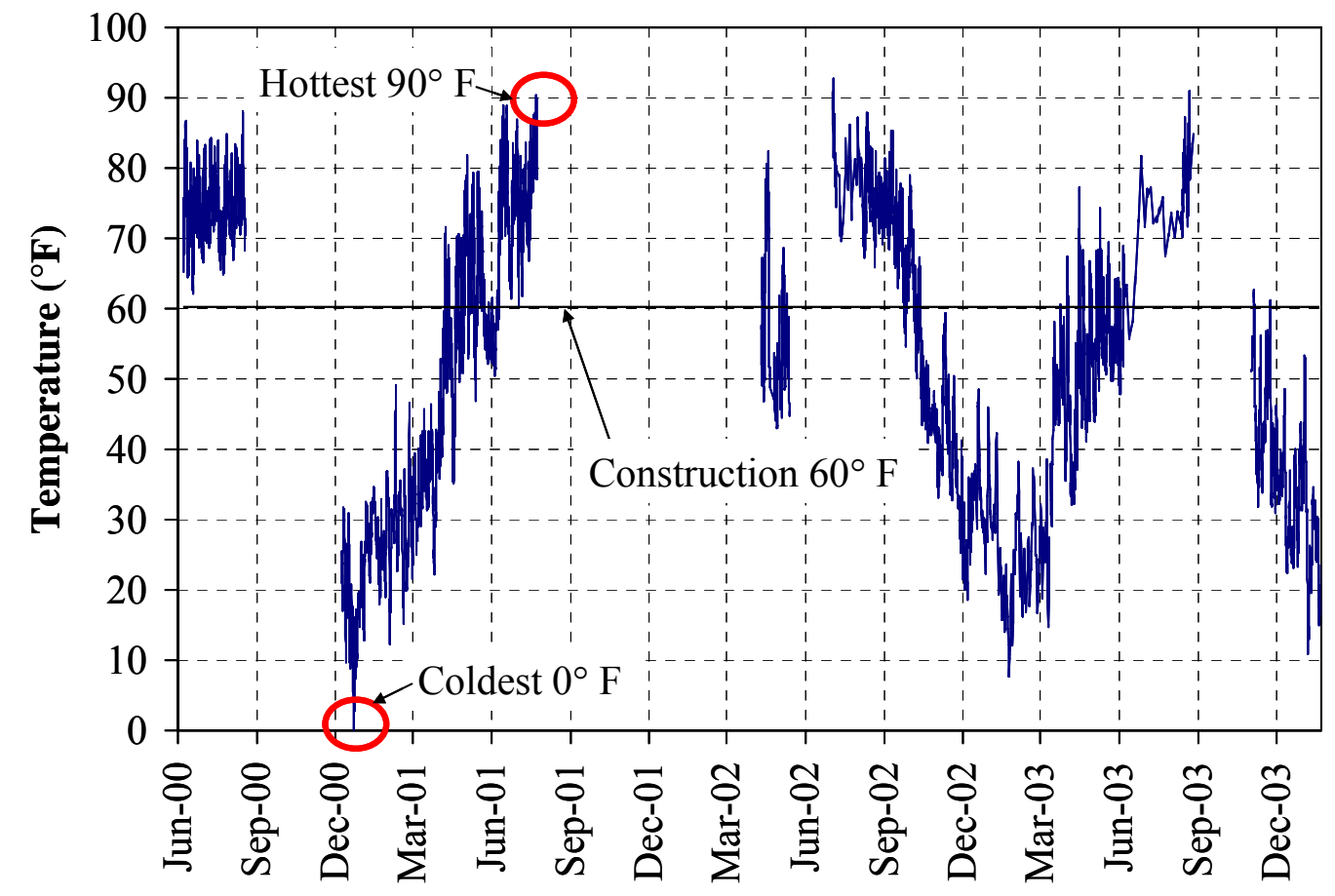

Figure 3.1: Air Temperature (SR249 over US12)

\subsubsection{Rotations of the Abutment}

Tiltmeters were used to measure the rotations of the abutment. Tiltmeters were located on the north side of Bent 1 and on the south side of Bent 11 as discussed in Section 2.2.3.1. Only rotations between June 2000 and July 2001 are considered due to the problem with the data acquisition system. Since the data acquisition system was connected to an external power source, electric interference or noise can be observed by the jumps in the data over the course of a day. The average rotations of Bents 1 and 11 were calculated to filter the noise as illustrated in Figures 3.2 and 3.3. The average 
rotations were calculated considering the rotations four hours before and after the given time. The sign convention is illustrated in Figure 3.4. Positive rotation indicates that the abutment rotates inward or contracts and negative rotation indicates that the abutment rotates outward or expands. The rotations of both bents were almost identical and range from -0.1 to 0.1 degrees. In other words, the top of the abutment moved approximately 0.2 in. relatively to the bottom of the abutment considering the height of the abutment to be approximately equal to $9.84 \mathrm{ft}(3 \mathrm{~m})$. The results indicate that the abutment does not rotate significantly but rather translates during expansion and contraction.

Table 3.1: Construction Temperature (SR249 over US12)

\begin{tabular}{|c|l|c|c|}
\hline \multirow{2}{*}{ Date } & \multirow{2}{*}{ Section Cast } & \multicolumn{2}{|c|}{ Daily Temperature ( ${ }^{\circ}$ F) } \\
\cline { 3 - 4 } & & Low & High \\
\hline September 10, 1999 & Bent 1 & 45 & 77 \\
\hline September 16, 1999 & Span A (East) & 47 & 74 \\
\hline September 20, 1999 & Span B & 41 & 68 \\
\hline September 20, 1999 & Span A (West) & 41 & 68 \\
\hline September 23, 1999 & Span C/D & 49 & 75 \\
\hline October 1, 1999 & Span E/F & 41 & 76 \\
\hline October 6, 1999 & Span G/H & 42 & 58 \\
\hline October 8, 1999 & Span J, Bent 11 & 52 & 56 \\
\hline October 11, 1999 & Span I & 45 & 64 \\
\hline \multicolumn{2}{|c|}{ Average } & 45 & 68 \\
\hline
\end{tabular}

Table 3.2: Air Temperature (SR249 over US12)

\begin{tabular}{|l|c|l|}
\hline Temperature Type & Temperature $\left({ }^{\circ} \mathbf{F}\right)$ & \multicolumn{1}{|c|}{ Date } \\
\hline Construction & 60 & $\begin{array}{l}\text { "Average" over September 10, } \\
1999 \text { to October 11, 1999 }\end{array}$ \\
\hline Maximum & 90 & July 22, 2001 at 16:00 \\
\hline Minimum & 0 & December 22, 2000 at 8:00 \\
\hline
\end{tabular}




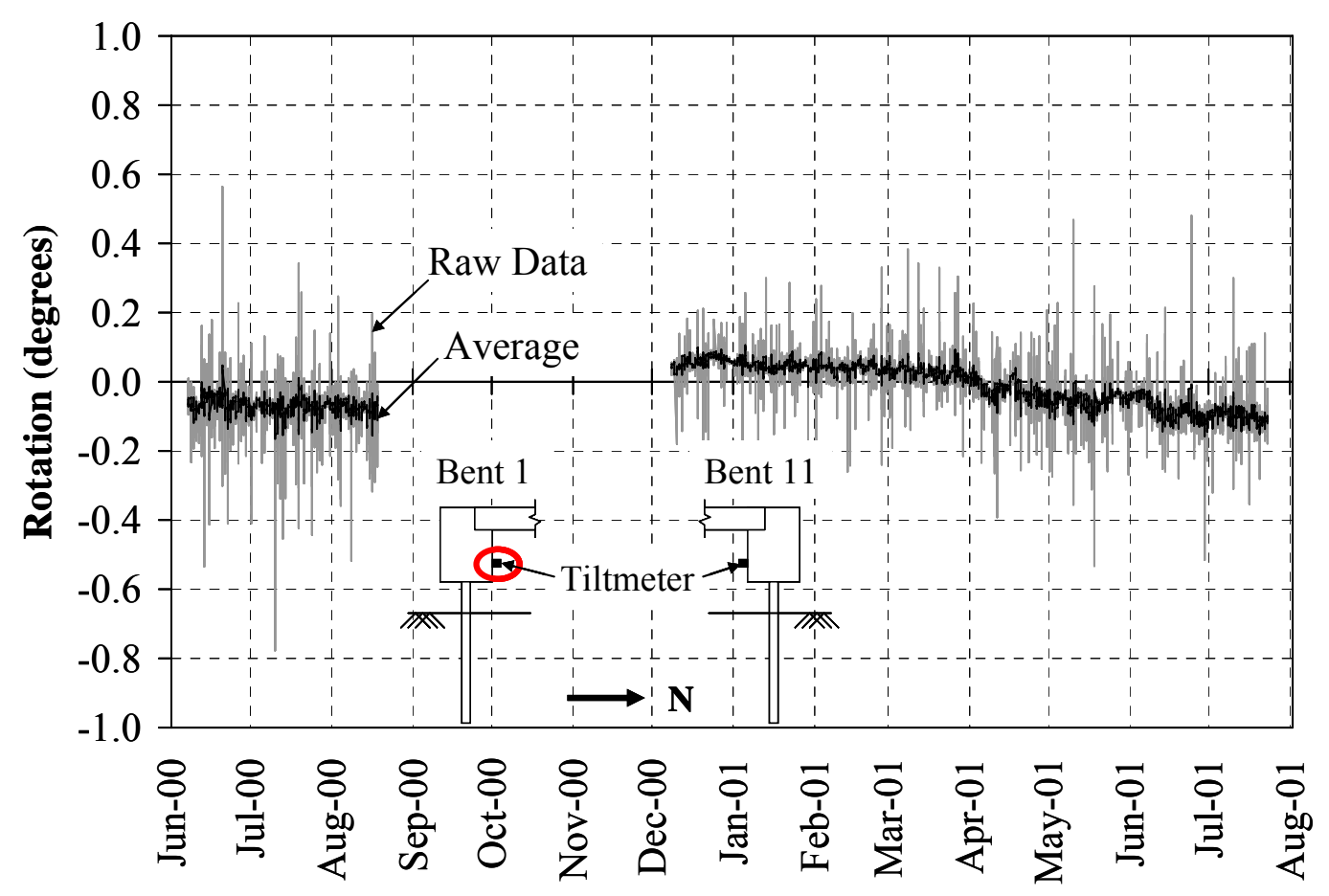

Figure 3.2: Rotations of Bents 1 (SR249 over US12)

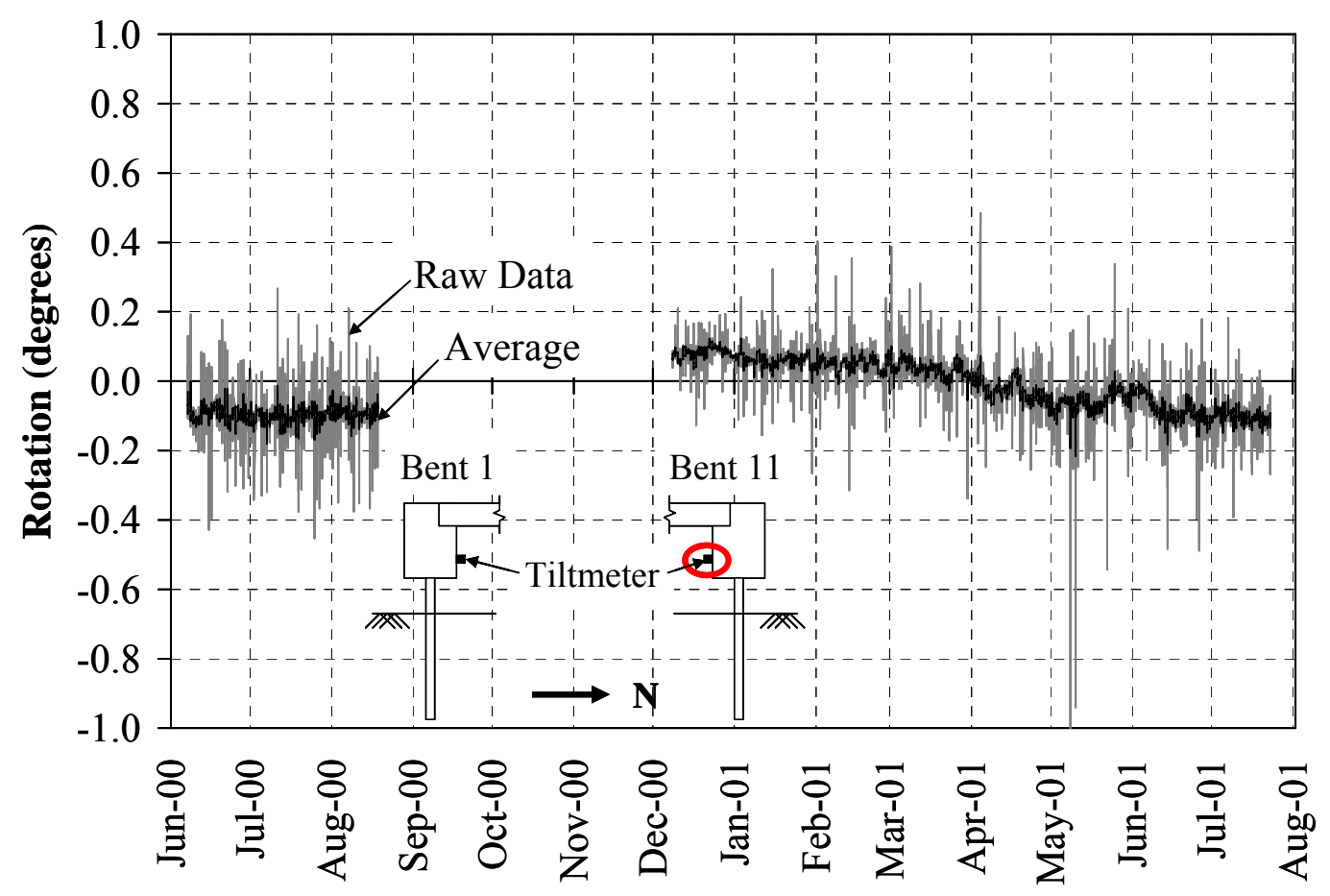

Figure 3.3: Rotations of Bent 11 (SR249 over US12) 

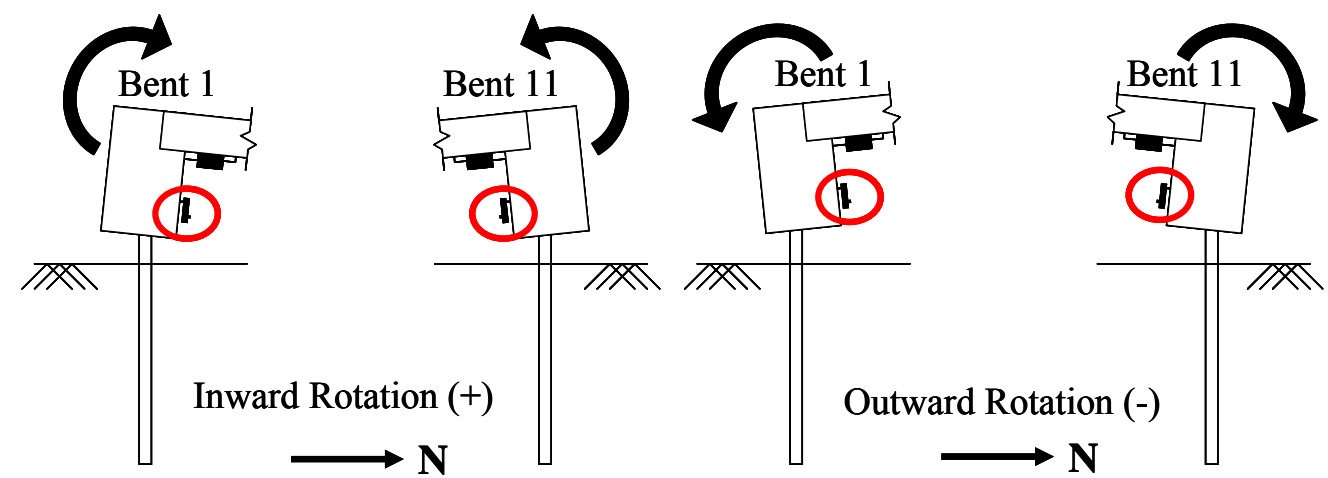

Figure 3.4: Sign Convention for Tiltmeter (SR249 over US12)

\subsubsection{Relative Displacement}

Crackmeters were used to measure the relative displacement between the girder and the abutment as well as between the girder and the pier. The sign convention for the crackmeters is illustrated in Figure 3.5. A positive sign indicates extension of the crackmeter or physically that the girder is moving away from the abutment. A negative sign indicates shortening, the abutment and girder are moving close together. The results from the crackmeters on Bents 1 and 11 are shown in Figure 3.6. Disregarding the erratic jumps, the crackmeter data from Bents 1 and 11 are essentially identical. The results indicate that as the temperature increased or the bridge expanded, the relative displacement between the girder and the abutment decreased. The relative displacement varied from approximately 0.04 in. during contraction to -0.02 in. during expansion indicating very small relative movement between the abutment and the girder. Thus, it can be concluded that the abutment and the girder moved together during expansion and contraction phases; in other words, it is appropriate to consider the abutment-girder connection as rigid.

The results from crackmeters on Piers 2 and 10 shown in Figure 3.7 indicate that Girder 3 moved very little relative to Pier 2. However, larger relative movement was observed at Pier 10. The larger movement resulted from both the pile detail and the construction. The girders were designed to move separately from the pier cap through the installation of a Styrofoam liner between the girder and the pier cap. However, this is 
strong evidence that the girder remained bonded to Pier 2, but this connection broke free at Pier 10. Figure 3.8 shows spalling of concrete at Pier 10 indicating that the girder moved relative from the pier cap.
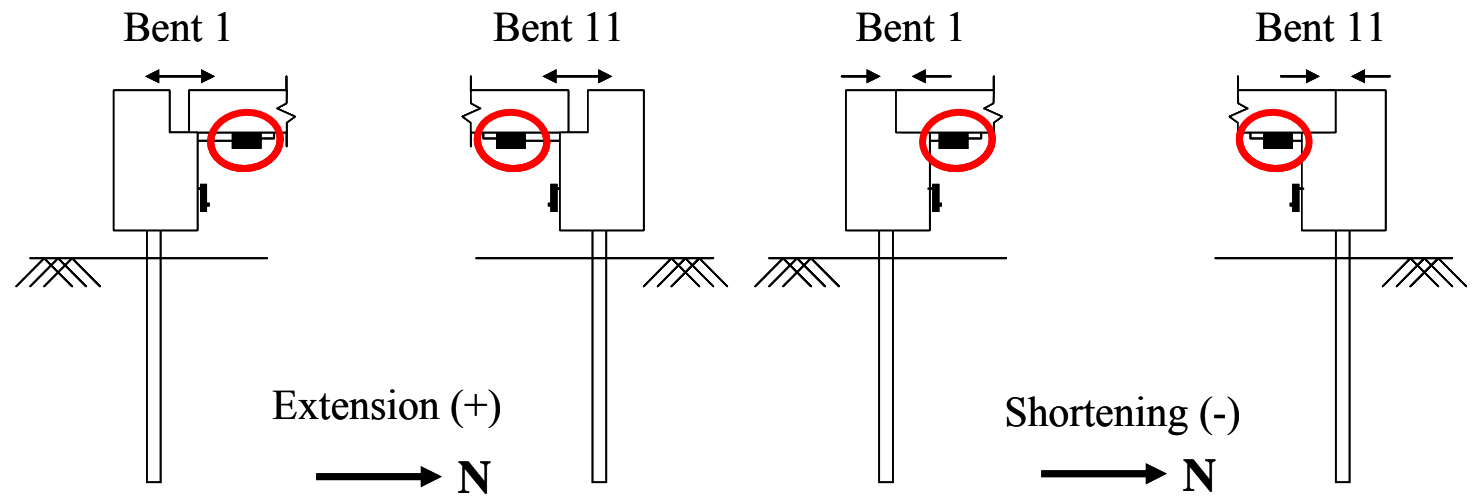

Figure 3.5: Sign Convention for Crackmeter (SR249 over US12)

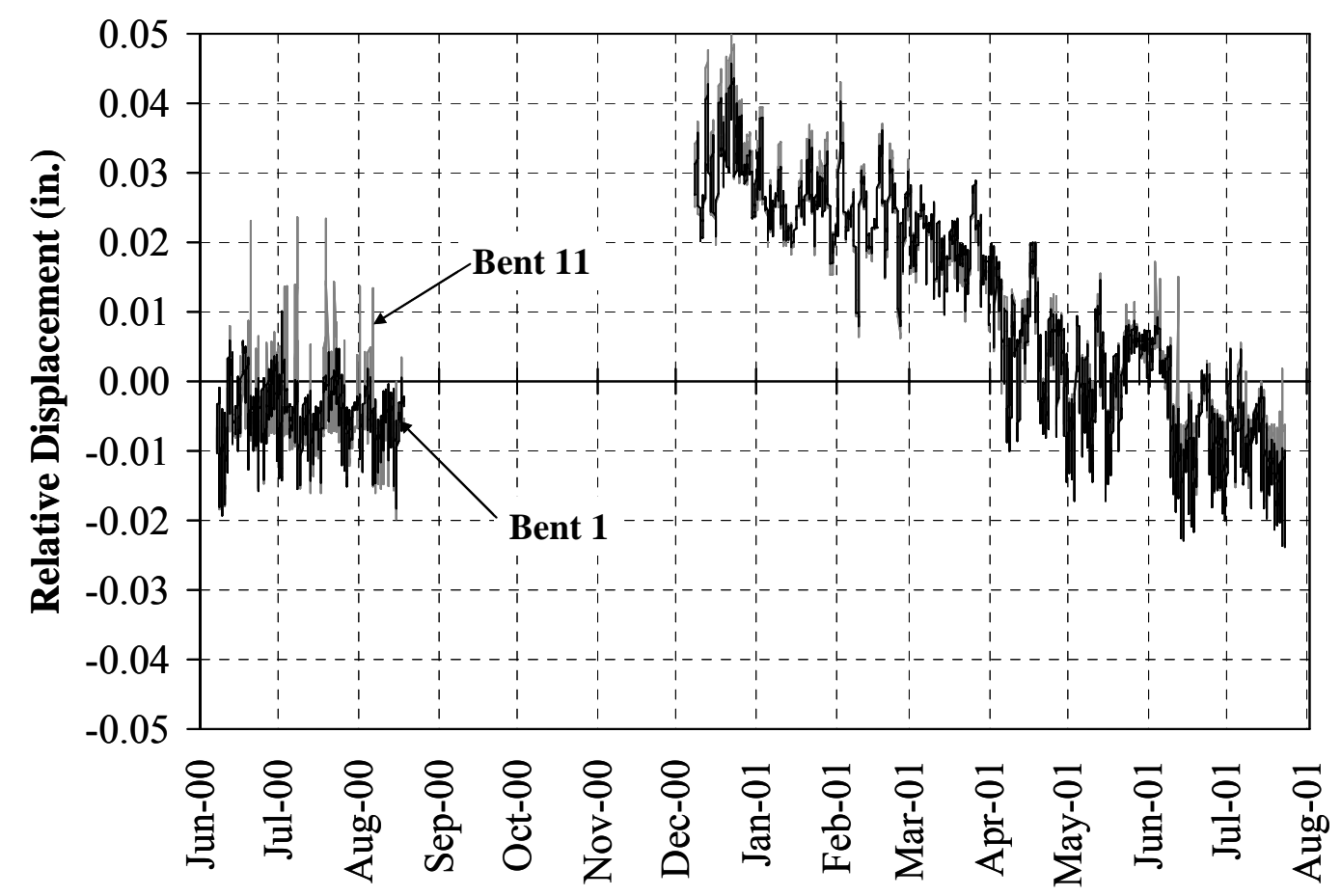

Figure 3.6: Relative Displacement on Bents 1 and 11 (SR249 over US12) 


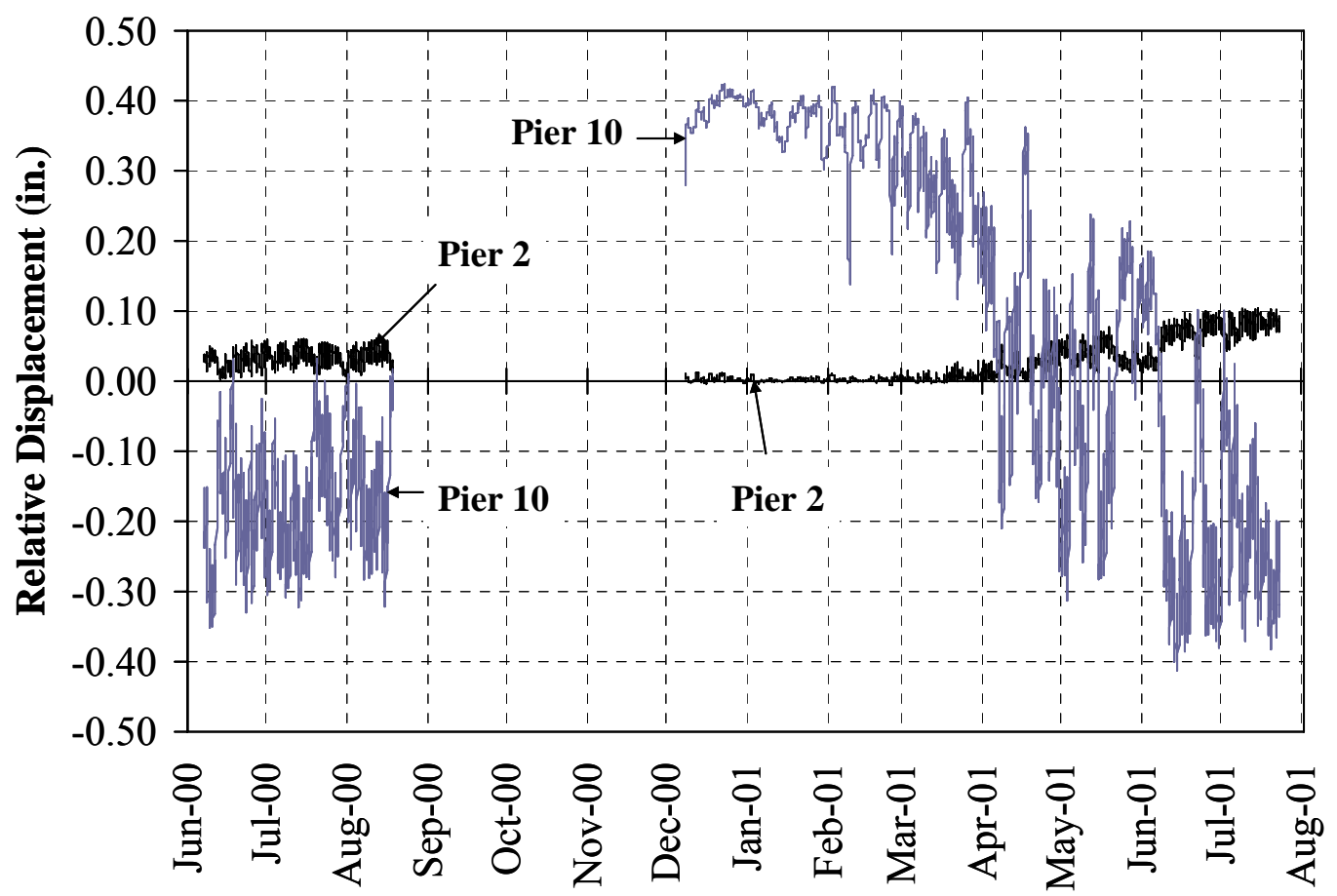

Figure 3.7: Relative Displacement on Piers 2 and 10 (SR249 over US12)

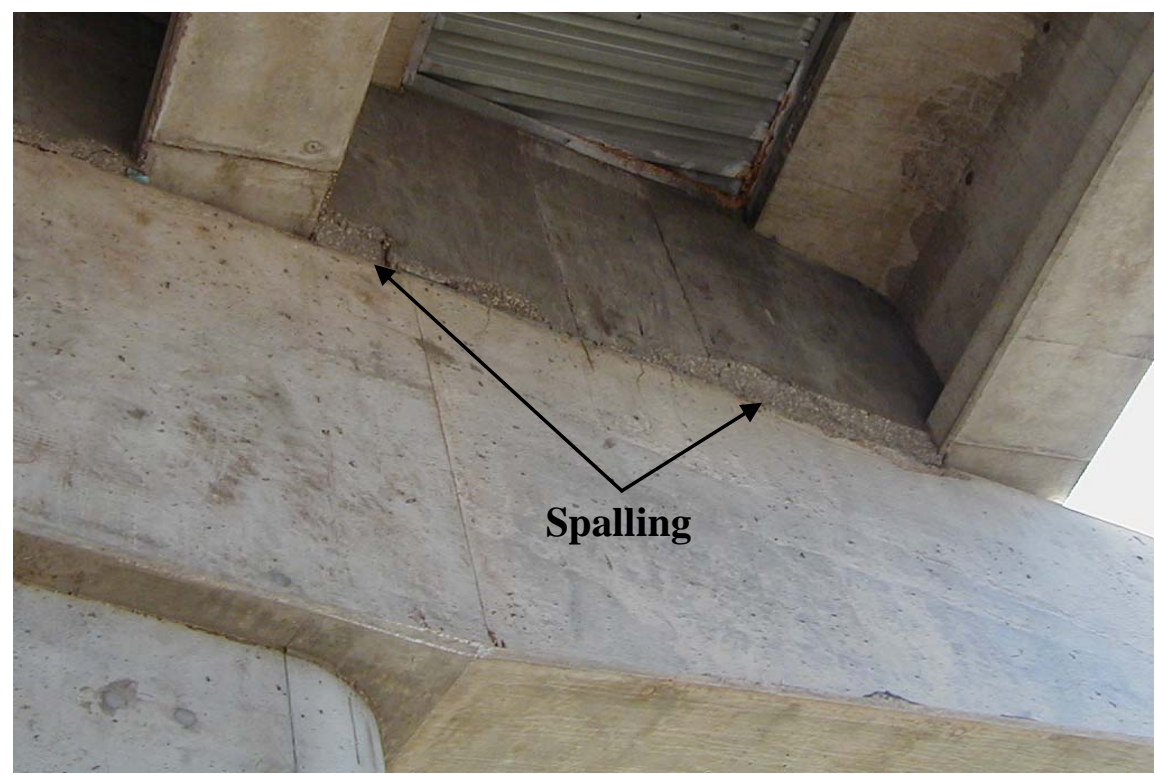

Figure 3.8: Spalling of Concrete at Pier 10 Cap (SR249 over US12) 


\subsubsection{Pier Strains}

Strain gages were installed on sister bars at various locations as described in Section 2.2.3.3. The rebar strain data at the base of Piers 2, 3, 4, 5 and 10 are shown in Figures 3.9 to Figure 3.13, respectively. The strain gages measured positive strain for tension and negative strain for compression. The strain gages located on the same face of the pier (NW-NE, SW-SE) as well as the neutral axis gages $(\mathrm{E}-\mathrm{W})$ provided almost identical readings. The strain results indicate that during the contraction phase, the north side of the base of Piers 2, 3, 4, and 5 experienced in compression, while the south side of the base of Piers 2, 3, 4, and 5 experienced in tension. On the other hand, during the expansion phase, the north side of the base of Piers 2, 3, 4, and 5 experienced in tension while the south side of the base of Piers 2, 3, 4, and 5 experienced in compression. Strain gages on Pier 10 measured strain in the opposite direction to the strains measured on Piers 2. For instance, while the north side of Pier 2 was in tension, the north side of Pier 10 was in compression and vice versa. Figure 3.14 illustrates the deformed shape of the piers observed during the contraction phase.

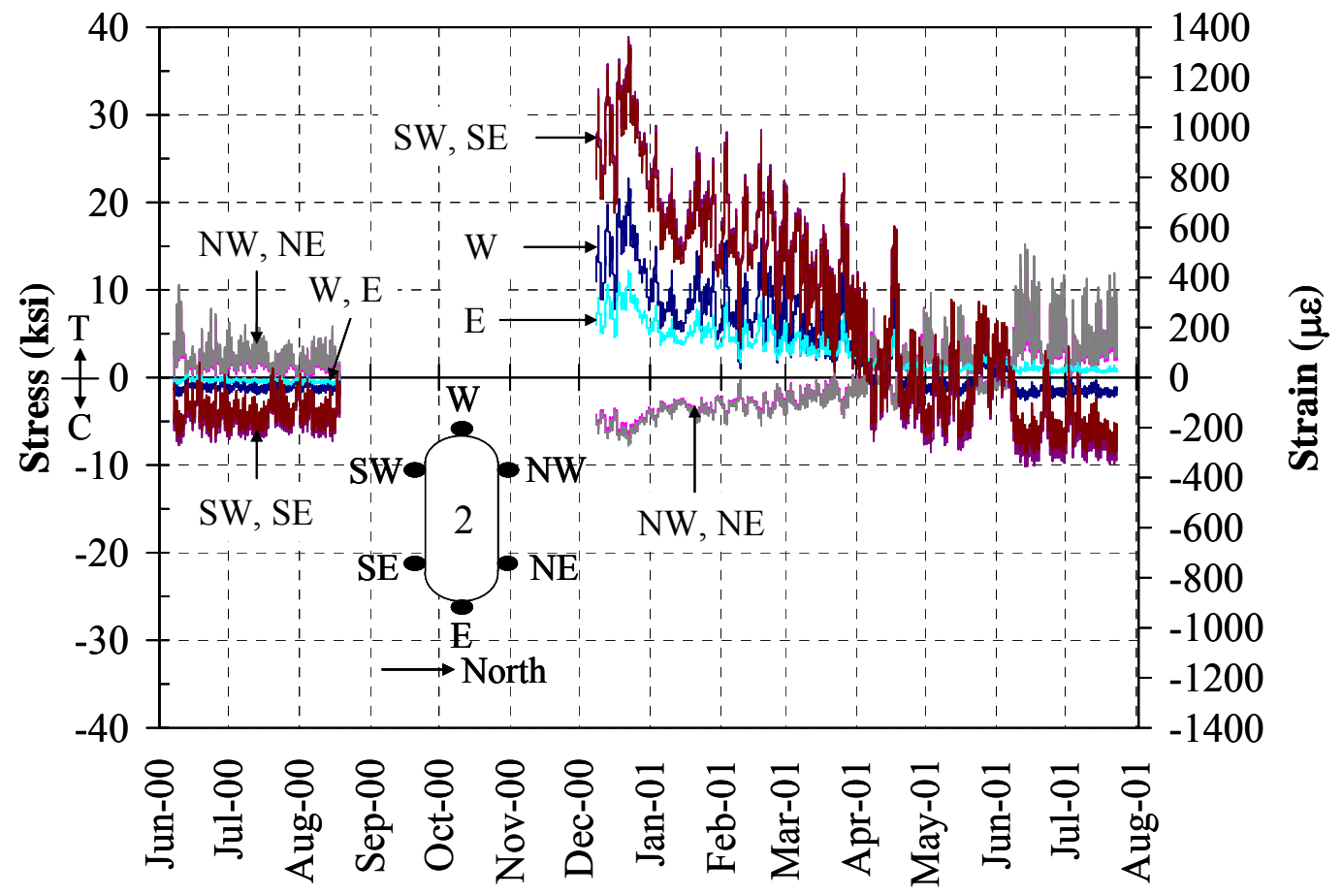

Figure 3.9: Strains and Stresses at the Base of Pier 2 (SR249 over US12) 


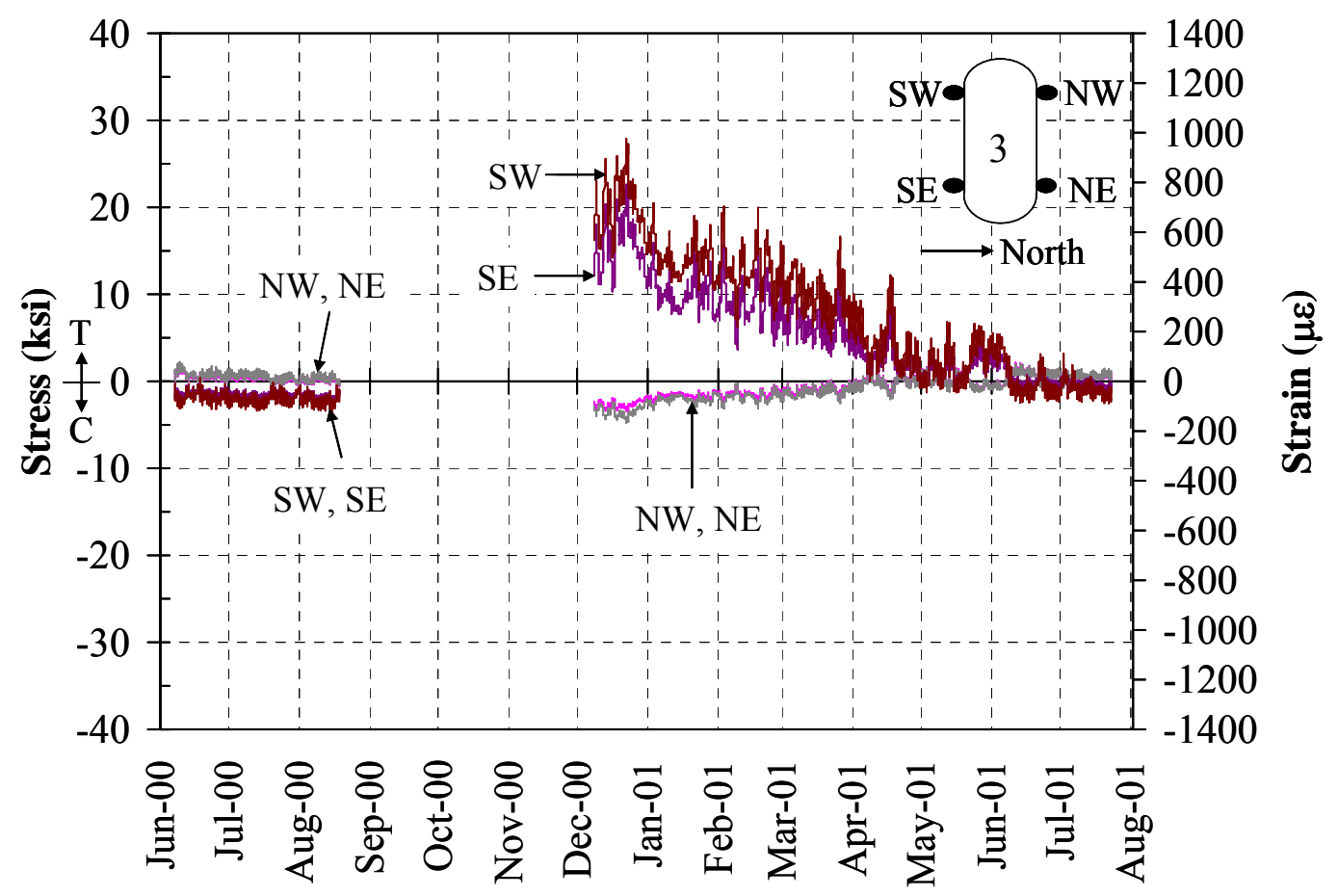

Figure 3.10: Strains and Stresses at the Base of Pier 3 (SR249 over US12)

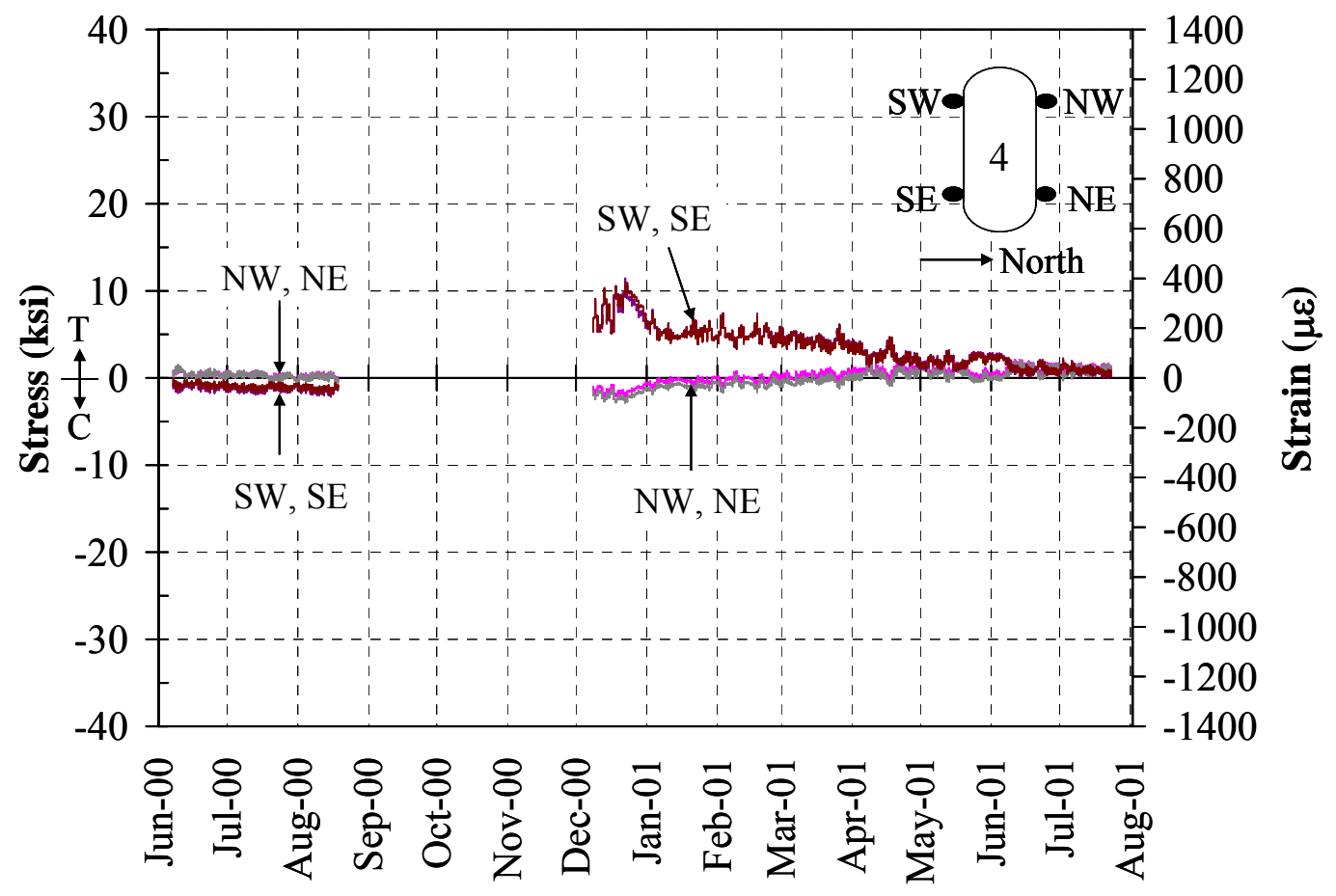

Figure 3.11: Strains and Stresses at the Base of Pier 4 (SR249 over US12) 


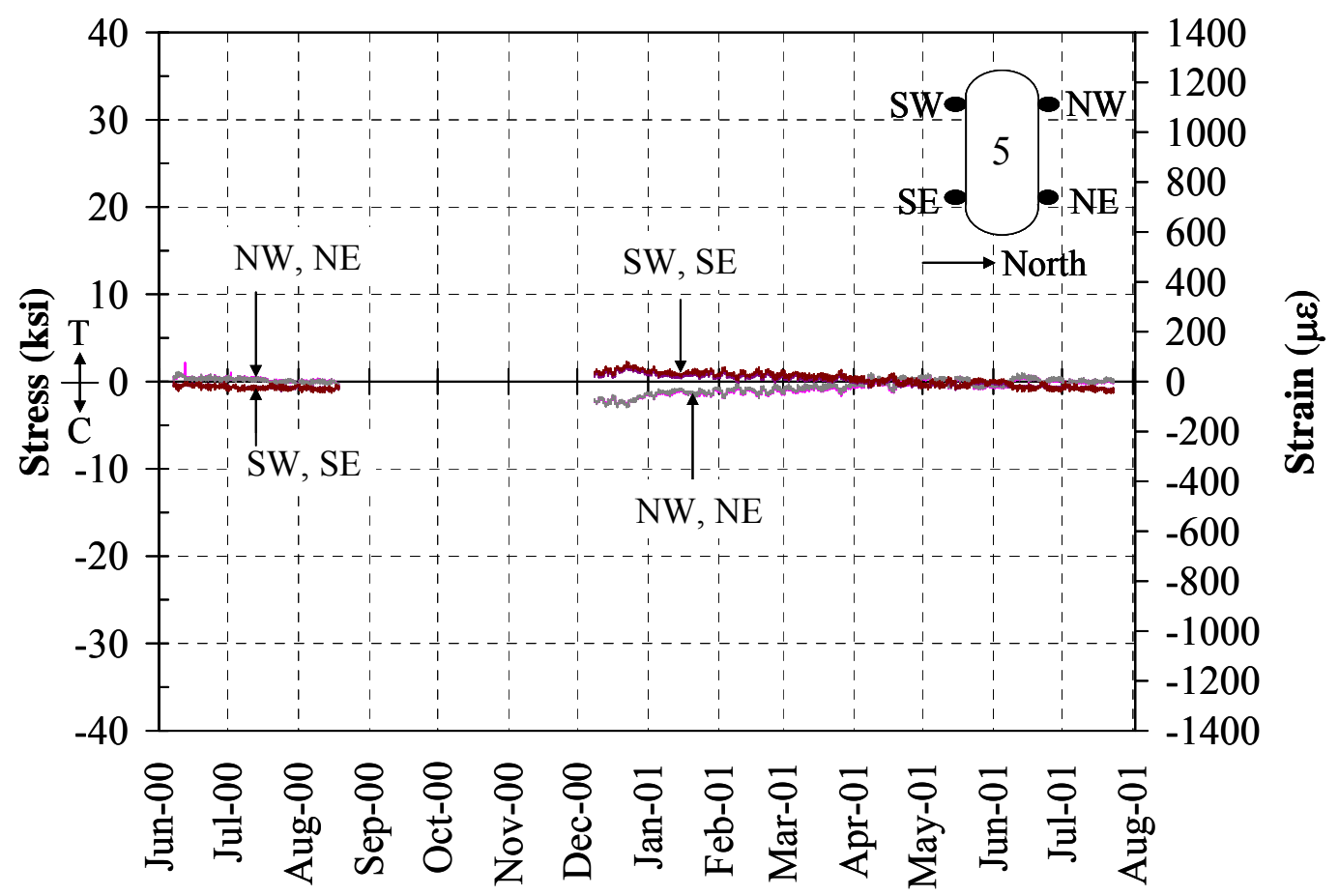

Figure 3.12: Strains and Stresses at the Base of Pier 5 (SR249 over US12)

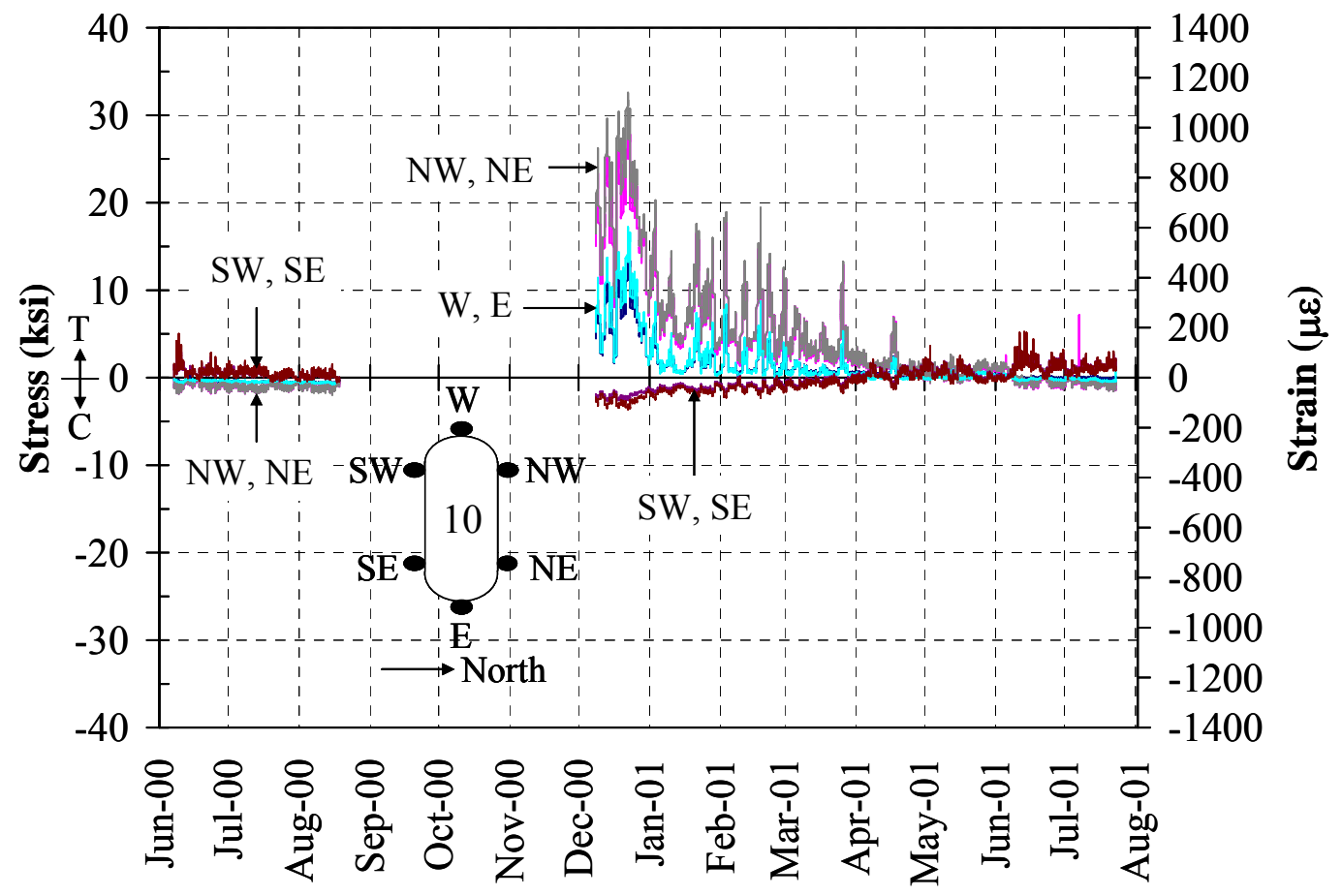

Figure 3.13: Strains and Stresses at the Base of Pier 10 (SR249 over US12) 


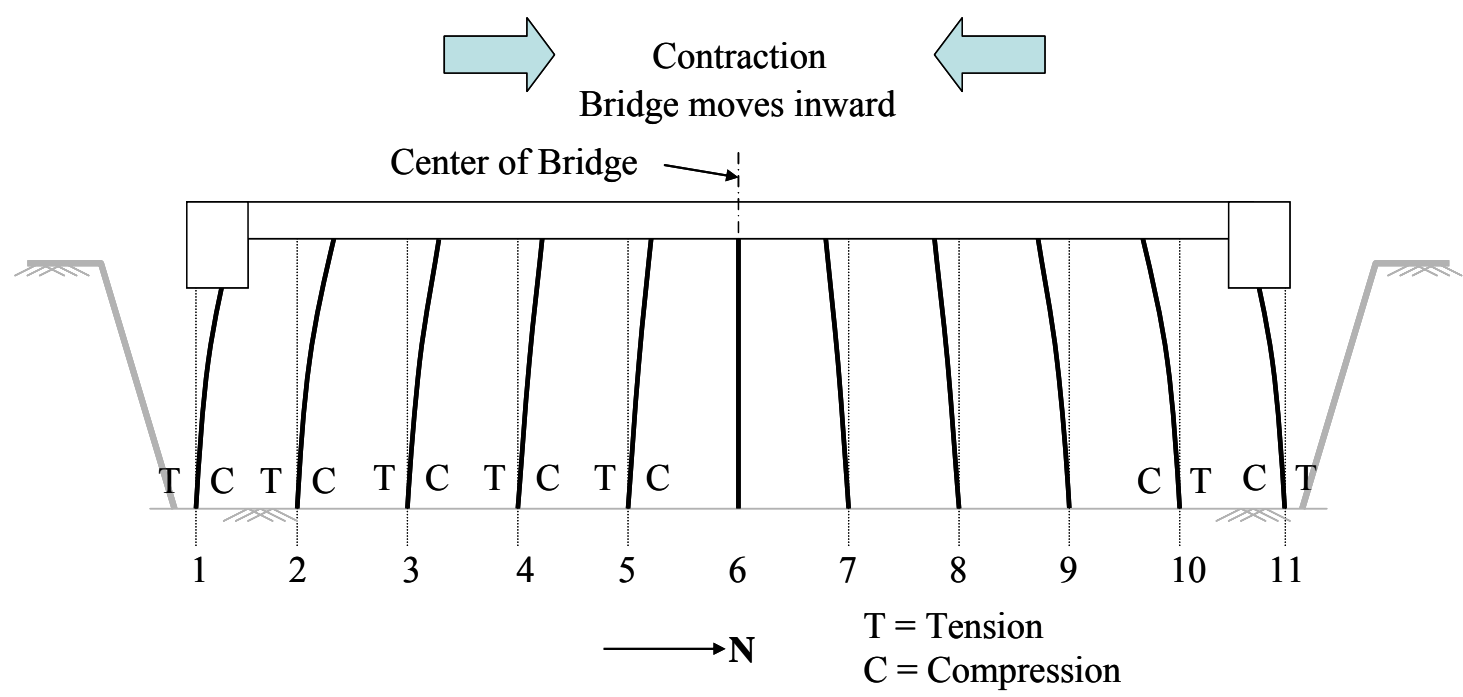

Figure 3.14: Contraction Phase (SR249 over US12)

\subsubsection{Pile Strains}

Strain gages were installed on the piles as described in Section 2.2.3.2. Strains and stresses of the piles on Bents 1 and 11 on the north face at ground level are presented in Figure 3.15. While electrical noise is evident in the measurements, the trend of the strains and stresses on the piles for both bents was similar. Measurements from Pile 5 for Bent 1 and Pile 2 for Bent 11 are not shown since these gages malfunctioned. It can be noticed that the pile strain of Bent 11 is relatively higher than that of Bent 1 during the contraction period. The maximum tensile stresses were approximately 6 and $8 \mathrm{ksi}$ for Bents 1 and 11, respectively, while the maximum compressive pile stresses were approximately 4 and $17 \mathrm{ksi}$ for Bents 1 and 11, respectively. The higher bending stresses for Bent 11 are likely explained because the girder/pier connection at Pier 10 had broken free while that of Pier 2 was still locked together. The interior face of the piles at ground level experienced tension during the expansion phase and compression during the contraction phase (Figure 3.14). Since expanded polystyrene (EPS) was applied on the top of the pile embedded in the abutment, it cannot be determined from this measurement whether the abutment-pile connection behaves fully rigid or pinned. In addition, the bending mode of the pile cannot be determined from this measurement alone. 


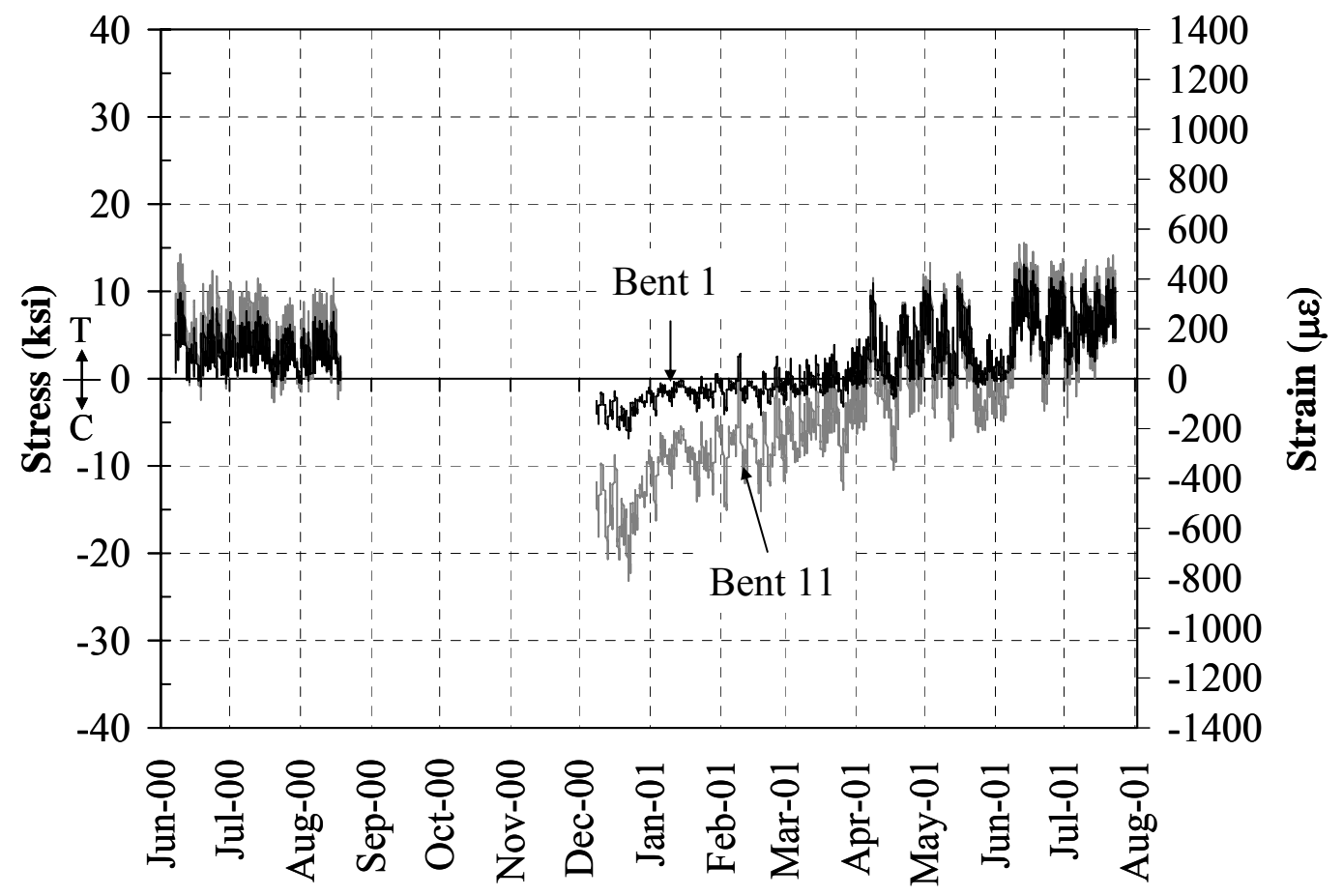

Figure 3.15: Stresses and Strains on Piles Supporting Bents 1 and 11

(SR249 over US12) 


\subsection{I65 over SR25 Bridge}

The instrumentation of I65 over SR25 included both the northbound and southbound structures. Strain gages, thermocouples, and linear potentiometers were installed on the bridges as described in Chapter 2. The measurements provide useful data to evaluate the pile and abutment behavior.

\subsubsection{Temperature}

The air temperature was measured by a thermocouple located on Beam 7 at midspan and is plotted in Figure 3.16. The results over the three year period shown compare well with average high and low temperature for Lafayette, IN, based on historical data provided by the Weather Channel (www.weather.com). Table 3.3 summarizes construction, maximum, and minimum temperatures for the I65 over SR25 site during the duration of the study.

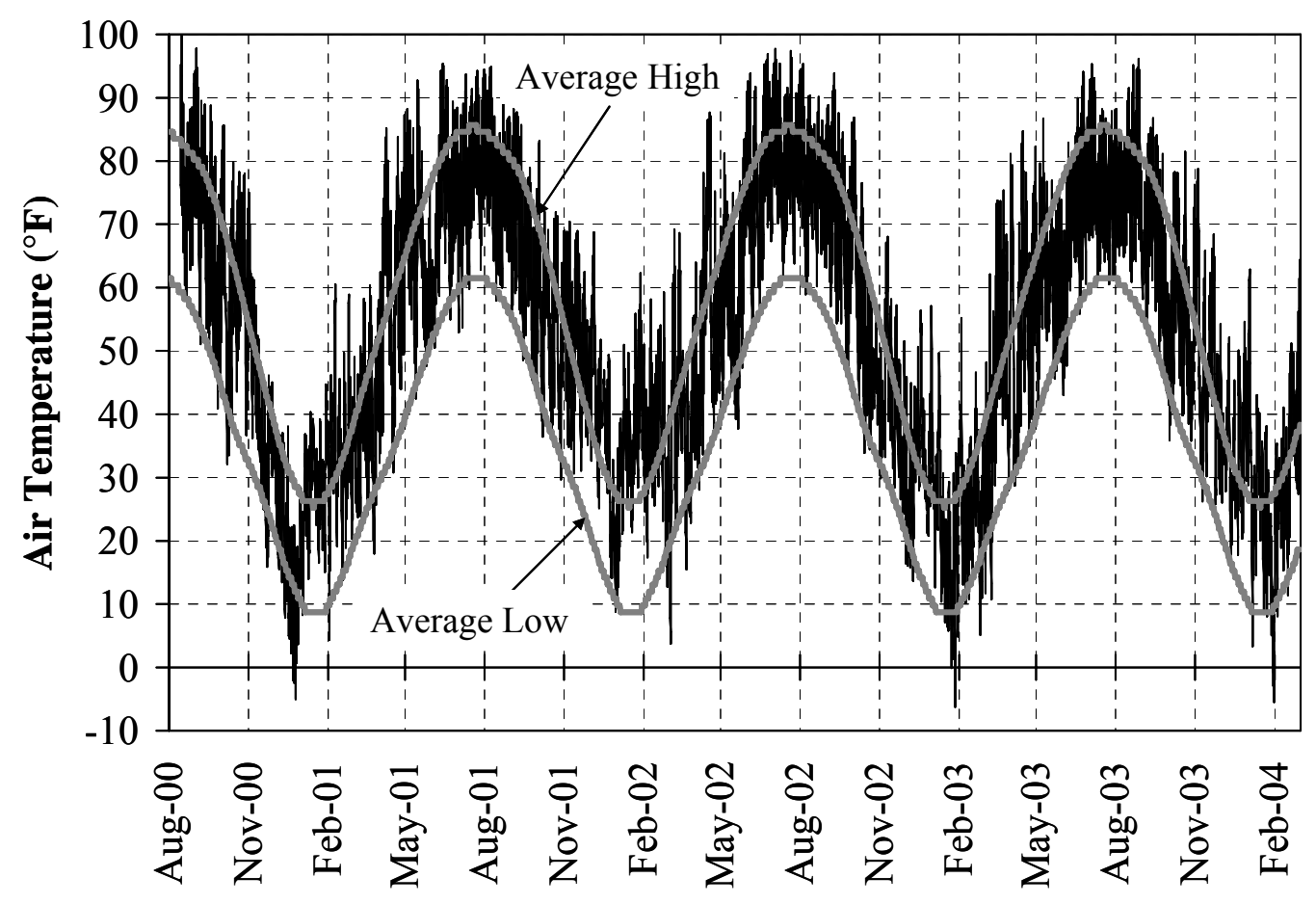

Figure 3.16: Air Temperature (I65 over SR25) 
Table 3.3: Air Temperature (I65 over SR25)

\begin{tabular}{|l|c|l|}
\hline Temperature Type & Temperature $\left({ }^{\circ} \mathbf{F}\right)$ & \multicolumn{1}{|c|}{ Date } \\
\hline Construction & 85 & August 15,2000 \\
\hline Maximum & 100 & September 1, 2000 at 16:00 \\
\hline Minimum & -7 & December 25, 200 at 19:00 \\
\hline
\end{tabular}

Southbound Structure

\begin{tabular}{|l|c|l|}
\hline Temperature Type & Temperature $\left.^{(}{ }^{\circ} \mathbf{F}\right)$ & \multicolumn{1}{|c|}{ Date } \\
\hline Construction & 58 & October 18, 2000 \\
\hline Maximum & 98 & July 3, 2002 at 16:00 \\
\hline Minimum & -7 & December 25, 2000 at 19:00 \\
\hline
\end{tabular}

\subsubsection{Abutment Movement}

The movement of Bent 1 on the southbound structure was measured by both longitudinal and transverse linear potentiometers as described in Section 2.3.3.2. The movement recorded by the longitudinal potentiometer is shown in Figure 3.17. Water infiltration may have occurred for this instrument causing abrupt changes in the recorded measurement. That data was adjusted by removing the sudden jumps which provided reasonable results. Due to the erratic behavior of the gage especially following March 2001, the data was replotted only illustrating the results from September 2000 to March 2001 in Figure 3.18. From September 2000 to December 2000, it is observed that the bridge contracts as the temperature decreases. From January 2001 to March 2001, the bridge expanded due to the slight increase in temperature. After March 2001, the gage was problematic resulting in erratic jumps in the data.

The transverse movement of the end bent was adjusted and is presented in Figure 3.19. Neglecting the erratic jumps, the results reveal that the transverse movement due to bridge skew is minimal (Figure 3.20). As previously done for the longitudinal gage, this figure concentrates on the initial results from September 2000 to March 2001. The results from both the transverse and longitudinal gages should be considered with caution due to their performance issues and considering that data correction was necessary. 


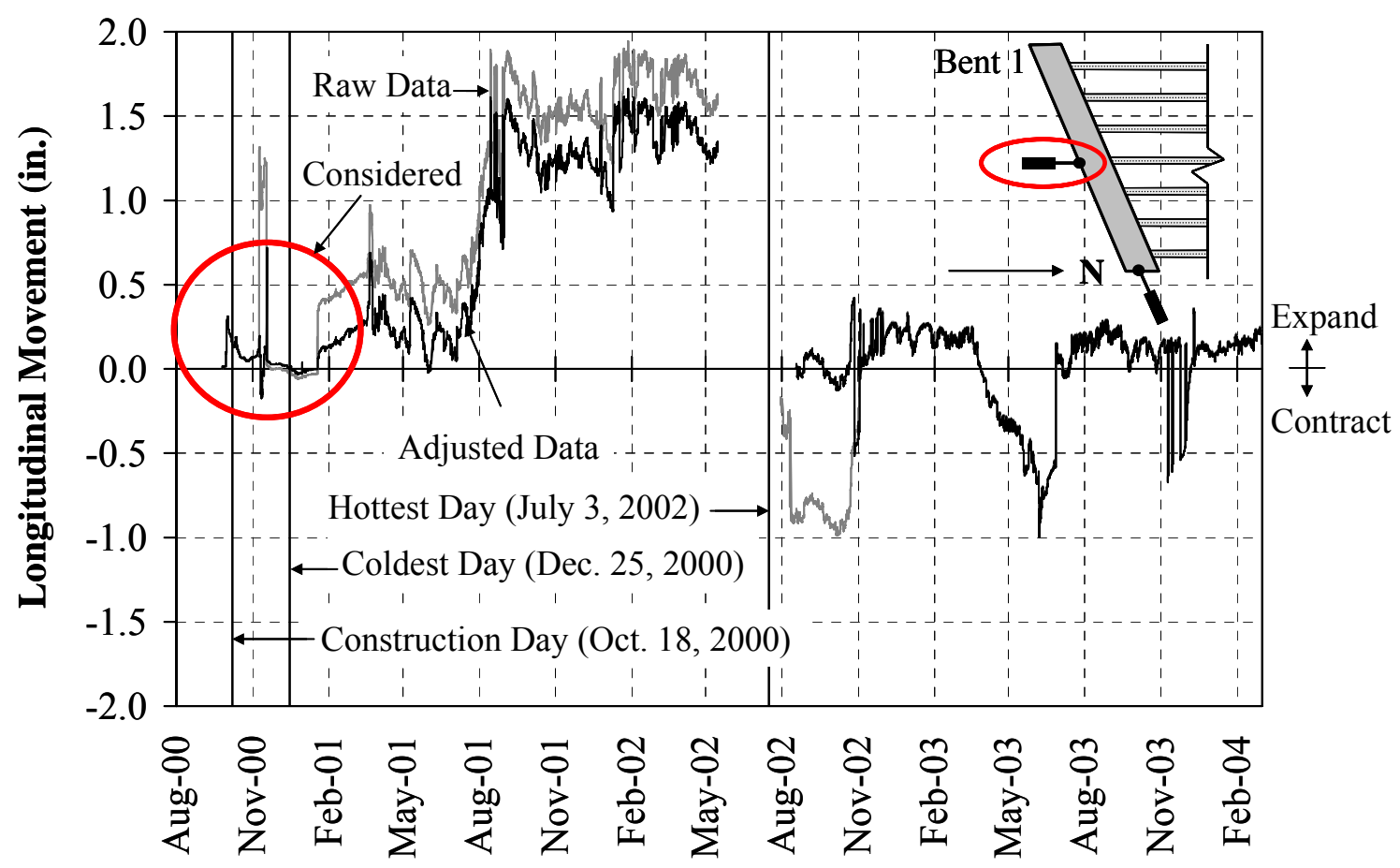

Figure 3.17: Longitudinal Movement (I65 over SR25)

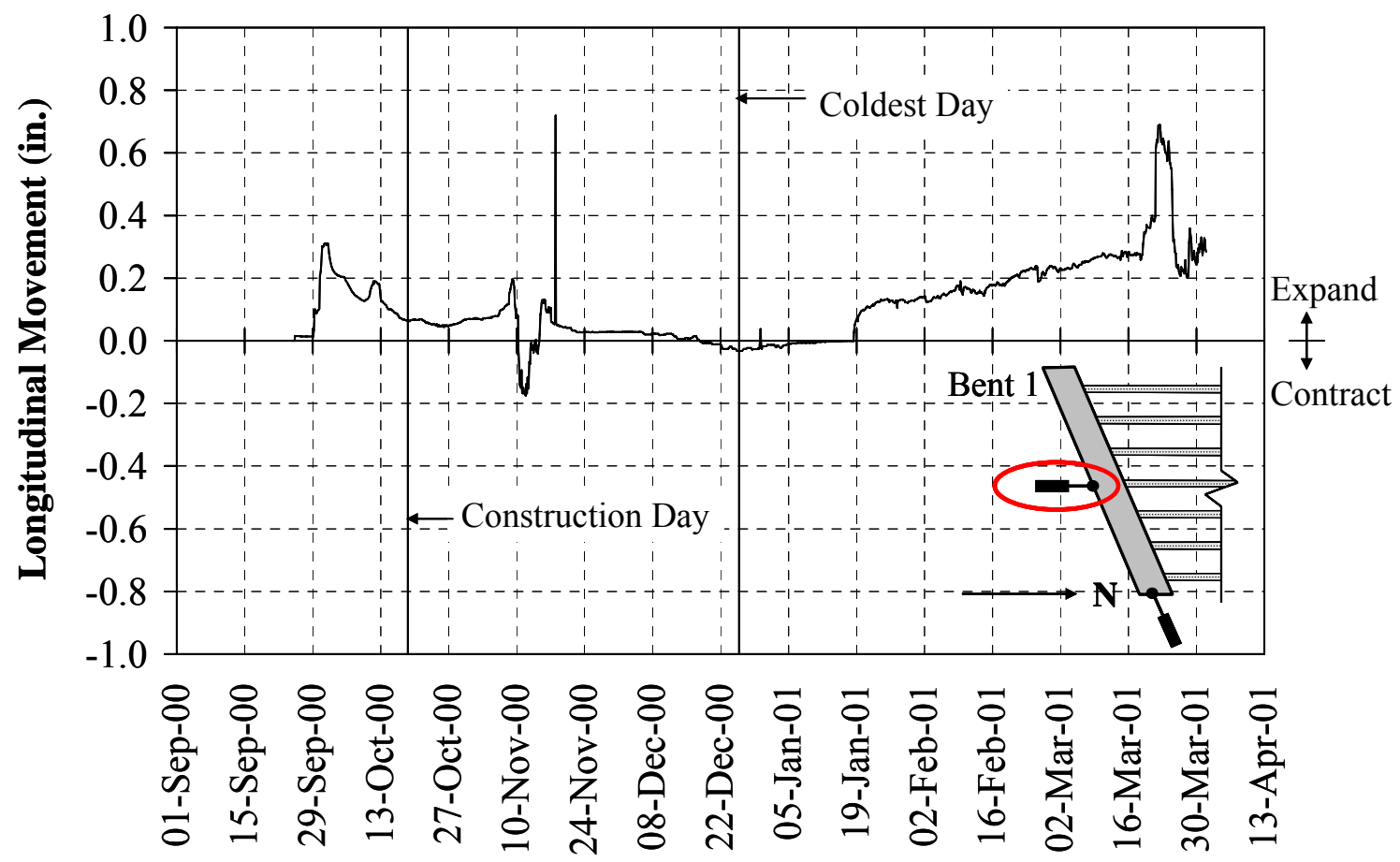

Figure 3.18: Initial Longitudinal Movement (I65 over SR25) 


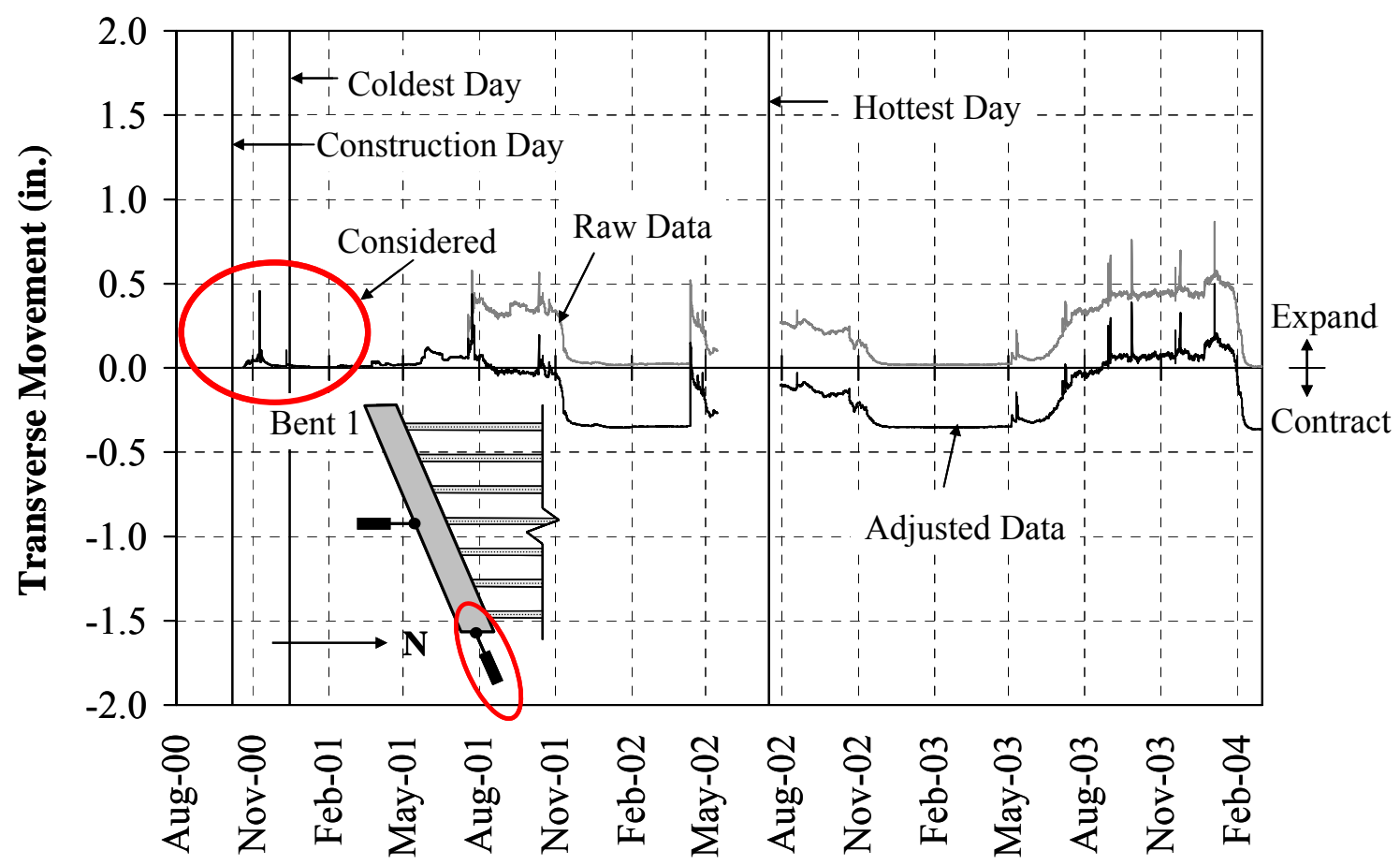

Figure 3.19: Transverse Movement (I65 over SR25)

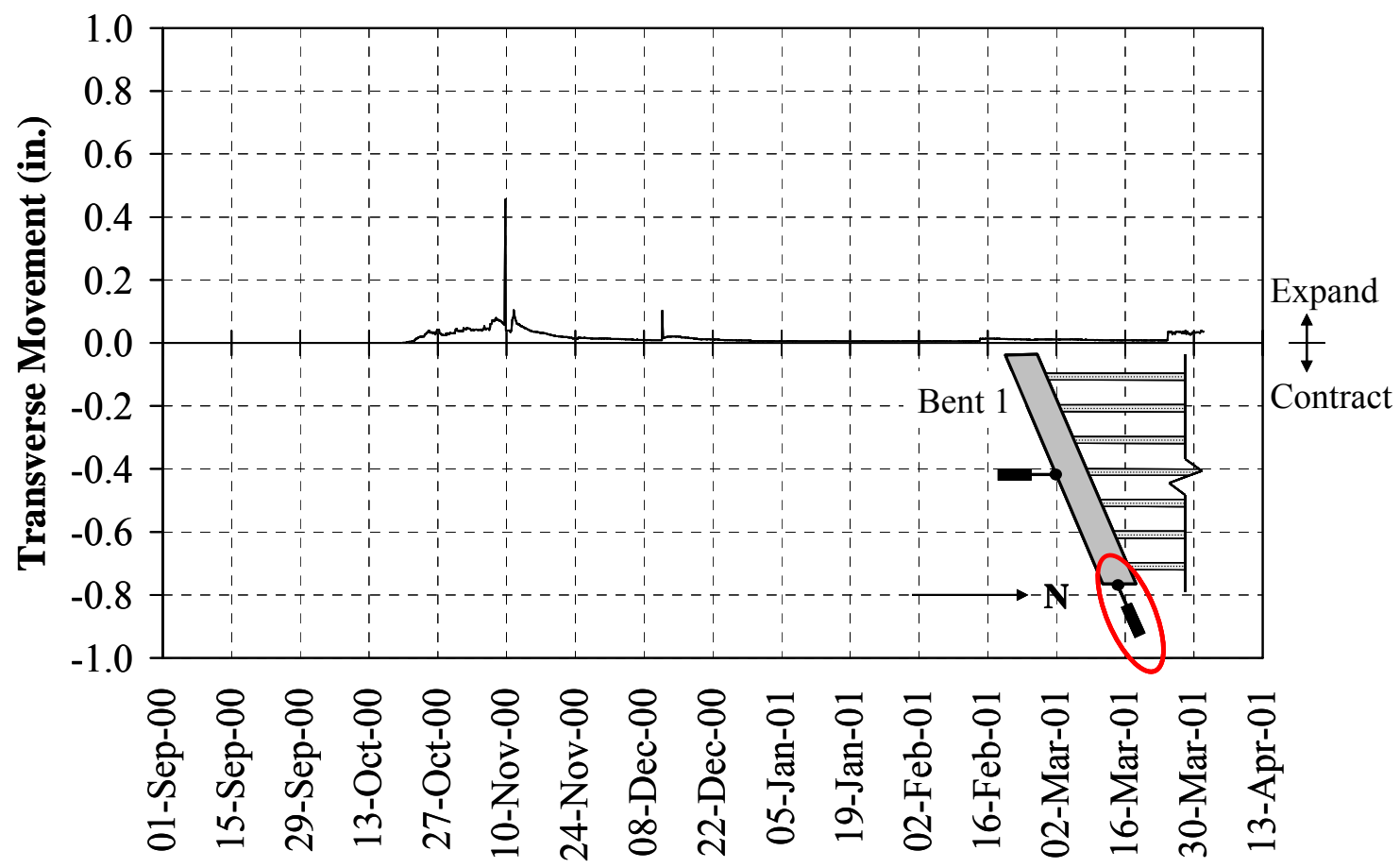

Figure 3.20: Initial Transverse Movement (I65 over SR25) 


\subsubsection{Pile Strains}

Pile strains were monitored at different locations as described in Sections 2.3.3.2. Figure 3.21 shows the strain gage locations on Piles 6 and 9 supporting Bent 1 of the southbound structure. Due to a loss of battery power, data between approximately May 2002 and August 2002 were lost as well as the initial zero readings. Therefore, the magnitudes of strains after August 2002 are not highly reliable. For Pile 9, only the gage on the SW flange was still functioning over the duration of the study; therefore, data from this pile is not considered. Based on these problems, the results from Pile 6 are considered only from August 2000 to May 2002.

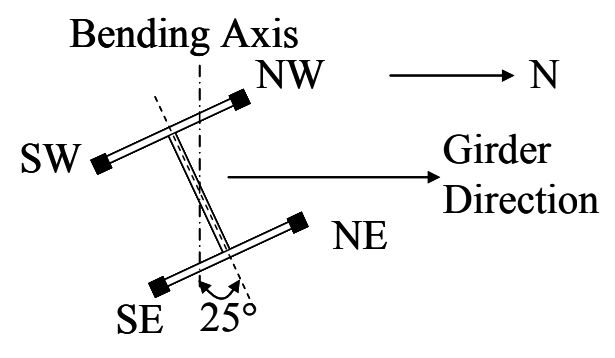

\section{Figure 3.21: Strain Gage Locations on Piles 6 and 9 (Bent 1, Southbound Structure of I65 over SR25)}

The strain on Pile 6 at the NE and NW locations is plotted in Figure 3.22 while the strain on Pile 6 at the SE and SW locations is shown in Figure 3.23. During contraction (approximately August through December), strains on the north face experienced tension while strains on the south face experienced compression. Moreover, as the temperature increased and the bridge expanded (approximately January through September), strains on the north face indicated compression while strains on the south face were in tension. This behavior indicates that the pile bent in double curvature during the expansion and contraction phases.

It is noted that the bending axis of the piles is neither about the weak nor strong axis, but rather about the $25^{\circ}$ axis. As anticipated, during the expansion phase, the maximum tension strain occurred on the NE flange while the maximum compression strain occurred on the SW flange. The piles were essentially loaded in the direction of the girders as shown in Figure 3.21. 


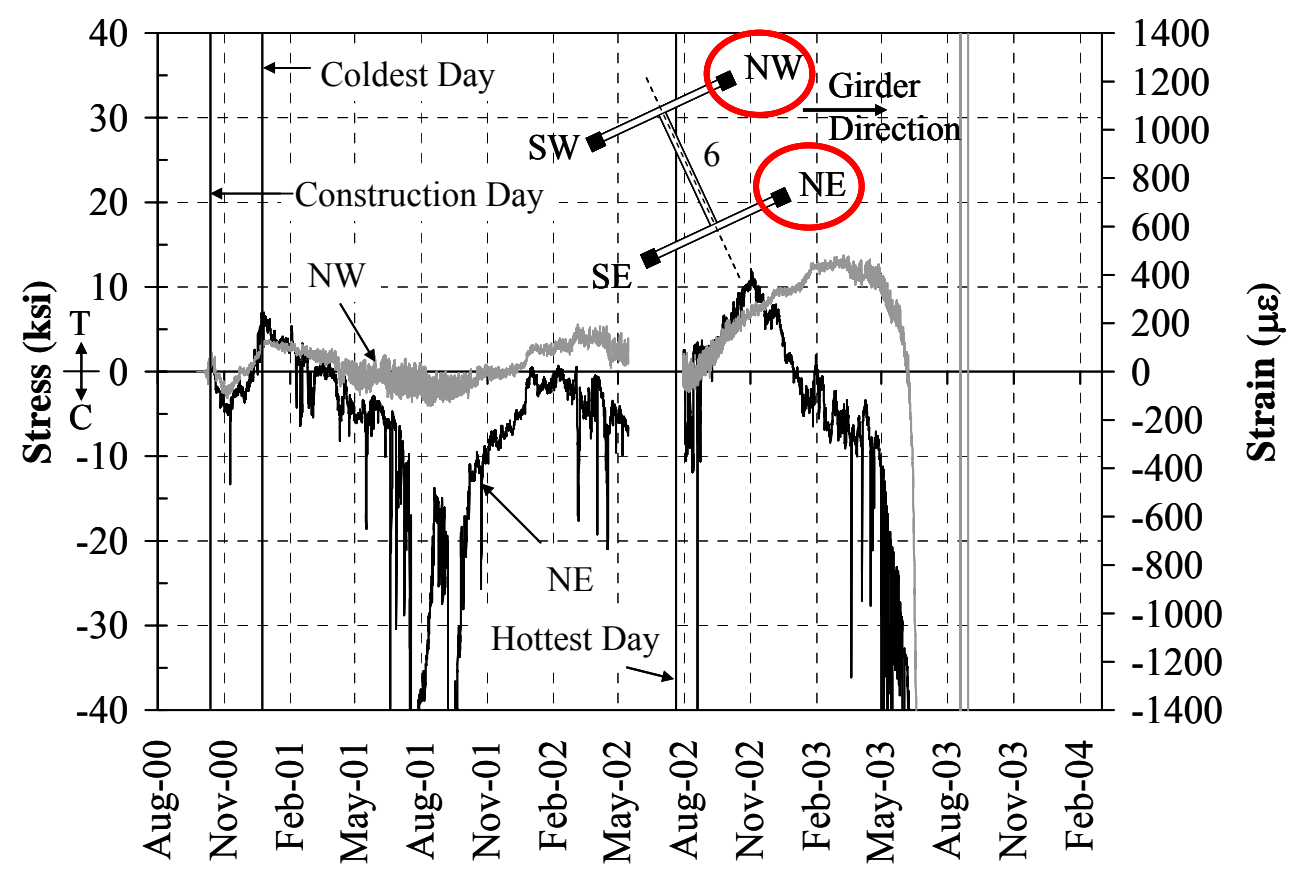

Figure 3.22: Strain at NW and NE Locations on Pile 6 (Bent 1, Southbound Structure of I65 over SR25)

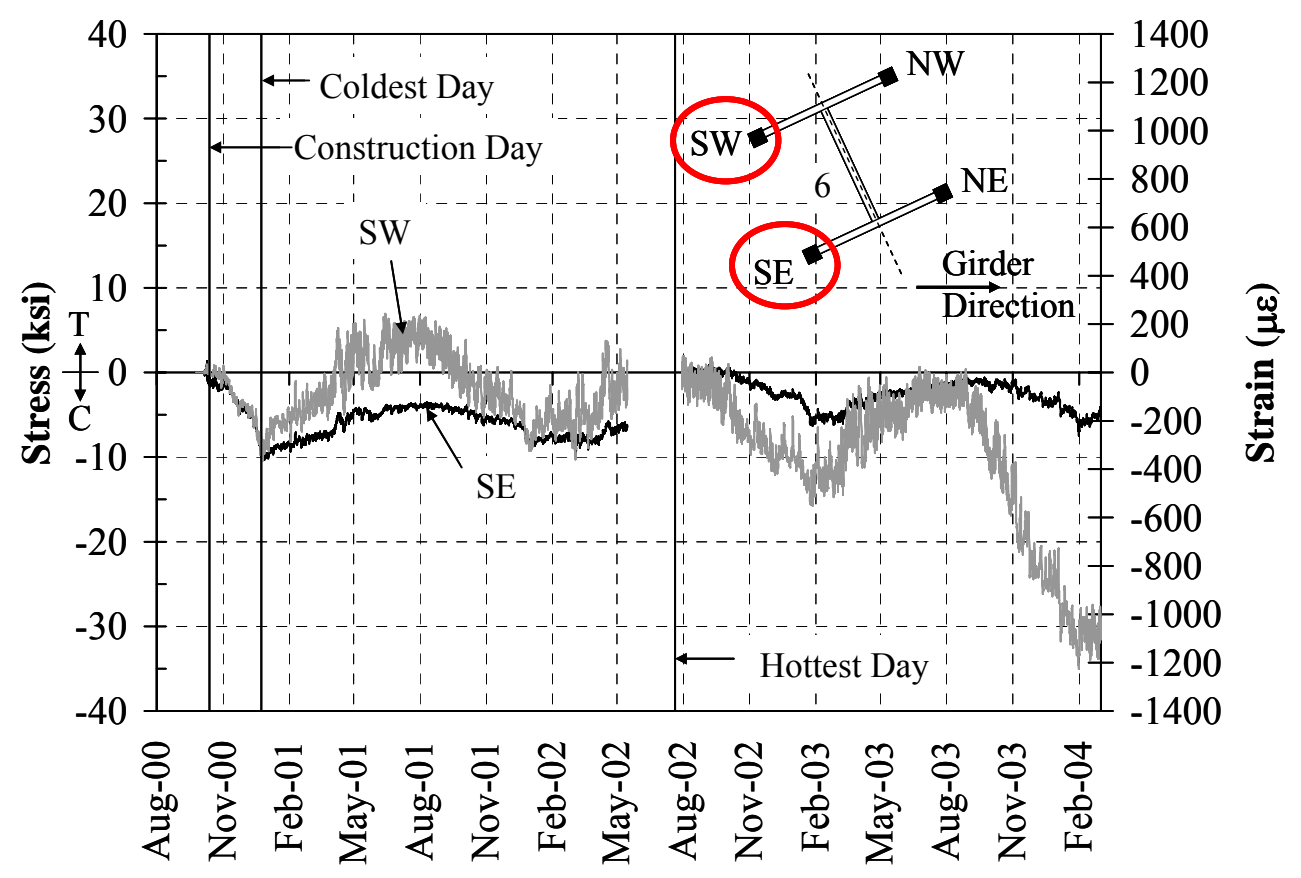

Figure 3.23: Strain at SW and SE Locations on Pile 6 (Bent 1, Southbound Structure of I65 over SR25) 
During the coldest period, the south face of the pile experienced a compressive stress of approximately $10 \mathrm{ksi}$, while the pile experienced tensile stresses of approximately $6 \mathrm{ksi}$ at the NE flange and $3 \mathrm{ksi}$ at the NW locations. Neglecting the gage at the NE location due to off-scale readings, the NW and SE flanges experienced compression of 3 and 4 ksi, respectively during the expansion phase (August 2001), while the SW flange experienced tension of $6 \mathrm{ksi}$.

The recorded strains for Pile 7, Bent 1 on the northbound structure which is a CFT pile is shown in Figure 3.24. Due to the low strain recorded by the gages on the south face, it was considered not reliable. It is suspected that debonding of this gage occurred following installation. Based on the results of the north gage, however, double curvature behavior was observed. For instance, the north gage experienced tension during contraction (cold periods) and compression during expansion (hot periods). This behavior is in agreement with that observed for the $\mathrm{H}$ piles.

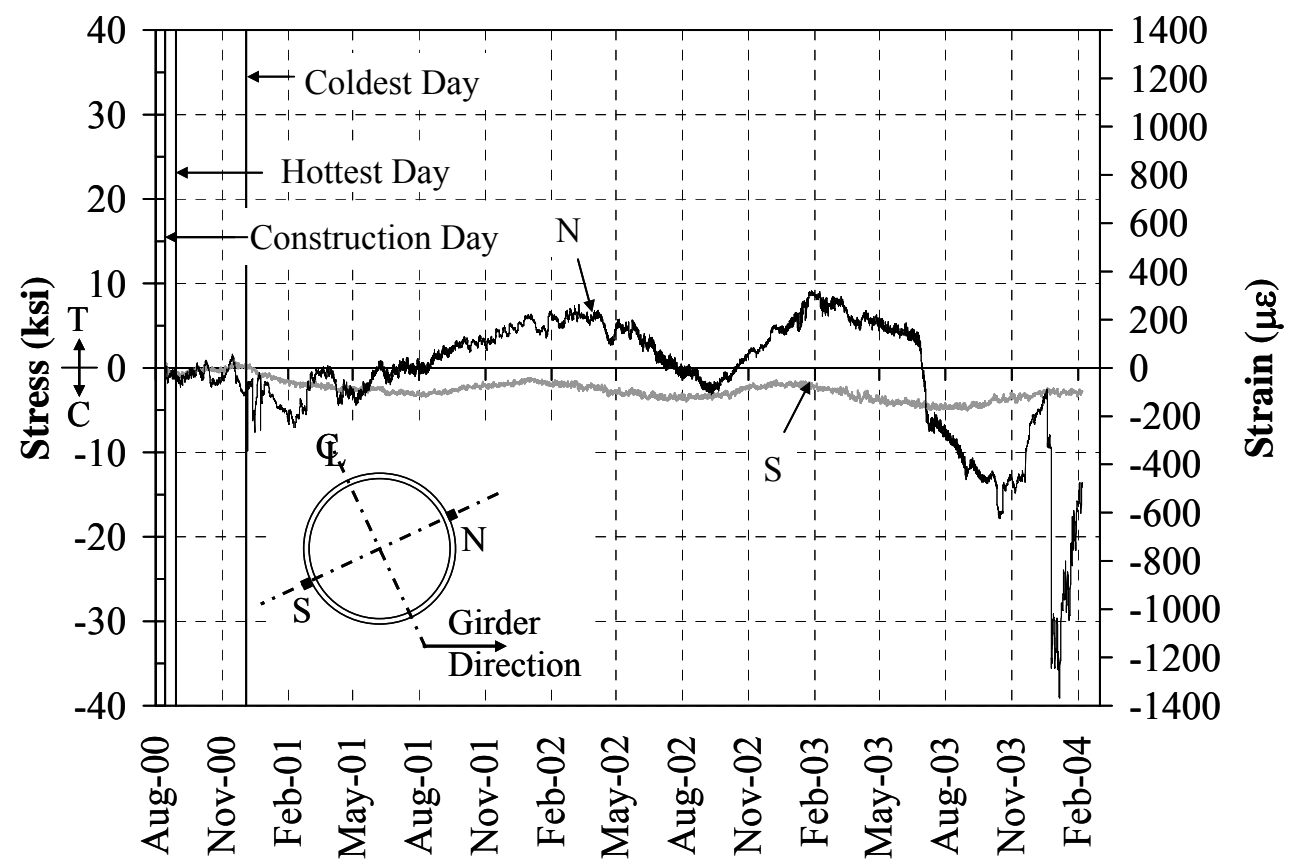

Figure 3.24: Strain on the North and South Locations on Pile 7 (Bent 1, Northbound Structure of I65 over SR25) 


\subsection{SR18 over Mississinewa River Bridge}

The SR18 over Mississinewa River bridge was instrumented to compensate for the incomplete data from SR249 over US12 and I65 over SR25. The instruments on Bent 6 were installed in June 2003, while those on Bent 1 were installed in July 2003 as described in Chapter 2. Because the bridge deck was cast on September 26, 2003, only data between September 26, 2003 and March 9, 2004 are interpreted in the following section. Data in this period represent the behavior of the piles and abutments during the contraction phase. It should be noted that the instrumentation systems were connected to external power that initiated electrical noise in the signals beginning December 2, 2003. The problem was resolved on February 23, 2003.

\subsubsection{Temperature}

The temperature on the SR18 bridge was measured by temperature gages located on a girder and in the deck between Pier 5 and Bent 6 as shown in Figure 3.25. The temperature measured by both gages was almost identical. The response of the deck is slower than that of the girder. The construction, maximum, and minimum temperatures are summarized in Table 3.4 .

\subsubsection{Rotations of the Abutment}

The rotation of the abutment was measured by tiltmeters located on the east and west faces of Bents 1 and 6 , respectively. The rotations of the abutments were filtered by taking the average of the data recorded between the time interval four hours before and four hours after the desired measurement time. The filtered rotations of both bents are plotted in Figure 3.26. The results indicate that Bents 1 and 6 translated and hardly rotated. 


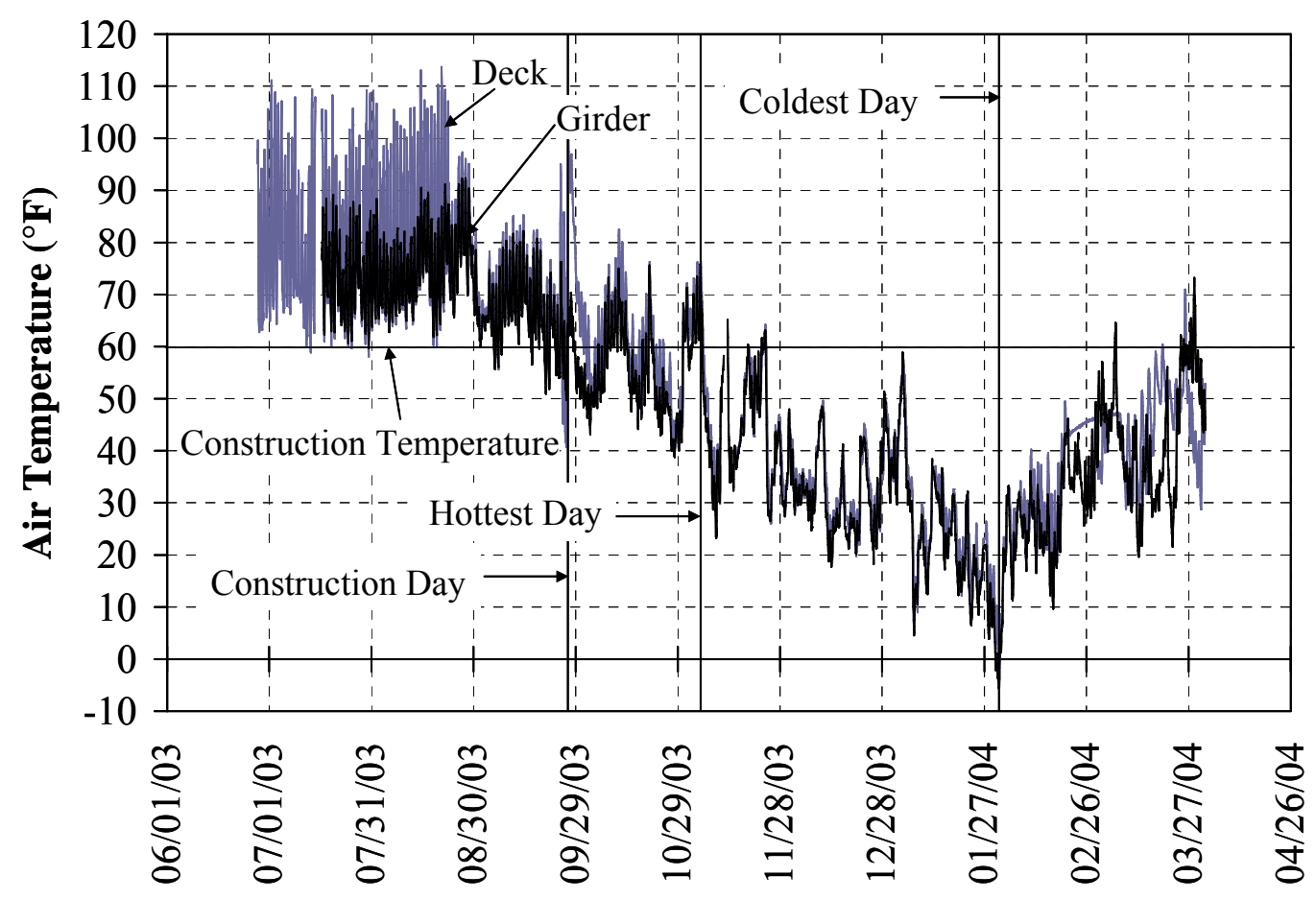

Figure 3.25: Air Temperature (SR18)

Table 3.4: Air Temperature (SR18)

\begin{tabular}{|l|c|l|}
\hline Temperature Type & Temperature $\left({ }^{\circ} \mathbf{F}\right)$ & \multicolumn{1}{|c|}{ Date } \\
\hline Construction & 60 & September 26, 2003 \\
\hline Maximum & 76 & November 4, 2003 at 16:00 \\
\hline Minimum & -6 & January 31, 2004 at 8:00 \\
\hline
\end{tabular}

\subsubsection{Abutment Movement}

The movements of the abutments were measured by convergence meters in different locations as discussed in Section 2.4.3. The abutment movements of Bents 1 and 6 are plotted in Figure 3.27. The convergence meters were slightly moved from the zero position before casting of the bridge deck. If the data are zeroed immediately prior to casting, however, the results are essentially identical (Figure 3.28). These results indicate that the abutment movement corresponds well with temperature. For instance, as the temperature decreases (contraction phase), both abutments move toward each other as anticipated. 


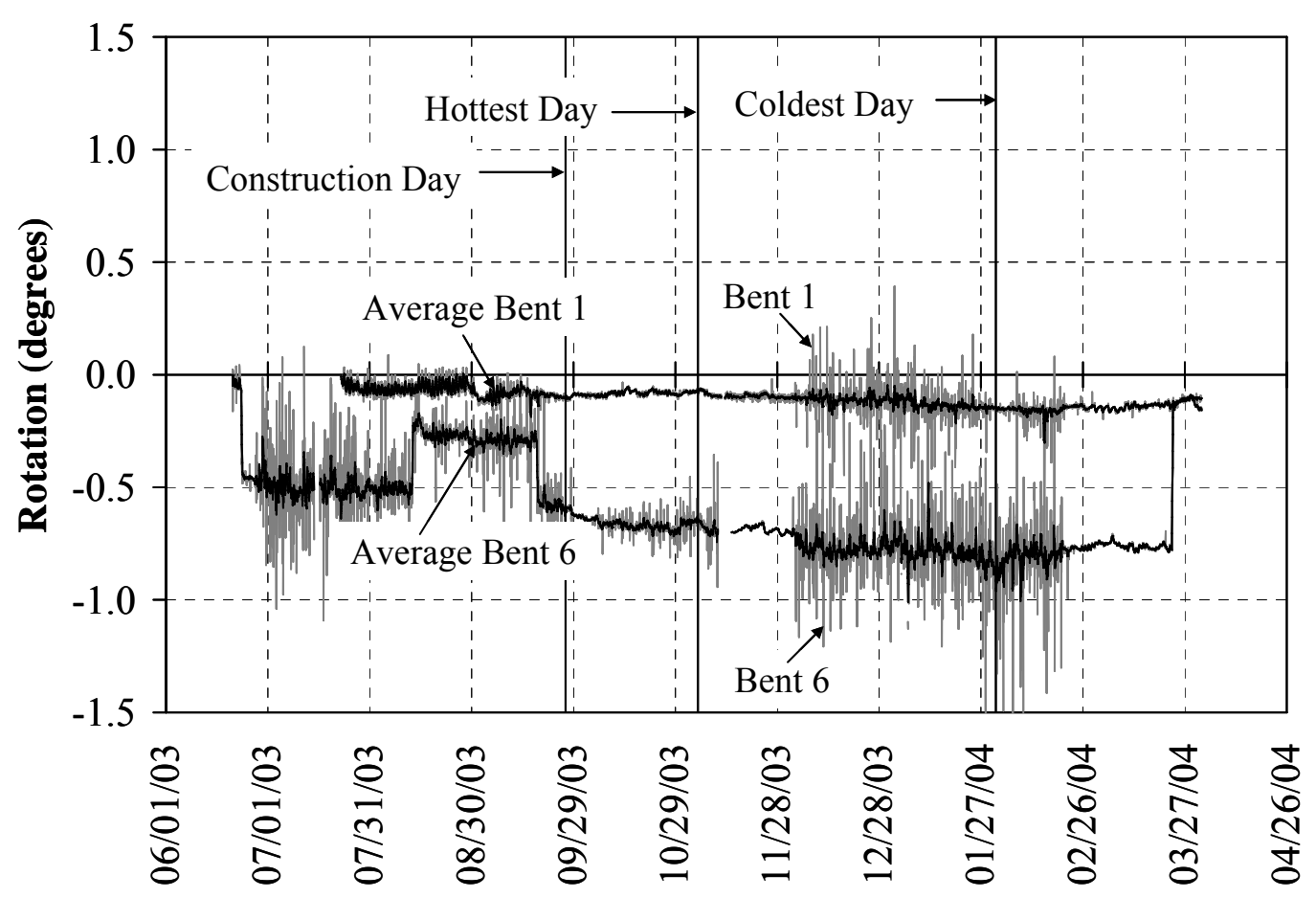

Figure 3.26: Rotations of the Abutment (SR18)

The measured movement of Bent 1 was compared to the thermal movement calculated according to Equation 3-1 as shown in Figure 3.29. The expansion and contraction longitudinal movements of Bents 1 and 6 on the hottest and coldest days obtained from the field were also compared to the calculated thermal movement in Table 3.5. It can be seen that the calculated abutment movements are greater than the measured values. This difference is most likely due to backfill restraint, pile resistance, and friction from the approach slab.

$$
\Delta \mathrm{L}=\alpha(\Delta \mathrm{T}) \mathrm{L}
$$

where:

$$
\begin{aligned}
\alpha \quad= & \text { thermal coefficient of concrete, taken as } 6.0 \times 10^{-6} /{ }^{\circ} \mathrm{F} ; \\
\Delta \mathrm{T}= & \text { change in temperature, taken as } 16^{\circ} \mathrm{F} \text { on the hottest day and } \\
& 66^{\circ} \mathrm{F} \text { on the coldest day; } \\
\mathrm{L} \quad= & \text { half of the total span length, taken as } 367 \mathrm{ft} / 2=183.5 \mathrm{ft} .
\end{aligned}
$$




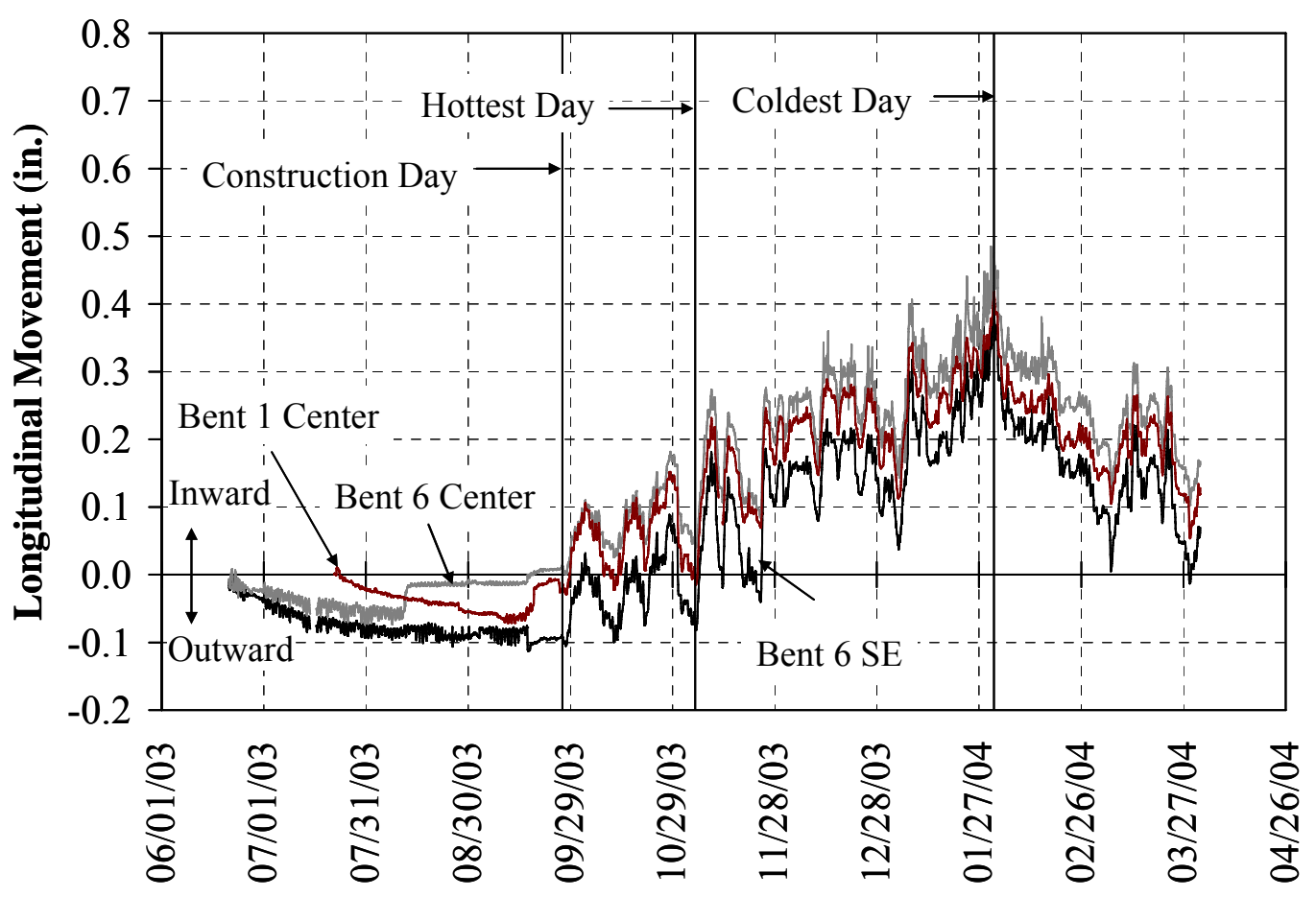

Figure 3.27: Abutment Movement (SR18)

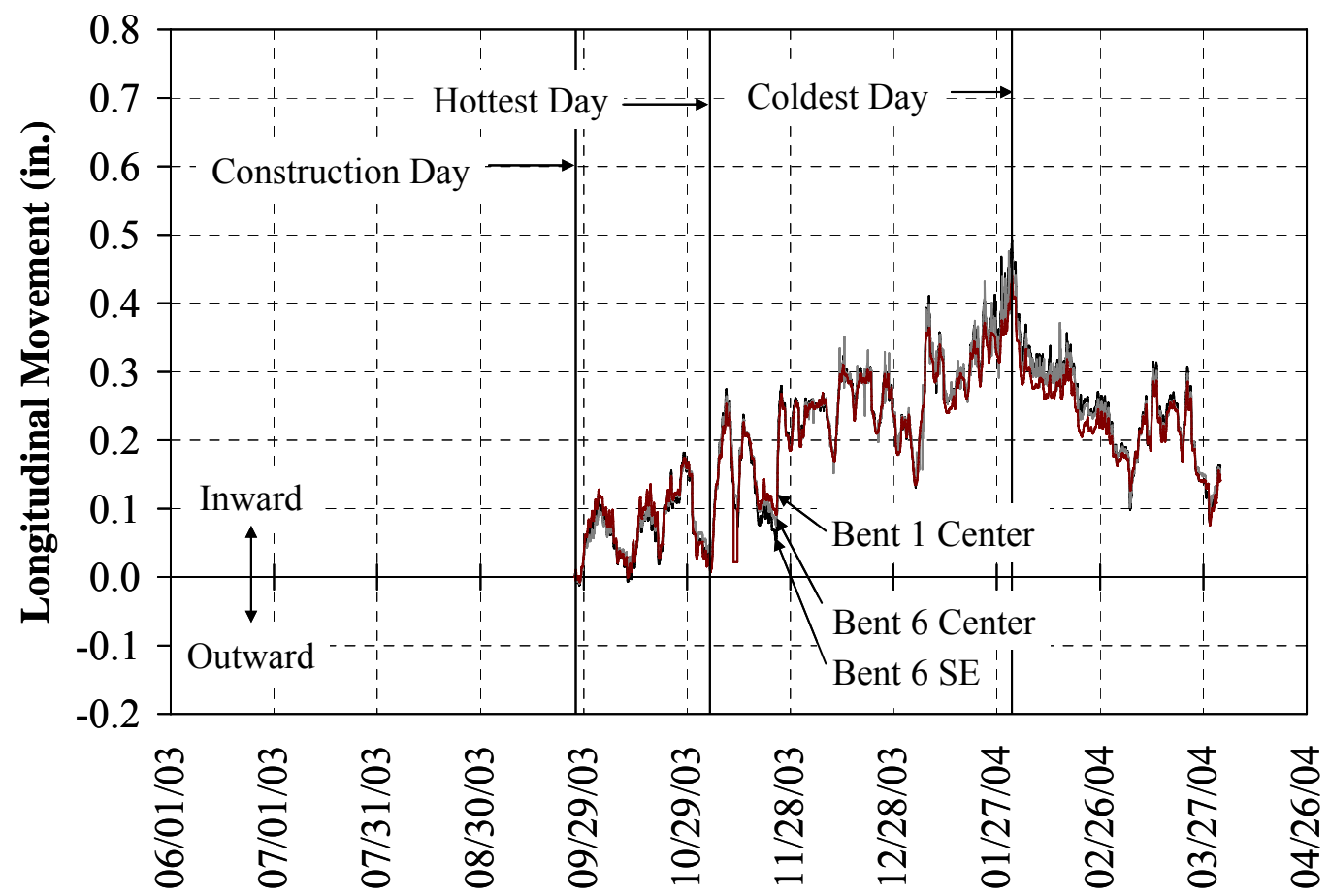

Figure 3.28: Adjusted Longitudinal Movement (SR18) 


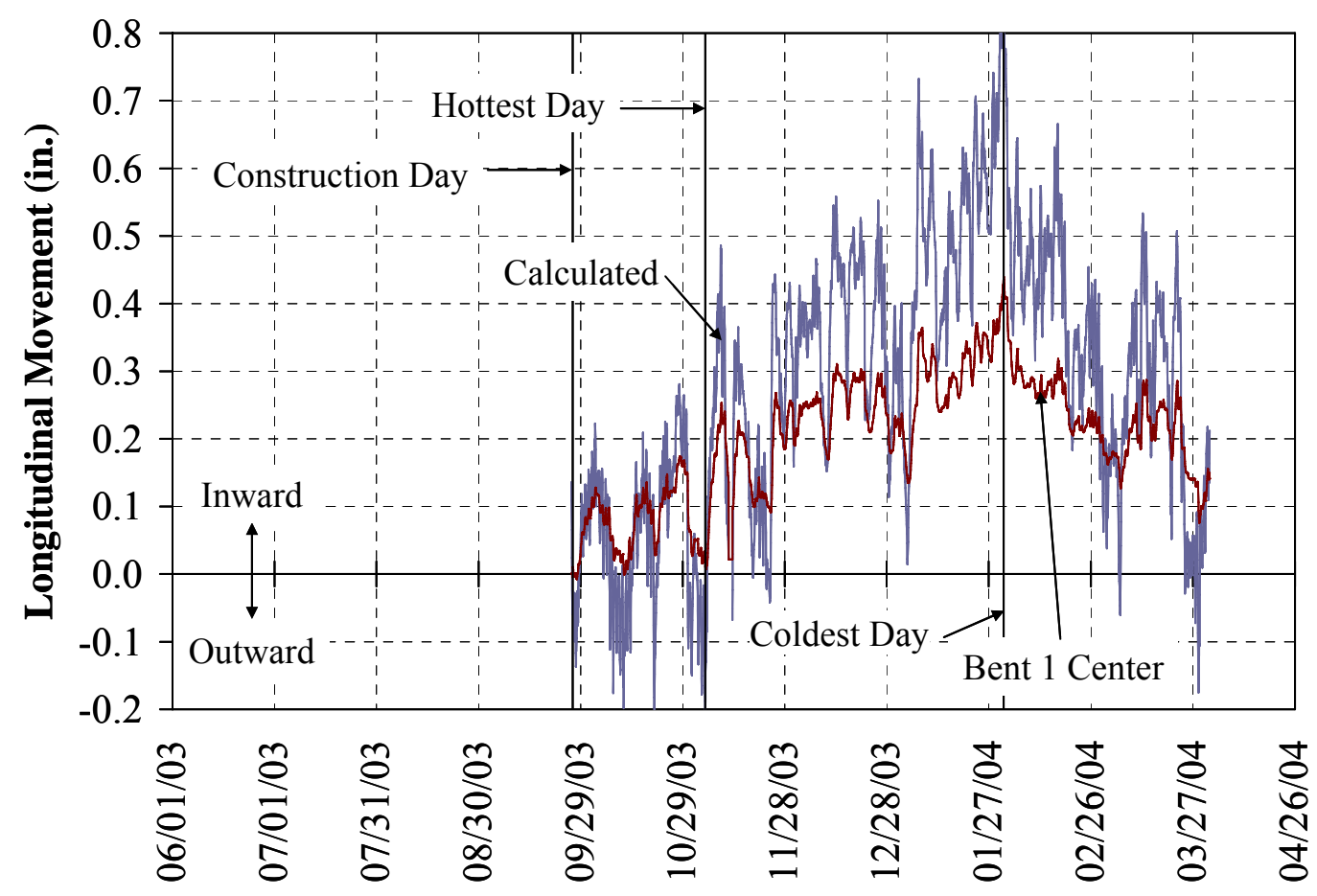

Figure 3.29: Calculated vs. Measured Movements (SR18)

Table 3.5: Abutment Movement (SR18)

\begin{tabular}{|l|c|c|c|}
\hline Movement (in.) & Bent 1 & Bent 6 & Calculated \\
\hline Expansion & 0.07 & 0.03 & 0.19 \\
\hline Contraction & 0.41 & 0.46 & 0.80 \\
\hline
\end{tabular}

\subsubsection{Pile Strains}

Strain gages were installed on the piles of Bents 1 and 6 as illustrated in Section 2.4.3.2. The data for Bent 1 are available beginning July 17, 2003 (zeroed), while the data for Bent 6 are available beginning June 18, 2003. The data are presented until March 31, 2004.

As previously discussed, strain gages were installed along the length of Pile 6 (Bent 1) on the east, west, and south faces of the pile. These results are presented in Figures 3.30, 3.31, and 3.32, respectively. It should be noted that a strain gage located on the west face at a depth of $20 \mathrm{ft}$ below ground level was damaged during driving. 
In general, strain on the east and west faces at each depth are almost mirror images of one another. It is evident that the pile is sensitive to temperature change. As the temperature dropped, the pile on the east face at ground level experienced tension while the pile on the west face experienced compression. The strain profile along the pile length clearly indicates double curvature bending.

On the coldest day (January 31, 2004), Pile 6 of Bent 1 experienced 14 ksi of tension on the east face and $14 \mathrm{ksi}$ of compression on the west face (Figures 3.30 and 3.31). Stresses on the east and west locations at a depth of $4,8,12$, and $16 \mathrm{ft}$ were progressively lower. On the east side of the pile, the stress at a depth of $20 \mathrm{ft}$ was typically between the stresses that occurred at a depth of $4 \mathrm{ft}$ and $8 \mathrm{ft}$ (Figure 3.30). No data were recorded at the $20 \mathrm{ft}$ depth at the west location because the gage was lost while driving (Figure 3.31).

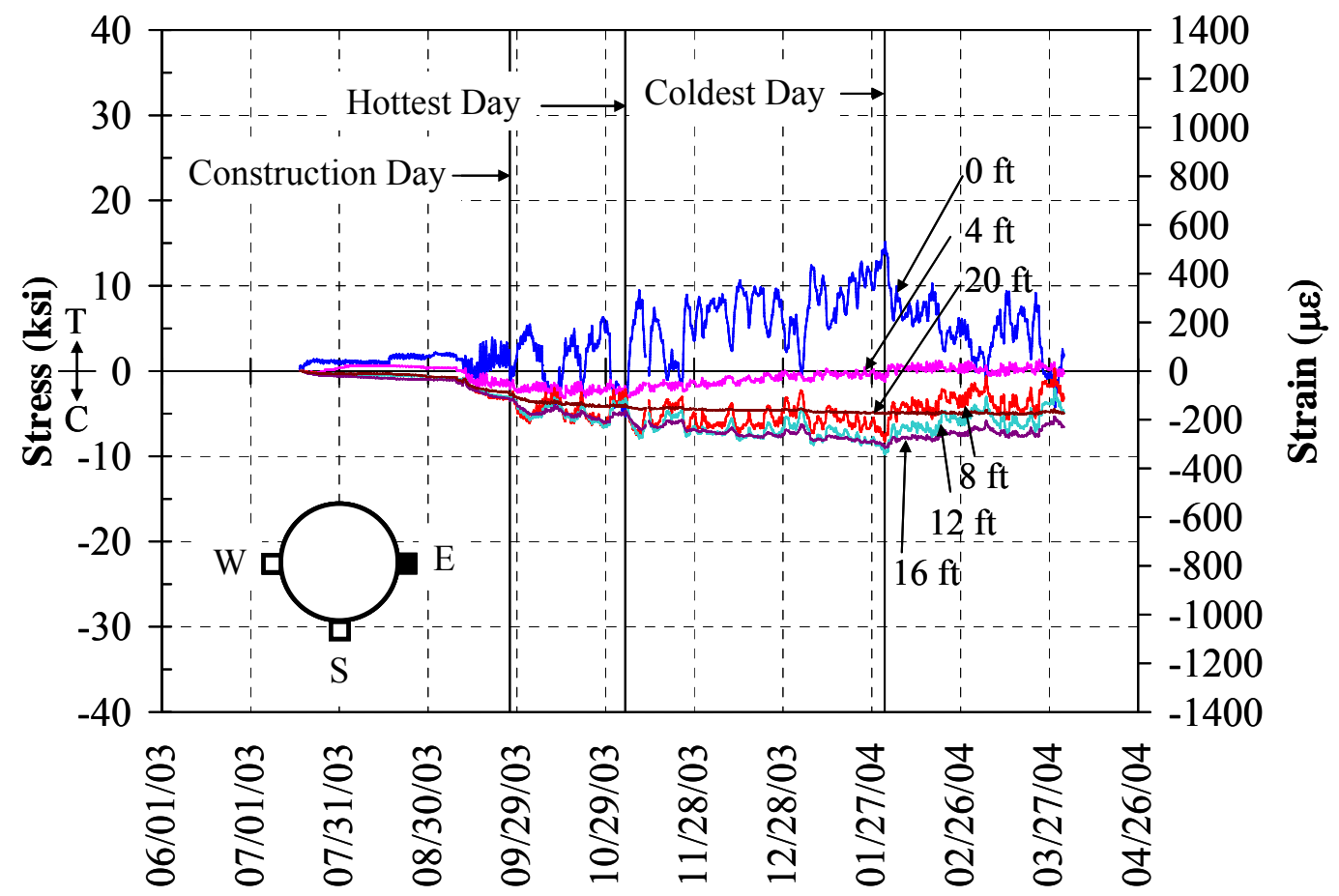

Figure 3.30: Strain at the East Locations on Pile 6, Bent 1 (SR18) 


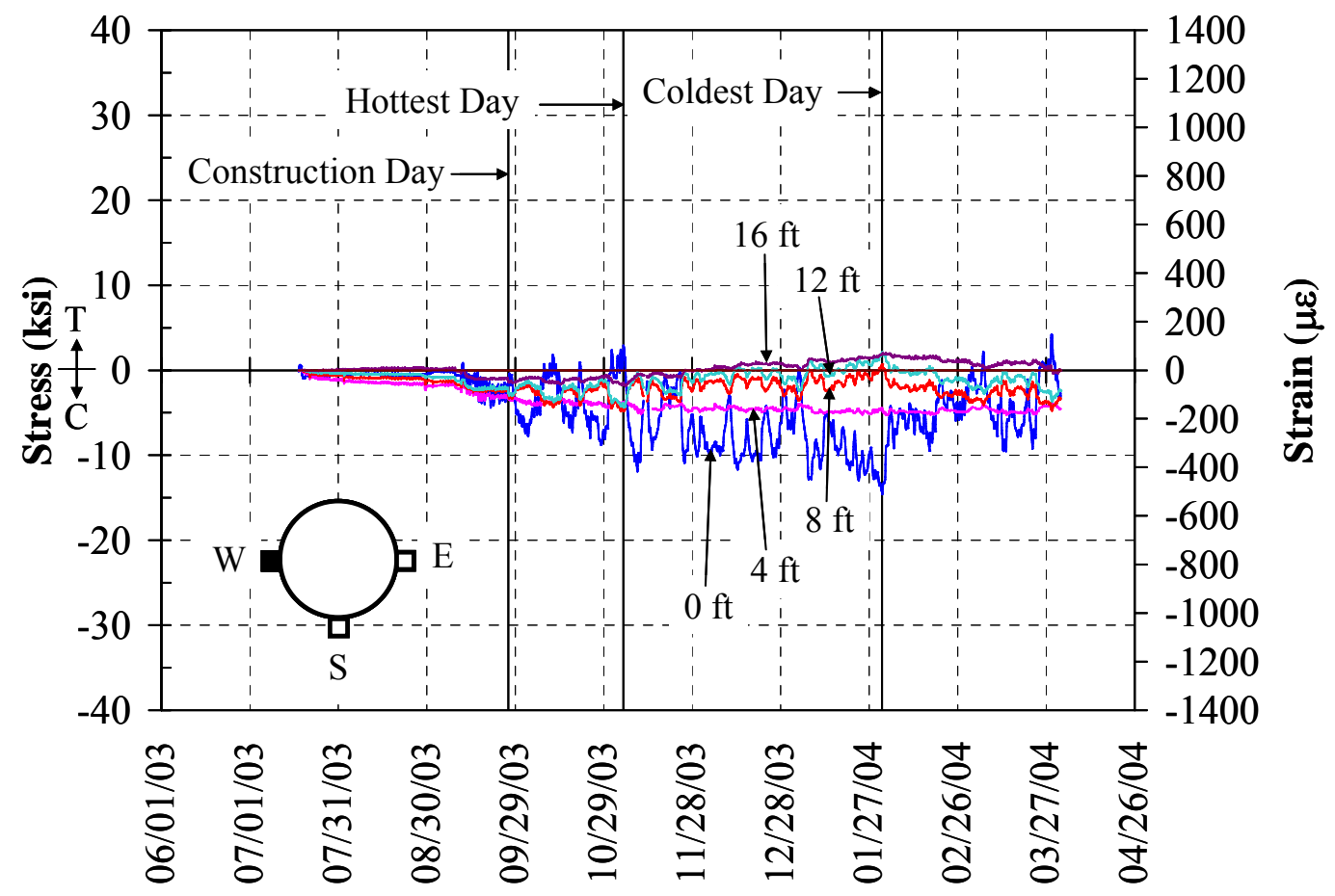

Figure 3.31: Strain at the West Locations on Pile 6, Bent 1 (SR18)

The south strains over the depth of the pile below ground were nearly constant after casting of the bridge deck while the strains at the ground level fluctuated slightly. Stresses on the south face have been fairly constant in the range of 2 to $4 \mathrm{ksi}$ in compression. Axial stress induced by the weight of the beam, deck, diaphragm, precast, abutment, and live load was estimated to be equal to $2.6 \mathrm{ksi}$. A comparison of the measured stresses with the calculated dead/live load stresses indicates that the gages are performing well and providing reasonable results. Furthermore, it appears that the gages located on the south face are essentially located at the neutral axis as designed (Figure $3.32)$. 


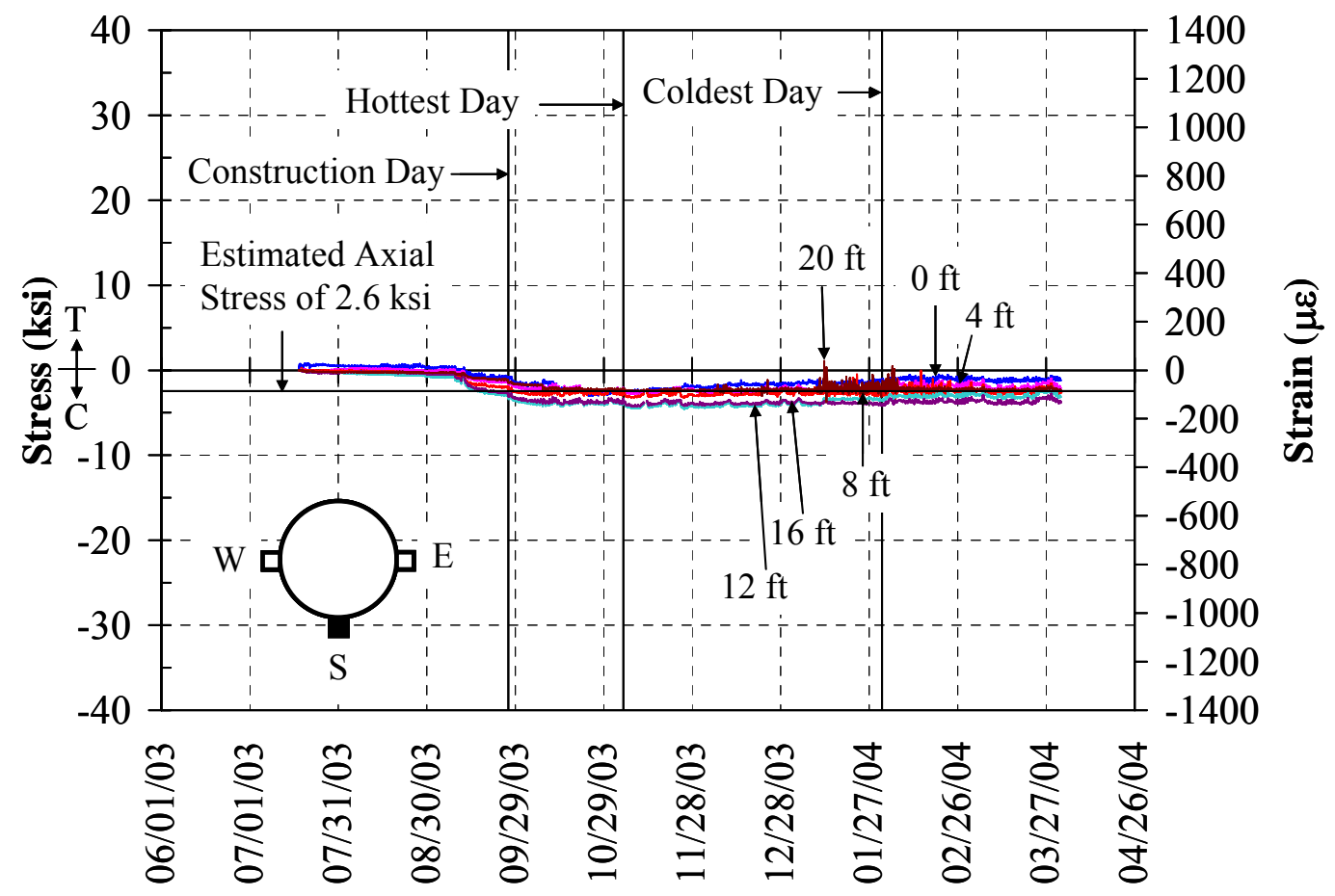

Figure 3.32: Strain at the South Locations on Pile 6, Bent 1 (SR18)

The gages located on Piles 3, 9, and 10 on Bent 1 and Piles 3, 7, and 10 on Bent 6 were positioned at ground level on both the east and west locations as described in Section 2.4.3.2. At each location, the gages on the piles responded identically with temperature changes.

For Bent 1, variations can be observed in the east measurements (Figure 3.33); however, the measurements from the west face were almost identical (Figure 3.34). The maximum pile stress measured on the west face was $15 \mathrm{ksi}$ of compression while the maximum on the east face was $35 \mathrm{ksi}$ of tension.

For Bent 6, strains at the east and west locations were mirror images of each other (Figures 3.35 and 3.36). The maximum and minimum stresses at ground level on the piles on Bent 6 were observed to be in the range of approximately \pm 20 ksi.

The readings obtained from the strain gages located at ground level also support double curvature pile bending. 


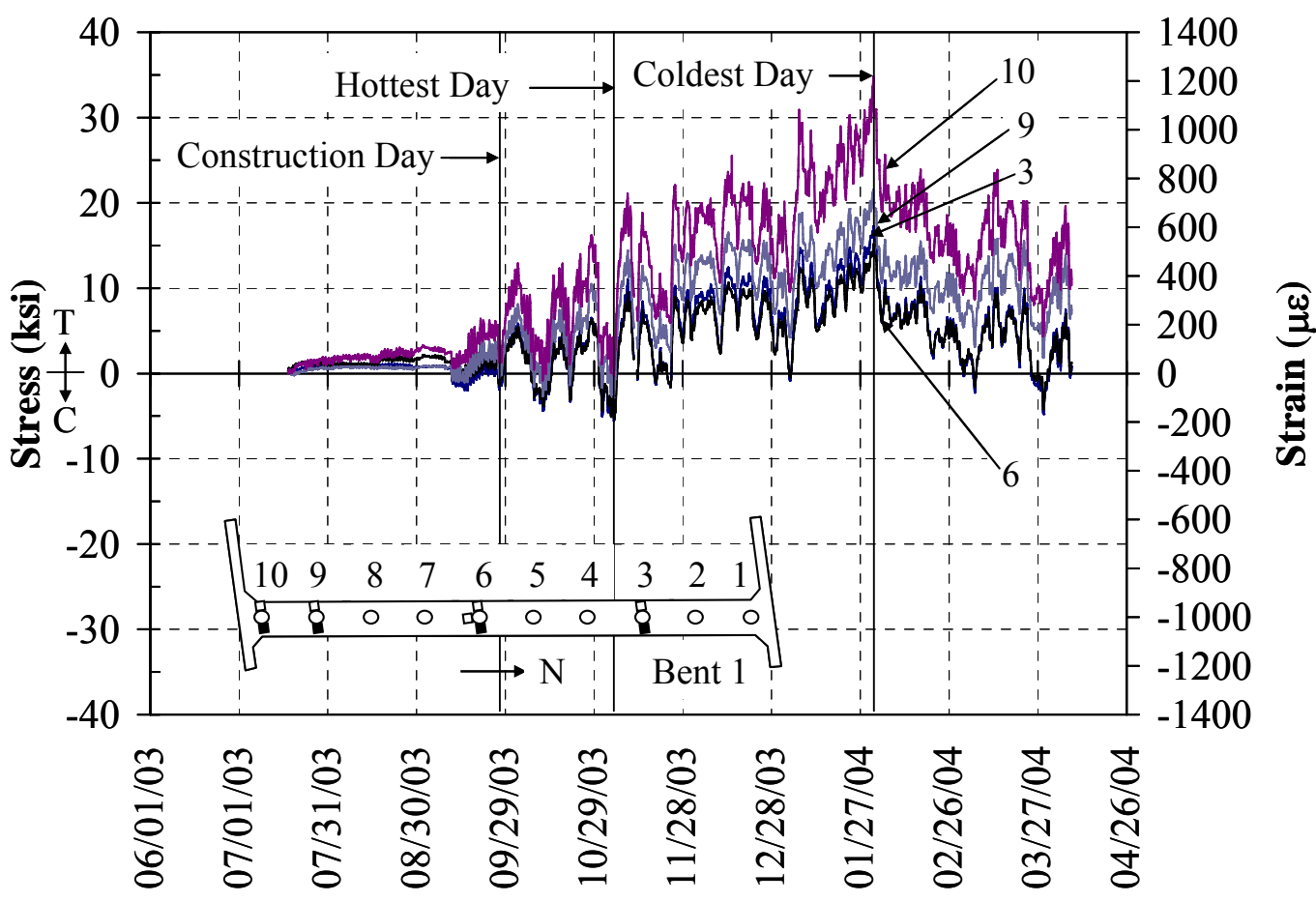

Figure 3.33: Pile Strains, East Face, Bent 1 (SR18)

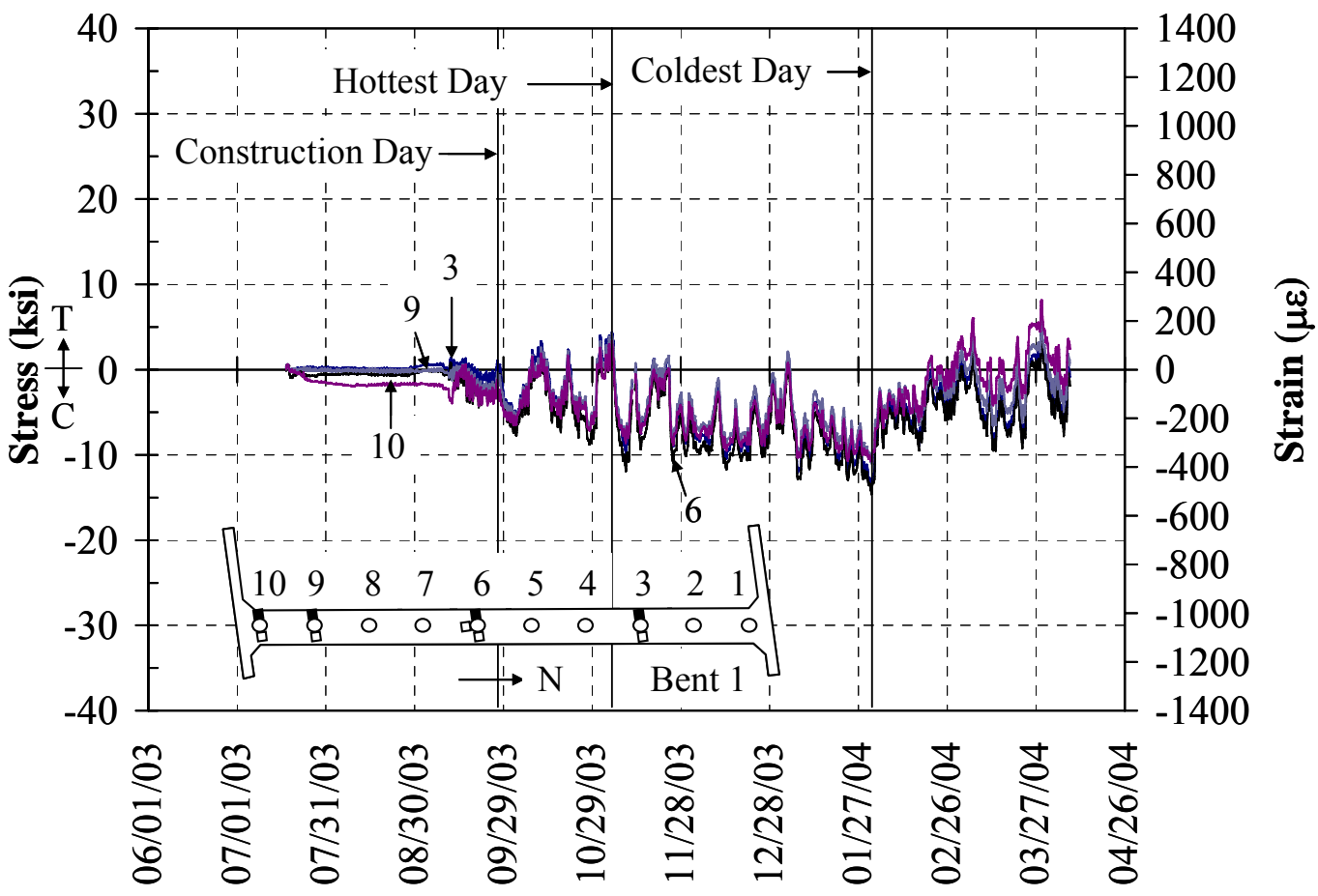

Figure 3.34: Pile Strains, West Face, Bent 1 (SR18) 


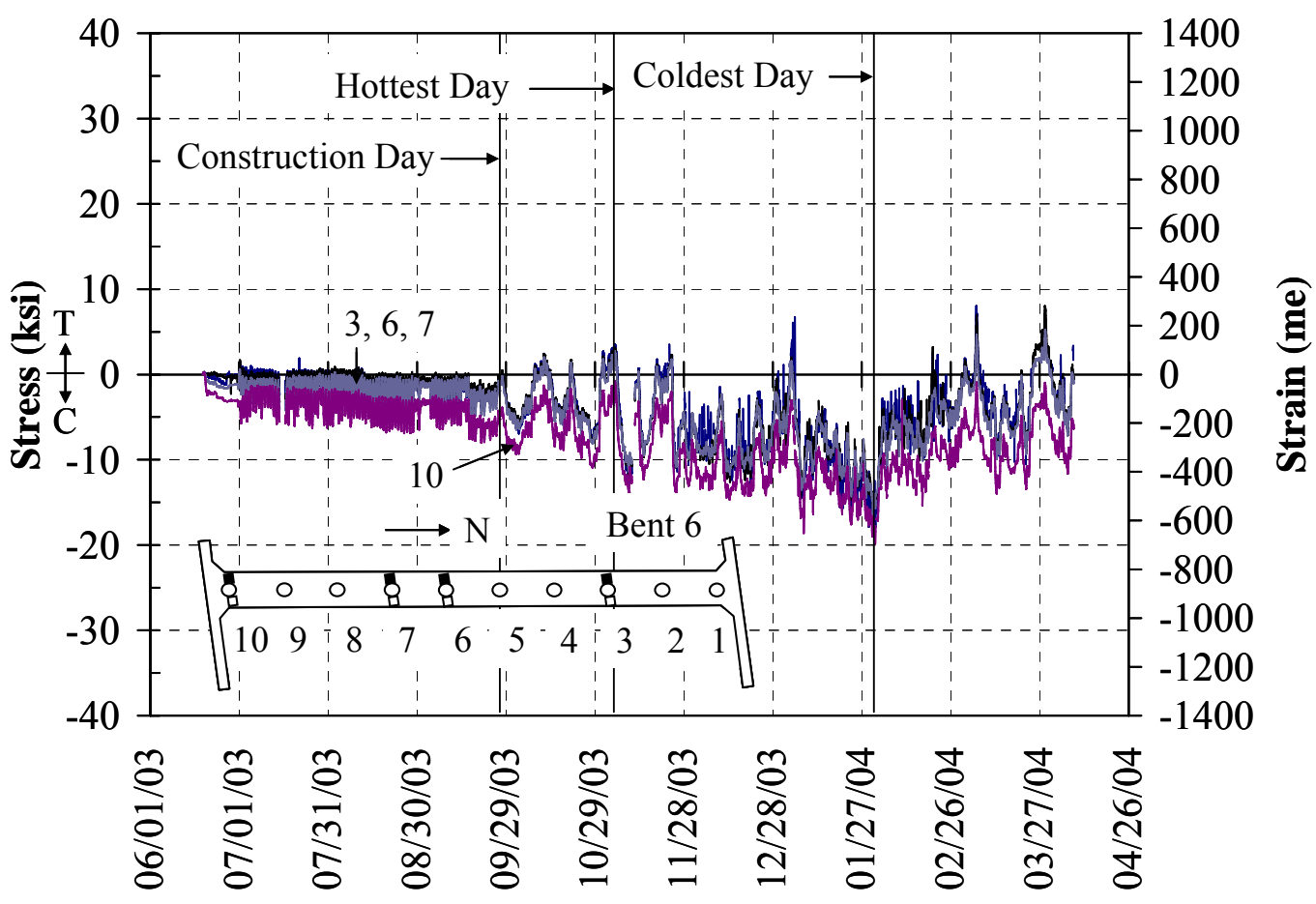

Figure 3.35: Pile Strains, East Face, Bent 6 (SR18)

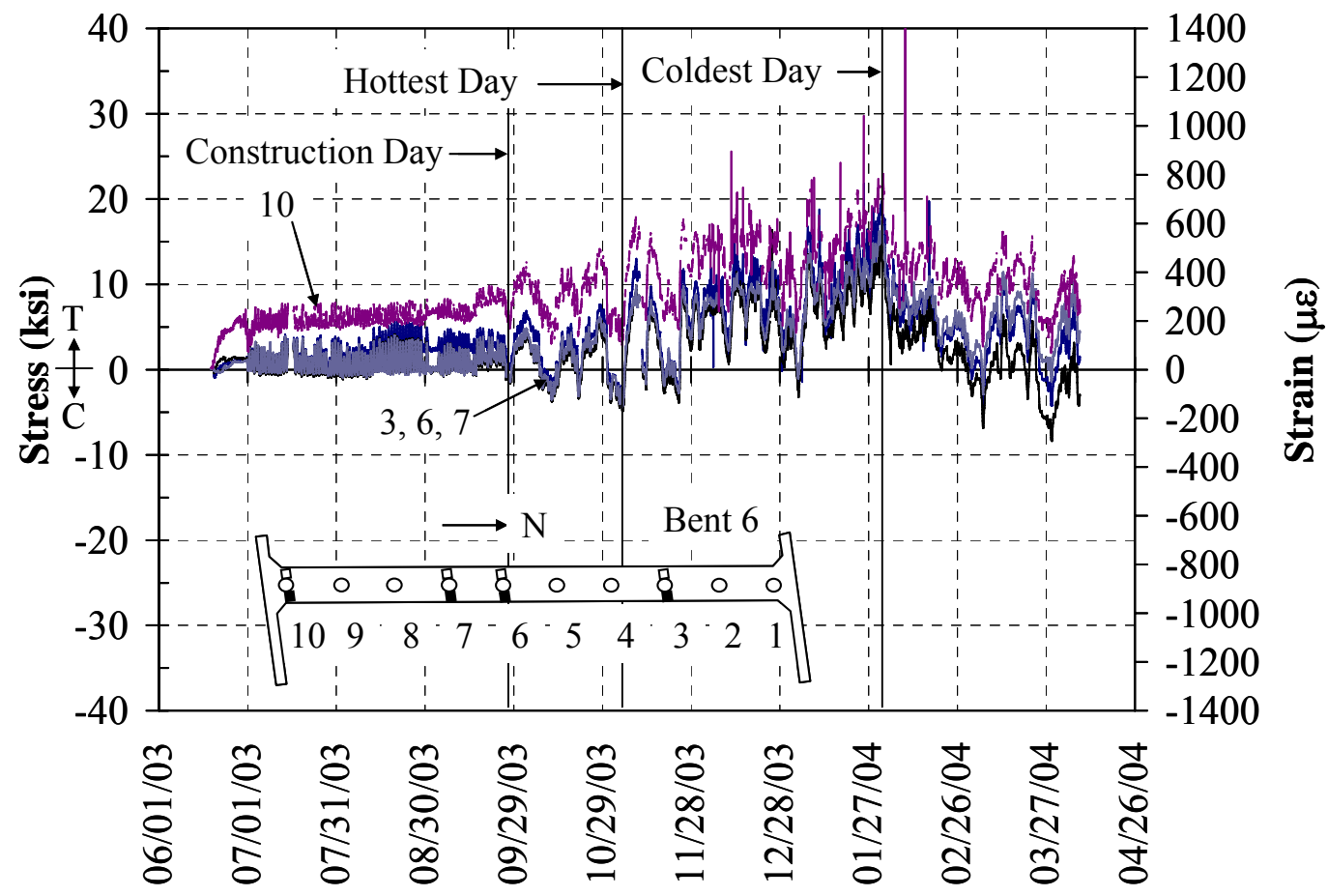

Figure 3.36: Pile Strains, West Face, Bent 6 (SR18) 


\subsection{Analysis of End Bent and Pile Movement}

\subsubsection{SR249 over US12 Bridge}

The rebar strain gages on sister bars at the base of the piers were used to calculate the pier movement. Deflections at the top of the piers were calculated based on these recorded strains. Finally, the bent movements were extrapolated from the pier movements. Details of this analysis are presented in the following sections.

\subsubsection{Pier Cross Section}

The pier cross section used in the SR249 over US12 bridge is presented in Figure 3.37. A simplified pier cross section was used for calculation purposes as shown Figure 3.38. Considering this section, the moment-curvature relationship was determined (Figure 3.39). The compressive concrete strength, $\mathrm{f}_{\mathrm{c}}^{\prime}$, was taken as 3,500 psi representative of the Class A concrete used in the piers. The steel yield strength, $f_{y}$, was assumed to be 60,000 psi. The details of the simplified cross section are tabulated in Table 3.6.

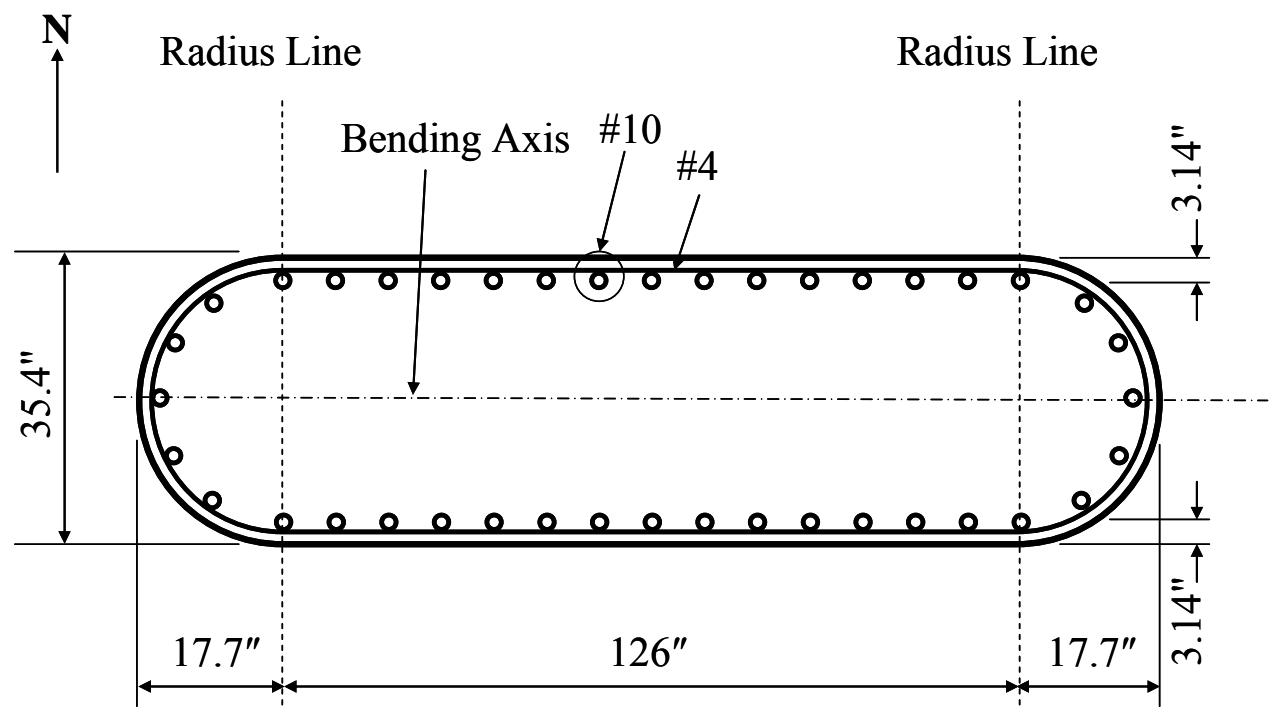

Figure 3.37: Pier Cross Section (SR249 over US12) 


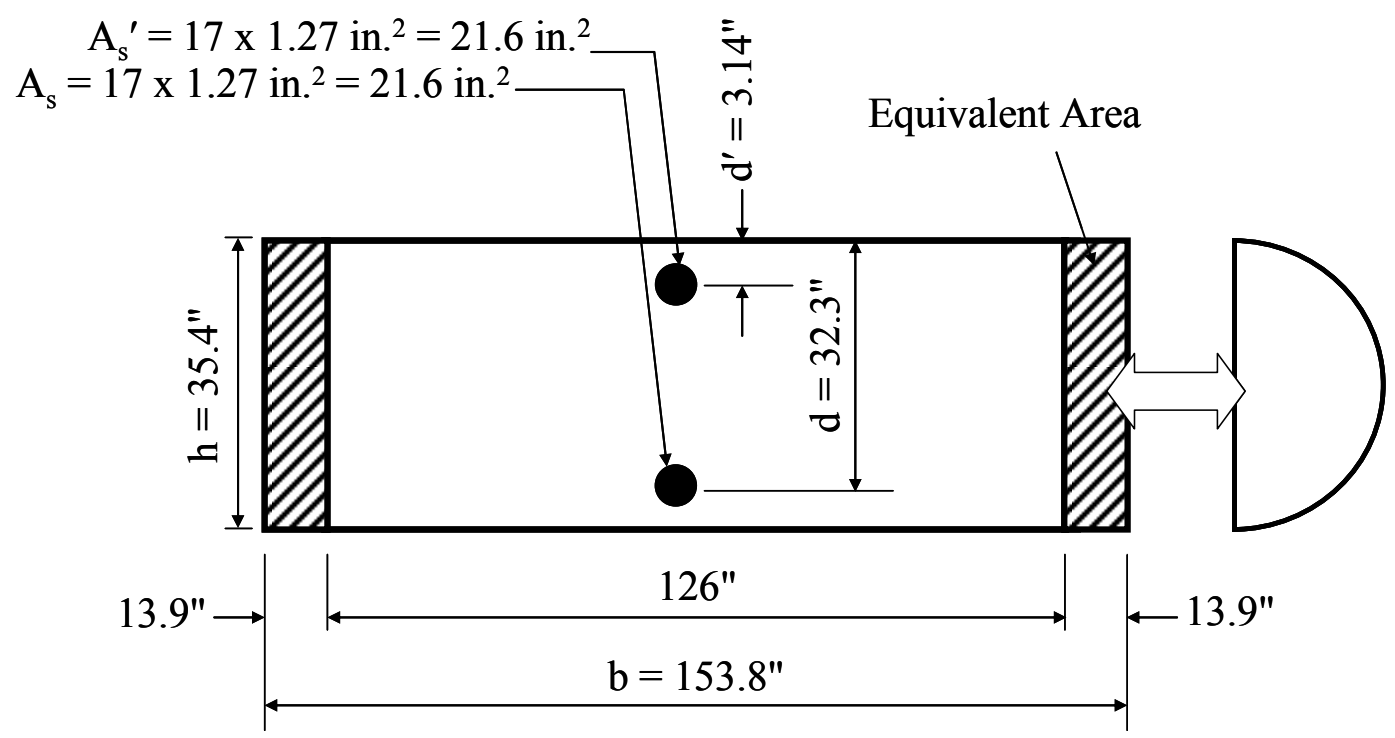

Figure 3.38: Simplified Pier Cross Section (SR249 over US12)

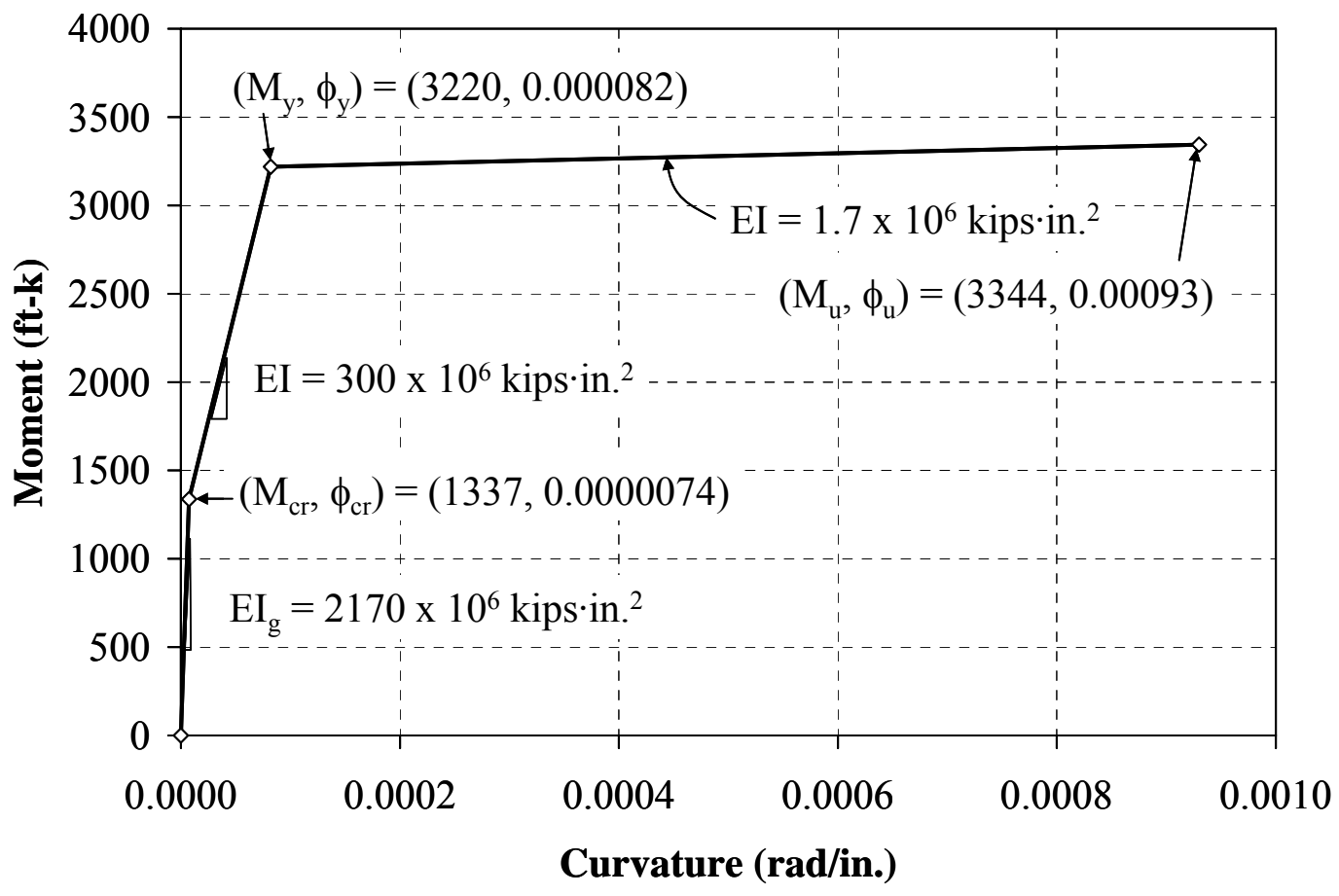

Figure 3.39: Moment-Curvature Relationship of Pier Cross Section

(SR249 over US12) 
Table 3.6: Simplified Pier Cross Section Details (SR249 over US12)

\begin{tabular}{|l|c|}
\hline \multicolumn{1}{|c|}{ Details } & Values \\
\hline Concrete Strength, $\mathrm{f}_{\mathrm{c}}{ }^{\prime}$ & $3500 \mathrm{psi}$ \\
\hline Steel Yield Strength, $\mathrm{f}_{\mathrm{y}}$ & $60000 \mathrm{psi}$ \\
\hline Concrete Modulus of Elasticity, $\mathrm{E}_{\mathrm{c}}$ & $3372 \mathrm{ksi}$ \\
\hline Steel Modulus of Elasticity, $\mathrm{E}_{\mathrm{s}}$ & $29000 \mathrm{ksi}$ \\
\hline Moment of Inertia of the Gross Uncracked Section, $\mathrm{I}_{\mathrm{g}}$ & $640293 \mathrm{in}^{4}$ \\
\hline Moment of Inertia of the Cracked Section Transformed to Concrete, $\mathrm{I}_{\mathrm{cr}}$ & $16207 \mathrm{in}^{4}$ \\
\hline Moment at Cracking, $\mathrm{M}_{\mathrm{cr}}$ & $1337 \mathrm{ft}-\mathrm{k}$ \\
\hline Moment at First Yield, $\mathrm{M}_{\mathrm{y}}$ & $3220 \mathrm{ft}-\mathrm{k}$ \\
\hline Moment at Ultimate, $\mathrm{M}_{\mathrm{u}}$ & $3344 \mathrm{ft}-\mathrm{k}$ \\
\hline Curvature at Cracking, $\phi_{\mathrm{cr}}$ & $7.4 \times 10^{-6} \mathrm{rad} / \mathrm{in}$. \\
\hline Curvature at First $\mathrm{Yield}, \phi_{\mathrm{y}}$ & $82 \times 10^{-6} \mathrm{rad} / \mathrm{in}$. \\
\hline Curvature at Ultimate, $\phi_{\mathrm{u}}$ & $930 \times 10^{-6} \mathrm{rad} / \mathrm{in}$. \\
\hline
\end{tabular}

\subsubsection{Pier Movement}

The piers were modeled as cantilever columns with a fixed end at the base subjected to a lateral load at the top as shown in Figure 3.40. The height of the pier, L, was $30.35 \mathrm{ft}$. A first order analysis was performed with the assumption of that the pier axial load does not affect the moment-curvature relationship. The top pier movement was calculated using strains obtained from rebar strain gages at the base of the piers as described below:

a) Average strains per day were determined.

b) Curvature was computed using the average strains on the north and south faces.

$\phi=\frac{\text { Average strain at the north face }- \text { Average strain at the south face }}{\text { Distance between the north and south gages }=29.16 \mathrm{in} .}$

c) Moment at the base of the pier was determined from the calculated curvature in Step b) using the moment-curvature relationship presented in Figure 3.39.

d) The lateral load, $\mathrm{H}$, at the top of the pier was calculated from the moment at the base, $\mathrm{M}_{\mathrm{base}}$, divided by the height of the pier, $\mathrm{L}$. 
e) Moments along the pier height were calculated by applying the lateral load at the top of the pier.

f) Curvatures along the pier height were calculated using the moment-curvature relationship of the pier cross section shown in Figure 3.39

g) The lateral movements of the pier top, $\Delta$, were computed using the momentarea theorem. The deflection was calculated using the moment of area under the curvature relationship about the top of the pile.

\subsubsection{Abutment Movement}

The end bent movements of the SR249 over US12 were extrapolated from the pier movements calculated in Section 3.5.1.2. The movement of Bent 1 was extrapolated from the calculated movement at the top of Piers 2 and 3 (Figure 3.41) plus the relative displacements measured by the crackmeters located at the top of Bent 1 and Pier 2 (Figures 3.6 and 3.7). The movement of Bent 11 was extrapolated from the movement at the top of Pier 10 and the movement at the center of the bridge taken as zero (Figure 3.42) plus the relative displacements measured by crackmeters located at the top of Pier 10 and Bent 11 (Figures 3.6 and 3.7). Due to the problems with the data acquisition system, only data between June 7, 2000 and July 23, 2001 were considered. 


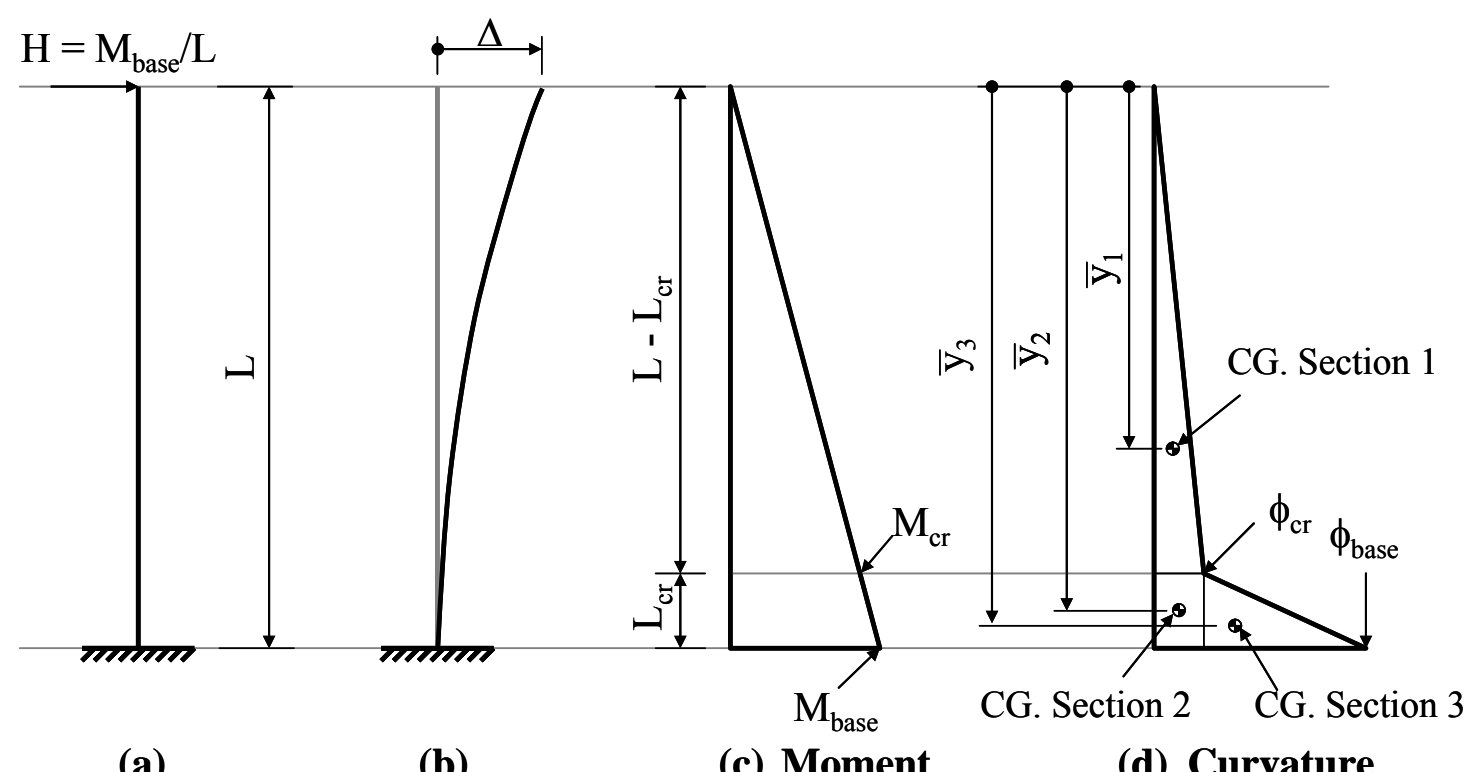

where:

$$
\begin{aligned}
& \mathrm{H}=\text { lateral load, kips } \\
& \mathrm{M}_{\text {base }}=\text { moment at the base of the pier, ft-kips } \\
& \phi_{\text {base }}=\text { curvature at the base of the pier, } \mathrm{rad} / \mathrm{in} \text {. } \\
& \mathrm{M}_{\mathrm{cr}} \quad=\text { moment at cracking, } \mathrm{ft}-\mathrm{k} \\
& \phi_{\mathrm{cr}}=\text { curvature at cracking, } \mathrm{rad} / \mathrm{in} \text {. } \\
& \mathrm{L} \quad=\text { height of the pier, } \mathrm{ft} \\
& \mathrm{L}_{\mathrm{cr}} \quad=\text { distance from the fixed end to the moment at cracking, so called } \\
& \text { "crack height," ft } \\
& \Delta \quad=\text { lateral displacement at the pier top, in. } \\
& \bar{y}_{1}, \bar{y}_{2}, \bar{y}_{3}=\text { moment arm from the free end to the centroid of the section }
\end{aligned}
$$$$
\text { No. 1, 2, and 3, respectively, } \mathrm{ft}
$$

Figure 3.40: Pier Model (SR249 over US12)

To compare the extrapolated bent movements with the thermal movement, the average temperature per day was calculated as shown in Figure 3.43. The thermal movements can be calculated by Equation 3-1, 


$$
\Delta \mathrm{L}=\alpha(\Delta \mathrm{T}) \mathrm{L}
$$

where:

$$
\begin{aligned}
\Delta \mathrm{L}= & \text { bridge movement, in. } \\
\alpha \quad= & \text { coefficient of thermal expansion of concrete, taken as } \\
& 6.0 \times 10^{-6} /{ }^{\circ} \mathrm{F} . \\
\Delta \mathrm{T}= & \text { change in temperature, }{ }^{\circ} \mathrm{F}, \text { the reference temperature was } \\
& \text { taken as } 65^{\circ} \mathrm{F} \text { for the first day rebar strain gages started reading } \\
& (\text { June } 7,2000 \text { at } 9: 00 \mathrm{AM}) . \\
= & \text { half of the total bridge length taken as } 990 \mathrm{ft} / 2=495 \mathrm{ft} .
\end{aligned}
$$

Because the EPS backfill is behind the abutment, earth pressures do not exist behind the end bent to resist movement. Theoretically, the bridge should expand and contract corresponding to temperature $(\Delta \mathrm{L}=\alpha(\Delta \mathrm{T}) \mathrm{L})$. The comparison between extrapolated movements and calculated thermal movements of Bents 1 and 11 is shown in Figures 3.44 and 3.45, respectively. The graphs show that the movement of Bents 1 and 11 corresponds well to temperature; however, the extrapolated movement on Bent 1 is slightly lower than the calculated thermal movement. This difference is likely due to the locking of the girders with Pier 2 as discussed in Section 3.2.3. As mentioned, the girders connecting to Pier 10 had been unlocked. Locking of the girders with the piers causes lateral forces to be resisted by the piers and reduces overall displacement at the end bent.

To provided an example, on the coldest day (December 22, 2000), the average temperature was $4^{\circ} \mathrm{F}$ while the measured lowest temperature reading was $0^{\circ} \mathrm{F}$. Based on the average temperature, the calculated thermal movements of Bents 1 and 11 were computed by Equation 3-1. The comparison between the extrapolated and calculated values is tabulated in Table 3.7. The table shows the small difference between the extrapolated and calculated values of the movements. This smaller movement is expected likely due to the lateral resistance provided by the piles and restraint along the bridge length provided by the piers. 


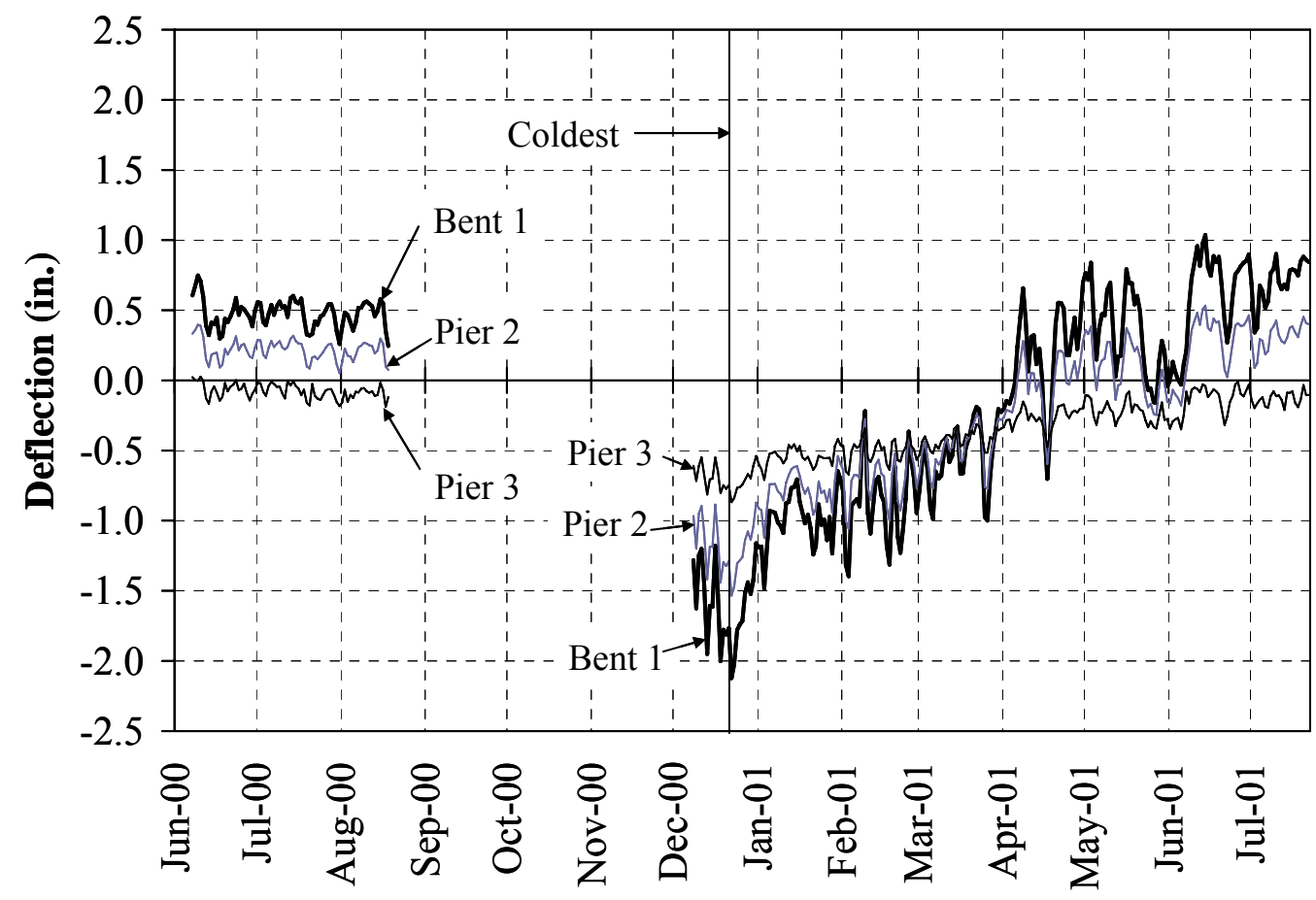

Figure 3.41: Extrapolation of Bent 1 Movement (SR249 over US12)

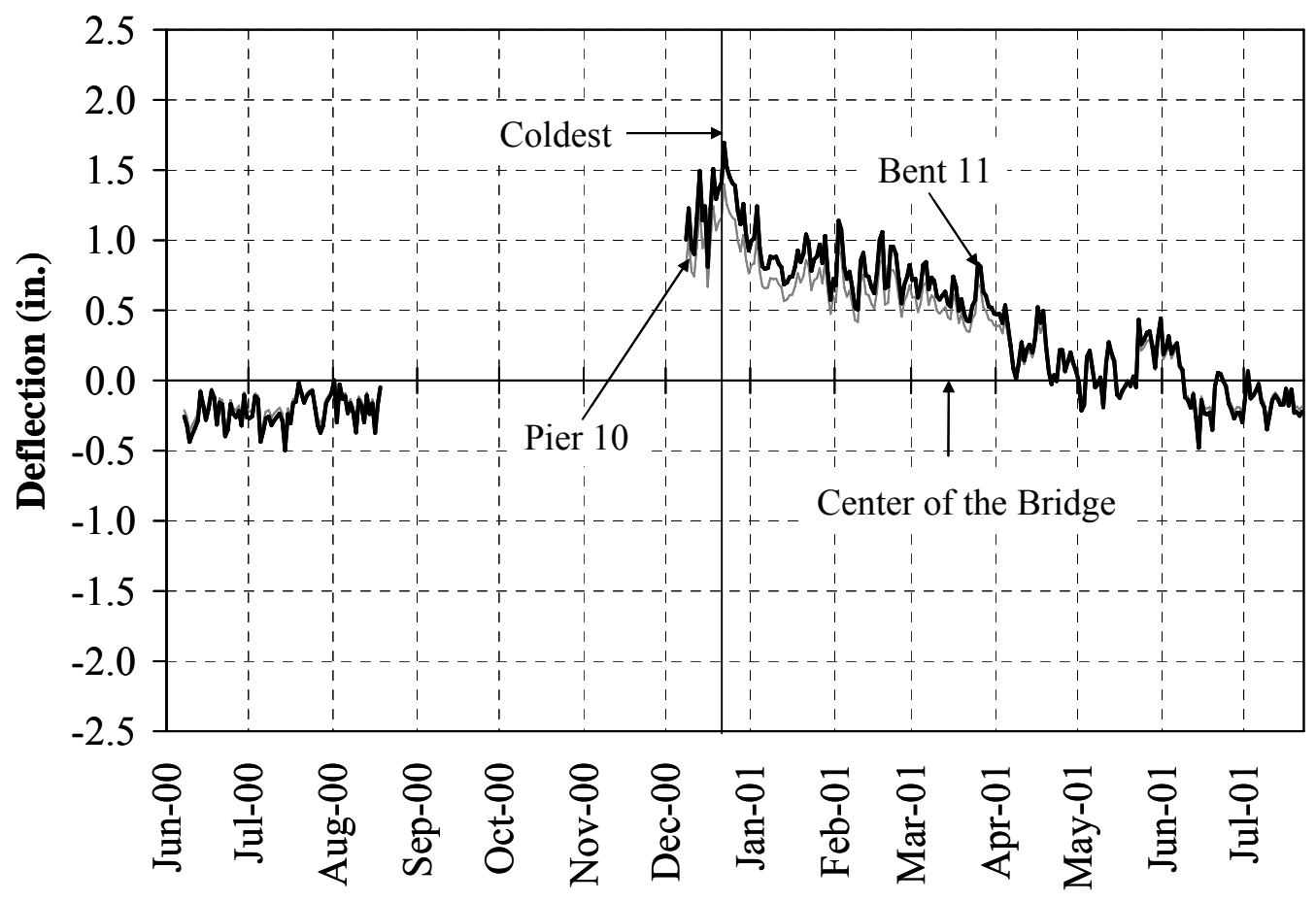

Figure 3.42: Extrapolation of Bent 11 Movement (SR249 over US12) 


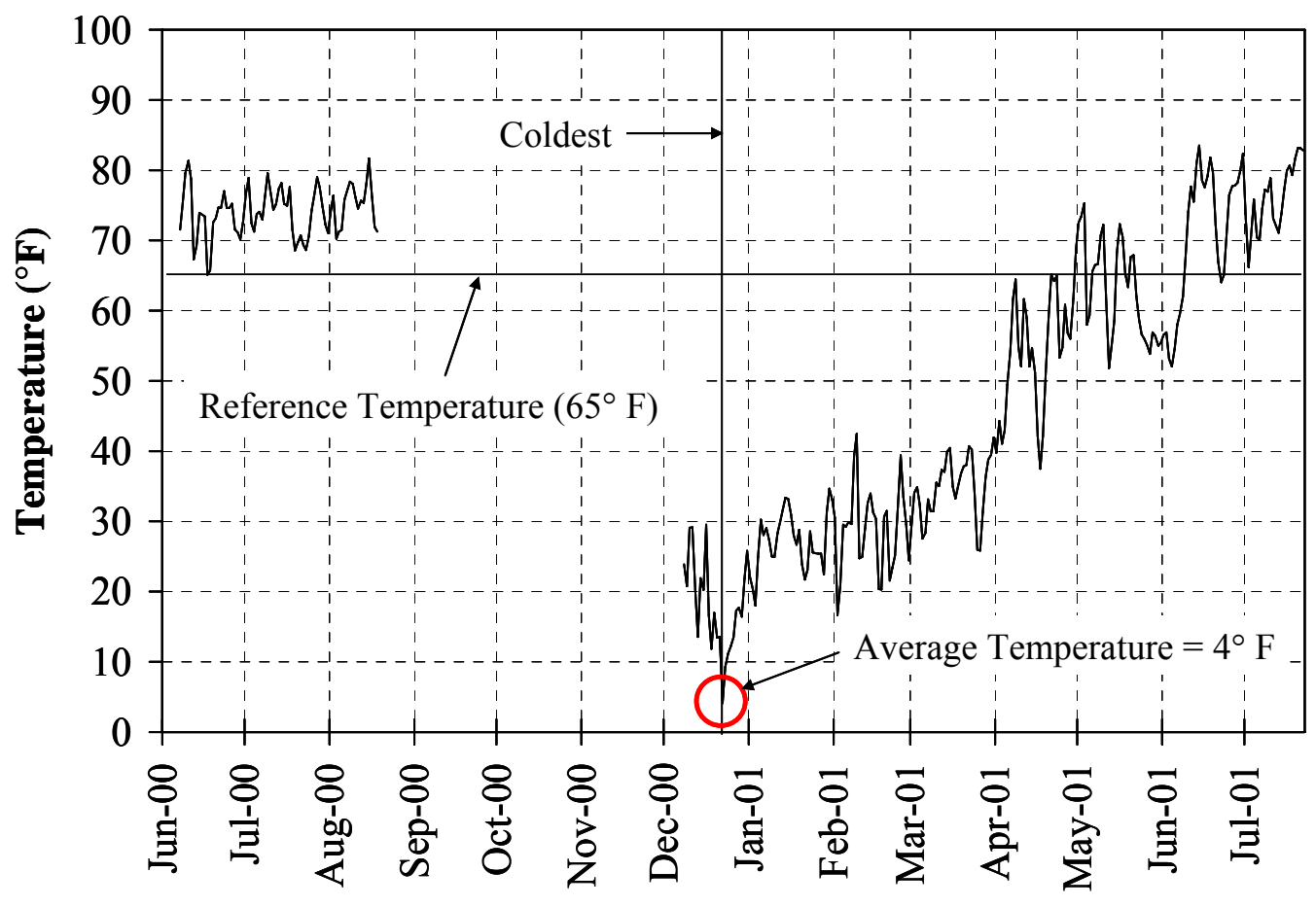

Figure 3.43: Average Daily Air Temperature (SR249 over US12) 


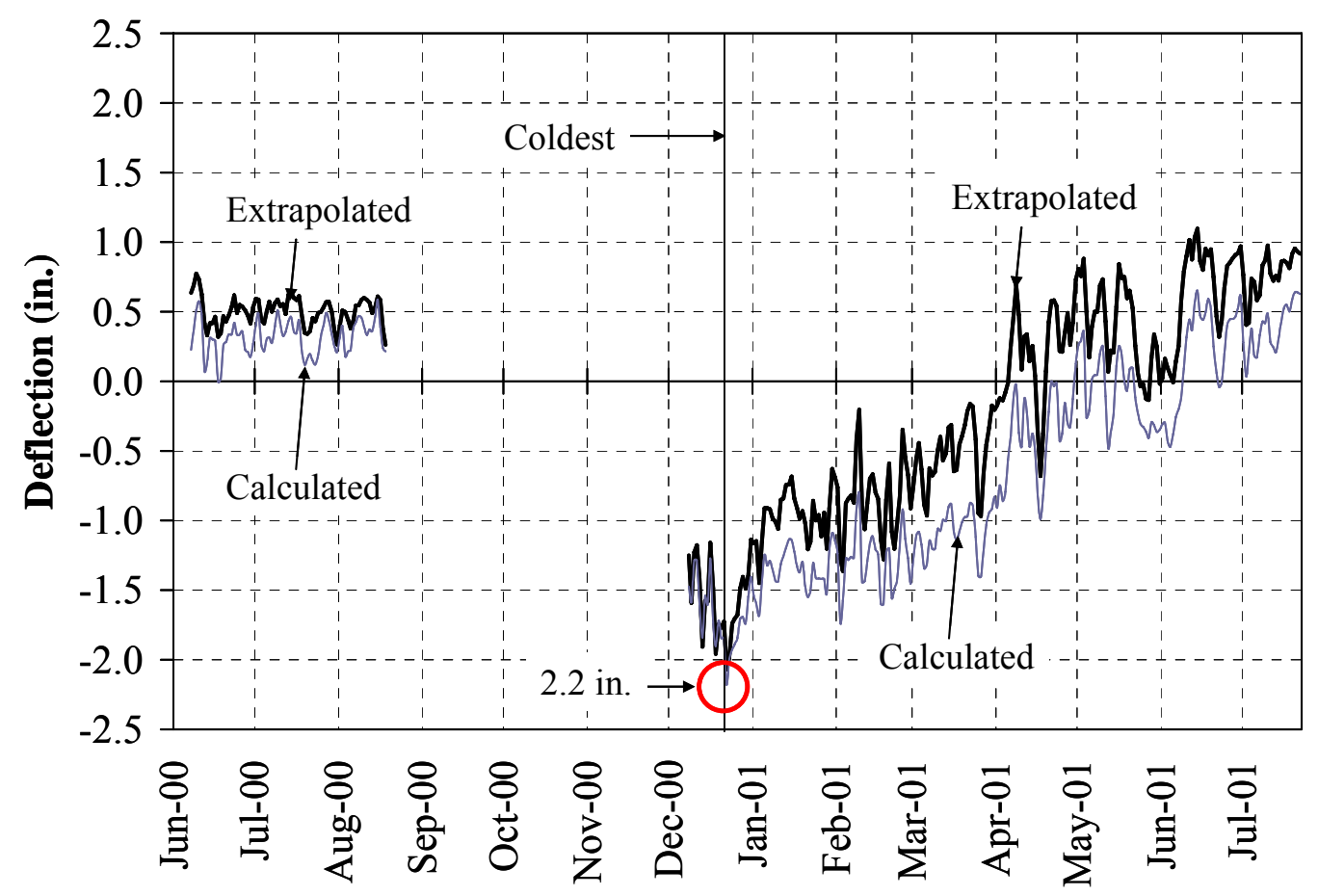

Figure 3.44: Extrapolated and Calculated Movement of Bent 1 (SR249 over US12)

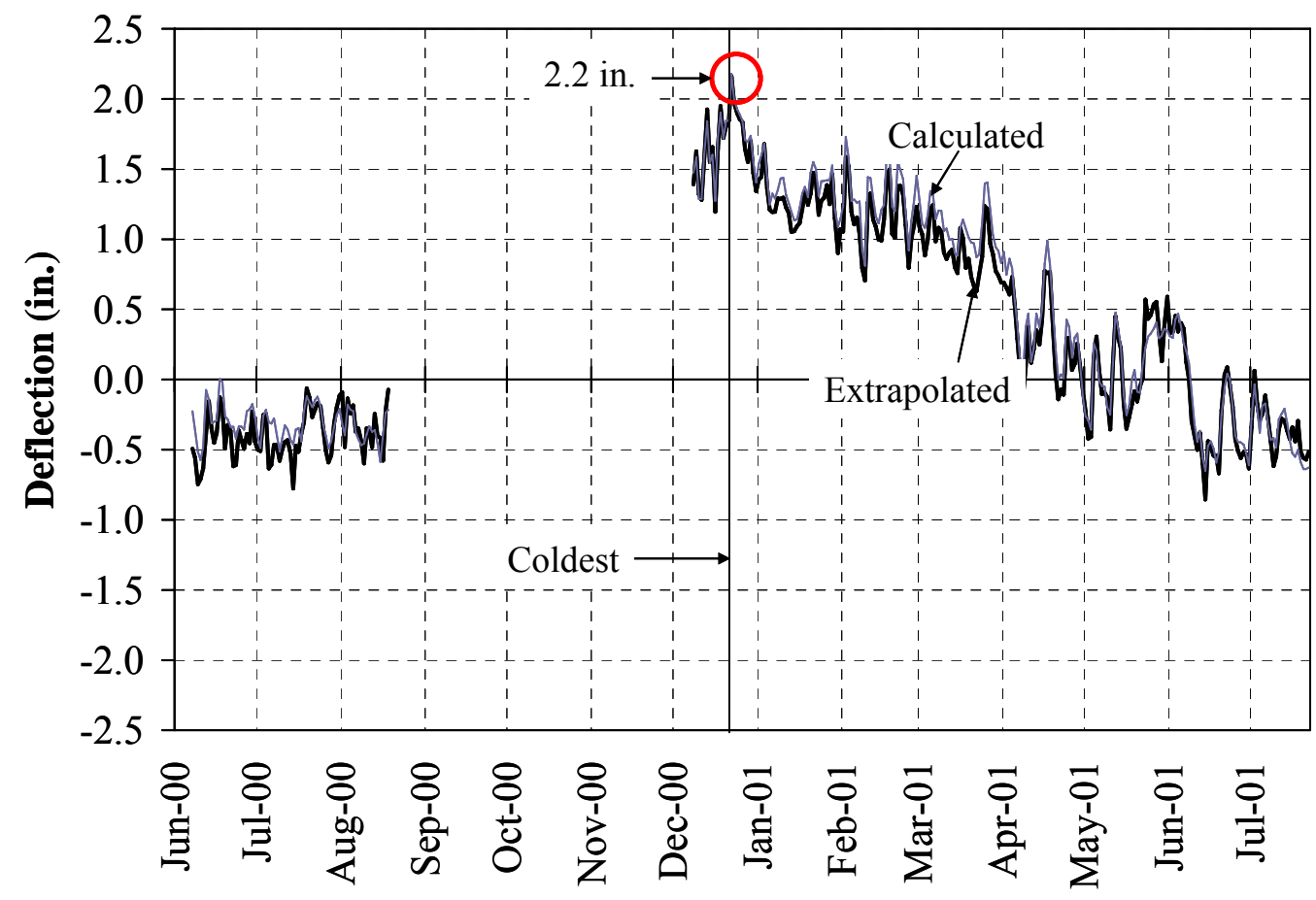

Figure 3.45: Extrapolated and Calculated Movement of Bent 11 (SR249 over US12) 
Table 3.7: Comparison between Extrapolated and Calculated Movements (in.)

\begin{tabular}{|c|c|c|c|c|}
\hline \multicolumn{5}{|c|}{ Bent 1 } \\
\hline $\begin{array}{c}\text { Displacement } \\
\text { extrapolated } \\
\text { from Piers 2 } \\
\text { and 3 }\end{array}$ & $\begin{array}{c}\text { Relative } \\
\text { displacement } \\
\text { from } \\
\text { crackmeter at } \\
\text { Bent 1 }\end{array}$ & $\begin{array}{c}\text { Relative } \\
\text { displacement } \\
\text { from } \\
\text { crackmeter } \\
\text { at Pier 2 }\end{array}$ & $\begin{array}{c}\text { Total } \\
\text { displacement }\end{array}$ & Theoretical \\
movement
\end{tabular}

\begin{tabular}{|c|c|c|c|c|}
\hline \multicolumn{5}{|c|}{ Bent 11 } \\
\hline $\begin{array}{c}\text { Displacement } \\
\text { extrapolated } \\
\text { from Piers 10 } \\
\text { and center of } \\
\text { the Bridge }\end{array}$ & $\begin{array}{c}\text { Relative } \\
\text { displacement } \\
\text { from } \\
\text { crackmeter at } \\
\text { Bent 11 }\end{array}$ & $\begin{array}{c}\text { Relative } \\
\text { displacement } \\
\text { from } \\
\text { crackmeter } \\
\text { at Pier 10 }\end{array}$ & $\begin{array}{c}\text { Total } \\
\text { displacement }\end{array}$ & Theoretical \\
movement & & \\
\hline 1.70 & +0.05 Ext. & +0.40 Ext. & 2.15 & 2.20 \\
\hline
\end{tabular}

\subsubsection{I65 over SR25 Bridge}

The longitudinal movement measured by the linear potentiometer is compared to the calculated movement based on Equation 3-1, where the reference temperature is taken as the construction temperature of the southbound structure $\left(\mathrm{T}=58^{\circ} \mathrm{F}\right)$, the coefficient of thermal expansion of steel, $\alpha$, is taken as $6.5 \times 10^{-6} /{ }^{\circ} \mathrm{F}$, and the half of the total bridge length, $\mathrm{L}$, is taken as $152 \mathrm{ft} / 2=76 \mathrm{ft}$. The comparison of the calculated movement and measured movement of the abutment is presented in Figure 3.46. As discussed in Section 3.3.2, only the trend of the measured movement should be considered, not the magnitude due to water infiltration. The graph indicated that the end bent movement corresponding to temperature changes, but this movement was not very sensitive to temperature changes.

\subsubsection{SR18 over Mississinewa River Bridge}

To better understand the behavior of piles supporting integral end bents, strain gages were installed along the length of Pile 6 of Bent 1 as described previously. 
Recorded strains were used to determine the deflected shape of the pile. For this analysis, data between September 26, 2003 and March 31, 2004 were considered.

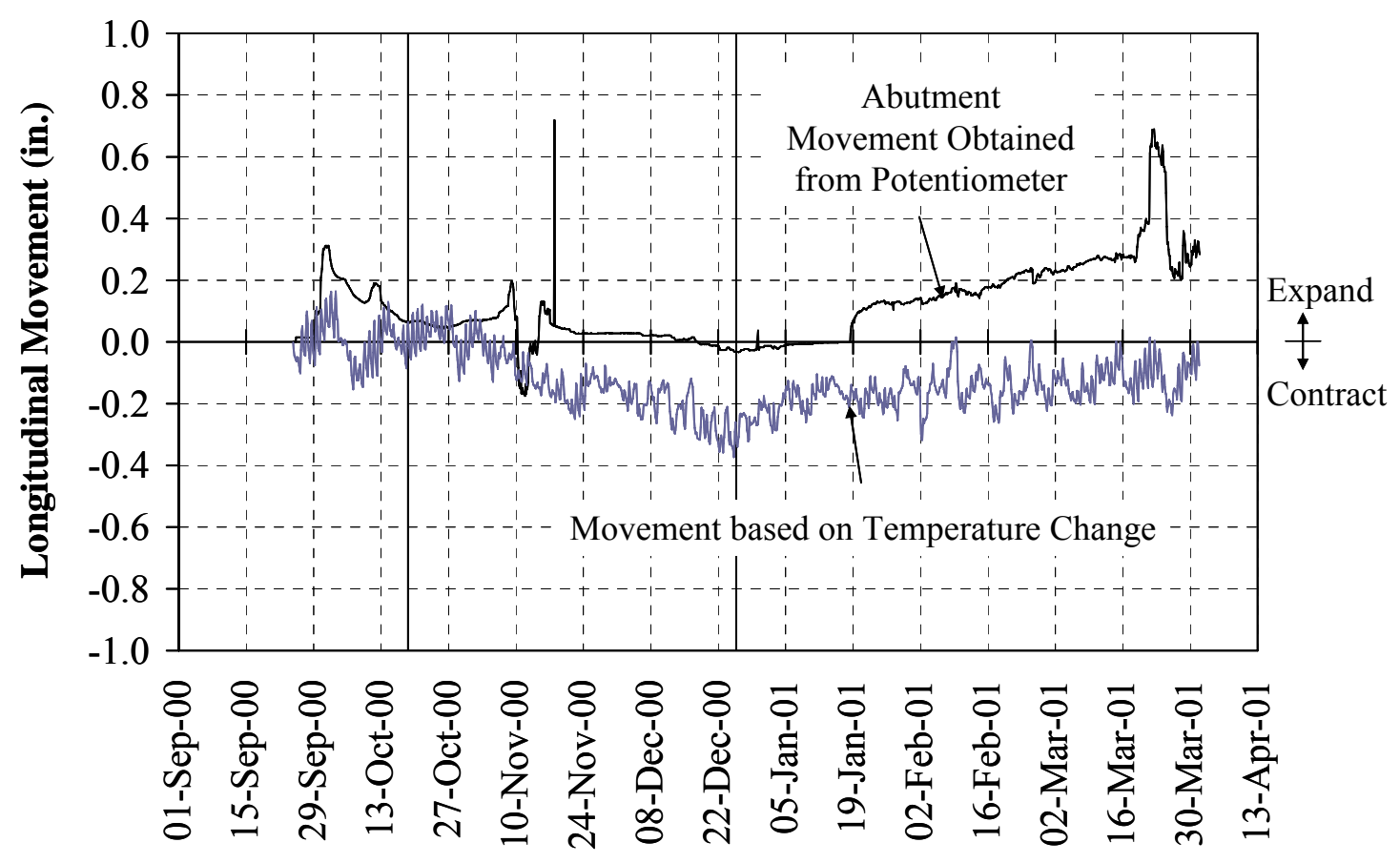

Figure 3.46: Comparison of Measured and Calculated Movements (I65 over SR25)

\subsubsection{Stresses and Strains along the Pile Length}

Stresses and strains on the east, west, and south faces of Pile 6 of Bent 1 over various temperature changes are plotted in Figures 3.47, 3.48, and 3.49, respectively. Stresses and strains along the pile length over various temperature change ranges, $\Delta \mathrm{T}$, were determined by grouping the strain according to the temperature range. The average strains of each temperature range were calculated. The increment of the temperature change range is $10^{\circ} \mathrm{F} \pm 5 \%$ except for $\Delta \mathrm{T}$ equal to $0^{\circ} \mathrm{F}$. At $\Delta \mathrm{T}=0^{\circ} \mathrm{F}$, the range considered was from -1 to $1^{\circ} \mathrm{F}$. The temperature ranges are shown in Table 3.8. It is noted that the construction temperature was considered as $60^{\circ} \mathrm{F}$, and all temperature changes are referenced from this temperature. 


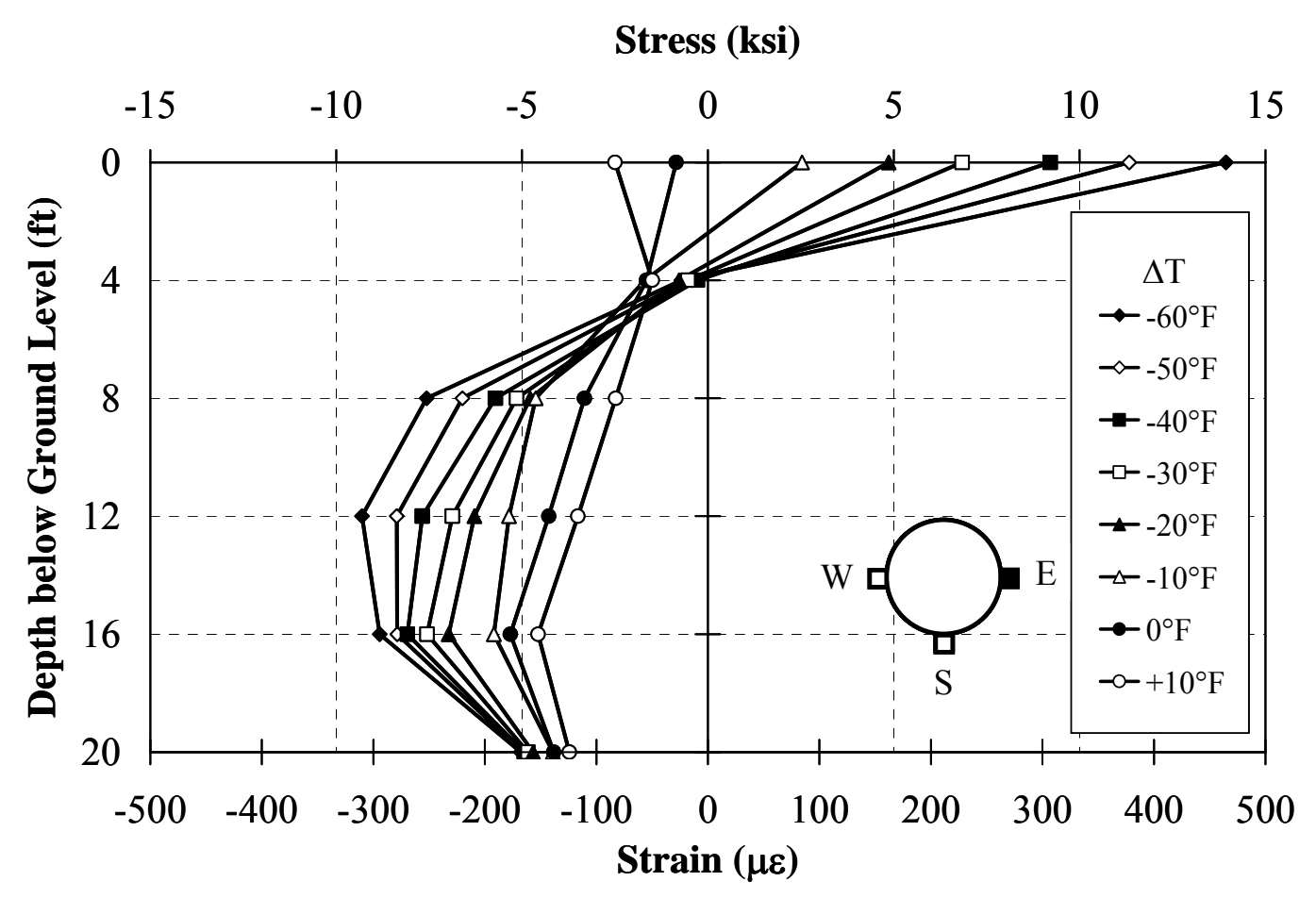

Figure 3.47: Stresses and Strains on Pile 6 on East Face (SR18)

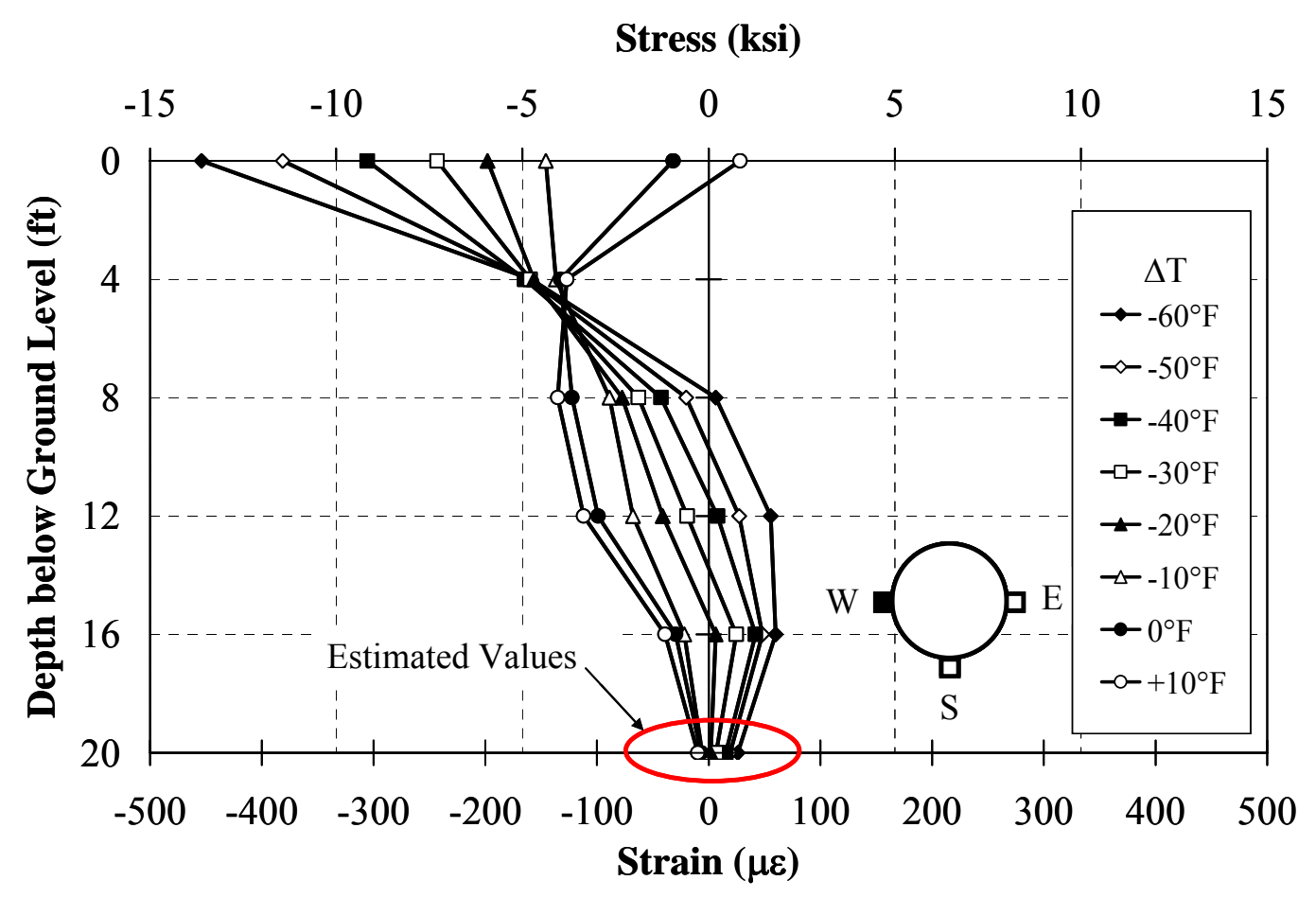

Figure 3.48: Stresses and Strains on Pile 6 on West Face (SR18) 


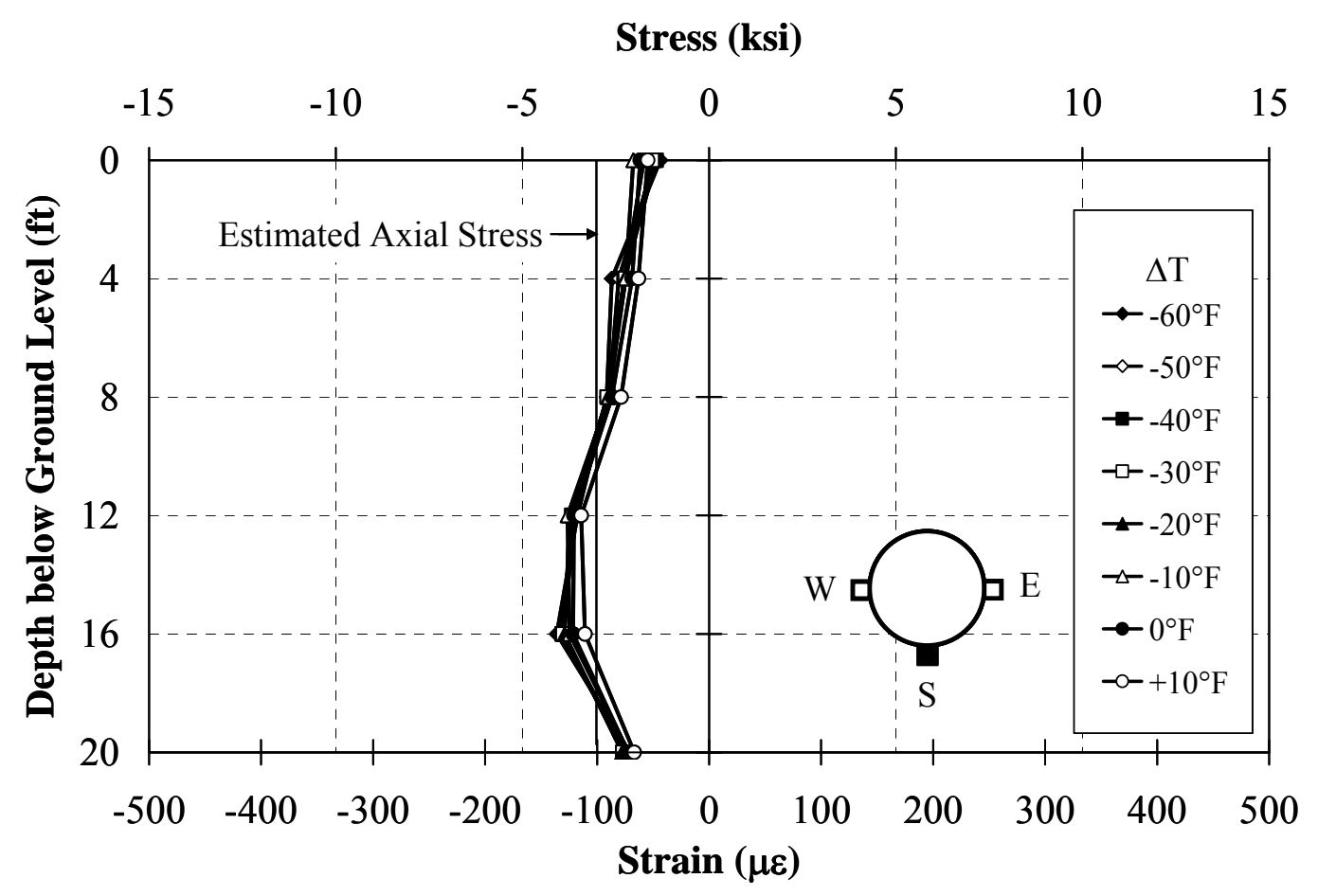

Figure 3.49: Stresses and Strains on Pile 6 on South Face (SR18)

Table 3.8: Temperature Change Range (SR18)

\begin{tabular}{|c|c|c|}
\hline$\Delta \mathbf{T}\left({ }^{\circ} \mathbf{F}\right)$ & \multicolumn{2}{|c|}{ Range $\left({ }^{\circ} \mathbf{F}\right)$} \\
\hline-60 & -63.0 & -57.0 \\
\hline-50 & -52.5 & -47.5 \\
\hline-40 & -42.0 & -38.0 \\
\hline-30 & -31.5 & -28.5 \\
\hline-20 & -21.0 & -19.0 \\
\hline-10 & -10.5 & -9.5 \\
\hline 0 & -1.0 & 1.0 \\
\hline+10 & 10.5 & 9.5 \\
\hline
\end{tabular}


It appears that the difference in stresses from the east and south face is almost equal to the difference in stresses from the west and south face. In other words, plane sections remain plane. It is noted that no data were recorded by the west strain gage at a depth of $20 \mathrm{ft}$ below ground level due to damage during driving. However, stresses and strains on the west gage at a depth of $20 \mathrm{ft}$ below ground level were estimated using the values from the east and south gages (Figure 3.48). These values were estimated assuming that plane sections remain plane.

Strains on the south gages were not zero because of the contribution of axial load (Figure 3.49). The axial load consists of dead loads from the abutment, bridge deck, girder, and diaphragm as well as highway live loads. An analysis was performed to determine the reasonableness of the measured values. A design axial load of approximately $80 \mathrm{kips}$ was applied to each pile. The axial load was distributed to both the steel shell and the concrete core based on their relative axial stiffness. Therefore, an axial load of 35 kips was distributed to the steel shell area of 13.4 in. $^{2}$, while an axial load of 45 kips was distributed to the concrete core area of 140.5 in. ${ }^{2}$ This resulted in an average axial stress of $2.6 \mathrm{ksi}$ on the steel shell that was calculated by dividing the axial load on the shell by its area as illustrated in Figure 3.50. The calculated value compares fairly well with the measured values (Figure 3.49).

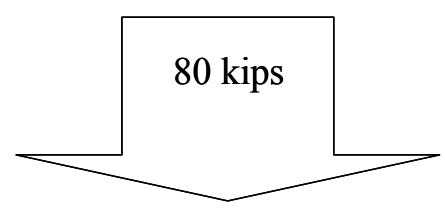

35 kips on steel shell

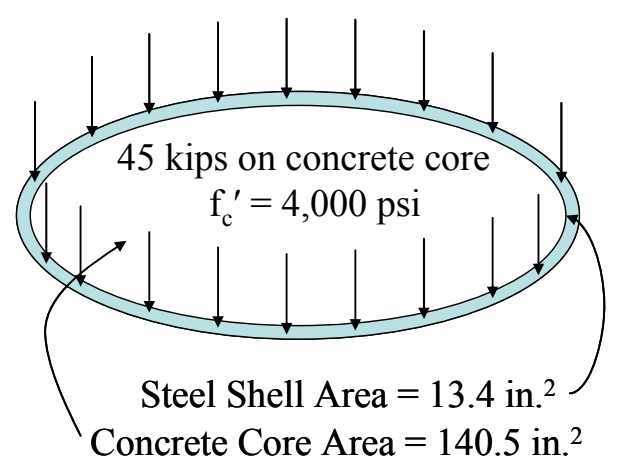

Figure 3.50: Axial Load Distribution (SR18) 


\subsubsection{Deflection of Pile 6}

The pile was assumed to have a horizontally guided support at the top and a hinged support at the bottom. The top of the pile is free to translate but does not rotate, while the bottom of the pile is allowed to rotate without translation as illustrated in Figure 3.51. To determine deflections of the pile, curvatures were determined from strains on the east and west faces as illustrated in Figure 3.52. The curvatures were computed according to Equation 3-2.

$$
\phi=\frac{\mathrm{SG}_{\mathrm{E}}-\mathrm{SG}_{\mathrm{W}}}{\text { O.D. }}
$$

where:

$\phi \quad=$ curvature, $\mathrm{rad} / \mathrm{in}$.

$\mathrm{SG}_{\mathrm{E}}=$ strain on the east face, in./in.

$\mathrm{SG}_{\mathrm{W}}=$ strain on the west face, in./in.

O.D. $=$ outer diameter $=14$ in.

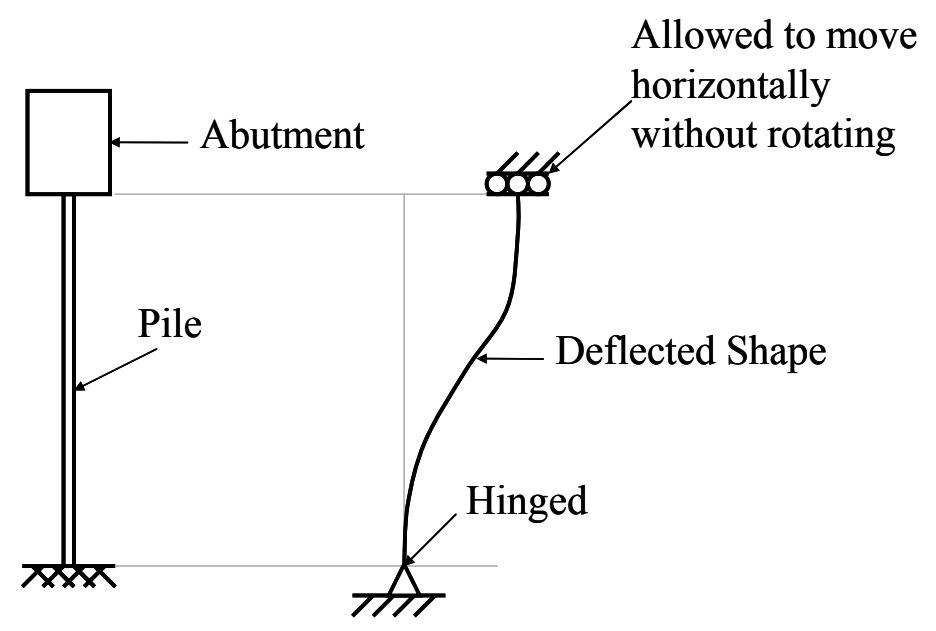

Figure 3.51: Assumption of Pile Movement 


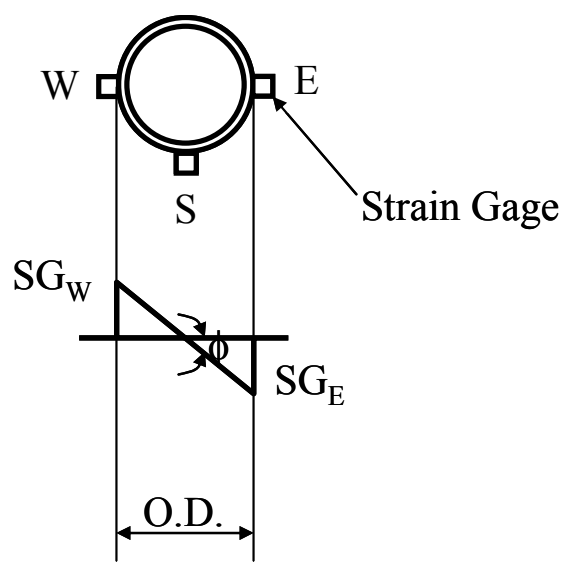

Figure 3.52: Computation of Curvature

Curvatures on Pile 6 over various temperature change ranges were plotted in Figure 3.53. The bottom of the pile is located at a depth of $22.25 \mathrm{ft}$; therefore, strain gages were not installed at this location. The curvatures at this depth were assumed to be zero. As shown, the pile is clearly bending in double curvature.

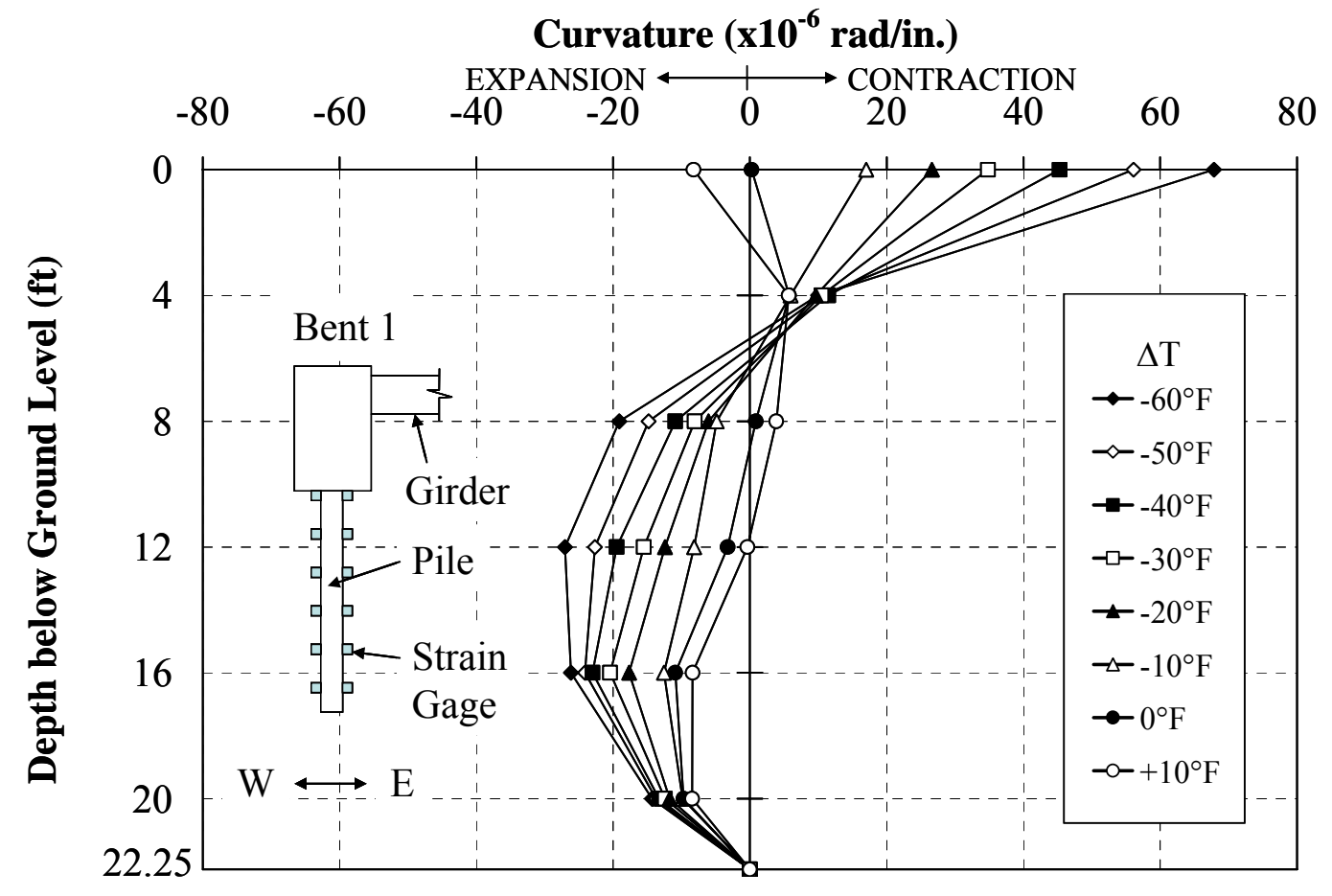

Figure 3.53: Curvature on Pile 6 over Various Changes in Temperature (SR18) 
Deflections along the pile depth were computed by integrating the moment of the area under the curvature diagram considering the deflection measured at the pile top as measured by the convergence meter located at the center of Bent 1 . Details of the computation of the deflected shape are provided in Appendix E. The deflected shape of Pile 6 over various temperature change ranges were estimated as shown in Figure 3.54. The estimated deflected shapes correspond very well to the temperature change, $\Delta \mathrm{T}$. Double curvature bending occurs with the inflection point located between a depth of 4 and $8 \mathrm{ft}$. The deflection at the bottom of the pile is zero as assumed in the calculation. This displacement at this depth was not measured.

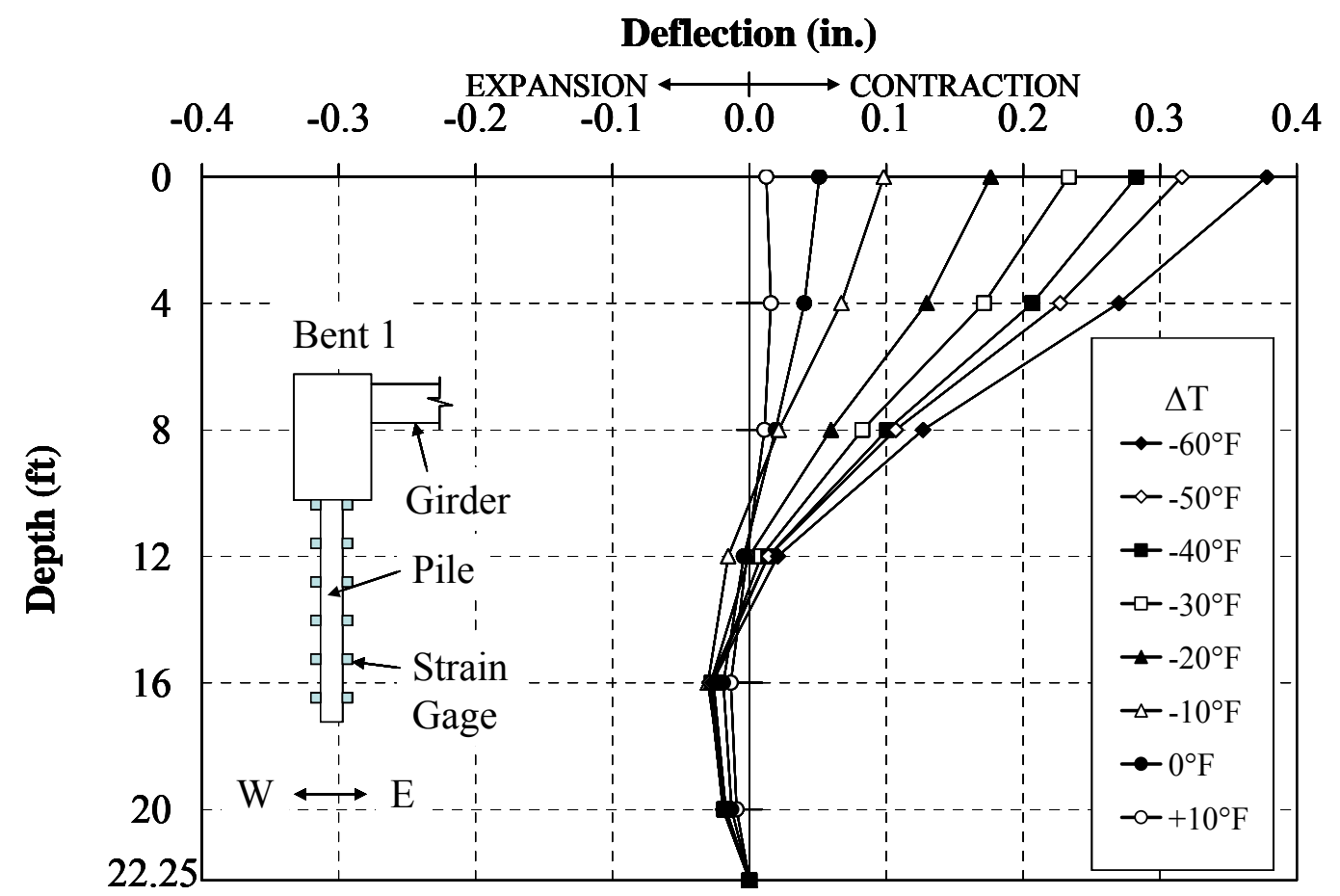

Figure 3.54: Deflection of Pile 6 over Various Changes in Temperature (SR18) 
The estimated deflections at the top of Pile 6 were compared to the thermal movement calculated by Equation 3-1,

$$
\Delta \mathrm{L}=\alpha(\Delta \mathrm{T}) \mathrm{L}
$$

where:

$\alpha \quad=$ coefficient of thermal expansion of concrete, taken as

$$
6.0 \times 10^{-6} /{ }^{\circ} \mathrm{F}
$$

$\Delta \mathrm{T}=$ change in temperature, taken as $-60,-50,-40, \ldots,+10^{\circ} \mathrm{F}$

$\mathrm{L}=$ half of the total span length, taken as $367 \mathrm{ft} / 2=183.5 \mathrm{ft}$.

The comparison of the deflections obtained from the convergence meter at the center of Bent 1 and the thermal movements calculated by Equation 3-1 is presented in Figure 3.55. It can be noticed that the deflections from the convergence meter are approximately half of the thermal movements. This difference is possibly due to restraint provided by the backfill, pile, and friction from the approach slab.

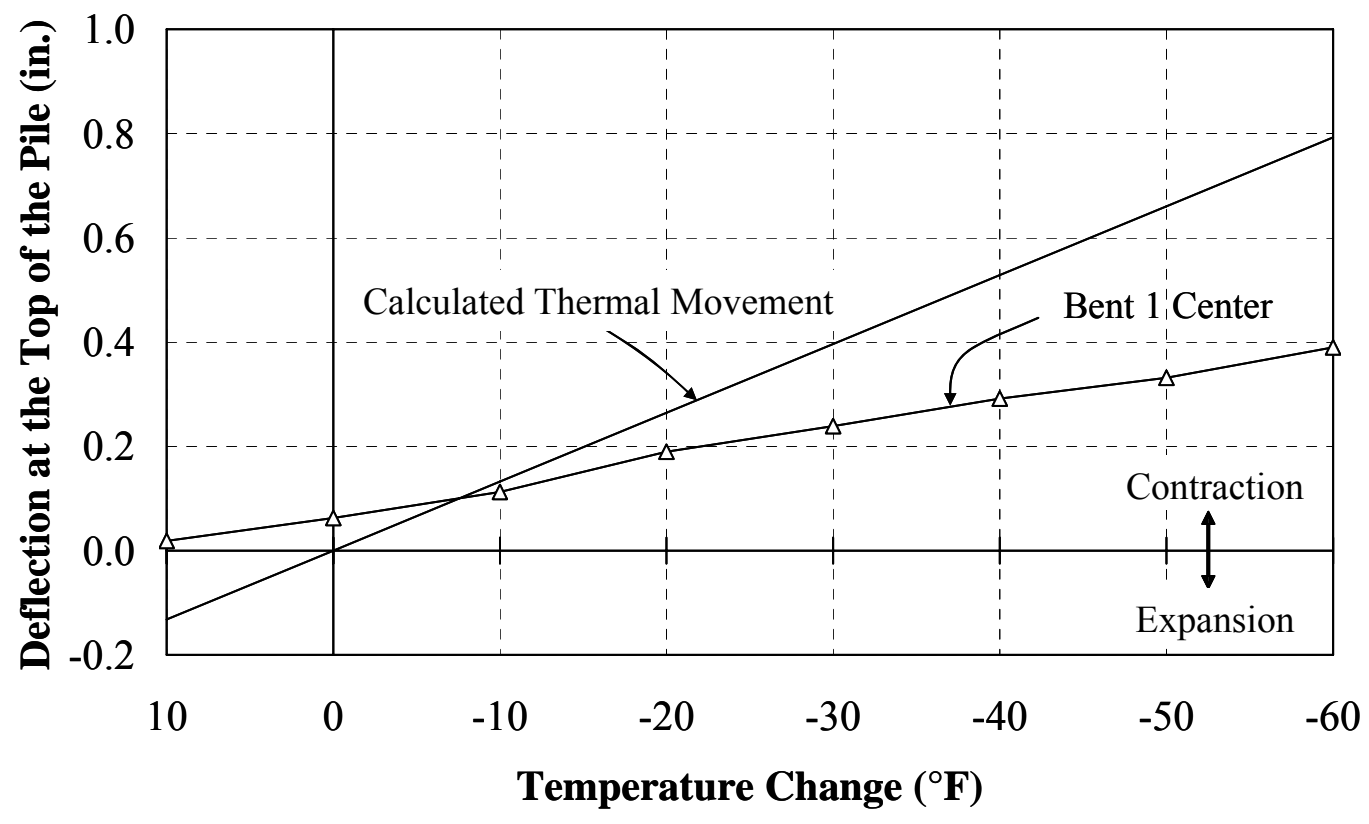

Figure 3.55: Deflection at the Top of Pile 6 (SR18) 


\section{CHAPTER 4: ANALYSIS OF FIELD RESULTS}

\subsection{Introduction}

To evaluate the bridge data, two computer programs were used to model piles for the SR249 over US12 bridge, the I65 over SR25 bridge, and the SR18 over Mississinewa River bridge. The deflected shapes and moments along the pile length were calculated. Bridge data from SR249 over US12 and I65 over SR25 were not sufficient to estimate deflections and moments along the pile length, while strain data from SR18 provided enough information to approximate deflections and moments along the pile length. Therefore, only deflected shapes and moments on pile of SR18 calculated using strains can be compared to the results calculated using the two computer models.

Parametric studies were performed to determine the minimum acceptable pile length to be provided for typical integral abutment bridges. Variables include lateral displacement, axial load level, pile length, pile type, pile orientation, and soil type. Conclusions of the parametric studies are presented, and design recommendations are provided.

\subsection{P-y Curve}

The p-y curve presents the relationship between the lateral soil pressure against the pile (force per unit length of pile) and the corresponding lateral pile displacement. The soil characteristics in the soil-pile system are represented by the p-y curves. The p-y curve is dependent upon many variables such as soil type, shear strength parameters,

moisture conditions, effective stress, stress history, and loading conditions (Welch and Reese, 1972). The p-y curves are different for short term static loading, sustained load, 
cyclic loading, and dynamic loading. This study will consider only short term static loading which is considered appropriate for the pile response investigated here. A typical p-y curve is presented in Figure 4.1.

In the actual case of a laterally loaded pile, the soil response is usually nonlinear. As shown in Figure 4.1, the initial portion of the curve at a specific depth is a straight line, as defined by the initial soil modulus or initial soil stiffness, $\mathrm{E}_{\mathrm{si}}(\mathrm{z})$. The value of the initial soil modulus may vary with lateral deflection, $y$, and with the depth of the pile, $z$. A set of p-y curves along the pile length as illustrated in Figure 4.2 indicates that p-y curves are dependent upon the depth below ground surface.

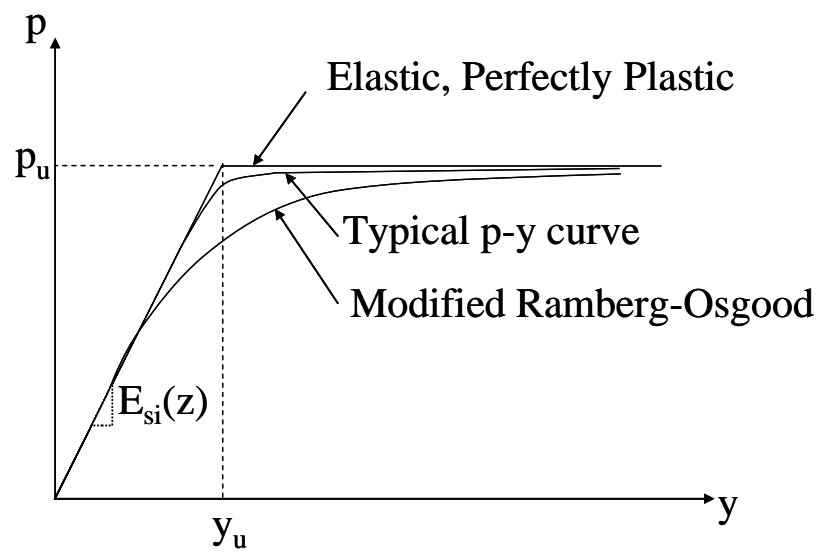

where:

$$
\begin{aligned}
& \mathrm{p} \quad=\text { soil resistance in units of force per linear length. } \\
& \mathrm{y} \quad=\text { deflection of the pile perpendicular to the axis in units of length. } \\
& \mathrm{p}_{\mathrm{u}} \quad=\text { ultimate soil resistance in units of force per linear length. } \\
& \mathrm{y}_{\mathrm{u}} \quad=\text { ultimate deflection corresponding to } \mathrm{p}_{\mathrm{u}} \text { in units of length. } \\
& \mathrm{E}_{\mathrm{si}}(\mathrm{z})=\text { initial soil modulus or initial soil stiffness at the depth } \mathrm{z} \text { in units } \\
& \text { of force per unit area. }
\end{aligned}
$$

\section{Figure 4.1: Typical p-y Curve}

The modified Ramberg-Osgood model can be used to approximate the p-y soil resistance and displacement curve for use in finite element analysis (Greimann, 1987). For convenience, the p-y curve can be assumed to be elastic, perfectly plastic as illustrated in Figure 4.1. 


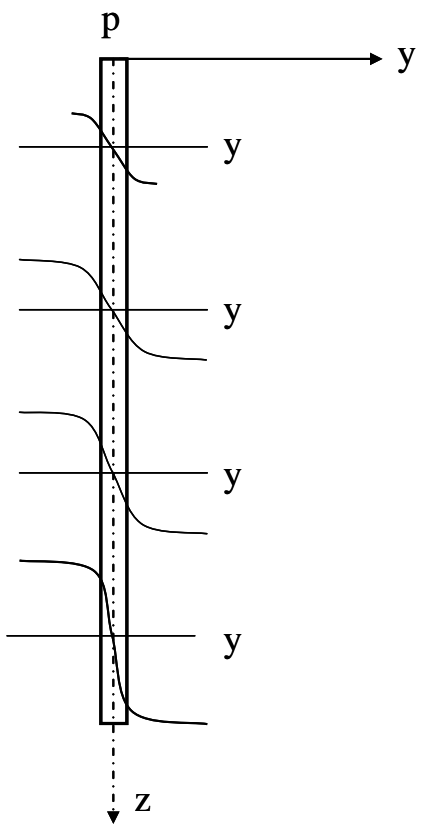

Figure 4.2: Set of p-y Curves (Reese et al., 1974)

\subsubsection{Clay Model}

Reese (1958) developed an expression for the ultimate soil resistance for clay, and Matlock (1970) modified the expression for soft, stiff, and very stiff clay. According to Griemann (1987), the ultimate soil resistance, $\mathrm{pu}_{\mathrm{u}}(\mathrm{z})$, and the initial soil modulus, $\mathrm{E}_{\mathrm{si}}(\mathrm{z})$, for soft clay and stiff clay are given by Equations 4-1 and 4-2, respectively.

$$
\begin{aligned}
& \mathrm{p}_{u}(\mathrm{z})=\text { lesser of }\left\{\begin{array}{l}
{\left[3+\frac{\gamma}{c_{u}} \mathrm{z}+\frac{0.5}{\mathrm{~B}} \mathrm{z}\right] \cdot \mathrm{c}_{\mathrm{u}} \mathrm{B}} \\
9 \mathrm{c}_{\mathrm{u}} \mathrm{B}
\end{array}\right. \\
& \mathrm{E}_{\mathrm{si}}(\mathrm{z})=\frac{\mathrm{p}_{\mathrm{u}}}{\mathrm{y}_{50}}
\end{aligned}
$$

The ultimate soil resistance, $\mathrm{pu}_{\mathrm{u}}(\mathrm{z})$, and the initial soil modulus, $\mathrm{E}_{\mathrm{si}}(\mathrm{z})$, for very stiff clay are given by Equations 4-3 and 4-4, respectively.

$$
\mathrm{p}_{\mathrm{u}}(\mathrm{z})=\text { lesser of }\left\{\begin{array}{l}
{\left[3+\frac{\gamma}{\mathrm{c}_{u}} \mathrm{z}+\frac{2}{\mathrm{~B}} \mathrm{z}\right] \cdot \mathrm{c}_{\mathrm{u}} \mathrm{B}} \\
9 \mathrm{c}_{\mathrm{u}} \mathrm{B}
\end{array}\right.
$$




$$
\mathrm{E}_{\mathrm{si}}(\mathrm{z})=\frac{\mathrm{p}_{\mathrm{u}}}{2 \mathrm{y}_{50}}
$$

where:

$$
\begin{aligned}
\mathrm{p}_{\mathrm{u}}= & \text { ultimate soil resistance, kips/ft. } \\
\gamma & =\text { effective unit soil weight, } \mathrm{lb} / \mathrm{ft}^{3} \text { or use } \gamma=50,60 \text {, and } 65 \mathrm{lb} / \mathrm{ft}^{3} \\
& \text { for soft, stiff, and very stiff clay, respectively (Griemann, 1987). } \\
\mathrm{C}_{\mathrm{u}} & =\text { undrained shear strength from tri-axial test or use the values } \\
& \quad \text { given in Table } 4.1 . \\
\mathrm{B} & =\text { dimension of the pile parallel to bending axis, } \mathrm{ft} \text {, as shown in }
\end{aligned}
$$$$
\text { Figure 4.3. For example, }
$$

$\mathrm{B}$ is the width of $\mathrm{H}$ pile, $\mathrm{b}_{\mathrm{f}}$, for the strong axis pile bending.

$\mathrm{B}$ is the depth of $\mathrm{H}$ pile, $\mathrm{d}$, for weak axis pile bending.

B is outer diameter, O.D., for concrete-filled steel tube piles.

$\mathrm{z} \quad=$ depth of a spring from soil surface, $\mathrm{ft}$.

$\mathrm{y}_{50}=$ displacement at one-half ultimate soil resistance, $\mathrm{ft}$. Taken as

$2.5 \mathrm{~B} \varepsilon_{50}$ for soft and stiff clay, and $2.0 \mathrm{~B} \varepsilon_{50}$ for very stiff clay

(Griemann, 1987).

$\varepsilon_{50}=$ axial strain at one-half peak stress difference from triaxial test; or use $0.02,0.01$, and 0.005 for soft, stiff, and very stiff clay, respectively

(Reese et al., 2000a and Reese et al., 2000b).

The p-y curve for soft and stiff clays proposed by Matlock (1970) is shown in

Figure 4.4. The p-y curve for soft and stiff clays can be determined using Equation 4-5.

The value of $\mathrm{p}$ remains constant beyond $\mathrm{y}=8 \mathrm{y}_{50}$.

$$
\mathrm{p}=0.5\left(\frac{\mathrm{y}}{\mathrm{y}_{50}}\right)^{\frac{1}{3}} \cdot \mathrm{p}_{\mathrm{u}}
$$

where:

$$
\begin{array}{ll}
\mathrm{P} & =\text { generalized soil resistance, } \mathrm{kips} / \mathrm{ft} . \\
\mathrm{p}_{\mathrm{u}} & =\text { ultimate soil resistance, } \mathrm{kips} / \mathrm{ft} . \\
\mathrm{y} & =\text { generalized displacement, } \mathrm{ft} . \\
\mathrm{y}_{50} & =\text { displacement at one-half ultimate soil reaction, } \mathrm{ft} .
\end{array}
$$


Table 4.1: Undrained Shear Strength and Soil Modulus Parameter for Clays (Reese et al., 2000b)

\begin{tabular}{|c|c|c|c|}
\hline Clay Type & $\begin{array}{c}\text { Undrained Shear } \\
\text { Strength, } \mathbf{c}_{\mathbf{u}}\end{array}$ & ${\text { Average } \mathbf{c}_{\mathbf{u}}}$ & $\mathbf{k}\left(\mathbf{l b} / \mathbf{i n}^{3}{ }^{3}\right)$ \\
\hline \multirow{2}{*}{ Soft } & $\begin{array}{c}250-500 \mathrm{psf} \\
1.74-3.47 \mathrm{psi}\end{array}$ & $\begin{array}{c}375 \mathrm{psf} \\
2.6 \mathrm{psi}\end{array}$ & \multirow{2}{*}{30} \\
\hline \multirow{2}{*}{ Medium } & $\begin{array}{c}500-1000 \mathrm{psf} \\
3.47-6.94 \mathrm{psi}\end{array}$ & $\begin{array}{c}750 \mathrm{psf} \\
5.2 \mathrm{psi}\end{array}$ & \multirow{2}{*}{100} \\
\hline \multirow{2}{*}{ Stiff } & $\begin{array}{c}1000-2000 \mathrm{psf} \\
6.94-13.9 \mathrm{psi}\end{array}$ & $\begin{array}{c}1500 \mathrm{psf} \\
10.4 \mathrm{psi}\end{array}$ & \multirow{2}{*}{500} \\
\hline \multirow{2}{*}{ Very Stiff } & $\begin{array}{c}2000-4000 \mathrm{psf} \\
13.9-27.8 \mathrm{psi}\end{array}$ & $\begin{array}{c}3000 \mathrm{psf} \\
20.8 \mathrm{psi}\end{array}$ & \multirow{2}{*}{1000} \\
\hline \multirow{2}{*}{ Hard } & $\begin{array}{c}4000-8000 \mathrm{psf} \\
27.8-55.6 \mathrm{psi}\end{array}$ & $\begin{array}{c}6000 \mathrm{psf} \\
41.7 \mathrm{psi}\end{array}$ & \multirow{2}{*}{2000} \\
\hline
\end{tabular}

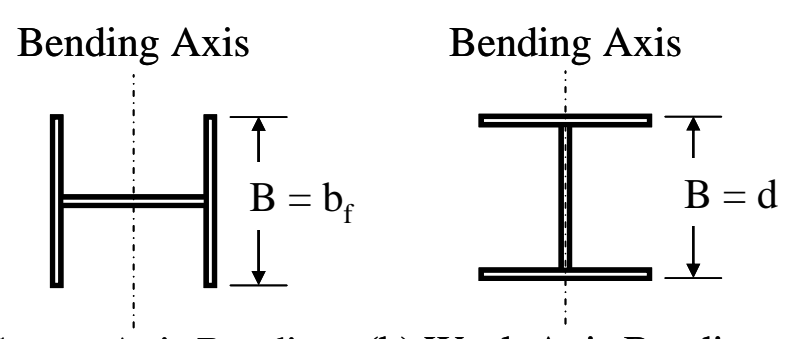

(a) Strong Axis Bending

(b) Weak Axis Bending
Bending Axis

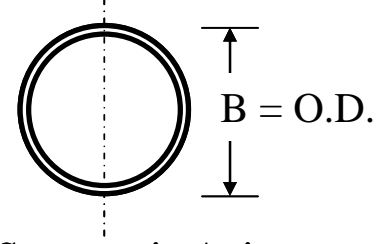

(c) Symmetric Axis

Figure 4.3: Definition of the Width, B

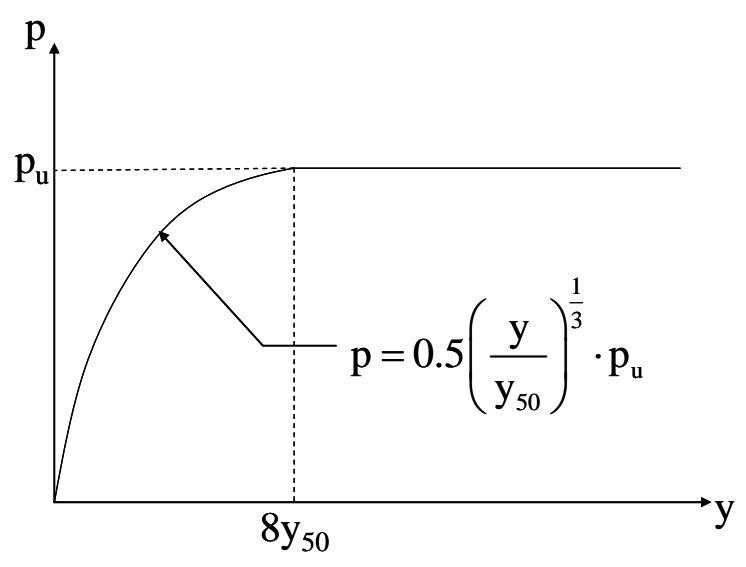

Figure 4.4: Typical p-y Curve for Soft Clay and Stiff Clay 
Very stiff clay as modeled by Reese and Welch (1975) is shown in Figure 4.5. The p-y curve for very stiff clay can be determined using Equation 4-6. The value of $\mathrm{p}$ remains constant beyond $\mathrm{y}=16 \mathrm{y}_{50}$.

$$
\mathrm{p}=0.5\left(\frac{\mathrm{y}}{\mathrm{y}_{50}}\right)^{\frac{1}{4}} \cdot \mathrm{p}_{\mathrm{u}}
$$

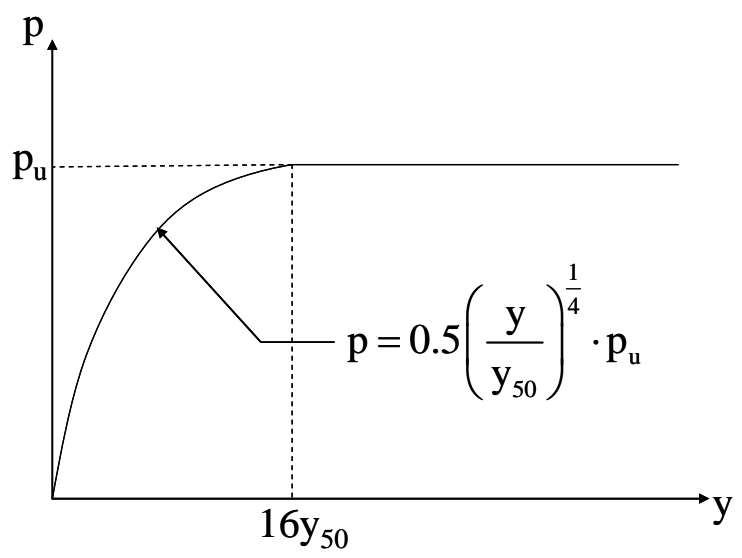

Figure 4.5: Typical p-y Curve for Very Stiff Clay

\subsubsection{Sand Model}

If values of Young's modulus of soil, $\mathrm{E}_{\mathrm{m}}$, were not obtained from laboratory tests, Terzaghi (1955) suggested numerical values for $E_{m}$ as a function of the unit weight and relative density of sand (Equation 4-7). Based on experiments, $E_{m}$ is suggested to be zero at the ground surface and increases linearly with depth. The initial slope or soil modulus of the p-y curve, $E_{\text {si }}(\mathrm{z})$, is defined by Equation 4-8.

$$
\begin{gathered}
\mathrm{E}_{\mathrm{m}}=\mathrm{J} \gamma \mathrm{z} \\
\mathrm{E}_{\mathrm{si}}(\mathrm{z})=\frac{\mathrm{E}_{\mathrm{m}}}{1.35}=\frac{\mathrm{J} \gamma \mathrm{z}}{1.35}
\end{gathered}
$$

where:

$$
\begin{array}{ll}
\mathrm{E}_{\mathrm{m}} & =\text { Young's Modulus for the soil, } \mathrm{lb} / \mathrm{ft}^{2} \\
\gamma & =\text { average effective unit weight, } \mathrm{lb} / \mathrm{ft}^{3} \\
\mathrm{z} & =\text { depth to } \mathrm{p}-\mathrm{y} \text { curve, } \mathrm{ft} .
\end{array}
$$




$$
\begin{aligned}
\mathrm{J}= & 200,600 \text {, and } 1500 \text { for loose, medium, and dense sand, } \\
& \text { respectively. } \\
\mathrm{E}_{\mathrm{si}}(\mathrm{z})= & \text { initial slope or soil modulus of the p-y curve at the depth } \mathrm{z} \text {, } \\
& \mathrm{kips} / \mathrm{ft}^{2} \text {. }
\end{aligned}
$$

Reese et al. (1974) proposed the ultimate soil resistance per unit length of the pile given by the smaller of $\mathrm{p}_{\mathrm{st}}$ in Equation 4-9 and $\mathrm{p}_{\mathrm{sd}}$ in Equation 4-10. Equation 4-9 is used for computing the ultimate resistance near the ground surface, and Equation 4-10 is used for computing the ultimate resistance well below the ground surface. The computational procedure of the p-y curves for sand is provided in Appendix F.

$$
\begin{aligned}
\mathrm{p}_{\mathrm{st}}=\gamma \mathrm{z}[ & \frac{\mathrm{K}_{\mathrm{o}} \mathrm{z} \tan \phi \sin \beta}{\tan (\beta-\phi) \cos \alpha}+\frac{\tan \beta}{\tan (\beta-\phi)}(\mathrm{B}+\mathrm{z} \tan \beta \tan \alpha) \\
& \left.+\mathrm{K}_{0} \mathrm{z} \tan \beta(\tan \phi \sin \beta-\tan \alpha)-\mathrm{K}_{\mathrm{A}} \mathrm{B}\right] \\
\mathrm{p}_{\mathrm{sd}} & =\mathrm{K}_{\mathrm{A}} \mathrm{B} \gamma \mathrm{z}\left(\tan ^{8} \beta-1\right)+\mathrm{K}_{0} \mathrm{~B} \gamma \mathrm{z} \tan \phi \tan ^{4} \beta
\end{aligned}
$$

where:

$$
\begin{aligned}
\alpha & =\frac{\phi}{3} \text { for loose sand, } \frac{\phi}{2} \text { for medium or dense sand (Welch and } \\
& \text { Reese, 1972, Bowman, 1958, and Parker and Reese, 1971). } \\
\beta & =45^{\circ}+\frac{\phi}{2} \text { (Mohr-Coulomb Theory). } \\
\gamma & =\text { unit weight of soil, lb/ft }{ }^{3} . \\
\mathrm{z} & =\text { depth from soil surface, } \mathrm{ft} . \\
\phi & =\text { angle of internal friction, degrees. } \\
\mathrm{K}_{0} & =\text { coefficient of earth pressure at rest }=1-\sin \phi(G r e i m a n n, \text { et al., } \\
\mathrm{K}_{\mathrm{A}} & =\text { 1987). }
\end{aligned}
$$




\subsection{LPILE PLUS}

LPILE PLUS Version 4.0 (Reese et al., 2000a and Reese et al., 2000b) is a computer program for the analysis of piles and drilled shafts under lateral loads. Soil springs in LPILE PLUS are modeled by lateral resistance-displacement curves or p-y curves. For LPILE PLUS, Matlock’s (1970) approach was used to model soft clay while Reese and Welch’s (1975) approach was used to model stiff clay and very stiff clay. Reese et al’s (1974) approach was used to model the p-y curve for sand.

For LPILE PLUS, $\mathrm{E}_{\mathrm{si}}(\mathrm{z})$ is defined by Equation 4-11. The values of $\mathrm{k}$ recommended by Terzaghi (1955) are shown in Table 4.2. Reese et al. (1974) reported that the values of $\mathrm{k}$ for submerged sand from a test performed at Mastang Island are higher than the values reported by Terzaghi (1955); therefore, the values of k provided in Table 4.3 are used for the LPILE PLUS analysis.

$$
\mathrm{E}_{\mathrm{si}}(\mathrm{z})=\mathrm{kz}
$$

where:

$$
\begin{array}{ll}
\mathrm{E}_{\mathrm{si}}(\mathrm{z}) & =\text { initial soil modulus at the depth } \mathrm{z}, \mathrm{lb} / \mathrm{in}^{2}{ }^{2} \\
\mathrm{k} & =\text { soil modulus parameter, } \mathrm{lb} / \mathrm{in} .^{3} \\
\mathrm{z} & =\text { depth to } \mathrm{p}-\mathrm{y} \text { curve, in. }
\end{array}
$$

Table 4.2: Terzaghi's Values of $k$ for Submerged Sand (Terzaghi, 1955)

\begin{tabular}{|c|c|c|c|}
\hline Relative Density & Loose & Medium & Dense \\
\hline Terzaghi's k (lb/in. ${ }^{3}$ ) & $2.6-7.7$ & $7.7-26$ & $26-51$ \\
\hline
\end{tabular}

Table 4.3: Recommended Values of $k$ (lb/in. ${ }^{3}$ ) (Reese et al., 1974)

\begin{tabular}{|c|c|c|c|}
\hline \multirow{2}{*}{ Sand } & \multicolumn{3}{|c|}{ Relative Density } \\
\cline { 2 - 4 } & Loose & Medium & Dense \\
\hline Submerged & 20 & 60 & 125 \\
\hline Dry & 25 & 90 & 225 \\
\hline
\end{tabular}


LPILE PLUS performs a nonlinear analysis to determine deflected shapes and moments along the pile length. LPILE PLUS solves the problem of a laterally loaded pile with any arbitrary variation of pile stiffness or soil modulus along pile depth. An iterative solution method is used with values of the initial soil modulus, $\mathrm{E}_{\mathrm{si}}(\mathrm{z})$, adjusted until the values of soil resistance, $\mathrm{p}$, and deflection, $\mathrm{y}$, obtained in the solution are compatible with the external applied load.

\subsubsection{Soil Models (LPILE PLUS)}

\subsubsection{Clay Model}

The p-y curves of clay in LPILE PLUS are modeled in accordance with Section 4.2.1. The undrained shear strength, $\mathrm{c}_{\mathrm{u}}$, and soil modulus parameter, $\mathrm{k}$, are provided in Table 4.1.

\subsubsection{Sand Model}

The p-y curves of sand in LPILE PLUS are modeled in accordance with Section 4.2.2.

\subsubsection{Equivalent Diameter}

The recommendations for p-y curves are based strongly on the results of experiments with cylindrical shapes. At the outset, it can be assumed that the soil in the flanges of $\mathrm{H}$ piles will move with the pile and that it will behave as a rectangular shape. The equivalent diameter of the pile, $\mathrm{d}_{\mathrm{e}}$, can be computed by finding a circular section with the same area as the rectangular section (Figure 4.6). Thus, the circular area of $\pi \mathrm{d}_{\mathrm{e}}{ }^{2} / 4$ is set to be equal to $\mathrm{b}_{\mathrm{f}} \cdot \mathrm{d}$. Finally, the equivalent diameter can be solved. If the equivalent diameter, $d_{e}$, is greater than $b_{f}$ or $d$, the lower value will be used. For CFT piles, the outer diameter, O.D., is used as the actual diameter $\left(d_{e}=\right.$ O.D. $)$. 


\subsubsection{Transformed Section}

Concrete-filled steel tube piles were transformed into an equivalent steel pile to determine pile properties (Figure 4.7). The concrete section of the pile was transformed to an equivalent steel section using the modular ratio, n, given by Equation 4-12. To replace the area of concrete with an area of steel having the same axial stiffness, AE, the equivalent steel section diameter, $\mathrm{d}_{\mathrm{e}}$, is computed by dividing the concrete section diameter, I.D., by n.

$$
\mathrm{n}=\mathrm{E}_{\mathrm{s}} / \mathrm{E}_{\mathrm{c}}
$$

where:

$$
\begin{aligned}
& \mathrm{E}_{\mathrm{s}} \quad=\text { modulus of elasticity of steel, } \mathrm{ksi}\left(\mathrm{E}_{\mathrm{s}}=29,000 \mathrm{ksi}\right) \\
& \mathrm{E}_{\mathrm{c}} \quad=\text { modulus of elasticity of concrete, } \mathrm{ksi}\left(\mathrm{E}_{\mathrm{c}}=57 \sqrt{\mathrm{f}_{\mathrm{c}}^{\prime}}\right)
\end{aligned}
$$

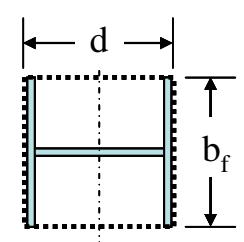

Bending Axis

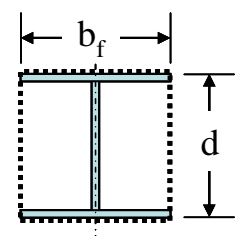

Bending Axis

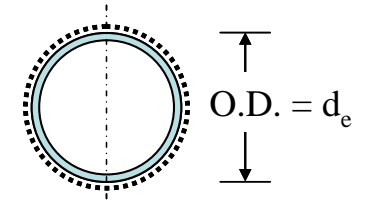

Bending Axis

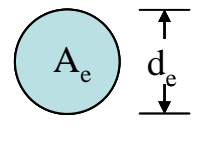

$d_{e}$

(a) Strong Axis Bending

(b) Weak Axis Bending

(c) Symmetric Axis

(d) Equivalent Area

Figure 4.6: The Computation of Equivalent Diameter and Equivalent Area

The moment of inertia of the equivalent steel section, $I_{e}$, is the summation of the

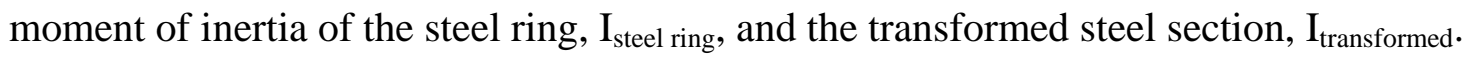

$$
\begin{gathered}
\mathrm{I}_{\mathrm{e}}=\mathrm{I}_{\text {steel ring }}+\mathrm{I}_{\text {transformed }} \\
\mathrm{I}_{\text {steel ring }}=\frac{\pi}{64}\left(\text { O.D. }^{4}-\text { I.D. }^{4}\right) \\
\mathrm{I}_{\text {transformed }}=\mathrm{I}_{\mathrm{y}}=\frac{1}{4} \pi \mathrm{a}^{3} \mathrm{~b}=\frac{1}{4} \pi\left(\frac{\text { I.D. }}{2}\right)^{3}\left(\frac{\text { I.D. }}{2 \mathrm{n}}\right)
\end{gathered}
$$


where:
$\mathrm{a}, \mathrm{b} \quad=$ major and minor axes, in.
O.D. = outer diameter, in.
I.D. = inner diameter, in.

\subsection{SAP2000}

SAP2000, a finite element program, was also used to model the piles. Piles were modeled as a beam-column element with springs positioned along the length representing the soil-spring stiffness. The pile was subjected to the same axial load and lateral displacement as used in LPILE PLUS. Deflected shapes and moments of the piles were determined and compared to the results analyzed using LPILE PLUS.

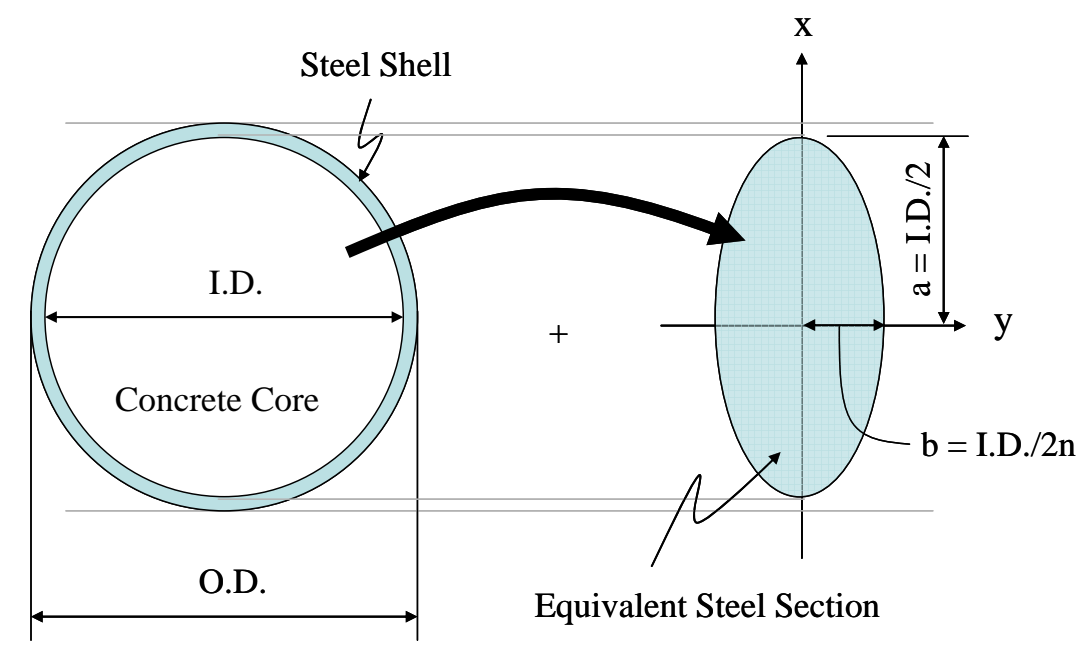

Figure 4.7: Transformed Concrete-Filled Steel Section

\subsubsection{Elastic Soil Spring Method}

Pile behavior is depended upon pile type, pile size, pile orientation, and the influence of soil surrounding the pile. The piles can be modeled using the equivalent cantilever pile method (Abendroth et al., 1989, Davisson, 1970, Greimann et al., 1987, and Girton et al., 1991) or using the elastic soil spring method (Wolde-Tinsae et al., 1982, Greimann et al., 1986, and Greimann et al., 1987). Because the actual pile length was used in the model and the lateral stiffness of the soil was calculated at each node level 
along the pile member, according to Durbin (2001), the elastic soil spring method is recommended for modeling integral abutment piles because of its accuracy and various utilizations. For example, one pile length is used to determine the maximum moment, horizontal displacement, and elastic stability of the pile, whereas different lengths are required for each of these calculations in the equivalent cantilever method.

The effect of soil on pile behavior is represented by a series of Winkler springs continuous along the pile length. A Winkler's spring assumes no interaction between the different soil springs as the pile is displaced. Soil springs are applied over the length of the pile below ground level. Each spring has a stiffness based on the soil type, pile size, and depth from ground surface. Greimann (1987) provides equations for calculating the spring stiffness values for different soil types. Sand and clay models are discussed in the following sections.

For all analyses, the ground water table (GWT) was assumed to be at ground level unless otherwise stated. This is a conservative assumption. The initial spring stiffness values also known as soil modulus, $\mathrm{E}_{\mathrm{si}}(\mathrm{z})$, varied along the length of the pile and can be calculated based on Sections 4.2.1 and 4.2.2. The stiffness of individual soil springs spaced over the length of the pile, $\mathrm{k}(\mathrm{z})$, is calculated by multiplying the soil spring stiffness, $\mathrm{E}_{\mathrm{si}}(\mathrm{z})$, by a distance equal to half of the spring spacing above and below the specific spring ( $\mathrm{s}_{1} / 2$ and $\mathrm{s}_{2} / 2$, respectively). The distinction between initial soil stiffness, $\mathrm{E}_{\mathrm{si}}(\mathrm{z})$, and soil spring stiffness, $\mathrm{k}(\mathrm{z})$, is illustrated in Figure 4.8. The soil spring applied on the pile along the pile depth, $\mathrm{k}(\mathrm{z})$, can be calculated by Equation 4-16.

$$
\mathrm{k}(\mathrm{z})=\mathrm{E}_{\mathrm{si}}(\mathrm{z}) \cdot \mathrm{s}
$$

where:

$$
\begin{aligned}
& \mathrm{E}_{\mathrm{si}}(\mathrm{z})=\text { soil spring at the depth of } \mathrm{z}, \mathrm{kips} / \mathrm{ft} . \\
& \mathrm{s} \\
& \mathrm{s}_{1}, \mathrm{~s}_{2}=\text { spring spacing, ft. Equal to } \mathrm{s}_{1} / 2+\mathrm{s}_{2} / 2 .
\end{aligned}
$$




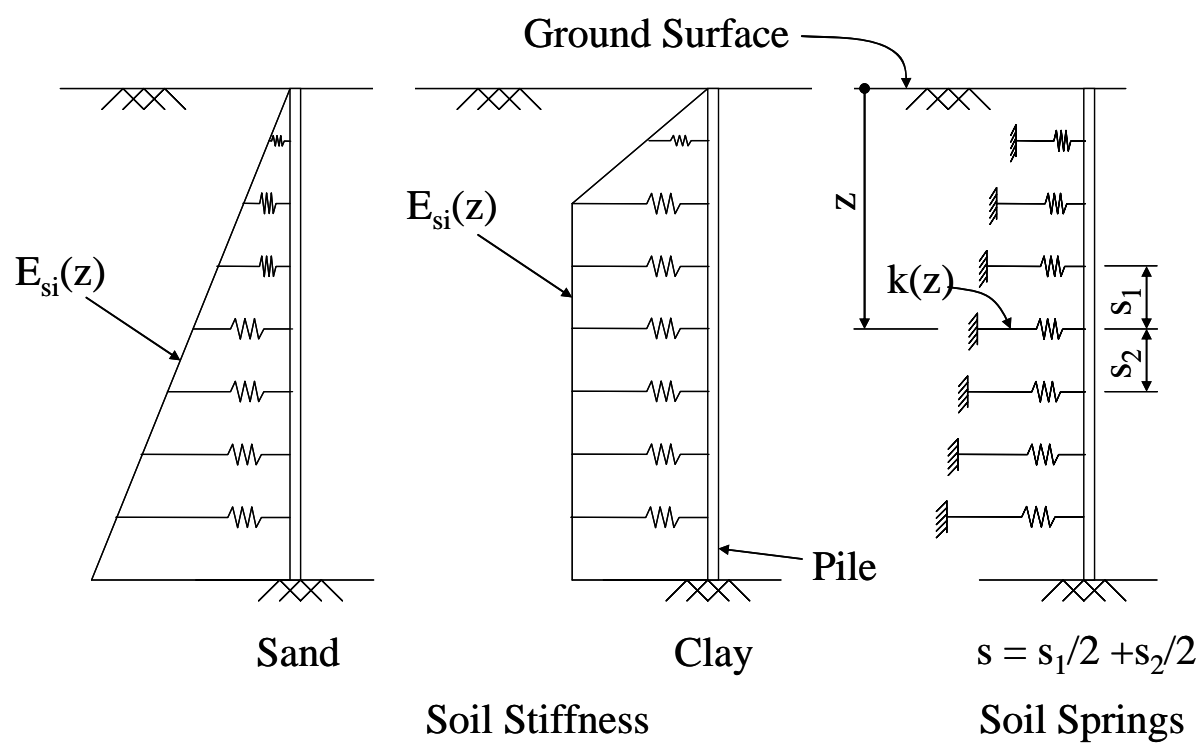

Figure 4.8: Initial Soil Stiffness and Soil Spring Stiffness

\subsubsection{Soil Models (SAP2000)}

\subsubsection{Clay Model}

The initial soil stiffness of clay, $\mathrm{E}_{\mathrm{si}}(\mathrm{z})$, was determined according to Section 4.2.1 along with the undrained shear strength given in Table 4.1.

\subsubsection{Sand Model}

The initial soil stiffness of sand, $\mathrm{E}_{\mathrm{si}}(\mathrm{z})$, was determined according to Section 4.2.2.

\subsubsection{Transformed Section}

The concrete-filled steel tube piles were transformed in accordance with Section 4.3.3 to determine the moment of inertia. 


\subsection{LPILE PLUS vs. SAP2000}

The difference between LPILE PLUS and SAP2000 is that LPILE PLUS uses nonlinear p-y curves to iteratively calculate the deflections and moments along the pile length, while the SAP2000 models only use the initial slope of the p-y curve, $E_{\text {si }}(z)$, which is linear. For large lateral displacements, the nonlinear soil springs are more reasonable.

\section{$\underline{4.6 \quad \text { Analytical Bridge Models }}$}

\subsubsection{SR249 over US12 Bridge}

Due to insufficient field data to verify the deflected shape of the pile supporting the end bents, the deflected shape cannot be estimated using the field data. However, the deflected shapes estimated by LPILE PLUS and SAP2000 are presented and compared to each other. In addition, the magnitude of strains at the ground level of the pile is compared with the analytical results.

\subsubsection{Pile Model}

HP14x89 piles bending about their strong axis were modeled for the piles supporting both end bents. For convenience, the pile lengths for all models were slightly modified from the actual length to ease positioning of the soil springs. For Bent 1, the total length of the piles was modified to be $133.5 \mathrm{ft}$ (the actual total pile length for Bent 1 is approximately $131 \mathrm{ft}$ ). The piles of both Bents 1 and 11 are embedded $1.5 \mathrm{ft}$ in the abutment. The pile length above ground level is $17 \mathrm{ft}$ measured from the ground surface to the bottom of the abutment; therefore, the pile length below ground level in the model is $115 \mathrm{ft}$ (Figure 4.9). For Bent 11, the total length of the piles is assumed to be $165.5 \mathrm{ft}$ (the actual total pile length for Bent 11 is $164 \mathrm{ft}$ ). The pile length above ground level is $19 \mathrm{ft}$ measured from the ground surface to the bottom of the abutment; therefore, the pile length below ground level in the model is $145 \mathrm{ft}$ (Figure 4.9). 


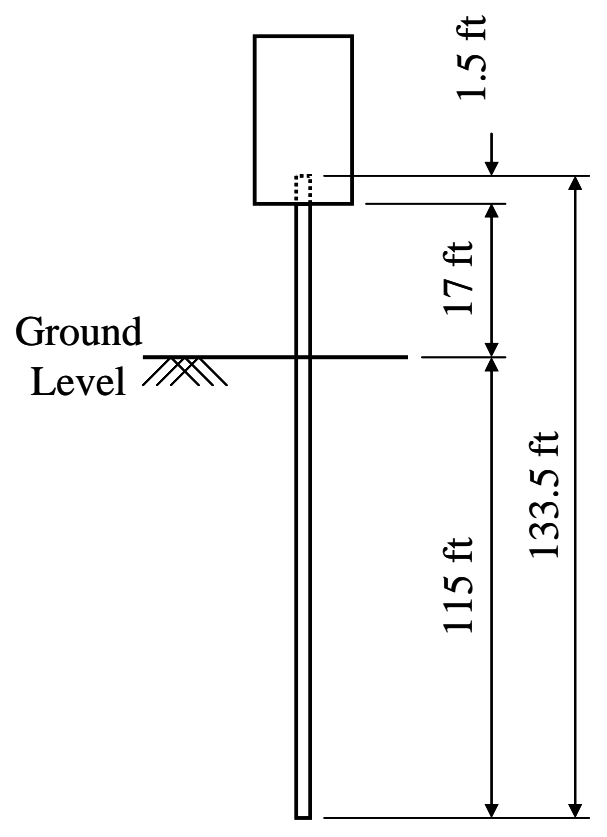

Bent 1

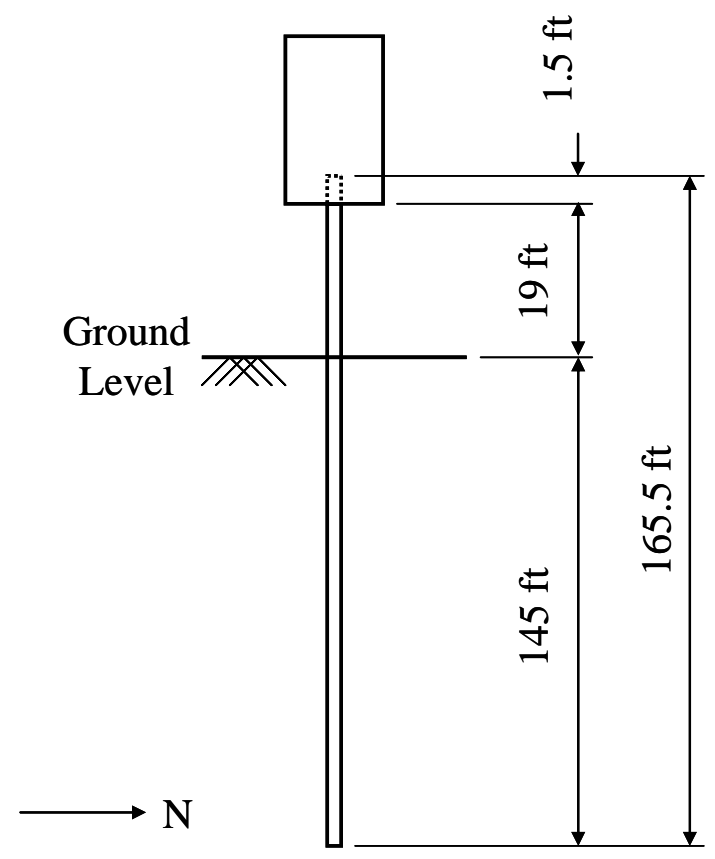

Bent 11

Figure 4.9: Pile Length for Piles of Bents 1 and 11 (SR249 over US12)

Since the piles embedded in the abutment are surrounded by expanded polystyrene to provide for a pin connection, the pile was modeled to have a roller support at the top and a hinged support at the bottom as illustrated in Figure 4.10. A roller support allows the pile to translate horizontally and rotate, and a hinged support allows the pile to rotate without translation. In reality, however, the abutment-pile connection likely behaves in-between a hinged and a fixed support. Therefore, a horizontally-guided support was also analyzed at the top of the pile. The horizontally-guided support allows the pile to translate horizontally without rotation. As shown in Figure 4.10, depths (z) are measured from the ground level. Positive values indicate below ground level and negative values indicate above ground level.

Each pile was subjected to an axial load of 200 kips according to calculations provided by the bridge designer (Section 2.2.1.2). The pile was subjected to a lateral movement of 2.2 in. based on the thermal movement calculated by Equation 4-17. 


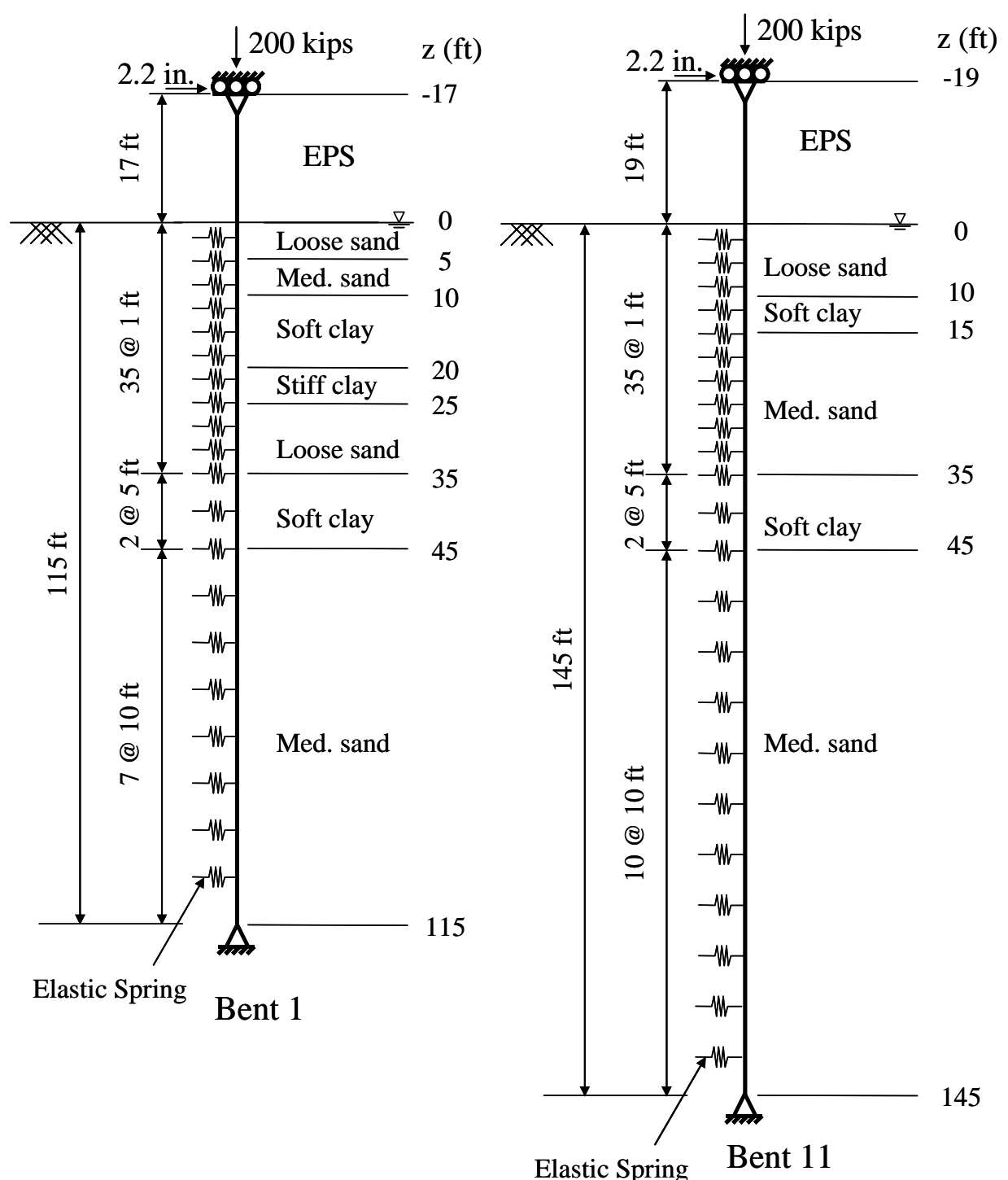

Figure 4.10: Pile Models for Bents 1 and 11 (SR249 over US12)

$$
\Delta \mathrm{L}=\alpha(\Delta \mathrm{T}) \mathrm{L}
$$

where:

$\alpha=$ coefficient of thermal expansion for concrete taken as $6 \times 10^{-6} /{ }^{\circ} \mathrm{F}$.

$\Delta \mathrm{T}=$ temperature change of $60^{\circ} \mathrm{F}$ taken on the coldest day (December 22, 2000 at 8:00AM).

$\mathrm{L}=$ = half of the total bridge length taken as $990 \mathrm{ft} / 2=495 \mathrm{ft}$. 
For LPILE PLUS, the cross-sectional area, A, equivalent diameter, $\mathrm{d}_{\mathrm{e}}$, and moment of inertia, I, of the pile were calculated and are listed in Table 4.4. The pile section properties are provided in Table 4.5. The modulus of elasticity of steel was assumed to be equal to $29,000 \mathrm{ksi}$.

Table 4.4: Input for LPILE Program (SR249 over US12)

\begin{tabular}{|c|c|c|c|}
\hline Pile Section & A (in. ${ }^{2}$ ) & d $_{\mathbf{e}}$ (in.) & I (in. ${ }^{\mathbf{4}}$ ) \\
\hline HP14x89 & 26.1 & 6.2 & 904 \\
\hline
\end{tabular}

Table 4.5: HP14x89 Cross Section Properties

\begin{tabular}{|c|c|c|c|c|c|c|c|c|c|c|c|}
\hline & A & d & $\mathbf{t}_{\mathrm{w}}$ & $\mathbf{b}_{\mathrm{f}}$ & $\mathbf{t}_{\mathrm{f}}$ & $\mathbf{I}_{\mathbf{x}}$ & $\mathbf{I}_{\mathbf{y}}$ & $\mathrm{S}_{\mathrm{x}}$ & $\mathrm{S}_{\mathrm{y}}$ & $\mathbf{Z}_{\mathrm{x}}$ & $\mathrm{Z}_{\mathbf{y}}$ \\
\hline & & 0.0 & & & & & & & & & \\
\hline
\end{tabular}

\subsubsection{Soil Model}

Soil surrounding the piles on both end bents was simplified as illustrated in Figure 4.10. Table 4.6 provides soil properties used in the analysis for Bents 1 and 11 . As indicated in Figure 4.10, elastic springs were placed on the pile elements every foot for the first $35 \mathrm{ft}$ below the ground level, every $5 \mathrm{ft}$ for the next $10 \mathrm{ft}$, and every $10 \mathrm{ft}$ for the rest of the pile length. For this analysis, the ground water table was assumed to be at ground level. The actual ground water table was approximately $4.2 \mathrm{ft}$ and $5.9 \mathrm{ft}$ below ground level for Bents 1 and 11, respectively. The spring stiffness for SAP2000 models was calculated according to Section 4.4.2 and the values of the soil spring stiffness are provided in Appendix G. 
Table 4.6: Soil Properties on Bents 1 and 11 (SR249 over US12)

\begin{tabular}{|c|c|c|c|c|c|c|c|}
\hline \multicolumn{8}{|c|}{$\overline{\text { BENT } 1}$} \\
\hline $\begin{array}{c}\text { Begin } \\
\text { Depth } \\
\text { (ft) }\end{array}$ & $\begin{array}{c}\text { End } \\
\text { Depth } \\
\text { (ft) }\end{array}$ & Soil Type & $\begin{array}{c}\gamma \\
\left(\mathbf{l b} / \mathbf{f t}^{3}\right)\end{array}$ & $\begin{array}{c}\mathbf{k} \\
\left(\mathbf{l b} / \mathbf{i n} .^{3}\right)\end{array}$ & $\begin{array}{c}\phi \\
\text { (degrees) }\end{array}$ & $\begin{array}{c}\mathrm{c}_{\mathrm{u}} \\
\left(\mathrm{lb} / \mathrm{in} .^{2}\right)\end{array}$ & $\begin{array}{c}\varepsilon_{50} \\
\text { (in./in.) }\end{array}$ \\
\hline 0 & 5 & loose sand & 55 & 20 & 30 & - & - \\
\hline 5 & 10 & med. sand & 60 & 60 & 35 & - & - \\
\hline 10 & 20 & soft clay & 50 & 30 & - & 2.6 & 0.02 \\
\hline 20 & 25 & stiff clay & 60 & 500 & - & 10.4 & 0.01 \\
\hline 25 & 35 & loose sand & 55 & 20 & 30 & - & - \\
\hline 35 & 45 & soft clay & 50 & 30 & - & 2.6 & 0.02 \\
\hline 45 & 115 & med. sand & 60 & 60 & 35 & - & - \\
\hline
\end{tabular}

\begin{tabular}{|c|c|c|c|c|c|c|c|}
\hline \multicolumn{8}{|c|}{ BENT 11} \\
\hline $\begin{array}{c}\text { Begin } \\
\text { Depth } \\
\text { (ft) }\end{array}$ & $\begin{array}{c}\text { End } \\
\text { Depth } \\
\text { (ft) }\end{array}$ & Soil Type & $\begin{array}{c}\gamma \\
\left(\mathbf{l b} / \mathbf{f t}^{3}\right)\end{array}$ & $\begin{array}{c}k \\
\left(\mathbf{l b} / \text { in. }^{3}\right)\end{array}$ & $\begin{array}{c}\phi \\
\text { (degrees) }\end{array}$ & $\begin{array}{c}\mathrm{c}_{\mathrm{u}} \\
\left(\mathrm{lb} / \mathrm{in}^{2}{ }^{2}\right)\end{array}$ & $\begin{array}{c}\varepsilon_{50} \\
\text { (in./in.) }\end{array}$ \\
\hline$\overline{0}$ & 10 & loose sand & 55 & 20 & 30 & - & - \\
\hline 10 & 15 & soft clay & 50 & 30 & - & 2.6 & 0.02 \\
\hline 15 & 35 & med. sand & 60 & 60 & 35 & - & - \\
\hline 35 & 45 & soft clay & 50 & 30 & - & 2.6 & 0.02 \\
\hline 45 & 145 & med. sand & 60 & 60 & 35 & - & - \\
\hline
\end{tabular}

\subsubsection{Results}

\subsection{Deflected Shapes}

The deflected shapes for the piles of Bents 1 and 11 are presented in Figures 4.11 and 4.12, respectively. The deflected shapes calculated using LPILE PLUS and SAP2000 correlate well. Differences in the deflected shape occur because the soil spring stiffness using LPILE PLUS is slightly stiffer than that used in the SAP2000 analysis. As illustrated in Table 4.7, for the pile models with a roller at the top of the pile, the average inflection point depths determined from the deflected shapes are $21.9 \mathrm{ft}$ and $23.5 \mathrm{ft}$ for Bents 1 and 11, respectively. For the pile models with a fixed support at the top of the pile, the average inflection point depths are 2.3 and $2.9 \mathrm{ft}$ above ground level for Bents 1 and 11. The difference in the inflection point depths occurs because the pile models with 
a roller support at the top of the pile bend in single curvature, while the pile models with a fixed support at the top of the pile bend in double curvature. Therefore, the inflection point depths of the pile models with a fixed support are higher than those with a roller support. These results indicate that the inflection point depth varies from $-2.3 \mathrm{ft}$ to 23.5 $\mathrm{ft}$.

The location where lateral movement of the pile does not occur was also determined. A comparison of the depth that provides zero lateral displacement is presented in Table 4.8. The depths that provide zero lateral displacement do not change significantly. On average, this depth was calculated as $28.5 \mathrm{ft}$.

\subsection{Moment vs. Depth}

The moments along the pile length for Bents 1 and 11 are presented in Figures 4.13 and 4.14, respectively. The results indicate good correlation between the two analysis methods. The moments at ground level obtained from both analyses were compared with calculated moments from strain gages on Pile 5 of Bent 1 and Pile 2 of Bent 11 as tabulated in Table 4.9. Since strain gages on piles were zeroed and started reading after the bridge was cast, all strain values are relative. The strain values were assumed to be caused by flexure only. Strain on the opposite face of the pile was assumed to equal to the same value as the strain read by the gage on the other face but of different sign. The values of strains on the coldest day (December 22, 2000 at 8:00AM) were approximately $240 \mu \varepsilon$ and $800 \mu \varepsilon$ of Bents 1 and 11, respectively. Based on these assumptions, moments at ground level were calculated to be $75 \mathrm{ft}-\mathrm{k}$ on Bent 1 and 250 $\mathrm{ft}-\mathrm{k}$ on Bent 11. One can note that the strain gage on Pile 2 of Bent 11 was not reliable because strain decreased very significantly compared to that of Pile 5 of Bent 1 during cold weather and changed to approximately the same value of strain of Bent 1 during warm weather as indicated in Figure 3.15. Therefore, only moment calculated from the strain gage on Pile 5 of Bent 1 will be considered. It appears that the moments at ground level calculated based on the strain gage measurement is between those calculated based

on the roller- and fixed-support models. However, this abutment-pile connection behaves closer to a hinged connection rather than a fixed connection. 


\section{Lateral Deflection (in.)}

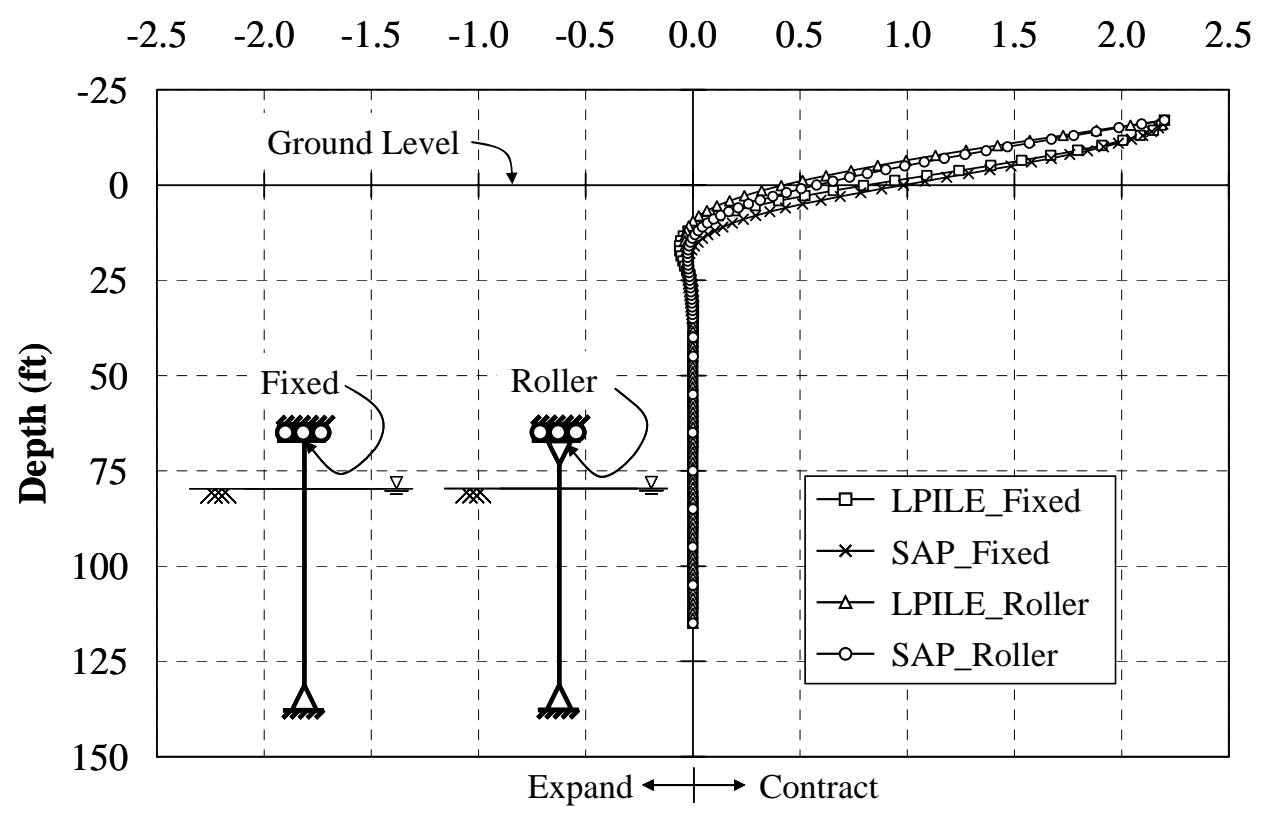

Figure 4.11: Deflected Shape of the Pile of Bent 1 (SR249 over US12)

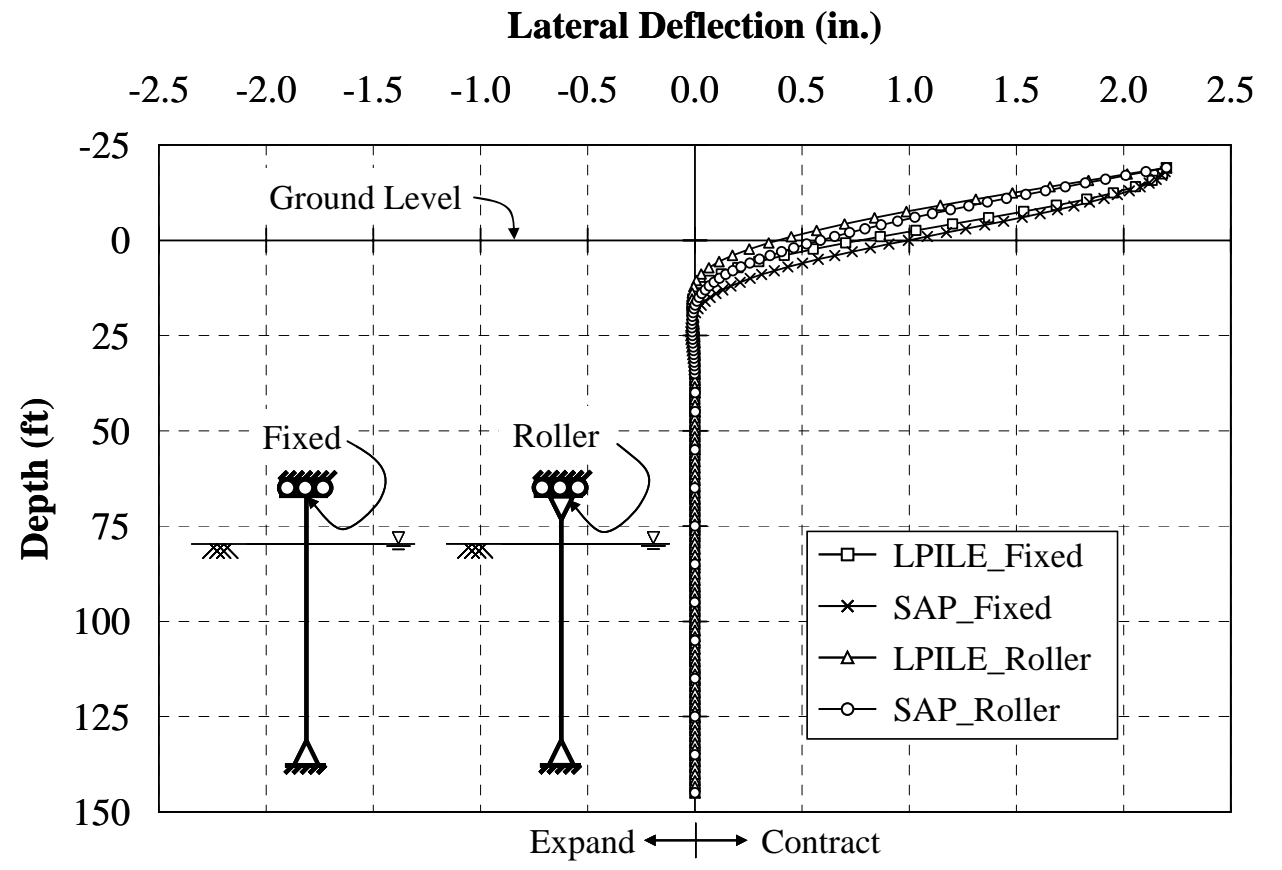

Figure 4.12: Deflected Shape of the Pile of Bent 11 (SR249 over US12) 
Table 4.7: Inflection Point (SR249 over US12)

\begin{tabular}{|c|c|c|c|}
\hline \multirow{2}{*}{ Bent } & \multicolumn{3}{|c|}{ Inflection Point for Roller Model ${ }^{*}$ (ft) } \\
\cline { 2 - 4 } & LPILE & SAP & Average \\
\hline 1 & 19.7 & 24.0 & 21.9 \\
\hline 11 & 19.1 & 27.9 & 23.5 \\
\hline
\end{tabular}

\begin{tabular}{|c|c|c|c|}
\hline \multirow{2}{*}{ Bent } & \multicolumn{3}{|c|}{ Inflection Point for Fixed Model ${ }^{*}$ (ft) } \\
\cline { 2 - 4 } & LPILE & SAP & Average \\
\hline 1 & -2.7 & -1.8 & -2.3 \\
\hline 11 & -3.7 & -2.1 & -2.9 \\
\hline
\end{tabular}

${ }^{*}$ Depths measured from ground surface. Positive indicates depth below ground

Table 4.8: Depth of Zero Lateral Displacement (SR249 over US12)

\begin{tabular}{|c|c|c|c|}
\hline \multirow{2}{*}{ Bent } & \multicolumn{3}{|c|}{ Depth of Zero Lateral Displacement for Roller Models (ft) } \\
\cline { 2 - 4 } & LPILE & SAP & Average \\
\hline 1 & 23.9 & 31.0 & 27.5 \\
\hline 11 & 22.0 & 30.0 & 26.0 \\
\hline
\end{tabular}

\begin{tabular}{|c|c|c|c|}
\hline \multirow{2}{*}{ Bent } & \multicolumn{3}{|c|}{ Depth of Zero Lateral Displacement for Fixed Models (ft) } \\
\cline { 2 - 4 } & LPILE & SAP & Average \\
\hline 1 & 27.9 & 35.0 & 31.5 \\
\hline 11 & 25.3 & 33.0 & 29.2 \\
\hline
\end{tabular}




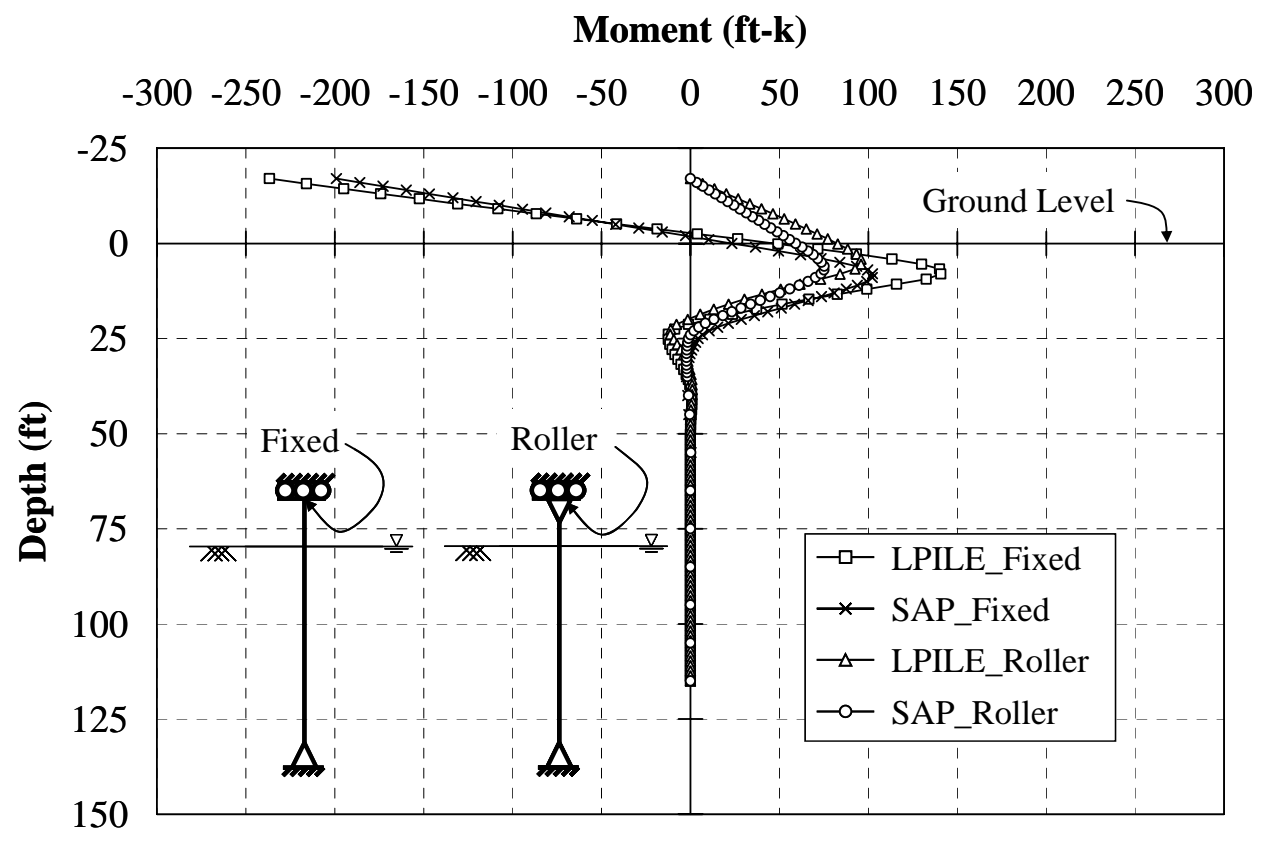

Figure 4.13: Moment vs. Depth of the Pile of Bent 1 (SR249 over US12)

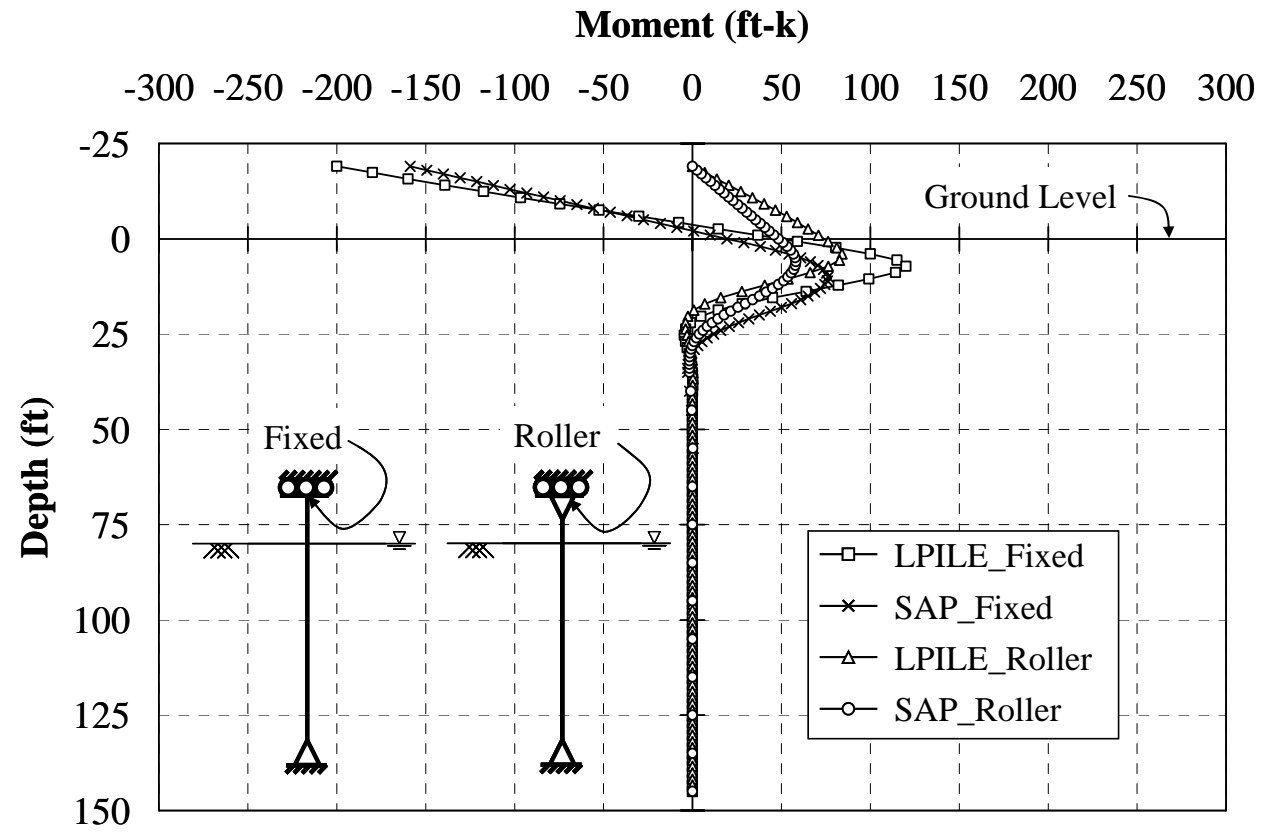

Figure 4.14: Moment vs. Depth of the Pile of Bent 11 (SR249 over US12) 
Table 4.9: Moments at Ground Level (SR249 over US12)

\begin{tabular}{|c|c|c|c|}
\hline \multirow{2}{*}{ Bent } & \multicolumn{3}{|c|}{ Moment at Ground Level of Roller Models (ft-k) } \\
\cline { 2 - 4 } & LPILE & SAP & Strain Gage \\
\hline 1 & 82 & 59 & 75 \\
\hline 11 & 74 & 48 & $253^{*}$ \\
\hline
\end{tabular}

\begin{tabular}{|c|c|c|c|}
\hline \multirow{2}{*}{ Bent } & \multicolumn{3}{|c|}{ Moment at Ground Level of Fixed Models (ft-k) } \\
\cline { 2 - 4 } & LPILE & SAP & Strain Gage \\
\hline 1 & 47 & 23 & 75 \\
\hline 11 & 50 & 19 & $253^{*}$ \\
\hline
\end{tabular}

* Questionable Value

\subsubsection{I65 over SR25 Bridges}

Due to insufficient field data to verify the deflected shape of the pile supporting the end bents, the deflected shape cannot be estimated using the field data. However, the estimated deflected shapes from the LPILE PLUS and SAP2000 analyses are presented and compared. In addition, the magnitude of strains at the base of the abutment is compared with the analytical results.

\subsubsection{Pile Model}

HP12x53 piles bending about their weak axis and CFT14.5x0.25 piles were modeled for the piles supporting the end bent. An approximate total pile length of all end bents is $42 \mathrm{ft}$, and the piles were embedded $2 \mathrm{ft}$ in the abutment; therefore, the pile length below ground level is $40 \mathrm{ft}$. According to Durbin (2001), since the abutments only translate over temperature change, only the pile length below ground line will be considered.

The pile was modeled having a horizontally-guided support at the top and a pin connection at the bottom as illustrated in Figure 4.15. The total axial load applied on the ten piles of each bent is 156 kips according to bridge design calculations (Section 2.3.1.2). The $H$ piles were subjected to an axial load of 11.1 kips, while the CFT piles were subjected to an axial load of 21.9 kips based on the axial stiffness of each pile. The piles were subjected to a lateral movement of 0.55 in. calculated by Equation 4-17, 


$$
\Delta \mathrm{L}=\alpha(\Delta \mathrm{T}) \mathrm{L}
$$

where:

$\alpha=$ coefficient of thermal expansion for steel taken as $6.5 \times 10^{-6} /{ }^{\circ} \mathrm{F}$.

$\Delta \mathrm{T} \quad=$ temperature change of $92^{\circ} \mathrm{F}$ taken on the coldest day for the northbound structure (December 25, 2000 at 19:00).

$\mathrm{L}=\quad=$ half of the total bridge length, taken as $152 \mathrm{ft} / 2=76 \mathrm{ft}$.

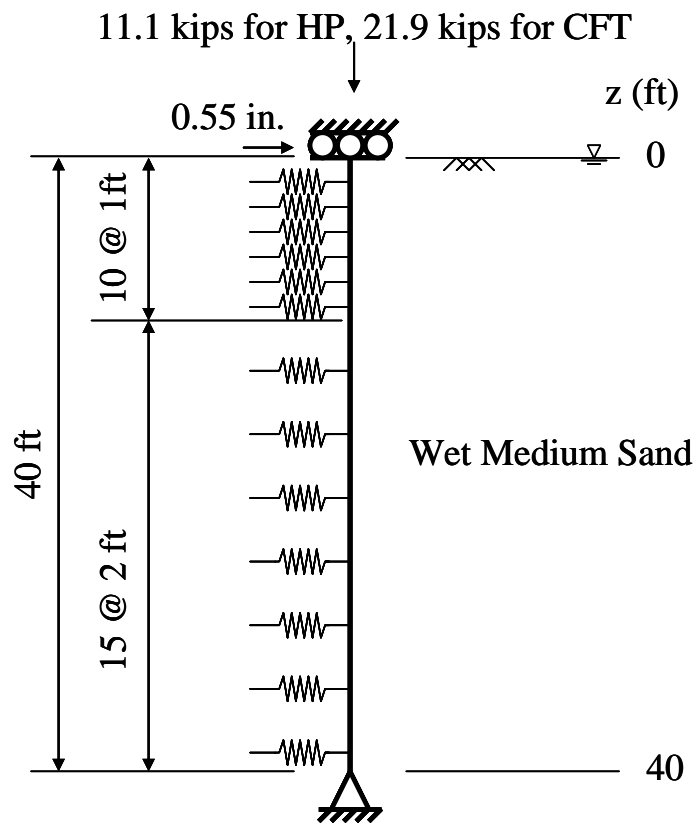

Figure 4.15: Pile Model (I65 over SR25)

For the LPILE PLUS model, the equivalent area and moment of inertia of the CFT piles and the equivalent diameter of the $\mathrm{H}$ piles were computed and are listed in Table 4.10. The specified compressive strength of concrete, $\mathrm{f}_{\mathrm{c}}^{\prime}$ is taken as 4,000 psi (INDOT Class C concrete), and the specified yield strength of steel is taken as $60 \mathrm{ksi}$ for the $\mathrm{H}$ piles and $35 \mathrm{ksi}$ for the CFT piles, respectively. The modulus of elasticity of concrete and steel is assumed to be 3,605 ksi and 29,000 ksi, respectively. 
Table 4.10: Summary of Pile Properties for LPILE

\begin{tabular}{|c|c|c|c|}
\hline Pile Section & A (in. ${ }^{2}$ ) & d (in.) & I (in. ${ }^{\mathbf{4}}$ ) \\
\hline HP12x53 & 15.5 & $11.8^{*}$ & 127 \\
\hline CFT & $30.3^{* *}$ & 14.5 & $519^{* *}$ \\
\hline
\end{tabular}

For the SAP2000 model, cross-sectional properties are required. The H pile cross section properties are provided in Table 4.11, and the CFT pile cross section properties are provided in Table 4.12.

Table 4.11: Cross Section Properties of HP12x53

\begin{tabular}{|c|c|c|c|c|c|c|c|c|c|c|c|}
\hline & A & d & $\mathbf{t}_{\mathrm{w}}$ & $\mathbf{b}_{\mathbf{f}}$ & $\mathbf{t}_{\mathbf{f}}$ & $\begin{array}{c}I_{x} \\
\left(\text { in. }^{4}\right)\end{array}$ & $\begin{array}{c}I_{y} \\
\left(\text { (in. }^{4}\right)\end{array}$ & $\begin{array}{c}S_{x} \\
\left(\text { in. }^{3}\right)\end{array}$ & $S_{y}$ & $\mathbf{Z}_{\mathbf{x}}$ & $\mathbf{Z}_{\mathbf{y}}$ \\
\hline & 5.5 & 11.0 & | & 12.0 & טJד. & 393 & 12 & 0. & 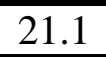 & $\cdots$ & \\
\hline
\end{tabular}

Table 4.12: Cross Section Properties of CFT14.5x0.25

\begin{tabular}{|c|c|c|c|}
\hline Pile Section & $\begin{array}{c}\text { Outer } \\
\text { Diameter (in.) }\end{array}$ & $\begin{array}{c}\text { Inner } \\
\text { Diameter (in.) }\end{array}$ & $\begin{array}{c}\text { Wall Thickness } \\
\text { (in.) }\end{array}$ \\
\hline CFT14.5x0.25 & 14.5 & 14.0 & 0.25 \\
\hline
\end{tabular}

\subsubsection{Soil Model}

The analysis models considered the HP12x53 and CFT14.5 piles embedded $40 \mathrm{ft}$ in a medium density sand. Elastic springs were placed along the pile length to represent soil resistance. For this analysis, the ground water table was assumed to be at ground level, and the effective unit weight of medium sand was therefore assumed to be $60 \mathrm{lb} / \mathrm{ft}^{3}$. One can note that the actual ground water table varied from $6.5 \mathrm{ft}$ to $22.5 \mathrm{ft}$ below ground level. A summary of the soil properties for both LPILE PLUS and SAP2000 models is listed in Table 4.13. For the SAP2000 models, elastic springs were placed on the pile elements every foot for the first $10 \mathrm{ft}$ below the ground level and every $2 \mathrm{ft}$ for the next $30 \mathrm{ft}$ as indicated in Figure 4.15. The soil spring stiffness was determined according to Section 4.4.2.2 and is listed in Appendix G. 
Table 4.13: Soil Properties (I65 over SR25)

\begin{tabular}{|c|c|c|c|c|c|}
\hline $\begin{array}{c}\text { Begin } \\
\text { Depth } \\
\text { (ft) }\end{array}$ & $\begin{array}{c}\text { End } \\
\text { Depth } \\
\text { (ft) }\end{array}$ & Soil Type & $\begin{array}{c}\gamma \\
\left(\mathbf{l b} / \mathbf{f} \mathbf{t}^{3}\right.\end{array}$ & $\begin{array}{c}\mathbf{k} \\
\left(\mathbf{l b} / \mathbf{i n} .^{3}\right)\end{array}$ & $\begin{array}{c}\phi \\
\text { (degrees) }\end{array}$ \\
\hline$\overline{0}$ & 40 & Med. Sand & 60 & 60 & 35 \\
\hline
\end{tabular}

\subsubsection{Results}

\subsection{Deflected Shapes}

The deflected shapes of the $\mathrm{H}$ and CFT piles are presented in Figures 4.16 and 4.17, respectively. For both pile types, the deflected shapes from LPILE PLUS and SAP2000 provide good correlation. Again, it should be noted that the soil models in LPILE PLUS are slightly stiffer than those used for the SAP2000 analysis. As shown in Table 4.14, the inflection points for both models are fairly constant with an average of 4.6 $\mathrm{ft}$ for the $\mathrm{H}$ piles and $6.1 \mathrm{ft}$ for the CFT piles. The depths of zero lateral displacement are listed in Table 4.15. The depth of zero displacement based on the SAP2000 analysis is deeper than that based on LPILE PLUS. 


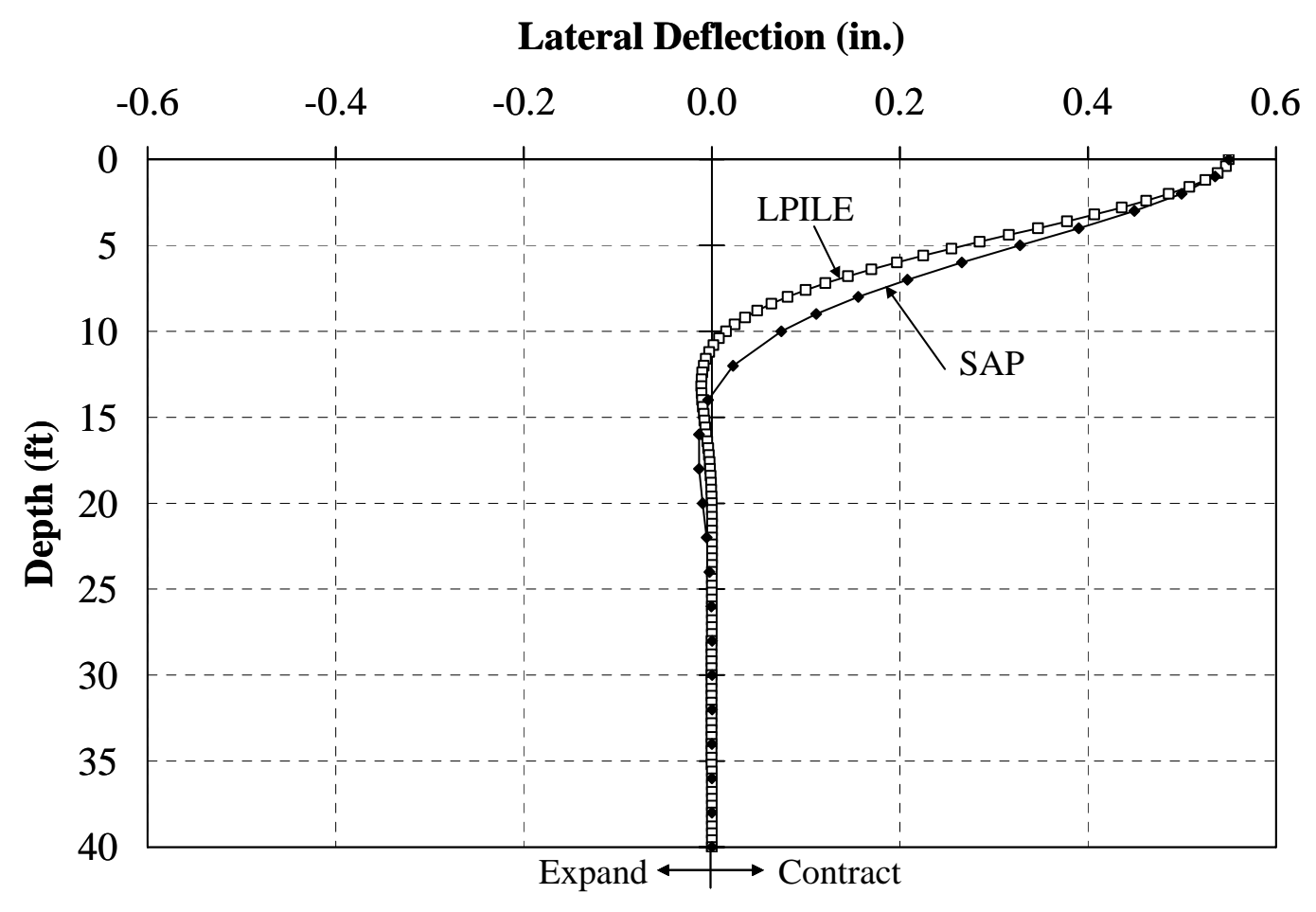

Figure 4.16: Deflected Shape of the H Pile (I65 over SR25)

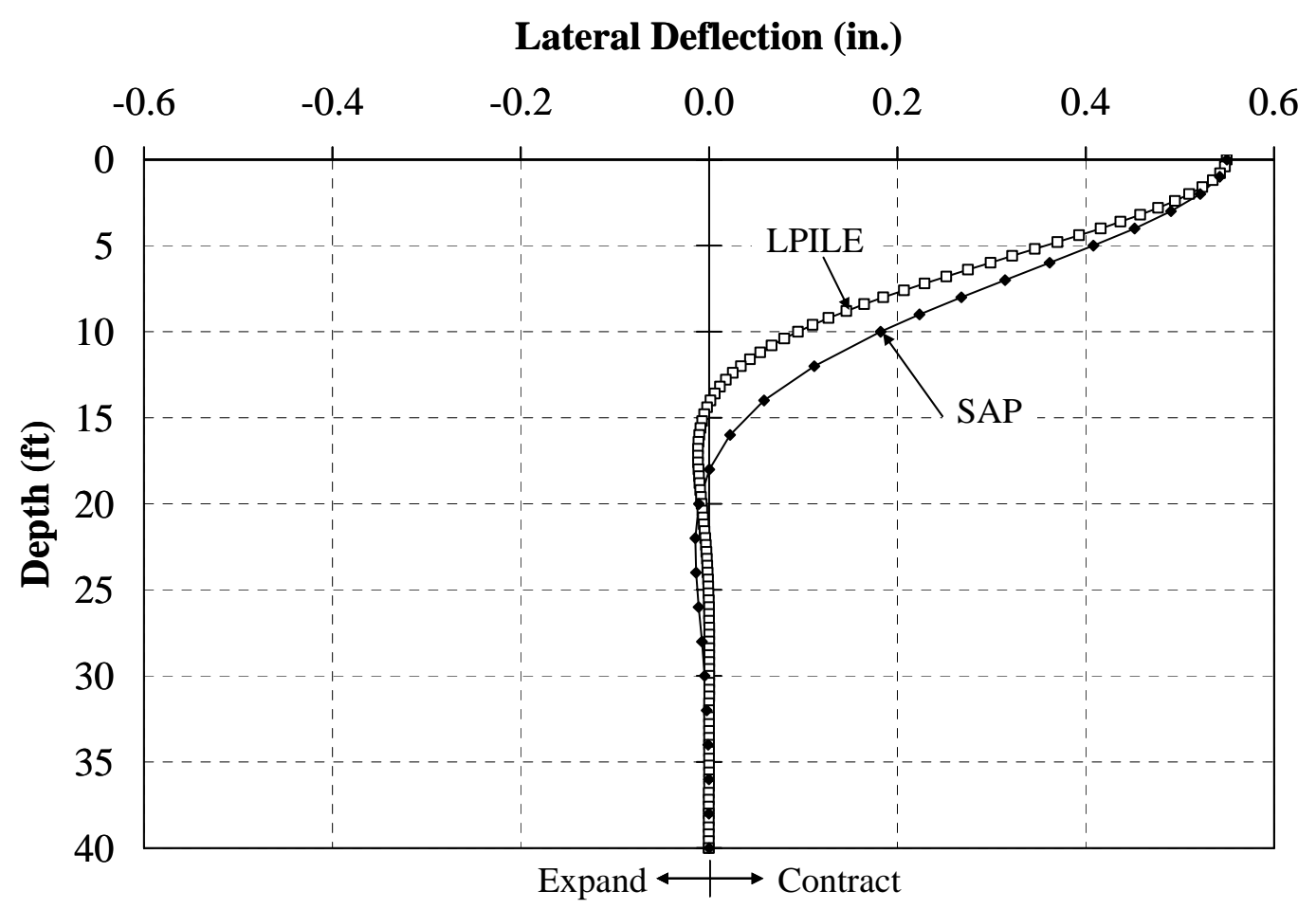

Figure 4.17: Deflected Shape of the CFT Pile (I65 over SR25) 
Table 4.14: Inflection Point (I65 over SR25)

\begin{tabular}{|c|c|c|c|}
\hline \multirow{2}{*}{ Pile Section } & \multicolumn{3}{|c|}{ Inflection Point (ft) } \\
\cline { 2 - 4 } & LPILE & SAP & Average \\
\hline HP12x53 & 4.3 & 4.9 & 4.6 \\
\hline CFT14.5 & 5.6 & 6.5 & 6.1 \\
\hline
\end{tabular}

Table 4.15: Depth of Zero Lateral Displacement (I65 over SR25)

\begin{tabular}{|c|c|c|c|}
\hline \multirow{2}{*}{ Pile Section } & \multicolumn{3}{|c|}{ Depth of Zero Lateral Displacement (ft) } \\
\cline { 2 - 4 } & LPILE & SAP & Average \\
\hline HP12x53 & 16.4 & 23.0 & 19.7 \\
\hline CFT14.5 & 21.6 & 29.0 & 25.3 \\
\hline
\end{tabular}

\subsection{Moment vs. Depth}

The moments along the pile length for the $\mathrm{H}$ and CFT piles calculated using LPILE PLUS and SAP2000 are presented in Figures 4.18 and 4.19, respectively. The moment curves obtained by both analysis methods have the same trend. The moments calculated using LPILE PLUS are slightly higher than analyzed using SAP2000. This results from the smaller depth of zero displacement noted in the LPILE analysis. The depth that the pile does not rotate, defined as the depth of zero rotation, is listed in Table 4.16. As shown, the depth of zero rotation is approximately the same according to both methods. A comparison of the moments at ground level is tabulated in Table 4.17. The moments at ground level calculated from strain gages on Piles 2, 6, and 7 of the south end of the northbound structure are $-28,-10$, and $8 \mathrm{ft}-\mathrm{k}$ which are much less than the moments calculated based on this analysis. It should be noted that Piles 2 and 6 of the south end of the northbound structure are $\mathrm{H}$ piles, while Pile 7 is a CFT pile. The difference in moments is likely due to softening of the soil surrounding the piles caused by cyclic response or possible softening of the abutment-pile connection. 


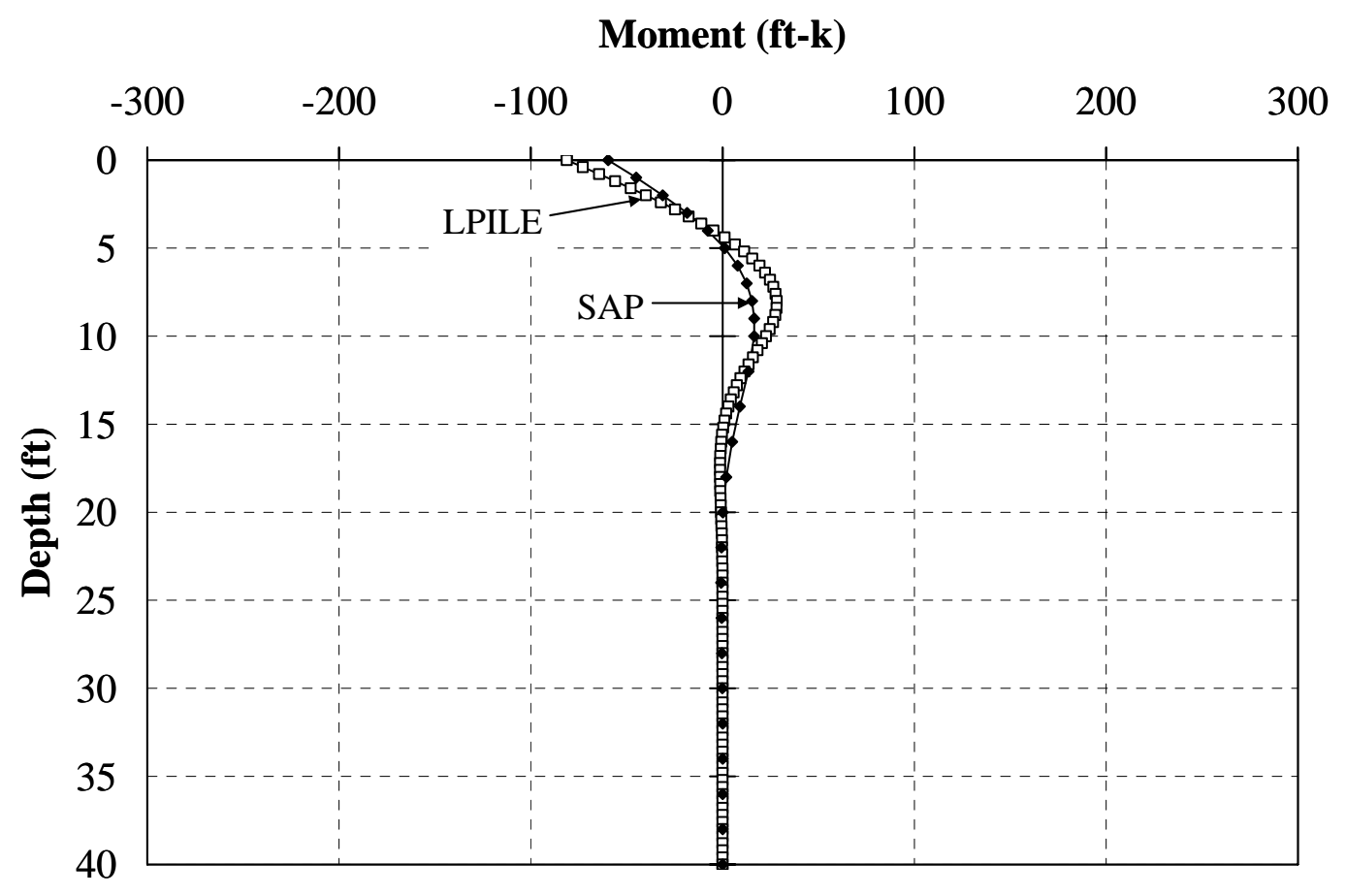

Figure 4.18: Moment vs. Depth of the H Pile (I65 over SR25)

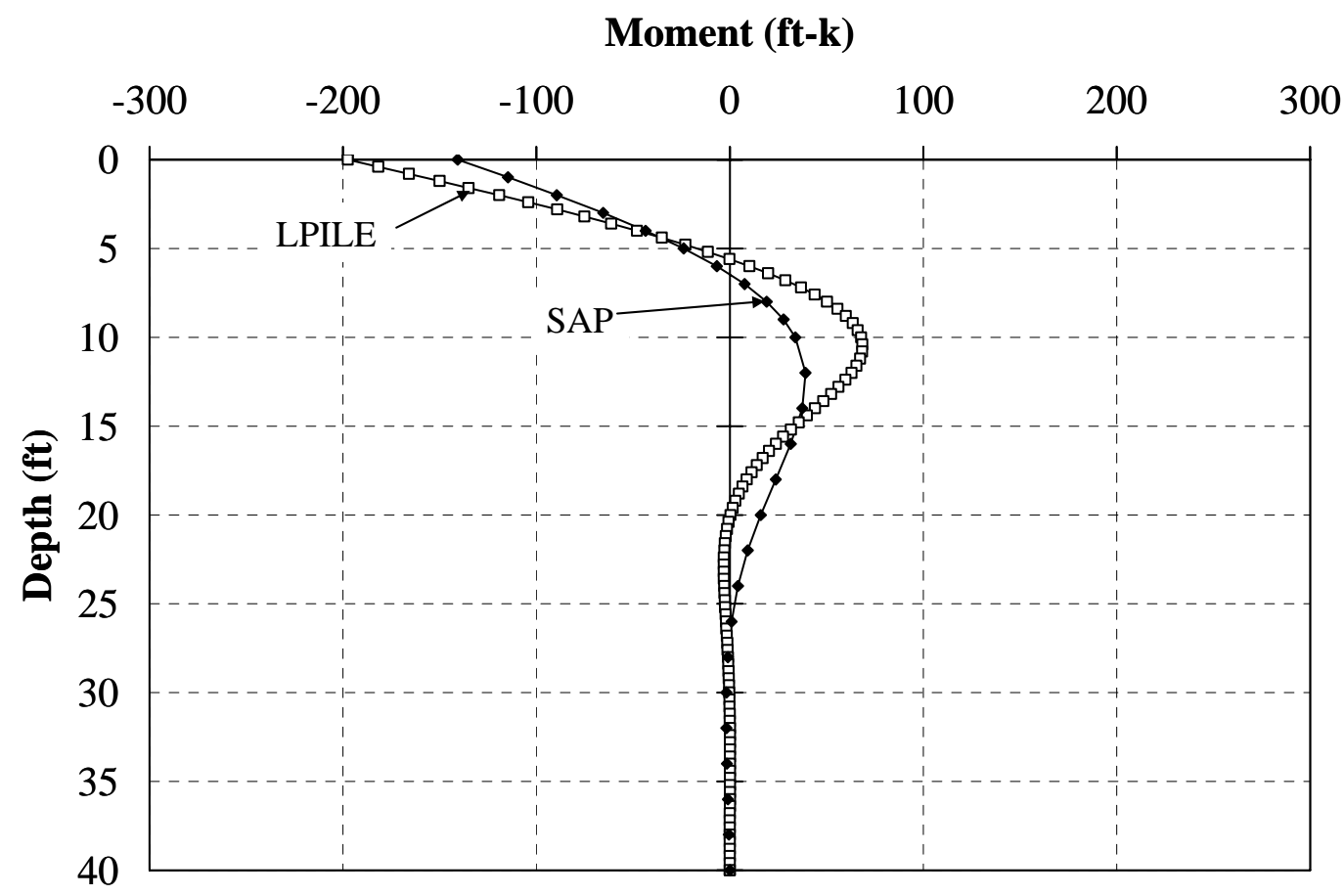

Figure 4.19: Moment vs. Depth of the CFT Pile (I65 over SR25) 
Table 4.16: The Depth of Zero Rotation (I65 over SR25)

\begin{tabular}{|c|c|c|c|}
\hline \multirow{2}{*}{ Pile Section } & \multicolumn{3}{|c|}{ Depth of Zero Rotation (ft) } \\
\cline { 2 - 4 } & LPILE & SAP & Average \\
\hline HP12x53 & 20.0 & 20.0 & 20.0 \\
\hline CFT14.5 & 28.0 & 27.0 & 27.5 \\
\hline
\end{tabular}

Table 4.17: Moments at Ground Level (I65 over SR25)

\begin{tabular}{|c|c|c|c|}
\hline \multirow{2}{*}{ Pile Section } & \multicolumn{3}{|c|}{ Moment at Ground Level (ft-k) } \\
\cline { 2 - 4 } & LPILE & SAP & Average \\
\hline HP12x53 & -81 & -60 & -70 \\
\hline CFT14.5 & -198 & -141 & -169 \\
\hline
\end{tabular}

\subsubsection{SR18 over Mississinewa River Bridge}

Pile 6 of Bent 1 was modeled in two different soil types. The deflected shapes and moments along the length of the pile were calculated using LPILE PLUS and SAP2000 and compared. Due to nearly complete strain data obtained along the length of this pile, the calculated deflections and moments were also compared with the deflections and moments calculated using strain data from the bridge.

\subsubsection{Pile Model}

The 14-in. concrete-filled steel tube pile having a 14-in. outer diameter and 0.312in. wall thickness (CFT14.0x0.312) was modeled. The total length of the pile as driven in the field is $23.50 \mathrm{ft}$. The pile was embedded $15 \mathrm{in}$. into the abutment, and thus the pile length below ground level is $22.25 \mathrm{ft}$ (267 in.). This value was used in the analysis (Figure 4.20). The specified compressive strength of concrete was 4,000 psi (INDOT Class C), while the specified yield strength of steel was $35 \mathrm{ksi}$ according the ASTM A252 Grade 2 steel. The modulus of elasticity of concrete and steel are 3,605 ksi and 29,000 ksi, respectively.

The CFT14 pile was modeled having a horizontally-guided support at the top and a hinge at the bottom as illustrated in Figure 4.20. The pile was subjected to axial load of 
80 kips according to bridge design calculations (Section 2.4.1.2) and a lateral movement of $0.38 \mathrm{in}$. based on measurements provided by the convergence meter at $0^{\circ} \mathrm{F}$ (maximum temperature change, $\Delta \mathrm{T}=-60^{\circ} \mathrm{F}$ ).

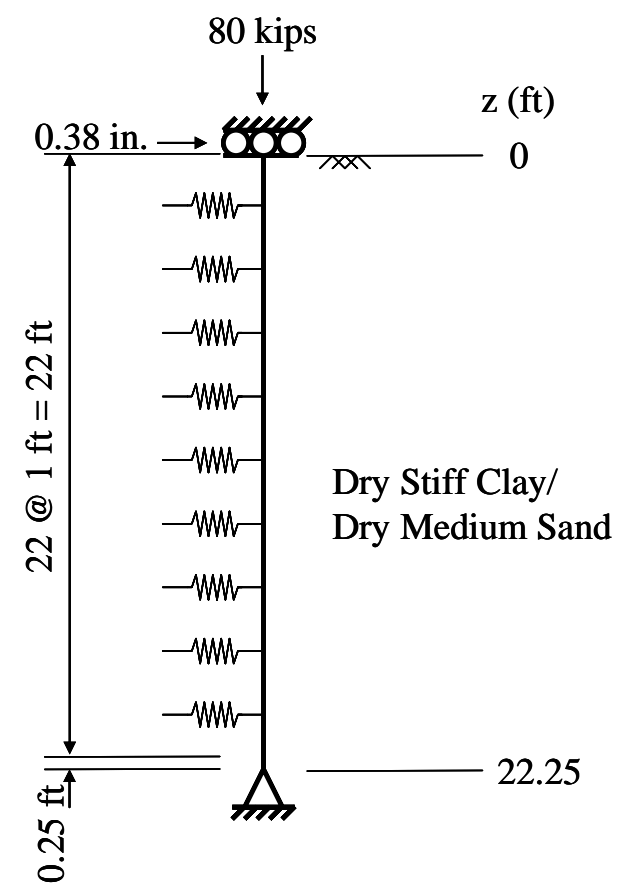

Figure 4.20: Pile Model (SR18)

For both LPILE PLUS and SAP2000 models, the transformed section of CFT pile was needed. The equivalent area, outer diameter, and moment of inertia of the equivalent steel section were computed and are listed in Table 4.18

Table 4.18: Cross Section Properties of CFT14

\begin{tabular}{|c|c|c|c|}
\hline Pile Section & $\mathbf{A}_{\mathbf{e}}$ (in. $^{2}$ ) & $\mathbf{d}$ (in.) & $\mathbf{I}_{\mathbf{e}}$ (in. $^{\mathbf{4}}$ ) \\
\hline CFT14.0x0.312 & 30.9 & 14.0 & 510 \\
\hline
\end{tabular}

\subsubsection{Soil Model}

Soils surrounding the pile consist of mostly silt, which is a combination of sand and clay. Soil spring models are not available in the present literature; therefore, two different analysis cases were considered. The first case considered is dry medium density 
sand, and the second case is dry stiff clay. These cases were considered most similar to the in-site strength of soil as obtained from the soil borings. For each case, soil surrounds the pile from ground level to the bottom of the pile. The ground water level was measured deeper than $22.25 \mathrm{ft}$ from ground level. Therefore, the unit weight of dry medium sand and dry stiff clay is assumed to be $120 \mathrm{lb} / \mathrm{ft}^{3}{ }^{3}$ The soil properties tabulated in Table 4.19 are used for both the LPILE and SAP models. For SAP models, elastic springs were placed on the pile elements every foot along the pile length as indicated in Figure 4.20. The soil spring stiffnesses were calculated according to Section 4.4.2 and are provided in Appendix G.

Table 4.19: Soil Properties (SR18)

\begin{tabular}{|c|c|c|c|c|c|c|c|c|}
\hline Case & $\begin{array}{c}\text { Begin } \\
\text { Depth } \\
\text { (ft) }\end{array}$ & $\begin{array}{c}\text { End } \\
\text { Depth } \\
(\mathrm{ft})\end{array}$ & Soil Type & $\begin{array}{c}\gamma \\
\left(\mathbf{l b} / \mathbf{f t}^{3}\right)\end{array}$ & $\begin{array}{c}\mathbf{k} \\
\left(\mathbf{l b} / \mathbf{i n} .^{3}\right)\end{array}$ & $\begin{array}{c}\phi \\
\text { (degrees) }\end{array}$ & $\left|\begin{array}{c}\mathbf{c}_{\mathbf{u}} \\
\left(\mathbf{l b} / \mathbf{i n}^{2}{ }^{2}\right)\end{array}\right|$ & $\begin{array}{c}\varepsilon_{50} \\
\text { (in./in.) }\end{array}$ \\
\hline $\bar{I}$ & $\overline{0}$ & 22.25 & Med. Sand & $\overline{120}$ & 60 & 35 & - & - \\
\hline II & $\overline{0}$ & 22.25 & \begin{tabular}{|l|} 
Stiff Clay \\
\end{tabular} & 120 & 500 & - & 10.4 & 0.01 \\
\hline
\end{tabular}

\subsubsection{Results}

\subsection{Deflected Shapes}

Comparisons of the deflected shapes of the pile embedded in dry medium sand and dry stiff clay are presented in Figures 4.21 and 4.22, respectively. The deflected shapes calculated using LPILE PLUS and SAP2000 correlate very well. The model for both dry medium sand and dry stiff clay used in LPILE PLUS is slightly stiffer than that used in the SAP2000 analysis. It can be seen that both models slightly underestimate the measured deflected shape for both soil types. It can be concluded, however, that the analytical results in general are in excellent agreement with the results from the strain gages. The inflection points are tabulated in Table 4.20. The inflection points obtained from the two models are fairly constant. On average, the inflection point is located approximately $5 \mathrm{ft}$ from the ground level which corresponds to the location of inflection point expected based on the strain gage measurements. 
Lateral Deflection (in.)

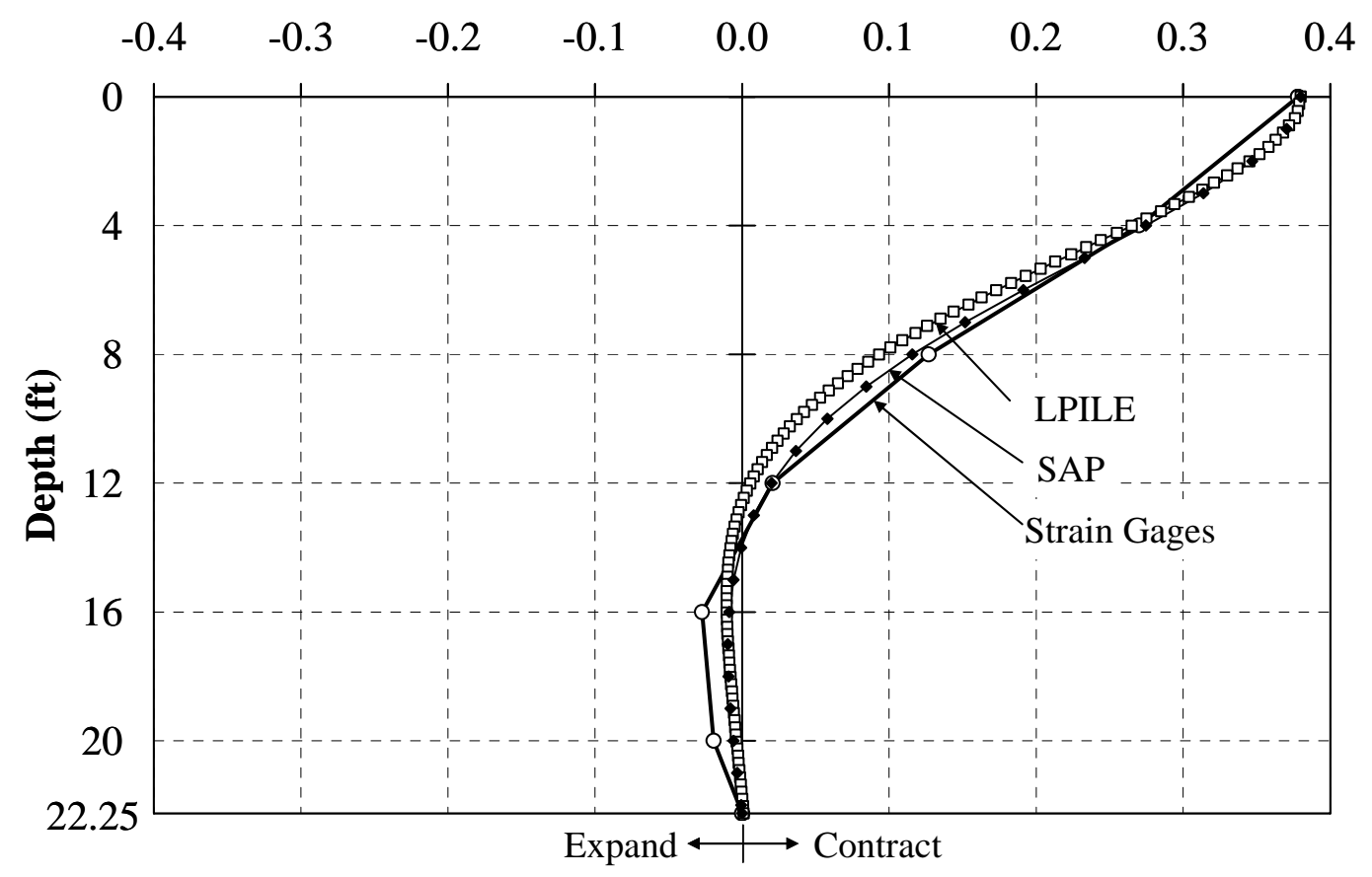

Figure 4.21: Deflected Shape of the Pile surrounding in Dry Medium Sand (SR18)

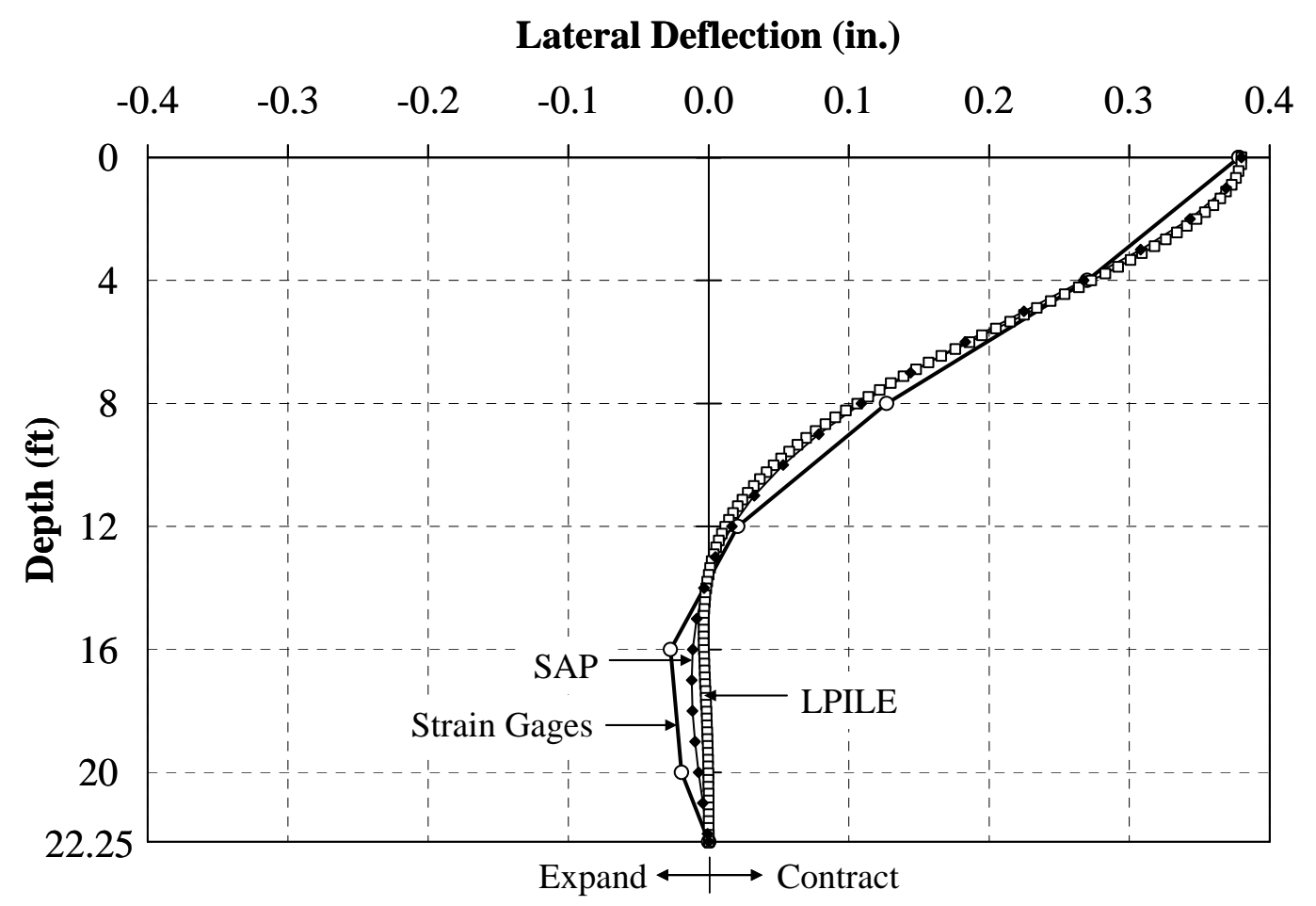

Figure 4.22: Deflected Shape of the Pile surrounding in Dry Stiff Clay (SR18) 
Table 4.20: Inflection Point (SR18)

\begin{tabular}{|c|c|c|c|c|}
\hline \multirow{2}{*}{ Soil Type } & \multicolumn{4}{|c|}{ Inflection Point (ft) } \\
\cline { 2 - 5 } & LPILE & SAP & Average & Strain Gages \\
\hline Dry Medium Sand & 4.8 & 5.0 & 4.9 & Between 4 and 8 \\
\hline Dry Stiff Clay & 5.1 & 4.7 & 4.9 & Between 4 and 8 \\
\hline
\end{tabular}

\subsection{Moment vs. Depth}

Moments along the pile length calculated using LPILE PLUS and SAP2000 are presented in Figures 4.23 and 4.24, respectively. Moments calculated using both analysis methods provide the same trend. The results indicate that above the depth of approximately $13 \mathrm{ft}$, both dry medium sand and dry stiff clay models used in LPILE PLUS is slightly stiffer than that used in the SAP2000 analysis. The strain gage measurements also suggest that the soil spring stiffnesses are overestimated. Below the depth of approximately $13 \mathrm{ft}$, both soil models used in LPILE PLUS are less stiff than that used in the SAP2000 analysis and that determined from the strain gage measurements. Moments at ground level estimated using the two models were compared to the moments calculated using measured strains from Pile 6 as shown in Table 4.21. For both soil cases, the results show that the calculated moments at ground level using strain values are approximately 50\% less than those obtained based on analysis. The difference may be caused by softening of the soil near ground level or softening of the abutment-pile connection which reduces the moment at ground level. It can be observed that above a depth of approximately $13 \mathrm{ft}$, the analyses overestimated the bending moments while they underestimated the moment below this depth.

Based on these results, it appears that from ground level to a depth of approximately $13 \mathrm{ft}$, the analytical soil models are slightly stiffer than the actual soils in the field while below a depth of approximately $13 \mathrm{ft}$, the soil models are softer than those present in the field. Overall, both analysis methods calculated the deflected shapes well. However, the bending moment was slightly overestimate. 


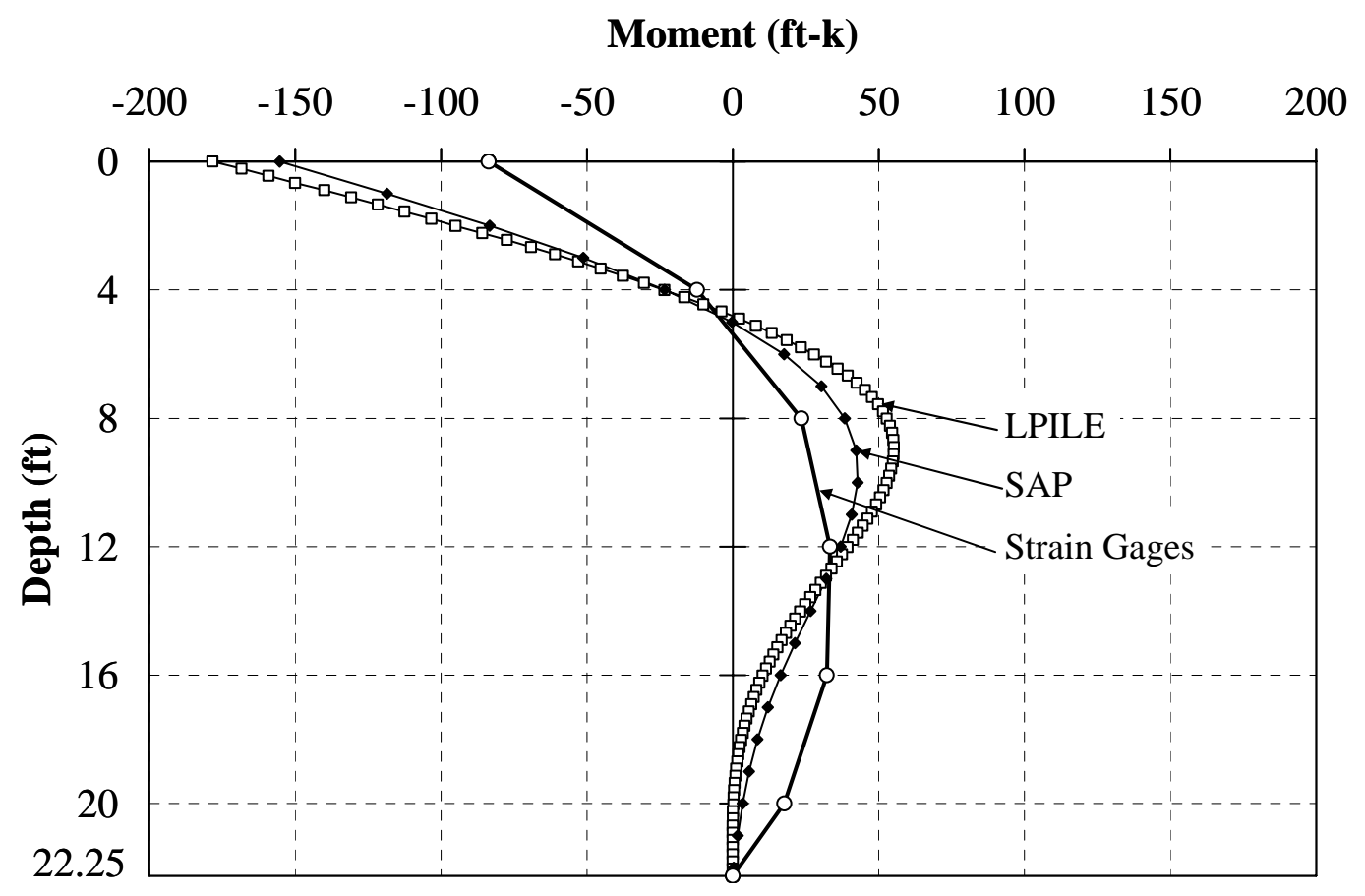

Figure 4.23: Moment vs. Depth of the Pile in Dry Medium Sand (SR18)

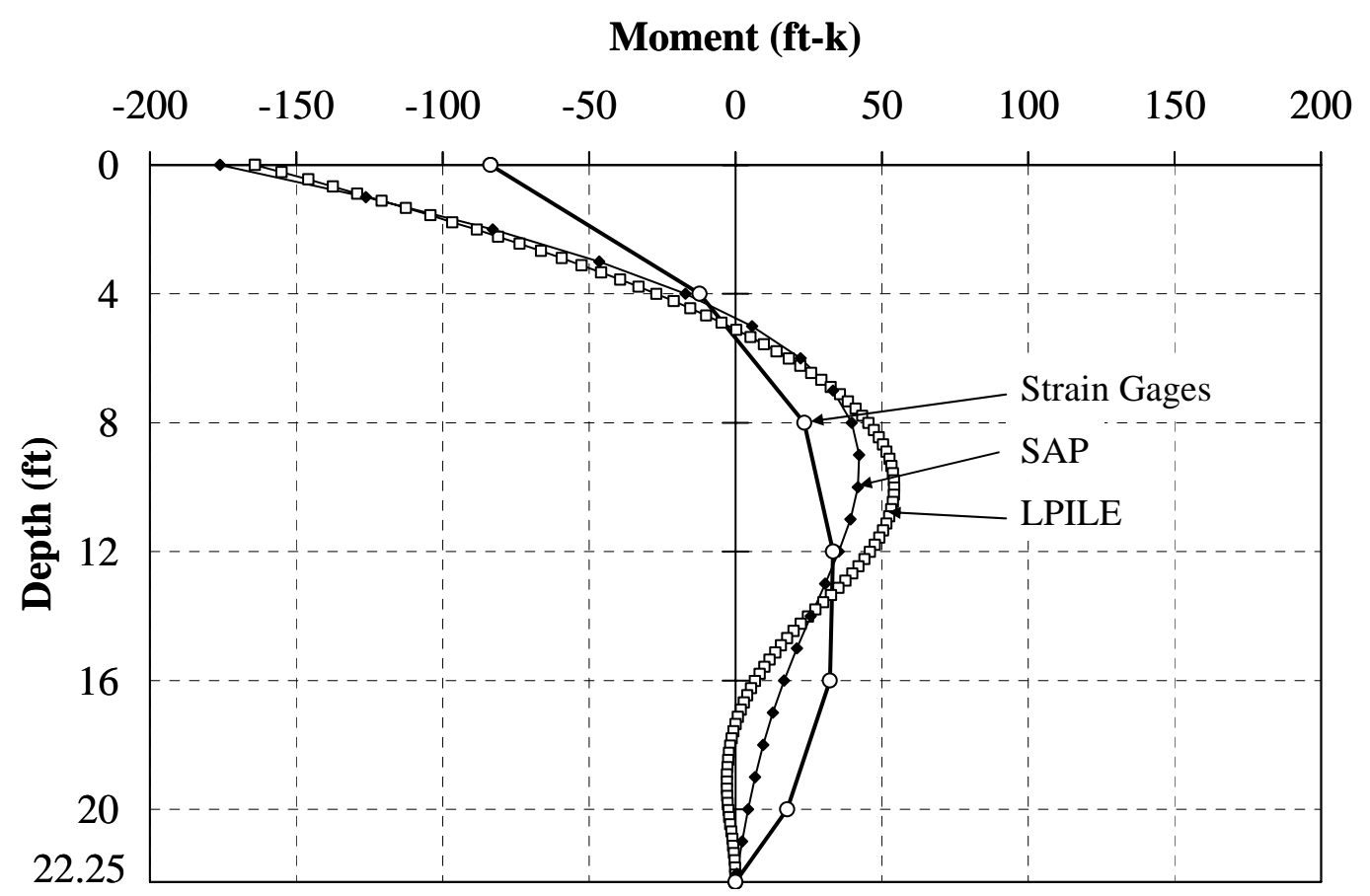

Figure 4.24: Moment vs. Depth of the Pile in Dry Stiff Clay (SR18) 
Table 4.21: Moment at Ground Level (SR18)

\begin{tabular}{|c|c|c|c|c|}
\hline \multirow{2}{*}{ Soil Type } & \multicolumn{4}{|c|}{ Moment at Ground Level (ft-k) } \\
\cline { 2 - 5 } & LPILE & SAP & Average & Strain Gages \\
\hline Dry Medium Sand & 178 & 155 & 167 & 84 \\
\hline Dry Stiff Clay & 164 & 176 & 170 & 84 \\
\hline
\end{tabular}

\subsection{Parametric Study}

To evaluate the behavior of typical piles used in Indiana bridge construction, piles were modeled with a horizontally-guided support at the top of the pile. This support condition is representative of normal abutment-pile connection details and provides a reasonable model of actual behavior. According to the results described earlier in this chapter, LPILE PLUS provides results approximately the same as from the SAP2000 analysis. Therefore, all parametric studies were performed using LPILE PLUS due to the ease of use of this analysis package.

\subsubsection{Variables}

The parametric study investigated the effect of the following variables: lateral displacement, axial load, pile length, pile type, pile orientation, and soil type.

\subsubsection{Lateral Displacement}

Lateral movements, $\Delta \mathrm{L}$, of 1,2 , and 4 in. were investigated for all pile models unless otherwise stated. These lateral movements were calculated based on Equation 4-17,

$$
\Delta \mathrm{L}=\alpha(\Delta \mathrm{T}) \mathrm{L}
$$

where:

$\alpha=$ coefficient of thermal expansion of steel, taken as $6.5 \times 10^{-6} /{ }^{\circ} \mathrm{F}$.

$\Delta \mathrm{T}=$ temperature change, taken as 25,50 , and $100^{\circ} \mathrm{F}$.

$\mathrm{L}=$ half of the total bridge length, taken as $1000 \mathrm{ft} / 2=500 \mathrm{ft}$. 


\subsubsection{Axial Load}

According to INDOT Memorandum \#233 (INDOT, 1992a), piles used in integral end bents shall be stressed to no more than $9 \mathrm{ksi}$. To evaluate the effect of the axial load, axial stresses of 0,9 , and 18 ksi were investigated unless otherwise stated.

\subsubsection{Pile Length}

In typical bridge construction, piles are driven until they reach a hard soil layer or their required bearing capacity. Even though the pile reaches a given depth based on axial capacity, the pile length may not be long enough to provide fixity at the bottom of the pile considering lateral displacements. To evaluate the appropriate length, L, such that the pile does not displace or rotate at the bottom, piles with lengths varying from 15 to $100 \mathrm{ft}$ were analyzed with the assumption of that the bearing capacity of the pile is sufficient.

\subsubsection{Pile Type}

According to INDOT Memorandums \#233 and \#243 (INDOT, 1992a and INDOT, 1992b), only steel H pile and steel-encased concrete (SEC) or concrete-filled steel tube (CFT) pile shall be permitted for integral end bents. HP10x42 and HP12x53 piles are the most common H pile sections, while HP14x89 can be used for higher load capacities. In addition, CFT piles with an outer diameter of 14 in. and with a wall thickness of $0.213,0.250$, and 0.312 in. (CFT14x0.213, CFT14x0.250, and CFT14x0.312) are suggested according to INDOT Memorandum \#243 (INDOT, 1992b). Therefore, two types of piles were investigated: steel H piles including HP10x42, HP12x53, and HP14x89 and CFT piles including CFT14x0.213 and CFT14x0.312 piles. The pile type and size were considered to evaluate the minimum pile lengths that can be provided for the piles recommended by INDOT. Section properties for these piles are provided in Table 4.22. 
Table 4.22: Section Properties in Parametric Study*

\begin{tabular}{|c|c|c|c|c|c|c|}
\hline \multirow{2}{*}{ Pile Type } & $\begin{array}{c}\text { Bending } \\
\text { Axis }\end{array}$ & $\begin{array}{c}\mathbf{A} \\
\text { (in. }{ }^{2} \text { ) }\end{array}$ & $\begin{array}{c}\mathbf{d}_{\mathbf{e}} \\
\text { (in.) }\end{array}$ & $\begin{array}{c}\mathbf{I} \\
\text { (in. }{ }^{4} \text { ) }\end{array}$ & $\begin{array}{c}\mathbf{A}_{\mathbf{s}} \\
\text { (in. }^{{ }^{2}} \text { ) }\end{array}$ & $\begin{array}{c}\text { P } \\
\text { (kips) }\end{array}$ \\
\hline \multirow{2}{*}{ HP10x42 } & Weak & 12.4 & 9.7 & 71.7 & 12.4 & 112 \\
\cline { 2 - 7 } & Strong & 12.4 & 10.1 & 210 & 12.4 & 112 \\
\hline \multirow{2}{*}{ HP12x53 } & Weak & 15.5 & 11.8 & 127 & 15.5 & 140 \\
\cline { 2 - 7 } & Strong & 15.5 & 12.0 & 393 & 15.5 & 140 \\
\hline \multirow{2}{*}{ HP14x89 } & Weak & 26.1 & 13.8 & 326 & 26.1 & 235 \\
\cline { 2 - 7 } & Strong & 26.1 & 14.7 & 904 & 26.1 & 235 \\
\hline CFT14x0.203 & - & 26.8 & $14.0^{* *}$ & 418 & 8.8 & 79 \\
\hline CFT14x0.312 & - & 30.9 & $14.0^{* *}$ & 510 & 13.4 & 120 \\
\hline
\end{tabular}

${ }^{*}$ Cross sectional area and moment of inertia of CFT sections are based on steel transformed section

${ }^{* *}$ Equivalent diameter of CFT section is equal to its outer diameter

\subsubsection{Pile Orientation}

According to INDOT Memorandum \#233 (INDOT, 1992a), piles bending about their weak axis are recommended. However, piles in some integral bridges are oriented for bending about the strong axis (for example, the SR249 over US12 bridge). Therefore, $\mathrm{H}$ piles bending about both weak and strong axes as well as CFT piles bending about one symmetric axis were analyzed. The moments of inertia of each section are provided in Table 4.22.

\subsubsection{Soil Type}

To simplify the parametric study, each pile was modeled to be embedded in one soil layer. Two soil types considering various strengths were used in the analyses. Soil types include clay (soft, stiff, very stiff) and sand (loose, medium, dense). The properties of these soil types are provided in Table 4.23. The ground water table is assumed to be at ground level for all analyses; therefore the effective unit weight of soil is used. This is a conservative assumption. The effective unit weight of soil, $\gamma$, and the friction angle, $\phi$, are in accordance with Greimann (1987). The values of the parameter, k, are based on Reese et al. (1974). The undrained shear strength, $\mathrm{C}_{\mathrm{u}}$, and the strain, $\varepsilon_{50}$, are as suggested by the LPILE PLUS User's manual (Reese et al., 2000b). 
Table 4.23: Soil Properties in Parametric Study

\begin{tabular}{|c|c|c|c|c|c|c|}
\hline $\begin{array}{l}\text { Soil } \\
\text { Type }\end{array}$ & $\begin{array}{c}\text { Soil } \\
\text { Consistence }\end{array}$ & $\begin{array}{c}\gamma \\
\left(\mathbf{l b} / \mathrm{ft}^{3}\right)\end{array}$ & $\begin{array}{c}k \\
\left(\mathbf{l b} / \mathbf{i n} .^{3}\right)\end{array}$ & $\begin{array}{c}\phi \\
\text { (degrees) }\end{array}$ & $\begin{array}{c}\mathrm{c}_{\mathrm{u}} \\
\left(\mathrm{lb} / \mathbf{i n} .^{2}\right)\end{array}$ & $\begin{array}{c}\varepsilon_{50} \\
\text { (in./in.) }\end{array}$ \\
\hline \multirow{3}{*}{ Clay } & Soft & 50 & 30 & - & 2.6 & 0.020 \\
\hline & Stiff & 60 & 500 & - & 10.4 & 0.010 \\
\hline & Very Stiff & 65 & 1000 & - & 20.8 & 0.005 \\
\hline \multirow{3}{*}{ Sand } & oose & $\overline{55}$ & 20 & $\overline{30}$ & - & - \\
\hline & Medium & 60 & 60 & 35 & - & - \\
\hline & Dense & 65 & 125 & 40 & - & - \\
\hline
\end{tabular}

\subsubsection{Results of Parametric Study}

Axial load, pile length, pile orientation, and pile type are of interest in evaluating their effect on the deflected shape and bending moment along the length of the pile as well as the inflection point depth, the zero lateral deflection depth, and the zero moment depth of the pile.

\subsubsection{Effect of Axial Load}

Piles for the SR249 over US12 and the SR18 over Mississinewa River bridges were modeled to evaluate the effect of axial load on the deflected shape and bending moment along the length. It should be noted that that LPILE PLUS accounts for of P- $\Delta$ effects.

The model of the pile of Bent 1 of SR249 over US12 described in Section 4.6.1 was used. The top of the pile was modeled with a roller. The pile was subjected to lateral displacement of 2.2 in. based on the extrapolated end bent movement in Section 3.5.1.3 and to an axial load of 0, 200, and 400 kips (0, 7.7, $15.4 \mathrm{ksi})$. The axial load of 200 kips was based on the bridge design calculations in Section 2.2.1.2. Soil properties are provided in Table 4.6. The results are presented in Figures 4.25 and 4.26. 
Lateral Deflection (in.)

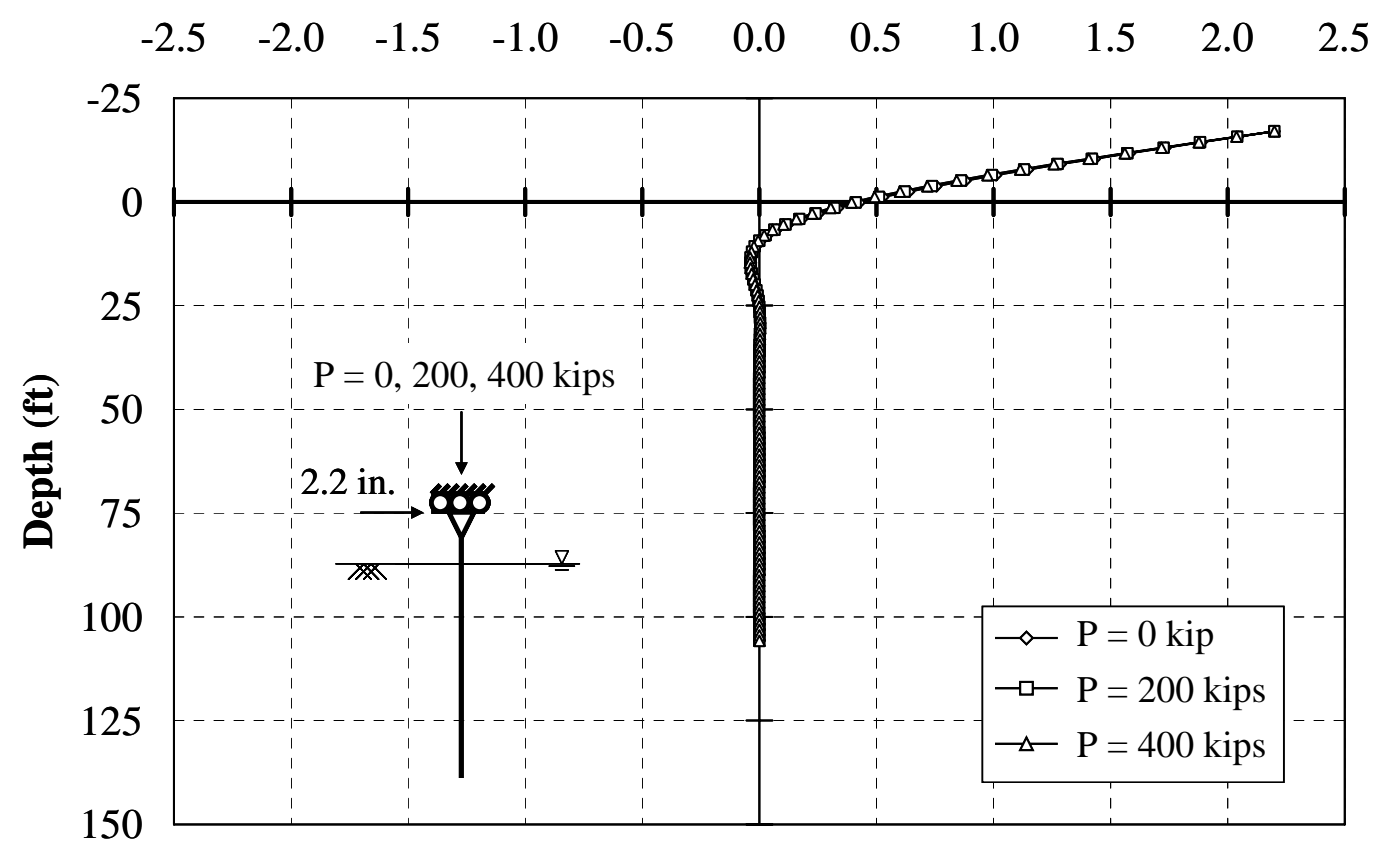

Figure 4.25: Effect of Axial Load on Lateral Deflection (SR249 over US12)

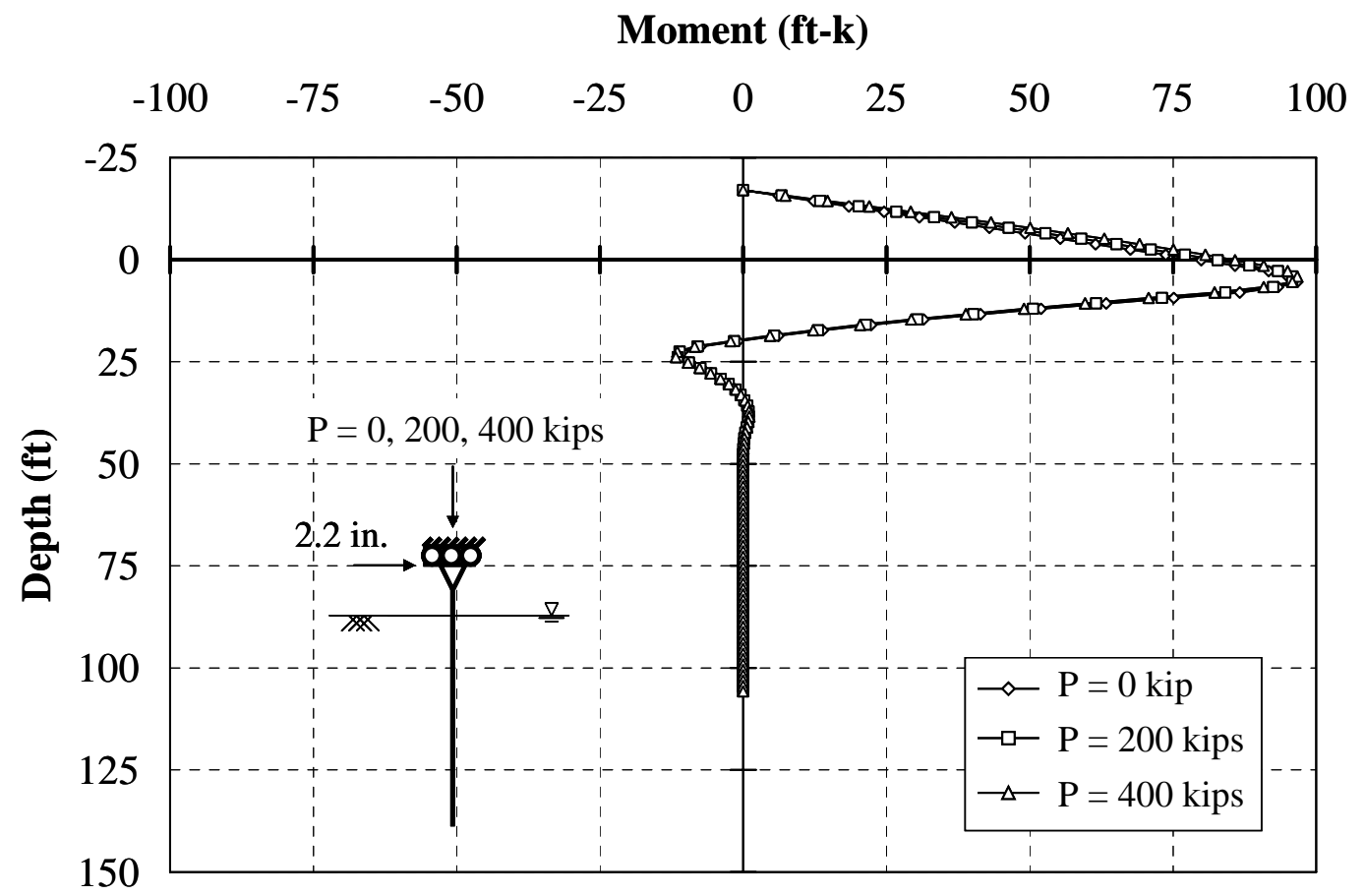

Figure 4.26: Effect of Axial Load on Bending Moment (SR249 over US12) 
Another example is the pile for SR18 over the Mississinewa River. The pile was modeled with a horizontally-guided support at the top of the pile. The pile embedded in medium sand was subjected to lateral displacements of 0.38 in. and 4.0 in. Soil properties are provided in Table 4.23. The lateral displacement of 0.38 in. is the average bridge movement measured by the convergence meter located at the center of Bent 1 of the SR18 bridge during a temperature change ranging from $-63^{\circ} \mathrm{F}$ to $-57^{\circ} \mathrm{F}(\Delta \mathrm{T}=$ $-60^{\circ} \mathrm{F}$ ). The large lateral displacement of 4 in. is calculated based on Equation 4-17, where $\Delta \mathrm{T}$ is taken as $100^{\circ} \mathrm{F}$ for a hypothetical $1000 \mathrm{ft}$ bridge. Axial stresses of 0,9 , and $18 \mathrm{ksi}(\mathrm{P}=0,121$, and $242 \mathrm{kips})$ were applied at the top of the pile. The results are presented in Figures 4.27 and 4.28. Based on both of these analyses, the axial load has an insignificant effect on both the deflected shape and bending moment along the length of the pile.

\subsubsection{Effect of Pile Length}

The effect of pile length was evaluated. Of particular interest was the length required such that the lateral displacement and rotation at the bottom of the pile were eliminated. To illustrate the effect of length, an analysis was performed for an HP12x53 pile embedded in a medium sand, bending about its weak axis, and subjected to an axial stress of $9 \mathrm{ksi}$ and a lateral displacement of $4 \mathrm{in}$. at the top. The deformed shape and bending moment diagram of the pile for various pile lengths are presented in Figures 4.29 and 4.30, respectively. From this analysis, it can be seen that a pile length greater than 22 $\mathrm{ft}$ is required to eliminate lateral displacement and a pile length greater than $25 \mathrm{ft}$ is required to eliminate rotation at the bottom of the pile. This analysis was also performed for other pile sections and soil conditions to evaluate minimum pile lengths.

For convenience, the pile length that eliminates lateral displacement is defined as the final zero deflection depth. The pile length that eliminates rotation is defined as the final zero moment depth. These terms are used to differentiate between other locations that produce zero displacement and moment. 


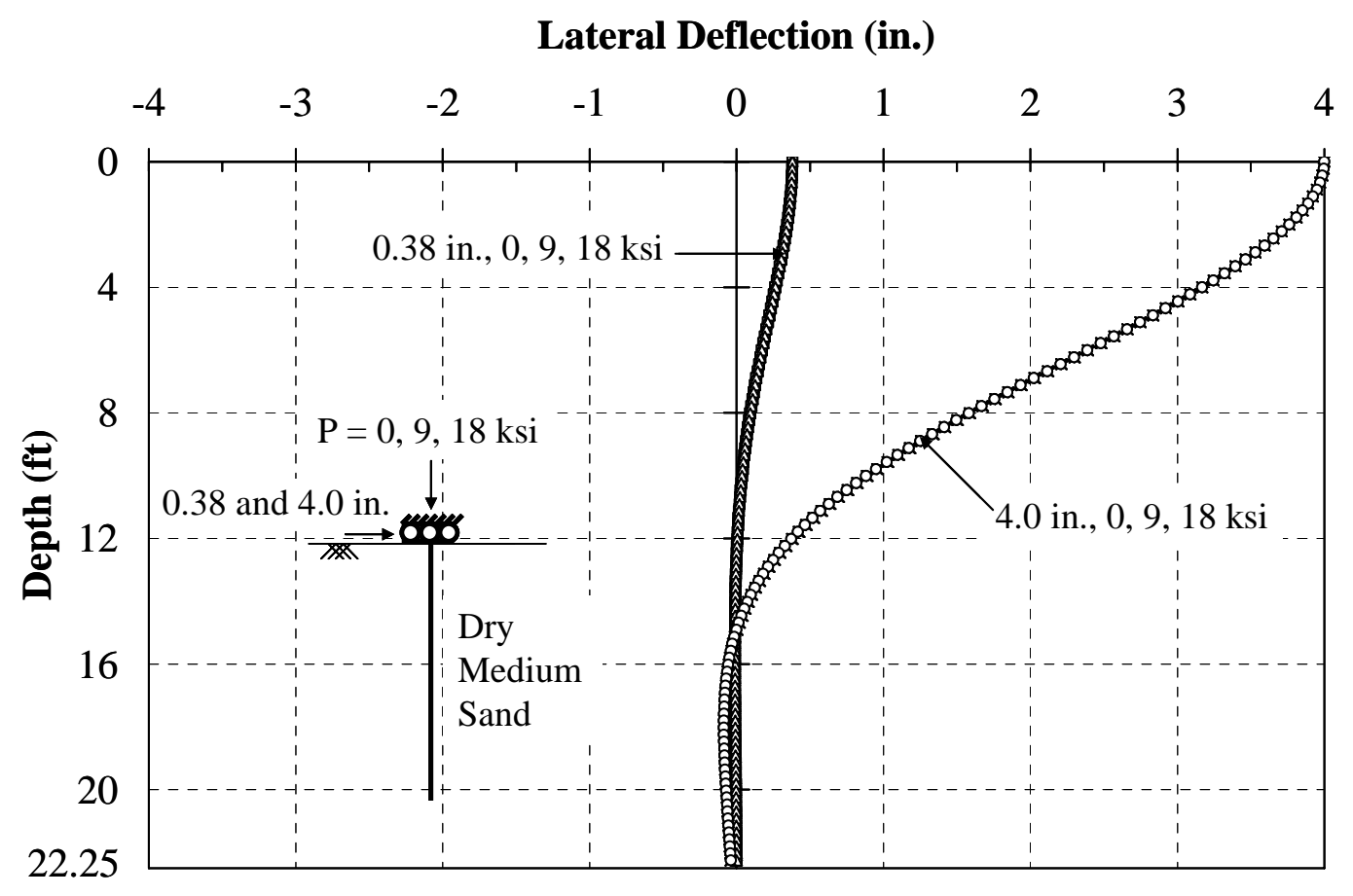

Figure 4.27: Effect of Axial Load on Lateral Deflection (SR18)

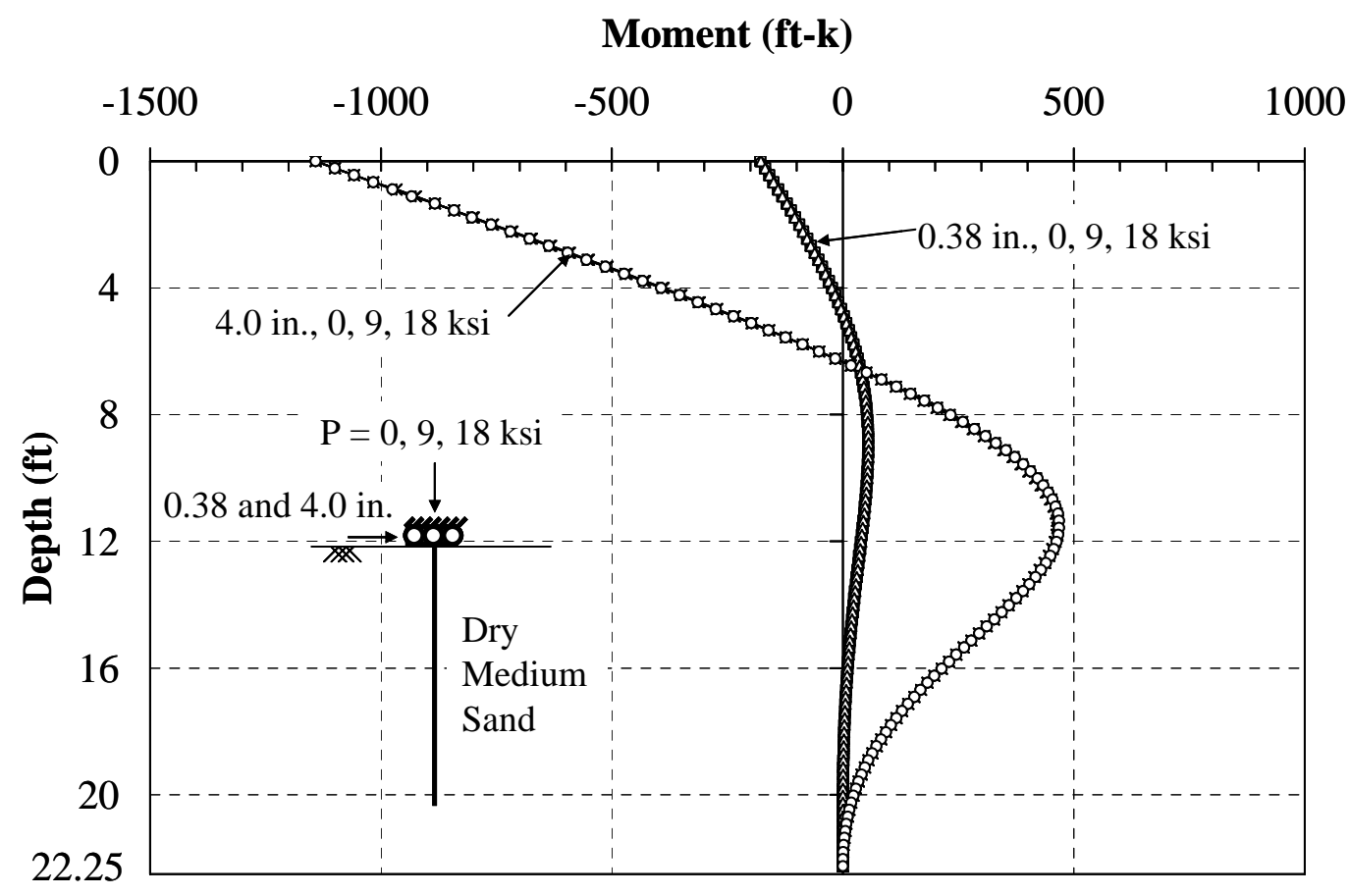

Figure 4.28: Effect of Axial Load on Bending Moment (SR18) 


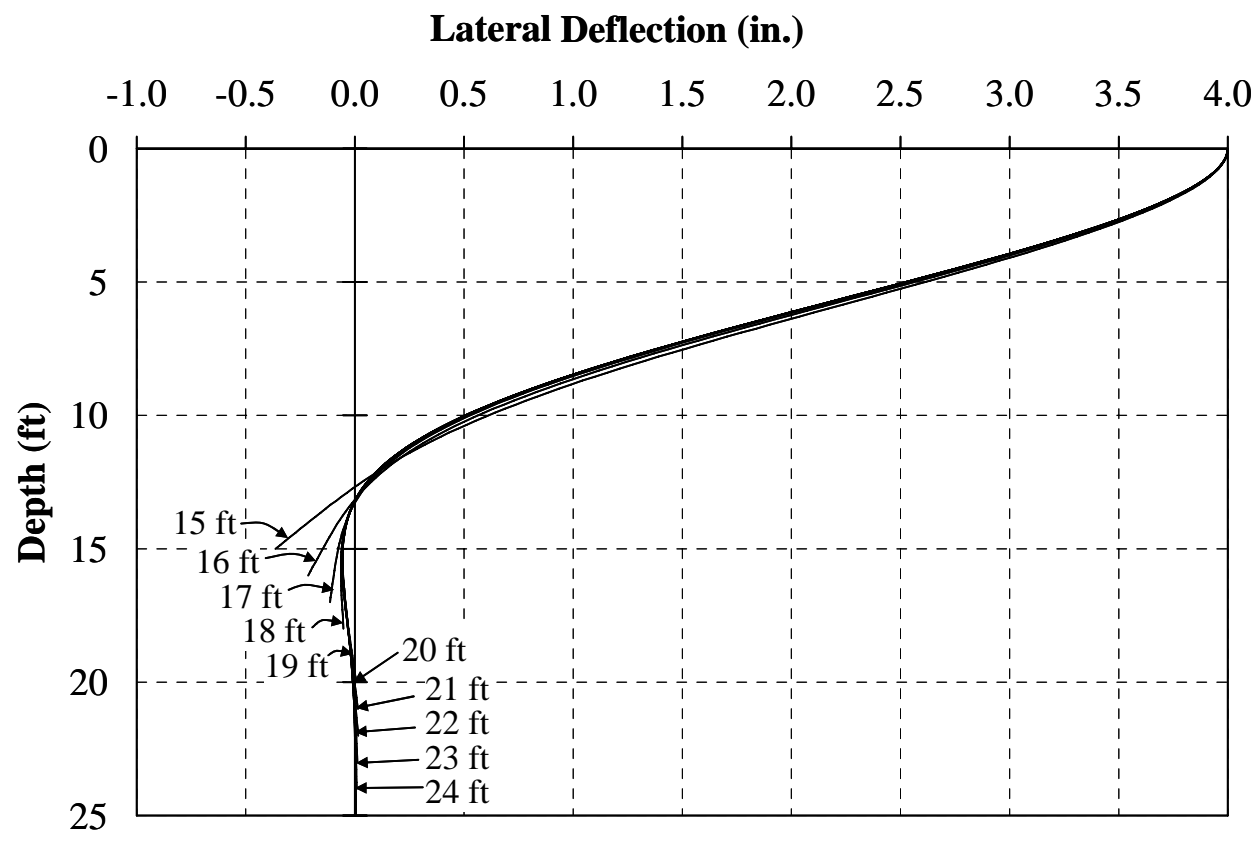

Figure 4.29: Deflected Shape of the Pile with Various Pile Lengths

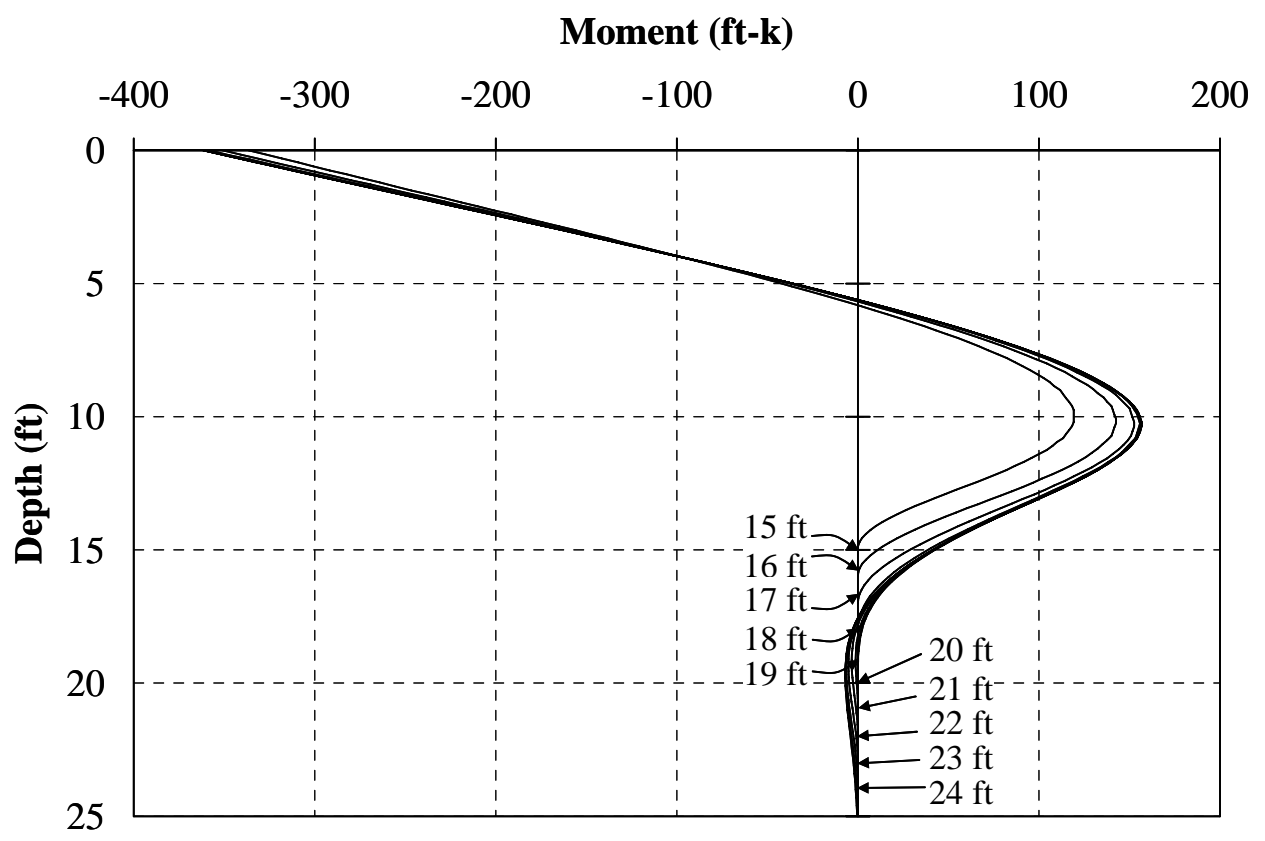

Figure 4.30: Moment of the Pile with Various Pile Lengths 


\subsubsection{Depth of Inflection Point}

The depth to the inflection point was evaluated since this point is of interest in developing the experimental program for this research program. This depth is significant in that it is the location where bending moment is zero along the pile length.

The depth to the inflection point of HP10x42, HP12x53, and HP14x89 piles are presented in Figures 4.31, 4.32, and 4.33, respectively, while the depth to the inflection point of CFT14x0.213 and CFT14x0.312 piles are presented in Figure 4.34. Several conclusions can be reached.

1. For the same pile section, the results indicate that the inflection points of a pile embedded in various soil types are fairly constant. As the soil becomes softer, the inflection point moves slightly deeper.

2. For different pile orientations, bending about the strong axis (stiffer) provides a deeper inflection point than bending about the weak axis (less stiff).

3. For the same pile section but subjected to different tip lateral displacements (as the lateral displacement increases from 1 in. to 4 in.), the inflection point is located deeper.

4. Considering all pile analyzed, the inflection points range from 4 to $12 \mathrm{ft}$ below ground level.

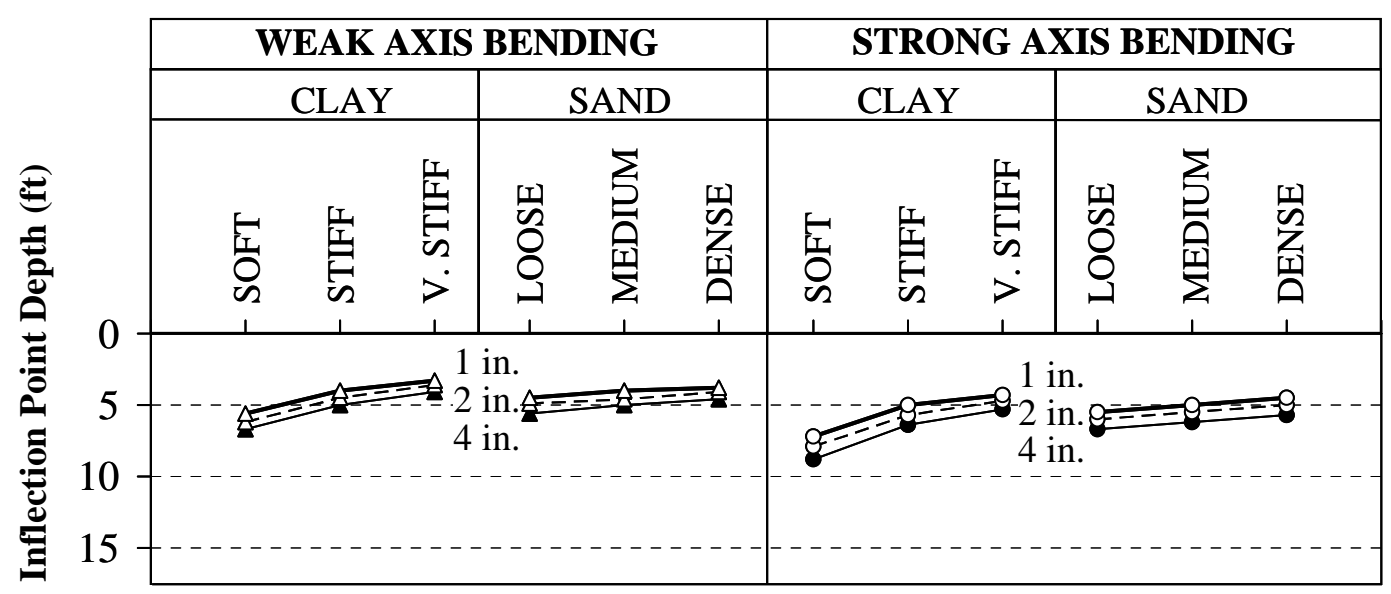

Figure 4.31: Inflection Point Depth of HP10x42 


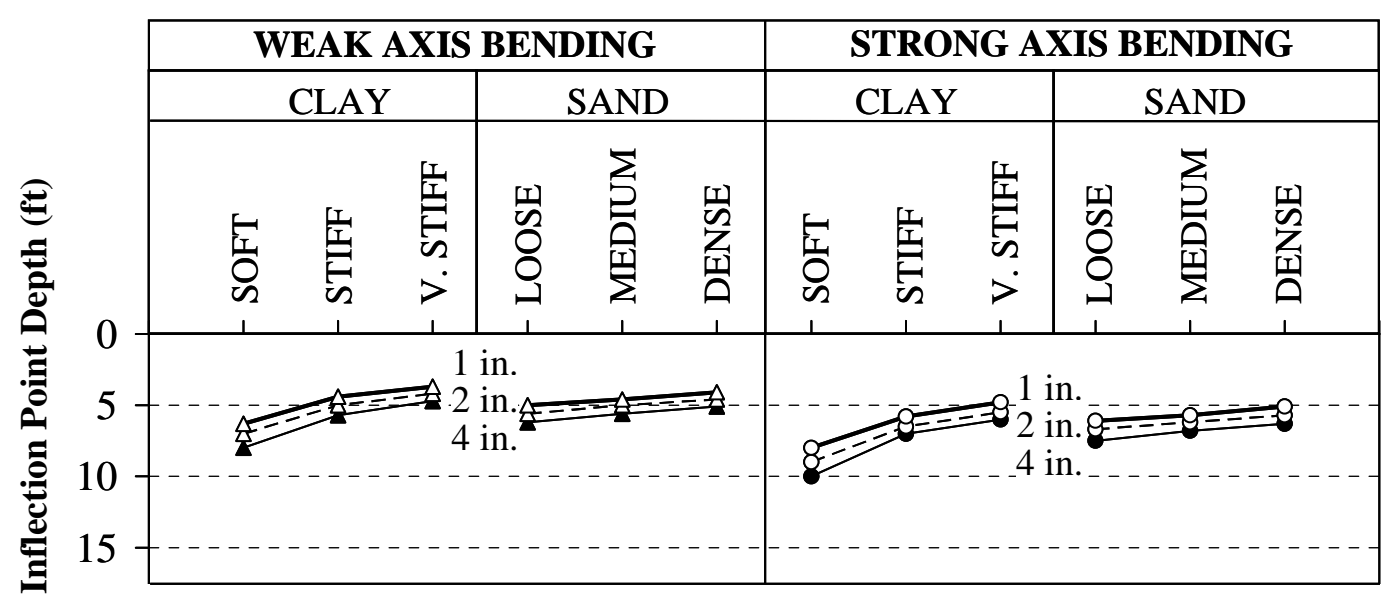

Figure 4.32: Inflection Point Depth of HP12x53

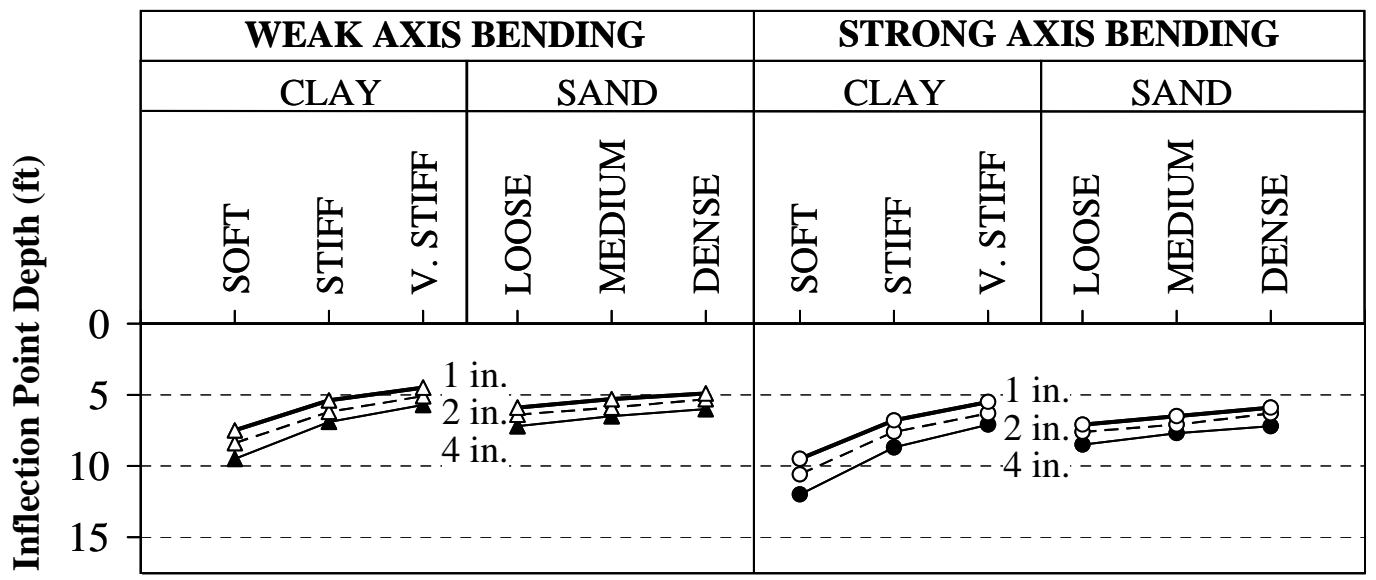

Figure 4.33: Inflection Point Depth of HP14x89

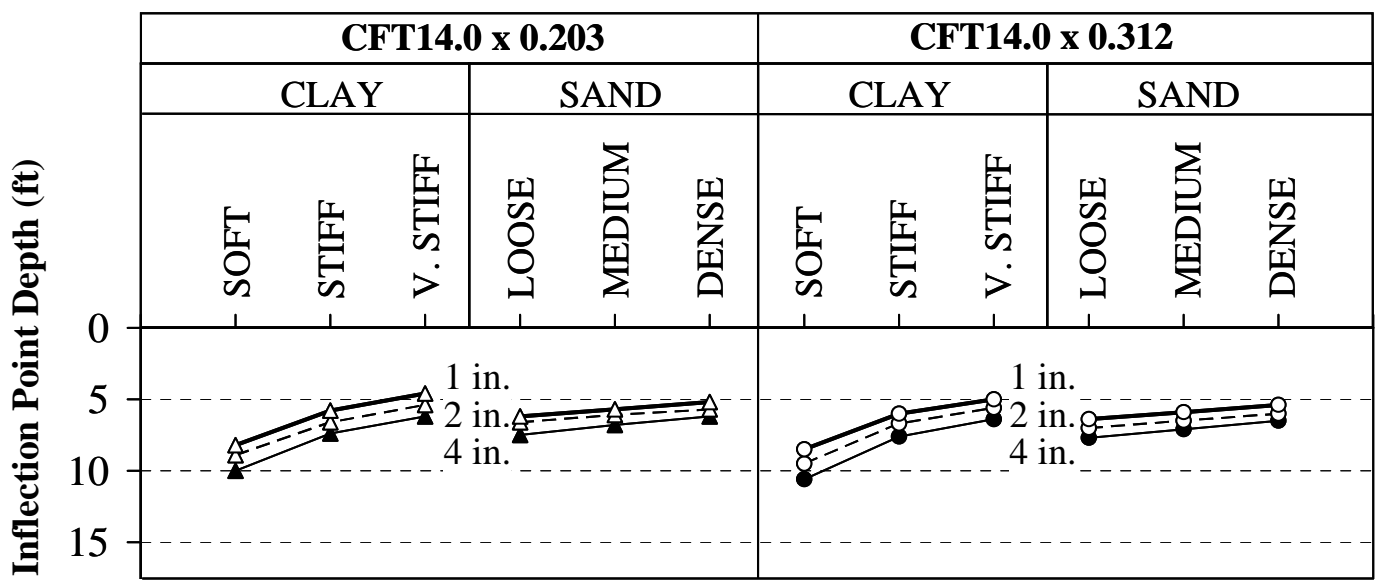

Figure 4.34: Inflection Point Depth of CFT14 


\subsubsection{The Final Zero Deflection and Zero Moment Depths}

The final zero deflection depths of HP10x42, HP12x53, and HP14x89 are presented in Figures 4.35, 4.36, and 4.37, respectively, while the final zero deflection depths of CFT14x0.213 and CFT14x0.312 are presented in Figure 4.38. The final zero moment depths of HP10x42, HP12x53, and HP14x89 are presented in Figures 4.39, 4.40, and 4.41, respectively, while the final zero moment depths of CFT14x0.213 and CFT14x0.312 are presented in Figure 4.42.

The final zero deflection and zero moment depths are influenced by soil type, bending axis or stiffness of the pile, and tip lateral displacement in the same manner as the inflection depth. It can be noted, however, that soil type plays more a significant role in the final zero deflection and the final zero moment depths. For example, as the stiffness of the soil increases, the inflection point depth is fairly constant (Figures 4.31 4.34), while the final zero deflection depth and the final zero moment depth change significantly. Considering the same pile section, clay provides a more significant effect on the final zero deflection depth than that provided by sand. 


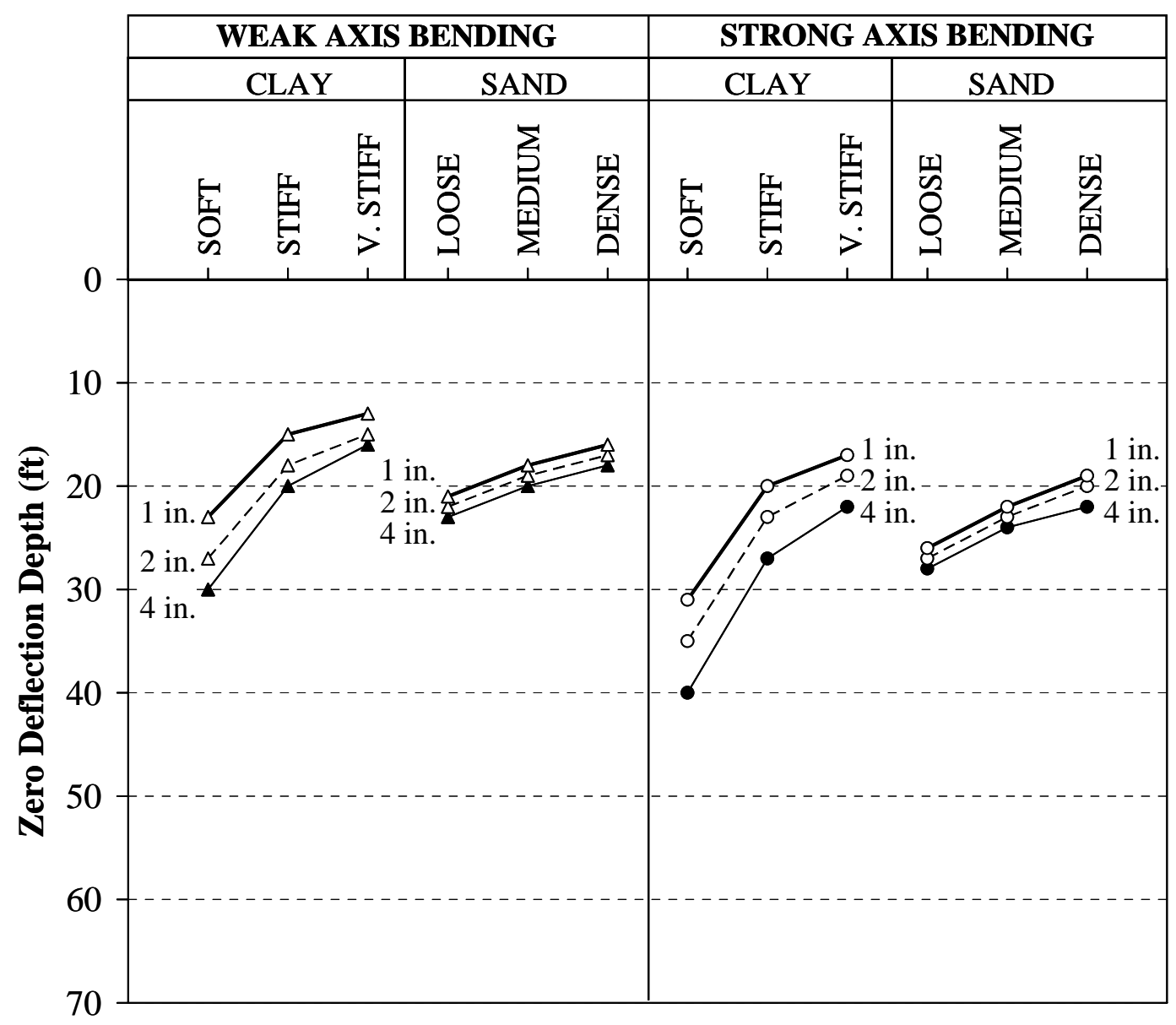

Figure 4.35: Zero Deflection Depth of HP10x42 


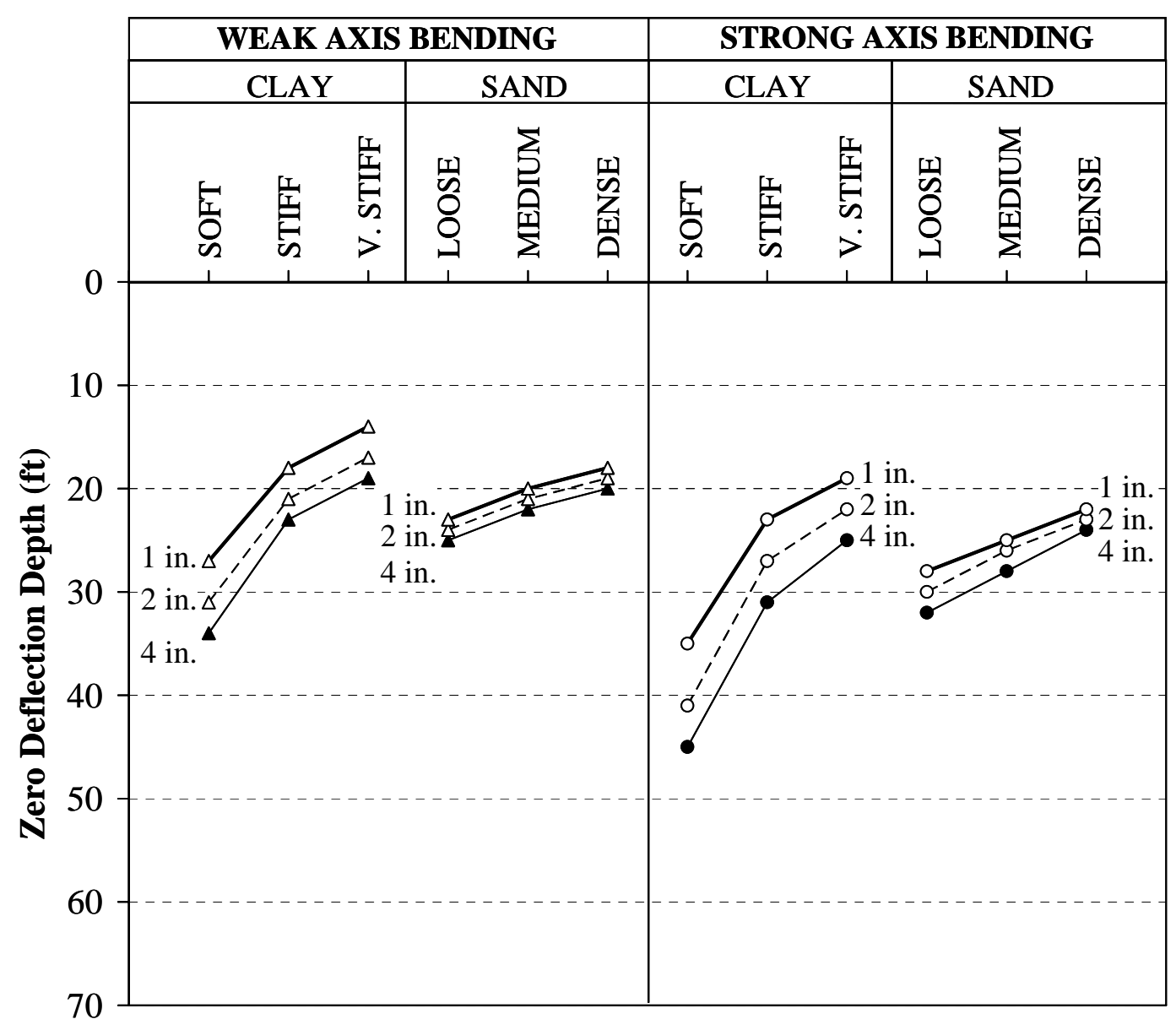

Figure 4.36: Zero Deflection Depth of HP12x53 


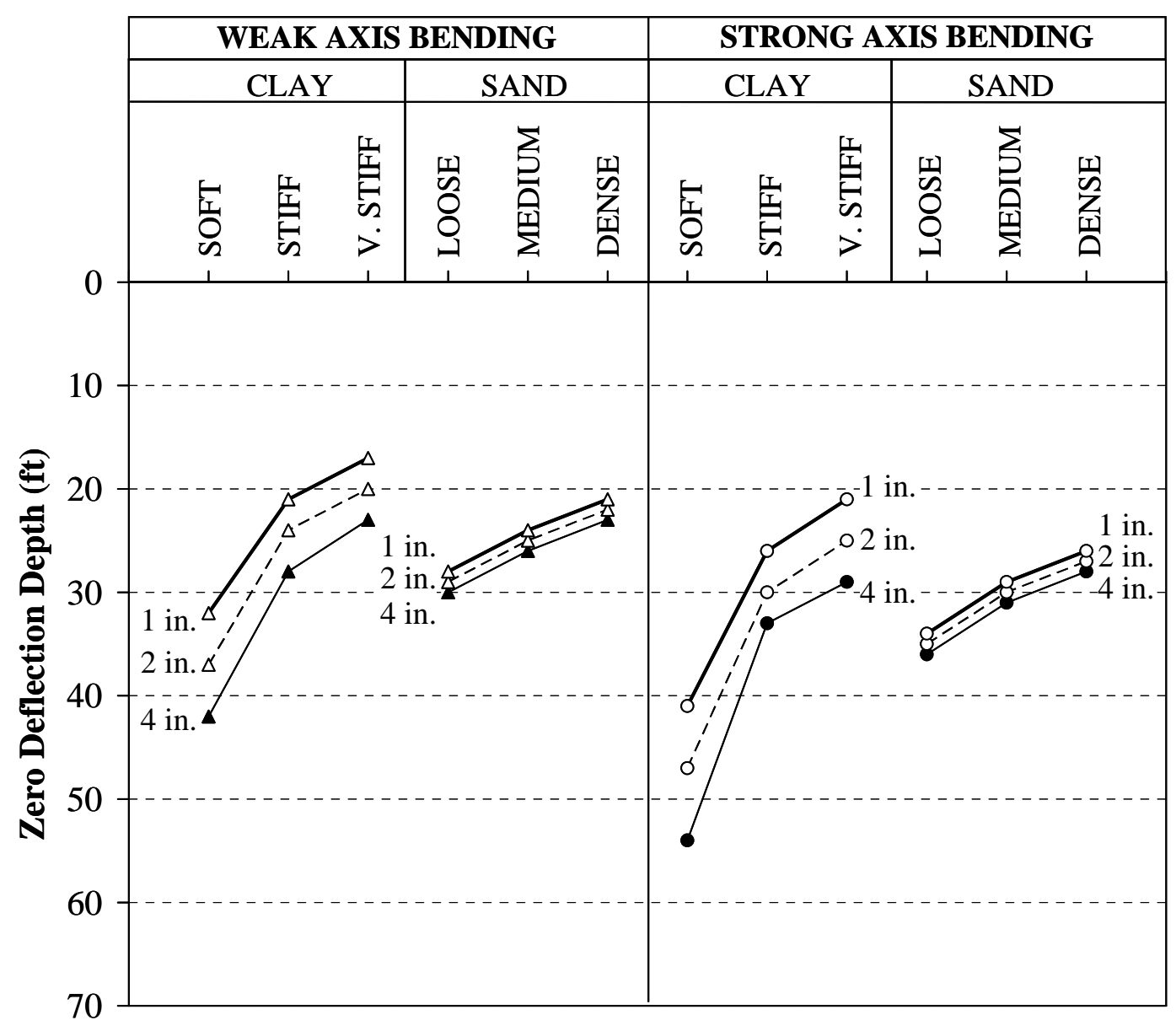

Figure 4.37: Zero Deflection Depth of HP14x89 


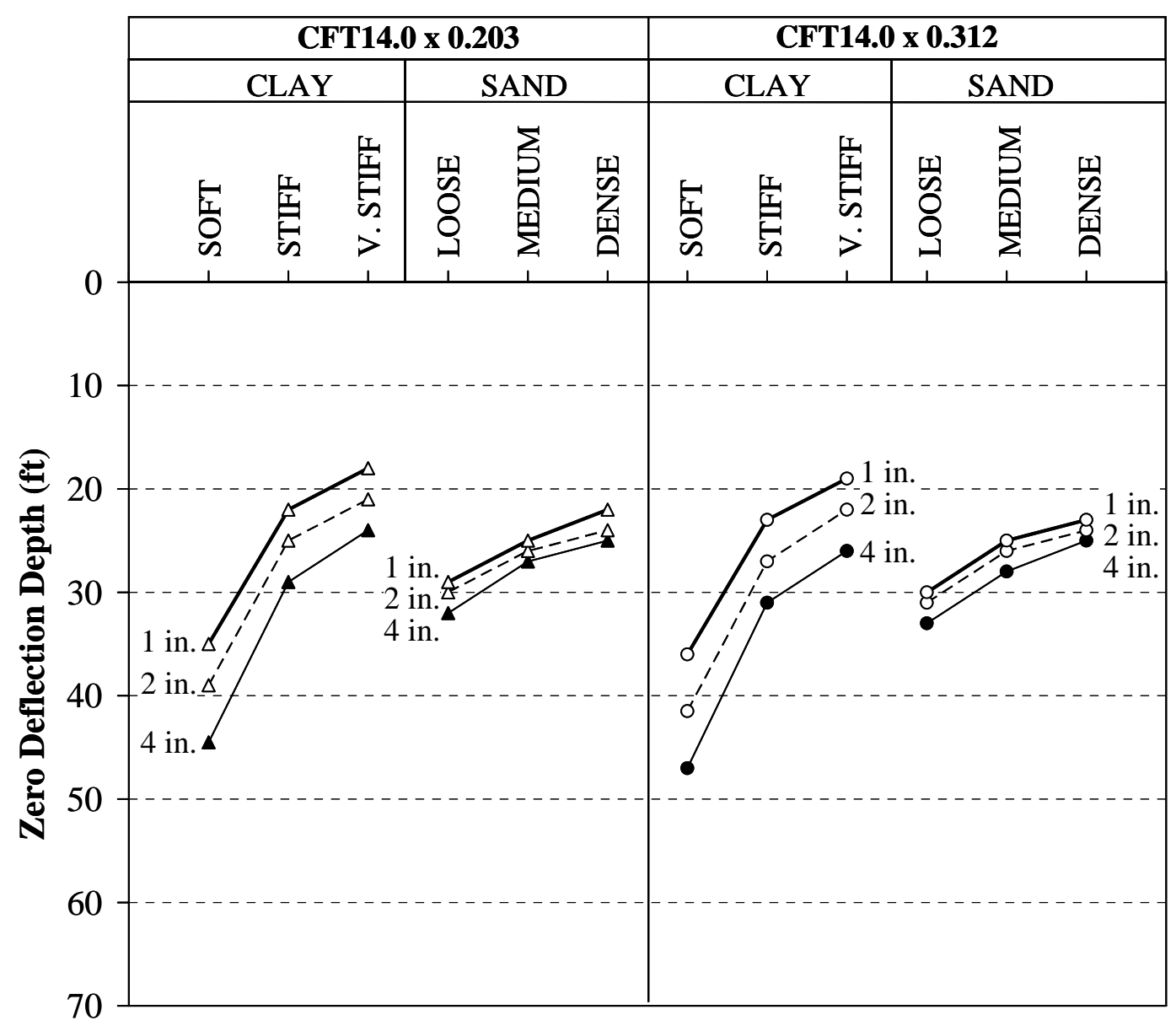

Figure 4.38: Zero Deflection Depth of CFT14 


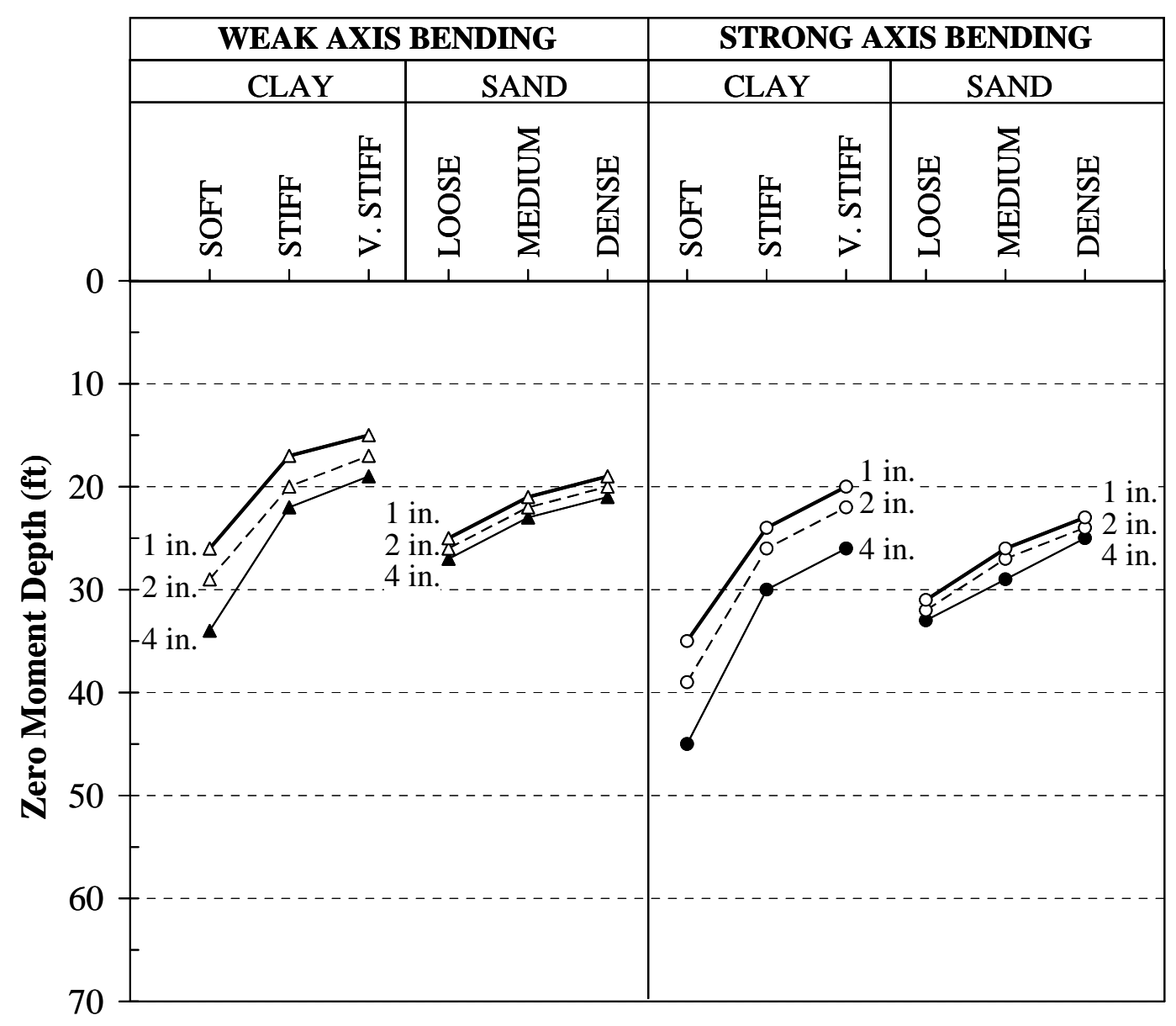

Figure 4.39: Zero Moment Depth of HP10x42 


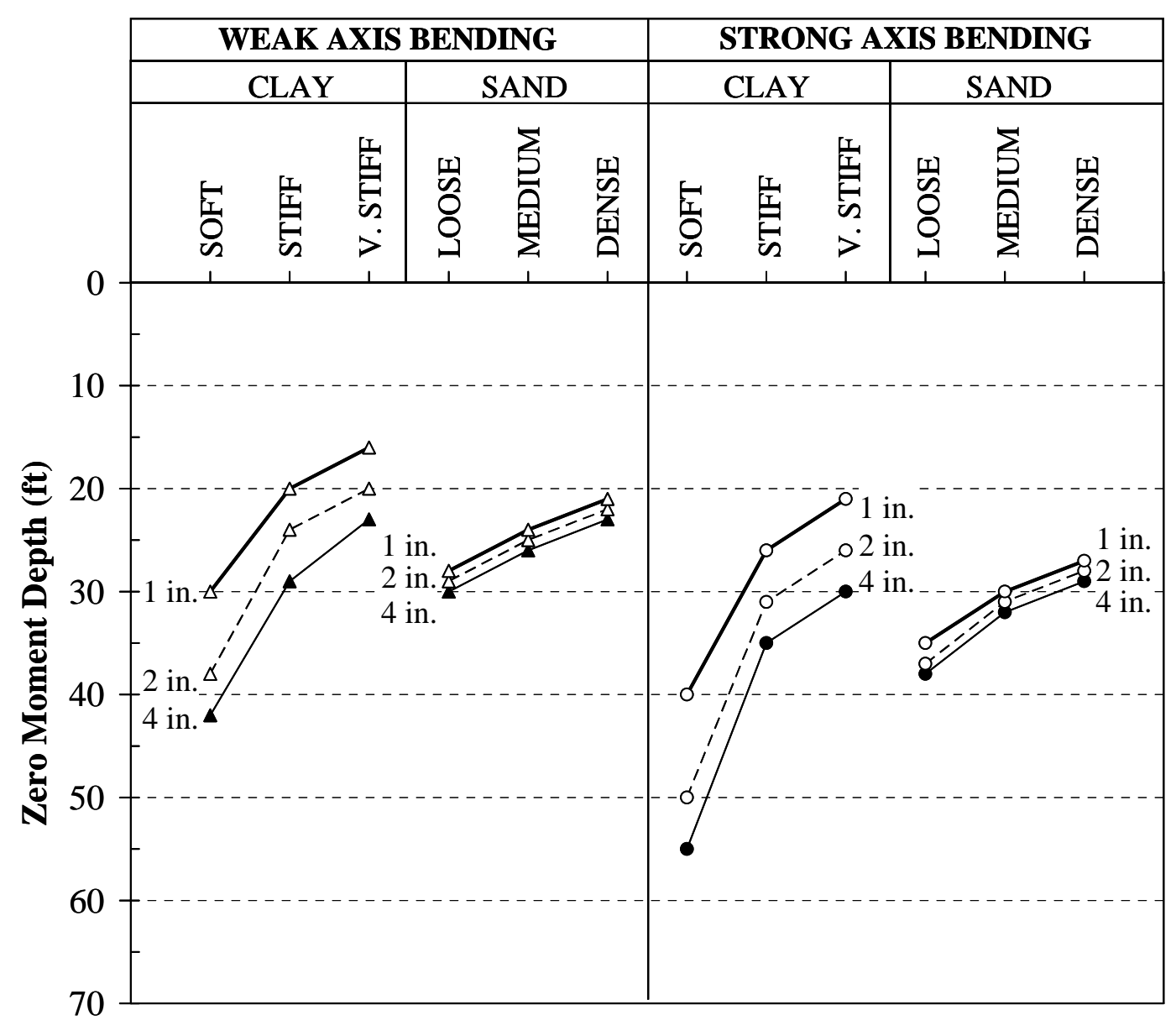

Figure 4.40: Zero Moment Depth of HP12x53 


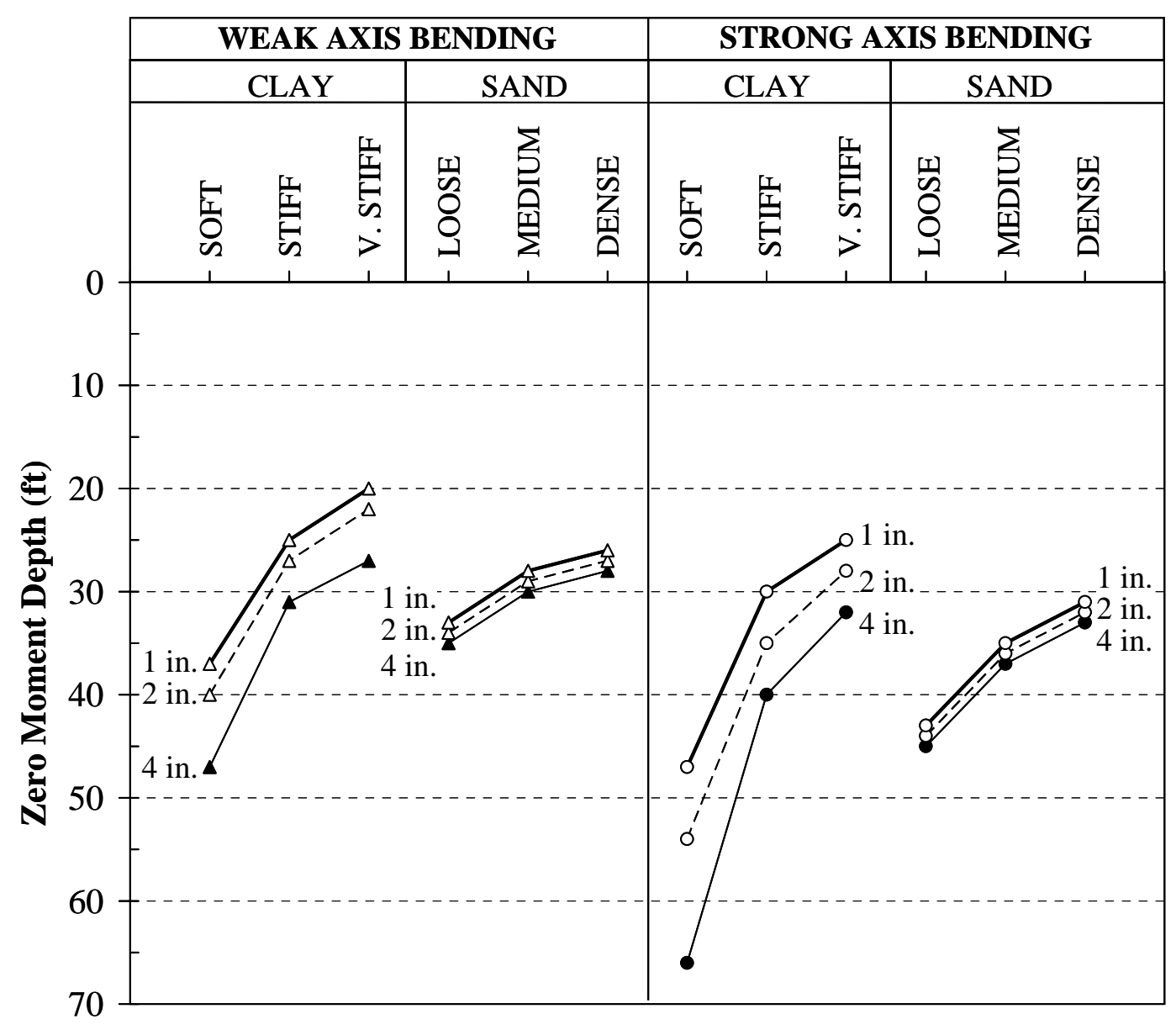

Figure 4.41: Zero Moment Depth of HP14x89 


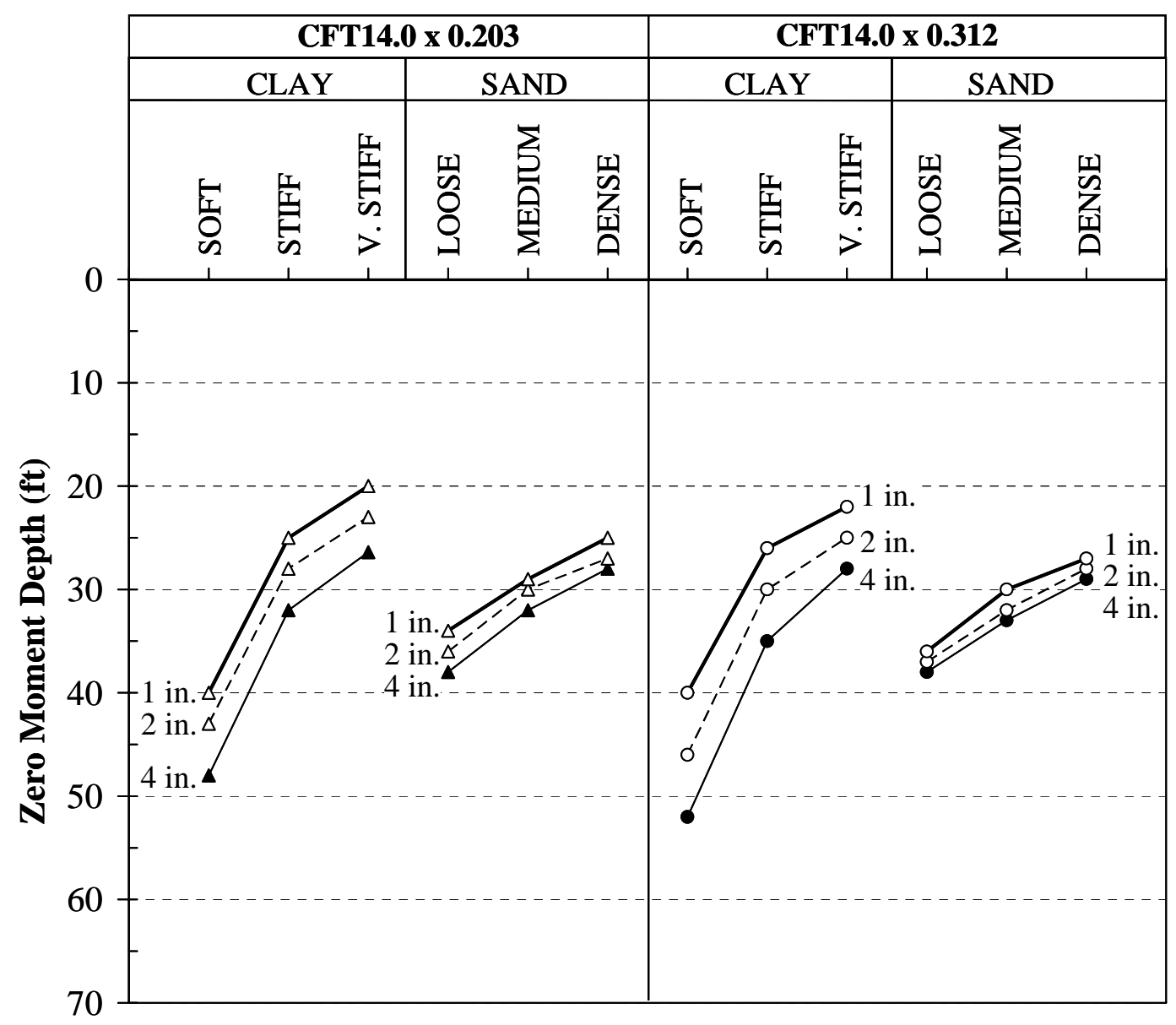

Figure 4.42: Zero Moment Depth of CFT14 
The results of these analyses were reviewed and compared. Several findings are provided:

1. Considering the same pile section bending about different axes, the final zero deflection and final zero moment depths are deeper for the stiffer pile orientation.

2. As the stiffness of the pile is increased, the final zero deflection and final zero moment depths increase.

3. Considering different tip displacements, the final zero deflection and final zero moment are deeper as the tip displacement is increased.

4. The final zero deflection depth ranges from $13 \mathrm{ft}$ (HP10x42 Weak, Very stiff clay, $\Delta=1$ in.) to $54 \mathrm{ft}$ (HP14x89, Strong, Soft Clay, $\Delta=4$ in.).

5. The final zero moment depth ranges from $15 \mathrm{ft}$ (HP10x42 Weak, Very stiff clay, $\Delta=1$ in.) to $66 \mathrm{ft}$ (HP14x89, Strong, Soft Clay, $\Delta=4$ in.).

6. For the same pile embedded in the same soil and subjected to the same tip displacement, the final zero moment depth is 15 to $20 \%$ greater than the final zero deflection depth.

For the selection of a minimum acceptable pile length, however, the final zero deflection depth should be considered rather than the final zero moment depth.

Relatively small moments occur below the depth of final zero deflection and small rotations at the base of the pile are considered acceptable. The minimum pile lengths that provide no displacement at the bottom of the pile are listed in Table 4.24. These lengths are based on the analysis presented and are conservative as they were selected based on the critical soil condition.

Table 4.24: The Minimum Pile Length (ft)

\begin{tabular}{|c|c|c|c|c|}
\hline \multirow{2}{*}{ Pile } & \multicolumn{2}{|c|}{ Weak Axis Bending } & \multicolumn{2}{c|}{ Strong Axis Bending } \\
\cline { 2 - 5 } & Clay & Sand & Clay & Sand \\
\hline HP10x42 & 30 & 23 & 40 & 28 \\
\hline HP12x53 & 34 & 25 & 45 & 32 \\
\hline HP14x89 & 42 & 30 & 54 & 36 \\
\hline CFT14 & - & - & 47 & 33 \\
\hline
\end{tabular}




\section{$\underline{4.8 \quad \text { Conclusions }}$}

According to the analysis performed, several conclusions can be drawn.

1. Axial load has minimal influence on the deflected shape and bending moment along the length of the pile.

2. Considering the $\mathrm{H}$ and CFT piles recommended by INDOT Memorandums \#233 and \#243, the inflection point of those piles ranges from 4 to $12 \mathrm{ft}$ below ground level.

3. The inflection point depth, the final zero deflection depth, and the final zero moment depth are dependent upon soil type, bending axis of the pile, stiffness of the pile, and tip lateral displacement. In general, these depths increase as the stiffness of the pile relative to the soil increases. The depths also increase as the tip displacement increase.

4. Considering the $\mathrm{H}$ and $\mathrm{CFT}$ piles recommended by INDOT, the final zero deflection depth ranges from 13 to $54 \mathrm{ft}$, while the final zero moment depth ranges from 15 to $66 \mathrm{ft}$.

5. The final zero deflection depth is considered to provide the minimum acceptable pile length.

\subsection{Design Recommendation}

Based on the analysis presented in this chapter, it is recommended that a minimum pile length be specified to provide sufficient anchorage to develop the lateral capacity of the pile. These minimum lengths are based on minimizing displacement and rotation at the bottom of the pile. Table 4.25 provides the minimum recommended lengths below ground level.

Table 4.25: Minimum Design Pile Length (ft)

\begin{tabular}{|c|c|c|c|c|}
\hline \multirow{2}{*}{ Pile } & \multicolumn{2}{|c|}{ Weak Axis Bending } & \multicolumn{2}{c|}{ Strong Axis Bending } \\
\cline { 2 - 5 } & Clay & Sand & Clay & Sand \\
\hline HP10x42 & 30 & 25 & 40 & 30 \\
\hline HP12x53 & 35 & 25 & 45 & 30 \\
\hline HP14x89 & 40 & 30 & 55 & 35 \\
\hline CFT14 & - & - & 50 & 35 \\
\hline
\end{tabular}




\section{CHAPTER 5: EXPERIMENTAL INVESTIGATION}

\subsection{Introduction}

To evaluate the behavior of typical piles used in Indiana bridge construction, six steel H piles (HP) and three concrete-filled steel tube piles (CFT) were investigated in the Kettelhut Structural Engineering Laboratory at Purdue University. These tests were used to evaluate the capability of the piles to maintain axial load under low-cycle, largeamplitude lateral displacement expected during thermal movements and to investigate the performance of the abutment-pile connection.

\section{$\underline{5.2 \quad \text { Specimen Design }}$}

The pile supporting the abutment can be represented as a cantilever beam subjected to axial load, P, and cyclic lateral load, H, as shown in Figure 5.1. To determine an appropriate pile length, L, that would provide behavior similar to that experienced in service, a series of analyses were performed using LPILE PLUS (Reese et al., 2000a) as discussed in Chapter 4. Of particular interest was the determination of the inflection point. As the pile responds similar to a cantilever between the abutment and inflection point, the depth to the inflection point was considered as the design cantilever length.

Figure 5.2 illustrates an example analysis for soil conditions similar to the I65 over SR25 site. A medium sand is assumed with its properties provided in Table 5.1 according to Chapter 4. A horizontally-guided support is assumed at the pile top. As shown in Figure 5.2, the inflection depth is fairly stable considering a variety of pile types and sizes. Following additional analyses of various pile types and soil conditions 
(Chapter 4), a pile length of $5 \mathrm{ft}$ was selected. Softer soils generally provide for an increase in the inflection depth. As the inflection depth is decreased, increased flexure stresses occur for a given lateral displacement. Therefore, results from using the critical depth of $5 \mathrm{ft}$ are considered conservative.

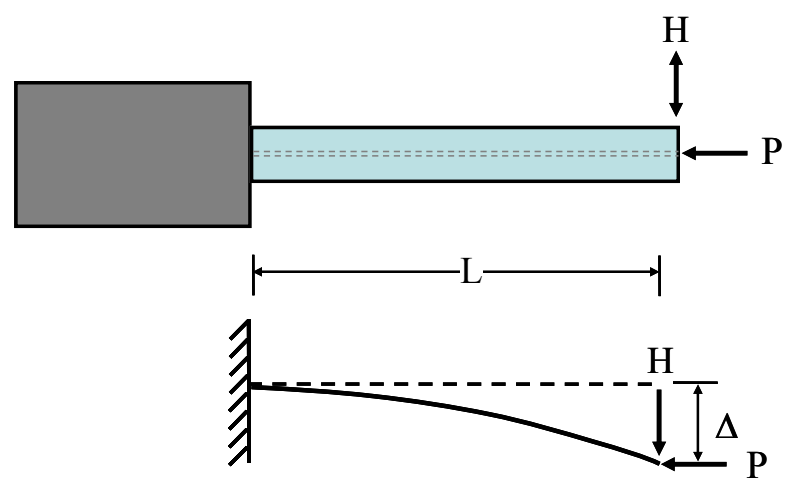

Figure 5.1: Test Design

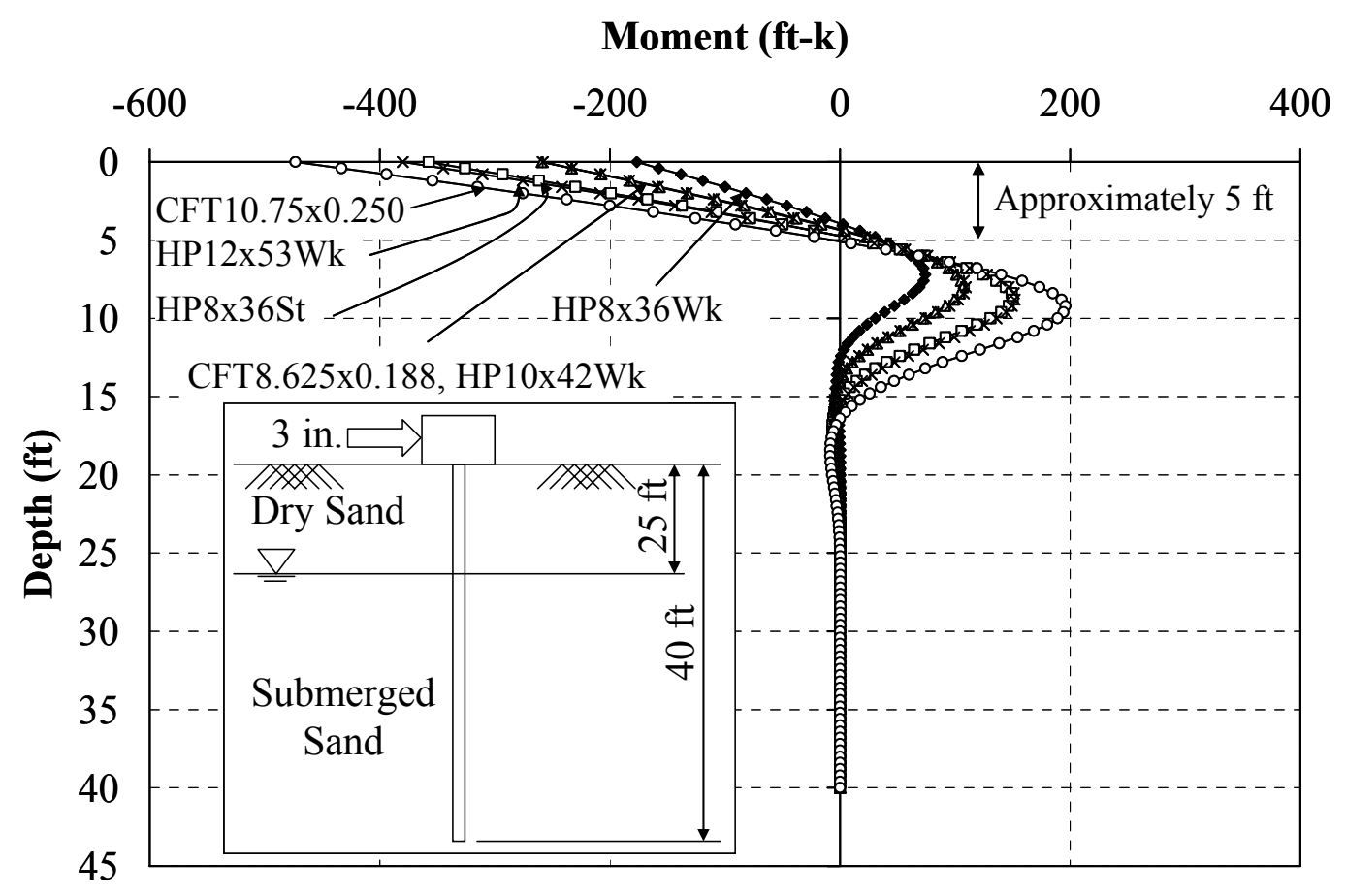

Figure 5.2: Example of Bending Moment versus Depth from LPILE Program 
Table 5.1: Soil Properties for LPILE Model

\begin{tabular}{|l|c|c|}
\hline & Dry Sand & Submerged Sand \\
\hline Unit Weight, $\gamma, \mathrm{pcf}$ & 120 & 60 \\
\hline Relative Density, $\mathrm{k}, \mathrm{pci}$ & 90 & 60 \\
\hline Angle of Friction, $\phi, \mathrm{deg}$ & 35 & 35 \\
\hline
\end{tabular}

\section{$\underline{5.3 \quad \text { Test Variables }}$}

The experimental program included the following variables: pile type, pile orientation, and axial load. The test matrix is shown in Table 5.2.

Table 5.2: Summary of Test Variables

\begin{tabular}{|c|c|c|c|c|c|c|}
\hline \multirow{2}{*}{ Specimen } & \multirow{2}{*}{ Section } & \multicolumn{3}{|c|}{ Bending Axis } & \multicolumn{2}{|c|}{ Axial Load Level } \\
\hline & & Weak & Strong & $45^{\circ}$ & $0.25 f_{y} A_{s}+0.40 f_{c}{ }^{\prime} A_{c}$ & $0.50 f_{y} A_{s}+0.40 f_{c}{ }^{\prime} A_{c}$ \\
\hline 1 & HP8x36 & $\mathrm{X}$ & & & $\mathrm{X}$ & \\
\hline 2 & HP8x36 & & $\mathrm{X}$ & & $\mathrm{X}$ & \\
\hline 3 & HP8x36 & & & $\mathrm{X}$ & $\mathrm{X}$ & \\
\hline 4 & HP8x36 & $\mathrm{X}$ & & & & $\mathrm{X}$ \\
\hline 5 & HP10x42 & $\mathrm{X}$ & & & $\mathrm{X}$ & \\
\hline 6 & HP12x53 & $\bar{X}$ & & & $\mathrm{X}$ & \\
\hline 7 & CFT8 & $\mathrm{X}^{*}$ & & & $\mathrm{X}$ & \\
\hline 8 & CFT8 & $\mathrm{X}^{*}$ & & & & $\mathrm{X}$ \\
\hline 9 & CFT10 & $\mathrm{X}^{*}$ & & & $\mathrm{X}$ & \\
\hline
\end{tabular}

*Concrete-Filled Steel Tube (CFT) piles have only one bending axis

\subsubsection{Pile Type}

Steel H piles (HP) and concrete-filled steel tube (CFT) piles were investigated in the study as these are the only pile types permitted in Indiana according to INDOT Memorandum \#233 (INDOT, 1992a). Three steel H pile shapes and two concrete-filled steel tube (CFT) pile shapes were examined: HP8x36, HP10x42, HP12x53, CFT8.625x0.188 (8.625-in. outer diameter and 0.188-in. wall thickness) identified as CFT8, and CFT10.75x0.250 (10.75-in. outer diameter and 0.250-in. wall thickness) identified as CFT10. 
These piles were selected considering actual piles used in the field as well as laboratory constraints. HP8x36 was selected because this section is the smallest HP section available; therefore, it can be easily tested in both weak, strong, and $45^{\circ}$ axis bending as well as for the $0.25 f_{\mathrm{y}}$ and $0.5 \mathrm{f}_{\mathrm{y}}$ axial load cases. HP10x 42 was chosen because this section is one of the most commonly-used piles. In addition, results from the HP10x42 could be compared with a similar test conducted by Construction Technology Laboratories (CTL). HP12x53, the last HP section, was tested because this section was used in the I65 over SR 25 bridge that has been instrumented. The HP12x53 test was used to correlate with the measured response. Note that even though HP14x89 piles were used in the SR249 over US12 bridge, this section was not tested because of laboratory limitations. The CFT8.625x0.188 sections were selected because they were small enough to test in bending along with the application of the $0.25 \mathrm{~F}_{\mathrm{y}}$ and $0.5 \mathrm{~F}_{\mathrm{y}}$ axial load. In addition, the CFT10.75x0.250 was tested to provide another point of reference.

Note that in INDOT Memorandum \#233 (INDOT, 1992a), only 14-in. outer diameter concrete-filled steel tube piles are permitted in integral abutment bridges. Wall thicknesses of $0.203-, 0.250$-, and 0.312 -in. are typically used according to INDOT Memorandum \#243 (INDOT, 1992b). The CFT14 pile, however, could not be investigated because of laboratory capacity limitations. Therefore, a smaller concretefilled steel tube pile was selected to examine the behavior of this pile type.

\subsubsection{Pile Orientation}

The HP8x36 section was tested in both weak- and strong- axis bending to evaluate the effect of pile orientation. In addition, it was tested in $45^{\circ}$ - axis bending to investigate the effect of skew angle on pile behavior and displacement capacity. Other HP sections were tested in only weak-axis bending. For CFT piles, no orientation exists due to symmetry.

\subsubsection{Axial Load Level}

Piles were tested under various levels of axial load. The maximum allowable axial stress of steel $\mathrm{H}$ piles as given by INDOT Memorandum \#233 (INDOT, 1992a) is 
$9 \mathrm{ksi}$. This value is based on $25 \%$ of the yield strength of $36 \mathrm{ksi}$ as specified by AASHTO (1996). In addition, the maximum allowable stress on a concrete-filled steel tube pipe is specified by AASHTO as $25 \%$ of the specified yield strength of the steel shell (35 ksi, A252 Grade 2 steel) plus $40 \%$ of the concrete compressive strength $\left(0.25 f_{y} A_{s}+0.4 f_{c}^{\prime} A_{c}\right)$. These axial load levels were examined. Furthermore, higher axial stresses of $50 \%$ of the specified yield strength of the steel pile material were tested to determine if these axial load levels could still be maintained under cyclic displacement. Thus, piles were axially loaded to $0.50 \mathrm{f}_{\mathrm{y}} \mathrm{A}_{\mathrm{s}}$ for one HP8x36 and $0.50 \mathrm{f}_{\mathrm{y}} \mathrm{A}_{\mathrm{s}}+0.4 \mathrm{f}_{\mathrm{c}}^{\prime} \mathrm{A}_{\mathrm{c}}$ for one CFT8 where $A_{s}$ is the area of steel and $A_{c}$ is the area of concrete.

\subsubsection{Embedment Length}

The required embedment length was determined based on INDOT design requirements and was checked using Equation 5-1 given by Frosch (1999). The selected embedment length was $1 \mathrm{ft}-3$ in. which is the minimum provided by INDOT (1992a).

$$
\alpha \mathrm{V}_{\mathrm{n}}^{\text {Pipe }}=\phi\left(0.85 \mathrm{f}_{\mathrm{c}}^{\prime} \sqrt{\frac{\mathrm{A}_{2}}{\mathrm{~A}_{1}}}\right) \Phi_{\mathrm{OD}} \cdot \mathrm{d}
$$

where:

$$
\begin{aligned}
\alpha \quad= & \text { overstrength factor } \geq 1.25 \\
V_{\mathrm{n}}^{\text {Pipe }}= & \text { nominal pipe shear strength }\left(=0.6 \mathrm{f}_{\mathrm{yw}} \mathrm{A}_{\mathrm{w}}\right. \text { for shear yielding } \\
& \text { LRFD Eq.(F2-1) and }=\mathrm{M}_{\mathrm{p}} / \mathrm{L} \text { for flexural hinge shear) } \\
\phi \quad= & \text { strength reduction factor }=0.65 \text { (ACI 318-02, Sec. 9.3.2.2) } \\
\mathrm{A}_{\mathrm{w}}= & \text { shear area (web area for strong-axis bending steel pile, } 2 \text { times } \\
& \text { flange area for weak-axis bending pile, and cross-sectional area } \\
& \text { of pipe for concrete-filled steel tube pile) } \\
\mathrm{f}_{\mathrm{c}}^{\prime}= & \text { compressive strength of concrete, ksi } \\
\Phi_{\mathrm{OD}}= & \text { outside diameter of steel pipe, in. } \\
\mathrm{d}= & \text { embedment length, in. } \\
\sqrt{\frac{\mathrm{A}_{2}}{\mathrm{~A}_{1}}=}= & \text { confinement factor } \leq 2 \text { (ACI 318-02, Sec. 10.17). }
\end{aligned}
$$


Equation 5-1 provides for the embedment length of steel pipes under cyclic loading. This equation was extended for the calculation of embedment length of both the $\mathrm{H}$ and CFT piles. Based on this analysis, embedment length less than 15 -in. should be sufficient.

\section{$\underline{5.4 \quad \text { Construction Materials }}$}

\subsubsection{Concrete}

To represent a pile supported abutment in Indiana bridge construction, INDOT Class $\mathrm{C}$ concrete was used for the experimental program. This mix was supplied from Irving Materials Inc. (IMI), a local ready-mix concrete supplier. The mix included a maximum aggregate size of $3 / 4$ in. and a water-to-cement ratio of 0.38 . The specified slump was 4 in. Specific mix proportions are shown in Table 5.3.

Table 5.3: Mix Design

\begin{tabular}{|l|c|}
\hline \multicolumn{1}{|c|}{ Material } & Quantity \\
\hline$\# 8$ Gravel & 1840 pcy \\
\hline Sand $\# 23$ & 1240 pcy \\
\hline Cement & 655 pcy \\
\hline Water & 250 pcy \\
\hline Air & 6.6 ozcy \\
\hline Water Reducer & 20 ozcy \\
\hline
\end{tabular}

Compression tests were performed for all concrete used in the testing program. Modulus of elasticity tests were also conducted for the concrete used in the CFT piles since the stiffness of this material is of interest relative to the behavior of these piles. Both the compression and modulus of elasticity tests were performed on 6- by 12-in. cylinders after casting. The compression tests were performed using a 600-kip Forney compression testing machine according to ASTM-C39-01. A 120-kip Baldwin universal testing machine was used to perform the modulus of elasticity tests. The testing procedure followed ASTM-C469-02. 
The nine different test specimens presented in Table 5.2 were cast at five different times as listed in Table 5.4. Strength gain curves for the concrete abutments and concrete in the CFT piles are presented in Figures 5.3 and 5.4, respectively. As shown, the specimen compressive strengths at the time of testing are identified by specimen number. The compressive strength, $\mathrm{f}_{\mathrm{c}}$, for all specimens as well as the modulus of elasticity for the CFT piles on the day of testing are tabulated in Table 5.5.

Table 5.4: Casting Sequence

\begin{tabular}{|c|c|l|}
\hline Casting No. & Date & \multicolumn{1}{c|}{ Description } \\
\hline 1 & $2 / 13 / 2003$ & - Support Block Specimen 1 Abutment \\
\hline 2 & $4 / 22 / 2003$ & $\begin{array}{l}\text { - Specimen 2 and 5 Abutments } \\
\text { - CFT Piles for Specimens 7, 8 and 9 }\end{array}$ \\
\hline 3 & $6 / 11 / 2003$ & - Specimen 4 and 6 Abutments \\
\hline 4 & $7 / 17 / 2003$ & - Specimen 3 and 7 Abutments \\
\hline 5 & $8 / 4 / 2003$ & - Specimen 8 and 9 Abutments \\
\hline
\end{tabular}

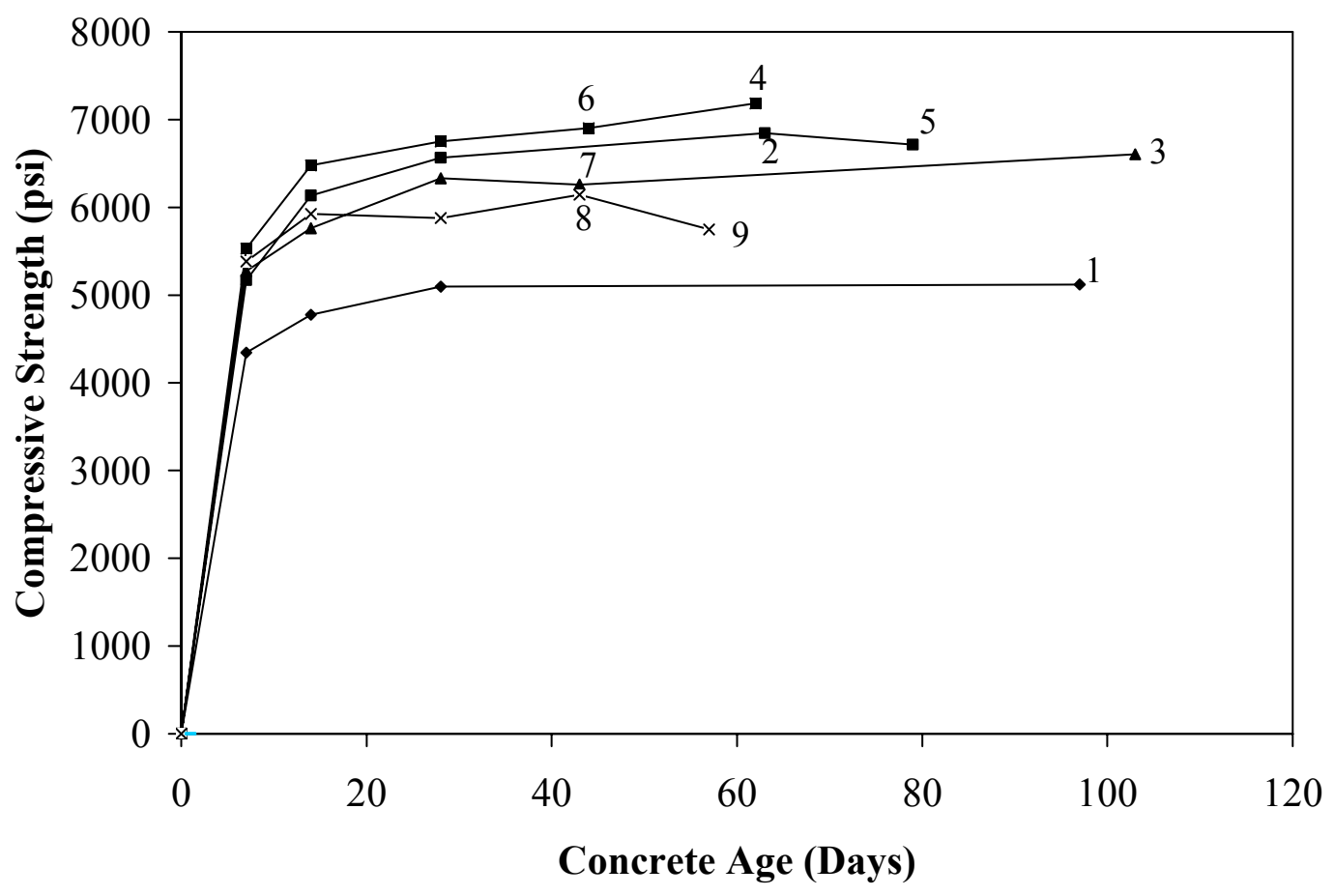

Figure 5.3: Abutment Concrete Compressive Strength Gain 


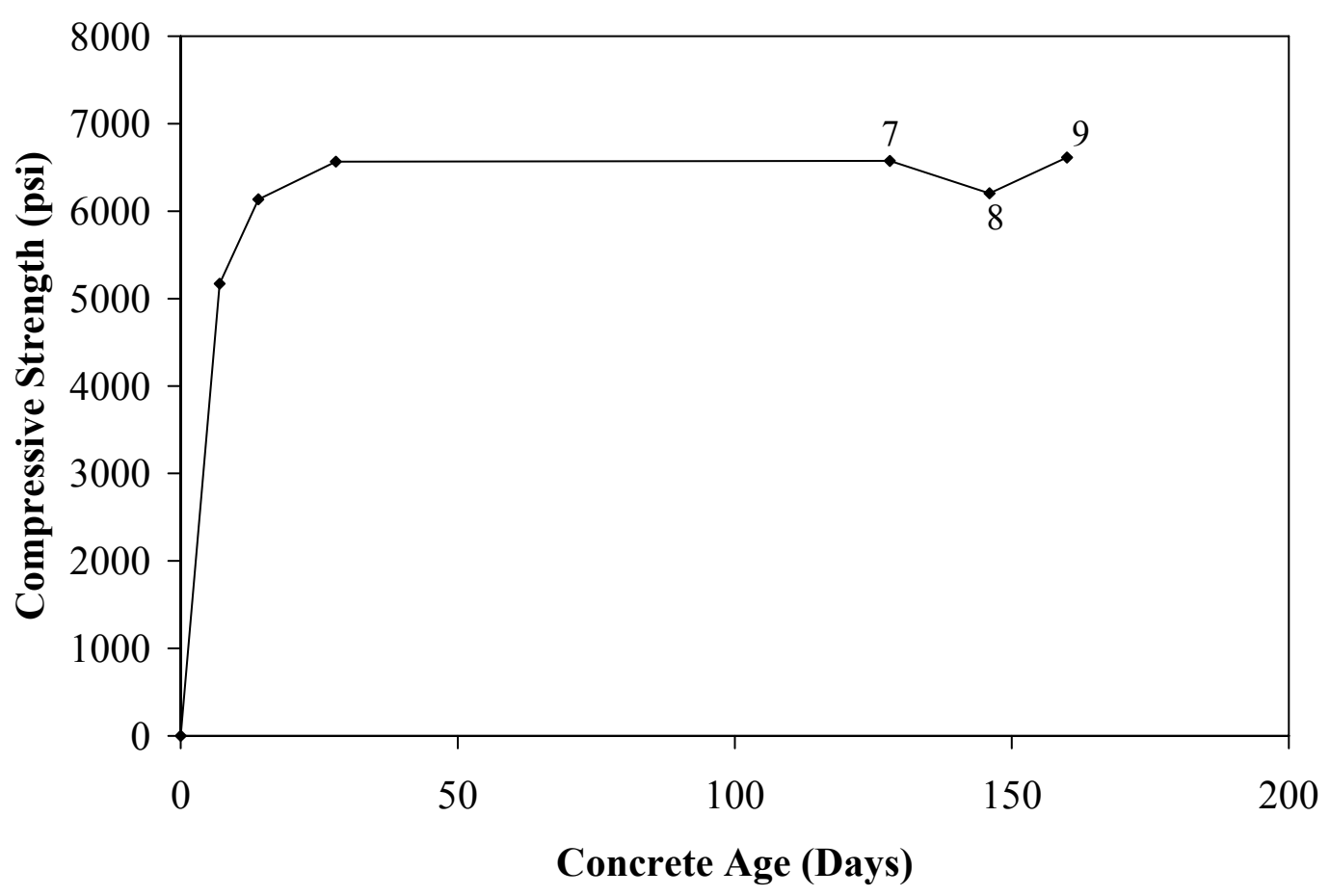

Figure 5.4: Compressive Strength Gain of Concrete in CFT Piles

Table 5.5: Average Concrete Compressive Strength and Modulus of Elasticity

\begin{tabular}{|c|c|c|c|c|c|}
\hline \multirow{3}{*}{ Specimen } & \multicolumn{2}{|c|}{ Concrete Strength, $\mathbf{f}_{\mathbf{c}}$} & Modulus of Elasticity, $\mathbf{E}_{\mathbf{c}}$ & \multicolumn{2}{|c|}{ Age at Testing } \\
\cline { 2 - 6 } & $\begin{array}{c}\text { Abutment } \\
(\mathbf{p s i})\end{array}$ & $\begin{array}{c}\text { CFT Pile } \\
(\mathbf{p s i})\end{array}$ & $\begin{array}{c}\text { CFT Pile } \\
(\mathbf{p s i})\end{array}$ & $\begin{array}{c}\text { Abutment } \\
(\mathbf{d a y s})\end{array}$ & $\begin{array}{c}\text { CFT Pile } \\
(\mathbf{d a y s})\end{array}$ \\
\hline 1 & 5100 & - & - & 97 & - \\
\hline 2 & 6800 & - & - & 63 & - \\
\hline 3 & 6600 & - & - & 103 & - \\
\hline 4 & 7200 & - & - & 62 & - \\
\hline 5 & 6700 & - & - & 79 & - \\
\hline 6 & 6900 & - & - & 44 & - \\
\hline 7 & 6300 & 6600 & 4000 & 43 & 128 \\
\hline 8 & 6100 & 6200 & 4100 & 43 & 146 \\
\hline 9 & 5700 & 6600 & 4000 & 57 & 160 \\
\hline
\end{tabular}




\subsubsection{Reinforcing Steel}

Grade 60, \#4 and \#6 reinforcing bars were used in the concrete abutment while \#5 reinforcing bars were used in the support block to provide minimum shrinkage and temperature reinforcement. As these material were part of the test setup and not part of the specimen under evaluation, material tests were not performed.

\subsubsection{Steel Piles}

The steel piles were $7 \mathrm{ft}-6$ in. long. Coupons that were 22-in. long were cut from each pile. The remaining $5 \mathrm{ft}-8$ in. long piles were used in the cyclic tests. Tests were conducted on the representative coupons cut from each specimen. A MTS universal test machine (Figure 5.5) was used to perform tensile tests according to ASTM A370-02. The dimensions of strips cut from the $\mathrm{H}$ piles and tubular piles (also known as shell/pipe piles) are shown in Figures 5.6 and 5.7, respectively. The total length of the coupons for the HP sections was $1 \mathrm{ft}-6$ in. while the total length of the tubular pile coupons was $1 \mathrm{ft}-$ 10 in. Fifteen steel coupons were cut from the pile flanges (6), webs (6), and pipe walls (3) for evaluating their material properties. Figure 5.8 shows samples of the coupons. Both yield and ultimate tensile strengths were obtained, and the results are presented in Table 5.6. Note that the coupons from the CFT piles presented in Figure 5.9 do not exhibit an obvious yield strength. Therefore, the $0.2 \%$ offset yield strength was determined. The stress-strain curves of all coupons are provided in Appendix H. 


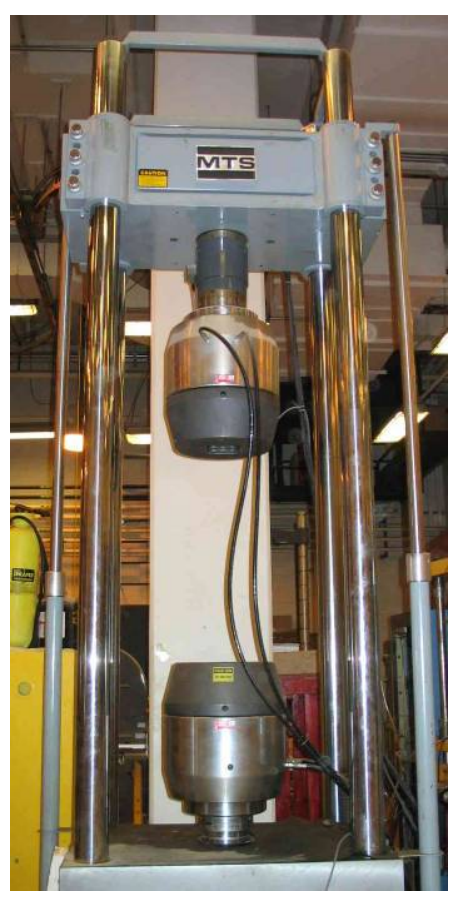

(a) MTS Universal Test Machine

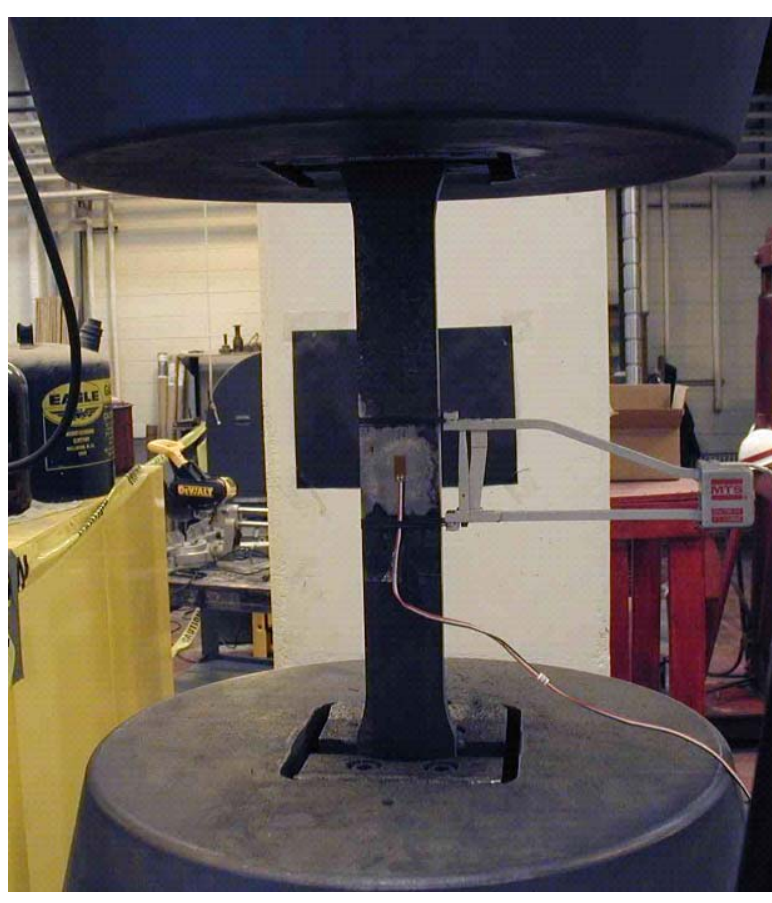

(b) Coupon

Figure 5.5: Coupon Test
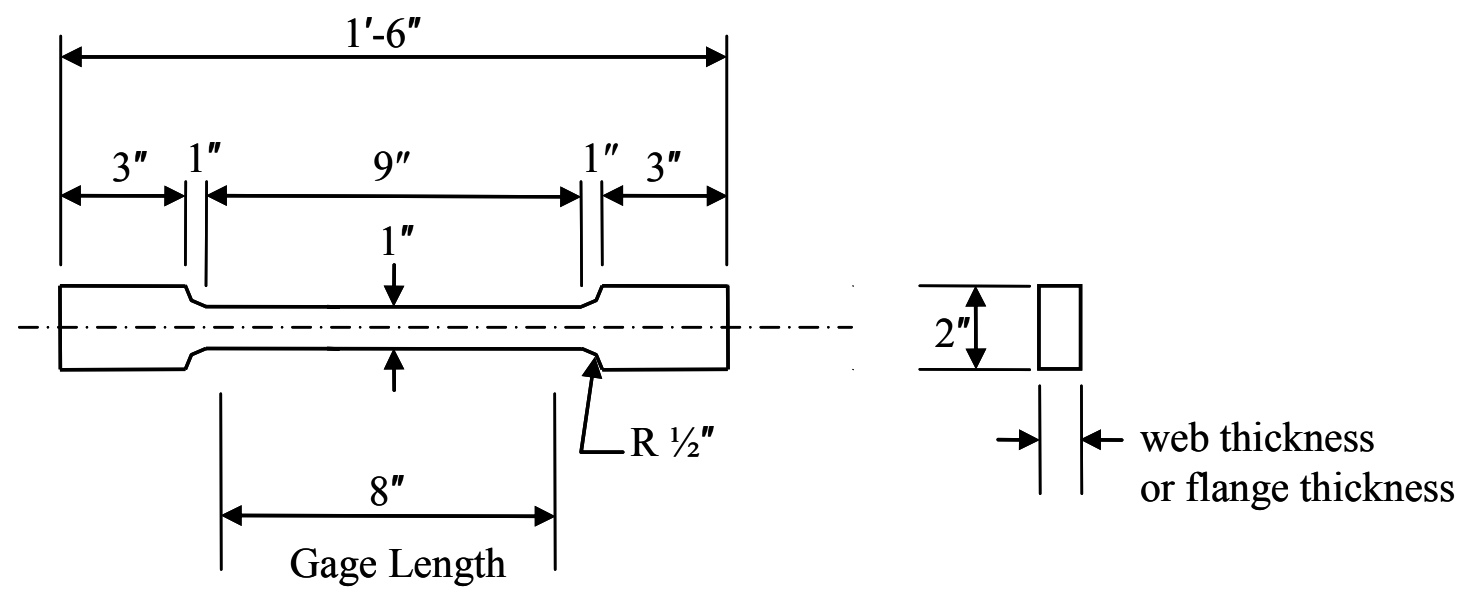

Figure 5.6: Rectangular Tension Test Specimens 


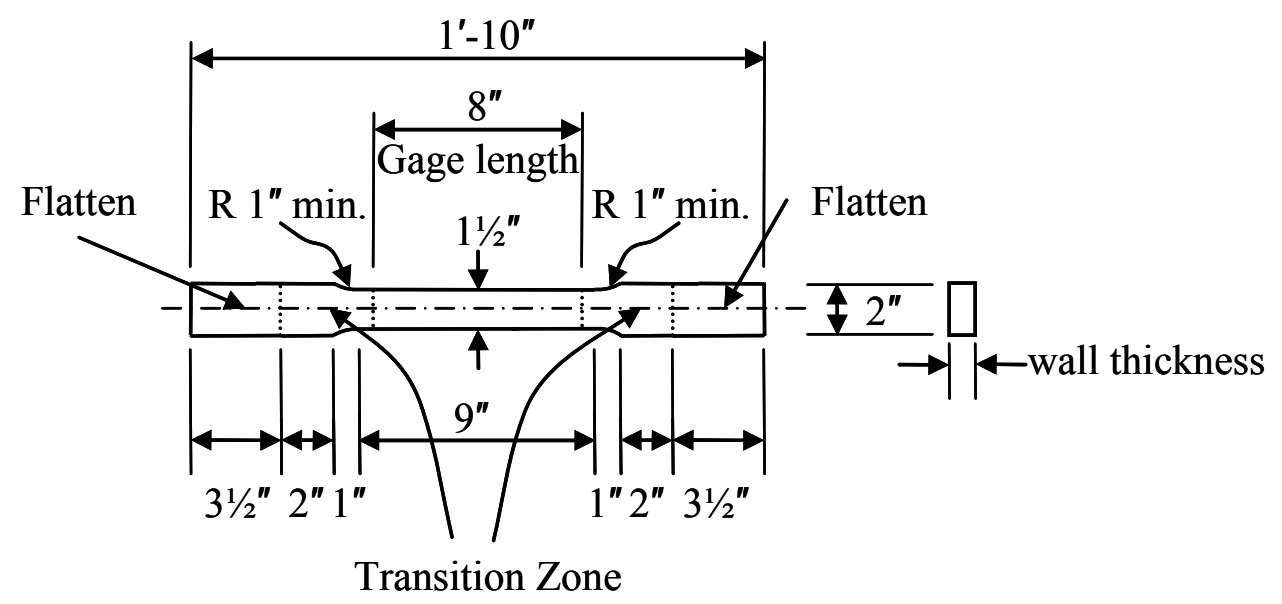

Figure 5.7: Tubular Tension Test Specimens

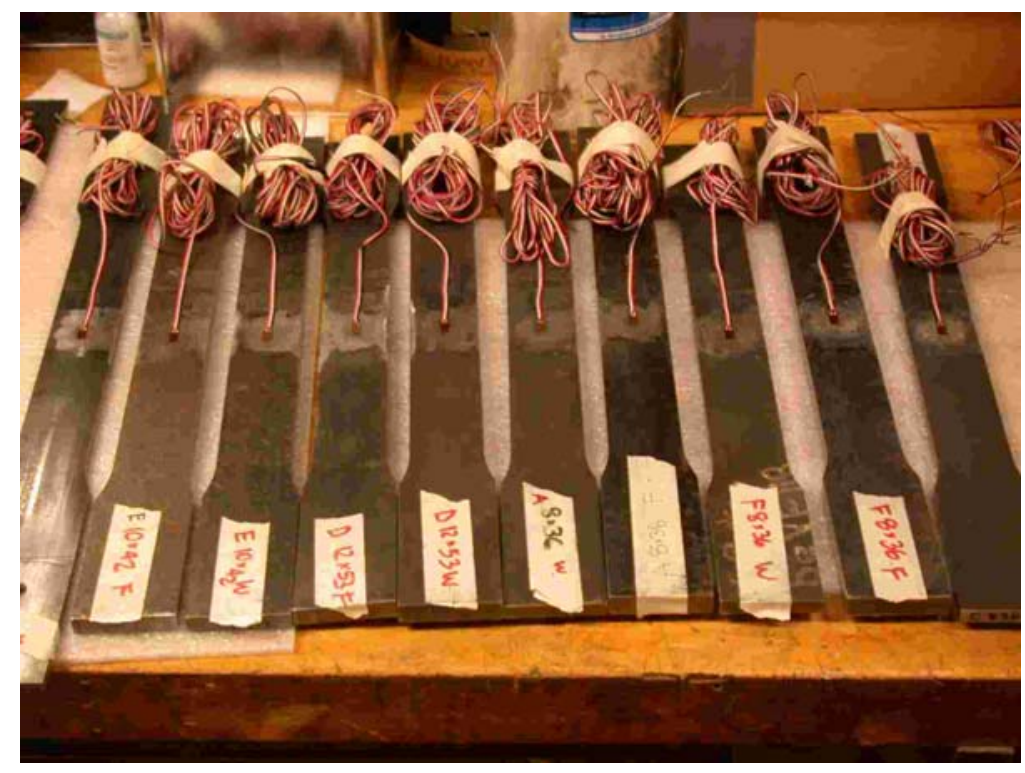

Figure 5.8: Coupon Specimens

Table 5.7 provides the dimension, and section properties for the steel $\mathrm{H}$ piles as obtained from AISC-LRFD (2001). Tables 5.8 and 5.9 provide the dimensions and transformed section properties calculated based on Section 4.3.3 for the CFT piles, respectively. 
Table 5.6: The Coupon Test Results

\begin{tabular}{|c|c|c|c|c|c|}
\hline \multirow{2}{*}{ Specimen } & Location & $\begin{array}{c}\text { Yield } \\
\text { Strength } \\
\text { (ksi) }\end{array}$ & $\begin{array}{c}\text { Yield } \\
\text { Strain } \\
\text { (in./in.) }\end{array}$ & $\begin{array}{c}\text { Ultimate } \\
\text { Strength } \\
\text { (ksi) }\end{array}$ & $\begin{array}{c}\text { Ultimate } \\
\text { Strain } \\
\text { (in./in.) }\end{array}$ \\
\hline \multirow{2}{*}{1} & Flange & 48 & 0.0017 & 67 & 0.1821 \\
\cline { 2 - 6 } & Web & $46^{*}, * *$ & 0.0011 & 45 & 0.1892 \\
\hline \multirow{2}{*}{2} & Flange & 48 & 0.0017 & 66 & 0.1780 \\
\cline { 2 - 6 } & Web & 46 & 0.0016 & 66 & 0.2103 \\
\hline \multirow{2}{*}{3} & Flange & 47 & 0.0016 & 66 & 0.1966 \\
\cline { 2 - 6 } & Web & $46^{* *}$ & 0.0016 & 66 & 0.1792 \\
\hline \multirow{2}{*}{4} & Flange & 47 & 0.0016 & 66 & 0.1792 \\
\cline { 2 - 6 } & Web & 47 & 0.0016 & 66 & 0.1925 \\
\hline \multirow{2}{*}{5} & Flange & 40 & 0.0014 & 57 & 0.1981 \\
\cline { 2 - 6 } & Web & 38 & 0.0013 & 57 & 0.2429 \\
\hline \multirow{2}{*}{6} & Flange & 41 & 0.0014 & 61 & 0.2279 \\
\cline { 2 - 6 } & Web & 49 & 0.0017 & 71 & 0.2301 \\
\hline 7 & - & 42 & 0.0034 & 65 & 0.1938 \\
\hline 8 & - & 54 & 0.0039 & 68 & 0.1637 \\
\hline 9 & - & 52 & 0.0038 & 68 & 0.1731 \\
\hline \multirow{2}{*}{7} & & &
\end{tabular}

This was the first coupon test conducted. A problem occurred during testing. A yield strength of $33 \mathrm{ksi}$ was measured; however, a yield strength of $46 \mathrm{ksi}$ was assumed because the yield strengths of the web sections from Specimens 2, 3, and 4 were approximately 46 ksi. These specimens were from the same pile section.

**Fracture did not occur inside the gage length. 


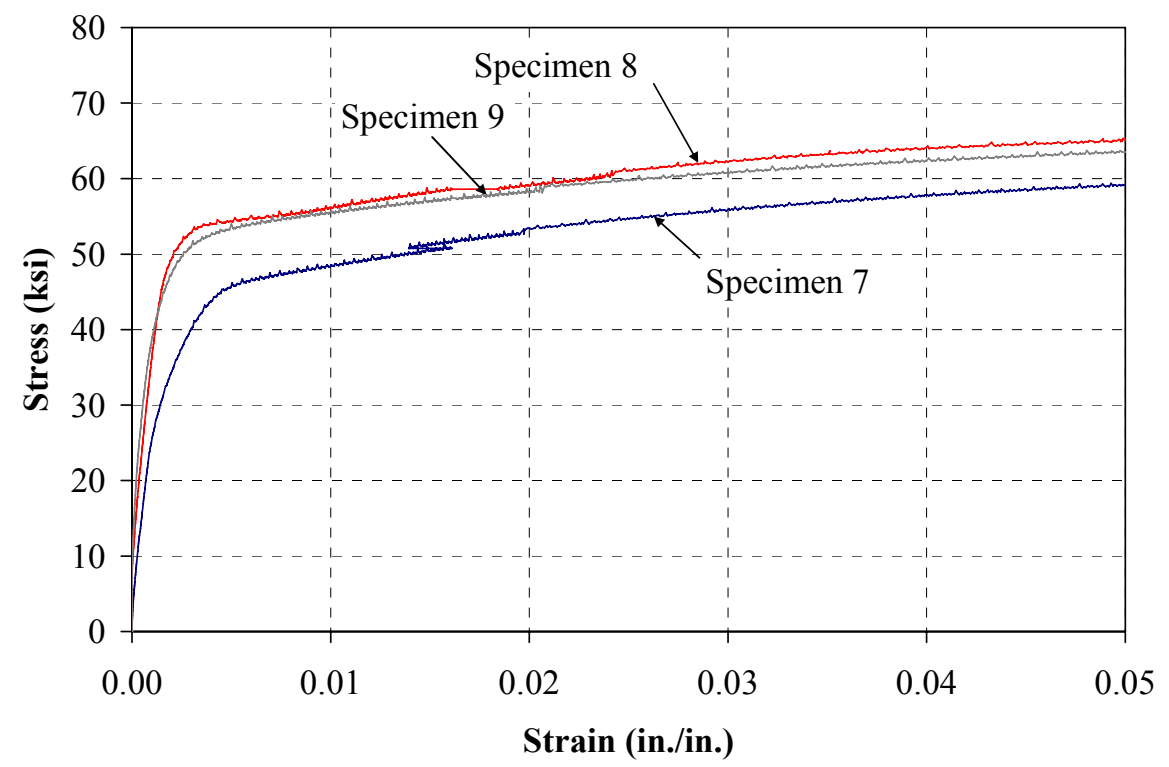

Figure 5.9: Initial Stress-Strain Relationship of Specimens 7, 8, and 9

Table 5.7: Nominal Cross-Sectional Properties of Steel H Piles

\begin{tabular}{|c|c|c|c|c|c|c|c|c|c|c|c|}
\hline Section & $\begin{array}{c}A \\
\left.\text { (in. }^{2}\right)\end{array}$ & $\begin{array}{c}d \\
\text { (in.) }\end{array}$ & $\begin{array}{c}t_{w} \\
\text { (in.) }\end{array}$ & $\begin{array}{c}\mathbf{b}_{\mathrm{f}} \\
\text { (in.) }\end{array}$ & $\begin{array}{c}\mathbf{t}_{\mathrm{f}} \\
\text { (in.) }\end{array}$ & $\begin{array}{c}I_{x} \\
\left(\text { in. }^{4}\right)\end{array}$ & $\begin{array}{c}I_{y} \\
\left(\text { in. }^{4}\right)\end{array}$ & $\begin{array}{c}S_{x} \\
\left(\text { in. }^{3}\right)\end{array}$ & $\begin{array}{c}S_{y} \\
\left(\text { in. }^{3}\right)\end{array}$ & $\begin{array}{c}Z_{x} \\
\text { (in. }{ }^{3} \text { ) }\end{array}$ & $\begin{array}{c}\mathrm{Z}_{\mathrm{y}} \\
\text { (in. }^{3} \text { ) }\end{array}$ \\
\hline HP8x36 & 10.6 & 8.02 & 0.445 & 8.15 & 0.445 & 119 & 40.3 & 29.8 & 9.88 & 33.6 & 15.2 \\
\hline HP10x42 & 12.4 & 9.70 & 0.415 & 10.1 & 0.420 & 210 & 71.7 & 43.4 & 14.2 & 48.3 & 21.8 \\
\hline HP12x53 & 15.5 & 11.8 & 0.435 & 12.0 & 0.435 & 393 & 127 & 66.7 & 21.1 & 74.0 & 32.2 \\
\hline
\end{tabular}

Table 5.8: Dimensions of CFT Piles

\begin{tabular}{|c|c|c|c|}
\hline Specimen & $\begin{array}{c}\text { Outer Diameter } \\
\text { (in.) }\end{array}$ & $\begin{array}{c}\text { Inner Diameter } \\
\text { (in.) }\end{array}$ & $\begin{array}{c}\text { Wall Thickness } \\
\text { (in.) }\end{array}$ \\
\hline CFT8.625x0.188 & 8.625 & 8.249 & 0.188 \\
\hline CFT10.75x0.250 & 10.75 & 10.25 & 0.250 \\
\hline
\end{tabular}

Table 5.9: Transformed Section Properties of CFT Piles

\begin{tabular}{|c|c|c|c|c|}
\hline Pile Section & $A_{e}\left(\right.$ in. $\left.^{2}\right)$ & d (in.) & I $_{\text {steel ring }}\left(\right.$ in. $\left.^{4}\right)$ & $\overline{I_{e}\left(\text { in. }^{4}\right)}$ \\
\hline CFT8.625x0.188 & 11.6 & 8.625 & 44.4 & 72.6 \\
\hline CFT10.75x 0.250 & 18.5 & 10.75 & 114 & 181 \\
\hline
\end{tabular}




\subsection{Specimen Construction}

\subsubsection{Specimen Support Block}

A concrete block was used to support the abutment-pile specimens for the testing setup. The dimension of the concrete base was $3.5 \times 4.5 \times 4.0 \mathrm{ft}(\mathrm{W} \times \mathrm{L} \times \mathrm{H})$ as illustrated in Figure 5.10. Twelve-\#5 longitudinal reinforcing bars and eight-\#5 stirrups were used to provide minimum shrinkage and temperature reinforcement. INDOT Class C concrete (Section 5.4.1) was provided for the block. The assembled formwork for the support block is shown in Figure 5.11.

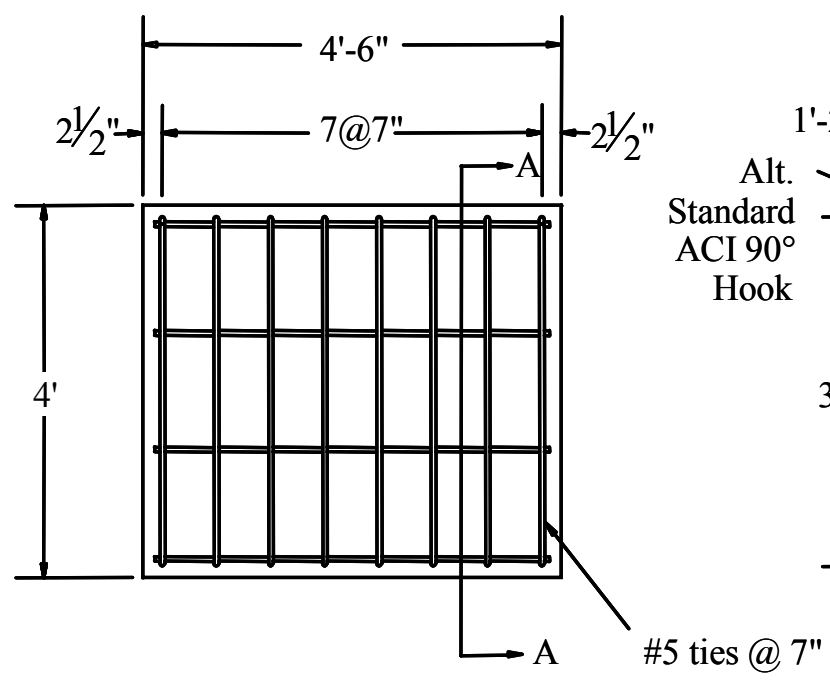

SIDE VIEW

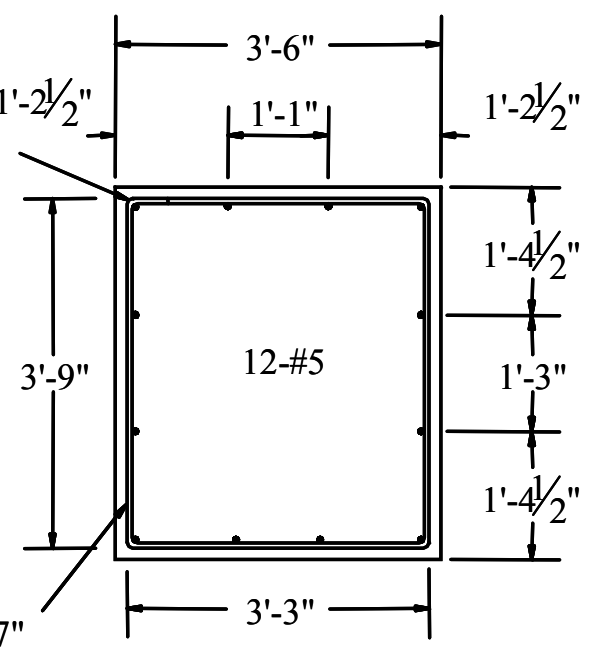

SECTION A - A

NOTE: 1.5" CLEAR COVER

\section{Figure 5.10: Support Block Details}

Formwork was constructed by the following sequence. First, the side forms were attached to the base using wood screws. Second, adjacent side forms were bolted together by steel angles. Then, form oil was applied to provide ease in form removal. Then, wales and ties were used to maintain dimensional tolerance and brace the formwork during casting (Figure 5.11). Finally, four single flared loops were attached to the formwork by four coil bolts for lifting the concrete base after casting as shown in Figure 5.12. The support block following casting is shown in Figure 5.13. 


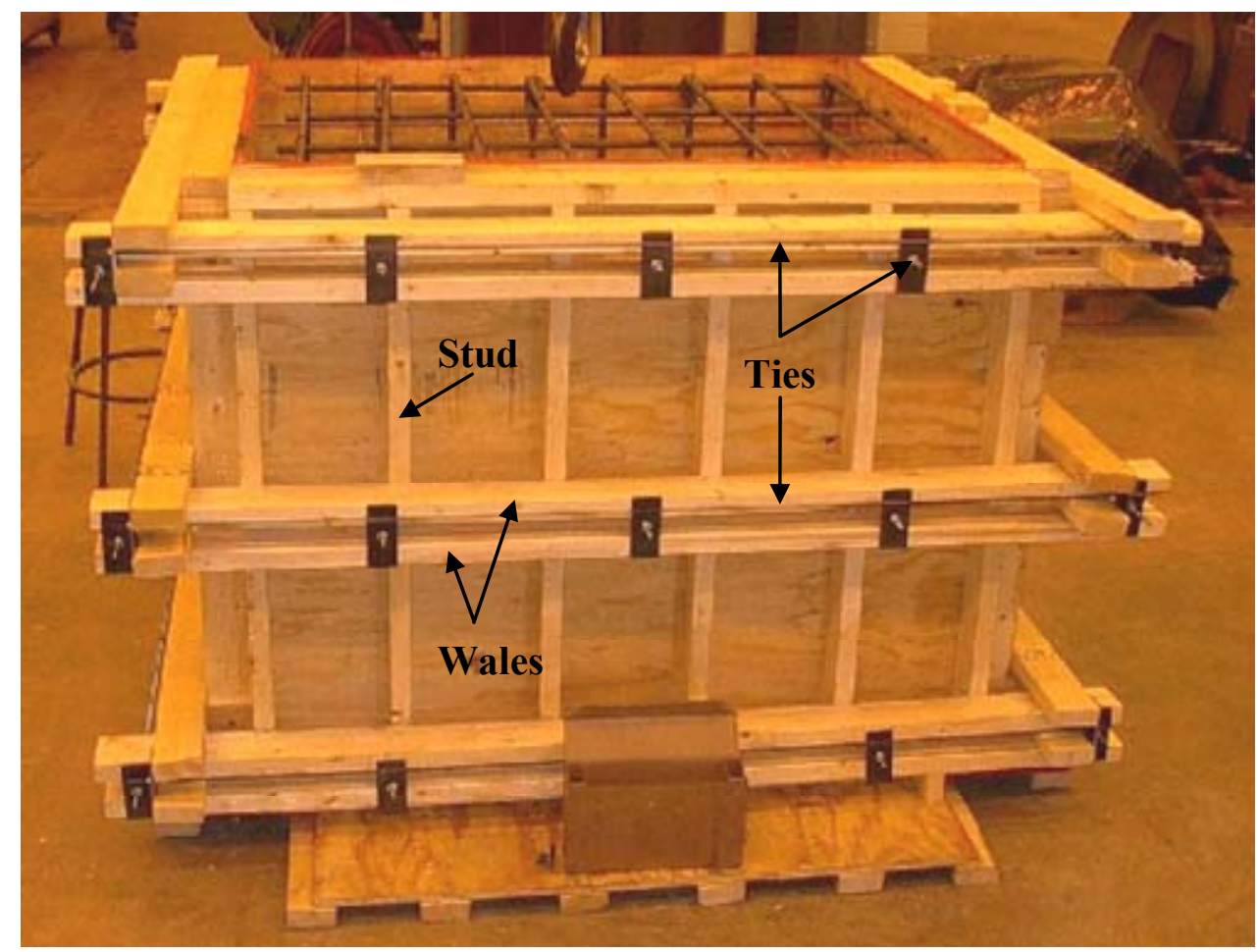

Figure 5.11: Support Block Formwork

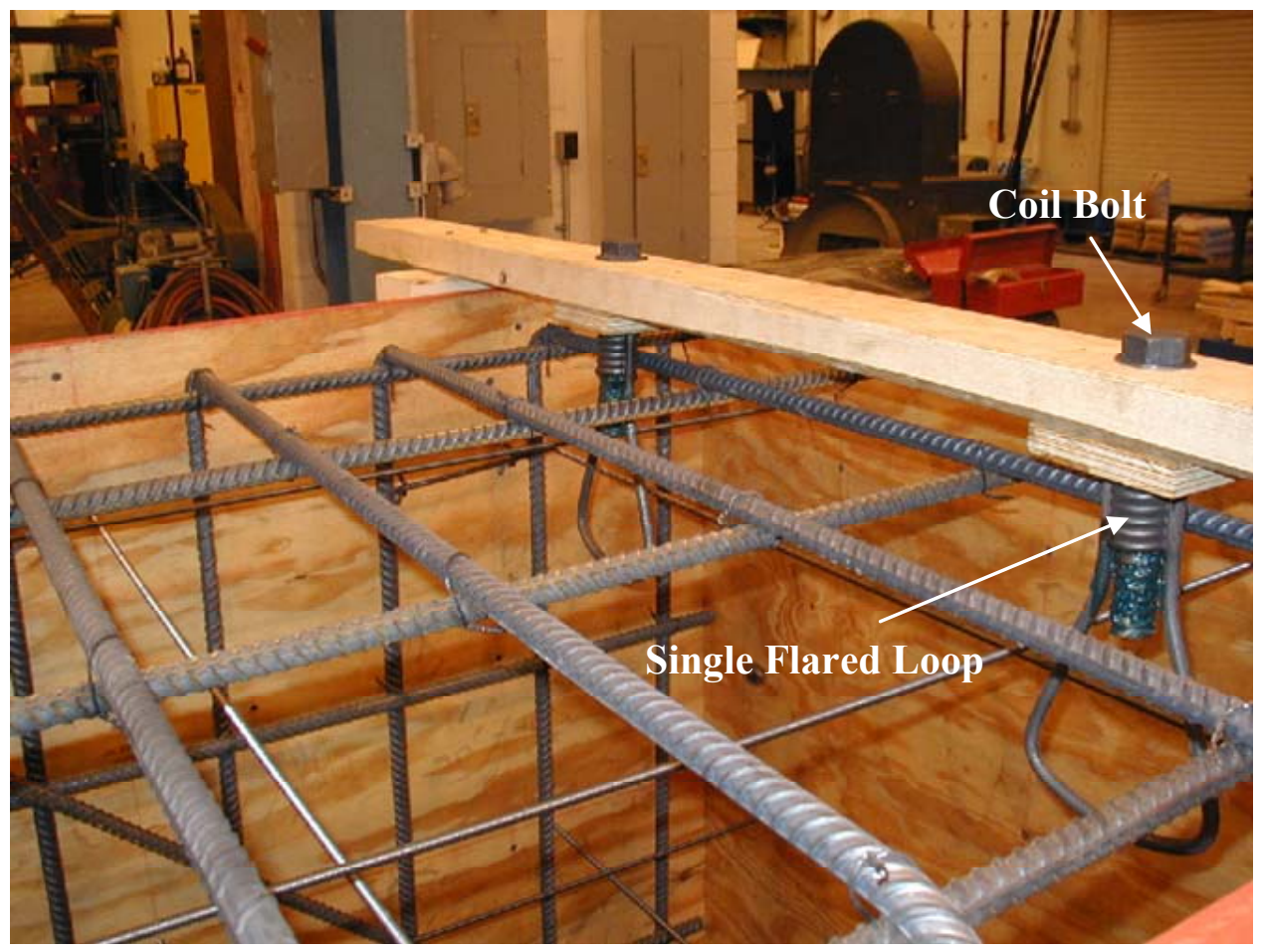

Figure 5.12: Single Flared Loops for Support Block Formwork 


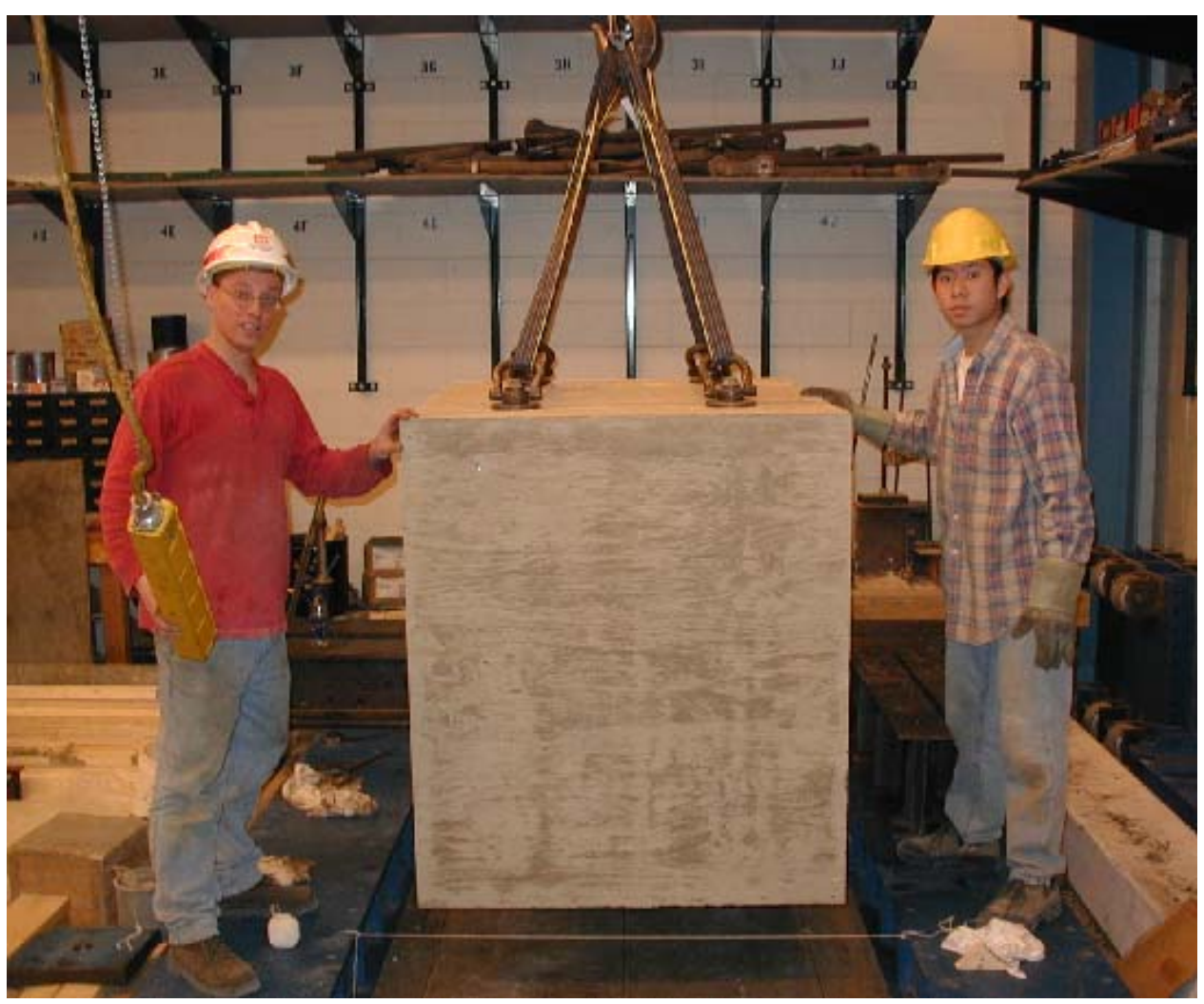

Figure 5.13: Support Block

\subsubsection{Concrete Abutment Construction}

A concrete abutment was cast to represent a fixed connection to the pile specimen. The abutment was $2.5 \times 4 \times 2.5 \mathrm{ft}(\mathrm{W} \times \mathrm{L} \times \mathrm{H})$ as illustrated in Figure 5.14. Figure 5.15 shows the geometry and details of the typical abutment used in the test. The abutment forms were constructed in the same sequence as the support block forms. Wales and ties were also used to resist the lateral pressure during casting (Figure 5.16). Four flared loops were attached to the side of the formwork and coil bolts were then inserted into the flared loops and greased to facilitate in form removal as shown in Figure 5.17. To prevent bowing during casting, $1 / 4 " \varnothing$ rods were inserted through the forms, and the nuts were tightened. Figures 5.18 and 5.19 show the concrete abutment form and concrete abutment after casting. 


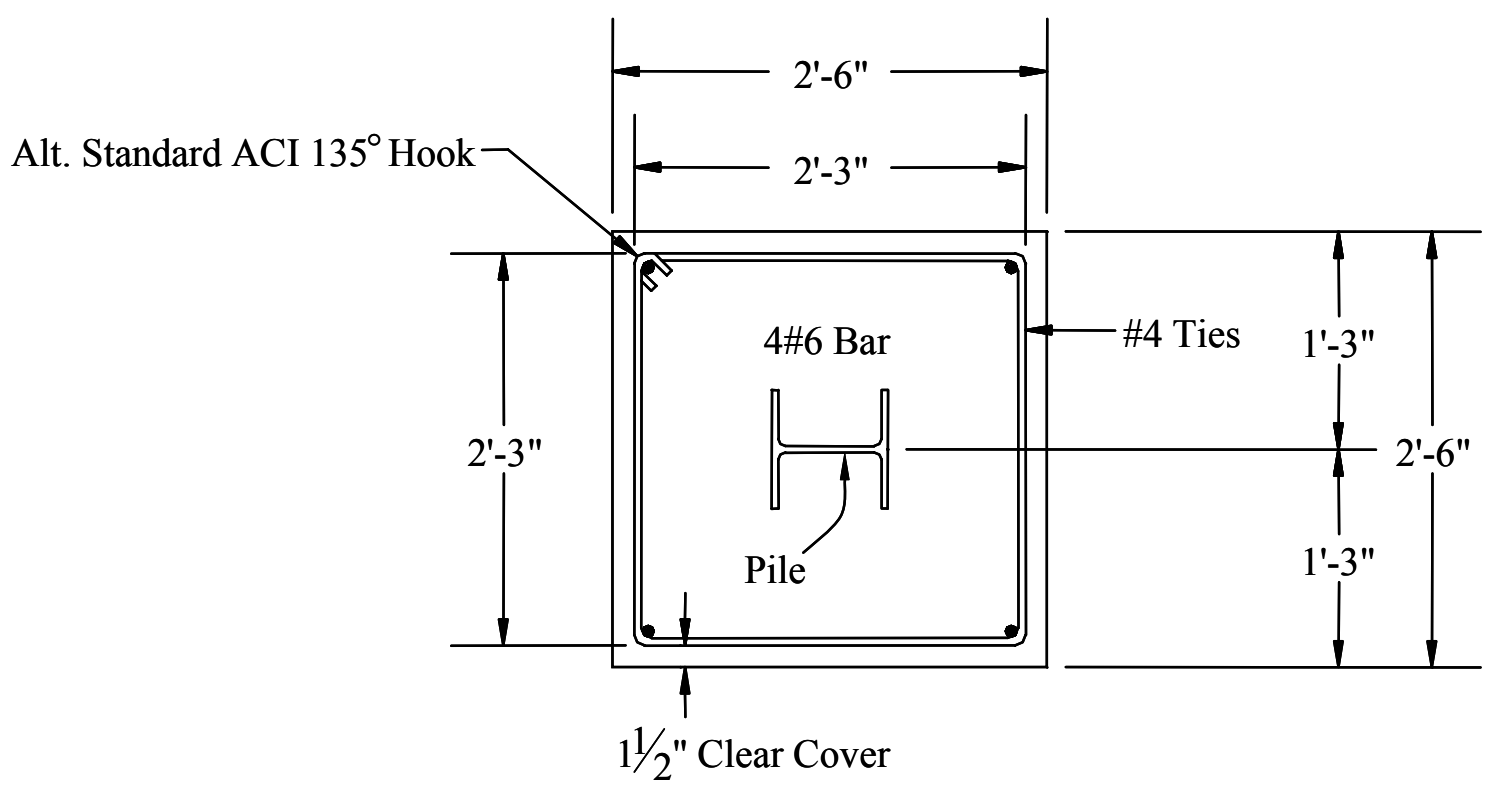

Figure 5.14: Concrete Abutment Cross Section

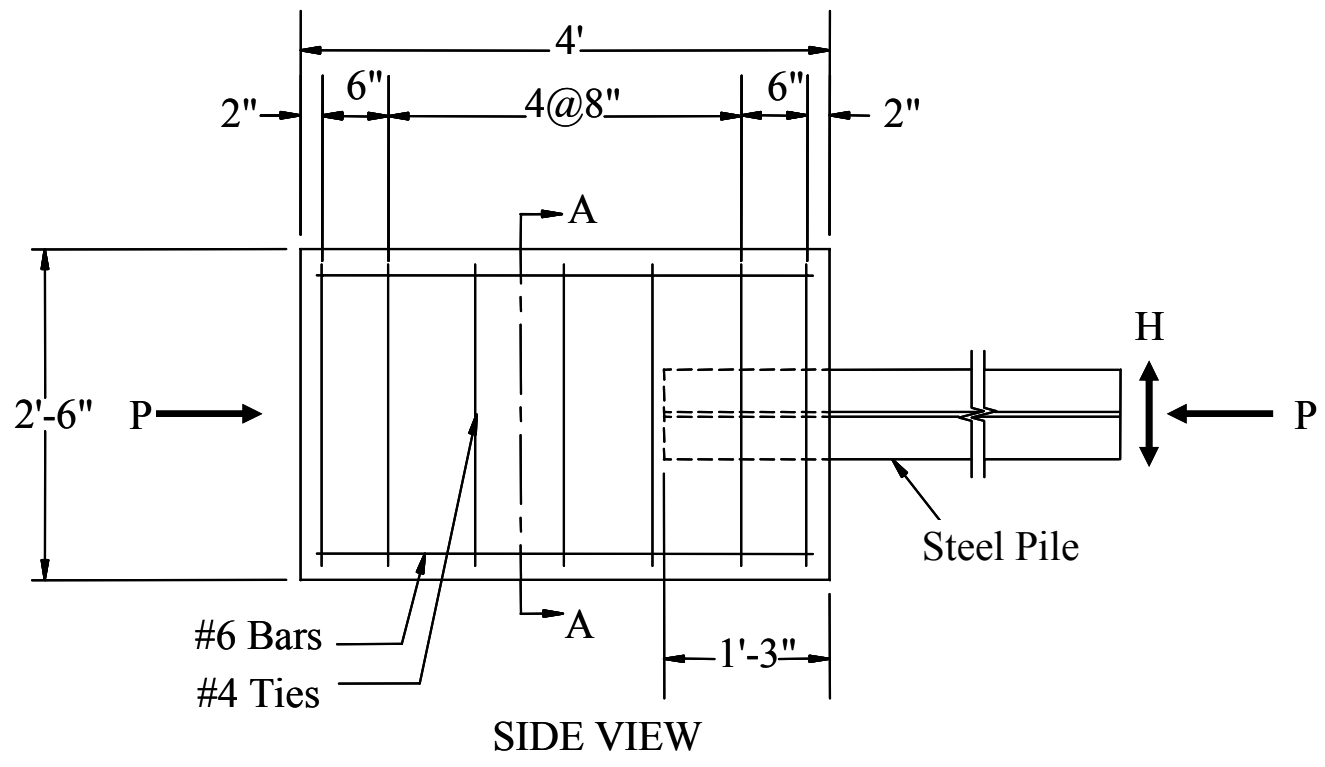

Figure 5.15: Concrete Abutment Details 


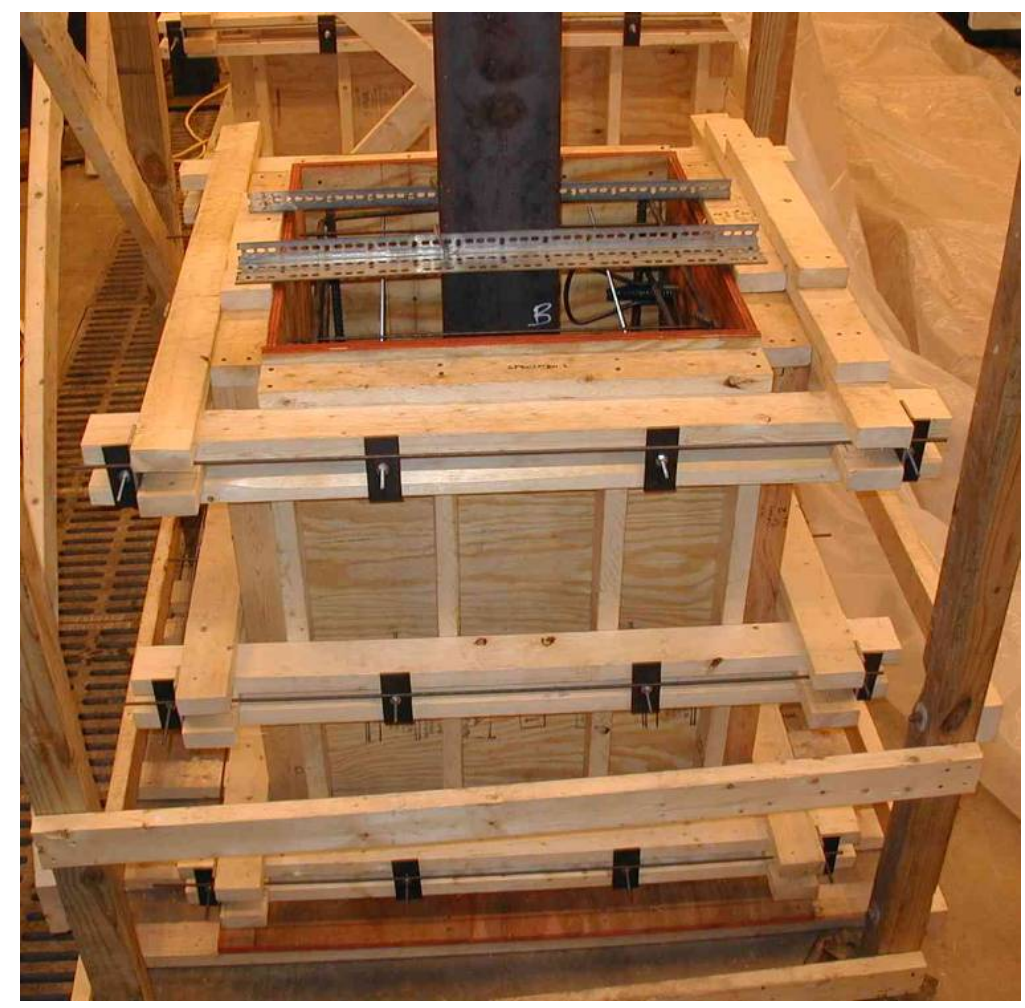

Figure 5.16: Wale and Tie System for Concrete Abutment Form

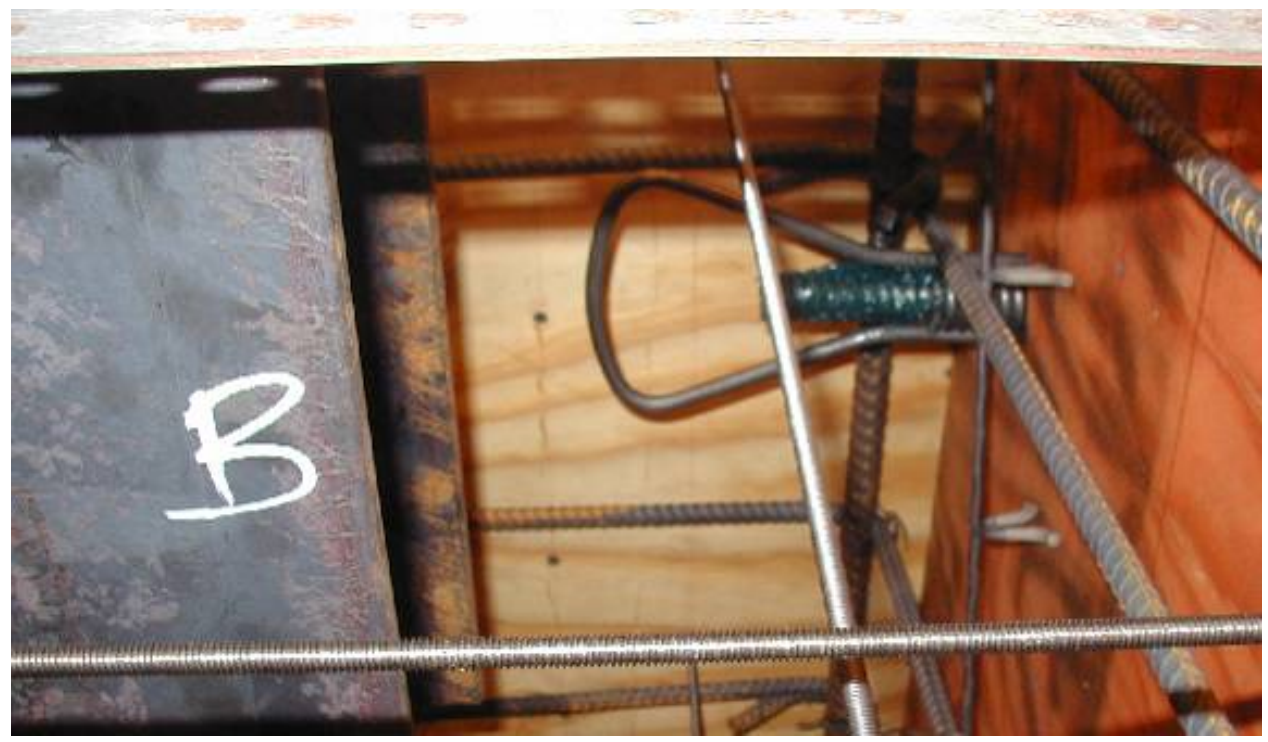

Figure 5.17: Flared Loop for Concrete Abutment Form 


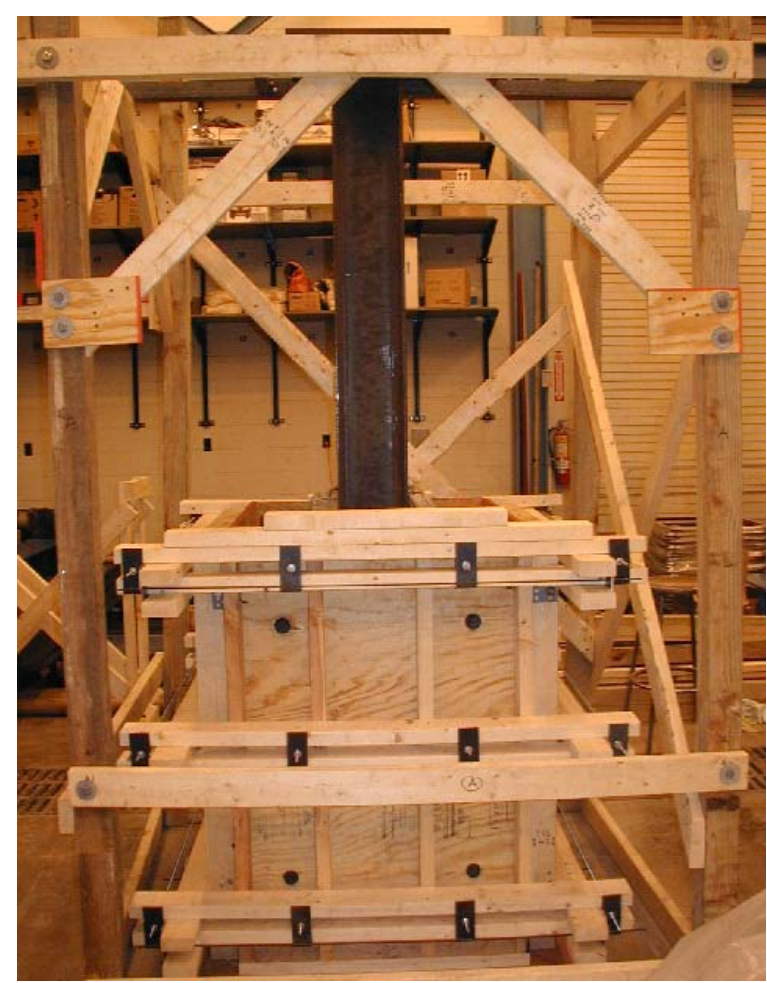

Figure 5.18: Concrete Abutment Form

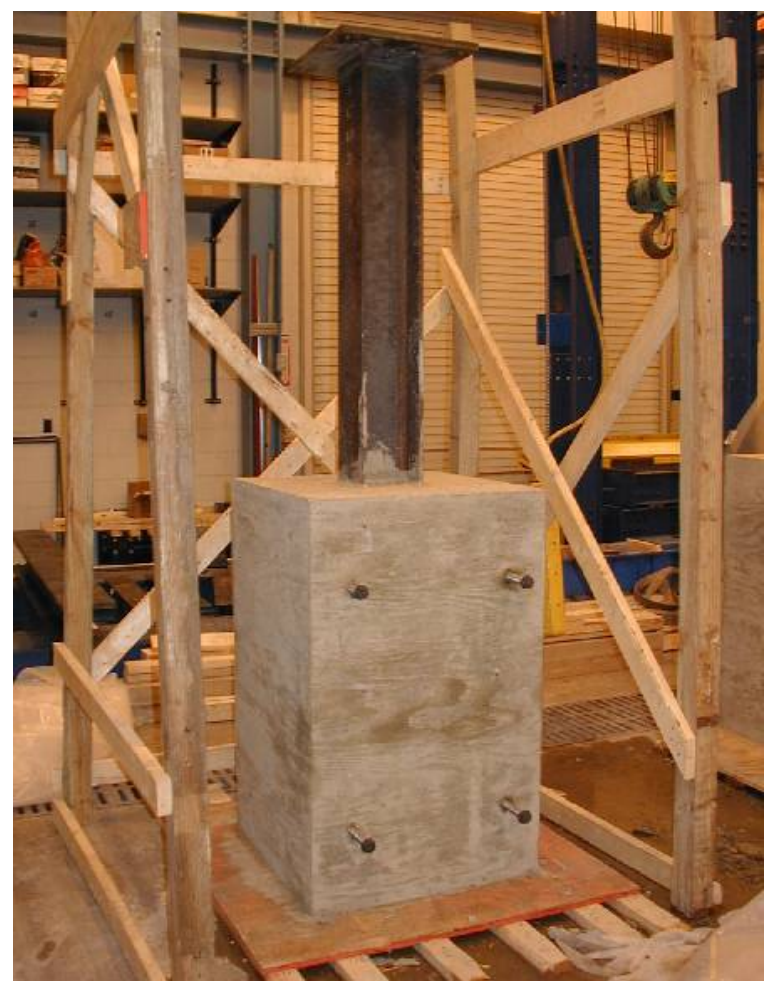

Figure 5.19: Concrete Abutment after Casting 


\subsubsection{Steel Pile-Abutment Connection}

A steel pile was attached to the concrete abutment form as shown in Figure 5.15. An 18- x 18- x 1-in. steel plate was welded to the steel pile allowing hanging of the pile during casting. The steel pile was lifted and supported by steel angles at the top of a wooden frame as shown in Figure 5.20. The steel pile was braced by two steel angles at the abutment-pile connection to prevent movement during casting (Figure 5.21).

\subsubsection{Clamping System}

The concrete abutment was clamped to the laboratory floor by two steel beams (W10x100) and sixteen $3 / 4 "-\varnothing$ Dywidag threadbars. Figure 5.22 illustrates the clamping system of Specimens 1 and 2. Concerns developed regarding confinement at the abutment-pile connection after testing Specimens 1 and 2; therefore, the clamping beams were moved to the middle of the concrete abutment for Specimens 3 to 9 as shown in Figure 5.23 to reduce the effect of confinement on the abutment-pile connection. A clamping force of 80 kips on each end of the beam was applied through four 100-kip hydraulic rams at the top of each beam. The total clamping force, therefore, was 320 kips.

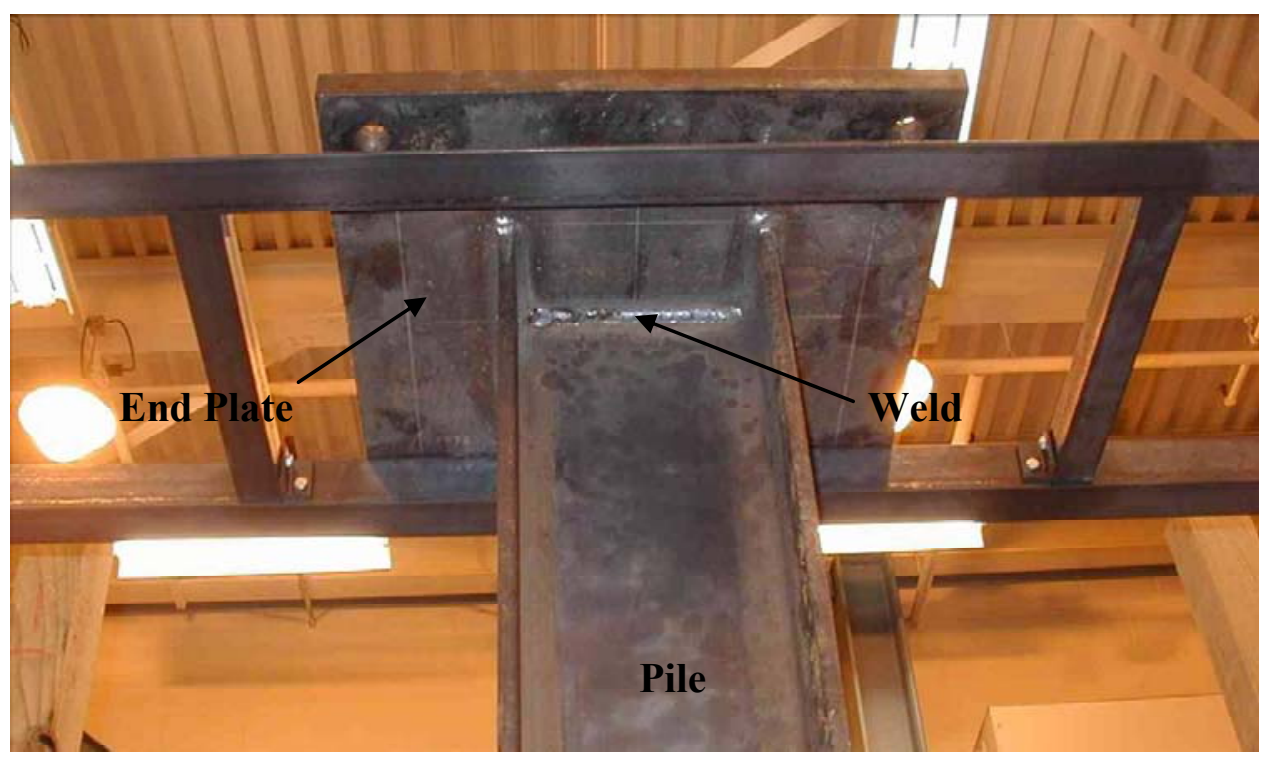

Figure 5.20: Hanging Steel Pile 


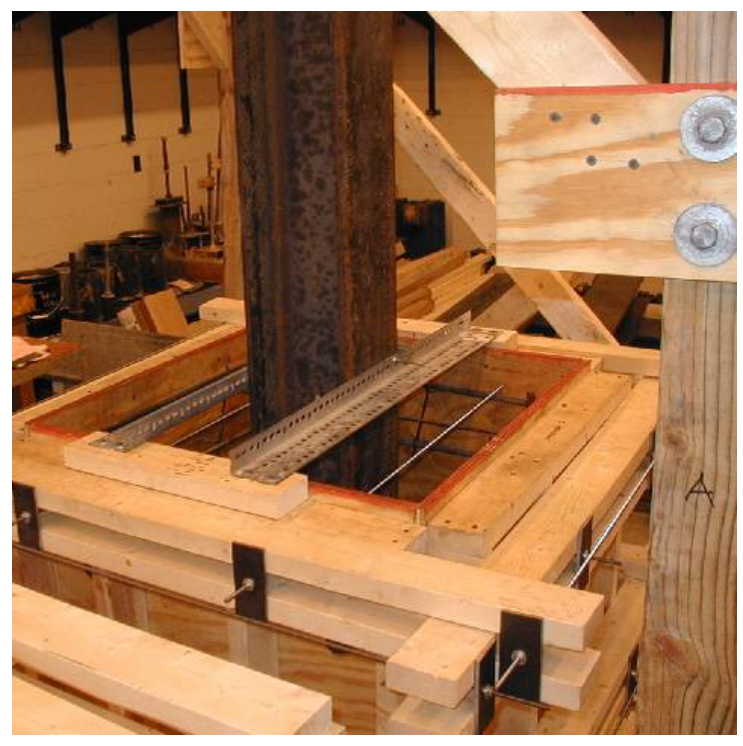

Figure 5.21: Pile Braced by Steel Angles

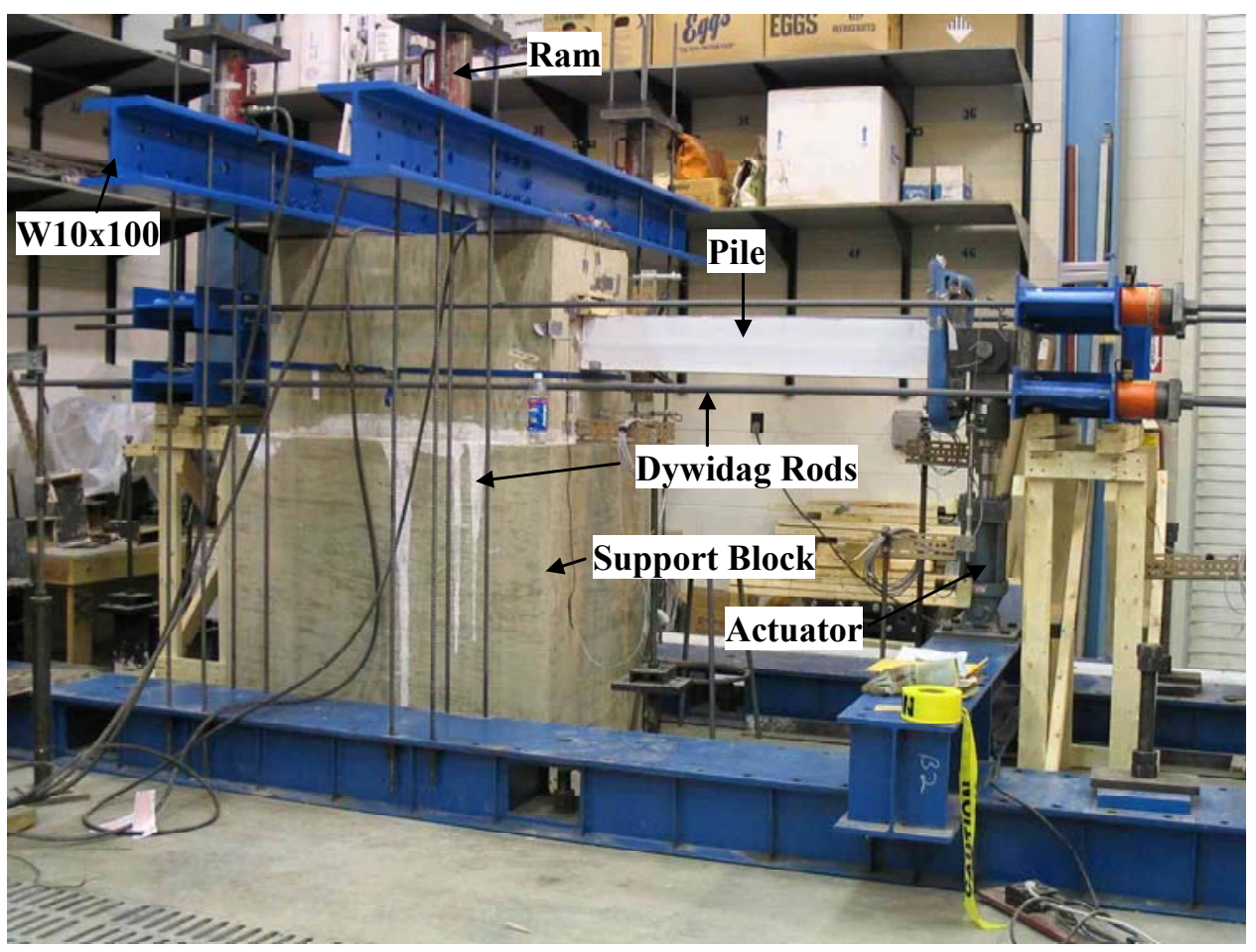

Figure 5.22: Clamping System 


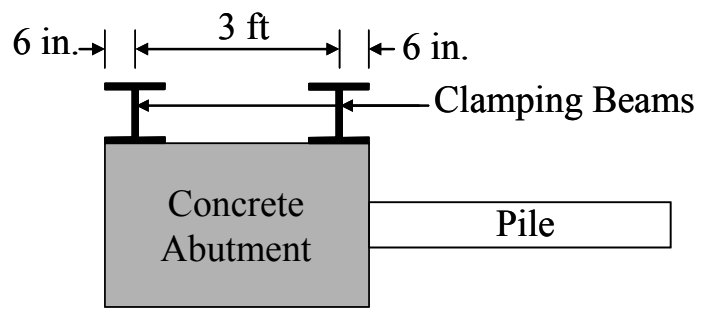

(a) Specimens 1 and 2

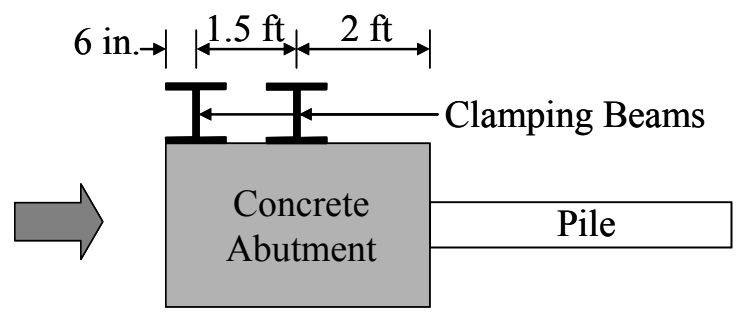

(b) Specimens 3 to 9

Figure 5.23: Clamping Beams

\subsubsection{Self-Equilibrating Load System}

A self-equilibrating load system consisting of four 1-in. $\varnothing$ Dywidag threadbars tied through W12x30 beams was used to provide axial load to the specimen. At the back of the concrete abutment, two W12x30 axial beams called "BA1" (Figure 5.24) were connected by two steel angles and WT sections. Four low-friction ball bearings were attached to each WT section to enable vertical movement of the axial load system. This system was designed to provide axial load while minimizing shear produced by the axial system. At the tip of the pile, two W12x30 axial beams called "BA2," were connected by two steel angles and a clevis plate ( $18 \times 18 \times 1$ in.) as shown in Figure 5.25. Four 1 -in. $\varnothing$ Dywidag threadbars tied through the axial beams, BA1 and BA2 were used to apply axial load to the pile specimen. The axial load was applied using four 30-ton hydraulic rams that were attached to the axial beams at the back of the concrete abutment. Hexagonal nuts and anchor plates were attached on each side of the Dywidag threadbars. The nuts were tightened when the axial load reached a specified value to maintain a constant axial load. 


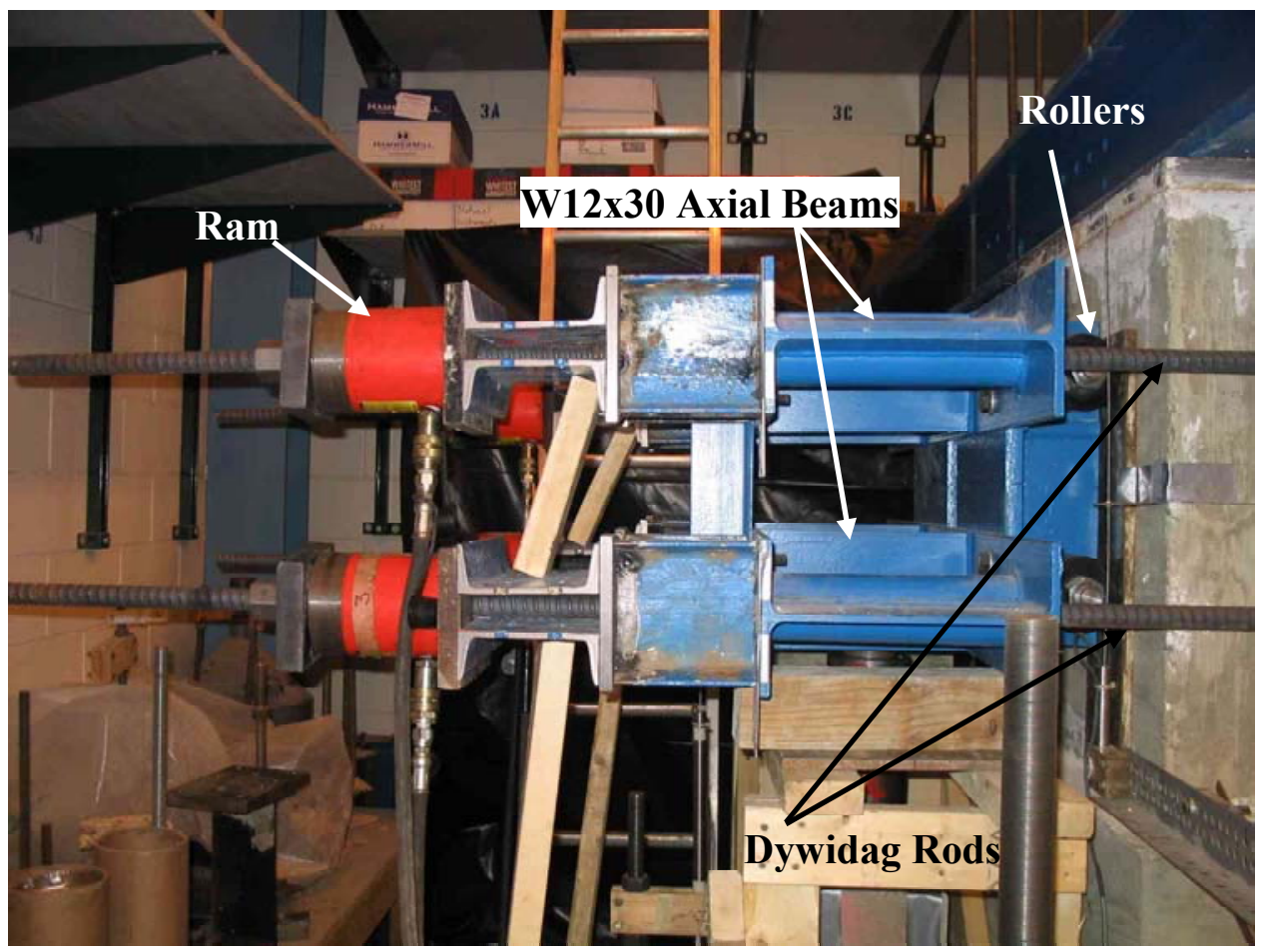

Figure 5.24: Axial Beam behind Concrete Abutment (BA1)

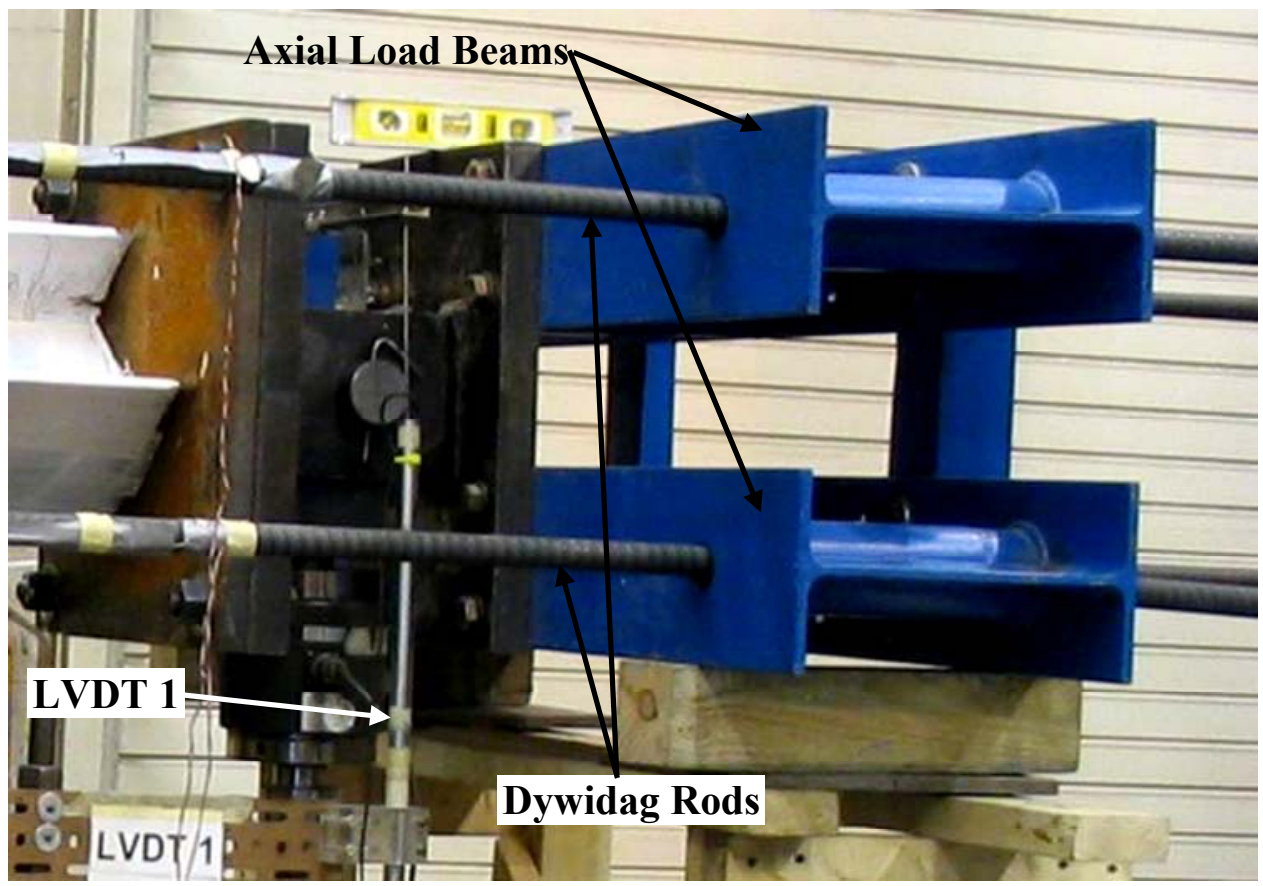

Figure 5.25: Axial Beam at the Pile Tip (BA2) 


\subsubsection{Casting and Curing}

After the concrete had been placed into the forms, the specimen and concrete base were screeded and finished with trowels. The specimens were then allowed to set for two hours before wet burlap and plastic sheeting were used to cover the exposed top surfaces. Both wet burlap and the plastic were removed after a three day wet cure.

\section{$5.6 \quad$ Test Setup}

The piles were cyclically tested as a cantilever to simulate in-service behavior (Figure 5.26). As soil resistance was not included over the pile length, this test was considered to provide conservative results. For the HP8x36 bending about its $45^{\circ}$ axis, a bracing frame was provided to prevent the pile from moving out-of-plane movement (Figure 5.27).

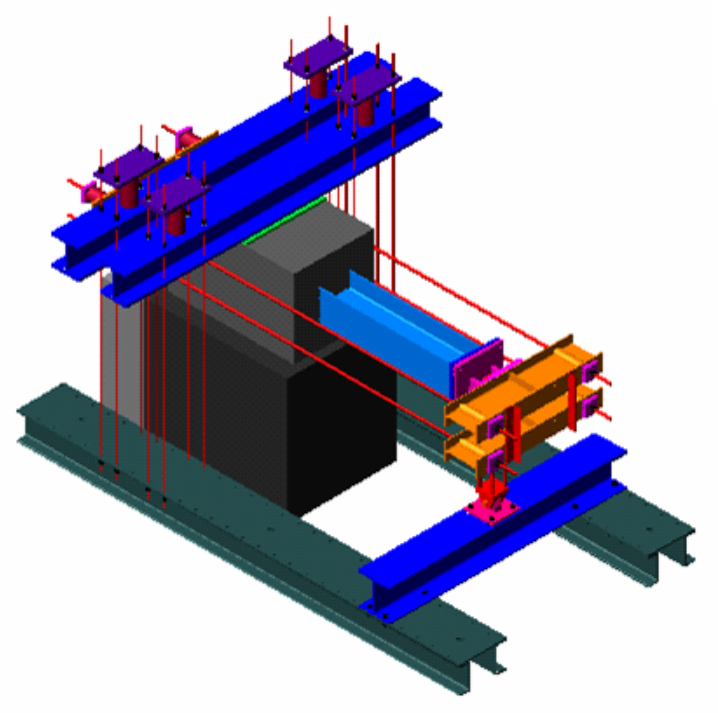

(a) Front View

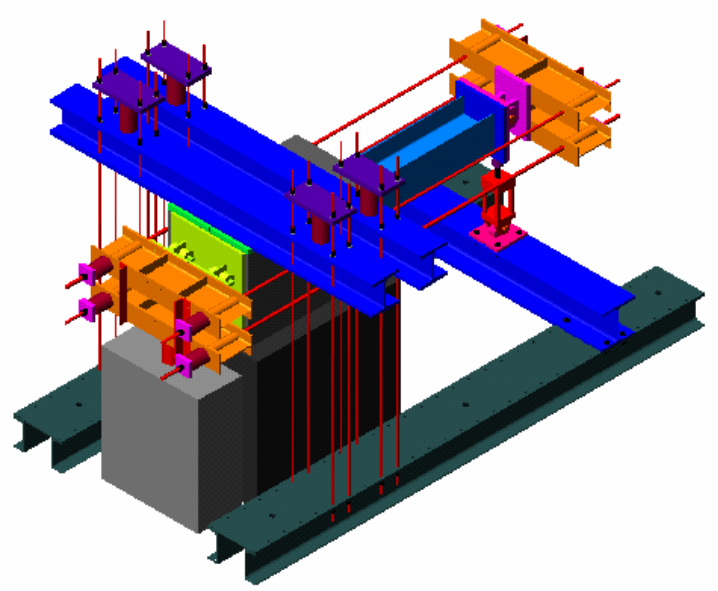

(b) Rear View

Figure 5.26: Scheme of Test Setup 


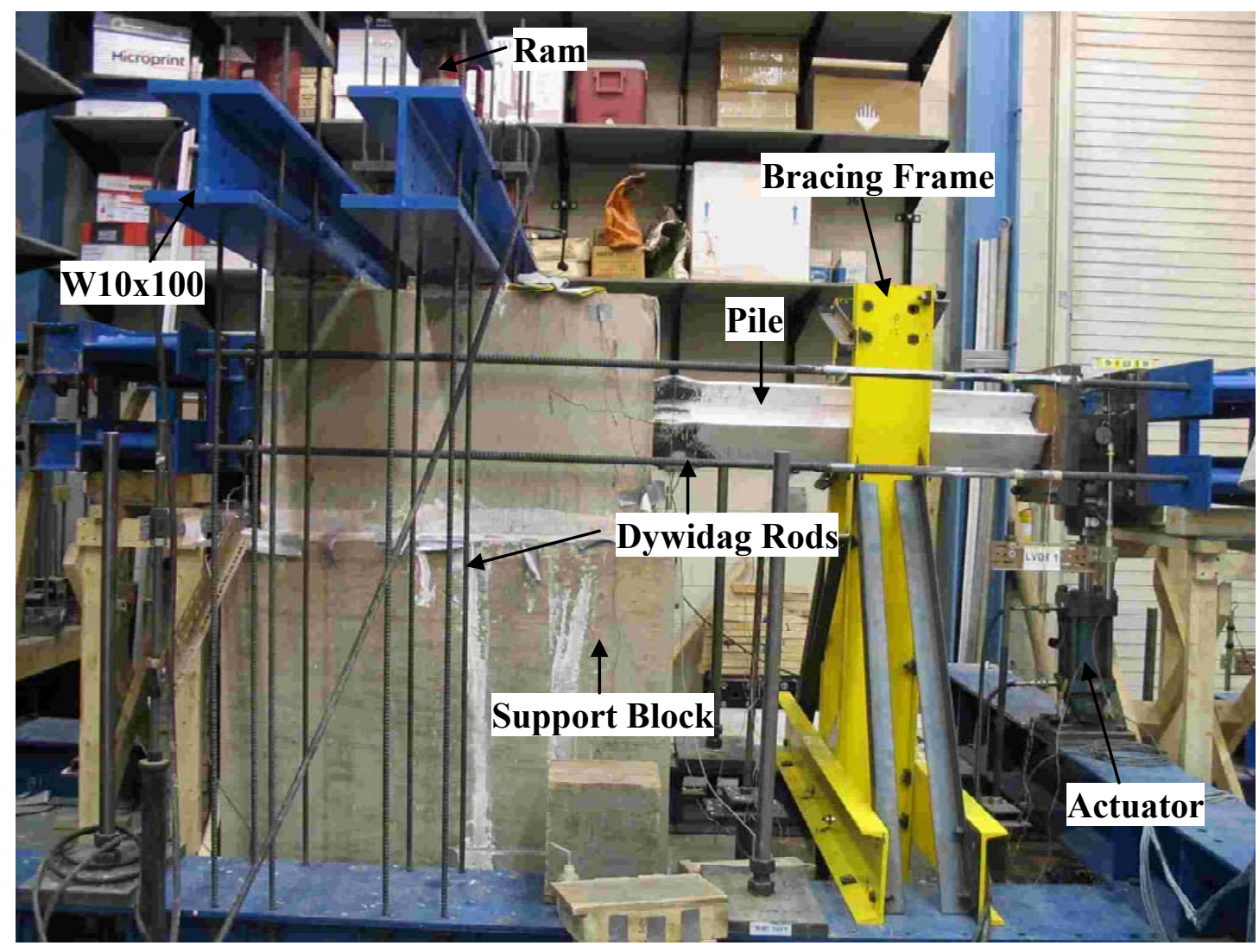

Figure 5.27: Test Setup in the Laboratory

Compressive axial load was applied horizontally to the end of the pile specimen through the self-equilibrating load system. Axial load was provided using four-60 kip hydraulic rams. The axial load was controlled using a 10,000-psi hand pump and monitored by strain gages on each of the 1 in.- $\varnothing$ Dywidag rods. The axial load capacity of the test system was 240 kips.

Cyclic lateral loads were applied through an actuator capable of both tension and compression. The actuator had a lateral load capacity of 50 kips and a maximum displacement capacity of \pm 3 in.

Lateral load was monitored through the use of a load cell attached to the actuator. The load cell had a capacity of 100 kips. Lateral displacement, elevation of axial beams, rotation of concrete abutment, and rotation of the pile were monitored by displacement transducers. Additionally, strain gages were attached to the pile $1 \mathrm{in}$. from the abutmentpile connection to monitor strains. 


\subsection{Test Instrumentation}

Linear voltage differential transducers (LVDT) and strain gages were used to monitor the response of the pile during testing.

\subsubsection{Displacement}

Figure 5.28 illustrates the locations of the LVDT's that were used to measure displacements.

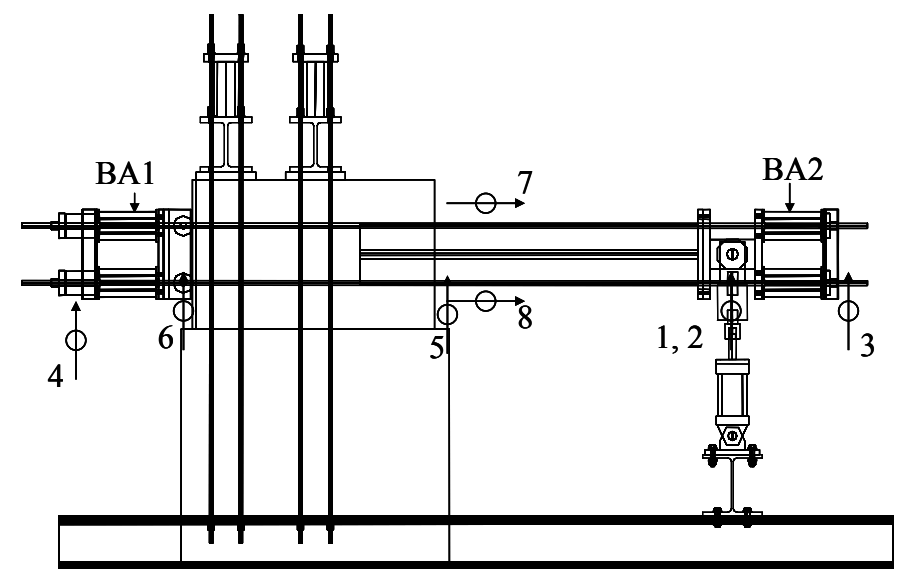

Figure 5.28: LVDT Locations

LVDTs No. 1 and 2 were located at the top of the knuckle connected to the load cell and the actuator to measure overall pile tip displacement. Due to the importance of this measurement, two LVDTs were used at this location to provide redundancy. LVDTs No. 3 and 4 were located at the center of the bottom of the axial beams, BA2 and BA1, respectively to measure the elevation of the Dywidag rods. LVDTs No. 5 and 6 were located at the face of the concrete abutment and were used to measure the rotation of the concrete abutment. LVDTs No. 7 and 8 were located 9 in. from the face of the concrete abutment and only attached to the $\mathrm{H}$ piles bending about their weak and strong axes. These LVDTs were used to measure localized connection rotation for the steel $\mathrm{H}$ piles. The relative rotation between the pile and the concrete abutment at an approximate distance of 9 in. from the face of the concrete abutment is determined using Equation 5-2.

$$
\theta=\frac{\delta_{7}-\delta_{8}}{\mathrm{D}_{7-8}}
$$


where:

$$
\begin{array}{ll}
\delta_{7} & =\text { displacement measured from LVDTs No. } 7 . \\
\delta_{8} & =\text { displacement measured from LVDTs No. } 8 . \\
\mathrm{D}_{7-8} & =\text { distance between LVDTs No. } 7 \text { and } 8 .
\end{array}
$$

\subsubsection{Strain Gages}

Strain gages were installed on the piles at the abutment-pile interface. Strain gages were obtained from Measurements Group Inc. Figure 5.29 shows the strain gage locations for the steel piles. For the $\mathrm{H}$ piles bending about the weak and $45^{\circ}$ axes, five gages were installed; four at the tips of the flanges and one at the center of the web. For the $\mathrm{H}$ pile bending about the strong axis, only four gages were installed at the tips of the flanges. For the CFT piles, only two gages were installed at the top and bottom of the tube perpendicular to the bending axis.

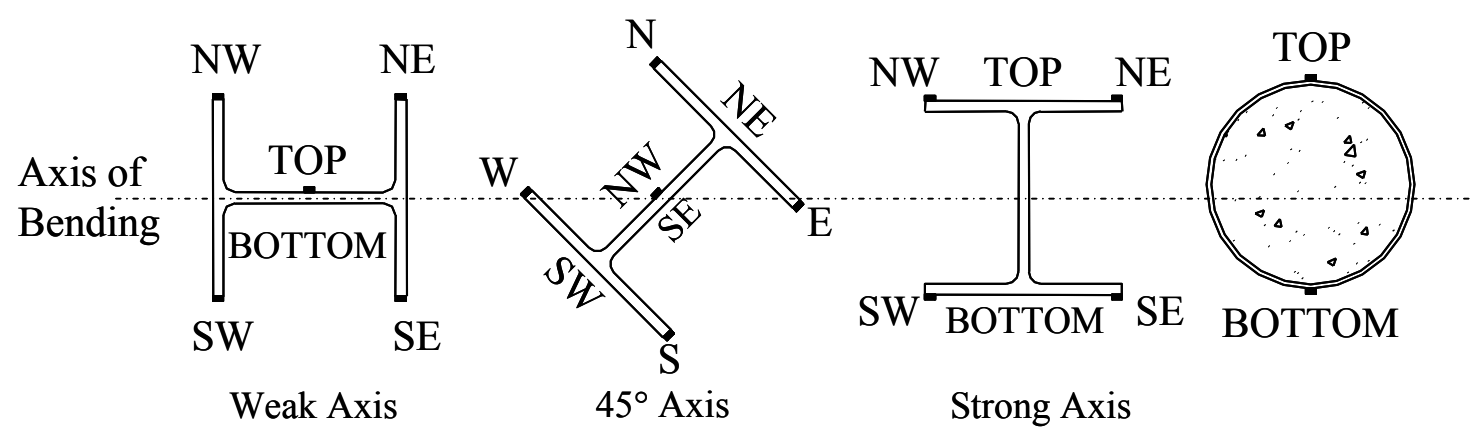

- Strain Gage

Figure 5.29: Strain Gages Location 
The strains measured from these locations were also used to calculate the curvature, $\phi$, of the pile cross section at the abutment-pile interface.

For the steel H-pile bending about the weak or strong axis:

$$
\phi=\frac{\operatorname{average}\left(\varepsilon_{\mathrm{SW}}, \varepsilon_{\mathrm{SE}}\right)-\operatorname{average}\left(\varepsilon_{\mathrm{NW}}, \varepsilon_{\mathrm{NE}}\right)}{\mathrm{D}}
$$

For the steel $\mathrm{H}$ pile bending about the $45^{\circ}$ axis:

$$
\phi=\frac{\varepsilon_{\mathrm{S}}-\varepsilon_{\mathrm{N}}}{\mathrm{D}}
$$

For the CFT piles:

$$
\phi=\frac{\varepsilon_{\mathrm{BOT}}-\varepsilon_{\mathrm{TOP}}}{\mathrm{D}}
$$

where:

$$
\begin{aligned}
& \varepsilon_{\mathrm{NW}}=\text { strain at NW tip of the } \mathrm{H} \text { pile. } \\
& \varepsilon_{\mathrm{NE}}=\text { strain at NE tip of the H pile. } \\
& \varepsilon_{\mathrm{SE}}=\text { strain at SE tip of the } \mathrm{H} \text { pile. } \\
& \varepsilon_{\mathrm{SW}}=\text { strain at SW tip of the } \mathrm{H} \text { pile. } \\
& \varepsilon_{\mathrm{N}} \quad=\text { strain at } \mathrm{N} \text { tip of the } \mathrm{H} \text { pile. } \\
& \varepsilon_{\mathrm{S}} \quad=\text { strain at } \mathrm{S} \text { tip of the } \mathrm{H} \text { pile. } \\
& \varepsilon_{\mathrm{TOP}}=\text { strain at the top of the CFT pile. } \\
& \varepsilon_{\mathrm{BOT}}=\text { strain at the bottom of the CFT pile. } \\
& \mathrm{D} \quad=\text { flange width for the steel } \mathrm{H} \text { pile bending about the weak axis, or } \\
& \mathrm{D}=\text { distance from NW to SE edges for the steel } \mathrm{H} \text { pile bending about } \\
& \text { its } 45^{\circ} \text { axis, or } \\
& \mathrm{D}=\text { depth of the steel } \mathrm{H} \text { pile bending about the strong axis, or } \\
& \mathrm{D}=\text { outer diameter of CFT piles. }
\end{aligned}
$$




\subsection{Test Procedure}

Prior to testing, the pile specimens were white-washed with a mixture of hydrated lime and water in a proportion of 1 lime to 3 water by weight in order to observe yielding of the pile. Next, axial load was applied to the specimen. This load was maintained constant throughout testing. Cyclic lateral loads were then applied to the specimen using displacement control. Both axial and cyclic lateral loads were applied at the pile tip until failure. The test was stopped when the pile could not maintain axial load, the abutmentpile connection deteriorated significantly, or the lateral load of the pile decreased significantly. Loads and lateral displacements were monitored continuously during testing to evaluate the behavior of the specimens.

In general, the pile was cycled using the displacement history listed in Table 5.10. The pile was cycled 0.25 in. for 5 cycles, 0.50 in. for 10 cycles and then 0.75 in. for 25 cycles to ensure that every part of test setup functioned properly before cycling at larger displacements. The piles were then cycled for 50 cycles at increasing displacement increments unless buckling of the pile or steel cracking was observed. Once the onset of buckling or cracking was evident, the pile was cycled for 100 cycles or until failure.

Throughout testing, data from strain gage measurements, displacement transducer readings, and actuator forces were collected. At each displacement stage and at other significant events in the behavior of the specimen, video and photographic recordings were taken.

Table 5.10: History of Testing

\begin{tabular}{|c|c|}
\hline $\begin{array}{c}\text { Displacement } \\
\text { Range (in.) }\end{array}$ & No. of Cycles \\
\hline 0.25 & 5 \\
0.50 & 10 \\
0.75 & 25 \\
\hline 1.00 & 50 \\
1.25 & 50 \\
1.50 & 50 \\
$\vdots$ & 50 \\
\hline Last & 100 \\
\hline
\end{tabular}




\section{CHAPTER 6: EXPERIMENTAL RESULTS}

\subsection{Introduction}

To better understand the behavior of piles for integral abutment bridges, lowcycle, large-amplitude lateral displacement tests were conducted. Nine piles were examined considering various pile types, orientations, and axial loads. The general behavior of the test specimens is discussed, and representative load-displacement relationships are presented. The effect of pile size, axial load, and pile orientation are also discussed. Detailed photographs of the pile response and individual loaddisplacement responses for each specimen are provided in Appendix I.

Throughout this chapter, the location conventions are as illustrated in Figure 6.1.

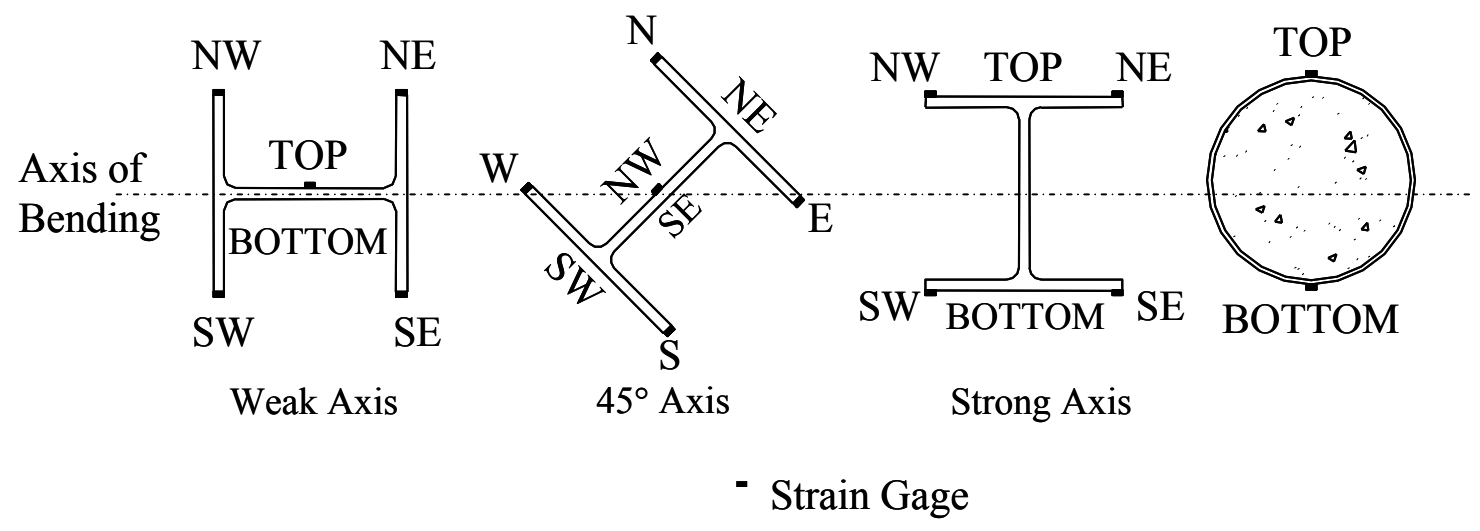

Figure 6.1: Location Conventions 


\subsection{General Behavior}

For all specimens, the piles behaved linearly elastic for the displacement range of \pm 0.25 in. For displacement ranges of \pm 0.50 in. and higher, most pile specimens exhibited nonlinear behavior. Regions of the pile located close to the abutment-pile connection yielded. As the lateral displacement range increased, the lateral load increased nonlinearly. After a certain numbers of cycles, a decrease in the lateral load was observed. The pile started buckling and initial cracks occurred. Cracks propagated as the lateral displacement range increased. Finally, most of the piles fractured. Most of the flanges of the pile specimens were fractured except the HP8x36 that was loaded about its strong and $45^{\circ}$ axes. In general, the lateral displacement capacity was controlled by the pile's fatigue performance. Table 6.1 shows the numbers of cycles achieved for each lateral displacement range for all specimens.

\section{Table 6.1: Numbers of Cycles}

\begin{tabular}{|c|c|c|c|c|c|c|c|c|c|}
\hline $\begin{array}{c}\text { Displacement } \\
\text { Range (in.) }\end{array}$ & \multicolumn{10}{|c|}{ Specimens } \\
\cline { 2 - 11 } & $\mathbf{1}$ & $\mathbf{2}$ & $\mathbf{3}$ & $\mathbf{4}$ & $\mathbf{5}$ & $\mathbf{6}$ & $\mathbf{7}$ & $\mathbf{8}$ & $\mathbf{9}$ \\
\hline 0.25 & 5 & 5 & 5 & 5 & 5 & 5 & 5 & 5 & 5 \\
\hline 0.50 & 10 & 10 & 10 & 10 & 10 & 10 & 10 & 10 & 10 \\
\hline 0.75 & 25 & 25 & 25 & 25 & 25 & 25 & 25 & 25 & 25 \\
\hline 1.00 & 50 & 50 & 50 & 50 & 50 & 50 & 50 & 50 & 50 \\
\hline 1.25 & $* *$ & $* *$ & 50 & 50 & 50 & 50 & 50 & 50 & 50 \\
\hline 1.50 & 50 & 100 & 50 & 50 & 50 & 100 & 100 & 100 & 50 \\
\hline 1.75 & $* *$ & 100 & 100 & 50 & 50 & 70 & 33 & 10 & 100 \\
\hline 2.00 & 50 & - & 100 & 50 & 50 & - & - & - & 100 \\
\hline 2.25 & 50 & - & - & 100 & - & - & - & - & - \\
\hline 2.50 & 100 & - & - & 66 & - & - & - & - & - \\
\hline 2.75 & 25 & - & - & - & - & - & - & - & - \\
\hline 3.00 & 80 & - & - & - & - & - & - & - & - \\
\hline
\end{tabular}

** This displacement range was not included for the specified specimens.

The behavior of Specimen 5, an HP10x42 pile bending about its weak axis is discussed to illustrate the general behavior experienced by the majority of the specimens. For the displacement range of $0.25 \mathrm{in}$., the pile behaved linearly elastic and no yielding 
was observed. The load-deflection curve remained linear (Figure 6.2) until a displacement range of $0.50 \mathrm{in}$. when all flanges demonstrated signs of yielding (Figure 6.3). For the displacement range of 0.75 in., the nonlinear behavior of the pile was more noticeable (Figure 6.4). Small local spalling of concrete was observed at the NE flange at the displacement range of $1.00 \mathrm{in}$. (Figure 6.5); however, the pile maintained its lateral load (Figure 6.6). A loss in lateral load was observed during cycling at a displacement range of $1.25 \mathrm{in}$. and all flanges started buckling at the end of $1.25 \mathrm{in.} \mathrm{cycles} \mathrm{(Figure} \mathrm{6.7).}$ As the displacement range was increased to 1.50 in., all flanges showed more obvious signs of buckling and a decrease in lateral load capacity was observed as shown in Figure 6.8. For the displacement range of 1.75 in. (Figure 6.9), the web started yielding. More superficial spalling of concrete occurred on both the east and west sides. Finally, the pile failed by the $50^{\text {th }}$ cycle at a displacement of 2.00 in. The failure was defined by the decrease in the lateral load capacity, which was decreased by $52 \%$ in the up direction and $67 \%$ in the down direction from the first cycle at the 2.00 in. displacement range (Figure $6.10)$.

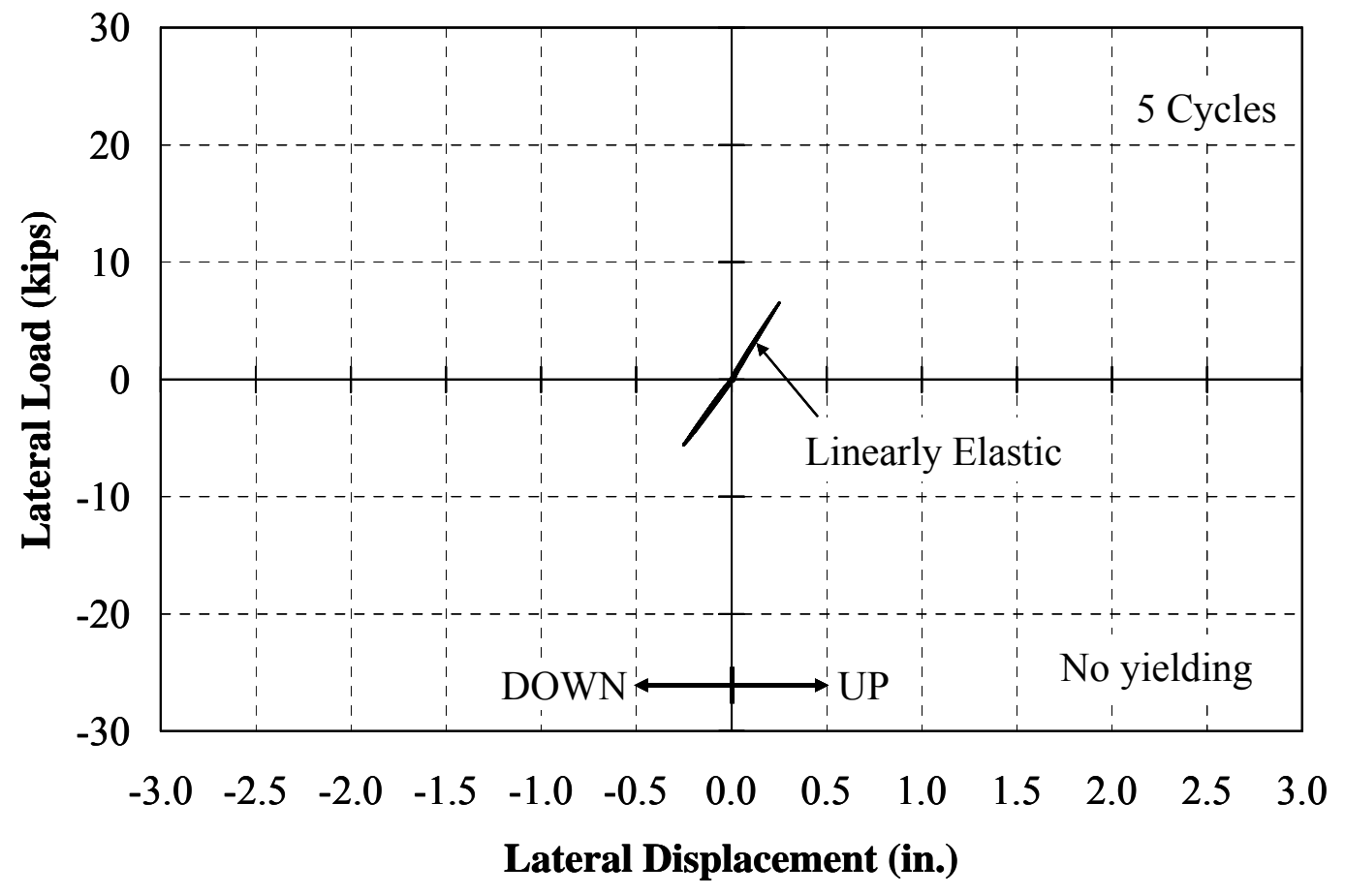

Figure 6.2: Specimen 5 - Load-Deflection Response ( \pm 0.25 in. Range) 

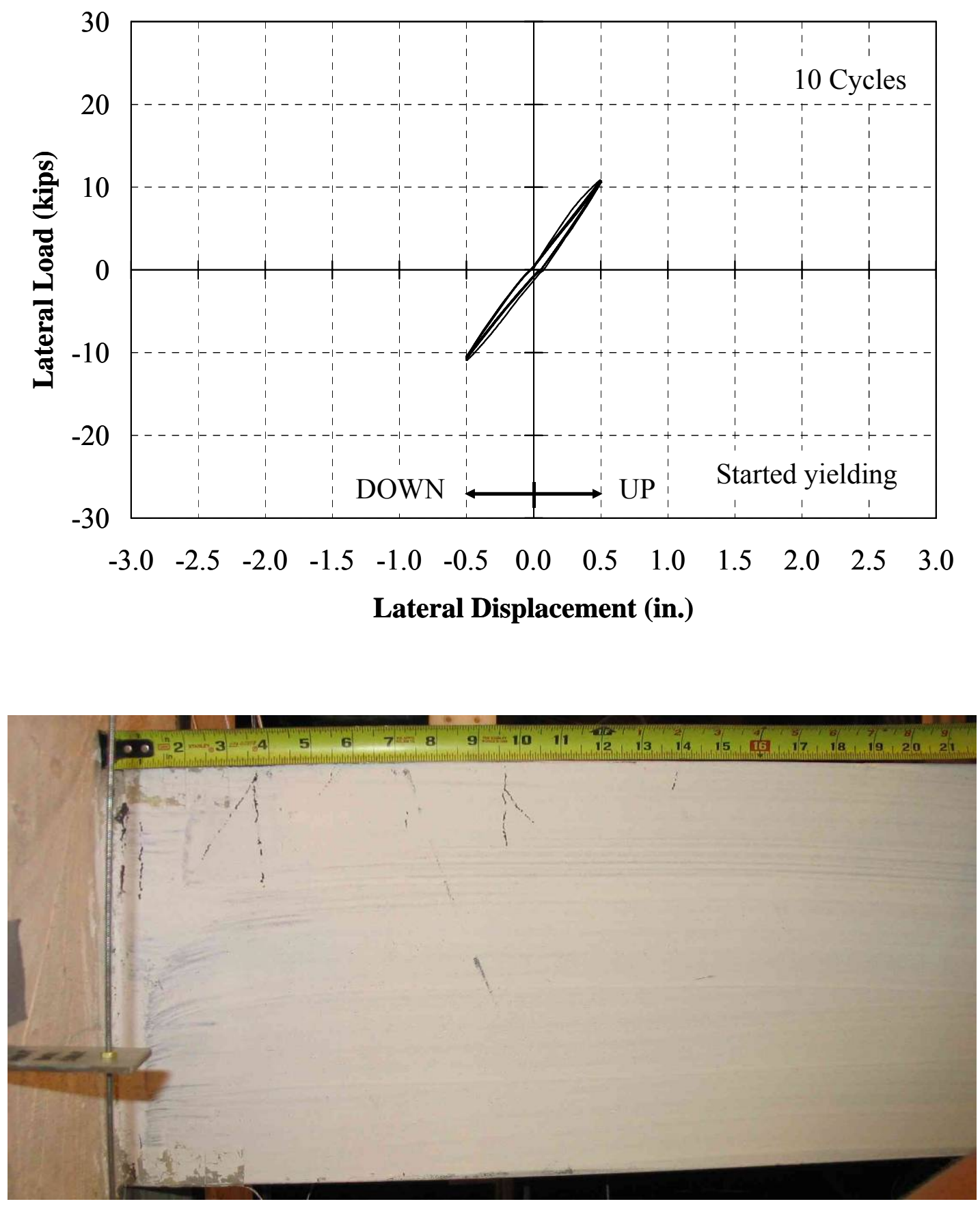

Figure 6.3: Specimen 5 - Load-Deflection Response ( \pm 0.50 in. Range) 

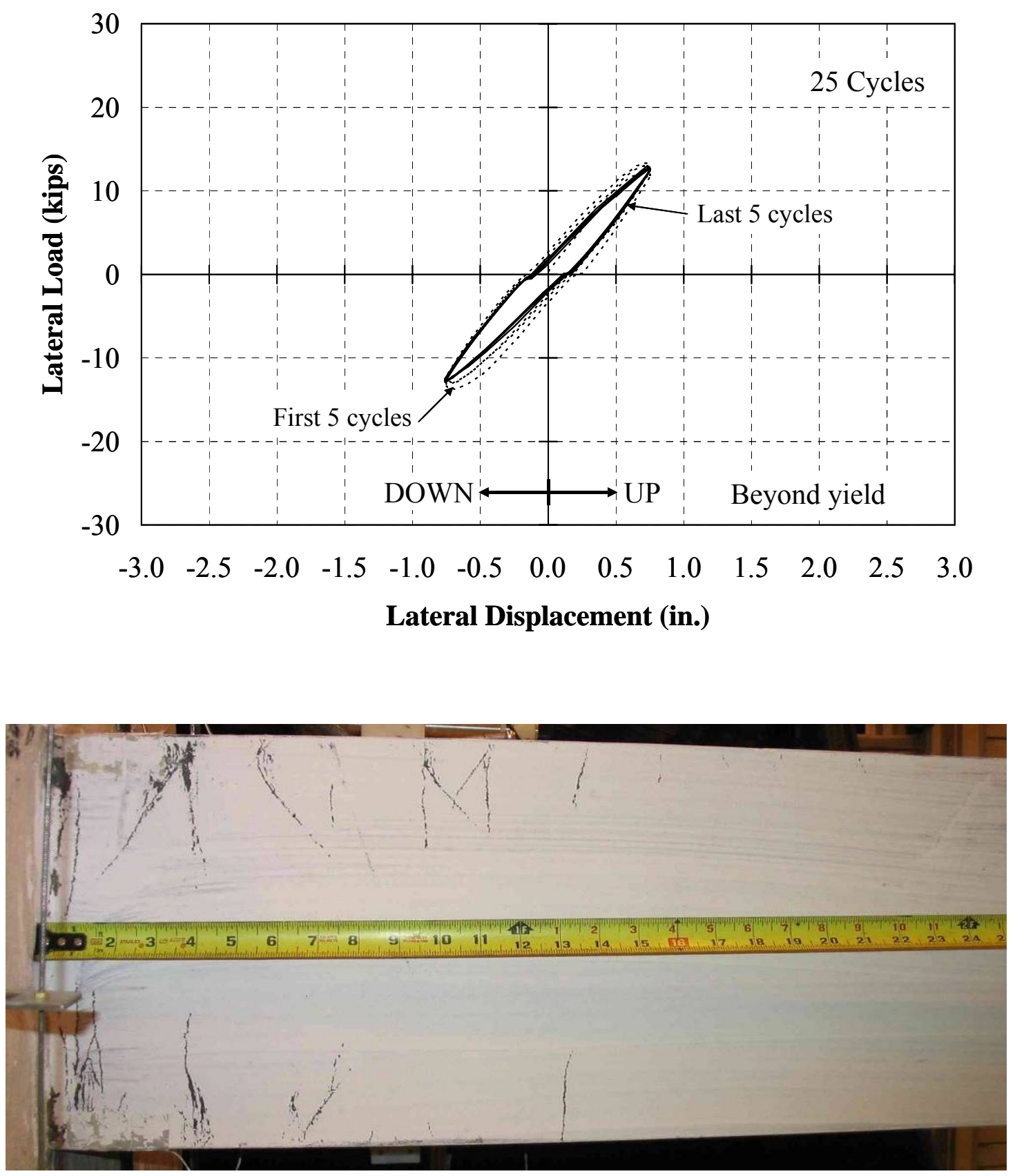

Figure 6.4: Specimen 5 - Load-Deflection Response $( \pm 0.75$ in. Range) 


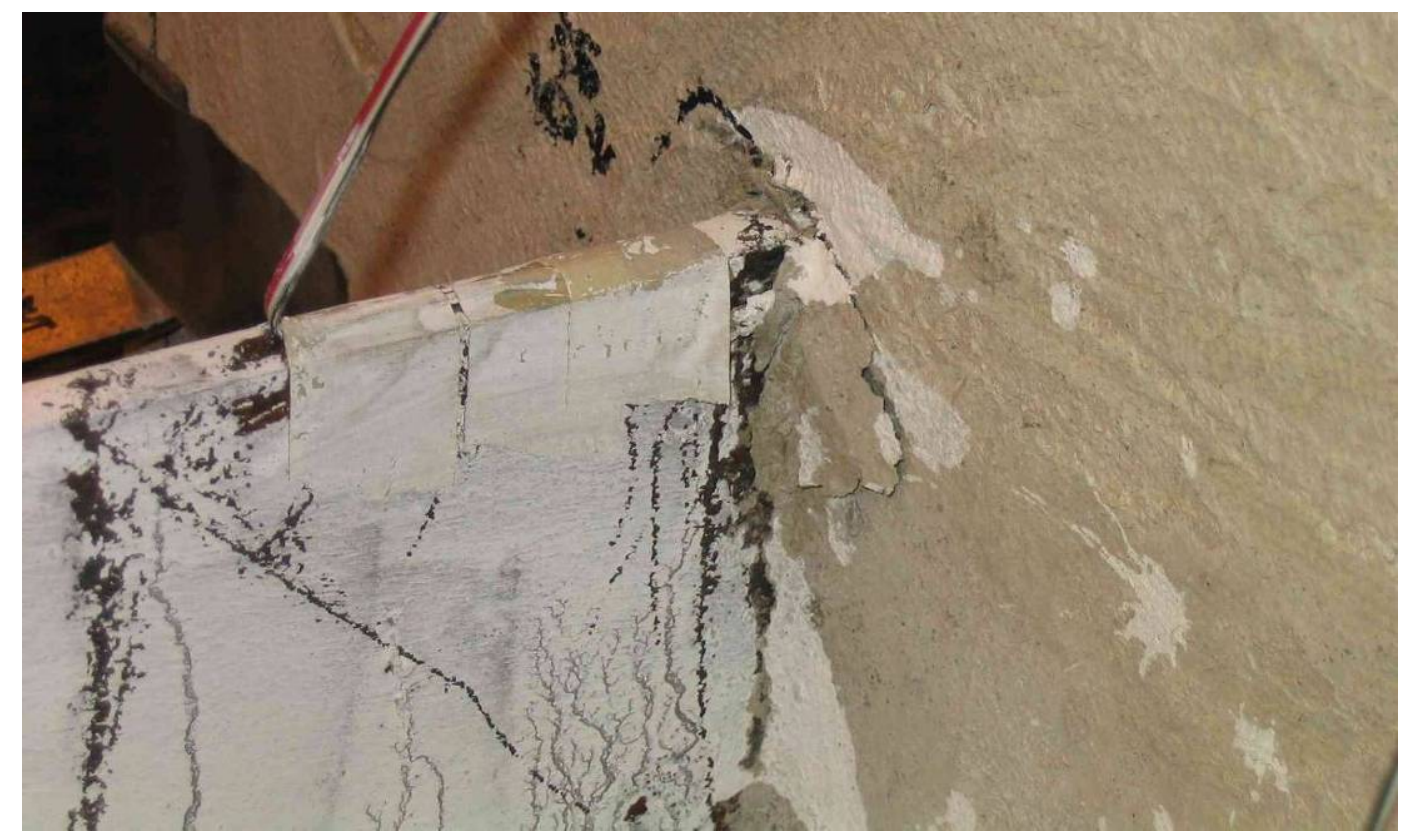

Figure 6.5: Specimen 5 - Spalling of Concrete at the NE Flange

In summary, the flanges started yielding at a displacement range of 0.50 in. Yield initiated from the fixed end and propagated toward the pile tip. All flanges began buckling at a displacement range of $1.25 \mathrm{in}$. A series of photographs illustrates the crack propagation that occurred in the NW flange as shown in Figure 6.11. Cracks in the steel flanges grew up to $1 / 8$ in. wide on the NW, NE, and SW flanges while a 1/16 in. crack occurred on the SE flange. The web started yielding during the $1.75 \mathrm{in}$. displacement range, and significant yielding was evident during the 2.00 in. displacement range (Figure 6.12). Ultimately, all flanges fractured during the 2.00 in. displacement range. Slight deterioration of the abutment-pile connection was observed as illustrated in Figure 6.13 which shows spalling of concrete on both the east and west sides of the pile. The displacement capacity is defined as the capacity of the pile to sustain the axial load until the lateral load started decreasing significantly. For this specimen, the lateral load started decreasing significantly in the 1.75 in. displacement range indicating a displacement capacity of $1.75 \mathrm{in}$. 

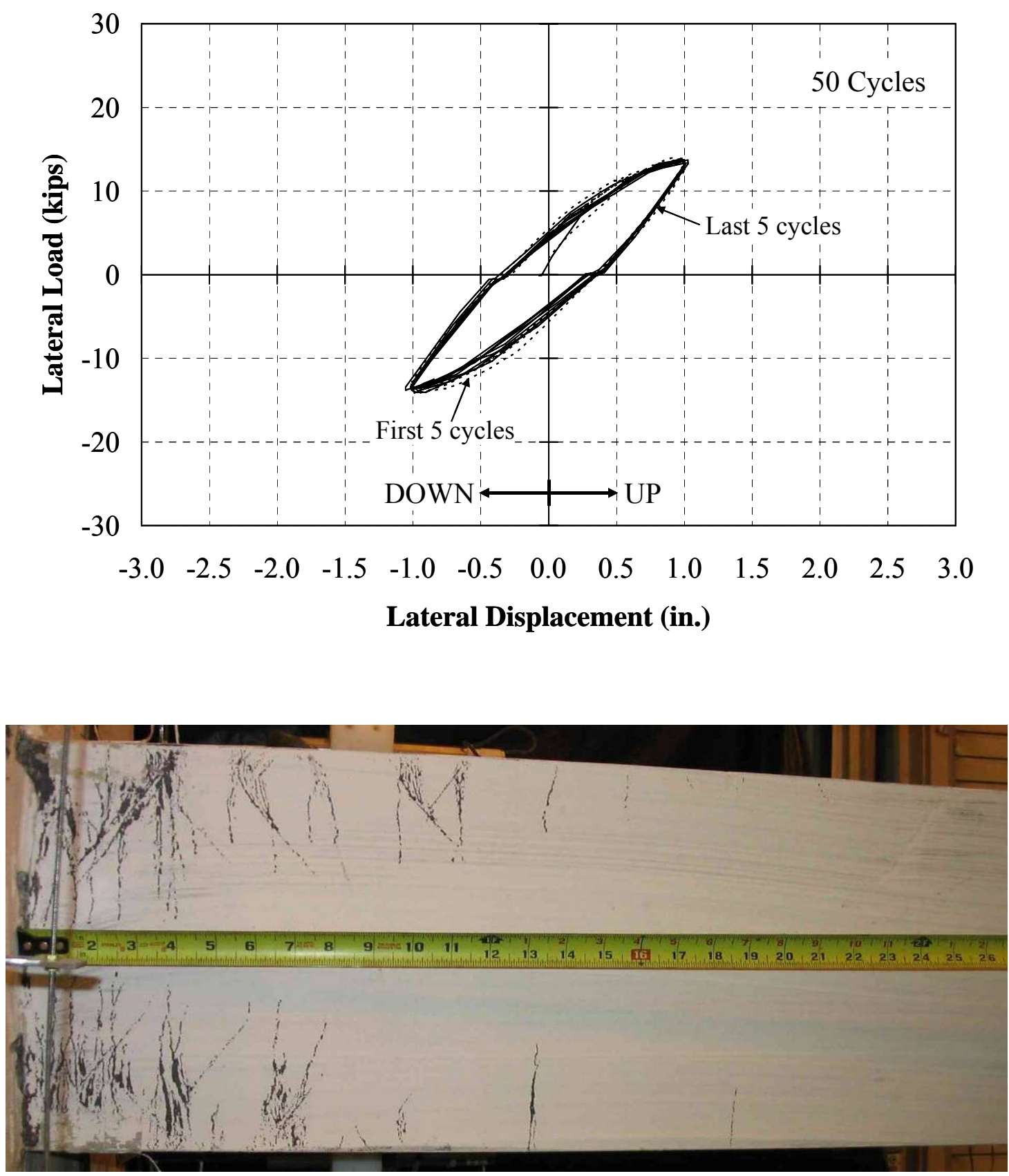

Figure 6.6: Specimen 5 - Load-Deflection Response ( \pm 1.00 in. Range) 

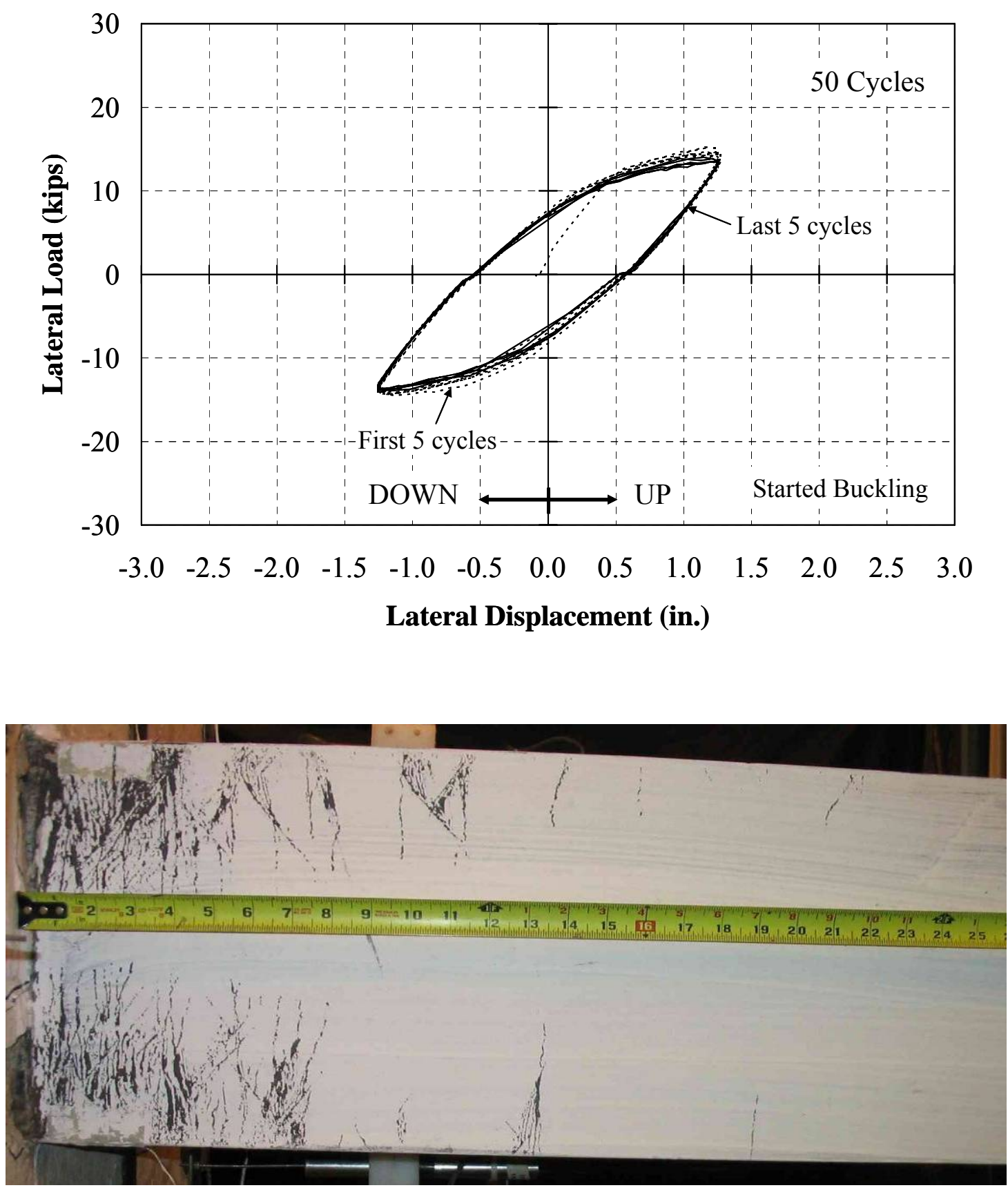

Figure 6.7: Specimen 5 - Load-Deflection Response ( \pm 1.25 in. Range) 

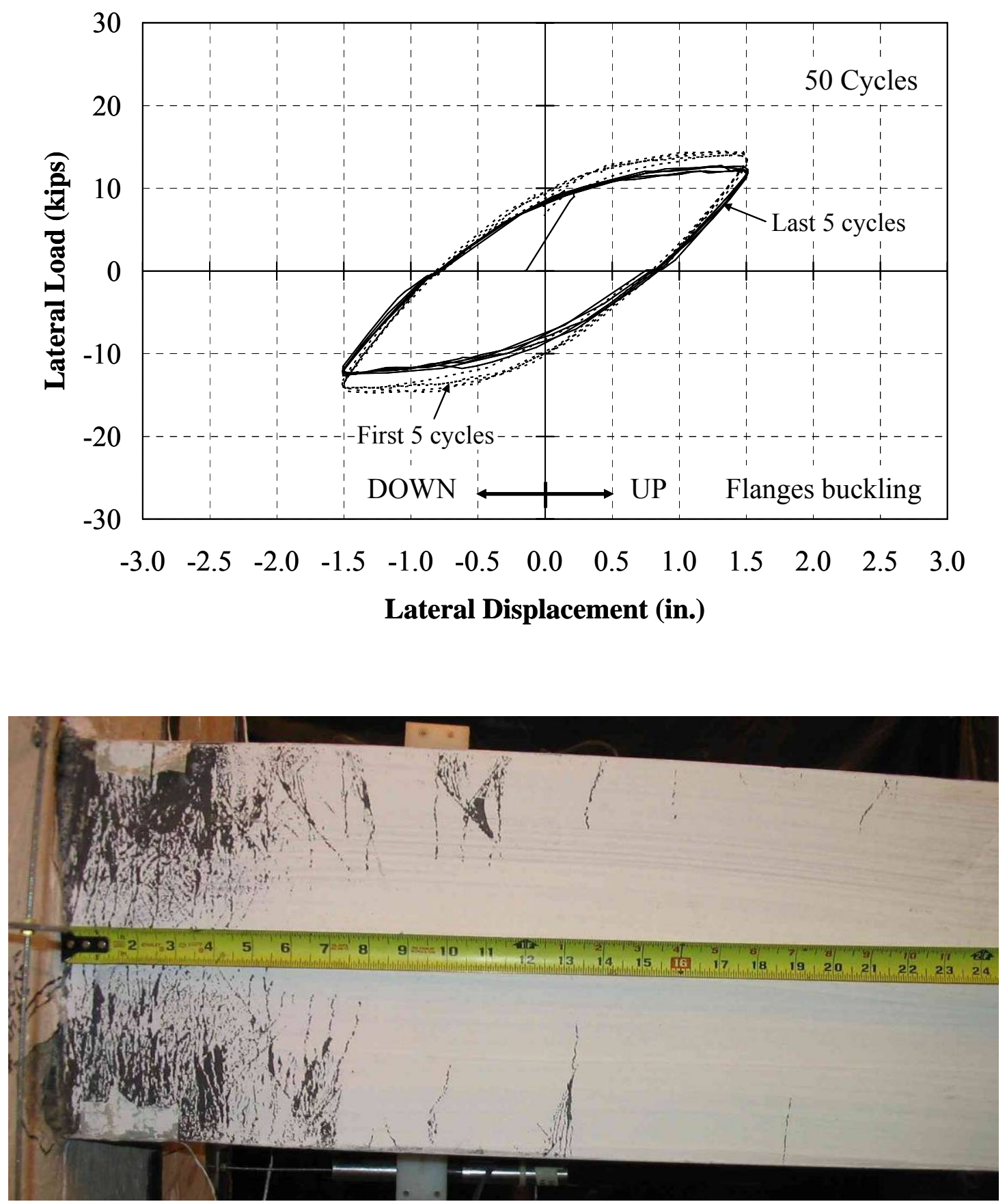

Figure 6.8: Specimen 5 - Load-Deflection Response ( \pm 1.50 in. Range) 

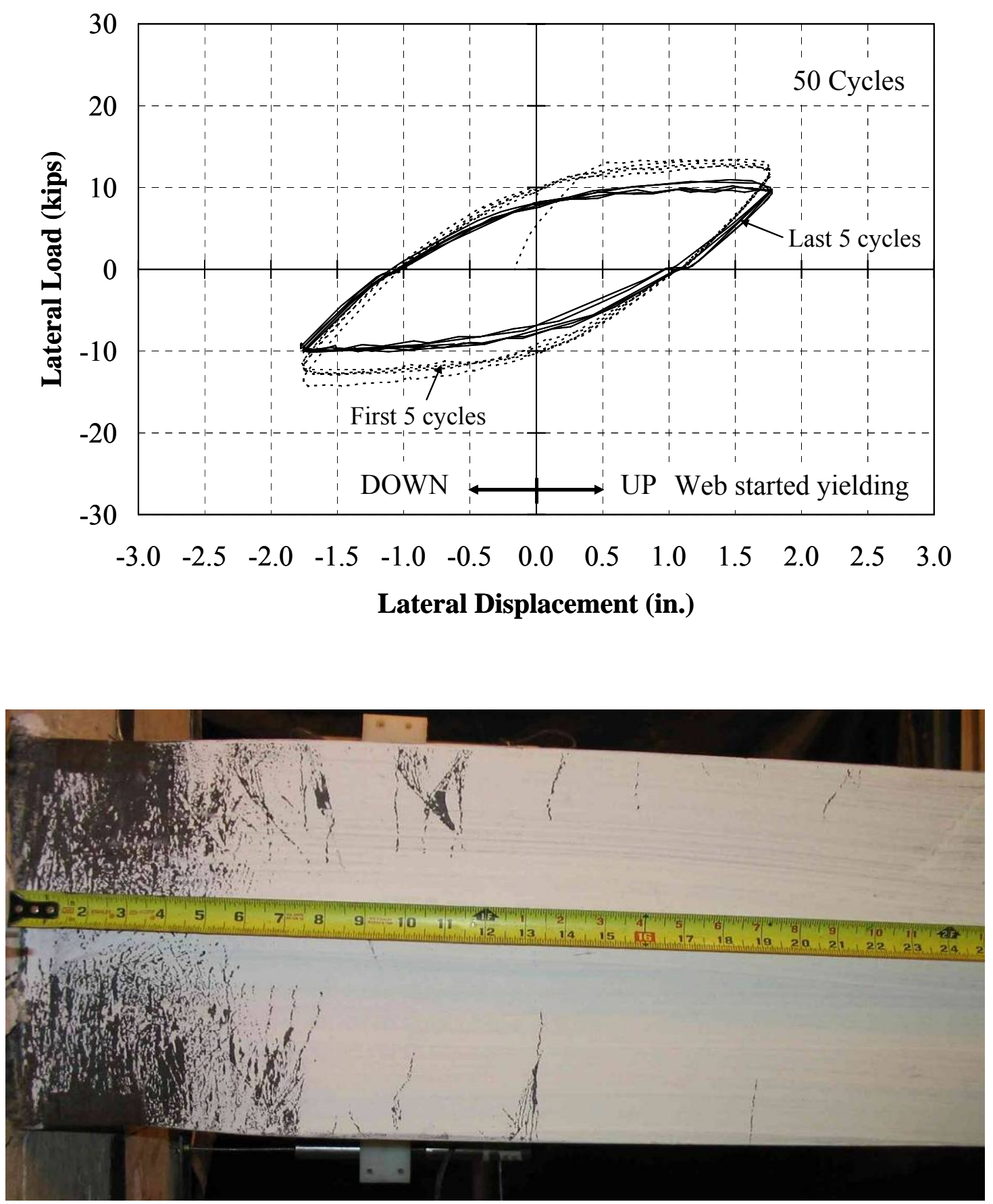

Figure 6.9: Specimen 5 - Load-Deflection Response ( \pm 1.75 in. Range) 

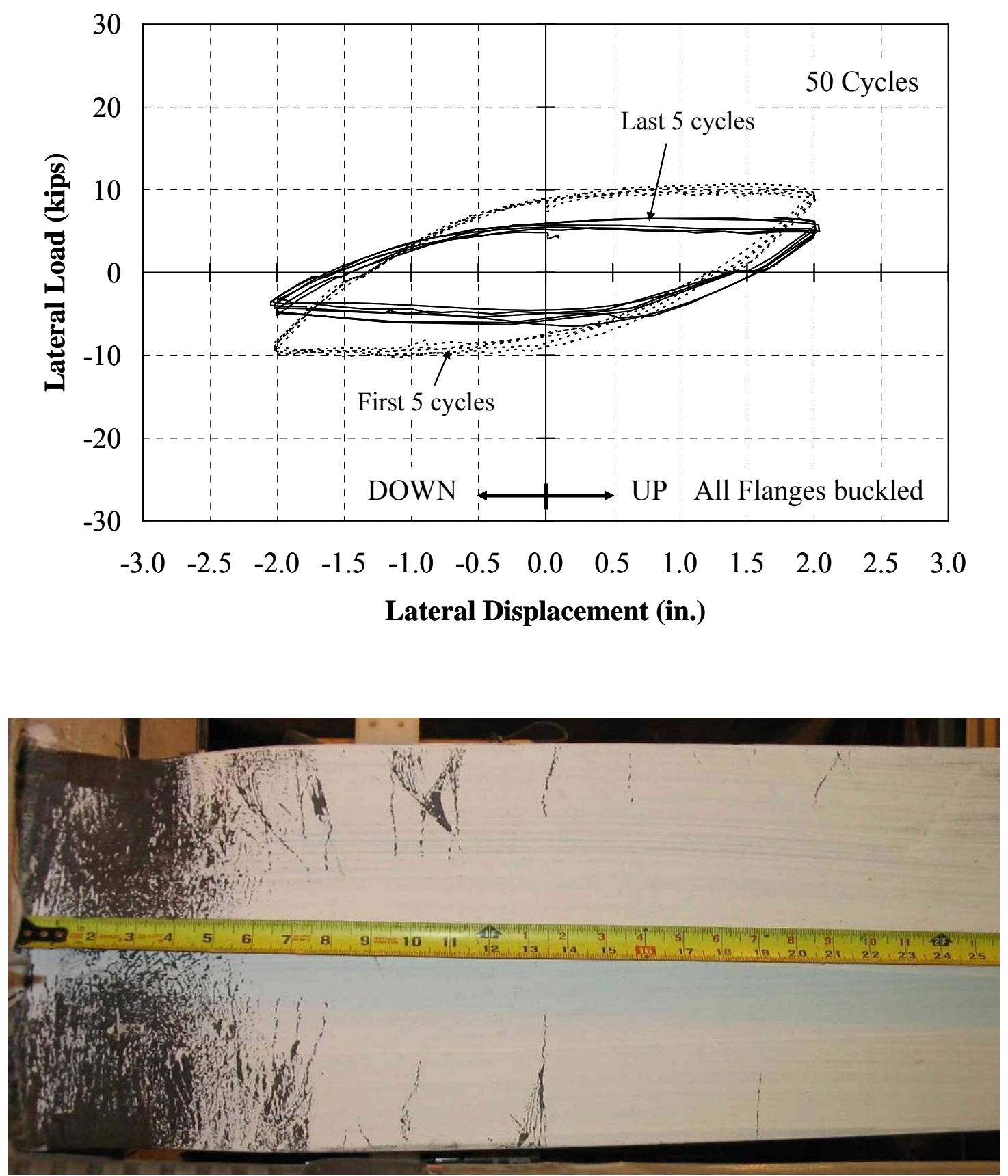

Figure 6.10: Specimen 5 - Load-Deflection Response ( \pm 2.00 in. Range) 


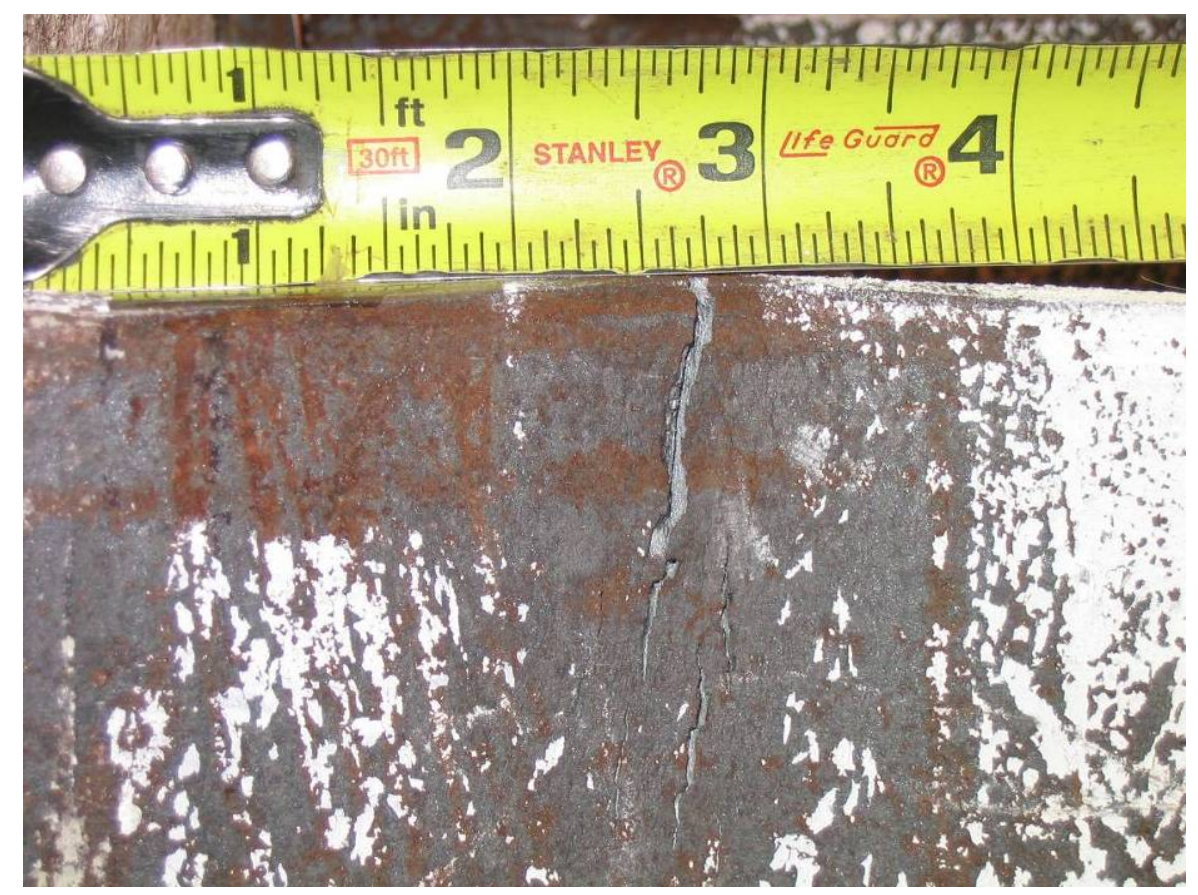

(a) Displacement Range of 1.25 in.

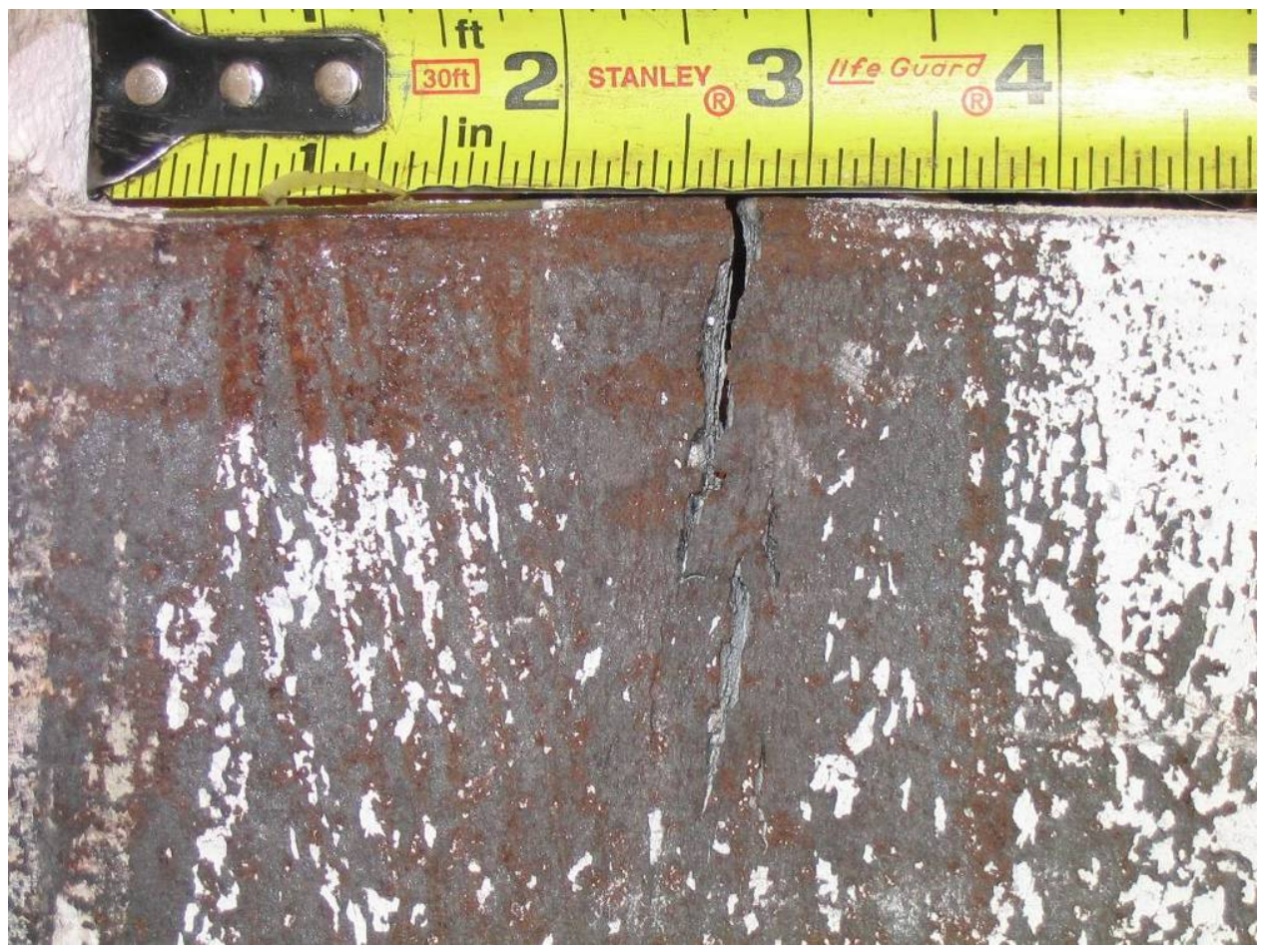

(b) Displacement Range of 1.50 in.

Figure 6.11: Specimen 5 - Crack Propagation 


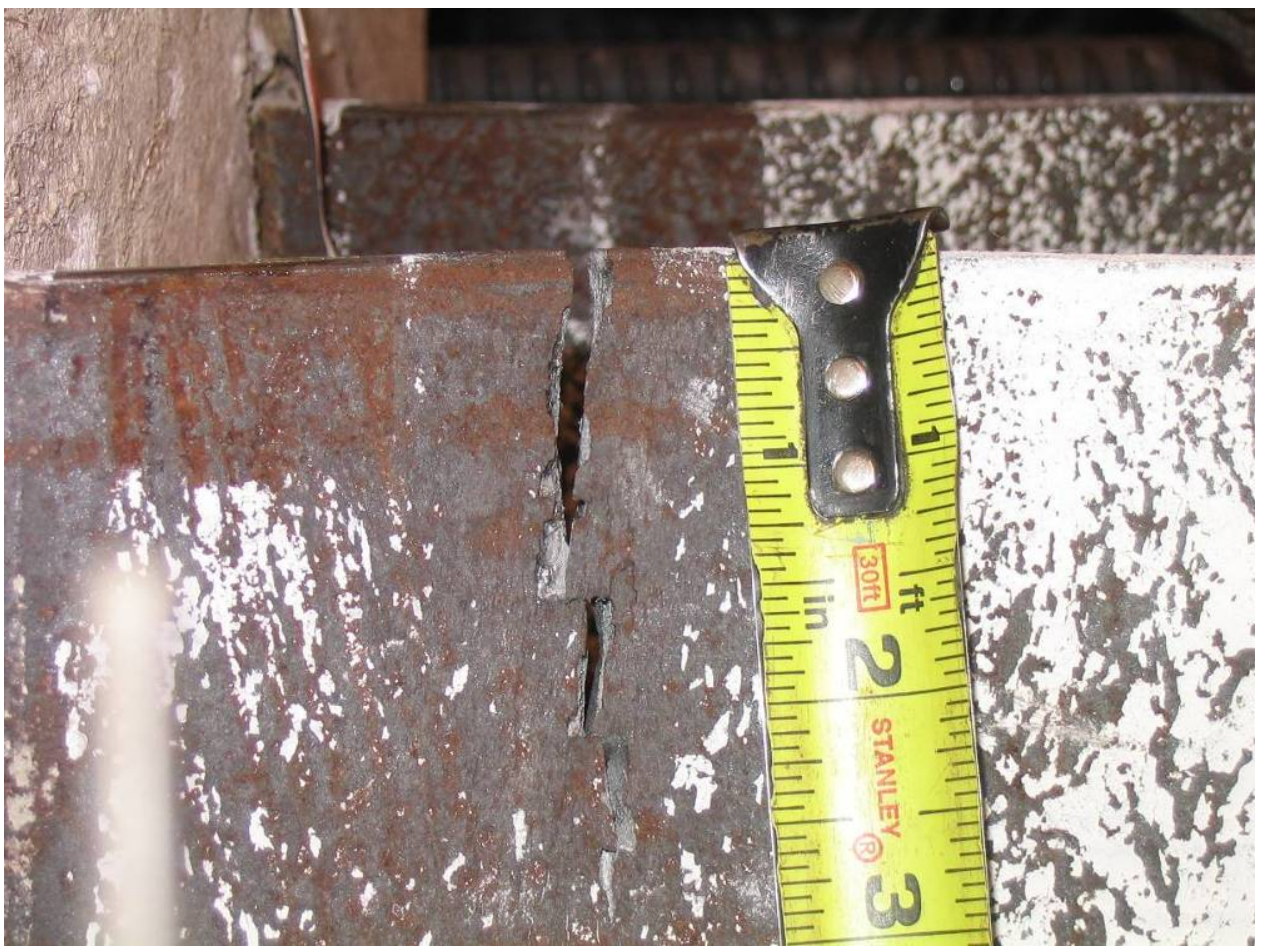

(c) Displacement Range of 1.75 in.

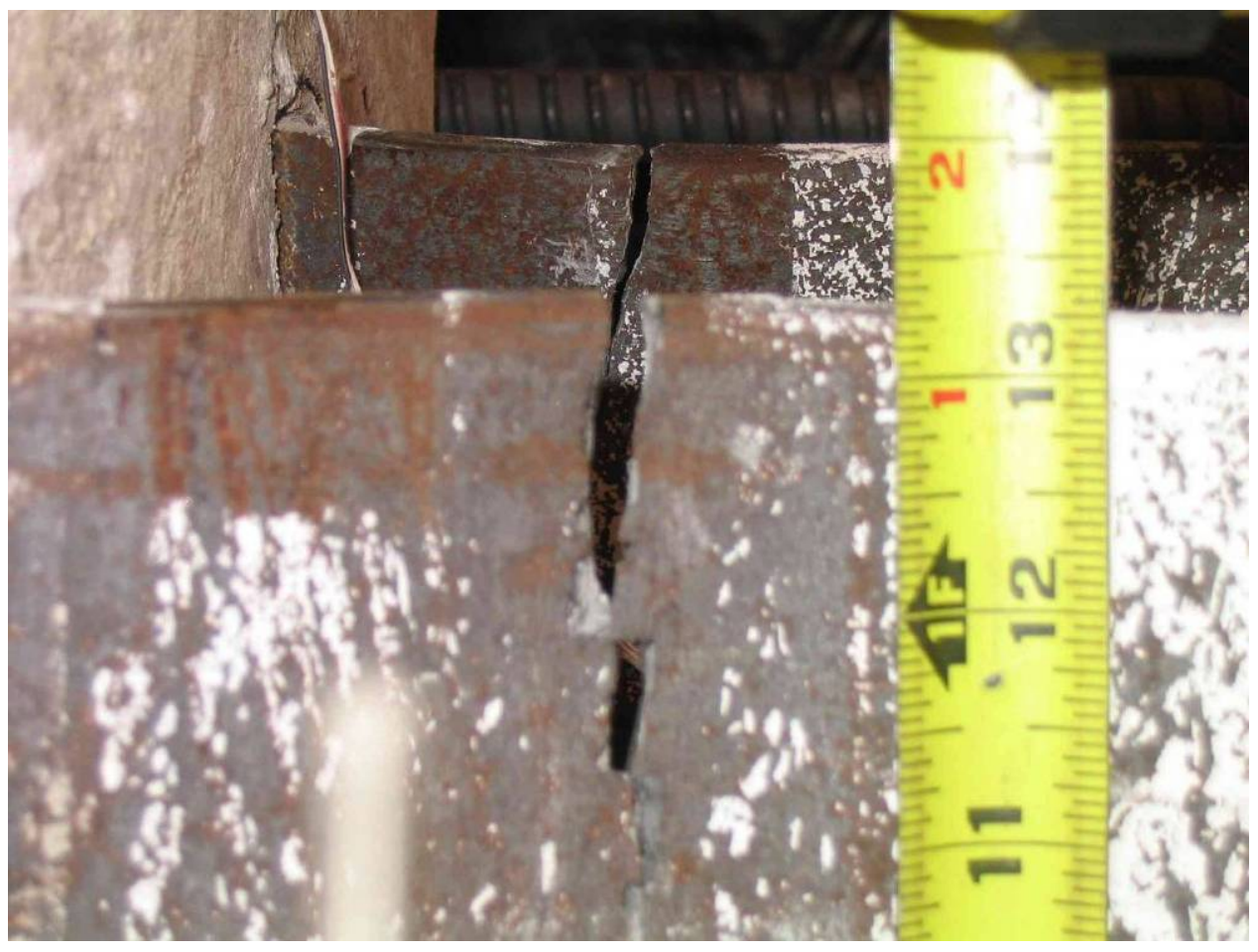

(d) Displacement Range of 2.00 in.

Figure 6.11: Specimen 5 - Crack Propagation (Continued) 


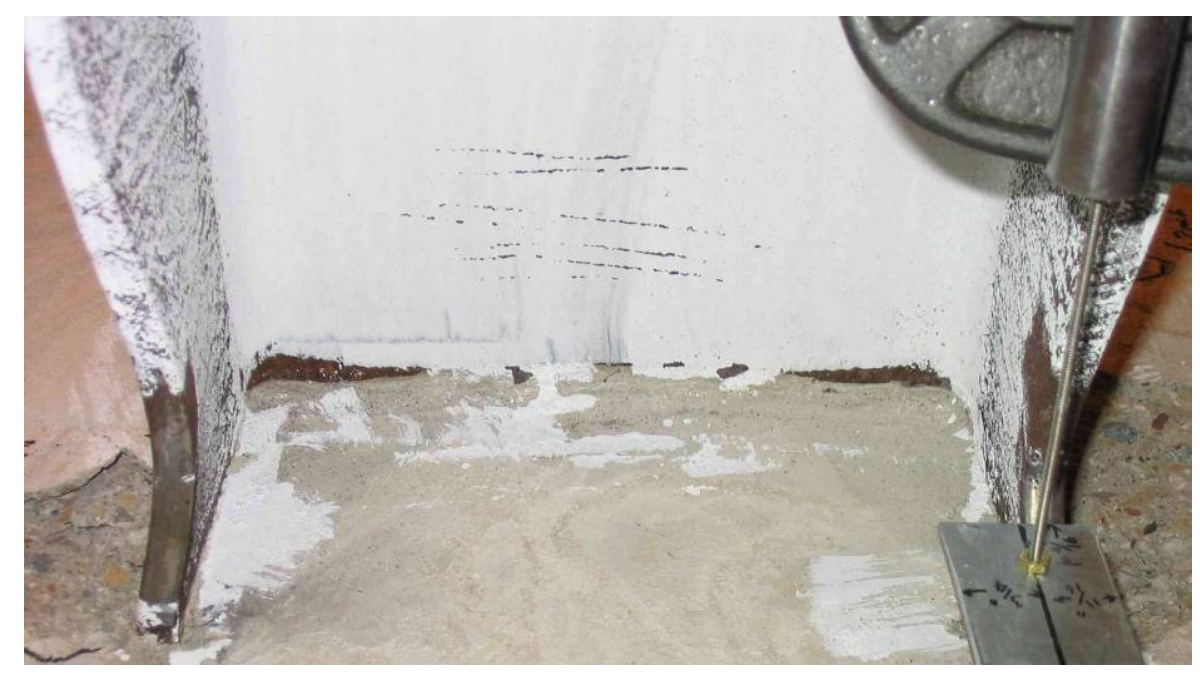

(a) Displacement Range of 1.75 in.

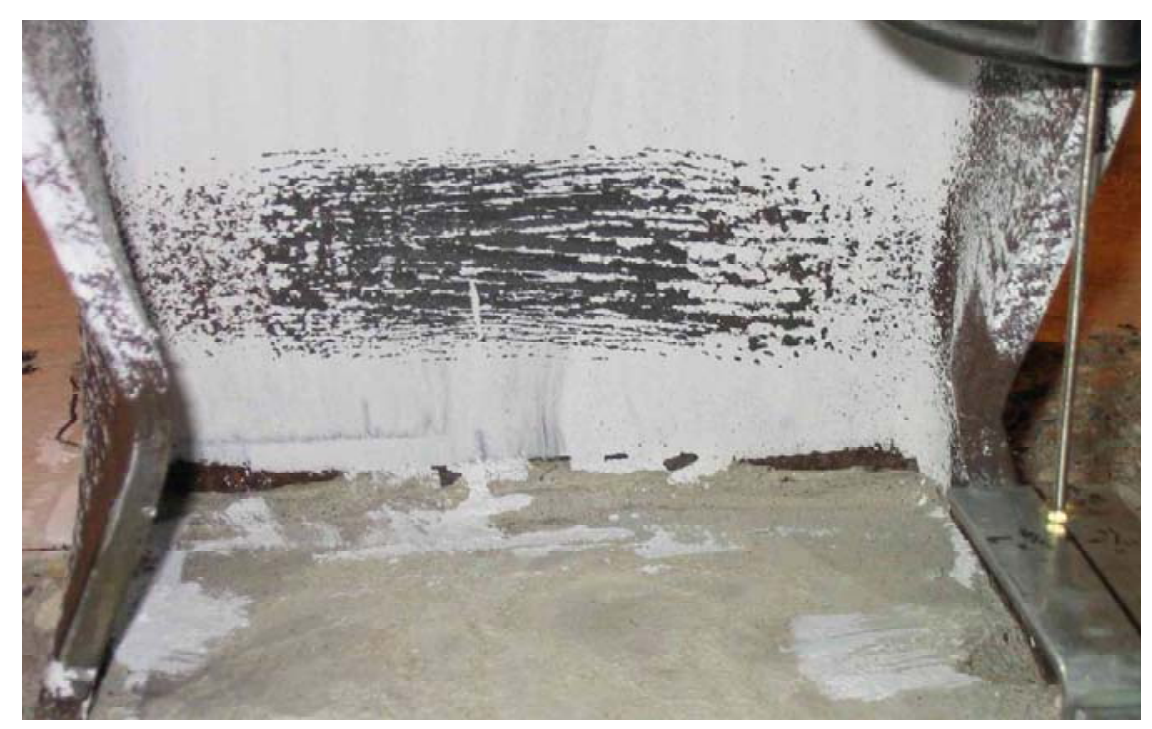

(b) Displacement Range of 2.00 in.

Figure 6.12: Specimen 5 - Web Yielding at the Bottom of the Web 


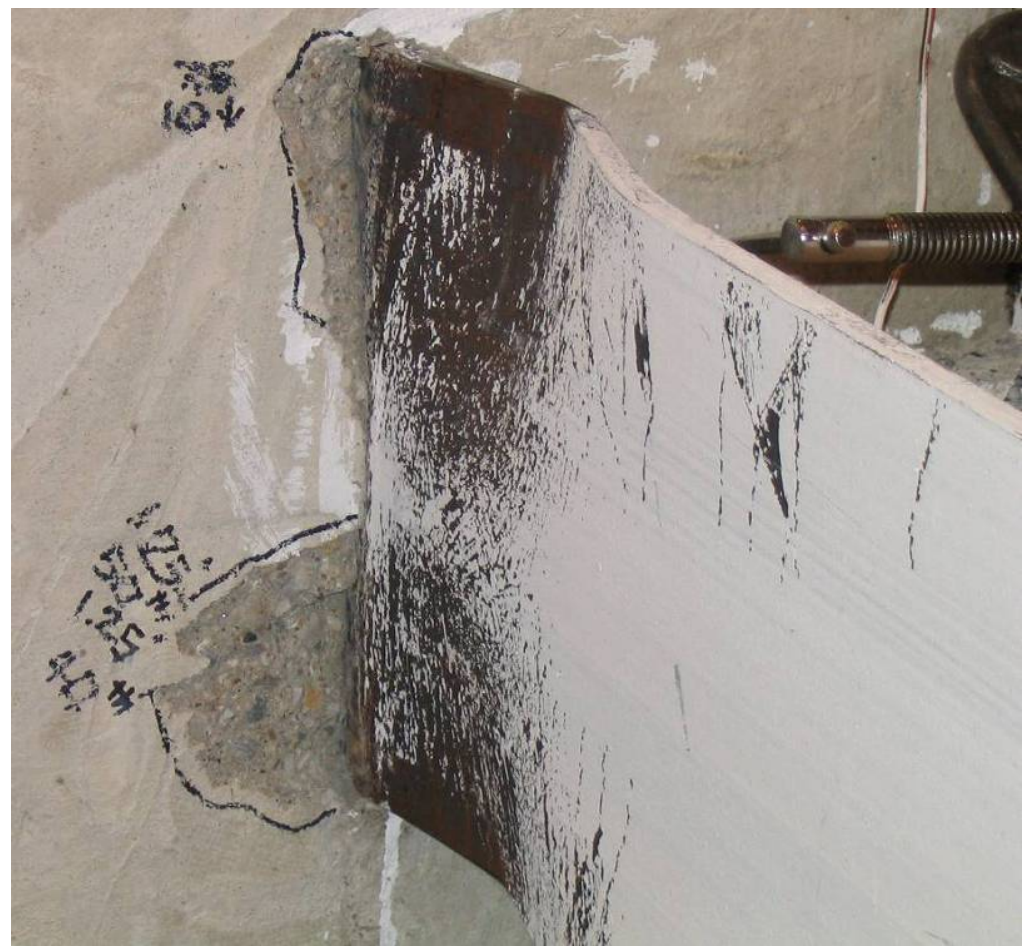

(a) 1.75 in. Displacement Range, West Side

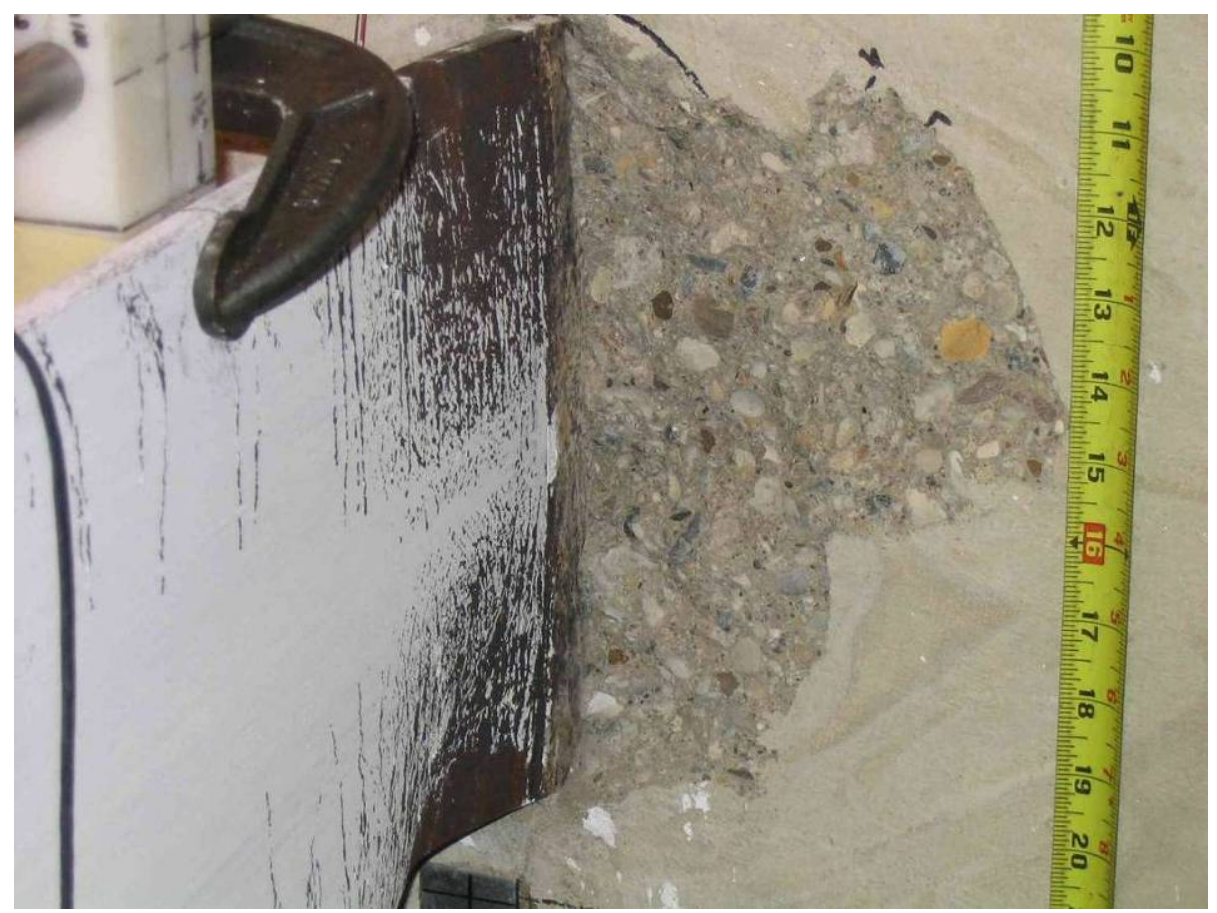

(b) 2.00 in. Displacement Range, East Side

Figure 6.13: Specimen 5 - Spalling of Concrete 
The axial load of Specimen 5 during the displacement range of 0.50, 1.00, 1.75, and 2.00 in. is shown in Figure 6.14. The axial load was maintained fairly well throughout the test. The axial load was observed to decrease while the pile tip was moved up and down due to shortening of the horizontal Dywidag rods during bending of the pile. The axial load variation during cycling increased as the displacement at the pile tip increased. The axial load at the neutral position (zero deflection) was continuously monitored. When the axial load was observed to decrease after a certain number of cycles (typically every 10 cycles), the axial load was reapplied at the neutral position to the force required to achieve the desired axial stress (9 ksi for Specimen 5).

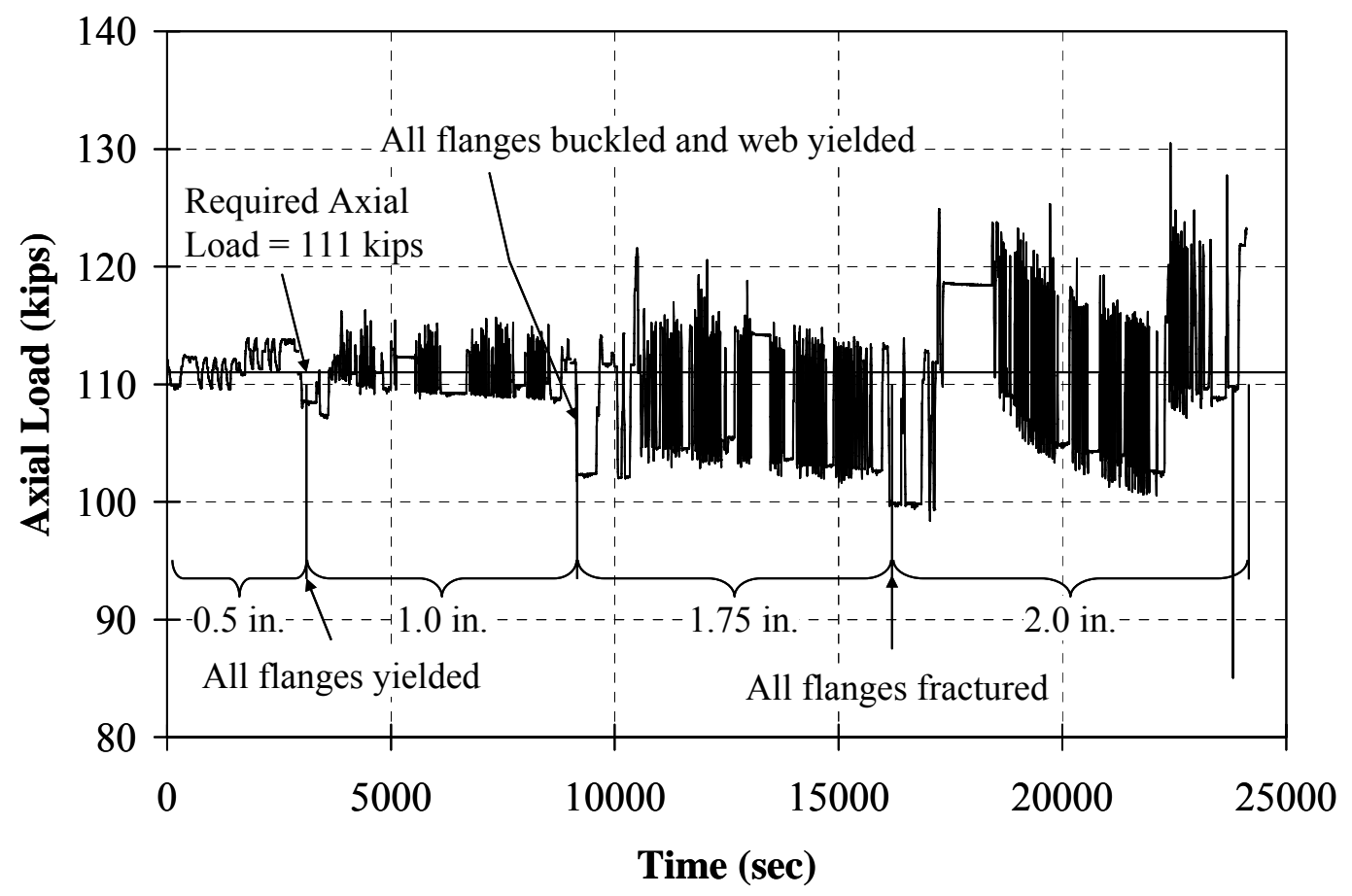

Figure 6.14: Specimen 5 - Axial Load 
The abutment rotations of Specimen 5 calculated from LVDTs 5 and 6 during the displacement range of $0.50,1.00,1.75$, and 2.00 in. are presented in Figure 6.15. As shown, the abutment rotation decreased after local flange buckling. The decrease of the abutment rotation indicated deterioration at the abutment-pile connection or buckling of the pile. The abutment rotation of Specimen 5 is representative of the typical abutment rotation for the other specimens.

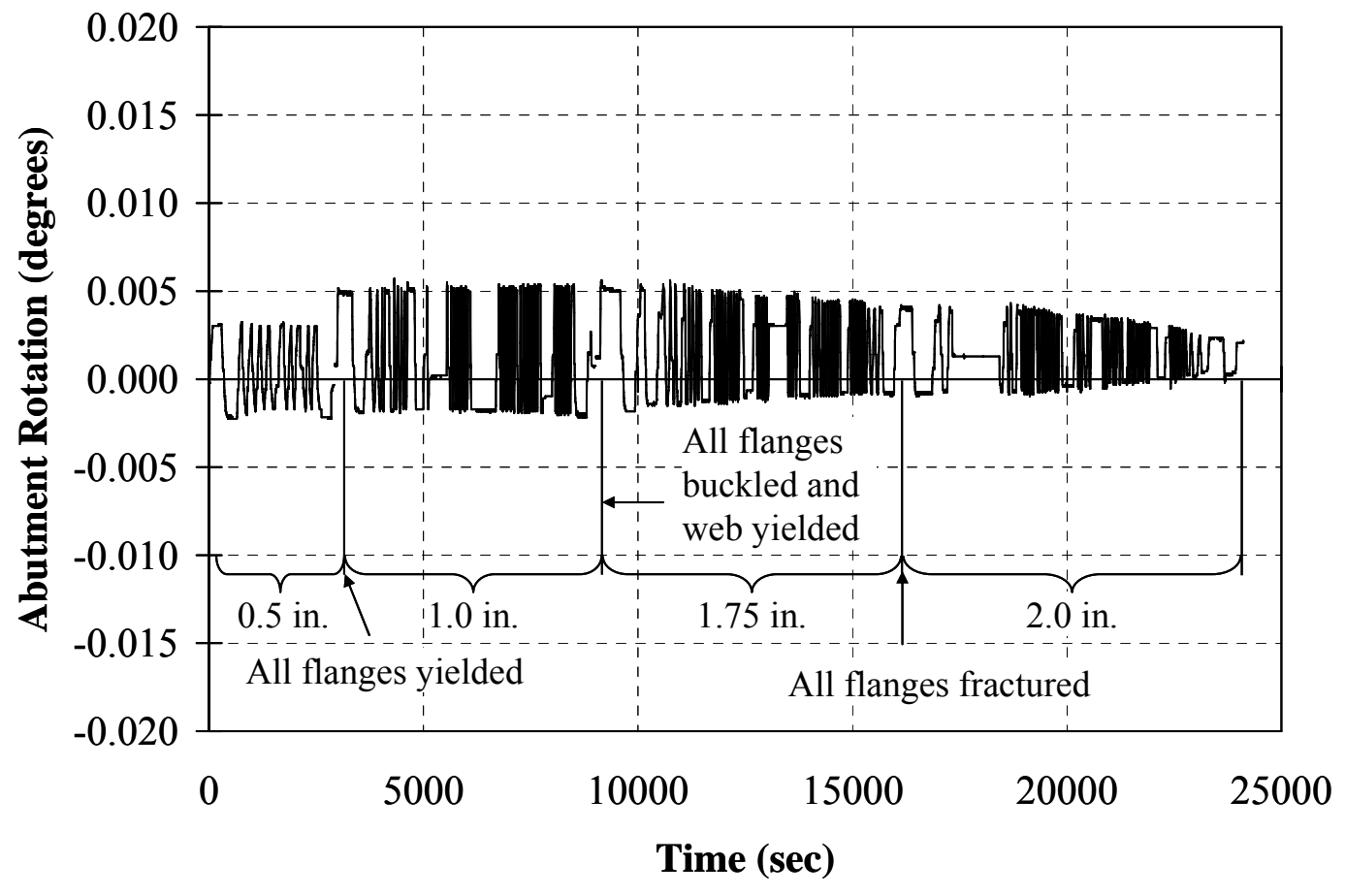

Figure 6.15: Specimen 5 - Abutment Rotation 
The pile rotation of Specimen 5 calculated from LVDTs 7 and 8 during the displacement range of $0.50,1.00,1.75$, and 2.00 in. is presented in Figure 6.16. The pile rotations did not change significantly even after the pile buckled. The pile rotation of Specimen 5 is also representative of the typical pile rotations experienced by the other specimens.

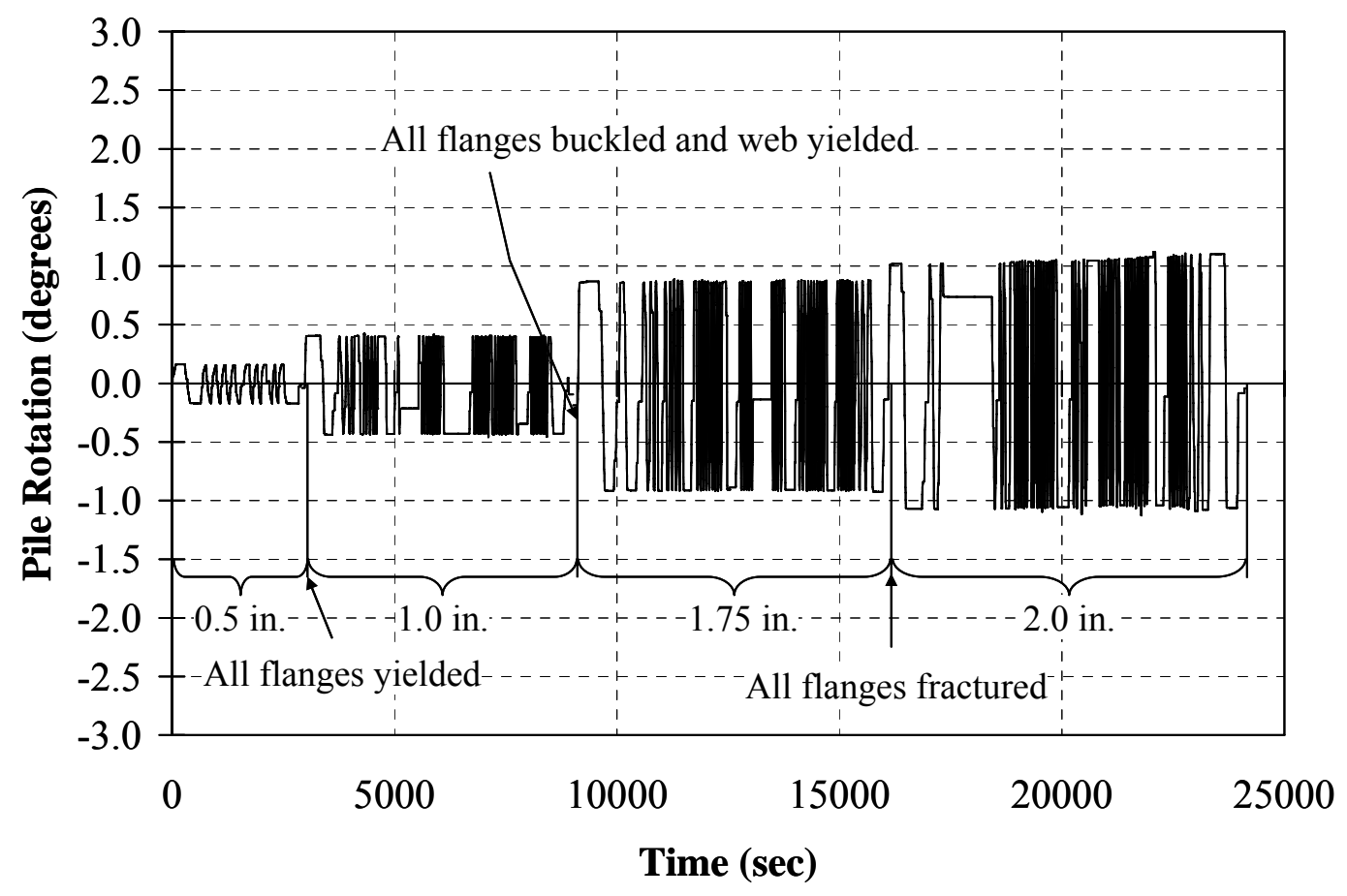

Figure 6.16: Specimen 5 - Pile Rotation 


\subsection{Experimental Results}

\subsubsection{Specimen 1 (HP8x36, Weak Axis, 9 ksi)}

Specimen 1 was the first $\mathrm{H}$ pile tested. An axial load of approximately 95 kips based on $25 \%$ of the specified yield strength, $\mathrm{f}_{\mathrm{y}}$, (taken as $36 \mathrm{ksi}$ for all $\mathrm{H}$ piles) was applied at the pile tip. This specimen is the reference for the evaluation of the effect of pile size, pile orientation, and axial load on pile behavior.

The NE, SW, and SE flanges of the pile started yielding at the $0.50 \mathrm{in}$. displacement range while the NW flanges of the pile started yielding at the $1.00 \mathrm{in}$. displacement range. The NE flange started buckling during the displacement range of 2.00 in., and all flanges buckled during the displacement range of 2.50 in. Figure 6.17 shows buckling of the NW and NE flanges.

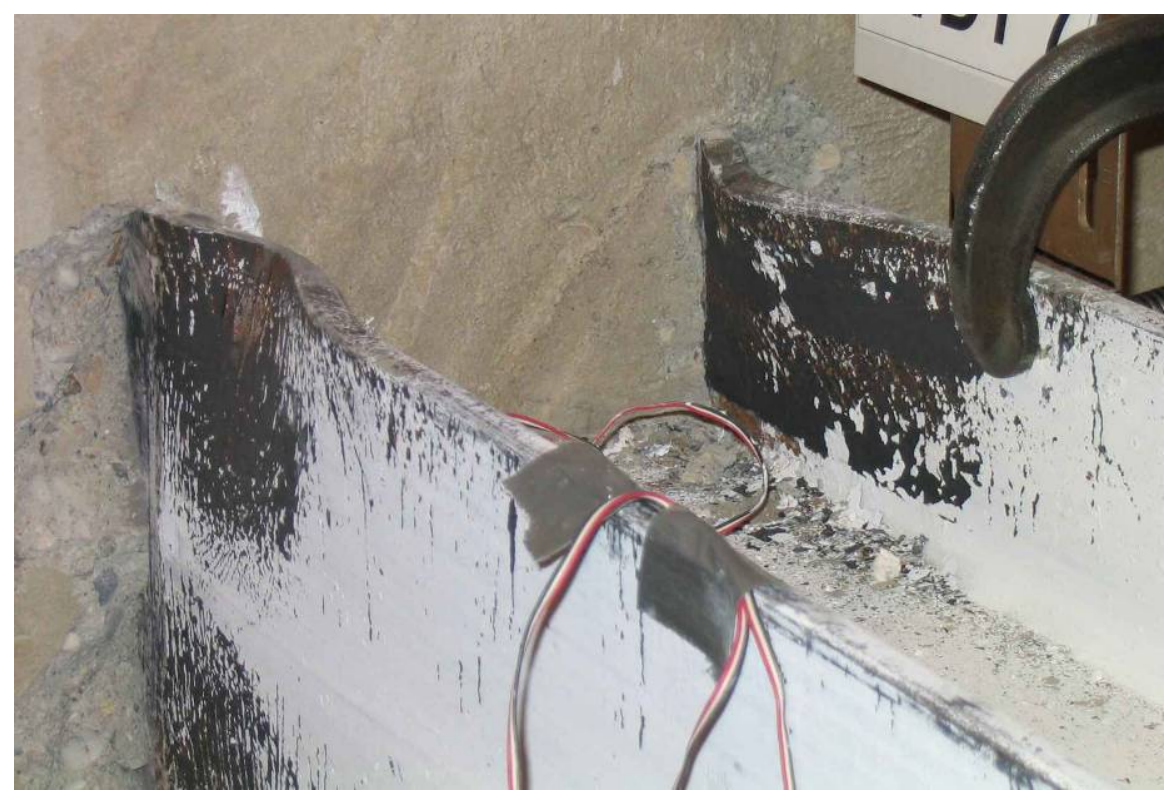

Figure 6.17: Specimen 1 - Pile Buckling

Cracks were observed in all flanges that resulted in complete flange fracture by the end of the test. Figure 6.18 shows minor deterioration at the abutment-pile connection along with the NE flange fracture. The lateral load was observed to decrease $19 \%$ in the up direction and $43 \%$ in the down direction over the course of the $3.00 \mathrm{in}$. 
displacement range. The pile had a lateral load capacity of 14 kips in the up direction and 13 kips in the down direction. The pile reached a deflection of $3.00 \mathrm{in}$. in the up direction (+3.00 in.) and $2.40 \mathrm{in.}$ in the down direction (-2.40 in.). The pile was limited to a deflection of $-2.40 \mathrm{in}$. because of the range of the actuator. The pile reached $+3.00 \mathrm{in}$. without major damage at the abutment-pile connection. Only small local spalling of the concrete occurred. The axial load measured at the neutral position was observed to be fairly constant during the test. The failure of the pile was denoted by a significant decrease of the lateral load capacity in the $80^{\text {th }}$ cycle of the 3.00 in. displacement range as shown in Figure 6.19.

The overall load-deflection response is presented in Figure 6.20, and a summary of the test is provided in Table 6.2. The displacement ductility is defined as a ratio of the displacement capacity and the displacement at first yield. The displacement ductility of the pile, $\mu$, was approximately 6.0 .

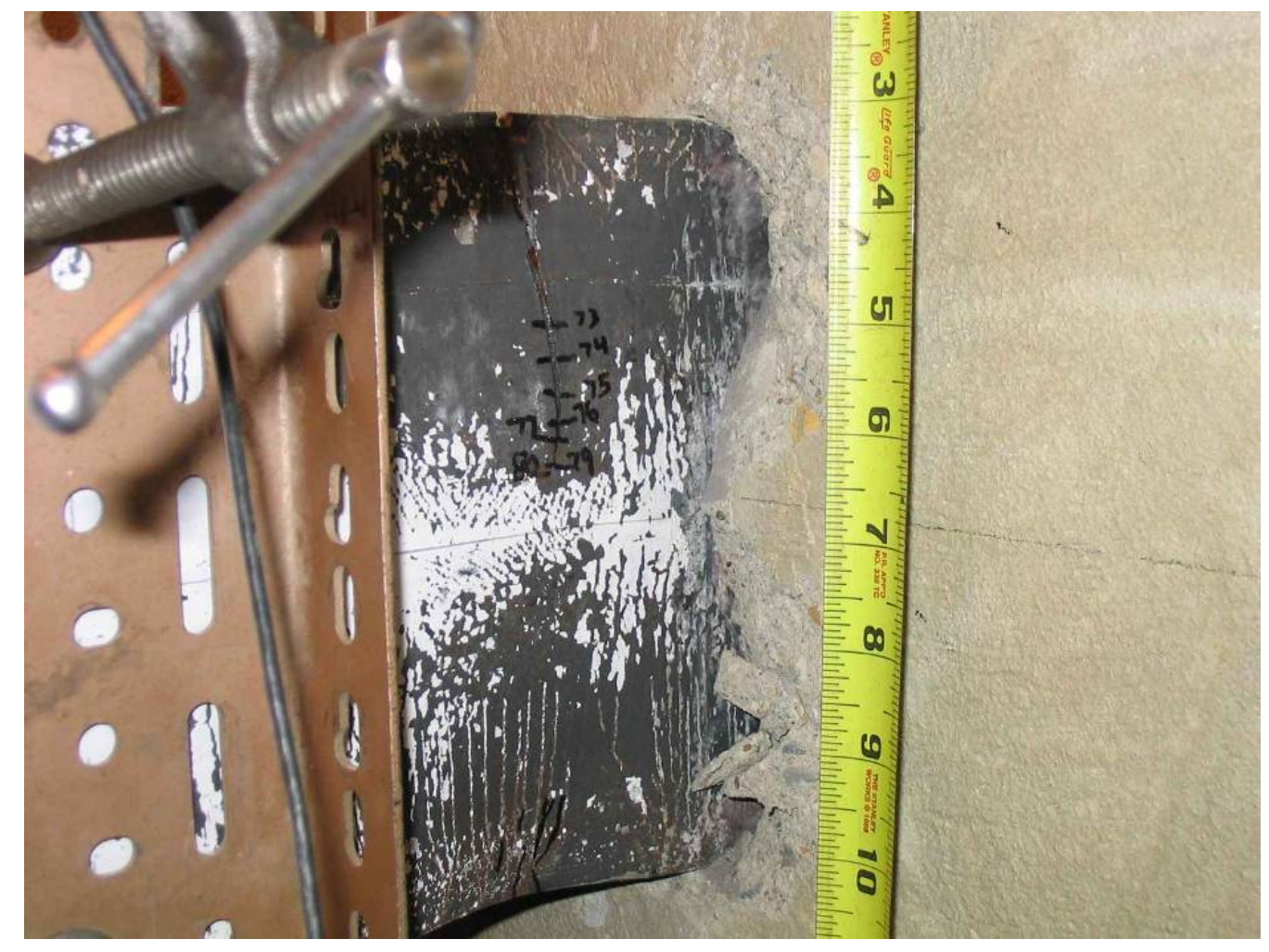

Figure 6.18: Specimen 1 - Flange Cracking 


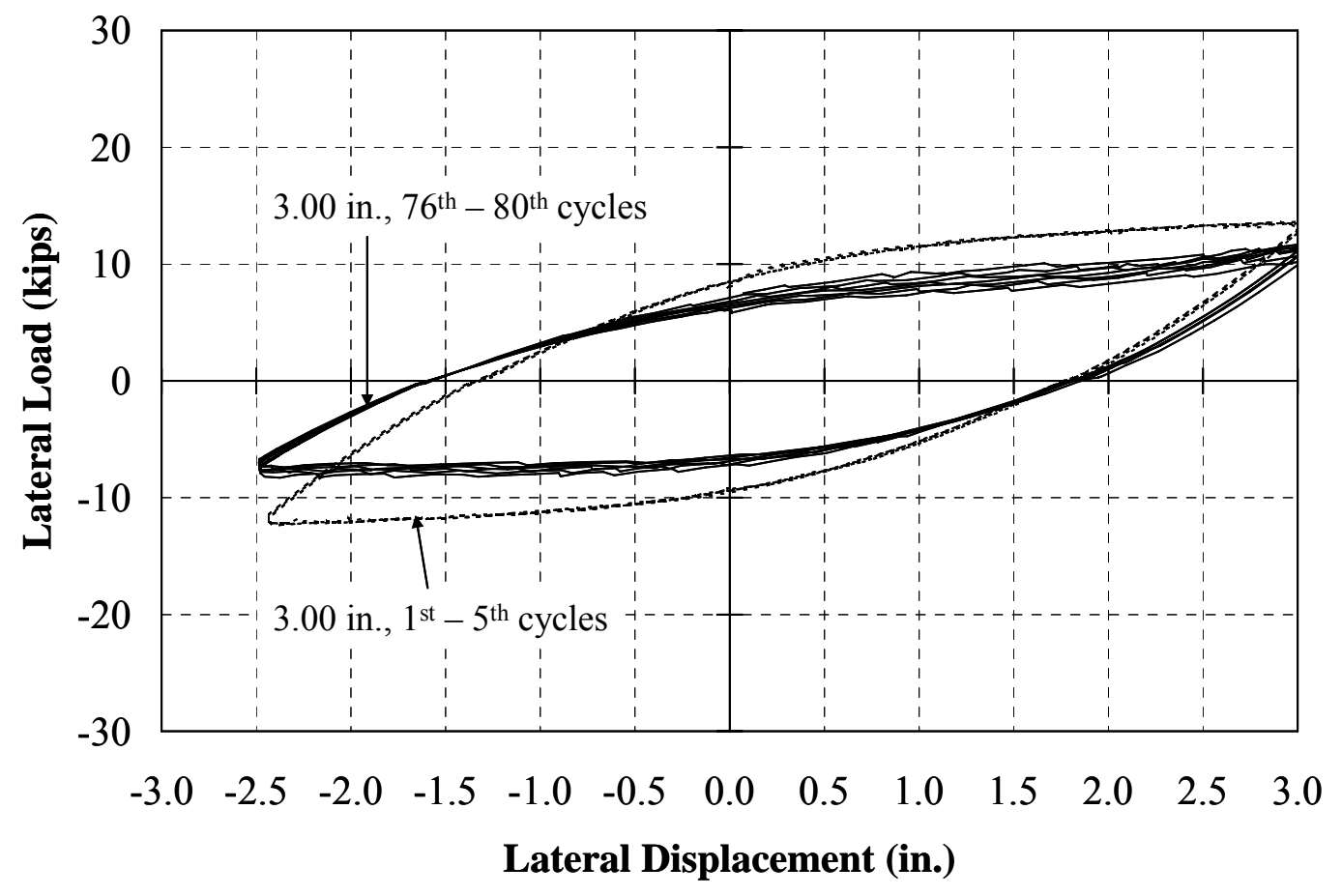

Figure 6.19: Specimen 1 - Load-Deflection Response ( \pm 3.00 in. Range)

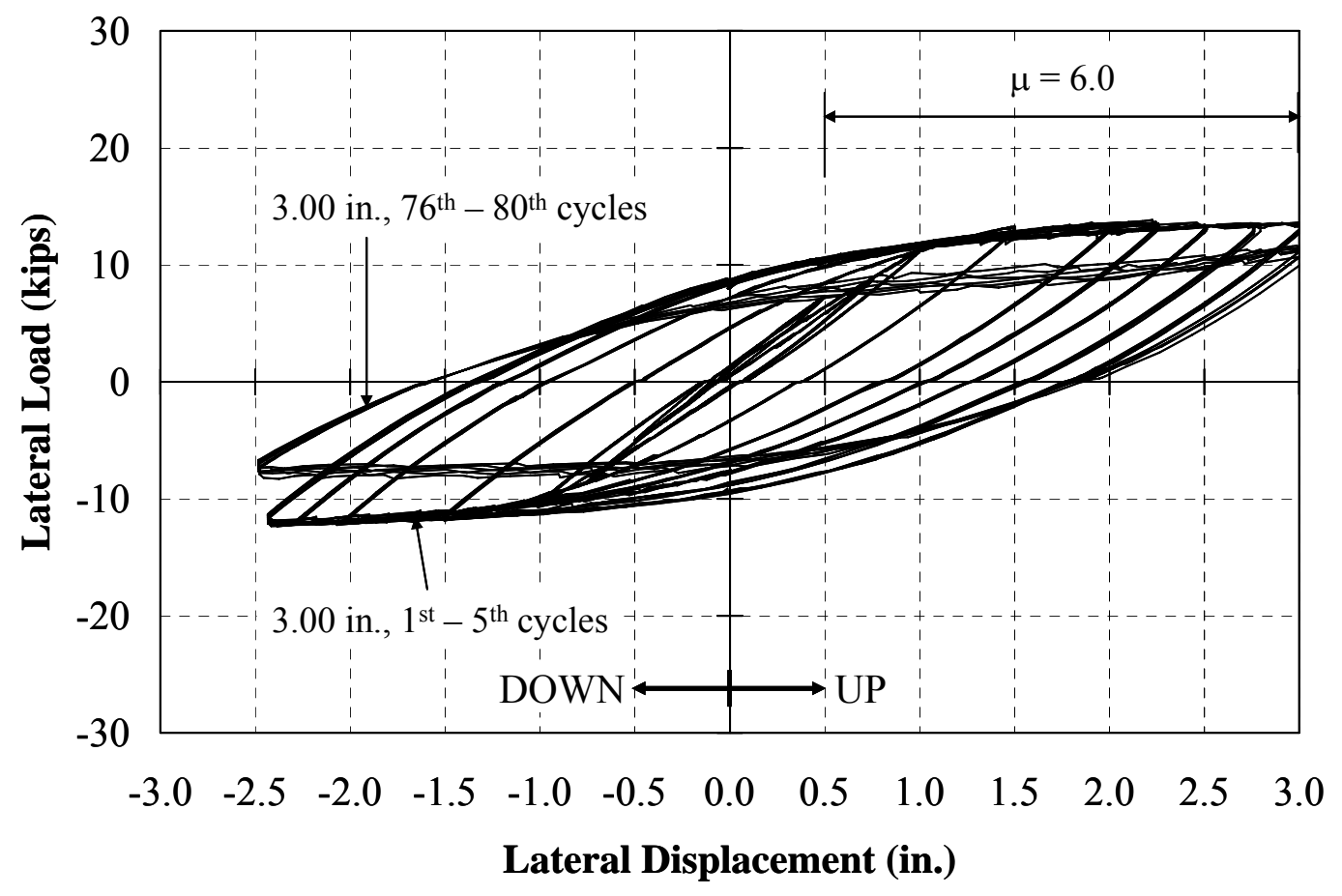

Figure 6.20: Specimen 1 - Overall Load-Deflection Response 


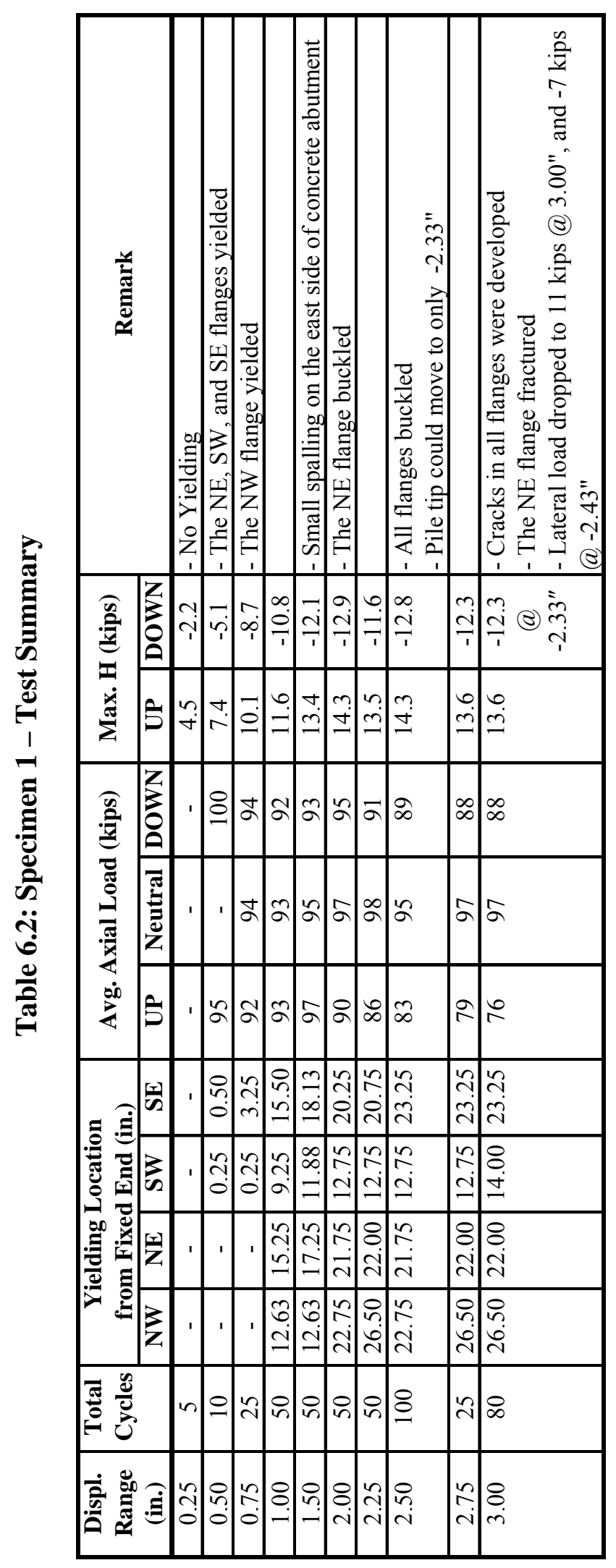




\subsubsection{Specimen 2 (HP8x36, Strong Axis, 9 ksi)}

Specimen 2 was the same pile size and was subjected to the same axial stress as Specimen 1. This specimen, however, was oriented for strong axis bending to evaluate the effect of pile orientation. By inspection, no yielding was observed until 0.75 in., but strain gages on the flanges indicated yielding of the NW and SW flanges in the $0.50 \mathrm{in}$. displacement range. Yielding of all flanges was evident and pull-out cracks on the concrete abutment were noted as early as the 0.75 in. displacement range. Pinching of the lateral load-deflection response was evident as early as the $1.00 \mathrm{in}$. displacement range. The pinching could be attributed to the deterioration of the concrete at the connection. The NW and SW flanges started buckling during the displacement range of 1.50 in. and all flanges buckled during the 1.75 in. displacement range. Figure 6.21 shows buckling of the NE and SE flanges along with deterioration at the abutment-pile connection.

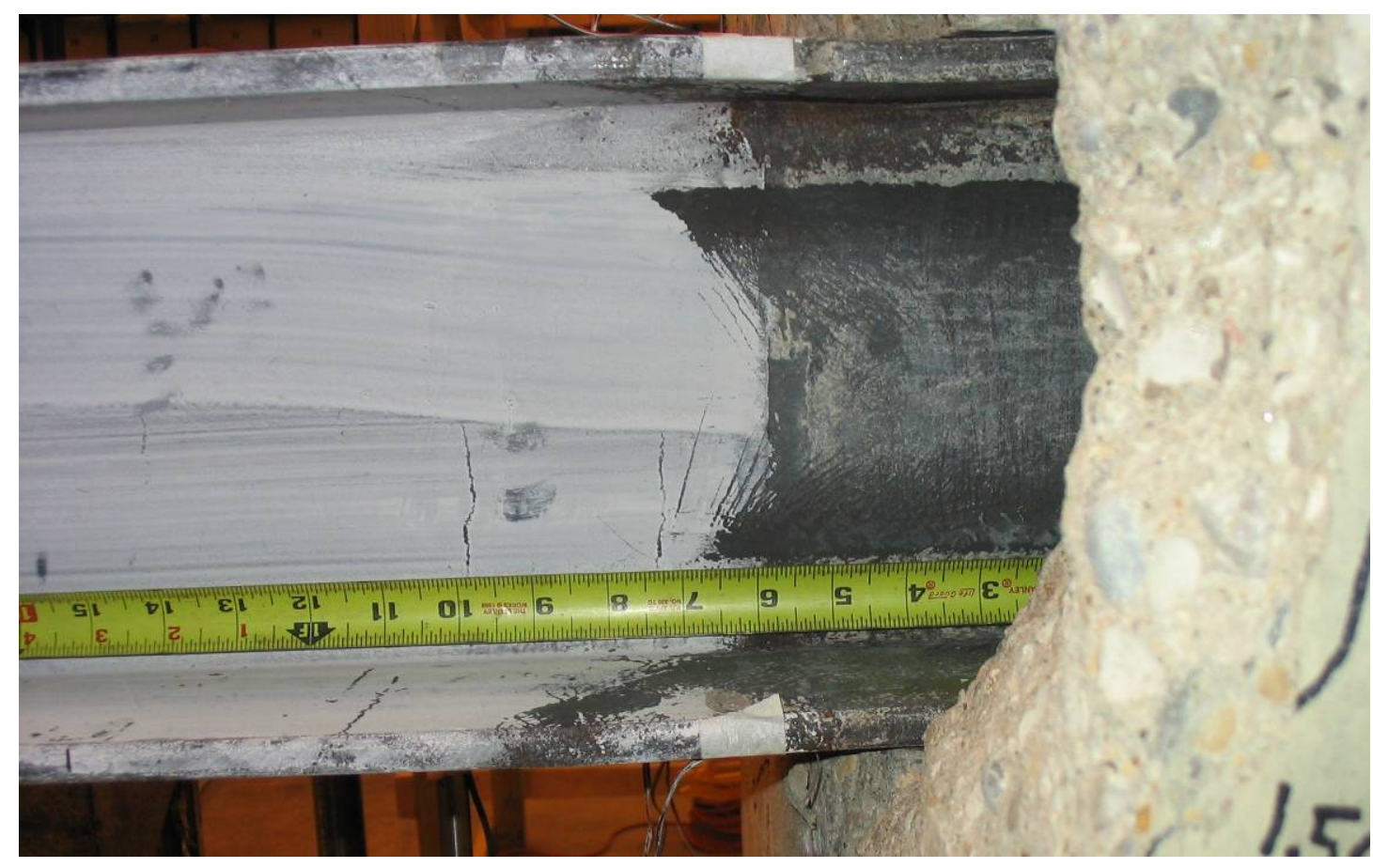

Figure 6.21: Specimen 2 - Flange Buckling on the East Side 
The pile response was limited to a displacement of only \pm 1.75 in. because of significant deterioration at the abutment-pile connection as shown in Figures 6.22 and 6.23. While the abutment-pile connection of Specimen 2 was more severely deteriorated than that of Specimen 1, only buckling of the pile flanges occurred. No cracks or fractures of flanges were observed. The axial load started to drop while cycling at the 1.75 in. displacement. Axial load was added at the neutral level to ensure that the pile carried approximately $9 \mathrm{ksi}$. Nevertheless the pile maintained its axial load. The lateral load was observed to slightly decrease $6 \%$ in the up direction and $3 \%$ in the down direction during the 1.75 in. displacement range. This response indicates that the pile can maintain both axial and lateral load during the final displacement range of $1.75 \mathrm{in}$. as shown in Figure 6.24.

The overall load-deflection response is shown in Figure 6.25 and a summary of the test is provided in Table 6.3. The pile had a lateral load capacity of 24 kips in the up direction and 23 kips in the down direction. The displacement ductility of the pile, $\mu$, was approximately 3.5. Failure was denoted by significant damage at the abutment-pile connection which was evident in the $100^{\text {th }}$ cycle of the $1.75 \mathrm{in}$. displacement range.

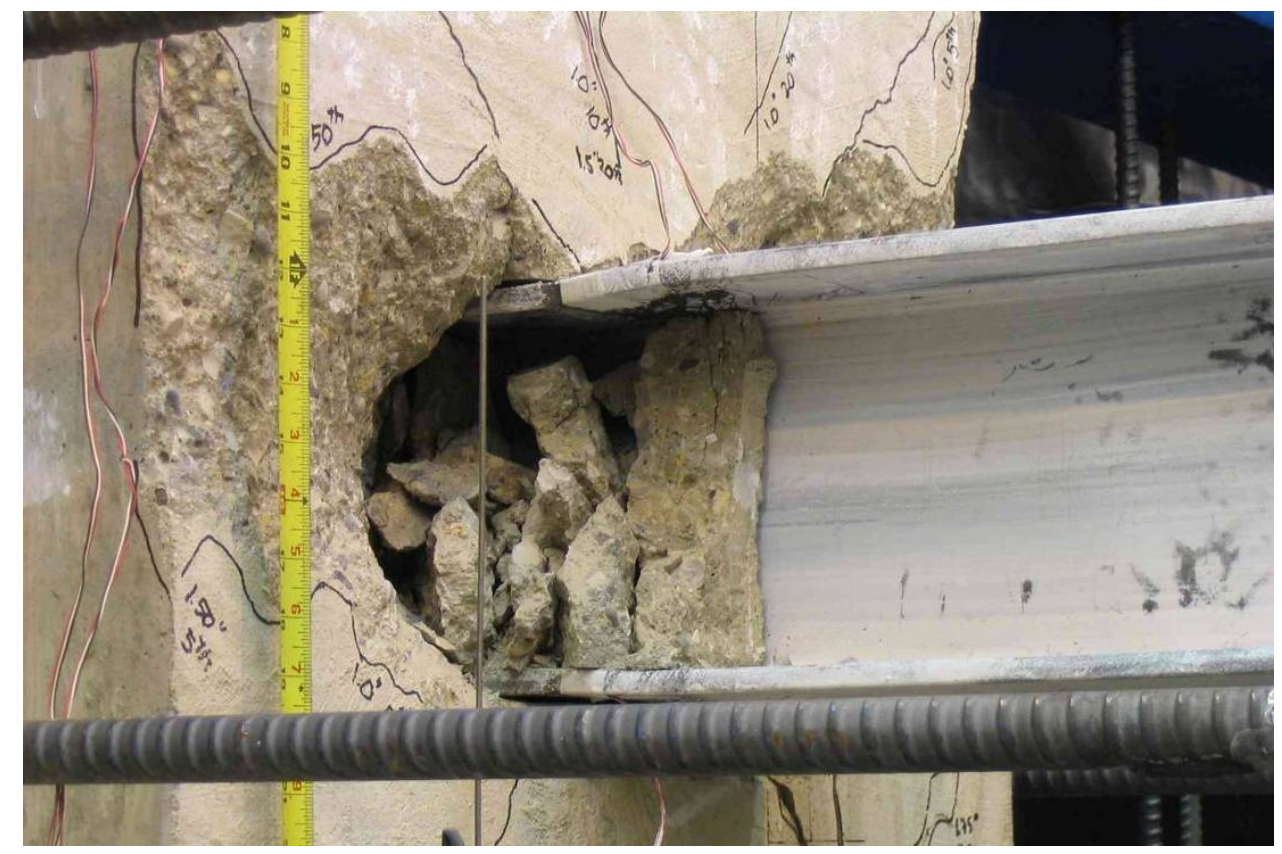

Figure 6.22: Specimen 2 -Abutment-Pile Connection Damage (West Side) 


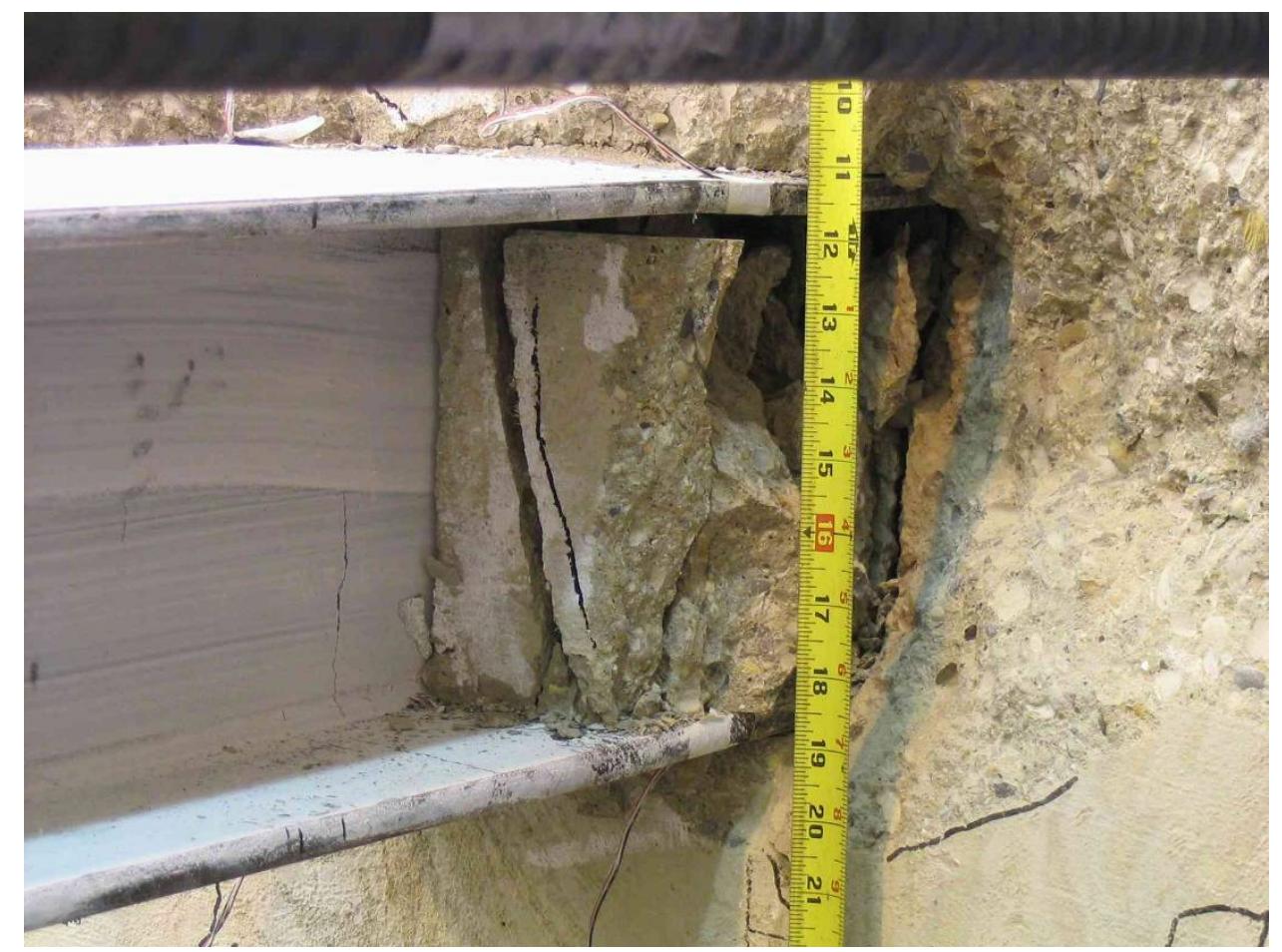

Figure 6.23: Specimen 2 -Abutment-Pile Connection Damage (East Side)

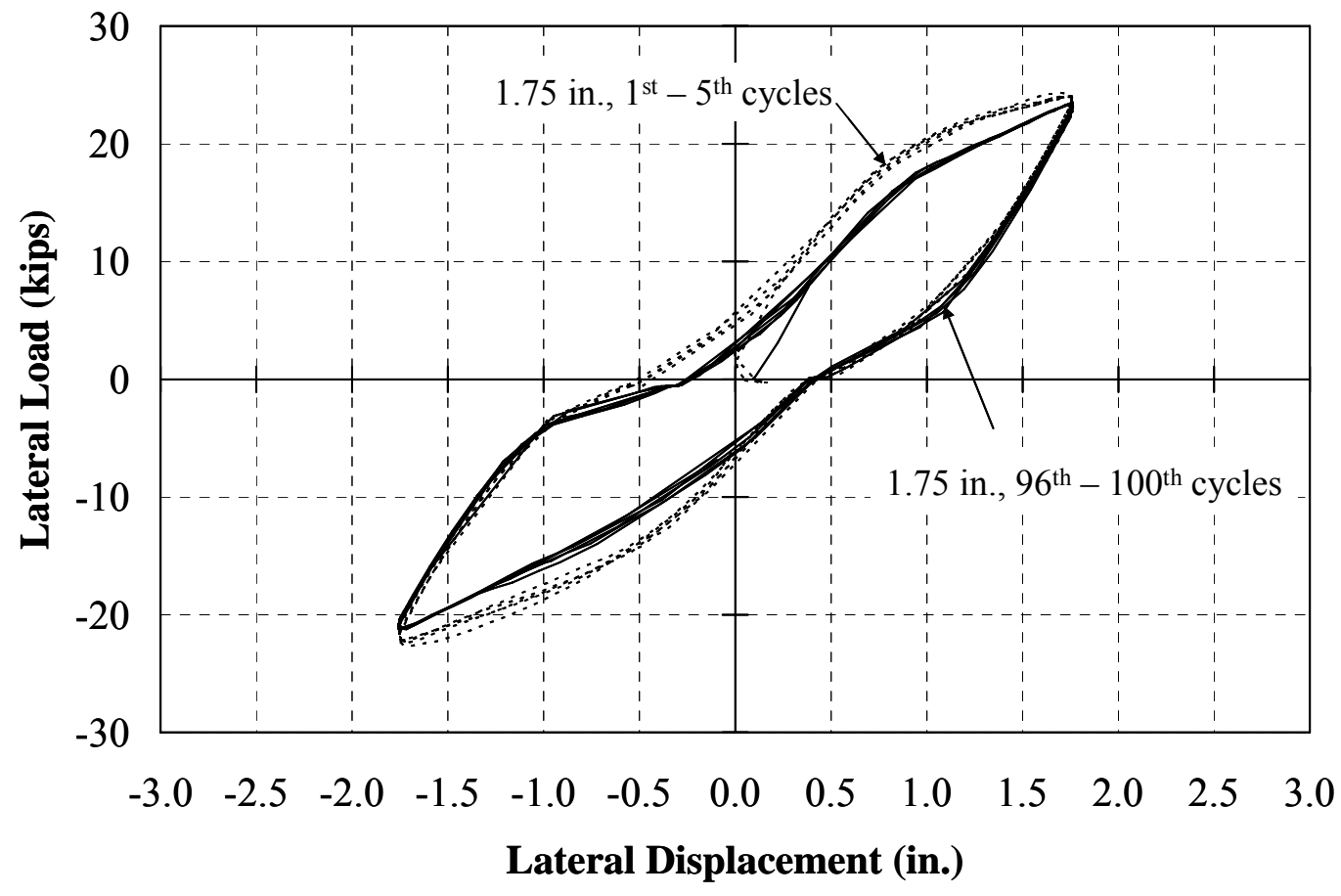

Figure 6.24: Specimen 2 - Load-Deflection Response ( \pm 1.75 in. Range) 


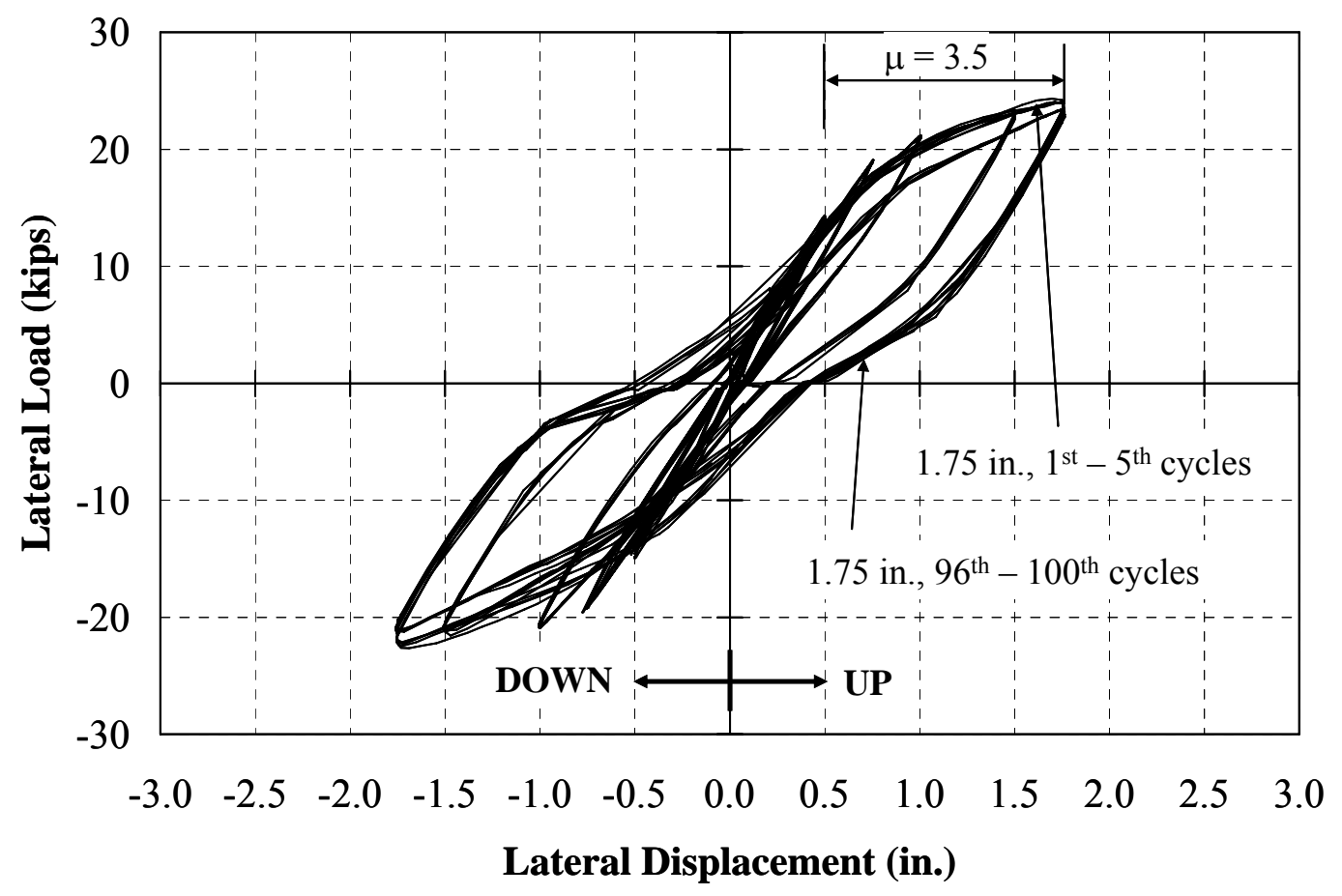

Figure 6.25: Specimen 2 - Overall Load-Deflection Response 


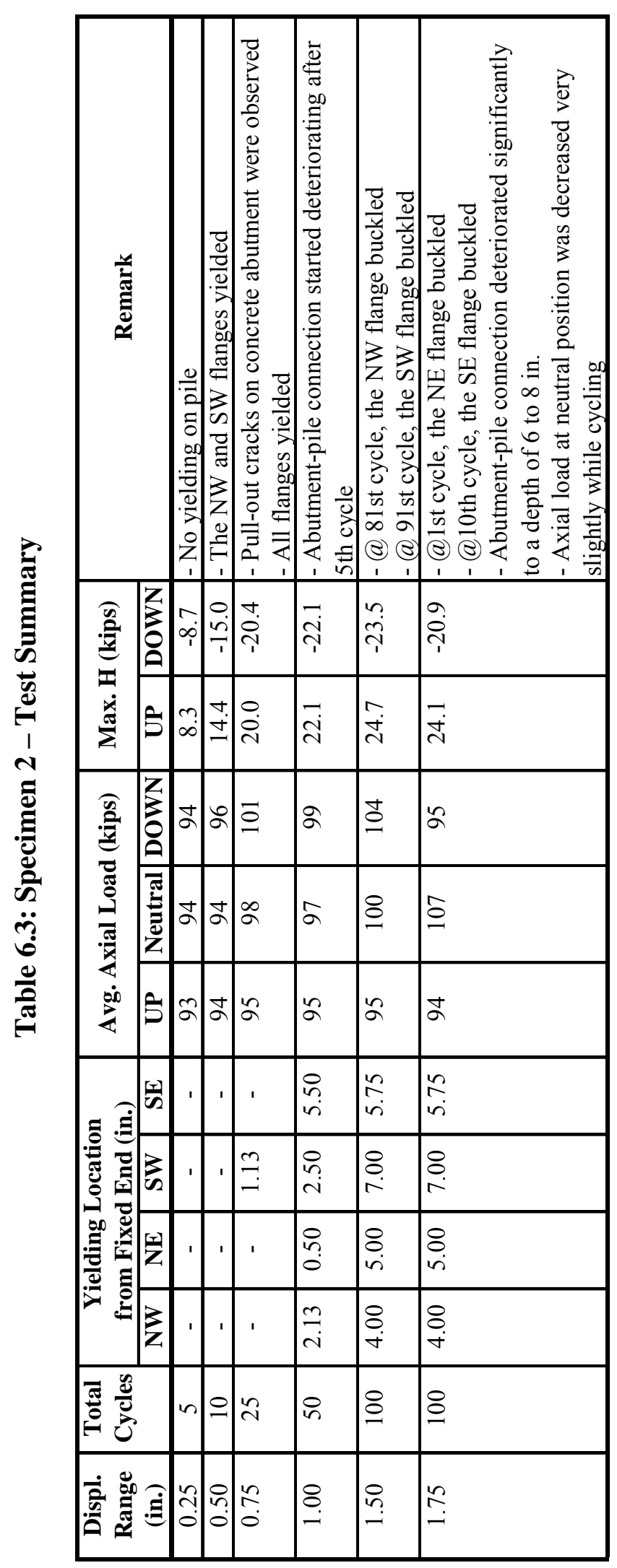




\subsubsection{Specimen 3 (HP8x36, $45^{\circ}$ Axis, 9 ksi)}

Specimen 3 was the same pile size as Specimens 1 and 2, but considered different orientation. Due to its $45^{\circ}$ axis bending, the pile tended to move out-of-plane. A bracing frame was established to prevent out-of-plane movement of the pile as shown in Figure 6.26. The frame was designed such that the pile could move $1 / 2$ in. out-of-plane; however, due to construction tolerance, only $3 / 8$ in. was provided between the pile and the frame.

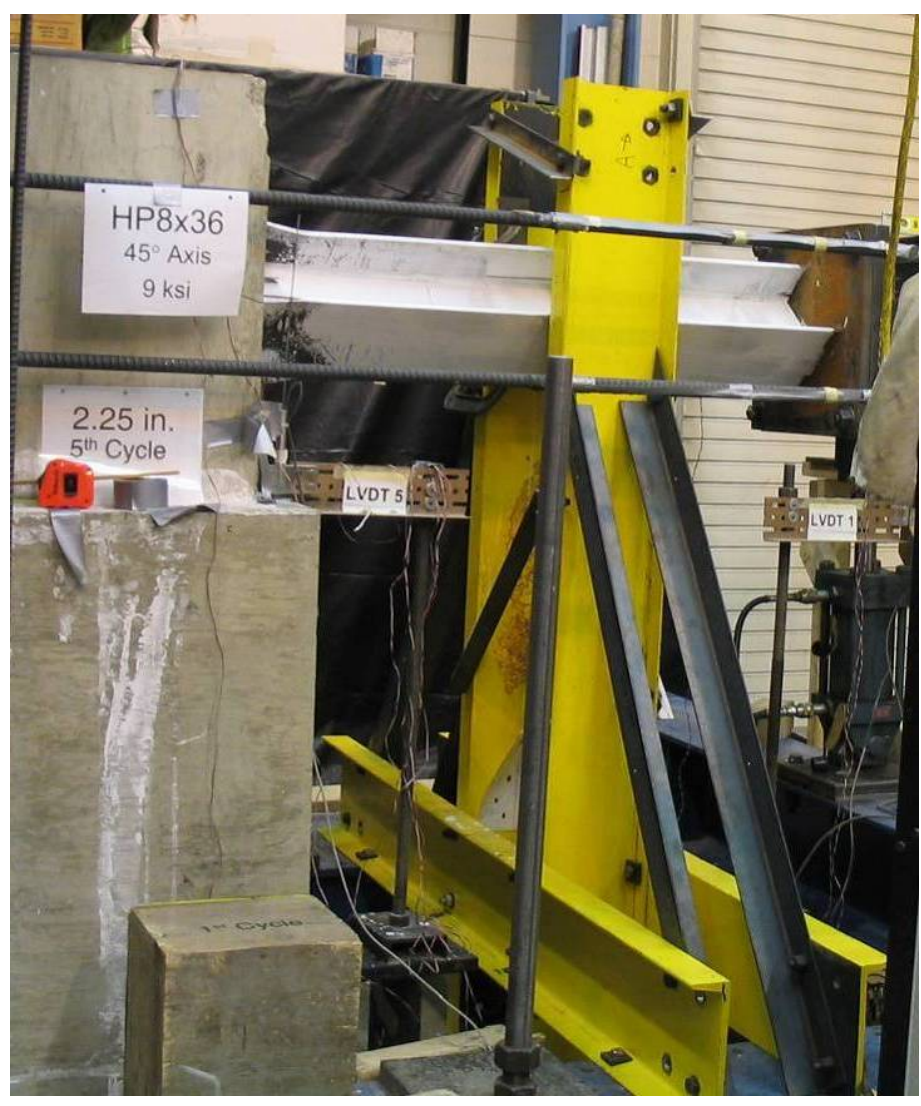

(a) Bracing Frame

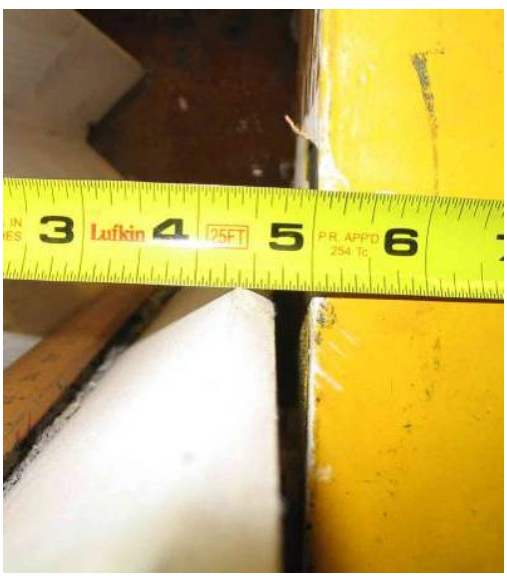

(b) $3 / 8$ in. Gap

Figure 6.26: Specimen 3 - Bracing Frame 
The north and south flanges started yielding as early as the $0.50 \mathrm{in}$. displacement range. Cracks in the concrete at the edges of all flanges were noticed during the $1.00 \mathrm{in}$. displacement range, and the pile slightly moved (1/8 in.) out-of-plane. At the end of the 1.25 in. displacement range, the crack in the concrete at the edge of the west flange extended to the edge of the abutment. At the beginning of the $1.50 \mathrm{in}$. displacement range, all flanges yielded, and cracks in the concrete at the edges of the north and east flanges extended to the edge of the abutment. The web started yielding and the pile moved $3 / 8$ in. out-of-plane. The north flange started buckling in the $30^{\text {th }}$ cycle of the 1.50 in. displacement range, while the south flange started buckling at the beginning of the 1.75 in. displacement range. These two flanges buckled first because they were at the extreme edges. The crack in the concrete at the south flange extended to the bottom edge of the abutment at the beginning of the 1.75 in. displacement range. Figure 6.27 shows the cracks in the concrete at the edges of the west, north, east, and south flanges extended to the edge of the abutment. Finally, the east and west flanges buckled, and fracture of the north flange was observed during the 2.00 in. displacement range as shown in Figure 6.28. In addition, severe web yielding extended 6 in. outward from the abutment-pile connection as illustrated in Figure 6.29. As indicated in Figure 6.30, the lateral load was observed to reduce $16 \%$ in the up direction and $22 \%$ in the down direction during the 2.00 in. displacement range. Nevertheless, the abutment-pile connection was only slightly damaged, and the axial load was maintained.

The overall load-deflection response of Specimen 3 is presented in Figure 6.31, and a summary of the test is provided in Table 6.4. A lateral load capacity of the pile was 18 kips in the up direction and 17 kips in the down direction. The displacement ductility, $\mu$, was approximately 4.0. The test was terminated due to loss of the lateral load capacity in the $80^{\text {th }}$ cycle of the 2.00 in. displacement range. 


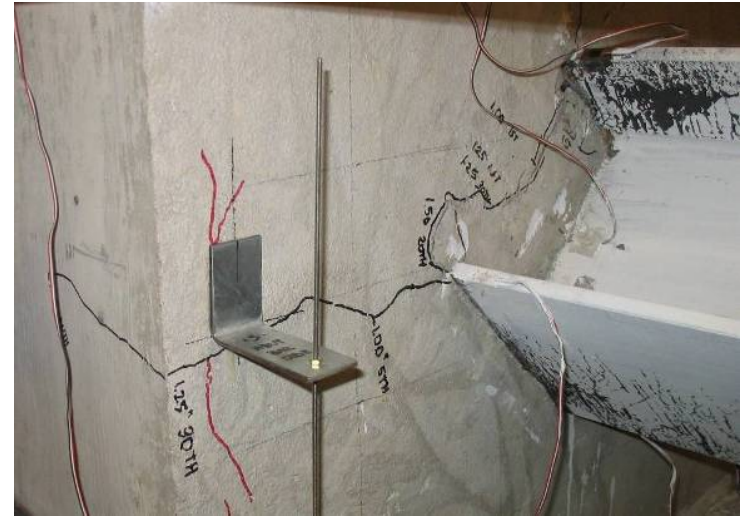

(a) West Flange

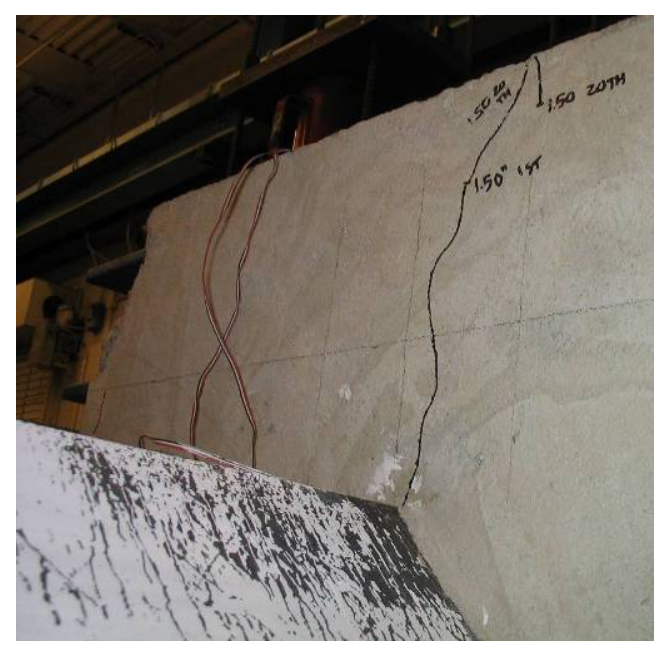

(b) North Flange

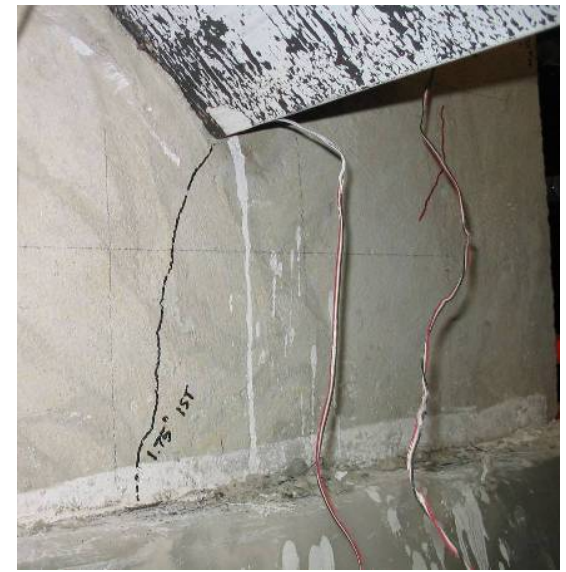

(c) South Flange

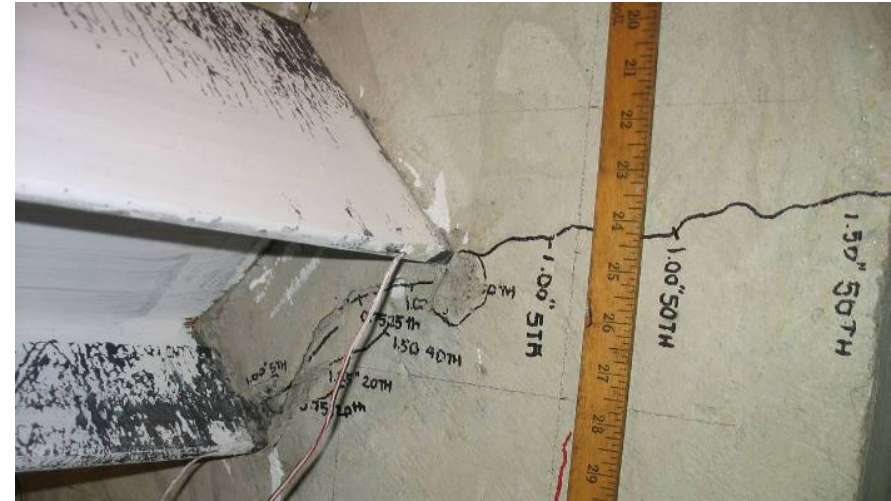

(d) East Flange

Figure 6.27: Specimen 3 - Cracks in Concrete 


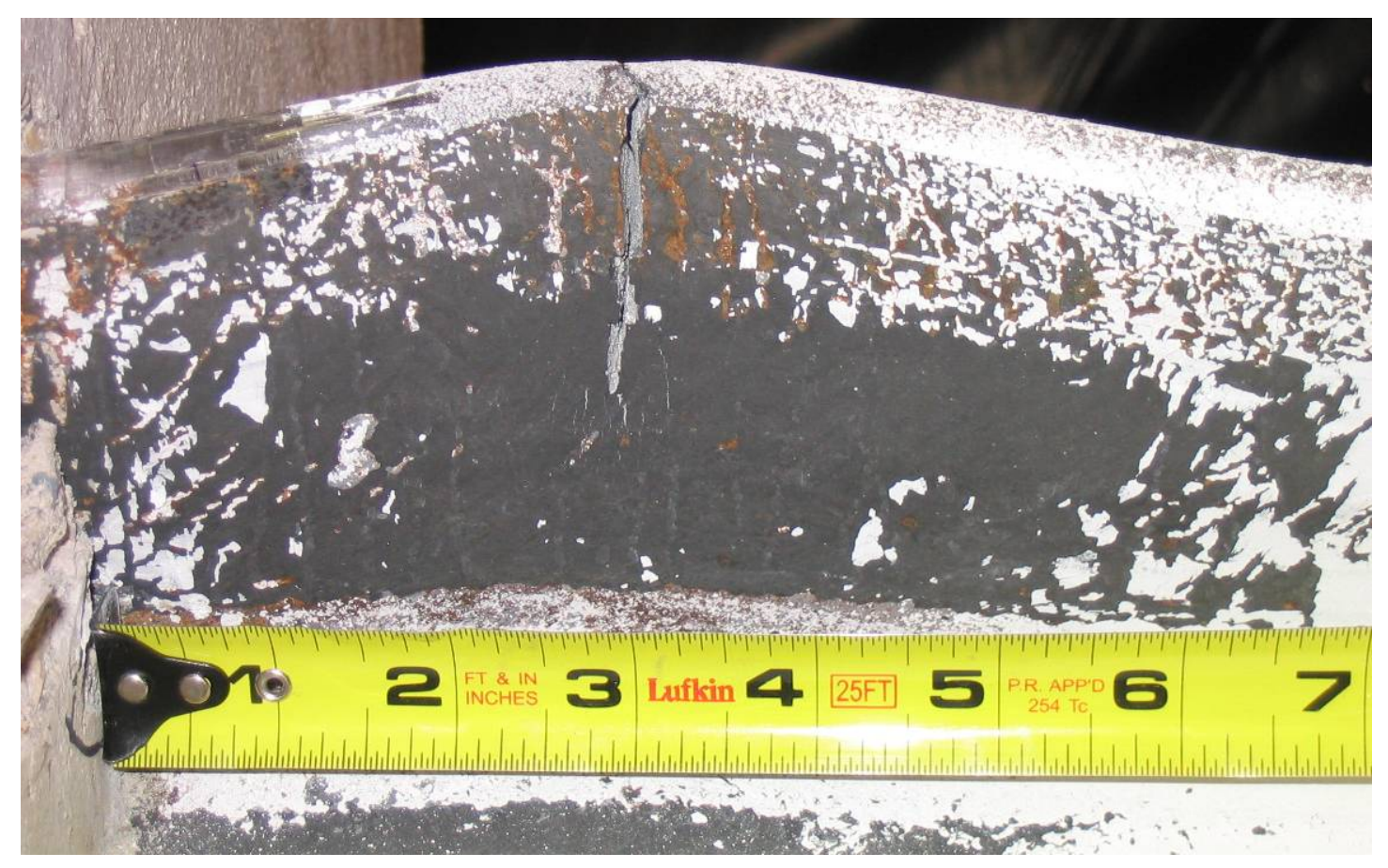

Figure 6.28: Specimen 3 - Fracture of the North Flange

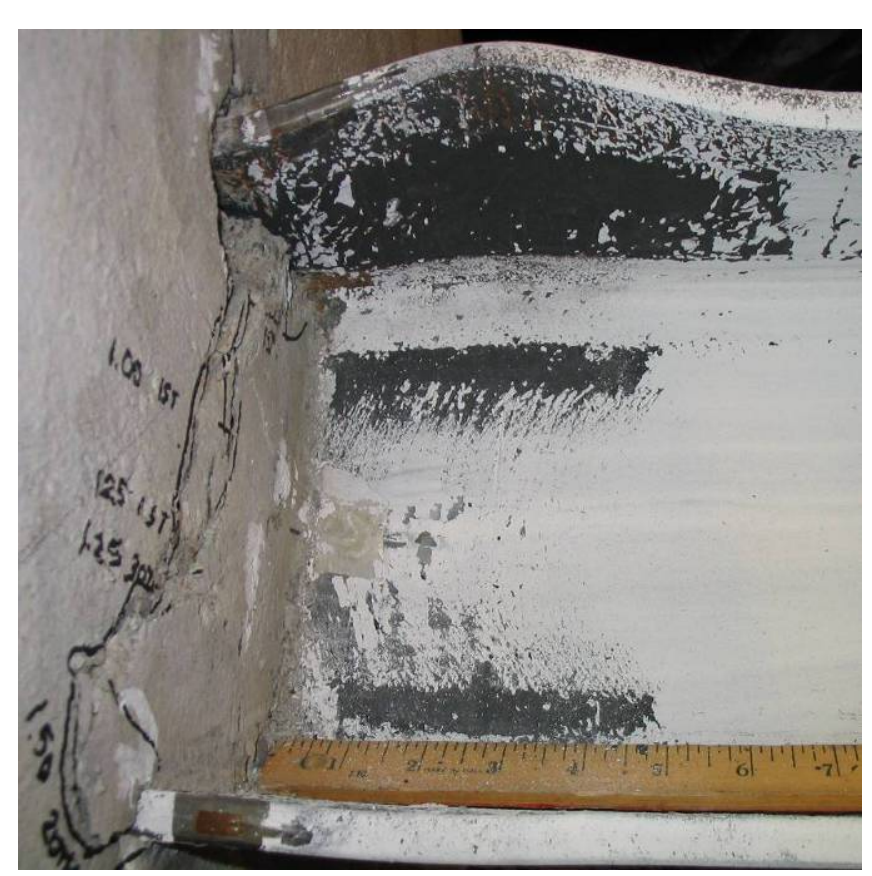

(a) NW Side

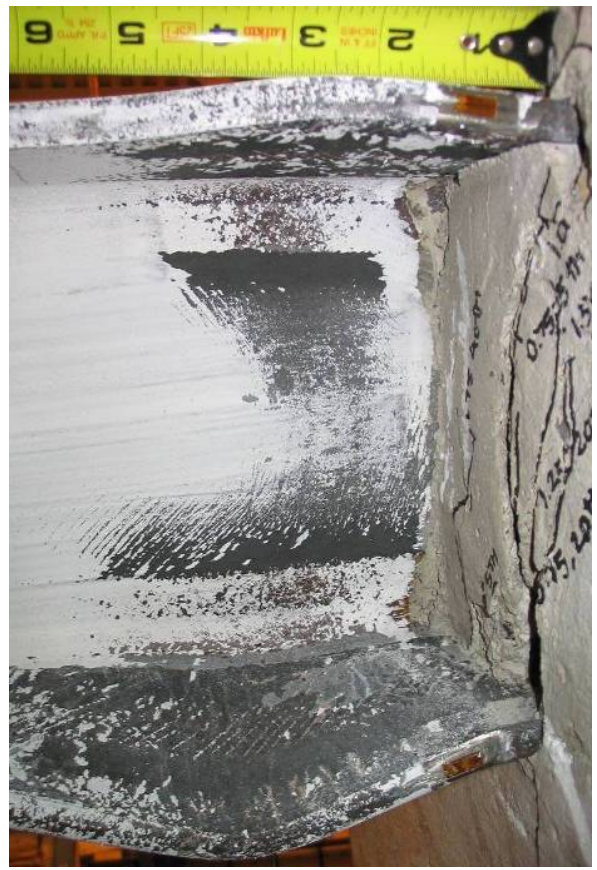

(b) SE Side

Figure 6.29: Specimen 3 - Web Yielding 


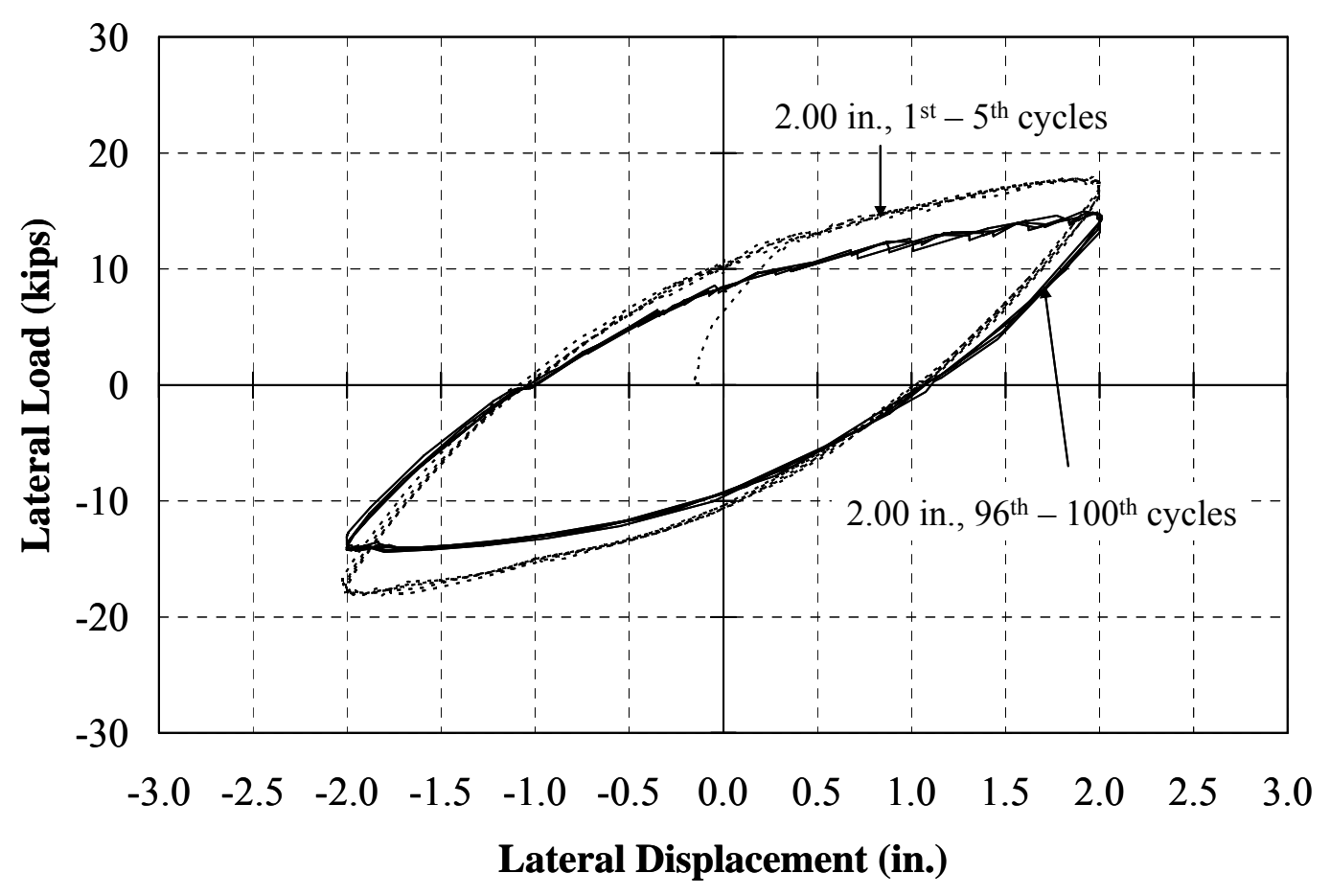

Figure 6.30: Specimen 3 - Load-Deflection Response ( \pm 2.00 in. Range)

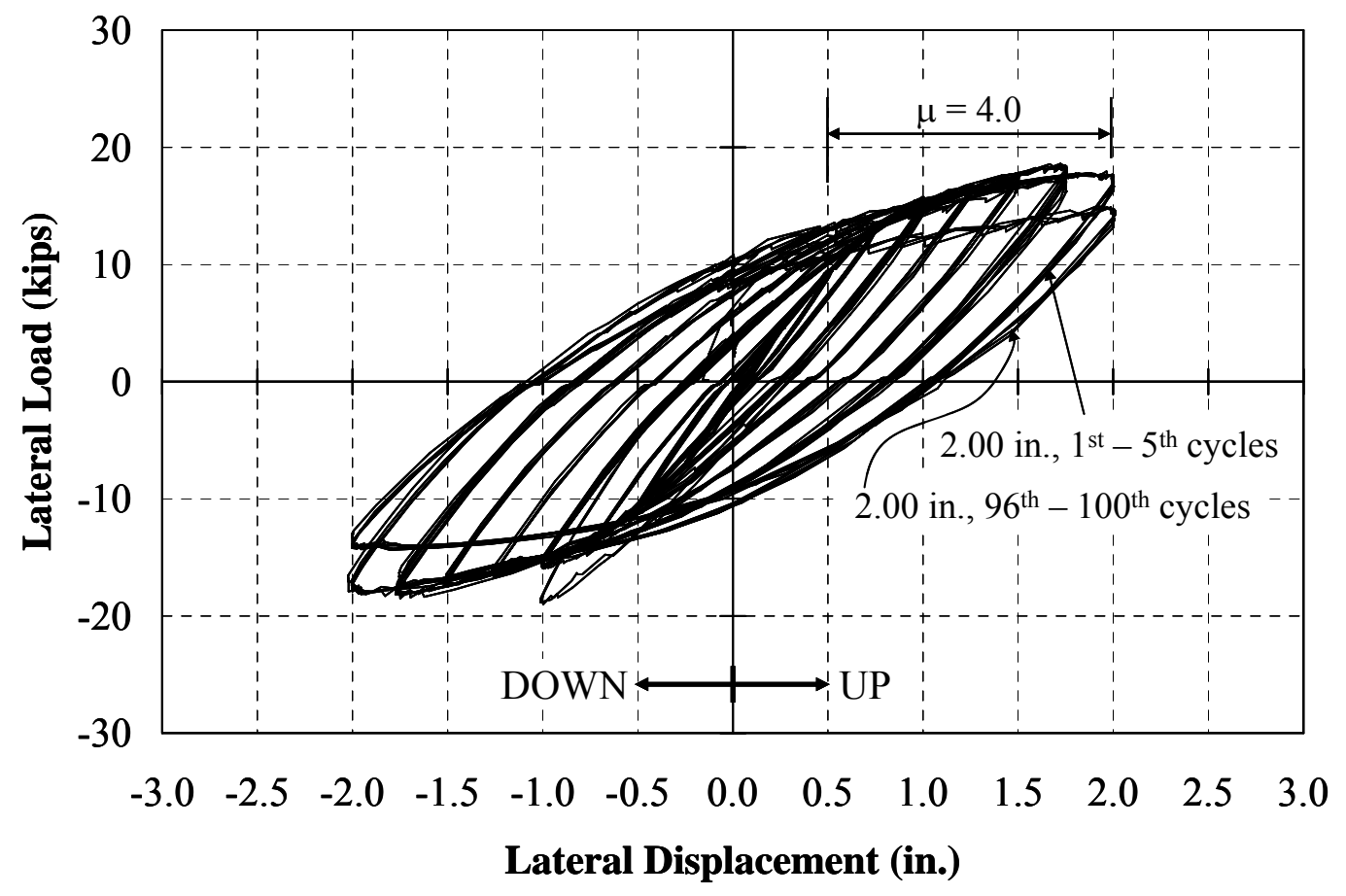

Figure 6.31: Specimen 3 - Overall Load-Deflection Response 


\begin{tabular}{|c|c|c|c|c|c|c|c|c|}
\hline 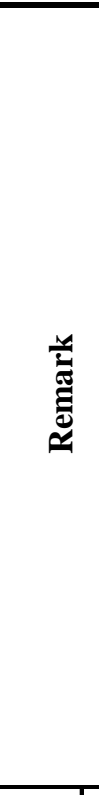 & 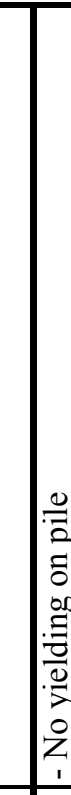 & 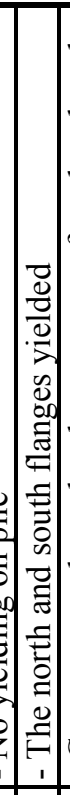 & 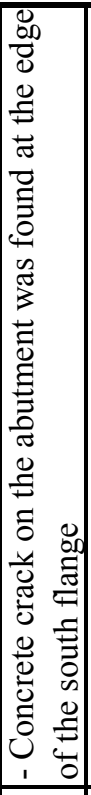 & 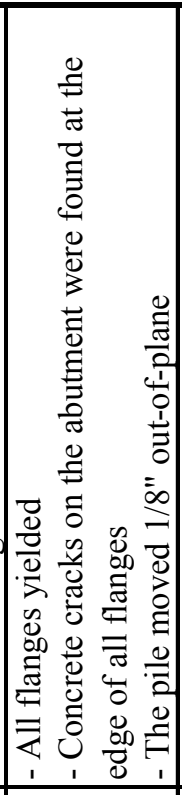 & 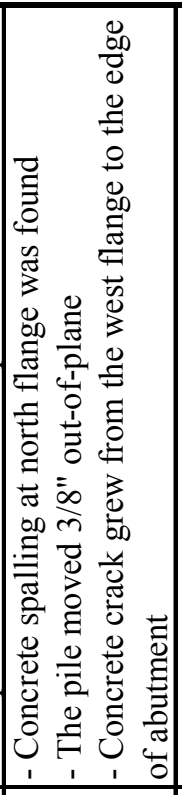 & 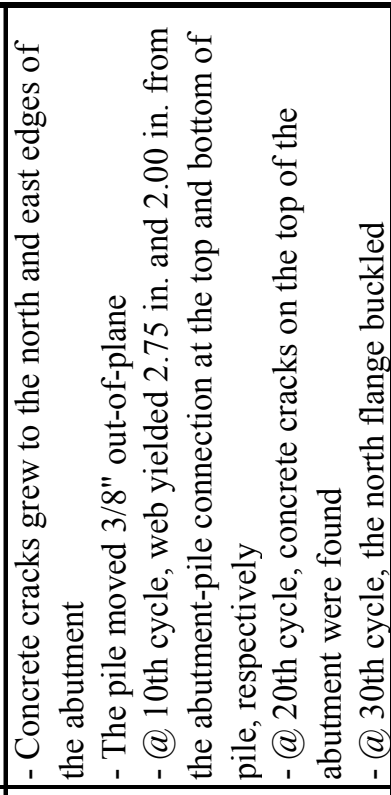 & 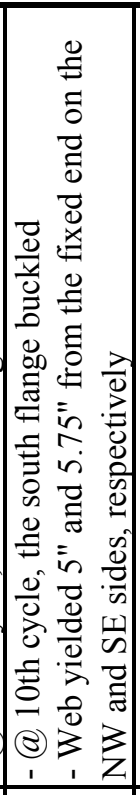 & 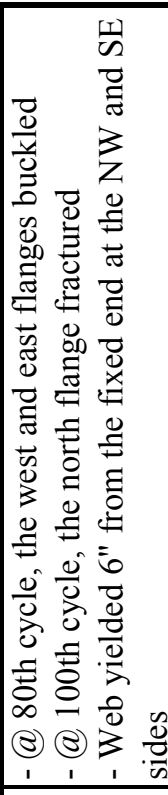 \\
\hline \multirow{2}{*}{ 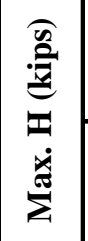 } & & \begin{tabular}{l} 
\\
\\
\hdashline \\
\end{tabular} & $\underset{+}{+}$ & $\begin{array}{l}0 \\
\stackrel{0}{0} \\
11\end{array}$ & $\mid \begin{array}{l}n \\
0 \\
1\end{array}$ & $\frac{1}{\pi}$ & $\frac{7}{\pi}$ & $\frac{m}{1}$ \\
\hline & $\stackrel{\sim}{\sigma}$ & $\dot{r}$ & $\vec{\rho}$ & ñ. & 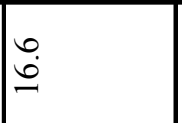 & $\stackrel{n}{\check{n}}$ & $\stackrel{9}{\stackrel{2}{2}}$ & $\ddot{0}$ \\
\hline \multirow{3}{*}{ 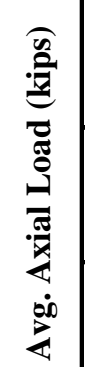 } & 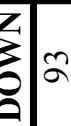 & 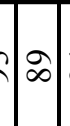 & t & \% & \% & హ゙ & $\hat{\alpha}$ & $\infty$ \\
\hline & हَّ & $\hat{\infty}$ & $\hat{\alpha}$ & పః & పః & ప゙ & 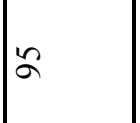 & ন \\
\hline & $\bar{s} \mid \approx$ & $N$ & ส & ন & ă & $\bar{a}$ & $\infty$ & $\infty$ \\
\hline \multirow{4}{*}{ 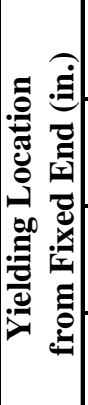 } & 되 ' & 1 & I & ' & ' & 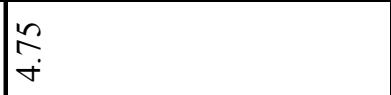 & $\stackrel{\Re}{\stackrel{n}{\sim}}$ & $\stackrel{n}{\stackrel{n}{+}}$ \\
\hline & & $\left.\mid \begin{array}{l}n \\
i n\end{array}\right]$ & $\begin{array}{l}i \\
i n \\
n\end{array}$ & $\begin{array}{l}\stackrel{n}{n} \\
2\end{array}$ & $\stackrel{n}{\stackrel{2}{a}}$ & $\begin{array}{l}\stackrel{n}{a} \\
\text { à }\end{array}$ & $\begin{array}{l}n \\
\stackrel{n}{i} \\
\end{array}$ & 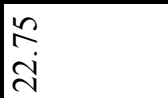 \\
\hline & & - & $\begin{array}{l}8 \\
i \\
i\end{array}$ & $\begin{array}{l}0 \\
2 \\
2\end{array}$ & $\frac{n}{a}$ & 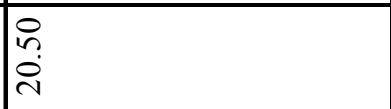 & $\begin{array}{l}\text { in } \\
\stackrel{n}{*}\end{array}$ & $\begin{array}{l}\text { in } \\
\stackrel{n}{*}\end{array}$ \\
\hline & 31 & 1 & ' & ' & 1 & ¿ & 8 & \& \\
\hline 焉 & n & 5 의 & $\approx$ & in & in & in & 응 & 응 \\
\hline 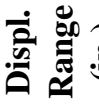 & 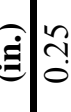 & $\stackrel{n}{\circ}$ & $\stackrel{n}{a}$ & $\stackrel{8}{-}$ & $\stackrel{\overbrace{}}{\Im}$ & $\stackrel{n}{-}$ & $\stackrel{n}{\stackrel{2}{*}}$ & $\underset{i}{\stackrel{8}{a}}$ \\
\hline
\end{tabular}




\subsubsection{Specimen 4 (HP8x36, Weak Axis, 18 ksi)}

Specimen 4 was the same pile size as Specimen 1; however, it was subjected to twice the axial load to evaluate the effect of axial load on pile behavior. The NW, SW, and SE flanges yielded at the 0.50 in. displacement range. The NE flange and the bottom of the web yielded during the $0.75 \mathrm{in}$. displacement range, and limited small spalling of concrete was noticed. At the beginning of the 2.00 in. displacement range, the top of the web yielded, and the lateral load capacity was observed to decrease. All flanges buckled during the $2.25 \mathrm{in}$. displacement range. At the end of the $2.50 \mathrm{in}$. displacement range, the web was severely buckled as illustrated in Figure 6.32. As indicated in Figure 6.33, the lateral load decreased $29 \%$ in the up direction and $23 \%$ in the down direction over the course of the $2.50 \mathrm{in}$. displacement range. Despite of the significant web yielding, the axial load continued to be maintained.

The overall load-deflection response of Specimen 4 is presented in Figure 6.34, and a summary of the test is provided in Table 6.5. The lateral load capacity of Specimen 4 was observed to be $8.5 \mathrm{kips}$ in the up direction and $9.5 \mathrm{kips}$ in the down direction. The displacement ductility, $\mu$, was approximately 5.0. The test was discontinued with flange buckling because of the loss of lateral load capacity and severe web buckling during the $66^{\text {th }}$ cycle of the 2.00 in. displacement range.

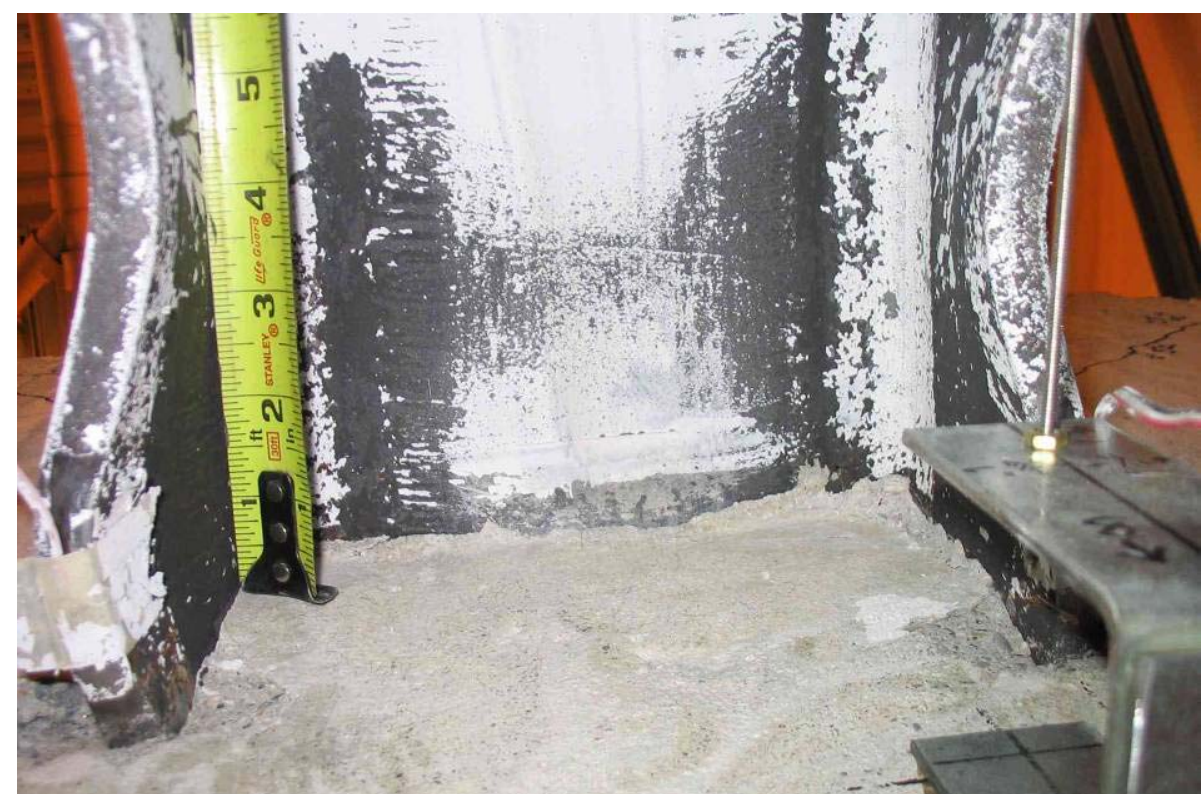

Figure 6.32: Specimen 4 - Web Yielding ( 2.50 in., $66^{\text {th }}$ Cycle) 


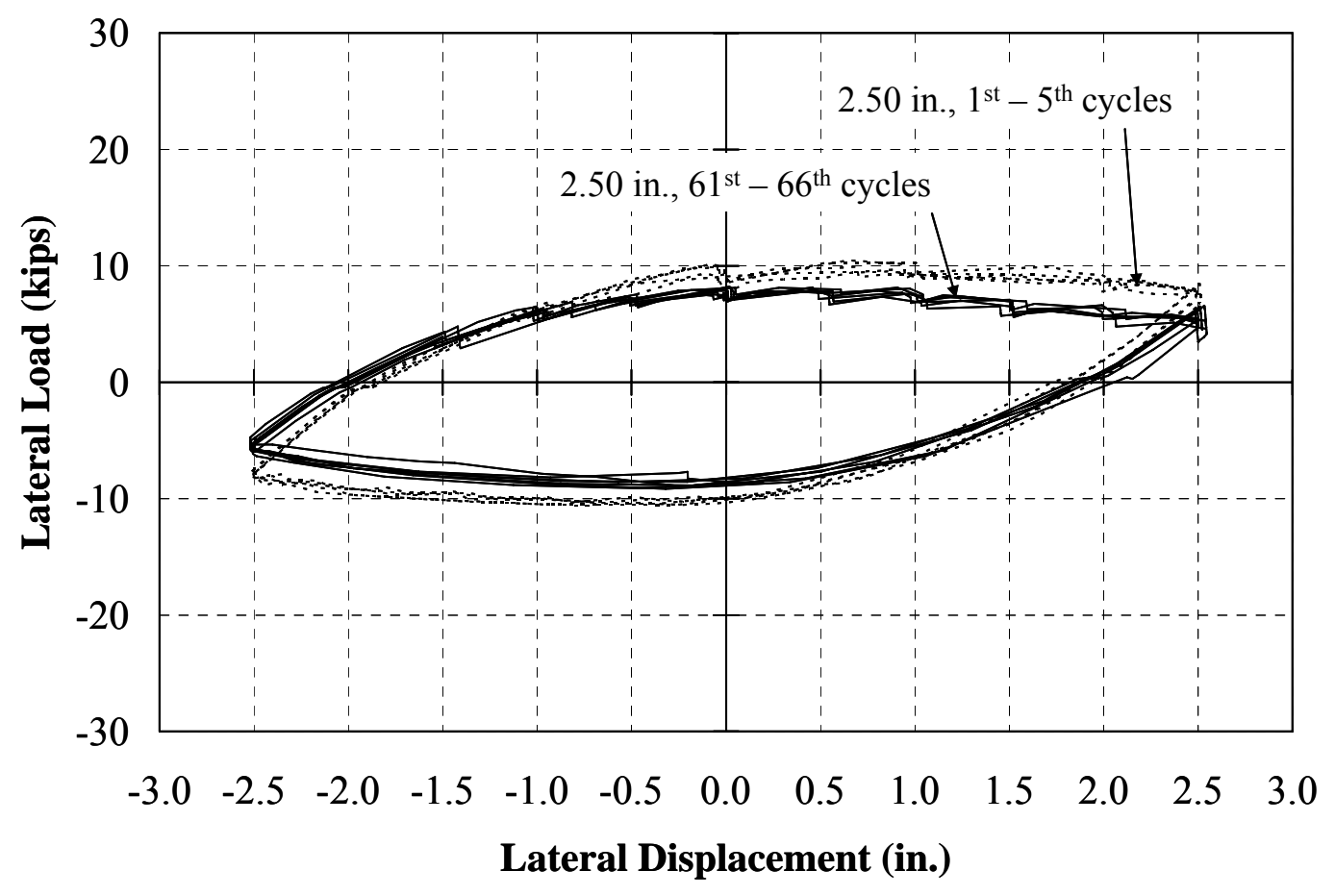

Figure 6.33: Specimen 4 - Load-Deflection Response ( \pm 2.50 in. Range)

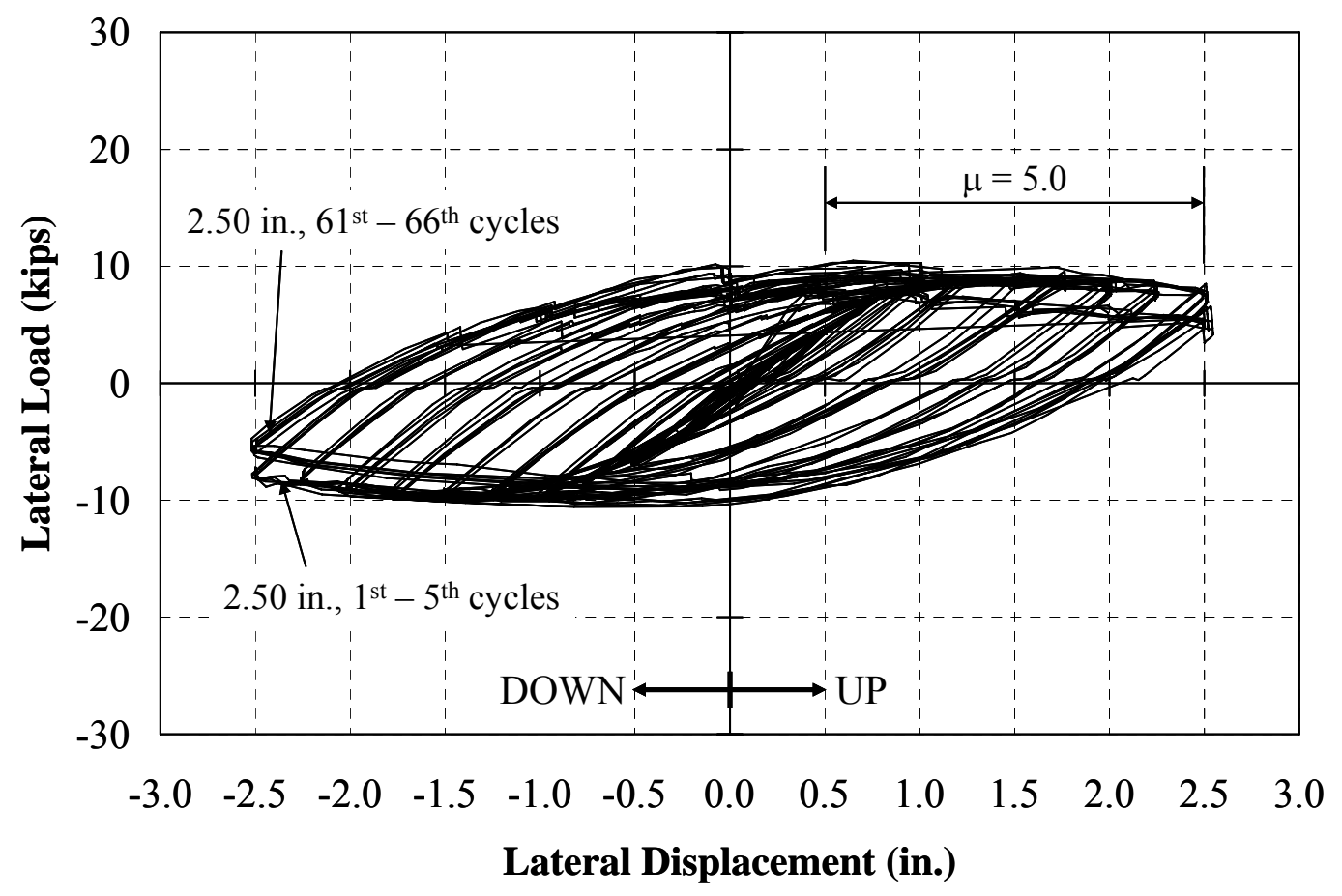

Figure 6.34: Specimen 4 - Overall Load-Deflection Response 


\begin{tabular}{|c|c|c|c|c|c|c|c|c|c|c|}
\hline 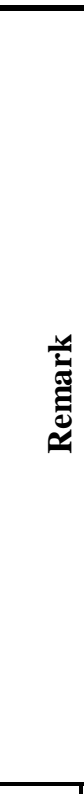 & & 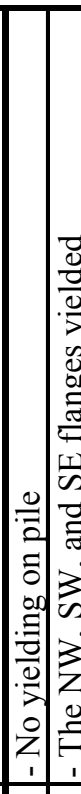 & 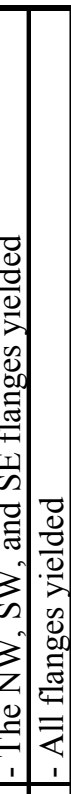 & 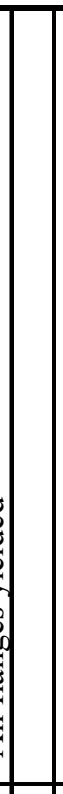 & & & 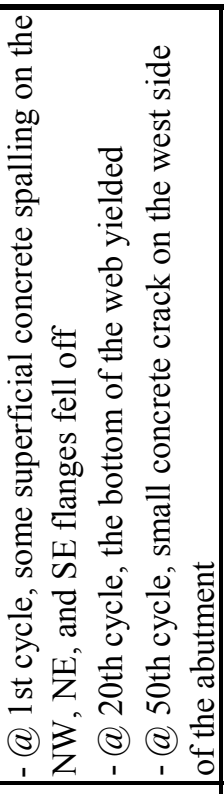 & 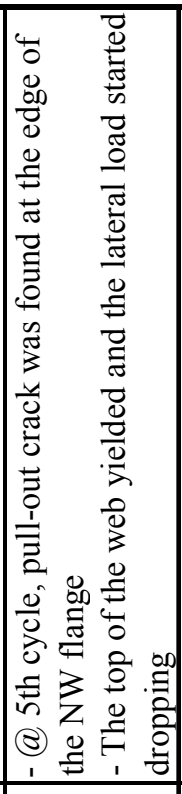 & 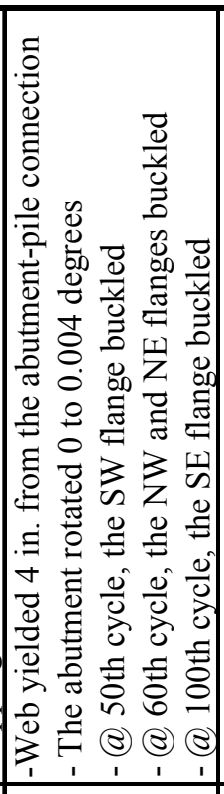 & 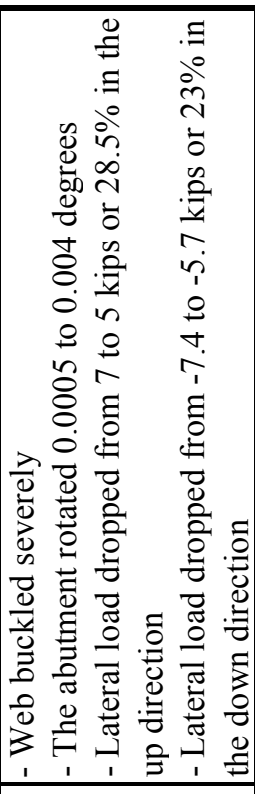 \\
\hline \multirow{2}{*}{ 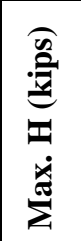 } & $\mid \begin{array}{l}z \\
3 \\
0 \\
0 \\
\vdots\end{array}$ & 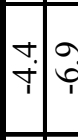 & \begin{tabular}{l|l} 
\\
\\
\\
\end{tabular} & $\dot{i}$ & 年 & $?$ & $\vec{i}$ & 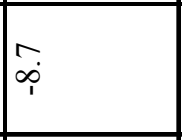 & $\overrightarrow{\infty_{1}}$ & $\underset{i}{\stackrel{0}{i}}$ \\
\hline & 官 & $\vec{i}$ & \begin{tabular}{l|l}
\multirow{+}{*}{} & $n$ \\
+ & $\infty$
\end{tabular} & {$\left[\begin{array}{c}\sim \\
\infty \\
\infty\end{array}\right.$} & $\begin{array}{l}n \\
\infty\end{array}$ & $\infty$ & $\vec{\infty}$ & $\cong$ & $\stackrel{r}{\pi}$ & $\stackrel{0}{\circ}$ \\
\hline \multirow{3}{*}{ 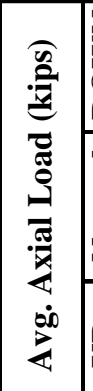 } & 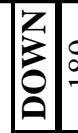 & $\stackrel{\sigma}{\circ}$ & $\sigma \mid \infty$ & 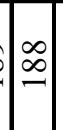 & $\stackrel{\infty}{\infty}$ & $-\infty$ & 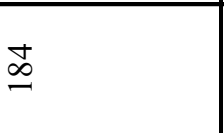 & $\infty$ & $\stackrel{\infty}{\beth}$ & $\Xi$ \\
\hline & 矛 & 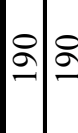 & 이잉 & 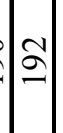 & $\approx$ & $\approx$ & $\hat{\sigma}$ & 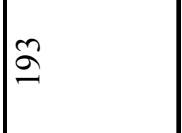 & 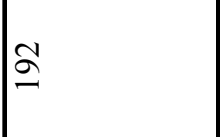 & $\infty$ \\
\hline & 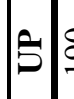 & 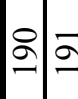 & $\overline{2} \infty$ & 2 & $\infty$ & $\infty$ & $\underset{-}{\ddagger}$ & 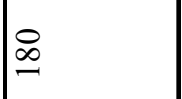 & $\stackrel{\infty}{=}$ & $\stackrel{2}{I}$ \\
\hline \multirow{4}{*}{ 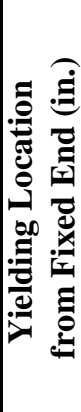 } & 贸 & ' & 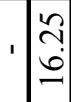 & 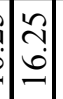 & $\begin{array}{l}\nexists \\
\infty \\
\infty\end{array}$ & $\begin{array}{l}8 \\
\infty \\
\infty\end{array}$ & $\begin{array}{l}8 \\
\infty \\
\infty\end{array}$ & $\begin{array}{l}8 \\
\infty \\
\infty \\
-1\end{array}$ & $\begin{array}{l}8 \\
\infty \\
\infty\end{array}$ & $\frac{n}{\stackrel{\sim}{\sim}}$ \\
\hline & 3 & & \begin{tabular}{l|l}
8 & 8 \\
0 & 0 \\
\hdashline & $\infty$ \\
- & 0 \\
\end{tabular} & $\begin{array}{l}2 \\
\vdots \\
\lambda \\
2\end{array}$ & 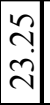 & 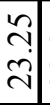 & $\begin{array}{l}\tilde{n} \\
\text { ָे } \\
\ddot{v}\end{array}$ & $\begin{array}{l}\approx \\
\sim \\
\ddot{n}\end{array}$ & 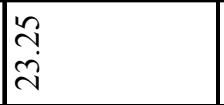 & $\begin{array}{l}8 \\
\ddot{1} \\
\ddot{1}\end{array}$ \\
\hline & Z & & 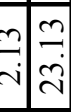 & $\begin{array}{l}8 \\
8 \\
2 \\
2\end{array}$ & $\begin{array}{l} \\
n \\
n \\
0 \\
n\end{array}$ & $\begin{array}{l}0 \\
0 \\
0 \\
0 \\
n\end{array}$ & $\begin{array}{l}0 \\
\stackrel{0}{n} \\
0 \\
n \\
n\end{array}$ & 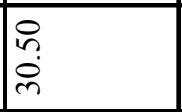 & 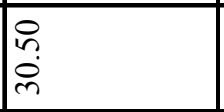 & $\begin{array}{l}0 \\
n \\
0 \\
n \\
n\end{array}$ \\
\hline & 3 & & 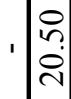 & 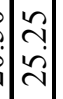 & $\begin{array}{l}8 \\
\dot{0} \\
\stackrel{1}{2}\end{array}$ & $\begin{array}{l}0 \\
n \\
0 \\
n\end{array}$ & 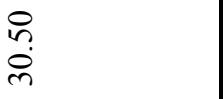 & $\begin{array}{l}0 \\
n \\
0 \\
n\end{array}$ & 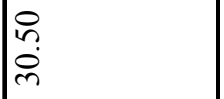 & $\mid \begin{array}{l}0 \\
n \\
0 \\
n \\
n\end{array}$ \\
\hline 줍 & & $\ln 0$ & $0 \approx$ & in & iㄴ. & in & in & in & \& & 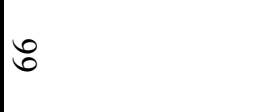 \\
\hline 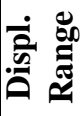 & $\stackrel{\Xi}{\Xi}$ & 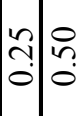 & \begin{tabular}{c|c}
0 & $n$ \\
\hdashline \\
\hdashline \\
\hdashline
\end{tabular} & 8 & $\stackrel{\sim}{\approx}$ & & 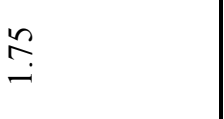 & $\underset{i}{8}$ & $\begin{array}{l}\stackrel{\sim}{r} \\
i \\
i\end{array}$ & $\mid \begin{array}{l}\stackrel{n}{n} \\
i\end{array}$ \\
\hline
\end{tabular}




\subsubsection{Specimen 5 (HP10x42, Weak Axis, 9 ksi)}

Specimen 5 was previously described in Section 6.2. The pile was larger than Specimens 1 to 4, and an axial load of approximately 112 kips was applied and maintained during the test. This pile was tested to evaluate the effect of pile size compared to Specimens 1 and 6. As indicated in Figure 6.10, the lateral load was observed to decrease $52 \%$ in the up direction and $67 \%$ in the down direction during the displacement range of $2.00 \mathrm{in}$. while the axial load continued to be maintained.

The overall load-deflection response of Specimen 5 is presented in Figure 6.35, and a summary of the test is provided in Table 6.6. The pile had a lateral load capacity of 15 kips in both the up and down directions. The displacement ductility, $\mu$, was approximately 3.5 , which was lower than that of Specimen 1. The significant reduction of the lateral load capacity led to the test being terminated at the $50^{\text {th }}$ cycle of the $2.00 \mathrm{in}$. displacement range.

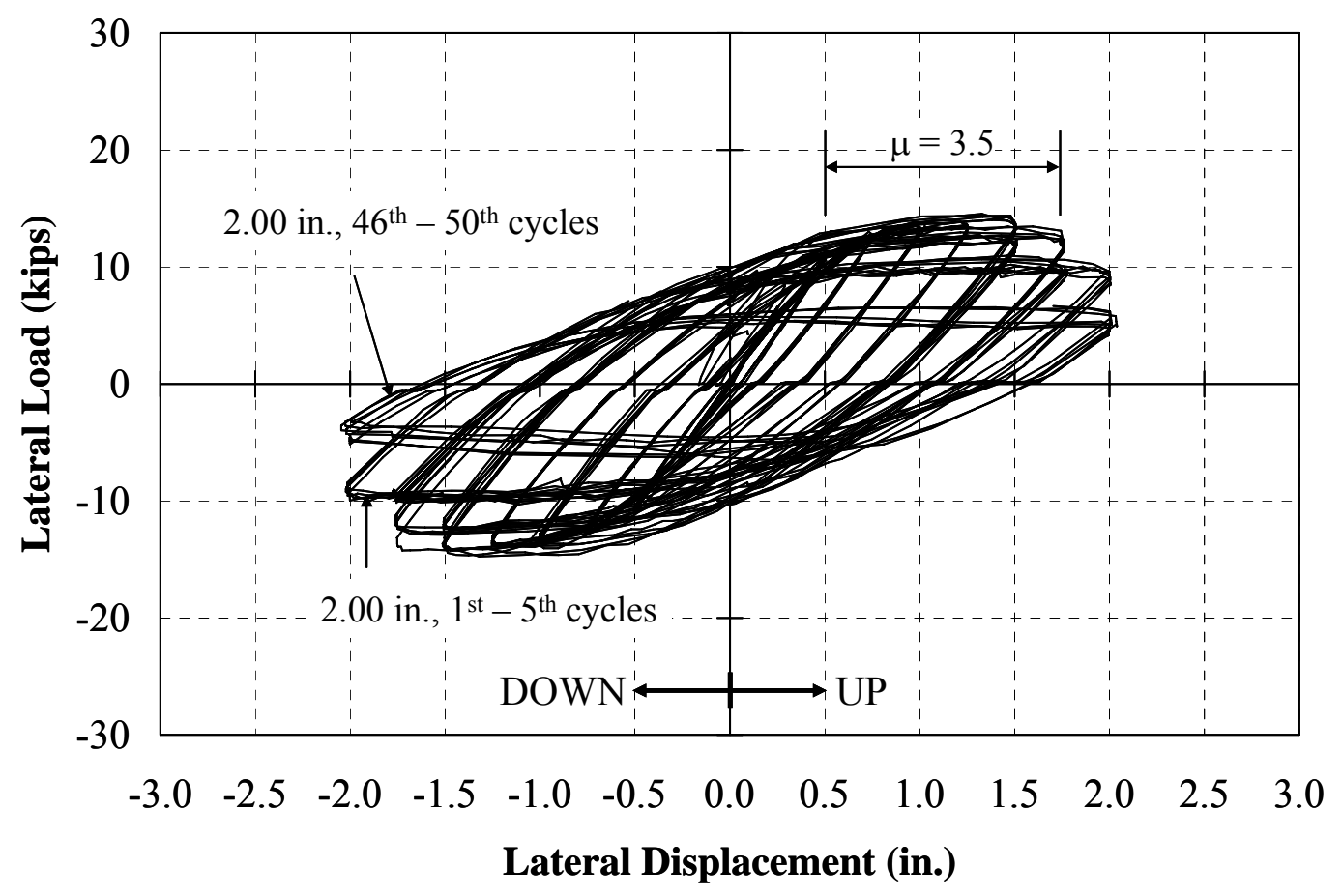

Figure 6.35: Specimen 5 - Overall Load-Deflection Response 


\begin{tabular}{|c|c|c|c|c|c|c|c|c|}
\hline 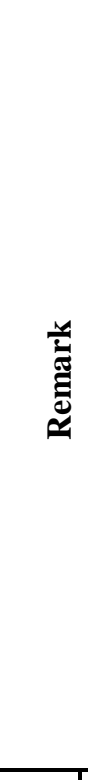 & & 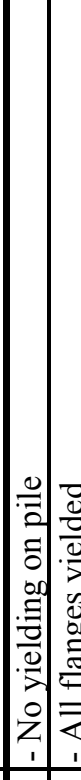 & 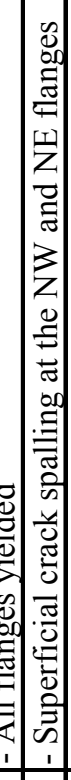 & 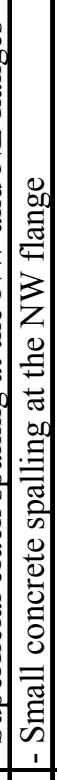 & 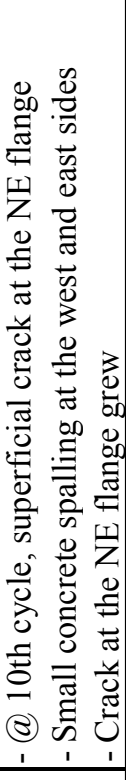 & 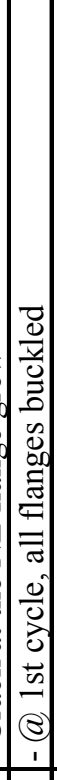 & 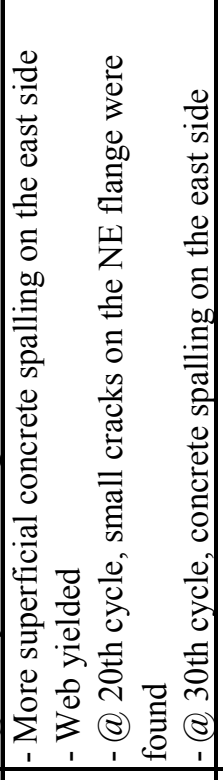 & 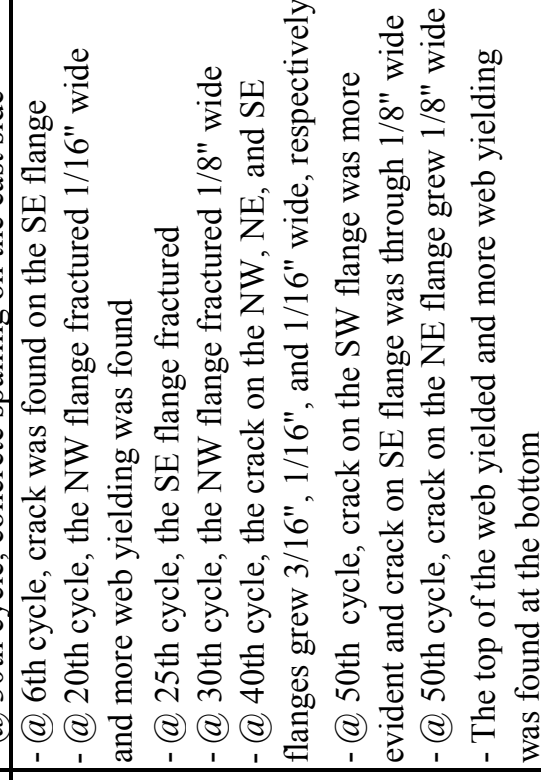 \\
\hline \multirow{2}{*}{ 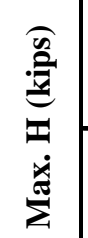 } & 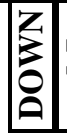 & $\begin{array}{lll}n & 0 \\
i & 0\end{array}$ & 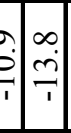 & \begin{tabular}{|l|}
0 \\
\\
\\
\end{tabular} & $\begin{array}{l}\stackrel{6}{0} \\
\stackrel{\oplus}{7}\end{array}$ & $\left|\begin{array}{l}\infty \\
\dot{m} \\
\hdashline\end{array}\right|$ & $\begin{array}{l}\infty \\
\stackrel{\infty}{1} \\
\end{array}$ & $\stackrel{0}{0}$ \\
\hline & 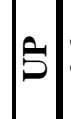 & $\stackrel{0}{0}: \infty$ & \begin{tabular}{l|l}
0 \\
$\dot{\theta}$ & $\overrightarrow{2}$ \\
\hdashline
\end{tabular} & $\begin{array}{l}\infty \\
\pm \\
\end{array}$ & $\ddot{n}$ & $\stackrel{1}{2}$ & 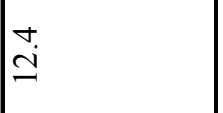 & $\hat{a}$ \\
\hline \multirow{3}{*}{ 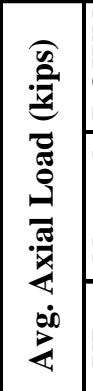 } & 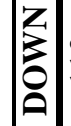 & $\stackrel{9}{=}$ & $=2$ 의 & $=$ & 8 & 이 & $\hat{\varrho}$ & $8 \stackrel{2}{0}$ \\
\hline & 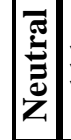 & $\exists \equiv$ & $\theta=$ & 을 & $\stackrel{ }{=}$ & 으 & $\stackrel{+}{0}$ & $8 \stackrel{2}{0}$ \\
\hline & 5 & $\cong \cong$ & $\exists \cong$ & $\cong$ & $\Xi$ & $=$ & $\Xi$ & $\stackrel{\infty}{=} \stackrel{\infty}{=}$ \\
\hline \multirow{4}{*}{ 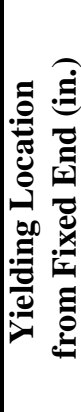 } & : & 1 & 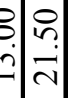 & \begin{tabular}{l}
0 \\
$\stackrel{n}{2}$ \\
\hdashline
\end{tabular} & $\begin{array}{l}8 \\
\text { ì } \\
\text { in }\end{array}$ & $\mid$ & $\begin{array}{l}8 \\
\text { ì } \\
\text { in }\end{array}$ & $\begin{array}{l}8 \\
\text { ì } \\
\text { in }\end{array}$ \\
\hline & 3 &, $\mid \begin{array}{l}\infty \\
\infty \\
0 \\
0\end{array}$ & 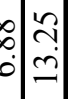 & 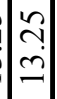 & $\begin{array}{l}\infty \\
\substack{n \\
\infty \\
\infty}\end{array}$ & $\left.\mid \begin{array}{l}\infty \\
i \\
\infty \\
-1\end{array}\right]$ & $\begin{array}{l}\infty \\
m \\
\infty \\
\infty \\
-1\end{array}$ & $\begin{array}{l}\infty \\
m \\
\infty \\
\infty \\
-1\end{array}$ \\
\hline & Z & 1.8 & 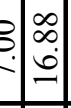 & $\begin{array}{l}\infty \\
\infty \\
0 \\
-0 \\
-\end{array}$ & $\begin{array}{l}\infty \\
\infty \\
0 \\
0 \\
-\end{array}$ & \begin{tabular}{|l|}
$\infty$ \\
$\infty$ \\
0 \\
-0 \\
\end{tabular} & $\begin{array}{l}\infty \\
\infty \\
0 \\
0 \\
\end{array}$ & $\begin{array}{l}\infty \\
\infty \\
0 \\
0\end{array}$ \\
\hline & 3 & $1 . \frac{n}{2}$ & 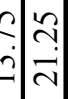 & 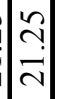 & $\begin{array}{l}\infty \\
\infty \\
\dot{\lambda}\end{array}$ & $\left|\begin{array}{l}\infty \\
\infty \\
\vec{\sim}\end{array}\right|$ & $\begin{array}{l}\infty \\
\infty \\
\dot{\vec{N}}\end{array}$ & $\begin{array}{l}\infty \\
\infty \\
\dot{\vec{\lambda}}\end{array}$ \\
\hline 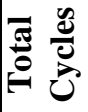 & & $\ln 0$ & $\theta \approx$ & in & in & 요 & in & in \\
\hline 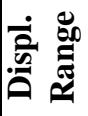 & 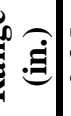 & 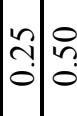 & \begin{tabular}{l|l|}
0 \\
\hdashline \\
\hdashline & 0 \\
\hdashline
\end{tabular} & 8 & $\stackrel{2}{\stackrel{n}{\imath}}$ & ?ำ & $\stackrel{n}{=}$ & i \\
\hline
\end{tabular}




\subsubsection{Specimen 6 (HP12x53, Weak Axis, 9 ksi)}

Specimen 6 was tested to provide another reference to evaluate the effect of pile size. An axial load of approximately 140 kips was applied and maintained during the test. The SW and SE flanges yielded as early as the $0.50 \mathrm{in}$. displacement range while the NW and NE flanges yielded in the 0.75 in. displacement range. Concrete cracks were noted on the west and east sides of the abutment. All flanges buckled during the 1.25 in. displacement range. Figure 6.36 shows buckling of the top flanges. Cracks on the NW, $\mathrm{NE}$, and SW flanges initiated in the $20^{\text {th }}$ cycle of the $1.75 \mathrm{in}$. displacement range while a crack on the SE flange initiated in the $30^{\text {th }}$ cycle.

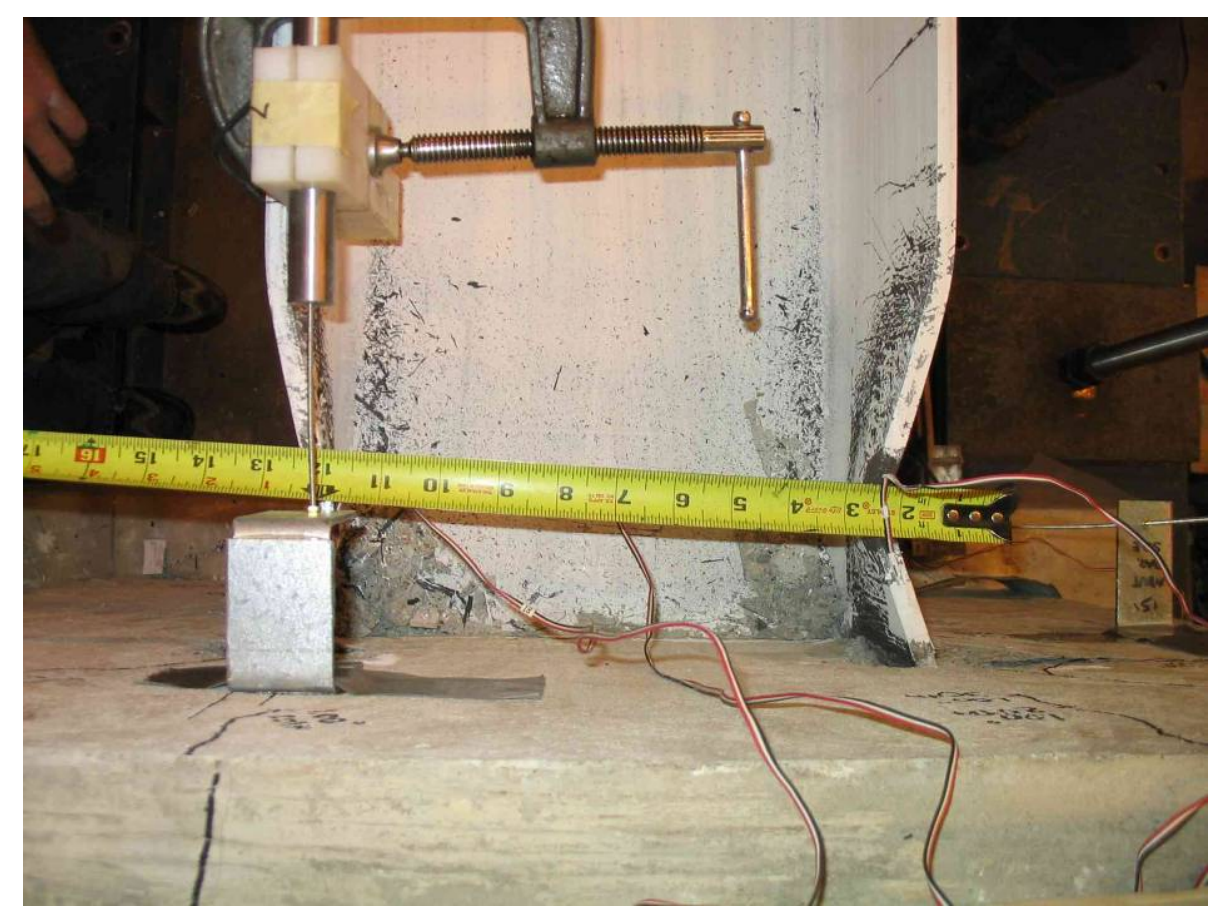

Figure 6.36: Specimen 6 - The NW and NE Flange Buckling

At the end of the 1.75 in. displacement range, all flanges were fractured. Figure 6.37 shows the fracture of the NE flange. The pile maintained the axial load despite the deterioration experienced at the abutment-pile connection (Figure 6.38). As illustrated in Figure 6.39 , the lateral load was observed to decrease $55 \%$ in the up direction and $75 \%$ in the down direction. 
The overall load-deflection response is presented in Figure 6.40 and a summary of the test is provided in Table 6.7. The pile had a lateral load capacity of $22.3 \mathrm{kips}$ in the up direction and 18.9 kips in the down direction. The displacement ductility, $\mu$, was approximately 3.0, which is lower than that of Specimens 1 and 5, respectively. The loss of lateral load caused the termination of the test in the $70^{\text {th }}$ cycle of the 1.75 in. displacement range.

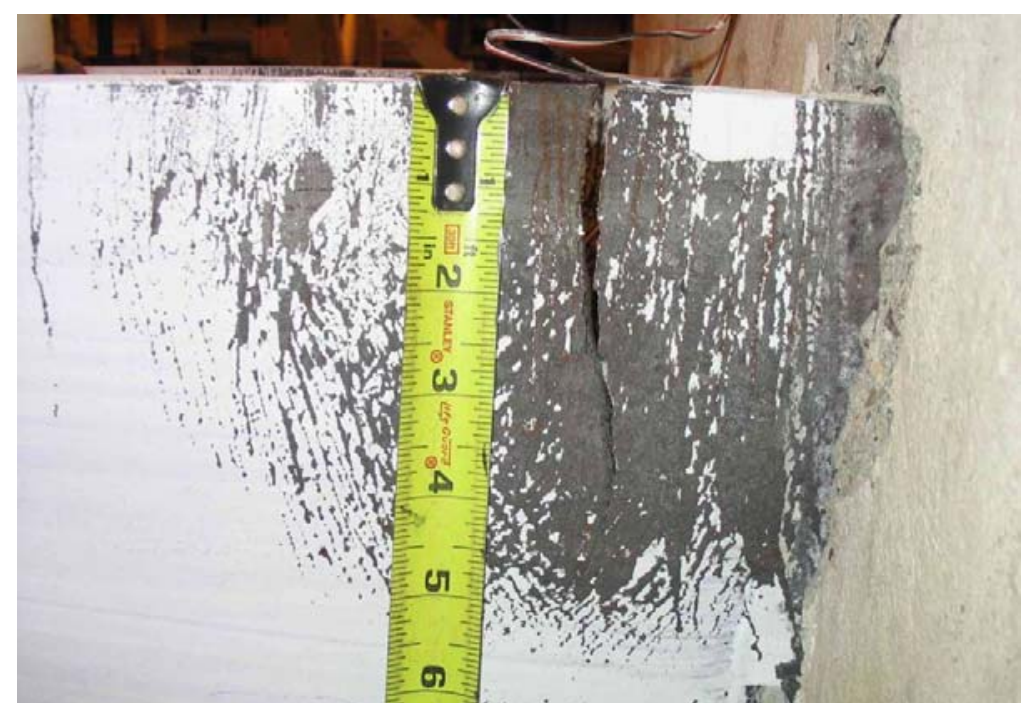

Figure 6.37: Specimen 6 - Flange Fracture (NE Flange)

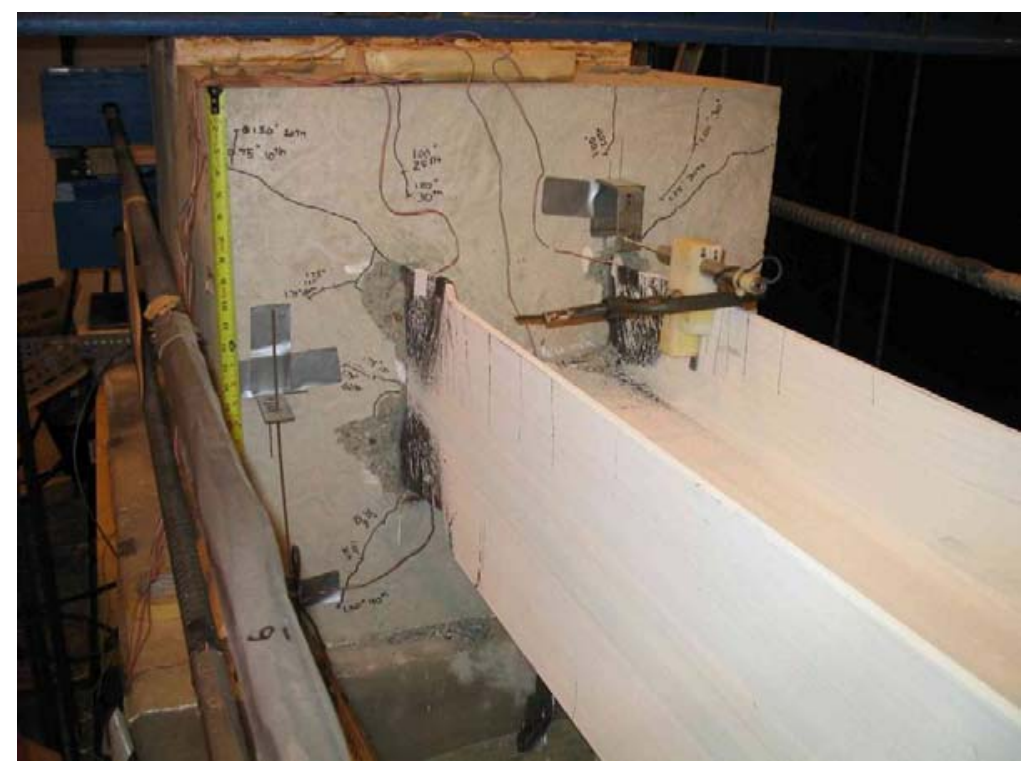

Figure 6.38: Specimen 6 - Deterioration at the Abutment Pile Connection 


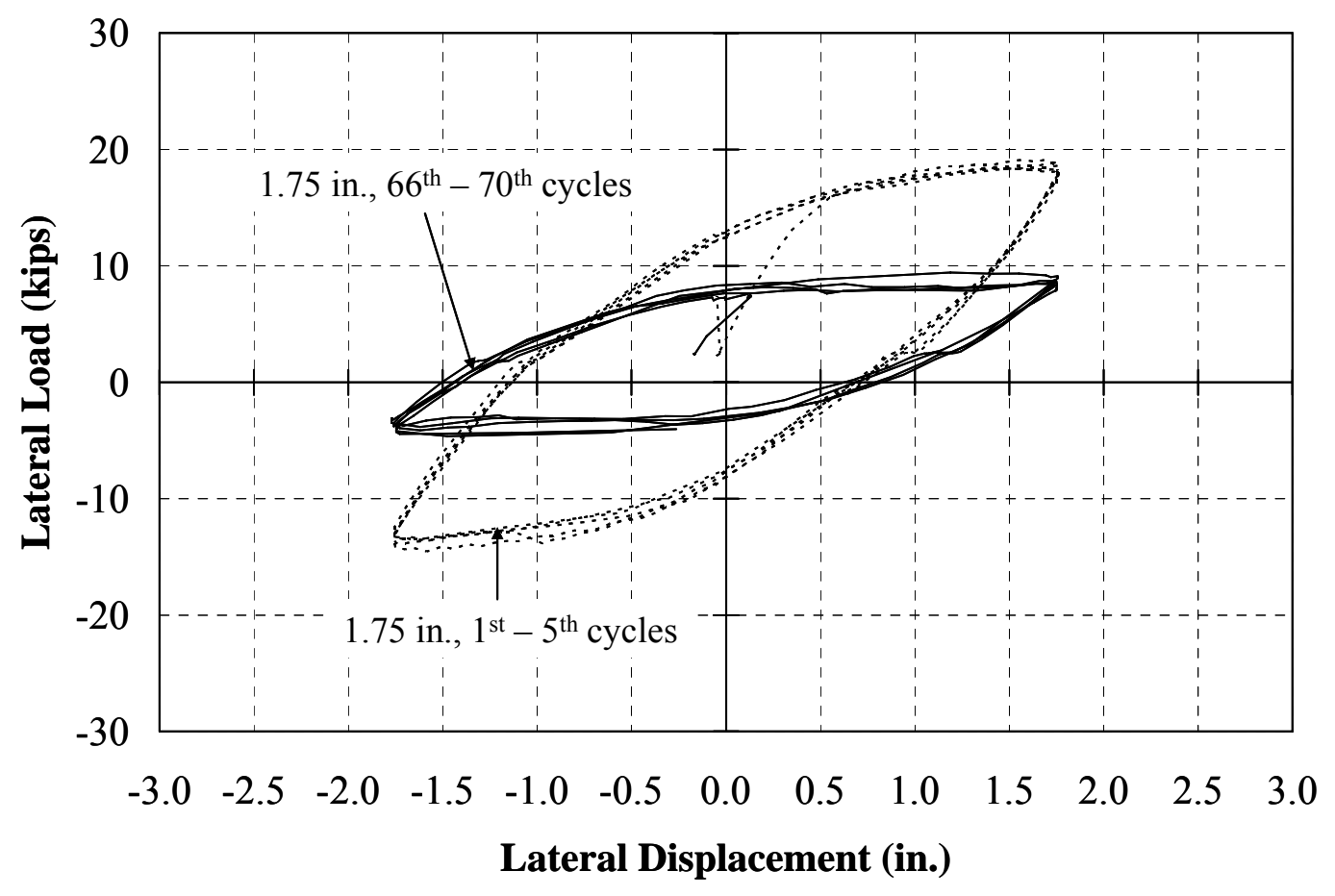

Figure 6.39: Specimen 6 - Load-Deflection Response ( \pm 1.75 in. Range)

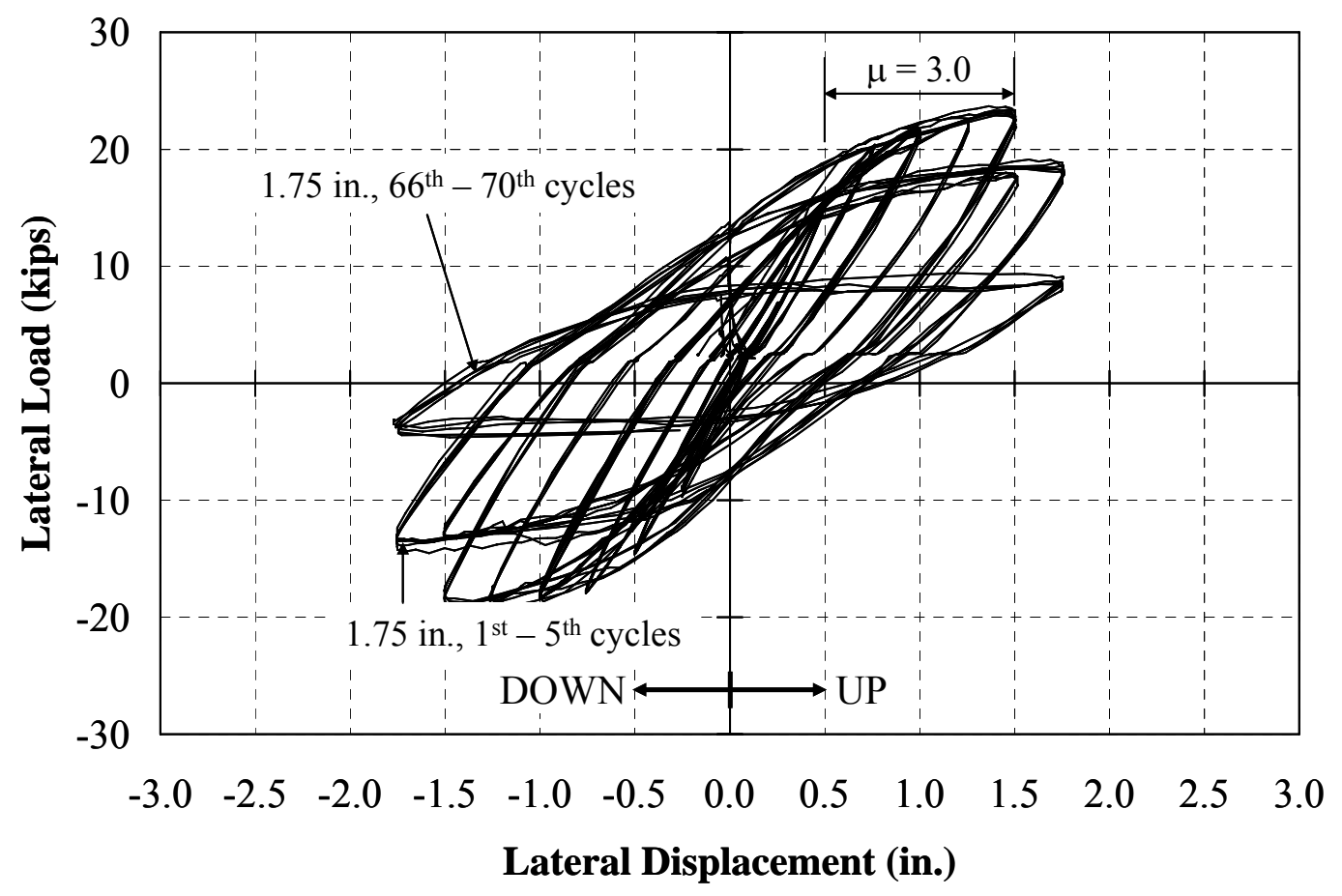

Figure 6.40: Specimen 6 - Overall Load-Deflection Response 


\begin{tabular}{|c|c|c|c|c|c|c|c|}
\hline 䔍 & & 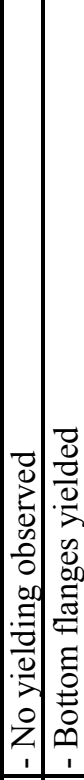 & 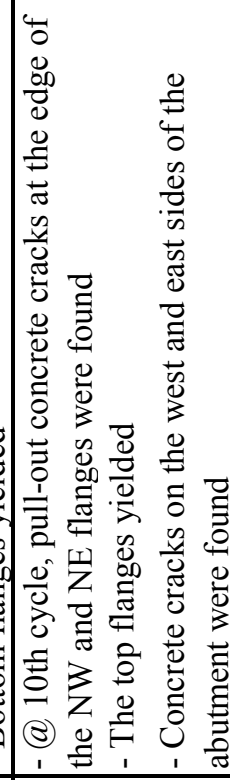 & 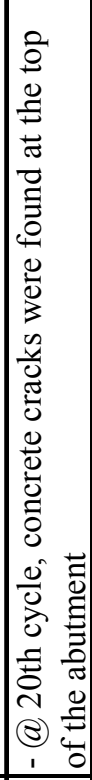 & 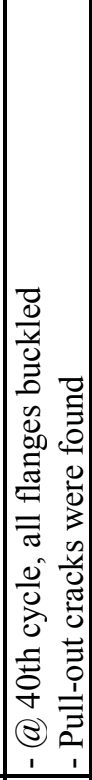 & 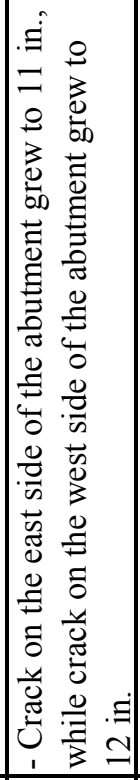 & 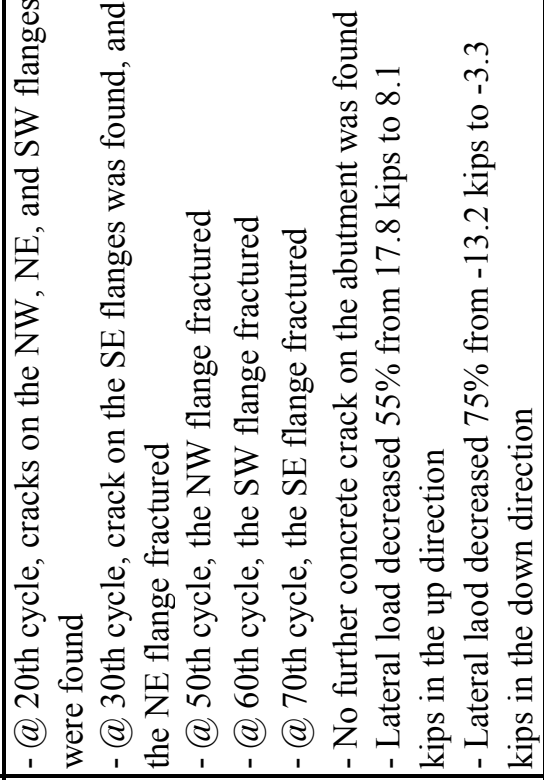 \\
\hline \multirow{2}{*}{ 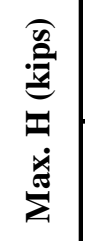 } & 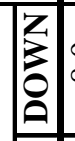 & \begin{tabular}{l|l}
\multirow{\infty}{*}{} & $\stackrel{+}{+}$ \\
\end{tabular} & $\stackrel{\infty}{1}$ & $\frac{\sigma}{\infty}$ & $\begin{array}{l}0 \\
\infty \\
0 \\
1\end{array}$ & $\frac{\partial}{\infty}$ & $\frac{N}{n}$ \\
\hline & 5 & 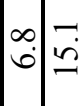 & $\stackrel{n}{\stackrel{2}{2}}$ & $\hat{\bar{\lambda}}$ & $\stackrel{\tilde{N}}{\mathrm{~N}}$ & त̃ & $\stackrel{\infty}{\stackrel{\infty}{\beth}}$ \\
\hline \multirow{3}{*}{ 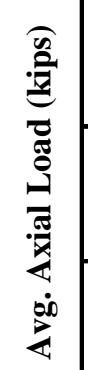 } & $\left|\begin{array}{l}z \\
z \\
z \\
0 \\
0\end{array}\right|$ & 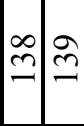 & $\stackrel{I}{ \pm}$ & 过 & $\vec{\Xi}$ & $\stackrel{\infty}{\cong}$ & $\underline{m}$ \\
\hline & $\mid$ & $\hat{\approx}$ & 早 & $\exists$ & $\stackrel{\sim}{ \pm}$ & 寻 & $\stackrel{\mathcal{I}}{\mathcal{I}}$ \\
\hline & s) & $\stackrel{\infty}{\sim}$ & $\hat{\overbrace{}}$ & $\hat{n}$ & $\stackrel{\infty}{\stackrel{\infty}{-}}$ & $\stackrel{m}{\varrho}$ & $\bar{m}$ \\
\hline \multirow{4}{*}{$\mid \begin{array}{ll}0 \\
0 \\
0\end{array}$} & 雨 & . & 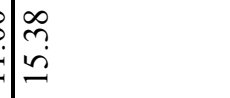 & $\begin{array}{l}\infty \\
i \\
n \\
n \\
n\end{array}$ & $\begin{array}{l}\infty \\
m \\
n \\
n \\
n\end{array}$ & $\begin{array}{l}\infty \\
m \\
n \\
n \\
n\end{array}$ & $\mid \begin{array}{l}\infty \\
n \\
n \\
n \\
n\end{array}$ \\
\hline & 3 & $\stackrel{8}{\Xi}$ & in & î̀ & 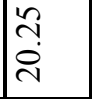 & 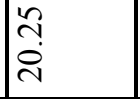 & 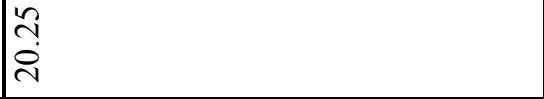 \\
\hline & Z & ' & $\begin{array}{l}\tilde{n} \\
\ddot{n} \\
\end{array}$ & 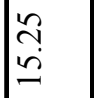 & 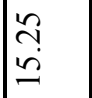 & $\begin{array}{l}\bumpeq \\
\\
\end{array}$ & 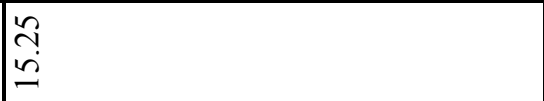 \\
\hline & $\frac{3}{z}$ & & $\begin{array}{l}8 \\
\ddot{1}\end{array}$ & 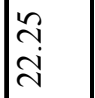 & 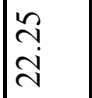 & 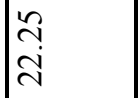 & 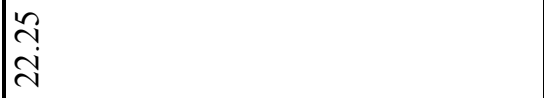 \\
\hline 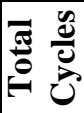 & & $\ln 10$ & 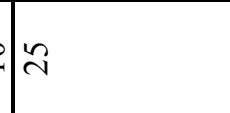 & in & in & 을 & $R$ \\
\hline 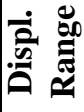 & 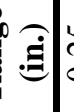 & 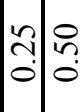 & $\stackrel{n}{0}$ & $\stackrel{8}{-}$ & 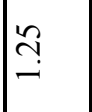 & $\stackrel{?}{?}$ & $\stackrel{n}{\stackrel{2}{2}}$ \\
\hline
\end{tabular}




\subsubsection{Specimen 7 (CFT8, 9 ksi)}

Specimen 7 was the first CFT pile tested. The specified yield strength, $\mathrm{f}_{\mathrm{y}}$, was 35 ksi based on ASTM A252, Grade 2. The specified concrete compressive strength, $\mathrm{f}_{\mathrm{c}}^{\prime}$, was 4,000 psi based on INDOT Class $C$ concrete. Steel area, $A_{s}$, and concrete area, $A_{c}$, were calculated to be 4.98 and 53.4 in. $^{2}$, respectively. An axial load of 43.6 kips was attributed to steel area considering $0.25 \mathrm{f}_{\mathrm{y}} \mathrm{A}_{\mathrm{s}}$, and an axial load of 85.4 kips was attributed to the concrete core area considering $0.4 \mathrm{f}_{\mathrm{c}}^{\prime} \mathrm{A}_{\mathrm{c}}$. Therefore, the total axial load is applied at the pile tip was $43.6+85.4=129$ kips. Nevertheless, the axial loads distributed to the steel area and the concrete core area calculated based on strain compatibility and a concrete modulus of elasticity of 4,500 ksi were approximately 49.0 and $80.0 \mathrm{kips}$, respectively. The actual stress on the steel area was approximately $9.8 \mathrm{ksi}$, while the stress on the concrete was approximately $1.5 \mathrm{ksi}$. The "9 ksi" axial load is denoted as the axial load of $0.25 f_{y} A_{s}+0.4 f_{c}^{\prime} A_{c}$.

By inspection, no yielding was observed until the 1.00 in. displacement range; however, strain gages indicated that the top and bottom of the pile were yielded as early as the $0.50 \mathrm{in}$. displacement range. During the $1.00 \mathrm{in}$. displacement range, the lateral load started dropping. During the $50^{\text {th }}$ cycle of the 1.25 in. displacement range, a small amount of concrete spalling was observed near the abutment-pile connection. The pile buckled at the top and bottom during the $1.50 \mathrm{in}$. displacement range. Cracks at the top and bottom of the steel shell formed during the $30^{\text {th }}$ cycle of the $1.75 \mathrm{in}$. displacement range, and fracture of the top and bottom of the steel shell was noticed during the $33^{\text {rd }}$ cycle as illustrated in Figure 6.41. 


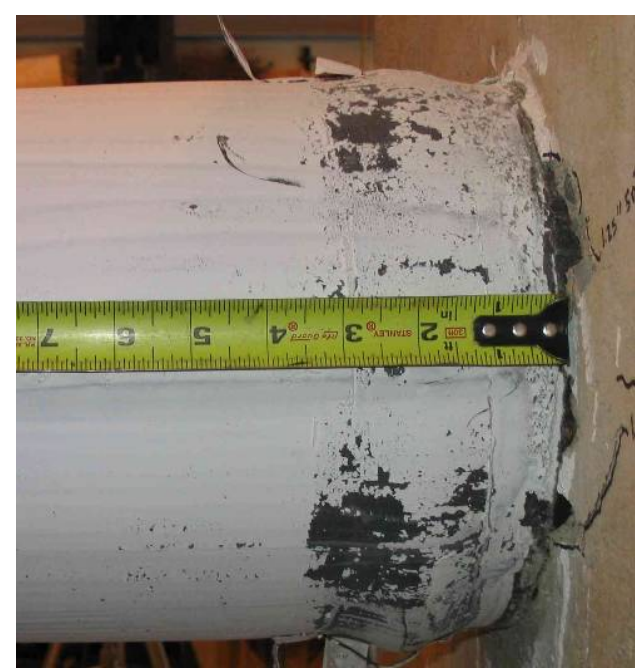

(a) Buckling on the East Side

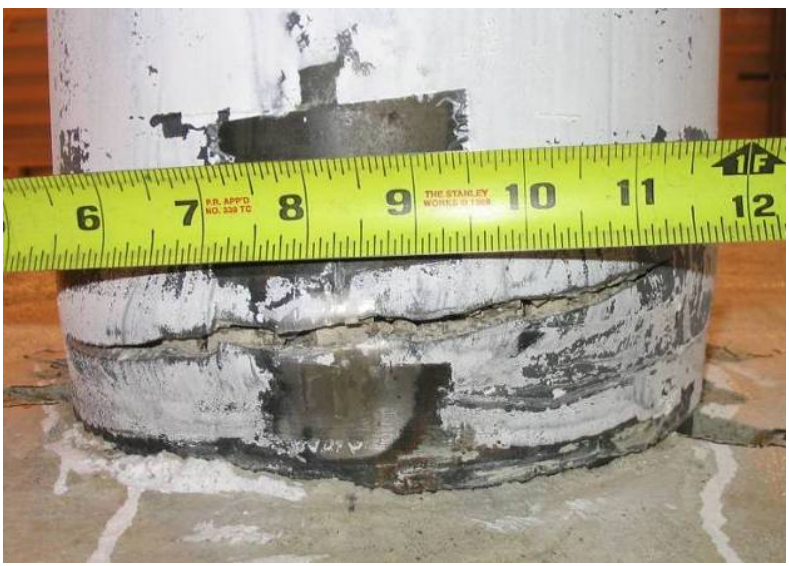

(b) Crack at the bottom of the Steel Shell

Figure 6.41: Specimen 7 - Pile at Failure (1.75 in., $33^{\text {rd }}$ Cycle)

A significant drop in the lateral load was observed between the $30^{\text {th }}$ and $33^{\text {rd }}$ cycles of the $1.75 \mathrm{in}$. displacement range while the axial load was maintained. As presented in Figure 6.42, the lateral load was observed to decrease 38\% in the up direction and $18 \%$ in the down direction. The overall load-deflection response is provided in Figure 6.43, and a summary of the test is provided in Table 6.8. The pile had a lateral load capacity of 13.3 kips in the up direction and 14.2 kips in the down direction. The displacement ductility, $\mu$, was approximately 3.5. Due to the decrease in the lateral load capacity, the test was terminated in the $33^{\text {rd }}$ cycle of the 1.75 in. displacement range. Only minor deterioration of the abutment-pile connection as shown in Figure 6.44 was evident. 


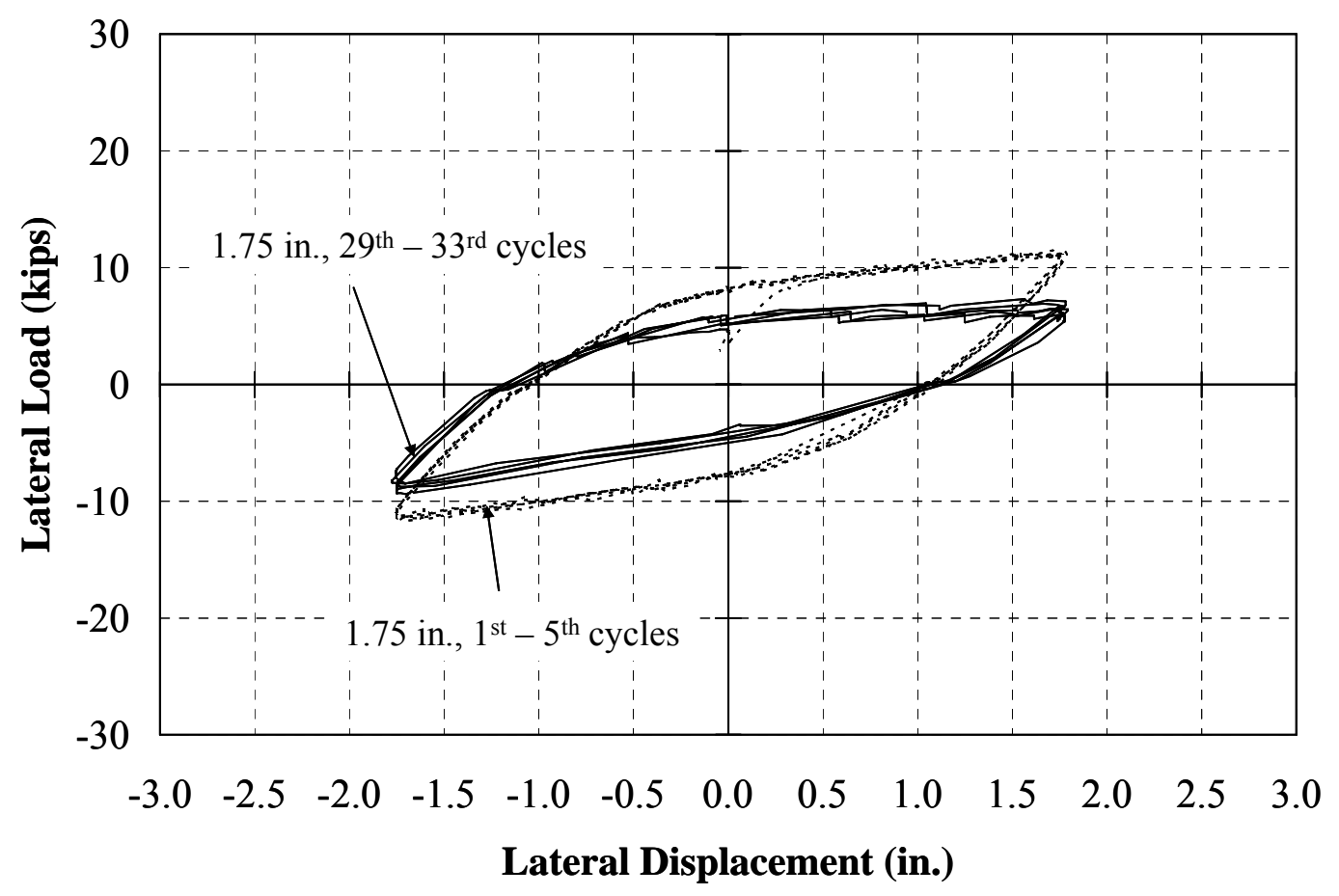

Figure 6.42: Specimen 7 -Load-Deflection Response ( \pm 1.75 in. Range)

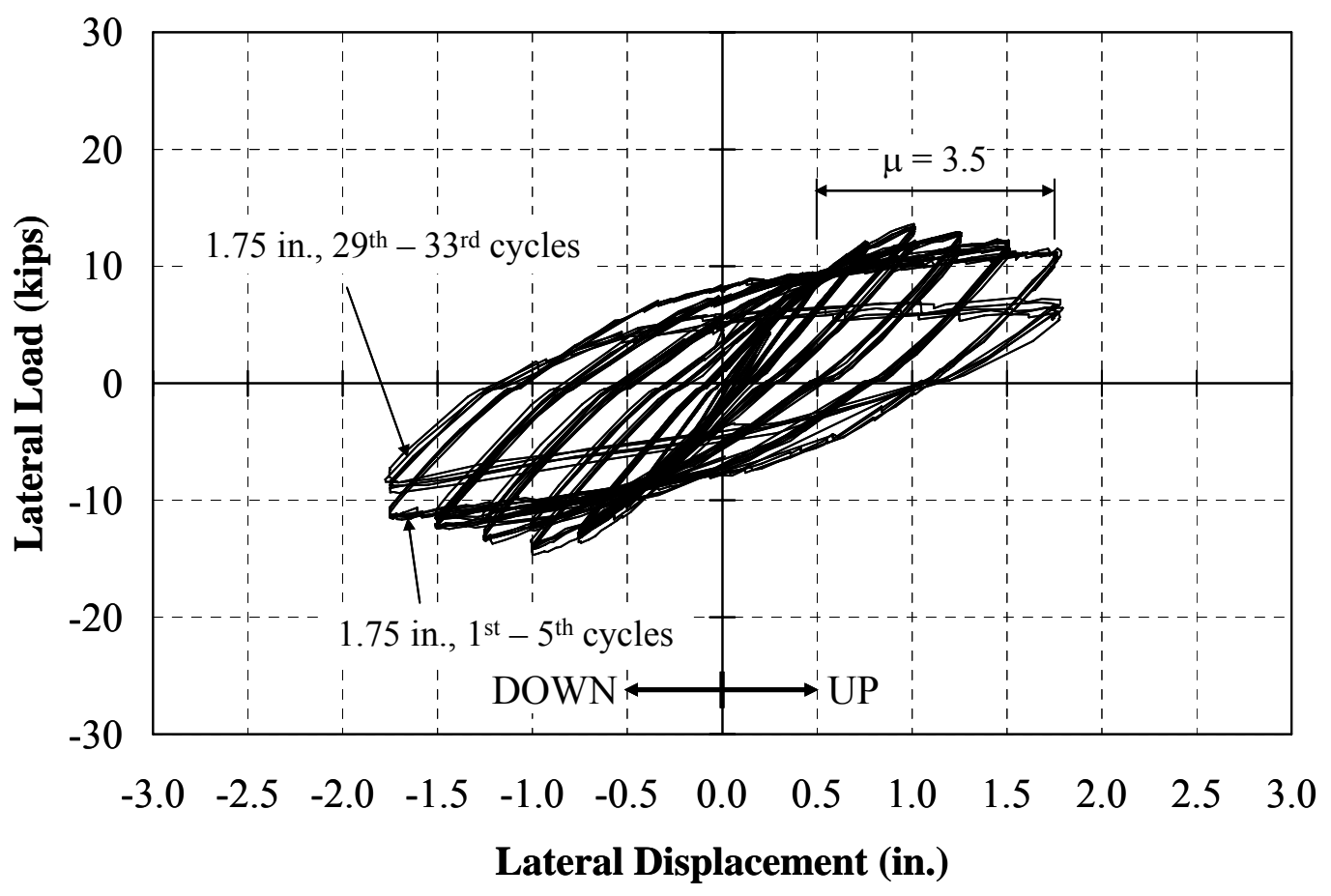

Figure 6.43: Specimen 7 - Overall Load-Deflection Response 


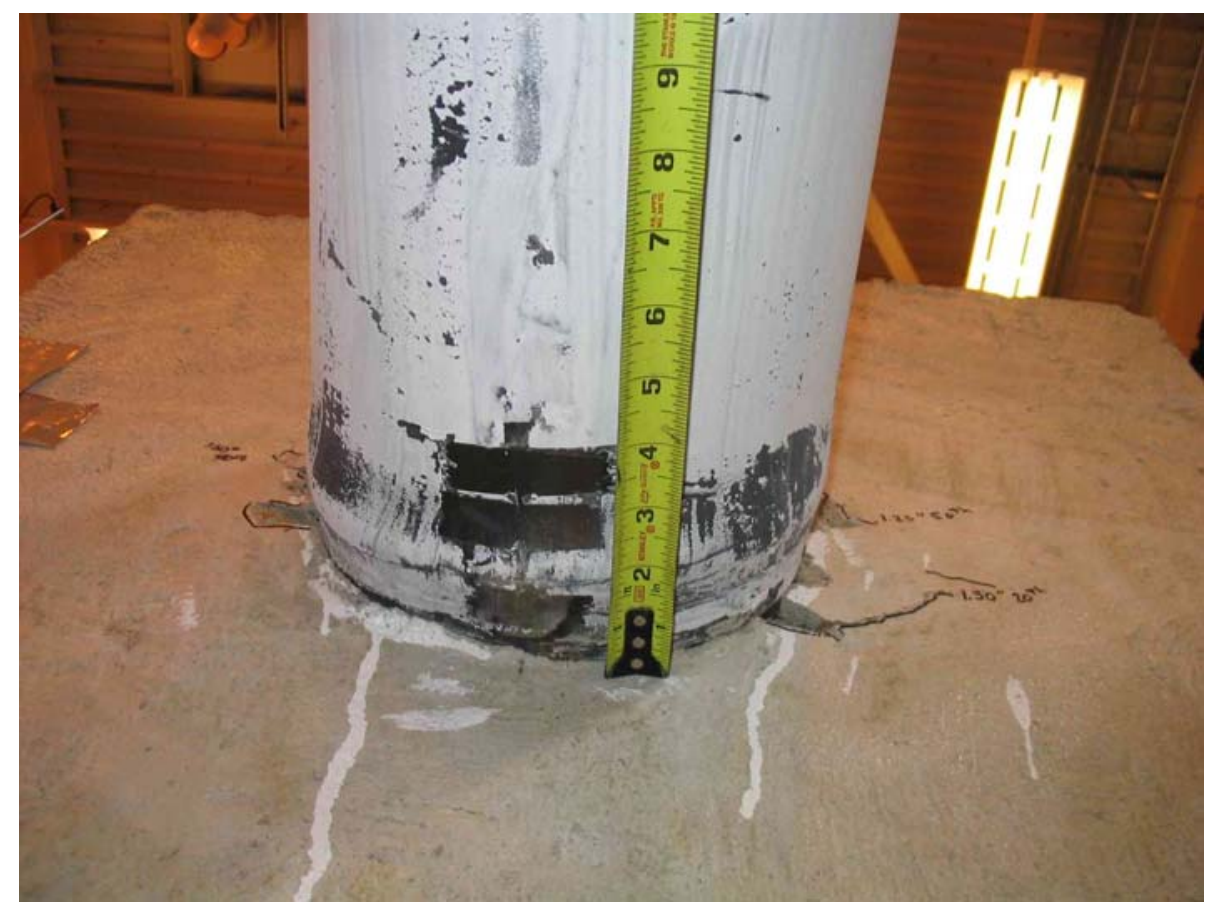

Figure 6.44: Specimen 7 -Deterioration at the Abutment-Pile Connection 


\begin{tabular}{|c|c|c|c|c|c|c|c|}
\hline 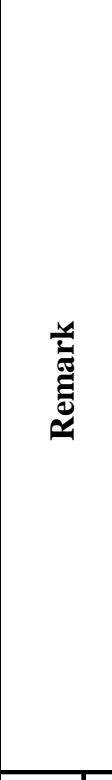 & 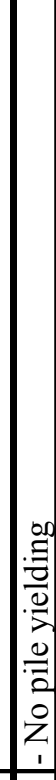 & \begin{tabular}{|c|}
0 \\
0 \\
0 \\
0 \\
0 \\
0 \\
0 \\
0 \\
0 \\
0 \\
0 \\
40 \\
0 \\
0 \\
0 \\
0 \\
0 \\
0 \\
0 \\
0 \\
0 \\
0 \\
0 \\
0 \\
$=$ \\
1 \\
\end{tabular} & & 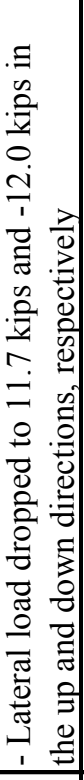 & 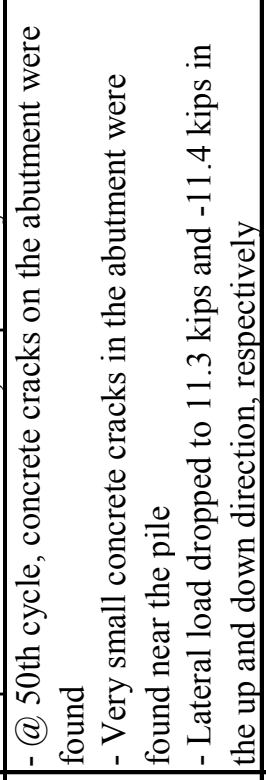 & 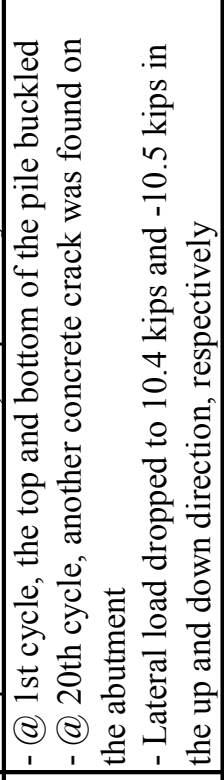 & 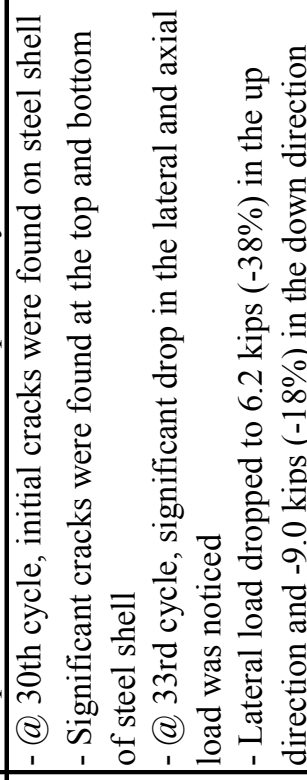 \\
\hline 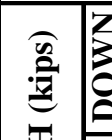 & $\begin{array}{l}a \\
\hat{\varphi} \\
1\end{array}$ & $\mid$\begin{tabular}{l}
0 \\
0 \\
\hdashline
\end{tabular} & & $\stackrel{\sim}{+}$ & $\frac{n}{m}$ & $\overrightarrow{\bar{i}}$ & $\stackrel{0}{\stackrel{0}{*}}$ \\
\hline 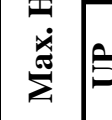 & $\stackrel{\sim}{+}$ & 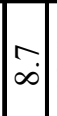 & $\overrightarrow{\mathrm{I}}$ & $\stackrel{m}{m}$ & 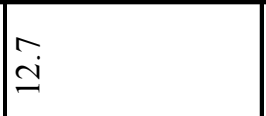 & 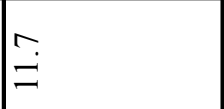 & $\ddot{0}$ \\
\hline 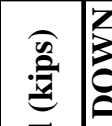 & $\stackrel{0}{-}$ & $\stackrel{0}{-2}$ & $\vec{m}$ & $\bar{\emptyset}$ & 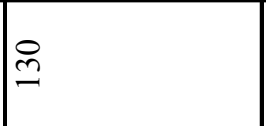 & $\stackrel{0}{\sim}$ & 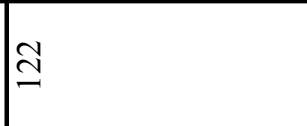 \\
\hline 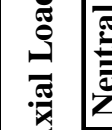 & $\stackrel{0}{-}$ & ปิ & 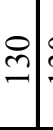 & $\stackrel{\ominus}{\longrightarrow}$ & 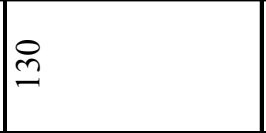 & $\stackrel{\infty}{\simeq}$ & $\stackrel{\infty}{\stackrel{\infty}{\beth}}$ \\
\hline$\sum^{\infty}$ & 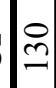 & 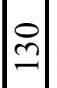 & $\overrightarrow{-}$ & $\bar{\varpi}$ & $\stackrel{0}{2}$ & $\stackrel{\infty}{\simeq}$ & $\stackrel{0}{\stackrel{1}{1}}$ \\
\hline 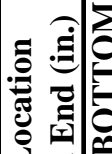 & ' & & & $\underset{i}{8}$ & $\begin{array}{l}0 \\
n \\
n\end{array}$ & ${ }_{0}^{\circ}$ & $\begin{array}{l}0 \\
n \\
a\end{array}$ \\
\hline 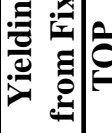 & ' & & & $\underset{\text { ¿ }}{\stackrel{\text { i }}{ }}$ & $\begin{array}{l}0 \\
n \\
n\end{array}$ & ${ }_{0}^{\circ}$ & $\begin{array}{l}\stackrel{n}{2} \\
a\end{array}$ \\
\hline 预 & in & $1 ㅇ$ & ¿̂: & in & in & \& & $\hat{m}$ \\
\hline 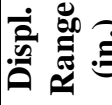 & $\begin{array}{l}n \\
0 \\
0\end{array}$ & : & $\overrightarrow{0}$ & $\stackrel{8}{8}$ & $\stackrel{\imath}{i}$ & nִ & $\stackrel{n}{\rightleftharpoons}$ \\
\hline
\end{tabular}




\subsubsection{Specimen 8 (CFT8, 18 ksi)}

Specimen 8 was the same size as Specimen 7 but was subjected to a higher axial load of approximately 172 kips. This pile was tested to evaluate the effect of axial load on CFT pile behavior. This level of axial load was determined based on the stress level $0.5 f_{y}$ for the steel $+0.4 f_{c}^{\prime}$ for the concrete. Therefore, the steel was assumed to resist $0.5 f_{y} A_{s}=87.1$ kips while the concrete was assumed to resist $0.4 f_{c}^{\prime} A_{c}=85.5$ kips. The total axial load was therefore equal to $87.1+85.5 \cong 172$ kips. Based on strain compatibility and a concrete modulus of elasticity of 4,500 ksi, the load distributed to the steel area and concrete area were approximately 65.4 and 106.6 kips, respectively. The actual stress on the steel area was approximately $13.1 \mathrm{ksi}$, and the stress on the concrete area was approximately $2.0 \mathrm{ksi}$. The " $18 \mathrm{ksi}$ " axial load is defined as the axial load of $0.5 \mathrm{f}_{\mathrm{y}} \mathrm{A}_{\mathrm{s}}+0.4 \mathrm{f}_{\mathrm{c}}^{\prime} \mathrm{A}_{\mathrm{c}}$.

Based on whitewash flaking, the pile did not yield until the 1.00 in. displacement range. Strain gages, however, indicated that the top and bottom of the pile yielded as early as the 0.50 in. displacement range. Cracks at the top of the abutment were noticeable at the beginning of the $1.25 \mathrm{in}$. displacement range. In the $1^{\text {st }}$ cycle of the 1.50 in. displacement range, the top and bottom of the pile buckled. A crack at the bottom of the steel shell was noticeable in the $1^{\text {st }}$ cycle of the 1.75 in. displacement range and propagated very quickly to a length of 4.75 in. within 10 cycles as shown in Figure 6.45. 


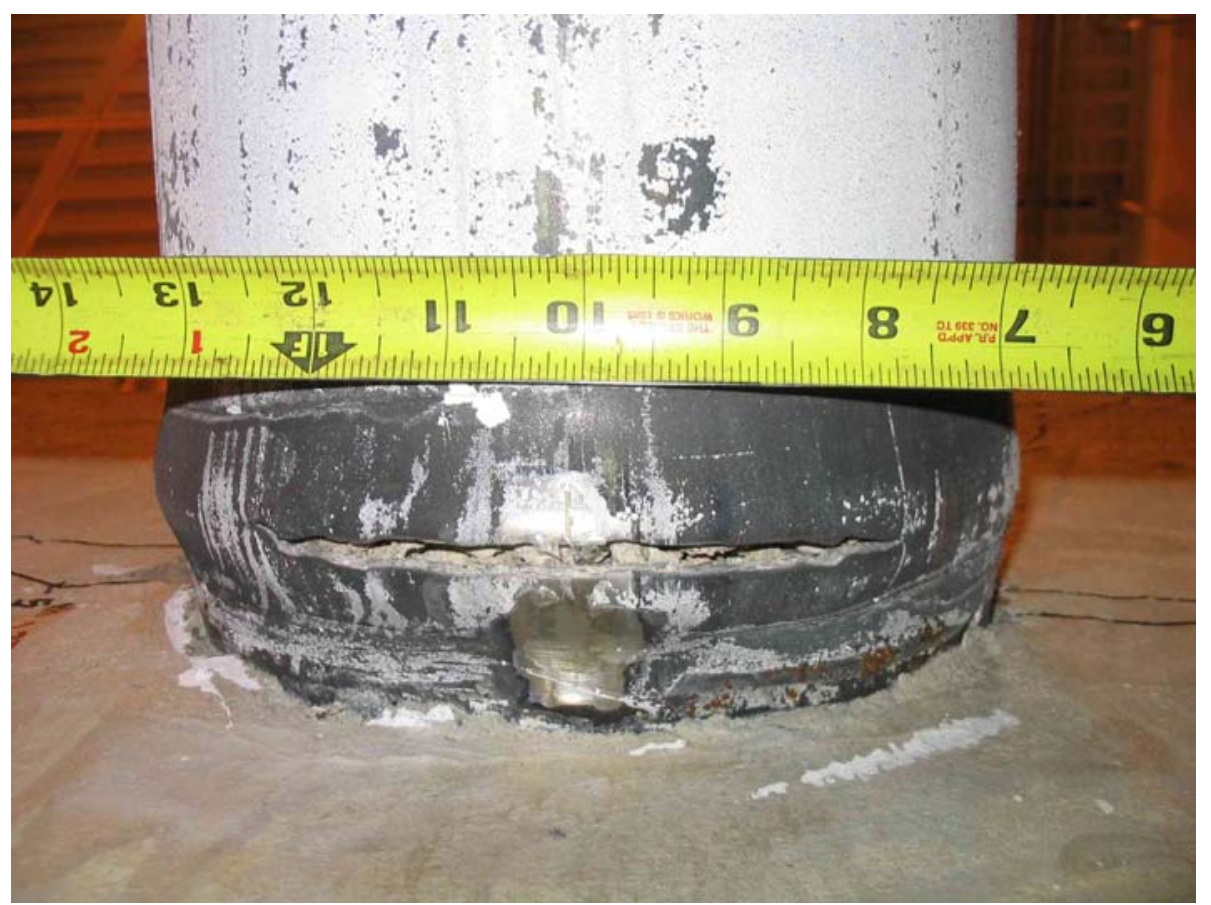

Figure 6.45: Specimen 8 - Steel Shell Fracture at the Bottom of the Pile

Only minor deterioration of the abutment-pile connection was observed as illustrated in Figure 6.46. While the cracking was more than that of Specimen 7, it was still only minor. As indicated in Figure 6.47, the lateral load decreased $26 \%$ in the up direction and $9.5 \%$ in the down direction in the course of the $1.75 \mathrm{in}$. displacement range. The overall load-deflection response is provided in Figure 6.48, and a summary of the test is provided in Table 6.9. The pile had a lateral load capacity of 12 kips in the up direction and 13 kips in the down direction. The displacement ductility, $\mu$, of Specimen 8 was approximately 3.0, which is lower than that of Specimen 7. The test was stopped a little earlier than that of Specimen 7 due to the higher axial load. The test was terminated in the $10^{\text {th }}$ cycle of the 1.75 in. displacement range because of the decrease in the lateral load. 


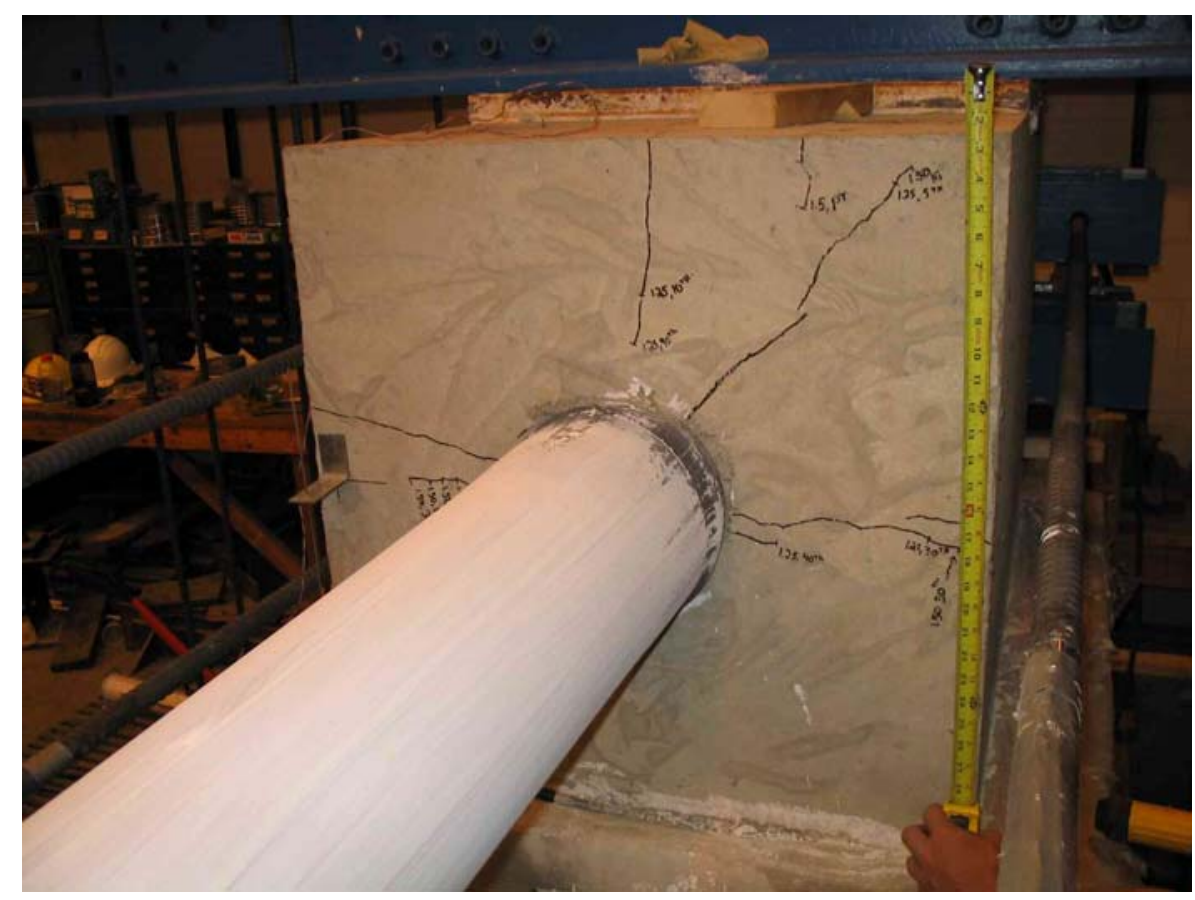

Figure 6.46: Specimen 8 -Deterioration at the Abutment-Pile Connection

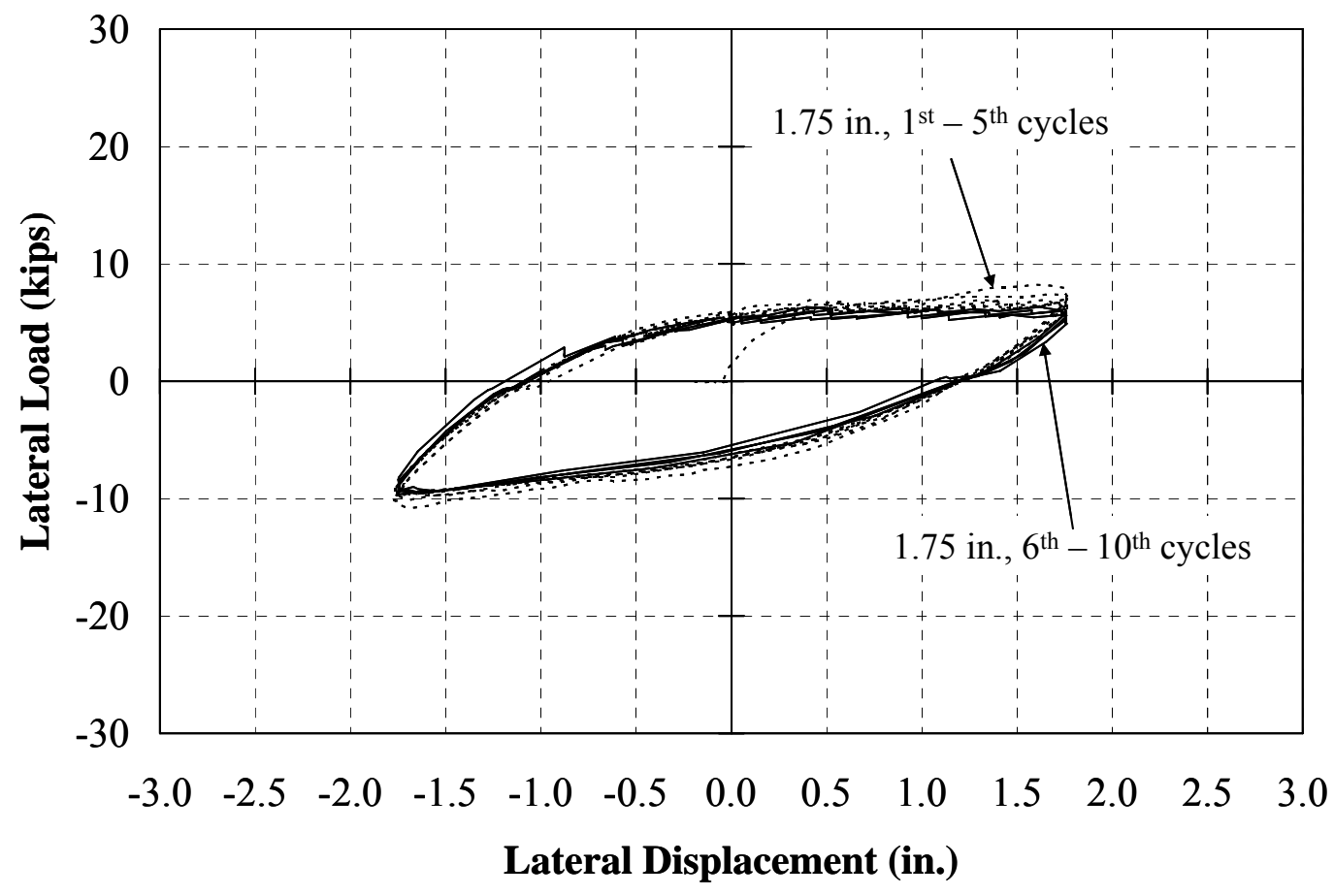

Figure 6.47: Specimen 8 - Load-Deflection Response ( \pm 1.75 in. Range) 


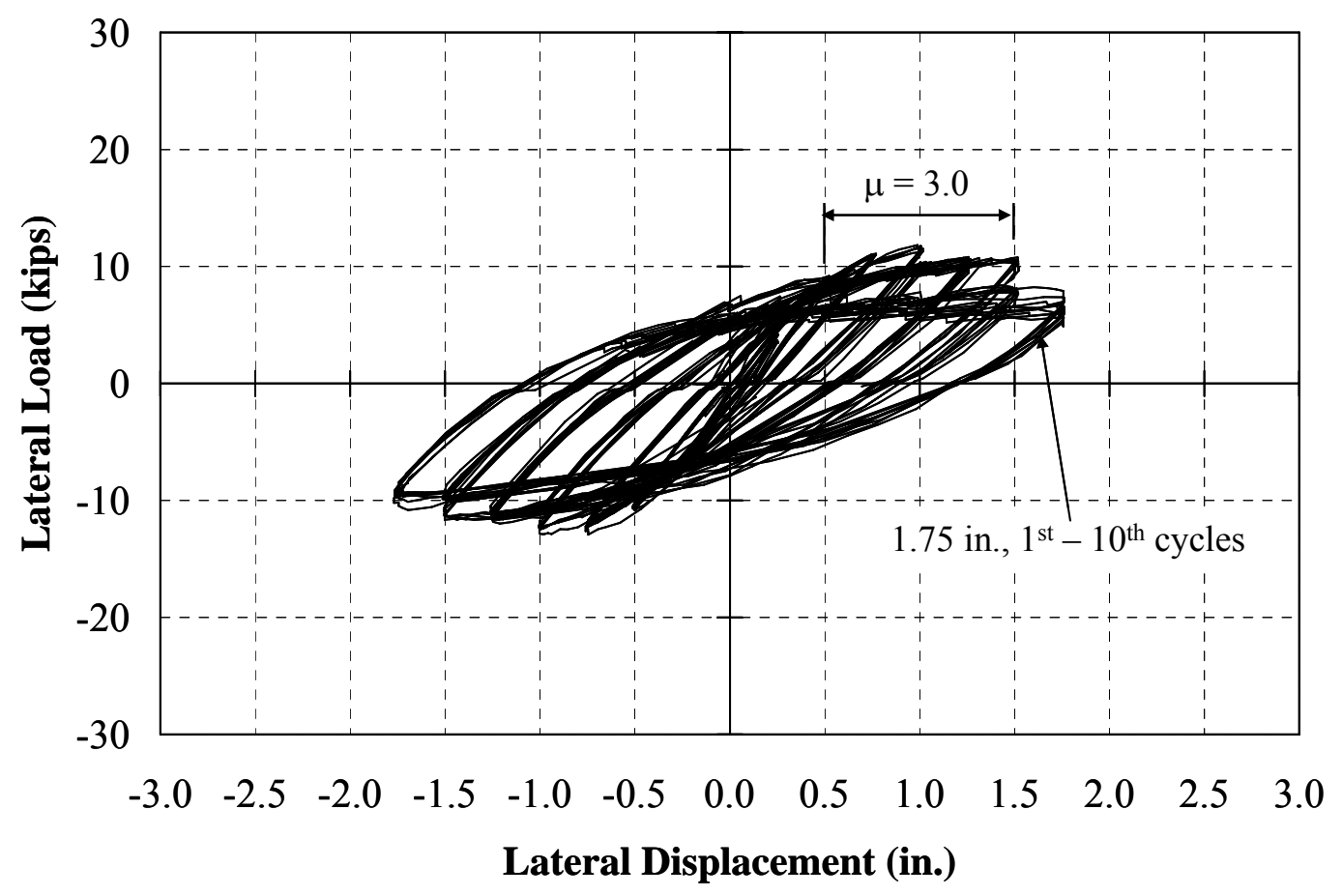

Figure 6.48: Specimen 8 - Overall Load-Deflection Response 


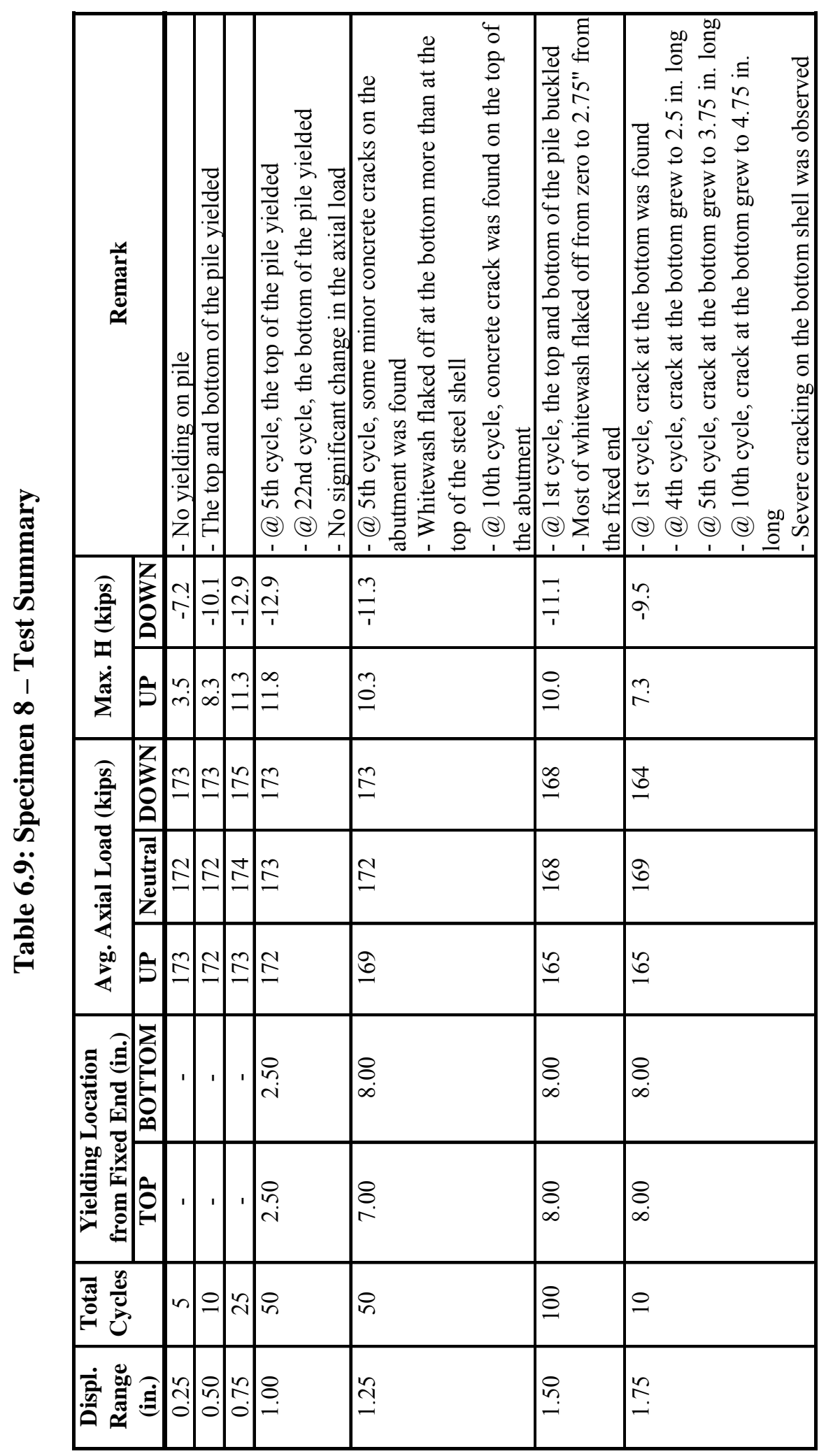




\subsubsection{Specimen 9 (CFT10, 9 ksi)}

Specimen 9 consisted of a larger pile than the two previous CFT piles tested. This pile was subjected to an axial load of approximately 204 kips which was calculated according to the same equation as Specimens $7,0.25 f_{y} A_{s}+0.4 f_{c}^{\prime} A_{c}$. The specified yield strength and concrete compressive strength were the same as those of Specimens 7 and 8 . Steel area, $\mathrm{A}_{\mathrm{s}}$, and concrete area, $\mathrm{A}_{\mathrm{c}}$, were calculated to be 8.25 and 53.4 in. $^{2}$, respectively. An axial load of 72.0 kips was calculated for the steel area, and an axial load of 132 kips was calculated for the concrete core. Thus, the total axial load is equal to $72.2+132.0 \cong 204$ kips. The axial loads distributed to the steel area and concrete area were approximately 81.6 and 122.4 kips based on strain compatibility and a concrete modulus of elasticity of 4,300 ksi. The stresses on steel area and concrete were calculated to be equal to approximately 9.9 and $1.5 \mathrm{ksi}$. The "9 ksi" axial load is defined as the axial load of $0.25 f_{y} A_{s}+0.4 f_{c}^{\prime} A_{c}$ for this specimen.

By inspection, yielding at the bottom of the pile was not noticeable until the 1.25 in. displacement range, and yielding at the top of the pile was not noticed until the 1.75 in. displacement range. The strain gages, however, indicated that the top and bottom of the pile yielded at the beginning of the $0.50 \mathrm{in}$. displacement range. At the $0.50 \mathrm{in}$. displacement range, concrete cracks at the top and east sides of the abutment were visible. The lateral load started dropping during the 0.75 in. displacement range suggesting deterioration at the abutment-pile connection. Several cracks formed around the abutment-pile connection and grew radially to the sides of the abutment. In the $25^{\text {th }}$ cycle of the $1.75 \mathrm{in}$. displacement range, the steel shell at the bottom buckled, and the lateral load continued to drop. The top of the pile buckled at the beginning of the $2.00 \mathrm{in}$. displacement range. In the $90^{\text {th }}$ cycle of the 2.00 in. displacement range, a crack at the bottom of the steel shell initiated and grew quickly from 1.75 in. to 3.75 in. in length wide within 5 cycles as illustrated in Figure 6.49. Despite of damage at the abutment-pile connection shown in Figure 6.50, the axial load was still maintained during the course of the 2.00 in. displacement range. However, the lateral load significantly decreased $23 \%$ in the up direction and $31 \%$ in the down direction (Figure 6.51). 
The overall load-deflection response is presented in Figure 6.52, and a summary of the test is provided in Table 6.10. The pile had a lateral load capacity of 23 kips in the up direction and 31 kips in the down direction. The difference in the lateral load capacity between the up and down directions is likely due to the self-weight of the pile and the deterioration at the abutment-pile connection. The displacement ductility was approximately 4.0, which is higher than that of Specimens 7 and 8 . The test was terminated at a lateral displacement of $2.00 \mathrm{in}$. due to the significant drop in the lateral load.

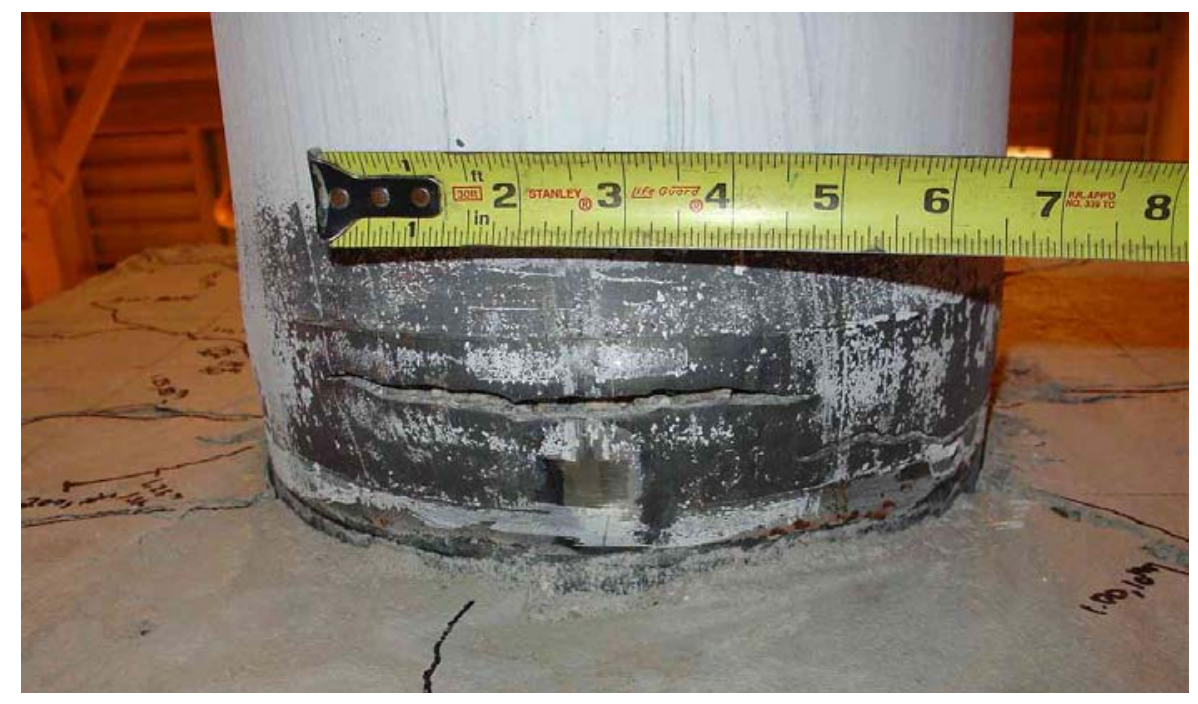

Figure 6.49: Specimen 9 - Crack on the Pile $\left( \pm 2.00\right.$ in. Range, $100^{\text {th }}$ Cycle $)$ 


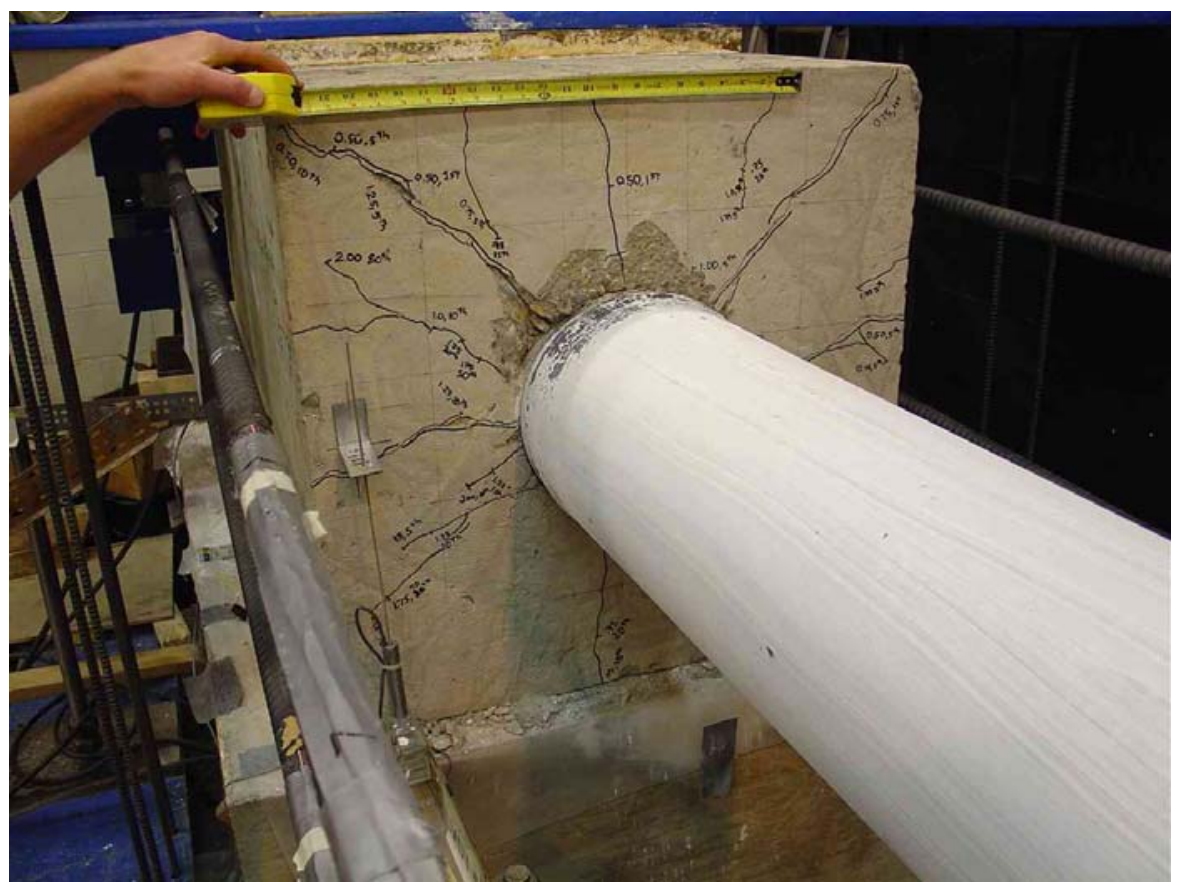

Figure 6.50: Specimen 9 - Deterioration of the Abutment-Pile Connection

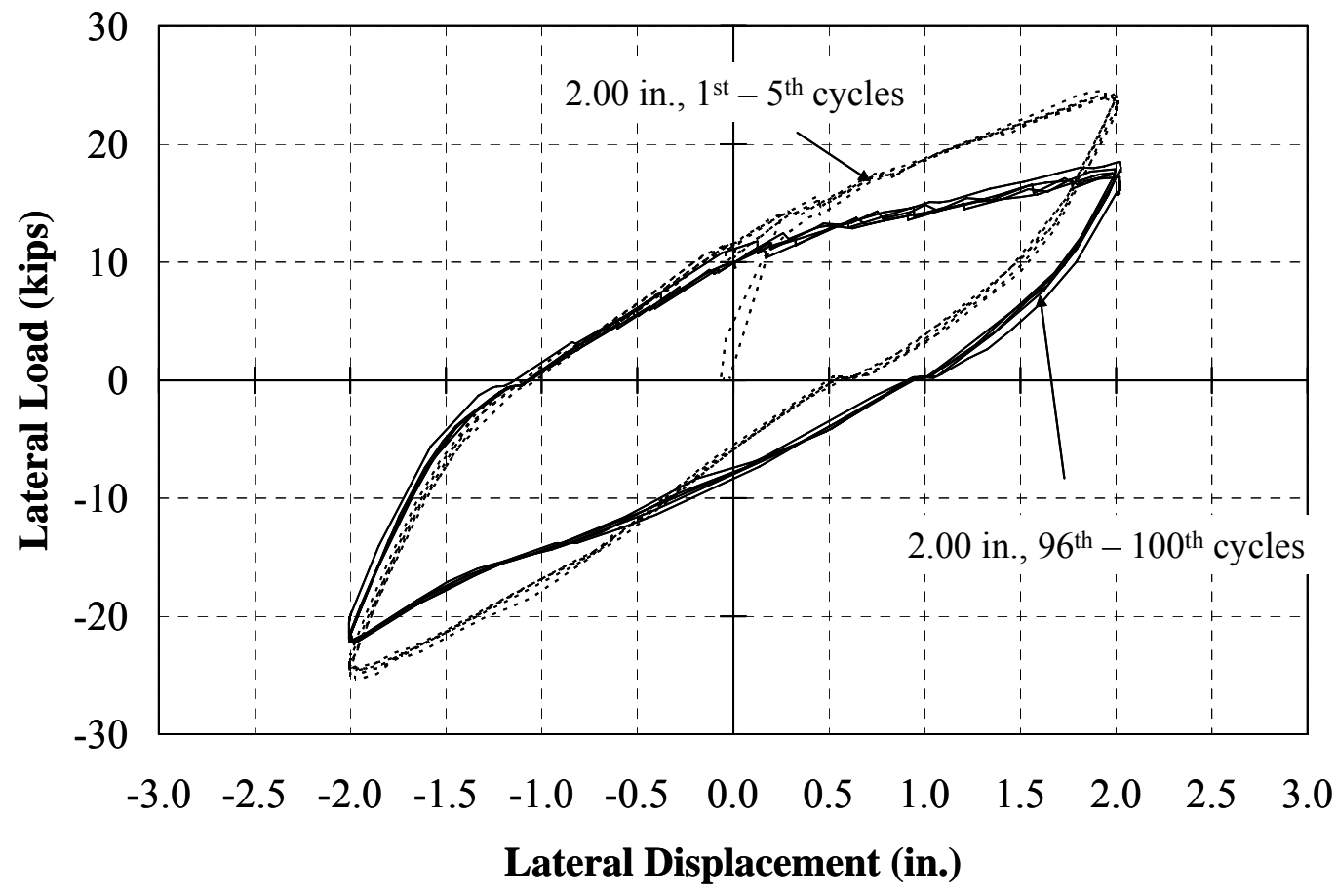

Figure 6.51: Specimen 9 - Load-Deflection Response ( \pm 2.00 in. Range) 


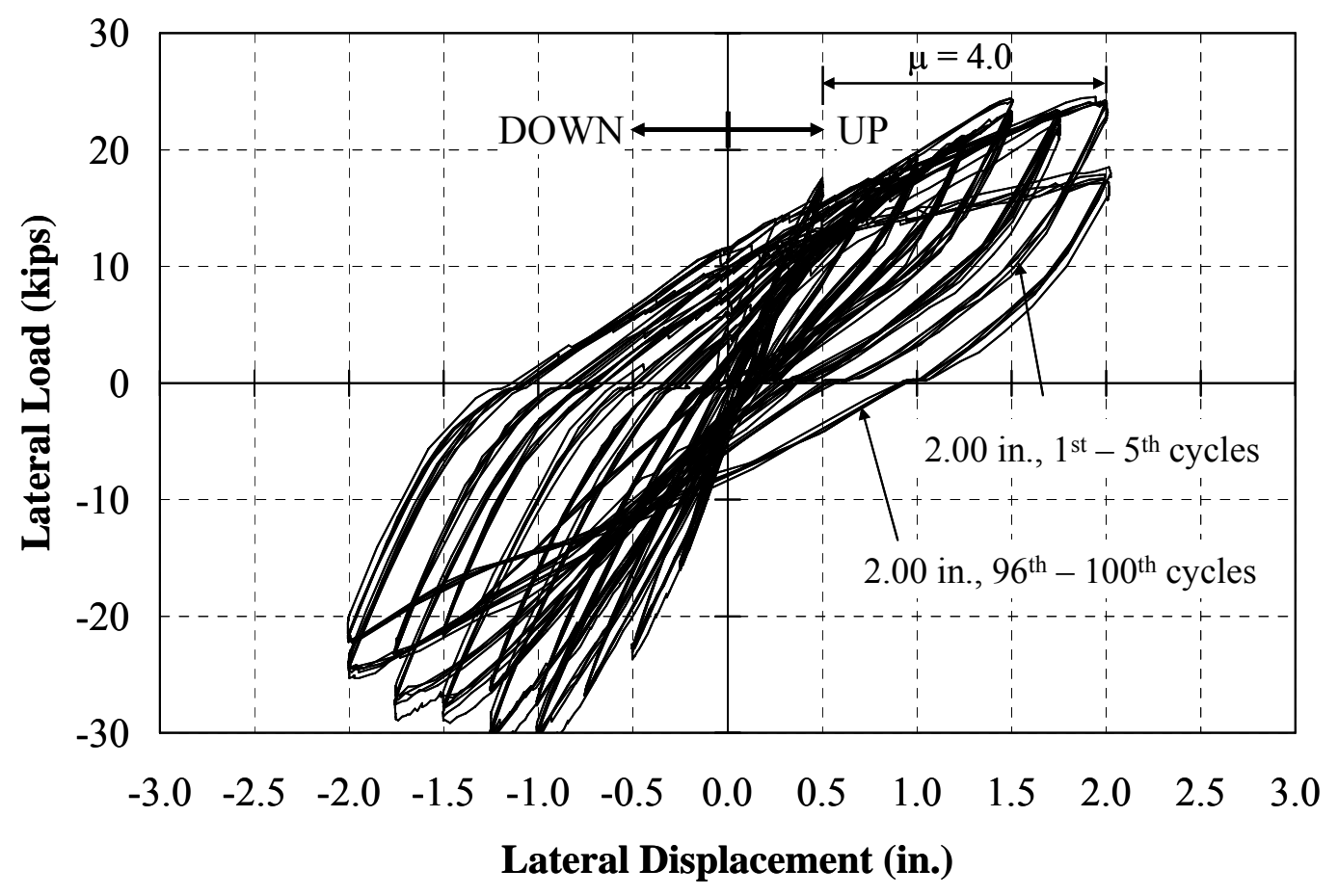

Figure 6.52: Specimen 9 - Overall Load-Deflection Response 


\begin{tabular}{|c|c|c|c|c|c|c|c|c|}
\hline 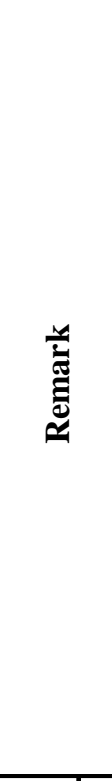 & 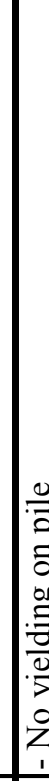 & 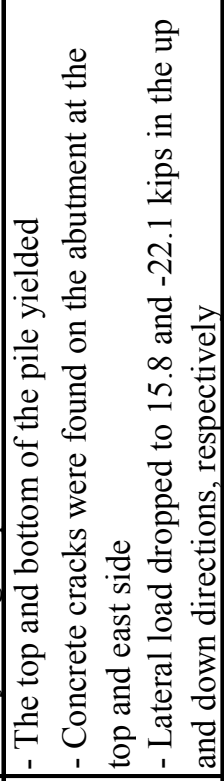 & 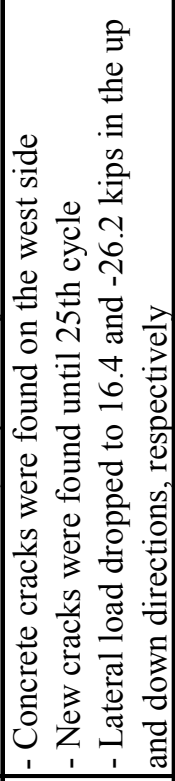 & 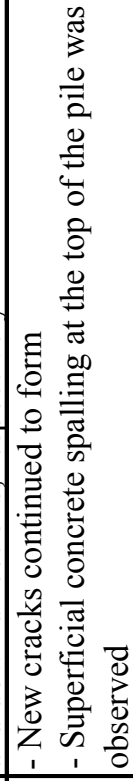 & 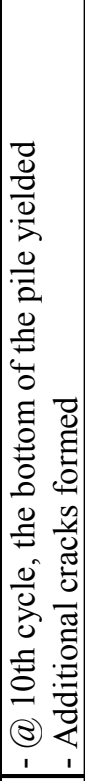 & & 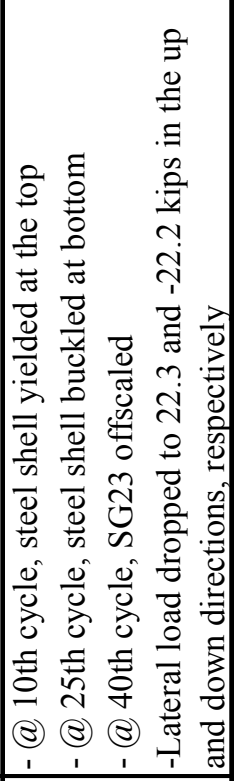 & 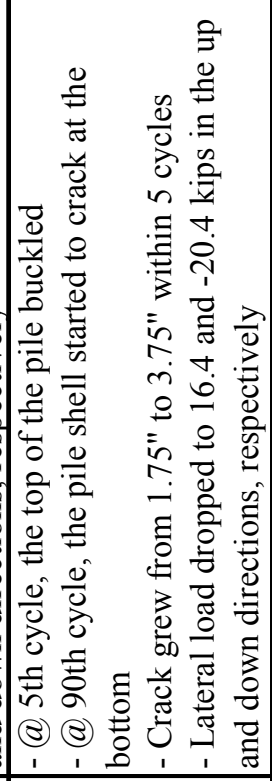 \\
\hline 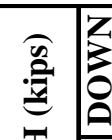 & $\begin{array}{l}0 \\
n \\
1\end{array}$ & 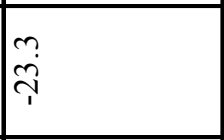 & $\begin{array}{l}\vec{\infty} \\
\stackrel{\sim}{\sim}\end{array}$ & $\frac{0}{\dot{m}}$ & 垈 & $\begin{array}{c}\vec{r} \\
\infty \\
\sim \\
\sim\end{array} \mid$ & $\frac{n}{\stackrel{T}{T}}$ & $\begin{array}{l}\hat{\hat{\lambda}} \\
\hat{\imath}\end{array}$ \\
\hline$\stackrel{\dot{x}}{\Sigma}$ & $\sqrt{\infty}$ & $\stackrel{?}{\simeq}$ & $\begin{array}{l}n \\
\infty \\
\infty\end{array}$ & $\stackrel{\sim}{2}$ & 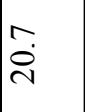 & $\mid \begin{array}{l}0 \\
\text { ते } \\
\end{array}$ & $\frac{\infty}{\vec{\sim}}$ & $\begin{array}{l}m \\
\tilde{v}\end{array}$ \\
\hline 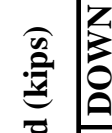 & 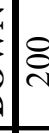 & 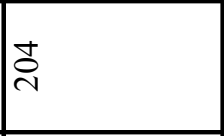 & ì & $\stackrel{\circ}{\sim}$ & $\stackrel{\sim}{\sim}$ & 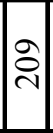 & 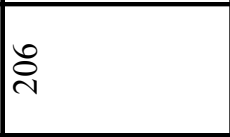 & 定 \\
\hline 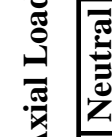 & 2 & $\overline{\mathrm{N}}$ & $\hat{\stackrel{\sim}{\sim}}$ & 音 & 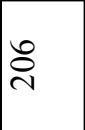 & 烃 & $\underset{\sim}{\stackrel{\Xi}{\sim}}$ & 水 \\
\hline$\stackrel{2}{20}$ & 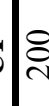 & 穴 & $\stackrel{\circ}{\circ}$ & ஓे & $\stackrel{\sim}{\sim}$ & $\frac{\sim}{\sim}$ & $\stackrel{\circ}{\sim}$ & $\begin{array}{l}n \\
\tilde{c} \\
\tilde{c}\end{array}$ \\
\hline 。ِ & & 1 & ' & ' & , & $\left|\begin{array}{c}8 \\
\dot{m}\end{array}\right|$ & $\stackrel{8}{\stackrel{+}{*}}$ & $\begin{array}{l}\stackrel{n}{r} \\
\dot{m}\end{array}$ \\
\hline فَ & & I & ' & ' & I & ' & $\begin{array}{l}\stackrel{n}{n} \\
i\end{array}$ & $\mid \begin{array}{l}\stackrel{n}{n} \\
\text { na }\end{array}$ \\
\hline 吾 & in & 10 & $\approx$ & in & in & in & 8 & 8 \\
\hline 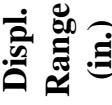 & 10 & in & $\frac{n}{0}$ & $\stackrel{8}{0}$ & $\stackrel{\sim}{-}$ & $\stackrel{n}{n}$ & $\stackrel{n}{\stackrel{2}{2}}$ & $\stackrel{8}{i}$ \\
\hline
\end{tabular}




\section{$\underline{6.4 \quad \text { Evaluation of Results }}$}

Based on the experimental results, the effect of the pile size, axial load, and pile orientation on the behavior of abutment-pile system are discussed.

\subsubsection{Effect of Pile Size}

To evaluate the effect of pile size on the pile-abutment response, the behavior of Specimens 1, 5, and 6 are compared. These specimens were oriented for bending about their weak axis under an axial stress of $9 \mathrm{ksi}$, and the only variable was the size of the pile. The lateral load-deflection responses of these specimens (HP8x36, HP10x42, and HP12x53) are presented in Figure 6.53 along with their displacement ductilities, $\mu$.

Furthermore, a comparison between pile sizes for CFT piles is also evaluated (Specimens 7 and 9). The lateral load-deflection response of these piles (CFT8 and CFT10) piles under the same axial stress of "9 ksi" are shown in Figure 6.54 along with their displacement ductilities, $\mu$.

The moments of inertia of the HP8x36, HP10x42, and HP12x53 bending about their weak axis are 40.3, 71.7, and 127 in. ${ }^{4}$, respectively. Based on the specified yield strength of $35 \mathrm{ksi}$ and the specified concrete strength of 4,000 psi, the transformed moments of inertia of CFT8 and CFT10 including the concrete are 72.6 and $181.1 \mathrm{in.}{ }^{4}$, respectively. It can be observed in both Figures 6.53 and 6.54 that as the size of the $\mathrm{H}$ and CFT sections are increased (stiffness increased), the lateral load capacity of both pile types is increased. In addition, more deterioration occurs at the abutment-pile connection. While this trend occurs for both $\mathrm{H}$ and CFT sections, the trend for lateral displacement capacity is different. For H sections, the lateral displacement capacity decreased with increased stiffness while it increased slightly for CFT sections. Furthermore, the onset of buckling for the $\mathrm{H}$ sections occurred earlier as the stiffness increased while it was delayed for the CFT sections. 

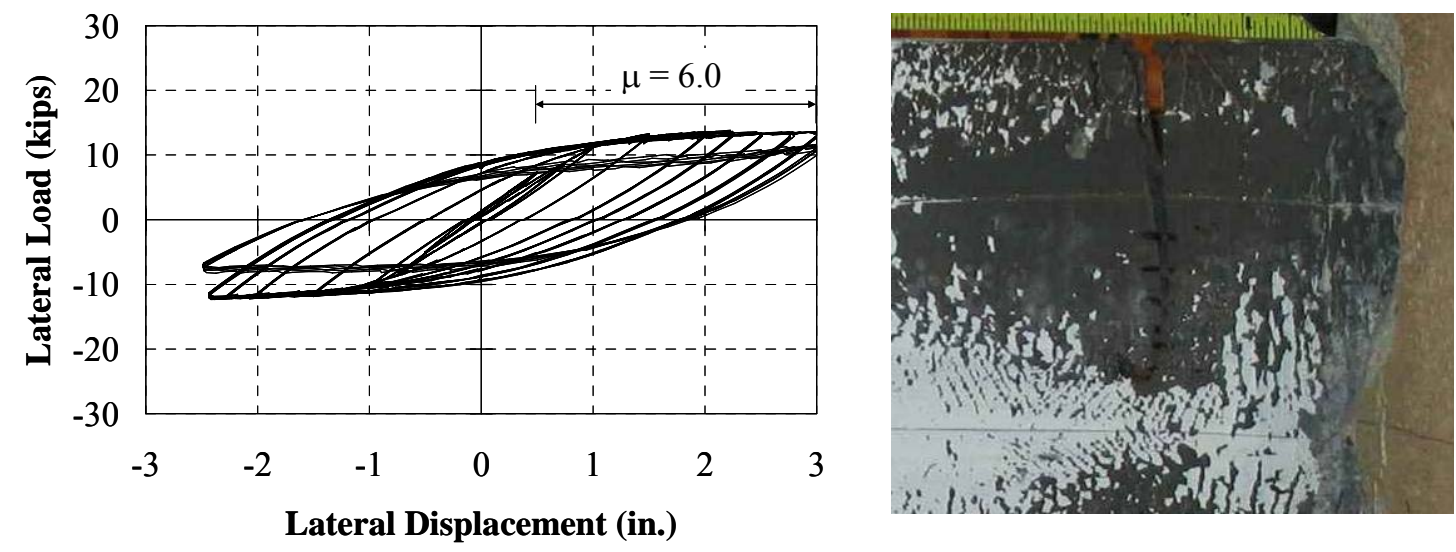

(a) HP8x36 (Specimen 1)
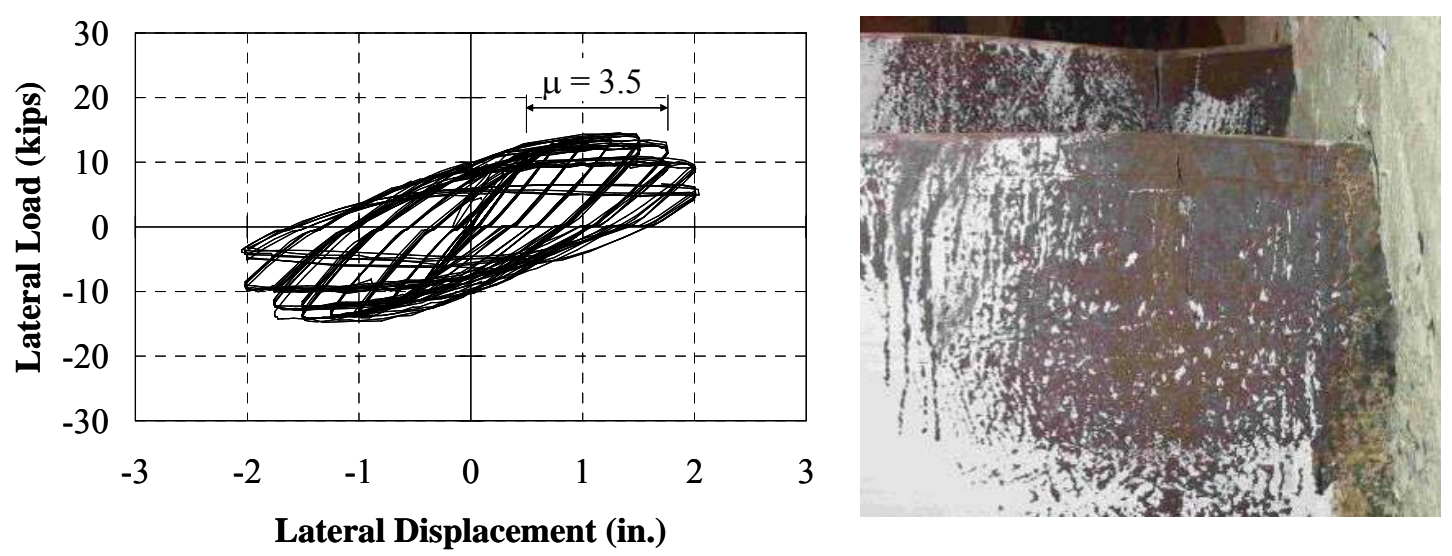

(b) HP10x42 (Specimen 5)
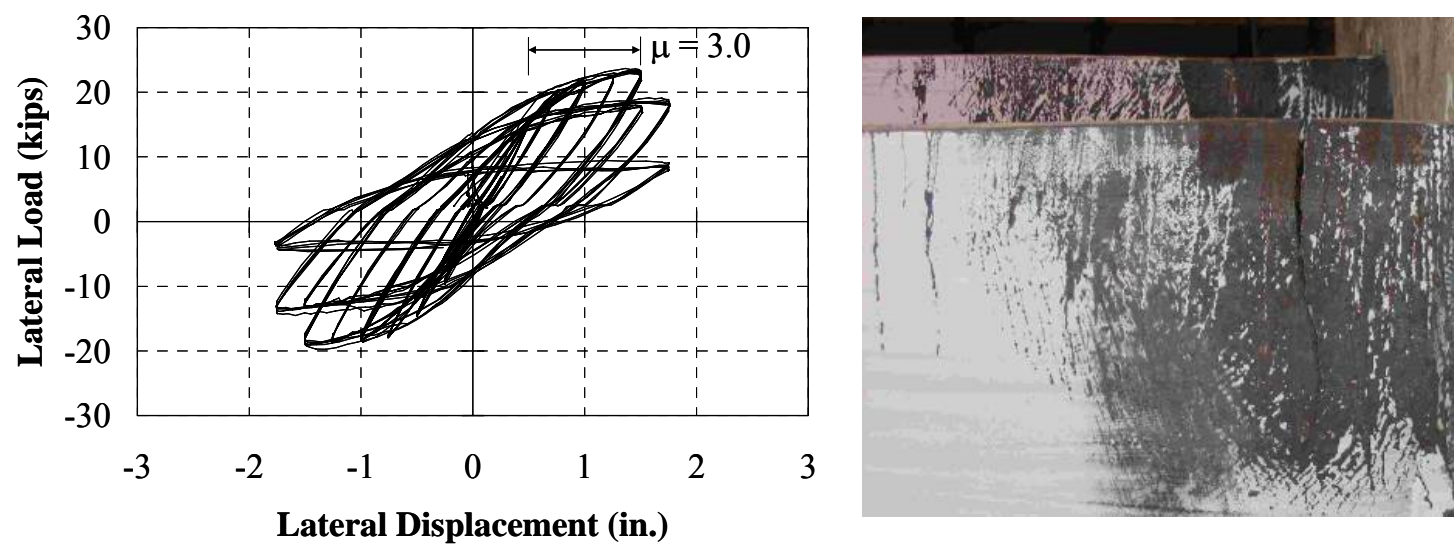

(c) HP12x53 (Specimen 6)

Figure 6.53: Lateral Load-Deflection Responses for H Piles 

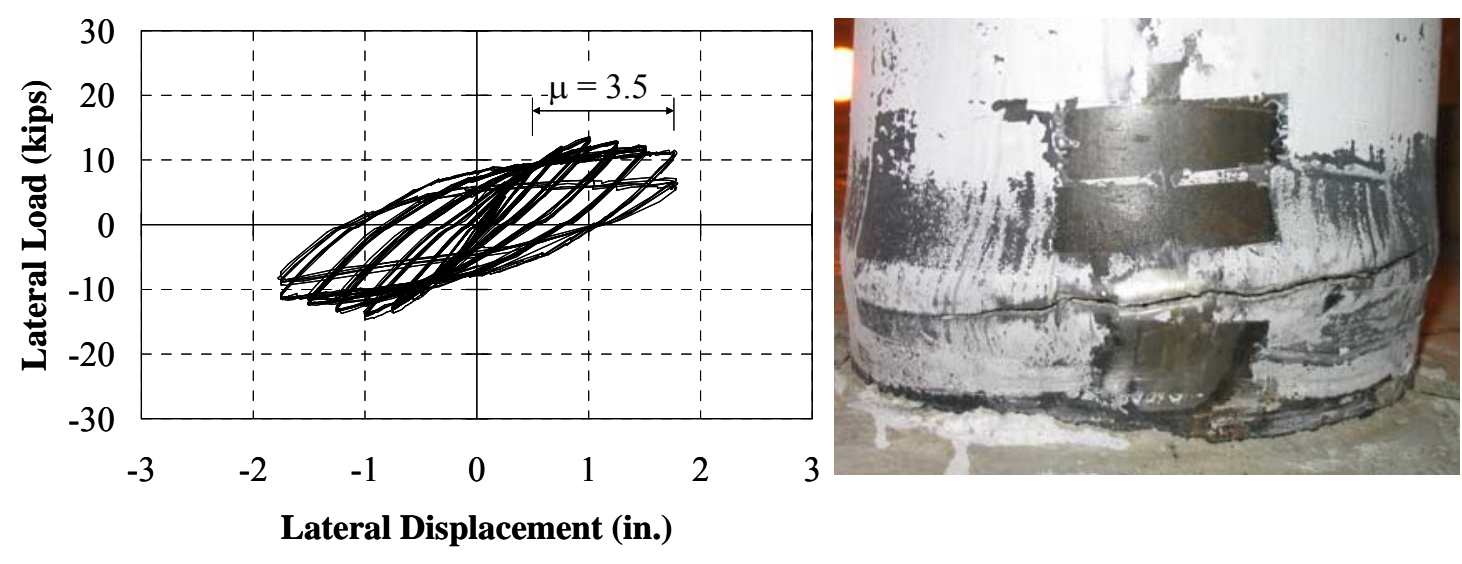

(a) CFT8 (Specimen 7)

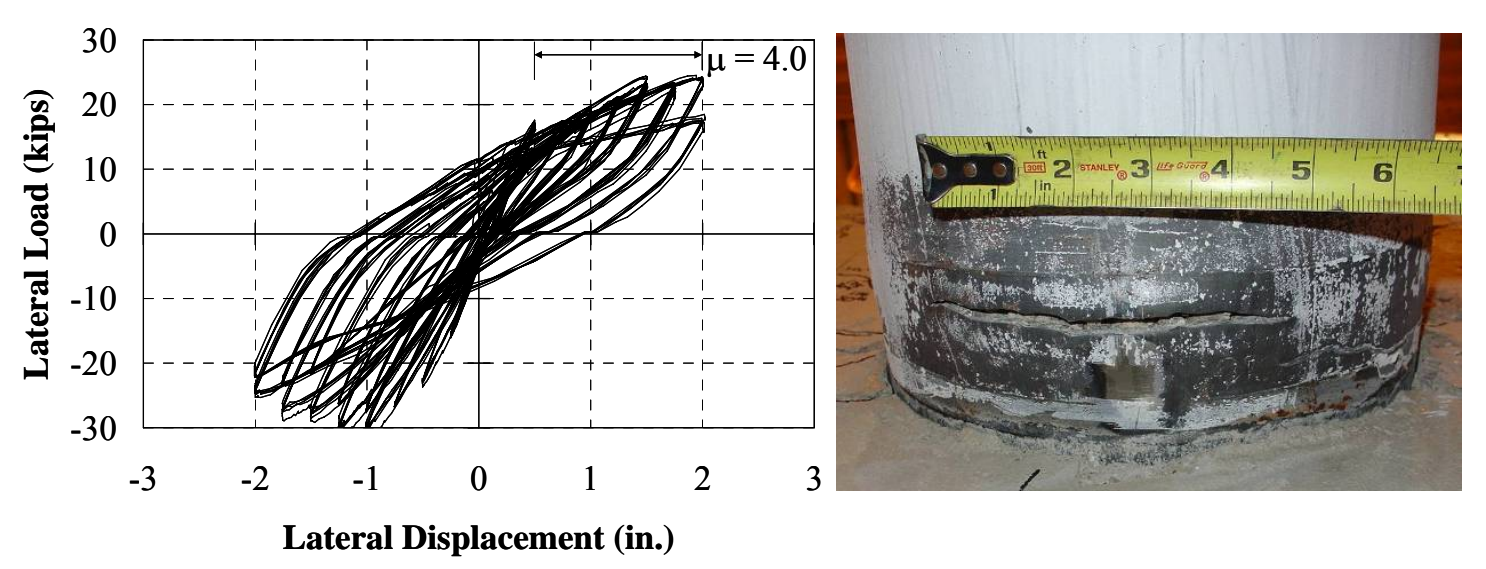

(b) CFT10 (Specimen 9)

Figure 6.54: Lateral Load-Deflection Responses for CFT Piles

The CFT sections were further analyzed to evaluate this behavior. A $1 \mathrm{ft}$ cut section of the CFT8 and CFT10 was considered to evaluate the concrete confinement as shown in Figure 6.55. It should be realized that the axial stress provided to both the steel shell ( $9.8 \mathrm{ksi}$ and $9.9 \mathrm{ksi}$ ) and the concrete ( $1.5 \mathrm{ksi}$ for both specimens) was essentially identical. Considering the yield strength of the steel shell based on the $0.2 \%$ offset steel strength (42 ksi for CFT8 and $52 \mathrm{ksi}$ for CFT10), the transverse forced provided by the steel shell is approximately 189.5 and 312.0 kips for the CFT8 and CFT10 sections, respectively. By equilibrium, this tension or hoop force is resisted by compression of the concrete core. The stress on the concrete core was calculated to be approximately $1.9 \mathrm{ksi}$ for the CFT8 and $2.5 \mathrm{ksi}$ for the CFT10. Therefore, the confinement increased by $32 \%$ 
which can explain the improved performance of the CFT10, especially the increase in lateral capacity that was observed with increasing displacement. This increase was not evident for the CFT8. It is also important to note that the wall thickness of the CFT10 section ( 0.250 in.) is approximately $33 \%$ thicker than that of the CFT8 section ( 0.188 in.) Besides being responsible for the increase in confinement stress, the increased wall thickness improved the local buckling behavior and is likely responsible for the increase ductility exhibited prior to buckling.

A summary of the lateral load capacity, lateral displacement capacity, lateral displacement ductility, and displacement at first buckling of Specimens 1, 5, 6, 7, and 9 is provided in Table 6.11 .

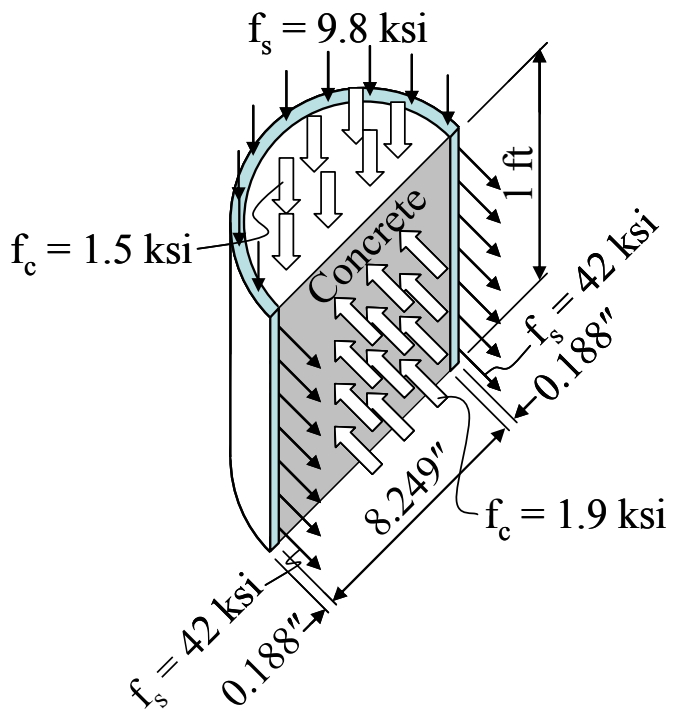

(a) CFT8 (Specimen 7)

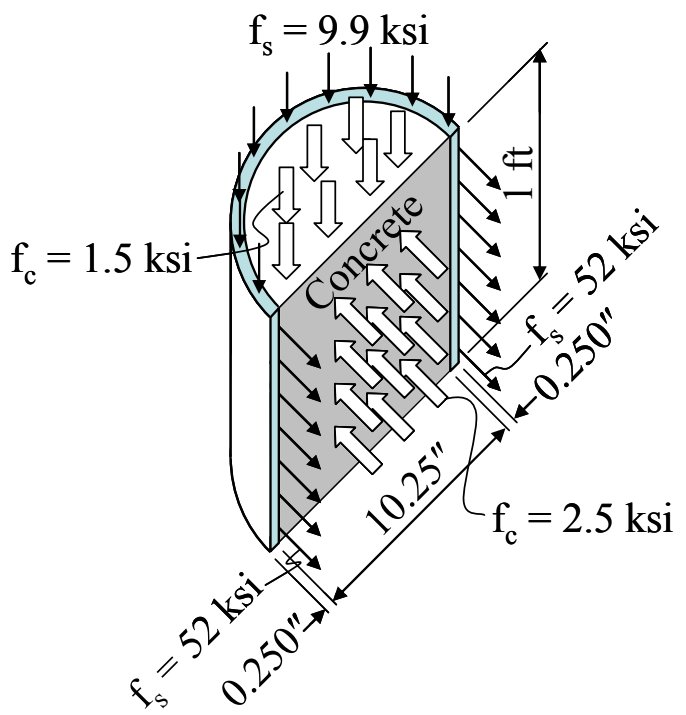

(b) CFT10 (Specimen 9)

Figure 6.55: Effect of Confinement

Table 6.11: Effect of Pile Size (Specimens 1, 5, vs. 6, and 7 vs. 9)

\begin{tabular}{|c|c|c|c|c|}
\hline Specimen & $\begin{array}{c}\text { Lateral Load } \\
\text { Capacity (kips) }\end{array}$ & $\begin{array}{c}\text { Lateral } \\
\text { Displacement } \\
\text { Capacity (in.) }\end{array}$ & $\begin{array}{c}\text { Lateral } \\
\text { Displacement } \\
\text { Ductility, } \boldsymbol{\mu}\end{array}$ & $\begin{array}{c}\text { First } \\
\text { Buckling } \\
\text { (in.) }\end{array}$ \\
\hline 1 & 14 & 3.00 & 6.0 & 2.00 \\
\hline 5 & 15 & 1.75 & 3.5 & 1.25 \\
\hline 6 & 22 & 1.50 & 3.0 & 1.25 \\
\hline 7 & 13 & 1.75 & 3.5 & 1.50 \\
\hline 9 & 23 & 2.00 & 4.0 & 1.75 \\
\hline
\end{tabular}




\subsubsection{Effect of Axial Load}

The effect of axial load on the pile-abutment response was evaluated for both $\mathrm{H}$ and CFT piles. This effect is important as the axial load is currently limited to a maximum steel stress of $9 \mathrm{ksi}$ for these pile types due to concerns regarding combined axial and lateral loading. To evaluate the axial load effect on $\mathrm{H}$ piles, the lateral loaddeflection responses of Specimens 1 and 4 were compared as shown in Figure 6.56.

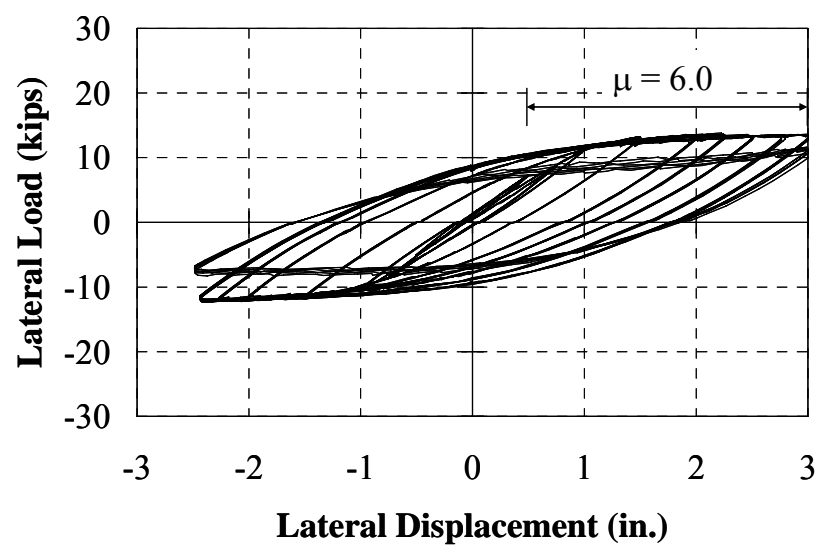

(a) $9 \mathrm{ksi}($ Specimen 1)

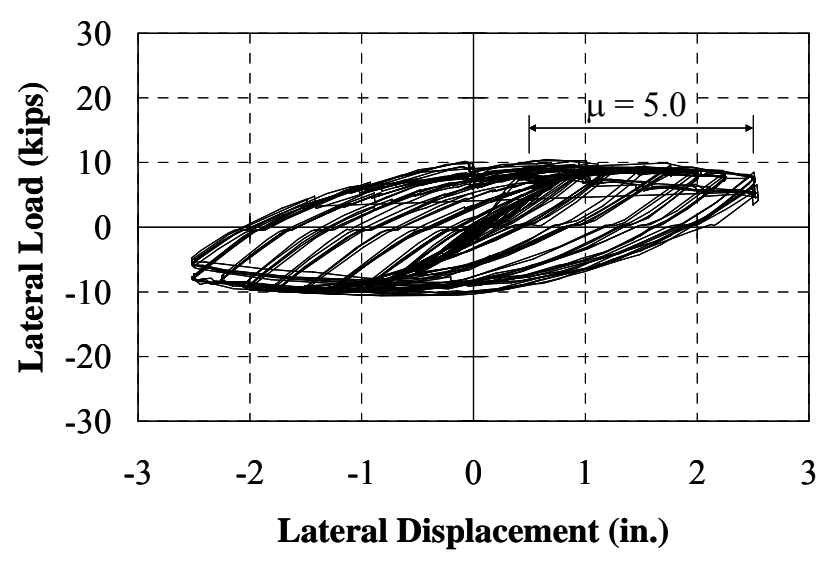

(b) $18 \mathrm{ksi}$ (Specimen 4)

Figure 6.56: Load-Deflection Responses in HP8x36 under Different Axial Stresses 
It can be observed that the $\mathrm{H}$ pile subjected to a stress of 18 ksi provided a lower lateral load and lateral displacement capacity than that of the pile subjected to $9 \mathrm{ksi}$. Even though significant deterioration of the concrete at the abutment-pile connection of both specimens did not occur and the axial load was maintained, the web of the pile with higher axial load yielded severely. The lower load and displacement capacity, therefore, was likely due to the effect of web yielding as shown in Figure 6.57. It can be seen that the web of the pile carrying higher axial load buckled while no buckling of the web occurred at the $9 \mathrm{ksi}$ level. It can also be noticed that as the axial load applied is increased, the lateral displacement ductility is decreased from 6.0 to 5.0, while the onset of local buckling is slightly delayed from the 2.00 to $2.25 \mathrm{in}$. displacement range as presented in Table 6.12. Moreover, it should be noted from the load-displacement response (Figure 6.56 (b)), a small loss of lateral load capacity occurred while the displacement was increased. This degradation was not evident for the $9 \mathrm{ksi}$ specimen (Figure $6.56(a)$ ).

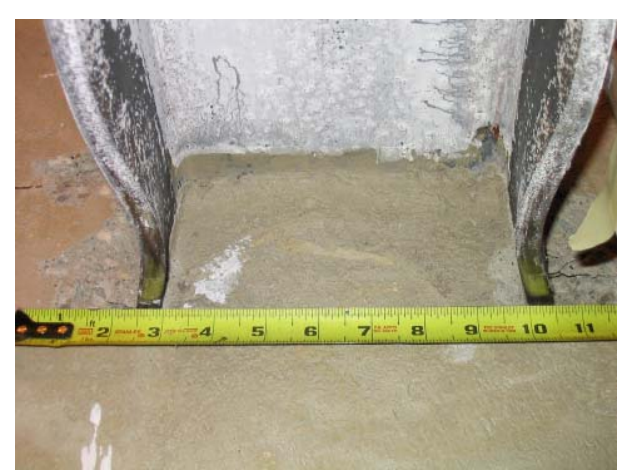

(a) 9 ksi (Specimen 1)

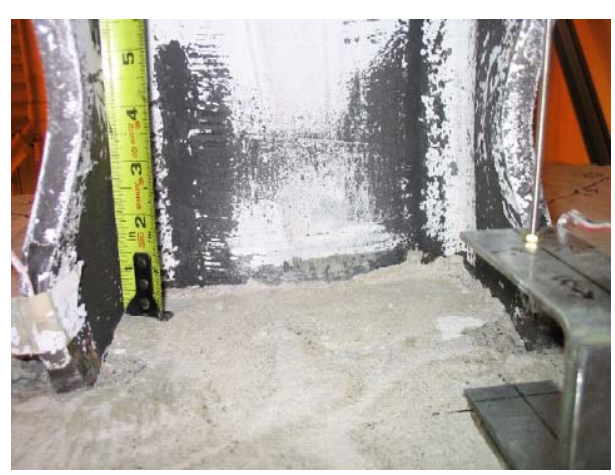

(b) $18 \mathrm{ksi}$ (Specimen 4)

Figure 6.57: Web Yielding of HP8x36 Bending about Weak Axis

Table 6.12: Effect of Axial Load (Specimens 1 vs. 4)

\begin{tabular}{|c|c|c|c|c|}
\hline Specimen & $\begin{array}{c}\text { Lateral Load } \\
\text { Capacity (kips) }\end{array}$ & $\begin{array}{c}\text { Lateral } \\
\text { Displacement } \\
\text { Capacity (in.) }\end{array}$ & $\begin{array}{c}\text { Lateral } \\
\text { Displacement } \\
\text { Ductility, } \mu\end{array}$ & $\begin{array}{c}\text { First } \\
\text { Buckling } \\
\text { (in.) }\end{array}$ \\
\hline 1 & 14 & 3.00 & 6.0 & 2.00 \\
\hline 4 & 9 & 2.50 & 5.0 & 2.25 \\
\hline
\end{tabular}


The lateral load-deflection responses of the CFT8 piles subjected to stress levels of "9 ksi" and "18 ksi" are shown in Figure 6.58. It is to be noted that the actual steel stress was increased from $9.8 \mathrm{ksi}$ to $13.1 \mathrm{ksi}$ and the concrete stress in the tube was increased from $1.5 \mathrm{ksi}$ to $2.0 \mathrm{ksi}$. As tabulated in Table 6.13, the CFT pile subjected to an axial stress of "9 ksi" had approximately the same lateral load and lateral displacement capacity as the CFT pile with an axial stress of " 18 ksi." According to the experiment results, the CFT pile with an axial load of "9 ksi" started buckling at the same displacement range as the CFT pile with an axial load of " 18 ksi." However, the CFT pile with " $9 \mathrm{ksi}$ " axial load failed in the $33^{\text {rd }}$ cycle of the $1.75 \mathrm{in}$. displacement range, while the CFT pile with " $18 \mathrm{ksi}$ " axial load failed in the $10^{\text {th }}$ cycle of the same displacement range. It was observed that as the axial load was increased, the displacement ductility decreased from 3.5 to 3.0, and more deterioration was observed at the abutment-pile as illustrated in Figure 6.59. The higher axial stress in the pile caused slightly earlier buckling. 

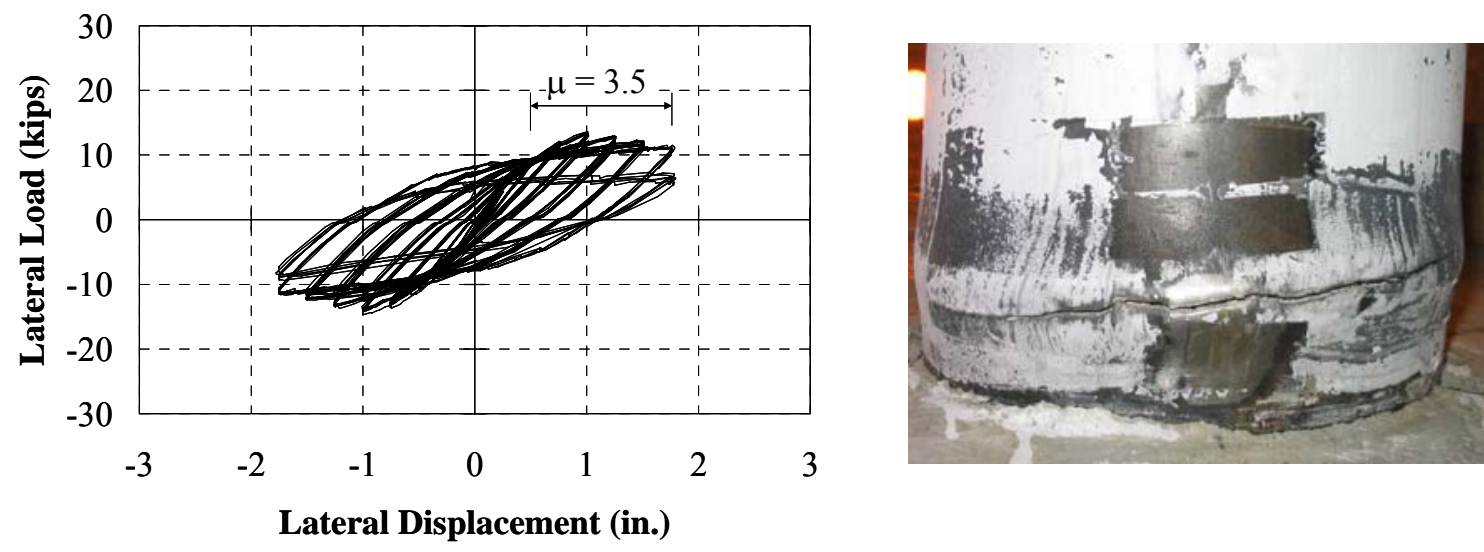

(a) “9 ksi” (Specimen 7)
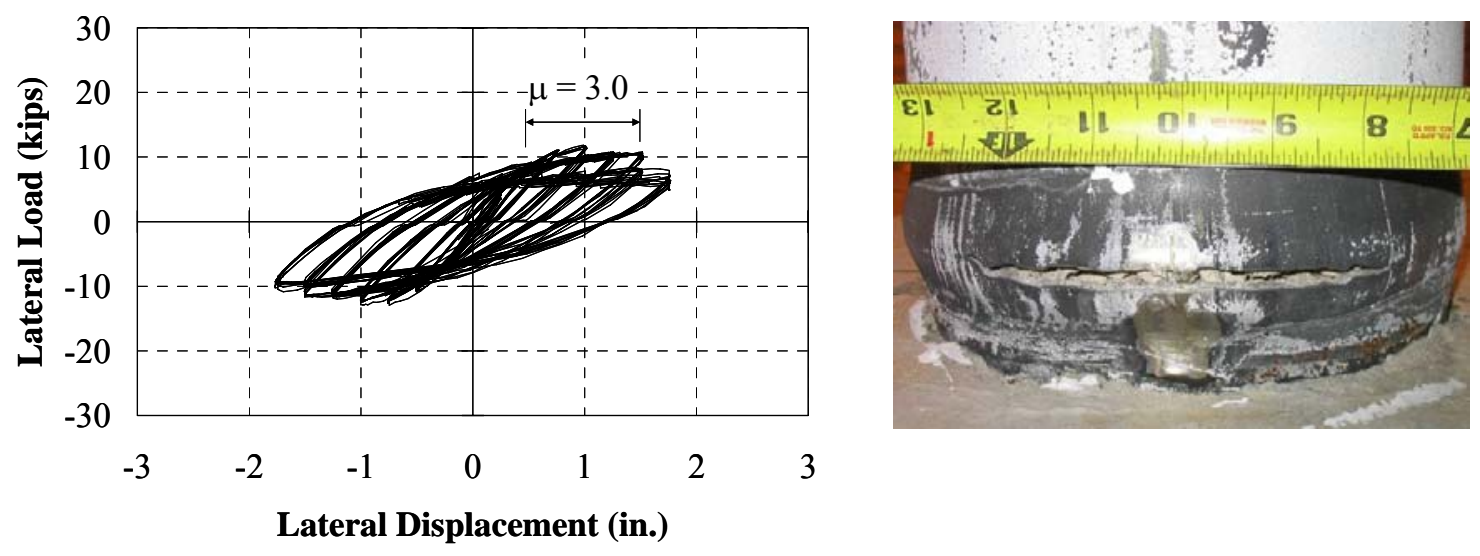

(b) "18 ksi" (Specimen 8)

Figure 6.58: Load-deflection Responses in CFT8 Piles under Different Axial Stress 


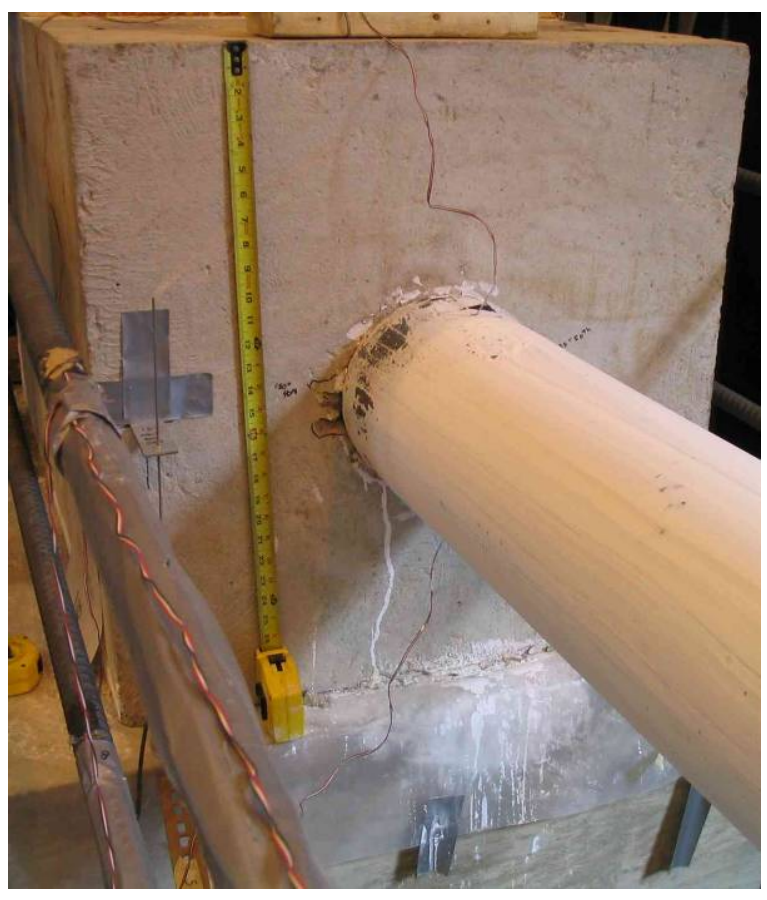

(a) “9 ksi” (Specimen 7)

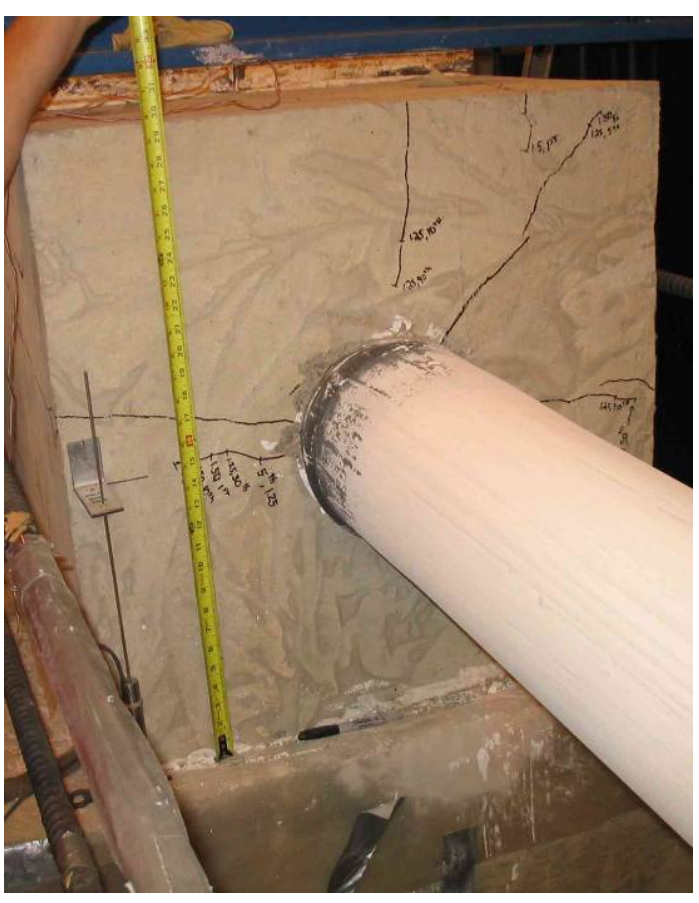

(b) “18 ksi” (Specimen 8)

Figure 6.59: Abutment-Pile Connection of CFT8 Piles under Different Axial Stress

Table 6.13: Effect of Axial Load (Specimens 7 vs. 8)

\begin{tabular}{|c|c|c|c|c|}
\hline Specimen & $\begin{array}{c}\text { Lateral Load } \\
\text { Capacity (kips) }\end{array}$ & $\begin{array}{c}\text { Lateral } \\
\text { Displacement } \\
\text { Capacity (in.) }\end{array}$ & $\begin{array}{c}\text { Lateral } \\
\text { Displacement } \\
\text { Ductility, } \mu\end{array}$ & $\begin{array}{c}\text { First } \\
\text { Buckling } \\
\text { (in.) }\end{array}$ \\
\hline 7 & 13 & 1.75 & 3.5 & 1.50 \\
\hline 8 & 12 & 1.50 & 3.0 & 1.50 \\
\hline
\end{tabular}




\subsubsection{Effect of Pile Orientation}

The lateral load-deflection responses of HP8x36 piles bending about weak-, $45^{\circ}$-, and strong-axes are shown in Figure 6.60. A summary of the lateral load capacity, displacement capacity, and displacement ductility is provided in Table 6.14. The lateral displacement capacity of the pile bending about its weak-, $45^{\circ}$-, and strong-axes are 3.00 , 2.00, and 1.75 in., respectively. Moreover, the lateral load capacity of the pile bending about its weak-, $45^{\circ}$-, and strong-axes are approximately 14,18 , and 25 kips, respectively. From this trend, it can be observed that the ultimate displacement decreased while the lateral load increased as the stiffness of the section increased due to the pile orientation. It can also be observed that the lateral displacement capacity of the pile bending about its weak axis is higher than that of the pile bending about the $45^{\circ}$ - and strong-axes, respectively. However, the lateral load capacity of weak axis bending was lower than that of the $45^{\circ}$ - and strong-axis bending pile, respectively. Perhaps more importantly, the amount of deterioration of the abutment-pile connection increased as the orientation changed from weak to $45^{\circ}$ to strong. This deterioration is evident in the loaddeflection response where significant pinching is observed for the strong-axis specimen. It must be noted that, whereas, the behavior of the weak- and $45^{\circ}$-axis specimens was dominated by the pile response, the strong-axis specimen was dominated by the deterioration of the abutment-pile connection. In fact, this deterioration limited its response and lateral load capacity. Improvement of the strong-axis connection may improve the response and lateral load capacity of the pile in this orientation. 

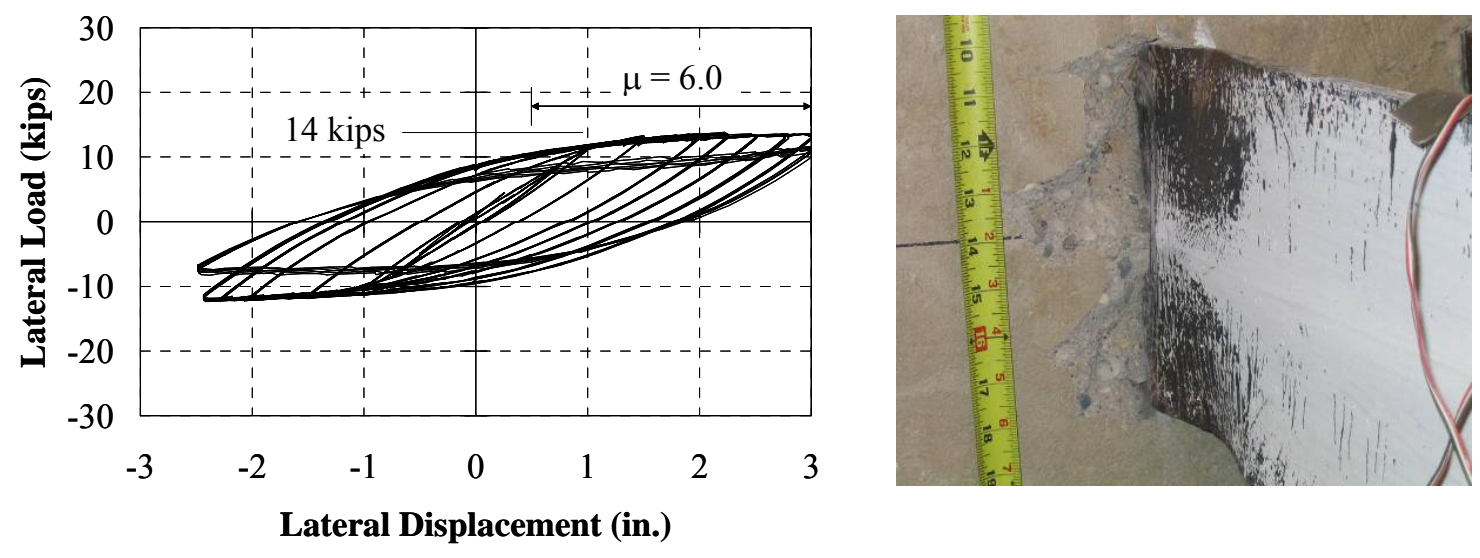

(a) Weak Axis (Specimen 1)
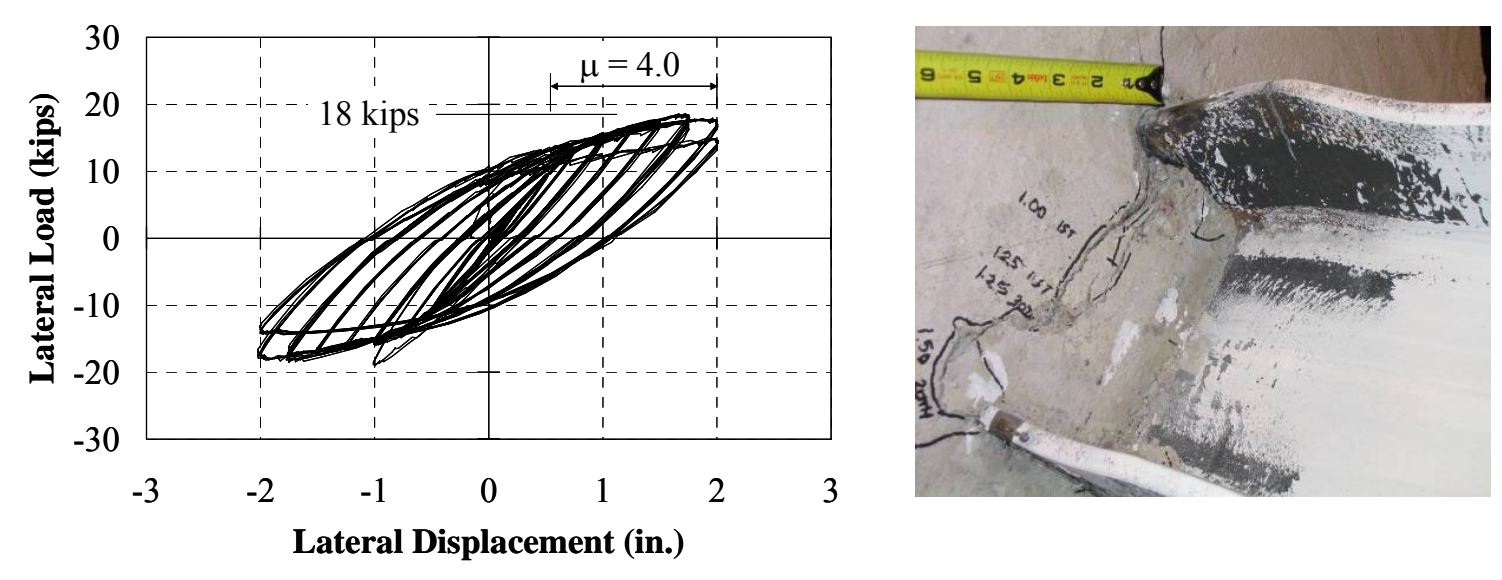

(b) $45^{\circ}$ Axis (Specimen 3)
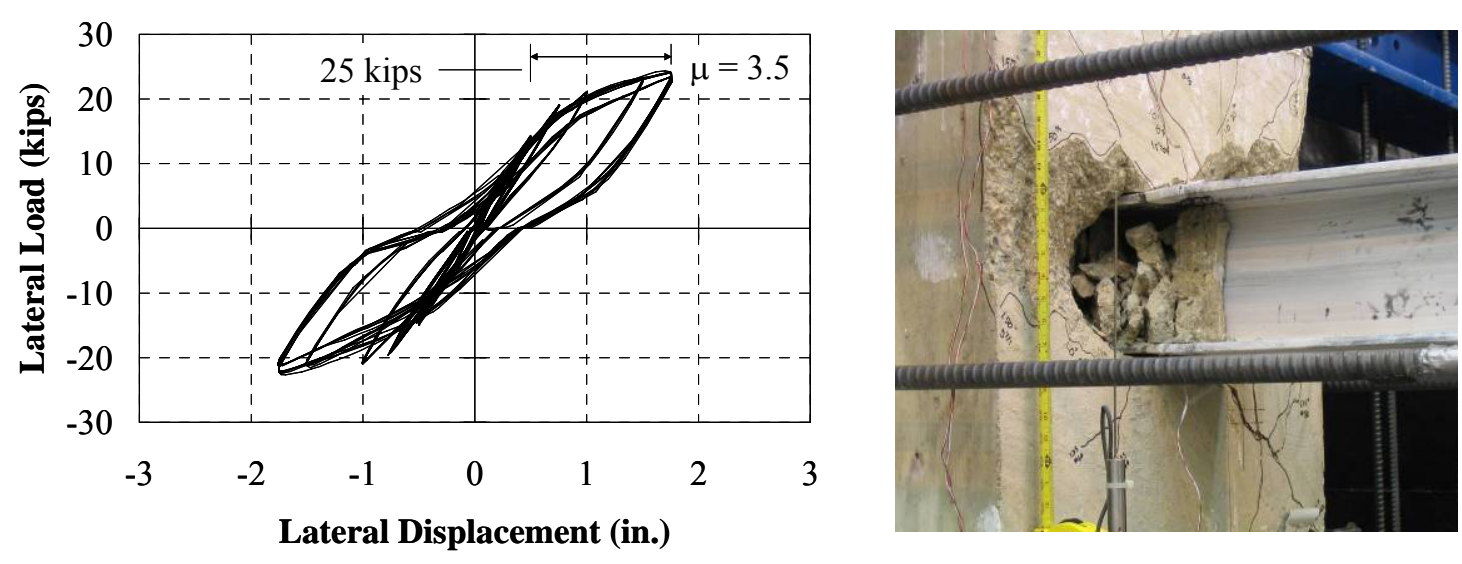

(c) Strong Axis (Specimen 2)

Figure 6.60: Lateral Load-Deflection Responses in HP8x36 
Table 6.14: Effect of Pile Orientation (Specimens 1, 2, vs. 3)

\begin{tabular}{|c|c|c|c|c|}
\hline Specimen & $\begin{array}{c}\text { Lateral Load } \\
\text { Capacity (kips) }\end{array}$ & $\begin{array}{c}\text { Lateral } \\
\text { Displacement } \\
\text { Capacity (in.) }\end{array}$ & $\begin{array}{c}\text { Lateral } \\
\text { Displacement } \\
\text { Ductility, } \boldsymbol{\mu}\end{array}$ & $\begin{array}{c}\text { First } \\
\text { Buckling } \\
\text { (in.) }\end{array}$ \\
\hline 1 & 14 & 3.00 & 6.0 & 2.00 \\
\hline 3 & 18 & 2.00 & 4.0 & 1.50 \\
\hline 2 & 25 & 1.75 & 3.5 & 1.50 \\
\hline
\end{tabular}

\subsection{Conclusions from Experimental Results}

A summary of the test results is tabulated in Table 6.15. A summary of the test variables was previously presented in Table 5.2. "Complete yielding" means all flanges or both the top and bottom of steel shell yield and "complete buckling" means all flanges or both the top and bottom of steel shell buckle. Conclusions regarding, axial load, pile orientation, pile stiffness, abutment-pile connection, and bridge length are discussed. A recommended length for integral abutment bridges, calculated based on the experimental results is also discussed.

Table 6.15: Summary of Test Results

\begin{tabular}{|c|c|c|c|c|c|c|c|c|c|}
\hline \multirow{2}{*}{ Specimen } & \multirow{2}{*}{$\begin{array}{c}\text { Axial } \\
\text { Load } \\
\text { (kips) }\end{array}$} & $\begin{array}{c}\text { First } \\
\text { Yielding }\end{array}$ & $\begin{array}{c}\text { Complete } \\
\text { Yielding }\end{array}$ & \multicolumn{2}{|c|}{ First Buckling } & \multicolumn{2}{c|}{$\begin{array}{c}\text { Complete } \\
\text { Buckling }\end{array}$} & \multicolumn{2}{|c|}{ Failure } \\
(in.) & $\begin{array}{c}\text { Displ. } \\
\text { (in.) }\end{array}$ & $\begin{array}{c}\text { Displ. } \\
\text { (in.) }\end{array}$ & Cycle & $\begin{array}{c}\text { Displ. } \\
\text { (in.) }\end{array}$ & Cycle & $\begin{array}{c}\text { Displ. } \\
\text { (in.) }\end{array}$ & Cycle \\
\hline 1 & 95.4 & 0.50 & 0.75 & 2.00 & 50 & 2.50 & 100 & 3.00 & 80 \\
\hline 2 & 95.4 & 0.50 & 0.75 & 1.50 & 80 & 1.75 & 10 & 1.75 & 100 \\
\hline 3 & 95.4 & 0.50 & 1.00 & 1.50 & 30 & 2.00 & 80 & 2.00 & 100 \\
\hline 4 & 191 & 0.50 & 0.75 & 2.25 & 50 & 2.25 & 100 & 2.50 & 66 \\
\hline 5 & 112 & 0.50 & 0.50 & 1.25 & 10 & 1.50 & 1 & 2.00 & 50 \\
\hline 6 & 140 & 0.50 & 0.75 & 1.25 & 5 & 1.25 & 50 & 1.75 & 70 \\
\hline 7 & 129 & 0.50 & 0.50 & 1.50 & 1 & 1.50 & 1 & 1.75 & 33 \\
\hline 8 & 173 & 0.50 & 0.50 & 1.50 & 1 & 1.50 & 1 & 1.75 & 10 \\
\hline 9 & 204 & 0.50 & 0.75 & 1.75 & 25 & 2.00 & 5 & 2.00 & 100 \\
\hline
\end{tabular}




\subsubsection{Axial Load}

For H sections, axial load has a detrimental effect on both lateral load and lateral displacement capacities. Even though, deterioration at the abutment-pile connection of piles with different axial loads was not significantly different, the pile with higher axial load could not maintain lateral load and failed earlier than the pile with a lower axial load. For example, the HP8x36 bending about its weak axis subjected to an axial stress

of $9 \mathrm{ksi}$ failed in the $80^{\text {th }}$ cycle of the $3.0 \mathrm{in}$. displacement range, while it failed in the $66^{\text {th }}$ cycle of the $2.5 \mathrm{in}$. displacement range when it was subjected to an axial load of $18 \mathrm{ksi}$.

For CFT sections, axial load has only a minor effect on both the lateral load and lateral displacement capacities. However, as the axial load increases, the lateral displacement ductility decreased from approximately 3.5 to 3.0 .

\subsubsection{Pile Orientation}

For H sections, as indicated in Figure 6.60, the abutment-pile connection of the HP8x36 bending about its strong axis deteriorated much more than that of the pile bending about its $45^{\circ}$ and weak axes. The weak axis provided higher lateral displacement capacity and ductility than for the $45^{\circ}$ and strong axes.

\subsubsection{Pile Stiffness}

According to INDOT Memorandum \#233, an H section with a depth of 14 in. is recommended for integral abutment bridges, for example, HP14x117, HP14x102, HP14x89, and HP14x73. Furthermore, according to INDOT Memorandum \#243, a CFT section with an outer diameter of 14 in. and a wall thickness of $0.203,0.250$, and 0.312 in. is recommended. Table 6.16 provides steel area, moment of inertia about the weak axis of the $\mathrm{H}$ piles and moment of inertia of steel transformed section for the CFT piles along with axial load capacity calculated based on the axial stress of 9 ksi distributed on steel area. One can note that the transformed section of the CFT piles is based on the compressive strength of concrete of 4,000 psi and the yield strength of steel of $35 \mathrm{ksi}$. HP14x117 and CFT14x0.250 are used to compare the effect of pile stiffness. It appears 
that for approximately the same moment of inertia, the $\mathrm{H}$ pile allows approximately three times higher axial load capacity than the CFT pile. In other words, for the same equivalent cross sectional area, $\mathrm{H}$ piles provide lower bending stiffness than CFT piles.

Table 6.16: H Piles vs. CFT Piles

\begin{tabular}{|c|c|c|c|}
\hline Section & $\begin{array}{c}\text { A } \\
\text { (in. }^{2} \text { ) }\end{array}$ & $\begin{array}{c}\mathbf{I}_{\mathbf{y}} \\
\text { (in. }^{4} \text { ) }\end{array}$ & $\begin{array}{c}\text { P } \\
\text { (kips) }\end{array}$ \\
\hline HP14x117 & 34.4 & 443 & 310 \\
\hline HP14x102 & 30.0 & 380 & 270 \\
\hline HP14x89 & 26.1 & 326 & 235 \\
\hline HP14x73 & 21.4 & 261 & 193 \\
\hline CFT14x0.312 & 13.4 & 510 & 121 \\
\hline CFT14x0.250 & 10.8 & 458 & 97 \\
\hline CFT14x0.203 & 8.8 & 418 & 79 \\
\hline
\end{tabular}

\subsubsection{Abutment-Pile Connection}

As the pile size or stiffness of the pile increased, the deterioration at the abutmentpile connection also increased. According to INDOT Memorandum \#233 and \#243, an H section with a depth of 14 in. and a CFT section with an outer diameter of 14 in. are recommended for integral abutment bridges. These two sections are larger than the largest $\mathrm{H}$ and CFT sections that were tested. Based on the results of Specimens 6 (HP12x53) and 9 (CFT10.75x0.250), however, the abutment-pile connections were cracked at the time that the piles started yielding and deteriorated significantly by the end of the test.

\subsubsection{Bridge Length}

Since the pile length used in the experimental study represents the typical distance from the abutment-pile connection to the inflection point, the abutment movement of the bridge is approximately twice the lateral displacement that occurred in the test. For example, the HP12x53 pile model for the I65 over SR25 bridges has the inflection point depth located at a depth of $5.6 \mathrm{ft}$ below ground level (Figure 6.61). The lateral 
displacement at the inflection point is 0.32 in., which is approximately half of the tip displacement of $0.55 \mathrm{in}$. The total bridge movement that can be accommodated is approximately four times the lateral displacement measured during testing. For instance, if the lateral displacement capacity measured during testing is 0.5 in., the abutment movement that can be accommodated is 1.0 in., with an overall bridge movement of $2.0 \mathrm{in.}$

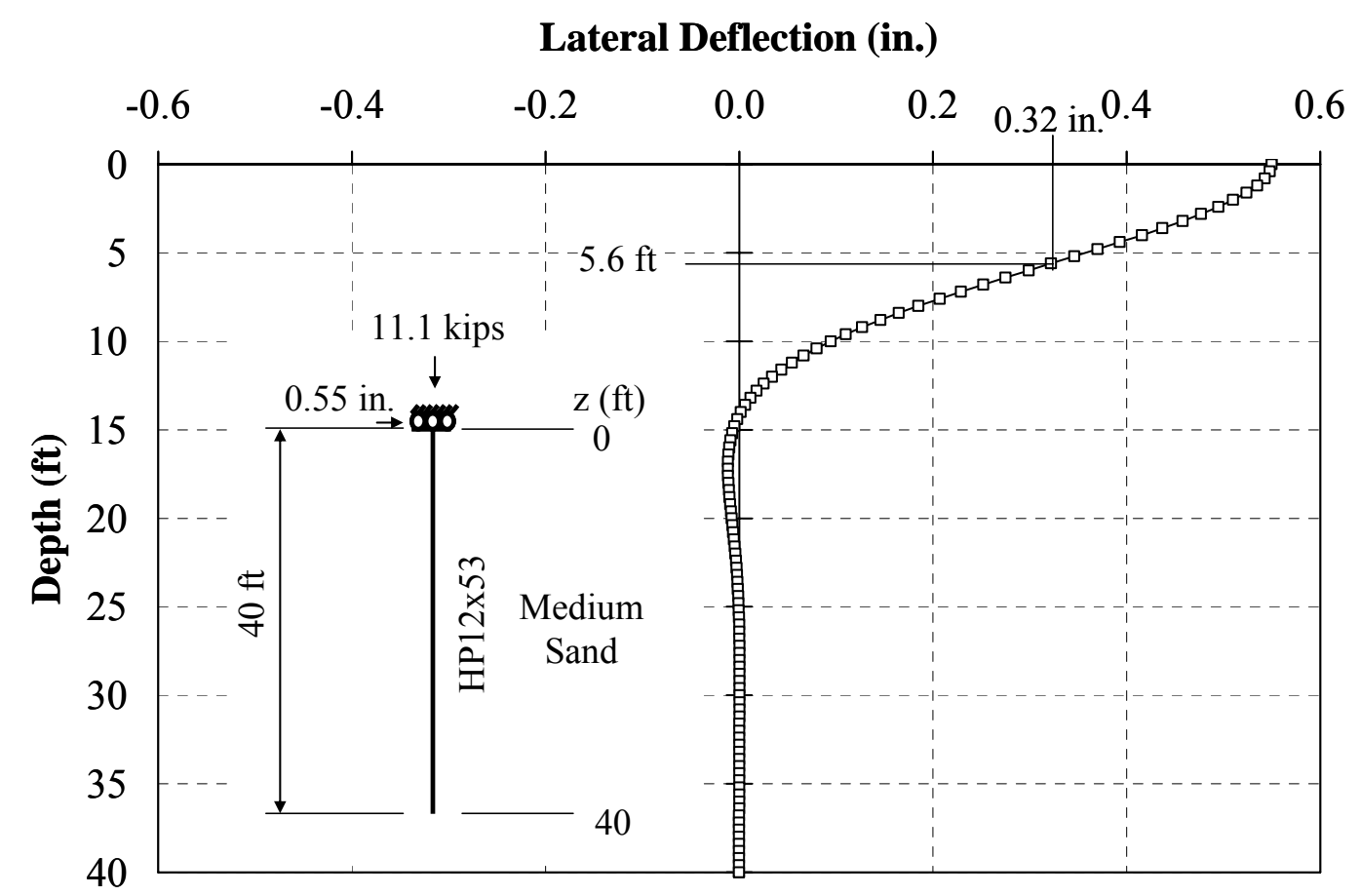

Figure 6.61: Inflection Point Depth of the HP12x53 on I65 over SR25

In general, piles except HP8x36 bending about its strong axis (Specimen 2) and CFT10 (Specimen 9) yielded without cracking at the abutment-pile connection at the 0.5 in. displacement range. Typically, piles experienced yielding on all flanges or both the top and bottom shell in the displacement range between 0.5 in. and 0.75 in. Beyond this displacement until $1.0 \mathrm{in}$., even though the piles yielded, the axial load and lateral load were maintained for fifty cycles which is equivalent to approximately 50 years. After the 1.0 in. displacement range, local buckling occurred, steel cracks started to initiate, and the lateral load capacity began to decrease. This indicates that piles should be limited to a displacement range of approximately $1.0 \mathrm{in}$. which allows pile yielding but prevents local 
buckling. This movement allows for a total end bent movement in each direction of 2.0 in. Considering a temperature change, $\Delta \mathrm{T}$, equal to $100^{\circ} \mathrm{F}$ and the coefficient of thermal expansion of steel, $\alpha$, equal to $6.5 \times 10^{-6} /{ }^{\circ} \mathrm{F}$, an overall bridge length of $500 \mathrm{ft}$ can be provided without buckling of the pile.

\subsection{Recommendations}

Based on the experimental results, the following recommendations are made:

1. H sections are recommended due to relatively higher displacement capacity and ductility. In addition, $\mathrm{H}$ piles can provide equivalent axial load capacity, but decreased bending stiffness causing lower stress at the abutment-pile connection. Therefore, the abutment-pile connection of $\mathrm{H}$ sections can deteriorate less than that of CFT sections.

2. To maximize lateral displacement and minimize deterioration at the abutment-pile connection, piles should be oriented for weak axis bending. This orientation minimizes stresses at the abutment-pile connection.

3. Axial load should be limited to $9 \mathrm{ksi}$ for $\mathrm{H}$ piles and $0.25 \mathrm{f}_{\mathrm{y}} \mathrm{A}_{\mathrm{s}}+0.4 \mathrm{f}_{\mathrm{c}}^{\prime} \mathrm{A}_{\mathrm{c}}$ for CFT piles.

4. Based on the observed deterioration of the connection, confinement reinforcement and/or deeper embedment length should be provided to control cracks and prevent or reduce deterioration at the abutment-pile connection. While additional research is needed to quantify the optimum amounts and lengths, any amounts provided would enhance the behavior of the connection.

5. The end abutment can be designed considering abutment movement up to $1.0 \mathrm{in}$. with no other treatment than embedment into the concrete. Displacement up to this range for the piles tested did not result in local pile buckling. Therefore, the maximum overall bridge length can easily be extended to $500 \mathrm{ft}$. 


\section{CHAPTER 7: ANALYTICAL INVESTIGATION}

\subsection{Introduction}

In calculating the load-deflection relationship, the development of momentcurvature diagrams for sections subjected to simultaneous flexure and axial compressive load is essential. A strain compatibility/equilibrium model was developed to calculate the moment-curvature relationship of both steel $\mathrm{H}$ piles and concrete-filled steel tube (CFT) piles. The curvature is integrated over the length of the pile to obtain the loaddeflection relationship. In this chapter, the steel and concrete models used to calculate the moment-curvature relationship and load-deflection relationship are presented. The results from the analysis are also discussed. The analytical results are compared to the experimental results and extended to evaluate typical piles used in integral abutment practice. Recommendations are provided based on this analysis for the maximum length of integral abutment bridges utilizing this foundation and correction system.

\subsection{Material Modeling of Steel Strength and Failure Criteria}

In this research, tri-linear models were employed for steel $\mathrm{H}$ piles while bilinear models were utilized for the steel shell of the CFT piles. These two steel models take into account strain hardening. The steel behaves elastically below the yield strain, $\varepsilon_{\mathrm{y}}$. The modulus of elasticity, or Young's modulus, $\mathrm{E}_{\mathrm{s}}$, is taken as 29,000 ksi. For steels exhibiting a yield point such as for $\mathrm{H}$ piles, steel in the plastic range deforms at a constant stress of $\mathrm{f}_{\mathrm{y}}$ up to the certain strain, denoted as the strain at the onset of strain hardening, $\varepsilon_{\text {st }}$. Salmon and Johnson (1996) state that $\varepsilon_{\text {st }}$ typically ranges from 15 to 20 times the yield strain, $\varepsilon_{\mathrm{y}}$. For strains greater than $\varepsilon_{\mathrm{st}}$, the stress increases but with a much flatter 
slope than the original elastic slope, $\mathrm{E}_{\mathrm{s}}$. The slope of the stress-strain curve beyond the plastic range is known as the strain-hardening modulus, $\mathrm{E}_{\mathrm{st}}$. The steel stress increases to the ultimate strength, $\mathrm{f}_{\mathrm{u}}$. This stress-strain curve is adopted for both compression and tension. The yield strain of steel can be calculated using Equation 7-1. The ultimate strain is limited to 0.05 .

$$
\varepsilon_{y}=\frac{f_{y}}{E_{s}}
$$

where:

$$
\begin{array}{ll}
\mathrm{E}_{\mathrm{s}} & =\text { Young's modulus of steel section, ksi. } \\
\varepsilon_{\mathrm{y}} & =\text { strain of steel section at yield, in./in. } \\
\mathrm{f}_{\mathrm{y}} & =\text { yield stress of steel section, ksi. }
\end{array}
$$

\subsubsection{Steel Model for $\mathbf{H}$ Piles}

For all A36 steel $\mathrm{H}$ piles, the average value of the strain at the onset of the strain hardening, $\varepsilon_{\mathrm{st}}$, is taken as $0.014 \mathrm{in./in.} \mathrm{(Salmon} \mathrm{and} \mathrm{Johnson,} \mathrm{1996)} \mathrm{and} \mathrm{the} \mathrm{strain}$ hardening modulus of steel, $\mathrm{E}_{\mathrm{st}}$, is assumed to be $300 \mathrm{ksi}$ to correspond with the coupon test results. A typical stress-strain curve for the $\mathrm{H}$ pile models is presented in Figure 7.1.

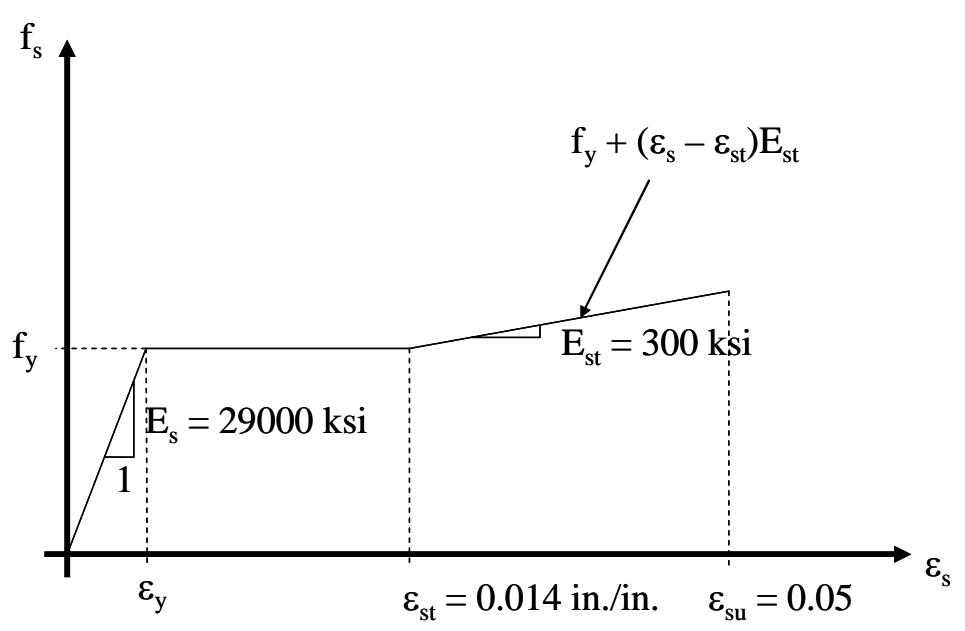

Figure 7.1: Stress-Strain Curves of $\mathbf{H}$ Piles 
To provide perspective, the stress-strain curves obtained from the coupon tests of the HP10x42 section compared with the analytical stress-strain curve are presented in Figure 7.2. The actual yield strain is equal to 0.00134 calculated from the average yield strength of 39 ksi divided by Young's modulus taken as 29,000 ksi. The strain at the onset of strain hardening was assumed to be 0.014 , and the strain hardening modulus was taken as $300 \mathrm{ksi}$ as described in Section 7.2. Figure 7.3 shows a complete stress-strain relationship compared to the proposed stress-strain relationship.

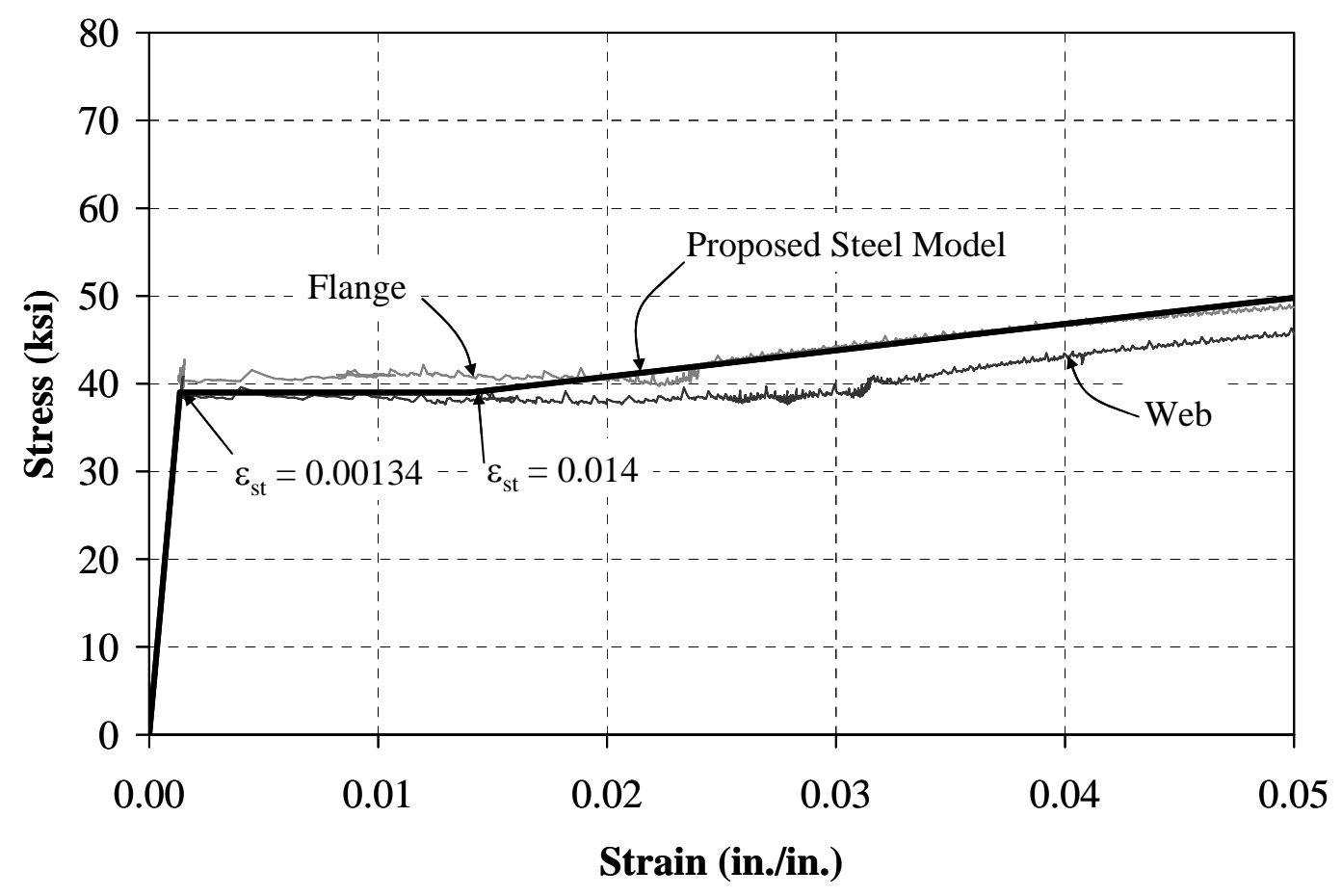

Figure 7.2: Specimen 5 - Stress-Strain Curve of Steel

\subsubsection{Steel Model for Steel Shell of CFT Piles}

Stress-strain curves for the steel shells of the CFT piles do not exhibit an obvious yield plateau; therefore, a bilinear stress-strain relationship was established. A steel shell is assumed to behave linear elastically with an initial modulus of 29,000 ksi up to yield followed by a linear relationship with a strain hardening modulus of $300 \mathrm{ksi}$ as illustrated in Figure 7.4. The yield strength was calculated considering coupon results and based on the bilinear model. 


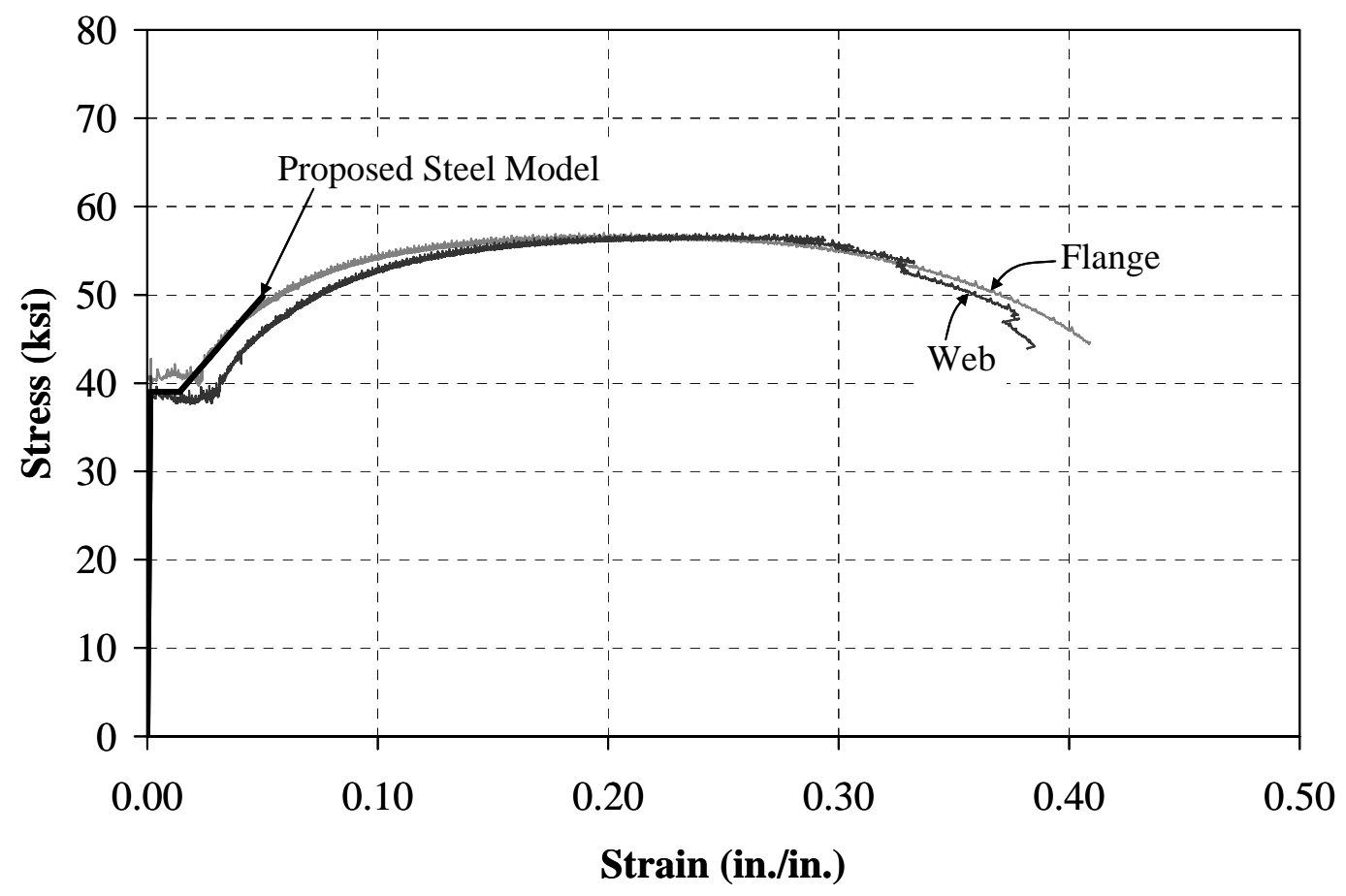

Figure 7.3: Specimen 5 - Complete Stress-Strain Curve

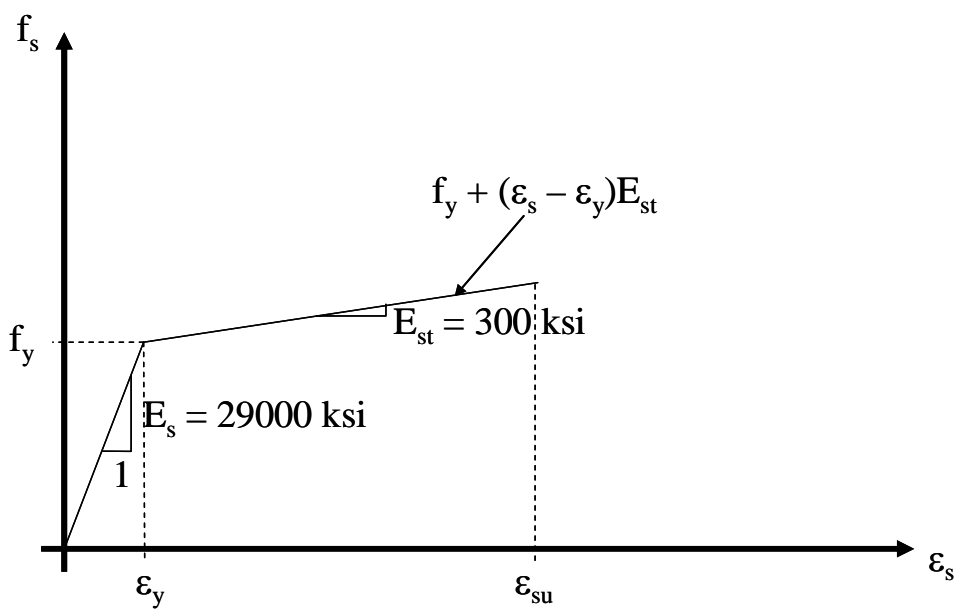

Figure 7.4: Stress-Strain Curve for Steel Shell of CFT Pile 
The proposed stress-strain curves for a steel shell of the CFT piles are slightly different from those of the $\mathrm{H}$ piles. The proposed stress-strain curve of Specimen 7, for example, is presented in Figure 7.5 . It can be noticed that the $0.2 \%$ offset yield strength was $42 \mathrm{ksi}$ but a yield strength of $46 \mathrm{ksi}$ was used in this model to fit the strain hardening portion of the curve. The yield strengths of Specimens 8 and 9 used in the models were approximately the same values as the yield strength obtained from the coupon test results based on the $0.2 \%$ offset and equal to 54 and 52 ksi, respectively. Figures 7.6 and 7.7 present the proposed stress-strain relationship for the steel shell of Specimens 8 and 9, respectively.

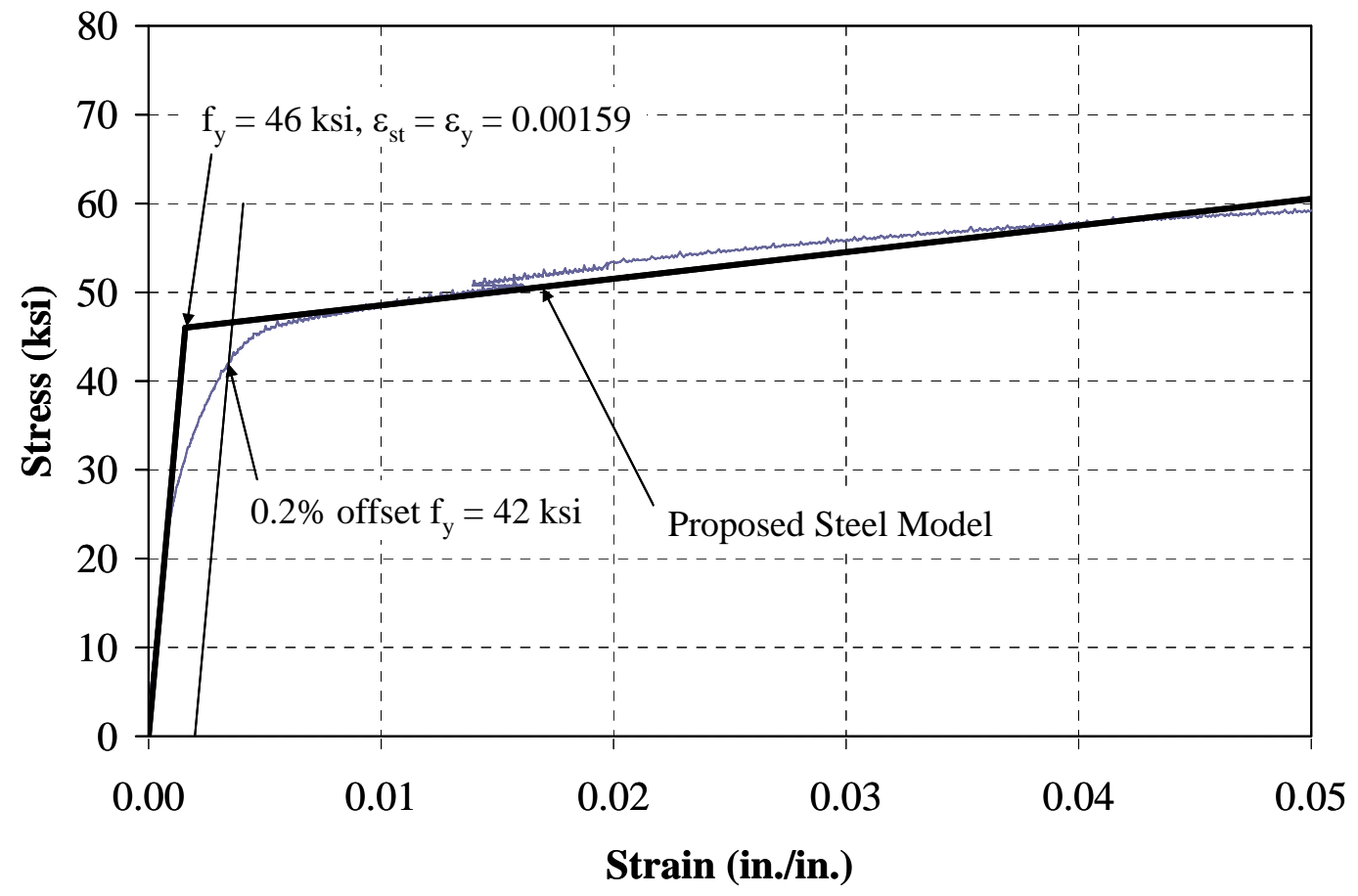

Figure 7.5: Specimen 7 - Stress-Strain Curve of Steel Shell 


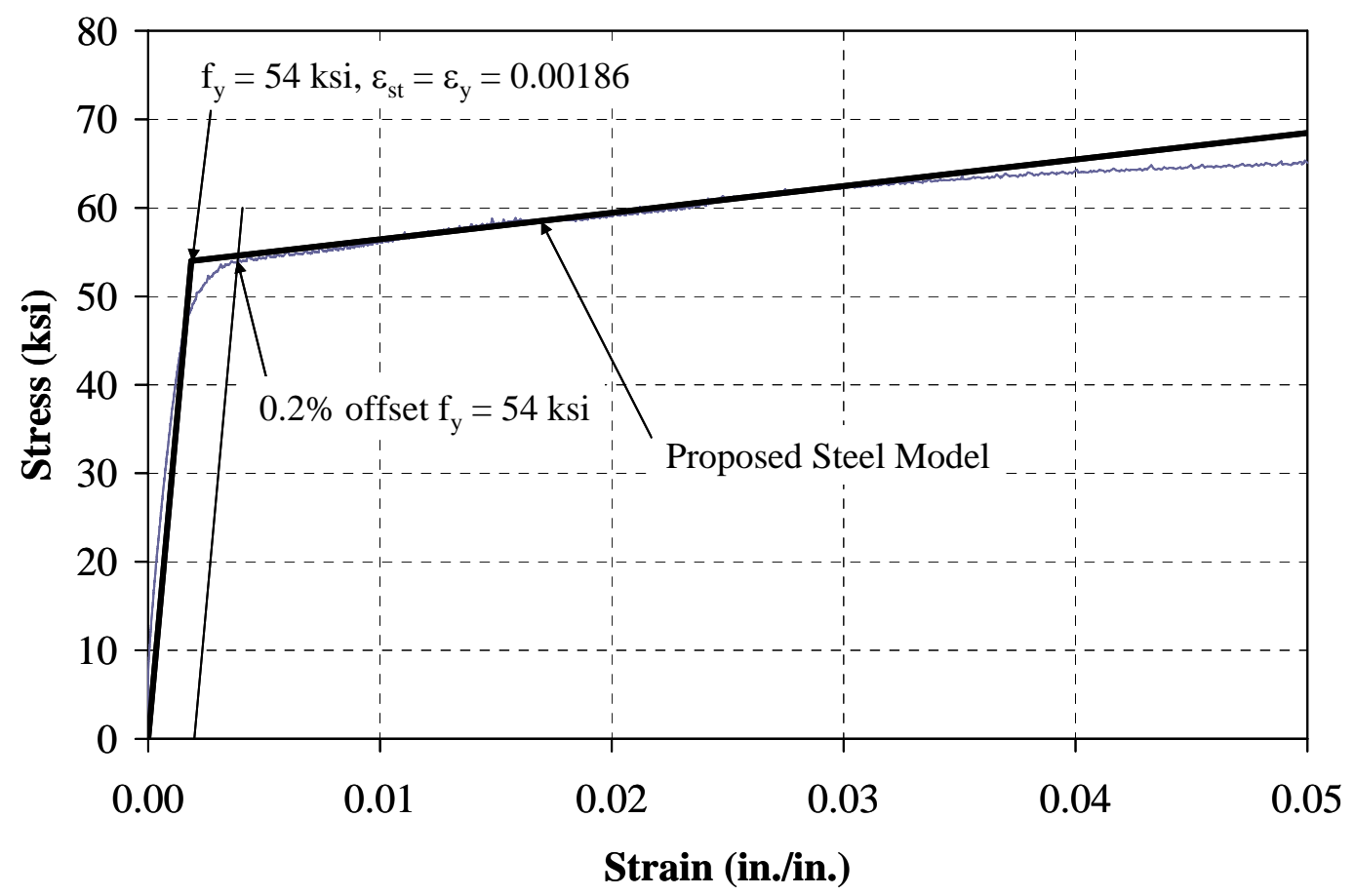

Figure 7.6: Specimen 8 - Stress-Strain Curve of Steel Shell

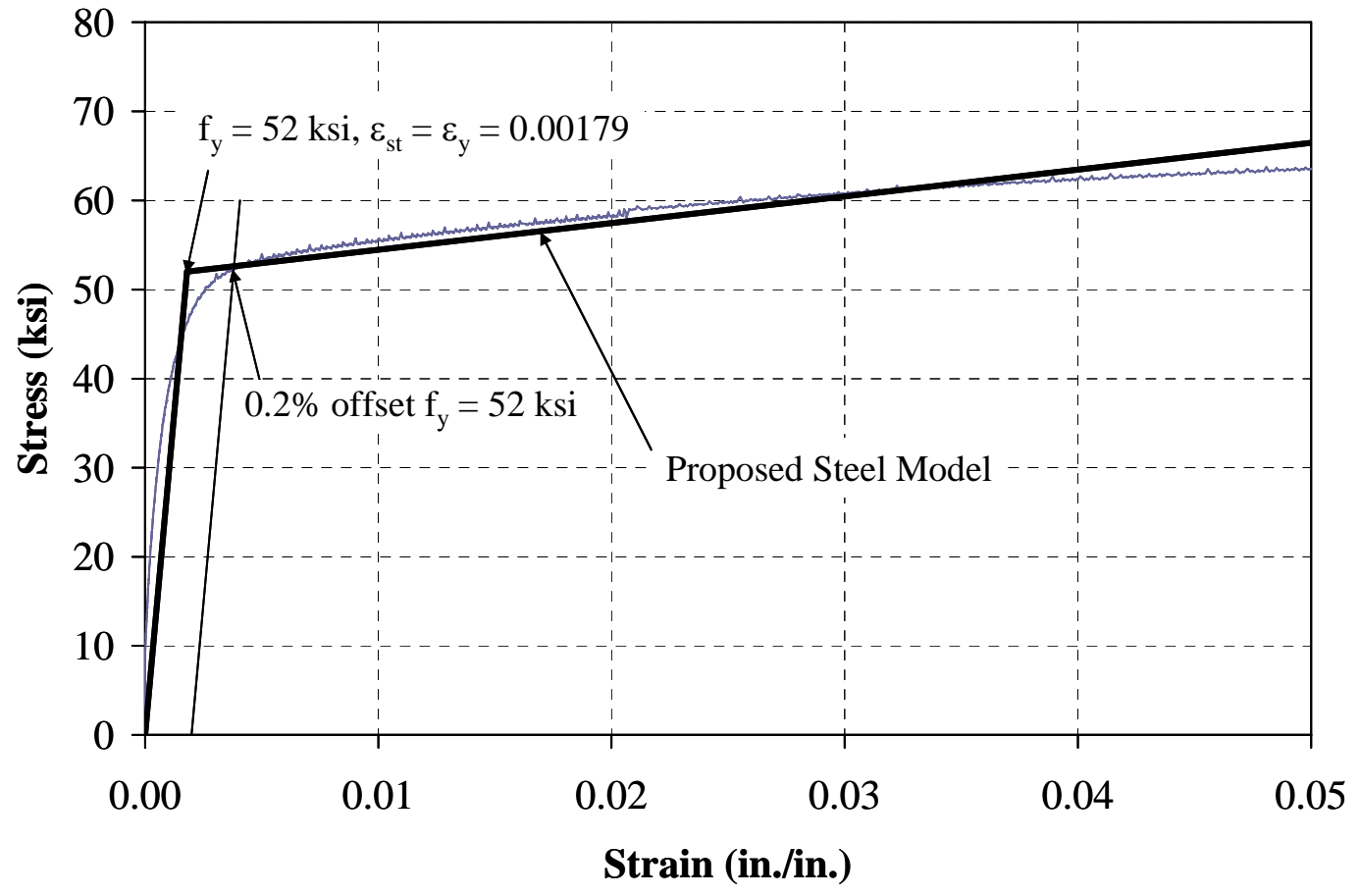

Figure 7.7: Specimen 9 - Stress-Strain Curve of Steel Shell 


\subsection{Material Modeling of Concrete Strength and Failure Criteria}

Because the concrete core was confined by a steel shell, a confined concrete stress-strain model should be considered. Several concrete models such as the Modified Hognestad model (1951), Kent and Park model (1971), and Modified Mander et al model (Elremaily and Azizinamini, 2002) are discussed.

\subsubsection{Modified Hognestad Model (Hognestad, 1951)}

The modified Hognestad stress-strain curve consists of a second-degree parabola followed by the linear line shown in Figure 7.8. The stress corresponding to any given strain is given by $\mathrm{f}_{\mathrm{c}}=\mathrm{f}_{\mathrm{c}}^{\prime \prime}\left[2 \frac{\varepsilon_{\mathrm{c}}}{\varepsilon_{0}}-\left(\frac{\varepsilon_{\mathrm{c}}}{\varepsilon_{0}}\right)^{2}\right]$. The strain at the maximum stress, $\mathrm{f}_{\mathrm{c}}^{\prime \prime}$, is assumed to be equal to $0.85 \mathrm{f}_{\mathrm{c}}^{\prime}$. The strain, $\varepsilon_{0}$, corresponding to the maximum stress is

given as $2 \frac{f_{c}^{\prime}}{E_{c}}$ where $E_{c}$ is the modulus of concrete, taken as $57,000 \sqrt{f_{c}^{\prime}}$. The ultimate concrete strain is limited to 0.003 for unconfined concrete. The ultimate concrete strain, $\varepsilon_{\mathrm{cu}}$, of 0.050 was assumed for confined concrete (Ashour et al, 2001). The stress corresponding with the ultimate strain is equal to $0.85 \mathrm{f}_{\mathrm{c}}^{\prime \prime}=0.72 \mathrm{f}_{\mathrm{c}}^{\prime}$. The equation of the line past ultimate can be calculated as $\mathrm{f}_{\mathrm{c}}=\mathrm{f}_{\mathrm{c}}^{\prime \prime}\left[1-0.15\left(\frac{\varepsilon_{\mathrm{c}}-\varepsilon_{0}}{\varepsilon_{\mathrm{cu}}-\varepsilon_{0}}\right)\right]$.

One of the objectives of this research is to develop a simplified model that can calculate the behavior of the pile. Therefore, this model is used to analyze the momentcurvature relationship due to its simplicity with the obvious goal of providing good correlation with the experiment results. 


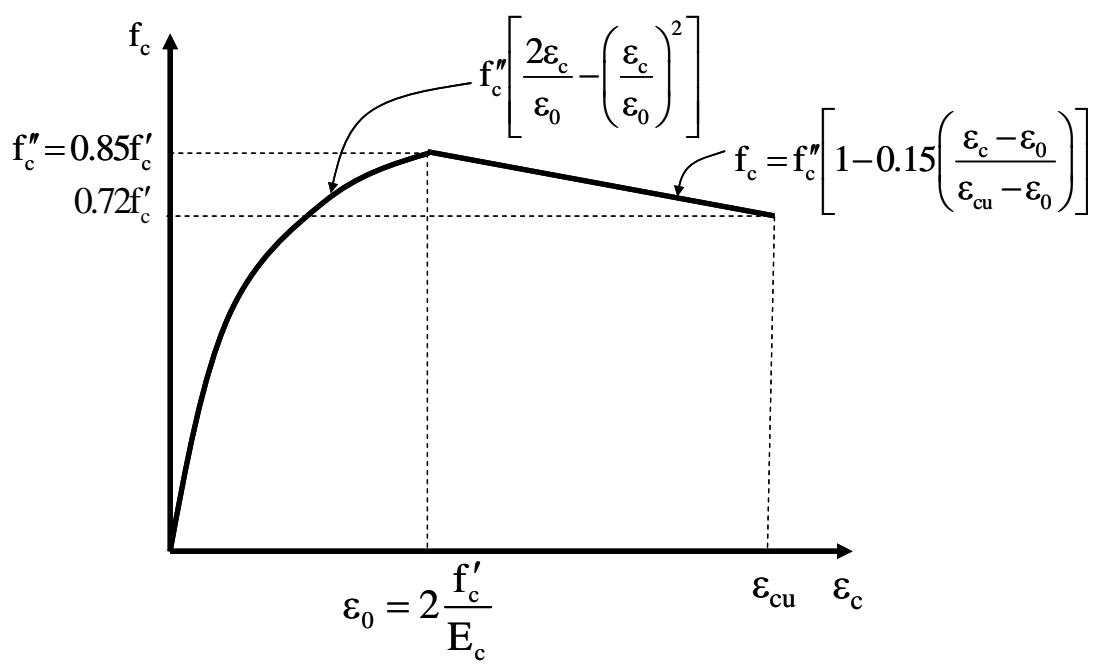

Figure 7.8: Modified Hognestad Model 


\subsubsection{Kent and Park Model (Kent and Park, 1971)}

This concrete model is widely used for concrete confined with spirals. The model assumes that the confined steel has no effect on the second-degree parabola curve until a concrete strain, $\varepsilon_{\mathrm{co}}$, of 0.002 . Following this strain, the concrete stress decreases linearly to 20 percent of $\mathrm{f}_{\mathrm{c}}^{\prime}$ at a strain of $\varepsilon_{20 \mathrm{c}}$ upon which it becomes constant. The Kent and Park stress-strain curve is presented in Figure 7.9. The equation of the line, $\mathrm{f}_{\mathrm{c}}=\mathrm{f}_{\mathrm{c}}^{\prime}\left[1-\mathrm{Z}_{\mathrm{c}}\left(\varepsilon_{\mathrm{c}}-\varepsilon_{0}\right)\right]$, is a function of the spacing of spirals. Because this model was developed for concrete confined with spirals, this model is not readily applicable to the CFT piles, and was not used in this research.

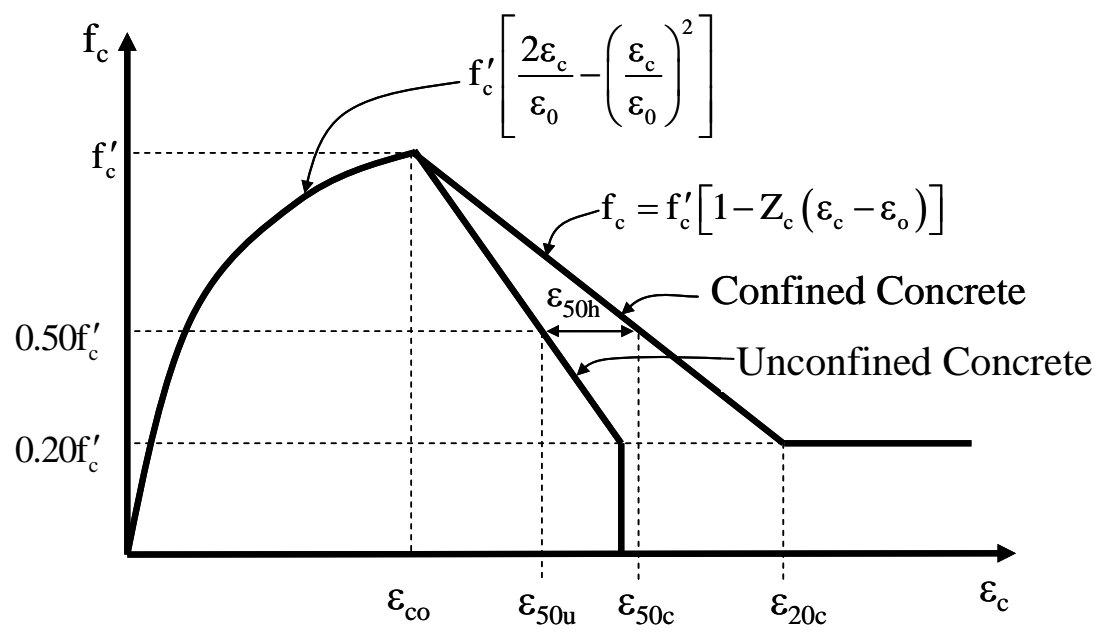

Figure 7.9: Kent and Park Model (Kent and Park, 1971) 


\subsubsection{Modified Mander et al. Model (Elremaily and Azizinamini, 2002)}

Mander et al. (1988) adopted a confined concrete model for both circular and rectangular concrete sections as shown in Figure 7.10. Elremaily and Azizinamini (2002) modified the Mander et al. model to apply to the CFT sections by considering the effective lateral confining stress provided to the concrete by the steel tube. The stressstrain relationship of the steel tube is represented by an elastic-perfectly plastic relationship with different yield stresses in the tension and compression regions. Strain hardening of the steel is ignored in the computation of the hoop stress using Von Mises' yield criterion. The Modified Mander et al. (1988) model is relatively more complex than the concrete models previously described. As previously noted, one of the objectives of this research is to develop a simplified model that can evaluate realistically the pile behavior. Therefore, due to its complexity, the Modified Mander et al. model is not practical for this application.

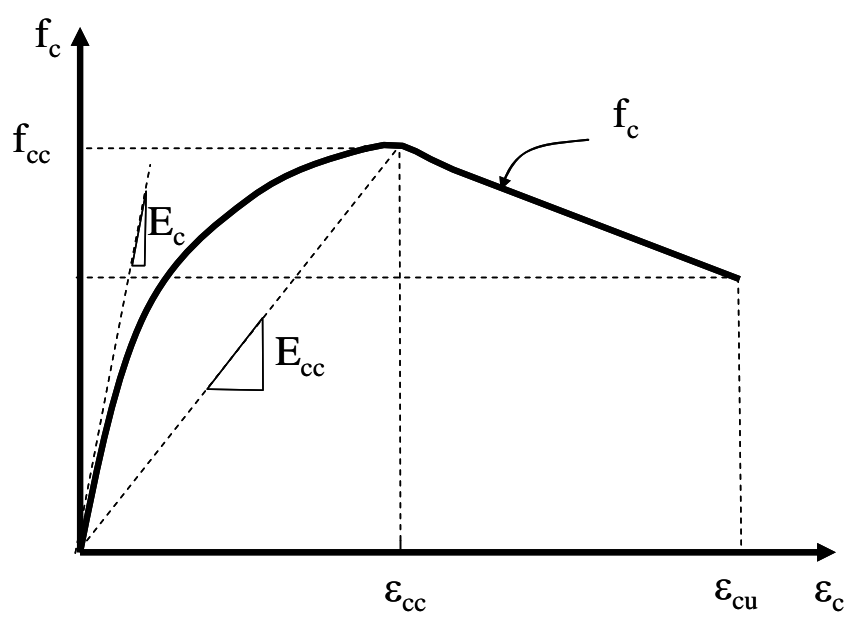

Figure 7.10: Modified Mander et al. Model (Elremaily and Azizinamini, 2002) 


\subsection{Analysis}

\subsubsection{Moment-Curvature Analysis}

The moment-curvature relationships of steel $\mathrm{H}$ piles subjected to different levels of axial load were obtained. The moment-curvature relationships are used to estimate the displacement capacity of $\mathrm{H}$ and CFT piles under cyclic lateral loading. These relationships of both the steel and composite sections under combined axial load, P, and bending moment, $\mathrm{M}$, are analyzed using a fiber-based method. The cross section is divided into a number of slices as shown in Figure 7.11. The steel tube is discretized into steel fibers and the concrete infill is discretized into concrete fibers. Each fiber has an associated area, distance from the centroid of the section, and a uniaxial stress-strain $(\sigma-\varepsilon)$ curve.

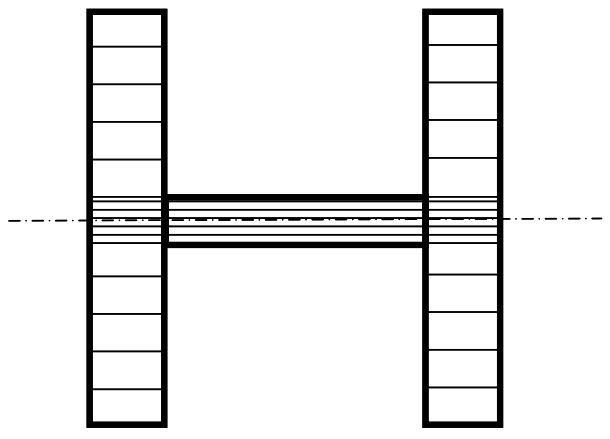

(a) H Pile, Weak Axis Bending

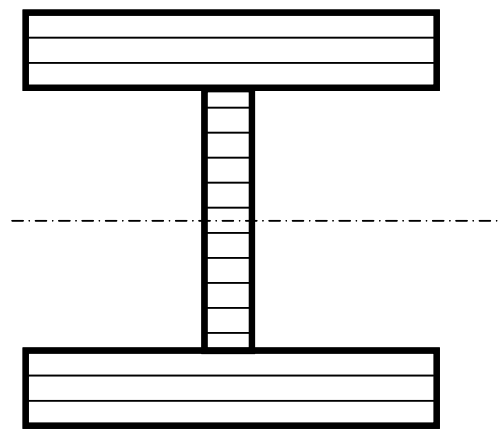

(c) H Pile, Strong Axis Bending

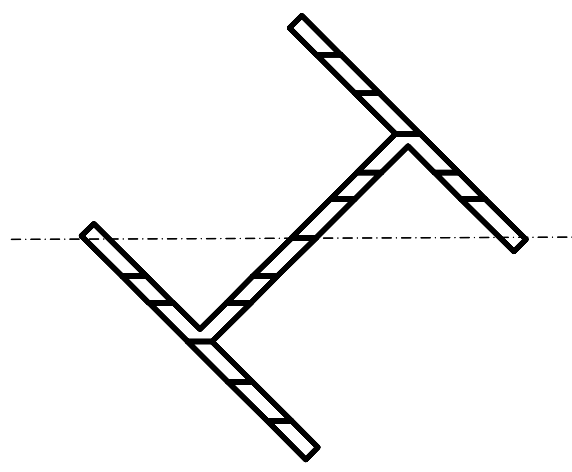

(b) H Pile, $45^{\circ}$ Axis Bending

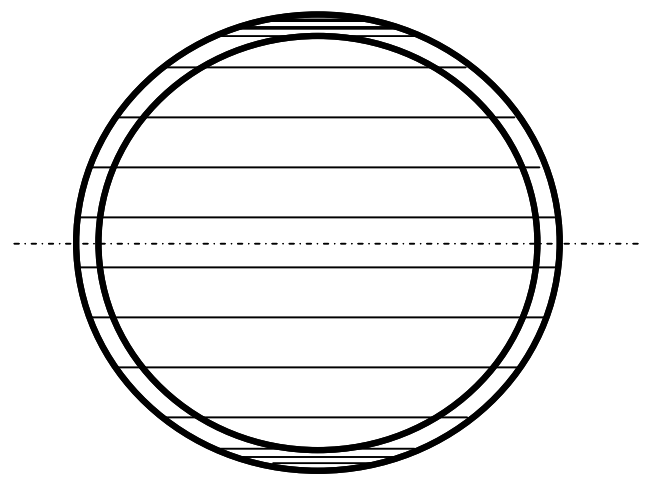

(d) CFT Pile

Figure 7.11: Fiber Discretization 
For the CFT models, the modified Hognestad stress-strain relationship for concrete given in Figure 7.8 was used. The following assumptions were made.

1. The contribution of concrete in tension is neglected.

2. No slip occurs between the steel tube and the concrete core (perfectly composite).

3. Plane sections perpendicular to the axis of bending before bending remain plane after bending.

4. Concrete creep and shrinkage are ignored. As stated by Hajjar and Gourley (1996), concrete-filled steel tubes rarely exhibit flexural-torsional or lateraltorsional buckling, these failure modes are thus not considered.

For a given strain profile, the stresses of each slice can be determined using the steel and concrete models described in Sections 7.2 and 7.3. The given axial load, P, and the corresponding bending moment, $\mathrm{M}$, on the section can be calculated by Equations 7-1 and 7-2.

$$
\begin{gathered}
P=\sum_{i=1}^{n} f_{s i} \cdot A_{s i}+\sum_{i=1}^{n} f_{c i} \cdot A_{c i} \\
M=\sum_{i=1}^{n} f_{s i} \cdot A_{s i} \cdot y_{i}+\sum_{i=1}^{n} f_{c i} \cdot A_{c i} \cdot y_{i}
\end{gathered}
$$

where:

$$
\begin{aligned}
& \mathrm{n} \quad=\text { number of slices. } \\
& \mathrm{y}_{\mathrm{i}} \quad \text { distance measured from the centroidal axis of the section to the } \\
& \quad \text { centroid of } \mathrm{i}^{\text {th }} \text { slice, in. } \\
& \mathrm{f}_{\mathrm{Si}}, \quad=\text { stress of steel in } \mathrm{i}^{\text {th }} \text { slice, } \mathrm{ksi} . \\
& \mathrm{f}_{\mathrm{Ci}} \quad=\text { compressive stress of concrete in } \mathrm{i}^{\text {th }} \text { slice, } \mathrm{ksi} . \\
& \mathrm{A}_{\mathrm{Si}}, \quad=\text { area of steel in } \mathrm{i}^{\text {th }} \text { slice, in. }{ }^{2} \\
& \mathrm{~A}_{\mathrm{Ci}} \quad=\text { area of concrete in } \mathrm{i}^{\text {th }} \text { slice, in. }{ }^{2} \\
& \mathrm{P} \quad=\text { axial load corresponding to the axial stress level of } 0.25 \mathrm{f}_{\mathrm{y}} \mathrm{A}_{\mathrm{s}}+ \\
& \quad \quad 0.4 \mathrm{f}_{\mathrm{c}}^{\prime} \mathrm{A}_{\mathrm{c}} \text {, and } 0.50 \mathrm{f}_{\mathrm{y}} \mathrm{A}_{\mathrm{s}}+0.4 \mathrm{f}_{\mathrm{c}}^{\prime} \mathrm{A}_{\mathrm{c}}, \text { kips. } \\
& \mathrm{M} \quad=\text { bending moment corresponding to the fixed end moment. }
\end{aligned}
$$




$$
\begin{array}{ll}
\mathrm{A}_{\mathrm{s}} & =\text { area of steel }=\sum_{\mathrm{i}=1}^{\mathrm{n}} \mathrm{A}_{\mathrm{si}}, \mathrm{in}^{2} \\
\mathrm{~A}_{\mathrm{c}} & =\text { area of concrete }=\sum_{\mathrm{i}=1}^{\mathrm{n}} \mathrm{A}_{\mathrm{ci}}, \mathrm{in}^{2} \\
\mathrm{f}_{\mathrm{y}} & =\text { specified yield strength of steel, ksi. } \\
\mathrm{f}_{\mathrm{c}}^{\prime} & =\text { specified compressive strength of concrete, ksi. }
\end{array}
$$

For a given strain at the top fiber, $\varepsilon_{\mathrm{t}}$, the location of the neutral axis, c, measured from the extreme top fiber was determined using trial-and-error to satisfy Equation 7-1. The curvature for a given top fiber strain is calculated by $\phi=\frac{\varepsilon_{\mathrm{t}}}{\mathrm{C}}$, and the corresponding moment can be calculated by Equation 7-2. Using this method, the moment-curvature relationship can be developed as shown in Figure 7.12.

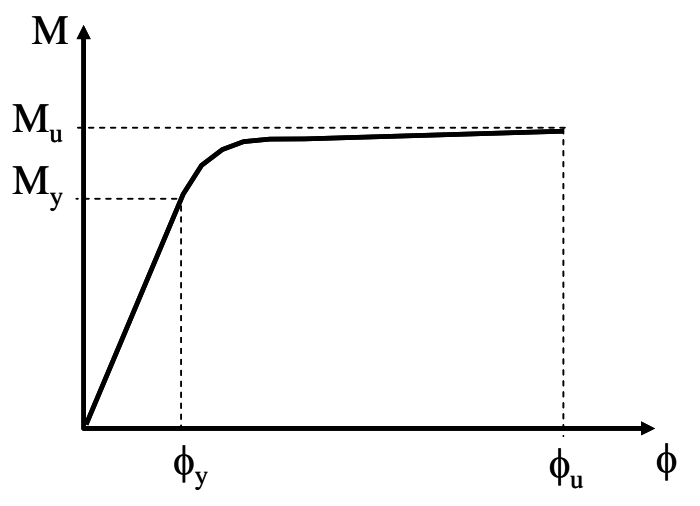

Figure 7.12: Moment-Curvature Relationship

\subsubsection{Load-Deflection Relationship}

The pile specimen was modeled as a cantilever beam subjected to an axial load, $\mathrm{P}$, and a lateral load, H, at the free end as illustrated in Figure 7.13. The load-deflection relationship of the pile was analyzed using the moment-curvature relationship as described in Section 7.4.1. 


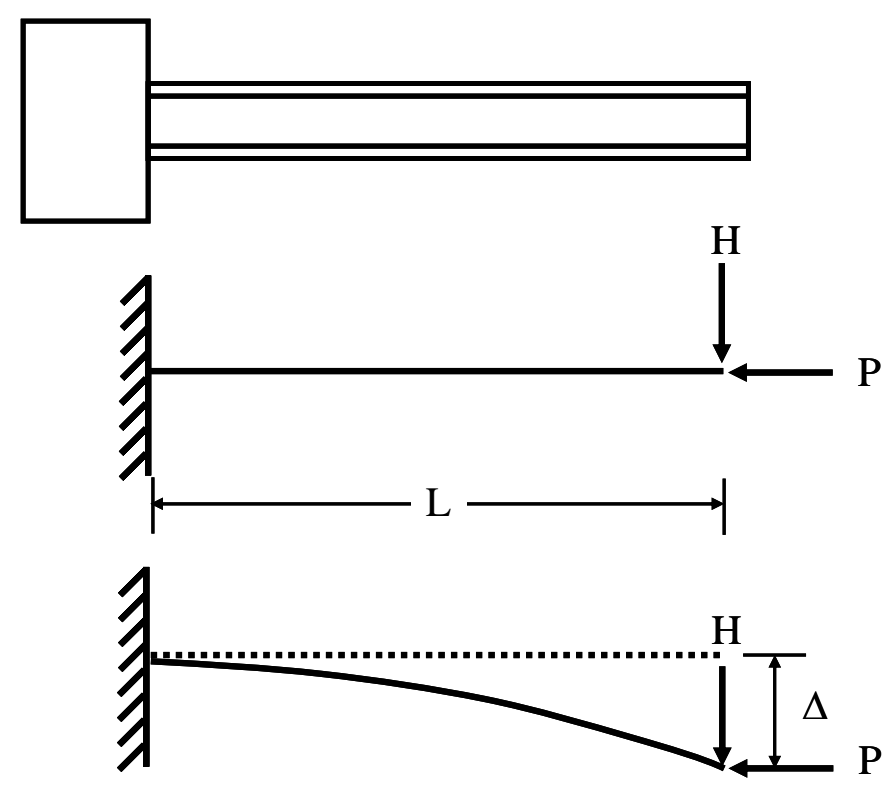

Figure 7.13: Cantilever Beam with Axial Load

For a given moment-curvature relationship, the displacement along the pile length can be calculated using following algorithm. Full details of the calculation of loaddeflection response are presented in Appendix J.

1. Determine the ultimate moment, $\mathrm{M}_{\mathrm{u}}$, from the given moment-curvature relationship.

2. Determine the corresponding lateral load, $H=M_{u} / L$.

3. Calculate the moment along the pile length.

4. Determine the corresponding curvature along the pile length from a given moment-curvature relationship.

5. Calculate the lateral displacement at the pile tip by integrating the moment of area under the curvature curve. The deflections, along the length of the cantilever pile can be calculated using the Moment-Area method.

6. Plot the first-order load-deflection curve. 


\section{$\underline{7.5 \quad \text { Analysis Results }}$}

The analytical load-deflection curves of all specimens were compared to the experimental load-deflection curves. The analytical displacements and strains were calculated at significant behavioral events, namely, yield, buckling, and failure.

The strain at first yield, $\varepsilon_{\text {yield, }}$ was determined based on the stress-strain relationship obtained from coupon tests. The displacement at first yield was determined by assuming the extreme compression fiber of the section yields. The corresponding displacement at first yield was calculated using the moment-curvature relationship up to

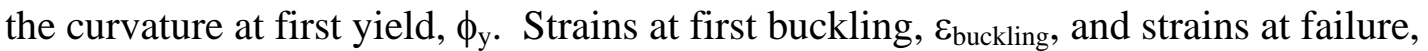
$\varepsilon_{\text {failure, }}$ were determined using the trial-and-error method. The strain at the extreme compression fiber was varied until the analytical lateral displacement was equal to the displacements at first buckling and at failure as observed from the experiments.

The models were calibrated based on the experimental results. In particular, the strains required to achieve local buckling and failure were calculated. Based on this calibration, the models were used to estimate the behavior of piles that were not tested, but are commonly used in integral bridge design. The models were used to estimate the load-deflection relationships of H piles with a depth of 14 in. and CFT piles with an outer diameter of 14 in. as recommended by INDOT Memorandums \#233 and \#243 (INDOT, 1992a and INDOT, 1992b), respectively.

\subsubsection{H Piles}

The analytical results of the load-deflection curves of Specimens 1 through 6 are presented in Figures 7.14 to 7.19. In general, the analytical results correlate well with the experimental results. The lateral load-deflection relationship of Specimen 1 was estimated fairly well. The analytical lateral load capacities of Specimens 2, 3, 4, and 6 are slightly overestimated because of the deterioration that occurred at the abutment-pile connection during testing. Since Specimens 5 and 6 are non-compact sections according to the AISC-LRFD specification (2001), these sections reach the yield stress in compression elements before local buckling occurs, but do not resist inelastic local buckling at the strain level required for a fully plastic stress distribution. This means that 
the cross-section can locally buckle prior to reaching the full plastic moment. One of the assumptions of the moment-curvature relationship is that the piles are compact. As a result, the lateral load capacity was slightly overestimated. It should also be noted that the analysis does not consider residual stresses. Therefore, for all sections, the yield transition is slightly more pronounced than the actual response. Finally, despite the deterioration of the abutment-pile connection of Specimen 5, the analytical loaddeflection curve provides a good correlation with the load-deflection curves obtained from test results up to the 1.50 in. displacement range. The calculated strains and curvatures along with the displacements at first buckling and failure of the $\mathrm{H}$ piles are summarized in Table 7.1.

Table 7.1: Strains at First Buckling and at Failure of the $H$ Specimens

\begin{tabular}{|c|c|c|c|c|c|c|c|c|}
\hline \multirow{3}{*}{ Specimen } & \multicolumn{4}{|c|}{ Buckling } & \multicolumn{4}{c|}{ Failure } \\
\cline { 2 - 9 } & $\begin{array}{c}\Delta_{\text {test }} \\
\text { (in.) }\end{array}$ & $\begin{array}{c}\boldsymbol{\varepsilon} \\
\text { (in./in.) }\end{array}$ & $\boldsymbol{\varepsilon} / \boldsymbol{\varepsilon}_{\mathbf{y}}$ & $\begin{array}{c}\boldsymbol{\phi} \\
\text { (rad/in.) }\end{array}$ & $\begin{array}{c}\Delta \\
\text { (in.) }\end{array}$ & $\begin{array}{c}\boldsymbol{\varepsilon} \\
\text { (in./in.) }\end{array}$ & $\boldsymbol{\varepsilon} / \boldsymbol{\varepsilon}_{\mathbf{y}}$ & $\begin{array}{c}\boldsymbol{\phi} \\
\text { (rad/in.) }\end{array}$ \\
\hline 1 & 2.00 & 0.031 & 19 & 0.0073 & 3.00 & 0.041 & 25 & 0.0096 \\
\hline 2 & 1.50 & 0.031 & 19 & 0.0052 & 1.75 & 0.034 & 21 & 0.0059 \\
\hline 3 & 1.50 & 0.036 & 22 & 0.0057 & 2.00 & 0.045 & 28 & 0.0073 \\
\hline 4 & 2.25 & 0.034 & 21 & 0.0075 & 2.50 & 0.037 & 23 & 0.0082 \\
\hline 5 & 1.25 & 0.026 & 20 & 0.0050 & 2.00 & 0.036 & 27 & 0.0070 \\
\hline 6 & 1.25 & 0.029 & 19 & 0.0048 & 1.75 & 0.037 & 24 & 0.0060 \\
\hline
\end{tabular}

In summary, the results of the analytical models correlate well with the loaddeflection curves of the piles that had little or no deterioration at the abutment-pile connection, but slightly overestimated the response if the abutment-pile connection was damaged. This overestimation is expected since deflection due to the softening of the connection was not included in the analysis procedure. 


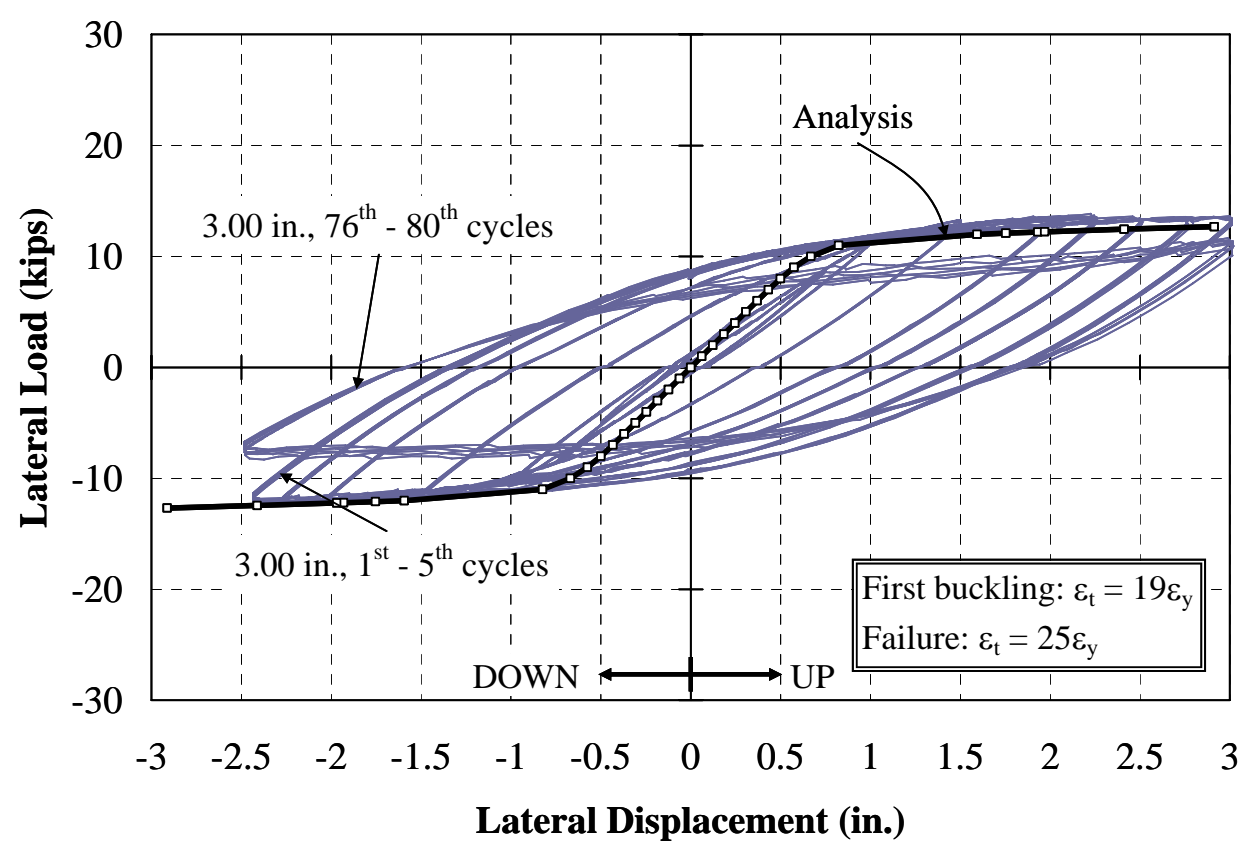

Figure 7.14: Specimen 1 - Load-Deflection Curve

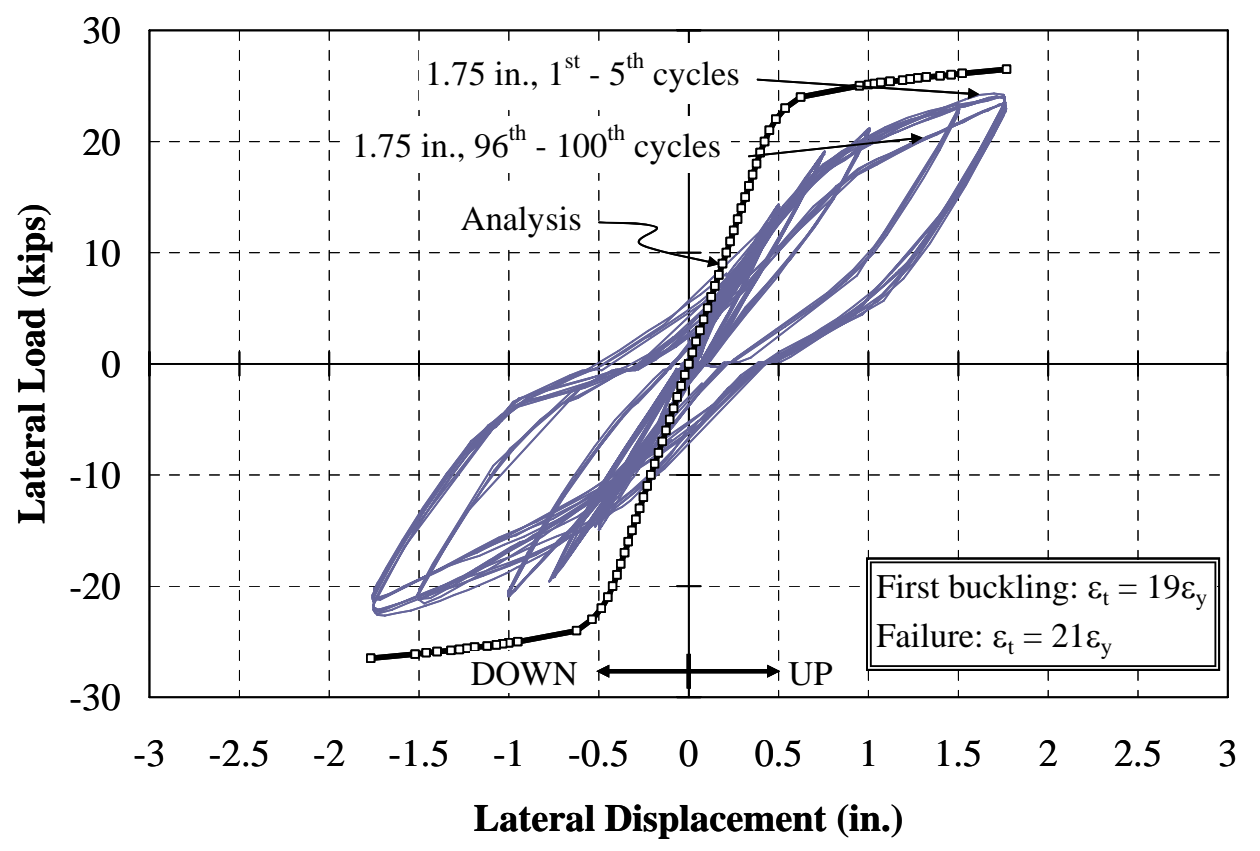

Figure 7.15: Specimen 2 - Load-Deflection Curve 


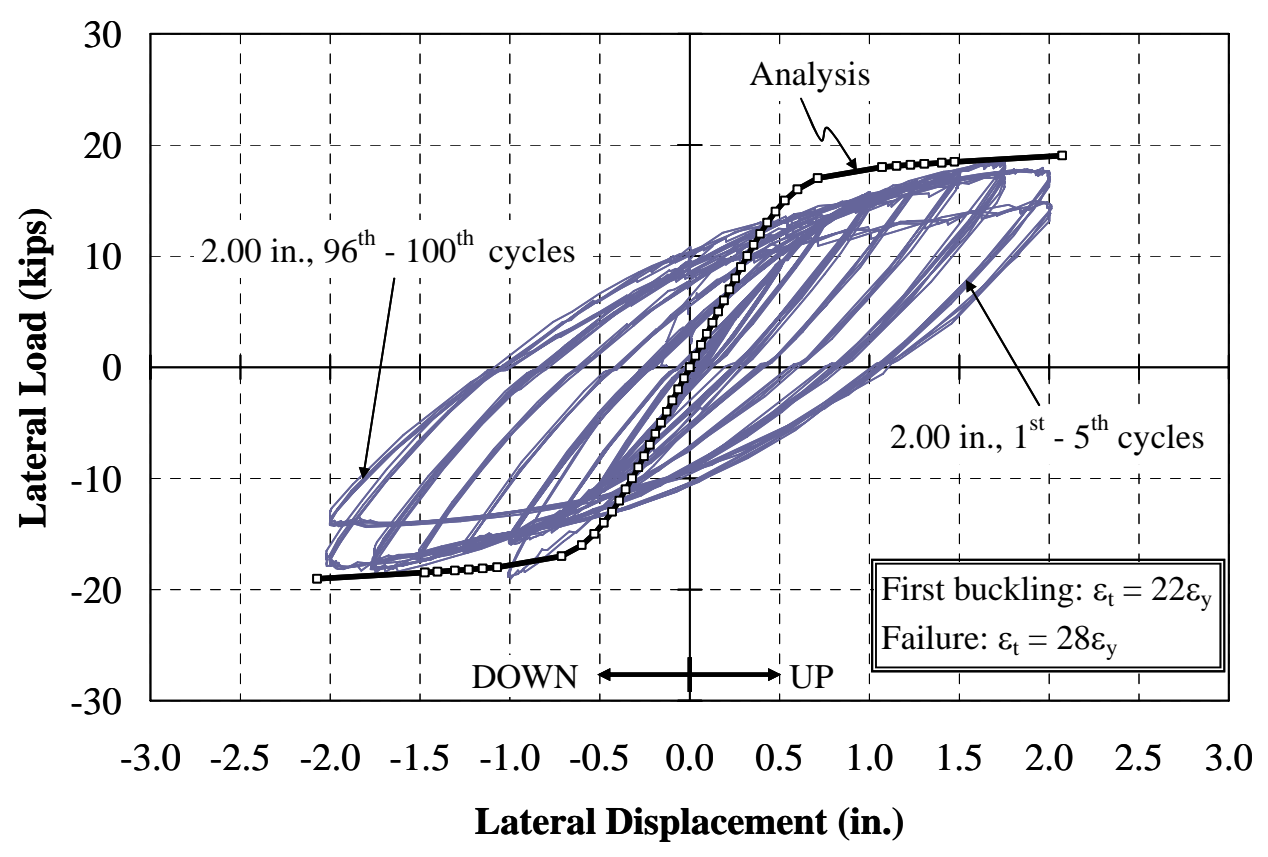

Figure 7.16: Specimen 3 - Load-Deflection Curve

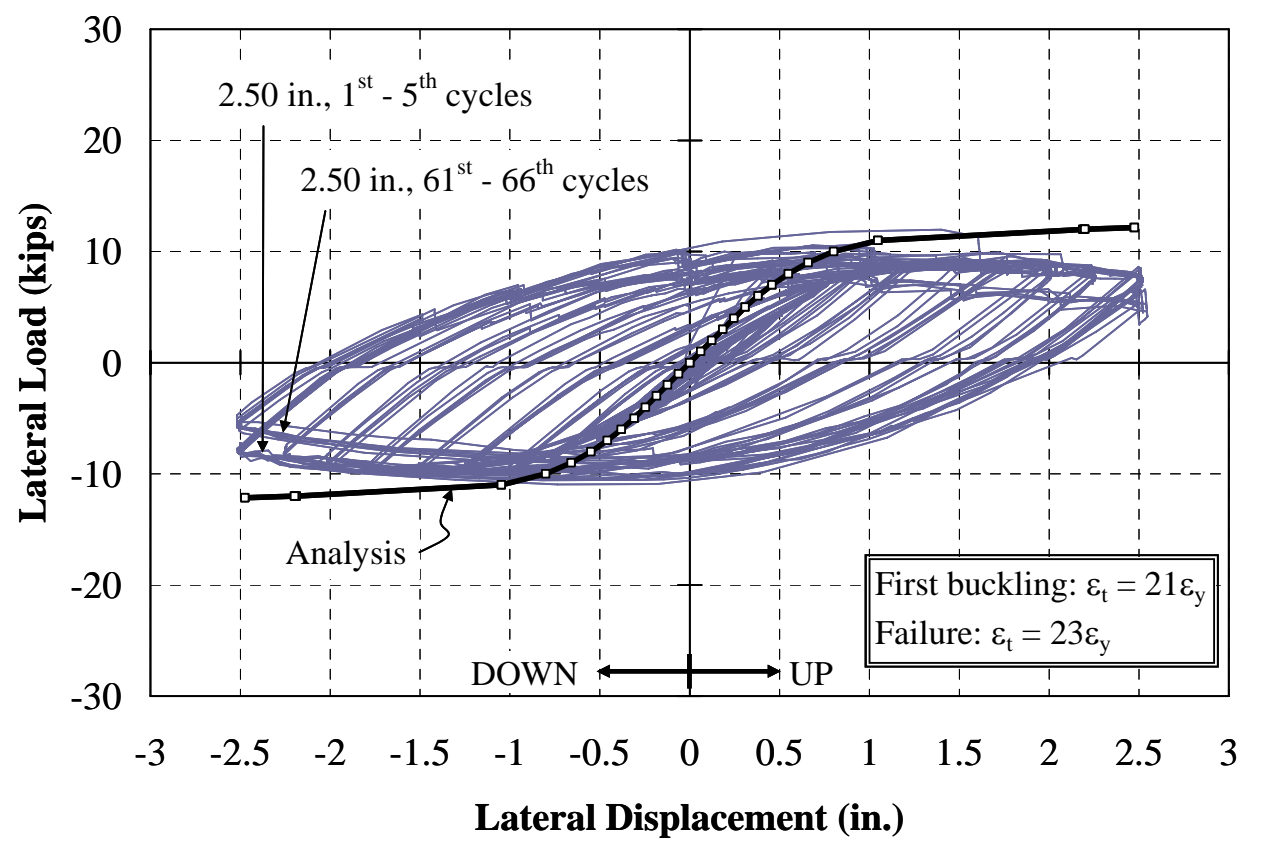

Figure 7.17: Specimen 4 - Load-Deflection Curve 


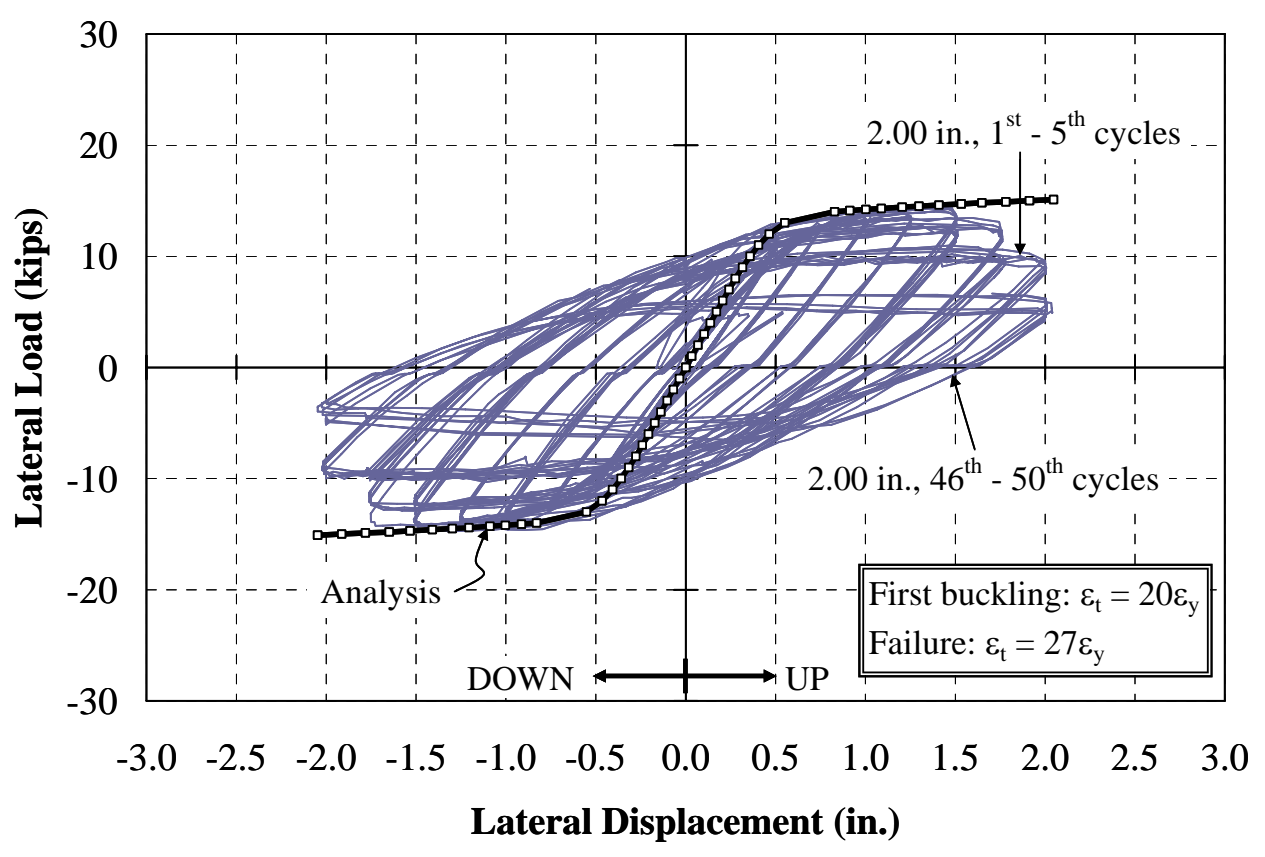

Figure 7.18: Specimen 5 - Load-Deflection Curve

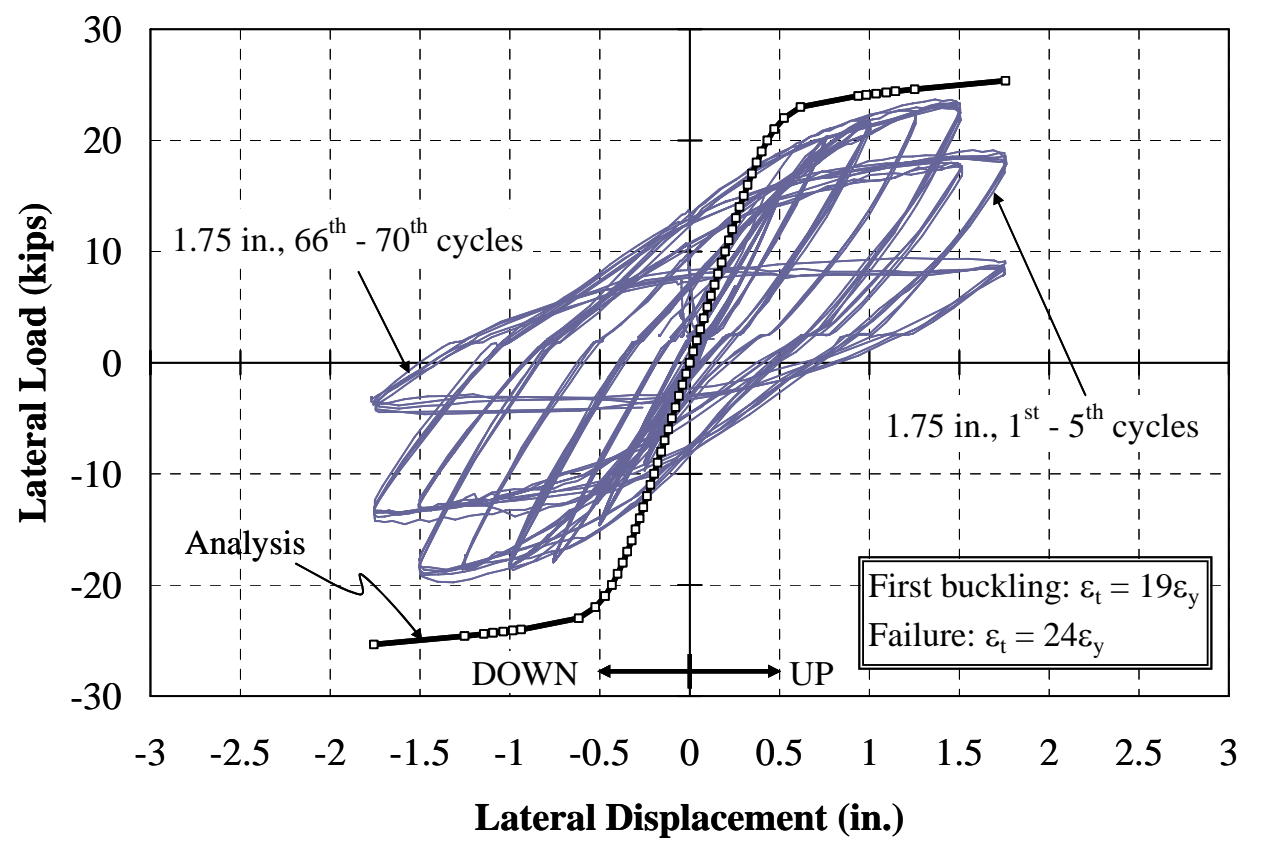

Figure 7.19: Specimen 6 - Load-Deflection Curve 


\subsubsection{CFT Piles}

The calculated strains and curvatures along with the displacements at first buckling and failure of Specimens 7 through 9 are provided in Table 7.2. The analytical load-deflection curves of the CFT piles are presented in Figures 7.20 to 7.22. Two models were analyzed to estimate the load-deflection curves of the CFT piles. The first model is the composite concrete-steel model and another is the steel-only model. While a coupon cut from Specimen 8 indicated a yield strength of approximately 54 ksi as shown in Figure 7.6, this value was inconsistent with Specimen 7. Specimens 7 and 8 were obtained from the same pile; therefore, these yield strengths should be similar if not identical. Both yield strengths were evaluated, and it was found that a yield of $46 \mathrm{ksi}$ was more appropriate based on the experimental results. This yield was used for Specimens 7 and 8. The stress-strain curve shown in Figure 7.5 was used. The yield strength of Specimen 9 was $52 \mathrm{ksi}$ as previously described in Section 7.2.2. The load-deflection curve obtained by the composite (concrete + steel) model correlates fairly well for Specimen 7. The composite model slightly overestimates the load-deflection curves of Specimens 8 and 9 due to deterioration that occurred at the abutment-pile connection. As the deterioration of the connection increases, the concrete-steel model provided a greater overestimation. It can be noticed that the composite model overestimates the capacity in the up direction more than in the down direction. The difference in the load and displacement capacity of the pile was likely due to its self weight and deterioration at the abutment-pile connection as described in Section 6.3.9. Due to deterioration at the connection and the lower confinement provided on top of the abutment from the location of the clamping system, the lateral load required to displace the pile in the up direction was lower than that in the down direction. On the other hand, the steel-only model correlates well with all of the final cycles of the last displacement range of Specimens 7 and 8 . The steel-only model slightly overestimates the final cycle of Specimen 9 because of significant deterioration of the abutment-pile connection as well as fracture of the pile. 
Table 7.2: Strains at First Buckling and at Failure of the CFT Specimens

\begin{tabular}{|c|c|c|c|c|c|c|c|c|c|}
\hline \multirow[b]{2}{*}{ Specimen } & \multirow[b]{2}{*}{ Model } & \multicolumn{4}{|c|}{ Buckling } & \multicolumn{4}{|c|}{ Failure } \\
\hline & & $\begin{array}{c}\Delta \\
\text { (in.) }\end{array}$ & $\begin{array}{c}\varepsilon \\
\text { (in./in.) }\end{array}$ & $\varepsilon / \varepsilon_{\mathrm{y}}$ & $\begin{array}{c}\phi \\
\text { (rad/in.) }\end{array}$ & $\begin{array}{c}\Delta \\
\text { (in.) }\end{array}$ & $\begin{array}{c}\varepsilon \\
\text { (in./in.) }\end{array}$ & $\varepsilon / \varepsilon_{\mathrm{y}}$ & $\begin{array}{c}\phi \\
\text { (rad/in.) }\end{array}$ \\
\hline 7 & \multirow{3}{*}{$\begin{array}{c}\text { Steel-Only } \\
\text { Model }\end{array}$} & 1.50 & 0.022 & 14 & 0.0030 & 1.75 & 0.025 & 16 & 0.0035 \\
\hline 8 & & 1.50 & 0.017 & 11 & 0.0022 & 1.75 & 0.021 & 13 & 0.0026 \\
\hline 9 & & 1.75 & 0.034 & 19 & 0.0040 & 2.00 & 0.039 & 22 & 0.0047 \\
\hline 7 & \multirow{3}{*}{$\begin{array}{c}\text { Composite } \\
\text { Model }\end{array}$} & 1.50 & 0.025 & 16 & 0.0060 & 1.75 & 0.029 & 18 & 0.0068 \\
\hline 8 & & 1.50 & 0.021 & 18 & 0.0043 & 1.75 & 0.025 & 21 & 0.0053 \\
\hline 9 & & 1.75 & 0.036 & 20 & 0.0068 & 2.00 & 0.041 & 23 & 0.0078 \\
\hline
\end{tabular}

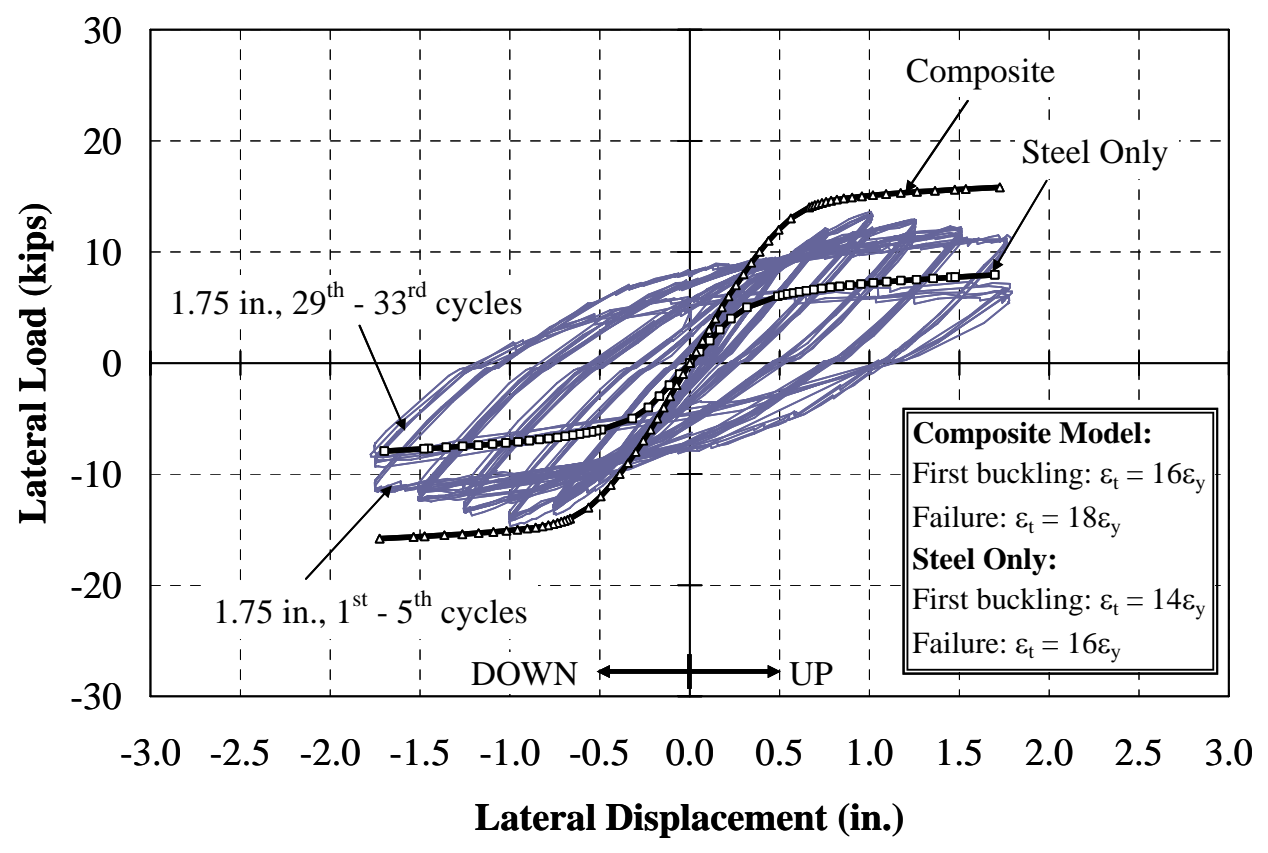

Figure 7.20: Specimen 7 - Load-Deflection Curve 


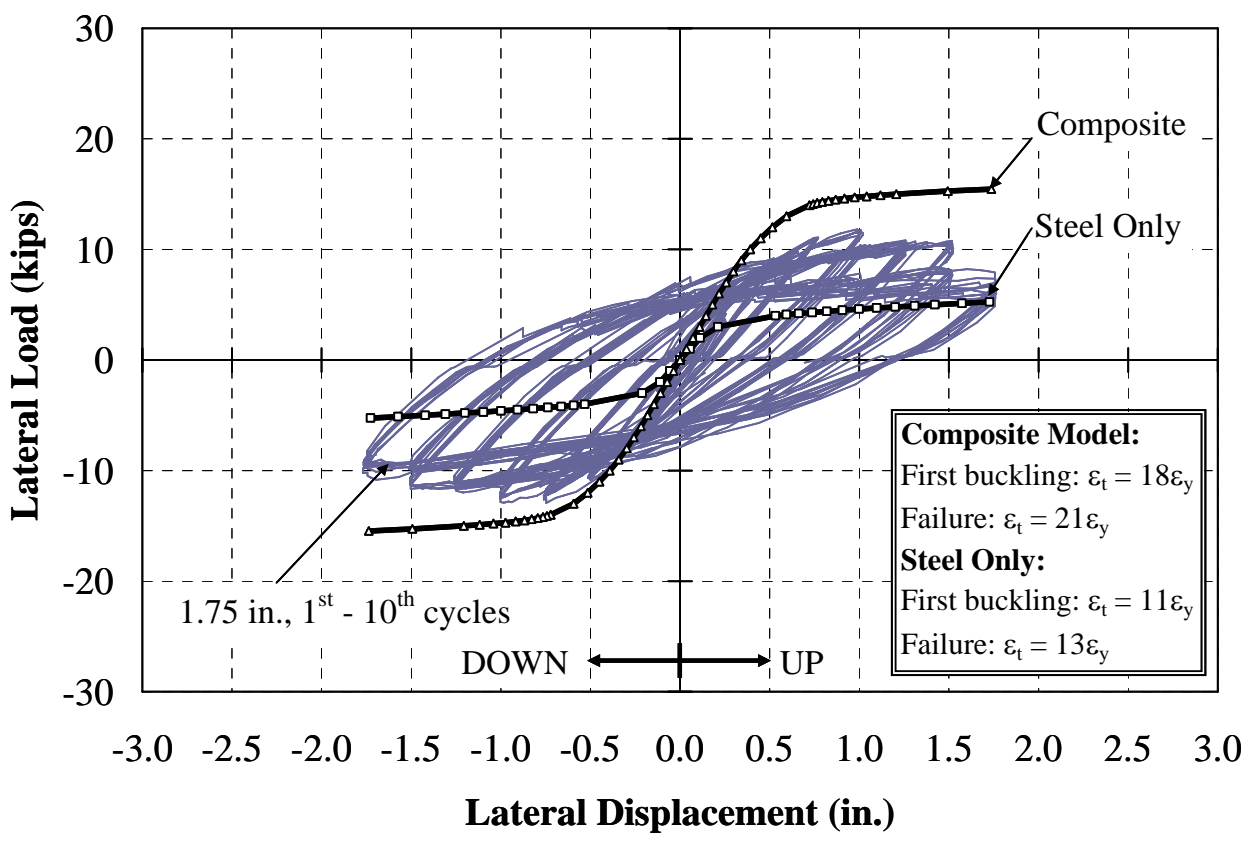

Figure 7.21: Specimen 8 - Load-Deflection Curve

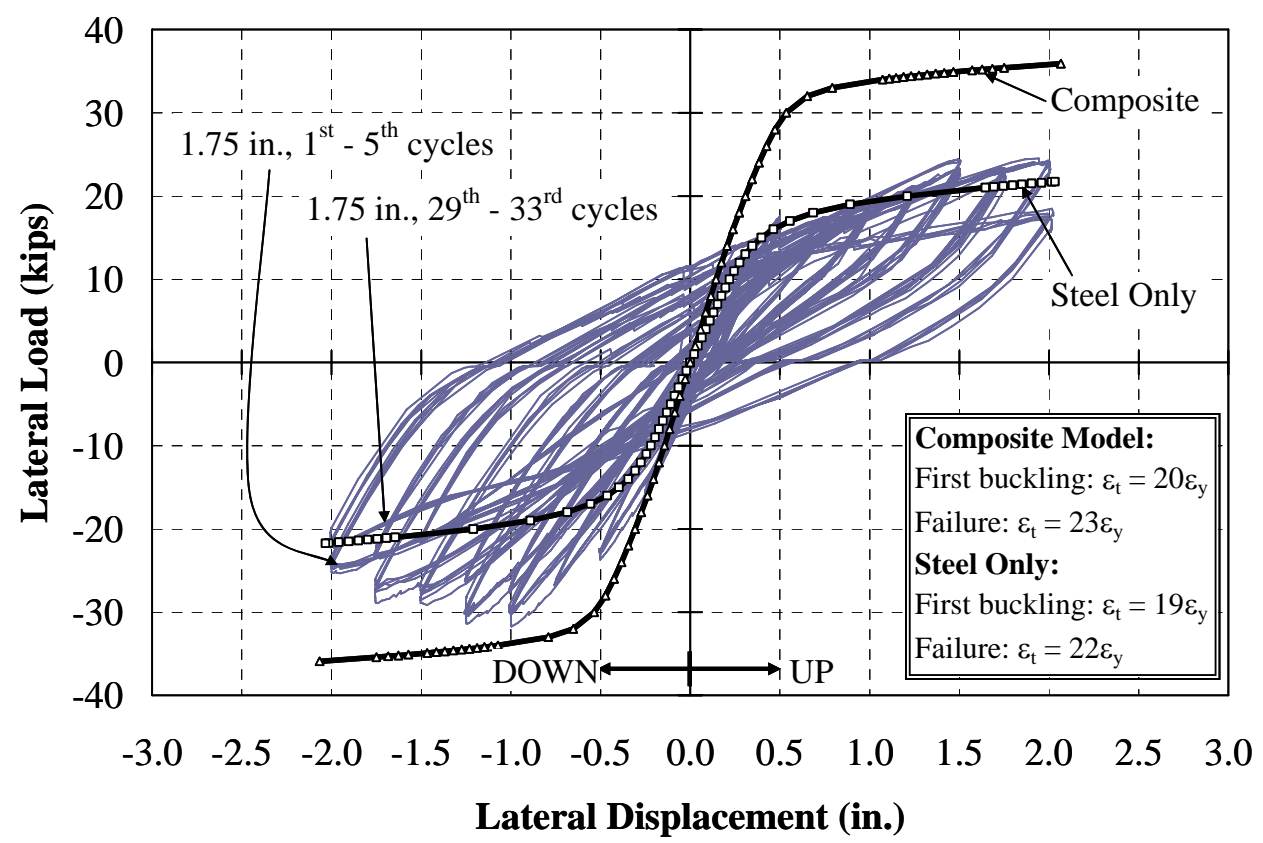

Figure 7.22: Specimen 9 - Load-Deflection Curve 


\subsubsection{Ductility Ratio}

In this research, the ratio of strain at first buckling to the strain at yield, $\varepsilon_{\text {buckling }} / \varepsilon_{\text {yield }}$, is defined as the buckling ductility ratio. The AISC-LRFD specification (2001) denotes the ratio of strain at fracture to strain at yield, $\varepsilon_{\text {failure }} / \varepsilon_{\text {yield }}$, as the inelastic ductility ratio. The buckling and inelastic ductility ratios of all specimens using the steel model for the $\mathrm{H}$ piles and a composite model for the CFT piles along with their width/thickness ratios (b/t) are summarized in Figure 7.23.

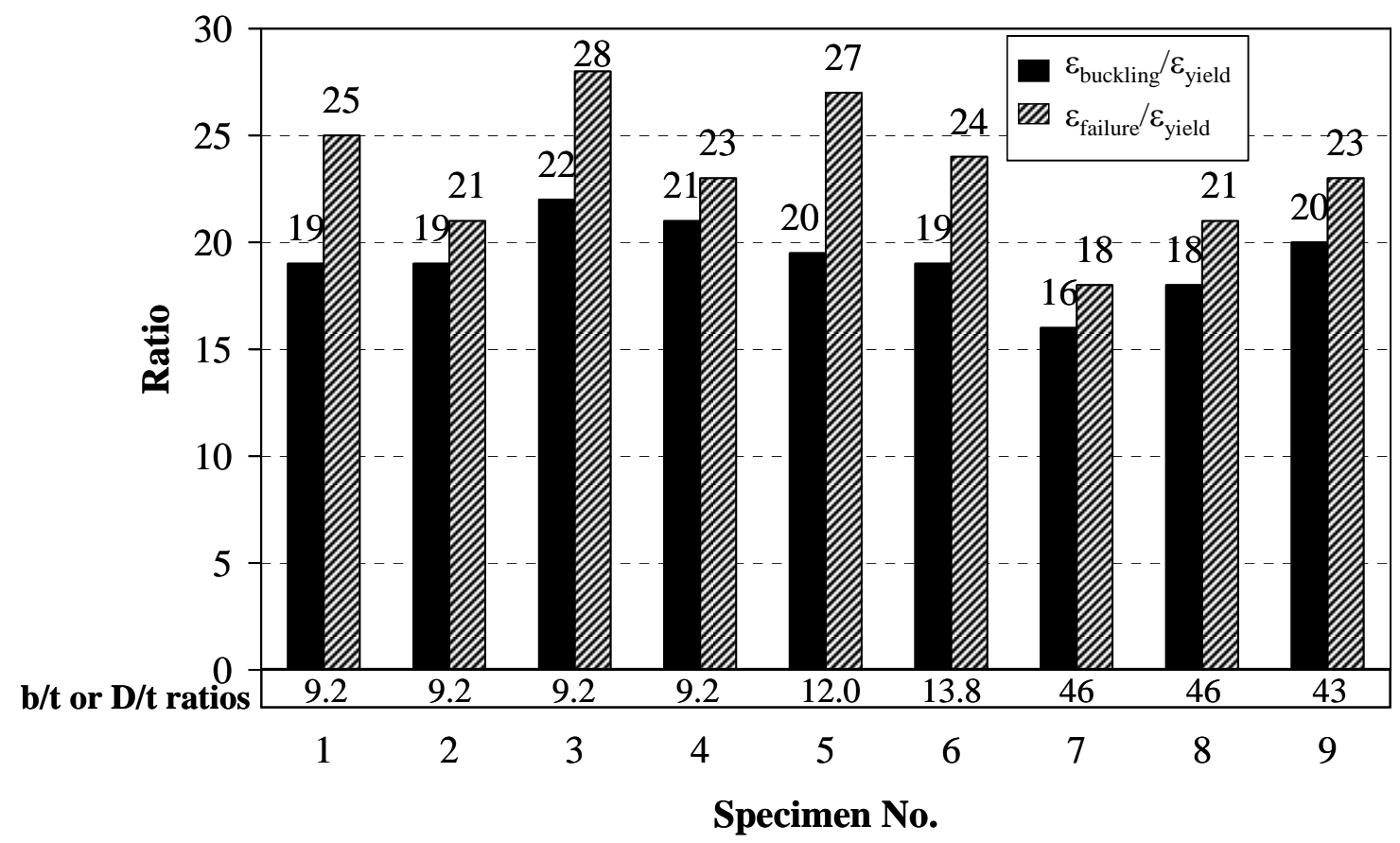

Figure 7.23: Ductility Ratios

In general, the buckling ductility ratios of the $\mathrm{H}$ piles are between approximately 19 and 22, while the buckling ductility ratios of the CFT piles vary from approximately 16 to 20 . As the $\mathrm{b} / \mathrm{t}$ ratio increases for the $\mathrm{H}$ piles, meaning the flange is more slender, both the buckling ductility and inelastic ductility ratios remain fairly constant, while as the D/t ratio increases for the CFT piles, both the buckling ductility and inelastic ductility ratios decrease. On average, the value of the strain at first buckling for the $\mathrm{H}$ piles was 
approximately $20 \varepsilon_{\mathrm{y}}$, while it was approximately $18 \varepsilon_{\mathrm{y}}$ for the CFT piles. The buckling and inelastic ratios are used to discuss the effect of pile size, axial load level, and pile orientation.

\subsubsection{Effect of Pile Size on Ductility Ratio}

The buckling ductility and inelastic ductility ratios of Specimens 1, 5, and 6 were compared to evaluate the effect of pile size on these ratios. One can note that the clamping system of Specimens 1 and 2 was placed differently from the other specimens, that is, the clamping beams of Specimens 1 and 2 were placed at the edges of the concrete abutment, while for the other specimens, one of clamping beams was placed at the middle of the concrete abutment as illustrated in Figure 7.24. The reason that the beam was moved after testing Specimens 1 and 2, was to reduce confinement provided at the abutment-pile connection as much as possible. Even though the confinement at the abutment-pile connection is reduced in the up direction, the concrete support block provides confinement in the down direction. This difference in the clamping system was considered in the evaluation; however, as evident, both ductility ratios remained approximately the same regardless of pile size.

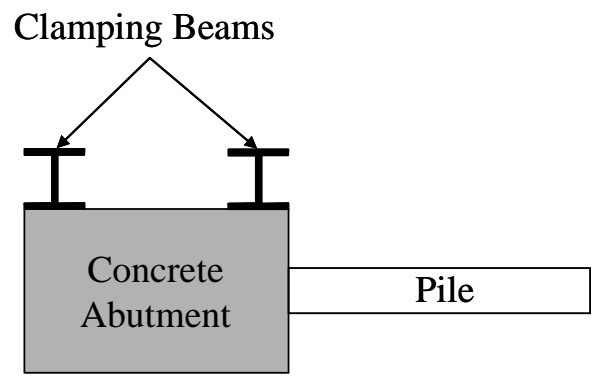

(a) Specimens 1 and 2

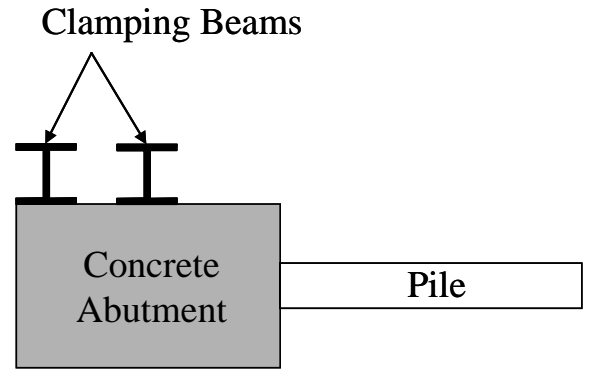

(b) Other Specimens

Figure 7.24: Clamping Beams 
Unlike the trend of the $\mathrm{H}$ piles, the CFT piles behaved differently. As the D/t ratio decreased from 46 to 43, both buckling and inelastic ductility ratios increased. Specimen 9 has a lower D/t, and a higher percentage of steel (7\%) than Specimens 7 and

8. This increase in ductility is likely a result of the increased wall thickness (33\% greater) that assists in preventing local buckling.

\subsubsection{Effect of Axial Load Level on Ductility Ratio}

The buckling and inelastic ductility ratios of Specimens 1 and 4 as well as Specimens 7 and 8 were compared to evaluate the effect of axial load level on these ratios. In general, it is expected that as the axial load increases, there would be a decrease in the ductility ratios. This comparison indicated that the $\mathrm{H}$ pile with a higher axial load had a lower inelastic ductility ratio but the buckling ductility ratio remained fairly constant. On the other hand, for the CFT piles, as the axial load increased, both ductility ratios increased. The pile with a higher axial load was expected to buckle and fail earlier than that with a lower axial load. Both Specimens 7 and 8 were able to achieve a displacement of 1.50 in. prior to buckling. The difference in buckling ductilities may be an artifact of the 0.25 in. displacement increment. Regardless, the higher axial load did not significantly affect the ductility of the CFT pile.

\subsubsection{Effect of Pile Orientation on Ductility Ratio}

Specimens 1, 2, and 3 were considered to evaluate the effect of pile orientation. The analytical results indicate that the pile orientation has only a minor effect on the buckling ductility ratio, but a significant effect on the inelastic ductility ratio. This difference in inelastic ductility ratio is likely caused by the deterioration that occurred at the abutment-pile connection of Specimen 2. Failure of this specimen was limited by deterioration of the connection rather than by failure of the pile. However, comparing weak- and $45^{\circ}$-axis bending piles (Specimens 1 and 3), the pile bending about its $45^{\circ}$ axis was observed to have a slightly higher inelastic ductility ratio than the pile bending about its weak axis. This difference is not significant. In general, the buckling ductility capacities were similar. 


\subsection{Previous Research}

Only two tests on $\mathrm{H}$ piles were obtained from the literature that are similar to those conducted here. Ravat (1997) performed tests on A36, HP14x89 piles, with a length of $20 \mathrm{ft}$ under combined axial and lateral loads. The piles were oriented for weak, $45^{\circ}$, and strong axes bending. The axial load, however, was varied throughout the test to simulate seismic loading. Construction Technology Laboratories (CTL) (Oesterle et al., 1998) also conducted a test on a HP10x42 section, with a length of $6.7 \mathrm{ft}$ under a constant axial load of 90 kips or 7.3 ksi subjected to lateral load. The pile was oriented for weak axis bending.

Several tests have been conducted for CFT columns under combined flexure and axial loads. These have been reported by Furlong (1967), Knowles and Park (1969), Neogi et al. (1969), Rangan and Joyce (1992), Boyd et al. (1995), Morino et al. (1996), Elremaily and Azizinamini (2000), and Kilpatrick and Rangan (1999). Except for the studies by Boyd et al. (1995), Morino et al. (1969), and Elremaily and Azizinamini (2000), all of the tested columns had a small diameter that ranged from 3 to 6 in. Boyd et al. (1995) tested columns with a diameter of 8 in., while Morino et al. (1996) tested columns with diameters ranging from 4 to $17 \mathrm{in}$. The diameter of the columns tested by Elremaily and Azizinamini (2000) was 12.75 in. Analytical models have been proposed by Neogi et al. (1969) and Rangan and Joyce (1992). These models, however, ignore the effect of confinement on the concrete strength, and the predicted capacities were conservative for columns with a length-to-diameter ratio (L/O.D.) less than 15 and with a small eccentricity. One can note that the piles tested in this research have length-todiameter ratios of 5.5 and 7.0 and diameter-to-thickness ratios (O.D./t) of 43 and 46.

\subsection{CTL Research}

Construction Technology Laboratories (CTL) (Oesterle et al., 1998) conducted a test on an $\mathrm{H}$ pile similar to that performed in this research. The results from this test were also compared with the model described in Section 7.2.1 to evaluate its applicability beyond the tests conducted here. 


\subsubsection{Test Setup (CTL Specimen)}

The steel pile cross section used in the CTL test was a HP10x42. The dimensions and section properties are shown in Table 7.3, and the material properties for this pile are provided in Table 7.4. It should be noted that the actual modulus of elasticity of steel is approximately 29,000 ksi, but the measured modulus of elasticity of steel is reported as 26,850 ksi in the CTL research. This difference is likely due to measurement error. The total length of the pile was $9 \mathrm{ft}-7 \mathrm{in}$., and the pile was embedded $2 \mathrm{ft}$ into a concrete abutment. The pile was bent about its weak axis with lateral load applied at a distance of 80 in. from the face of the concrete abutment. An axial load of 90 kips (7.25 ksi) was applied horizontally at the end of the pile and remained horizontal and in line with the pin at the end of the pile using a low-friction ball bearing assembly as illustrated in Figure 7.25. The specimen was subjected to cyclic loading at three different displacement ranges. One hundred (100) cycles were applied at a displacement range of 0.6 in. while 50 cycles were applied at a displacement range of 1.2 and 2.4 in. The pile was expected to experience first yielding during the 0.6 in. displacement range and first buckling during the 2.4 in. displacement range. First buckling was calculated based on an expression by Abendroth et al. (1989).

Table 7.3: Nominal Cross-Sectional Properties of HP10x42

\begin{tabular}{|c|c|c|c|c|c|c|c|c|c|c|c|}
\hline & $\begin{array}{c}\text { A } \\
\left(\text { in. }^{2}\right)\end{array}$ & $\begin{array}{c}\text { d } \\
\text { (in.) }\end{array}$ & $\begin{array}{c}\mathbf{t}_{\mathrm{w}} \\
\text { (in.) }\end{array}$ & $\begin{array}{c}\mathbf{b}_{\mathrm{f}} \\
\text { (in.) }\end{array}$ & $\begin{array}{c}\mathbf{t}_{\mathbf{f}} \\
\text { (in.) }\end{array}$ & $\begin{array}{c}I_{x} \\
\left(\text { in. }^{4}\right)\end{array}$ & $\begin{array}{c}I_{y} \\
\left(\text { in. }^{4}\right)\end{array}$ & $\begin{array}{c}S_{x} \\
\text { (in. }{ }^{3} \text { ) }\end{array}$ & $\begin{array}{c}S_{y} \\
\text { (in. }{ }^{3} \text { ) }\end{array}$ & $\begin{array}{c}\mathrm{Z}_{\mathrm{x}} \\
{\text { (in. }{ }^{3} \text { ) }}\end{array}$ & $\begin{array}{c}Z_{y} \\
\text { (in. }{ }^{3} \text { ) }\end{array}$ \\
\hline & 12.4 & 9.70 & 0.415 & 10.1 & 420 & 210 & 71.7 & 43.4 & 14.2 & 48.3 & 21.8 \\
\hline
\end{tabular}

Table 7.4: Material Properties ${ }^{*}$

\begin{tabular}{|c|c|c|}
\hline $\begin{array}{c}\text { Modulus of Elasticity } \\
\text { (ksi) }\end{array}$ & $\begin{array}{c}\text { Yield Strength } \\
\text { (ksi) }\end{array}$ & $\begin{array}{c}\text { Ultimate Strength } \\
\text { (ksi) }\end{array}$ \\
\hline 26,850 & 43.25 & 64.3 \\
\hline
\end{tabular}

* Reported by Oesterle et al. (1998) 


\subsubsection{Experimental Results (CTL Specimen)}

As reported by Oesterle et al. (1998), it was apparent that there was no significant degradation for 100 cycles at the 0.6 in. displacement range. Small concrete cracks were observed radiating from the four corners of the pile and propagating outward during the 1.2 in. displacement range as shown in Figure 7.26. During the tenth cycle of the $2.4 \mathrm{in}$. displacement range, local buckling was observed on the top and bottom sides of the flanges as shown in Figure 7.27. The abutment-pile connection exhibited minor cracking and spalling; however, the pile maintained axial load in the $50^{\text {th }}$ cycle. The selected loaddeflection curves of the 0.6, 1.2, and 2.4 in. displacement ranges are provided in Figure 7.28 .

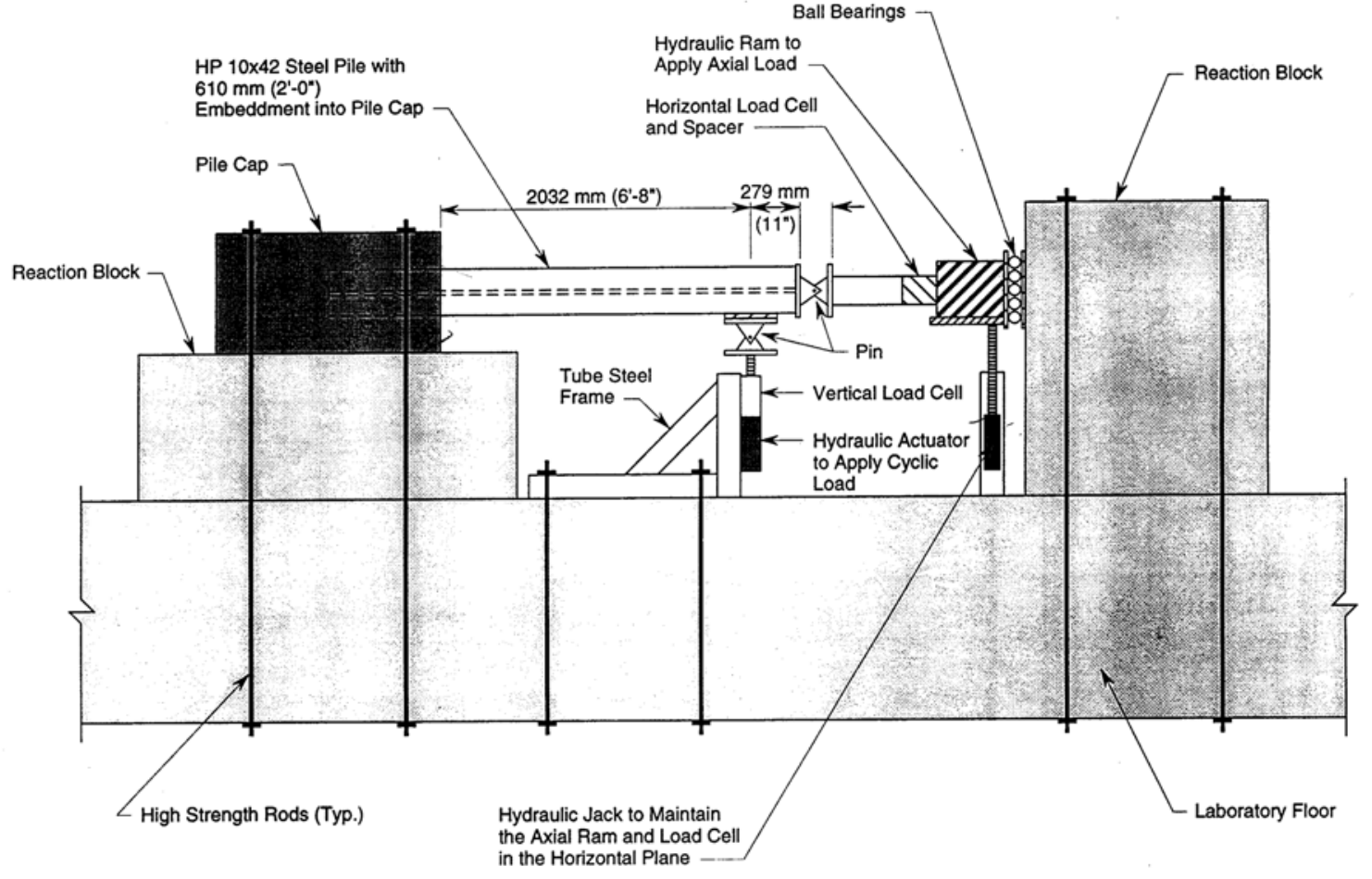

Figure 7.25: CTL Test Setup (Oesterle et al., 1998)

\subsubsection{Pile Model (CTL Specimen)}

The pile was modeled as a cantilever beam subjected to an axial load of 90 kips along with a lateral load at the pile tip. The pile length was $80 \mathrm{in}$. The model used the trilinear stress-strain model for steel as described in Section 7.2.1. A modulus of 
elasticity of 29,000 ksi and a yield strength of $43.25 \mathrm{ksi}$ were used. The strain at the onset of strain-hardening was assumed to be 0.014 in./in., and the modulus of strain hardening was taken as $300 \mathrm{ksi}$. Based on the previous analyses, the strain at first buckling was assumed to equal to $20 \varepsilon_{\mathrm{y}}$.

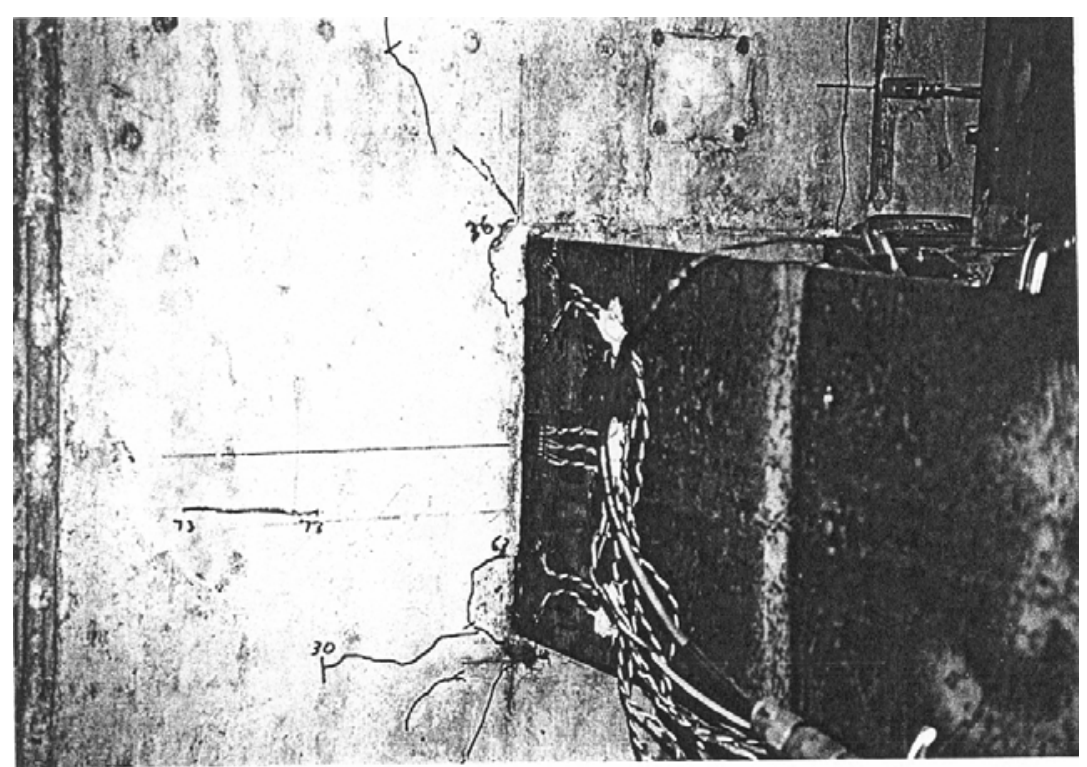

Figure 7.26: Cracks on Concrete Abutment (1.2 in. Cycle)

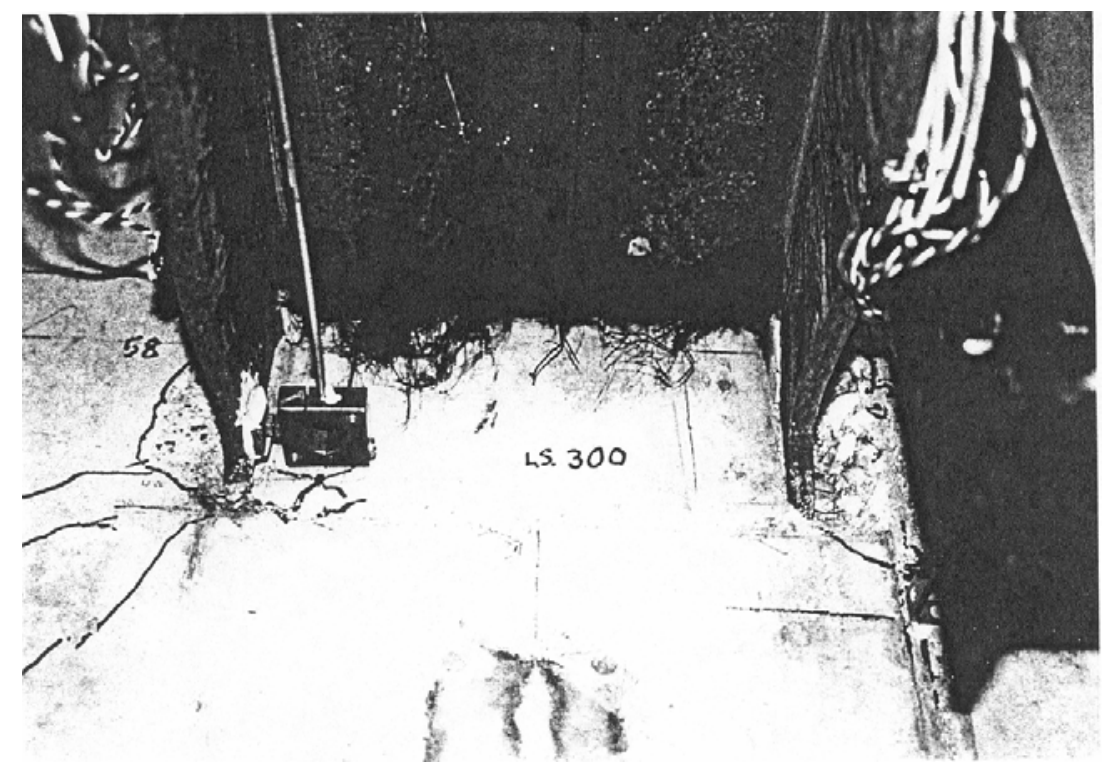

Figure 7.27: Buckling at the Bottom of the Flanges (2.4 in. Cycle) 


\subsubsection{Analytical Results (CTL Specimen)}

The analytical load-deflection curve is plotted in Figure 7.28. In general, the analysis provides a reasonable prediction of the pile response. Using a strain of $20 \varepsilon_{\mathrm{y}}$ estimated the displacement at first buckling as $2.7 \mathrm{in}$. which slightly overestimates the observed behavior. The difference in the lateral load capacity at larger displacements is caused by the deterioration that occurred at the abutment-pile connection.

\subsubsection{Comparison between Test Results}

The CTL results were compared with the experimental results from Specimen 5 (HP10x42) as this was the same pile size. The difference in the lateral load capacity and lateral displacement capacity is caused by the difference in material properties and the length of the pile. The CTL specimen had a yield strength of approximately $43 \mathrm{ksi}$, while that of Specimen 5 was approximately $39 \mathrm{ksi}$. The distance from the fixed support to the location of the applied load of the CTL specimen was 80 in., while that of Specimen 5 was $60 \mathrm{in}$. One should also note that the embedment length of the CTL test is 6 in. deeper than that of Specimen 5. The lower lateral load capacity is caused by the larger moment arm used in the CTL test. 


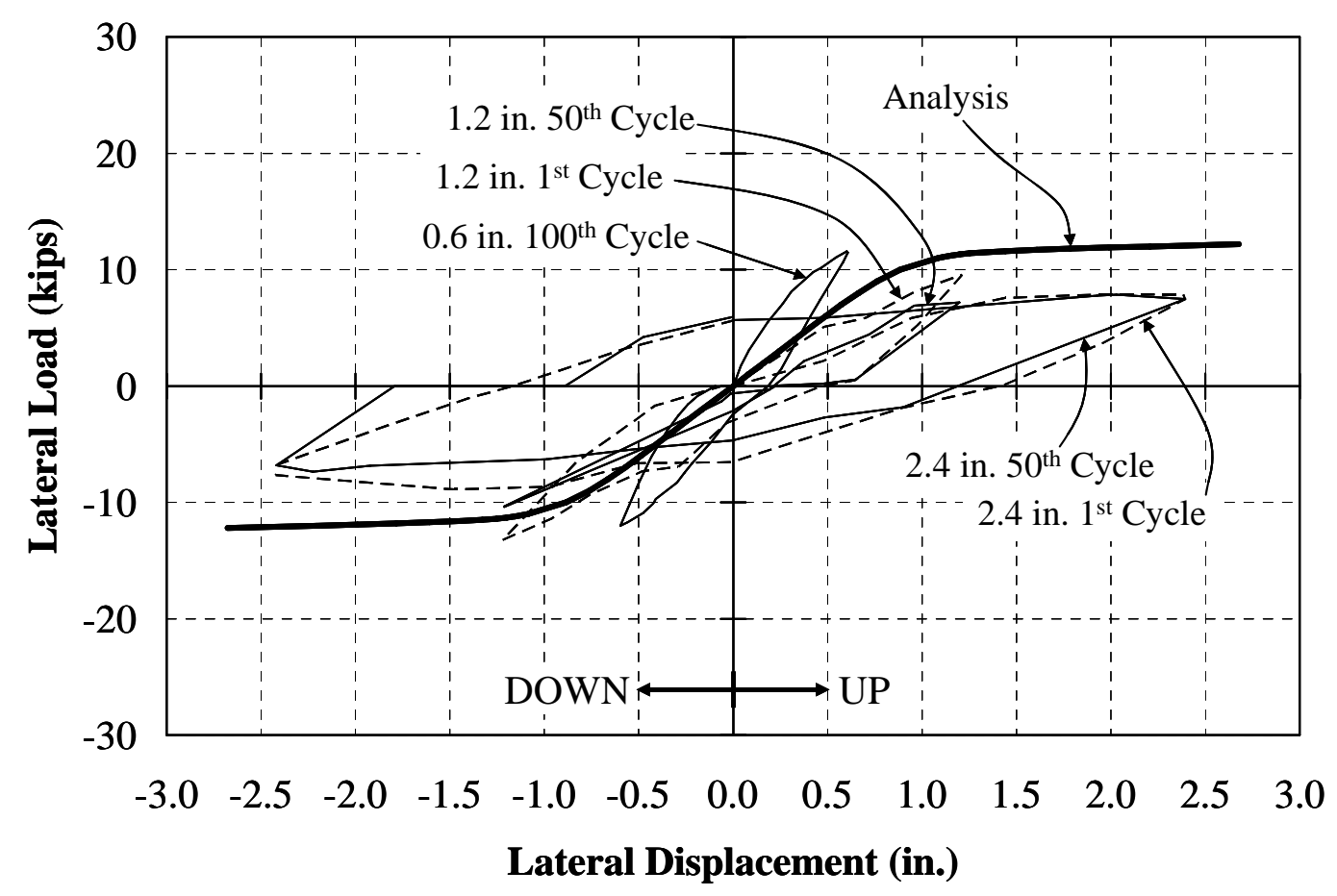

Figure 7.28: Load-Deflection Curves for CTL Specimen

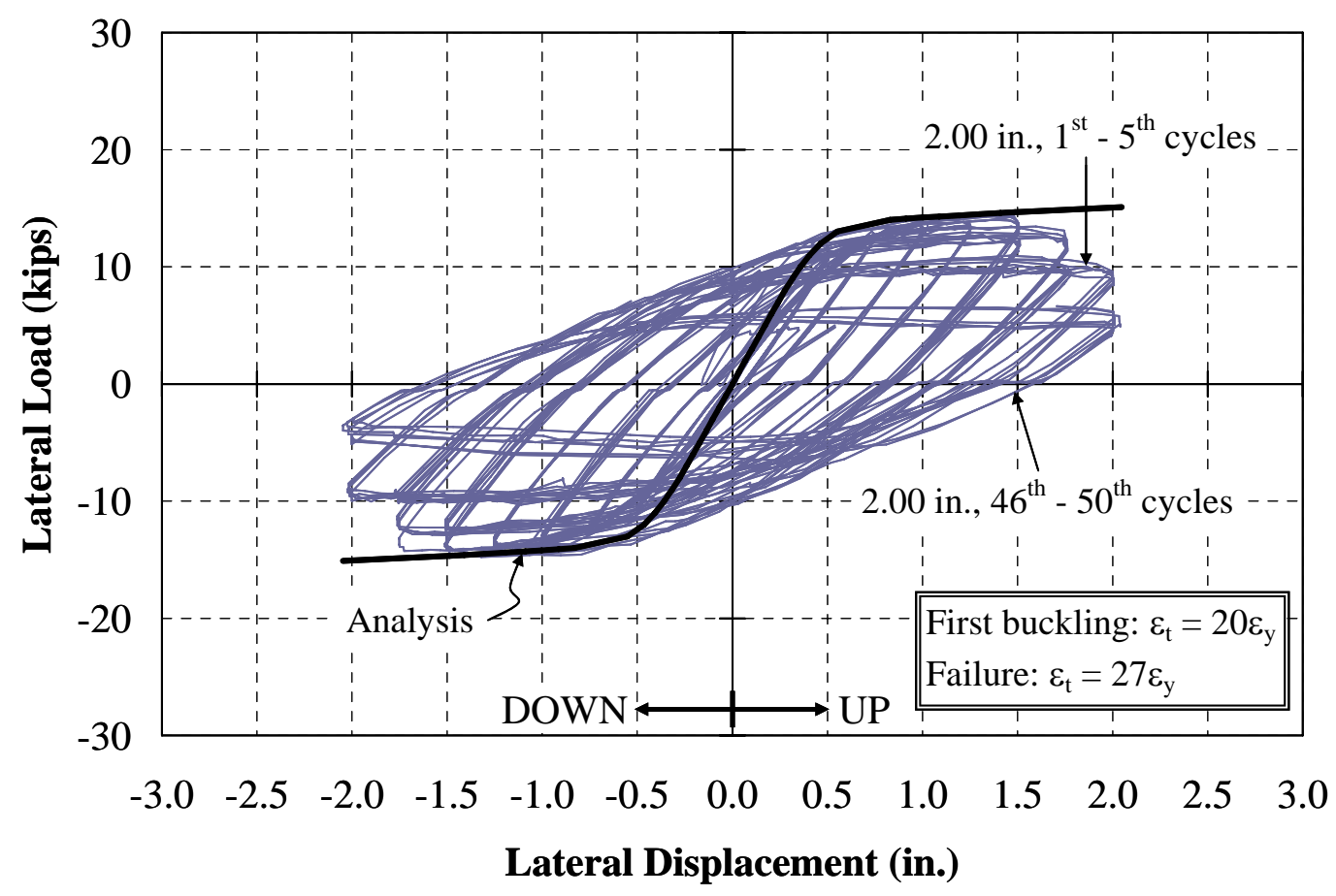

Figure 7.29: Load-Deflection Curves for Specimen 5 (HP10x42) 


\subsubsection{Comparison of Abendroth et al. (1989) and Buckling Strain Analysis Model}

Abendroth et al. (1989) proposed an equation for determining the displacement capacity of the pile based on plastic redistribution. Oesterle et al. (1998) adopted the Abendroth et al. method to calculate the theoretical lateral displacement at local flange buckling for $\mathrm{H}$ piles as given in Equations 7-3 and 7-4. A fixed-headed, equivalent cantilever pile with the length of the pile equal to $\mathrm{L} / 2$ was assumed as shown in Figure 7.30. A pile was assumed to be an elastic-perfectly plastic material where the plastic hinge moment remains constant and equal to the plastic moment capacity, $\mathrm{M}_{\mathrm{p}}$. Displacement relative to the inflection point at the local flange buckling limit is one-half of $\Delta$ calculated using Equation 7-3.

$$
\begin{gathered}
\Delta=\Delta_{\mathrm{p}}\left(0.6+2.25 \mathrm{C}_{\mathrm{i}}\right) \\
\mathrm{C}_{\mathrm{i}}=\frac{19}{6}-\frac{\mathrm{b}_{\mathrm{f}} \sqrt{\mathrm{f}_{\mathrm{y}}}}{60 \mathrm{t}_{\mathrm{f}}}
\end{gathered}
$$

where:

$$
\begin{array}{ll}
\Delta & =\text { lateral displacement at pile tip, in. } \\
f_{y} & =\text { yield strength of steel, ksi } \\
b_{f} & =\text { width of flange, in. } \\
t_{f} & =\text { thickness of flange, in. } \\
\Delta_{p} & =\frac{M_{p} L^{2}}{6 E I} \\
M_{p} & =f_{y} Z \\
Z & =\text { plastic modulus, in. }{ }^{3} \\
E & =\text { modulus of elasticity, ksi } \\
I & =\text { moment of inertia, in. }{ }^{4}
\end{array}
$$




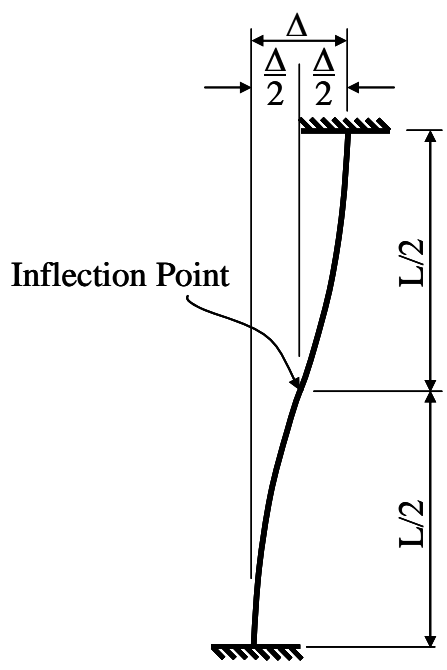

Figure 7.30: Equivalent Cantilever Pile

The theoretical displacement at buckling using the Abendroth equation and using the pile model developed based on the strain of $20 \varepsilon_{\mathrm{y}}$ were calculated and compared with the displacement at buckling observed from the experimental results as presented in Table 7.5. As the section increases, the theoretical displacement using the Abendroth equation is underestimated significantly. It was found that the use of a strain capacity of $20 \varepsilon_{\mathrm{y}}$ to estimate pile buckling capacity provides better results. Furthermore, the Abendroth equation was developed for $\mathrm{H}$ sections and is not applicable for CFT sections.

Table 7.5: Comparison of the Theoretical Displacement at Buckling

\begin{tabular}{|c|c|c|c|c|c|c|c|}
\hline Specimen & $\begin{array}{c}\mathbf{f}_{\mathbf{y}} \\
(\mathbf{k s i})\end{array}$ & $\begin{array}{c}\Delta_{\text {test }} \\
\text { (in.) }\end{array}$ & $\begin{array}{c}\mathbf{M}_{\mathbf{p}} \\
\text { (ft-k) }\end{array}$ & $\begin{array}{c}\text { Abendroth } \\
\Delta_{\text {calc }} \text { (in.) }\end{array}$ & $\Delta_{\text {calc }} / \Delta_{\text {test }}$ & $\begin{array}{c}\text { At 20 } \varepsilon_{\mathbf{y}} \\
\Delta_{\text {calc }} \text { (in.) }\end{array}$ & $\Delta_{\text {calc }} / \Delta_{\text {test }}$ \\
\hline 1 & 47 & 2.00 & 59.5 & 2.21 & 1.11 & 2.11 & 1.06 \\
\hline 2 & 47 & 1.50 & 131.6 & 1.66 & 1.10 & 1.63 & 1.09 \\
\hline 3 & 47 & 1.50 & 96.4 & 1.81 & 1.21 & 1.29 & 0.86 \\
\hline 4 & 47 & 2.25 & 59.5 & 2.21 & 0.98 & 2.07 & 0.92 \\
\hline 5 & 39 & 1.25 & 70.9 & 1.03 & 0.82 & 1.29 & 1.03 \\
\hline 6 & 45 & 1.25 & 120.8 & 0.37 & 0.30 & 1.35 & 1.08 \\
\hline
\end{tabular}




\subsection{Recommended Pile Sections}

\subsubsection{H Sections}

Based on the comparison of the results of the analytical model with experimental results, it was determined that the simplified analysis method could reasonably estimate the response up to first buckling of the pile system. First buckling was considered the maximum desired displacement range as increased cycling following local buckling eventually results in fracture of the pile. The analytical model was then used to evaluate all standard H sections as provided in the AISC-LRFD specification (2001). These sections were analyzed based on the following assumptions:

1. The specified yield strength of steel, $f_{y}$, equals $36 \mathrm{ksi}$.

2. Deterioration of the abutment-pile connection is prevented. The connection is assumed as fixed.

3. The lateral deflection at yield, $\Delta_{\mathrm{y}}$, was determined using the yield strain, $\varepsilon_{\mathrm{y}}$, assumed based on $\mathrm{f}_{\mathrm{y}}=36 \mathrm{ksi}$.

4. The lateral deflection at buckling, $\Delta_{\text {buckling, was determined using a strain }}$ value of $20 \varepsilon_{\mathrm{y}}$.

5. The pile length is $5 \mathrm{ft}$. This is assumed to be the inflection point of the pile and is constant for all $\mathrm{H}$ sections.

6. All piles can achieve the plastic moment, $\mathbf{M}_{\mathrm{p}}$, prior to local buckling.

7. All piles are subjected to an axial stress of $9 \mathrm{ksi}$.

H sections included HP14x117, HP14x102, HP14x89, HP14x73, HP12x84, HP12x74, HP12x63, HP12x53, HP10x57, HP10x42, and HP8x36. The momentcurvature relationships and the lateral load-deflection relationships of all $\mathrm{H}$ piles are presented in Figures 7.31 and 7.32, respectively. The lateral displacements at a strain of 20 times the yield strain based on above assumptions along with the compact section criteria $\left(\mathrm{b}_{\mathrm{f}} / 2 \mathrm{t}_{\mathrm{f}}\right.$ and $\mathrm{h} / \mathrm{t}_{\mathrm{w}}$ ratios) are summarized in Table 7.6. The compact section criterion is provided by Table B5.1 in AISC-LRFD specification (2001). 


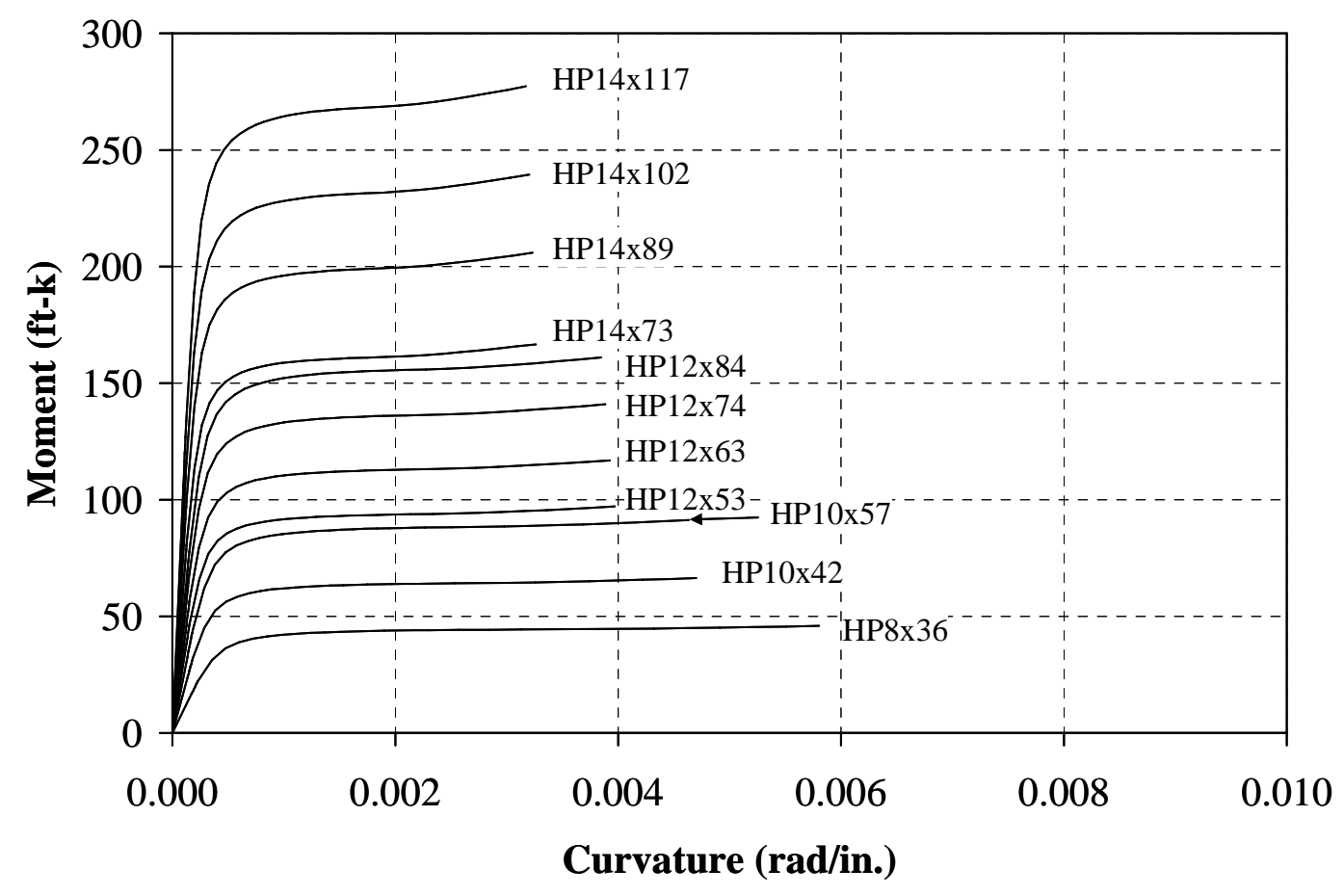

Figure 7.31: Moment-Curvature Relationships of All H Piles

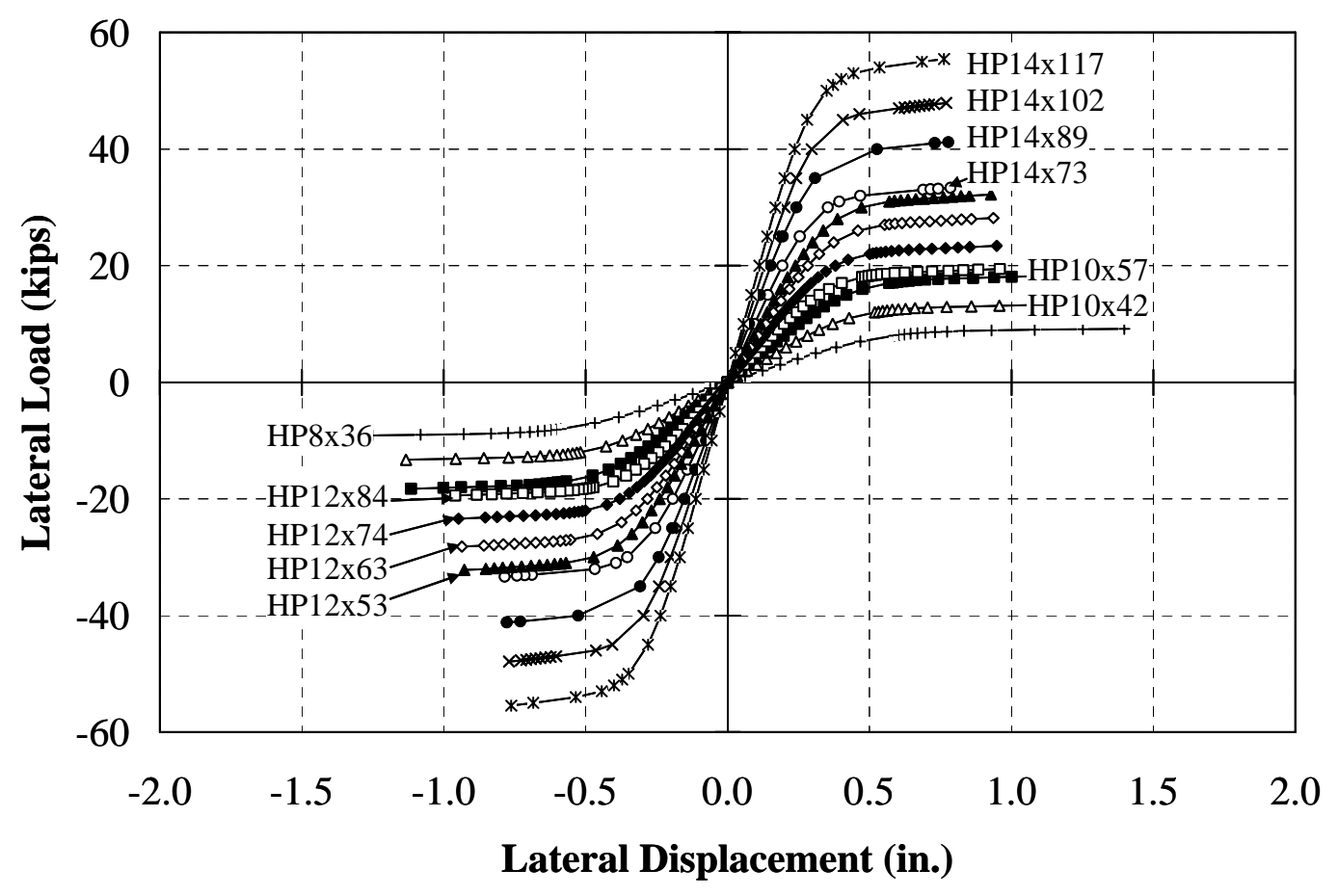

Figure 7.32: Load-Deflection Relationships of All H Piles 
Table 7.6: Displacement at $20 \varepsilon_{\mathrm{y}}$

\begin{tabular}{|c|c|c|c|c|c|}
\hline \multirow{2}{*}{ Section } & \multicolumn{3}{|c|}{ Compact Section Criteria ${ }^{*}$} & \multirow{2}{*}{$\begin{array}{c}\text { Axial Load } \\
\text { (kips) }\end{array}$} & \multirow{2}{*}{$\begin{array}{c}\Delta @ 20 \varepsilon_{\mathrm{y}} \\
\text { (in.) }\end{array}$} \\
\hline & $\mathbf{b}_{\mathrm{f}} / 2 \mathbf{t}_{\mathrm{f}}$ & $\mathbf{h} / \mathbf{t}_{\mathbf{w}}$ & & & \\
\hline HP14x117 & 9.25 & 14.2 & Compact & 310 & 0.76 \\
\hline HP14x102 & 10.5 & 16.2 & Compact & 270 & 0.77 \\
\hline HP14x89 & 11.9 & 18.5 & Noncompact & 235 & 0.78 \\
\hline HP14x73 & 14.4 & 22.6 & Noncompact & 193 & 0.79 \\
\hline HP12x84 & 8.97 & 14.2 & Compact & 221 & 0.93 \\
\hline HP12x74 & 10.0 & 16.1 & Compact & 196 & 0.94 \\
\hline HP12x63 & 11.8 & 18.9 & Noncompact & 166 & 0.95 \\
\hline HP12x53 & 13.8 & 22.3 & Noncompact & 140 & 0.96 \\
\hline HP10x57 & 9.05 & 13.9 & Compact & 151 & 1.12 \\
\hline HP10x42 & 12.0 & 18.9 & Noncompact & 112 & 1.13 \\
\hline HP8x36 & 9.16 & 14.2 & Compact & 95.4 & 1.40 \\
\hline
\end{tabular}

For a pile length of $5 \mathrm{ft}$, the piles with the same cross-sectional depth, $\mathrm{d}$, have approximately the same lateral displacement capacity. However, the length of the pile which represents the depth to the inflection point of the pile in soil actually varies depending upon the soil type and pile size. Consequently, the pile length should vary to account for these parameters. The inflection point of $5 \mathrm{ft}$ is reasonable for the HP10, but too shallow for HP12 and HP14 sections. HP10x42, HP12x53, and HP14x89 were further analyzed because they are commonly used in the field. HP12x84 and HP14x117 sections were also analyzed to conservatively represent the family of HP12 and HP14 sections. All piles were assumed to be embedded in stiff clay and medium sand. The pile lengths for the analysis based on the inflection point depth were determined using LPILE PLUS, and the displacements at first yield, $\Delta_{\mathrm{y}}$, and at buckling, $\Delta_{\text {buckling, were }}$ calculated as presented in Table 7.7. The load-deflection curves of those piles were calculated and are shown in Figure 7.33. As the length of the pile increases, the lateral load decreases, but the lateral displacement capacity increases. Due to the adjustment in the pile length to reflect the stiffness changes in the pile, larger displacement capacities result as compared to considering only a fixed pile length (Table 7.6). 
Table 7.7: Length of the H Piles Based on LPILE PLUS

\begin{tabular}{|c|c|c|c|c|}
\hline \multirow{2}{*}{ Section } & Soil Type & $\begin{array}{c}\text { Pile Length } \\
\text { (ft) }\end{array}$ & $\begin{array}{c}\Delta_{\mathbf{y}} \\
\text { (in.) }\end{array}$ & $\begin{array}{c}\Delta_{\text {buckling }} \\
\text { (in.) }\end{array}$ \\
\hline \multirow{2}{*}{ HP14x117 } & Med. Sand & 7.0 & 0.30 & 1.50 \\
\cline { 2 - 5 } & Stiff Clay & 7.4 & 0.33 & 1.67 \\
\hline \multirow{2}{*}{ HP14x89 } & Med. Sand & 6.5 & 0.26 & 1.31 \\
\cline { 2 - 5 } & Stiff Clay & 6.9 & 0.29 & 1.47 \\
\hline \multirow{2}{*}{ HP12x84 } & Med. Sand & 6.1 & 0.27 & 1.38 \\
\cline { 2 - 5 } & Stiff Clay & 6.3 & 0.28 & 1.42 \\
\hline \multirow{2}{*}{ HP12x53 } & Med. Sand & 5.6 & 0.23 & 1.20 \\
\cline { 2 - 5 } & Stiff Clay & 5.7 & 0.24 & 1.25 \\
\hline \multirow{2}{*}{ HP10x42 } & Med. Sand & 5.0 & 0.22 & 1.13 \\
\cline { 2 - 5 } & Stiff Clay & 5.0 & 0.22 & 1.13 \\
\hline
\end{tabular}

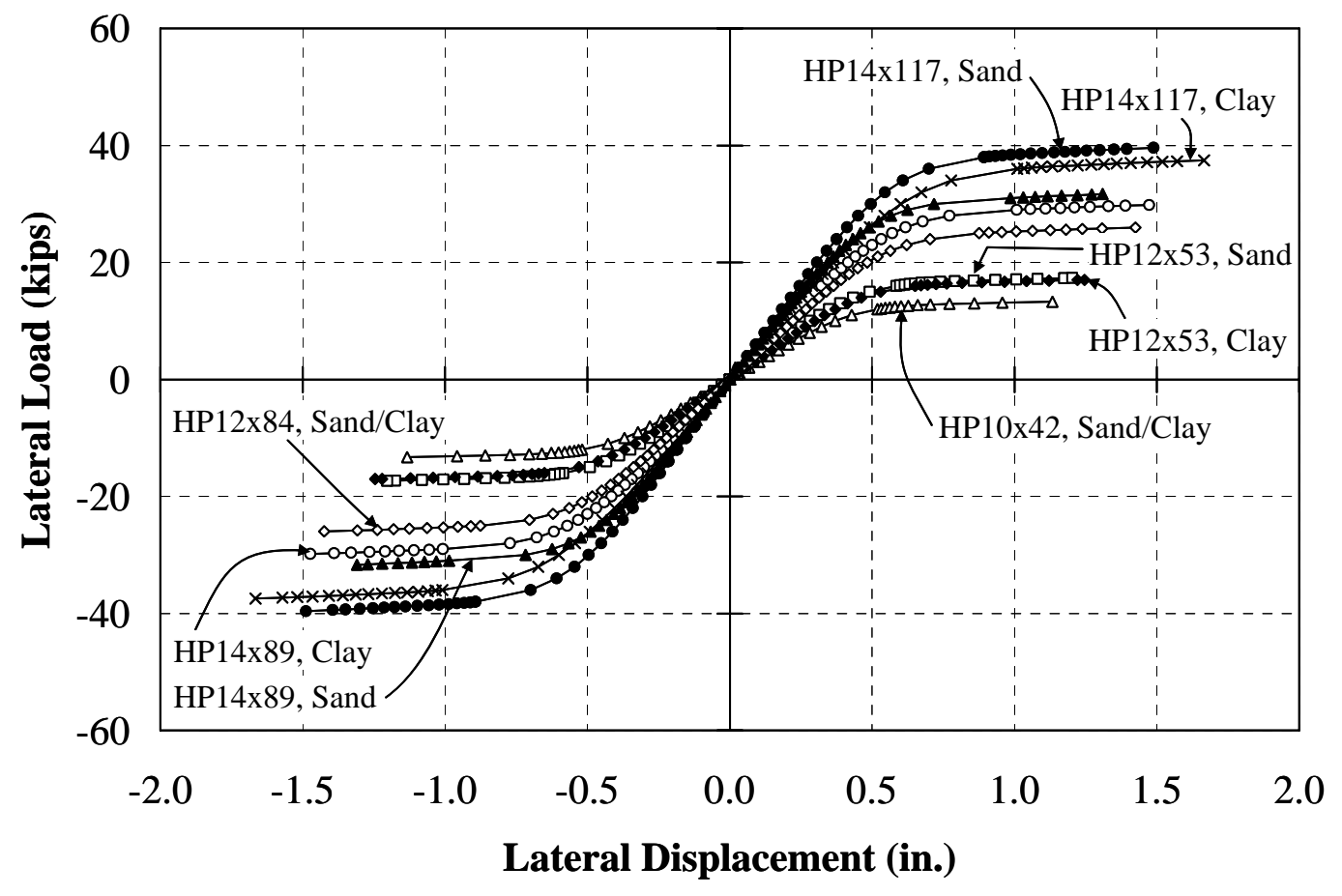

Figure 7.33: Displacement at $20 \varepsilon_{\mathrm{y}}$ Based on the Inflection Point using LPILE 


\subsubsection{CFT Sections}

Similar as Section 7.8.1, CFT sections recommended by INDOT Memorandum \#243, were analyzed based on the following assumptions:

1. The specified yield strength of steel, $f_{y}$, is assumed to be $35 \mathrm{ksi}$.

2. Deterioration of the abutment-pile connection is prevented. The connection is assumed fixed.

3. The lateral deflection at yield, $\Delta_{\mathrm{y}}$, was determined using the yield strain, $\varepsilon_{\mathrm{y}}$, assumed based on $\mathrm{f}_{\mathrm{y}}=35 \mathrm{ksi}$.

4. The lateral deflection at buckling, $\Delta_{\text {buckling, }}$ was determined using a strain value of $15 \varepsilon_{\mathrm{y}}$. This value was conservatively selected based on the analytical results.

5. The pile length is $5 \mathrm{ft}$. This is assumed to be the inflection point of the pile and is constant for all CFT sections.

6. All piles can achieve the plastic moment, $\mathrm{M}_{\mathrm{p}}$, prior to local buckling.

7. All piles are subjected to an axial stress of $0.25 f_{y} A_{s}+0.4 f_{c}^{\prime} A_{c}$.

CFT sections included CFT14.0x0.203, CFT14.0x0.250, and CFT14.0x0.312.

The moment-curvature relationships and the lateral load-deflection relationships of all CFT piles are presented in Figures 7.34 and 7.35, respectively. The lateral displacements at a strain of 15 times the yield strain based on above assumptions along with the compact section criteria (D/t ratios) are summarized in Table 7.8. The compact section criterion is provided by Table B5.1 of AISC-LFRD specification (2001).

For a pile length of $5 \mathrm{ft}$, the piles have approximately the same lateral displacement capacity. As mentioned in Section 7.8.1, the pile length should vary to account for the soil type and pile thickness. The CFT14.0x0.203 and CFT14.0x0.312 sections were further analyzed to evaluate the boundaries of the family of CFT14 sections. Both piles were assumed to be embedded in stiff clay and medium sand. The lengths of the pile for the analysis based on the inflection point depth were determined using LPILE PLUS, and the displacements at first yield, $\Delta_{\mathrm{y}}$, and at buckling, $\Delta_{\text {buckling, }}$ were calculated as presented in Table 7.9. The load-deflection curves of those piles were calculated and are shown in Figure 7.36. Similar to the $\mathrm{H}$ pile behavior, as the length of 
the pile increases, the lateral load decreases, but the lateral displacement capacity increases. Due to the adjustment in the pile length to reflect the stiffness changes in the pile, larger displacement capacities result as compared to considering only a fixed pile length (Table 7.8).

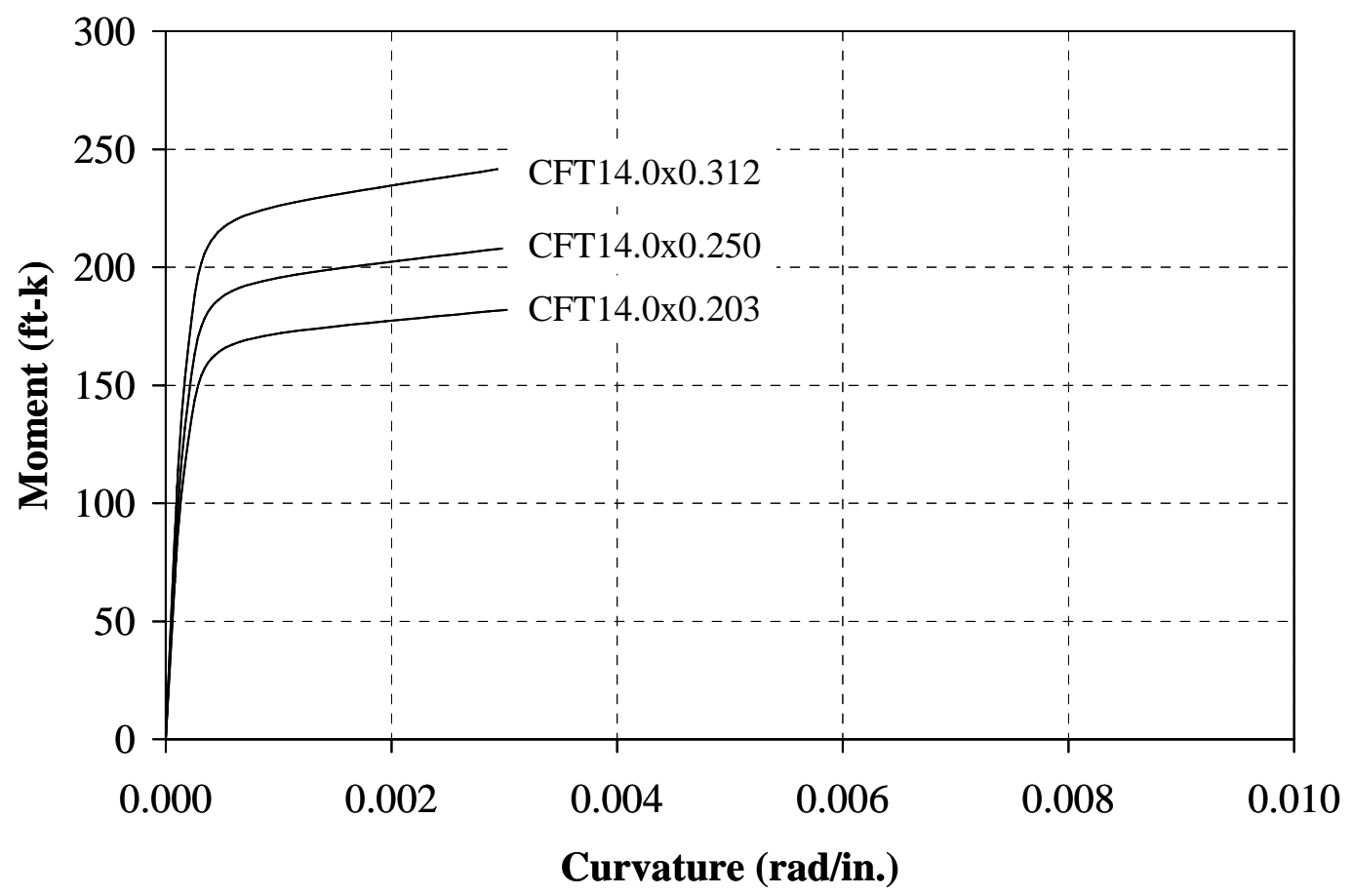

Figure 7.34: Moment-Curvature Relationships of CFT14 Piles

The same method was applied to piles embedded in a very stiff clay and a dense sand to calculate their displacement capacities. Soil properties of a very stiff clay and a dense sand are given in Chapter 4 . The displacements at first yield, $\Delta_{\mathrm{y}}$, and at buckling,

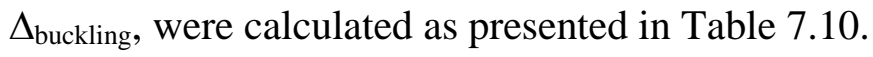




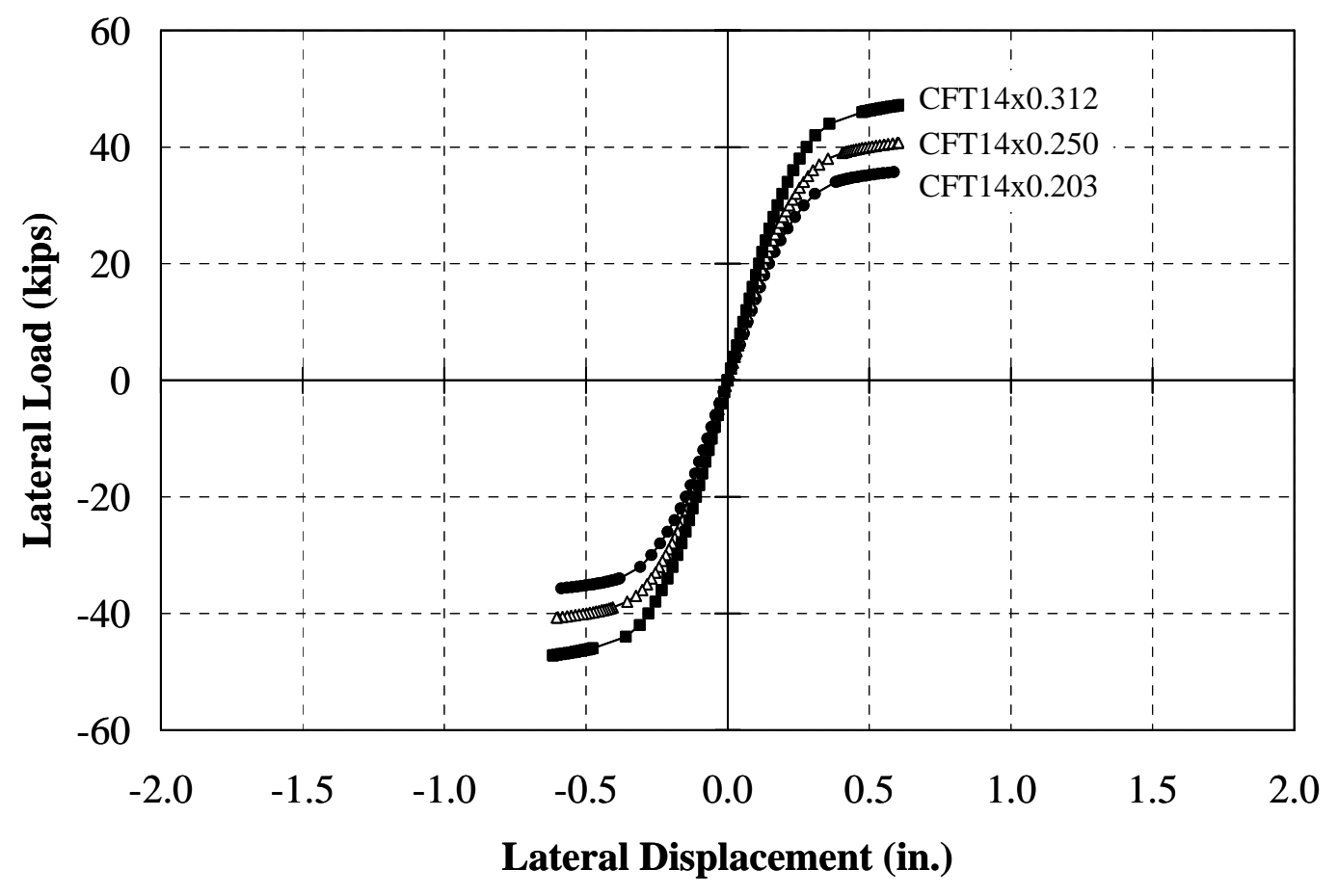

Figure 7.35: Load-Deflection Relationships of CFT14 Piles

Table 7.8: Displacement at $15 \varepsilon_{\mathrm{y}}$

\begin{tabular}{|c|c|c|c|c|}
\hline \multirow{2}{*}{ Section } & \multicolumn{2}{|c|}{ Compact Section Criterion } & Axial Load & $\Delta @ 15 \varepsilon_{\mathbf{y}}$ \\
\cline { 2 - 3 } & $\mathbf{D} / \mathbf{t}$ & & 309 & 0.59 \\
\hline CFT14.0x0.203 & 69 & Noncompact & 309 \\
\hline CFT14.0x0.250 & 56 & Compact & 324 & 0.60 \\
\hline CFT14.0x0.312 & 45 & Compact & 342 & 0.62 \\
\hline
\end{tabular}

$\lambda_{\mathrm{p}}=0.07 \mathrm{E} / \mathrm{F}_{\mathrm{y}}=58$ and $\lambda_{\mathrm{r}}=0.31 \mathrm{E} / \mathrm{F}_{\mathrm{y}}=257$

Table 7.9: Length of the CFT Piles based on LPILE PLUS

\begin{tabular}{|c|c|c|c|c|}
\hline Section & Soil Type & $\begin{array}{c}\text { Pile Length } \\
\text { (ft) }\end{array}$ & $\begin{array}{c}\Delta_{\mathbf{y}} \\
\text { (in.) }\end{array}$ & $\begin{array}{c}\Delta_{\text {buckling }} \\
\text { (in.) }\end{array}$ \\
\hline \multirow{2}{*}{ CFT14.0x0.312 } & Med. Sand & 7.1 & 0.25 & 1.21 \\
\cline { 2 - 5 } & Stiff Clay & 7.6 & 0.30 & 1.46 \\
\hline \multirow{2}{*}{ CFT14.0x0.203 } & Med. Sand & 6.8 & 0.22 & 1.09 \\
\cline { 2 - 5 } & Stiff Clay & 7.4 & 0.27 & 1.29 \\
\hline
\end{tabular}




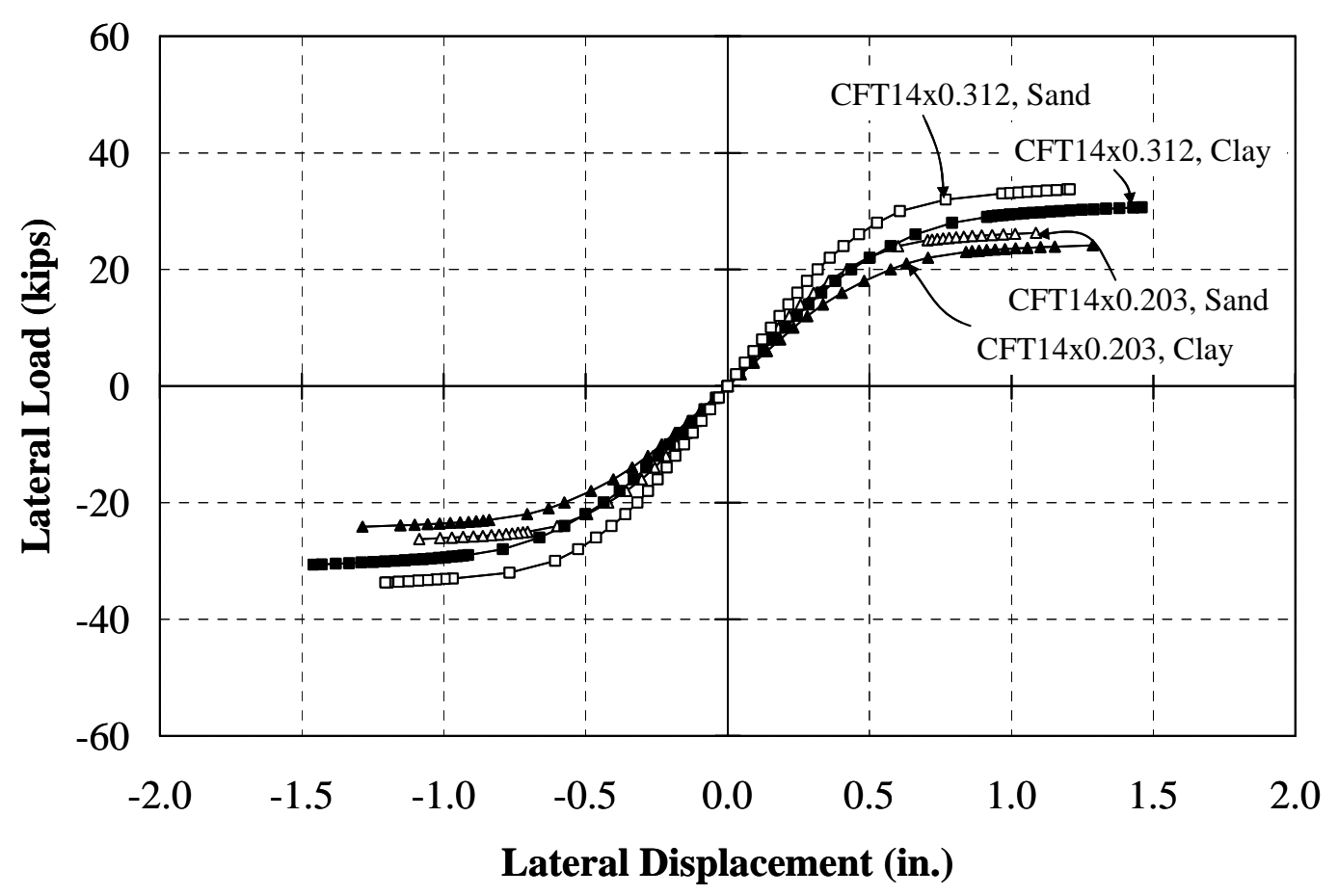

Figure 7.36: Displacement at $15 \varepsilon_{y}$ Based on the Inflection Point using LPILE Table 7.10: Length of the Piles Embedded in Very Stiff Clay and Dense Sand

\begin{tabular}{|c|c|c|c|c|}
\hline Section & Soil Type & $\begin{array}{c}\text { Pile Length } \\
\text { (ft) }\end{array}$ & $\begin{array}{c}\Delta_{\mathbf{y}} \\
\text { (in.) }\end{array}$ & $\begin{array}{c}\Delta_{\text {buckling }} \\
\text { (in.) }\end{array}$ \\
\hline \multirow{2}{*}{ HP14x117 } & Dense Sand & 6.5 & 0.25 & 1.29 \\
\cline { 2 - 5 } & V. Stiff Clay & 6.1 & 0.22 & 1.13 \\
\hline \multirow{2}{*}{ HP14x89 } & Dense Sand & 6.0 & 0.22 & 1.12 \\
\cline { 2 - 5 } & V. Stiff Clay & 5.7 & 0.20 & 1.01 \\
\hline \multirow{2}{*}{ HP12x84 } & Dense Sand & 5.6 & 0.23 & 1.17 \\
\cline { 2 - 5 } & V. Stiff Clay & 5.2 & 0.20 & 1.01 \\
\hline \multirow{2}{*}{ HP12x53 } & Dense Sand & 5.1 & 0.19 & 1.00 \\
\cline { 2 - 5 } & V. Stiff Clay & 4.7 & 0.16 & 0.84 \\
\hline \multirow{2}{*}{ HP10x42 } & Dense Sand & 4.6 & 0.18 & 0.96 \\
\cline { 2 - 5 } & V. Stiff Clay & 4.1 & 0.15 & 0.76 \\
\hline \multirow{2}{*}{ CFT14x0.312 } & Dense Sand & 6.5 & 0.22 & 1.04 \\
\cline { 2 - 5 } & V. Stiff Clay & 6.4 & 0.21 & 1.01 \\
\hline \multirow{2}{*}{ CFT14x0.203 } & Dense Sand & 6.2 & 0.19 & 0.90 \\
\cline { 2 - 5 } & V. Stiff Clay & 6.0 & 0.17 & 0.85 \\
\hline
\end{tabular}




\subsection{Calculated and Measured Movements}

The pile models described in the previous sections were used to predict the behavior of the piles supporting the abutments of the I65 and SR18 bridges. The CFT14x5x0.250 and HP12x53 piles embedded in a wet medium sand as well as the CFT14.0x0.312 piles embedded in a dry medium sand and a dry stiff clay were evaluated as shown in Figures 7.37 and 7.38. The measured abutment movement is approximately twice the tip displacement calculated using the pile model. For I65 over SR25, the expansion and contraction abutment movements obtained from the longitudinal linear potentiometer (Figure 3.18) are approximately 0.2 and 0.7 in., respectively. Therefore, the lateral displacements provided in the pile model are approximately 0.10 and $0.35 \mathrm{in}$., respectively. For SR18 over the Mississinewa River, the expansion and contraction abutment movements measured from a displacement meter (Figure 3.28) are approximately 0.00 and 0.46 in., respectively. Therefore, the lateral displacements provided in the pile model are approximately 0.00 and 0.23 in., respectively. These displacement ranges are superimposed in Figures 7.37 and 7.38 to illustrate the range of pile behavior exhibited in service. As noted, the response is well within the capacity of the piles. Table 7.11 presents the measured movements compared with the calculated movements (displacement at first yield and at buckling) of both bridges. The table indicates that during contraction, the piles supporting abutments of the I65 bridge yielded but did not buckle, while during expansion, the piles did not yield. The piles of the SR18 bridge did not yield during both expansion and contraction. 


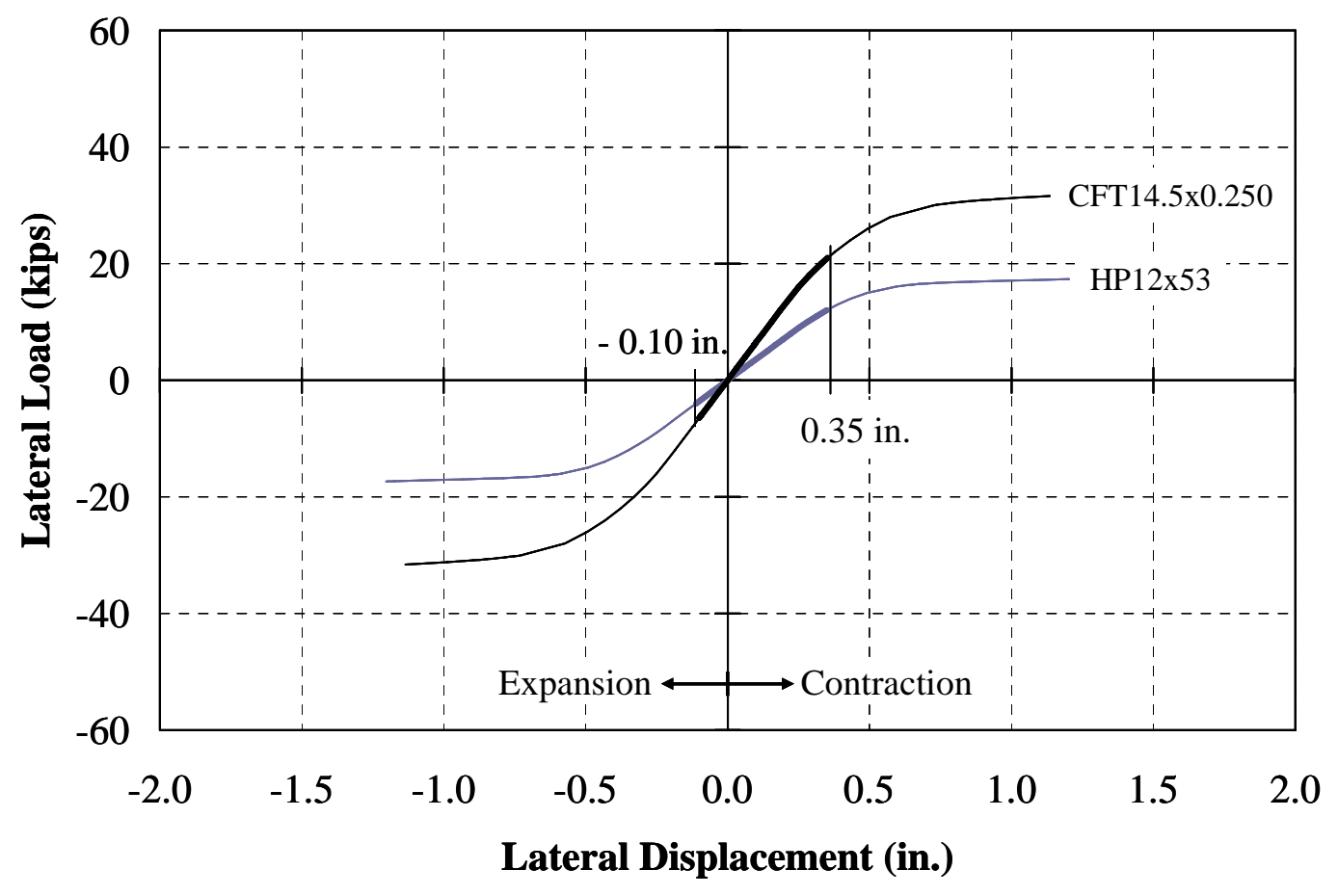

Figure 7.37: Load-Deflection Curves for Piles on I65

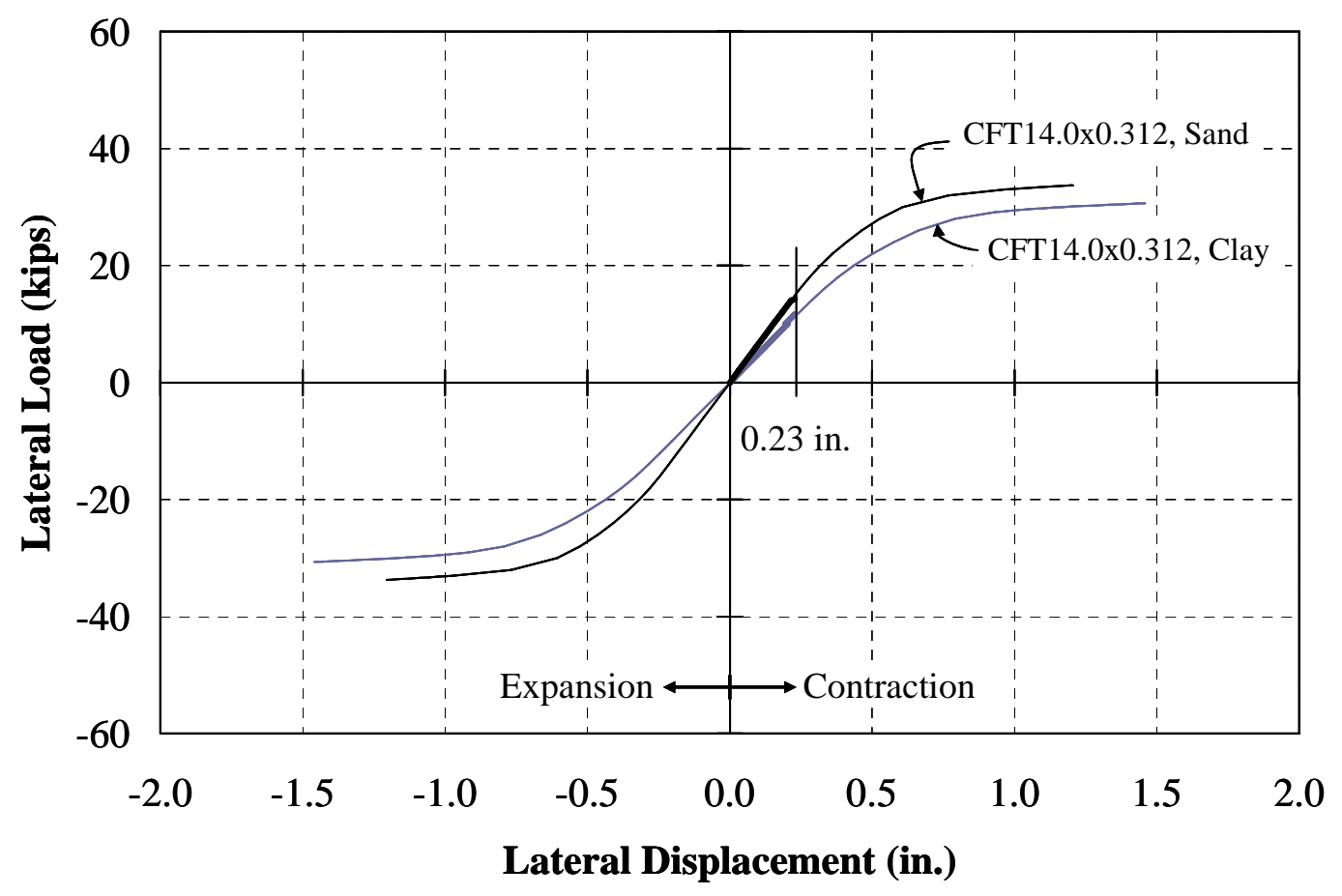

Figure 7.38: Load-Deflection Curves for Piles on SR18 
Table 7.11: Measured and Calculated Movements

\begin{tabular}{|l|c|c|c|c|}
\hline \multirow{2}{*}{ Pile Section } & \multicolumn{2}{|c|}{$\Delta_{\text {Measured }}$} & \multicolumn{2}{c|}{$\Delta_{\text {Calculated }}$} \\
\cline { 2 - 5 } & Contraction & Expansion & $\Delta_{\text {First Yield }}$ & $\Delta_{\text {Buckling }}$ \\
\hline HP12x53 & 0.35 & 0.10 & 0.23 & 1.20 \\
\hline CFT14.5x0.250 & 0.35 & 0.10 & 0.23 & 1.13 \\
\hline CFT14.0x0.312 Sand & 0.23 & 0.00 & 0.26 & 1.21 \\
\hline CFT14.0x0.312 Clay & 0.23 & 0.00 & 0.29 & 1.42 \\
\hline
\end{tabular}

\subsection{Recommended Bridge Length}

The lateral displacements calculated in Section 7.8 were used to calculate the maximum bridge length that these piles can accommodate. As previously discussed in Section 6.5.5, the movement that can be accommodated by the end bent is approximately twice the calculated lateral displacement capacity of the pile since only the depth to the inflection point is considered in the analysis. The total thermal movement of the bridge is, therefore, four times the lateral displacement calculated in Section 7.8. The total bridge lengths are solved using Equation 7-8 are presented in Figure 7.39.

$$
\Delta \mathrm{L}=\alpha(\Delta \mathrm{T}) \mathrm{L}
$$

where:

$\Delta \mathrm{L} \quad=$ four times the displacement calculated in Section 7.8, $\mathrm{ft}$.

$\alpha=$ coefficient of thermal expansion, taken as $6.5 \times 10^{-6} /{ }^{\circ} \mathrm{F}$.

$\Delta \mathrm{T} \quad=$ temperature change, assumed to be $100^{\circ} \mathrm{F}$.

$\mathrm{L} \quad=$ total bridge length, $\mathrm{ft}$. 


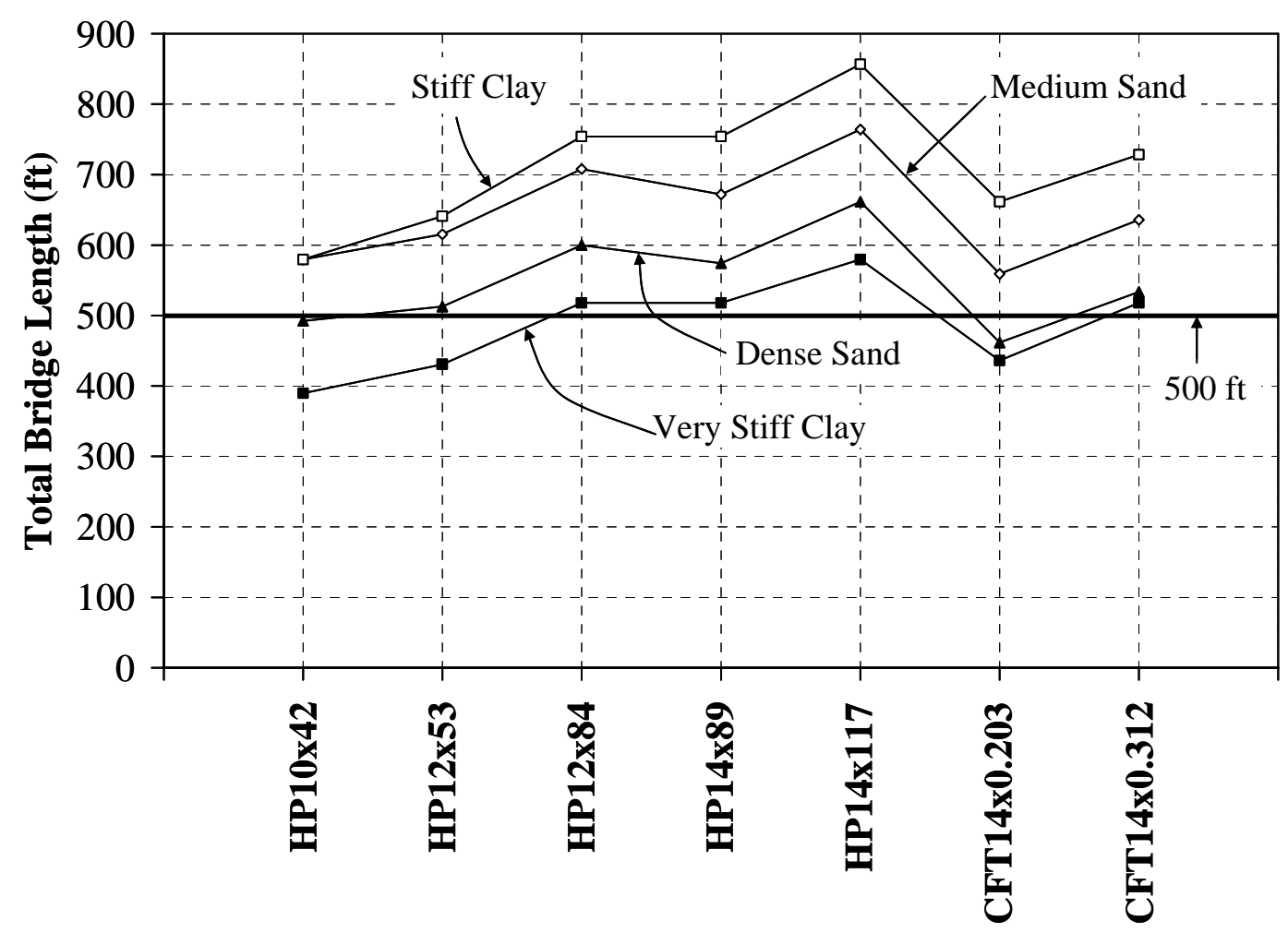

Figure 7.39: Expected Total Bridge Length

It should be noted that the change in temperature, $\Delta \mathrm{T}$, is assumed as $100^{\circ} \mathrm{F}$. This large temperature variation is used as typical bridge construction in Indiana occurs in the summer. Therefore, average construction temperatures are likely around $80^{\circ} \mathrm{F}$. This temperature change accommodates contraction to $-20^{\circ} \mathrm{F}$ and is considered reasonable. The temperature change considered varies from that provided by AASHTO. According to AASHTO, Indiana is located in a cold climate and provides temperature limits of -30 to $120^{\circ} \mathrm{F}$ for steel and 0 to $80^{\circ} \mathrm{F}$ for concrete design.

It is important to note that this analysis assumes minimal deterioration of the abutment-pile connection. Therefore, to achieve the proposed total bridge length, the abutment-pile connection must be detailed to prevent or minimize damage. It can be concluded that as the pile size increases, the total bridge length can be increased. Based on this analysis, Table 7.12 provides the recommended maximum bridge length where the pile is integrally connected to the abutment. This analysis considered embedment in medium and dense sand as well as stiff and very stiff clay. As noted the soil type 
influences the maximum bridge length as well as the stiffness of the pile relative to the soil.

Table 7.12: Recommended Bridge Length

\begin{tabular}{|c|c|c||c|c|}
\hline \multirow{2}{*}{ Section } & \multicolumn{4}{|c|}{ Bridge Length (ft) } \\
\cline { 2 - 5 } & \multicolumn{3}{|c|}{ Clay } & \multicolumn{2}{c|}{ Sand } \\
\cline { 2 - 5 } & Stiff & V. Stiff & Medium & Dense \\
\hline HP14x117 & 860 & 580 & 760 & 660 \\
\hline HP14x89 & 750 & 520 & 670 & 570 \\
\hline HP12x84 & 750 & 520 & 710 & 600 \\
\hline HP12x53 & 640 & 430 & 610 & 510 \\
\hline HP10x42 & 580 & 390 & 580 & 490 \\
\hline CFT14x0.312 & 730 & 520 & 640 & 530 \\
\hline CFT14x0.203 & 660 & 440 & 560 & 460 \\
\hline
\end{tabular}

To provide simplicity, it is recommended that a maximum bridge length of $500 \mathrm{ft}$ can be used without regard to pile type (Figure 7.39). This recommendation is provided for several reasons. First, the stiffnesses provided analytically for very stiff clays and dense sands are uncommon in practical field applications. Second, cyclic response tends to reduce the stiffness (soften) of the soil. Third, the pile sections that provide lengths below $500 \mathrm{ft}$ shown in Figure 7.39 are not typically used in bridge construction. Fourth, these lengths are based on the entire thermal movement being accommodated by the end bent. Field measurements indicate that this displacement is lower than the computed value due to restraint provided by the backfill, pile lateral resistance, and friction from the approach slab. This recommendation, therefore, is considered conservative. 


\section{CHAPTER 8: SUMMARY AND CONCLUSIONS}

\subsection{Introduction}

Integral abutment bridges have been used in the United States for decades. These structures eliminate expensive expansion joints by utilizing the end bent to accommodate the total thermal movement of the bridge. Due to their complexity of response, these bridges are designed based upon experience, and a rational design specification has not been developed. Furthermore, the interaction of the abutment, pile, and soil remains uncertain. A better understanding regarding the behavior of this system is needed. The objective of this research is to evaluate the behavior of the integral abutment-pile system and evaluate any limitations of its use. A goal of the research is to develop minimum design and detailing recommendations. Two phases were conducted: a field investigation and an experimental investigation. In both phases, analytical and parametric studies were performed to further understand the behavior of this structural system. Based on the research performed here, design recommendations are provided regarding the design of the pile system as well as limitations on the overall length for this structural type.

\subsection{Conclusions}

\subsubsection{Field Investigation}

Four integral abutment bridges were instrumented to investigate the in-service behavior of integral abutment bridges as well as the behavior of the piles. Based on the results of the field instrumentation, several conclusions were made: 
1. The abutment responds to temperature changes, and its movement can be estimated conservatively using the theoretical thermal expansion/contraction of the superstructure, $\Delta \mathrm{L}=\alpha(\Delta \mathrm{T}) \mathrm{L}$. The actual displacement is expected to be slightly less due to backfill restraint, pile resistance, and approach slab friction.

2. The abutment primarily translates or "slides" longitudinally in response to thermal expansion and contraction of the bridge. Only minor rotations of the abutment occur and for analysis purposes can be ignored.

3. Piles integrally connected with the abutment bend in double curvature. Lateral displacements in the soil correspond directly with temperature changes. Measures to eliminate the integral abutment-pile connection can be used such as in the SR249 structure to provide for a pinned connection. This connection eliminated the double curvature response.

4. For satisfactory bridge performance, the structure must be detailed and constructed properly.

a. Piles must be constructed and oriented as designed.

b. Intermediate piers should be designed to accommodate lateral displacement or the connection must be detailed to minimize lateral force transfer. If the piers are not designed for the lateral displacement, locking of the superstructure to the intermediate piers must be prevented through isolation.

\subsubsection{Analysis of Field Investigation}

Analytical models were calibrated using the field results. These models were then used to perform a parametric study to evaluate the effect of the primary variables involved in the pile-soil interaction. Based on this study, the following conclusions were reached:

1. Pile axial load does not have a significant effect on the behavior of the pile in the soil. The deflected shape and moment distribution along the pile were not significantly affected.

2. A minimum pile length must be provided below ground level in order to prevent displacement at the base of the pile. 
3. For the same soil type, as the pile stiffness increases due to size or orientation, the deflected shape of the pile is affected. The inflection point, the final zero deflection, and the final zero moment depths increase.

4. For the same pile type and orientation, as the soil stiffness increases, the deflected shape of the pile is affected. The inflection point, the final zero deflection, and the final zero moment depths decrease.

\subsubsection{Experimental Investigation}

Six steel $\mathrm{H}$ piles and three concrete-filled steel tube piles (CFT) were tested to evaluate the capability of the piles to maintain axial load under low-cycle, large amplitude lateral displacement and to investigate the performance of the abutment-pile connection. Variables included the pile size, axial load, and pile orientation. Based on the results of the experimental instrumentation, several conclusions were made:

1. The pile was able to maintain axial loads while undergoing cyclic lateral displacements post-yield. In general, no degradation in the load-displacement response was evident. The piles demonstrated that they can be loaded past the yield displacement and provide for a 50-100 year bridge life.

2. Once local buckling of the pile was observed, significant deterioration and damage occurred in the local region of the pile. Damage accumulation was observed and noted in the load-deflection response. Cycling at the displacement level that initiated local buckling eventually led to fracture of the section. Therefore, local buckling should be prevented to provide for a 50-100 year bridge life.

3. Significant deterioration occurred at the abutment-pile connection that can prevent achievement of design life. This deterioration was more severe as the pile stiffness increased.

4. As the pile size was increased, the lateral load resistance increased while the displacement capacity and ductility decreased.

5. As the axial load was increased, the lateral load resistance decreased along with the displacement capacity. 
6. As the pile orientation was rotated from weak axis to strong axis, the lateral load resistance increased while the displacement capacity decreased. Severe deterioration of the strong axis specimen was observed that limited its performance.

\subsubsection{Analysis of Experimental Investigation}

Analytical models were developed for the piles tested in the experimental

program. The models were compared with the measured response and calibrated. A goal of the analysis was to provide a model that could estimate the load-displacement response and predict local buckling of the pile. Both bilinear and trilinear steel models and the modified Hognestad concrete model were utilized to develop these simplified models. Based on this analysis, the following conclusions were reached:

1. For the H piles, a simple, trilinear steel model could be used to estimate the response. For the CFT piles, a composite model using a bilinear steel model and the modified Hognestad model could be used to estimate the response.

2. Local pile buckling could be reasonably estimated based on the extreme fiber strain. It was determined that a strain capacity of $20 \varepsilon_{y}$ could be used to estimate local buckling for $\mathrm{H}$ piles while a strain capacity of $15 \varepsilon_{\mathrm{y}}$ could be used for CFT piles.

\subsection{Design Recommendations}

Based on the results of the field, experimental, and analytical studies, the following recommendations are provided. In general, these recommendations are directed towards the pile behavior.

1. Piles sizes should be selected to provide adequate axial capacity while minimizing their bending resistance along the longitudinal axis of the bridge. This selection provides for maximum ductility response while minimizing stresses at the abutmentpile connection

2. Piles should be oriented about their weak axis. This orientation provides for maximum ductility response while minimizing stresses at the abutment-pile connection. 
3. Axial load should be limited to $0.25 f_{y} A_{s}$ for $H$ piles and $0.25 f_{y} A_{s}+0.4 f_{c}^{\prime} A_{c}$ for CFT piles. This axial load level which is currently stipulated by AASHTO based on pile driving stresses provides adequate displacement response and ductility. Higher stress levels demonstrate a lower ductility capacity.

4. The minimum embedment length of 15 in. often specified for pile embedment should be increased and/or confinement steel should be provided. Additional research in this regard is needed to quantify the effect, but it is recommended that a minimum of 24 in. be provided at this time. Significant deterioration of the pile-abutment connection occurred for the larger pile sections that can limit the response and behavior of the pile-abutment system.

5. A minimum pile length below ground is required to prevent displacement at the pile base. The minimum length depends on pile size as well as soil type and is provided as follows:

Table 8.1: Minimum Pile Length

\begin{tabular}{|l|c|c|}
\hline \multirow{2}{*}{ Pile Size } & \multicolumn{2}{|c|}{ Minimum Depth (ft) } \\
\cline { 2 - 3 } & Clay & Sand \\
\hline HP10 & 30 & 25 \\
\hline HP12 & 35 & 25 \\
\hline HP14 & 40 & 30 \\
\hline CFT14 & 50 & 35 \\
\hline
\end{tabular}

6. Bridges designed considering the above recommendations can be constructed up to a maximum total length of $500 \mathrm{ft}$ for both steel and concrete superstructures. This recommendation is based on consideration of structures with skews less than 30 degrees. The length limit was selected to limit local pile buckling and provide for a bridge life of 100 years. Lengths longer than this limit are possible if the bridge deck casting which provides continuity for the integral bridge is conducted at temperatures less than $60^{\circ} \mathrm{F}$. For temperatures in the range of $40-50^{\circ} \mathrm{F}$, the bridge length can be extended to $770 \mathrm{ft}$. Casting at moderate temperatures should be encouraged. 


\subsection{Recommendations for Further Research}

Several recommendations are provided regarding further research that should be conducted to further understand the behavior of this structural system.

1. Bridges instrumented as part of this study should be continued to be monitored to evaluate long term performance. Of particular interest is the effect of annual cycle on abutment ratcheting.

2. The current research provides information on the behavior of integral bridges with a small skew. Field instrumentation should be performed on integral bridges with greater skews to determine the effects of this parameter on the behavior of these bridges and in particular the pile response.

3. Due to laboratory restraints, the experimental study involved relatively small $\mathrm{H}$ and CFT piles relative to the piles widely used in typical integral bridges in Indiana. Fullscale laboratory experiments should be performed on larger $\mathrm{H}$ and CFT sections (for example, HP14x89 and CFT14.0x0.312). These tests should evaluate the effect of embedment length and confinement to provide additional guidance regarding this aspect of the design of the abutment-pile connection.

4. Additional piles should be instrumented in the field to further determine the effect of the soil on the pile behavior. It was be advantageous to embed in different soil types to refine analytical models and further understand the soil-structure interaction.

5. Nonlinear finite element models for the piles supporting integral abutment should be developed to improve the prediction of pile local buckling.

6. Integral bridges subjected to seismic loading should be evaluated. 


\section{LIST OF REFERENCES}




\section{LIST OF REFERENCES}

1. AASHTO (1996), Standard Specifications for Highway Bridge, $16^{\text {th }}$ Edition, American Association of State Highway and Transportation Officials, Washington, D.C., 1996.

2. Abendroth, R.E., Greimann, L.F., Ebner, P.B. (1989), “Abutment Pile Design for Jointless Bridges,” Journal of Structural Engineering, Vol. 115, No. 11, November 1989, pp. 2914-2929.

3. ACI Committee 318 (2002), "Building Code Requirements for Structural Concrete (318-02),” American Concrete Institute, Farmington Hills, MI, 443 pp.

4. AISC-LRFD Specification (2001), "Manual of Steel Construction, Load and Resistance Factor Design”, $3^{\text {rd }}$ edition, American Institute of Steel Construction, 2001.

5. Arsoy, S. et al. (1999), “The Behavior of Integral Abutment Bridges,” Final Contract Report, Virginia Transportation Research Council, Charlottesville, Virginia, November 1999.

6. ASTM A252-98 (Reapproved 2002), "Standard Specification for Welded and Seamless Steel Pipe Piles,” West Conshohocken, PA: ASTM, 1998, 7 pp.

7. ASTM A370-02 (2002), "Standard Test Methods and Definitions for Mechanical Testing of Steel Product,” West Conshohocken, PA, ASTM, 2002, 52 pp.

8. ASTM C39/C39M-01 (2001), "Standard Test Method for Compressive Strength of Cylindrical Concrete Specimens,” West Conshohocken, PA, ASTM, 2001, 5 pp.

9. ASTM C469-02 (2002), "Standard Test Method for Static Modulus of Elasticity and Poisson's Ratio of Concrete in Compression,” West Conshohocken, PA, ASTM, 2002, 4 pp. 
10. Ashour, M., Norris, G., and Shamsabadi, A. (2001), "Effect of the Non-Linear Behavior of Pile Material on the Response of Laterally Loaded Piles," Proceedings, Fourth International Conference on Recent Advances in Geotechnical Earthquake Engineeing and Soil Dynamics and Symposium in Honor of Professor W.D. Liam Finn, San Diego, California, March 26-31, 2001, pp. 1-8.

11. Bowman, E.R., (1958), "Investigation of the Lateral Resistance to Movement of a Plate in Cohesionless Soil," Thesis submitted to the University of Texas at Austin, 1958.

12. Boyd, P.F., Cofer, W.F., and McLean, D.I. (1995), "Seismic Performance of SteelEncased Concrete Columns under Flexural Loading," ACI Structural Journal, Technical Paper, Title No. 92-834, May-June 1995, pp. 355-364.

13. Burdette, E.G., Ingram, E.E., Goodpasture, D.W., and Deatherage, J.H. (2002), "Behavior of Concrete Integral Abutments," Concrete International, July 2002, pp.49-53.

14. Burke, M. P. Jr. (1993), “The Design of Integral Concrete Bridges,” Concrete International: Design and Construction, Vol. 15, No. 6, June 1993, pp. 37-42.

15. Davisson, M. T. (1970), "Lateral Load Capacity of Piles,” Highway Research Record No. 333, National Academy of Sciences, Washington, D.C., 1970, pp. 104-112.

16. Durbin, K.O. (2001), "Investigation of the Behavior of an Integral Abutment Bridge," M.S. Thesis, Purdue University, West Lafayette, IN, 2001, 138 pp.

17. Elremaily, A., and Azizinamini, A. (2000), "Behavior of Circular Concrete-Filled Steel Tube Columns," Composite Construction in Steel and Concrete IV, Proceedings of the Conference, May 28-June 2, 2000, Banff, Alberta, Canada; sponsored by United Engineering Foundation, Inc., by Jerome F. Hajjar, (editor), Mel Hosain, (editor), W. Samuel Easterling, (editor), and Bahram M. Shahrooz, (editor), 2002, pp. 573-583.

18. Federal Highway Administration (1980), "Integral, No-Joint Structures and Required Provisions for Movement,” FHWA Technical Advisory T5140.13, U.S. Department of Transportation, Washington, D.C., January 28, 1980.

19. Frosch, R. J. (1999), "Shear Transfer between Concrete Elements Using Steel Pipe Connection," ACI Structural Journal, Technical Paper, November-December 1999, pp. 1003-1008. 
20. Furlong, R.W. (1967), "Strength of Steel-Encased Concrete Beam Columns," Journal of the Structural Division, Proceedings of the American Society of Civil Engineers, Vol. 93, No. ST5, October 1967, pp. 113-124.

21. Girton, D.D., Hawkinson, T.R., and Greimann, L.F. (1991), "Validation of Design Recommendations for Integral-Abutment Piles,” Journal of Structural Engineering, ASCE, Vol. 117, No. 7, July 1991, pp. 2117-2134.

22. Greimann, L.F., et al. (1987), "Pile Design and Tests for Integral Abutment Bridges," Final Report, Department of Civil Engineering, Engineering Research Institute, Iowa State University, Ames, Iowa, December 1987, 302 pp.

23. Greimann, L.F., Yang, P.S., and Wolde-Tinsae, A.M. (1986), "Nonlinear Analysis of Integral Abutment Bridges,” Journal of Structural Engineering, ASCE, Vol. 112, No. 10, 1986, pp. 2263-2280.

24. Hajjar, J. F. and Gourley, B. C. (1996), "Representation of Concrete-Filled Steel Tube Cross-Section Strength," Journal of Structural Engineering, Vol. 122, No. 11, November 1996, pp. 1327-1336.

25. Hognestad, E., (1951), "A Study of Combined Bending and Axial Load in Reinforced Concrete Members," Bulletin 399, The Reinforced Concrete Research Council of the Engineering Foundation, University of Illinois Engineering Experiment Station, Urbana, Illinois, November 1951, 128 pp.

26. Indiana Department of Transportation (1992a), Inter-Department Communication, Bridge Design Memorandum \#233 Revised. Indiana, November 1992, 5 pp.

27. Indiana Department of Transportation (1992b), Inter-Department Communication, Bridge Design Memorandum \#243 Revised, Indiana, December 1992, 3 pp.

28. Indiana Department of Transportation (1992c), Inter-Department Communication, Bridge Design Memorandum \#246 Revised, Indiana, October 1992, 13 pp.

29. Indiana Department of Transportation (1999), Standard Specifications, 1999, 888 pp.

30. Kent, D.C., and Park, R. (1971), "Flexural Members with Confined Concrete," ASCE Journal, Vol. 97, No. ST7, July 1971. 
31. Kilpatrick, A., and Rangan, V. (1999), "Tests on High-Strength Concrete-Filled Steel Tubular Columns," ACI Structural Journal, March-April 1999, pp. 268-274.

32. Knowles, B. and Park, R. (1969), "Strength of Concrete Filled Steel Tubular Columns," Journal of the Structural Division, ASCE, Vol. 95, No. ST12, December 1969, pp. 2565-2587.

33. Mander, J.B., Priestley, J.N., and Park, R. (1988), "Theoretical Stress-Strain Model for Confined Concrete," Journal of Structural Engineering, Vol. 114, No. 8, August 1988, pp.1804-1826.

34. Matlock, H. (1970), “Correlations for Design of Laterally Loaded Piles in Soft Clay,” Proceedings, the Second Annual Offshore Technology Conference, Houston, Texas, Vol. I, Paper No. 1204, 1970, pp. 577-594.

35. Neogi, P.K., Sen, H.K., and Chapman, J.C. (1969), "Concrete-Filled Tubular Steel Columns under Eccentric Loading," Journal of Structural Engineering, Vol. 47, No. 5, May 1969, pp. 187-195.

36. Oesterle, R.G., Tabatabai, H., Lawson, T.J., Refai, T.M., Volz, J.S., and Scanlon, A. (1998), "Jointless and Integral Abutment Bridges: Summary Report," Final Report Summitted by Construction Technology Laboratories, Inc. of Skokie, IL, to be published, FHWA, Contract No. DTFH61-92-C-00154, 2002.

37. Parker, F. Jr. and Reese, L.C. (1971), "Experimental and Analytical Studies of Behavior of Single Piles in Sand under Lateral and Axial Loading," Research Report 117-2, Center for Highway Research, the University of Texas at Austin, 1971.

38. Rangan, V. and Joyce, M. (1992), "Strength of Eccentrically Loaded Slender Steel Tubular Columns Filled with High-Strength Concrete," ACI Structural Journal, November-December 1992, pp. 676-681.

39. Ravat, S.V. (1997), "Low Cycle Fatigue Behavior of Steel Piles," Master Thesis Submitted to the University of California at Berkeley, December 1997.

40. Reese, L.C. (1958), Discussion of “Soil Modulus for Laterally Loaded Piles," by McClelland and Focht, Transactions, American Society of Civil Engineers, Vol. 123, 1958, pp. 1071-1074. 
41. Reese, L.C. and Welch, R.C. (1975), "Lateral Loading of Deep Foundations in Stiff Clay," Journal of the Geotechnical Engineering Division, American Society of Civil Engineers, Vol. 101, No. GT7, February 1975, pp. 633-649.

42. Reese, L.C., Cox, W.R., and Koop, F.D. (1974), "Analysis of Laterally Loaded Piles in Sand," Proceedings, Offshore Technology Conference, Houston, Texas, Vol. II, Paper No. 2080, 1974, pp. 473-484.

43. Reese, L.C., et al., (2000a), "Computer Program LPILE Plus Version 4.0 - A Program for the Analysis of Piles and Drilled Shafts under Lateral Loads-Technical Manual," ENSOFT, INC., October 2000, 278 pp.

44. Reese, L.C., et al. (2000b), "Computer Program LPILE Plus Version 4.0 - A Program for the Analysis of Piles and Drilled Shafts under Lateral Loads-User's Manual," ENSOFT, INC., October 2000, 305 pp.

45. Russell, H. G. and Gerken, L. J. (1994), "Jointless Bridges - the Knowns and the Unknowns,” Concrete International, Vol. 16, No. 4, April 1994, pp. 44-48.

46. Salmon, C.G. and Johnson J.E., (1996), "Steel Structures Design and Behavior," Fourth Edition, HarperCollins Publishers Inc., 1996, 1024 pp.

47. Steel Bridges (1993), “Why Integral Bridges?,” Steel Bridges, News and Information from the Steel Bridge Forum, Summer/Fall, 1993, pp.1-6.

48. Terzaghi, K. (1955), "Evaluation of Coefficients of Subgrade Reaction,” Geotechnic, Vol. 5.5, December 1955, pp. 297-326.

49. Wasserman, E. P. and Walker, J. H. (1996), "Integral Abutments for Steel Bridges," Highway Structures Design Handbook, Tennessee Department of Transportation, Volume II, Chapter 5, American Iron and Steel Institute, October 1996.

50. Welch, R.C. and Reese, L.C., "Laterally Loaded Behavior of Drilled Shafts," Research Report No. 3-5-65-89, Center for Highway Research, the University of Texas at Austin, May 1972.

51. Wolde-Tinsae, A.M., Greimann, L.F., and Yang, P.S. (1982), "Nonlinear Pile Behavior in Integral Abutment Bridges,” Iowa DOT Project HR-227, ERI Project 1501, ISU-ERI-Ames 82123, February 1982. 
APPENDIX A

INDOT BRIDGE DESIGN MEMORANDUMS 


\section{INDIANA DEPARTMENT OF TRANSPORTATION}

INDIANAPOLIS, INDIANA 46204-2249

INTER-DEPARTMENT COMMUNICATION

November 2, 1992

\section{BRIDGE DESIGN MEMORANDUM \# 233 Revised}

TO: All Pesion, Qperations, and District Personnel, and Consultants

THRO:

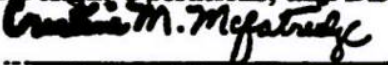

cristine H. Maratridge

Design 8ervices Hanager.

FROK:

piviajon of pesign

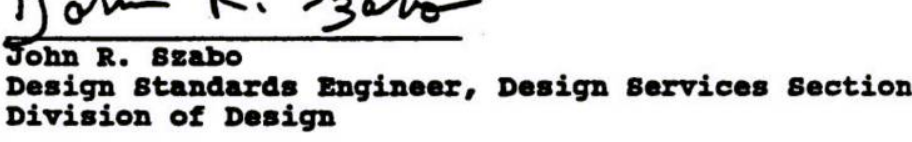

SUBJECT: Integral End Bents.

SUPERSEDES: Bridge Memorandum 233, Revised April 14, 1989.

EFFECTIVE: The revisions concerning reinforcing steel lap lengths shall be effective on all applicable bridge projects which are being designed using Grade 60 reinforcing steel in accordance with Bridge Design Memorandum "246, issued October 1, 1992. The revisions concerning the correction of the welding symbols shall be effective immediately.

\section{November 2, 1992 Revisions and Additions}

The November 2, 1992 revisions to this memorandum are on the attached Suggested Integral End Bent Details. The welding symbols have been corrected on both sets of details. Also, the lap lengths have been increased on both sets of details to correspond to the Department's changeover to the exclusive use of Grade 60 reinforcing steel, in accordance with Bridge Design Memorandum \$246, issued October 1, 1992. The sections concerning the effective date for beginning the use of integral end bent design, and the background of integral end bent design, have been deleted. The sections concerning the special provisions and pay items have been revised. The remainder of this memorandum is identical to the version issued on April 14, 1989.

\section{APPLICATION TO NEW BRIDGES}

(March 10, $1989 \&$ April 14, 1989)

The use of integral end bents for new steel beam or girder, and prestressed concrete I-beam and box beam bridges should be considered, and their use is strongly recommended at structures which meet the following geometric limitations;

Page 1 of 5 
Bridge Design Memorandum 1233 , Revised November 2, 1992 Be: Interral End Bents

\section{1) Kaximum Bridge Iength:}

a) steel structures - 250 feet (125 feet from the structure fixed point to the end bent);

b) Prestressed Concrete structures - 300 feet (150 feet from the structure fixed point to the end bent);

2) Maximum Bridge 8kew: 30 degrees.

The maximum lengths indicated above may be increased, subject to approval, if a rational analysis of induced pile stresses indicates that the piles are not over-stressed. Two rational analysis methods are presented in the report, "Pile Design and Tests for Integral Abutment Bridges", available from the Iowa Department of Transportation.

Integral end bents will continue to be used for reinforced concrete slab structures, regardless of the skew, using the same details as have been used in the past, but the maximum bridge length has been increased to 200 feet.

\section{APPLICATION TO BRIDGE REPAIR PROJECTS}

(March 10, 1989 \& April 14, 1989)

The conversion of existing bridges to integral end bent structures should also be considered for repair projects. Due to the many different types of bridges and the type of repair, no definite criteria can be suggested for when to make the conversion. However, when the mudwalls of the existing end bents are to be removed, conversion should be actively pursued, using the criteria for new bridges as a guideline.

\section{GENERAL DESIGN CRITERIA \\ (March 10, 1989 \& April 14, 1989)}

The following requirements must be satisfied in all cases where integral end bents are used;

1) "B" Borrow for Structure Backfill must be specified behind the end bents for a distance of $1^{\prime}-6^{\prime \prime}$ at the base of the cap, as shown on Bridge standard S1. This fill must be drained with a 6 " perforated pipe;

2) A reinforced concrete bridge approach, anchored to the end bent with $\$ 6$ bars spaced at 9 " centers, shall be used at all integral end bents regardless of the traffic count. Two layers of $6 \mathrm{mil}$ (minimum) polyethylene shall be specified between the concrete bridge approach and the subgrade. A rigid approach is necessary to prevent compaction of the backfill behind the end bent. Bituminous bridge approaches shall not be specified;

3) A 2'-on wide terminal joint or pavement relief joint shall be used at the roadway end of the concrete bridge approach slab if any portion of the adjacent pavement section is concrete. No sucr joint is required if the entire adjacent pavement section is bituminous. 
Bridge Design Memorandum 1233 , Revised November 2, 1992 Be: Internil End Bents

\section{SUPERSTRUCTURE AND INTERIOR SUBSTRUCTURE DESIGN CRITERIA (March 10, 1989 \& April 14, 1989)}

There will be no changes in the usual design methods for the superstructure or the interior piers when integral end bents are used. Although the ends of the superstructure are monolithically attached to the end bents, it shall be assumed that enough rotation occurs in the piling to provide a pinned end condition. The following design assumptions shall be made;

1) The ends of the superstructure are free to rotate and translate longitudinally;

2) The restraining effect of passive earth pressure behind the end bents shall be neglected when considering superstructure longitudinal force distribution to the interior piers;

3) When steel beam or girders are used, an interior diaphragm should be placed within 10 feet of the end support to provide beam stability during the deck pour.

END BENT DESIGN CRITERIA

(March 10, 1989 \& April 14, 1989)

1) Only vertical loads shall be considered when designing end bent piling for structures having lengths below the maximum values designated herein. Pile bending stresses due to temperature, shrinkage, and horizontal soil pressure forces shall be neglected;

2) Only steel $\mathrm{H}$ piles or steel encased concrete piles will be permitted at integral end bents. The use of steel $\mathrm{H}$ piles is preferred. When the $\mathrm{H}$ pile is used as a friction pile and soil conditions permit, the allowable bearing pressure shall be increased above the usual 40 tons when economically feasible, but the pile shall be stressed to no more than $9 \mathrm{ksi}$. Steel H pile webs shall be placed perpendicular to the centerline of the structure to minimize pile bending stresses. All end bent piling shall be driven vertically and only one row of piling will be permitted;

3) When an existing cohesive earth stratum, with a standard penetration resistance (N) exceeding 35 blows per foot, is located within the 10 foot interval below the bottom of the cap, the pile shall be placed in an oversized predrilled hole before driving. The predrilled hole shall extend 8 feet below the bottom of the cap. The minimum diameter of the oversized hole shall be 4 inches greater than the maximum cross sectional dimension of the pile. The hole shall be backfilled with uncrushed coarse aggregate size $\$ 12$ (pea gravel) following the pile driving operation; 
Bridge Design Memorandum $\dddot{233}$, Revised November 2, 1992

Re:Interal Find Bents

\section{END BENT DESIGN CRITERIA - CONT'D.}

(March 10, 1989 \& April 14, 1989)

4) The connection between the wingwall and the end bent cap should be given special attention. In general, the wingwall should extend no more than 10 feet behind the rear face of the cap. If longer extensions are necessary, stresses in the connection between the wingwall and cap, and in the wingwall itself, shall be investigated and adequate reinforcing steel provided.

END BENT DETAIIS

(March 10, 1989 \& April 14, 1989)

Integral end bents may be designed and detailed using either of the following methods:

METHOD A: The superstructure beams may be placed on, and attached directly to the end bent piling. The entire end bent shall then be poured integrally with the superstructure slab. This is the preferred method.

METHOD B: The superstructure beams may be set in place and anchored to the previously cast-in-place end bent.

Regardless of the method used, the end bent details shall conform to the following minimum requirements:

1) The minimum end bent width shall be $2^{\prime \prime}-6^{\prime \prime}$;

2) The piling shall extend a minimum of $2^{\prime}-0^{\prime \prime}$ into the cap when using Hethod $A$, and a minimum of $1^{\prime}-3^{\prime \prime}$ into the cap when using Method $B$;

3) The beams must be physically attached to the end bent piling when using Method A, and to the cast-in-place cap when using Method B;

4) The beams must extend at least 1'-9" into the bent, measured along the centerline of the beam;

5) Concrete cover beyond the farthest most edge of the beam at the rear face of the bent shall be a minimum of 4 inches. This minimum cover shall also apply to the pavement ledge area. The top flange of steel beams and prestressed I-beams may be coped to meet this requirement. When the 4 inch minimum cover cannot be maintained using a 2'-6' cap, the cap shall be widened;

6) Steel beams and girders shall have $1 / 2^{\mathrm{n}}$ stiffener plates welded to both sides of the web and to the flanges over the supports, to anchor the beams into the concrete. In addition, a minimum of three holes shall be provided thru the webs of steel beams and girders, and two holes thru prestressed I-beam webs near the front face of the bent, to allow $\$ 6$ bars to be inserted to further anchor the beam to the cap. Box beams shall have two $3 / 4$ inch inserts placed in each side panel for anchorage purposes; 
Bridge Design Memorandum 1233, Revised November 2, 1992 Re: Interral End Bents

END BENT DETAILS - CONT'D.

(March 10, 1989 \& April 14, 1989)

7) The minimum size and spacing of stirrups shall be \#6 a 1'-0". Longitudinal cap reinforcing shall be $\$ 7$ i'-0" maximum spacing along both faces of the bent;

8) The use of continuous corner bars extending from the rear face of the cap into the top of the slab at approximately 1'-0" spacing (as shown on the attached details) is mandatory.

\section{DETAIIS FOR PLANS \\ (Revised November 2, 1992)}

The attached details are only suggested details. They are not intended as absolute detailing requirements. Other reinforcing and connection details should be considered and used when they are structurally sound and afford a definite advantage over those shown on the attached sheets. The November 2, 1992 revisions to these details were changes to the welding symbols and the bar lap lengths.

\section{ADDITIONAL SOIL INFORMATION REQUIREMENTS (Added April 14, 1989)}

The Geotechnical Section of the Division of Materials and Tests will provide the additional soils information needed for integral end bent I-beam structures. This additional information is an estimated pile tip elevation for steel $\mathrm{H}$ piles, when the $\mathrm{H}$ pile is loaded to 55 and 70 tons. These are the capacities of the smallest 10 inch and 12 inch steel H piles, respectively, when the gross area is stressed to $9 \mathrm{ksi}$. These additional pile tip elevations will only be required for steel $\mathrm{H}$ piles used at the end bents of integral end bent I-beam structures. The following note shall be added to the soil boring location plan sheet, on those plans requiring this additional information:

"Pile tip elevations for steel H piles loaded to 40, 55, and 70 tons should be evaluated at Bents and ."

The designer shall be responsible for determining when the use of the longer, higher capacity piles, is economical.

\section{SPECIAL PROVISIONS AND PAY ITEMS \\ (Revised November 2, 1992)}

Special Provision 701-B-078, noversized Predrilled Pile Holes For Integral End Bent Structures" which was distributed with the April 14, 1989 issuance of this memorandum is now contained in the Department's Recurring Special Provisions Book. This special provision shall still be included in those contracts for integral end bent structures where the blow counts (N) exceed 35 blows per foot within the 10 foot interval below the bottom of the cap. The piles will be paid for in accordance with the standard specifications. The oversized predrilled pile holes and the uncrushed gravel backfill will be paid for in accordance with Special Provision 710-B-078.

[b2331192.wp] 
Attachment if - Bridae Desian Memorandum 2033. Revised Norember 2.1992

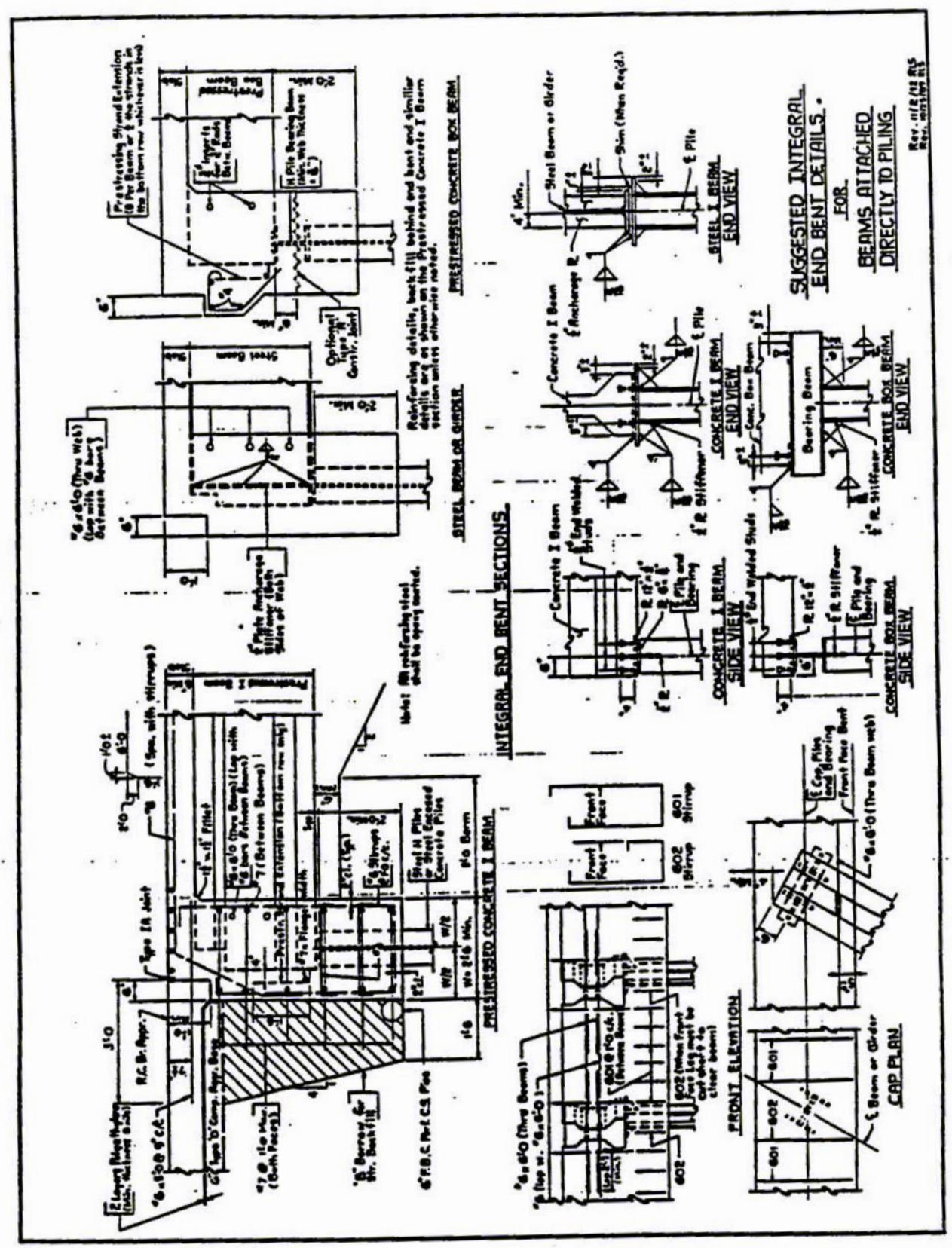


Attachment i2 - Bridge Desiqn Memorandum 233, Revised November 2, 1922

-.

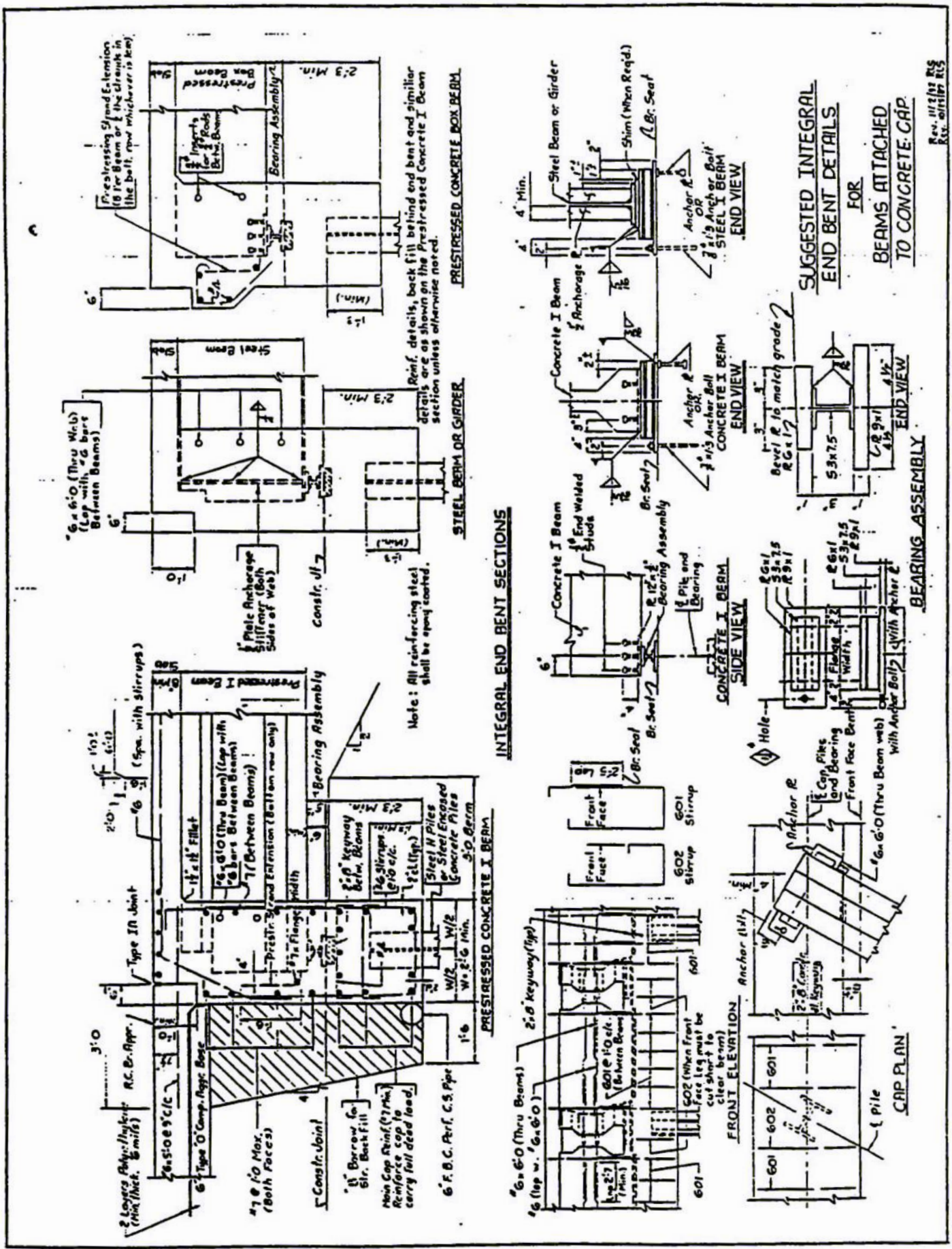




\section{INDIANA DEPARTMENT OF TRANSPORTATION}

INDIANAPOLIS, INDIANA 46204-2249

INTER-DEPARTMENT COMMUNICATION

DECEMBER 1, 1992

\section{BRIDGE MEMORANDUM \# 243 REVISED}

TO: All Design, Operations, and District Personnel, and Consultants

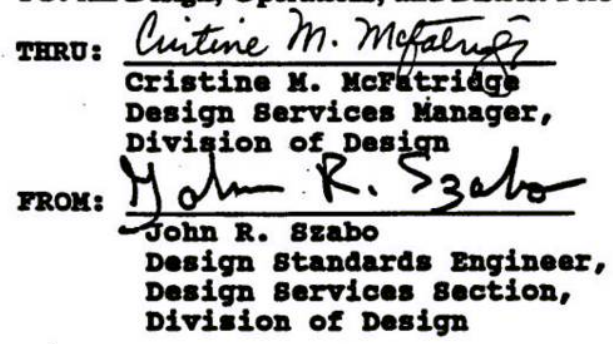

SUBJECT: Epoxy Coated Steel (Metal) Shell Encased Piles, Epoxy Coated Steel H Piles, and Revised Pay Items for All Pile Types.

EFFECTIVE: Immediately on all bridge projects.

SUPERSEDES: Bridge Memorandum $\# 243$, dated October 1, 1991; Item \#1 of Bridge Memorandum 226 dated August 24, 1987; Section 8-335.03 Metal Shell and the third paragraph of Section 8-355.12 Pile Bents of the Bridge Design Manual.

A) CARRY-OVER: The following items are a carry-over from Bridge Memorandum \$243, dated October 1, 1991:

1) only fusion bonded (powdered epoxy resin) epoxy coating shall be used to coat all epoxy coated piles. The liquid applied coal tar epoxy will no longer be allowed for this application;

2) Steel shell piles shall be fourteen (14) inch diameter only, and the $12^{\mathrm{m}}$ diameter shall no longer be allowed as an alternate.

3) The reinforced concrete portion of the steel shell pile shall extend to a depth of ten (10) feet below the flow line elevation.

4) The payment for steel shell pile shall be in accordance with the type of shell coating and the type of concrete filling;

5) Item $\$ 1$ of Bridge Memorandum $\$ 226$ dated August 24,1987 is deleted;

6) Section 8-355.12, Paragraph Three, Pile Bents, of the Bridge Design Manual is deleted;

7) The specified wall thickness of the steel pile shell shall be the minimum wall thickness that the contractor will be permitted to use;

Page 1 of 3 
Bridge Memo $\$ 243$ - Revised December 1, 1992

Re: Epoxy Coated Steel (Metal) Shell Encased Piles, Epoxy

Coated Steel H Piles, and Revised Pay Items for All Pile Tres.

CARRY-OVER - COntinued:

8) Exposed/Buried Piles: A pile which is composed of an "exposed portion" and a "buried portion", as shown on Bridge Standard C-1, Adopted December 1992, shall be paid for in two parts. For example, the buried portion of a steel $\mathrm{H}$ pile would be paid for as Steel $\mathrm{H}$ Pile, and the exposed portion would be paid for as Epoxy Coated Steel H Pile.

9) The pay item(s) for the pile(s) shall reflect the actual pile being specified. The pay item(s) will include such things as the pile diameter/size, the type of encasement, reinforcing steel requirements, and the wall thickness of the steel shell;

10) Except for timber piles, the "furnished and driven" phrase, previously contained in the pay item name, is now contained in the descriptive text preceding the pay item designations;

11) Pile encasement, reinforcing steel, and concrete filling will not be paid for separately, but will be included in the pay item for the pile(s);

B) REVI8ION8: These revisions are a result of the recent meetings of the Joint INDOT-ICI Sub-Committee on Bridges, co-chaired by Thomas Seeman, Division of Design. These revisions involve a change in the following:

1) Allowable wall thicknesses of steel shell piles;

2) The limit of the epoxy coating of steel shell piles now extends to only two (2) feet below the flow line elevation;

3) A change to the use of plain, instead of epoxy coated, reinforcing steel in the reinforced portion of the concrete filling;

1) A table of suggested bearing capacities for minimum steel shell wall thickness is now provided;

5) New details on Bridge Standard C-1, adopted December 1992, showing the limits of the reinforced concrete filling and the limits of the epoxy coating on the pile shell, previously contained in Bridge Memorandum \$243, dated October 1, 1991.

6) Section 8-335.03, Metal Shell, of the Bridge Design Manual is hereby deleted

C) DEsIGN REQUIREMEArs: The Geotechnical Section will routinely investigate bearing capacities of 40,55 , and 70 tons for shell piles, and $/$ or 45, 55, and 70 tons for H-piles, for most projects. The designer shall perform a preliminary feasibility analysis when bearing capacities other than these are desired, and shall notify the Geotechnical sectior of the desired bearing capacity prior to the beginning of the soils

Page 2 of 3 
Bridge Memo 243 - Revised December 1, 1992

Re: Epoxy Coated Steel (Metal) Shell Encased Piles, Epoxy

Coated Steel $1 \mathrm{P}$ Piles, and Revised Pay Items for All Pile Trpes.

C) DESIGA REQUIREMEIYS - Continued:

investigation. The table below gives suggested bearing values for a range of available steel shell wall thicknesses. The designer shall use these combinations of values only as a starting point in their analysis.

\begin{tabular}{|c|c|c|c|}
\hline \multicolumn{4}{|c|}{$\begin{array}{c}\text { 8hell wall Thickness } \\
\text { vs. Bearing }\end{array}$} \\
\hline $\begin{array}{l}\text { Minimum } \\
\text { shell Wall } \\
\text { Thickness } \\
\text { (Inches) }\end{array}$ & & $\begin{array}{l}\text { gesi } \\
\text { ari } \\
\text { aci } \\
\text { ons }\end{array}$ & \\
\hline .203 & 40 & to & 50 \\
\hline .250 & 55 & to & 65 \\
\hline .312 & 70 & to & 90 \\
\hline
\end{tabular}

All high capacity pile designs shall be verified by engineering analysis and shall require the concurrence of the geotechnical engineer assigned to the project. Consideration shall be given to the economics of using a single steel shell wall thickness on projects where the piling for the different substructure elements fall into different bearing capacity ranges. Other wall thicknesses are subject to limited availability and shail not be used without justification and assurance of availability.

D) sPECIFICArIOAs: The revised specifications distributed with Bridge Memorandum $\$ 243$, dated October 1, 1991, in the form of Special Provision 701-B-089, Revised 9/19/91, have since been acted upon by the Specifications Committee, and are now part of the Standard specifications via the current supplemental specifications.

The pile specifications which have been revised to reflect the changes detailed in this memorandum are now contained in the attached copy of Special Provision 701-B-089, Revised 12/1/92. This special provision shall be utilized by all designers on applicable bridge projects until such time as this information is incorporated into the standard Specifications by the Specifications Committee. 
STEEL SEELL ENCASED CONCRETE PILES

DESCRIPTION. This work ahall consist of furnishing and driving steel shell encased concrete filled piles of the size, location, and bearing as shown on the plans.

MATERIALS. Materials shall be in accordance with the following:

Epoxy Coating for Piles ........................... 914.01(d)

steel Encased Concrete Piles ......................... 914.01

structural Concrete ............................... 702

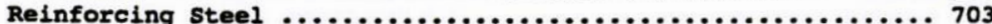

Powdered epoxy resin shall be used to coat the epoxy coated portion of the steel shell encased concrete piles.

CONSTRUCTION REQUIREMENTS. The construction requirements shall be in accordance with 701 except as noted herein. The specified steel shell wall thicknesses shall be the minimum allowable. The contractor may furnish and drive thicker walled steel shells with no additional payment. The limits of the epoxy coated steel shell portion of the pile, and the limits of the reinforced concrete shall be as shown on the plans.

METHOD OF MEASUREMENT. Steel shell encased concrete piles will be measured by the linear foot complete in place. Reinforcing steel, class A concrete filling, and epoxy coating will not be measured for payment.

BASIS OF PAYIENT. Epoxy coated wteel thell encased reinforced concrete piles and eteel shell encased concrete piles will be paid for at the contract unit price per linear foot for the shell thickness and diameter specified, complete in place.

Payment will be made under:

Pay Item

Pay Unit

Pile, Reinforced Concrete, Steel shell Bncaged, Epoxy Coated, in.. in. ........... Linear Foot

\section{shell} diameter thickness

Pile; Concrete, steel shell Encased, shell in.. diameter In. ...................... Iinear Foot thickness

The costs of furnishing and driving piles, and all necessary incidentals shall be included in the cost of this work. The cost of the reinforcing steel which extends beyond the limits of the epoxy coating as shown on the plans shall be included in the cost of the epoxy coated steel shell encased reinforced concrete pile. 
INDIANA DEPARTMENT OF TRANSPORTATION

INDIANAPOLIS, INDIANA 46204-2249

INTER-DEPARTMENT COMMUNICATION

October 1, 1992

\section{BRIDGE DESIGN MEMORANDUM \#246}

TO: All Design, Operations, and District Personnel, and Consultants

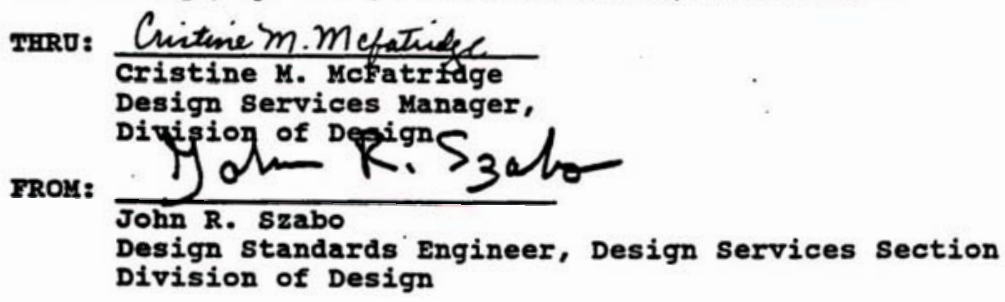

SUBJECT: Allowable Design Stresses for Concrete and Reinforcing Steel.

EFFECTIVE: Immediately on all bridge projects which have not reached the Structure Size and Type due date as of October 1, 1992.

SUPERSEDES: Figure 8-401.02, entitled "FLOOR SLAB CONTINUOUS OVER STRINGERS", dated May 1975 in Section 8-401.02 of the Department's Bridge Design Manual; the applicable portions of the Department's Bridge Design Manual Sections 8-215.03, 8-250.08, 8-250.09, 8-255.03, 8-255.07, $8-401.02,8-410.04 \mathrm{c}, 8-410.04$ d, 8-410.09(pg. 8-410.09A), and. Figure 8-250.12B dated May 1975 in Section 8-250.12; Bridge Memorandum \#172, entitied "Reinforcing Bar Lap And Embedment Lengths", issued September 2, 1976 .

IMPLEMENTATION: Designers shall implement this policy no later than the effective date stated above. The designer shall design the entire structure using one set of design stresses. Projects underway using the old design stresses shall not be revised, nor shall the new design stresses be applied to the undesigned components of these structures.

\section{A) - BACKGROUND}

Jack White has recommended that INDOT use higher allowable design stresses for concrete and reinforcing steel in structures. Mr. White based his recommendations on the following:

1) The concrete materials currently used exceed the recommended ultimate yield stresses by at least 500 psi. This was verified by

R. K. Smutzer of our Materials and Tests Division.

Page 1 of 13 
Bridge Design Memorandum \#246, October 1, 1992

Re: Allowable Design Stresses for Concrete and Reinforcing Steel

2) The reinforcing steel currently stocked by our fabricators is Grade 60 , and it is being placed in our structures whether we design for it or not. In fact, the Grade 40 steel now used in design was eliminated from the ASTM A615 Specs. in sizes above \# 6 almost ten years ago.

3) This change brings the Department in line with the practice of most states throughout the country.

4) AASHTO's new upcoming Load Resistance Factor Design Specification (LRFD) will be used as the basis for structural design in the Department's upcoming new Design Manual. Several design provisions of the IRFD require a minimum concrete compressive strength of 4000 psi and the use of Grade 60 Reinforcing Steel. These design allowables must be established before the LRFD is introduced in order to utilize these design provisions fully.

\section{B) - NEW ALLOWABLE DESIGN STRESSES}

The new design stresses are as follows:

$\begin{array}{ll}\text { Class C Concrete } & f^{\prime} c=4000 \text { psi } \\ \text { Class A Concrete } & f^{\prime} c=3500 \text { psi } \\ \text { Class B Concrete } & f^{\prime} c=3000 \text { psi } \\ \text { Reinforcing Steel (Grade 60) } & f^{\prime}=60,000 \text { psi }\end{array}$

\section{C) - -EFFECTS OF INCREASE IN ALLOWABLE DESIGN STRESSES}

1) Specifications: No immediate changes in the specifications are. required: The concrete mixes currentiy used provide compressive strengths that are more than ample. to meet the suggested stress levels: However, several changes related to reinforcing steel that will align the specifications with the new design stresses will be implemented in near future. The specifications currently state: "Unless otherwise specified, bars for concrete reinforcement shall be deformed billet.steel, grade 40 or 60 ; rail steel, grade 50 or 60 ; or axle steel, grade 40 or 60 .

The bars for cement concrete pavement shall be deformed billet steel, rail steel, or axle steel of the grades set out above except tie bars that are to be bent and subsequently straightened during construction shall be deformed bars conforming to ASTM $A 615$, grade 40. Tie bar assemblies used in lieu of bent tie bars shall meet the minimum total ultimate strength and minimum total yield strength requirements specified for bent tie bars; bend test and elongation will not be required. Steel splicing systems shall be as specified in 703.06 .

Reinforcing steel used in precast prestressed concrete structural members include deck panels shall be in accordance with ASTM A 615, grade 60." 
Bridge Design Memorandum $\# 246$, October 1, 1992

Re: Allowable Design Stresses for Concrete and Reinforcing Steel

The specifications will be changed to state that only Grade 60 steel shall be supplied unless Grade 40 is specified on the plans. Until the specification can be changed, the attached special Provision 703-B-097, "Reinforcing Steel Type and Grade", shall be required for all plans designed in accordance with these new design stresses.

2) standards sheets: The following standards Sheets will be revised as indicated, in time for the designers to utilize them in the plans that are designed with the new allowable stresses:

a) Bridge standards sheet c-1: Revise table of dimensions for standard hooks based on new design stresses for concrete and reinforcing steel; Delete table of dimensions for special hooks.

b) Bridge standards sheet c-3: optional Railing Reinforcing splice.

c) Road standards sheet Joint sheet B: Revise R. C. Bridge Approach reinforcing steel lap and bar lengths in Tables I and II based on new lap splices for grade 60 reinforcing steel.

d) Road standards sheet ME-1A: Revise reinforcing steel lap lengths in multiple pipe concrete anchor details based on new lap splices for grade 60 reinforcing steel.

e) Road standards sheet ME-3 thru ME-6: Revise reinforcing steel bending diagrams, Note \#3, and reinforcing steel quantities in tables for grated box end sections based on new lap splices for grade 60 reinforcing steel

3) Reinforcing steel Detailing: These new higher allowable design stresses will result in longer reinforcing steel lap lengths. The lap distance is related to the concrete compressive stress as well as the reinforcing steel yield strength. Theoretically, three different sets of required lap lengths will be needed if three concrete stress levels are used. Attached are new TENSION LAP SPIICE TABLES I thru VI for the designers use when designing with these new stresses. Detailing of all reinforcing bar lap and embedment lengths shall continue as was required by Bridge Design Memorandum \#172, issued September 2, 1976, and superseded by this memorandum.

4) Continuous Floor slab Design: Figure 8-401.02, entitled "FLOOR SLAB CONTINUOUS OVER STRINGERS", dated May 1975 and contained in section 8-401.06 of the Department's Bridge Design Manual has been replaced with the attached "CONTINUOUS FLOOR SLAB DESIGN CHART", dated October 1, 1992.

Page 3 of 13 
Bridge Design Menorandum \#246, October 1, 1992

Re: Allowable Design Stresses for Concrete and Reinforcing Steel

\section{D) - CLASS OF SUBSTRUCTURE CONCRETE}

All substructure concrete above the footing shall be class $A$. The cost of Class A over that of Class B in pier stems is insignificant one bag of cement per cubic yard. The increased durability, workability, and higher compressive strength in what is essentially a column element more than offsets the slight additional cost. The present item "Concrete, class B above Footing", shall be replaced with "Concrete, Class A, in Substructure". "Concrete, Class B, in Footing" shall continue to be used as in the past.

\section{E) - TRANSITION PERIOD}

During the transition period to convert all of the Department's structural designs to these new design stresses, the designer shall place the following table on the general plan sheet for bridge projects: ALLOWABLE DESIGN STRESSES

$\begin{array}{ll}\text { Class C Concrete } & f^{\prime} c=4000 \text { psi } \\ \text { Class A Concrete } & f^{\prime} c=3500 \text { psi } \\ \text { Class B Concrete } & f^{\prime} c=3000 \text { psi } \\ \text { Reinforcing Steel (grade 60) } f_{y}=60,000 \text { psi }\end{array}$

This table will identify those plans which were designed using the higher allowable design stresses. 
APPENDIX B

PILE DRIVING RECORD 


\section{Appendix B: Pile Driving Record}

\section{Table B.1: Pile Driving Record of Bent 1 (SR249 over US12)}

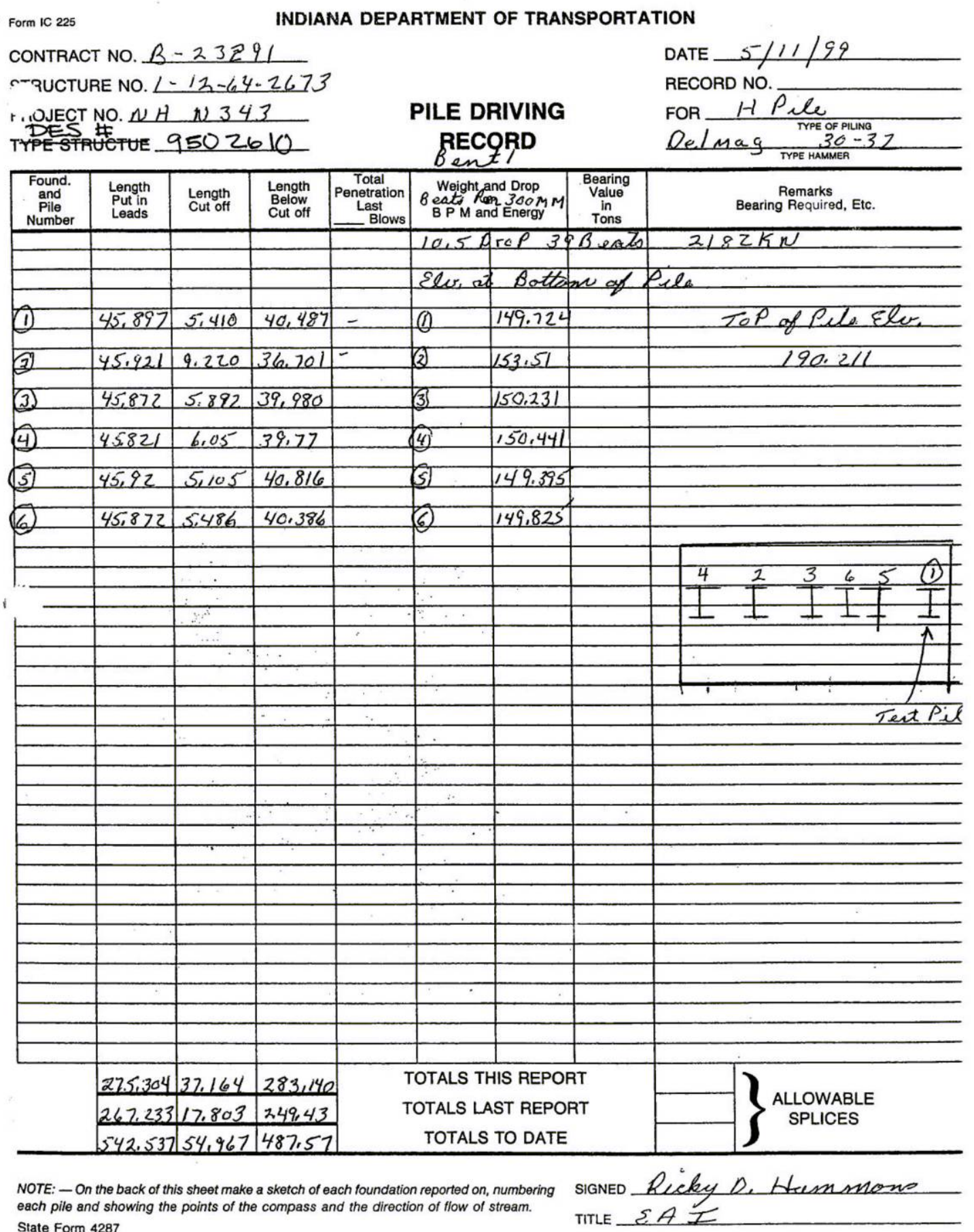




\section{Table B.2: Pile Driving Record of Bent 11 (SR249 over US12)}

\begin{tabular}{|c|c|c|c|c|c|c|c|c|}
\hline \multirow{3}{*}{\multicolumn{4}{|c|}{$\begin{array}{l}\text { INDIAN } \\
\text { CONTRACT NO. } 1323291 \\
\text { NTUCTURE NO. } 1-12-64-2623\end{array}$}} & NA DEPA & RTMENT & \multirow{2}{*}{\multicolumn{2}{|c|}{ OF TRANSPORTA }} & \multirow{2}{*}{$\begin{array}{l}\text { TION } \\
\text { DATE } 4 / 29 / 99\end{array}$} \\
\hline & & & & & & & \\
\hline & & & & \multirow{3}{*}{\multicolumn{4}{|c|}{$\begin{array}{l}\text { PILE DRIVING } \\
\text { RECORD } \\
\text { Bent }\end{array}$}} & RECORD NO. \\
\hline \multirow{2}{*}{\multicolumn{4}{|c|}{$\begin{array}{l}\text { r..JIECT NO. NHN } N 43 \\
\text { DES N }\end{array}$}} & & & & & FOR $H-P_{i} l_{0}$ \\
\hline & & & & & & & & Celmag ${ }_{\text {TYPE HAMMEA }}^{30-32}$ \\
\hline \multirow[t]{2}{*}{\begin{tabular}{|c|}
$\begin{array}{c}\text { Found. } \\
\text { and } \\
\text { Pile } \\
\text { Number }\end{array}$ \\
\end{tabular}} & $\begin{array}{l}\text { Length } \\
\text { Put in } \\
\text { Leads }\end{array}$ & $\begin{array}{l}\text { Length } \\
\text { Cut off }\end{array}$ & $\begin{array}{l}\text { Length } \\
\text { Below } \\
\text { Cut off }\end{array}$ & 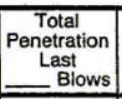 & \multicolumn{2}{|c|}{$\begin{array}{l}\text { Weight and Drop } \\
\text { of } \\
\text { B P M and Energy }\end{array}$} & $\begin{array}{l}\text { Bearing } \\
\text { Value } \\
\text { in } \\
\text { Tons }\end{array}$ & $\begin{array}{c}\text { Remarks } \\
\text { Bearing Required, Etc. }\end{array}$ \\
\hline & & & & & \multirow{2}{*}{\multicolumn{3}{|c|}{ slv. dtBattom of fele }} & $2.143 \mathrm{KN}$. \\
\hline (1) & & & & & & & & \\
\hline (1) & 53.492 & 2.844 & 50,648 & & (1) & 141,155 & & 6 Beats Pes $300 \mathrm{MM}$ \\
\hline (2) & 53,492 & 2.91 & 50,582 & & 3) & 141.221 & & Dras $10^{\circ}$ \\
\hline & & & & & & & & tpule El. \\
\hline (3) & $53 \cdot 34$ & 4.548 & 48,792 & & 3) & 143,011 & & \\
\hline (4) & 53.34 & 3453 & 49897 & & $\pi$ & (1) 911 & & .803 \\
\hline & & 2,422 & & & \multirow[b]{2}{*}{ 5) } & & & \\
\hline \multirow{2}{*}{ (5) } & 53.569 & 4.039 & 49.53 & & & \multicolumn{2}{|l|}{142.273} & \\
\hline & $(53.447)$ & & & & & & & \\
\hline & & & & & & & & \\
\hline & & & & & & & & \\
\hline & & & & & & & & \\
\hline & & & & & & & & \\
\hline & & & & & & & & \\
\hline & & & & & & & & \\
\hline & & & & & & & & \\
\hline & & & & & & & & 5 \\
\hline & & & & & & & & $T^{2}$ \\
\hline & & & & & & & & ـ \\
\hline & & & & & & & & \\
\hline & & & & & & & & $L$ Test Pile \\
\hline & & & & & & & & \\
\hline & & & & & & & & \\
\hline & & & & & & & & \\
\hline & $\cdot$ & & & & & & & \\
\hline & & & & & & & & \\
\hline & & & & & & & & \\
\hline & & & & & & & & \\
\hline & & & & & & . & & \\
\hline & & & & & & & & \\
\hline & & & & & & & & \\
\hline & & & & & & & & \\
\hline & & & & & & & & \\
\hline & 267.233 & 17,803 & 249430 & & OTALS THI & IS REPOR & & \\
\hline & 0 & 0 & 0 & & OTALS LAS & ST REPOR & & $\begin{array}{l}\text { LOWABLE } \\
\text { SPLICES }\end{array}$ \\
\hline & 267.233 & 17.863 & 249.430 & & TOTALS T & TO DATE & & \\
\hline
\end{tabular}

NOTE: - On the back of this sheet make a sketch of each foundation reported on, numbering SIGNED Ricky D. Ham mone each pile and showing the points of the compass and the direction of flow of stream. State Form 4287

TITLE EAI 
Table B.3: Pile Driving Record of Bent 1, North Bound (I65 over SR25)

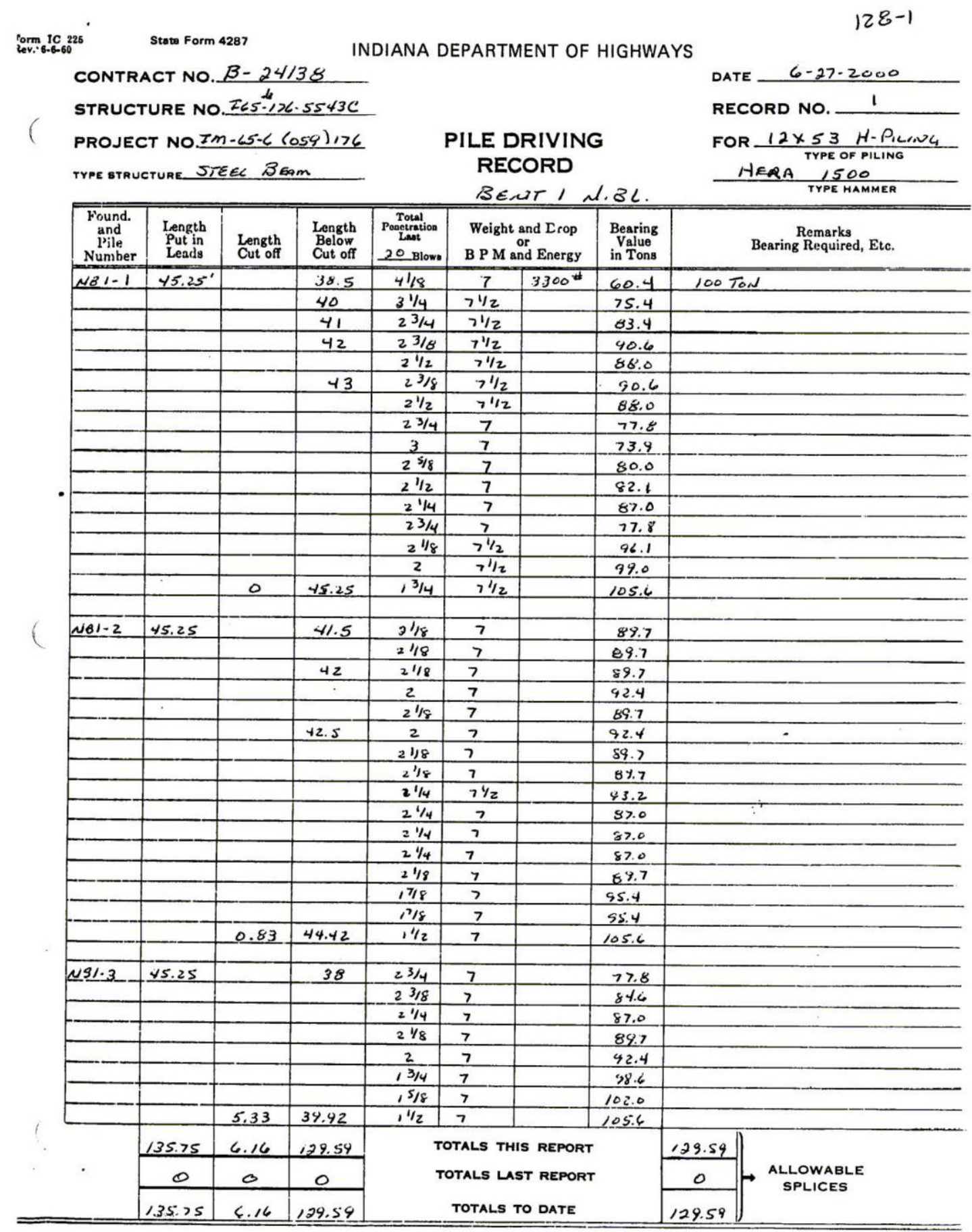


Table B.3: Pile Driving Record of Bent 1, North Bound (I65 over SR25) (Continued)

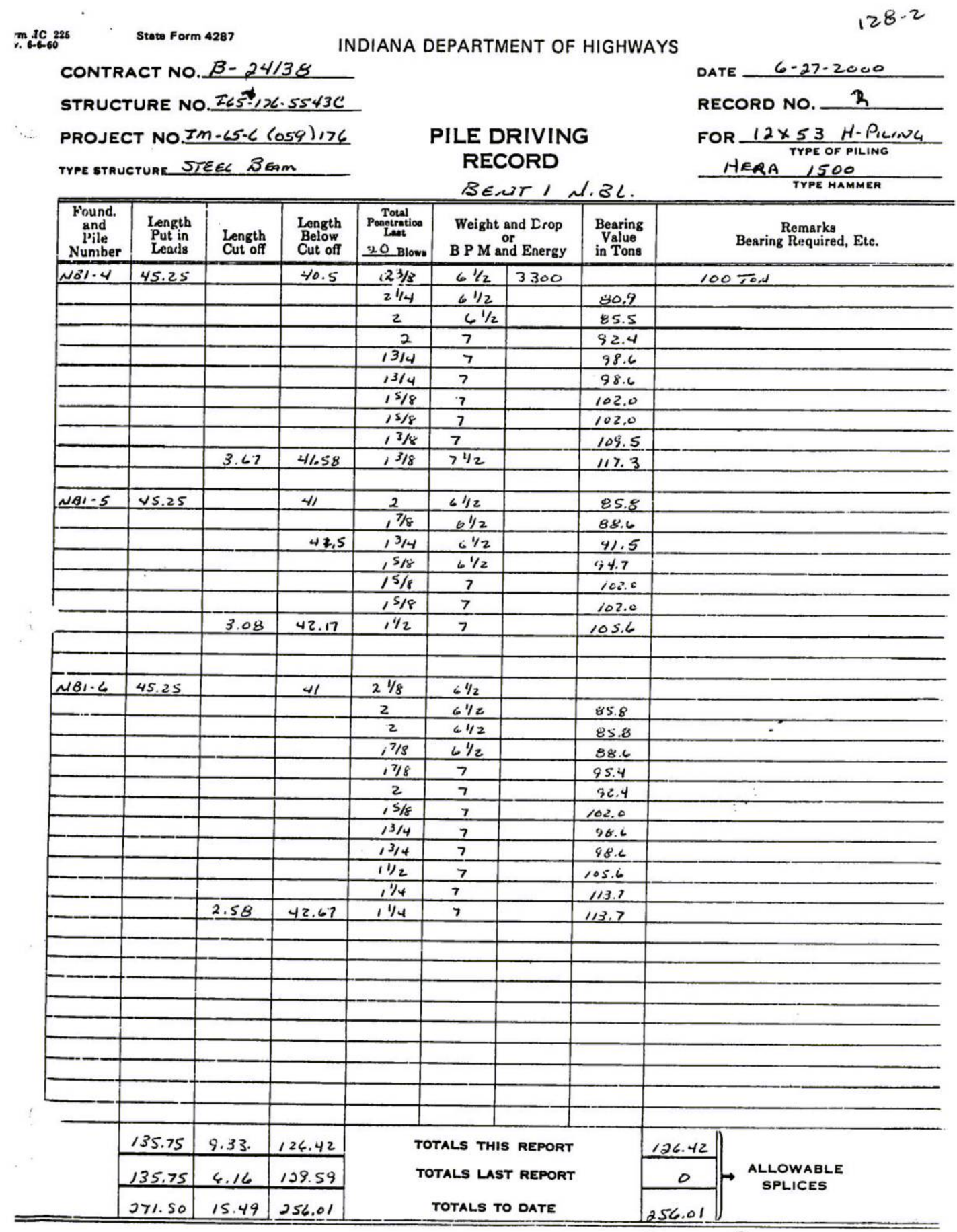


Table B.4: Pile Driving Record of Bent 3, North Bound (I65 over SR25)

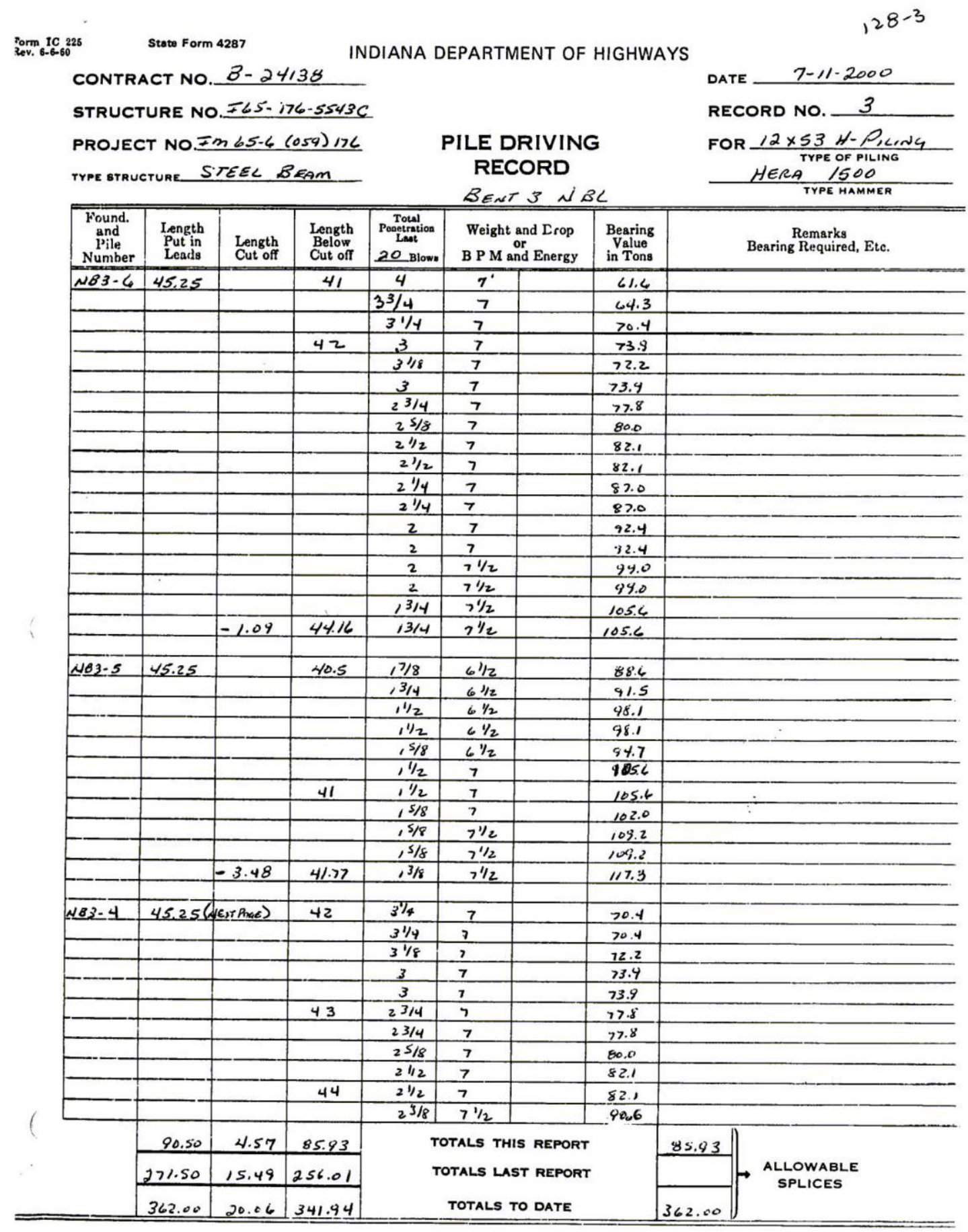


Table B.4: Pile Driving Record of Bent 3, North Bound (I65 over SR25) (Continued)

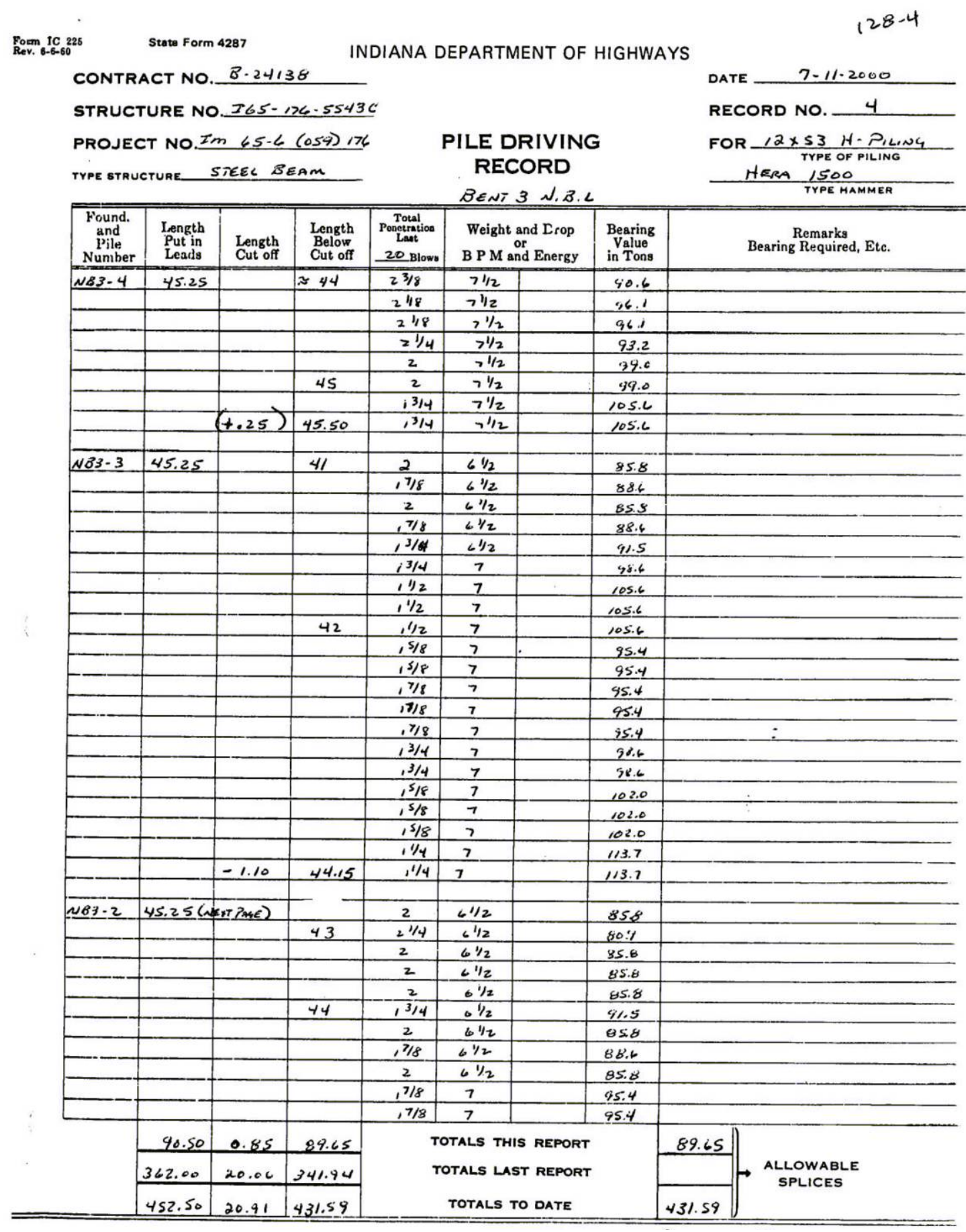


Table B.4: Pile Driving Record of Bent 3, North Bound (I65 over SR25) (Continued)

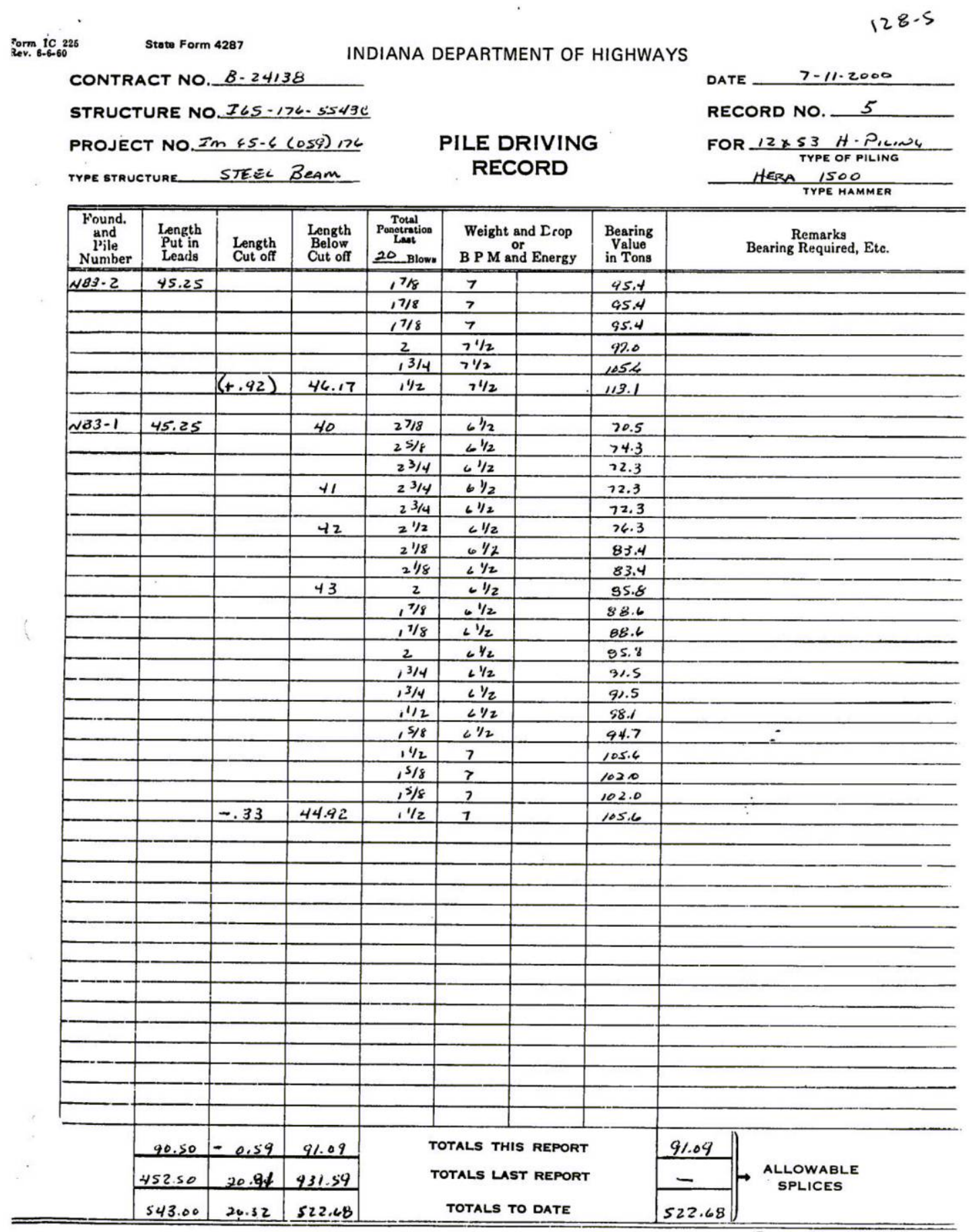


Table B.5: Pile Driving Record of Bent 1 (SR18)

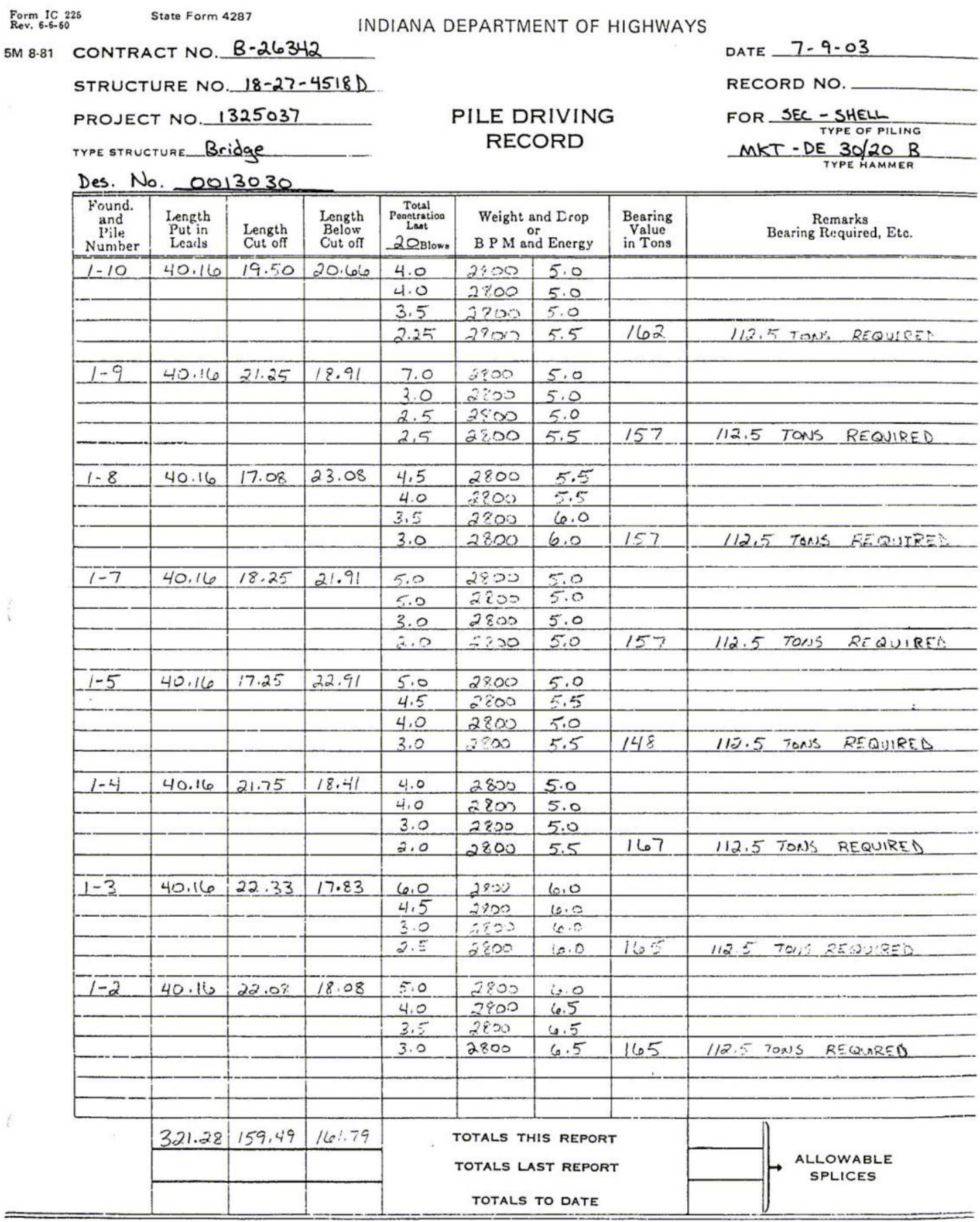




\section{Table B.5: Pile Driving Record of Bent 1 (SR18) (Continued)}

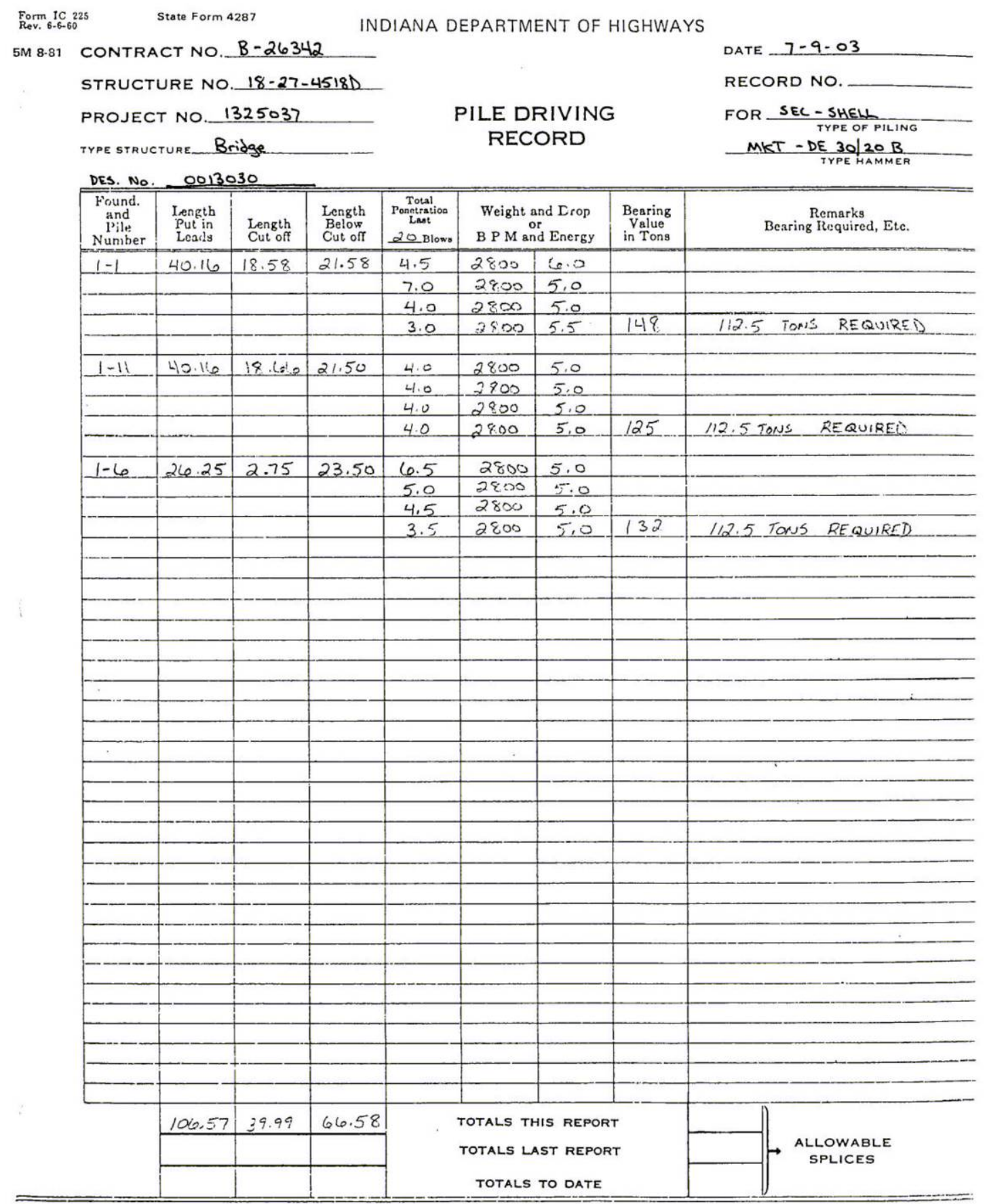




\section{Table B.6: Pile Driving Record for Pile 6, Bent 1 (SR18)}

\begin{tabular}{|c|c|c|c|c|c|c|c|c|c|}
\hline 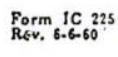 & \multicolumn{4}{|c|}{ Stato Form 4287} & \multicolumn{4}{|c|}{ NDIANA DEPARTMENT OF HIGHWAYS } & \multirow[b]{2}{*}{ DATE $6-12-03$} \\
\hline 5 M 8-81 & \multirow{2}{*}{\multicolumn{8}{|c|}{$\begin{array}{l}\text { CONTRACT NO.B }-26342 \\
\text { STRUCTURE NO. } 18-27-4518 . D\end{array}$}} & \\
\hline & & & & & & & & & RECORD NO. \\
\hline & \multirow{3}{*}{\multicolumn{4}{|c|}{$\begin{array}{l}\text { PROJECT NO.1325037 } \\
\text { TYPE STRUCTURE_Bcidge } \\
\text { DES. NO. - } 2013030\end{array}$}} & \multirow{3}{*}{\multicolumn{4}{|c|}{$\begin{array}{l}\text { PILE DRIVING } \\
\text { RECORD }\end{array}$}} & \multirow{3}{*}{$\begin{array}{l}\text { FOR SEC- SHELL } \\
\text { MYPE OF PILING } \\
\text { MKT-DE:3O/2OB } \\
\text { TYPE HAMMER }\end{array}$} \\
\hline & & & & & & & & & \\
\hline & & & & & & & & & \\
\hline \multirow{19}{*}{ 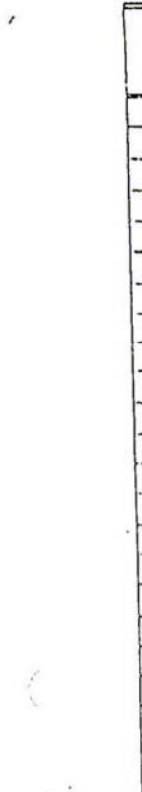 } & $\begin{array}{l}\text { Found. } \\
\text { and } \\
\text { anile: } \\
\text { Numiber }\end{array}$ & $\begin{array}{l}\text { Iength } \\
\text { Put in } \\
\text { Leaily } \\
\end{array}$ & $\begin{array}{l}\text { Length } \\
\text { Cut of }\end{array}$ & $\begin{array}{l}\text { Length } \\
\text { Below } \\
\text { Cut of } \\
\end{array}$ & $\begin{array}{c}\text { Total } \\
\text { Ponitutios } \\
\text { Ltition } \\
20 \text { Blow. } \\
\end{array}$ & \multicolumn{2}{|c|}{$\begin{array}{l}\text { Weight and Drop } \\
\text { or P M and Encrgy } \\
\text { B }\end{array}$} & $\begin{array}{c}\text { Bearing } \\
\text { Vnluc } \\
\text { in Tons } \\
\end{array}$ & $\begin{array}{l}\text { Remarks } \\
\text { Bearing Kequired, Elc. }\end{array}$ \\
\hline & $6-12$ & 28.83 & 1.25 & 27.58 & 7.0 & 2800 & 4.5 & & \\
\hline & & & & & 6.0 & 2800 & 4.5 & & \\
\hline & & & & & $\frac{5.5}{2.5}$ & 2800 & $\frac{5.5}{5.5}$ & 140.8 & \\
\hline & & & & & 3.5 & 2800 & 5.5 & & 100 TONS REQUIRED \\
\hline & $6-6$ & 40.16 & 12.33 & 27.83 & $\frac{7.0}{7.0}$ & 2800 & 4.5 & & \\
\hline & & & & & $\frac{7.0}{5.0}$ & 2800 & $\frac{4.5}{5}$ & & \\
\hline & & & & & $\frac{5.0}{4.0}$ & $\frac{2800}{2800}$ & $\frac{5.0}{5.5}$ & 134.0 & 100 TONS REQUIRED \\
\hline & & & & & & & & & TOO TONS KEQUTRED \\
\hline & $6-5$ & 40.16 & 11.16 & 29.00 & $\frac{5,5}{5.5}$ & 2800 & 4.5 & & \\
\hline & & & & & $\frac{5.5}{5.0}$ & $\frac{2800}{2800}$ & $\begin{array}{l}4.5 \\
5.0\end{array}$ & & \\
\hline & & & & & 4.5 & 2800 & $\frac{5.0}{5.5}$ & 129.0 & \\
\hline & & & & 299 & & & & 121.0 & 100 TONS REQUIRED \\
\hline & $6-4$ & 40.16 & 10.25 & 29.91 & $\frac{5.0}{4.75}$ & 2800 & 5.0 & & \\
\hline & & & & & $\frac{4.75}{4.50}$ & 2800 & 5.0 & & \\
\hline & & & & & $\begin{array}{l}4.50 \\
4.0\end{array}$ & 2800 & $\frac{5.5}{5.5}$ & 134.0 & \\
\hline & & & & & & 2800 & 5.5 & 134.0 & 100 TON REQUIRED \\
\hline & $16-3$ & 29.50 & 2.58 & 26.92 & $\frac{4.0}{4.0}$ & $\frac{2800}{2800}$ & $\frac{5.0}{5.0}$ & & \\
\hline & & & & & 3.0 & 2800 & $\begin{array}{l}5.0 \\
5.0\end{array}$ & & \\
\hline & & & & & 3.0 & 2800 & 5.5 & 148.1 & 100 TON REQUIRED \\
\hline & $6-2$ & 29.00 & & & & & & & \\
\hline & & & & 27.58 & $\frac{6.0}{6.0}$ & $\frac{2800}{2800}$ & $-\frac{4.5}{5.0}$ & & \\
\hline & & & & & 5.5 & 2800 & 5,5 & & \\
\hline & & & & & 5,0 & 2800 & 5,5 & 124.0. & 100 ION RERUIRED \\
\hline & $10=1$ & 29.08 & 2.83 & 26.25 & 6.0 & 2800 & 5.0 & & \\
\hline & & & & & 6.0 & 2800 & 5.5 & & \\
\hline & & & & & 5.5 & 2800 & 5.5 & & \\
\hline & & & & & 5.0 & 2800 & 6.0 & 131.0 & 100 TOW REQUIRED \\
\hline & $16-11$ & 29.33 & 2.25 & 27.08 & 6,5 & 2800 & 4.5 & & \\
\hline DWAY & & & & & $\frac{6.5}{6.0}$ & $\frac{2800}{2800}$ & $\frac{5.0}{5.5}$ & & \\
\hline & & & & & -6.0 & 2800 & 5.5 & 115.4 & \\
\hline . & & & & & & & & & 100 TOt) REQUIRED \\
\hline$\therefore$ & $-2+5$ & & & & & & & & \\
\hline 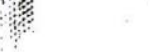 & & & & & & TOTALS TH & IIS REPOR & & \\
\hline & & & & & & TOTALS $\sqcup$ & AST REPOR & & $\rightarrow$ ALLOWABLE \\
\hline 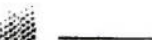 & & & & & & TOTALS & TO DATE & & shetcos \\
\hline
\end{tabular}




\section{Table B.6: Pile Driving Record for Pile 6, Bent 1 (SR18) (Continued)}

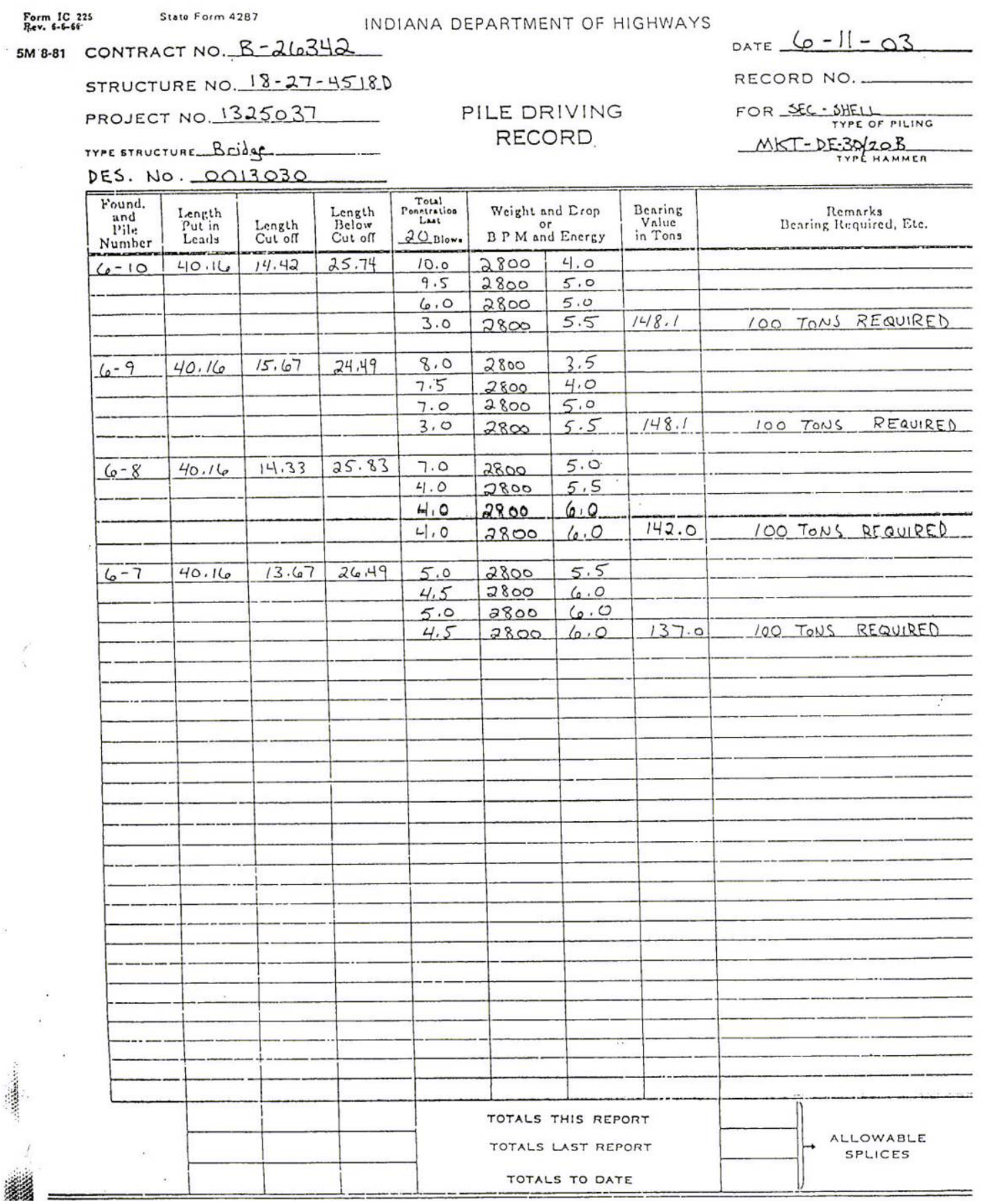


APPENDIX C

CONSTRUCTION PLANS 


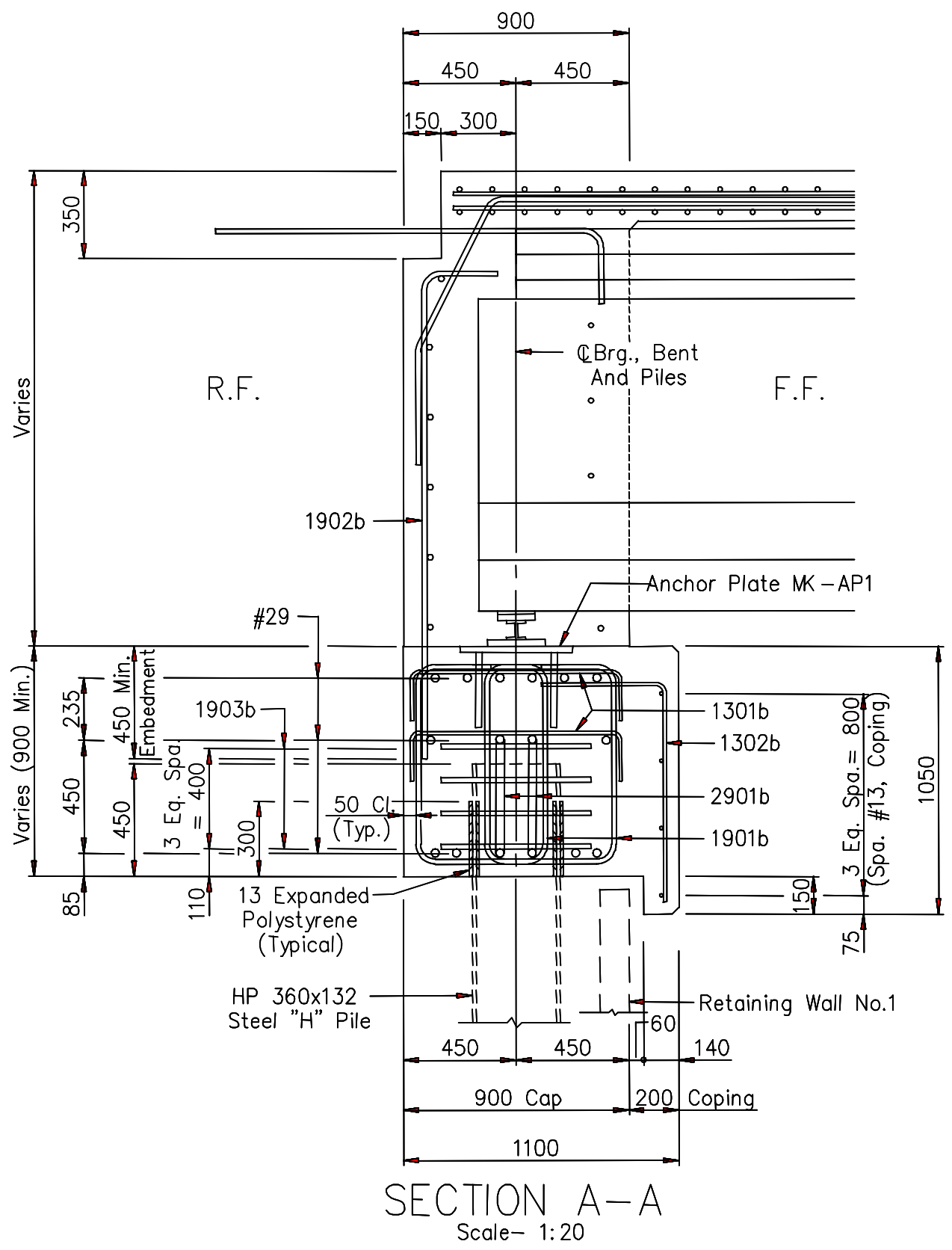

Figure C.1: End Bent Details of Bent 1 (SR249 over US12) 


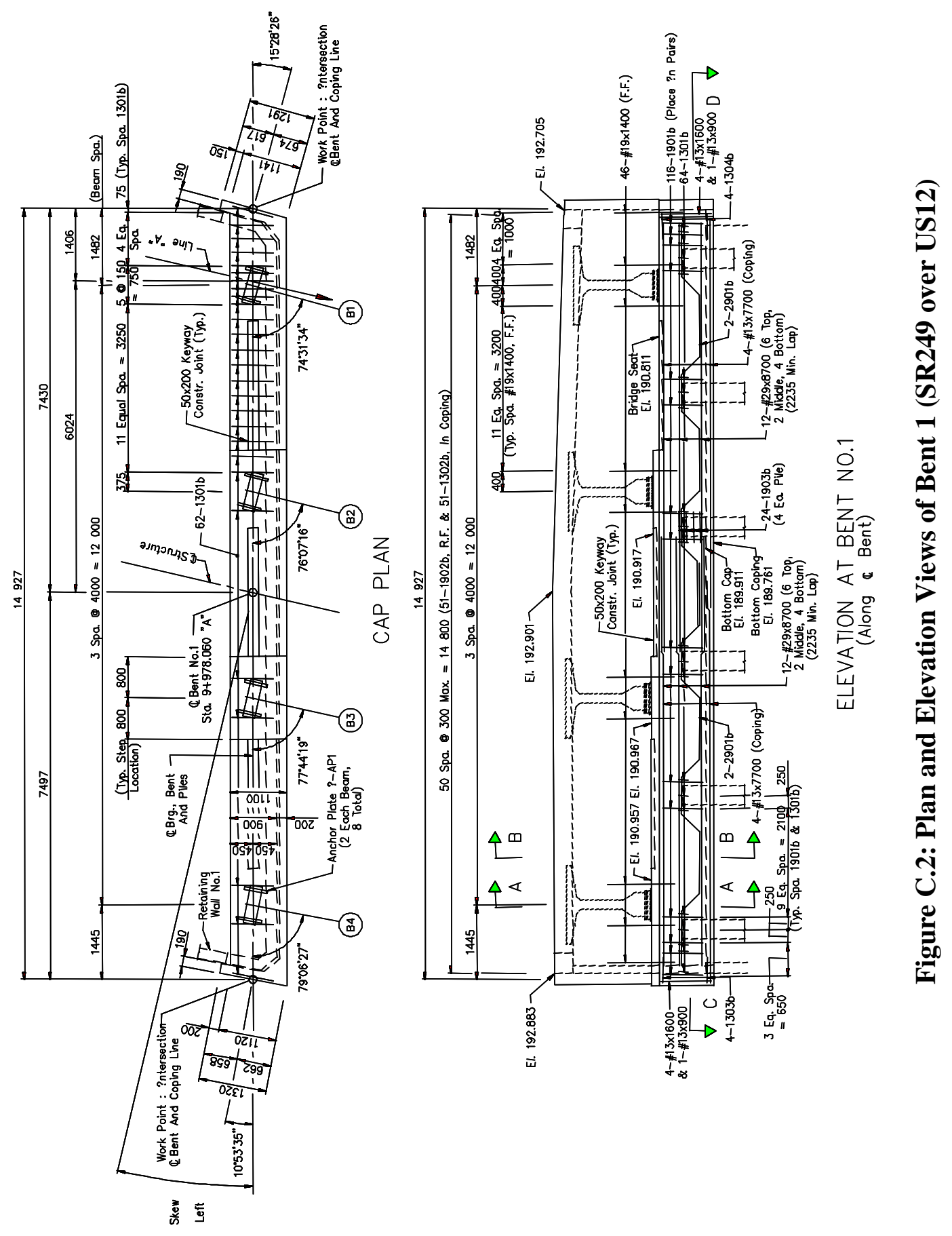




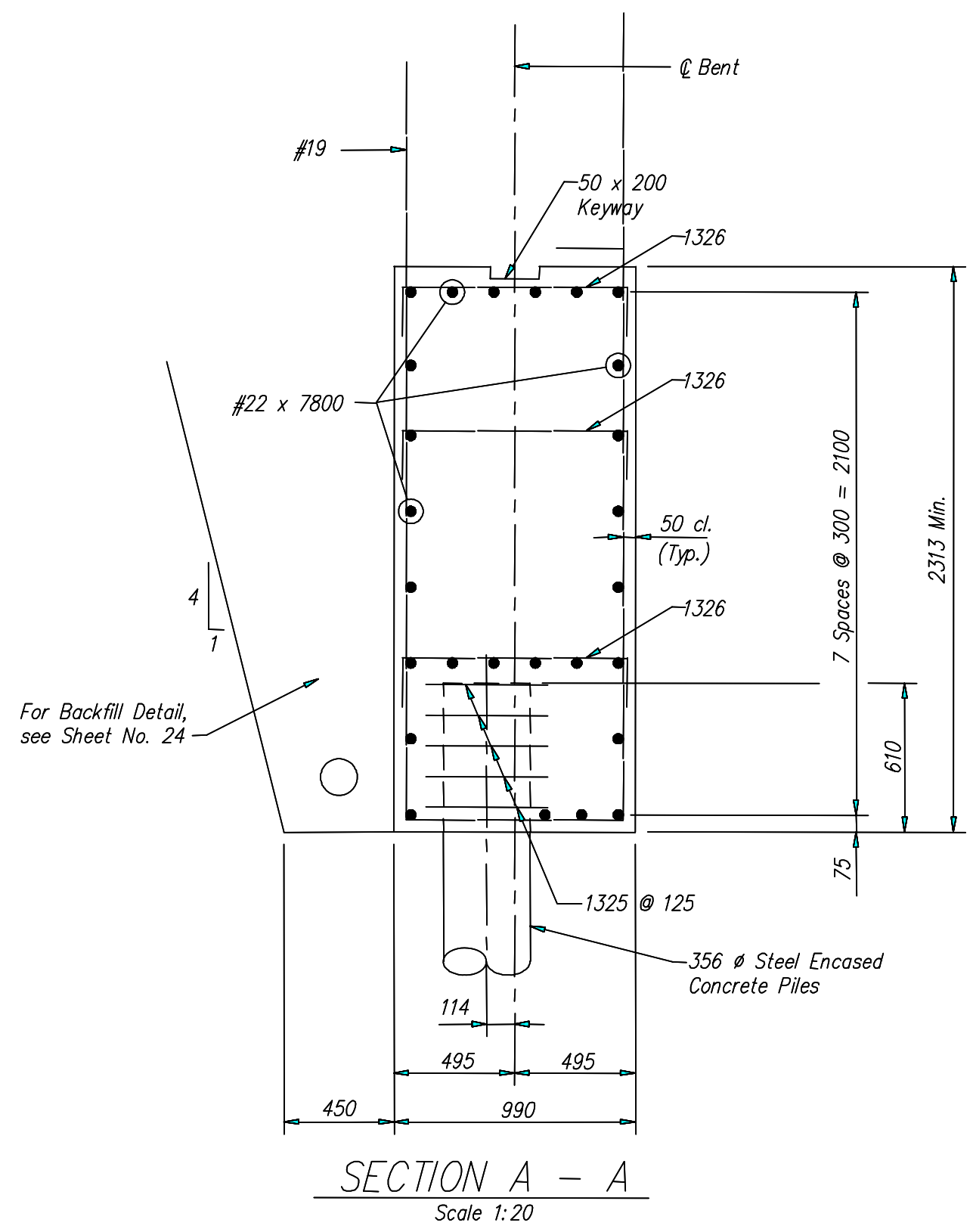

Figure C.3: End Bent Details of Bent 1 (I65 over US25) 

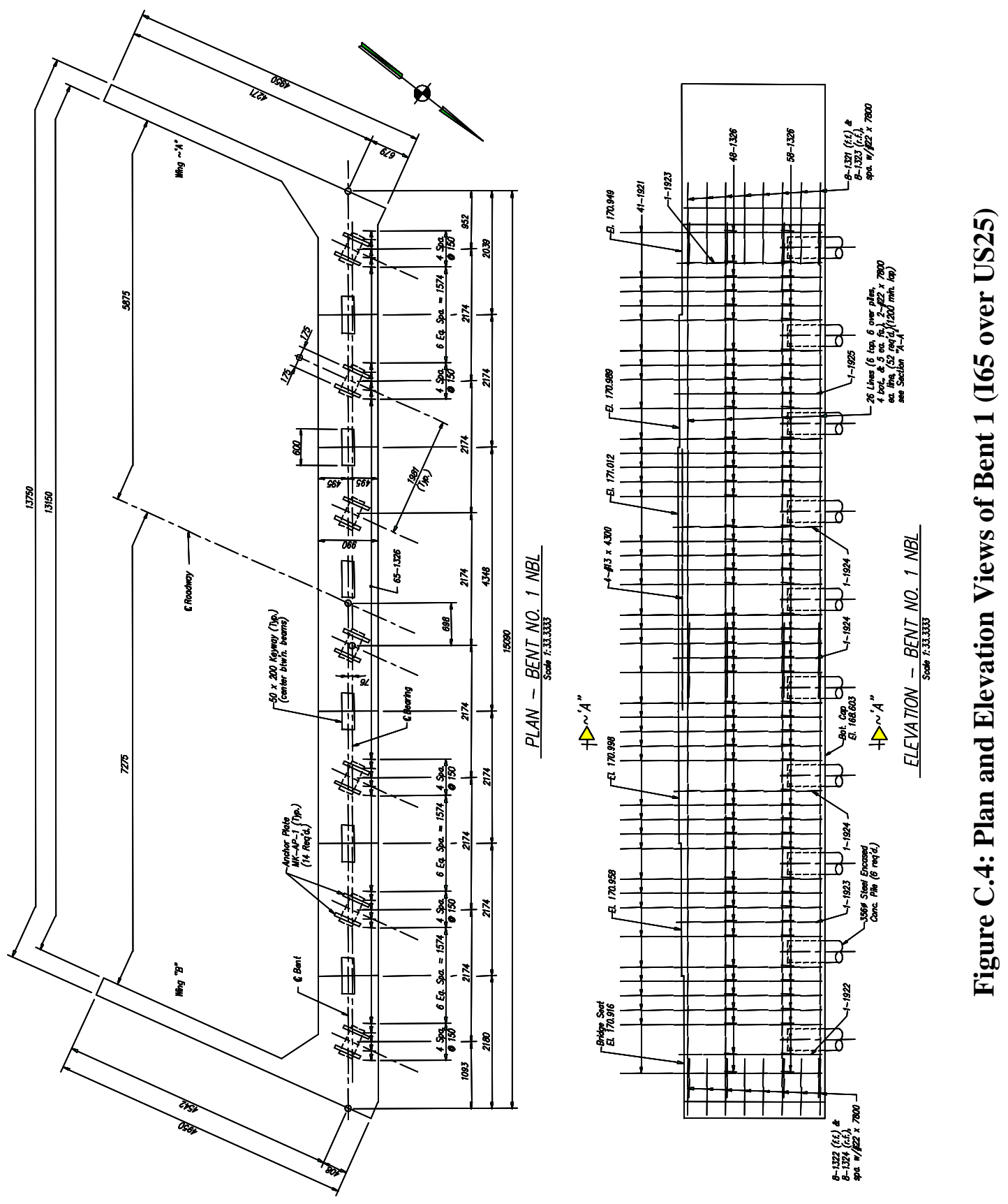


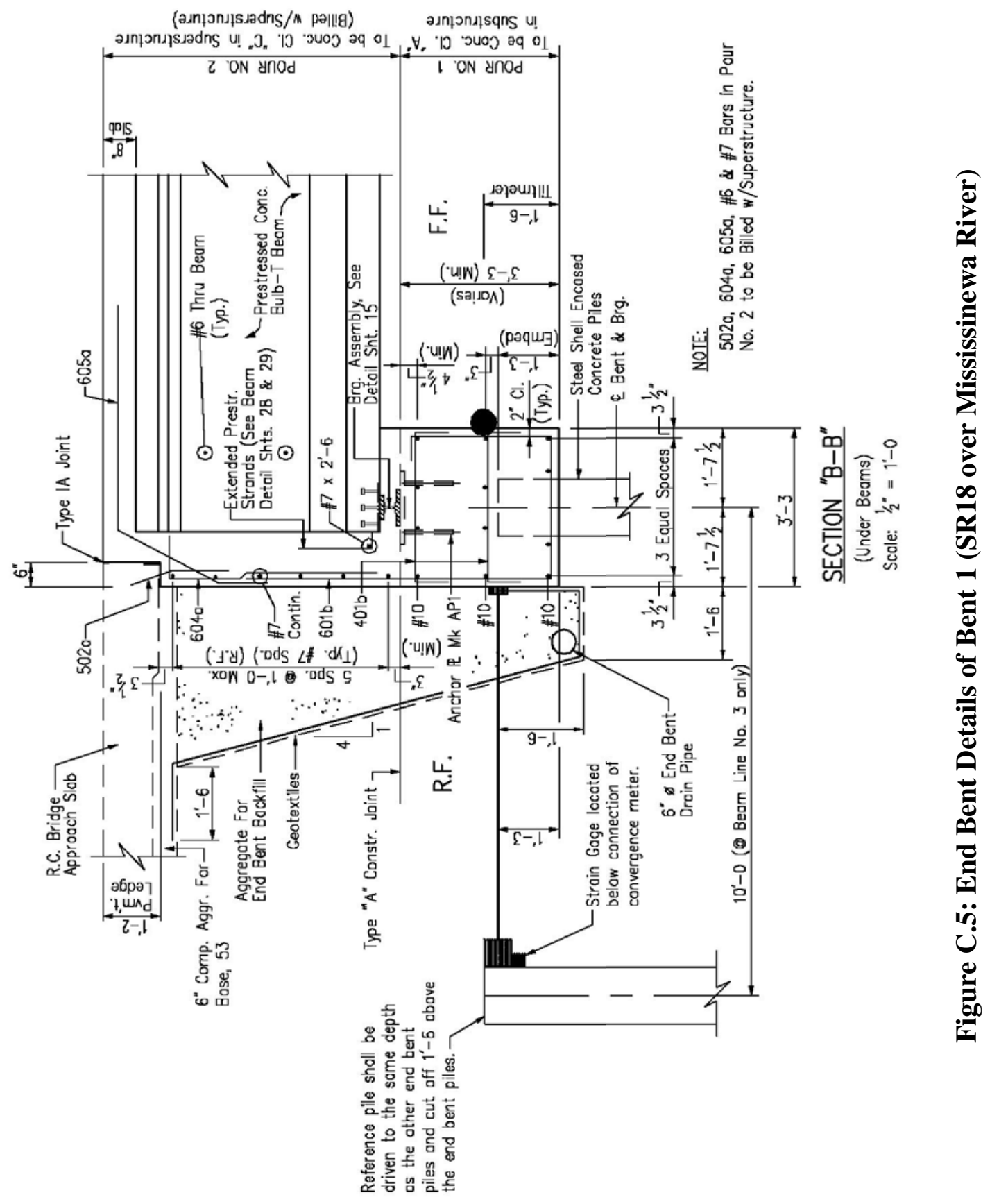


1
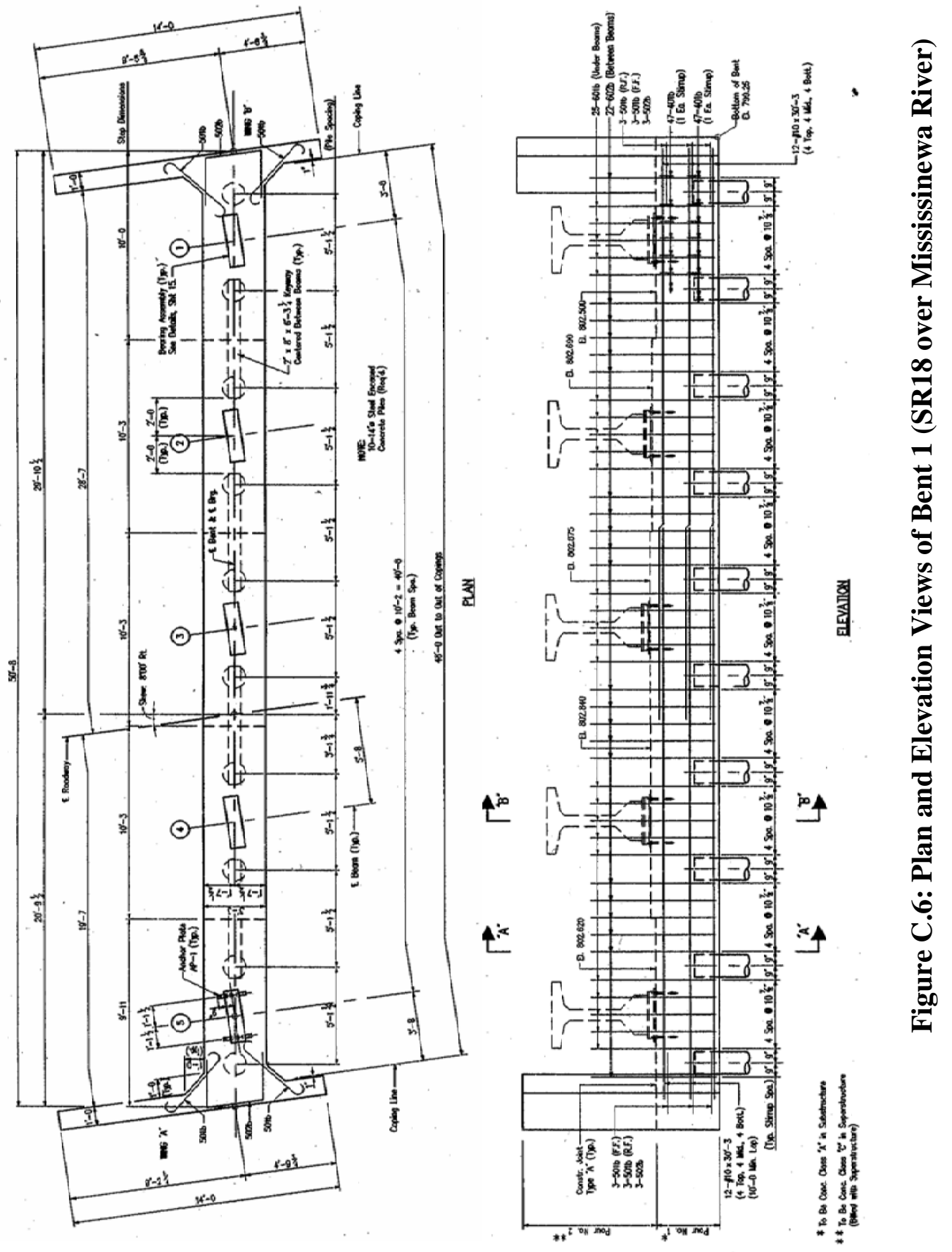
APPENDIX D

CONSTRUCTION SEQUENCE 


\section{Appendix D: Construction Sequence}

Table D.1: Construction Sequence (SR249 over US12)

\begin{tabular}{|r|l|}
\hline \multicolumn{1}{|c|}{ Date } & \\
\hline $5 / 5 / 1999$ & Driving HP at Bent 11 \\
\hline 5/10/1999 & Driving HP at Bent 1 \\
\hline $5 / 11 / 1999$ & Still driving HP at Bent 1 \\
\hline $5 / 12 / 1999$ & Driving piles at Pier 10 \\
\hline $5 / 19 / 1999$ & Driving piles at Piers 9 and 10 \\
\hline $5 / 24 / 1999$ & Began installing the instrumentation on Pier 10 \\
\hline $5 / 26 / 1999$ & Driving piles at Piers 8 and 9, poured footing at Pier 9 \\
\hline $5 / 27 / 1999$ & Driving piles at Pier 7 \\
\hline $6 / 1 / 1999$ & Poured Pier 10 (Stem) \\
\hline $6 / 2 / 1999$ & Poured Footing at Pier 7 \\
\hline $6 / 3 / 1999$ & Flexural beam test on Pier 10, 551 psi, driving piles at Pier 6 6 \\
\hline $6 / 4 / 1999$ & Poured Pier 9, driving piles at Pier 5 \\
\hline $6 / 7 / 1999$ & Poured Footing at Pier 8 \\
\hline $6 / 8 / 1999$ & Poured Pier 8 (Stem) \\
\hline $6 / 9 / 1999$ & Poured Pier 10 (Pier Cap) \\
\hline $6 / 10 / 1999$ & Poured Pier 7 (Stem) \\
\hline $6 / 14 / 1999$ & Driving piles at Pier 5, poured Pier 6 \\
\hline $6 / 16 / 1999$ & Poured Pier 9 (Pier Cap) \\
\hline $6 / 18 / 1999$ & Poured Pier 8 (Pier Cap) \\
\hline $6 / 22 / 1999$ & Poured Footing at Pier 5 \\
\hline $6 / 23 / 1999$ & Poured Pier 7 (Pier Cap), Pier 5 (Stem) \\
\hline $6 / 28 / 1999$ & Driving piles at Pier 2 \\
\hline $6 / 30 / 1999$ & Poured Footing at Pier 2 \\
\hline $7 / 2 / 1999$ & Poured Pier 6 (Pier Cap) \\
\hline $7 / 6 / 1999$ & Poured Pier 2 (Stem) \\
\hline $7 / 7 / 1999$ & Driving piles at Pier 4 \\
\hline $7 / 12 / 1999$ & Poured Pier 2 (Pier Cap) \\
\hline $7 / 13 / 1999$ & Poured Pier 5 (Pier Cap) \\
\hline $7 / 15 / 1999$ & Poured Footing at Pier 4 \\
\hline $7 / 15 / 1999$ & Foundation worked on Bent 1 \\
\hline $7 / 17 / 1999$ & Poured Pier 4 (Stem) \\
\hline $7 / 20 / 1999$ & Poured Pier 4 (Pier Cap) \\
\hline $7 / 24 / 1999$ & Driving Piles at Pier 3 \\
\hline $7 / 27 / 1999$ & Placing EPS fills at Bent 1 \\
\hline $8 / 4 / 1999$ & Poured Pier 3 (Stem) \\
\hline & \\
\hline
\end{tabular}


Table D.1: Construction Sequence (SR249 over US12) (Continued)

\begin{tabular}{|r|l|}
\hline \multicolumn{1}{|c|}{ Date } & \multicolumn{1}{|c|}{ Event } \\
\hline $8 / 9 / 1999$ & Poured Pier 3 (Pier Cap) \\
\hline $8 / 13 / 1999$ & Poured Bent 1 (1st pour) \\
\hline $8 / 17 / 1999$ & Set Beams on Span B \\
\hline $8 / 19 / 1999$ & Set Beams on Spans A and C \\
\hline $8 / 20 / 1999$ & Poured Span C Diaphragm \\
\hline $8 / 22 / 1999$ & Set Beams on Span D \\
\hline $8 / 23 / 1999$ & Set Beams on Span E, poured Span B Diaphragm \\
\hline $8 / 24 / 1999$ & Set Beams on Span F, poured Span A Diaphragm \\
\hline $8 / 25 / 1999$ & Poured foundation on Bent 11, set Beams on Span G, poured Span D \\
\hline & Diaphragm \\
\hline $8 / 26 / 1999$ & Set Beams on Span H, poured Spans F Diaphragms \\
\hline $8 / 27 / 1999$ & Set Beams on Span I, poured Span G Diaphragm \\
\hline $8 / 28 / 1999$ & Poured Spans H and I Diaphragms \\
\hline $8 / 31 / 1999$ & Began placing deck pan \\
\hline 9/2/1999 & Placing EPS fills at Bent 11 \\
\hline 9/9/1999 & Began placing reinforcing steel for deck \\
\hline 9/10/1999 & Poured Bent 1 (2nd pour) \\
\hline $9 / 16 / 1999$ & Poured Span A (East half of Phase \#1) \\
\hline 9/20/1999 & Poured Bent 11 (1st pour), , poured Span B (Phase \#2) \\
\hline 9/20/1999 & Poured Span A (West Half of Phase \#1) \\
\hline 9/23/1999 & Poured Deck on Spans C and D, poured diaphragm on Pier 3, set \\
\hline Beams on Span J \\
\hline 9/27/1999 & Poured Span J Diaphragm \\
\hline $10 / 1 / 1999$ & $\begin{array}{l}\text { Poured Deck on Spans E and F, poured diaphragm on Piers 2 and 5, } \\
\text { installed inclinometer on Bent 1 }\end{array}$ \\
\hline $10 / 4 / 1999$ & Poured Diaphragm on Pier 4 \\
\hline $10 / 5 / 1999$ & Poured Diaphragm on Pier 6 \\
\hline $10 / 6 / 1999$ & Poured Deck on Spans G and H, poured diaphragm on Pier 7 \\
\hline $10 / 8 / 1999$ & Poured Deck on Span J \\
\hline $10 / 11 / 1999$ & Poured Deck on Span I \\
\hline $10 / 12 / 1999$ & Poured Diaphragm on Pier 9, poured pavement north end of the bridge \\
\hline $10 / 13 / 1999$ & Poured the sleeper slab south end of the bridge \\
\hline $10 / 15 / 1999$ & Poured the approach slab south end of the bridge \\
\hline $10 / 21 / 1999$ & Poured the pavement south end of the bridge \\
\hline $10 / 22 / 1999$ & Poured he pavement north end of the bridge, poured gap in pavement \\
south end of the bridge \\
\hline $10 / 23 / 1999$ & Poured the sleeper slab north end of the bridge \\
\hline $10 / 26 / 1999$ & Poured the approach slab north end of the bridge \\
\hline
\end{tabular}


Table D.1: Construction Sequence (SR249 over US12) (Continued)

\begin{tabular}{|r|l|}
\hline \multicolumn{1}{|c|}{ Date } & \multicolumn{1}{|c|}{ Event } \\
\hline $11 / 9 / 1999$ & Opened to traffic northbound \\
\hline $11 / 24 / 1999$ & Opened to traffic for both bounds \\
\hline $3 / 20 / 2000$ & $\begin{array}{l}\text { Began placing conduit for the instrumentation wires, placing } \\
\text { instrumentation cabinet }\end{array}$ \\
\hline $3 / 28 / 2000$ & Hawk Inc. installed crackmeters \\
\hline $3 / 29 / 2000$ & Began placing wire through conduit \\
\hline $4 / 3 / 2000$ & Finished pulling wire through conduit \\
\hline $4 / 12 / 2000$ & Hooked up the cabinet \\
\hline $5 / 17 / 2000$ & Installed the instrumentation software \\
\hline $6 / 7 / 2000$ & All strain gages and crackmeters began reading \\
\hline $8 / 18 / 2000$ & Cellular modem was installed (no data obtained from 8/18/2000 to \\
& $12 / 8 / 2000$ ) \\
\hline
\end{tabular}


Table D.2: Northbound Lanes Construction Sequence (I65 over SR25)

\begin{tabular}{|r|l|}
\hline \multicolumn{1}{|c|}{ Date } & \multicolumn{1}{|c|}{ Event } \\
\hline $5 / 24 / 2000$ & Drilling bridge deck to locate edge of beams \\
\hline $5 / 25 / 2000$ & Drilling bridge deck to locate edge of beams \\
\hline $5 / 26 / 2000$ & Drilling bridge deck to locate edge of beams \\
\hline $5 / 29 / 2000$ & Memorial Day \\
\hline $5 / 30 / 2000$ & Started to remove barrier wall \\
\hline $5 / 31 / 2000$ & Removing barrier wall \\
\hline $6 / 1 / 2000$ & Removing barrier wall \\
\hline $6 / 2 / 2000$ & Removing barrier wall \\
\hline $6 / 5 / 2000$ & Sawing bridge deck into sections for removal \\
\hline $6 / 6 / 2000$ & Sawing bridge deck into sections for removal \\
\hline $6 / 7 / 2000$ & Sawing bridge deck into sections for removal \\
\hline $6 / 8 / 2000$ & Removing deck \\
\hline $6 / 9 / 2000$ & Removing deck \\
\hline $6 / 12 / 2000$ & Removing deck/hauling deck off site \\
\hline $6 / 13 / 2000$ & Removing deck/hauling deck off site \\
\hline $6 / 14 / 2000$ & Removing deck/hauling deck off site \\
\hline $6 / 15 / 2000$ & Breaking approach slabs and sleeper slabs; breaking slopewall on south \\
\hline & side \\
\hline $6 / 16 / 2000$ & Driving temporary piling in Bent 3 \\
\hline $6 / 17 / 2000$ & Driving temporary piling in Bents 1 and 3 \\
\hline $6 / 19 / 2000$ & Driving temporary piling in Bent 1 \\
\hline $6 / 20 / 2000$ & Jacking and supporting beams \\
\hline $6 / 21 / 2000$ & Jacking and supporting beams \\
\hline $6 / 22 / 2000$ & Jacking and supporting beams \\
\hline $6 / 23 / 2000$ & Removing Bent 1 \\
\hline $6 / 24 / 2000$ & Removing Bent 1 \\
\hline $6 / 26 / 2000$ & Removing Bent 1 \\
\hline $6 / 27 / 2000$ & Drove piling in Bent 1 \\
\hline $6 / 28 / 2000$ & Forming Bent 1 and wingwalls \\
\hline $6 / 29 / 2000$ & Forming Bent 1 and wingwalls \\
\hline $6 / 30 / 2000$ & Removing debris from old bent; Placed and tied steel in Bent 1 \\
\hline $7 / 3 / 2000$ & Forming Bent 1 and wingwalls \\
\hline $7 / 4 / 2000$ & Independence Day \\
\hline $7 / 5 / 2000$ & Setting plates for Bent 1 pour/Forming Bent1 and wingwalls \\
\hline $7 / 6 / 2000$ & Poured Bent 1/Removing Bent 3 \\
\hline $7 / 7 / 2000$ & Removing Bent 3 \\
\hline $7 / 8 / 2000$ & Removing Bent 3 \\
\hline $7 / 10 / 2000$ & Removing Bent 3/Removing forms, Bent 1 \\
\hline
\end{tabular}


Table D.2: Northbound Lanes Construction Sequence (I65 over SR25) (Continued)

\begin{tabular}{|c|c|}
\hline Date & Event \\
\hline $7 / 11 / 2000$ & $\begin{array}{l}\text { Drove piling Bent 3; Finished removing forms, Bent 1; Grinding seats } \\
\text { for bearing assemblies }\end{array}$ \\
\hline $7 / 12 / 2000$ & Forming Bent 3 and wingwalls \\
\hline $7 / 13 / 2000$ & Forming Bent 3 and wingwalls and backfilled Bent 1 \\
\hline $7 / 14 / 2000$ & Placed and tied steel in Bent 3 \\
\hline $7 / 15 / 2000$ & $\begin{array}{l}\text { Clean-up on Bent 3; Grading and forming Bent } 1 \text { (top portion); } \\
\text { Finished forming Bent } 3\end{array}$ \\
\hline $7 / 17 / 2000$ & Poured Bent 3 \\
\hline $7 / 18 / 2000$ & Removing forms, Bent 3 , setting beams \\
\hline $7 / 19 / 2000$ & Backfilled Bent 3 \\
\hline $7 / 20 / 2000$ & Preparing to remove damaged beams \\
\hline $7 / 21 / 2000$ & $\begin{array}{l}\text { Grading; Removing old drain pipe; Removed damaged beams and } \\
\text { diaphragms (span B) }\end{array}$ \\
\hline $7 / 24 / 2000$ & Tying re-steel in crash steel \\
\hline $7 / 25 / 2000$ & Set two new beams (span B); Tying resteel for crashwall \\
\hline $7 / 26 / 2000$ & Resetting diaphragms \\
\hline $7 / 27 / 2000$ & Forming crashwall; Finished setting beams; Bolting diaphragms \\
\hline $7 / 28 / 2000$ & Bolting diaphragms \\
\hline $7 / 31 / 2000$ & Forming Bent 1; Drilling and bolting splices and diaphragms \\
\hline $8 / 1 / 2000$ & $\begin{array}{l}\text { Forming Bent 1; Setting deck pans; Finished bolting diaphragms and } \\
\text { checking torque }\end{array}$ \\
\hline $8 / 2 / 2000$ & Grading for sleeper slabs; Forming end bents \\
\hline $8 / 3 / 2000$ & Installing deck pans and forming end bents \\
\hline $8 / 4 / 2000$ & $\begin{array}{l}\text { Installing deck pans, replacing damaged shear studs and forming end } \\
\text { bents }\end{array}$ \\
\hline $8 / 5 / 2000$ & Installing deck pans, installing new shear studs and forming end bents \\
\hline $8 / 7 / 2000$ & Installing deck pans and forming end bents \\
\hline $8 / 8 / 2000$ & Placing reinforcement in deck and forming end bents \\
\hline $8 / 9 / 2000$ & Placing reinforcement in deck and forming deck \\
\hline $8 / 10 / 2000$ & Placing reinforcement in deck and end bents \\
\hline $8 / 11 / 2000$ & Placing reinforcement in deck and end bents \\
\hline $8 / 12 / 2000$ & Forming end bents \\
\hline $8 / 14 / 2000$ & Forming/getting ready for deck pour \\
\hline $8 / 15 / 2000$ & $\begin{array}{l}\text { Poured deck (began at 7:00 am at Bent } 1 \text { and proceeded north to Bent } \\
\text { 3; finished pouring around 2:00 pm; placed burlene that evening) }\end{array}$ \\
\hline $8 / 16 / 2000$ & Stripping bents; Wet burlene \\
\hline $8 / 17 / 2000$ & $\begin{array}{l}\text { Forming South Approach Slab and placing rebar in South Approach } \\
\text { Slab (rained in evening) }\end{array}$ \\
\hline
\end{tabular}


TableD.2: Northbound Lanes Construction Sequence (I65 over SR25) (Continued)

\begin{tabular}{|c|l|}
\hline Date & \multicolumn{1}{|c|}{ Event } \\
\hline $8 / 18 / 2000$ & Finished shoulders and placing rebar in South Approach \\
\hline $8 / 21 / 2000$ & $\begin{array}{l}\text { Sealing joints; Clean up on bridge superstructure; Forming North } \\
\text { Approach }\end{array}$ \\
\hline $8 / 22 / 2000$ & Placing rebar in North Approach Slab \\
\hline $8 / 23 / 2000$ & Working on shoulders \\
\hline $8 / 24 / 2000$ & Sealed deck \\
\hline $8 / 25 / 2000$ & Slip-formed barrier walls \\
\hline $8 / 28 / 2000$ & Traffic switched to Northbound lanes at 2:25 pm \\
\hline $8 / 31 / 2000$ & Began work on SBL \\
\hline
\end{tabular}


Table D.3: Southbound Lanes Construction Sequence (I65 over SR25)

\begin{tabular}{|c|c|}
\hline Date & Event \\
\hline $8 / 28 / 2000$ & Switched traffic to northbound lanes \\
\hline $8 / 31 / 2000$ & Removed asphalt overlay and overhead sign \\
\hline $9 / 1 / 2000$ & $\begin{array}{l}\text { Began breaking pavement and removing concrete deck; removed } \\
\text { barrier wall }\end{array}$ \\
\hline 9/2/2000 & Continuing deck removal \\
\hline $9 / 4 / 2000$ & Continuing deck removal \\
\hline 9/5/2000 & Continuing deck removal \\
\hline 9/6/2000 & Completed deck removal \\
\hline 9/7/2000 & Began jacking and supporting beams \\
\hline $9 / 8 / 2000$ & Continued jacking and supporting beams and drove temporary piles \\
\hline 9/12/2000 & Finished jacking and supporting beams \\
\hline 9/13/2000 & Removing end bents \\
\hline 9/14/2000 & Removing end bents \\
\hline $9 / 15 / 2000$ & Finished removing bents and drove steel $\mathrm{H}$ piles for Bent 1 \\
\hline 9/16/2000 & Forming Bent 1 and drove steel $\mathrm{H}$ piles for Bent 3 \\
\hline $9 / 18 / 2000$ & Forming Bent 2 and placing steel in Bent 1 \\
\hline $9 / 19 / 2000$ & Placing steel in Bent 3 \\
\hline $9 / 20 / 2000$ & $\begin{array}{l}\text { Grading subbase and forming Bents No. } 1 \text { and 3; Placing steel in Bents } \\
\text { No. } 1 \text { \& } 3\end{array}$ \\
\hline $9 / 21 / 2000$ & $\begin{array}{l}\text { Grading subbase; Forming Bents No. } 1 \text { and 3; Placing steel in Bents } \\
\text { No. } 1 \text { and } 3\end{array}$ \\
\hline $9 / 22 / 2000$ & Poured concrete for Bents No. 1 and 3 \\
\hline $9 / 23 / 2000$ & Stripping forms on Bents No. 1 and 3; Placed geotextile fabric \\
\hline $9 / 25 / 2000$ & $\begin{array}{l}\text { Backfilled abutments; Preparing sleeper areas for concrete; Placed end } \\
\text { bent drains }\end{array}$ \\
\hline 9/26/2000 & Setting beams \\
\hline $9 / 27 / 2000$ & Setting beams \\
\hline $10 / 2 / 2000$ & Grading subbase for sleeper slabs \\
\hline $10 / 3 / 2000$ & $\begin{array}{l}\text { Poured crashwall footing; Welding bearing assembly in place; Bolting } \\
\text { end diaphragms }\end{array}$ \\
\hline $10 / 4 / 2000$ & Bolting end diaphragms \\
\hline $10 / 5 / 2000$ & Stripping forms for crashwall; Forming Bents No. 1 and 3 \\
\hline $10 / 6 / 2000$ & Installing deck pans and forming Bents No. 1 and 3 \\
\hline $10 / 7 / 2000$ & Installing deck pans and replacing damaged shear studs \\
\hline $10 / 8 / 2000$ & Installing deck pans and installing new shear studs \\
\hline $10 / 9 / 2000$ & Placing reinforcement in deck \\
\hline $10 / 10 / 2000$ & Placing reinforcement in deck \\
\hline $10 / 11 / 2000$ & Placing reinforcement in deck and end bents \\
\hline
\end{tabular}


Table D.3: Southbound Lanes Construction Sequence (I65 over SR25) (Continued)

\begin{tabular}{|c|c|}
\hline Date & Event \\
\hline $10 / 12 / 2000$ & Placing reinforcement in deck; Forming end bents and coping line \\
\hline $10 / 13 / 2000$ & Placing reinforcement in deck; Forming end bents \\
\hline $10 / 14 / 2000$ & Placing reinforcement in deck; Forming end bents \\
\hline $10 / 16 / 2000$ & Finished deck steel; Forming end bents \\
\hline $10 / 17 / 2000$ & Removing median asphalt; Forming end bents \\
\hline $10 / 18 / 2000$ & $\begin{array}{l}\text { Poured deck - began at Bent } 3 \text { at 7:30AM }\left(38^{\circ} \mathrm{F} \text {, foggy); Finished at }\right. \\
\text { Bent } 1 \text { around 1:30PM }\left(60^{\circ} \mathrm{F} \text {, sunny); Placed burlene over deck around }\right. \\
\text { 9:00PM }\end{array}$ \\
\hline $10 / 19 / 2000$ & Stripping end bent forms; Wet burlene \\
\hline $10 / 20 / 2000$ & Forming approach slabs \\
\hline $10 / 21 / 2000$ & Poured South Approach Slab (7:00-11:00AM) \\
\hline $10 / 23 / 2000$ & Poured North Approach Slab (AM) \\
\hline $10 / 24 / 2000$ & $\begin{array}{l}\text { Placed base in terminal joints/Placing steel in bridge railing/Stripping } \\
\text { coping forms }\end{array}$ \\
\hline $10 / 25 / 2000$ & Folded burlene \\
\hline $10 / 26 / 2000$ & Poured curbs; Removed burlene \\
\hline $10 / 27 / 2000$ & Working on shoulders \\
\hline $10 / 28 / 2000$ & Sealed deck \\
\hline $10 / 29 / 2000$ & Slip-formed barrier walls \\
\hline $10 / 30 / 2000$ & Clean-up \\
\hline $10 / 31 / 2000$ & Southbound traffic switched to Southbound lanes at 9:30AM \\
\hline
\end{tabular}


Table D.4: Construction Sequence (SR18)

\begin{tabular}{|r|l|}
\hline \multicolumn{1}{|c|}{ Date } & \multicolumn{1}{|c|}{ Event } \\
\hline $5 / 6 / 2003$ & Removal of existing deck and beams began \\
\hline $5 / 28 / 2003$ & Removed Pier 5 Cap \\
\hline $6 / 5 / 2003$ & Removed Bent 6 and old piling \\
\hline $6 / 6 / 2003$ & Poured Bent 5 Stem \\
\hline $6 / 11 / 2003$ & Bent 6 Piles Driven \\
\hline $6 / 12 / 2003$ & Pier 5 cap poured, Bent 6 pile driving completed \\
\hline $6 / 13 / 2003$ & Began forming Pour \#1 of Bent 6 \\
\hline $6 / 16 / 2003$ & Bent 6 Pile Strain gages attached to piles, pressure cells installed \\
\hline $6 / 17 / 2003$ & Bent 6 instrumentation conduit ran. East datalogger programmed and \\
uploaded and tested. Problems observed with readings
\end{tabular}


Table D.4: Construction Sequence (SR18) (Continued)

\begin{tabular}{|r|l|}
\hline \multicolumn{1}{|c|}{ Date } & \multicolumn{1}{|c|}{ Event } \\
\hline $8 / 12 / 2003$ & Placed beams on Span C \\
\hline $8 / 13 / 2003$ & Poured Pier 2 Stem \\
\hline $8 / 15 / 2003$ & Poured Span C midspan diaphragms \\
\hline 8/19/2003 & Poured Pier 2 Cap \\
\hline 8/21/2003 & Began work on SIP deck forms for Spans C, D, and E \\
\hline 9/2/2003 & Finished SIP deck forms for Spans C, D, and E \\
\hline 9/3/2003 & Began deck reinforcement for Spans D and E \\
\hline 9/4/2003 & Continued placing deck steel Spans C, D, and E \\
\hline 9/8/2003 & Placed Beams on Spans A and B \\
\hline 9/9/2003 & Poured Span B midspan diaphragms \\
\hline 9/10/2003 & Poured Pour \#2 on Bent 1 and wing walls. Reinforcing steel on Span B \\
\hline 9/12/2003 & Poured Span A Midspan Diaphragm. Tiltmeter and Crackmeter on \\
\hline & Pier 2, but problems with readout box so installation stopped. \\
\hline 9/16/2003 & Completed SIP deck forms and continued deck reinforcing steel. More \\
\hline & East End bent backfilling \\
\hline 9/18/2003 & Placed aggregate base on east approach. Poured west sleeper slab. \\
\hline 9/19/2003 & Placed aggregate base on west approach \\
\hline 9/20/2003 & Recompacted east approach \\
\hline 9/22/2003 & Completed deck steel. Started approach steel \\
\hline 9/26/2003 & Cast the deck \\
\hline 9/27/2003 & Saw cut the approaches \\
\hline $10 / 3 / 2003$ & Poured concrete curb on south side of bridge \\
\hline $10 / 7 / 2003$ & Poured concrete sidewalk on north side of bridge \\
\hline $10 / 13 / 2003$ & Poured bridge rail on north side \\
\hline $10 / 17 / 2003$ & Poured rail transition on North side \\
\hline $11 / 11 / 2003$ & Move East instrumentation from temporary cabinet to permanent \\
\hline $11 / 12 / 2003$ & Move West instrumentation from temporary cabinet to permanent \\
\hline $11 / 19 / 2003$ & Power lines run to instrumentation cabinets \\
\hline $11 / 25 / 2003$ & Bridge opened to traffic \\
\hline $12 / 3 / 2003$ & Power lines connected to dataloggers \\
\hline $12 / 19 / 2003$ & Phone line connected on west box, but not working \\
\hline $12 / 23 / 2003$ & Went to bridge for final inspection. West phone line repaired by LSI. \\
& Was able to download using modem. \\
\hline & \\
\hline
\end{tabular}




\section{APPENDIX E}

COMPUTATION OF DEFLECTED SHAPE OF PILE 6 (SR18) 


\section{Appendix E: Computation of Deflected Shape of Pile 6 (SR18)}

Curvatures along the depth of Pile 6 as shown in Figure E.1were determined from the strain gage measurement. The bottom of the pile was assumed to be fixed. Deflections, $\Delta_{1}(\mathrm{z})$, along the pile depth, $\mathrm{z}$, were computed by integrating the moment of the area under the curvature relationship as illustrated in Figure E.2. It is assumed that the bottom of the pile behaves as a hinged support. Thus, a rotation, $\theta$, can occur at the bottom of the pile. The previously calculated deflections, $\Delta_{1}(\mathrm{z})$, were calibrated with the value measured by a convergence meter, $\Delta_{\mathrm{cv}}(0)$, at the ground level $(\mathrm{z}=0)$. By assuming the values from the convergence meter is correct, the rotation at the bottom of the pile was determined by solving Equation E-1 for $\theta$.

$$
\Delta_{1}(0)=\Delta_{\mathrm{cv}}(0)+\theta \mathrm{L}
$$

where:

$$
\begin{aligned}
\Delta_{1}(0)= & \text { deflection at the top of the pile calculated by moment-area } \\
& \text { method assumed fixed end at the bottom of the pile, in. } \\
\Delta_{\mathrm{cv}}(0)= & \text { deflection at the center of Bent } 1 \text { measured by a convergence } \\
& \text { meter, in. } \\
\theta \quad= & \text { rotation at the bottom of the pile, radian. } \\
\mathrm{L} \quad= & \text { length of the pile below ground surface, in. }
\end{aligned}
$$

For example, at $\Delta \mathrm{T}=-60^{\circ} \mathrm{F}, \Delta_{1}(0)=0.59$ in., $\Delta_{\mathrm{cv}}(0)=0.21 \mathrm{in}$., and $\mathrm{L}=22.25 \mathrm{ft}$ (267 in.), $\theta$ can be solved by Equation E-1 to be equal to $0.00079 \mathrm{rad}$.

The final deflected shape can be calculated by subtracting the value of $\theta \mathrm{x}$ from the previously calculated deflection, $\Delta_{1}(\mathrm{z})$ where $\mathrm{x}$ is the distance from the bottom of the pile to a specific depth $(\mathrm{x}=22.25-\mathrm{z})$. For instance, at a depth of $8 \mathrm{ft}$ from the ground surface, $\Delta_{1}(8)=0.26$ in., $\theta \mathrm{x}=(0.00079 \mathrm{rad})(22.25 \mathrm{ft}-8 \mathrm{ft})(12 \mathrm{in} . / \mathrm{ft})=0.13 \mathrm{in}$. Therefore, adjusted $\Delta(8)=0.26$ in. -0.13 in. $=0.13$ in. 


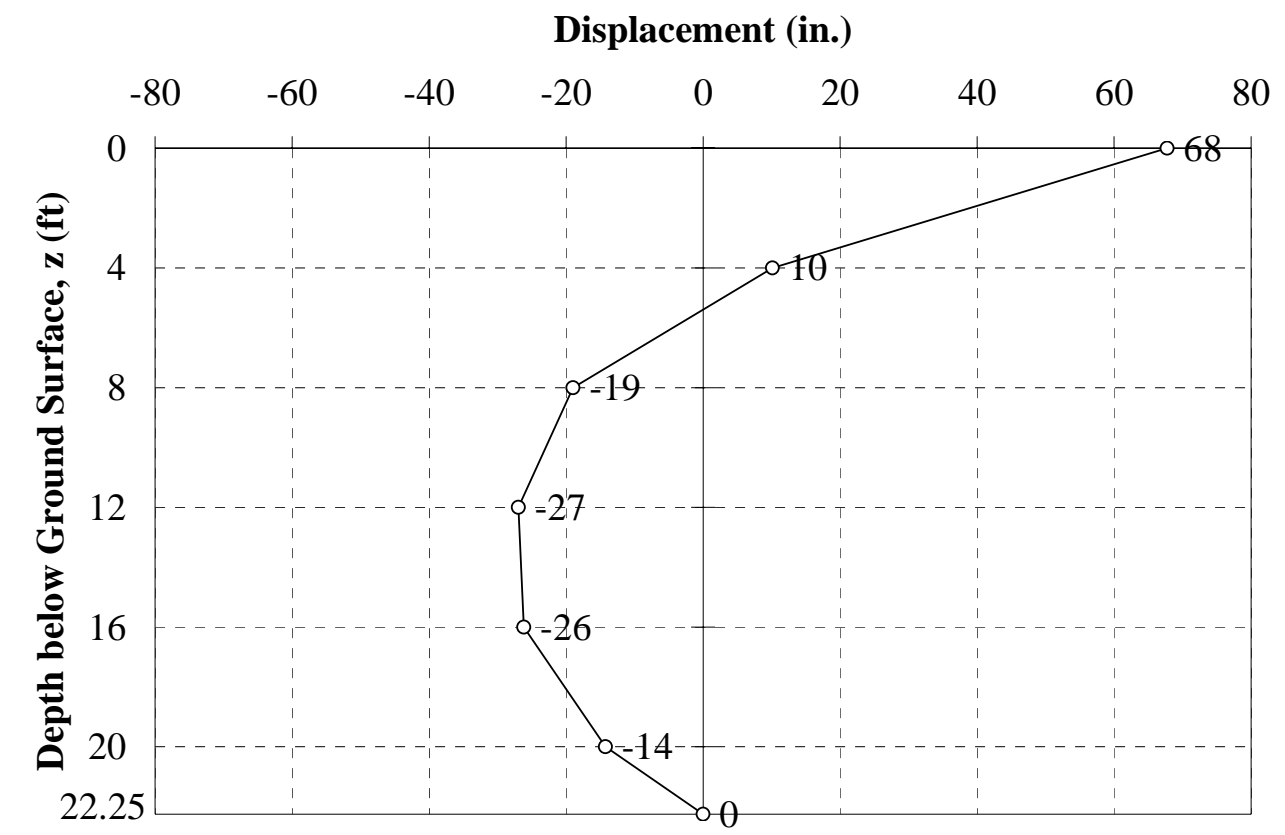

Figure E.1: Curvature of Pile 6 on Bent 1 (SR18) at $\Delta \mathrm{T}=-60^{\circ} \mathrm{F}$

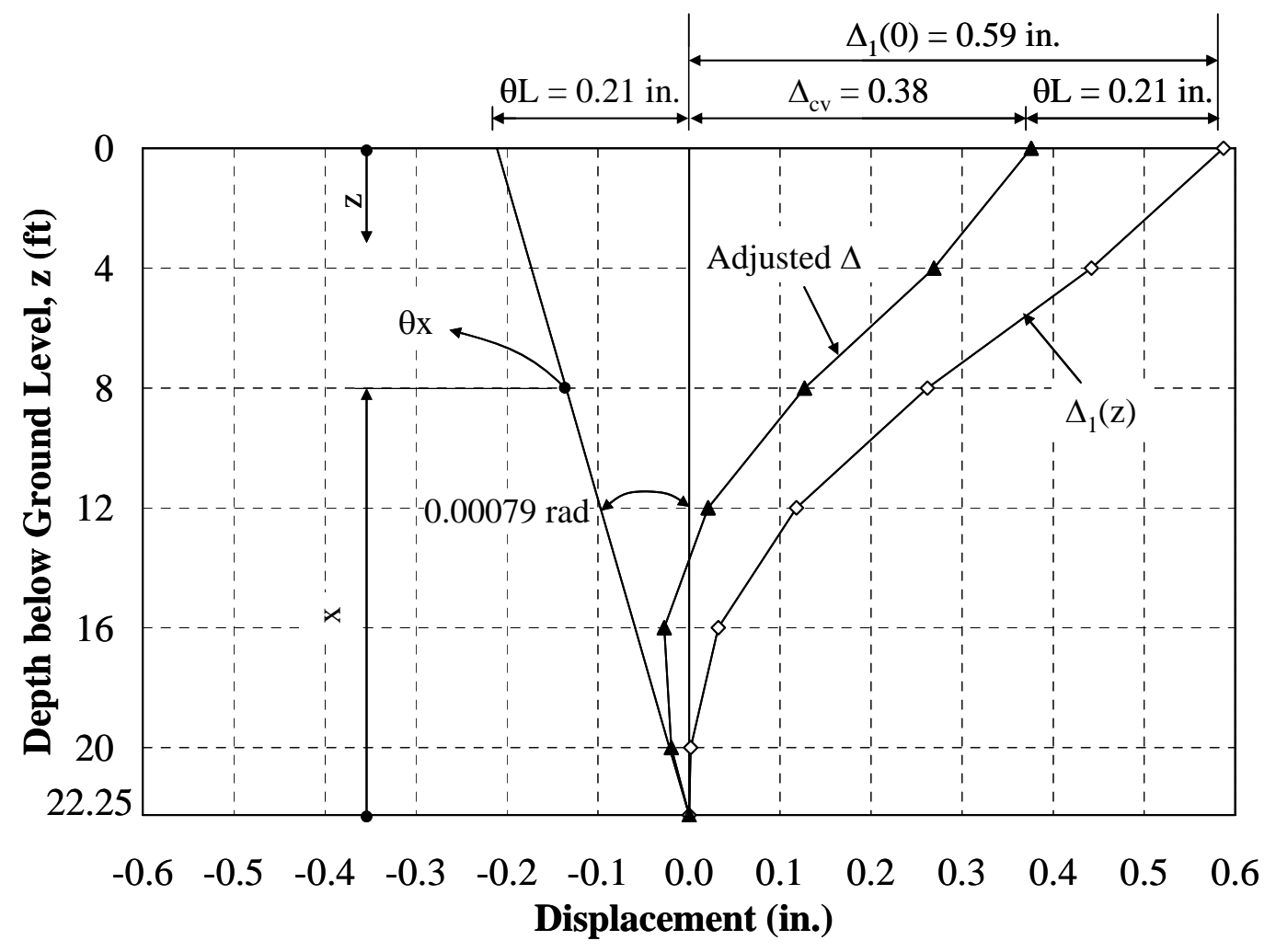

Figure E.2: Deflected Shape at $\Delta \mathrm{T}=-60^{\circ} \mathrm{F}$ 
APPENDIX F

LPILE SOIL MODEL 


\section{Appendix F: LPILE Soil Model}

The p-y curves for sand below ground surface illustrated in Figure F.1 can be created by the following procedure (Reese et al., 1974).

1. Obtain value for the angle of internal friction, $\phi$, the soil unit weight, $\gamma$, and pile diameter, B.

2. Compute the preliminary values.

$$
\begin{aligned}
& \alpha=\frac{\phi}{2} \\
& \beta=45^{\circ}+\frac{\phi}{2} \\
& \mathrm{~K}_{0}=0.4 ; \text { and } \mathrm{K}_{\mathrm{A}}=\tan ^{2}\left(45^{\circ}-\frac{\phi}{2}\right)
\end{aligned}
$$

3. Compute the ultimate soil resistance per unit length of pile, psi, using the smaller of the values given by Equations F-1, and F-2.

$$
\begin{aligned}
\mathrm{p}_{\mathrm{st}}=\gamma \mathrm{z}\left[\frac{\mathrm{K}_{\mathrm{o}} \mathrm{z} \tan \phi \sin \beta}{\tan (\beta-\phi) \cos \alpha}+\frac{\tan \beta}{\tan (\beta-\phi)}(\mathrm{B}+\mathrm{z} \tan \beta \tan \alpha)\right. \\
\left.+\mathrm{K}_{0} \mathrm{z} \tan \beta(\tan \phi \sin \beta-\tan \alpha)-\mathrm{K}_{\mathrm{A}} \mathrm{B}\right] \\
\mathrm{p}_{\mathrm{sd}}=\mathrm{K}_{\mathrm{A}} \mathrm{B} \gamma \mathrm{z}\left(\tan ^{8} \beta-1\right)+\mathrm{K}_{0} \mathrm{~B} \gamma \mathrm{z} \tan \phi \tan ^{4} \beta
\end{aligned}
$$

4. Find the intersection, $x_{t}$, by equating Equations F-1 and F-2. Above this depth, use Equation F-1 for the ultimate soil resistance near the ground surface. Below this depth, use Equation F-2 for the ultimate soil resistance well below the ground surface.

5. Select a depth at which a p-y curve is desired.

6. Establish $\mathrm{y}_{\mathrm{u}}$ as $3 \mathrm{~B} / 80$. Compute $\mathrm{p}_{\mathrm{u}}$ by Equation $\mathrm{F}-3$

$$
\mathrm{p}_{\mathrm{u}}=\mathrm{A}_{\mathrm{s}} \mathrm{p}_{\mathrm{s}} \text { or } \mathrm{p}_{\mathrm{u}}=\mathrm{A}_{\mathrm{c}} \mathrm{p}_{\mathrm{s}}
$$

The values of $A_{s}$ or $A_{c}$, coefficients for static and cyclic cases, respectively, can be obtained from Figure F.2. 


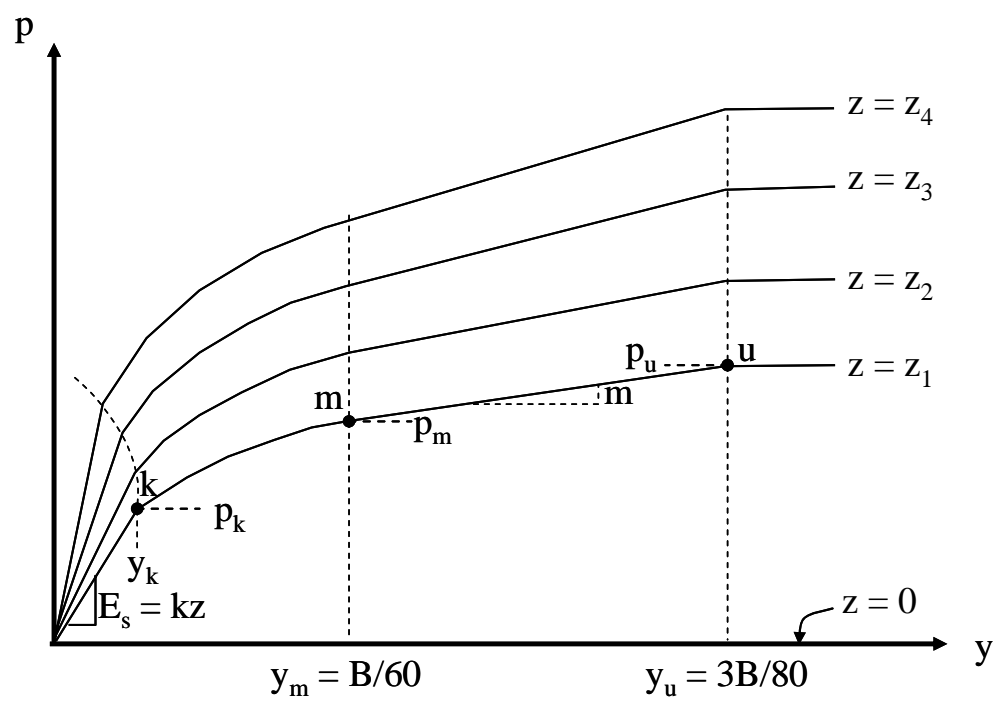

where: $\mathrm{z}=$ depth below ground level and $\mathrm{z}_{1}<\mathrm{z}_{2}<\mathrm{z}_{3}<\mathrm{z}_{4}$.

Figure F.1: Characteristic Shape of a Family of p-y Curves for Static and Cyclic Loading in Sand (Reese et al., 1974)

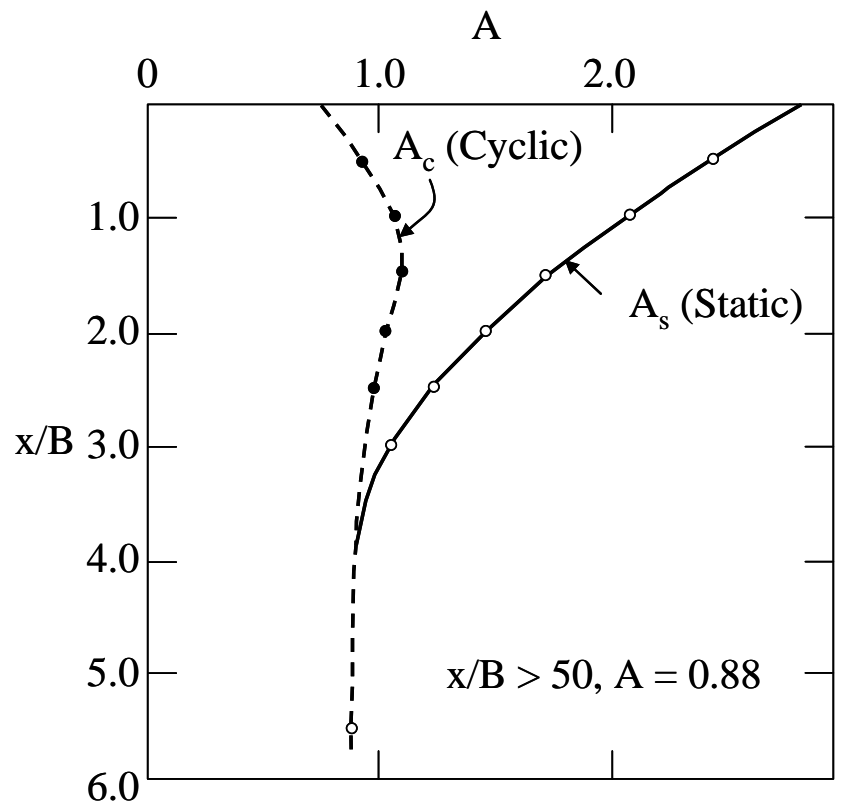

Figure F.2: Values of Coefficients $A_{s}$ and $A_{c}$ (Reese et al., 1974)

7. Establish $\mathrm{y}_{\mathrm{m}}$ as $\mathrm{B} / 60$. Compute $\mathrm{p}_{\mathrm{m}}$ by Equation F-4.

$$
\mathrm{p}_{\mathrm{m}}=\mathrm{B}_{\mathrm{s}} \mathrm{p}_{\mathrm{s}} \text { or } \mathrm{p}_{\mathrm{m}}=\mathrm{B}_{\mathrm{c}} \mathrm{p}_{\mathrm{s}}
$$


The values of $\mathrm{B}_{\mathrm{s}}$ or $\mathrm{B}_{\mathrm{c}}$, coefficients for static and cyclic cases, respectively, can be obtained from Figure F.3.

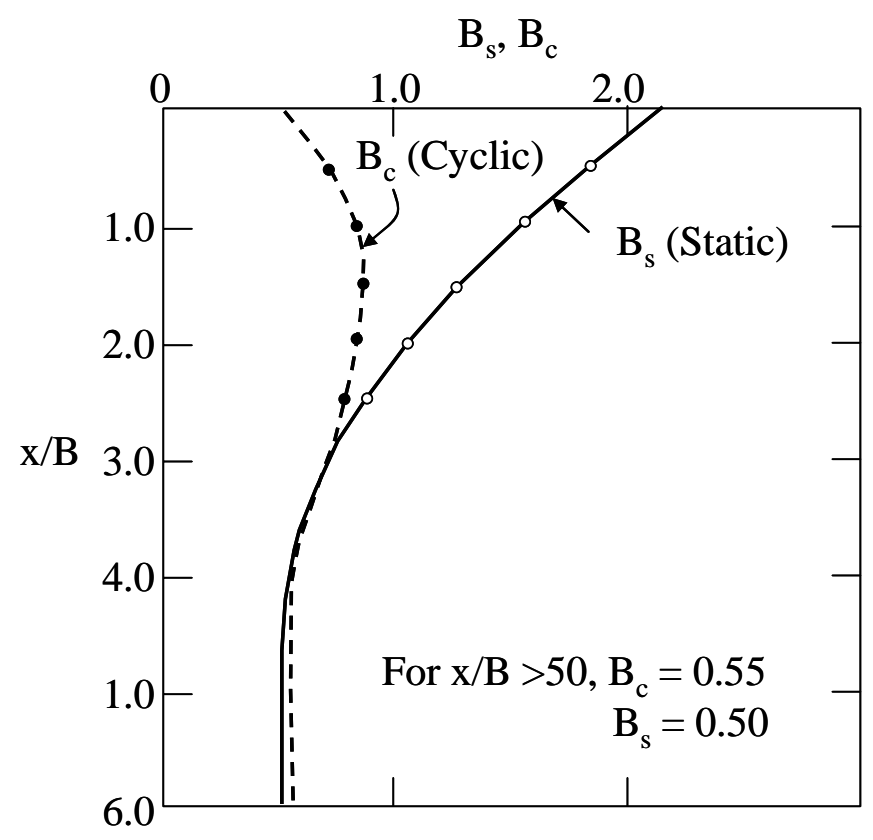

Figure F.3: Values of Coefficients $B_{s}$ and $B_{c}$ (Reese et al., 1974)

8. Establish the initial slope of the p-y curve, $\mathrm{k}$ from Table F.1

Table F.1: Recommended Values of $k$ for Sand (lb/in. $\left.{ }^{3}\right)$

\begin{tabular}{|c|c|c|c|}
\hline \multirow{2}{*}{ Sand } & \multicolumn{3}{|c|}{ Relative Density } \\
\cline { 2 - 4 } & Loose & Medium & Dense \\
\hline Submerged & 20 & 60 & 125 \\
\hline Dry & 25 & 90 & 225 \\
\hline
\end{tabular}

9. Fit a parabola between points $\mathrm{k}$ and $\mathrm{m}$ as follows:

a. Obtain the slope of the line between points $m$ and $u$ by,

$$
\mathrm{m}=\frac{\mathrm{p}_{\mathrm{u}}-\mathrm{p}_{\mathrm{m}}}{\mathrm{y}_{\mathrm{u}}-\mathrm{y}_{\mathrm{m}}}
$$

b. Obtain the power of the parabolic section by,

$$
\mathrm{n}=\frac{\mathrm{p}_{\mathrm{m}}}{\mathrm{my}_{\mathrm{m}}}
$$

c. Obtain the coefficient $\mathrm{C}$ as follows: 


$$
\mathrm{C}=\frac{\mathrm{y}_{\mathrm{m}}}{\mathrm{y}_{\mathrm{m}}^{1 / \mathrm{n}}}
$$

d. Determine point $\mathrm{k}$ as,

$$
\mathrm{y}_{\mathrm{k}}=\left(\frac{\mathrm{C}}{\mathrm{kz}}\right)^{\frac{\mathrm{n}}{\mathrm{n}-1}}
$$

10. Establish the parabolic section of the p-y curve between points $\mathrm{k}$ and $\mathrm{m}$.

$$
\mathrm{p}=\mathrm{Cy}^{1 / \mathrm{n}}
$$


APPENDIX G

SOIL SPRING STIFFNESS VALUES 


\section{Appendix G: Soil Spring Stiffness Values}

Table G.1: Soil Spring Stiffness Values for Piles (SR249 over US12)

\begin{tabular}{|c|c|c|}
\hline \multirow[b]{2}{*}{$\begin{array}{l}\text { Depth below } \\
\text { ground surface } \\
\text { (ft) }\end{array}$} & Bent 1 & Bent 11 \\
\hline & \begin{tabular}{|c|} 
Spring \\
Stiffness, \\
$\mathbf{k}(\mathbf{k} / \mathbf{f t})$
\end{tabular} & $\begin{array}{c}\text { Spring } \\
\text { Stiffness, } \\
\mathbf{k}(\mathbf{k} / \mathbf{f t})\end{array}$ \\
\hline$\overline{0}$ & $\overline{0}$ & 0 \\
\hline 1 & 5 & 5 \\
\hline 2 & 9 & 9 \\
\hline 3 & 14 & 14 \\
\hline 4 & 19 & 19 \\
\hline 5 & 24 & 24 \\
\hline 6 & 93 & 28 \\
\hline 7 & 108 & 33 \\
\hline 8 & 123 & 38 \\
\hline 9 & 139 & 42 \\
\hline 10 & 154 & 47 \\
\hline$\overline{11}$ & 67 & 67 \\
\hline 12 & 67 & 67 \\
\hline 13 & 67 & 67 \\
\hline 14 & 67 & 67 \\
\hline 15 & 67 & 67 \\
\hline 16 & 67 & 247 \\
\hline 17 & 67 & 262 \\
\hline 18 & 67 & 278 \\
\hline 19 & 67 & 293 \\
\hline 20 & 67 & 309 \\
\hline 21 & 567 & 324 \\
\hline 22 & 567 & 340 \\
\hline 23 & 567 & 355 \\
\hline 24 & 567 & 370 \\
\hline 25 & 567 & 386 \\
\hline 26 & 123 & 401 \\
\hline 27 & 127 & 417 \\
\hline 28 & 132 & 432 \\
\hline 29 & 137 & 448 \\
\hline 30 & 141 & 463 \\
\hline
\end{tabular}

\begin{tabular}{|c|c|c|}
\hline $\begin{array}{c}\text { Depth below } \\
\text { ground surface } \\
\mathbf{( f t )}\end{array}$ & $\begin{array}{c}\text { Bent 1 } \\
\text { Spring } \\
\text { Stiffness, } \\
\mathbf{k}(\mathbf{k} / \mathbf{f t})\end{array}$ & $\begin{array}{c}\text { Bent 11 } \\
\text { Stiffness, } \\
\mathbf{k}(\mathbf{k} / \mathbf{f t})\end{array}$ \\
\hline 31 & 146 & 478 \\
\hline 32 & 151 & 494 \\
\hline 33 & 156 & 509 \\
\hline 34 & 160 & 525 \\
\hline 35 & 495 & 1620 \\
\hline 40 & 335 & 335 \\
\hline 45 & 503 & 503 \\
\hline 55 & 8488 & 8488 \\
\hline 65 & 10031 & 10031 \\
\hline 75 & 11574 & 11574 \\
\hline 85 & 13117 & 13117 \\
\hline 95 & 14660 & 14660 \\
\hline 105 & 16204 & 16204 \\
\hline 115 & (fixed end) & 17747 \\
\hline 125 & & 19290 \\
\hline 135 & & 20833 \\
\hline 145 & & (fixed end) \\
\hline
\end{tabular}


Table G.2: Soil Spring Stiffness Values for Piles (I65 over SR25)

\begin{tabular}{|c|c|}
\hline $\begin{array}{l}\text { Depth below } \\
\text { ground surface } \\
\text { (ft) }\end{array}$ & $\begin{array}{c}\text { Spring } \\
\text { Stiffness, k } \\
(\mathbf{k} / \mathbf{f t})\end{array}$ \\
\hline$\overline{0}$ & $\overline{0}$ \\
\hline 1 & 15 \\
\hline 2 & 31 \\
\hline 3 & 46 \\
\hline 4 & 62 \\
\hline 5 & 77 \\
\hline 6 & 93 \\
\hline 7 & 108 \\
\hline 8 & 123 \\
\hline 9 & 139 \\
\hline 10 & 231 \\
\hline 12 & 370 \\
\hline 14 & 432 \\
\hline 16 & 494 \\
\hline 18 & 556 \\
\hline 20 & 617 \\
\hline 22 & 679 \\
\hline 24 & 741 \\
\hline 26 & 802 \\
\hline 28 & 864 \\
\hline 30 & 926 \\
\hline 32 & 988 \\
\hline 34 & 1049 \\
\hline 36 & 1111 \\
\hline 38 & 1759 \\
\hline 40 & (fixed end) \\
\hline
\end{tabular}


Table G.3: Soil Spring Stiffness Values for Piles (SR18 over Mississinewa River)

\begin{tabular}{|c|c|c|}
\hline \multirow{2}{*}{$\begin{array}{l}\text { Depth below } \\
\text { ground surface }\end{array}$} & \multicolumn{2}{|c|}{ Spring Stiffness, k (k/ft) } \\
\hline & Stiff Clay & Medium Sand \\
\hline 0 & 0 & 0 \\
\hline 1 & 211 & 53 \\
\hline 2 & 241 & 107 \\
\hline 3 & 271 & 160 \\
\hline 4 & 301 & 213 \\
\hline 5 & 331 & 267 \\
\hline 6 & 361 & 320 \\
\hline 7 & 391 & 373 \\
\hline 8 & 421 & 427 \\
\hline 9 & 451 & 480 \\
\hline 10 & 481 & 533 \\
\hline 11 & 511 & 587 \\
\hline 12 & 541 & 640 \\
\hline 13 & 541 & 693 \\
\hline 14 & 541 & 747 \\
\hline 15 & 541 & 800 \\
\hline 16 & 541 & 853 \\
\hline 17 & 541 & 907 \\
\hline 18 & 541 & 960 \\
\hline 19 & 541 & 1013 \\
\hline 20 & 541 & 1067 \\
\hline 21 & 541 & 1120 \\
\hline 22 & 406 & 880 \\
\hline 22.25 & (fixed end) & (fixed end) \\
\hline
\end{tabular}


APPENDIX H

COUPON TEST RESULTS 


\section{$\underline{\text { APPENDIX H :Coupon Test Results }}$}

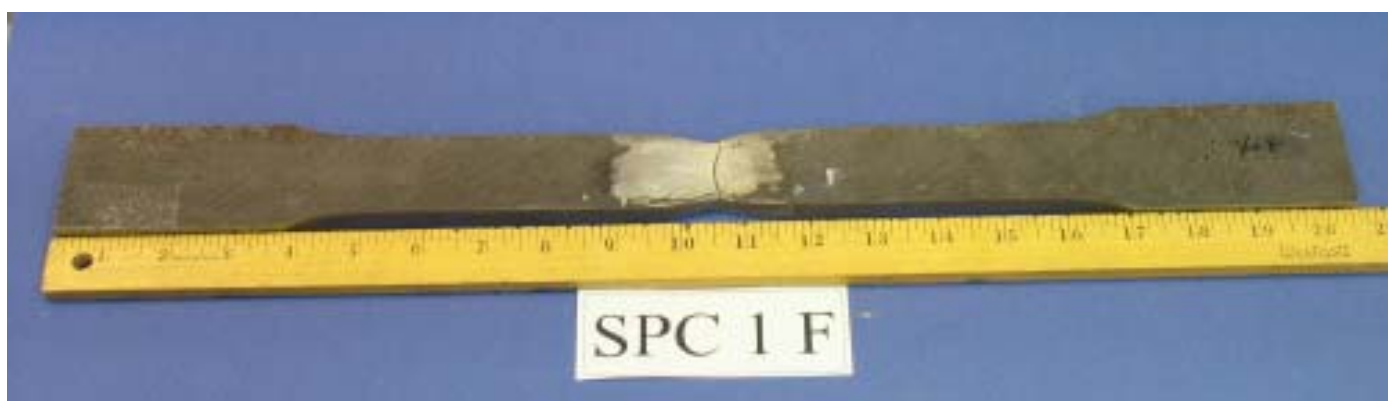

(a) Flange

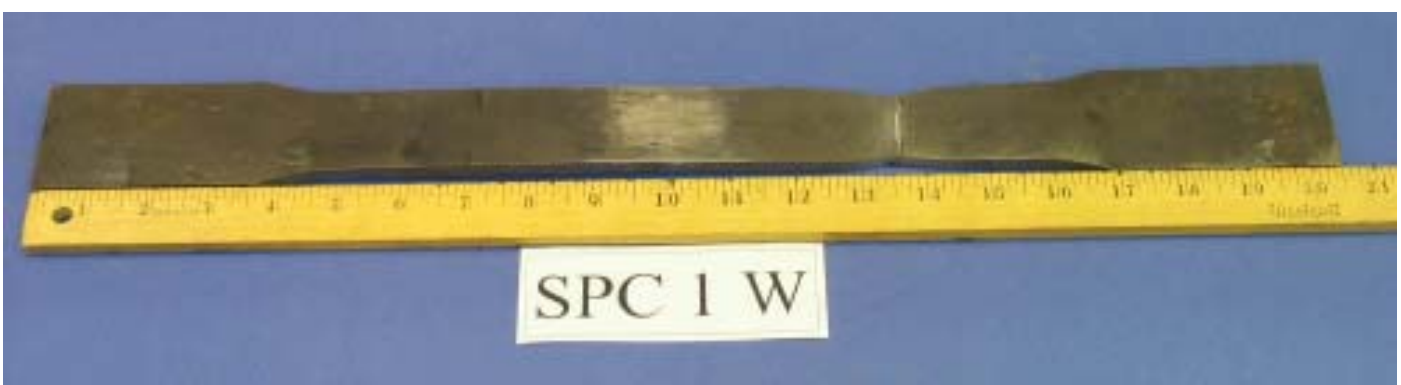

(b) Web

Figure H.1: Specimen 1 - Coupons

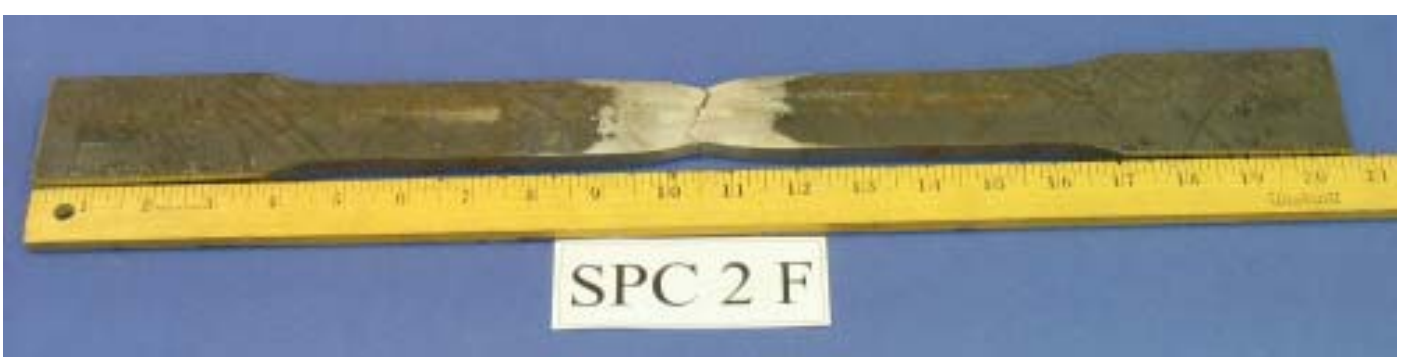

(a) Flange

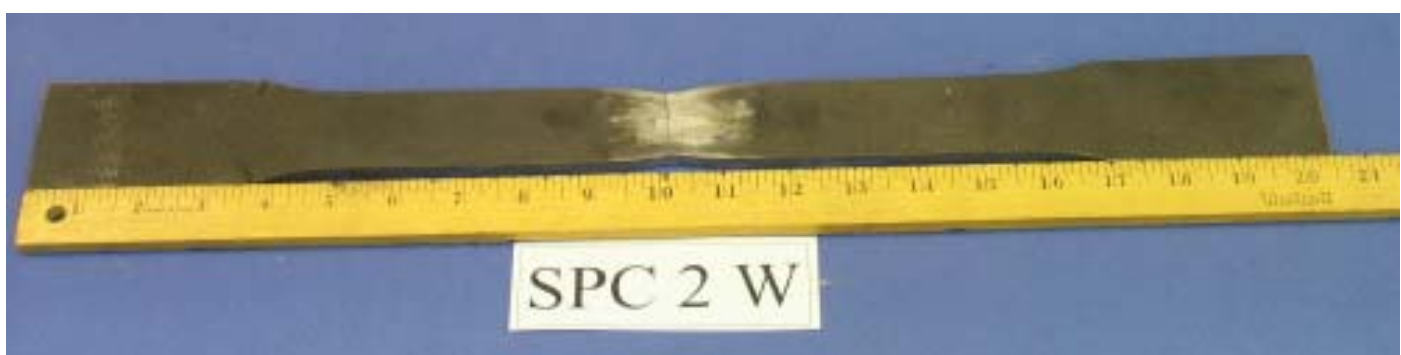

(b) Web

Figure H.2: Specimen 2 - Coupons 


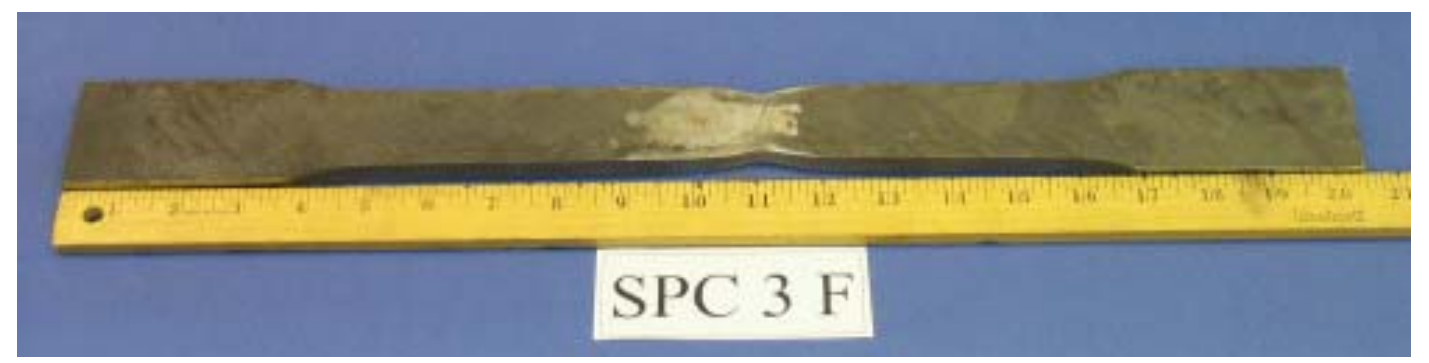

(a) Flange

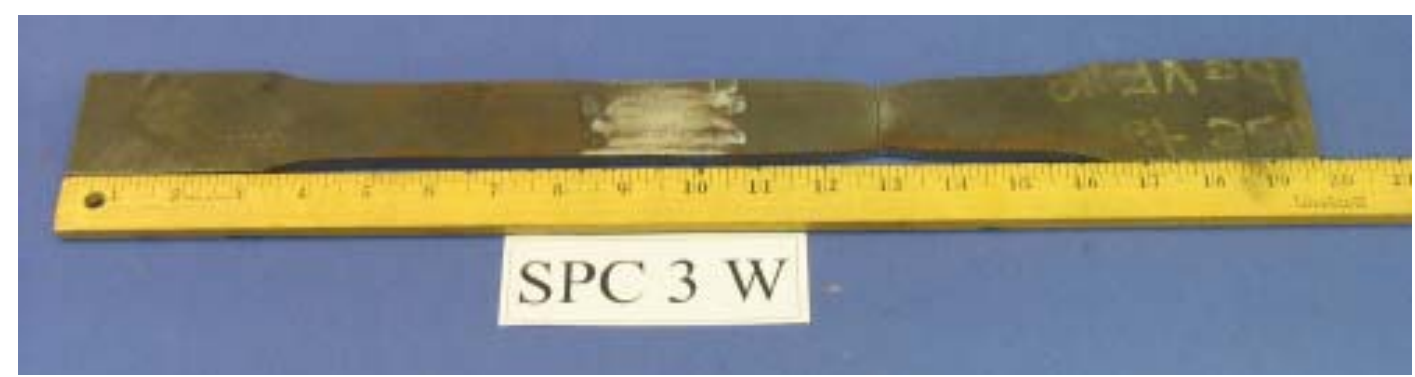

(b) Web

Figure H.3: Specimen 3 - Coupons

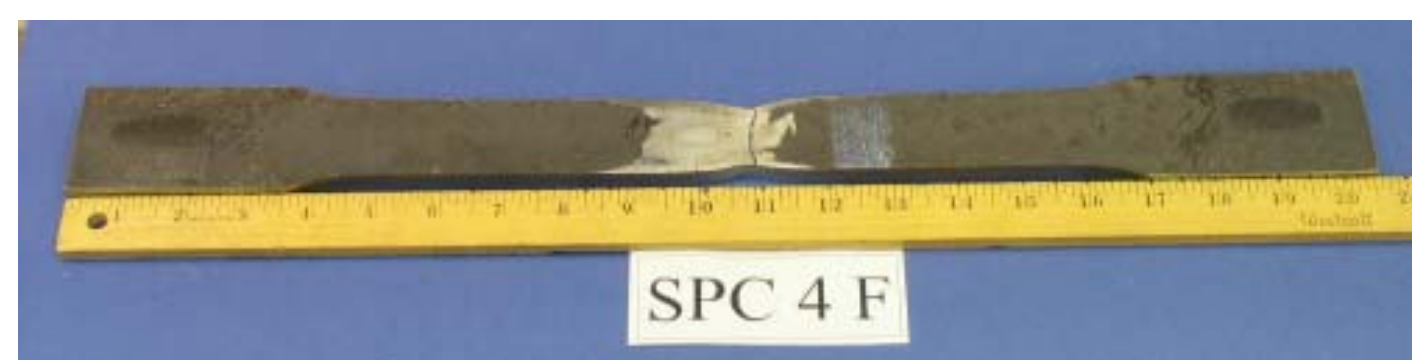

(a) Flange

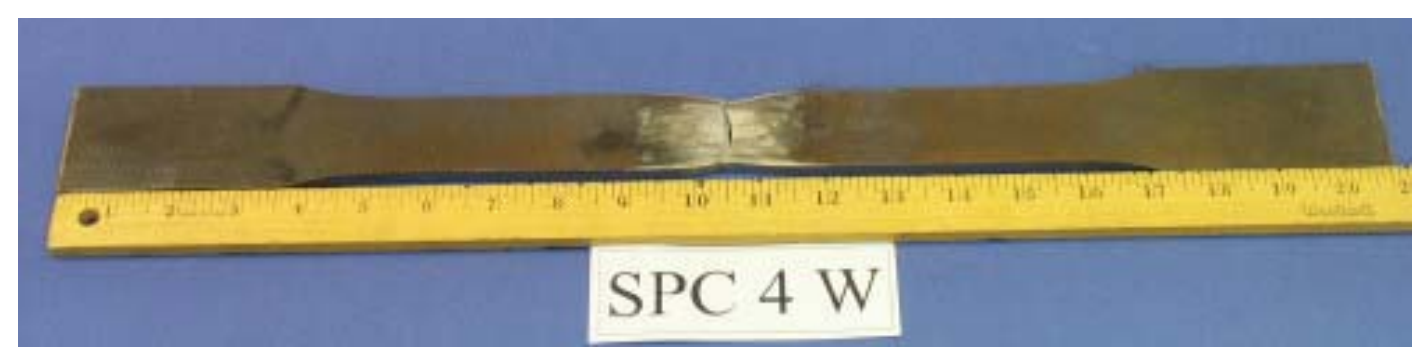

(b) Web

Figure H.4: Specimen 4 - Coupons 


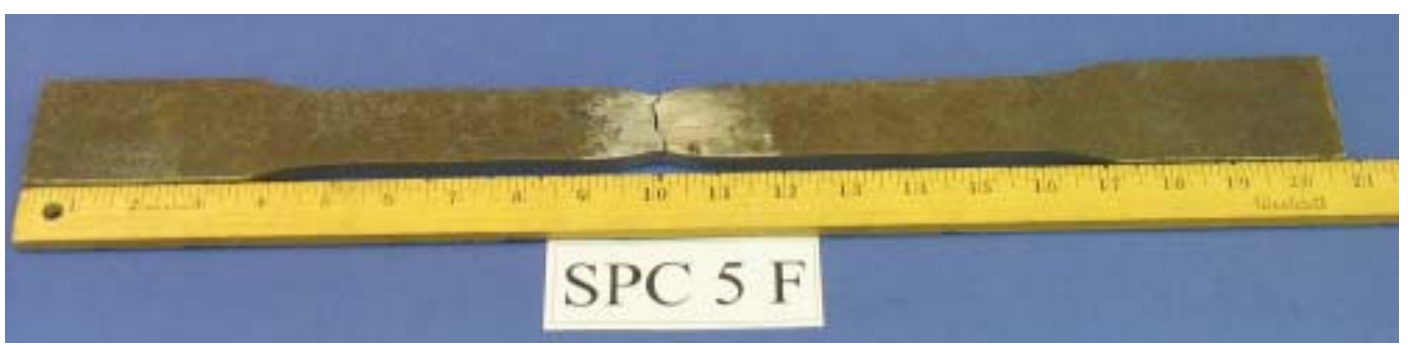

(a) Flange

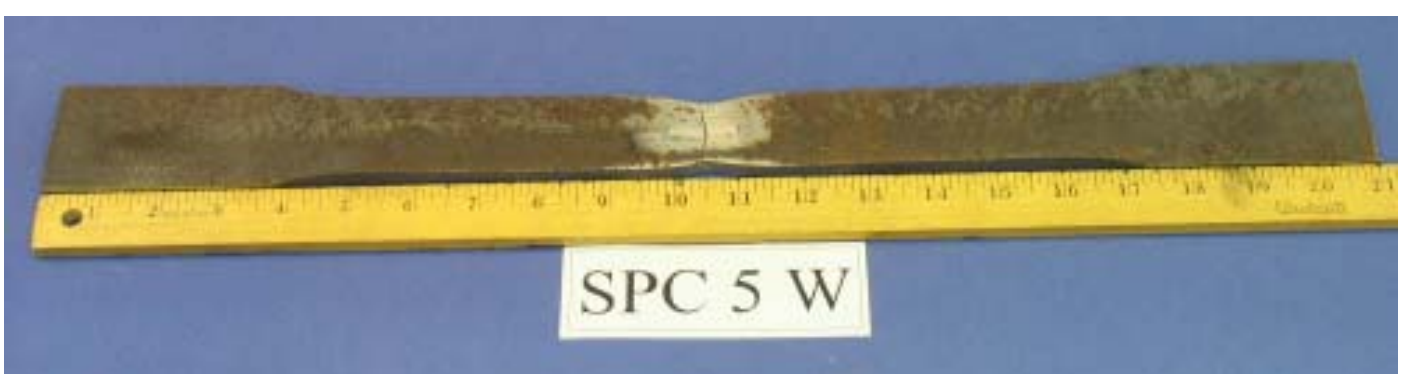

(b) Web

Figure H.5: Specimen 5 - Coupons

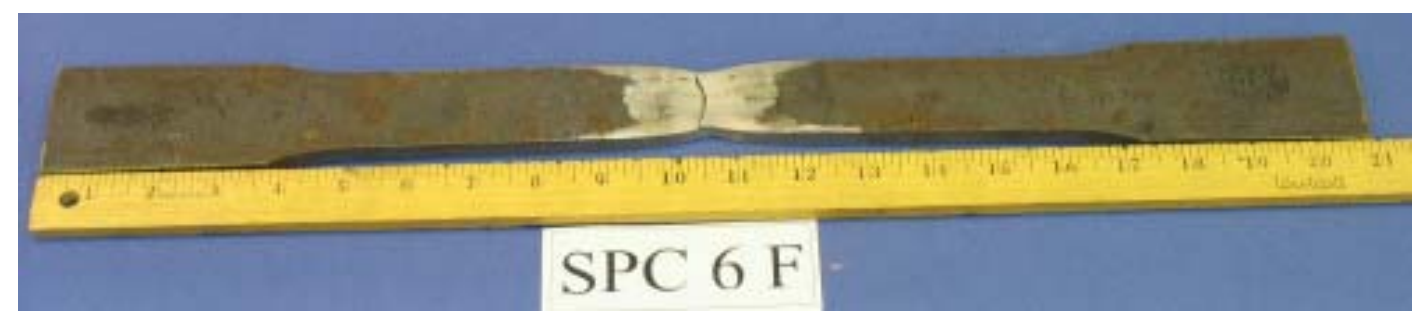

(a) Flange

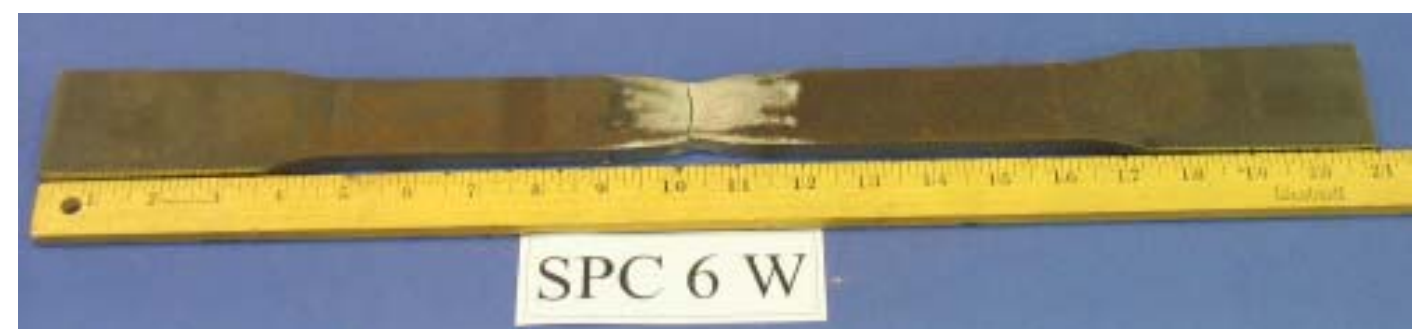

(b) Web

Figure H.6: Specimen 6 - Coupons 


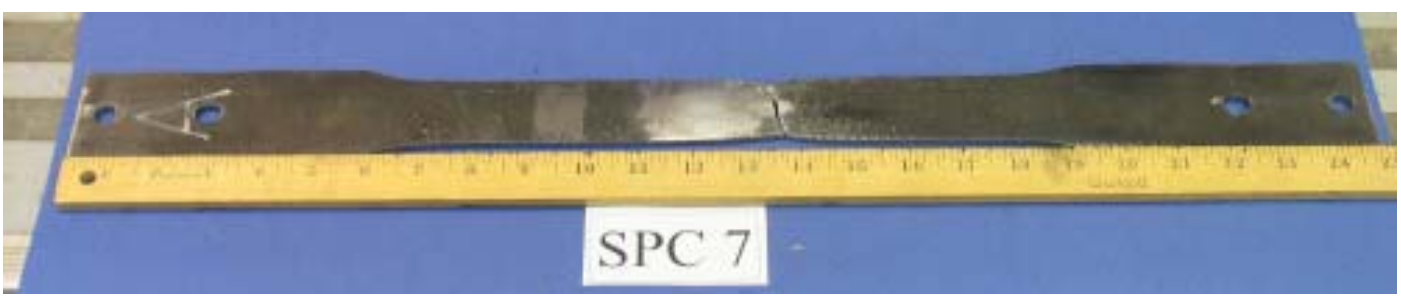

Figure H.7: Specimen 7 - Coupon

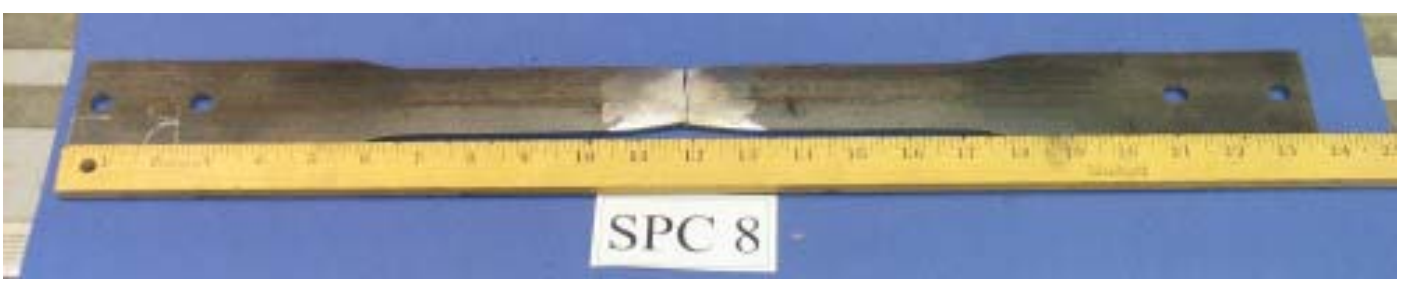

Figure H.8: Specimen 8 - Coupon

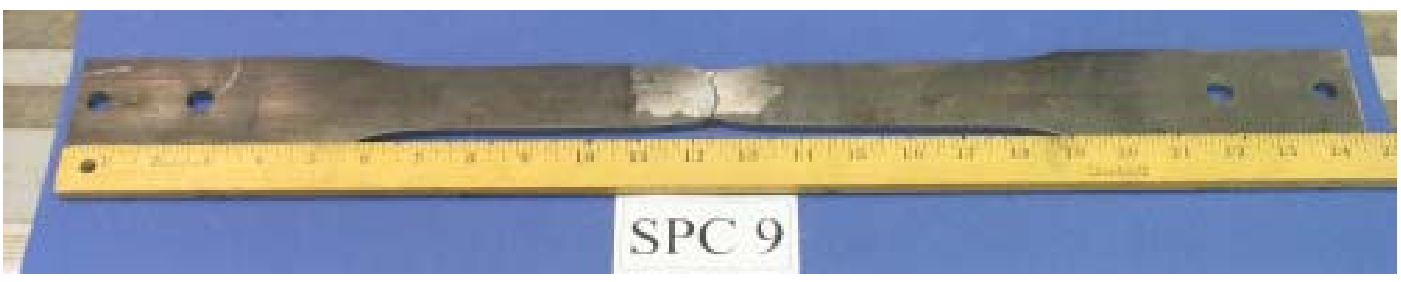

Figure H.9: Specimen 9 - Coupon 


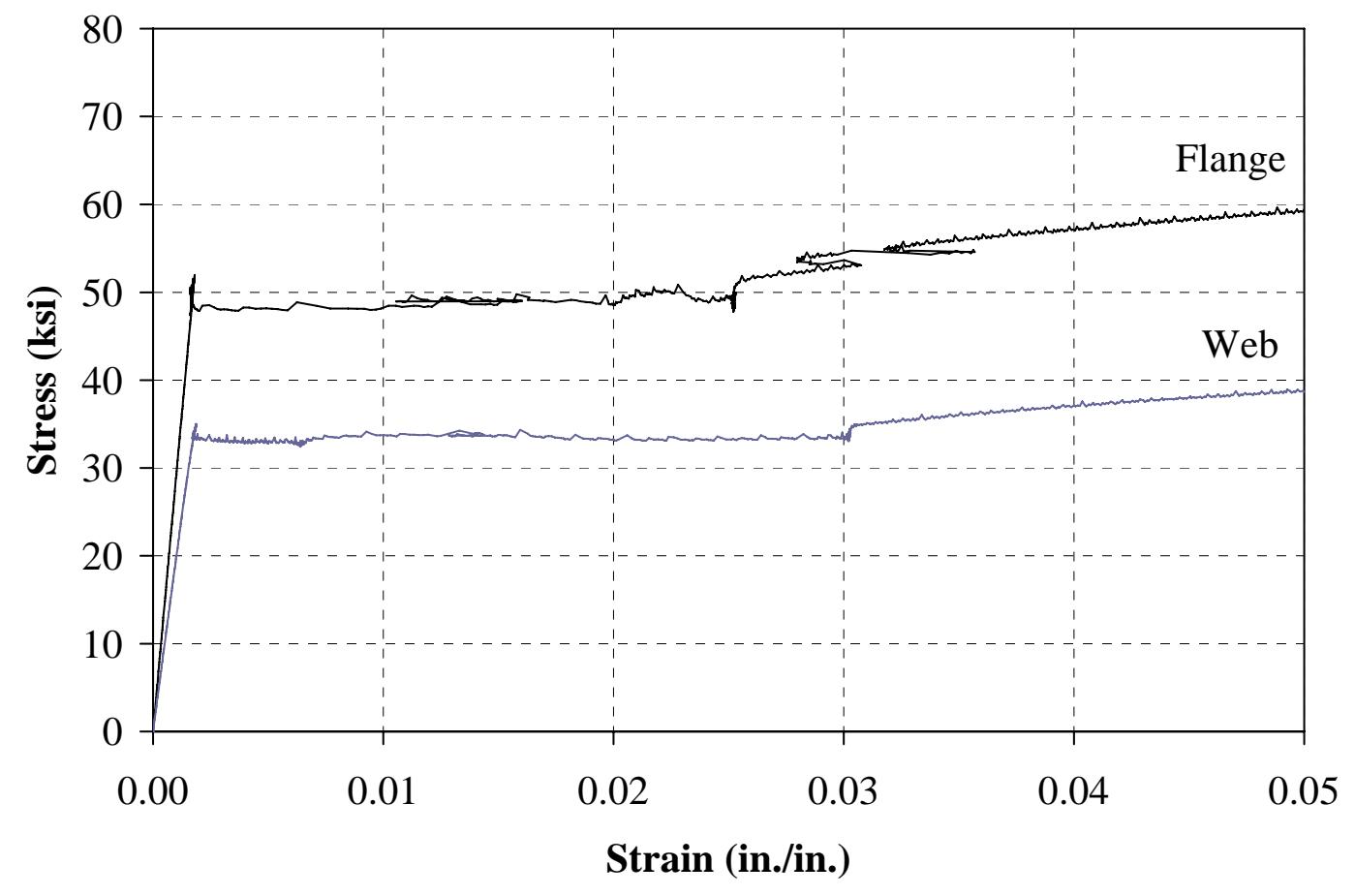

(a) Initial Curve

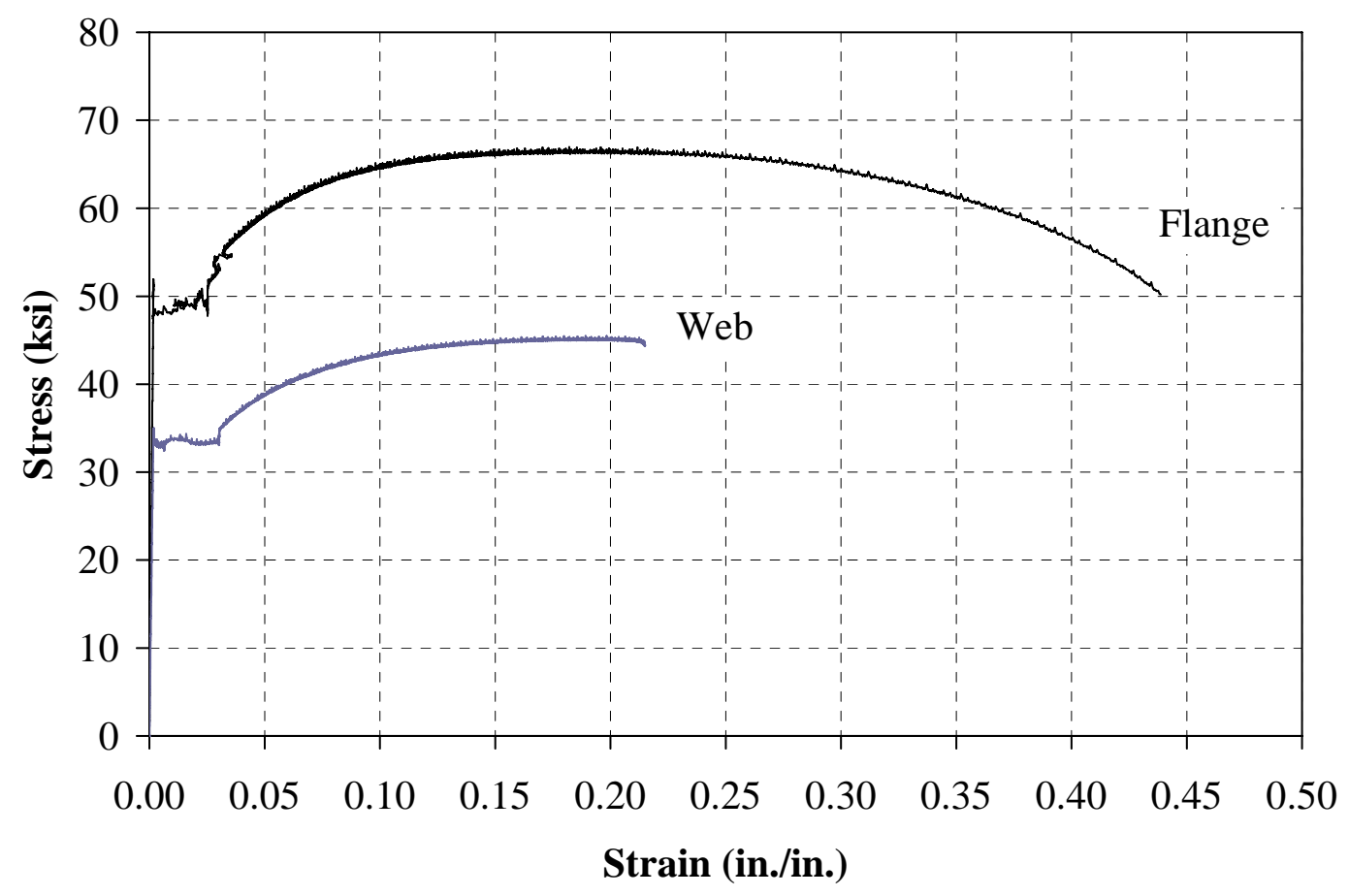

(b) Complete Curve

Figure H.10: Specimen 1 - Stress-Strain Relationship 


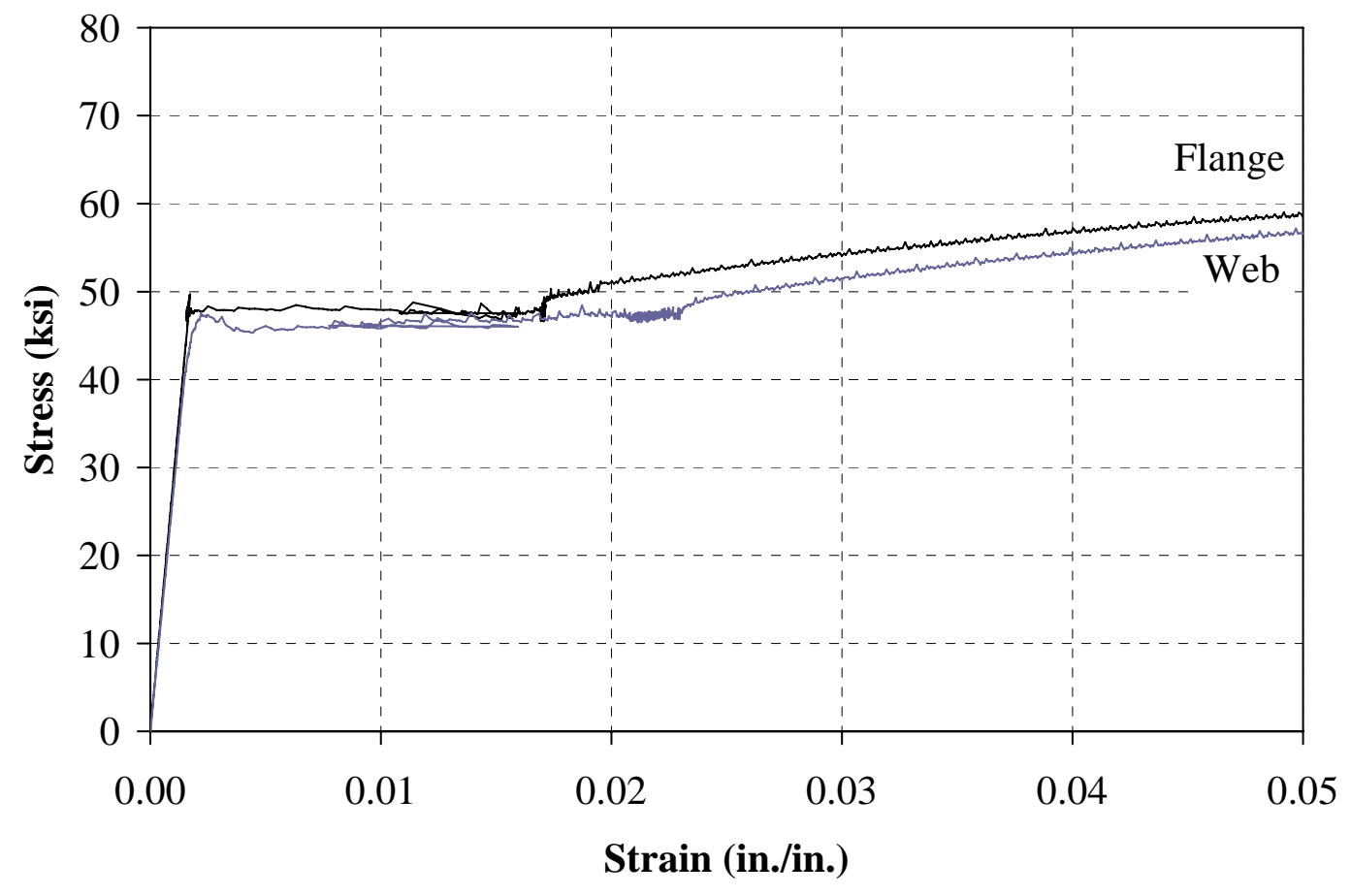

(a) Initial Curve

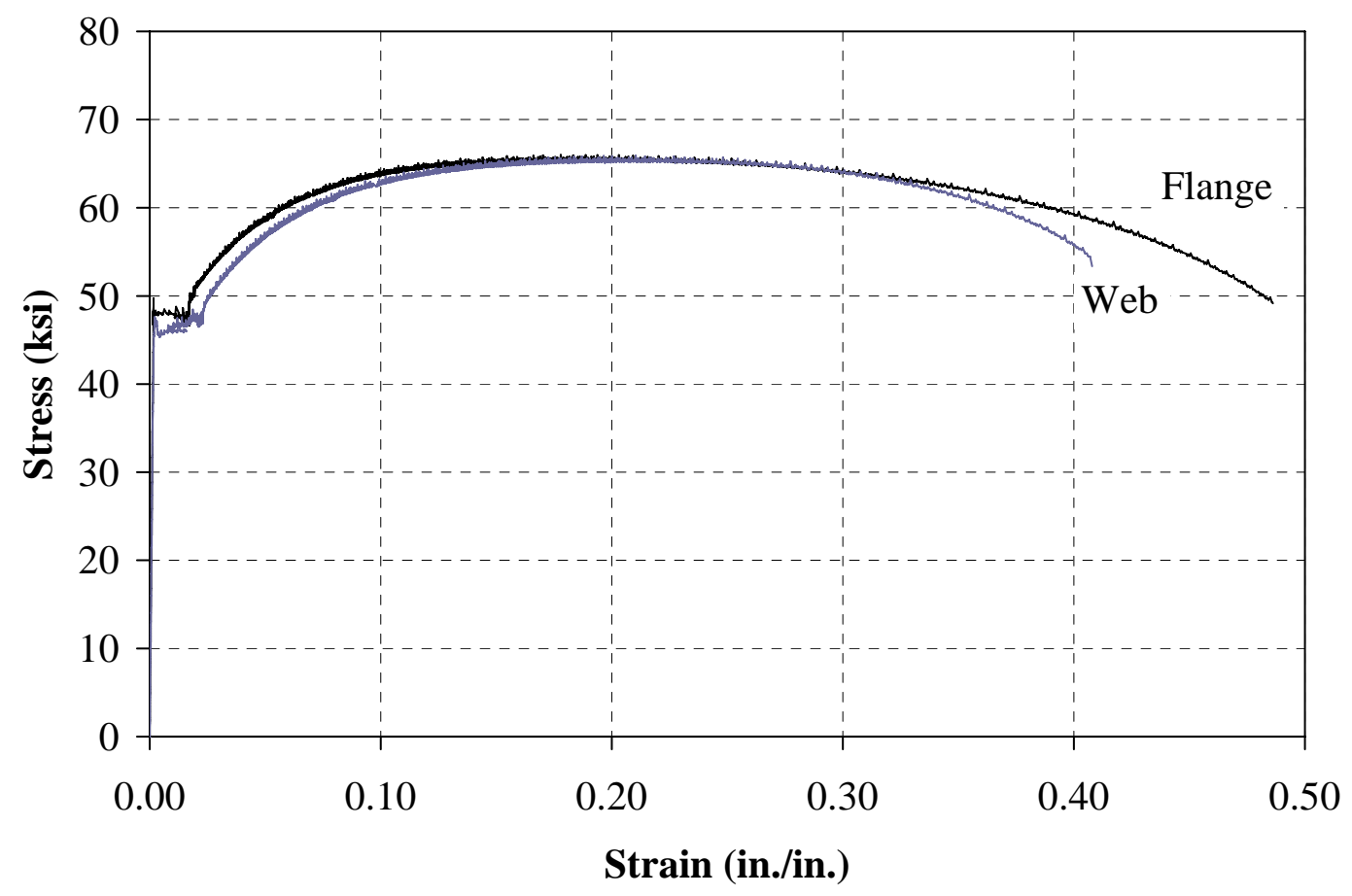

(b) Complete Curve

Figure H.11: Specimen 2 - Stress-Strain Relationship 


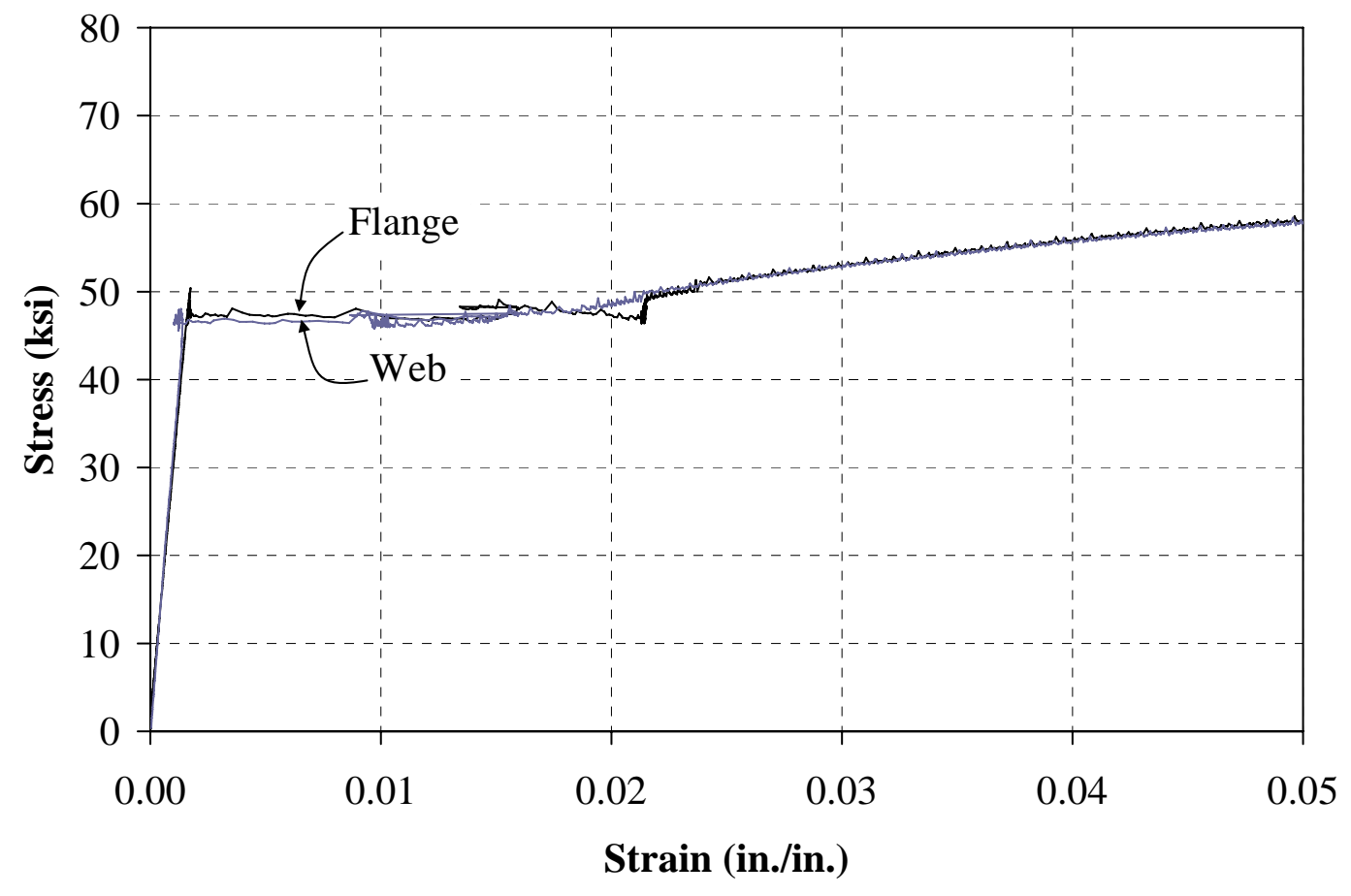

(a) Initial Curve

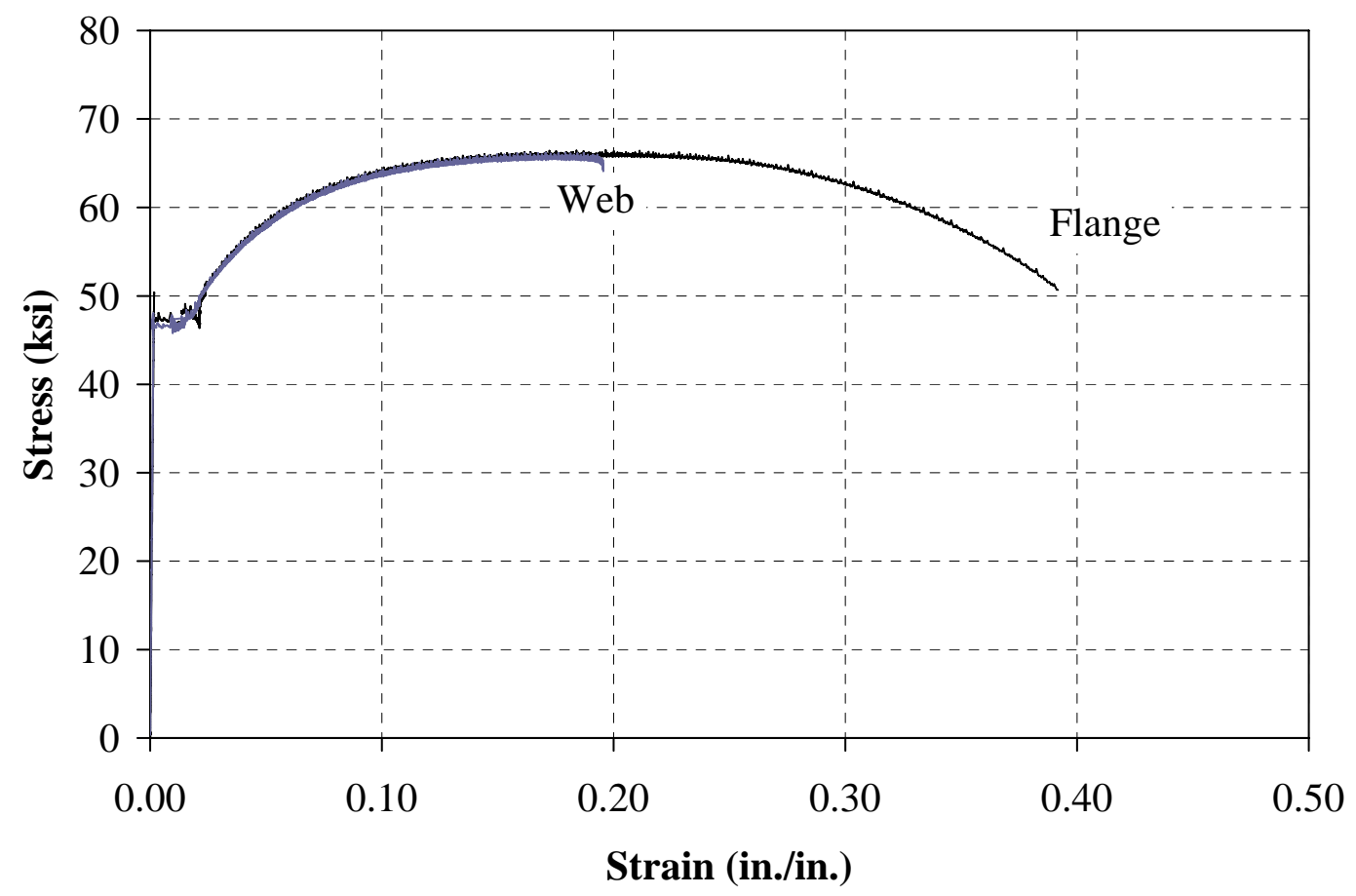

(b) Complete Curve

Figure H.12: Specimen 3 - Stress-Strain Relationship 


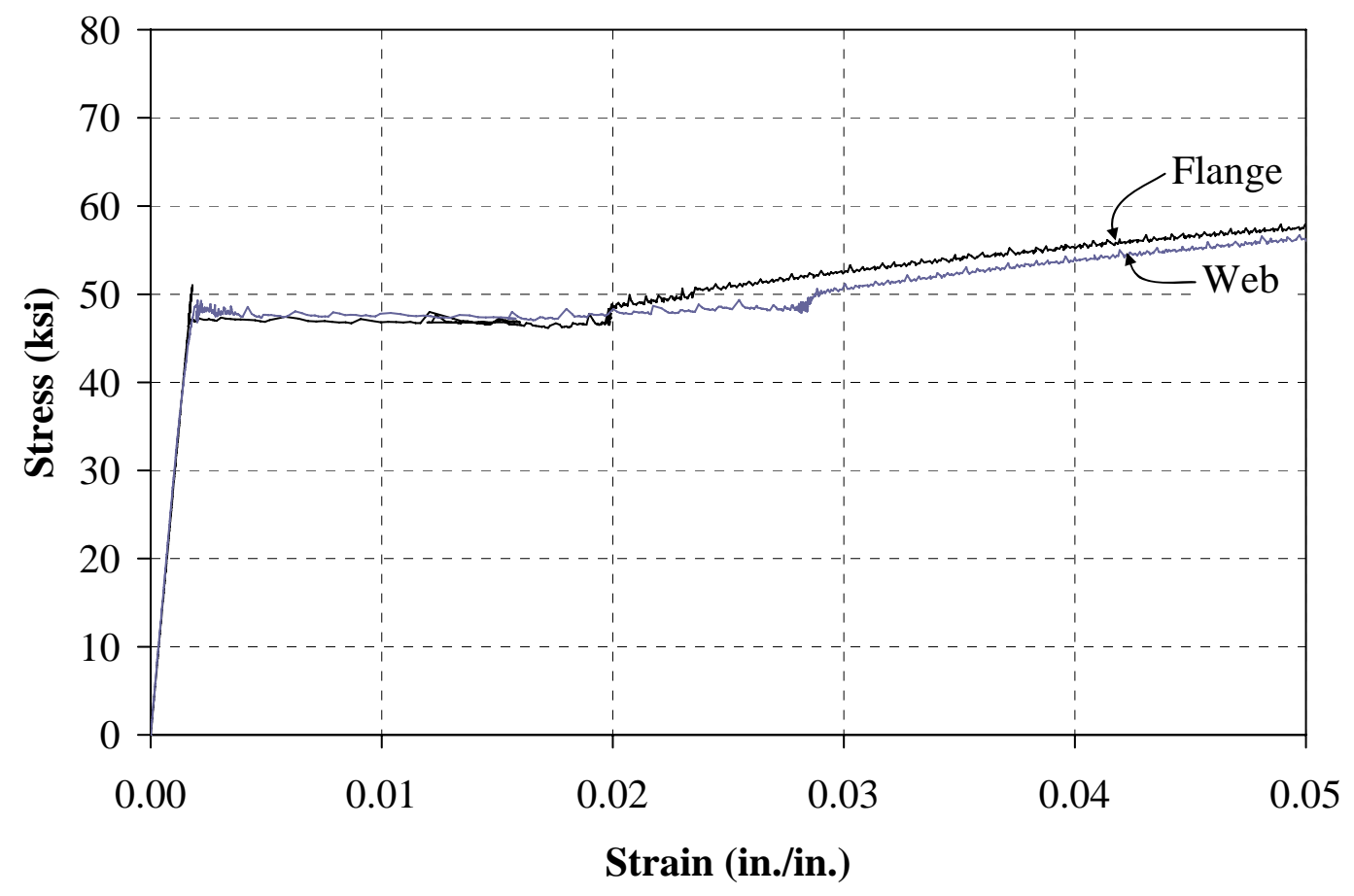

(a) Initial Curve

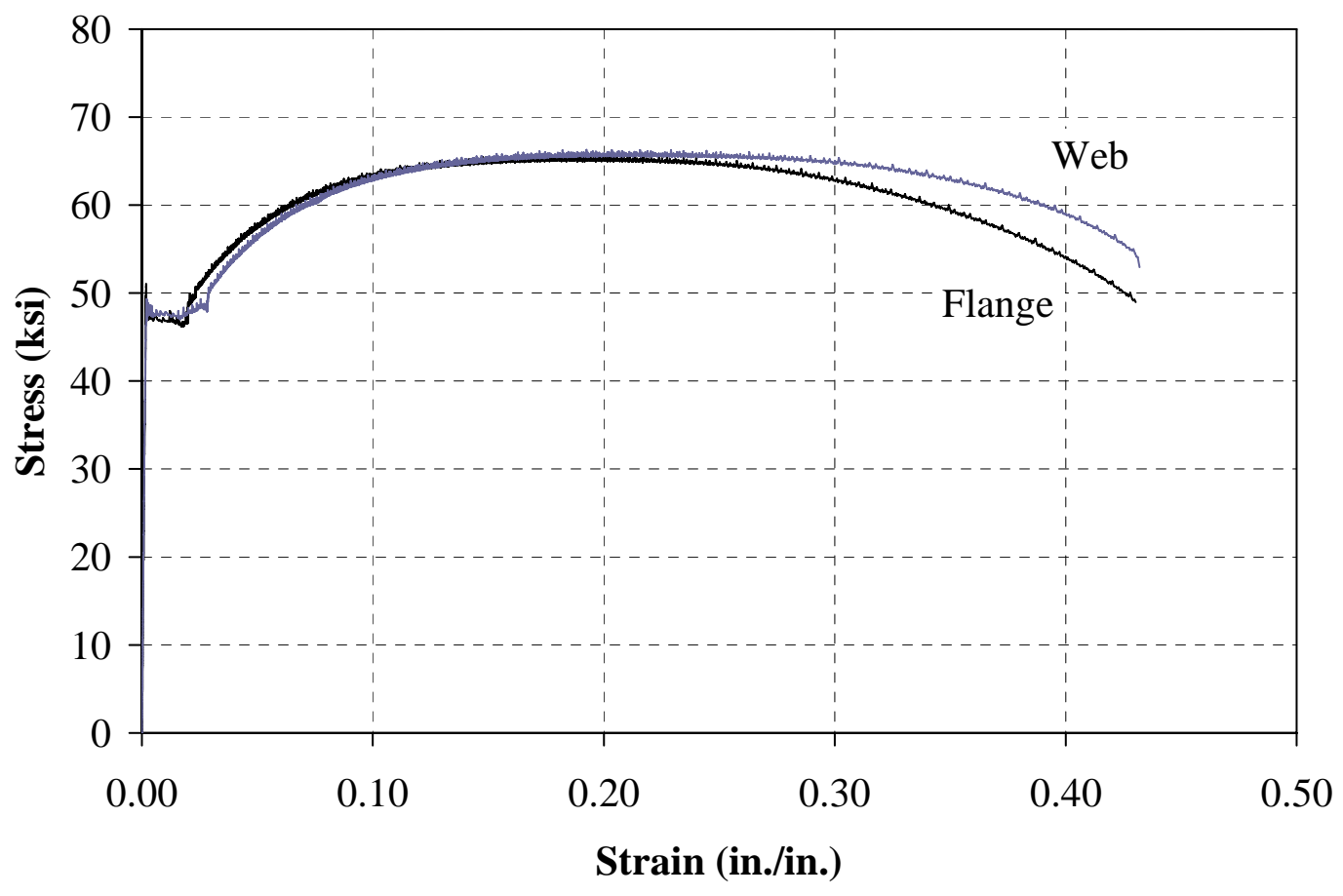

(b) Complete Curve

Figure H.13: Specimen 4 - Stress-Strain Relationship 


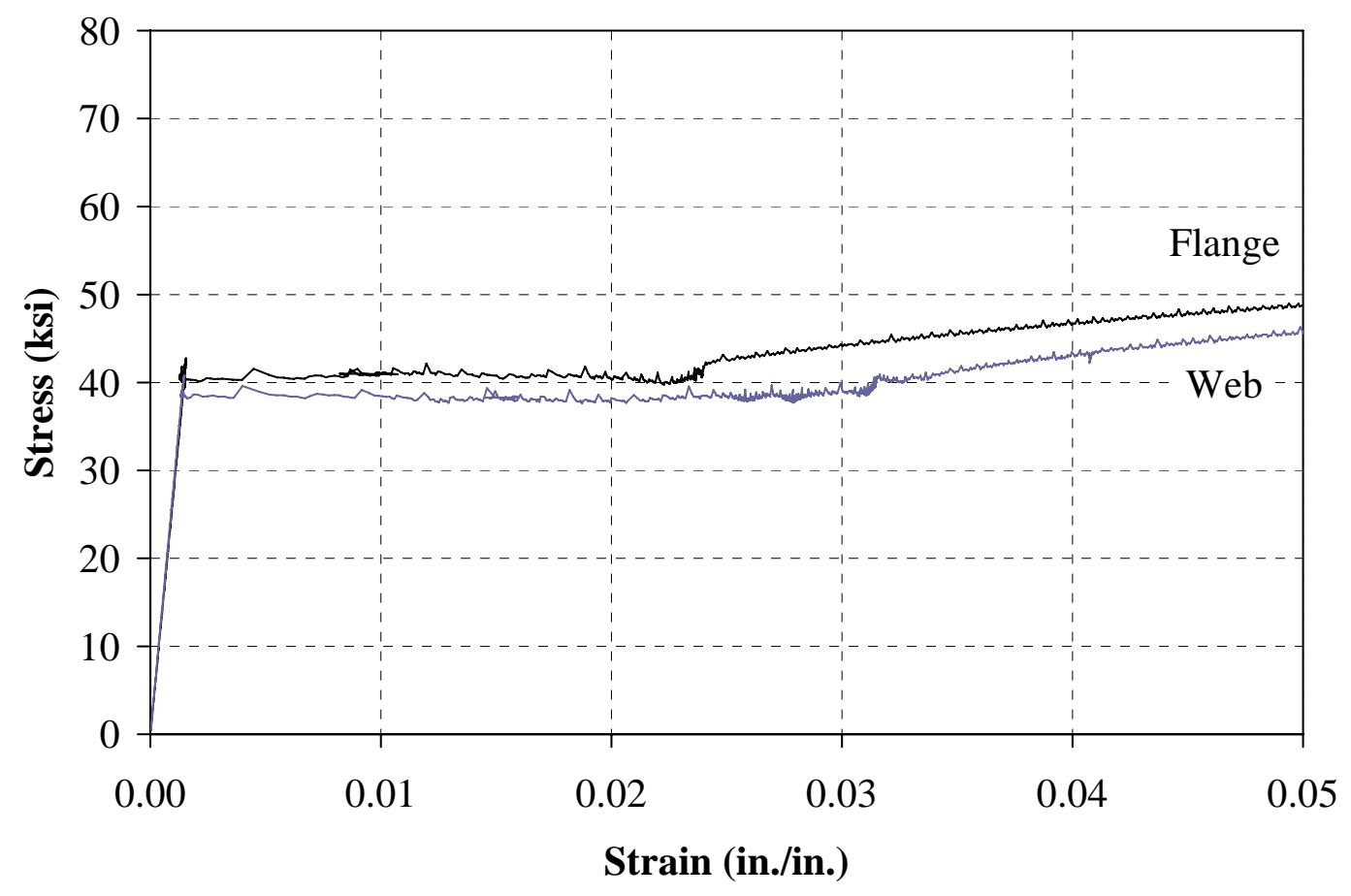

(a) Initial Curve

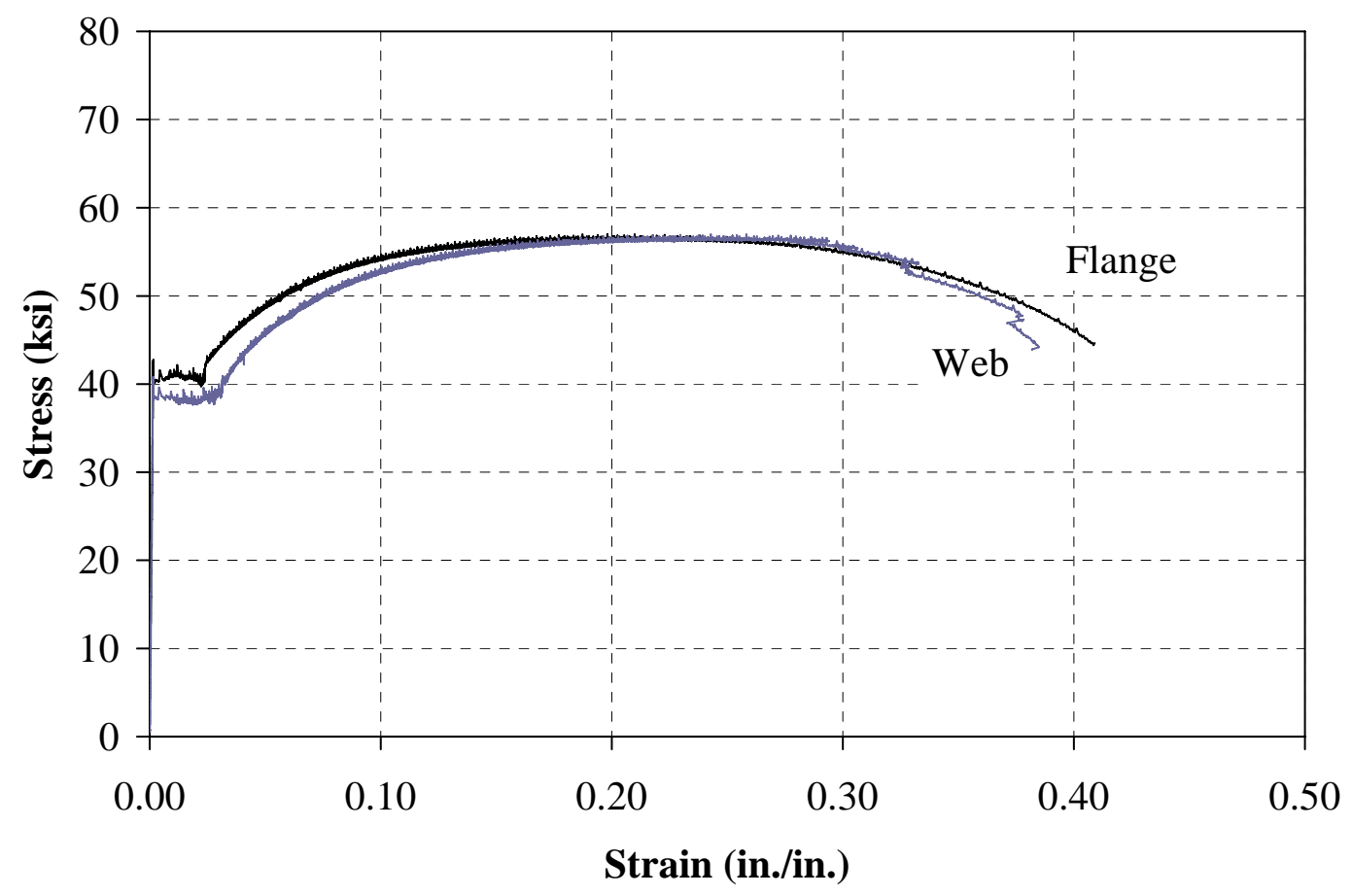

(b) Complete Curve

Figure H.14: Specimen 5 - Stress-Strain Relationship 


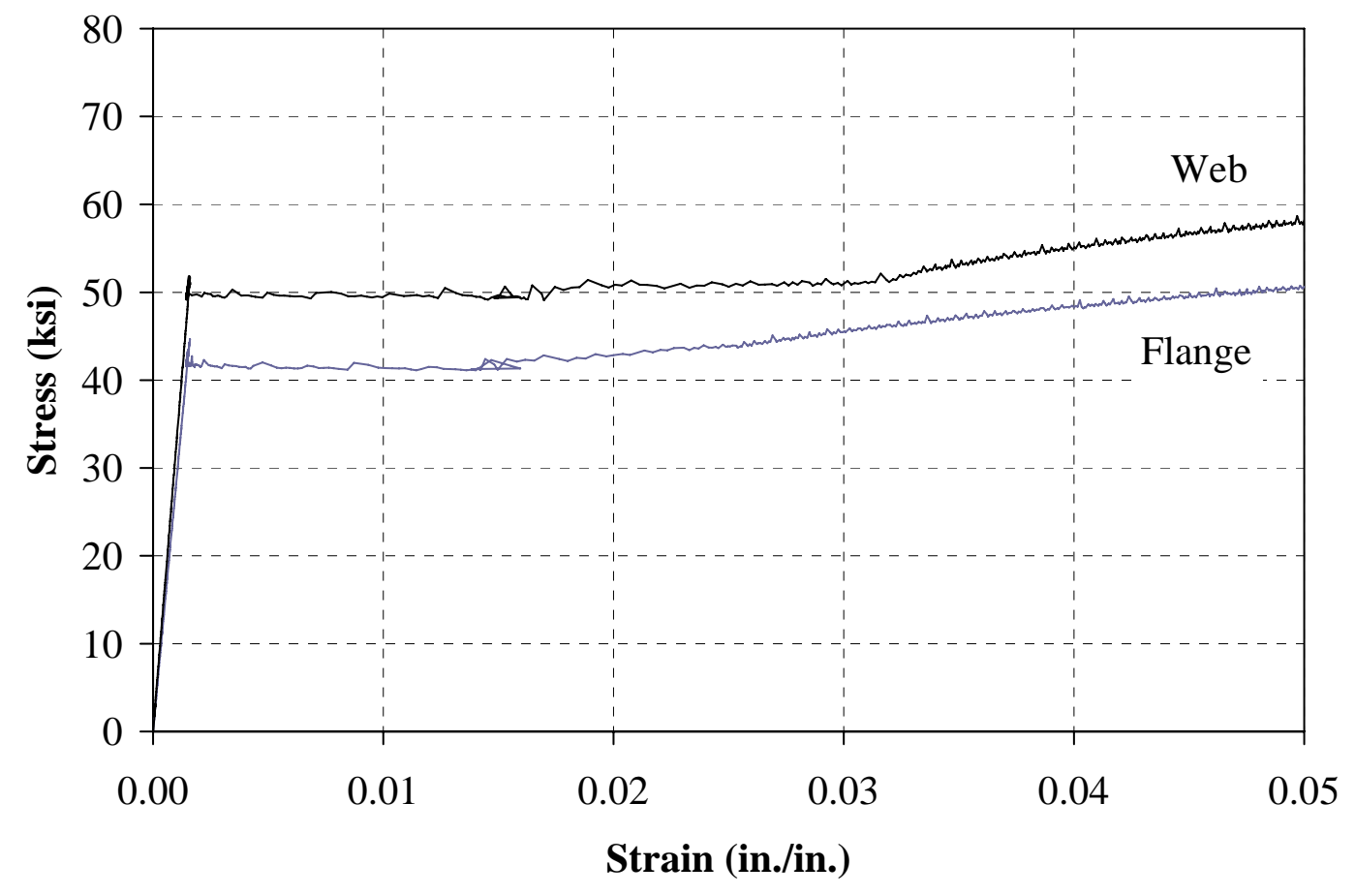

(a) Initial Curve

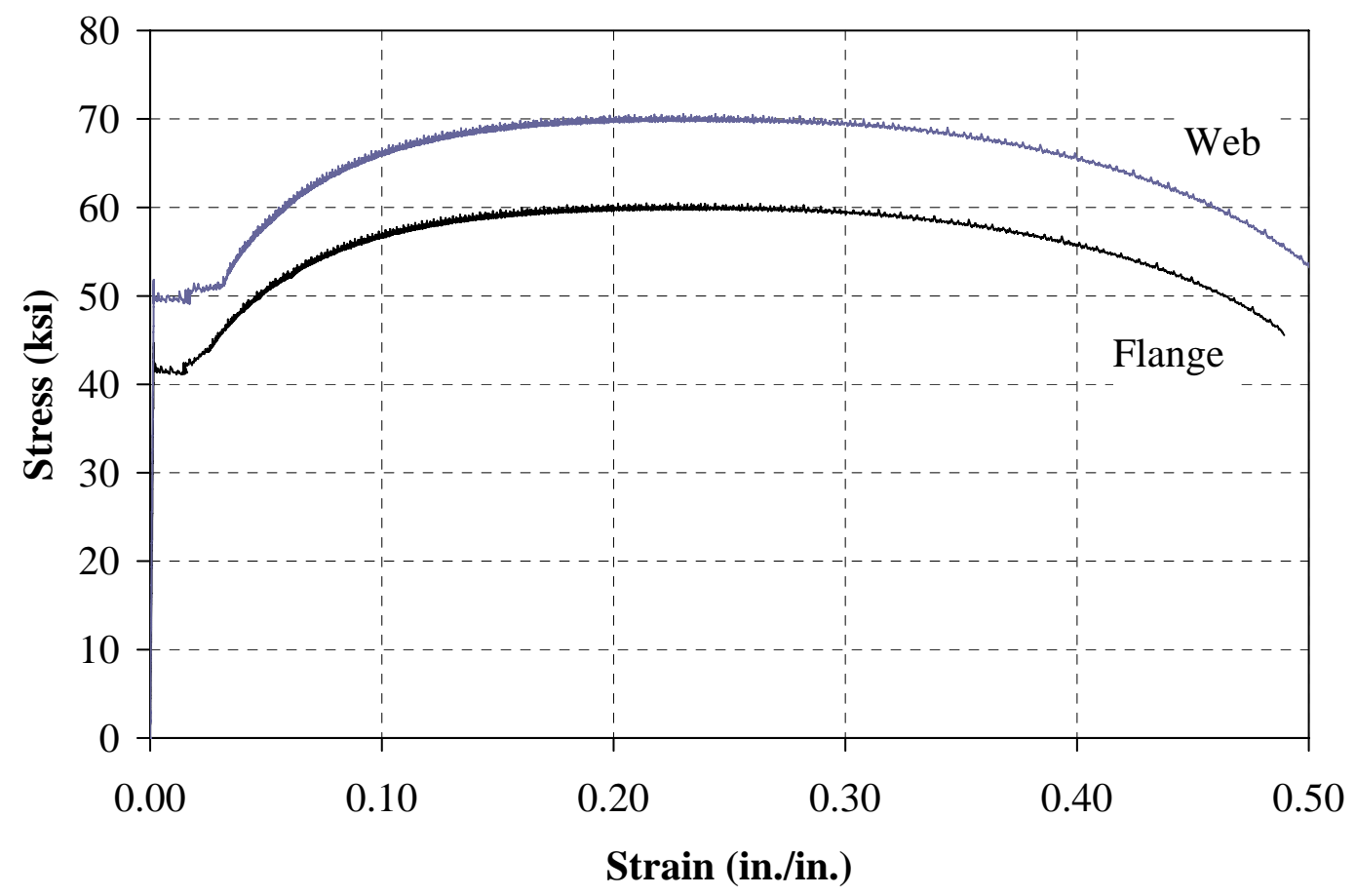

(b) Complete Curve

Figure H.15: Specimen 6 - Stress-Strain Relationship 


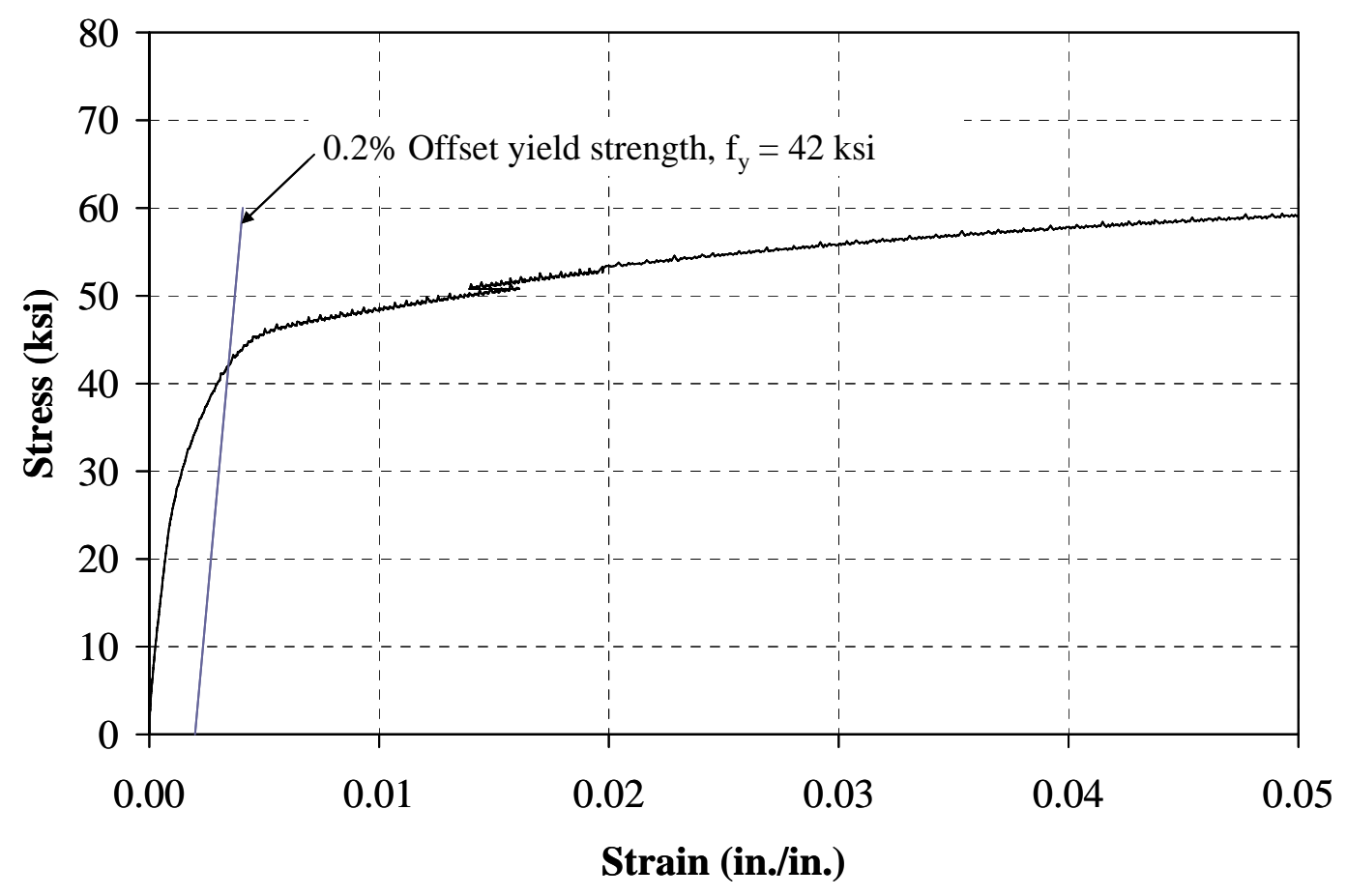

(a) Initial Curve

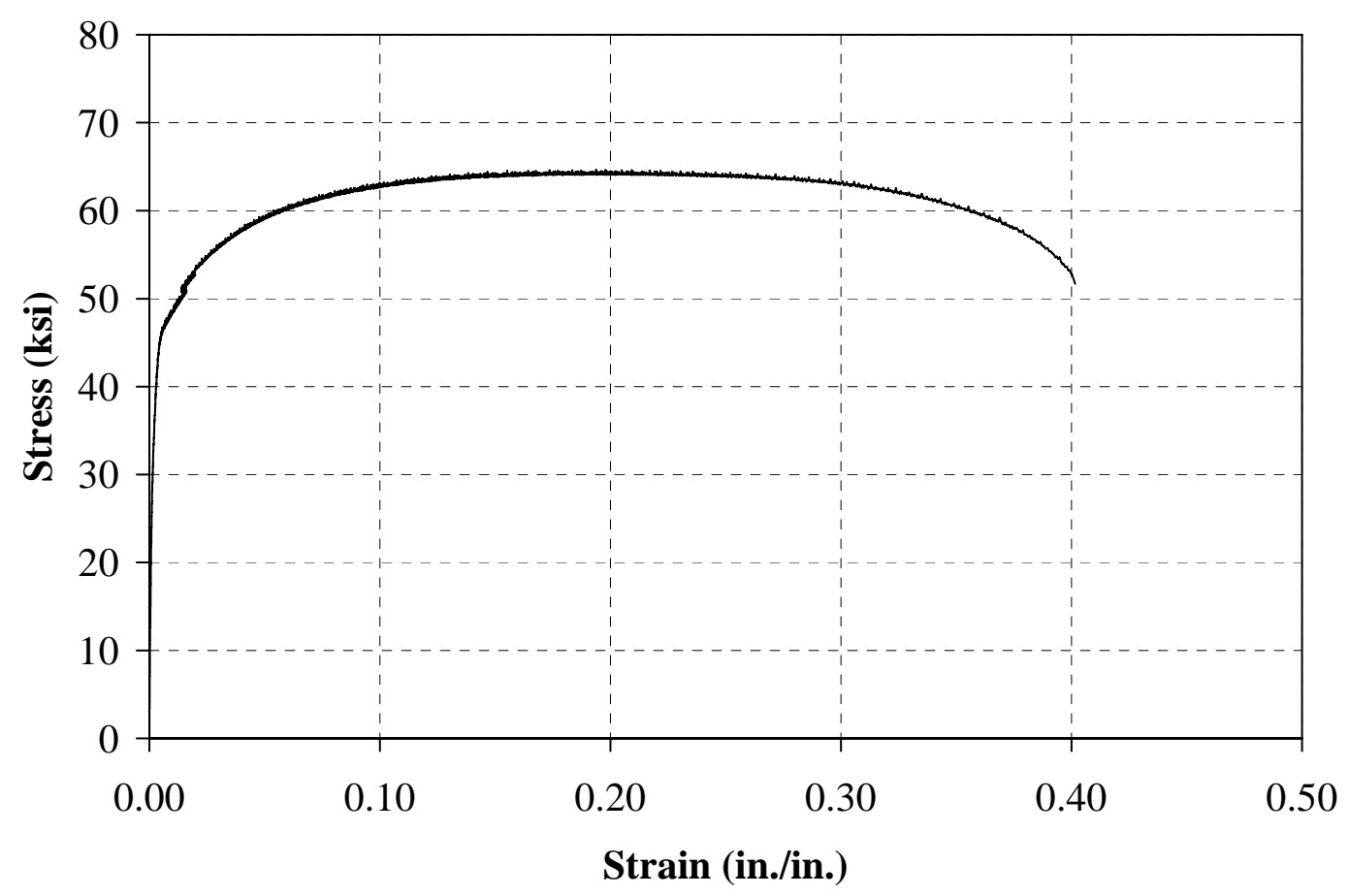

(b) Complete Curve

Figure H.16: Specimen 7 - Stress-Strain Relationship 


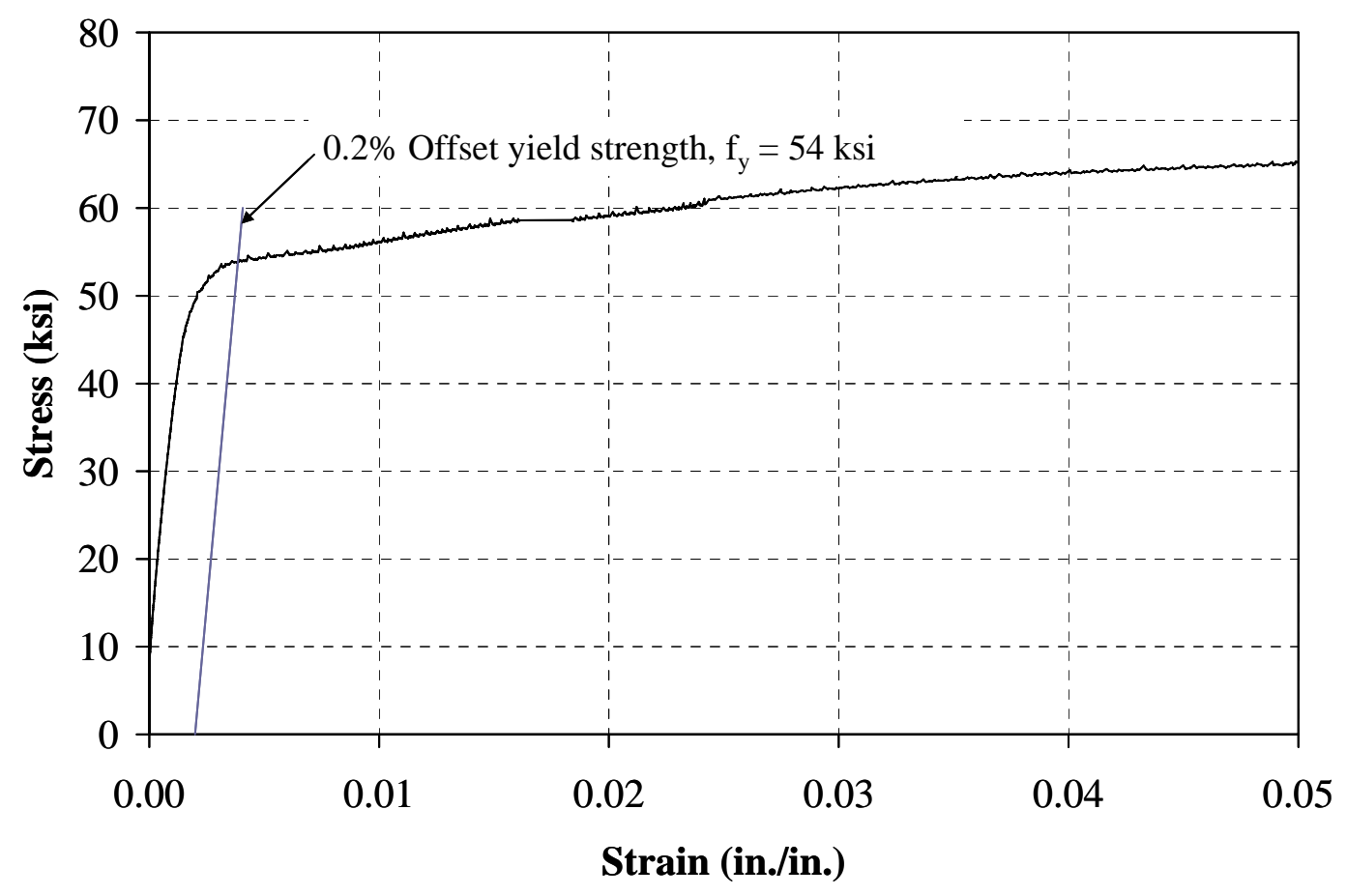

(a) Initial Curve

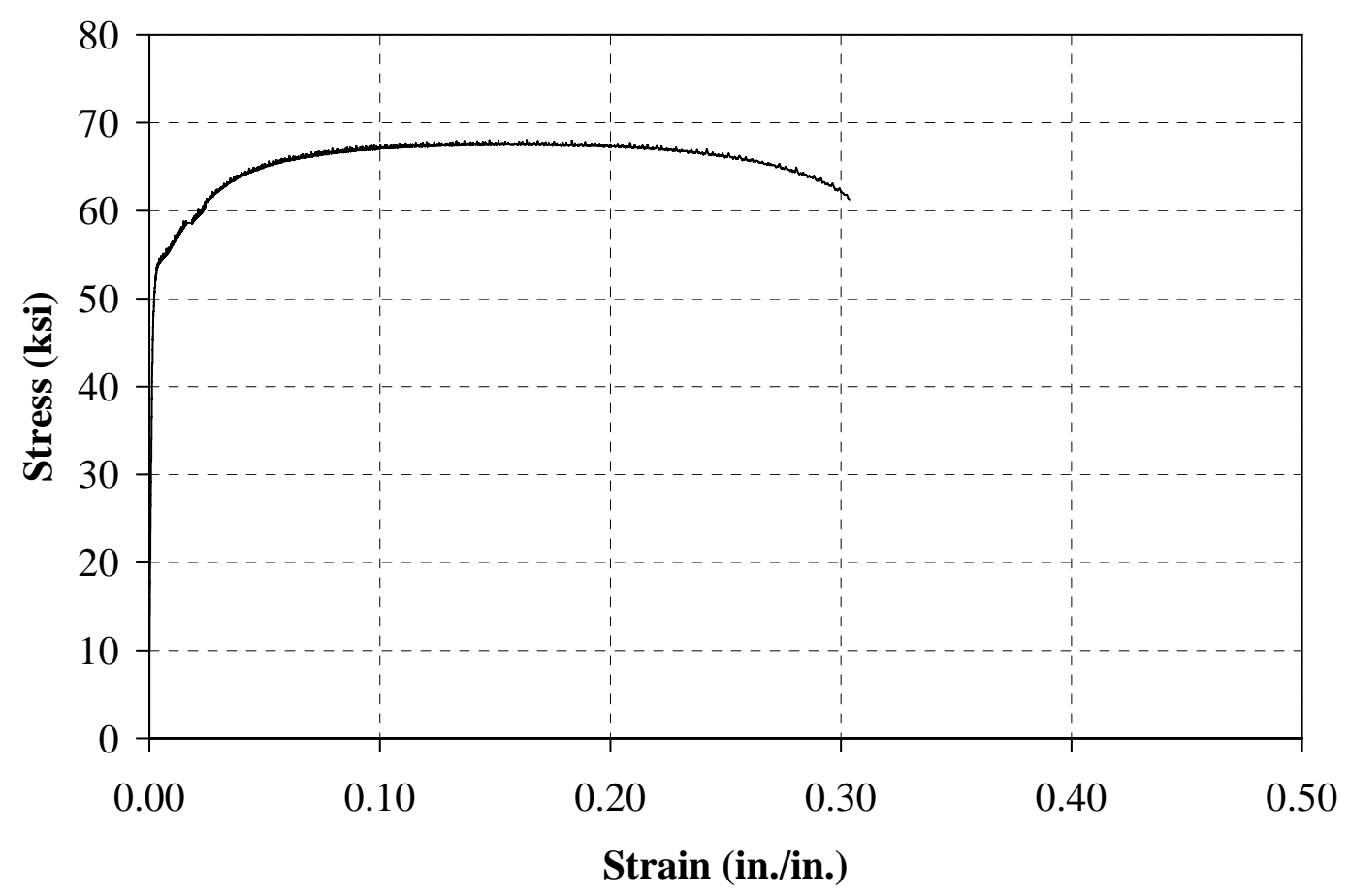

(b) Complete Curve

Figure H.17: Specimen 8 - Stress-Strain Relationship 


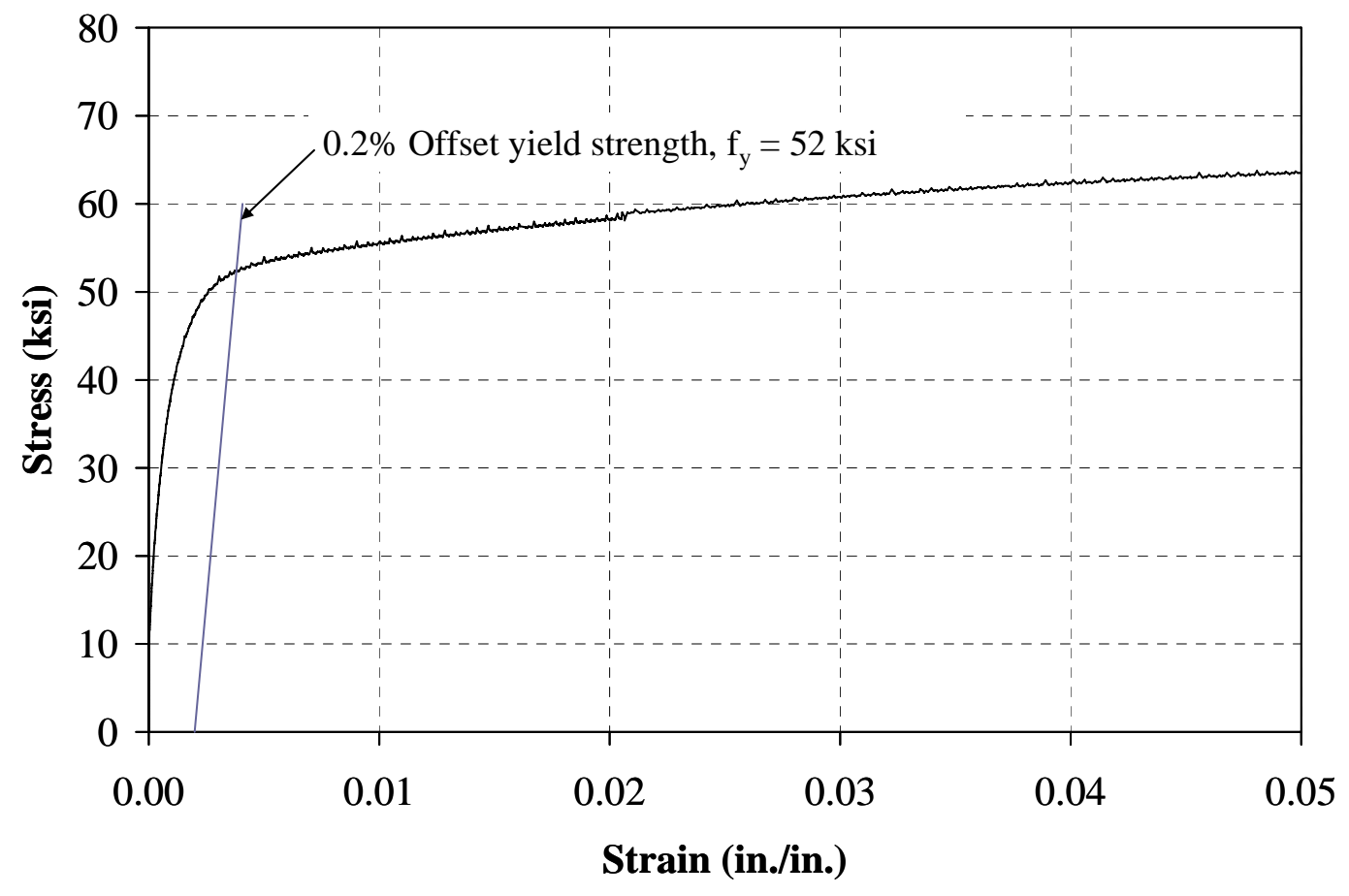

(a) Initial Curve

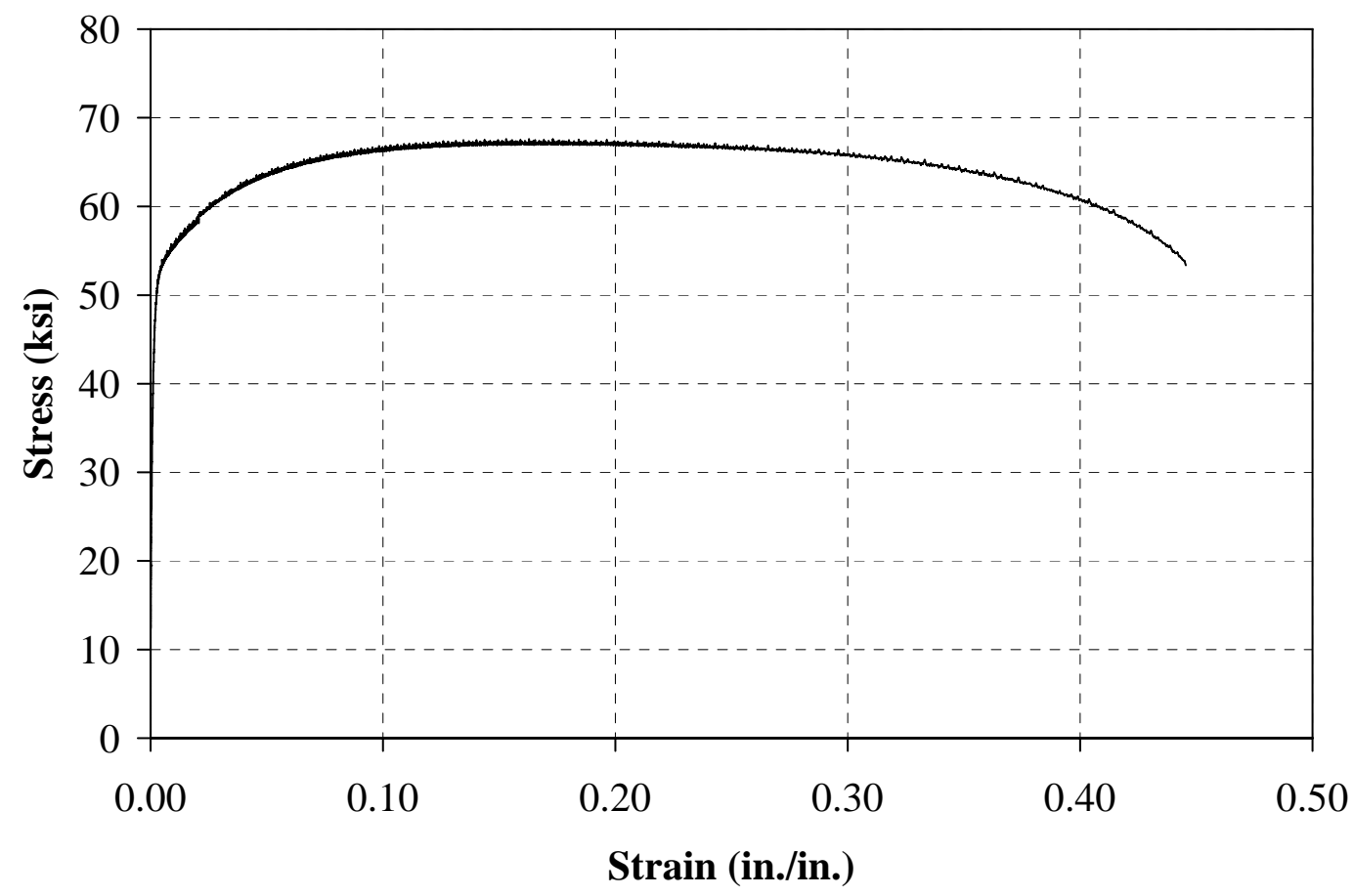

(b) Complete Curve

Figure H.18: Specimen 9 - Stress-Strain Relationship 
APPENDIX I

EXPERIMENTAL RESULTS 


\section{Appendix I: Experimental Results}

Specimen 1 (HP8x36, Weak, 9 ksi)

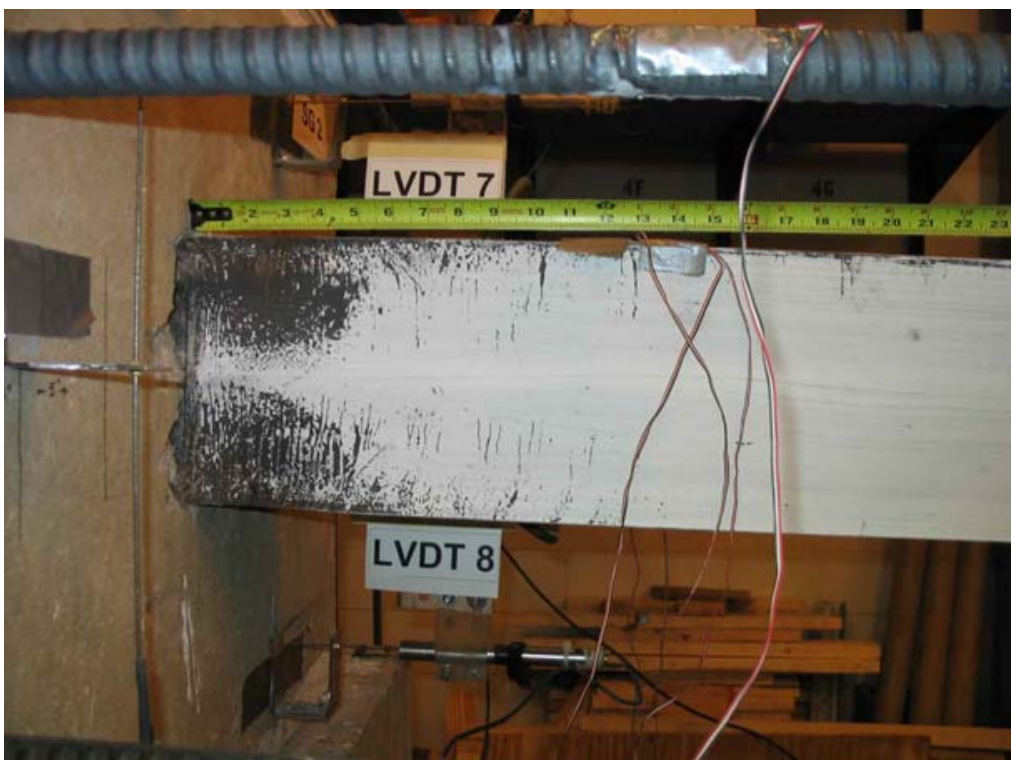

(a) West Side

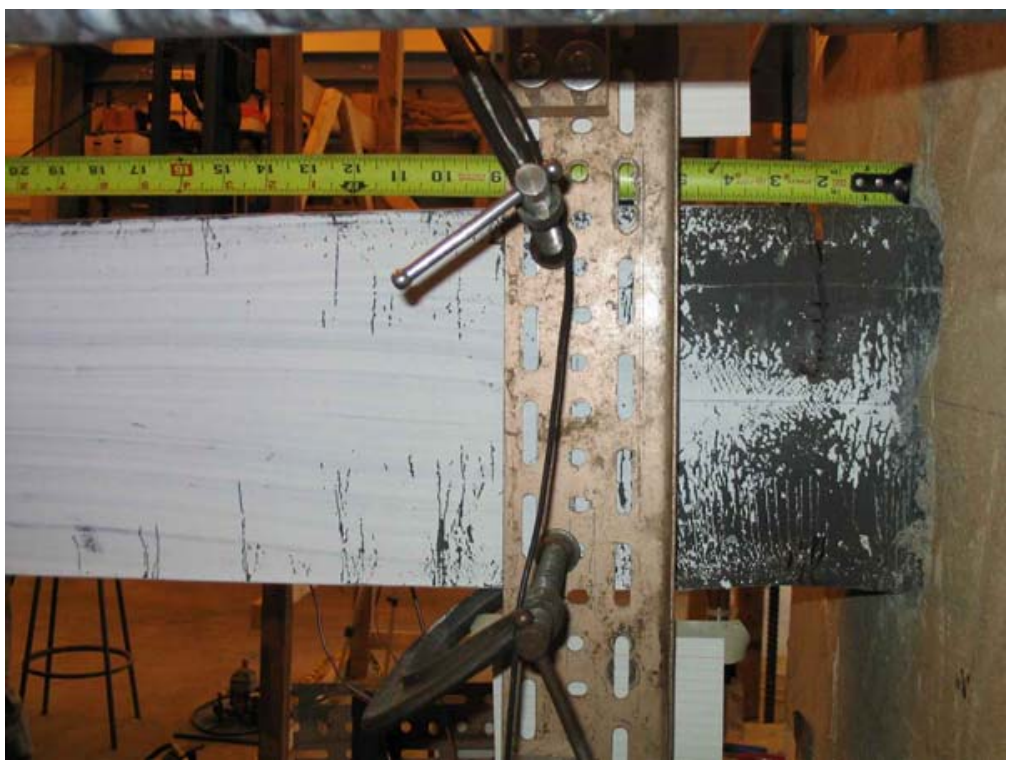

(b) East Side

Figure I.1: Specimen 1 - Yielding (3.00 in., $80^{\text {th }}$ Cycle) 


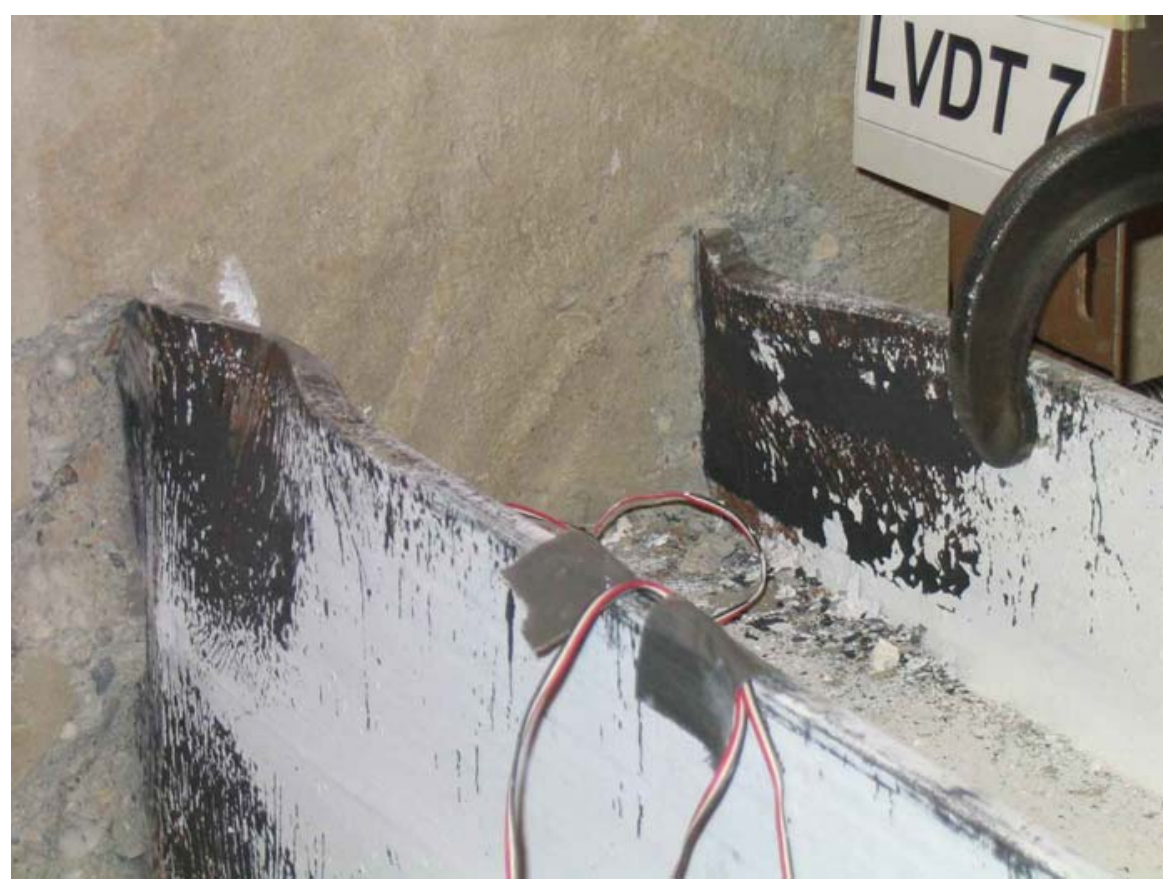

(a) Top

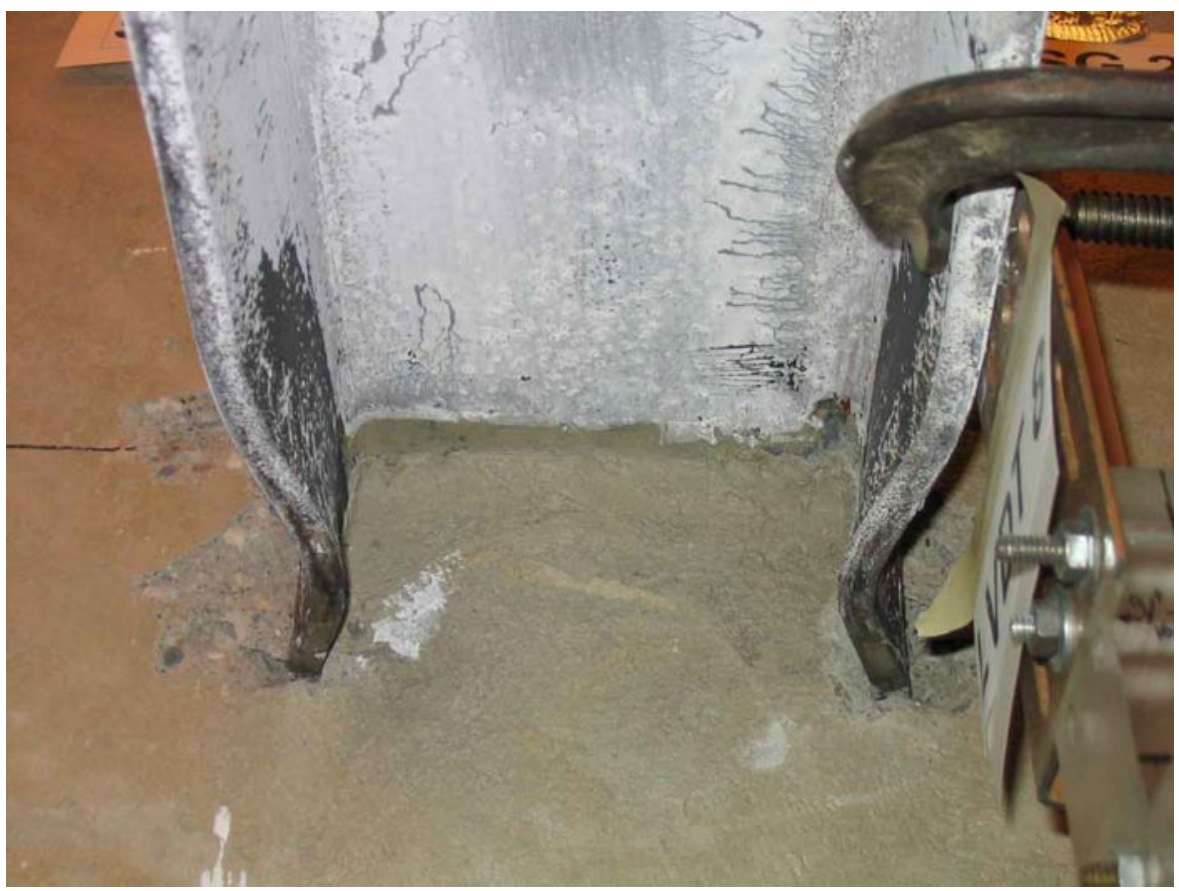

(b) Bottom

Figure I.2: Specimen 1 - Flange Buckling (3.00 in., $80^{\text {th }}$ Cycle) 


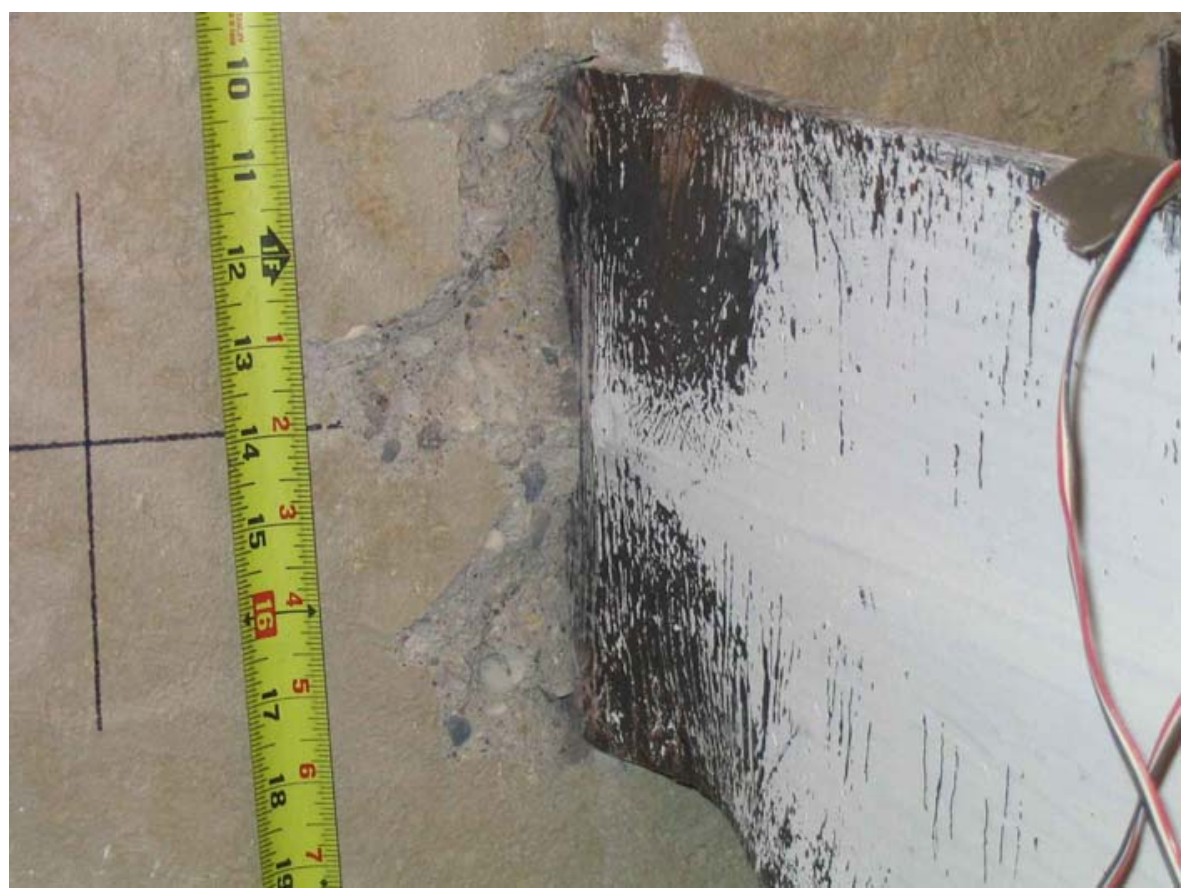

(a) NW Flange

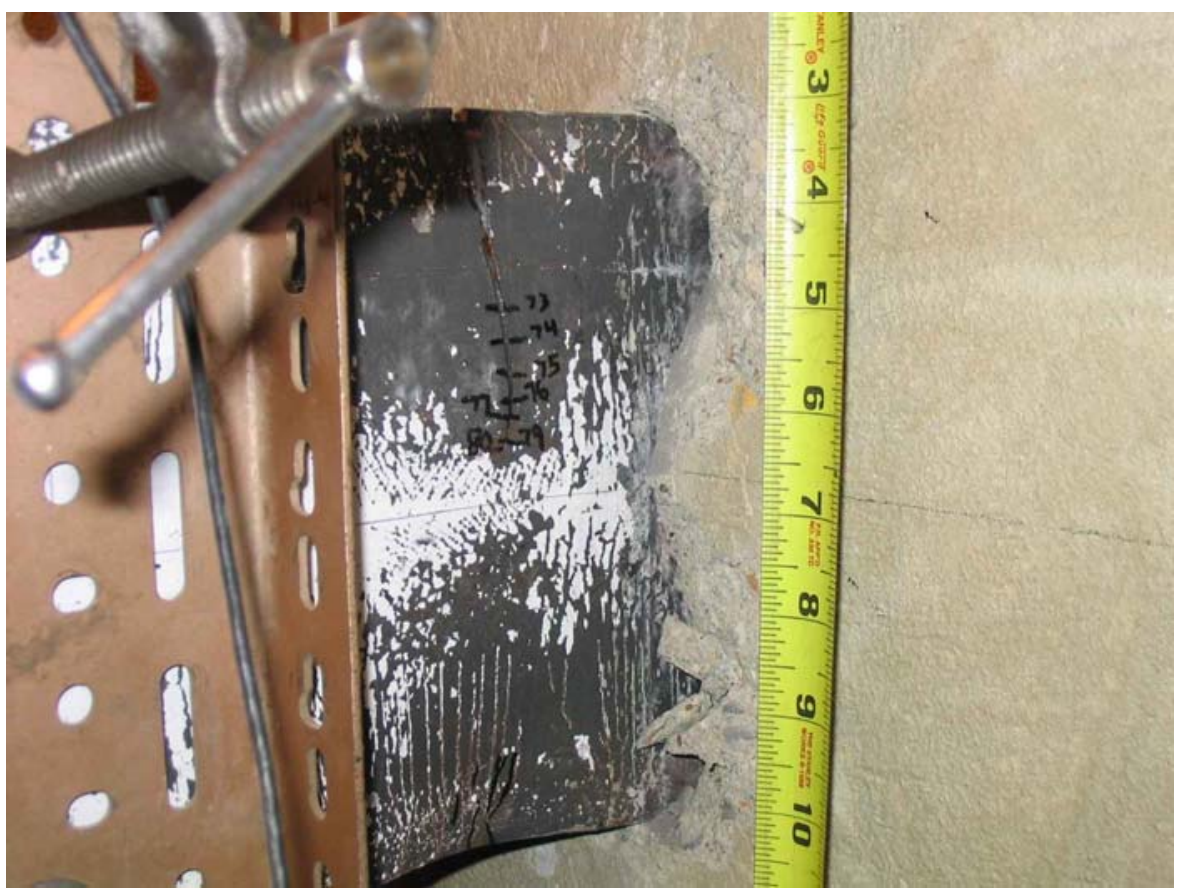

(b) NE Flange

Figure I.3: Specimen 1 - Crack on Steel Pile (3.00 in., 80 ${ }^{\text {th }}$ Cycle) 


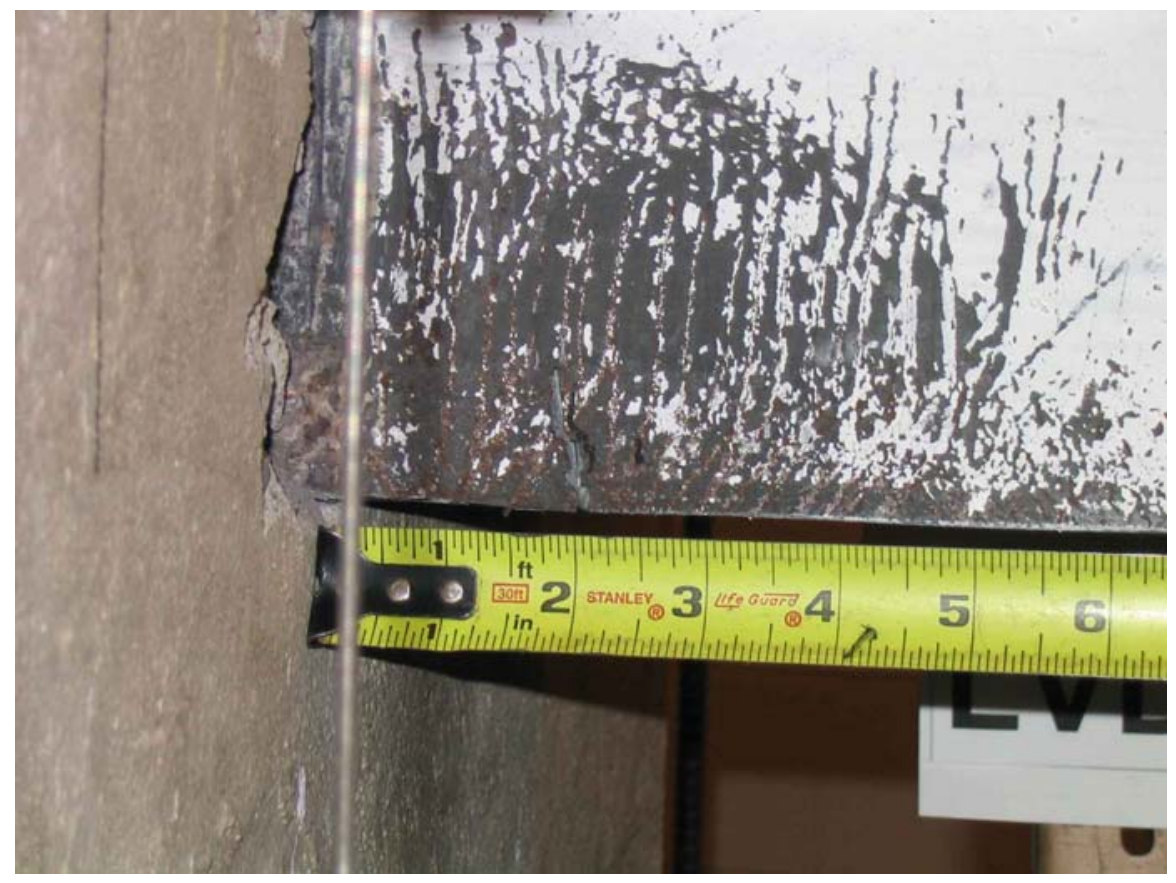

(c) SW Flange

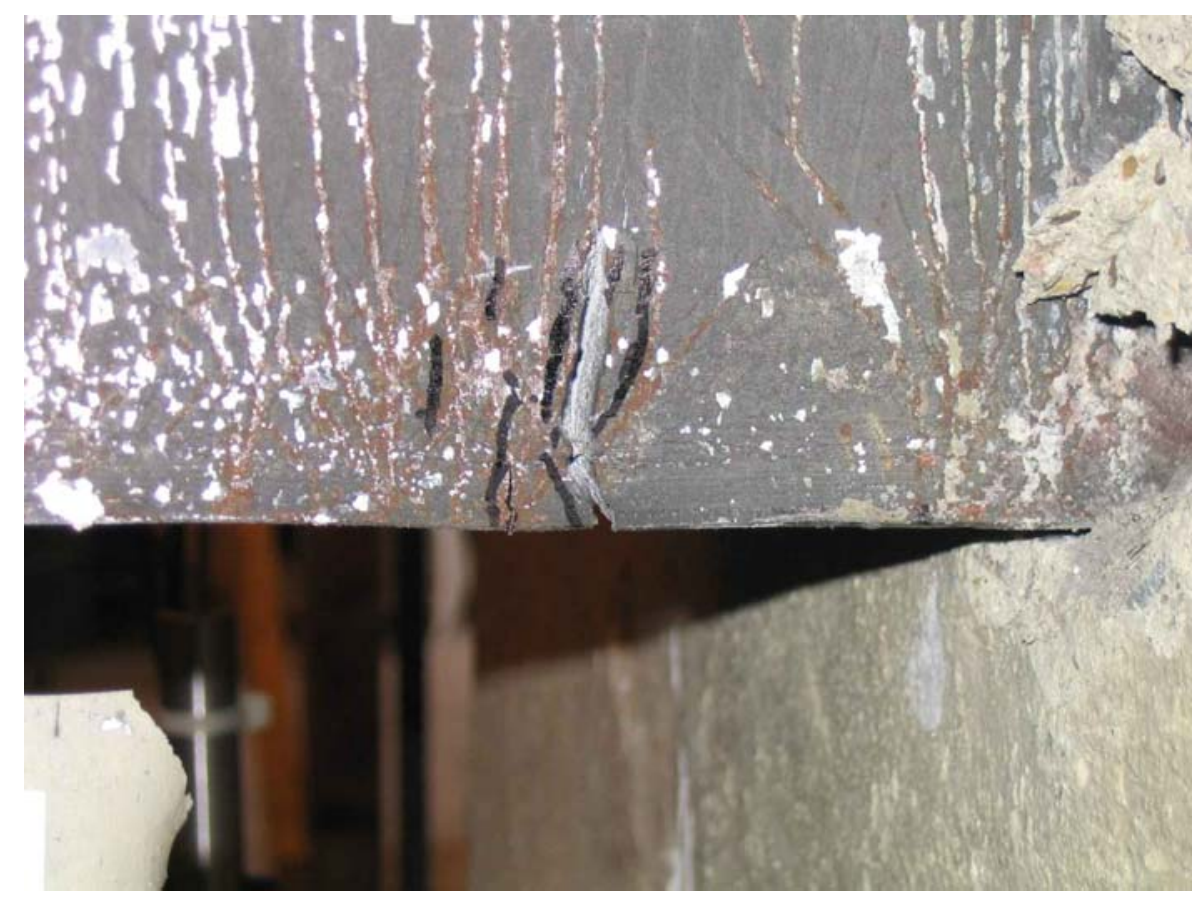

(d) SE Flange

Figure I.3: Specimen 1 - Crack on Steel Pile (3.00 in., 80 ${ }^{\text {th }}$ Cycle) (Continue) 


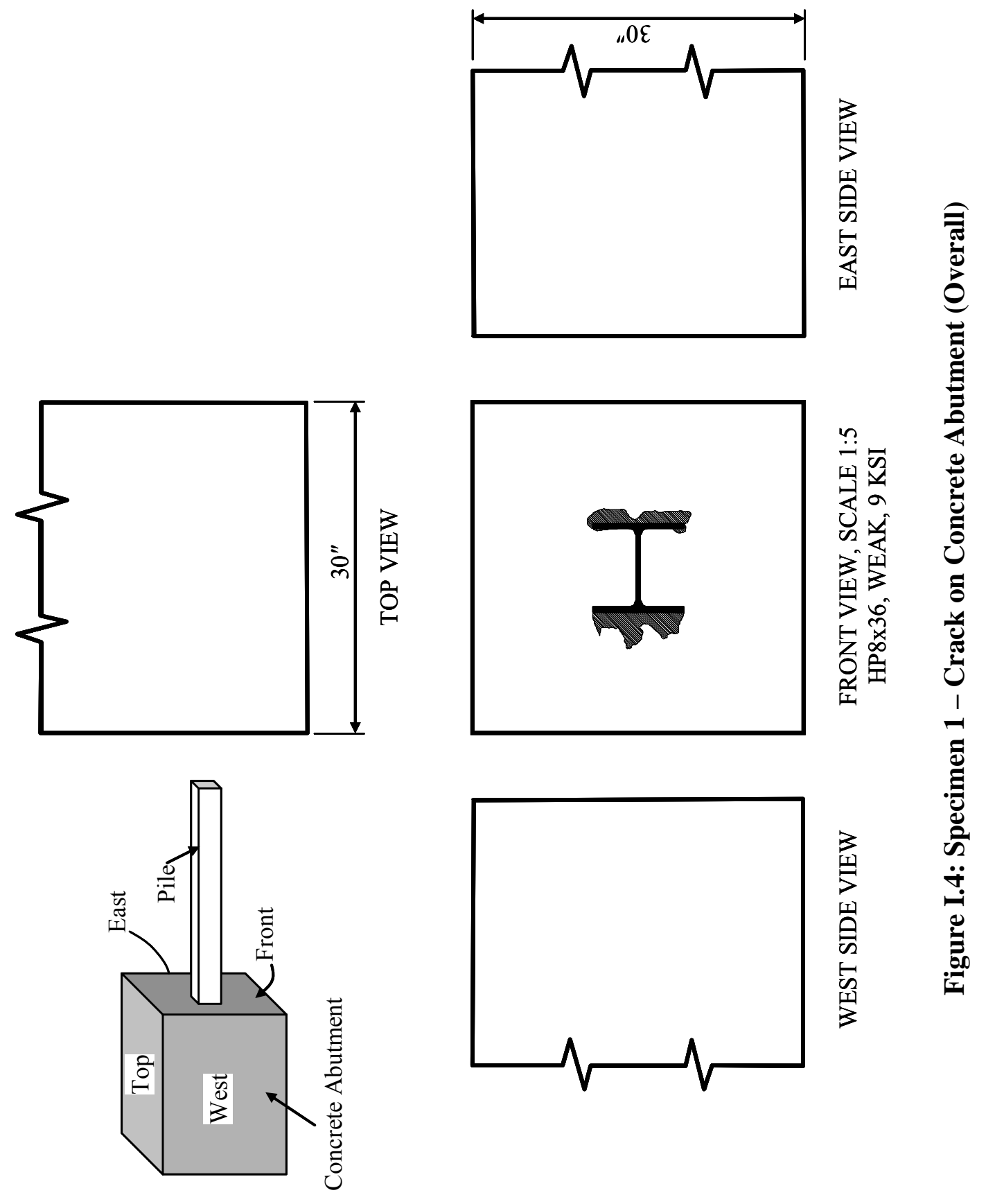




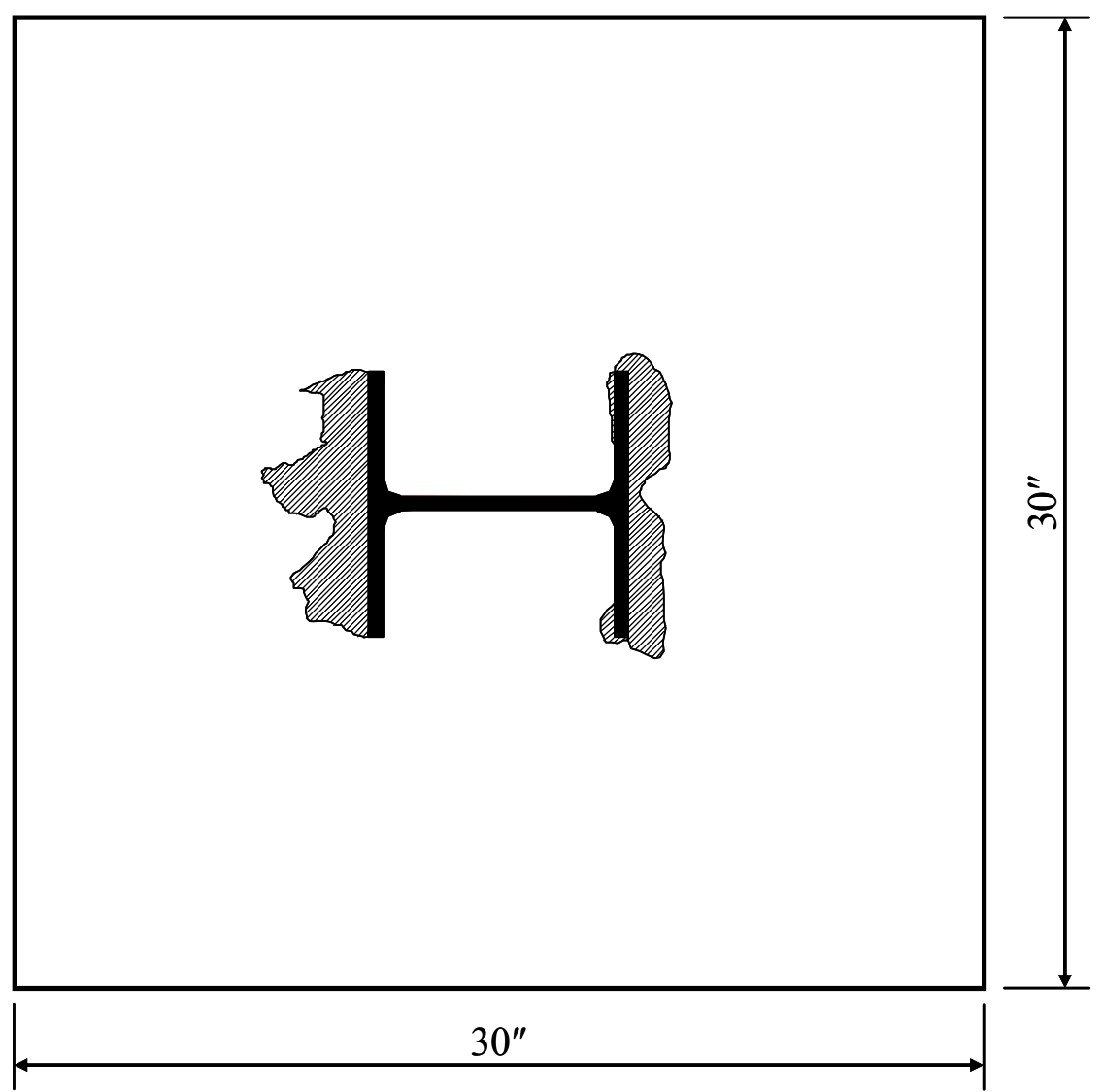

Figure I.5: Specimen 1 - Crack on Concrete Abutment (Front View)

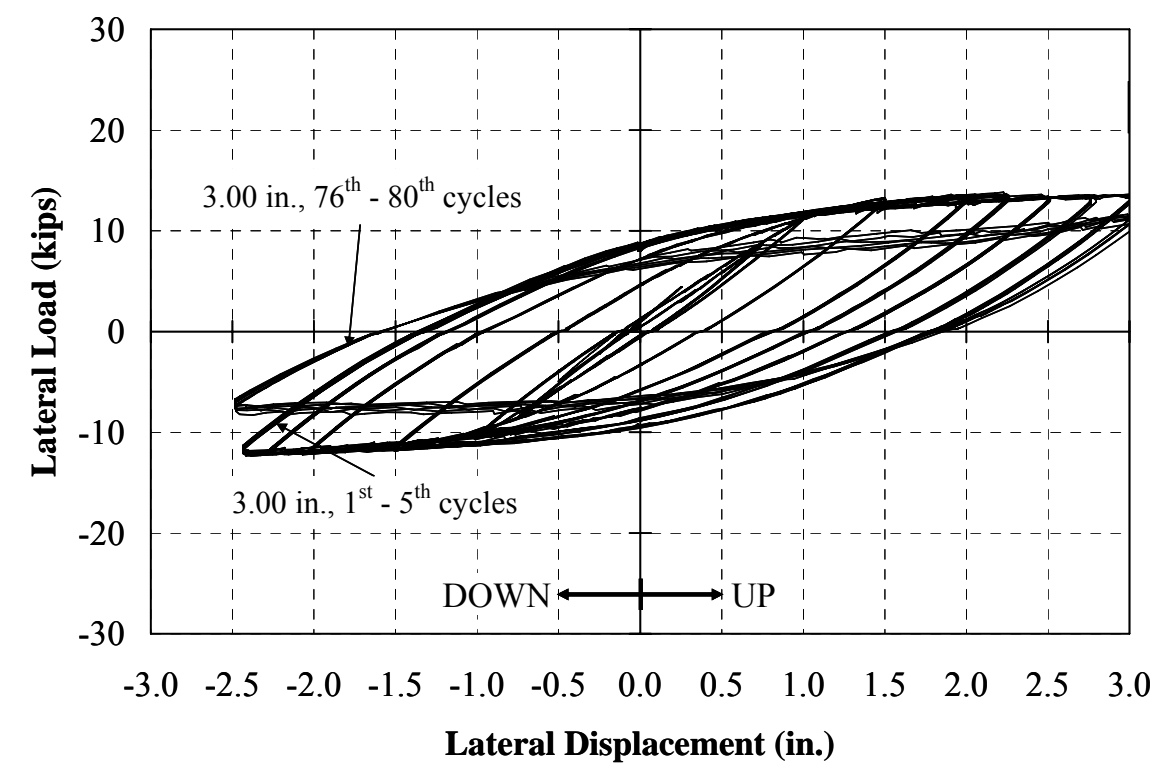

Figure I.6: Specimen 1 - Summary of Lateral Load-Deflection Curves 


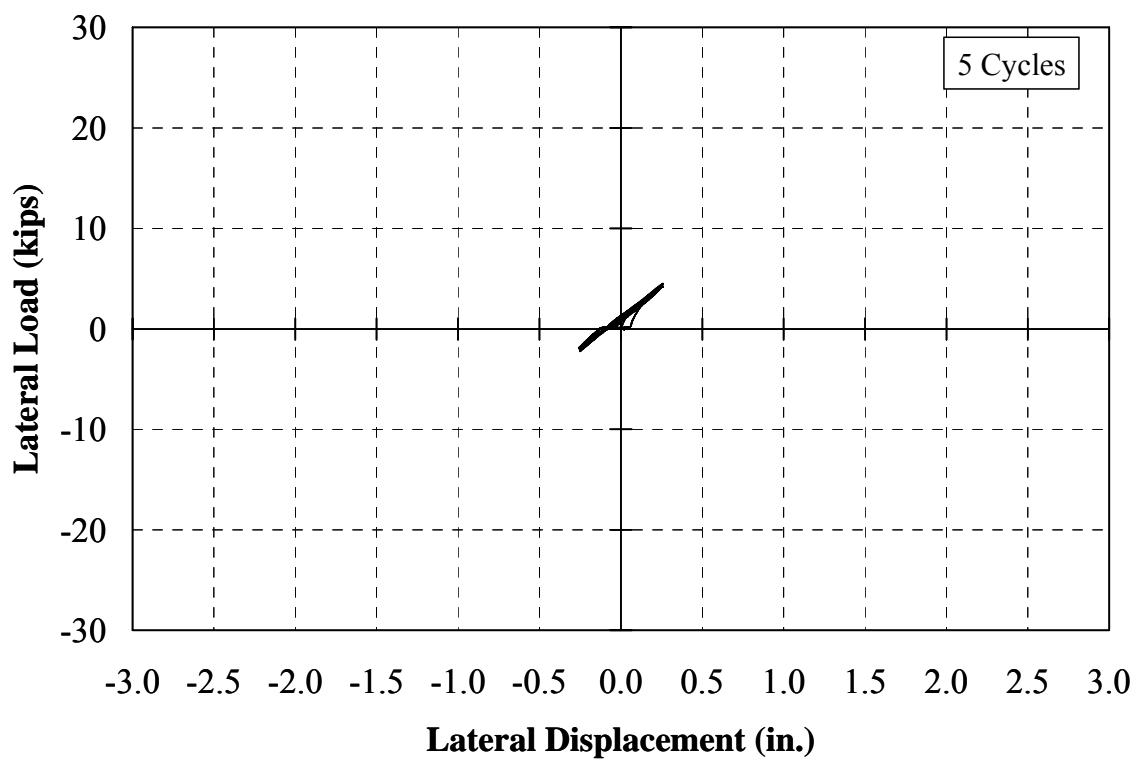

Figure I.7: Specimen 1 - Lateral Load-Deflection Response ( \pm 0.25 in.)

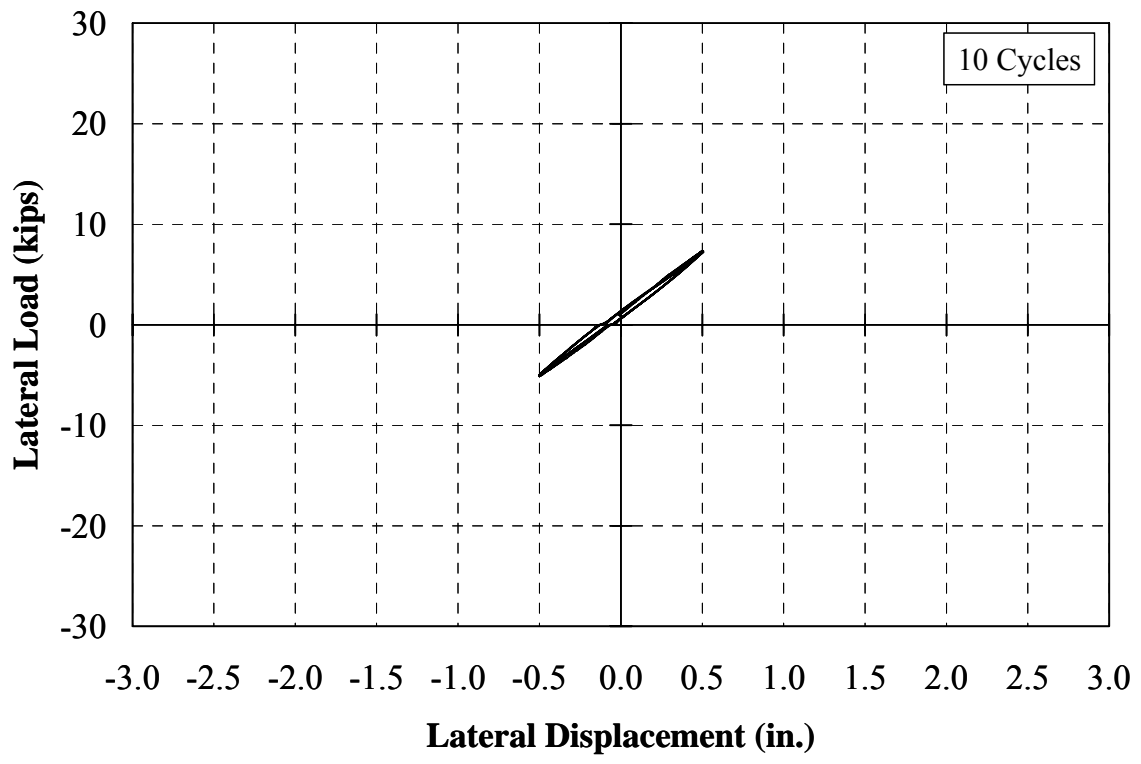

Figure I.8: Specimen 1 - Lateral Load-Deflection Response ( \pm 0.50 in.) 


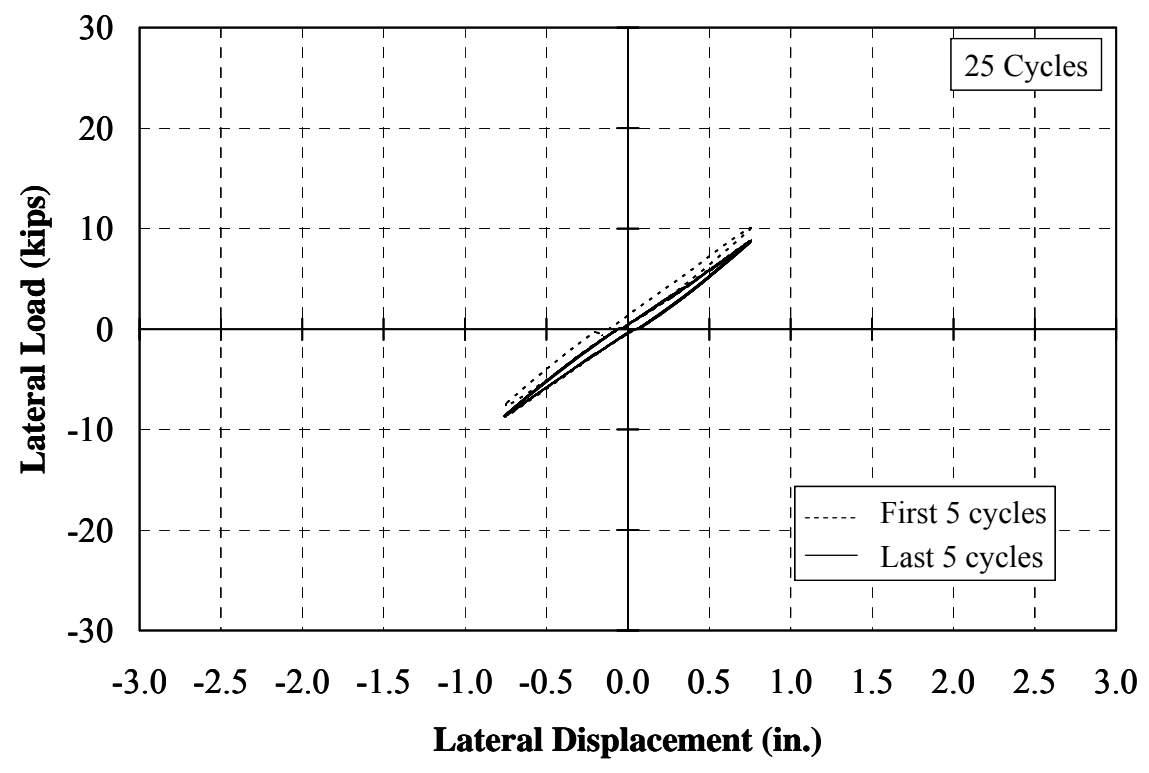

Figure I.9: Specimen 1 - Lateral Load-Deflection Response ( \pm 0.75 in.)

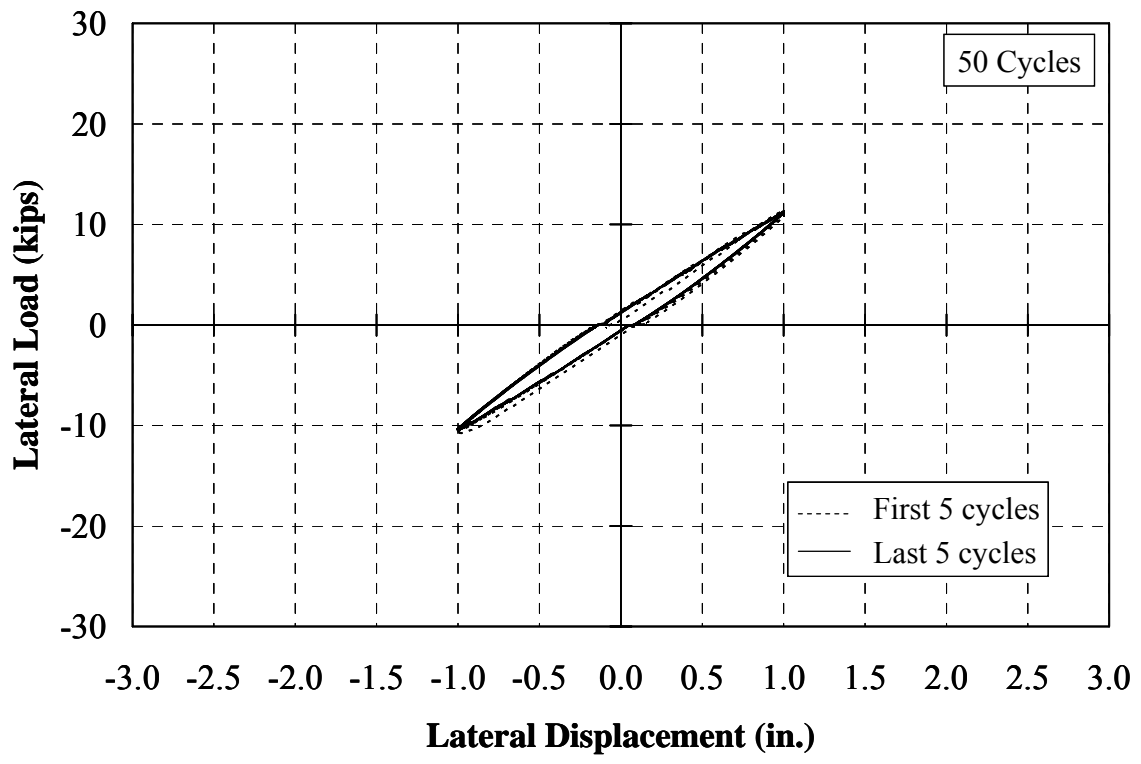

Figure I.10: Specimen 1 - Lateral Load-Deflection Response ( \pm 1.00 in.) 


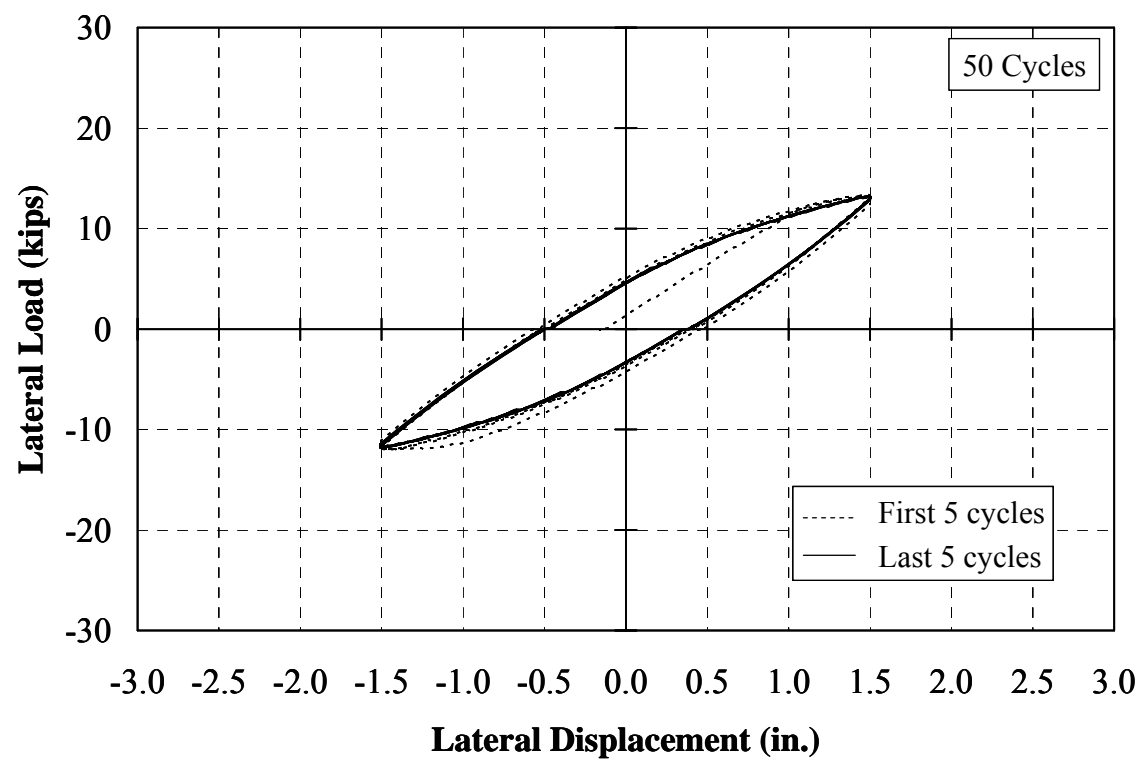

Figure I.11: Specimen 1 - Lateral Load-Deflection Response ( \pm 1.50 in.)

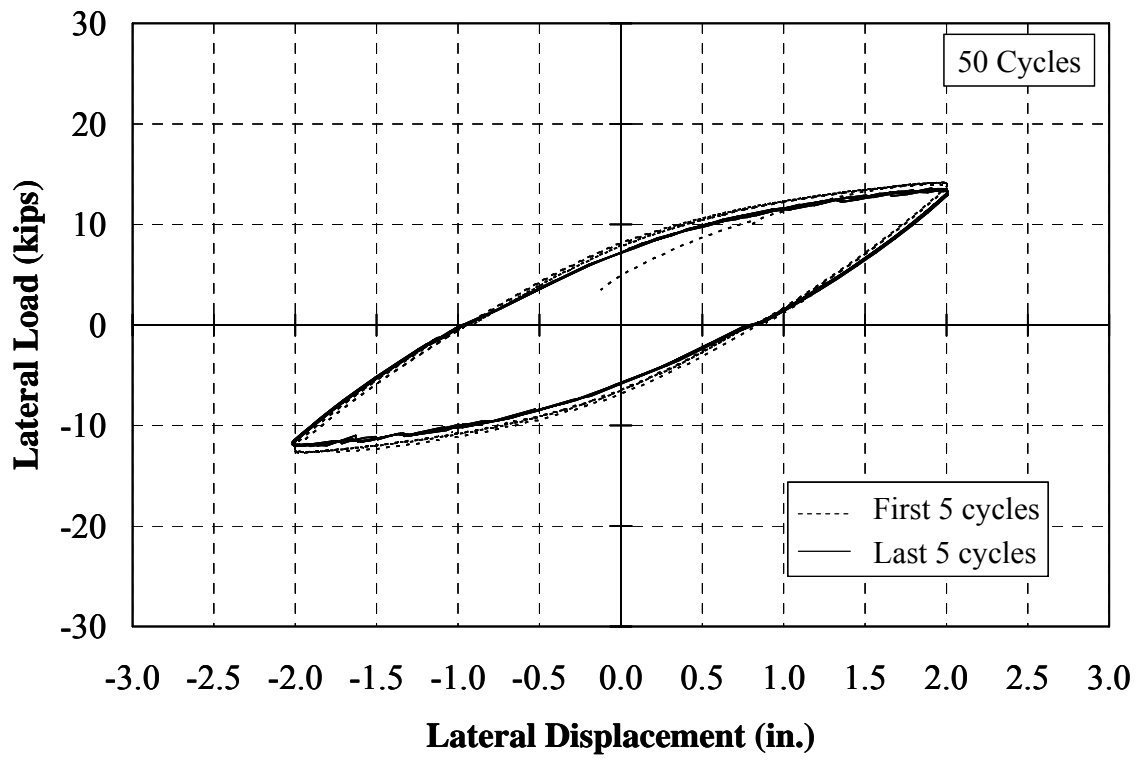

Figure I.12: Specimen 1 - Lateral Load-Deflection Response ( \pm 2.00 in.) 


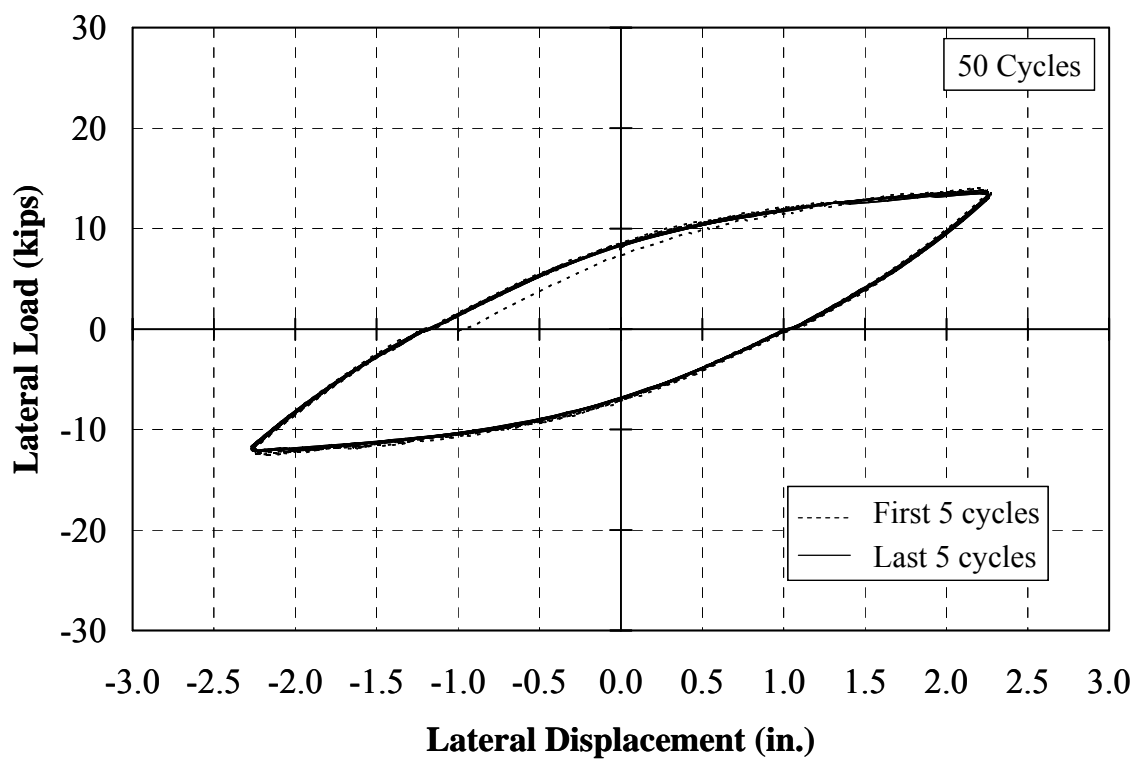

Figure I.13: Specimen 1 - Lateral Load-Deflection Response ( \pm 2.25 in.)

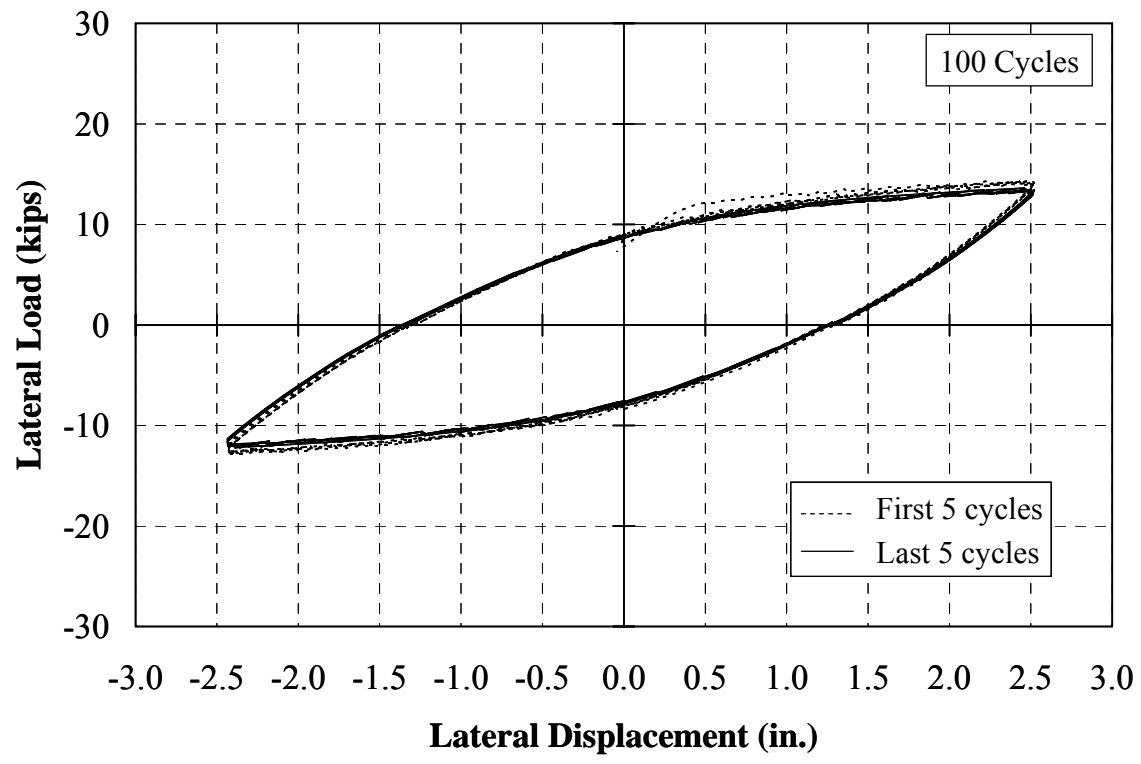

Figure I.14: Specimen 1 - Lateral Load-Deflection Response ( \pm 2.50 in.) 


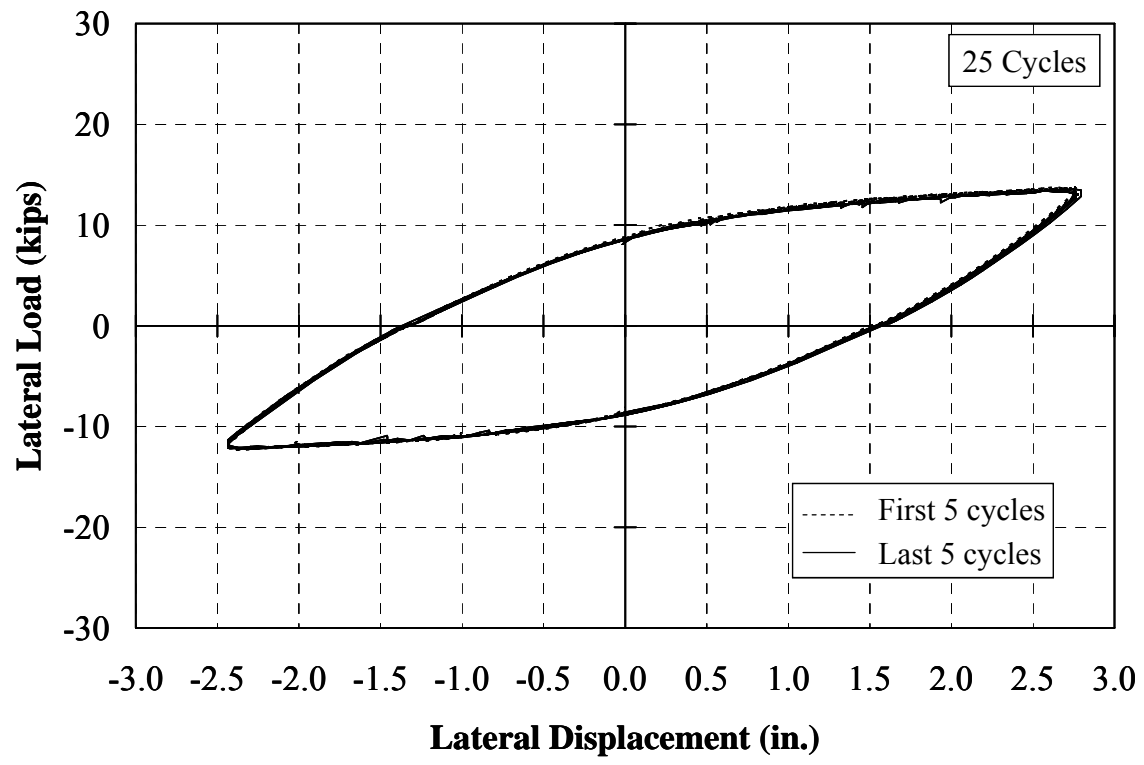

Figure I.15: Specimen 1 - Lateral Load-Deflection Response ( \pm 2.75 in.)

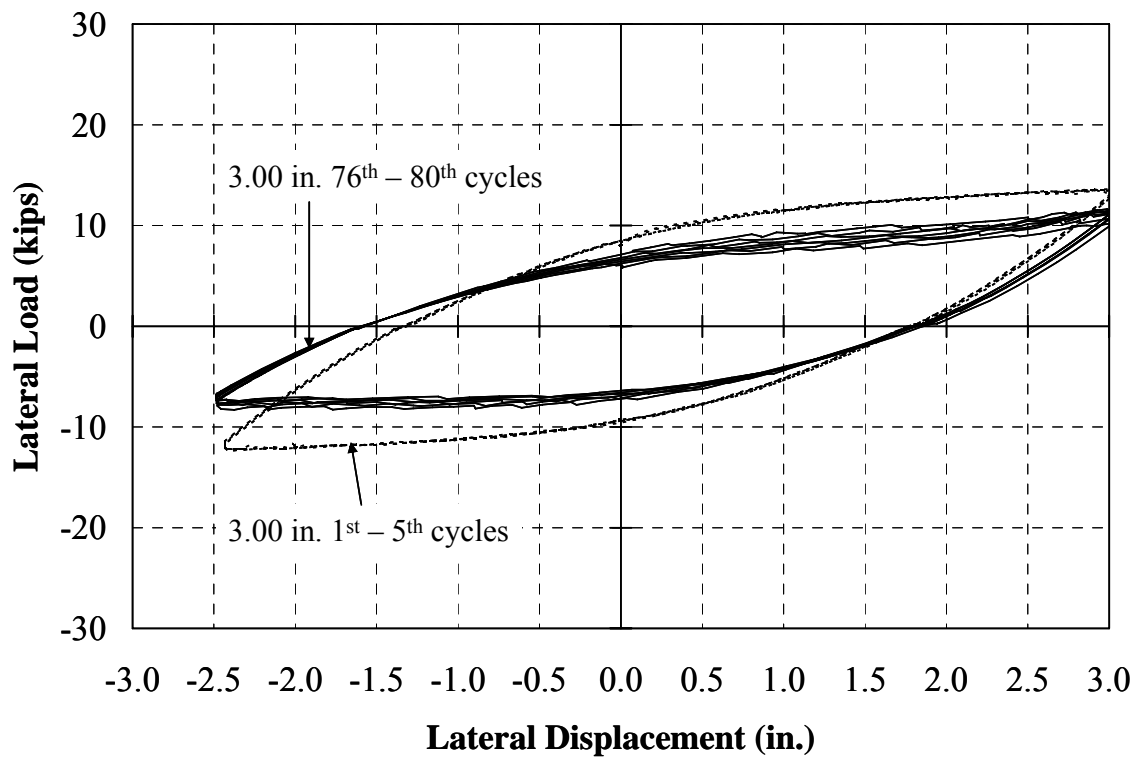

Figure I.16: Specimen 1 - Lateral Load-Deflection Response ( \pm 3.00 in.) 
Specimen 2 (HP8x36, Strong, 9 ksi)

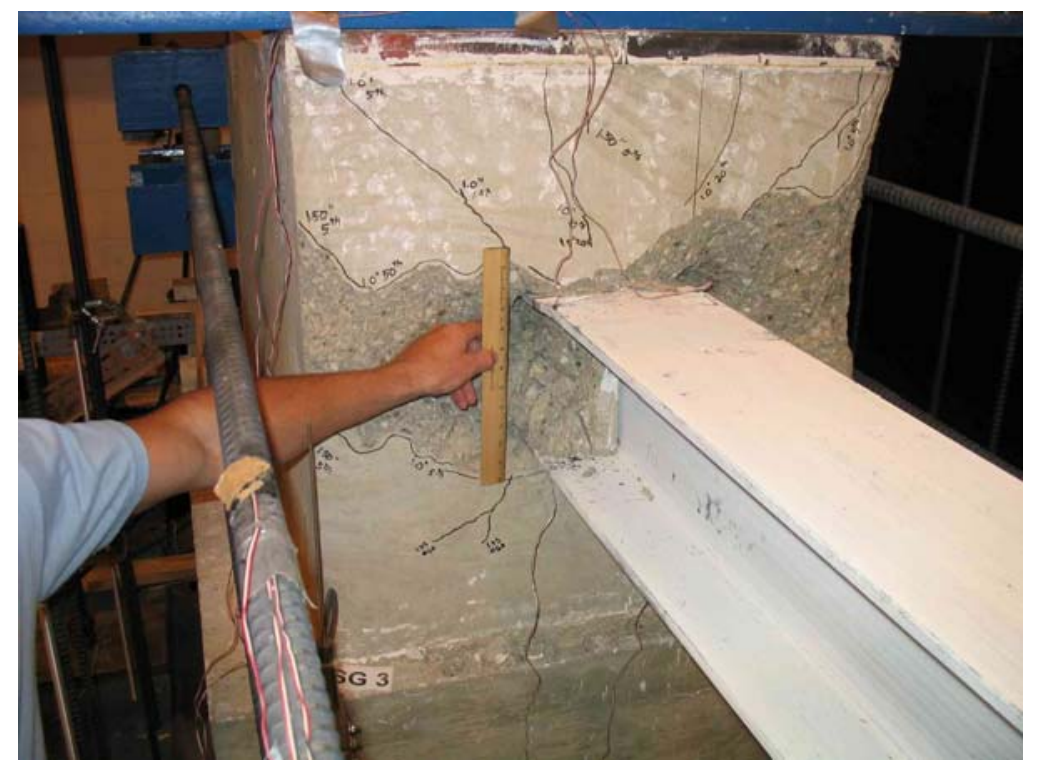

(a) West Side

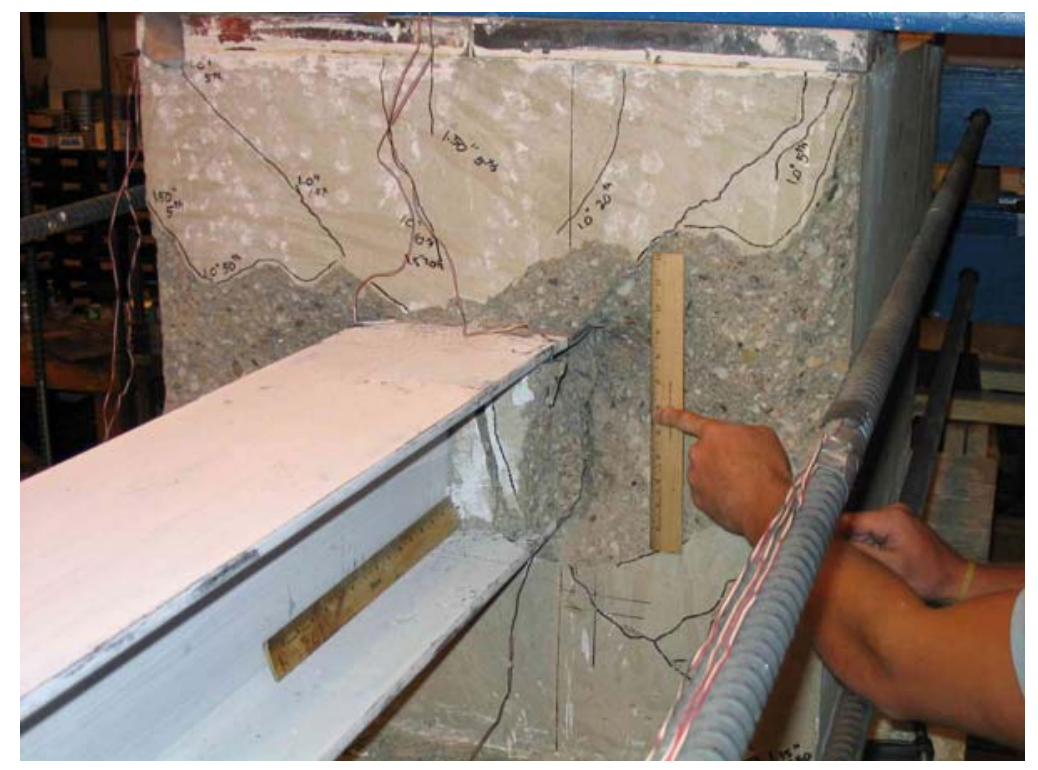

(b) East Side

Figure I.17: Specimen 2 - Cracking (1.75 in., 100 ${ }^{\text {th }}$ Cycle) 


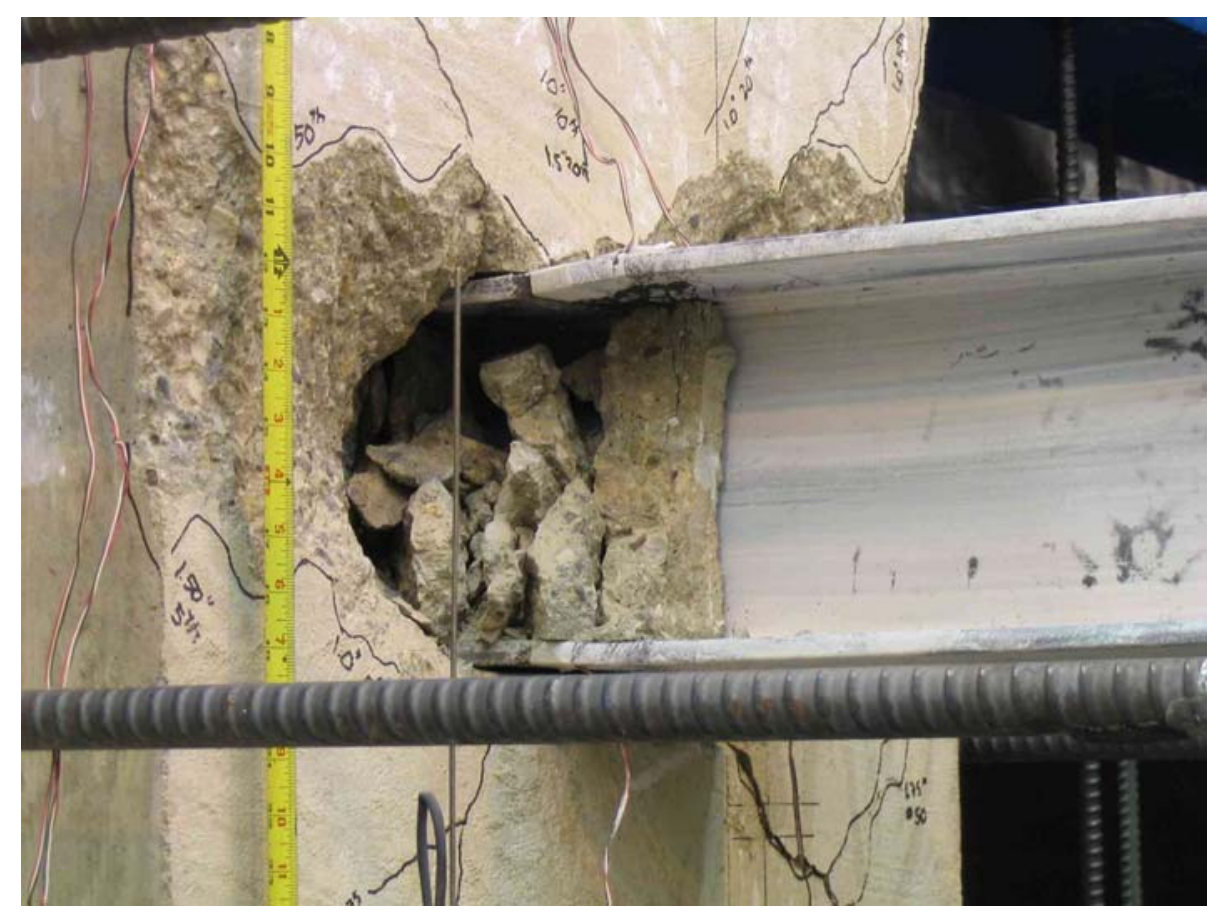

(a) West Side

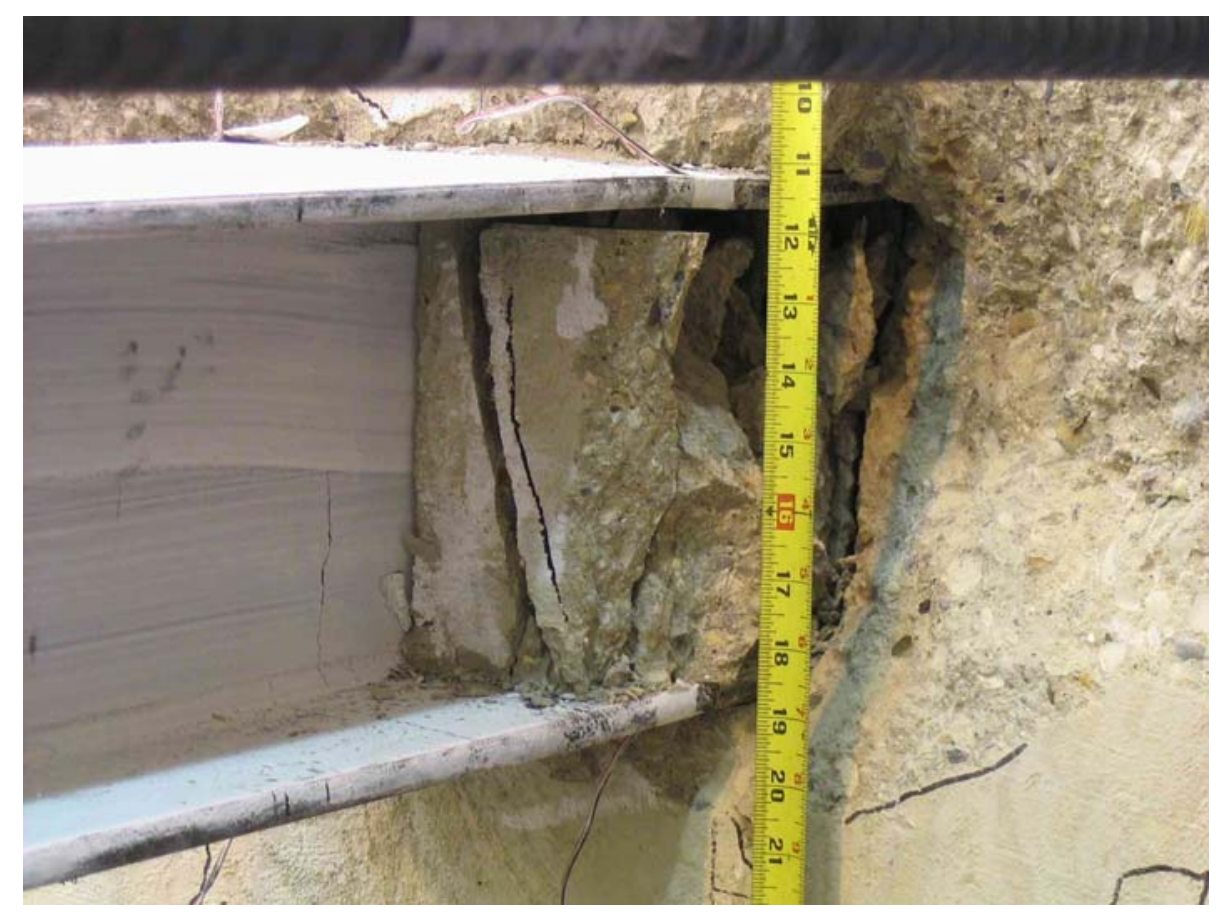

(b) East Side

Figure I.18: Specimen 2 - Deterioration at the Abutment-Pile Connection

(1.75 in., 100 ${ }^{\text {th }}$ Cycle) 


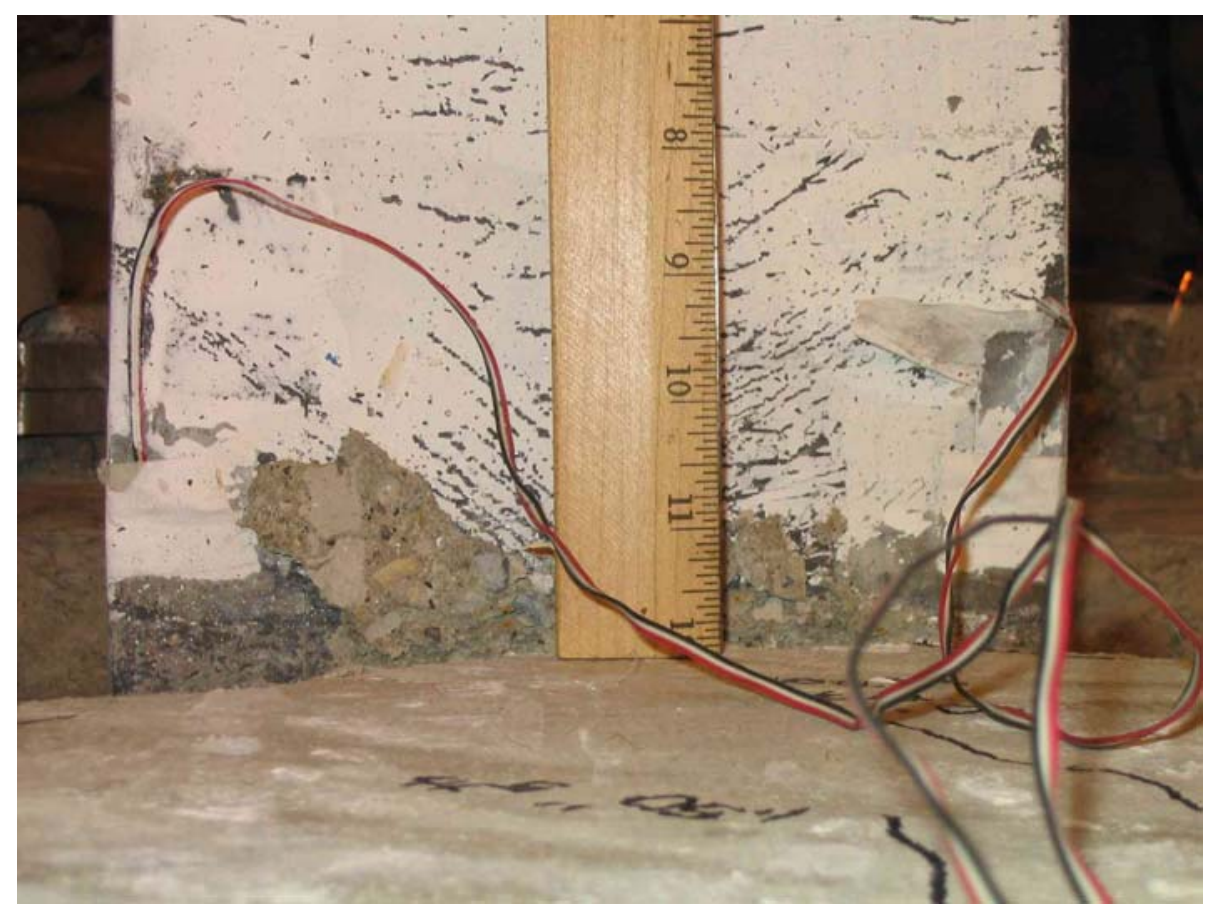

(a) Top Flange

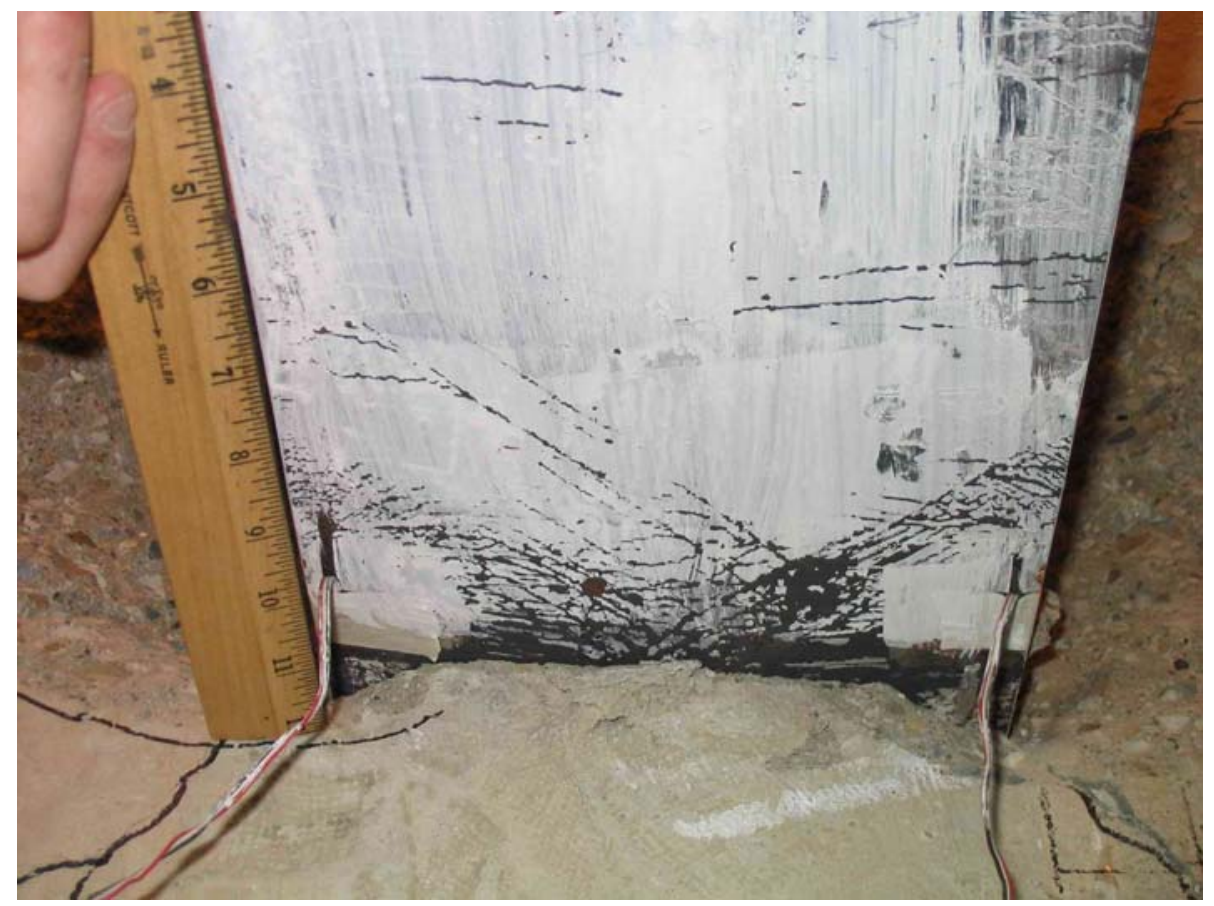

(b) Bottom Flange

Figure I.19: Specimen 2 - Pile Yielding - (1.75 in., $100^{\text {th }}$ Cycle $)$ 


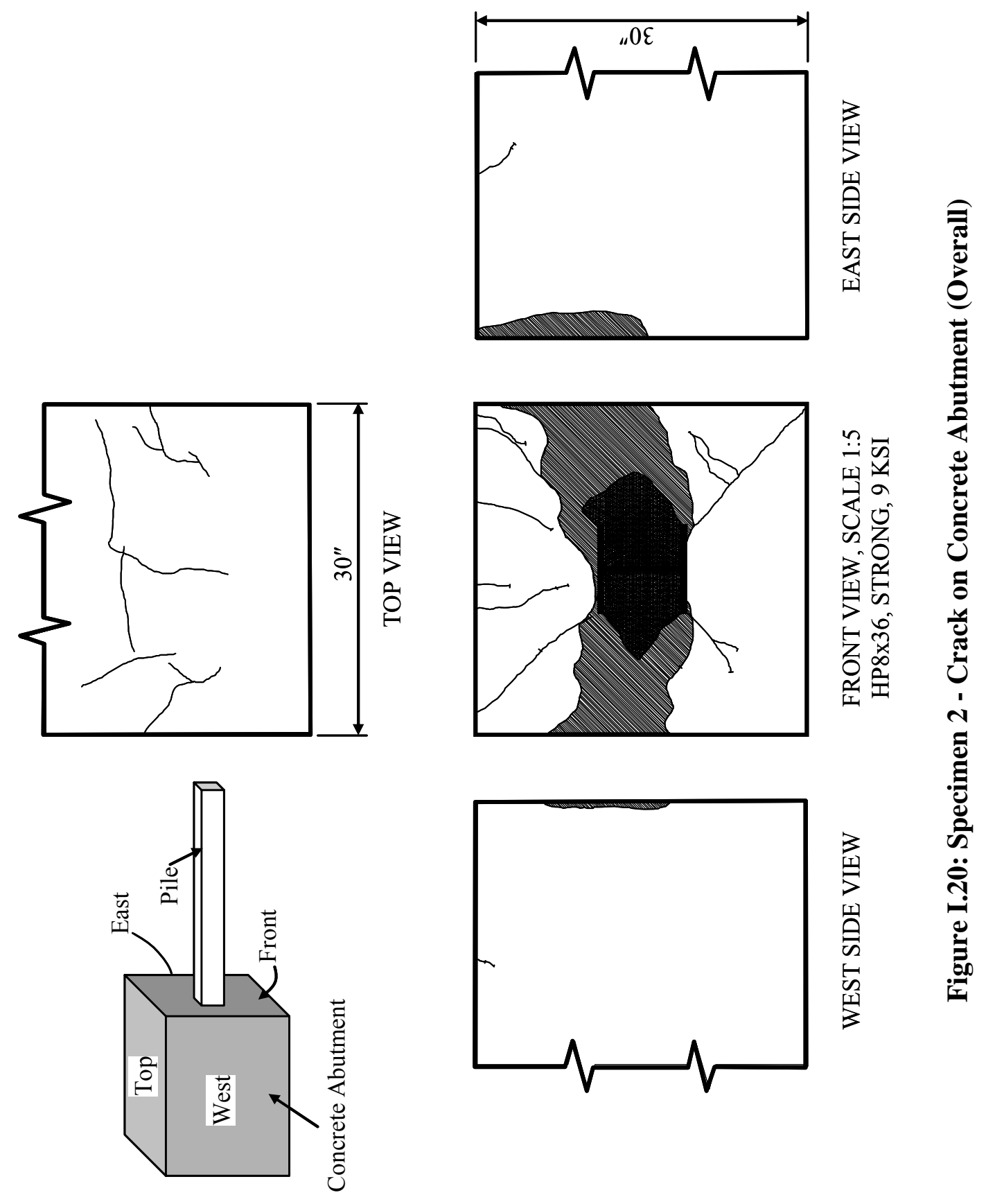




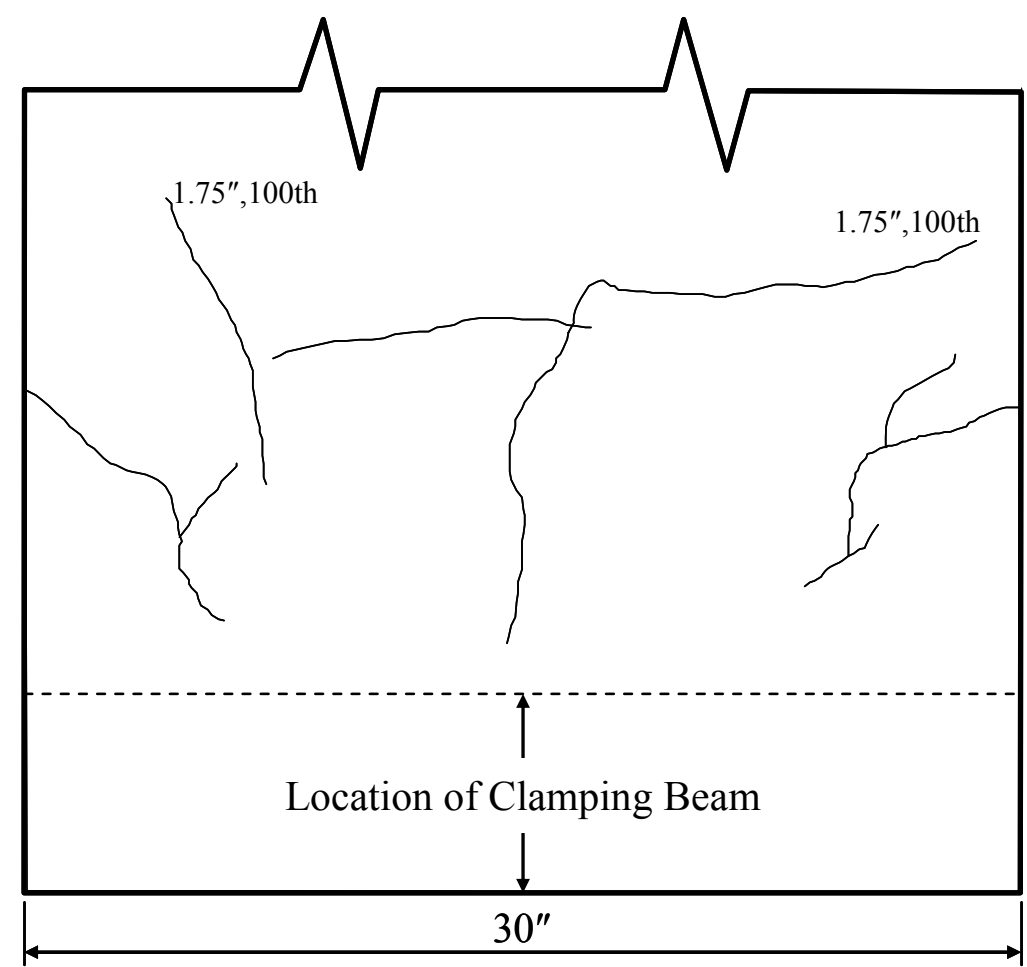

Figure I.21: Specimen 2 - Crack on Concrete Abutment (Top View)

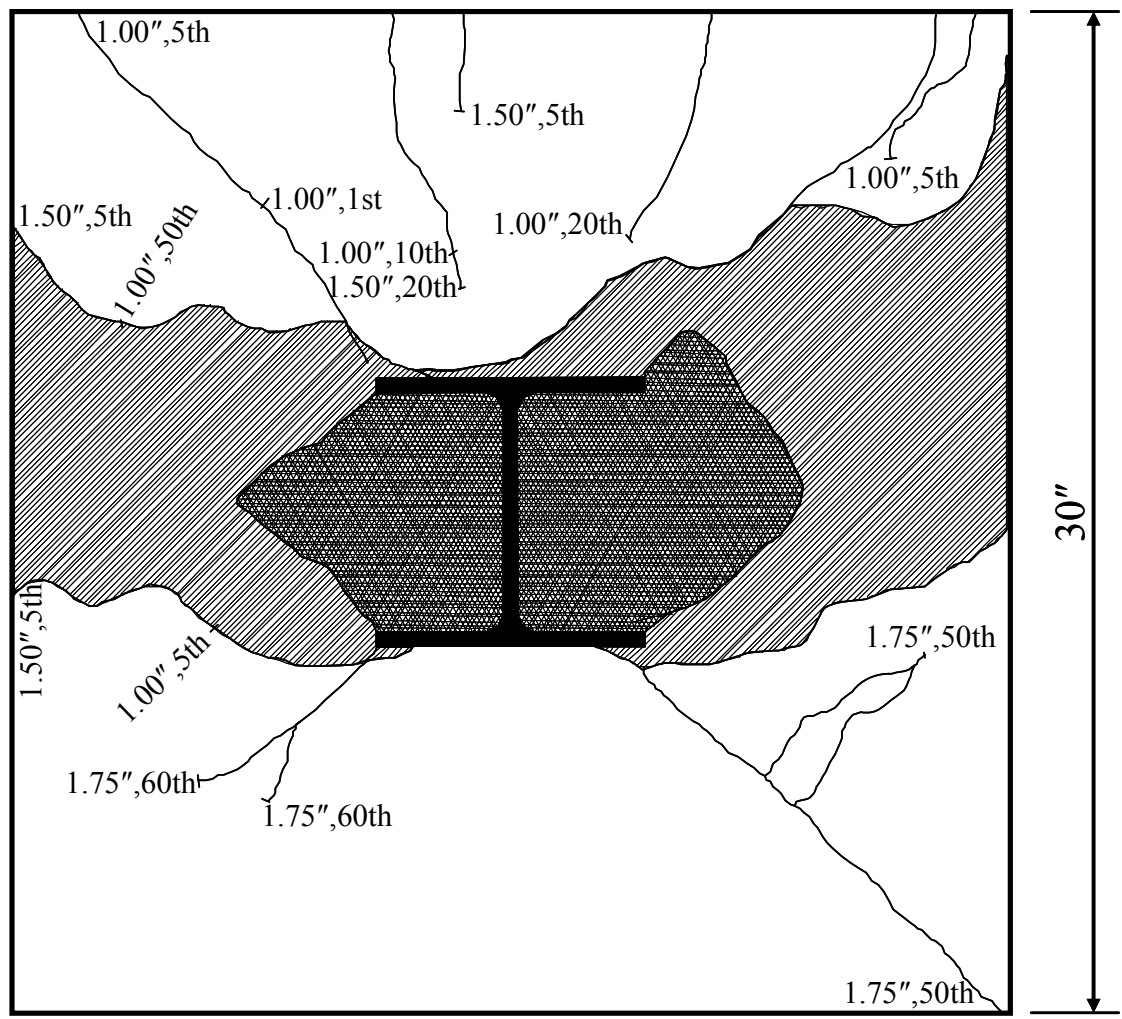

Figure I.22: Specimen 2 - Crack on Concrete Abutment (Front View) 


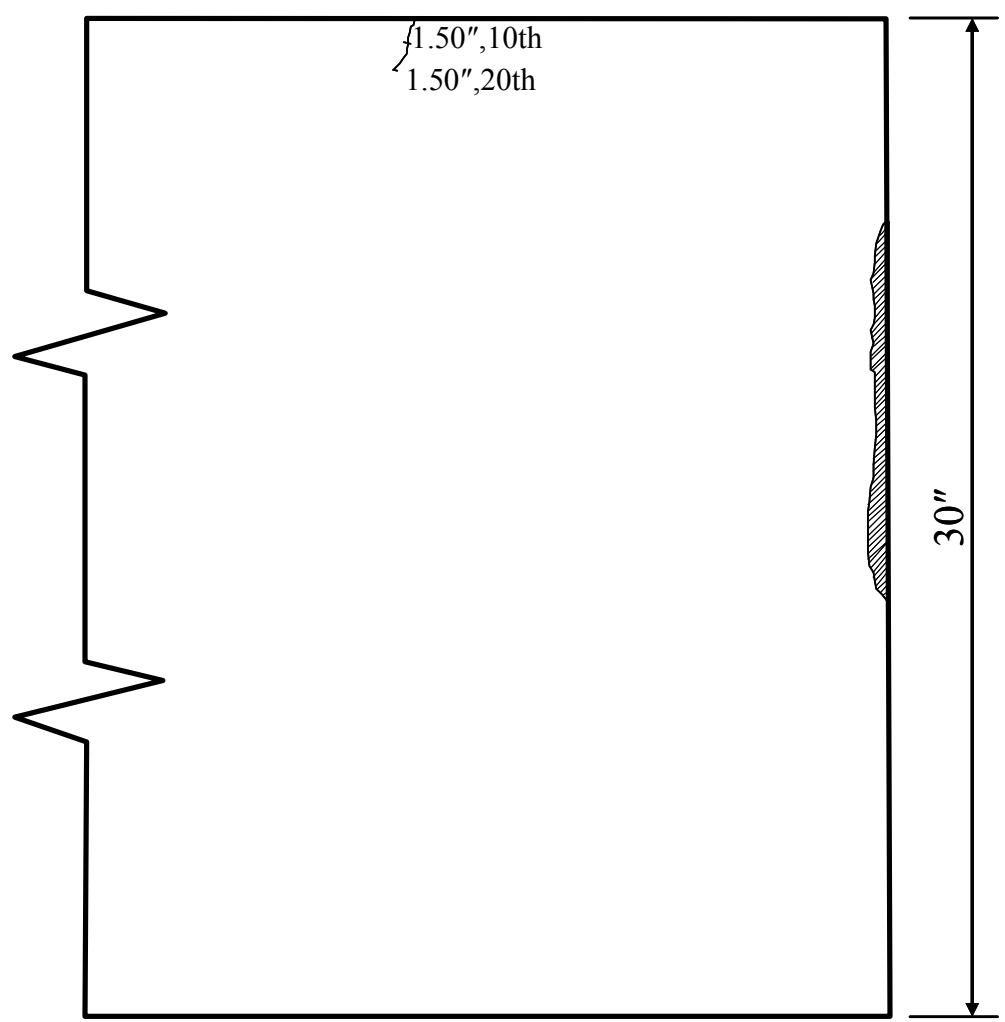

Figure I.23: Specimen 2 - Crack on Concrete Abutment (West View)

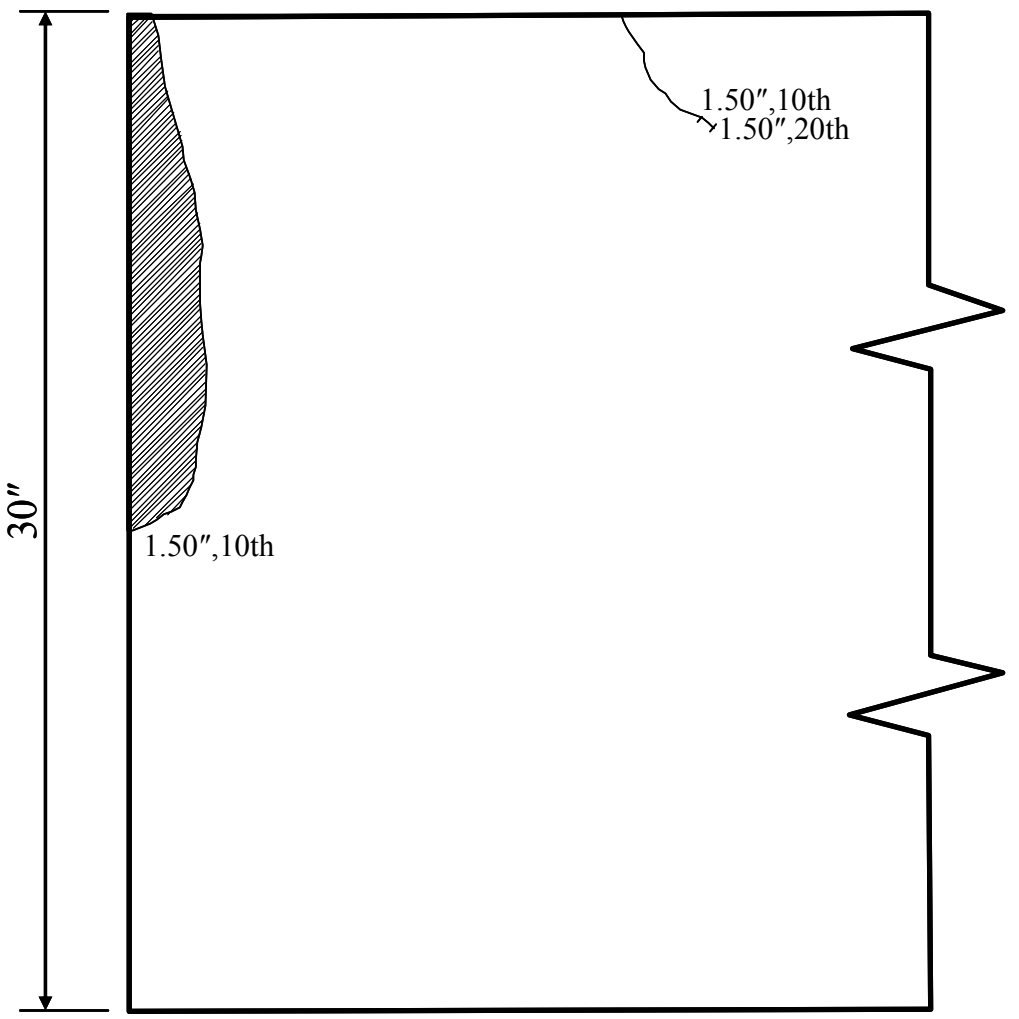

Figure I.24: Specimen 2 - Crack on Concrete Abutment (East View) 


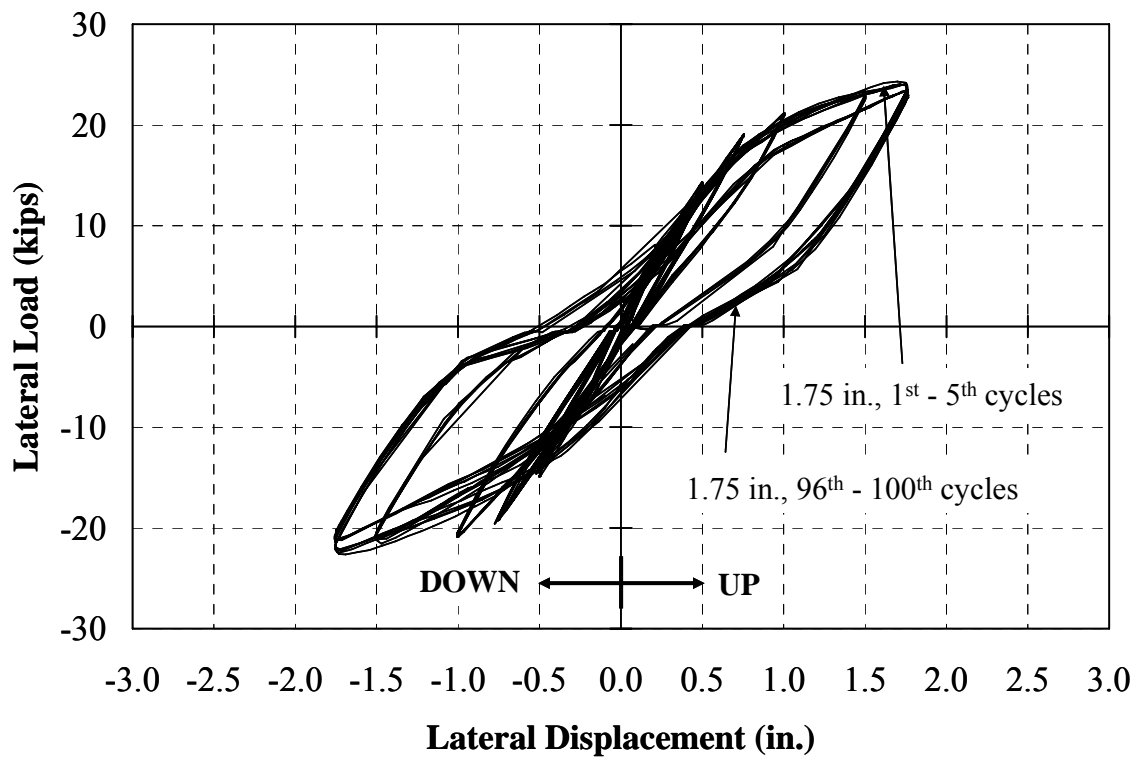

Figure I.25: Specimen 2 - Summary of Lateral Load-Deflection Curves 


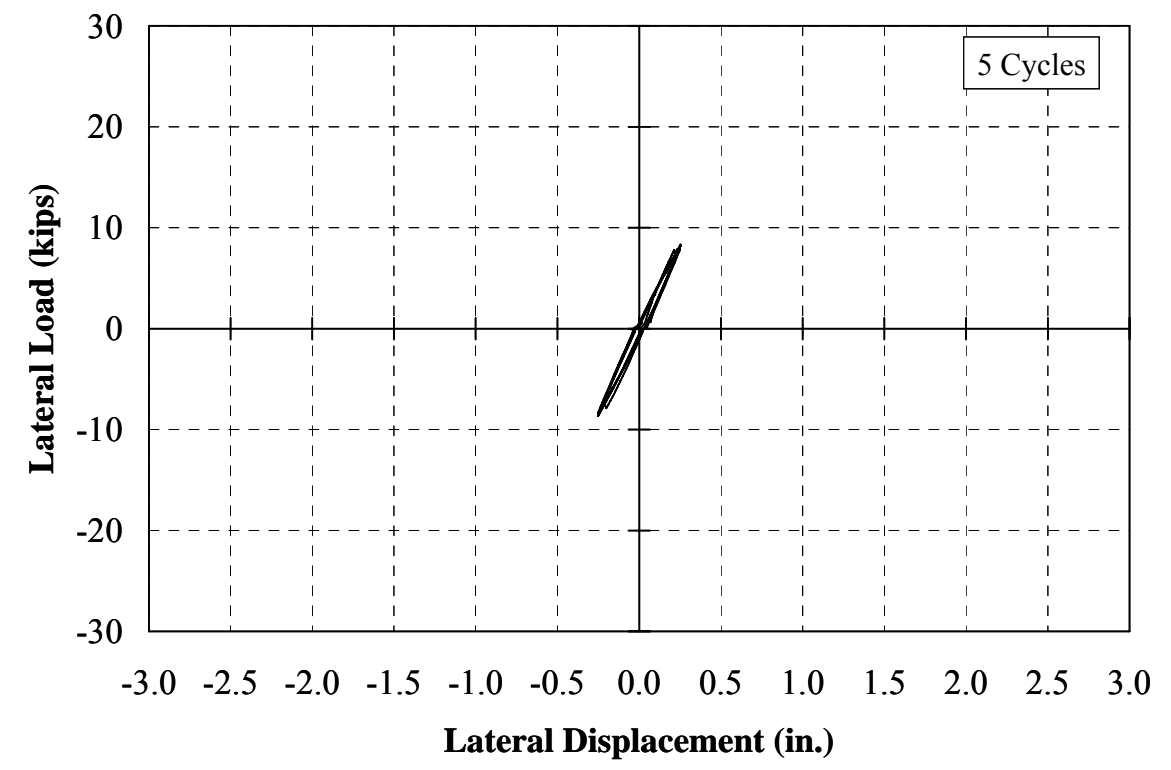

Figure I.26: Specimen 2 - Lateral Load-Deflection Response ( \pm 0.25 in.)

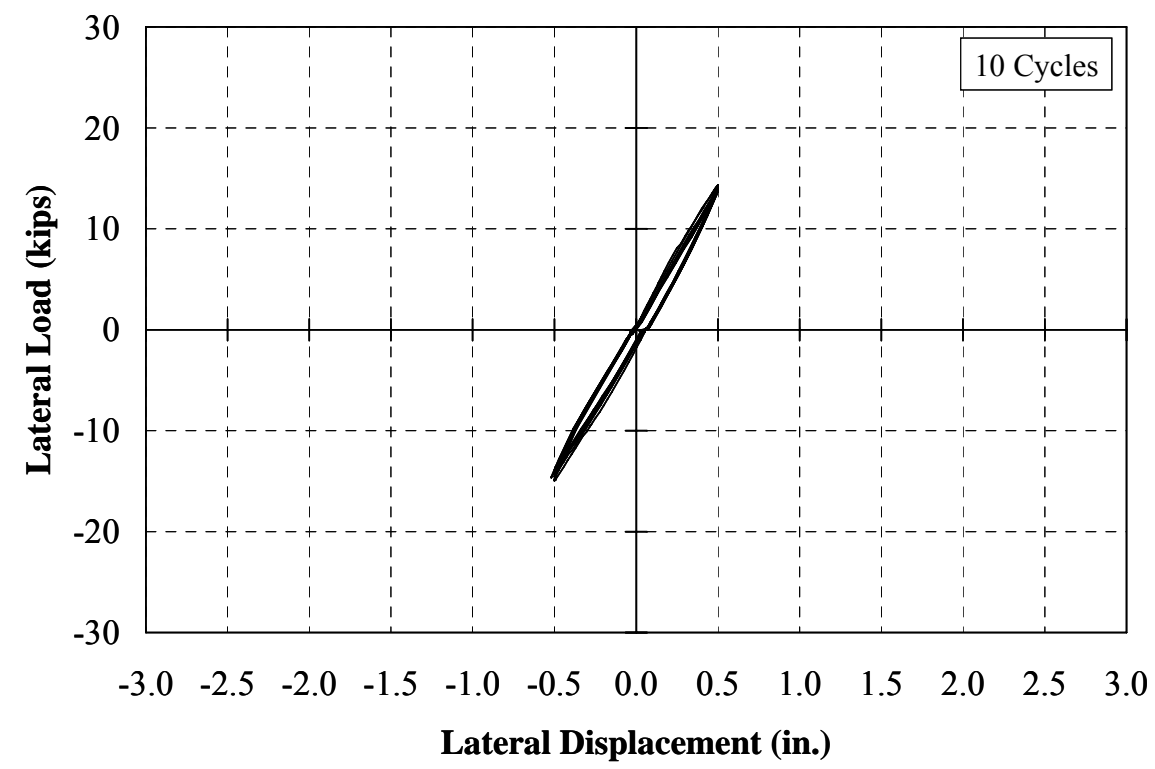

Figure I.27: Specimen 2 - Lateral Load-Deflection Response ( \pm 0.50 in.) 


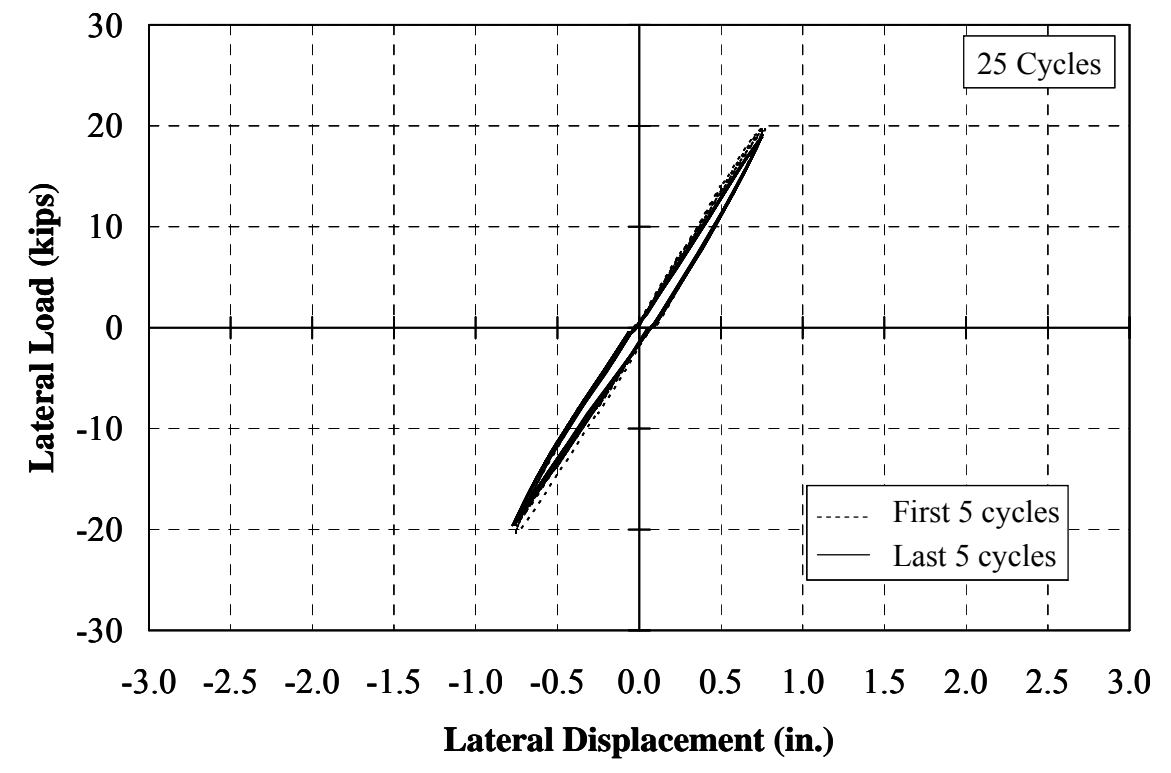

Figure I.28: Specimen 2 - Lateral Load-Deflection Response ( \pm 0.75 in.)

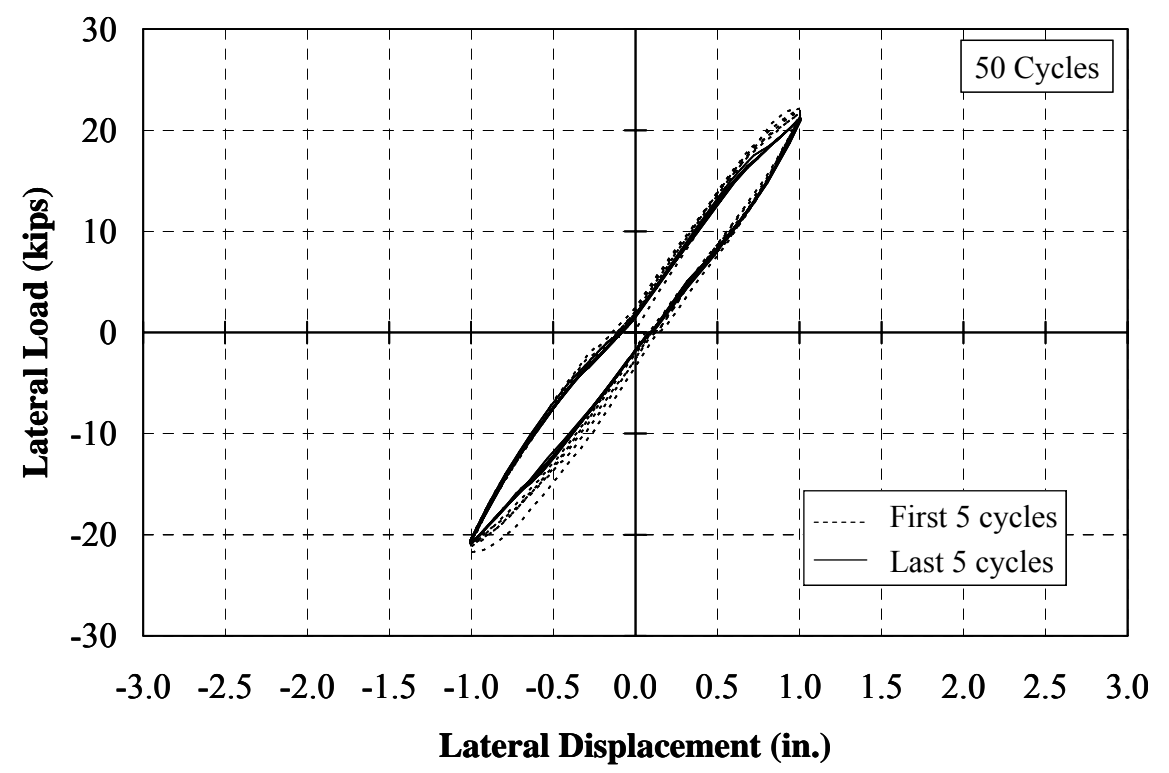

Figure I.29: Specimen 2 - Lateral Load-Deflection Response ( \pm 1.00 in.) 


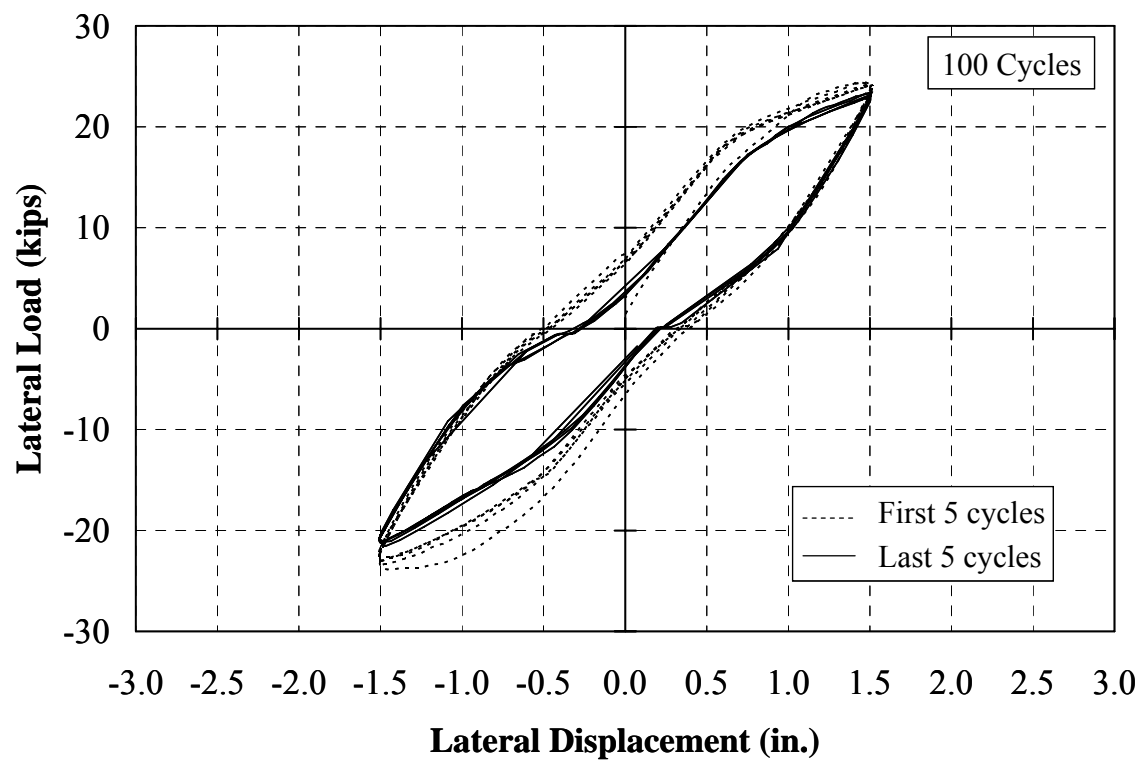

Figure I.30: Specimen 2 - Lateral Load-Deflection Response ( \pm 1.50 in.)

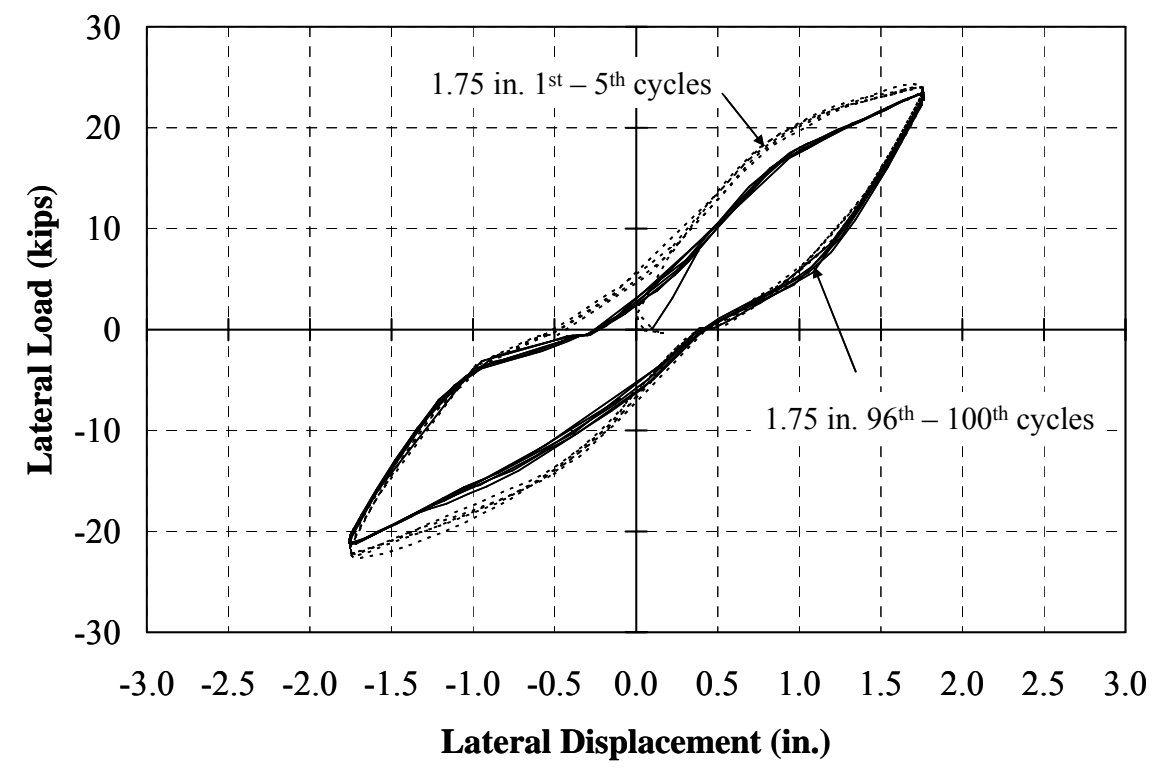

Figure I.31: Specimen 2 - Lateral Load-Deflection Response ( \pm 1.75 in.) 
Specimen 3 (HP8x36, 45, 9 ksi)

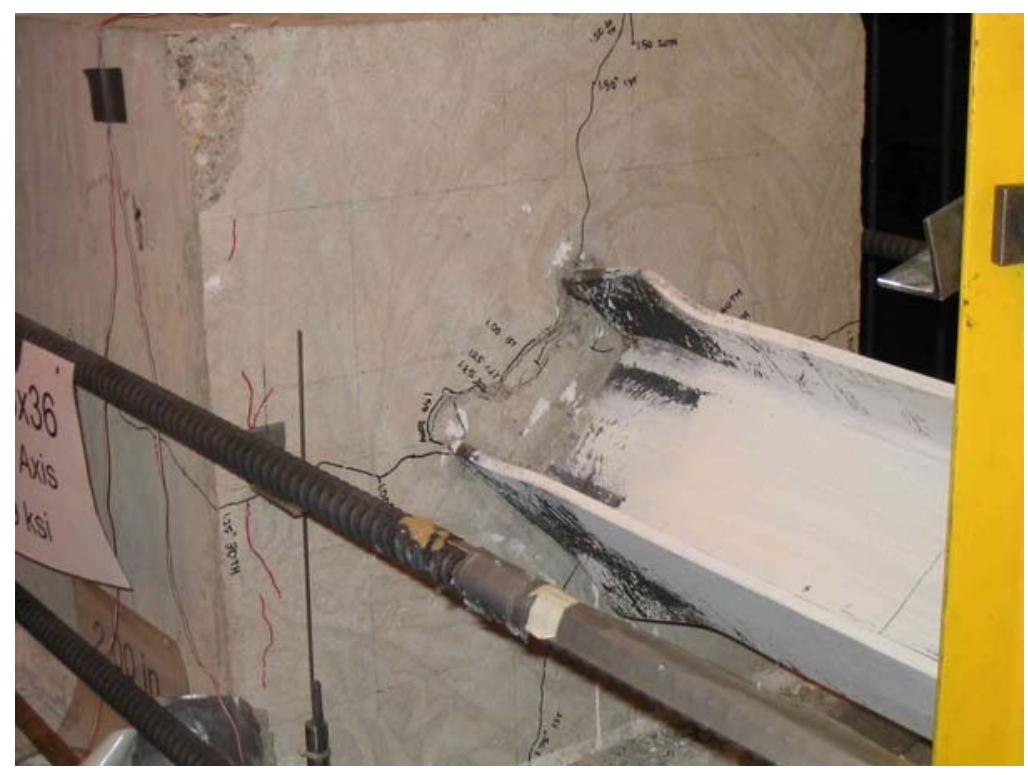

(a) West Side

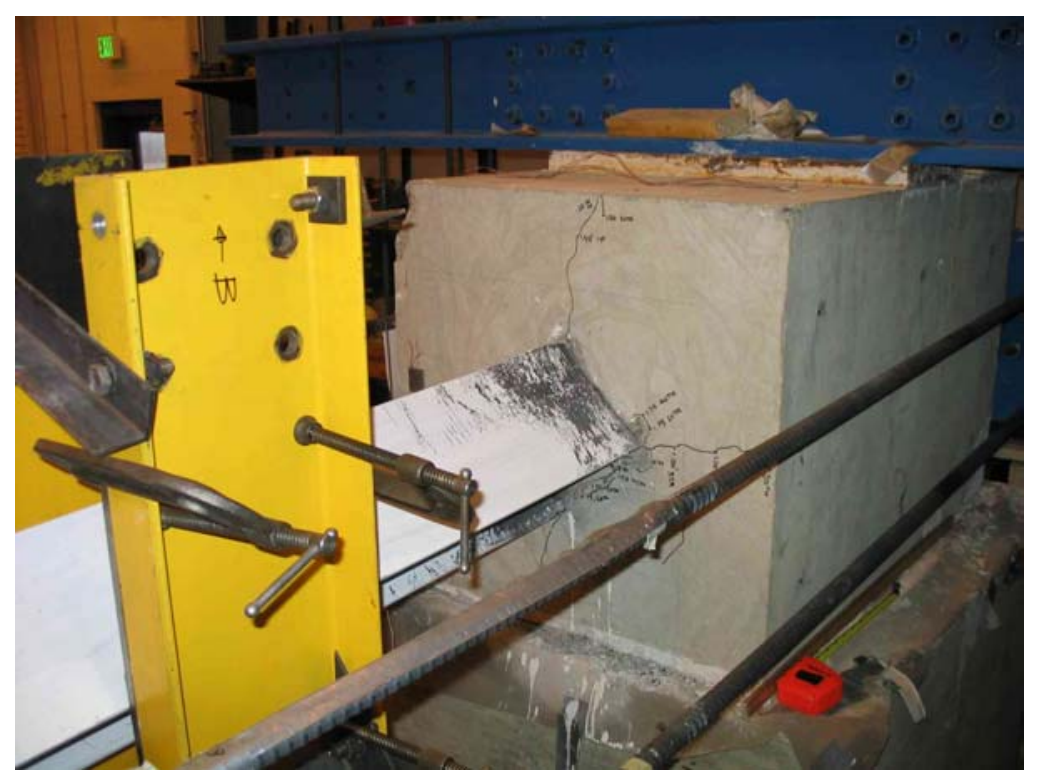

(b) East Side

Figure I.32: Specimen 3 - Cracking (2.00 in., $100^{\text {th }}$ Cycle) 


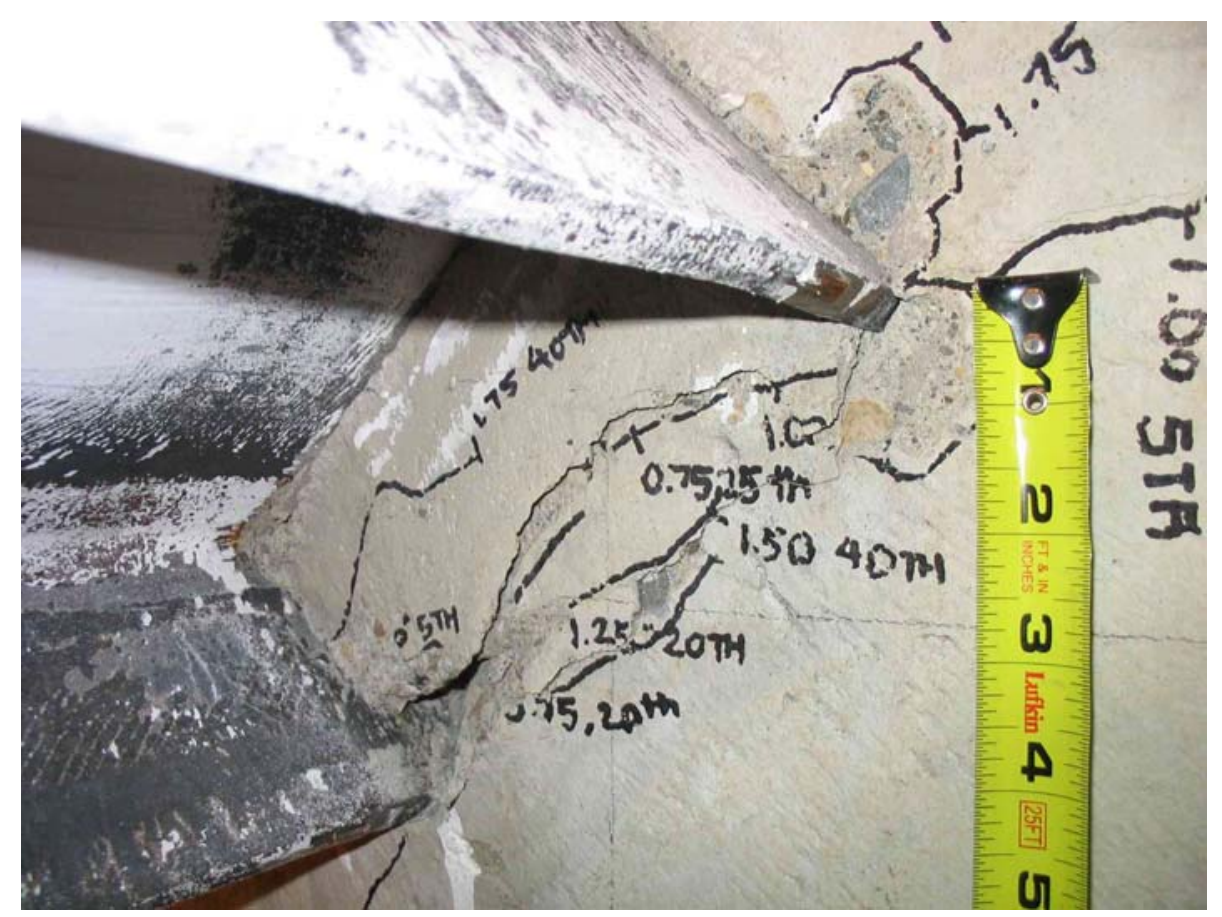

(c) Bottom

Figure I.32: Specimen 3 - Cracking (2.00 in., $100^{\text {th }}$ Cycle) (Continue) 


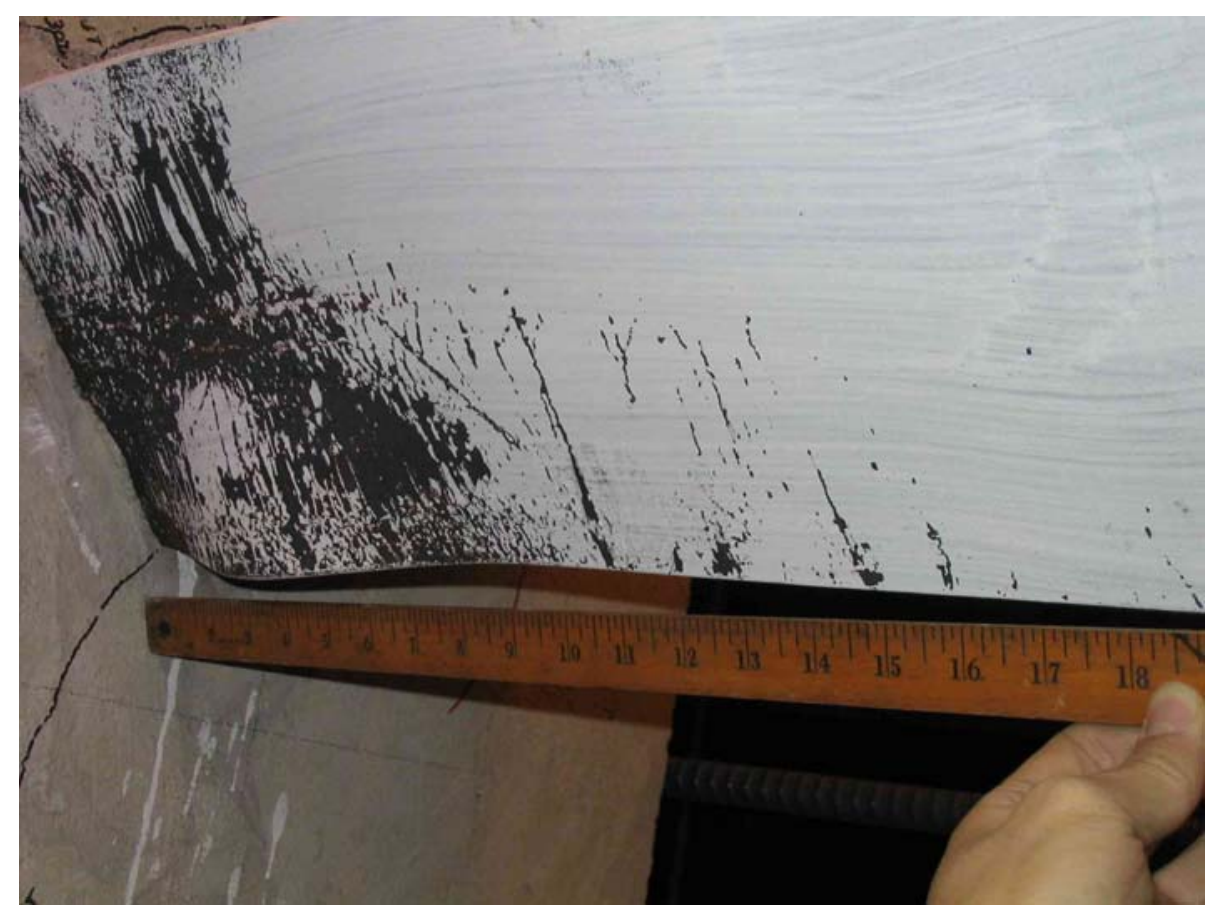

(a) West Side

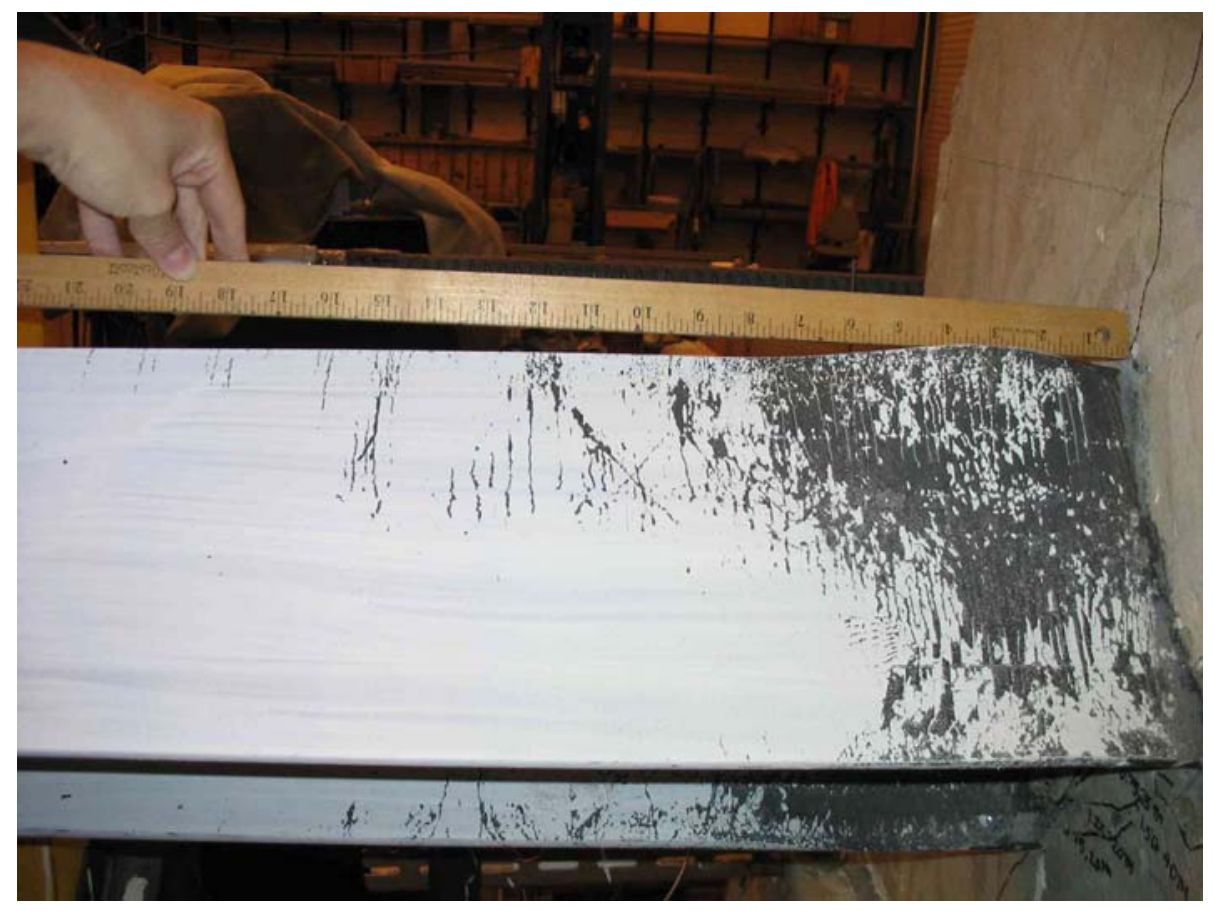

(b) East Side

Figure I.33: Specimen 3 - Pile Yielding (2.00 in., $100^{\text {th }}$ Cycle) 


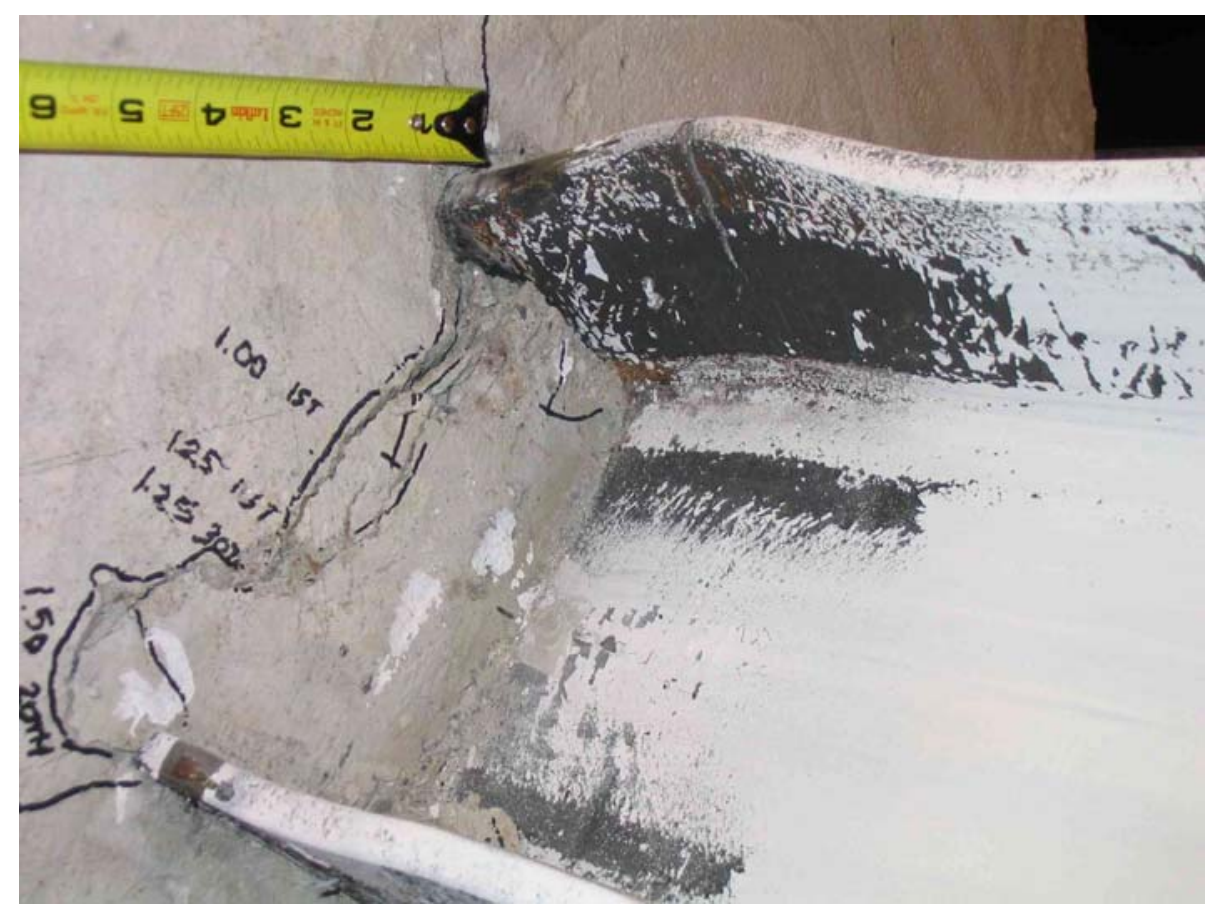

(a) Top

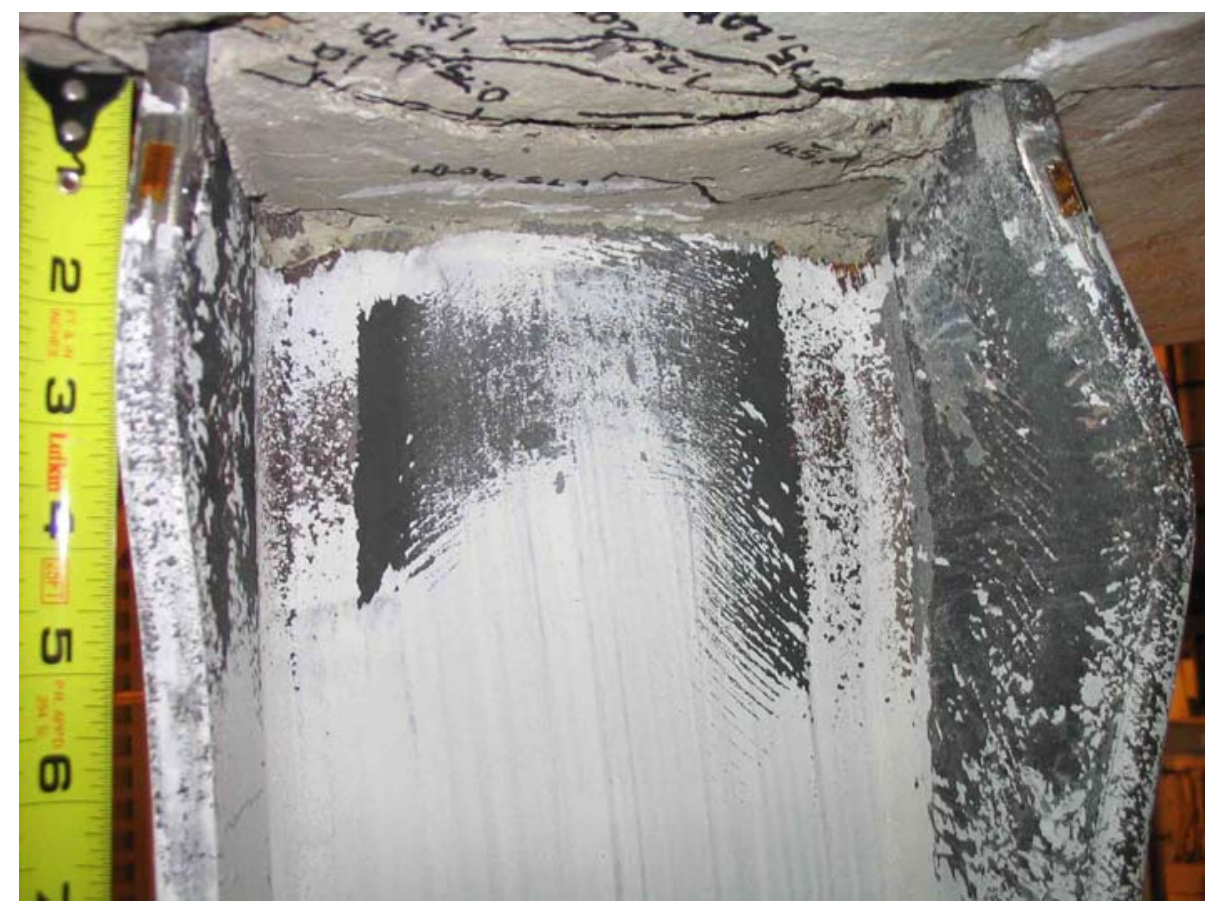

(b) Bottom

Figure I.34: Specimen 3 - Flange Buckling and Web Yielding (2.00 in., $100^{\text {th }}$ Cycle) 


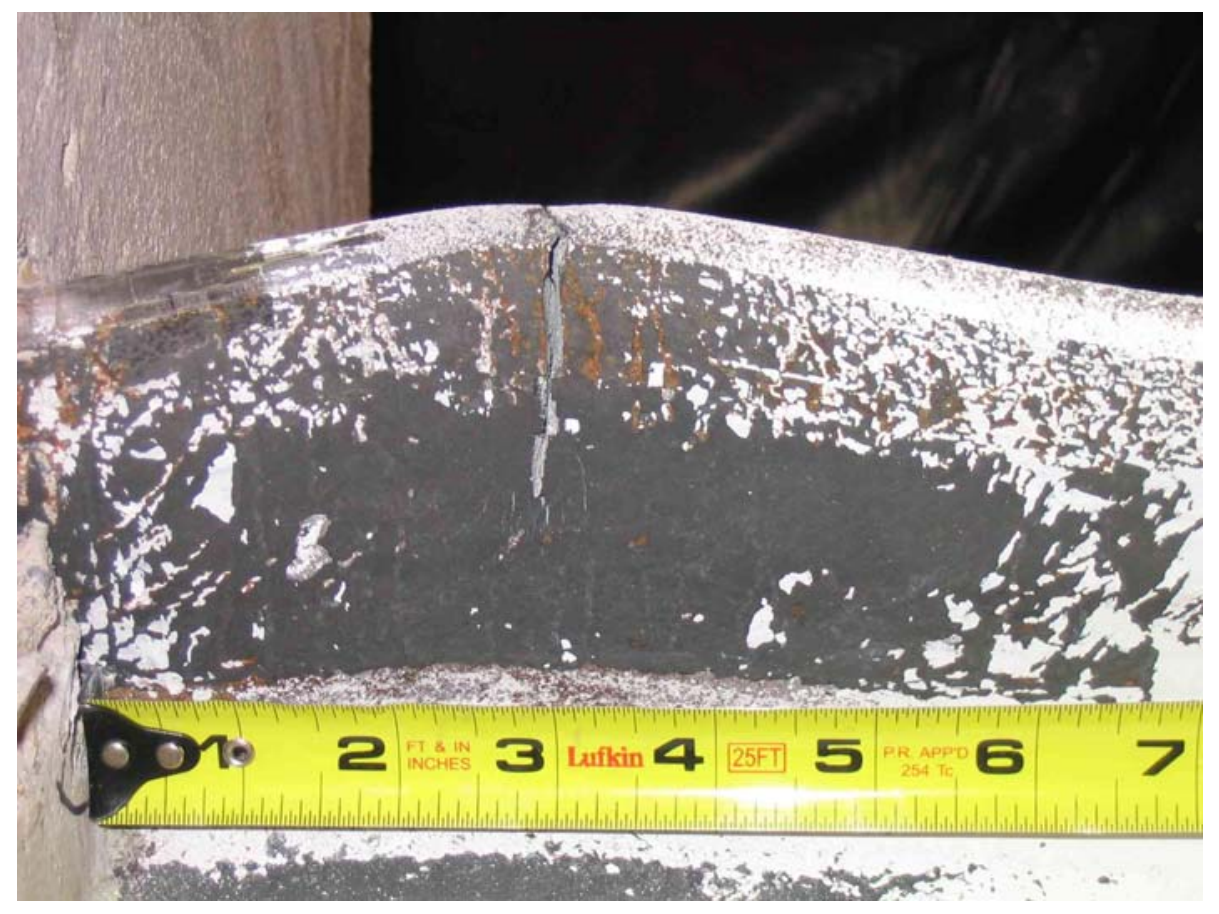

(a) North

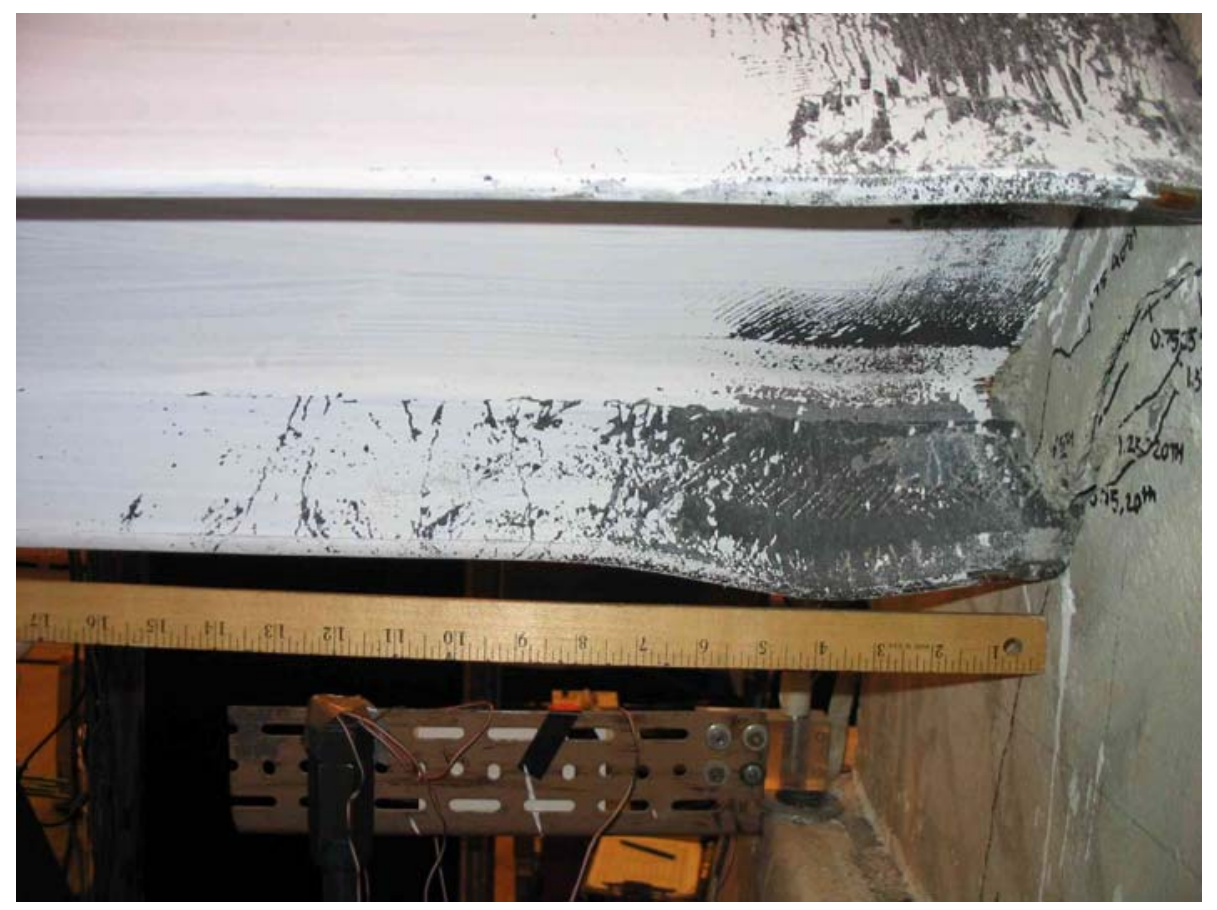

(b) South

Figure I.35: Specimen 3 - Flange Buckling along with Crack on Pile (2.00 in., $100^{\text {th }}$ Cycle) 


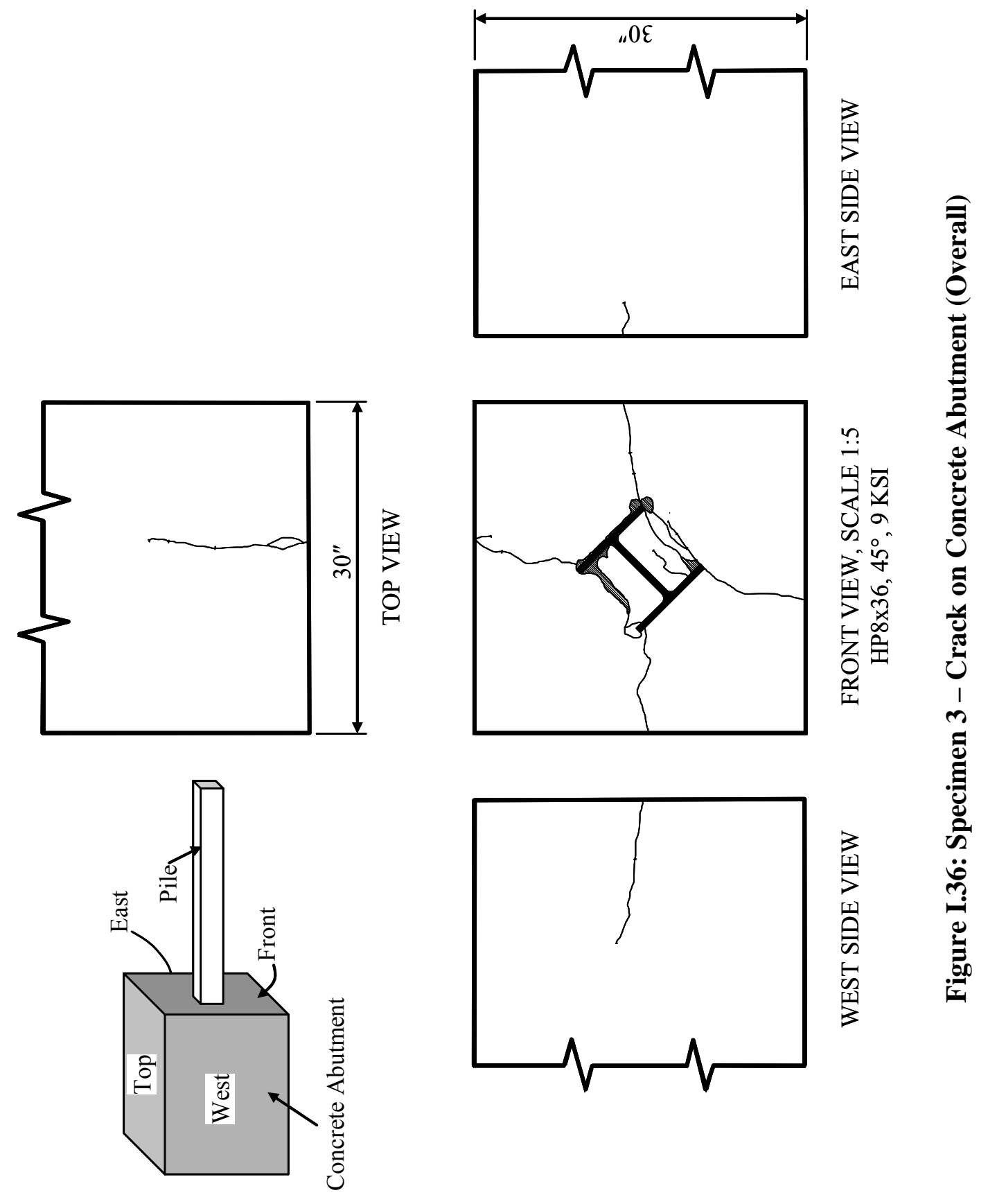




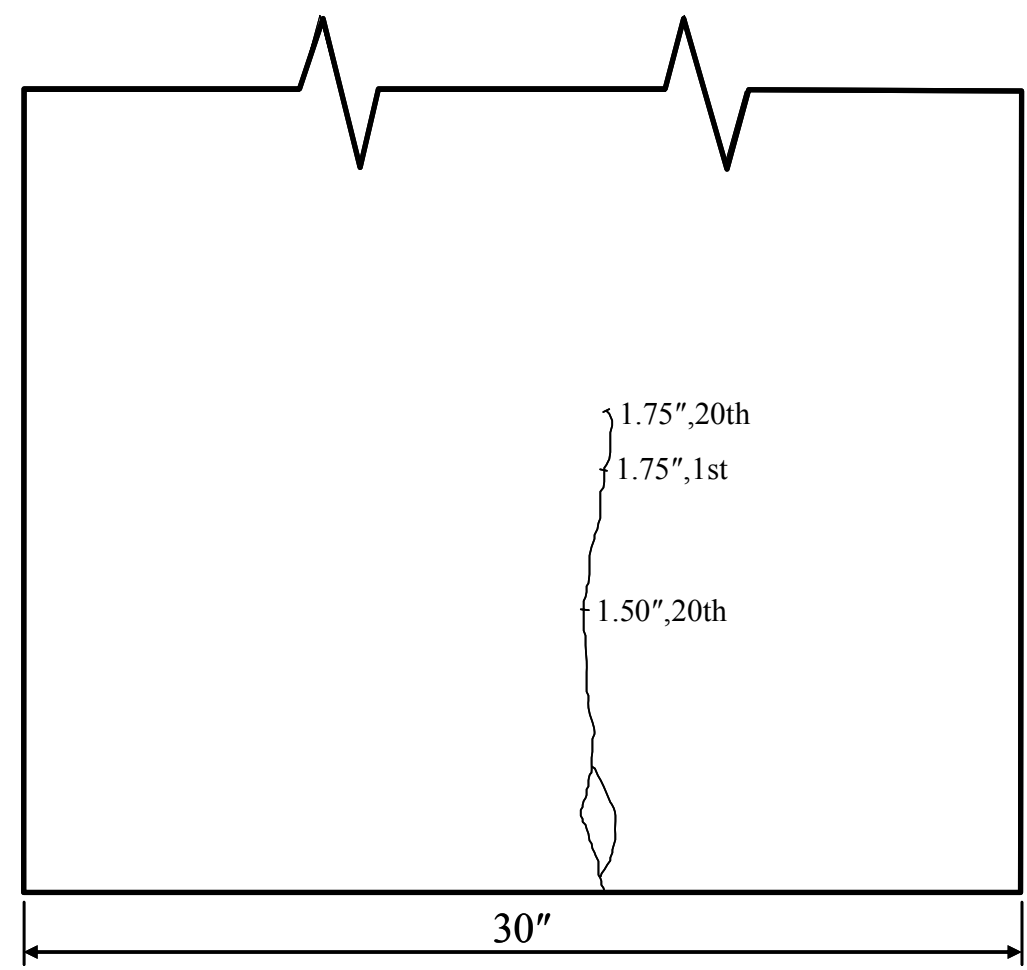

Figure I.37: Specimen 3 - Crack on Concrete Abutment (Top View)

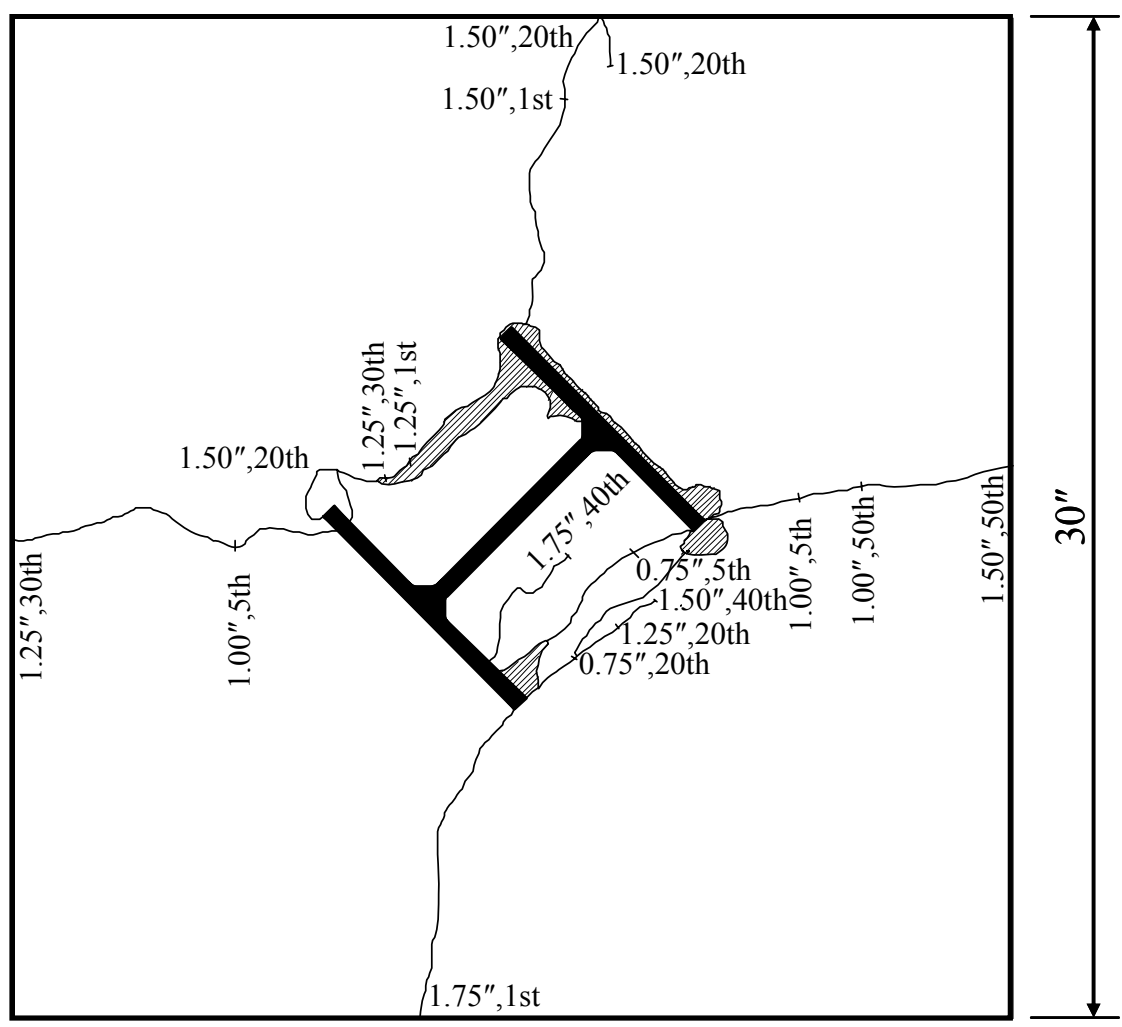

Figure I.38: Specimen 3 - Crack on Concrete Abutment (Front View) 


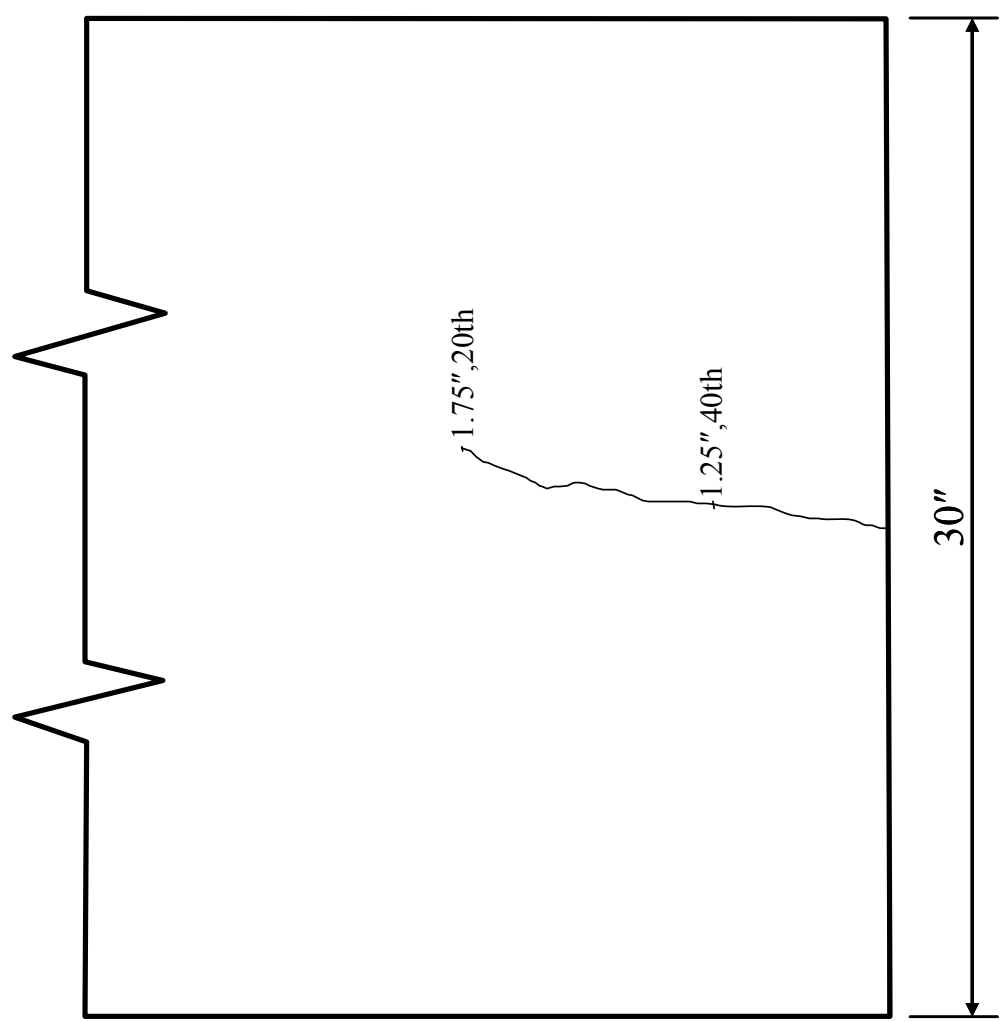

Figure I.39: Specimen 3 - Crack on Concrete Abutment (West View)

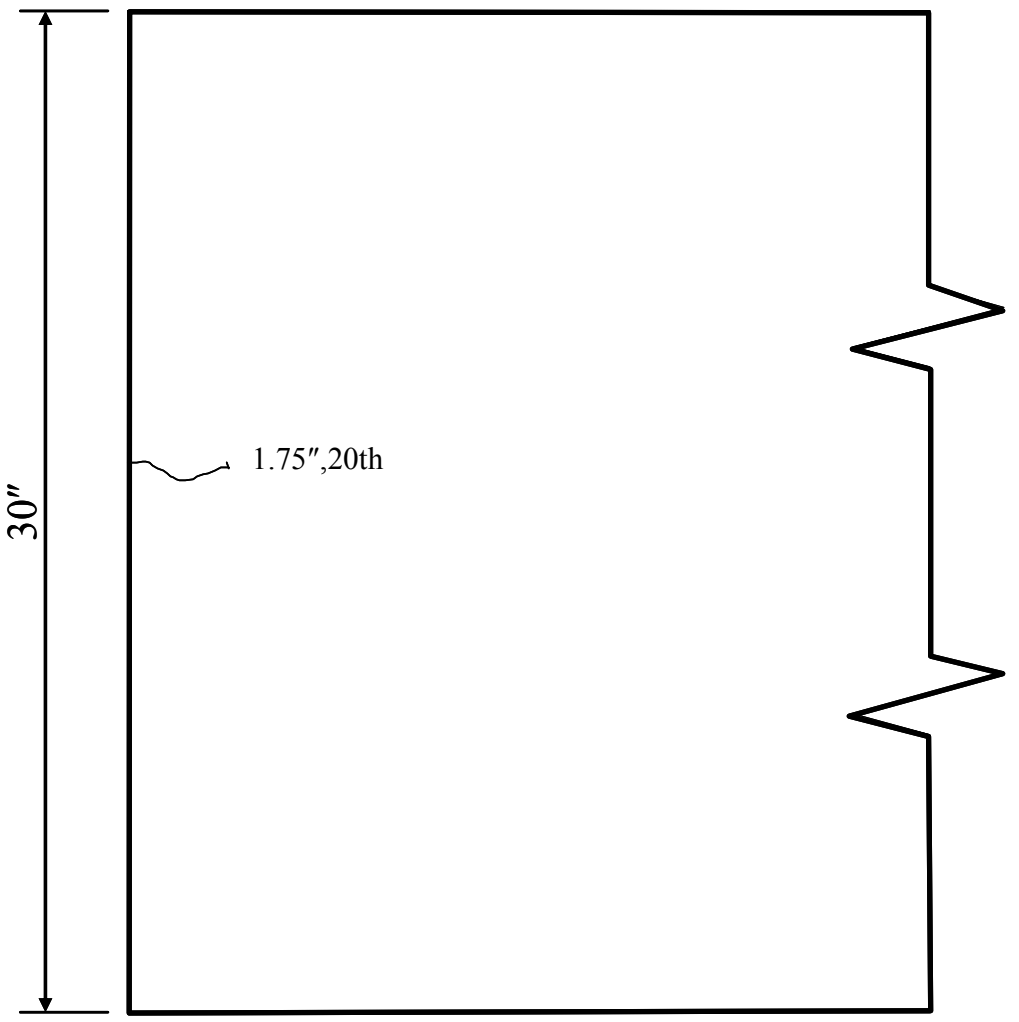

Figure I.40: Specimen 3 - Crack on Concrete Abutment (East View) 


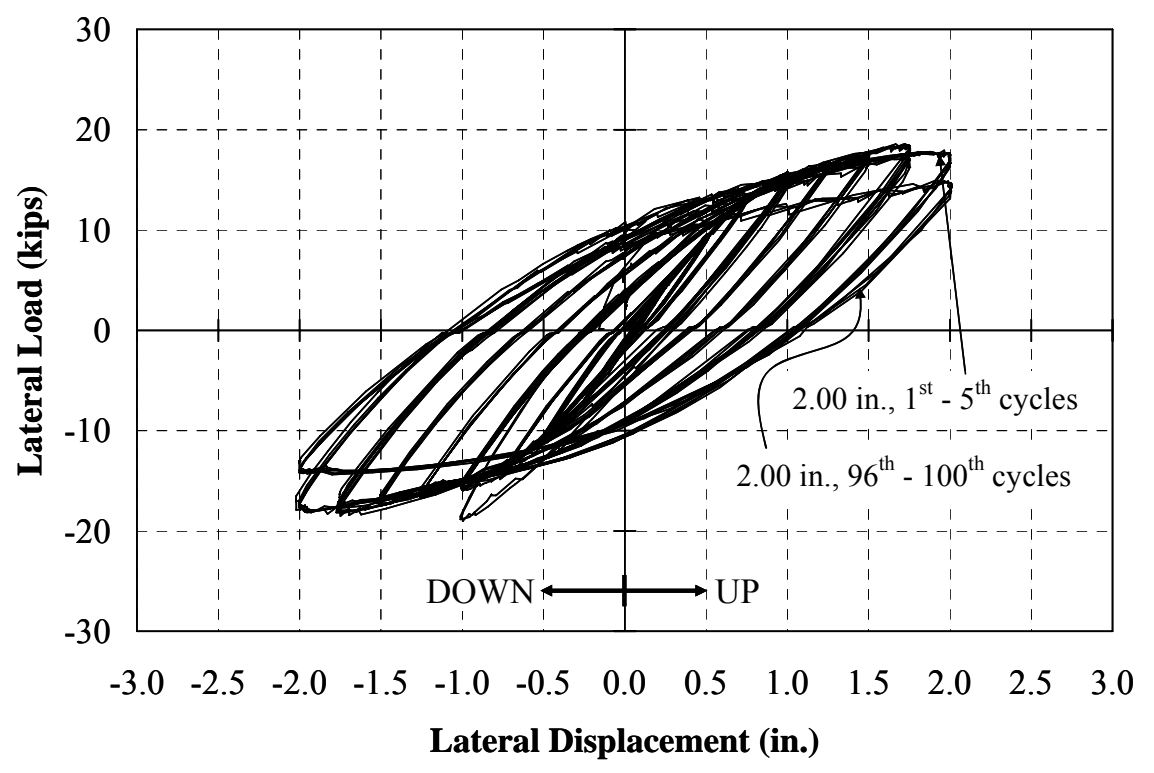

Figure I.41: Specimen 3 - Lateral Load-Deflection Curves

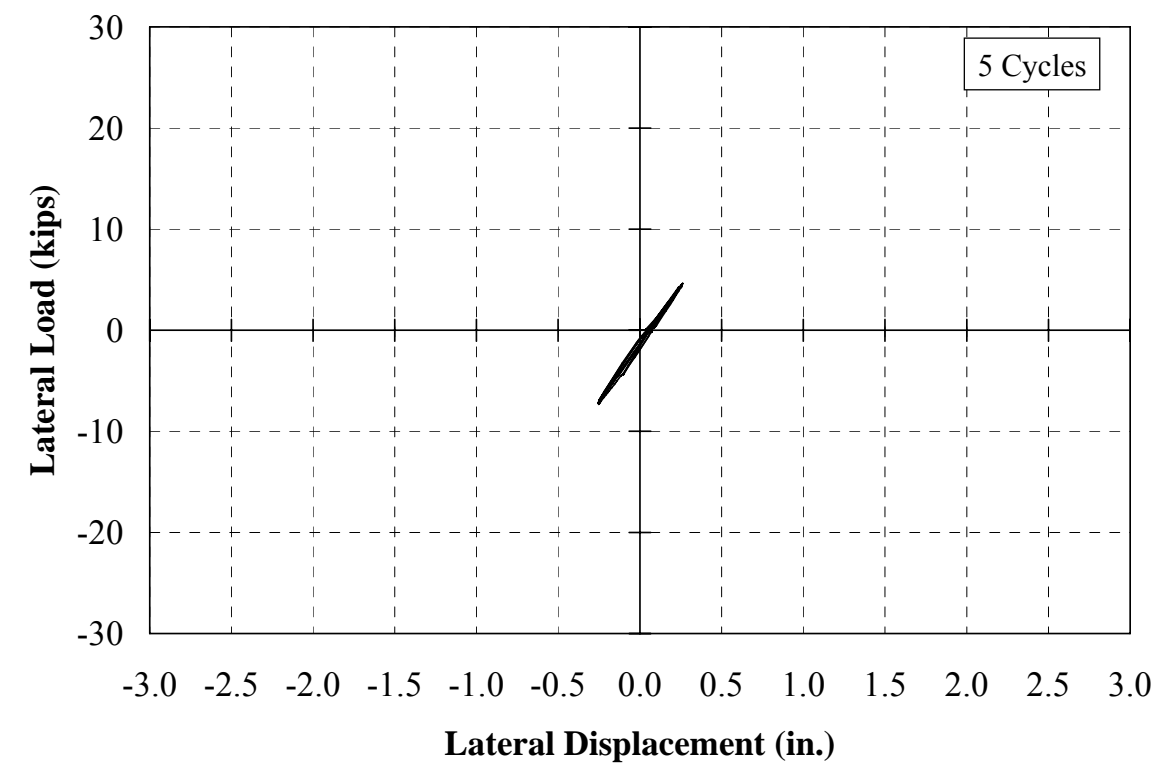

Figure I.42: Specimen 3 - Lateral Load-Deflection Response ( \pm 0.25 in.) 


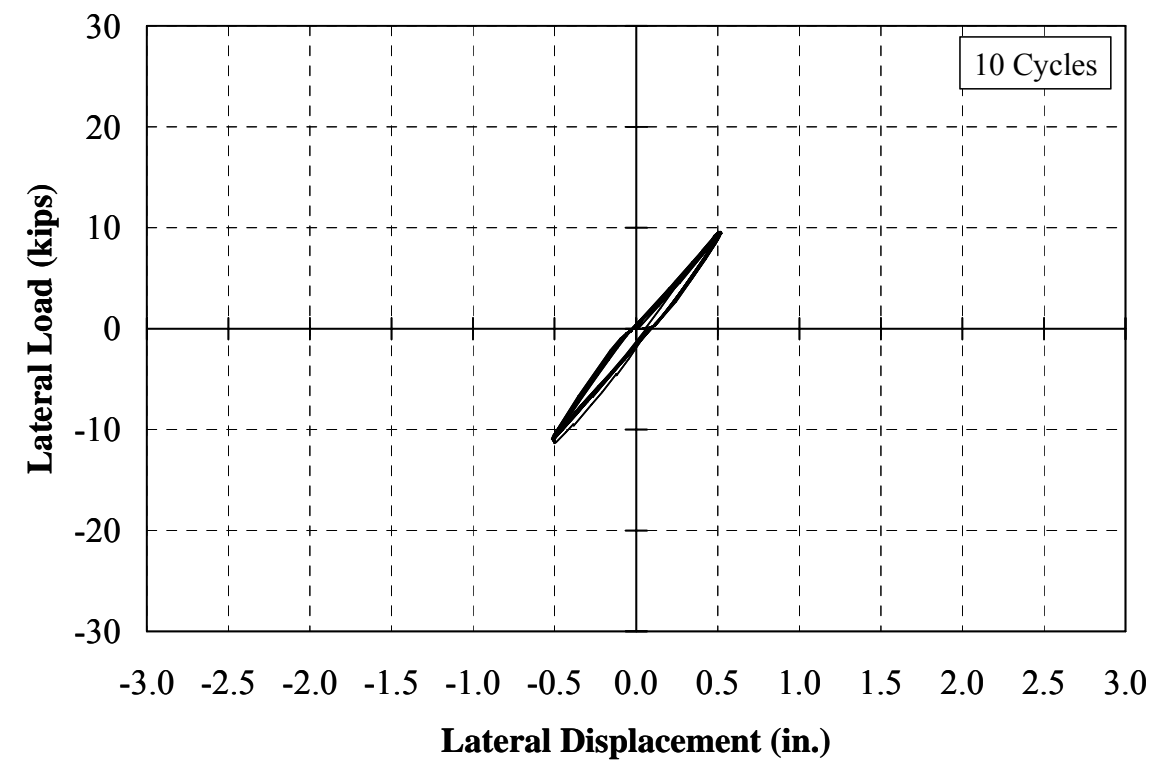

Figure I.43: Specimen 3 - Lateral Load-Deflection Response ( \pm 0.50 in.)

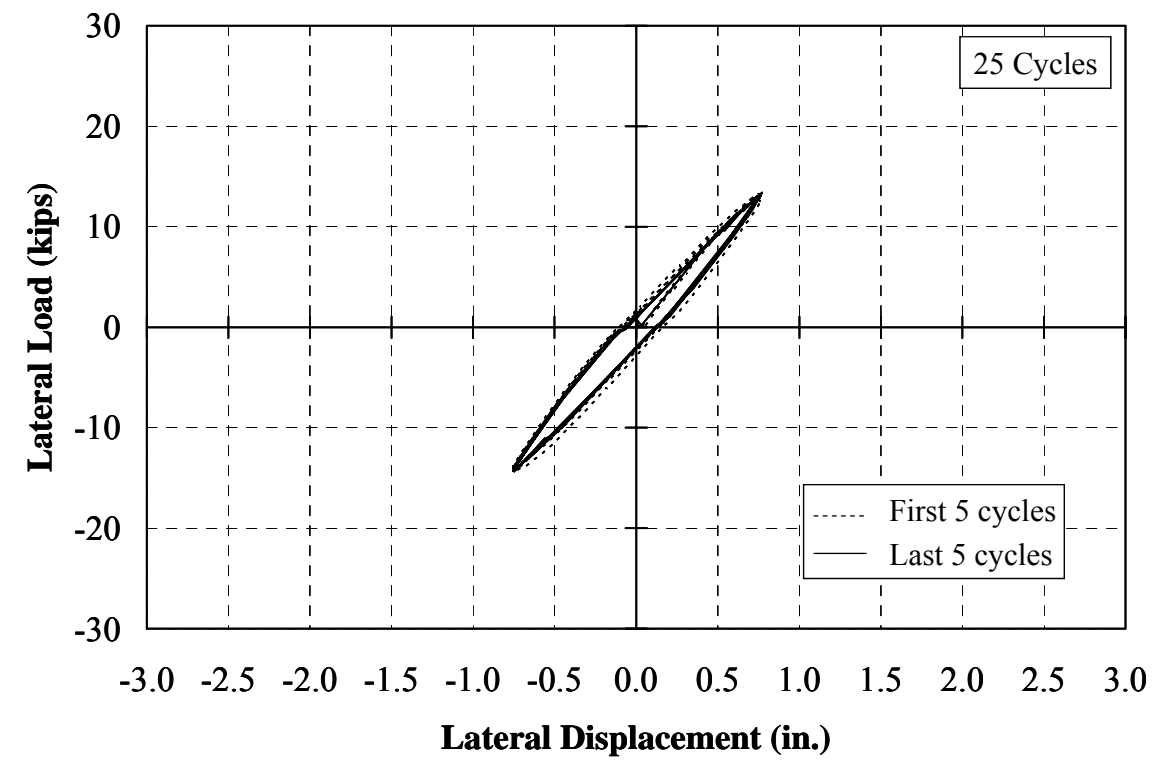

Figure I.44: Specimen 3 - Lateral Load-Deflection Response ( \pm 0.75 in.) 


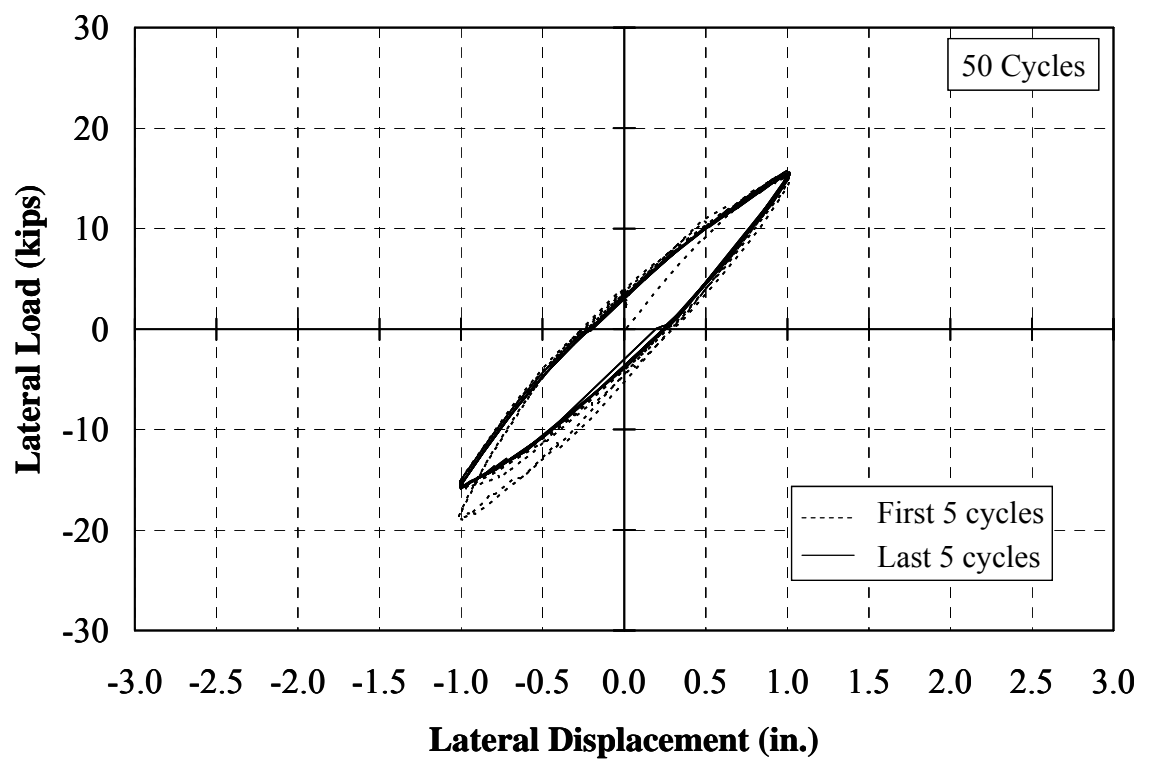

Figure I.45: Specimen 3 - Lateral Load-Deflection Response ( \pm 1.00 in.)

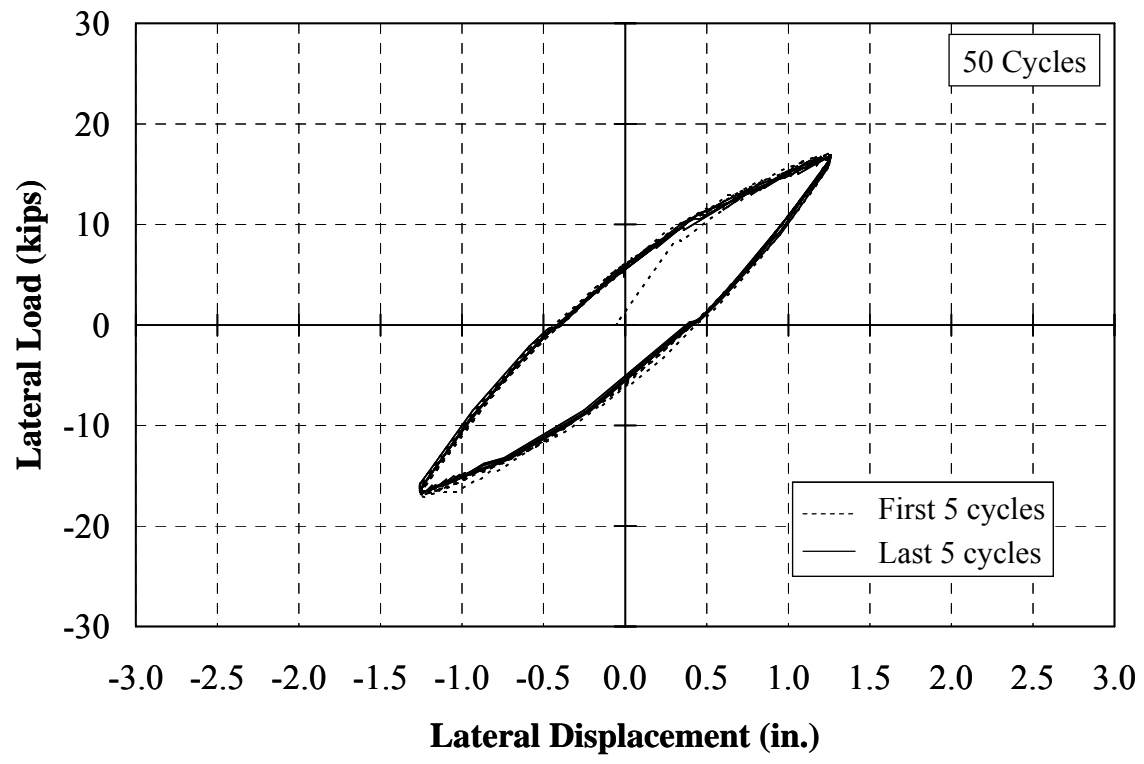

Figure I.46: Specimen 3 - Lateral Load-Deflection Response ( \pm 1.25 in.) 


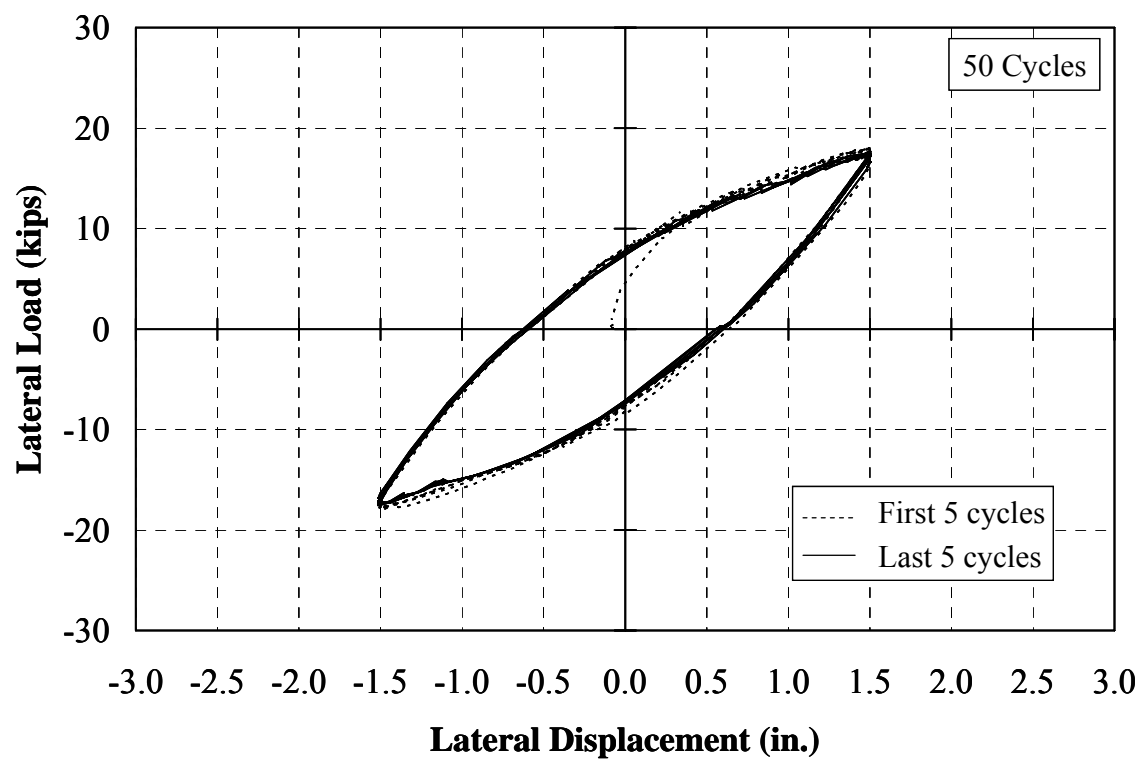

Figure I.47: Specimen 3 - Lateral Load-Deflection Response ( \pm 1.50 in.)

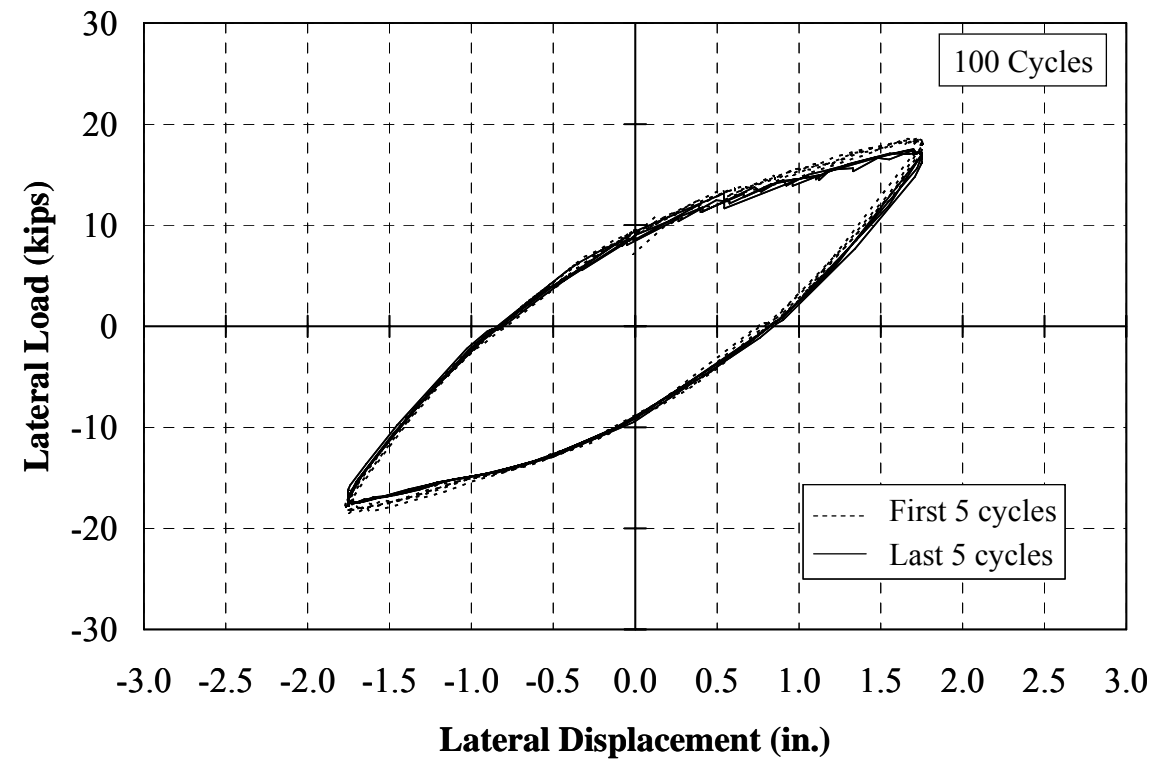

Figure I.48: Specimen 3 - Lateral Load-Deflection Response ( \pm 1.75 in.) 


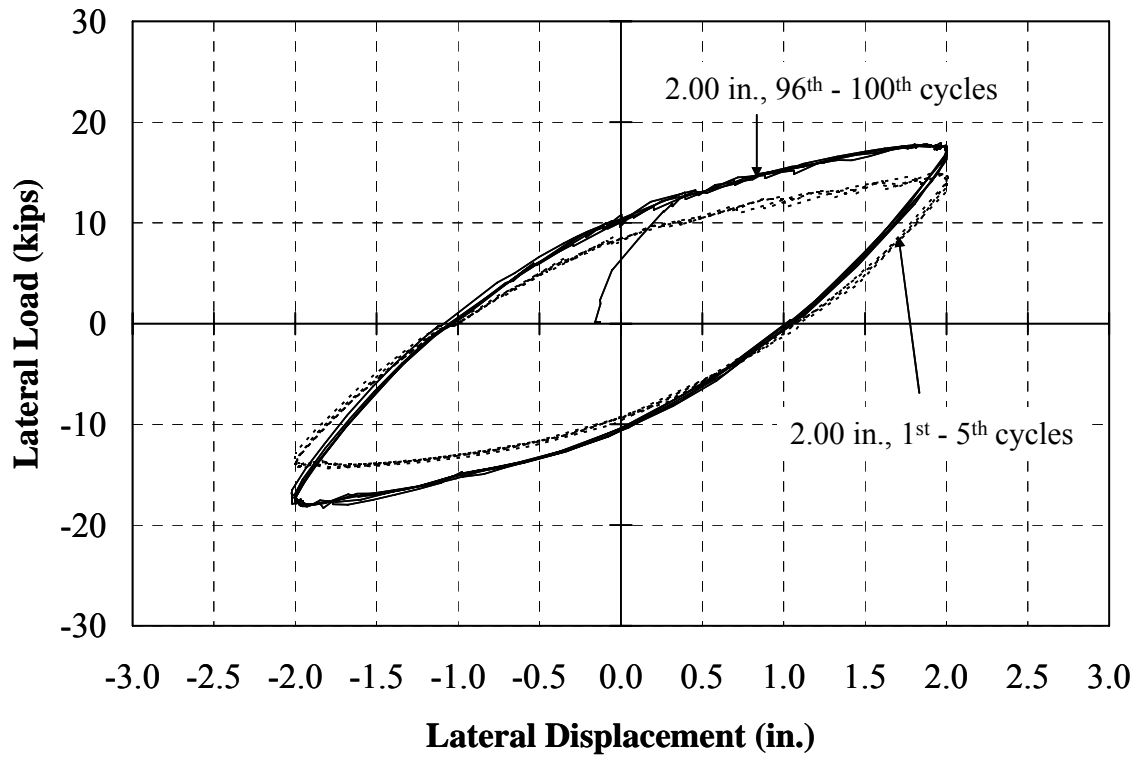

Figure I.49: Specimen 3 - Lateral Load-Deflection Response ( \pm 2.00 in.) 
Specimen 4 (HP8x36, Weak, 18 ksi)

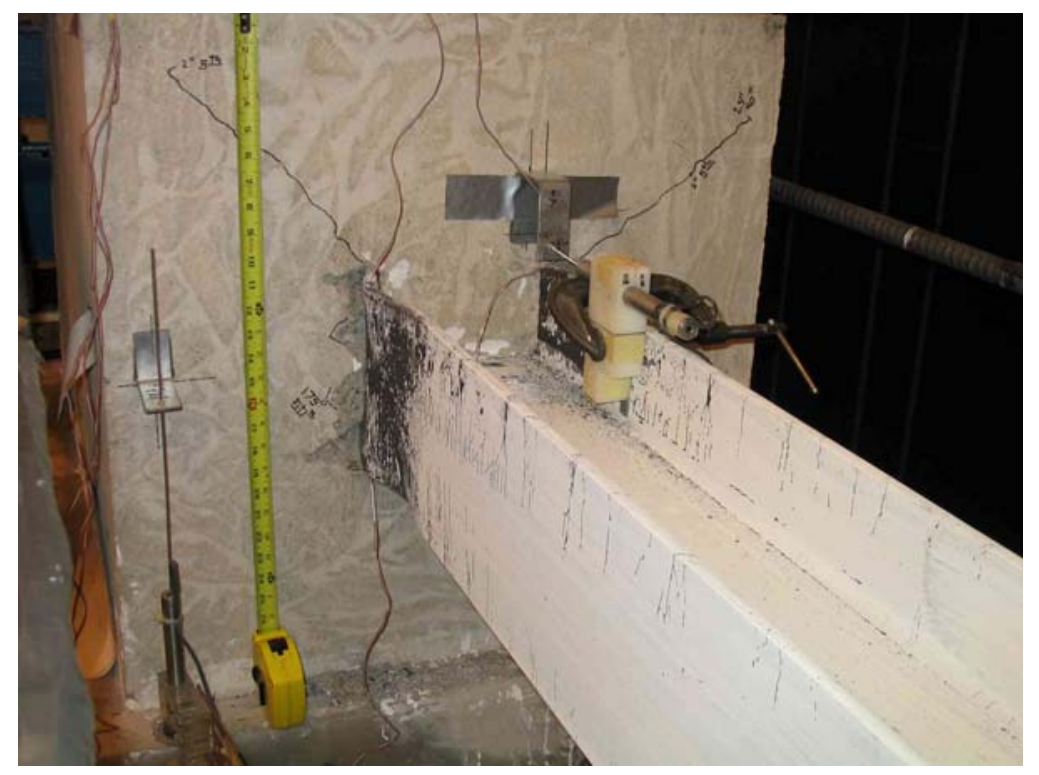

(a) West Side

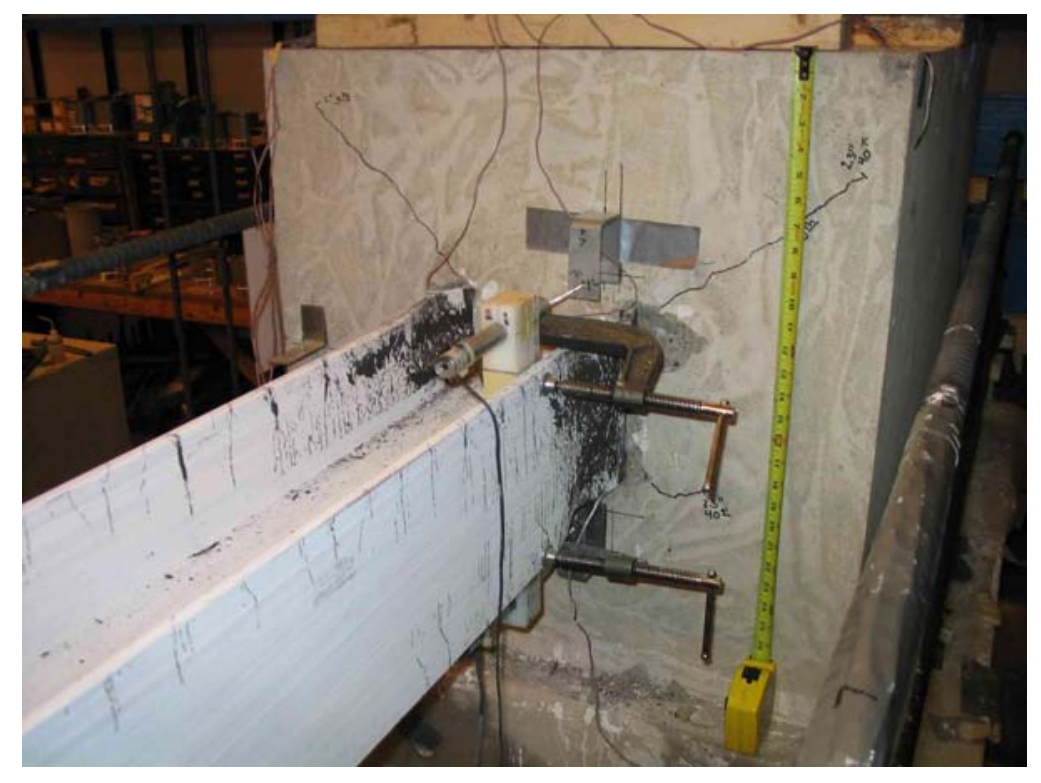

(b) East Side

Figure I.50: Specimen 4 - Cracking ( 2.50 in., $66^{\text {th }}$ Cycle) 


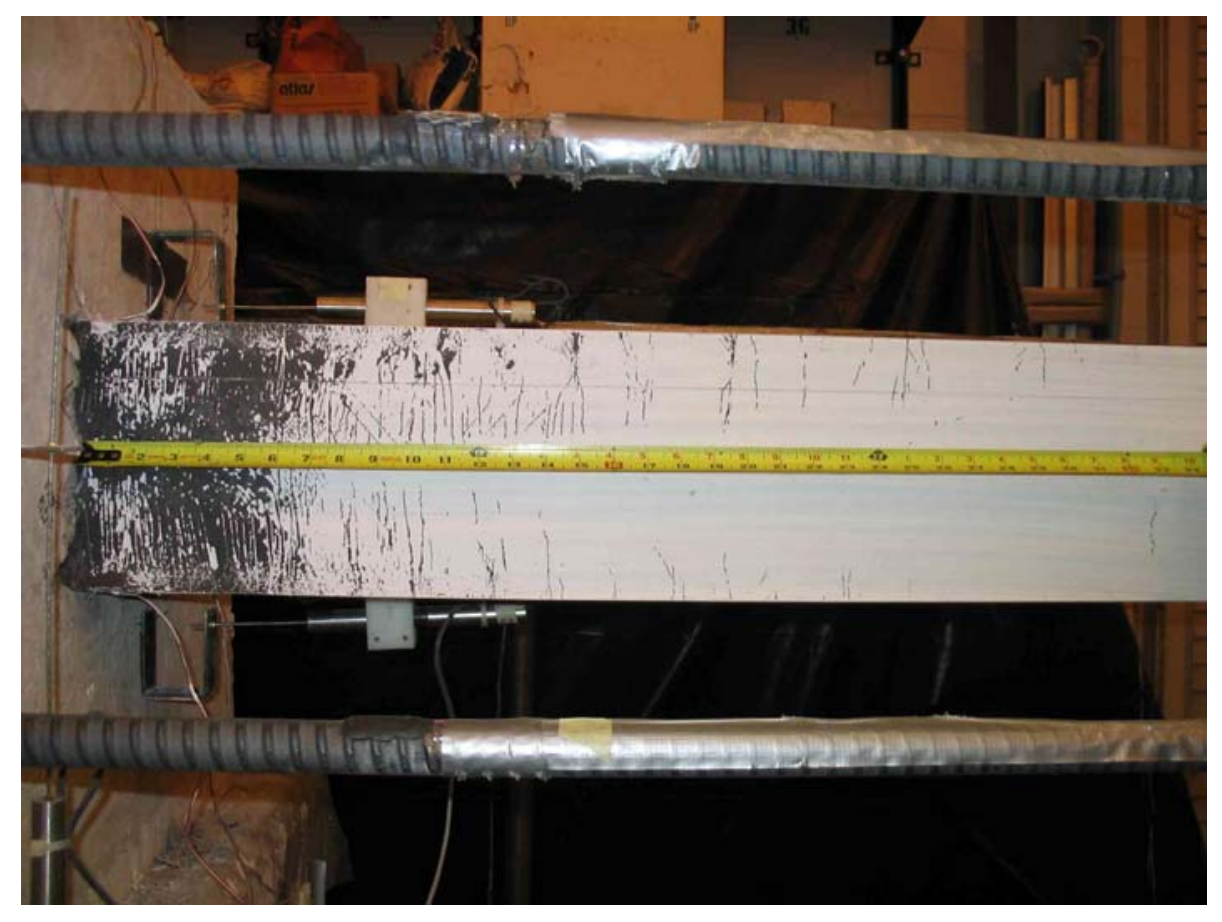

(a) West Side

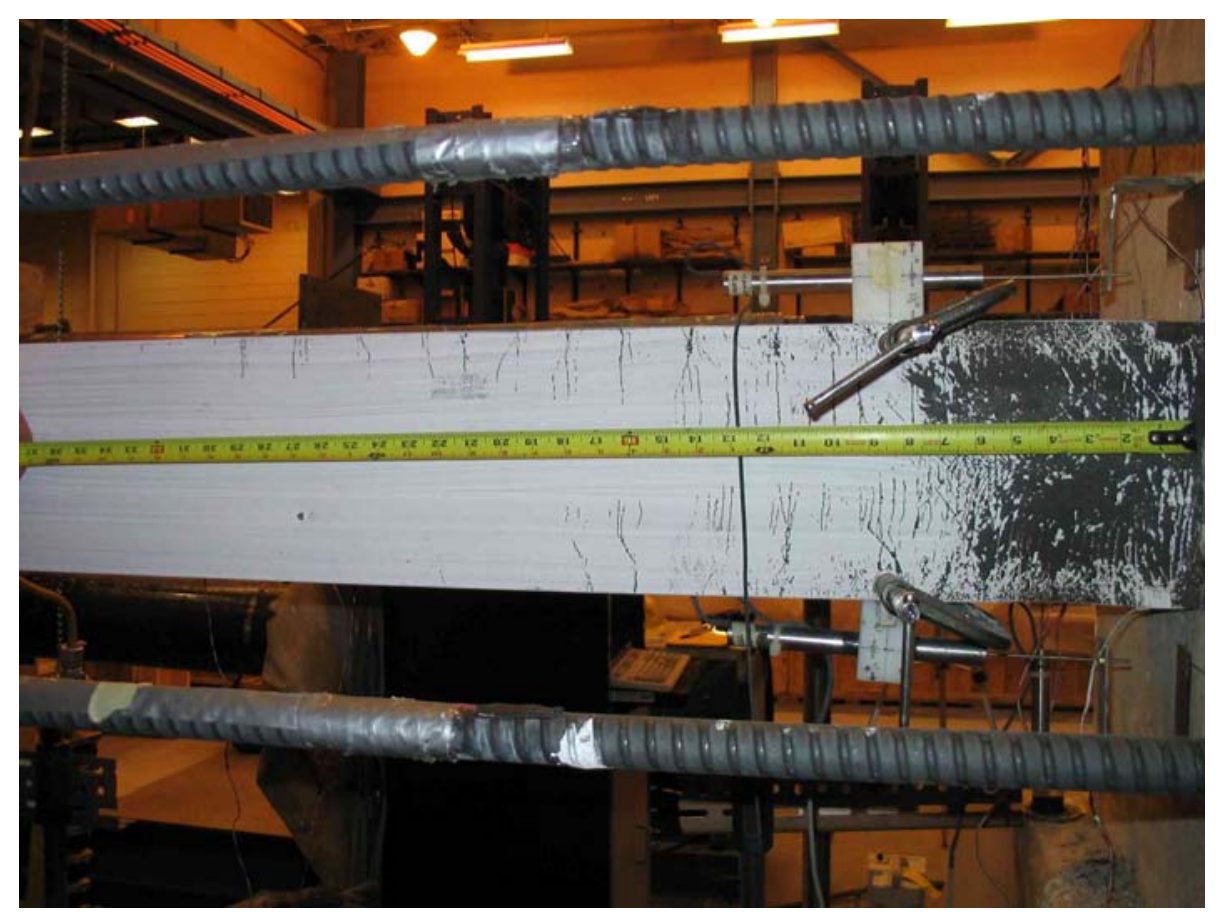

(b) East Side

Figure I.51: Specimen 4 - Yielding (2.50 in., $66^{\text {th }}$ Cycle) 


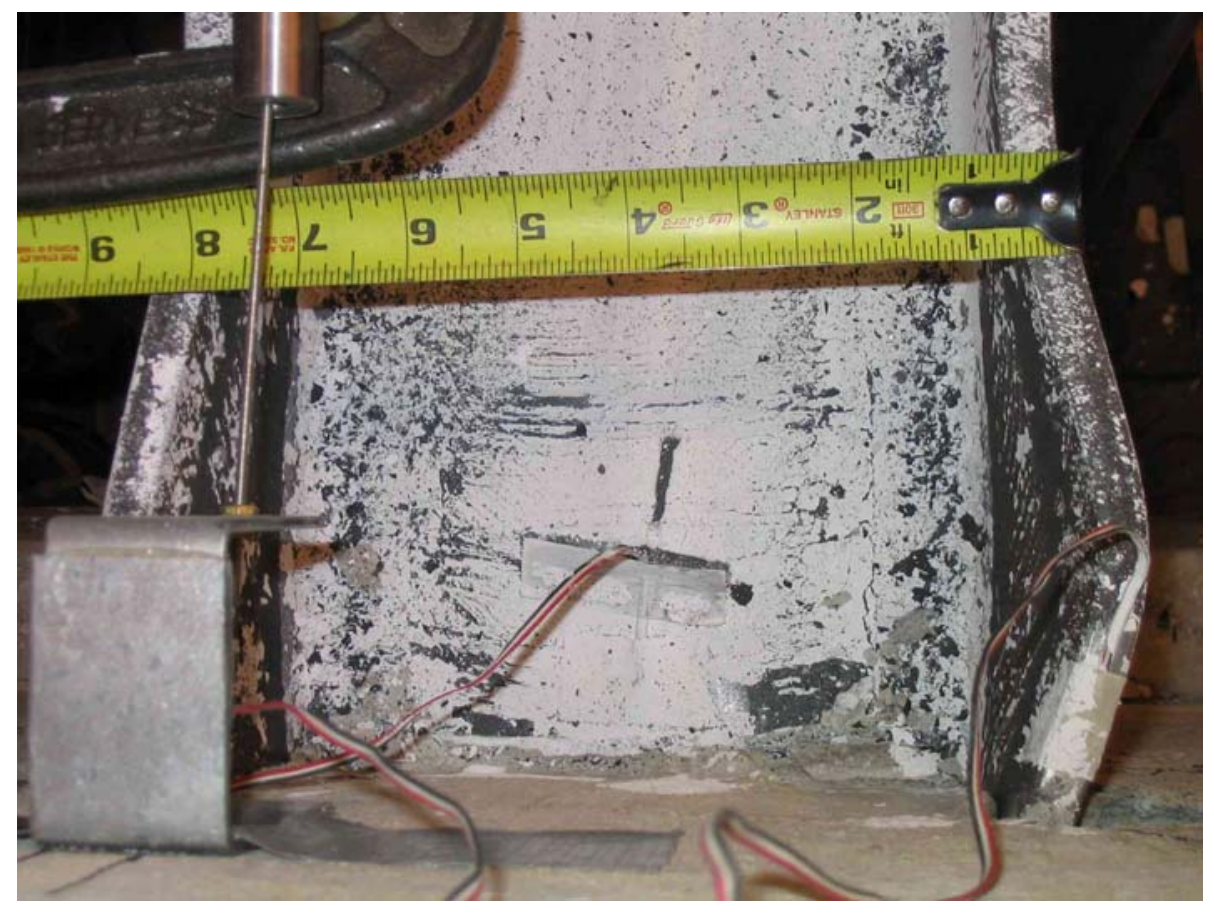

(a) Top

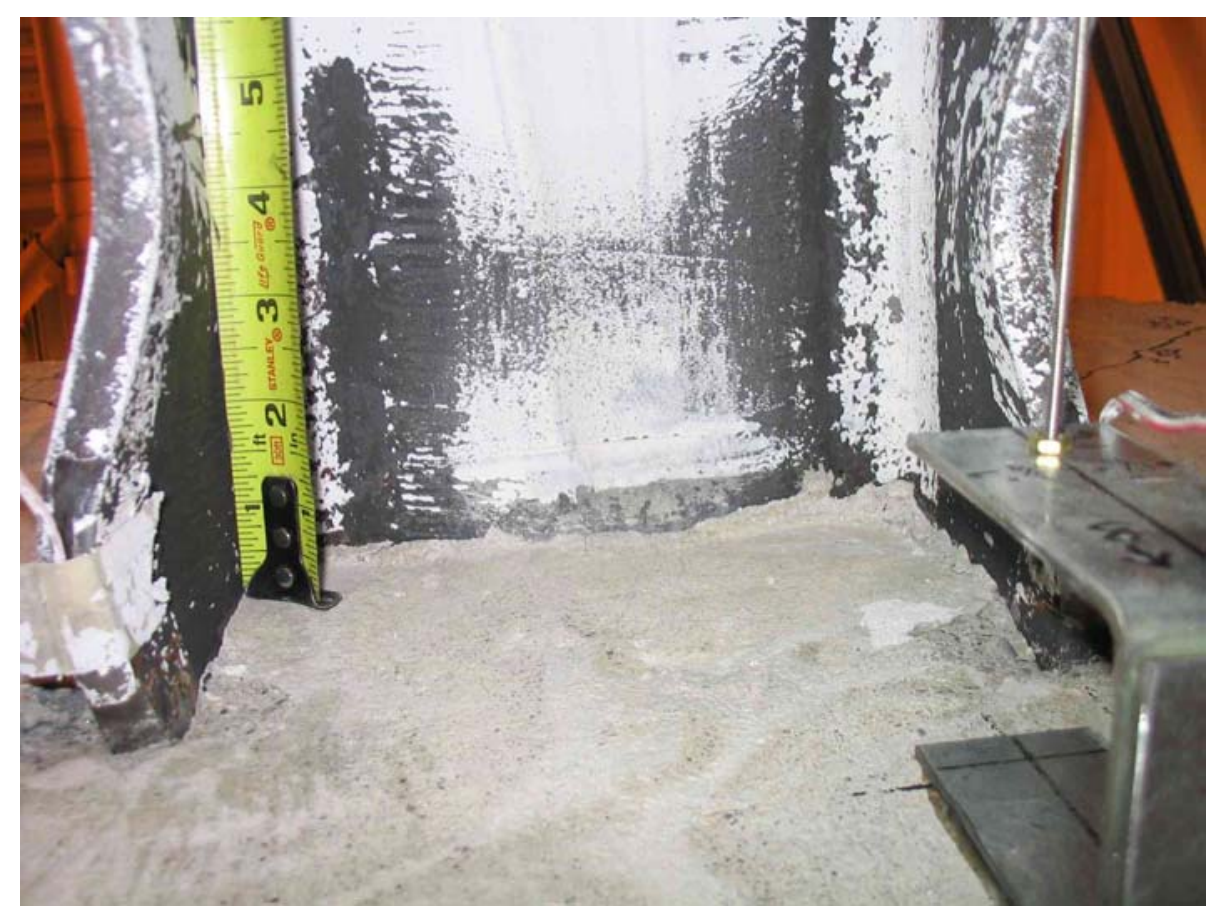

(b) Bottom

Figure I.52: Specimen 4 - Flange Buckling and Web Yielding (2.50 in., $66^{\text {th }}$ Cycle) 


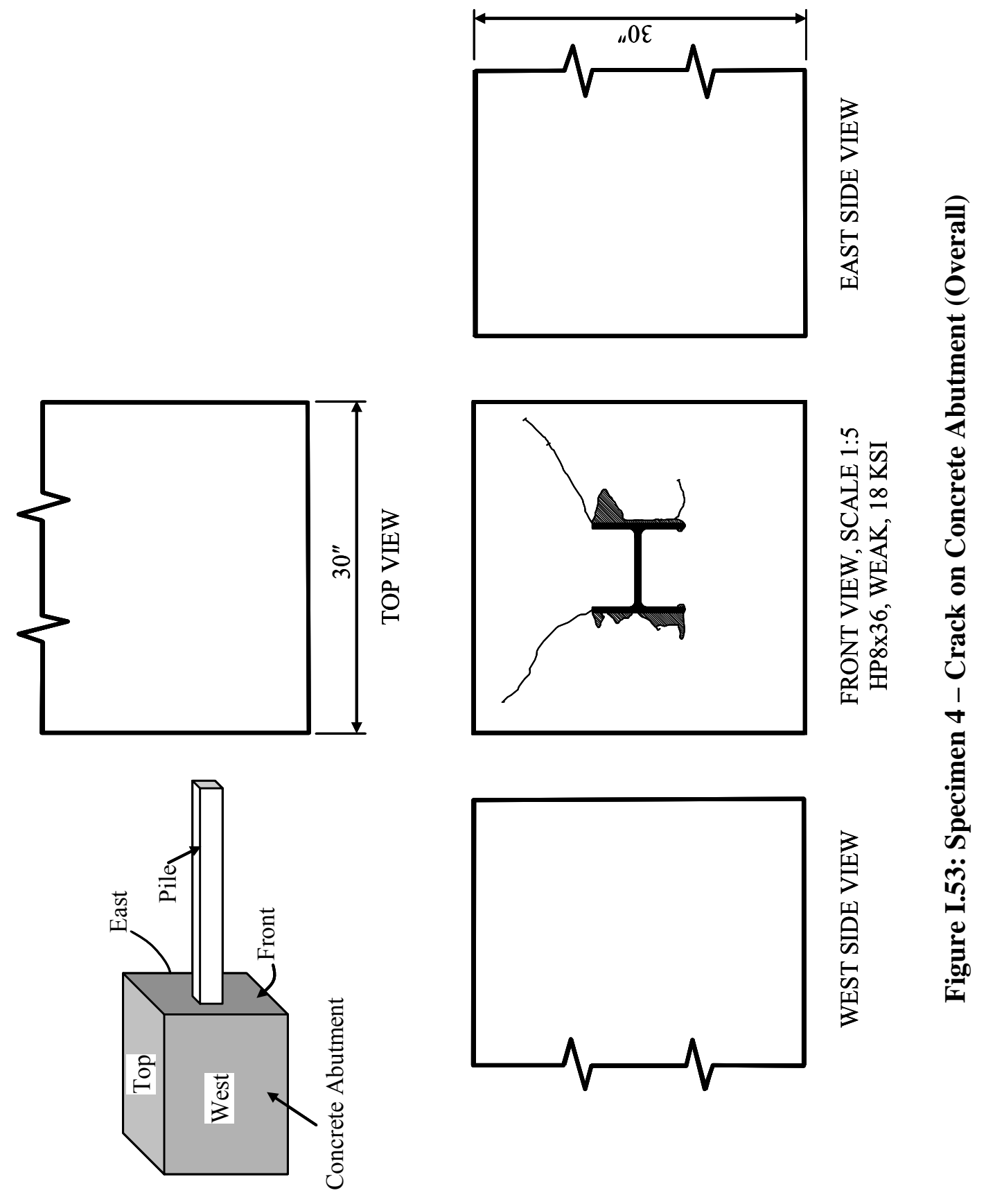




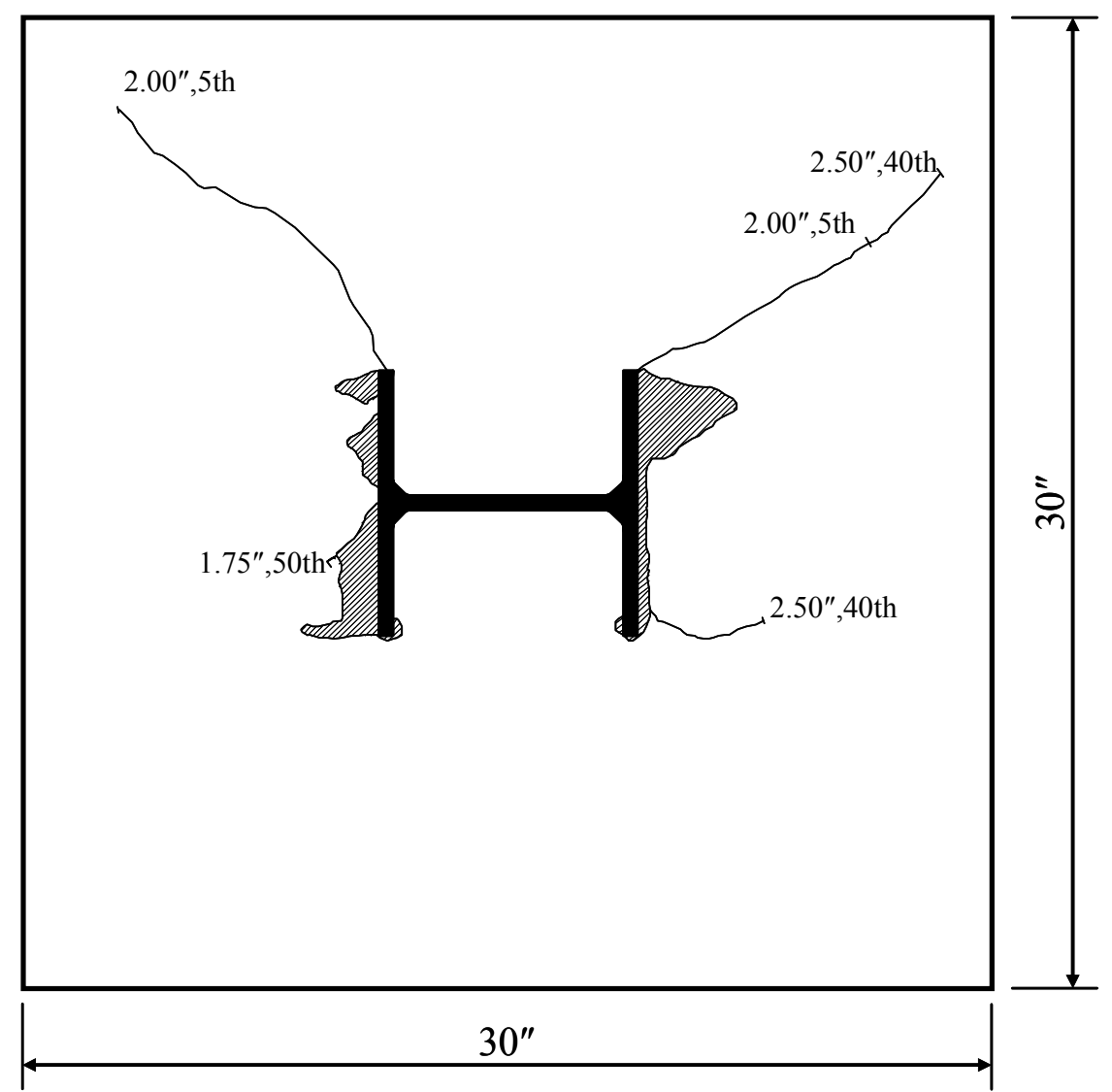

Figure I.54: Specimen 4 - Crack on Concrete Abutment (Front View)

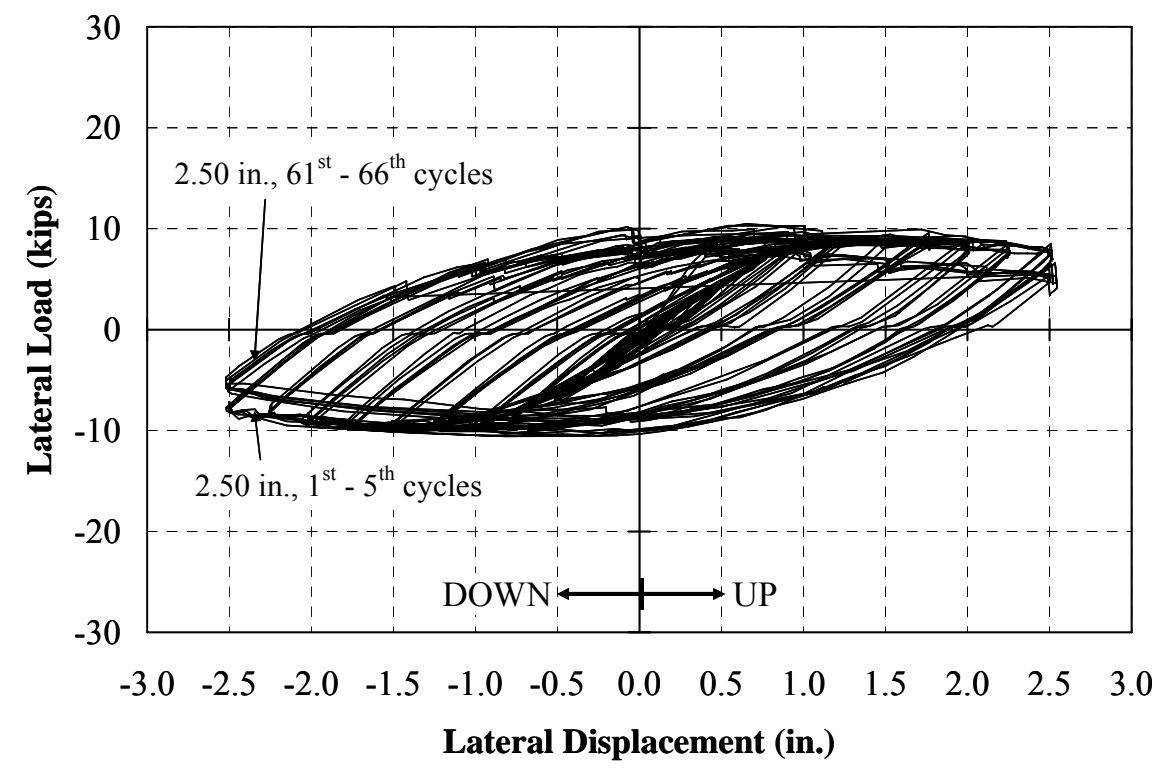

Figure I.55: Specimen 4 - Summary of Lateral Load-Deflection Curves 


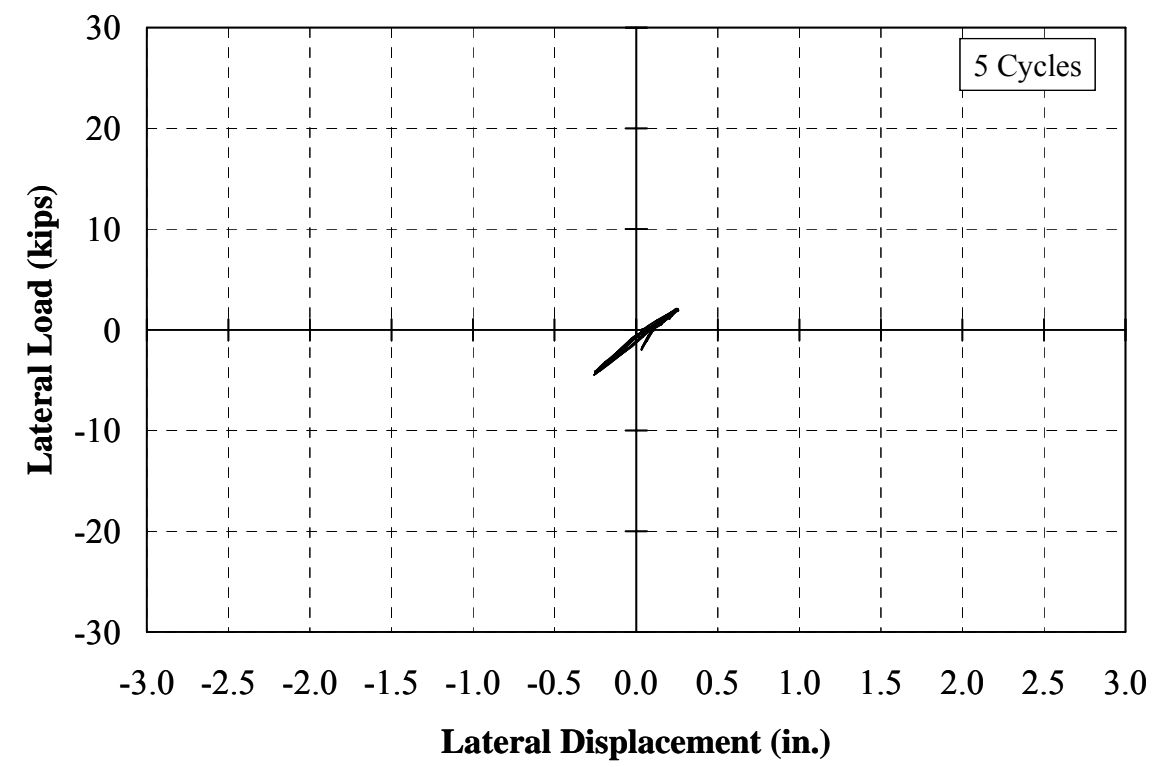

Figure I.56: Specimen 4 - Lateral Load-Deflection Response ( \pm 0.25 in.)

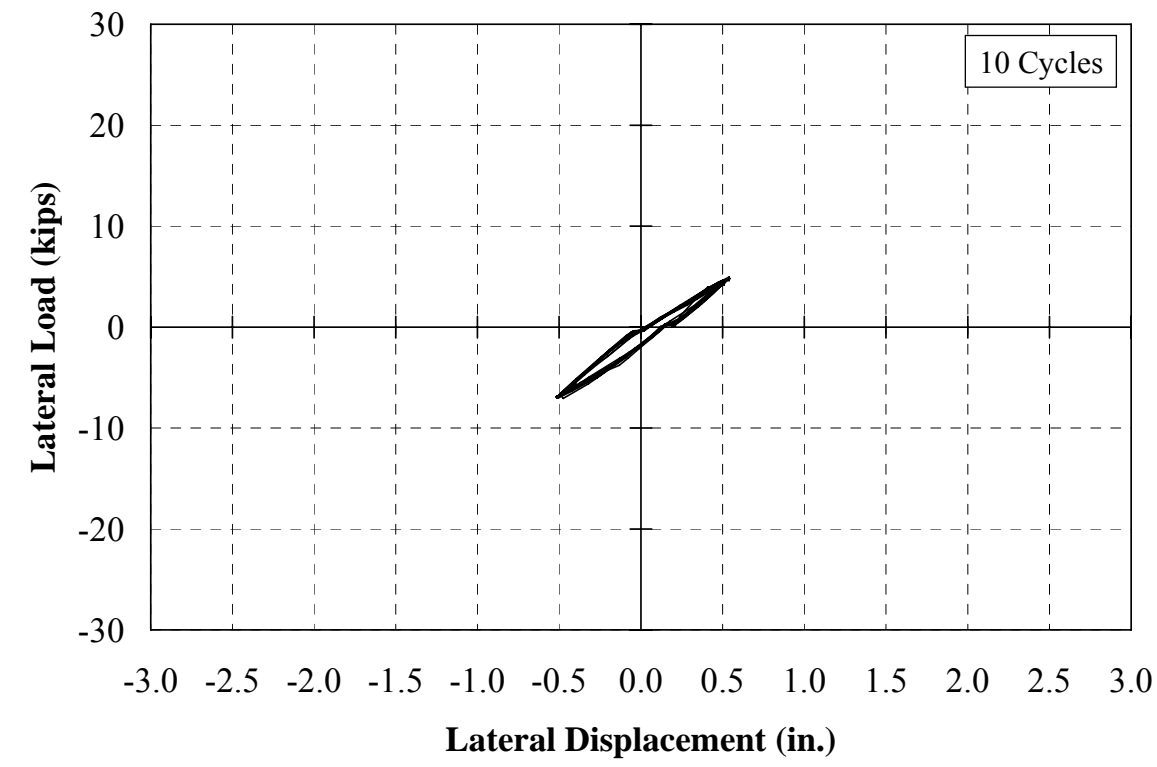

Figure I.57: Specimen 4 - Lateral Load-Deflection Response ( \pm 0.50 in.) 


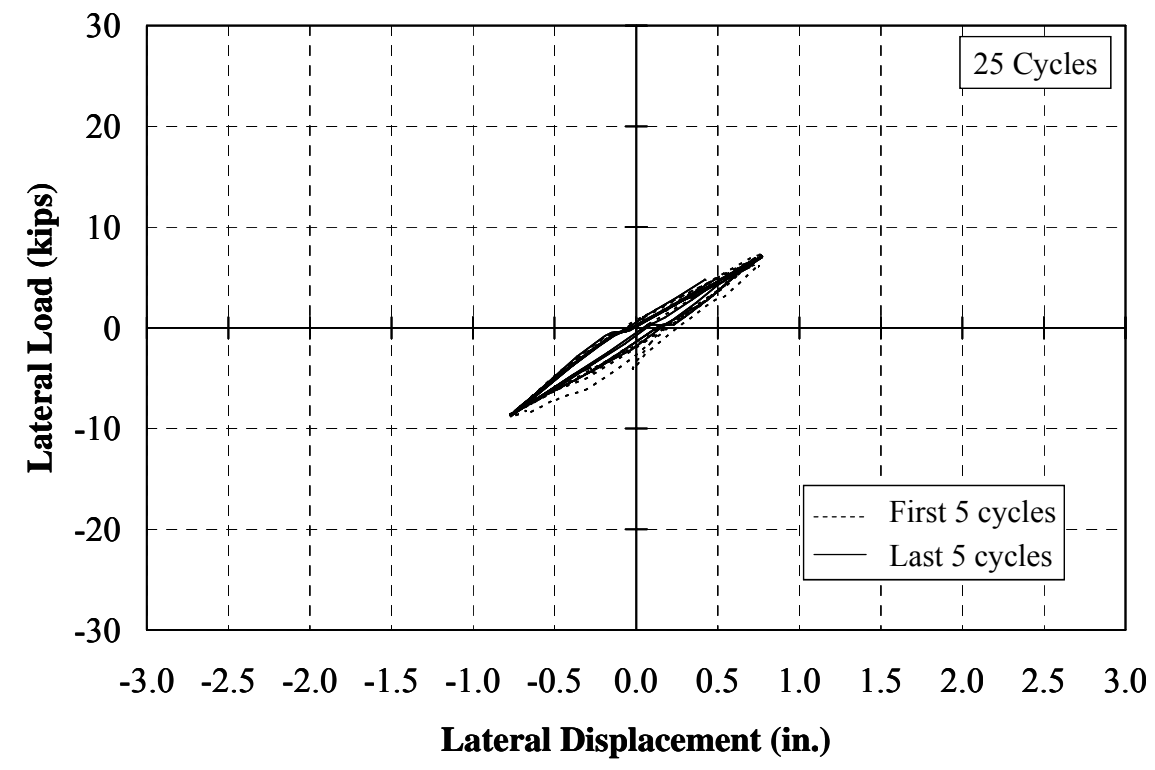

Figure I.58: Specimen 4 - Lateral Load-Deflection Response ( \pm 0.75 in.)

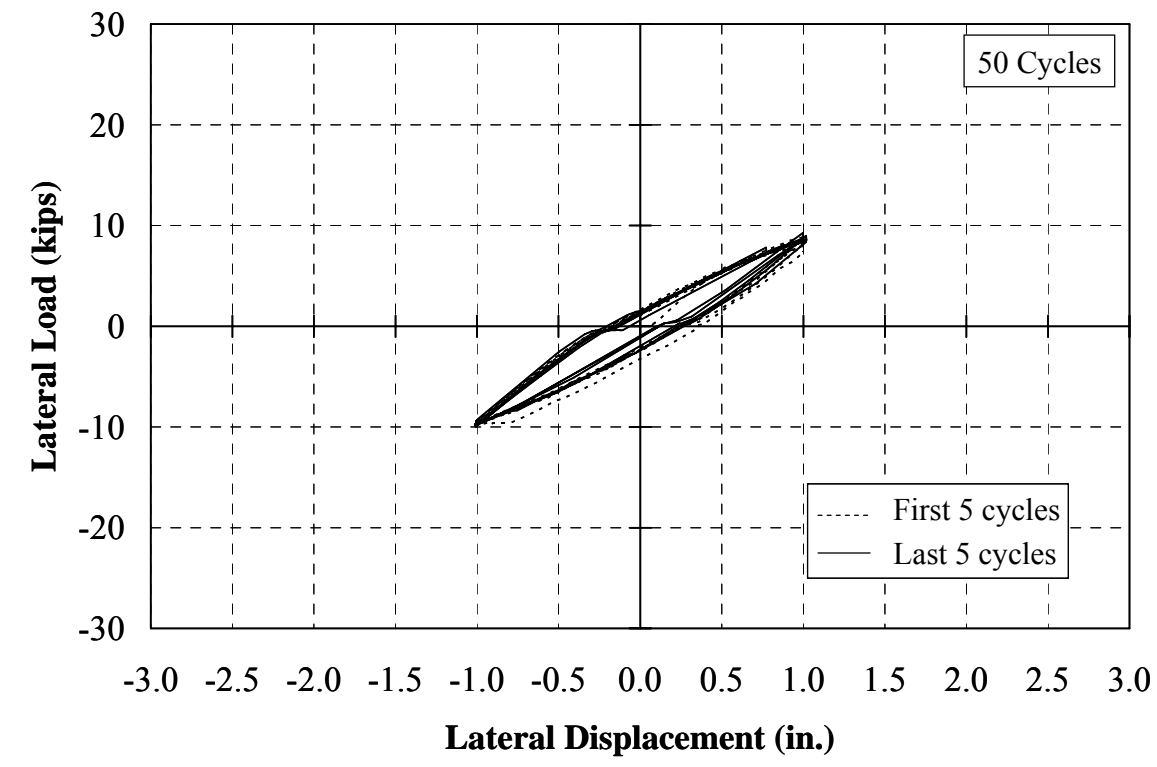

Figure I.59: Specimen 4 - Lateral Load-Deflection Response ( \pm 1.00 in.) 


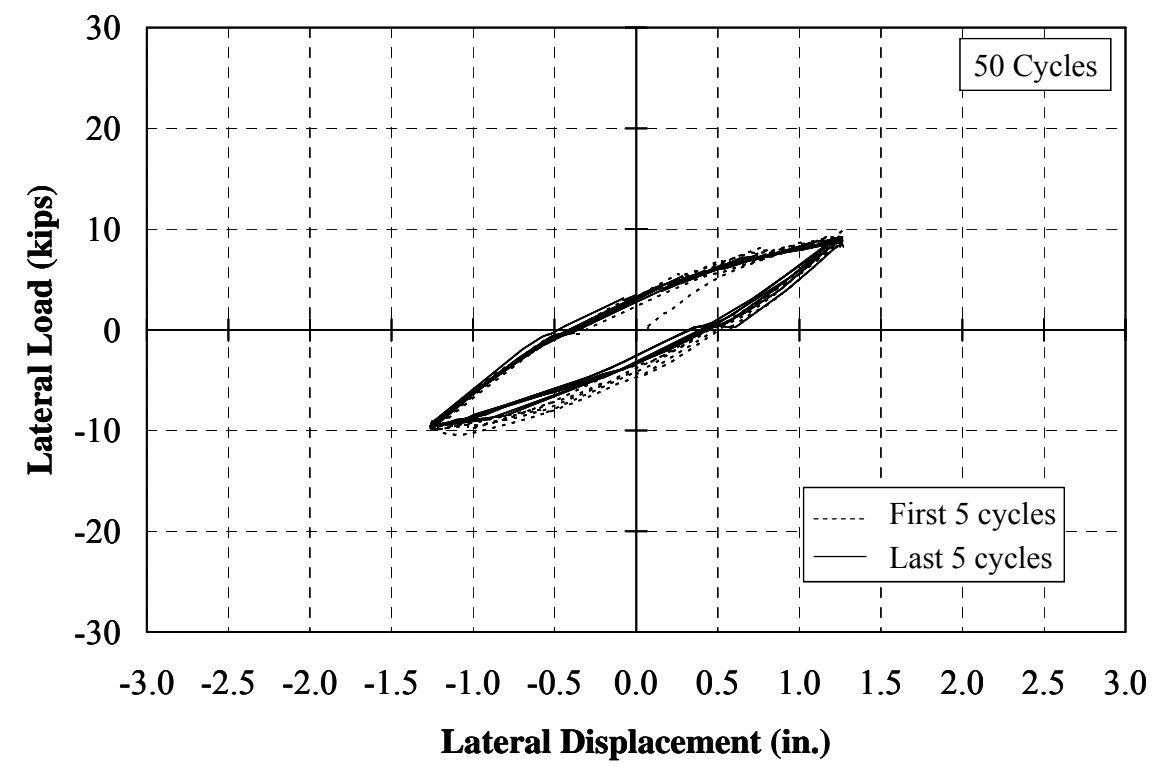

Figure I.60: Specimen 4 - Lateral Load-Deflection Response ( \pm 1.25 in.)

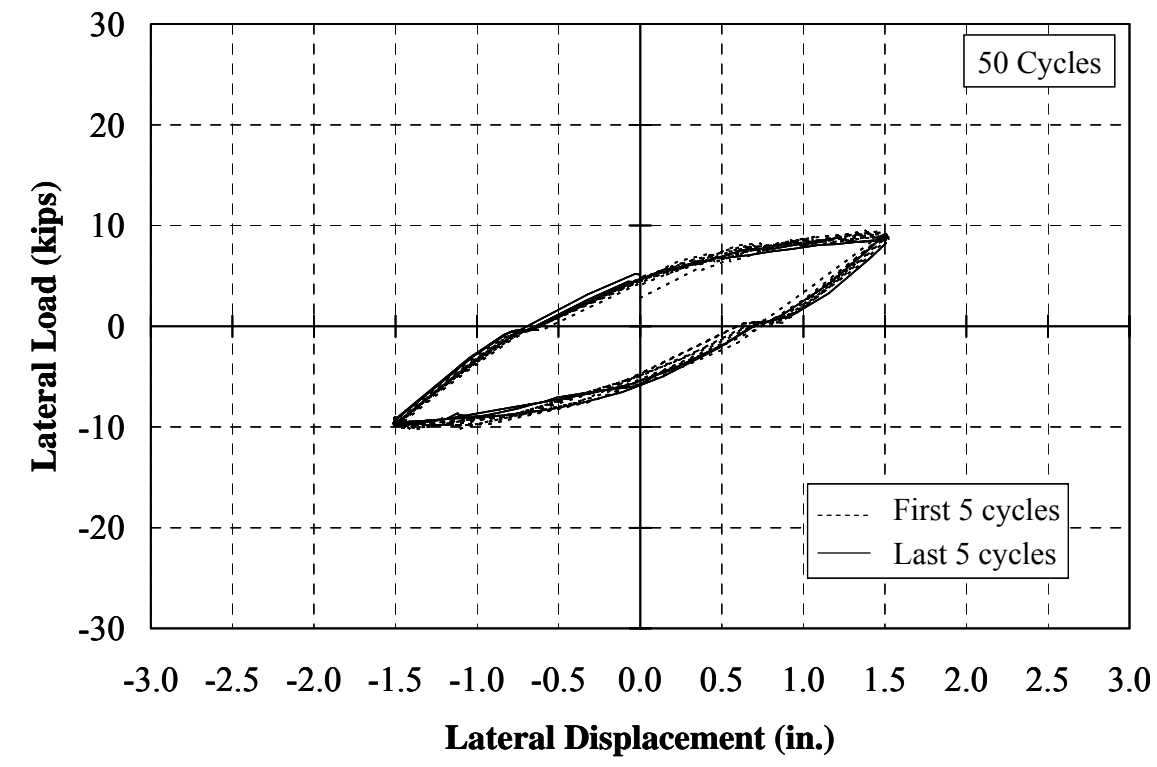

Figure I.61: Specimen 4 - Lateral Load-Deflection Response ( \pm 1.50 in.) 


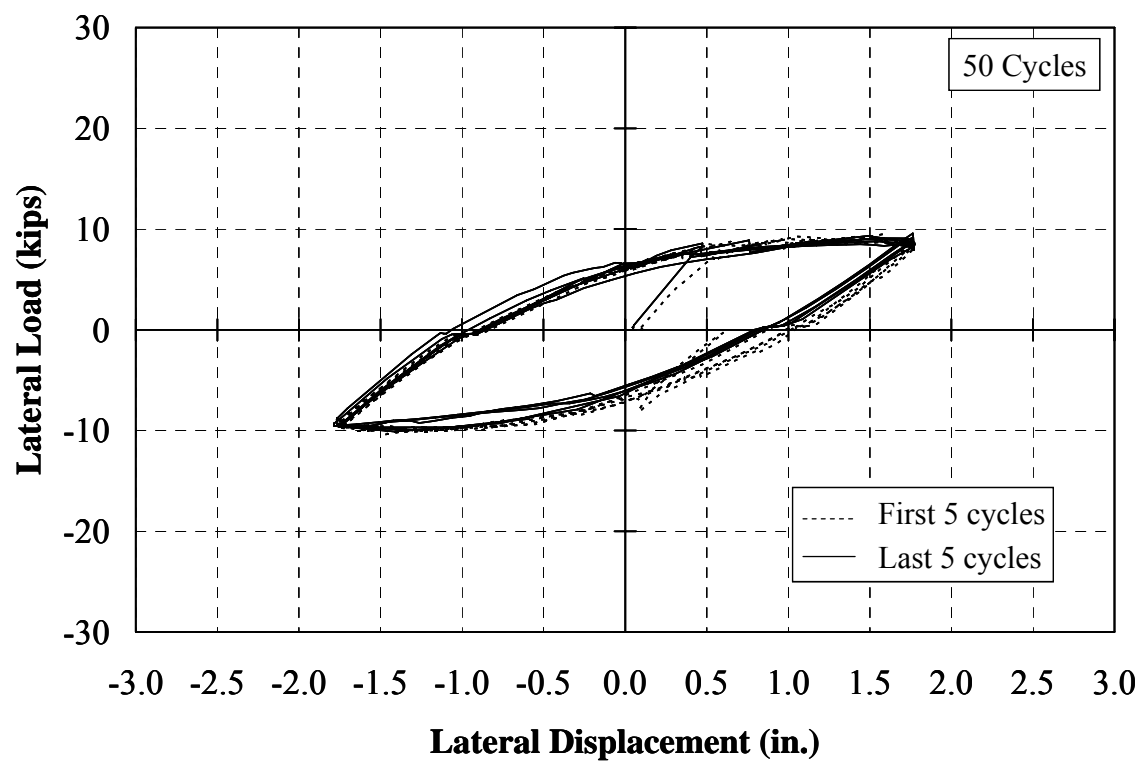

Figure I.62: Specimen 4 - Lateral Load-Deflection Response ( \pm 1.75 in.)

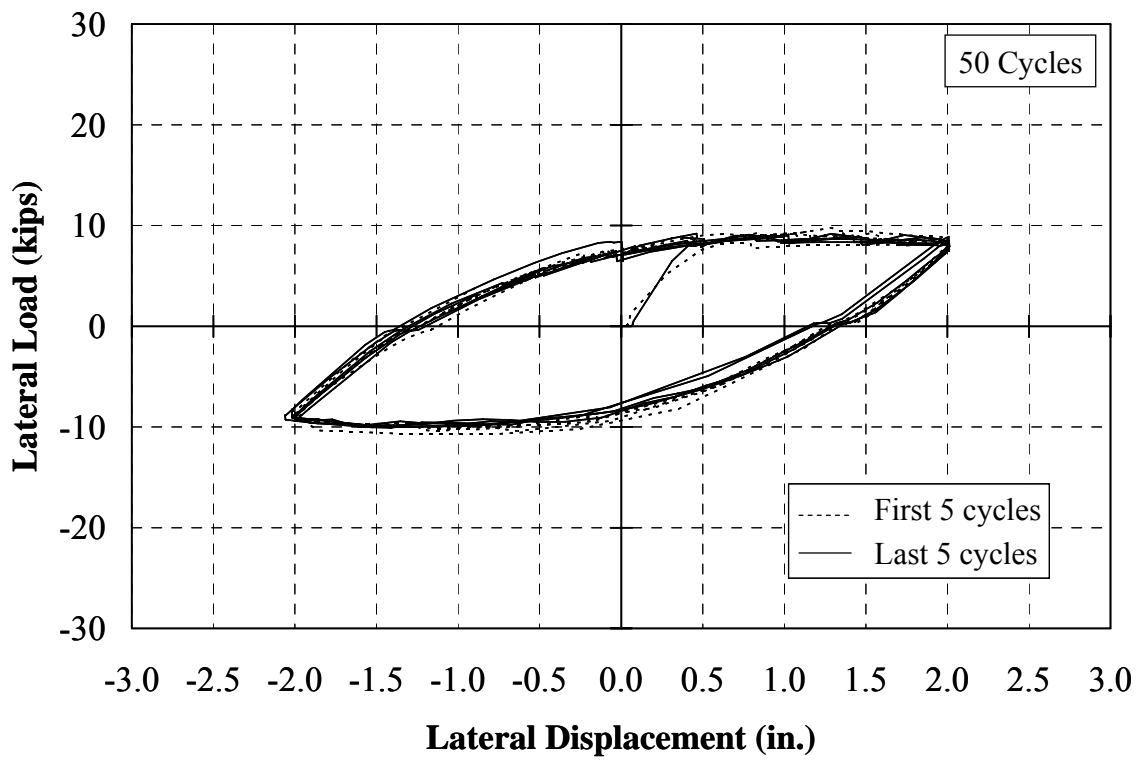

Figure I.63: Specimen 4 - Lateral Load-Deflection Response ( \pm 2.00 in.) 


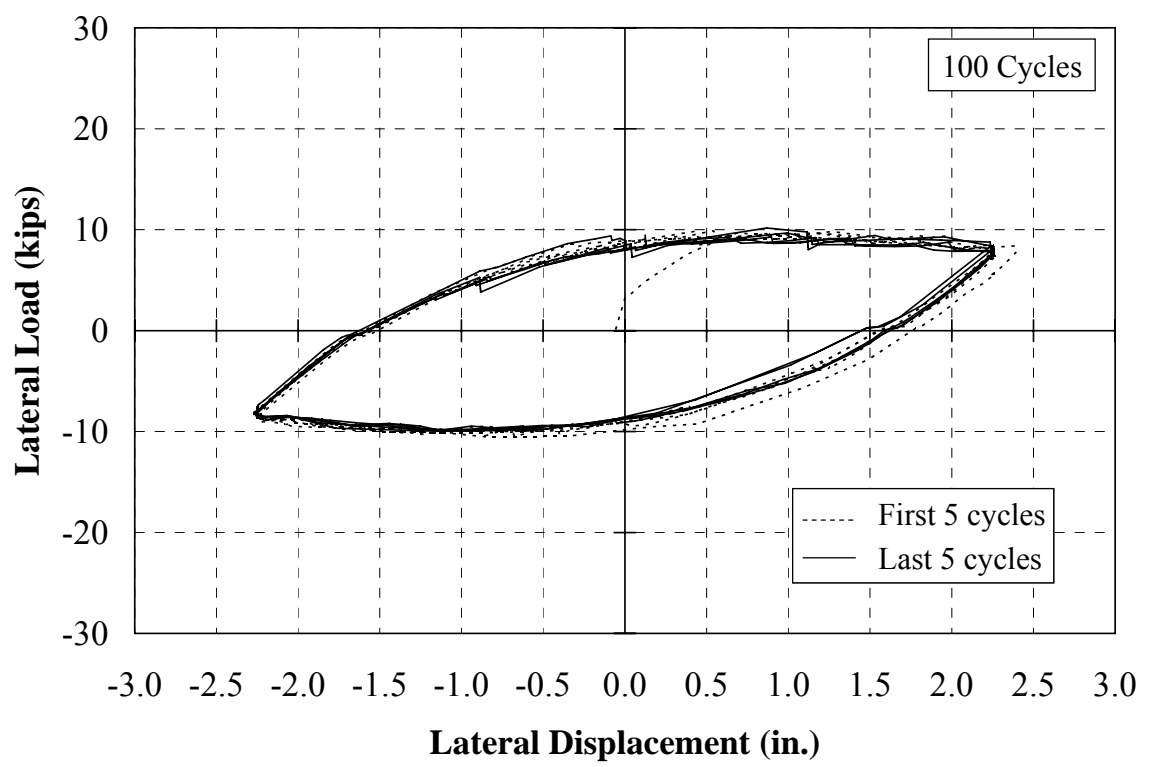

Figure I.64: Specimen 4 - Lateral Load-Deflection Response ( \pm 2.25 in.)

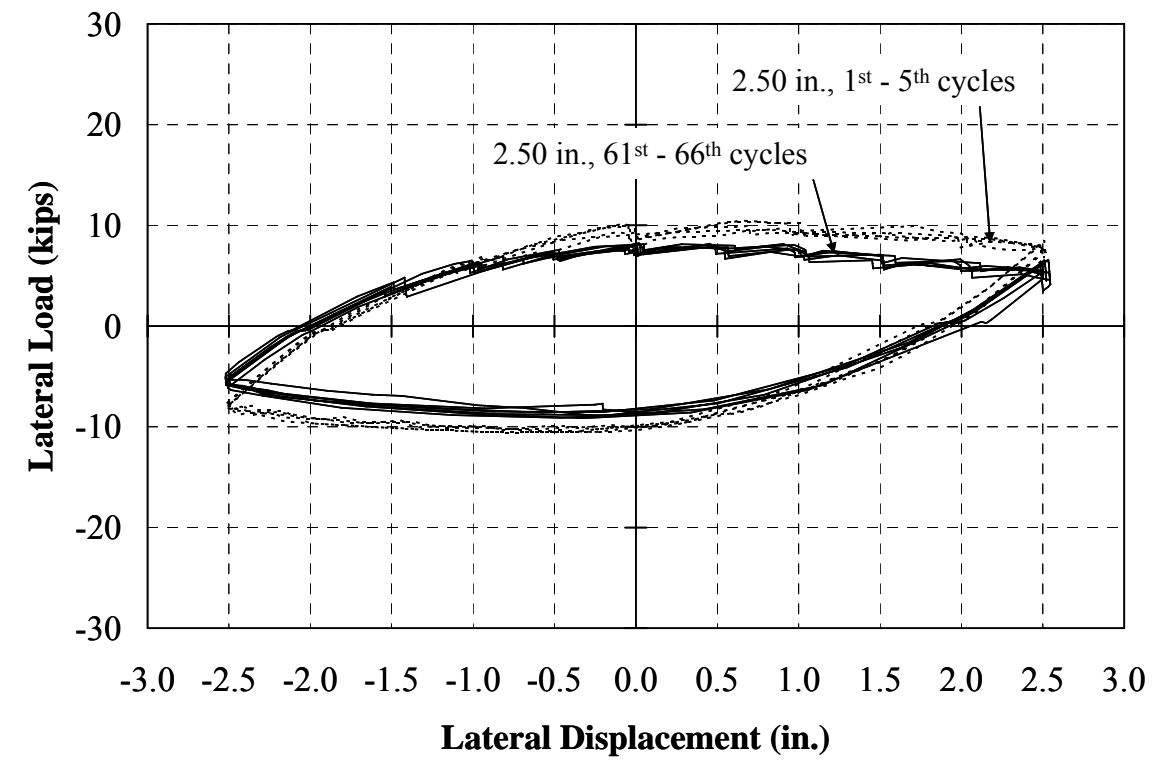

Figure I.65: Specimen 4 - Lateral Load-Deflection Response ( \pm 2.50 in.) 
Specimen 5: HP10x42, Weak, 9 ksi

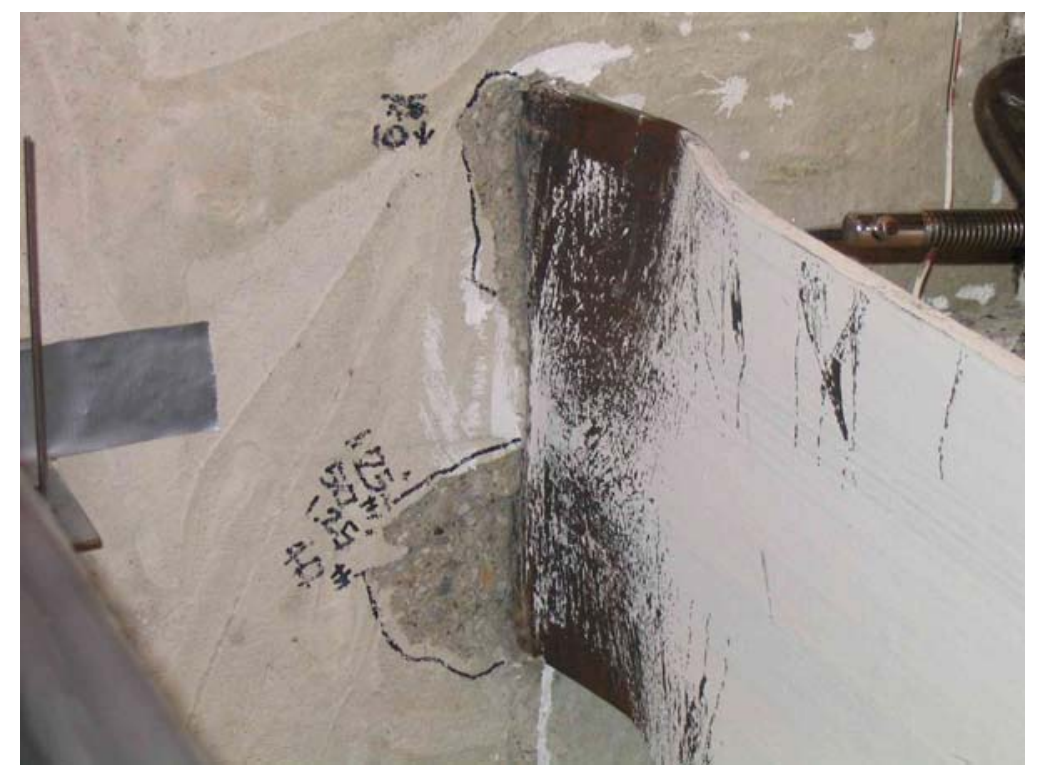

(a) West Side

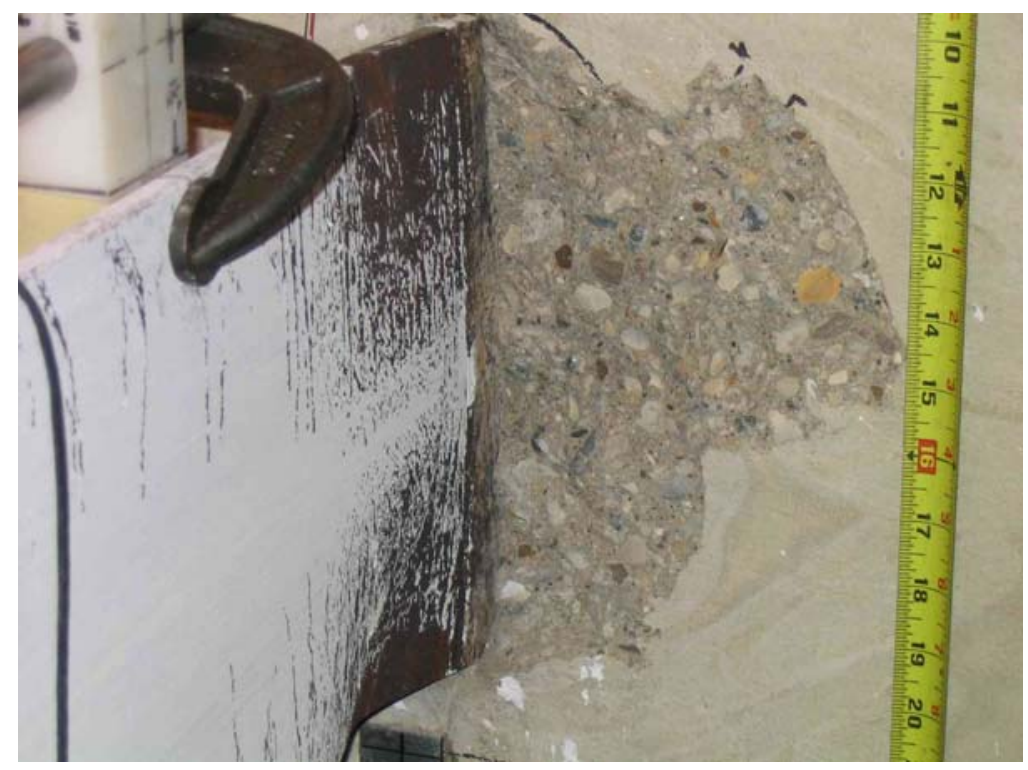

(b) East Side

Figure I.66: Specimen 5 - Cracking (2.00 in., $50^{\text {th }}$ Cycle) 


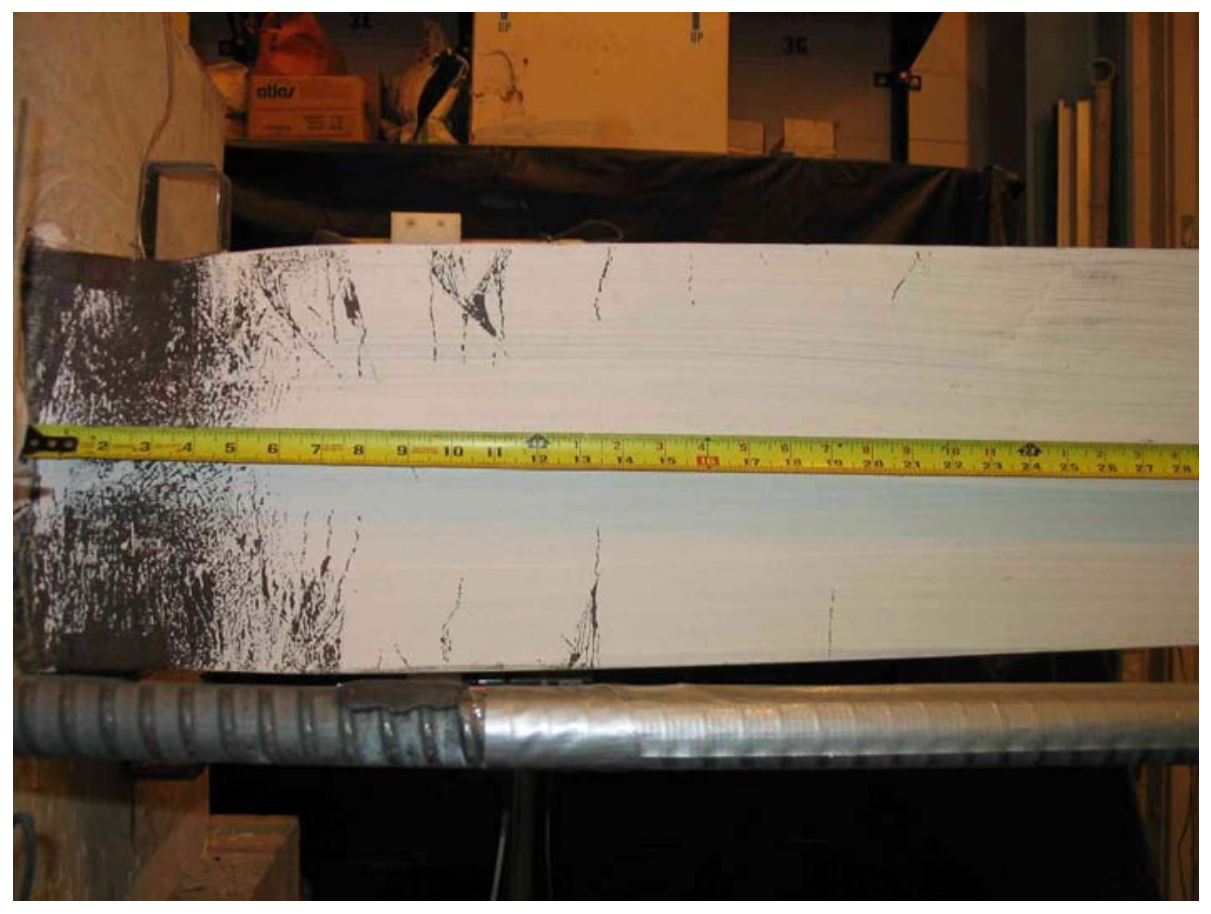

(a) West Side

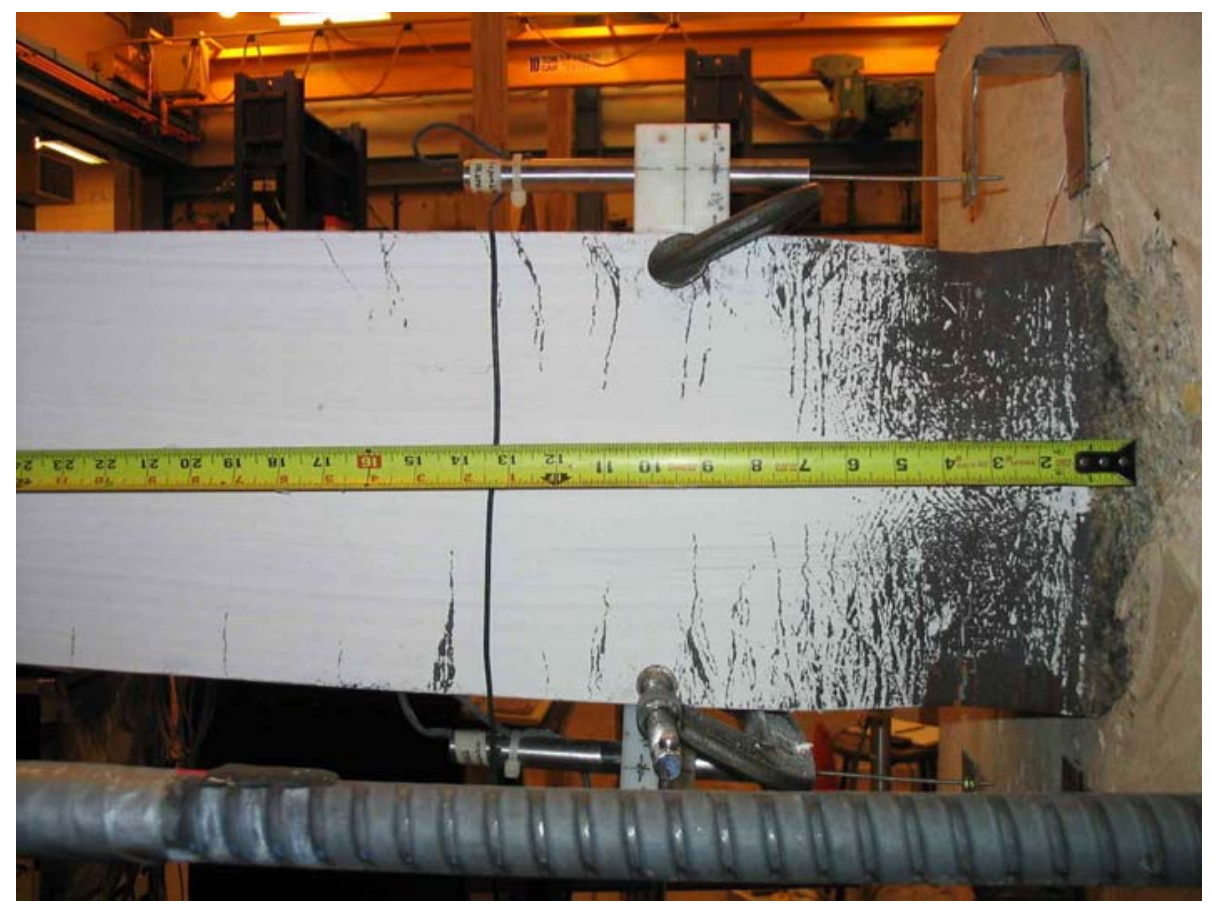

(b) East Side

Figure I.67: Specimen 5 - Pile Yielding (2.00 in., $50^{\text {th }}$ Cycle) 


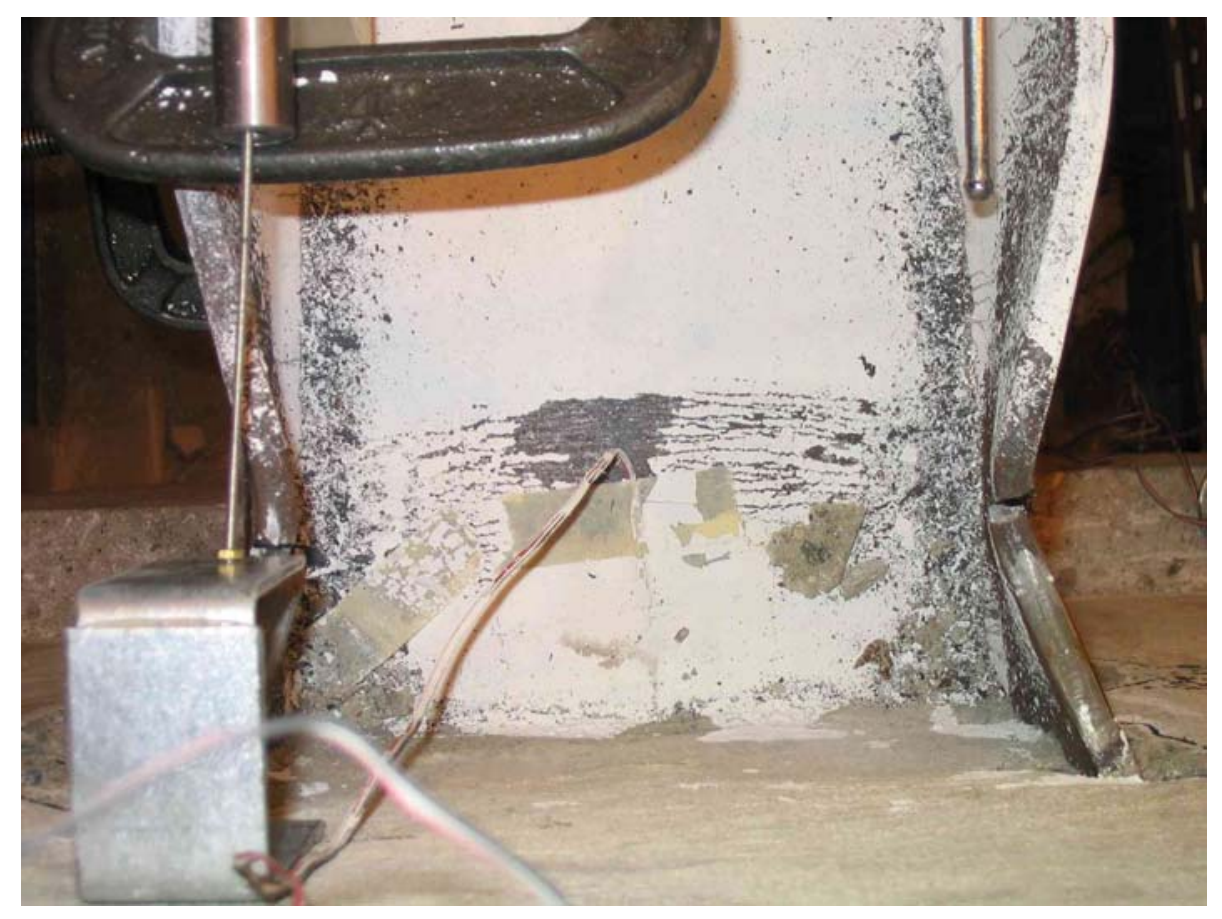

(a) Top

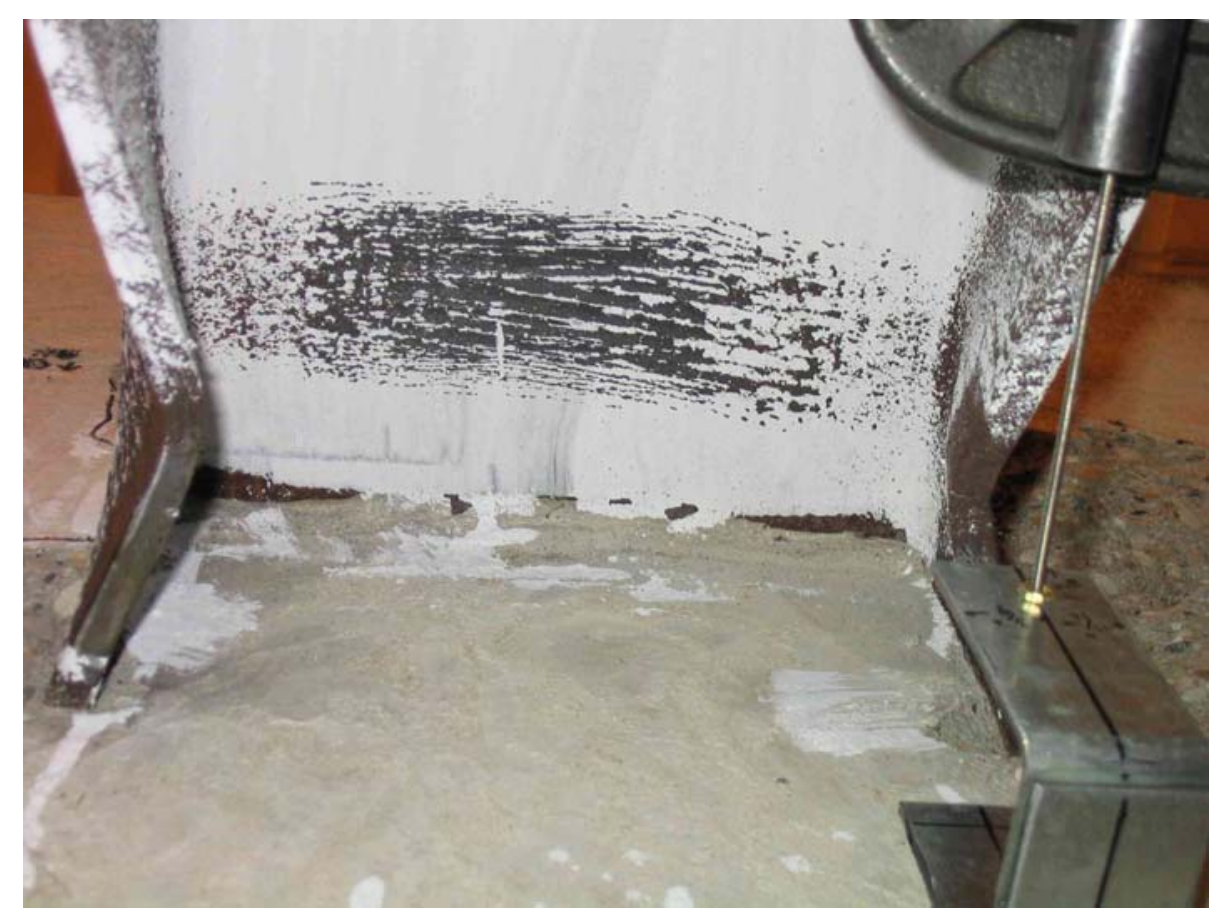

(b) Bottom

Figure I.68: Specimen 5 - Pile Flange Buckling and Web Yielding (2.00 in., $50^{\text {th }}$ Cycle) 


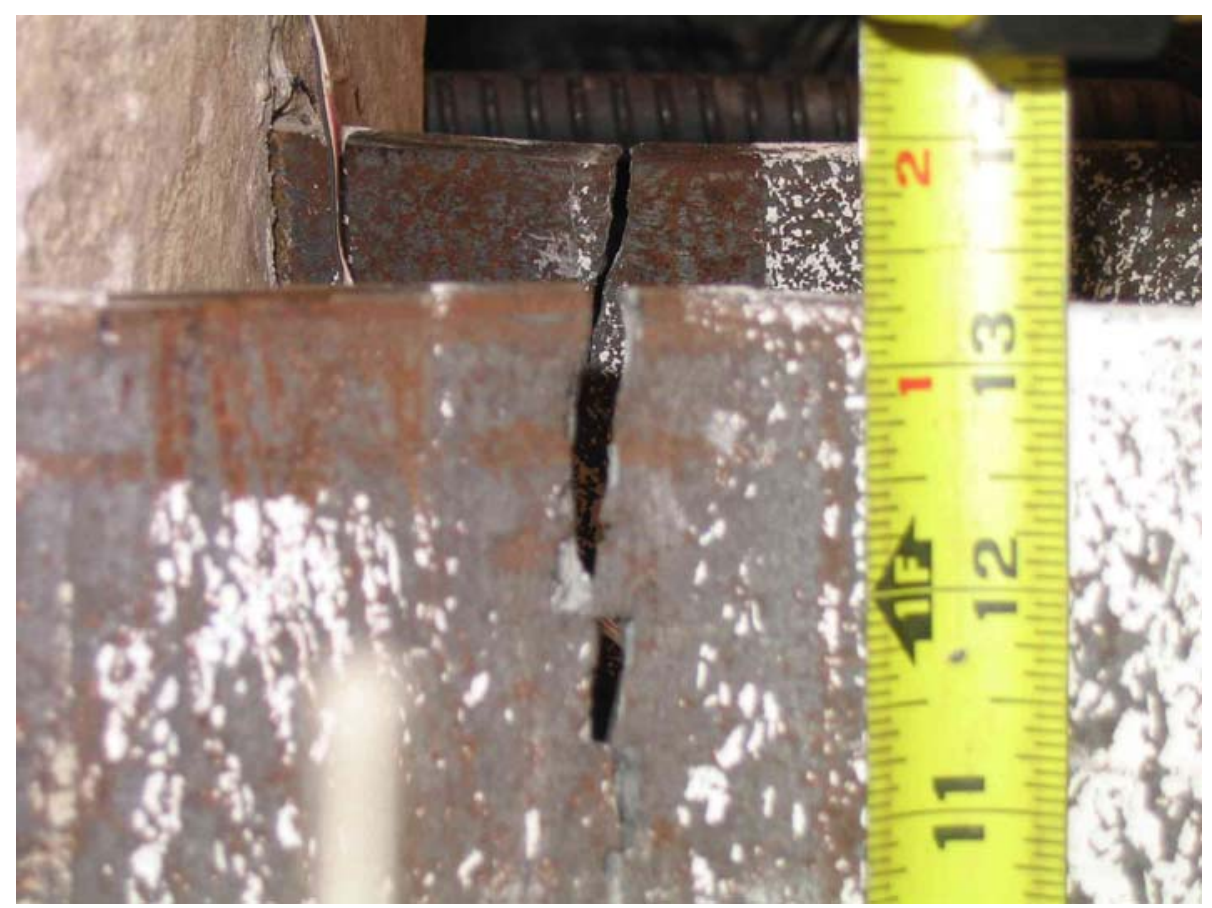

(a) NW Flange

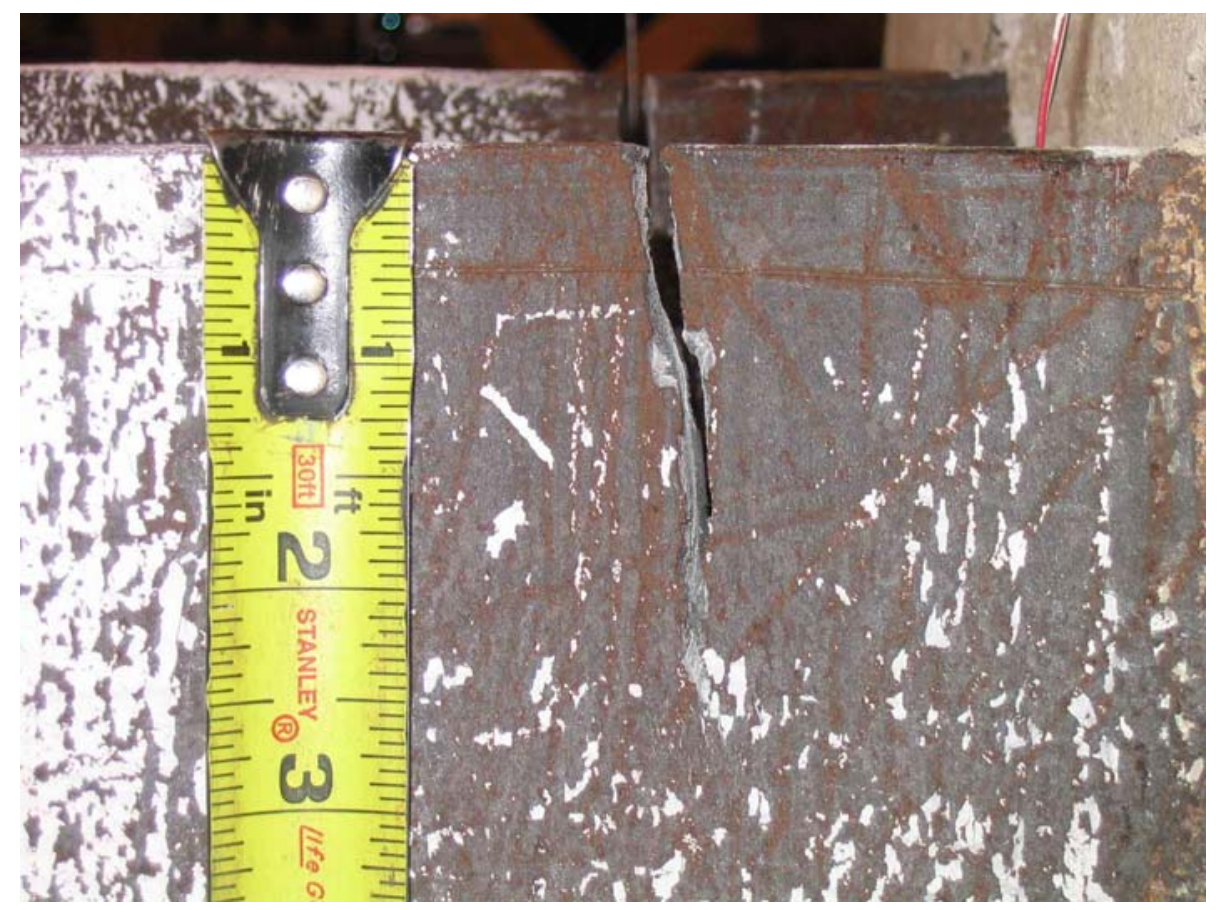

(b) NE Flange

Figure I.69: Specimen 5 - Crack on Steel Pile (2.00 in., $50^{\text {th }}$ Cycle) 


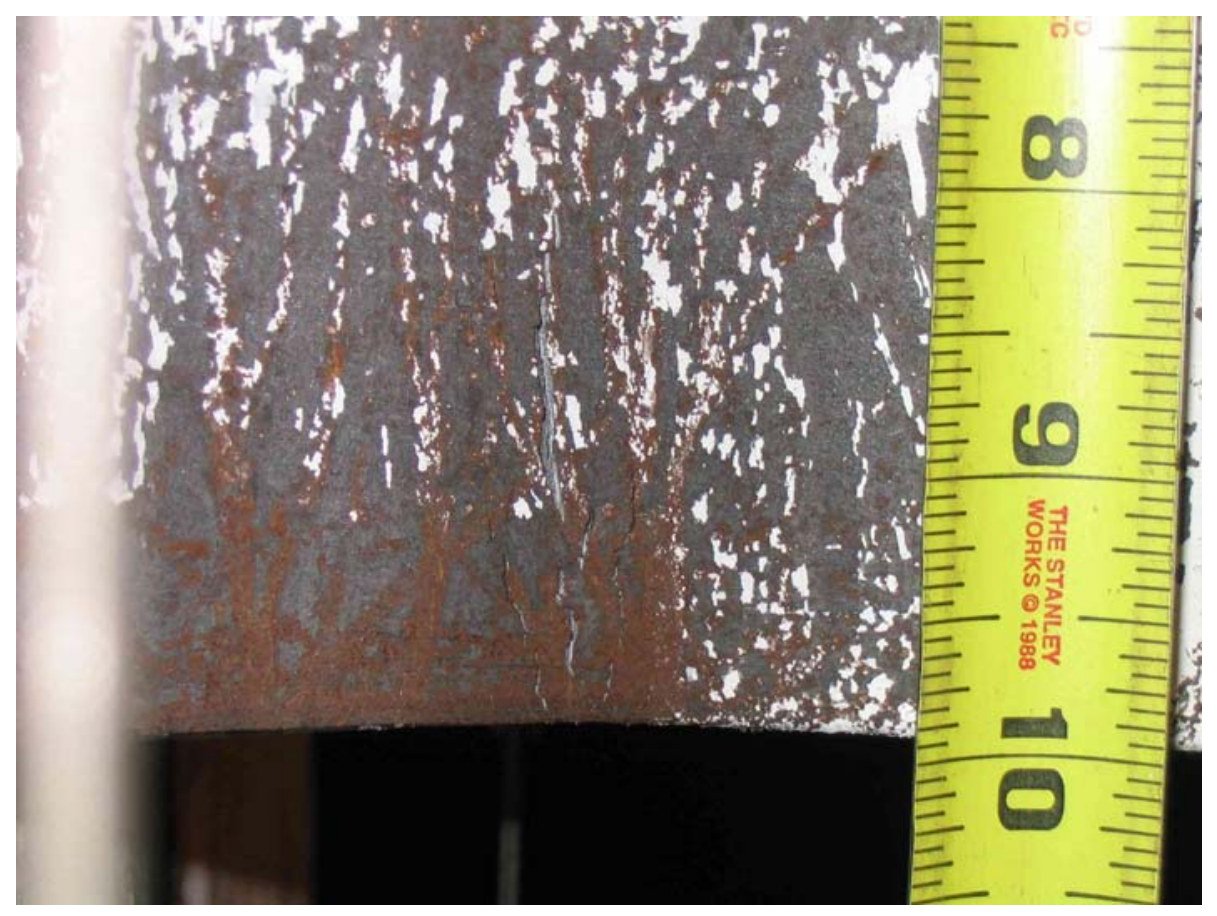

(c) SW Flange

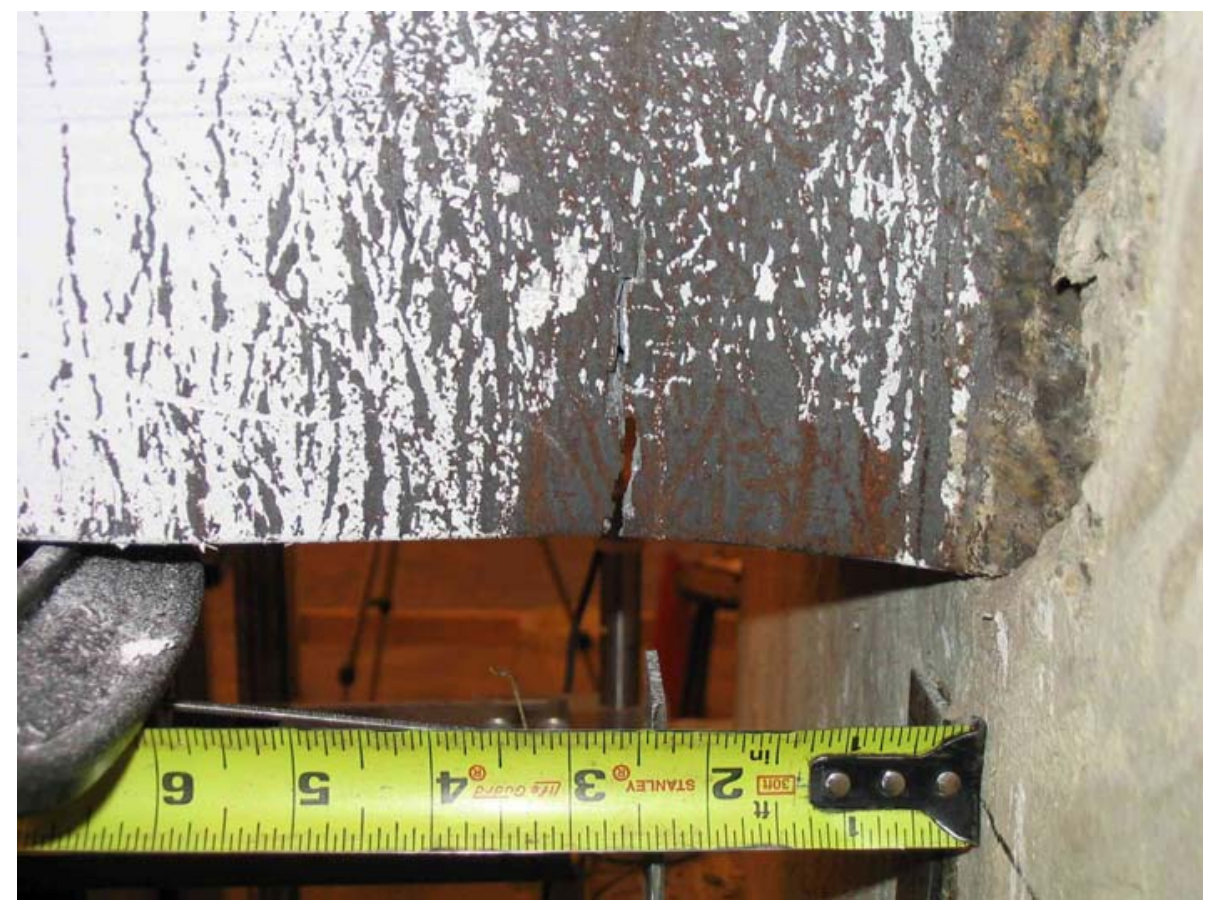

(d) SE Flange

Figure I.69: Specimen 5 - Crack on Steel Pile (2.00 in., 50 ${ }^{\text {th }}$ Cycle) (Continue) 


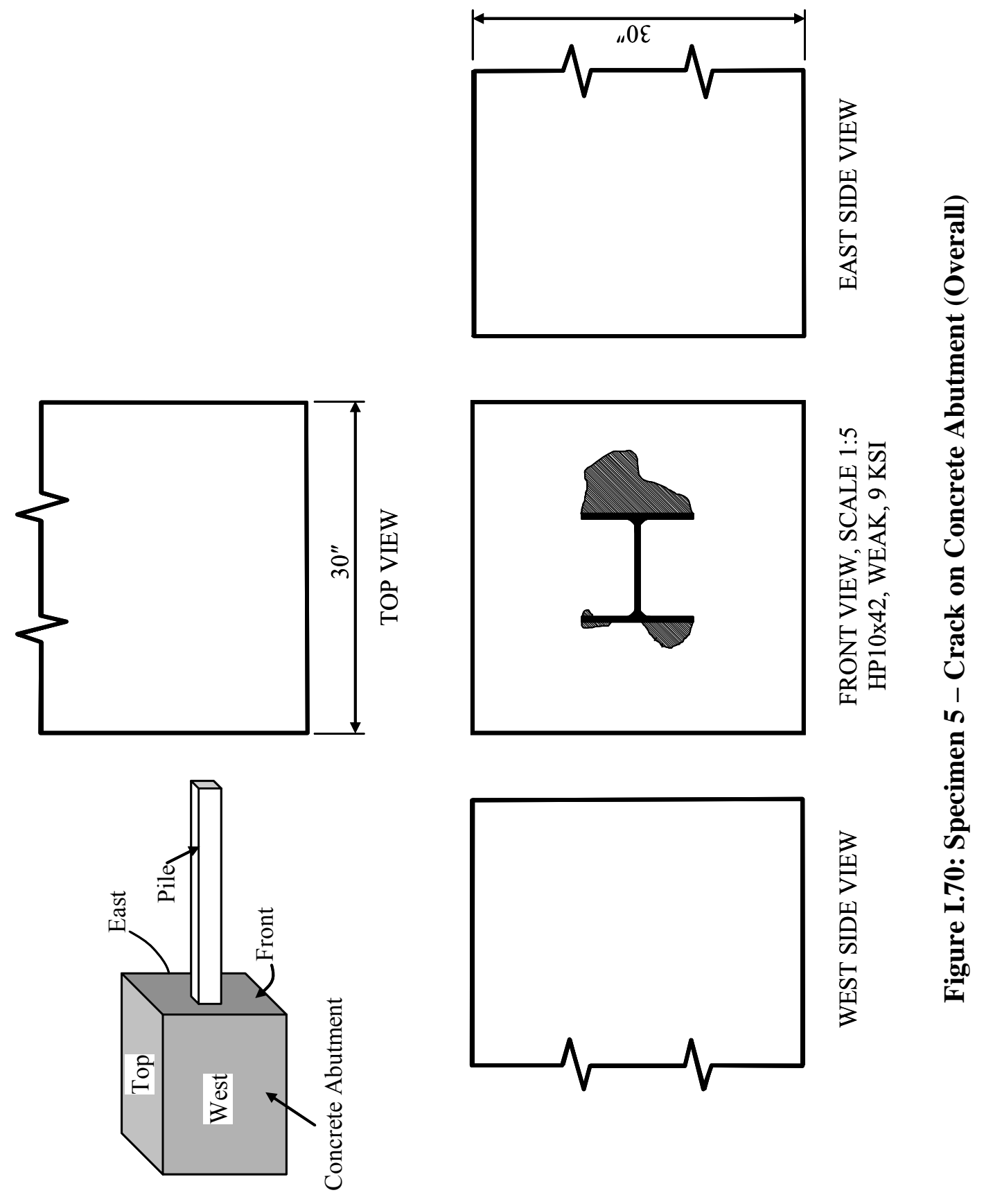




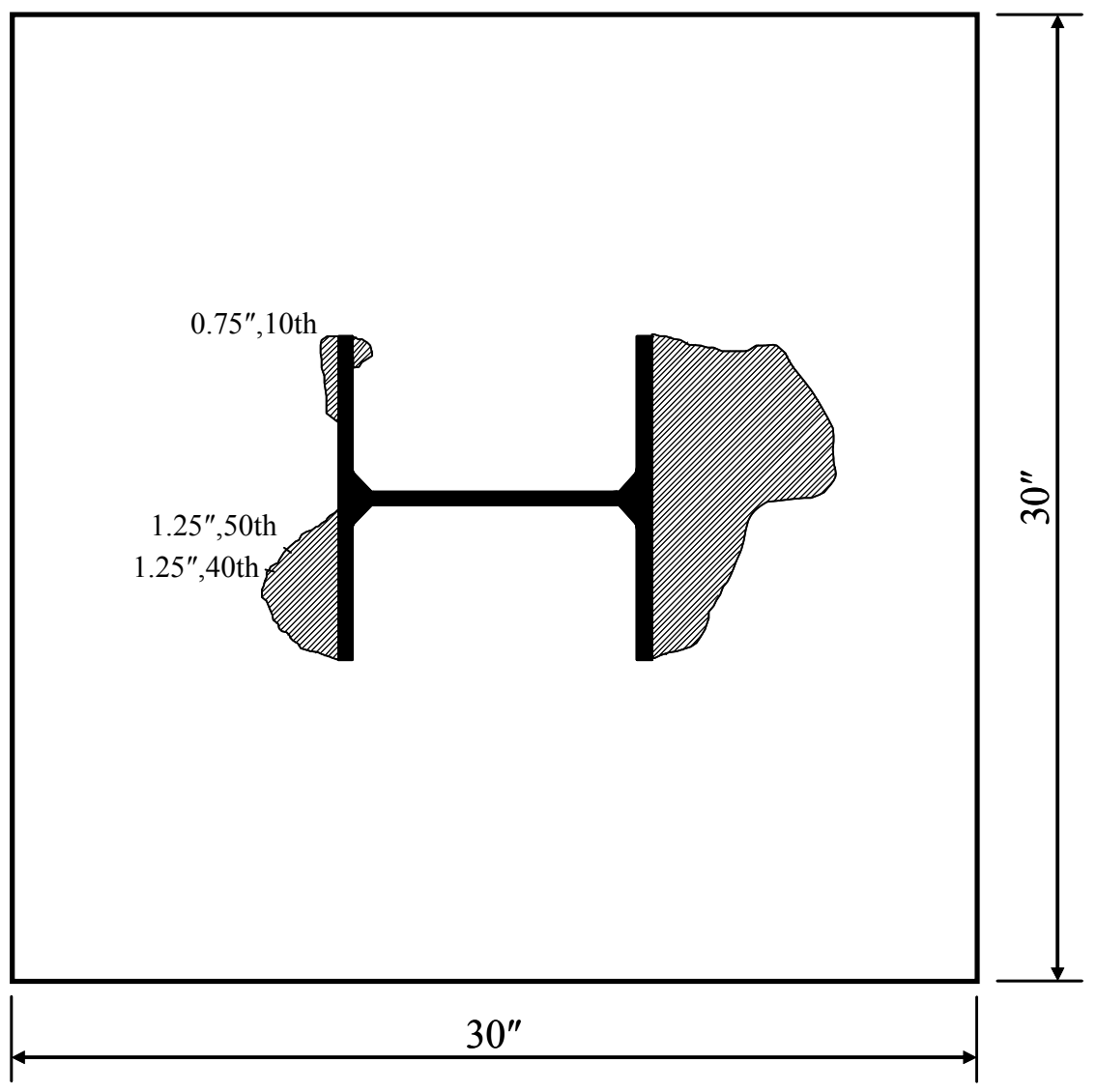

Figure I.71: Specimen 5 - Crack on Concrete Abutment (Front View)

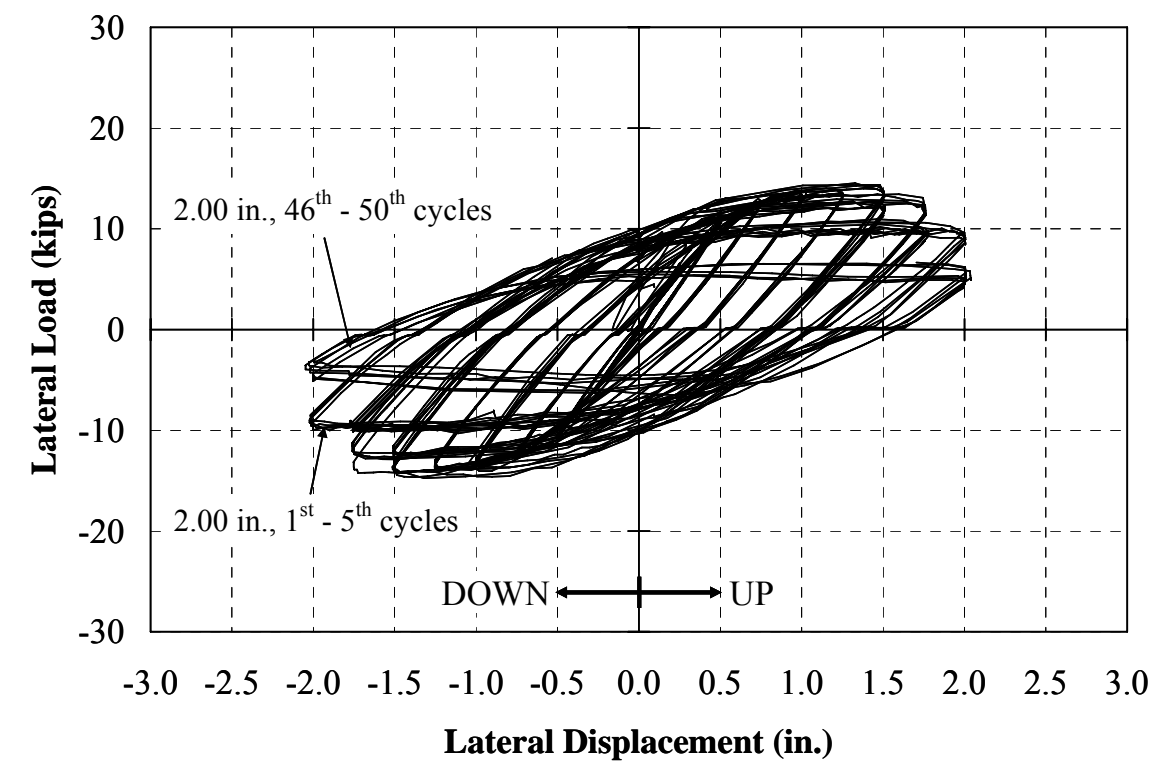

Figure I.72: Specimen 5 - Summary of Lateral Load-Deflection Curves 


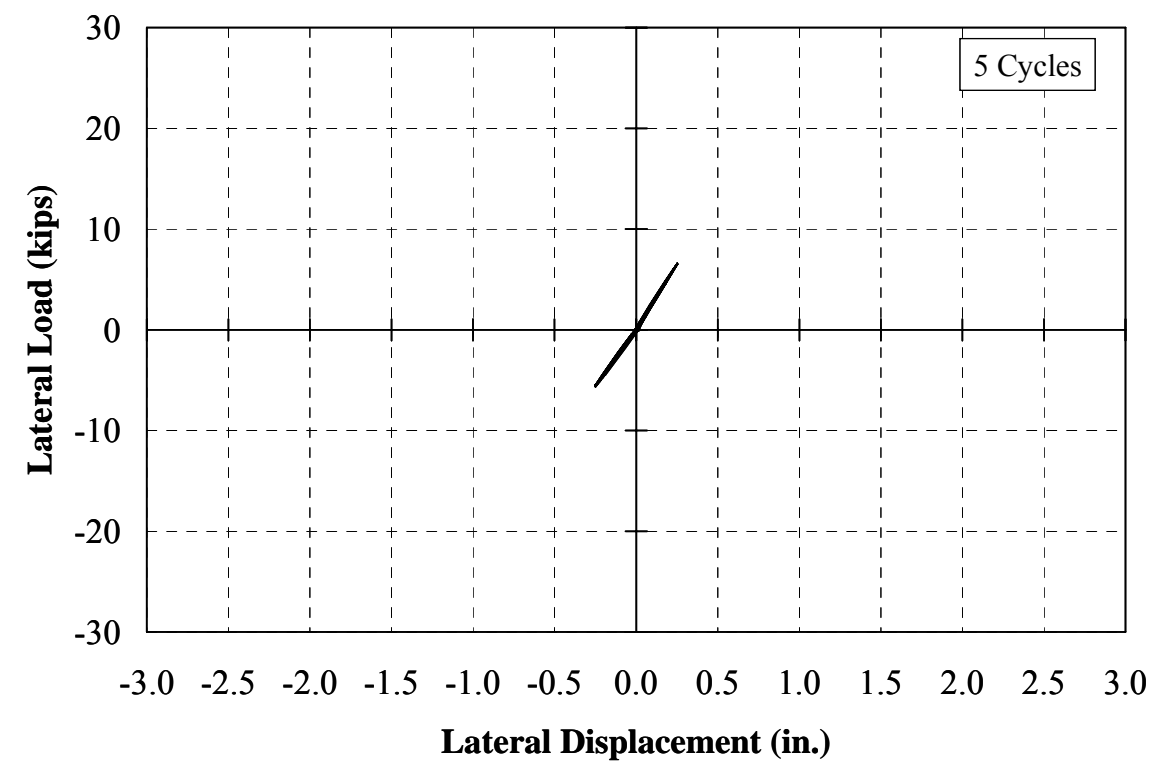

Figure I.73: Specimen 5 - Lateral Load-Deflection Response ( \pm 0.25 in.)

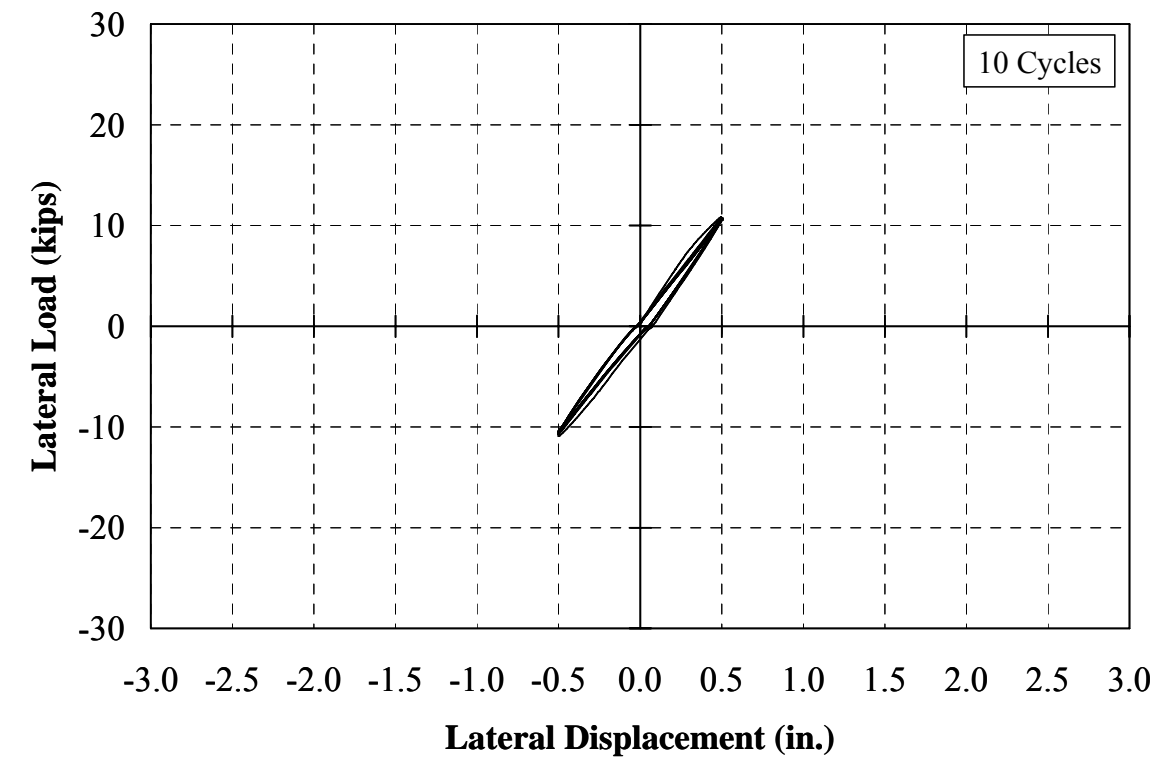

Figure I.74: Specimen 5 - Lateral Load-Deflection Response ( \pm 0.50 in.) 


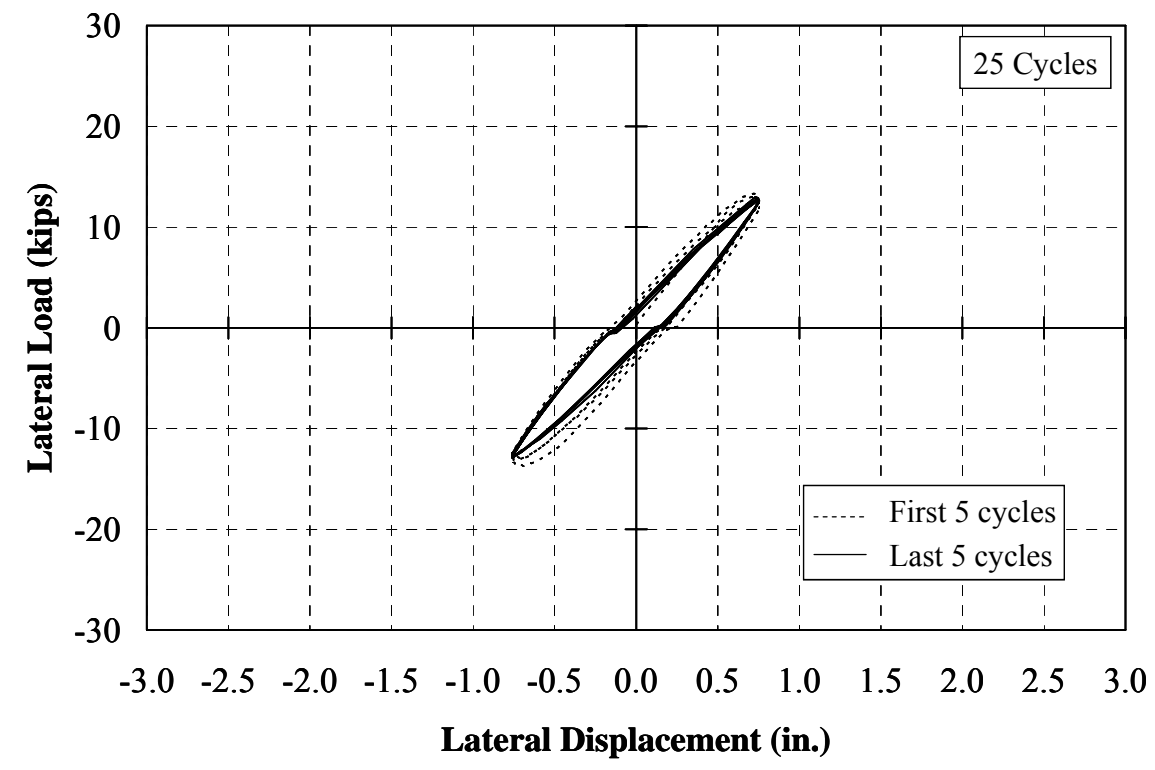

Figure I.75: Specimen 5 - Lateral Load-Deflection Response ( \pm 0.75 in.)

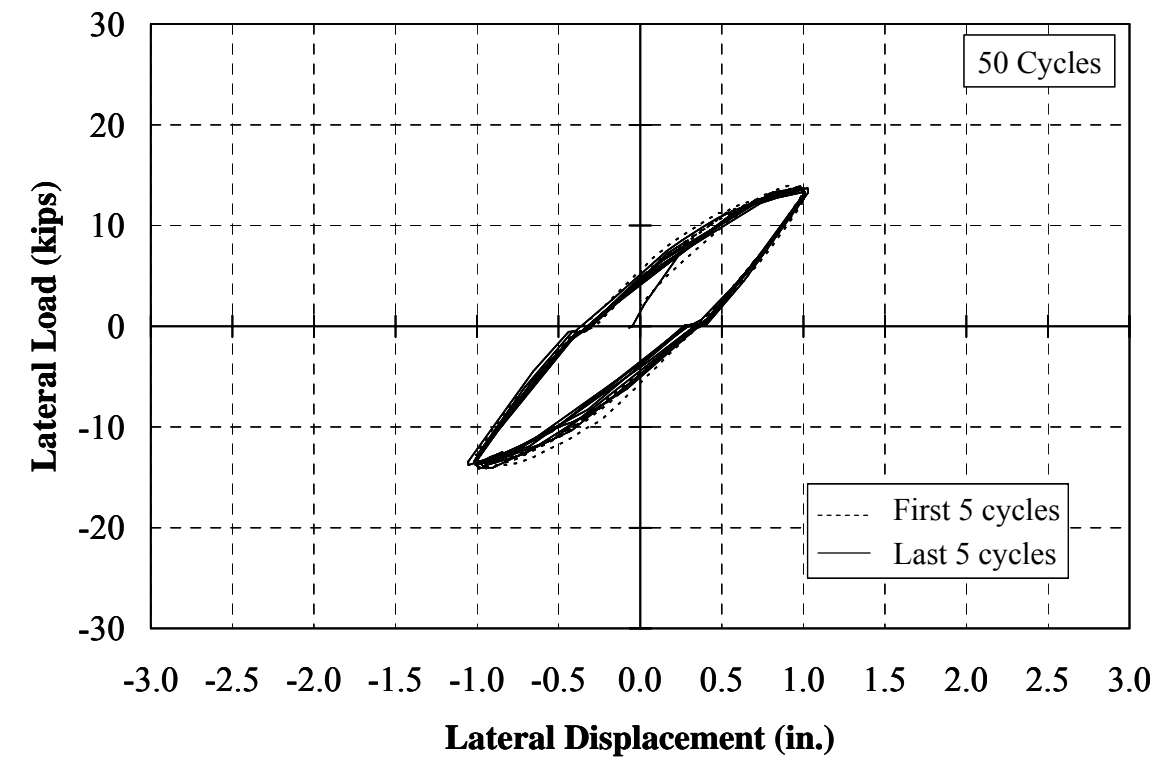

Figure I.76: Specimen 5 - Lateral Load-Deflection Response ( \pm 1.00 in.) 


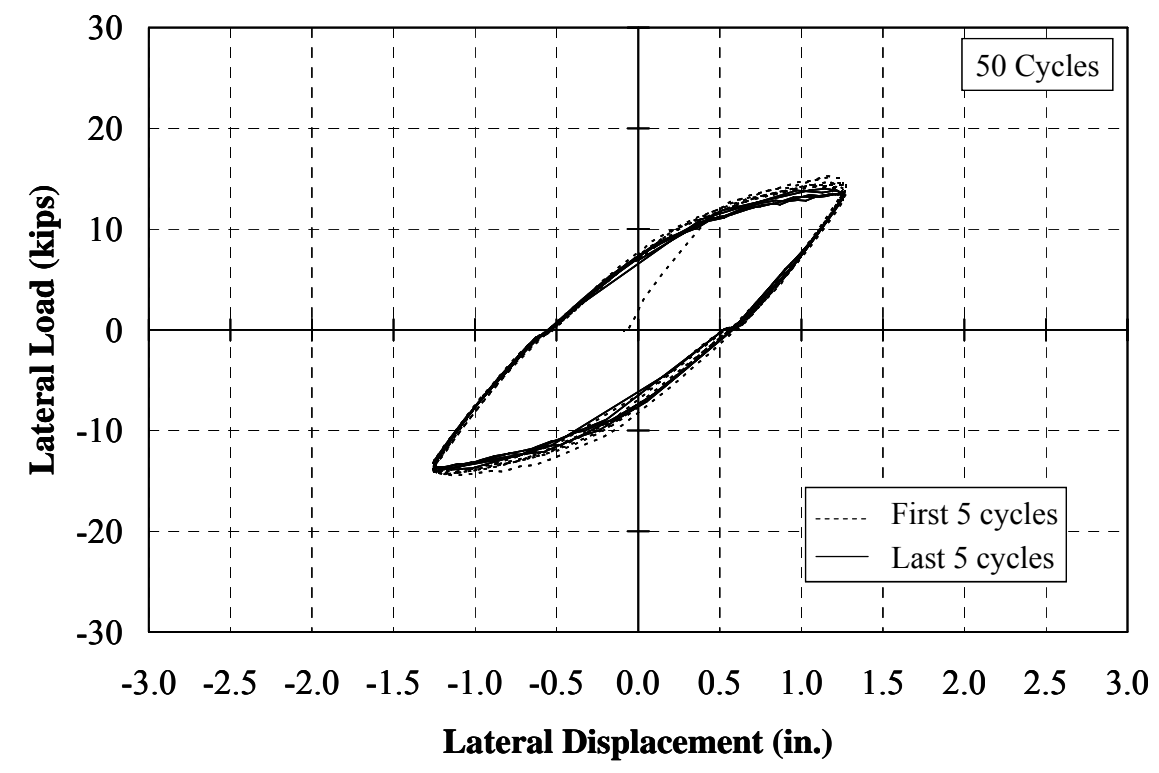

Figure I.77: Specimen 5 - Lateral Load-Deflection Response ( \pm 1.25 in.)

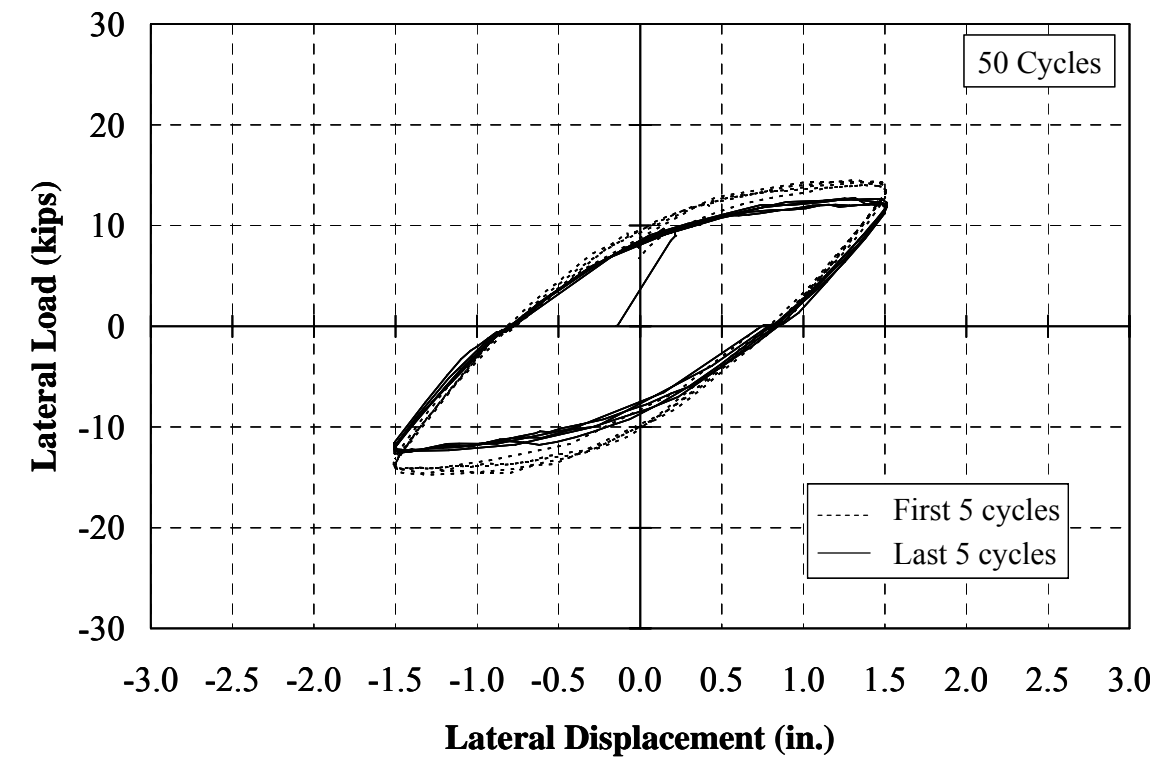

Figure I.78: Specimen 5 - Lateral Load-Deflection Response ( \pm 1.50 in.) 


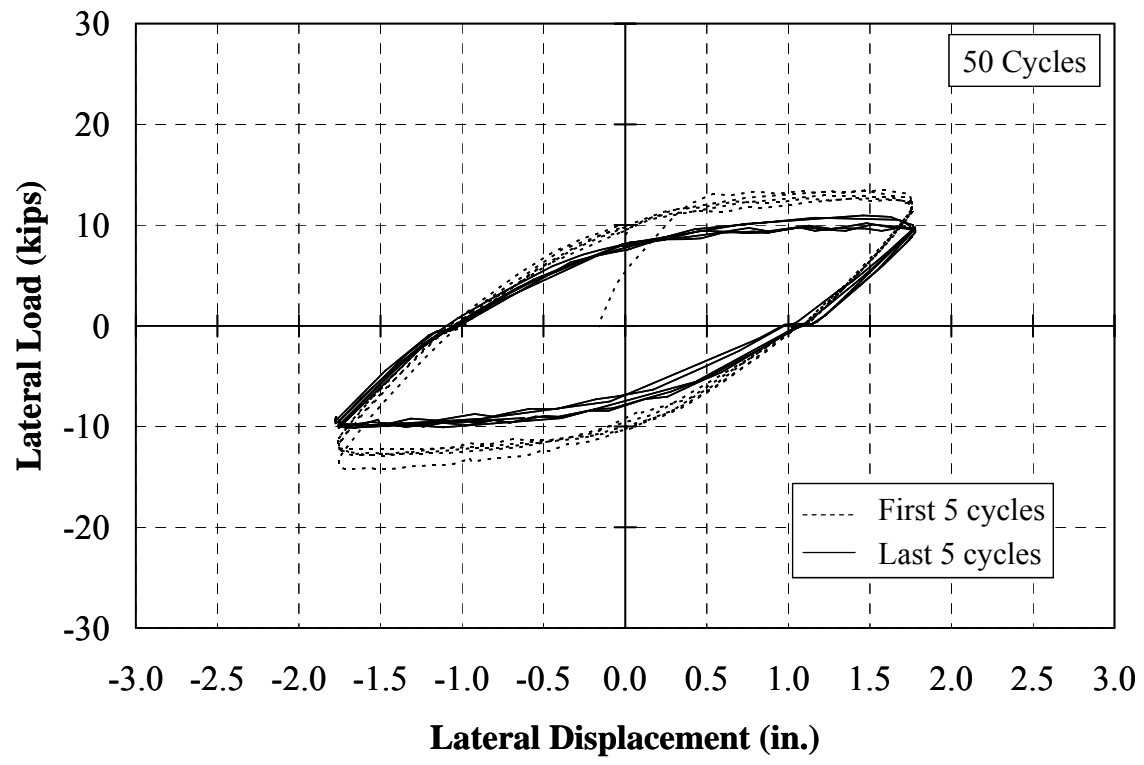

Figure I.79: Specimen 5 - Lateral Load-Deflection Response ( \pm 1.75 in.)

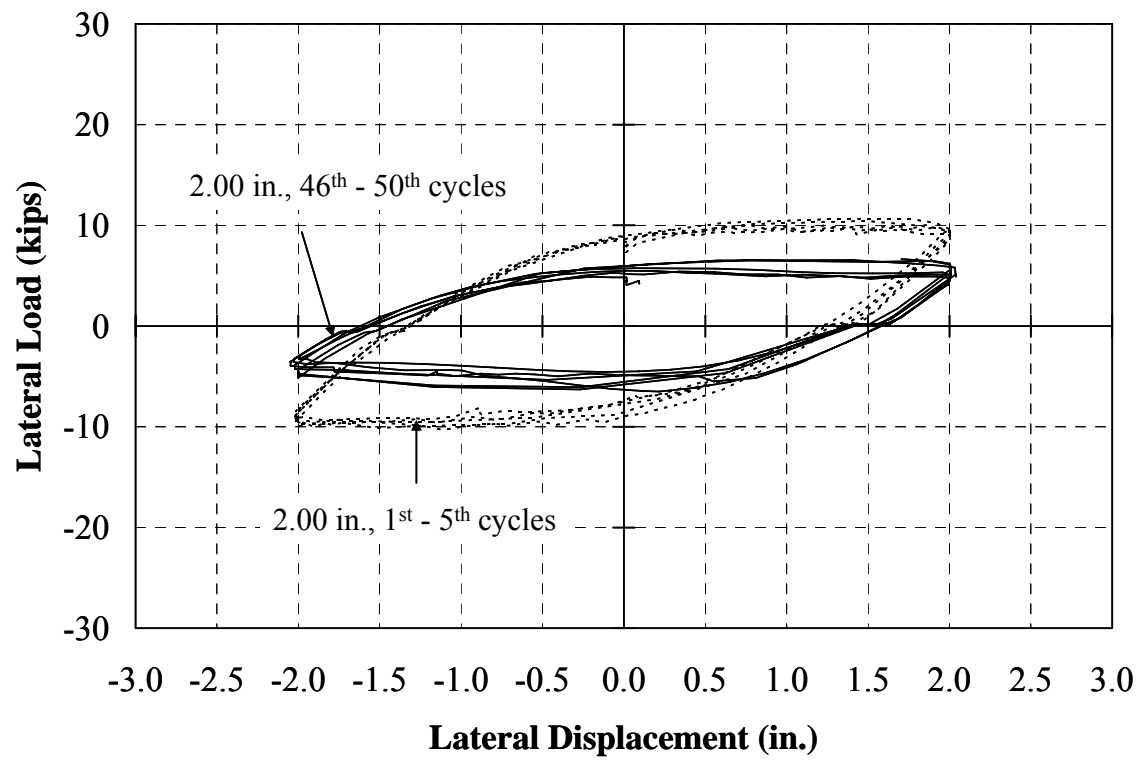

Figure I.80: Specimen 5 - Lateral Load-Deflection Response ( \pm 2.00 in.) 
Specimen 6: HP12x53, Weak, 9 ksi

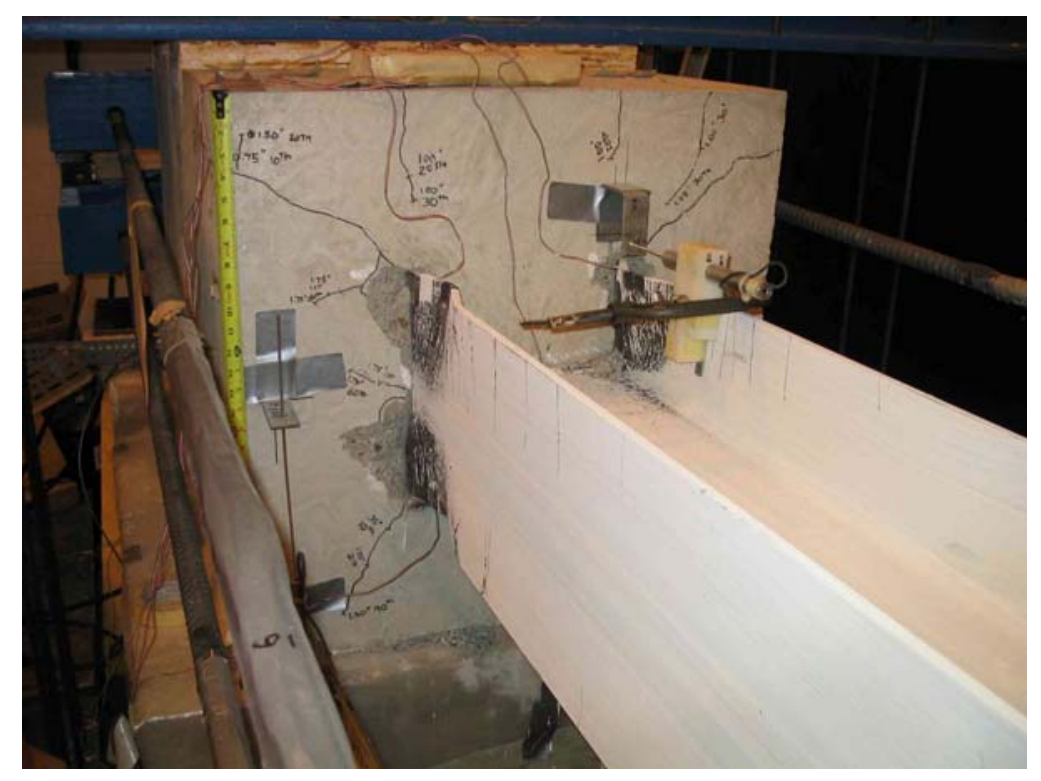

(a) West Side

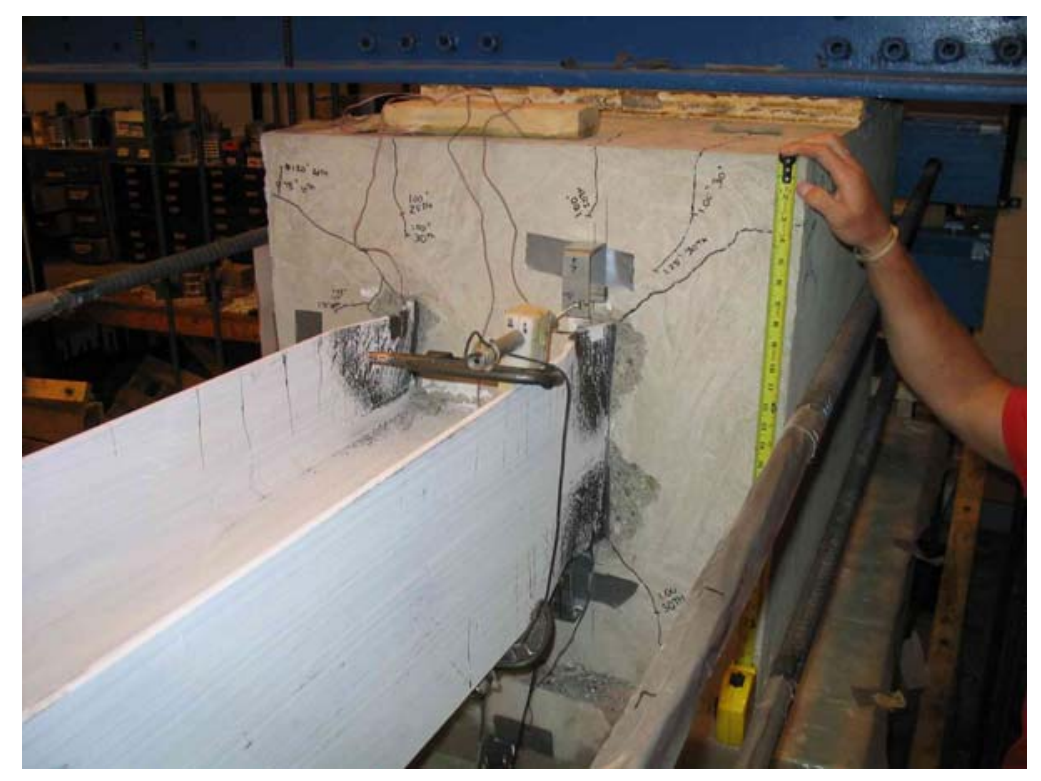

(b) East Side

Figure I.81: Specimen 6 - Cracking (1.75 in., $70^{\text {th }}$ Cycle) 


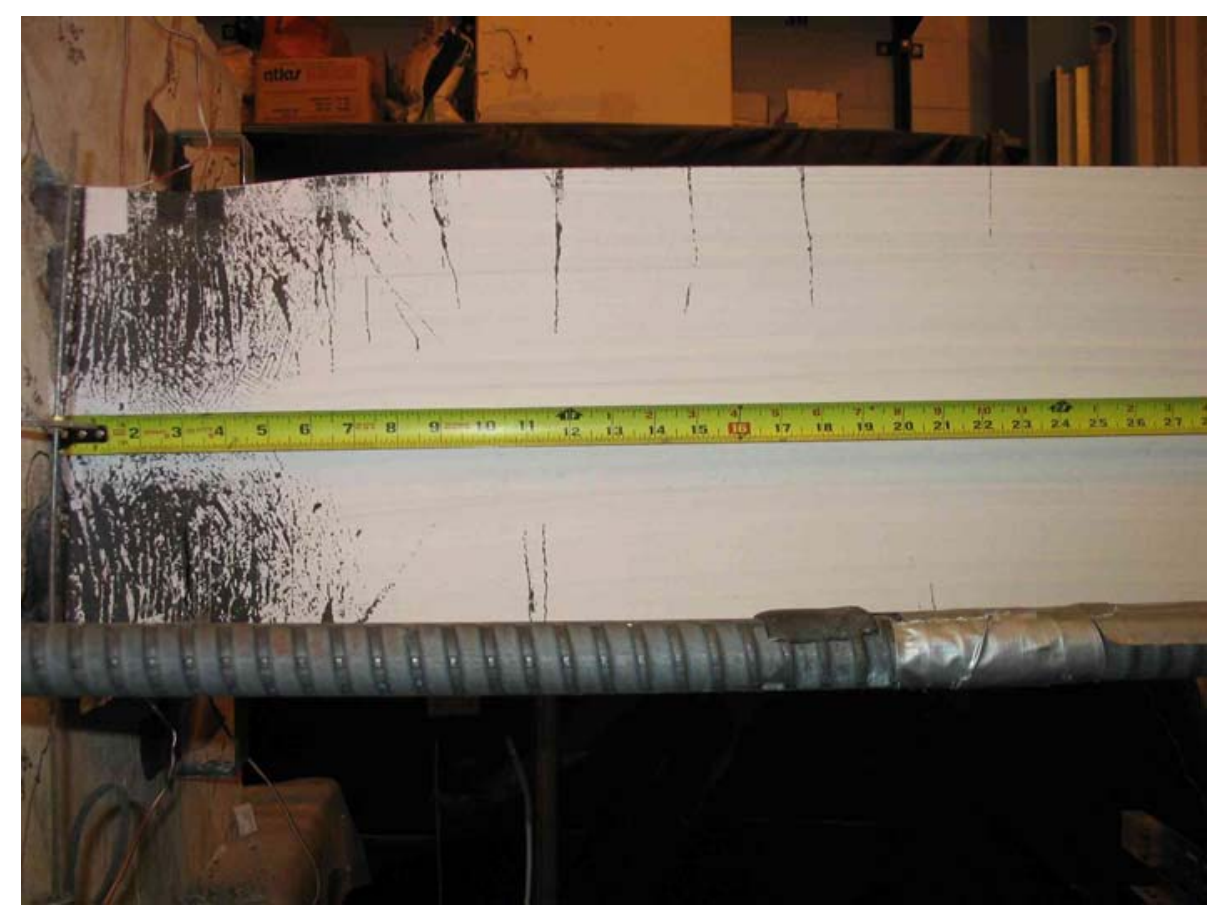

(a) West Side

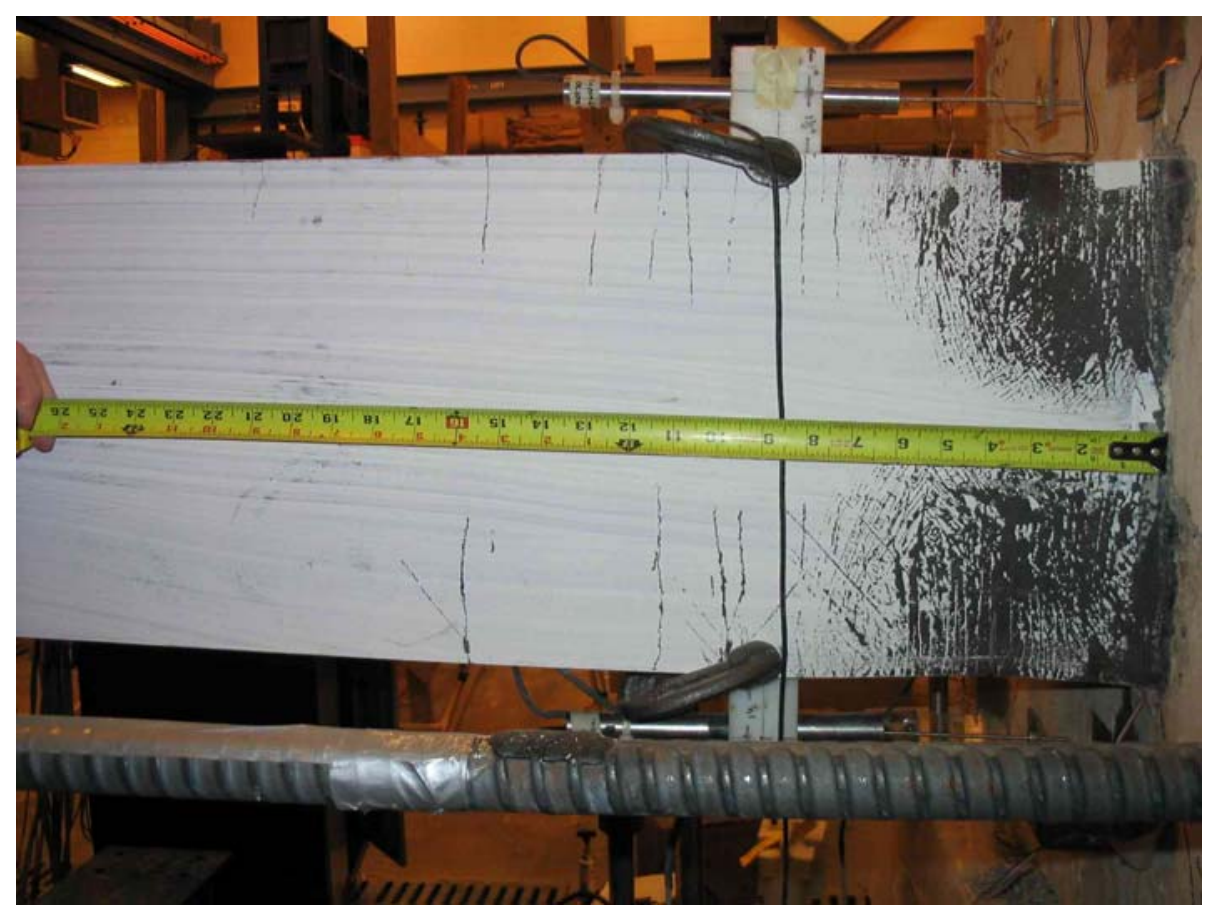

(b) East Side

Figure I.82: Specimen 6 - Pile Yielding (1.75 in., $70^{\text {th }}$ Cycle) 


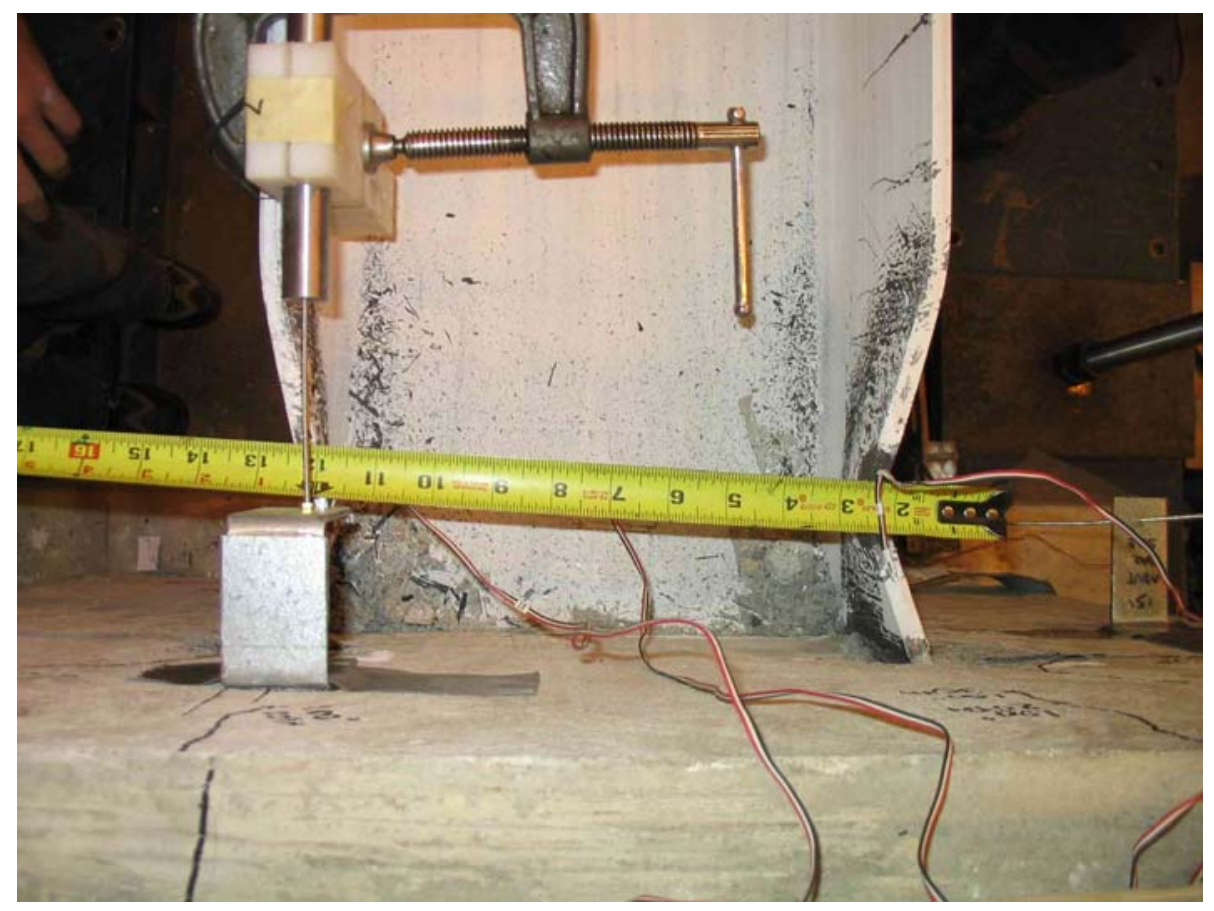

(a) Top

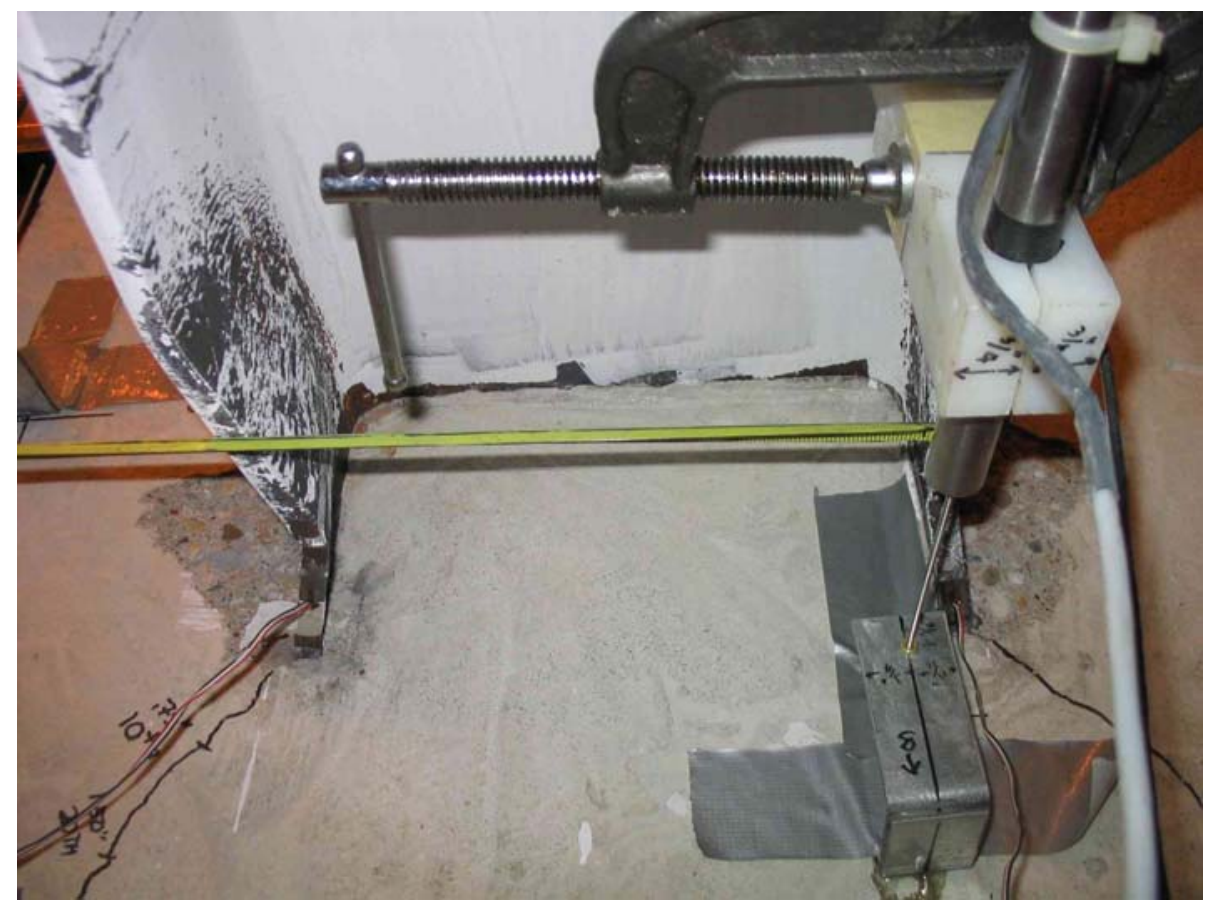

(b) Bottom

Figure I.83: Specimen 6 - Pile Flange Buckling (1.75 in., $70^{\text {th }}$ Cycle) 


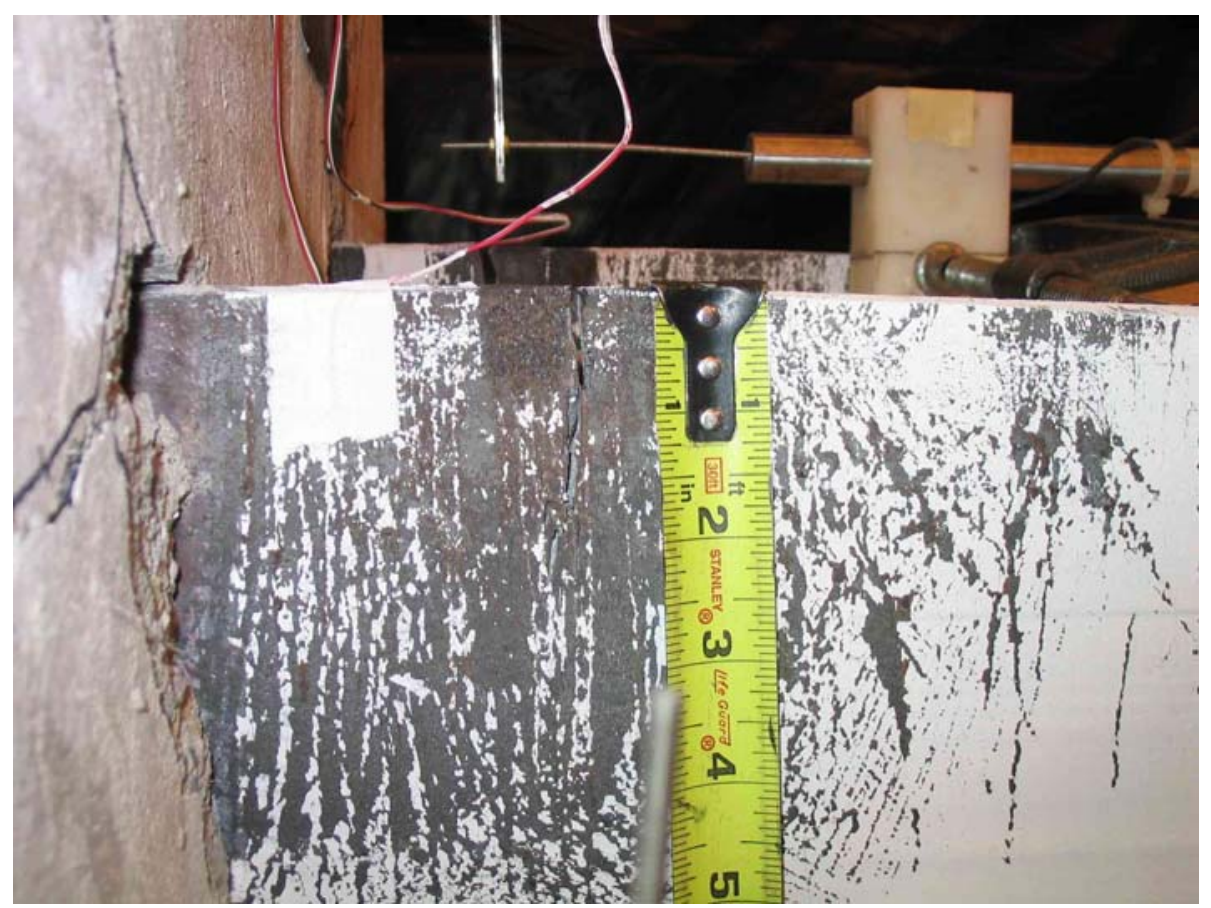

(a) NW Flange

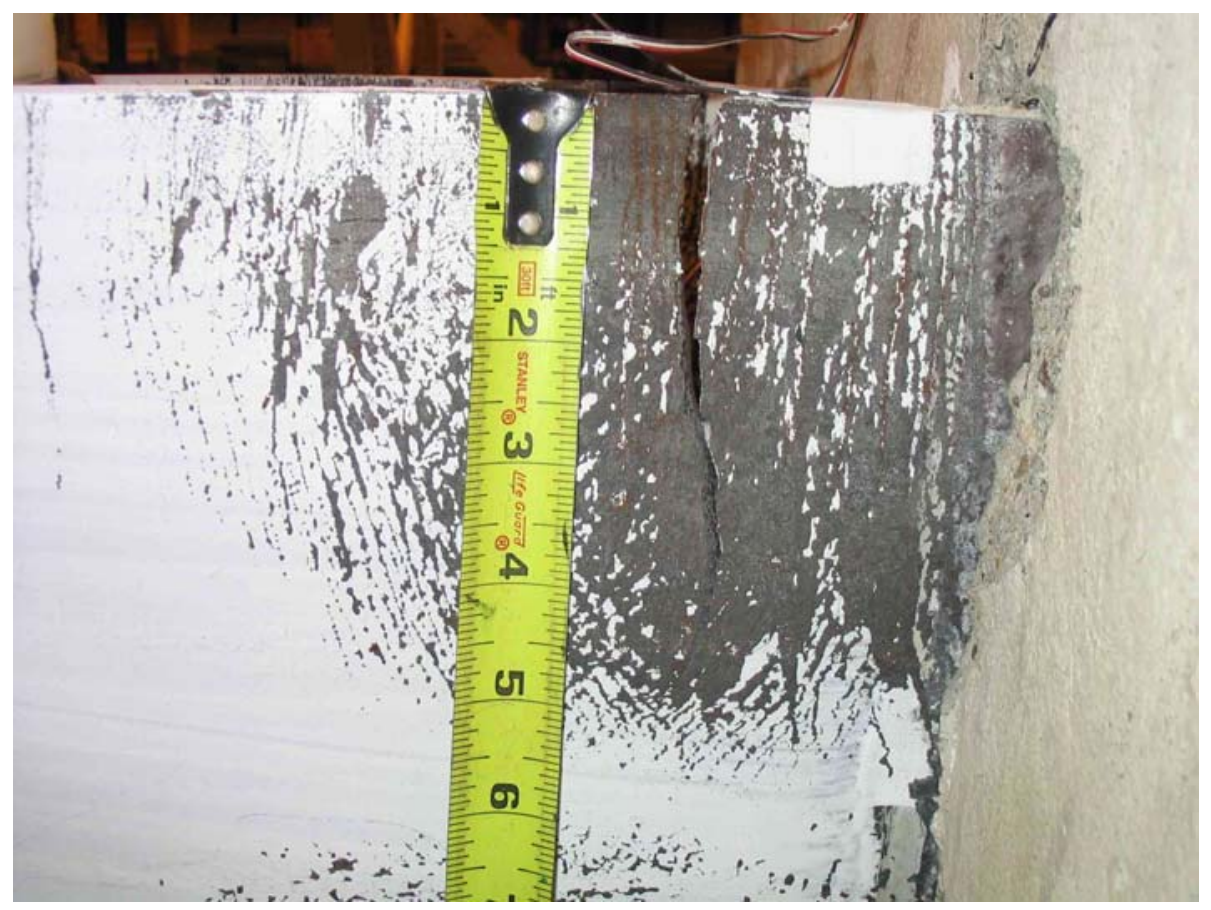

(b) NE Flange

Figure I.84: Specimen 6 - Crack on Steel Pile (1.75 in., $70^{\text {th }}$ Cycle) 


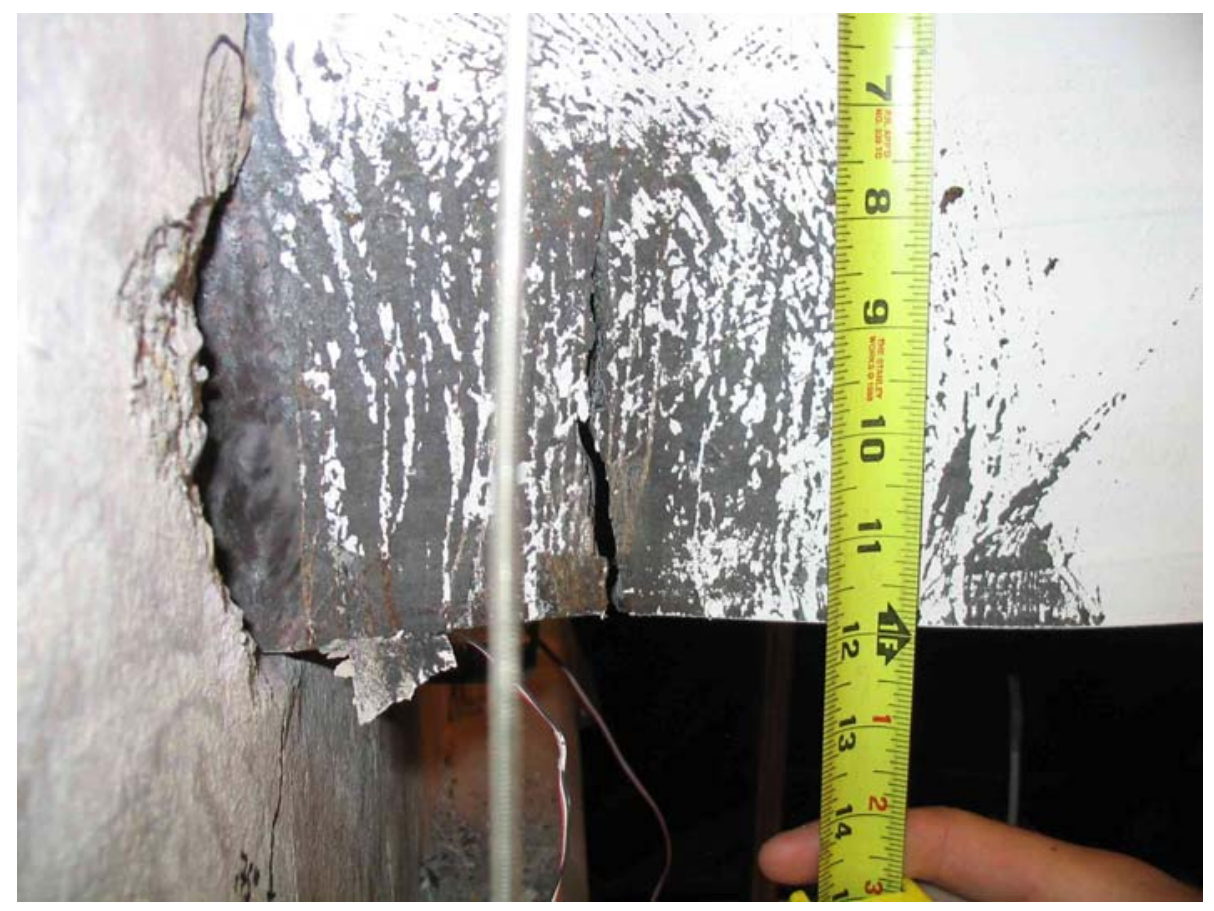

(c) SW Flange

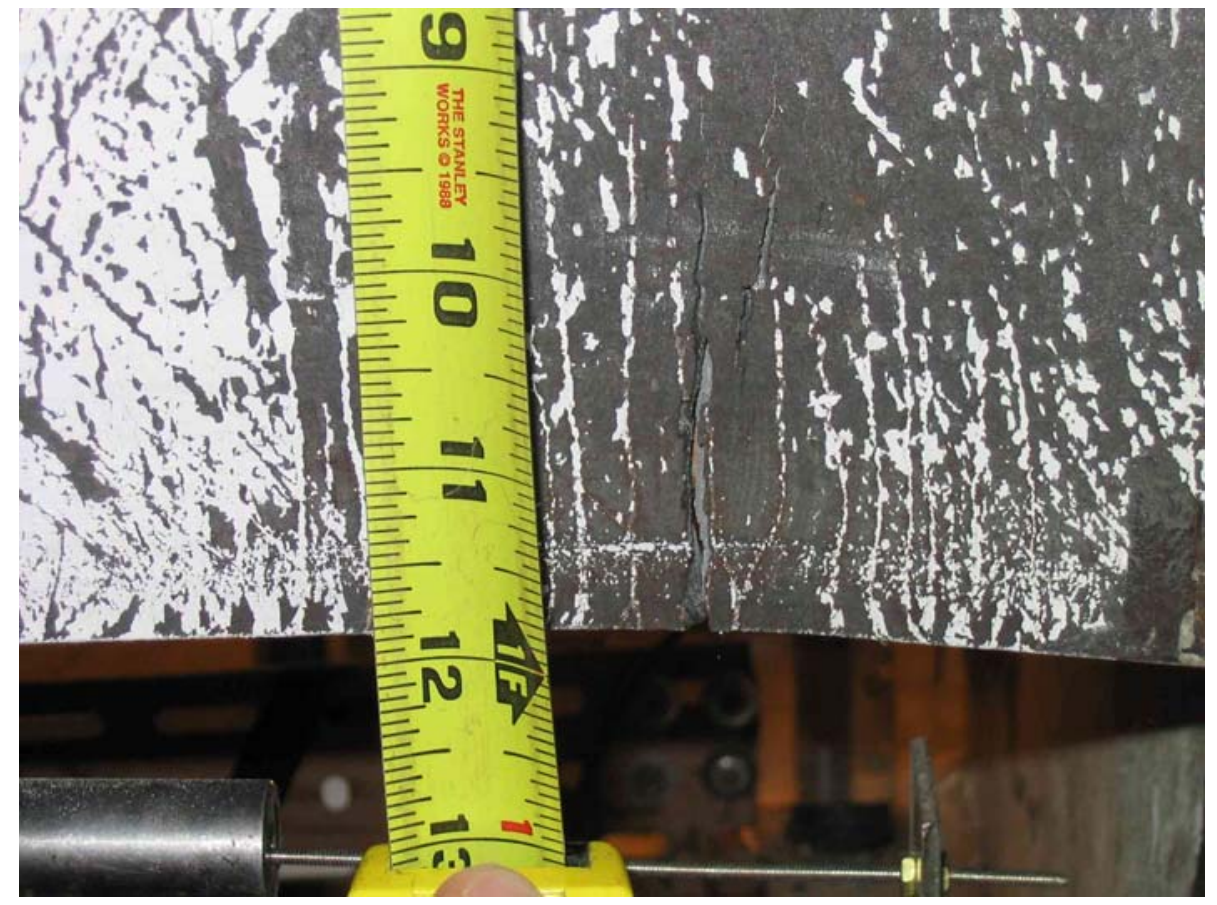

(d) SE Flange

Figure I.84: Specimen 6 - Crack on Steel Pile (1.75 in., 70 $^{\text {th }}$ Cycle) (Continue) 


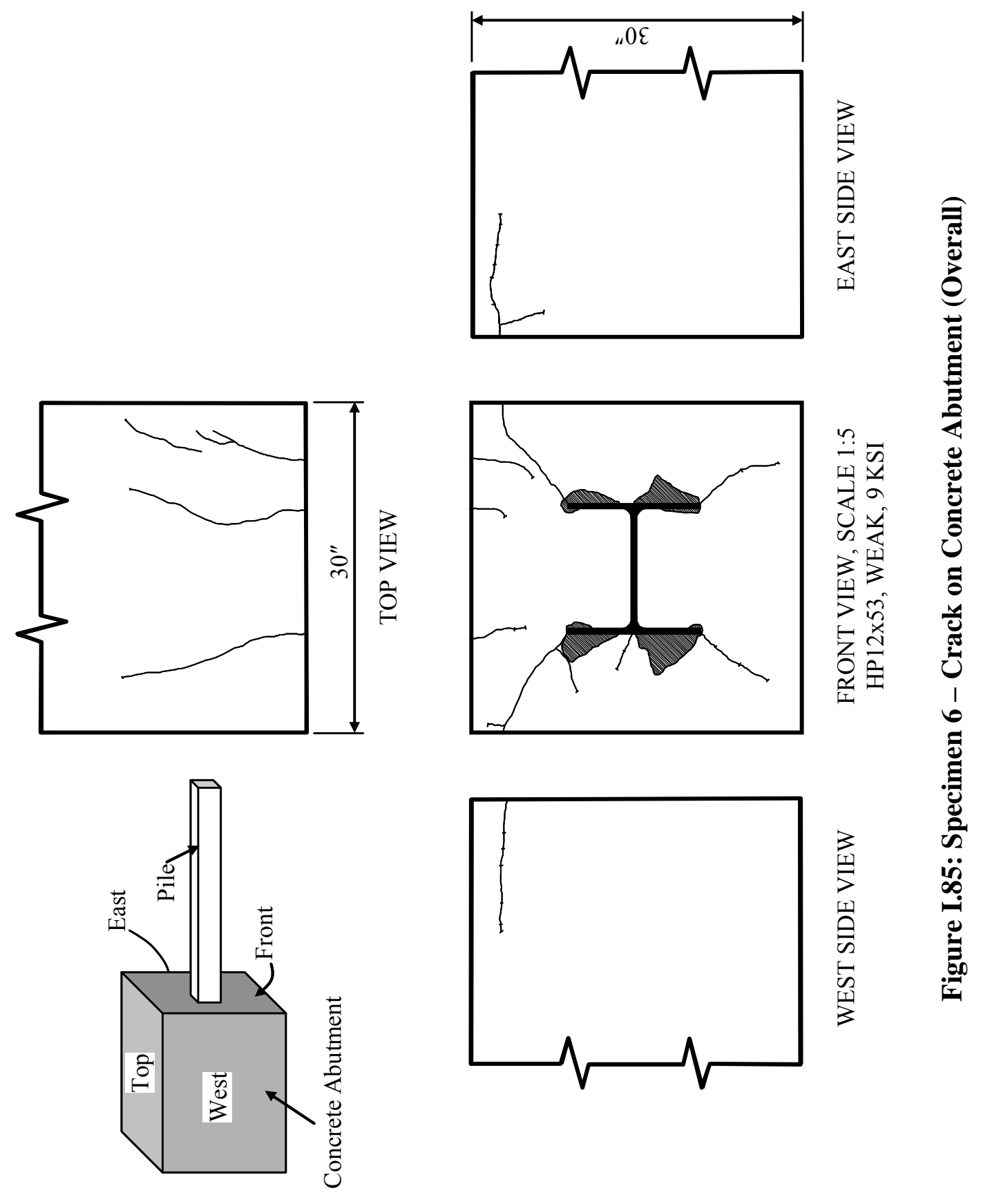




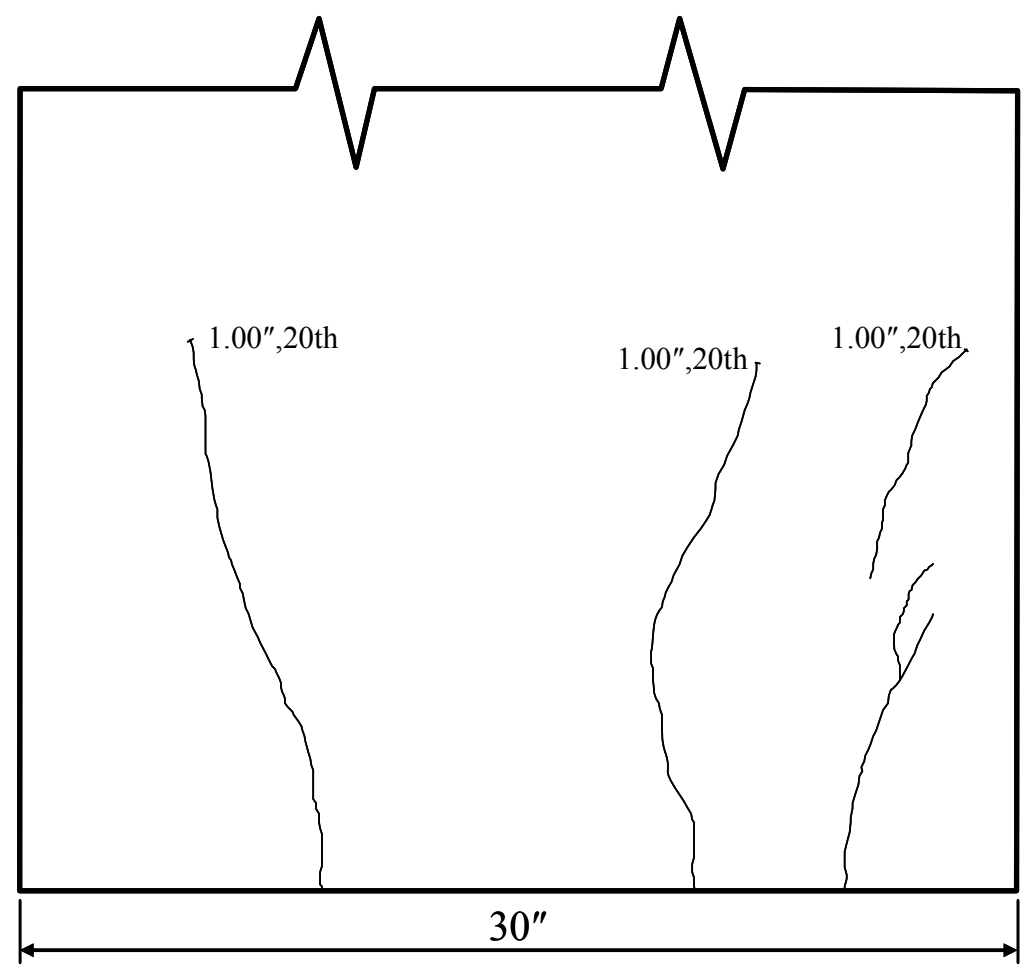

Figure I.86: Specimen 6 - Crack on Concrete Abutment (Top View)

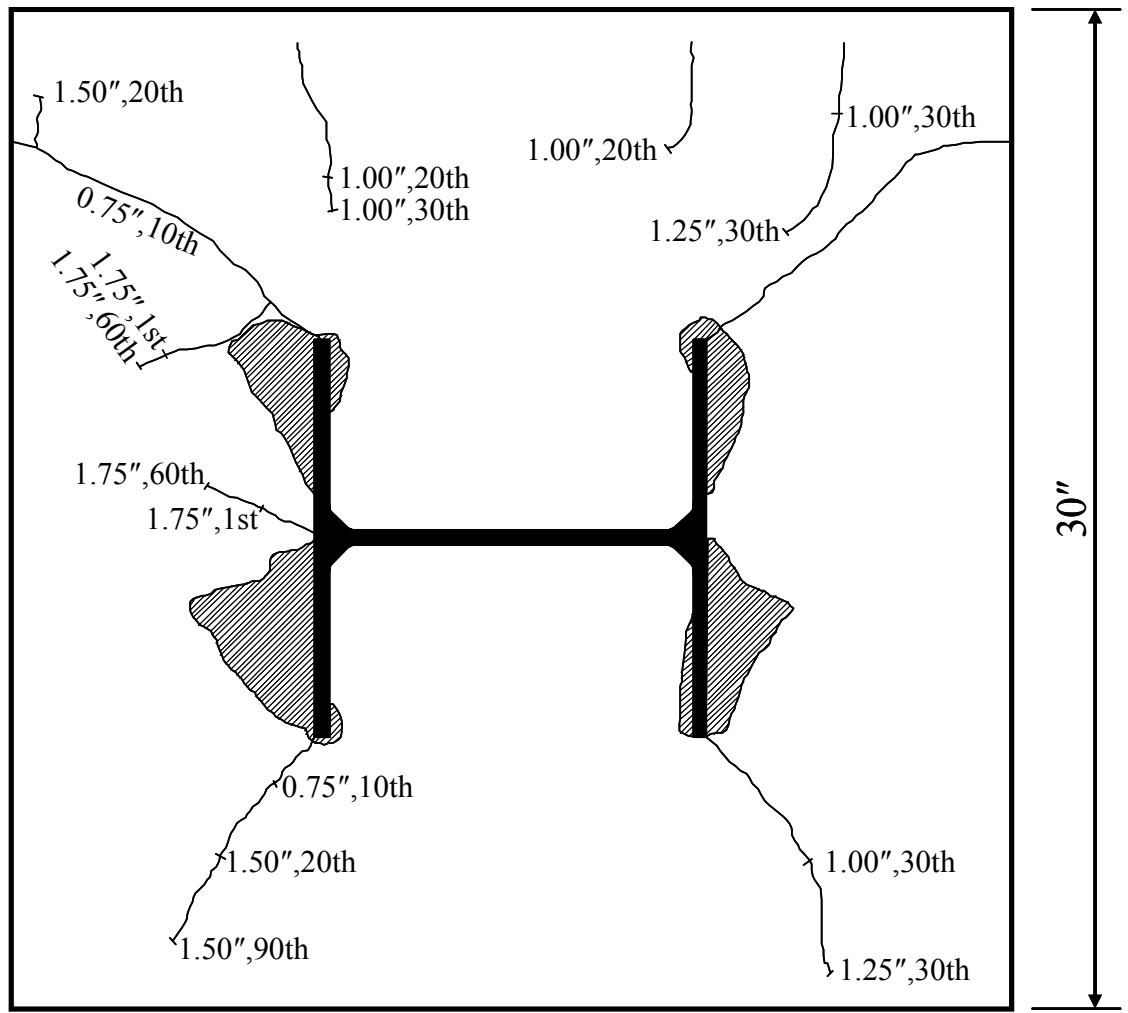

Figure I.87: Specimen 6 - Crack on Concrete Abutment (Front View) 


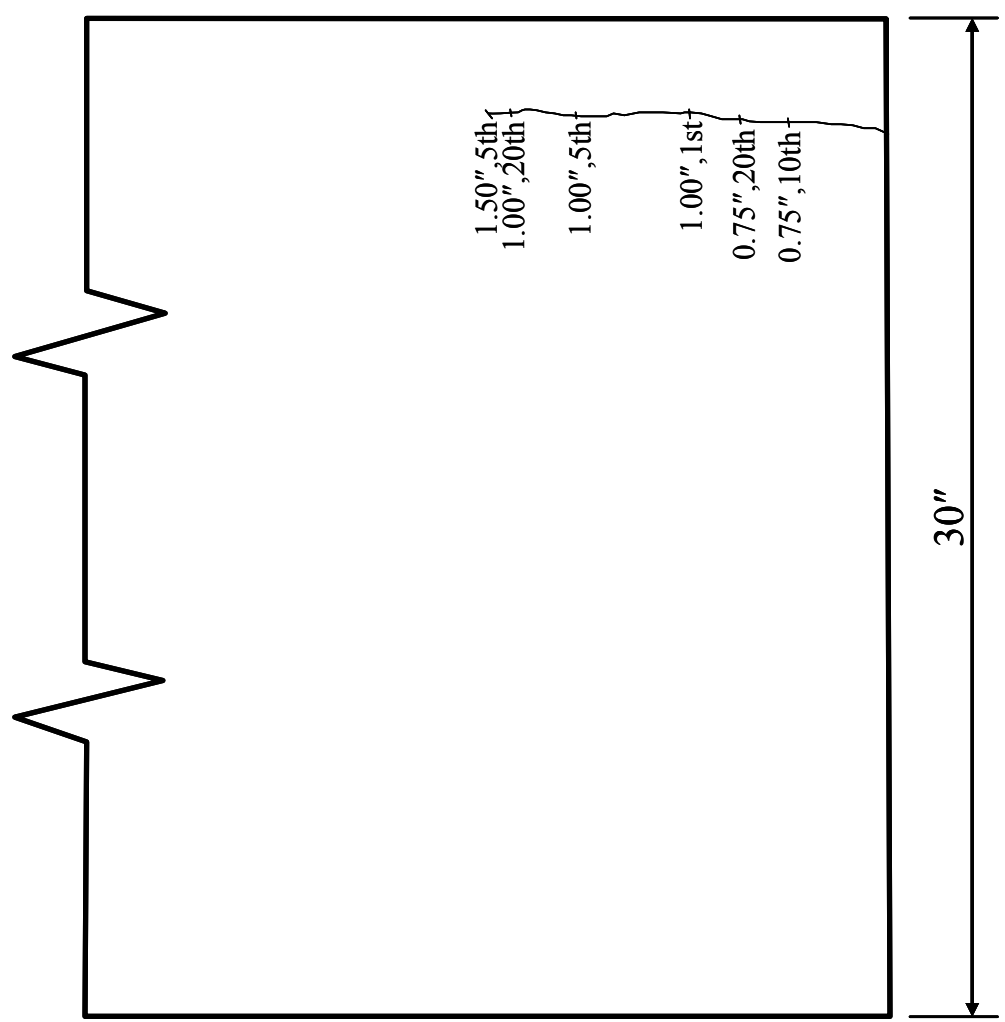

Figure I.88: Specimen 6 - Crack on Concrete Abutment (West View)

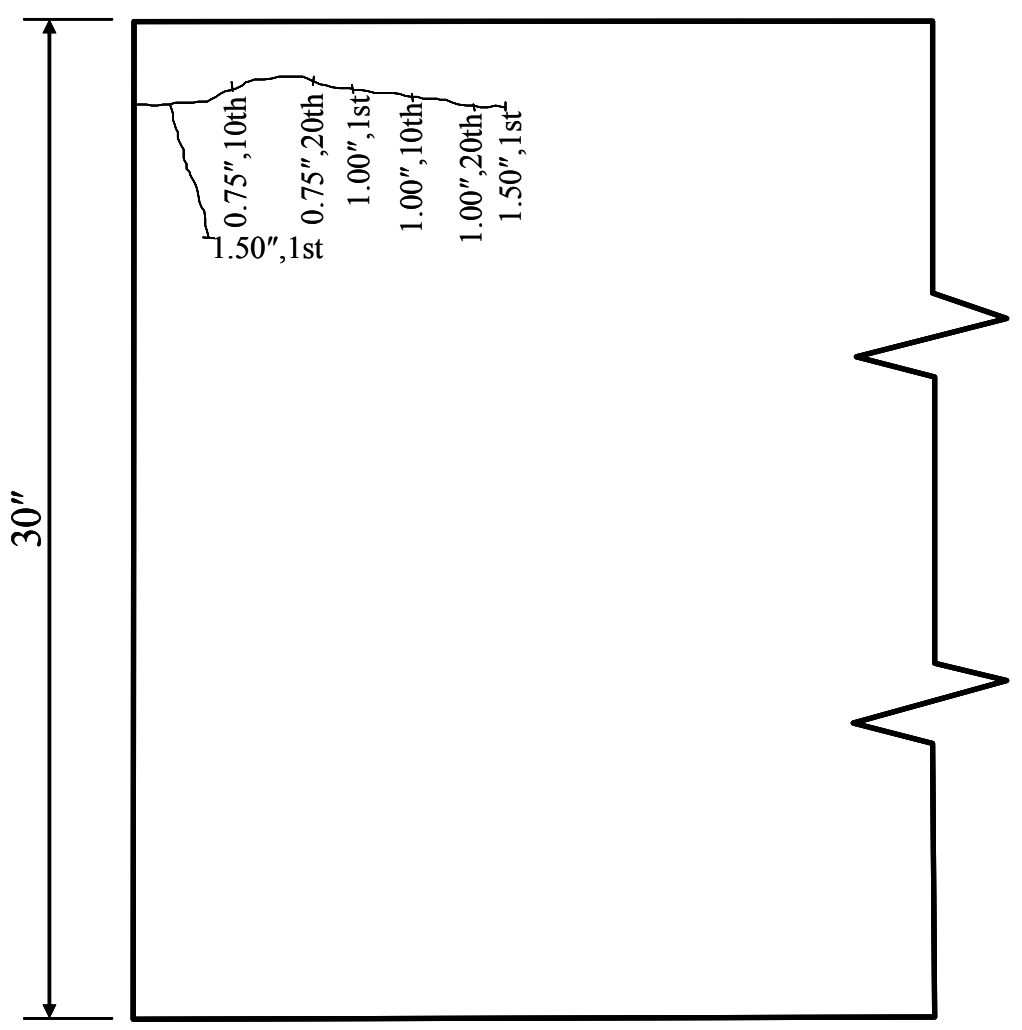

Figure I.89: Specimen 6 - Crack on Concrete Abutment (East View) 


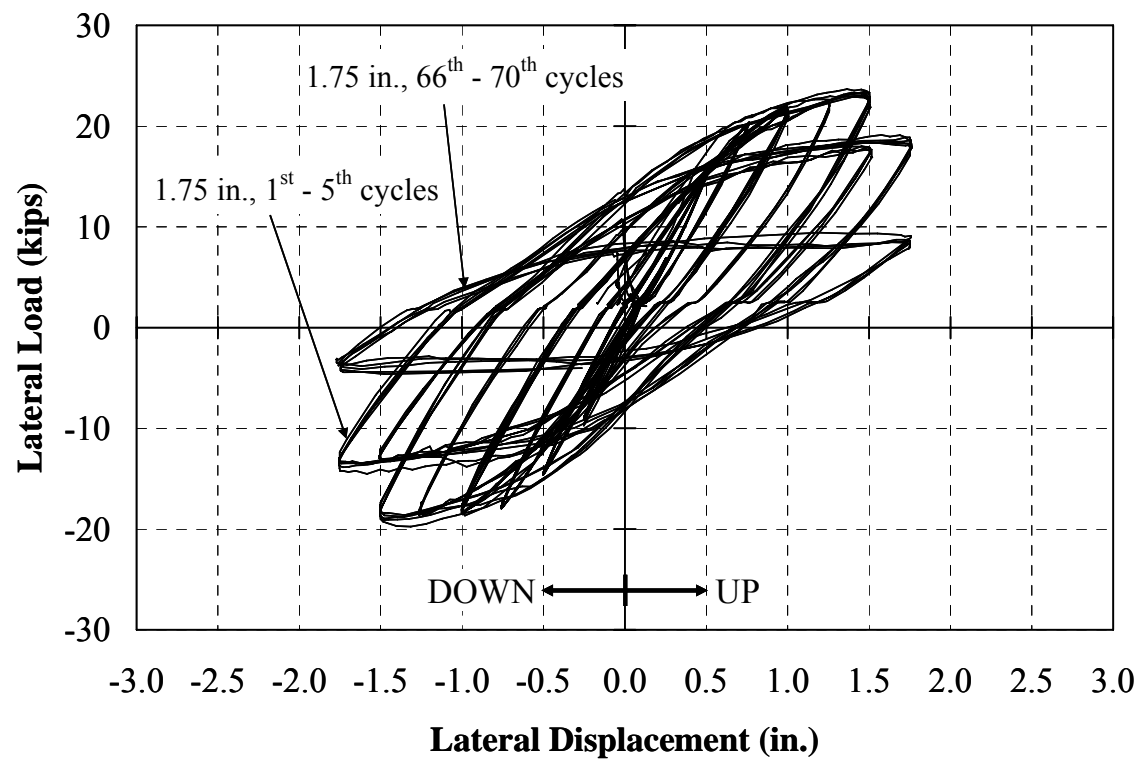

Figure I.90: Specimen 6 - Summary of Lateral Load-Deflection Curves

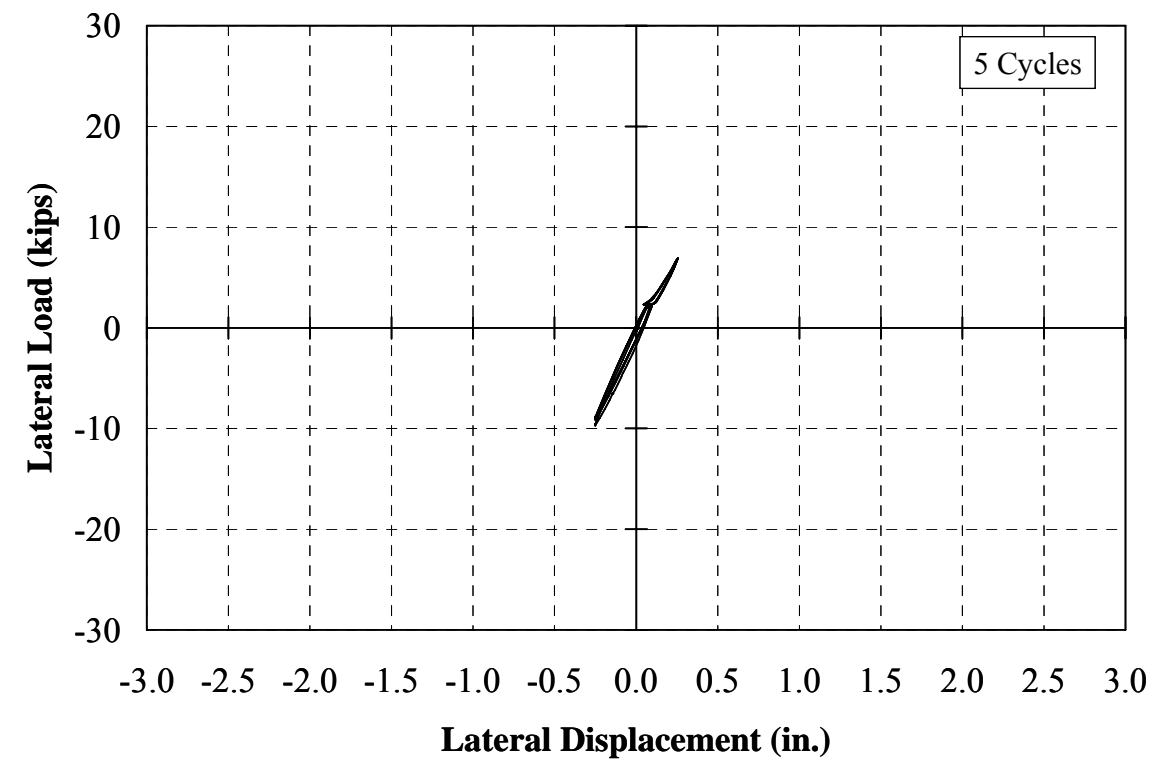

Figure I.91: Specimen 6 - Lateral Load-Deflection Response ( \pm 0.25 in.) 


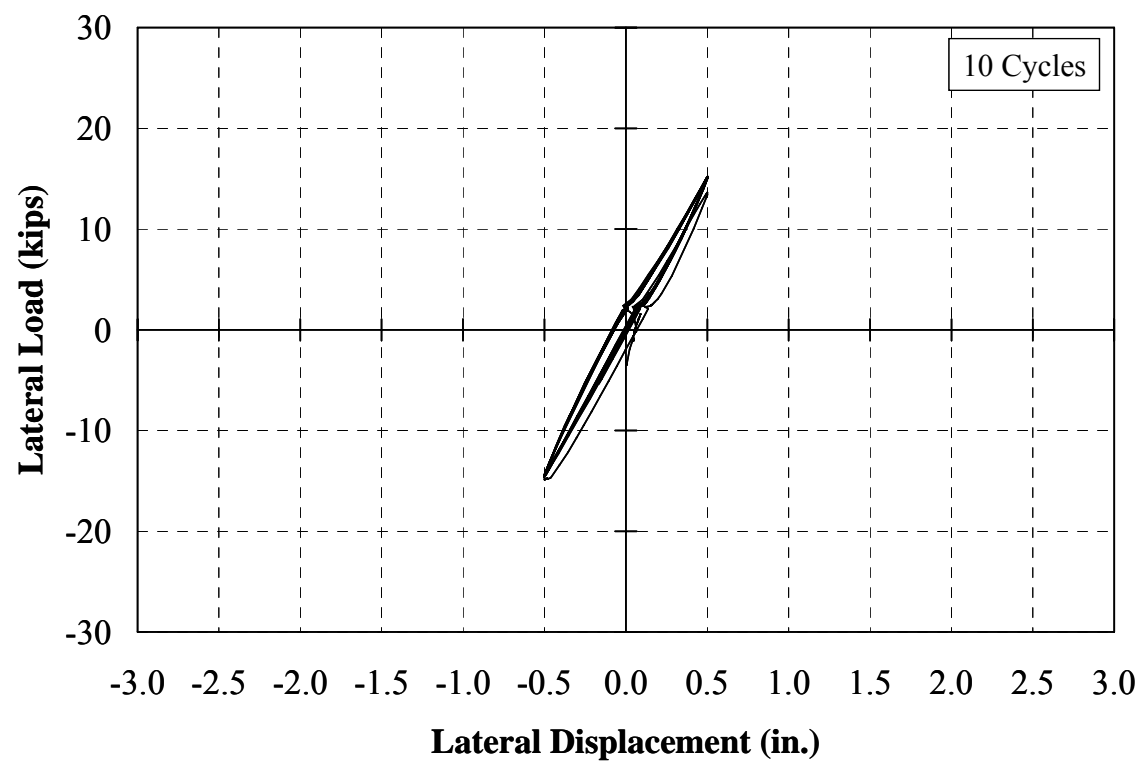

Figure I.92: Specimen 6 - Lateral Load-Deflection Response ( \pm 0.50 in.)

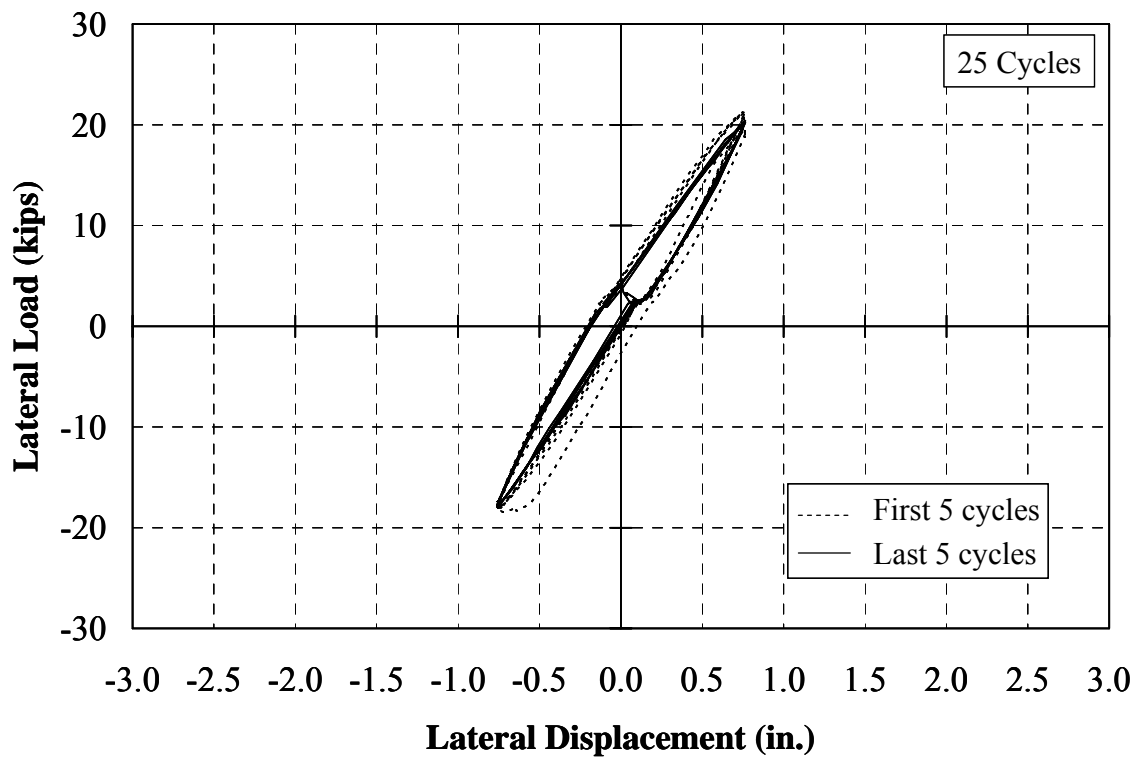

Figure I.93: Specimen 6 - Lateral Load-Deflection Response ( \pm 0.75 in.) 


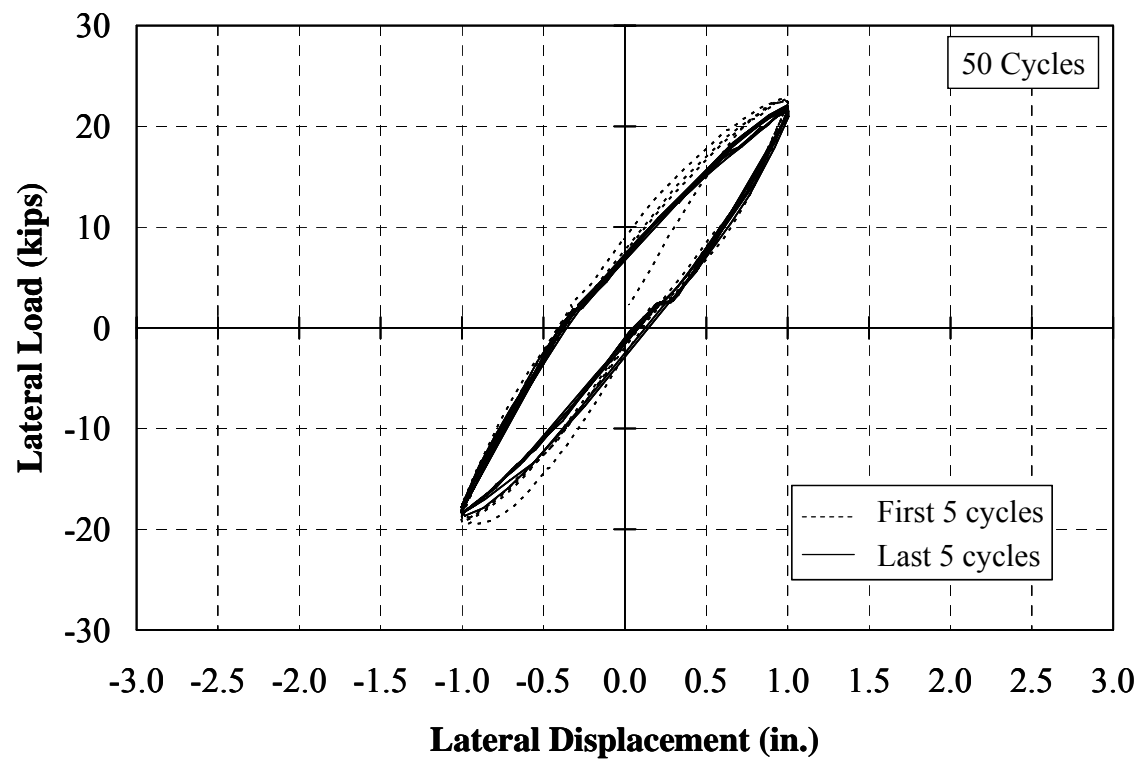

Figure I.94: Specimen 6 - Lateral Load-Deflection Response ( \pm 1.00 in.)

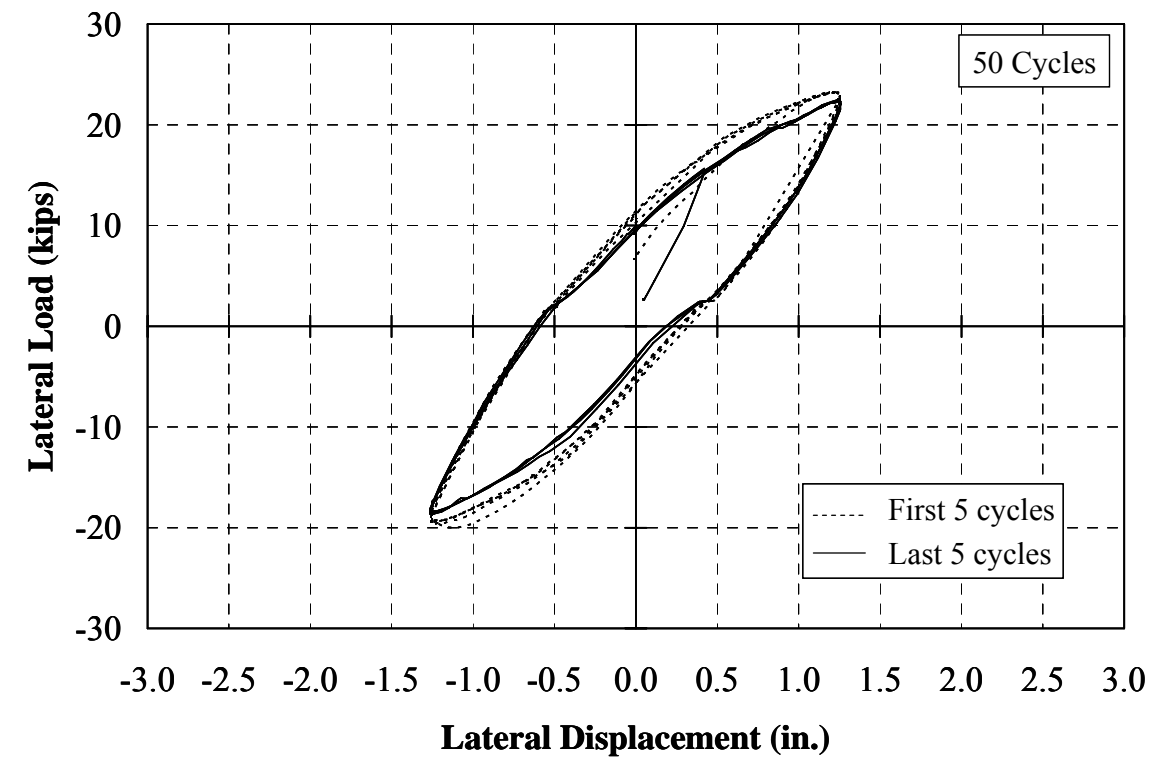

Figure I.95: Specimen 6 - Lateral Load-Deflection Response ( \pm 1.25 in.) 


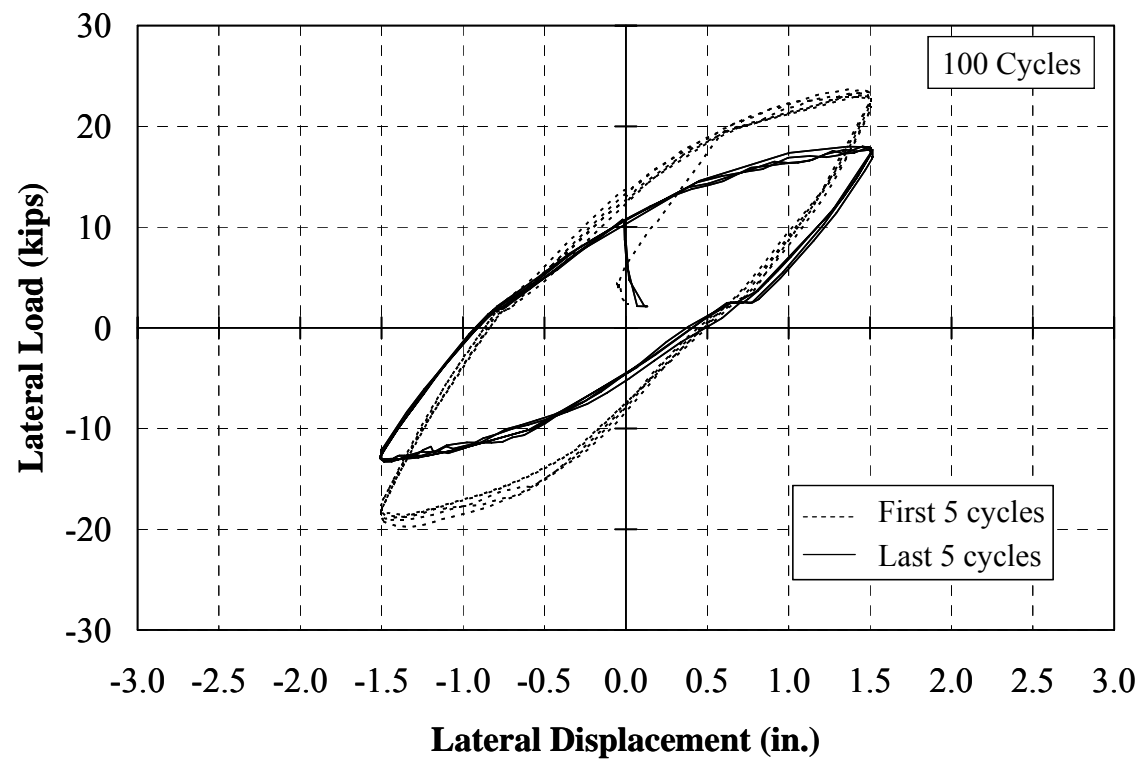

Figure I.96: Specimen 6 - Lateral Load-Deflection Response ( \pm 1.50 in.)

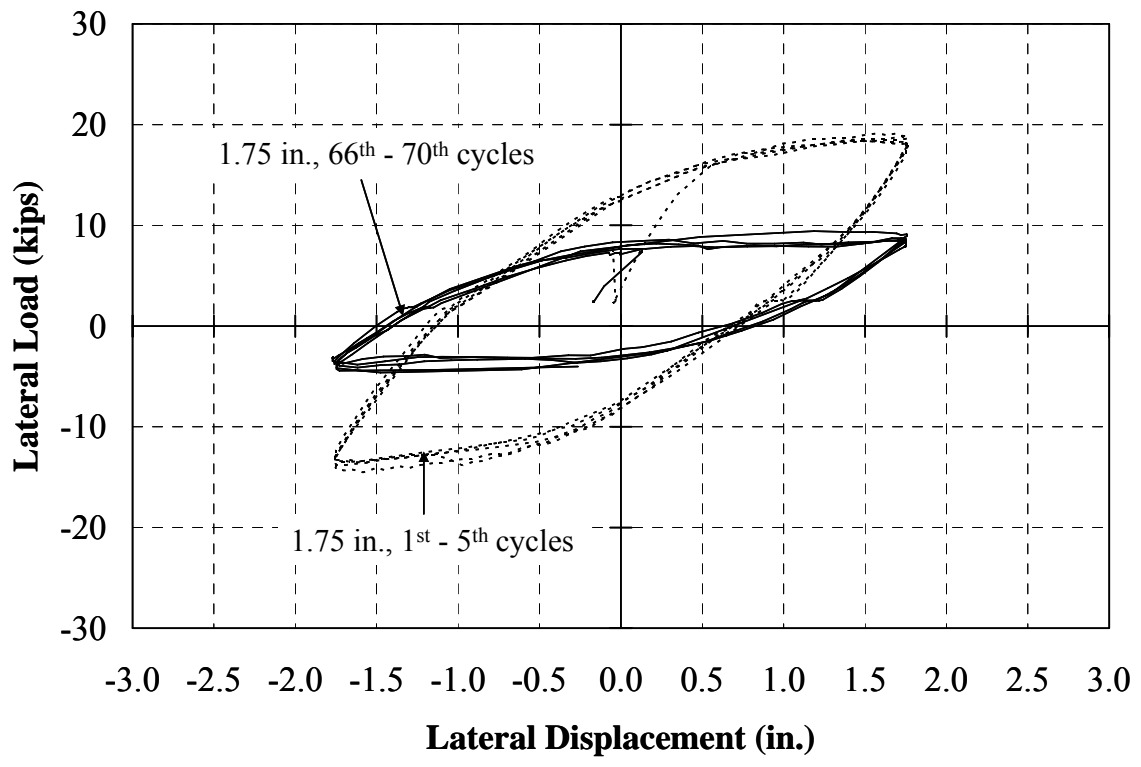

Figure I.97: Specimen 6 - Lateral Load-Deflection Response ( \pm 1.75 in.) 
Specimen 7: CFT8.625x0.188, “9 ksi”

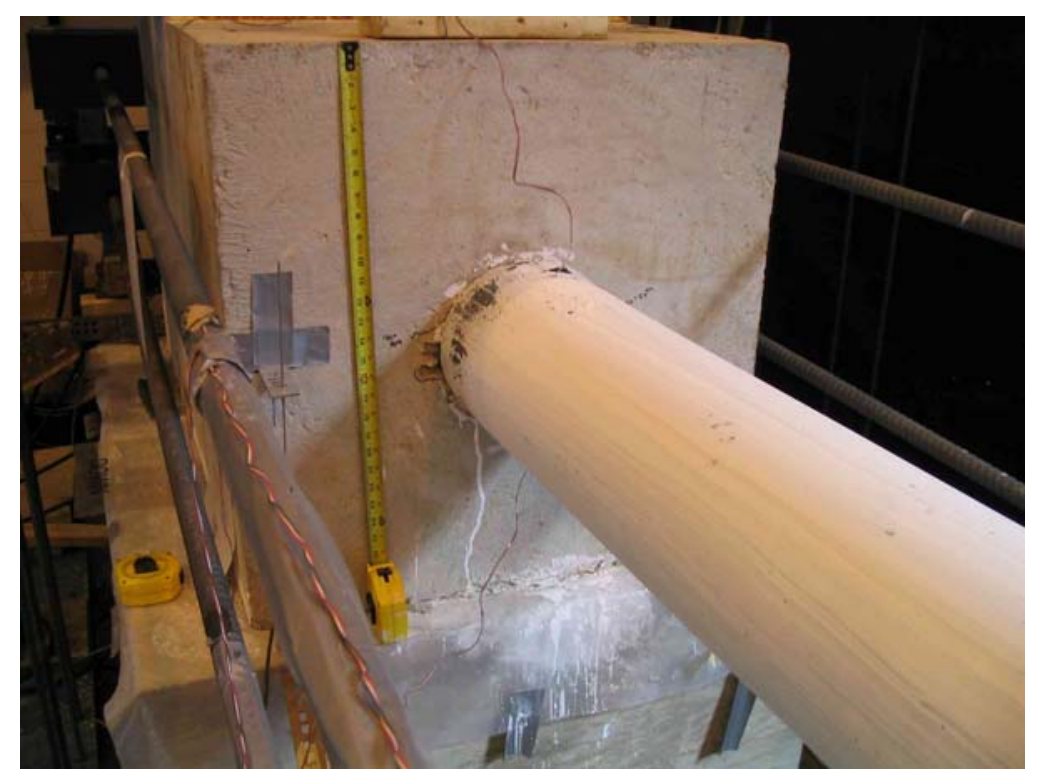

(a) West Side

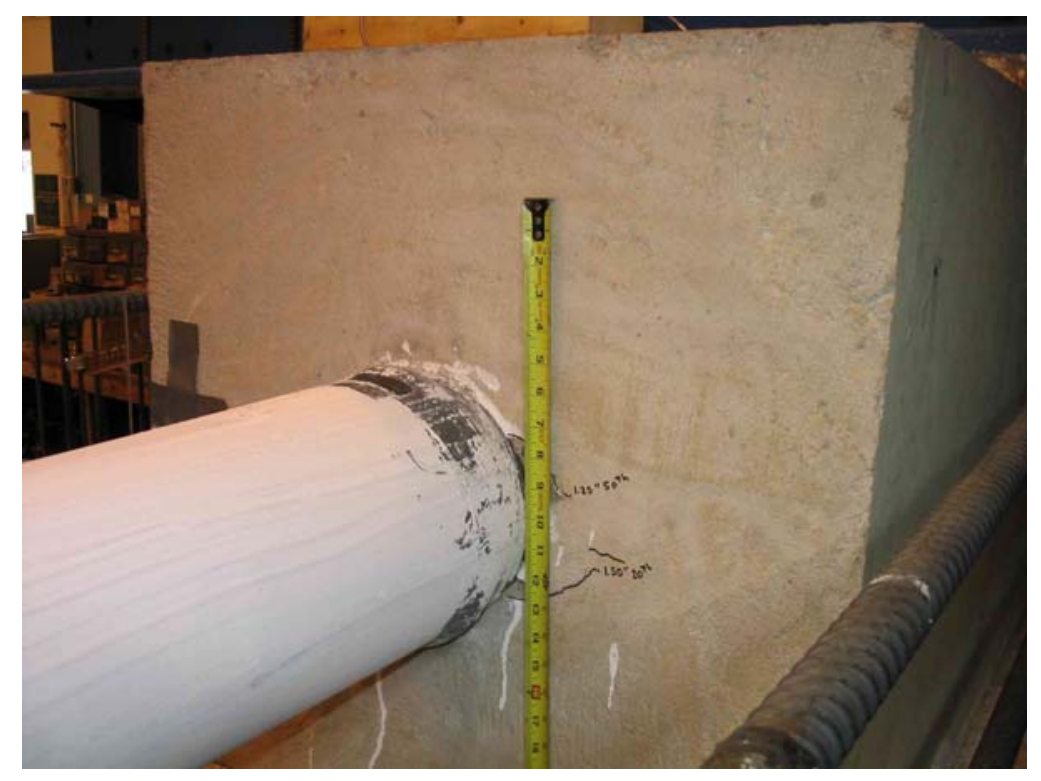

(b) East Side

Figure I.98: Specimen 7 - Cracking (1.75 in., $33^{\text {rd }}$ Cycle) 


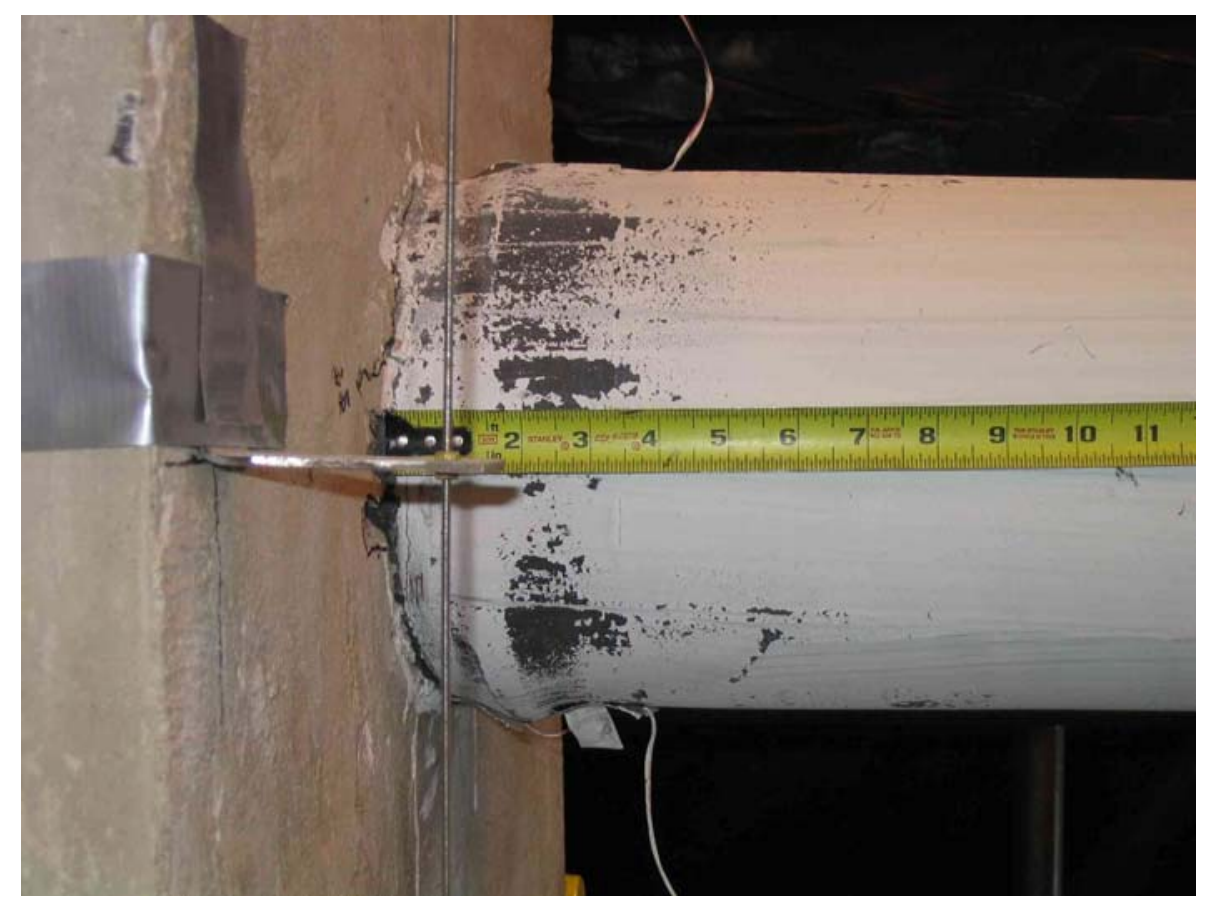

(a) West Side

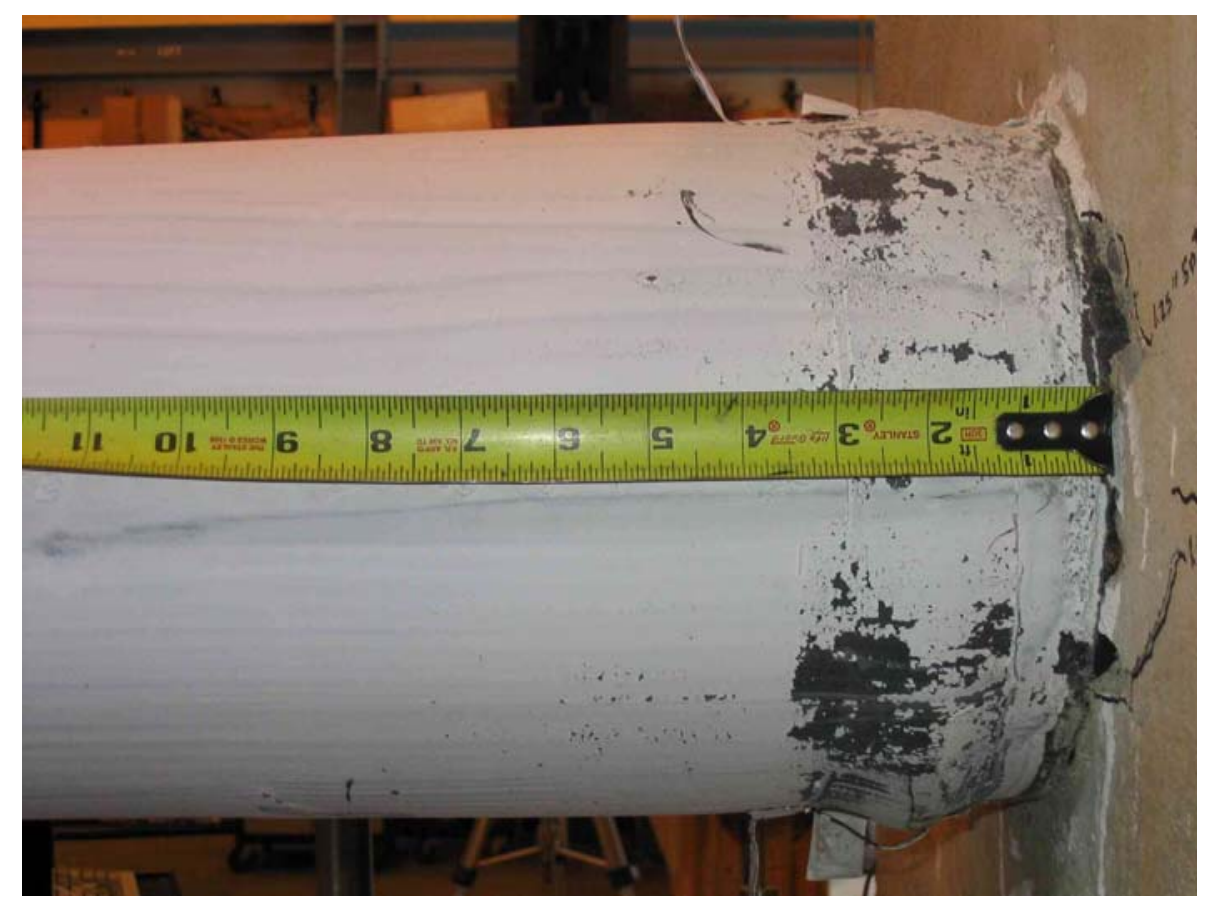

(b) East Side

Figure I.99: Specimen 7 - Pile Yielding (1.75 in., $33^{\text {rd }}$ Cycle) 


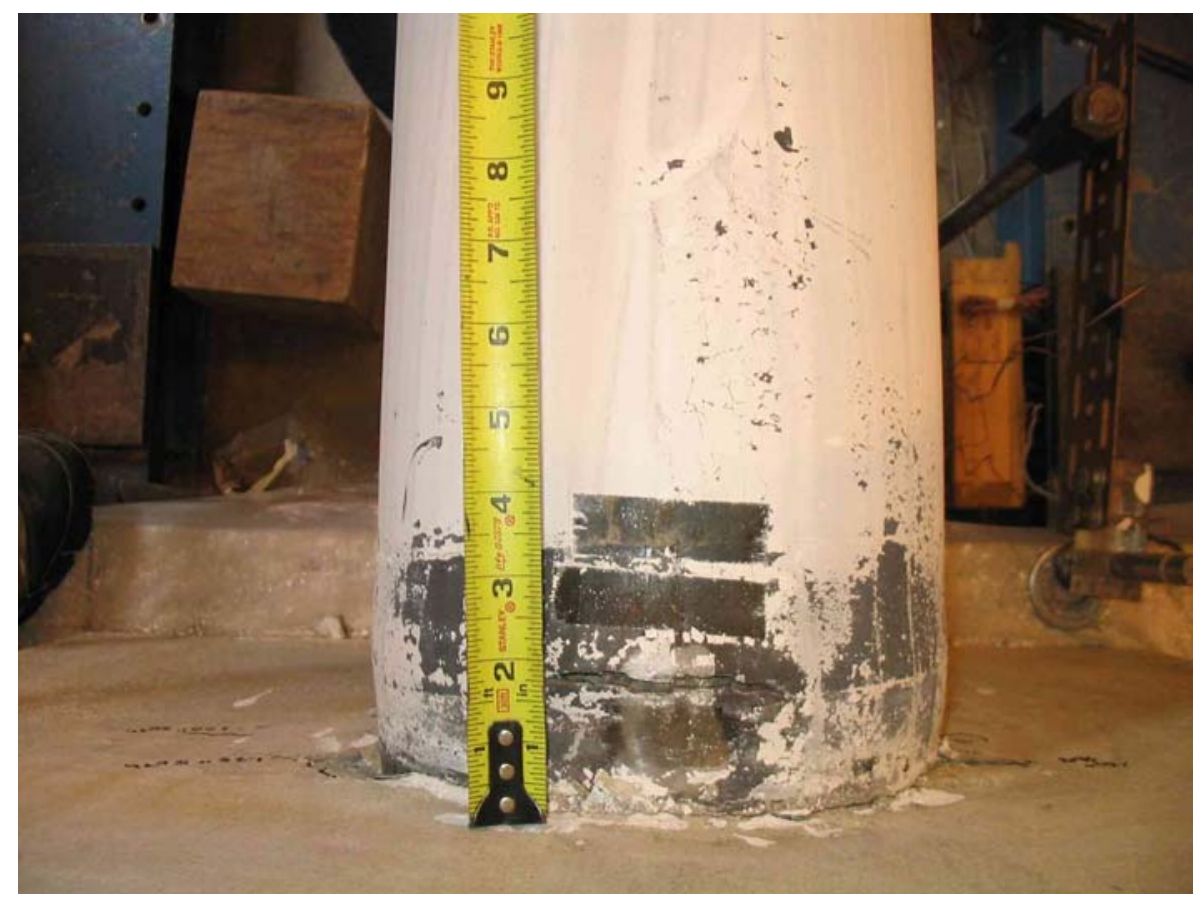

(c) Top

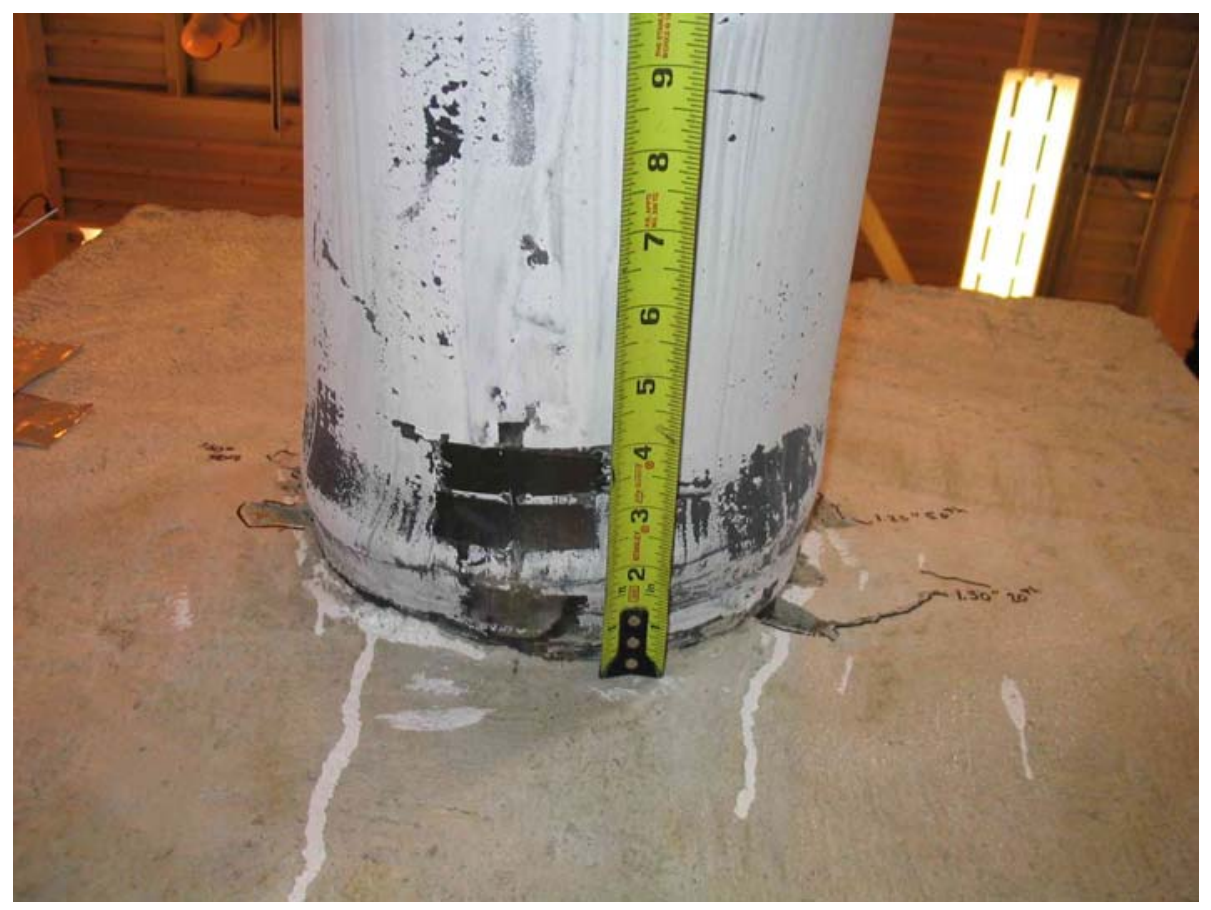

(d) Bottom

Figure I.99: Specimen 7 - Pile Yielding (1.75 in., $33^{\text {rd }}$ Cycle) (Continue) 


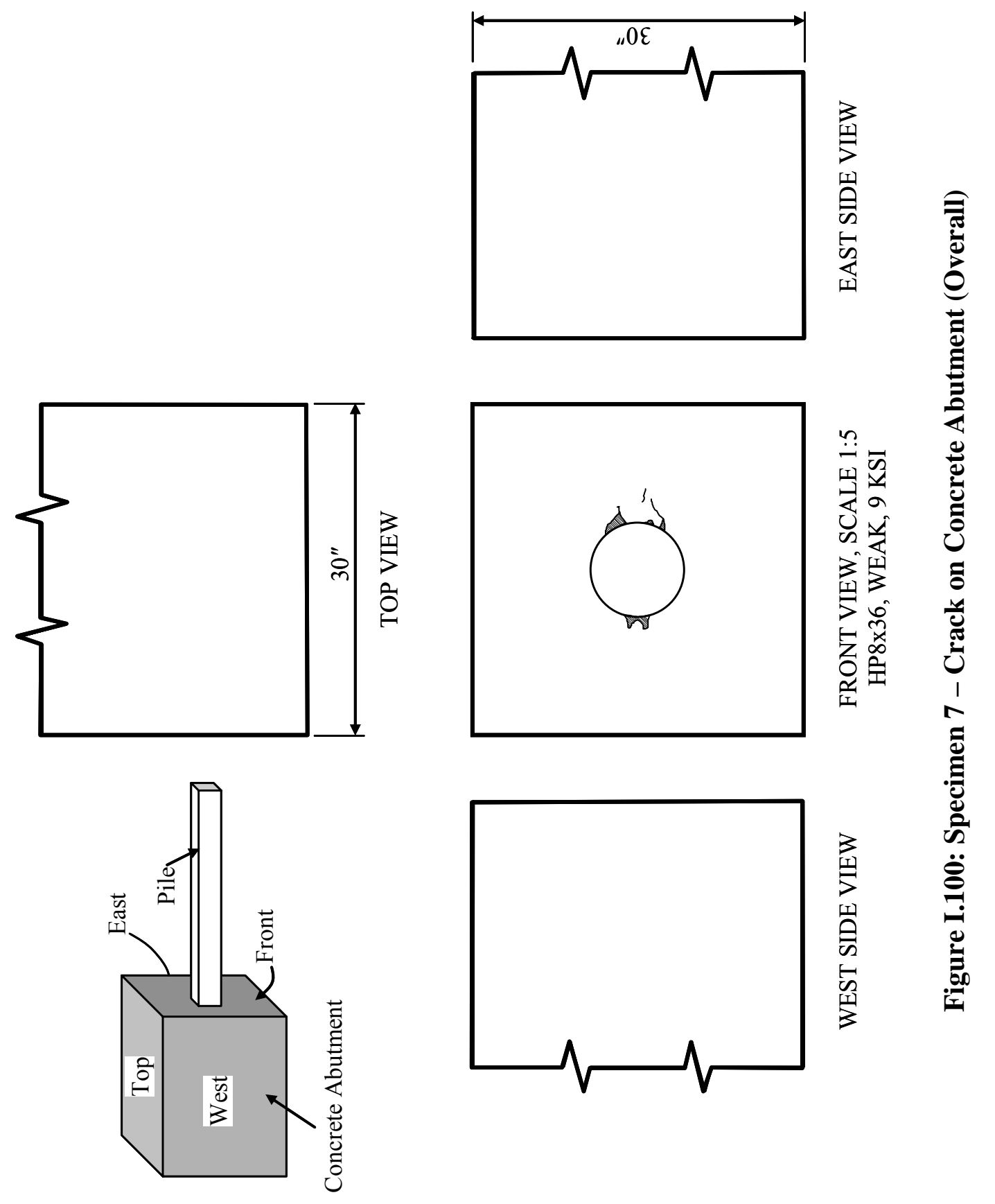




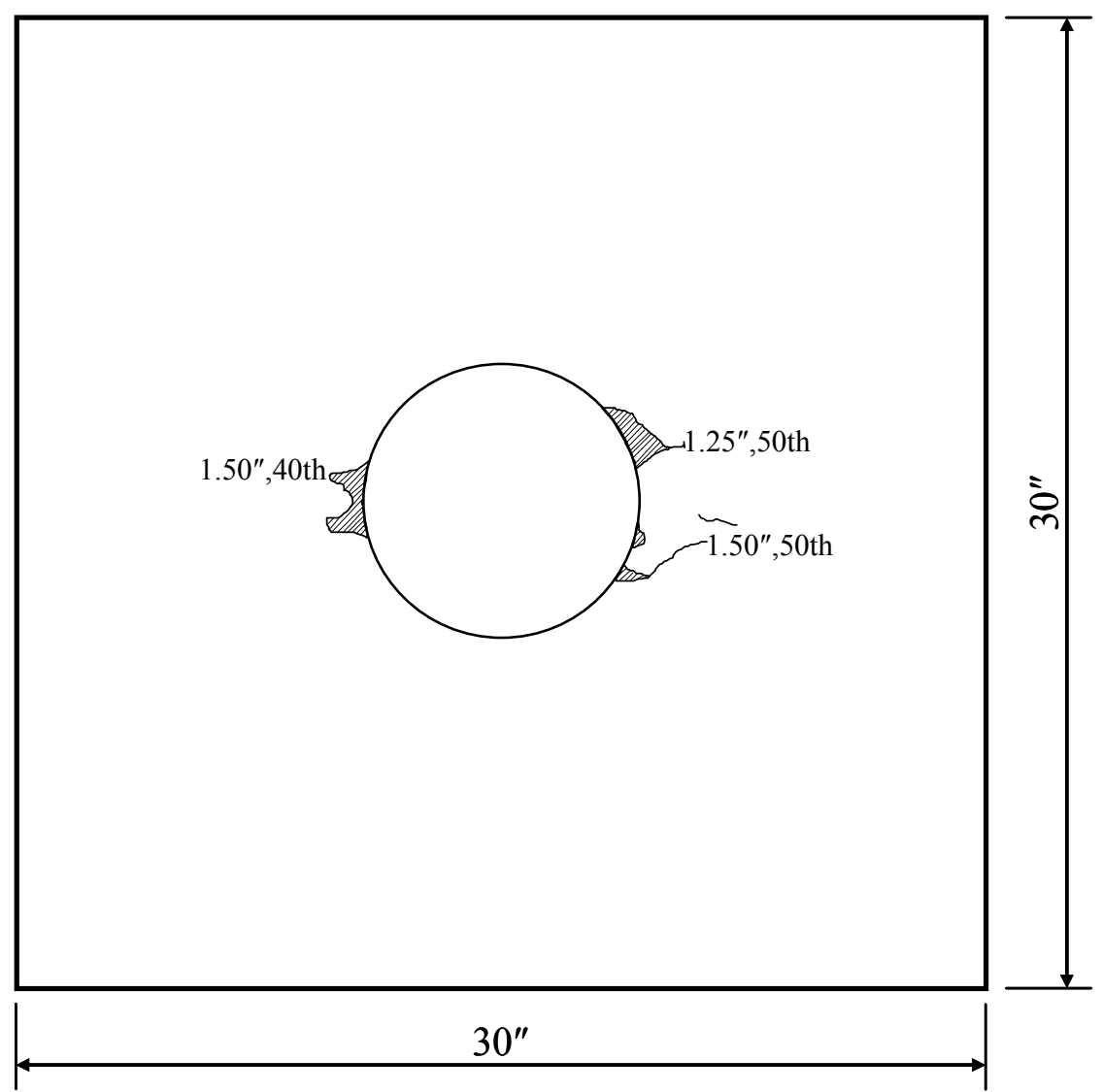

Figure I.101: Specimen 7 - Crack on Concrete Abutment (Front View)

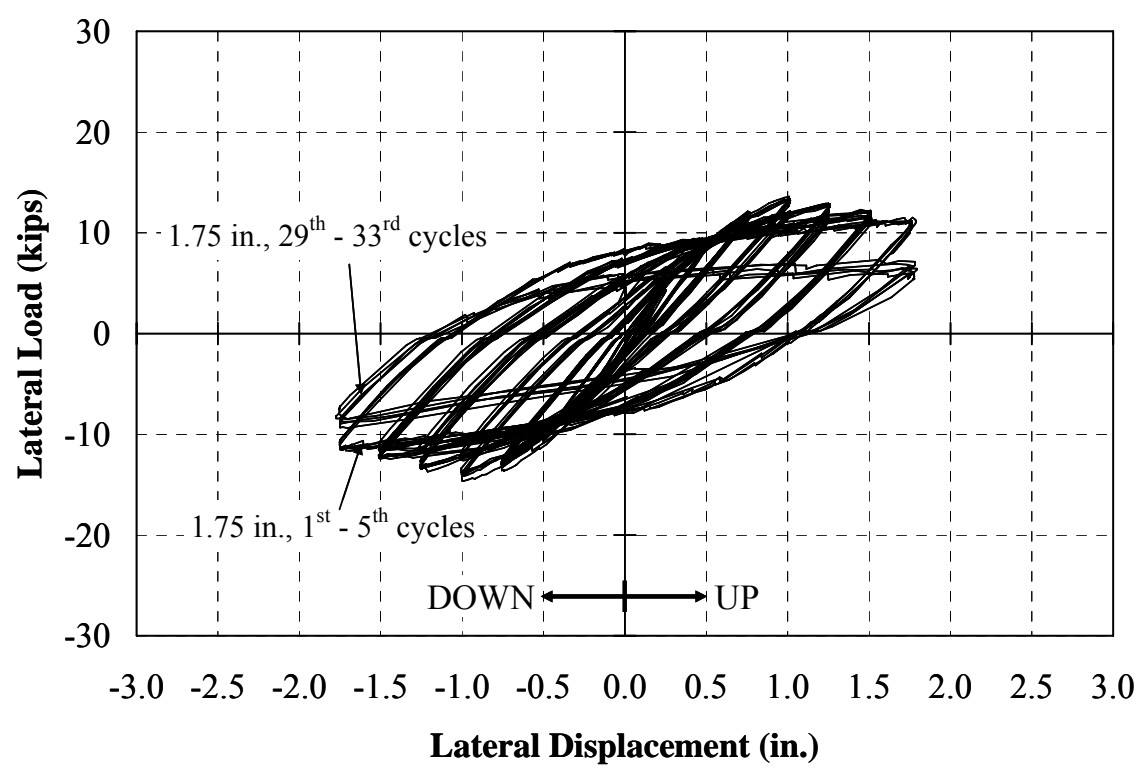

Figure I.102: Specimen 7 - Summary of Lateral Load-Deflection Curves 


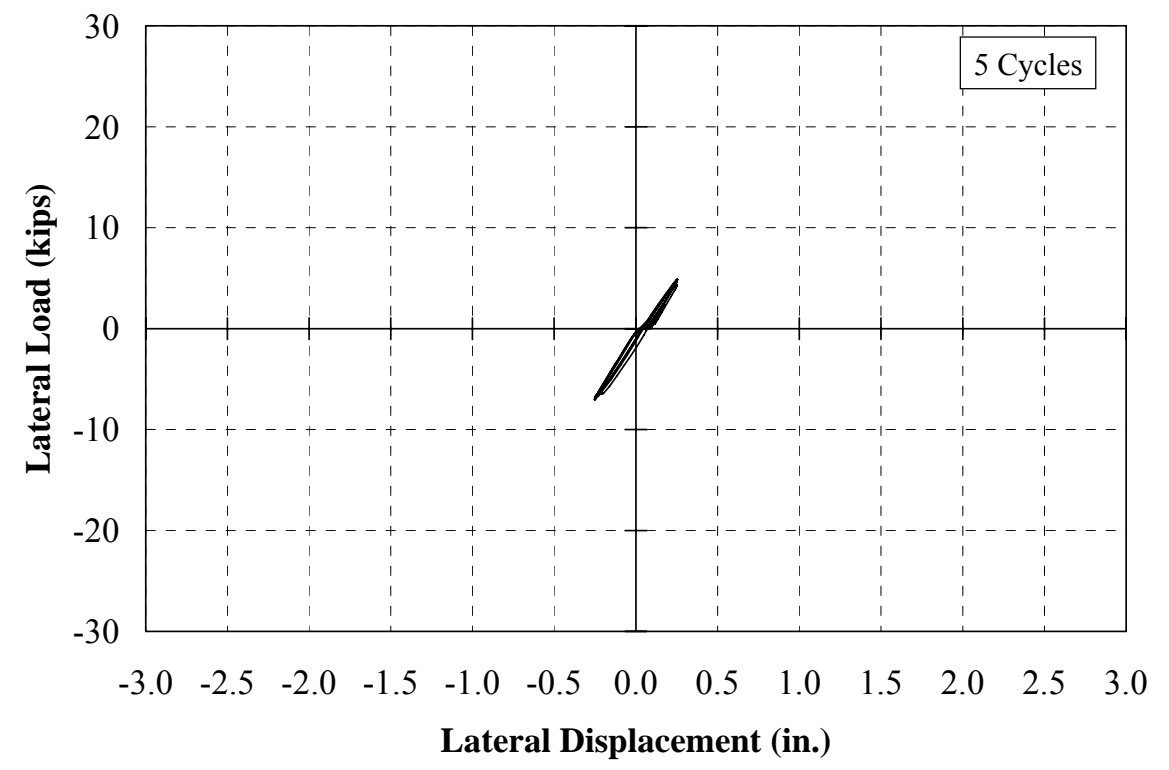

Figure I.103: Specimen 7 - Lateral Load-Deflection Response ( \pm 0.25 in.)

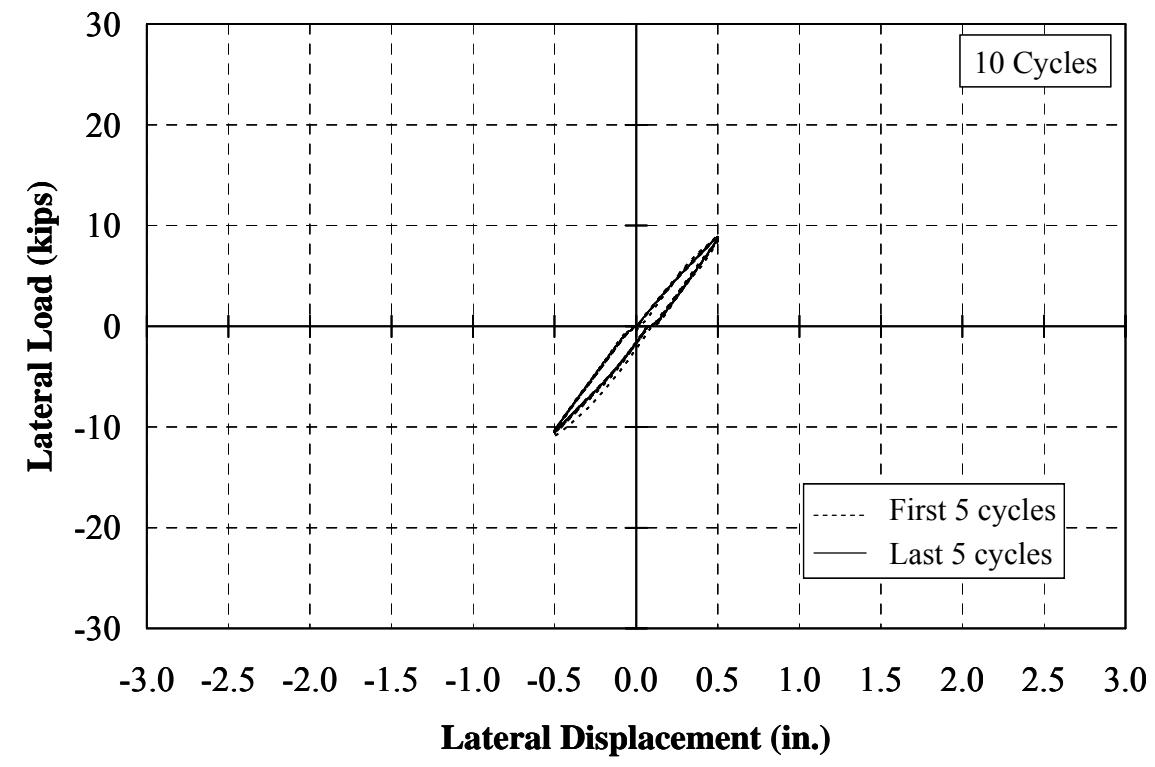

Figure I.104: Specimen 7 - Lateral Load-Deflection Response ( \pm 0.50 in.) 


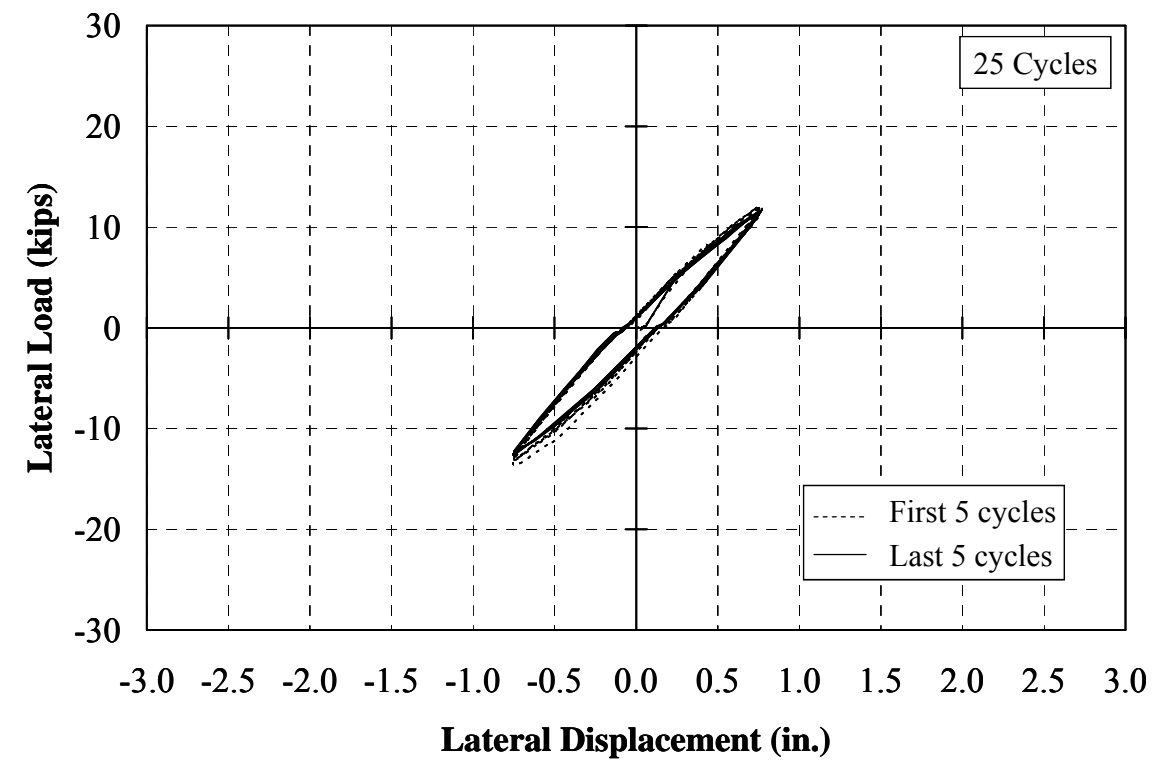

Figure I.105: Specimen 7 - Lateral Load-Deflection Response ( \pm 0.75 in.)

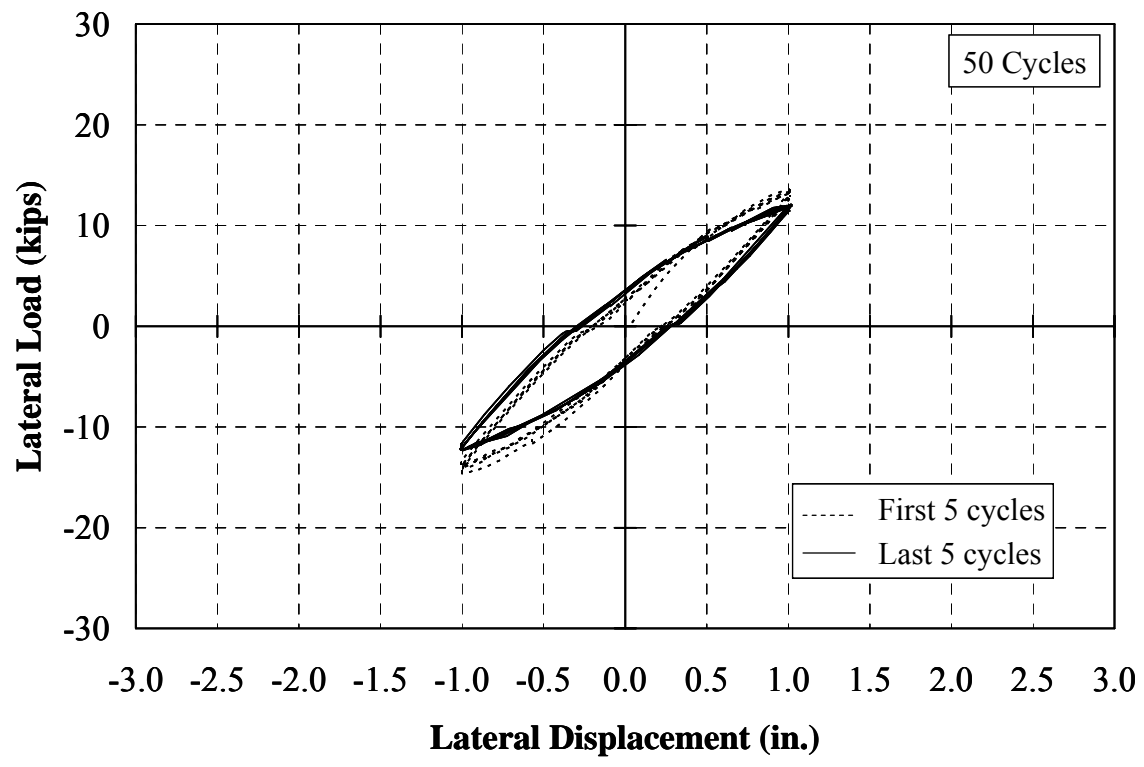

Figure I.106: Specimen 7 - Lateral Load-Deflection Response ( \pm 1.00 in.) 


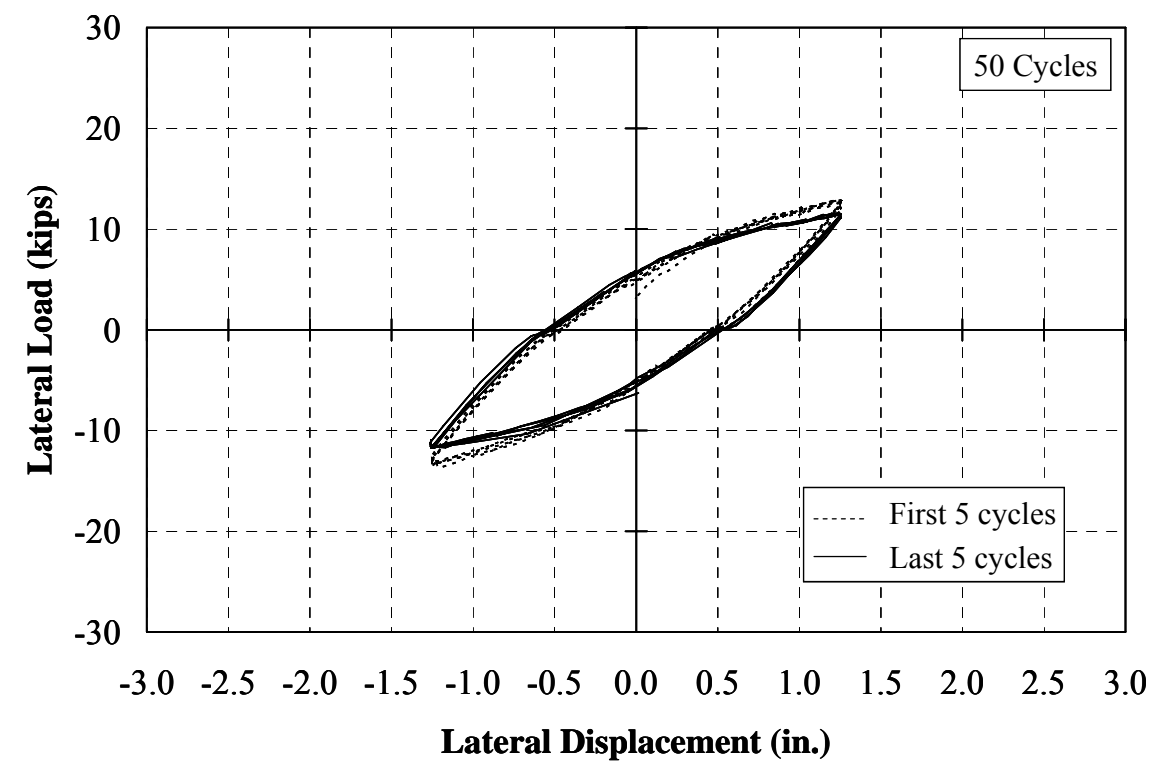

Figure I.107: Specimen 7 - Lateral Load-Deflection Response ( \pm 1.25 in.)

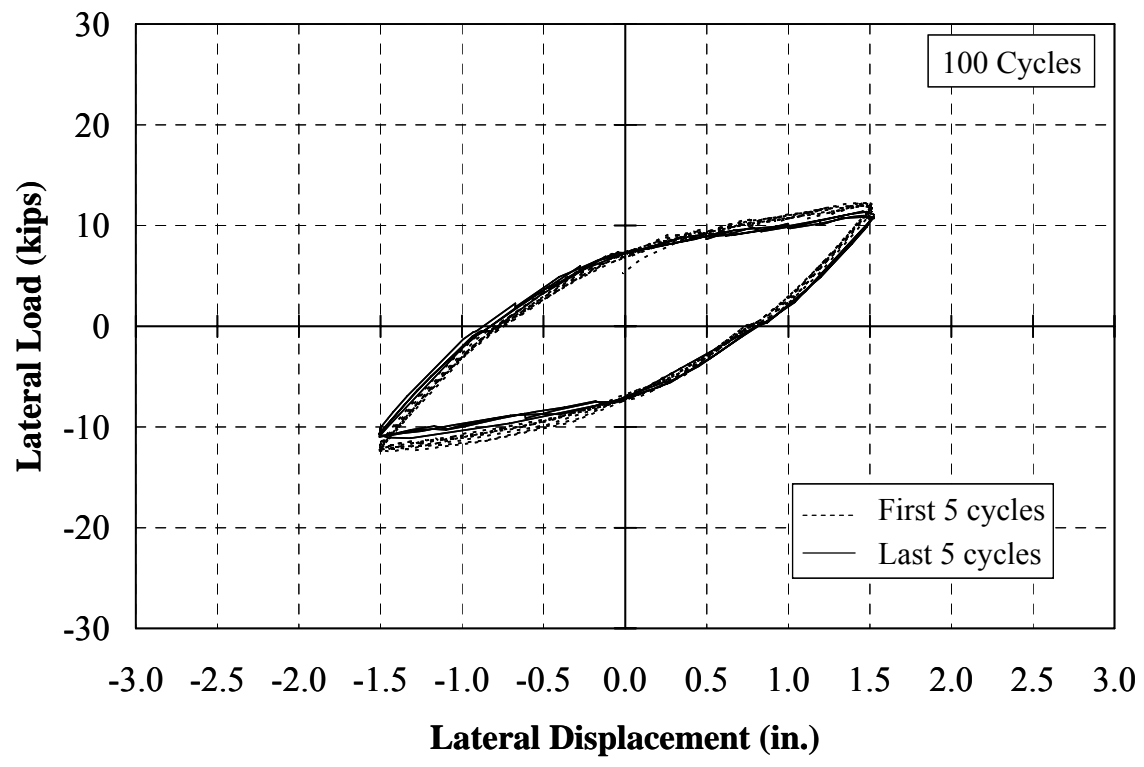

Figure I.108: Specimen 7 - Lateral Load-Deflection Response ( \pm 1.50 in.) 


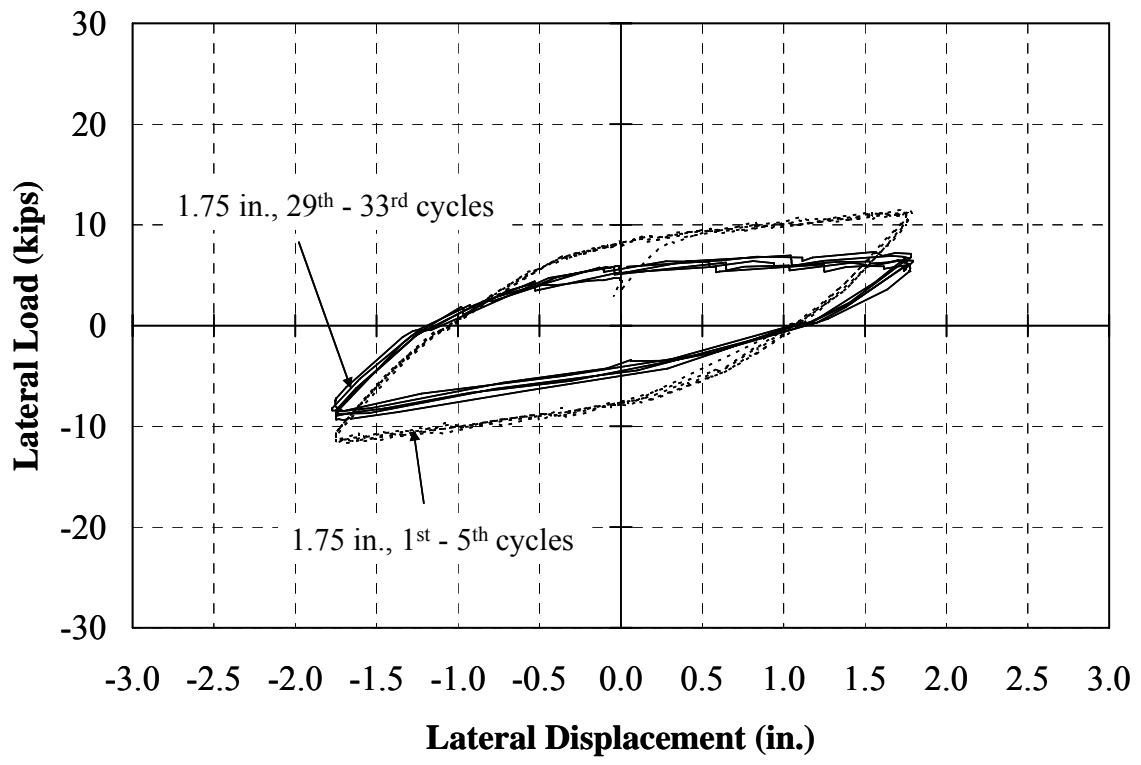

Figure I.109: Specimen 7 - Lateral Load-Deflection Response ( \pm 1.75 in.) 
Specimen 8: CFT8.625x0.188, “18 ksi”

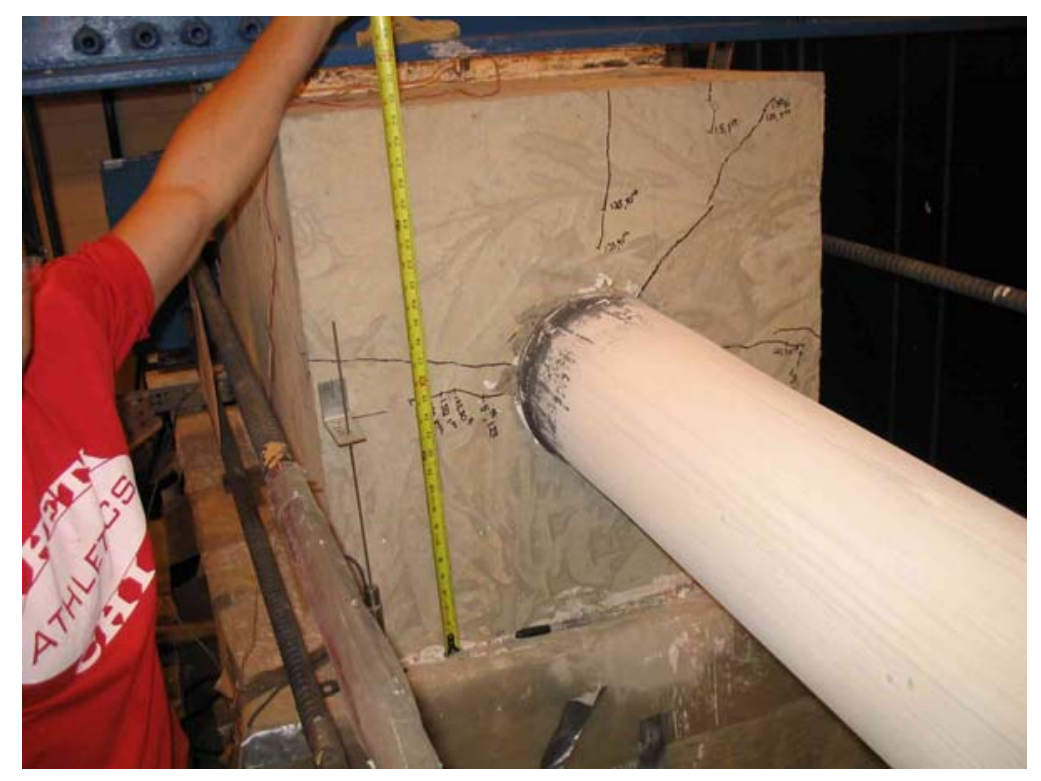

(a) West Side

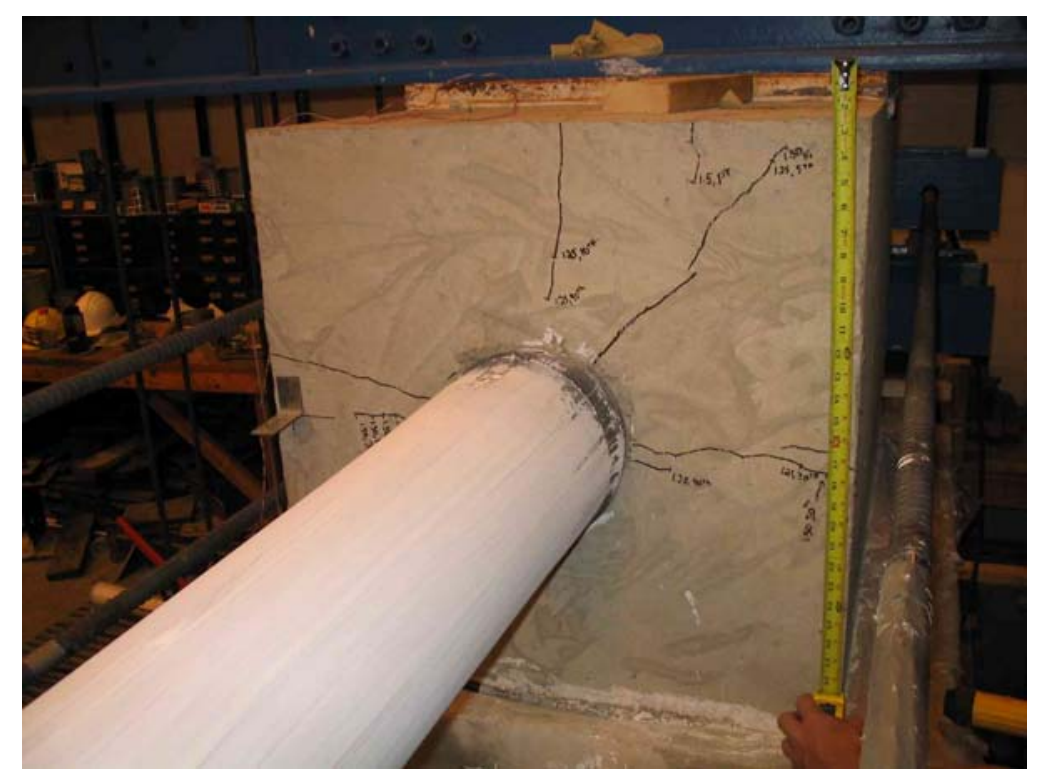

(b) East Side

Figure I.110: Specimen 8 - Cracking (1.75 in., $10^{\text {th }}$ Cycle) 


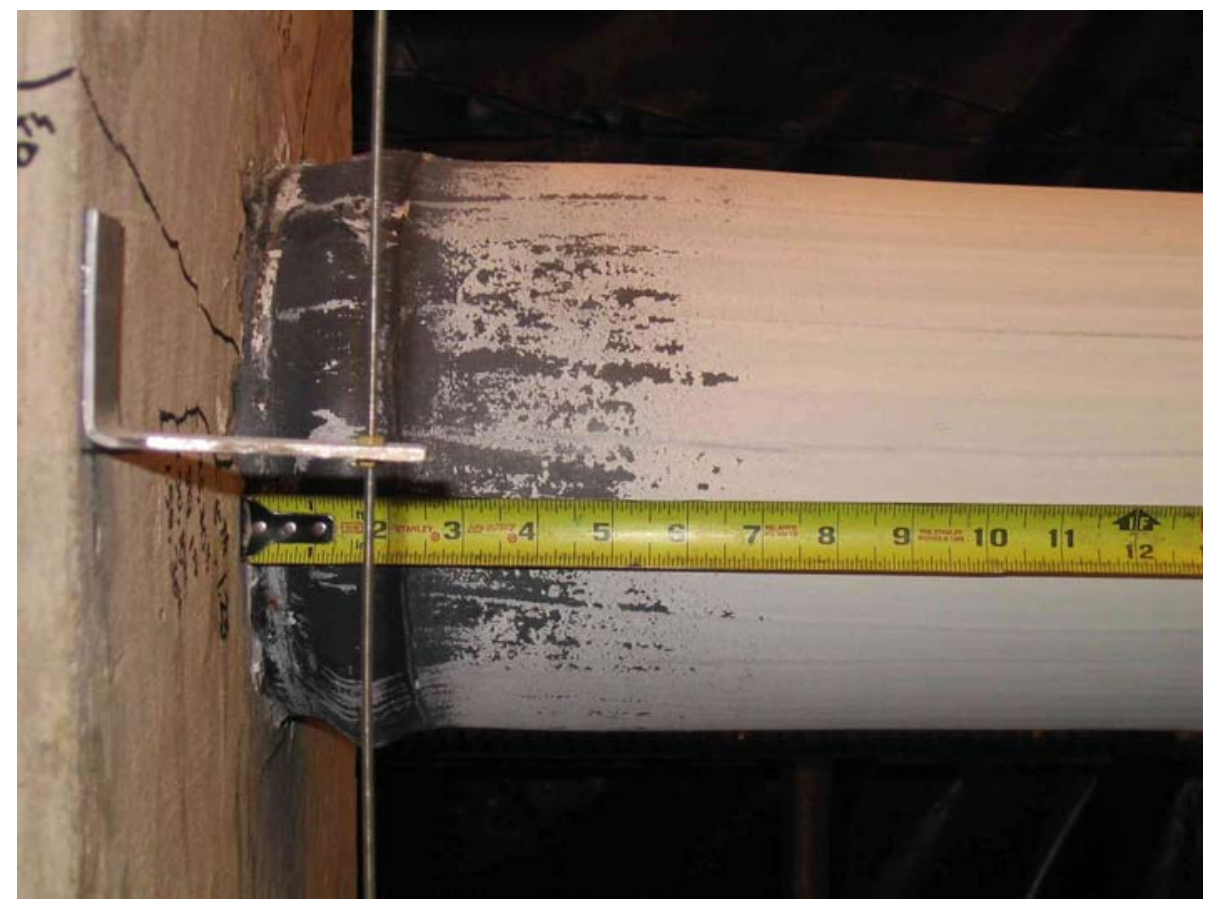

(a) West Side

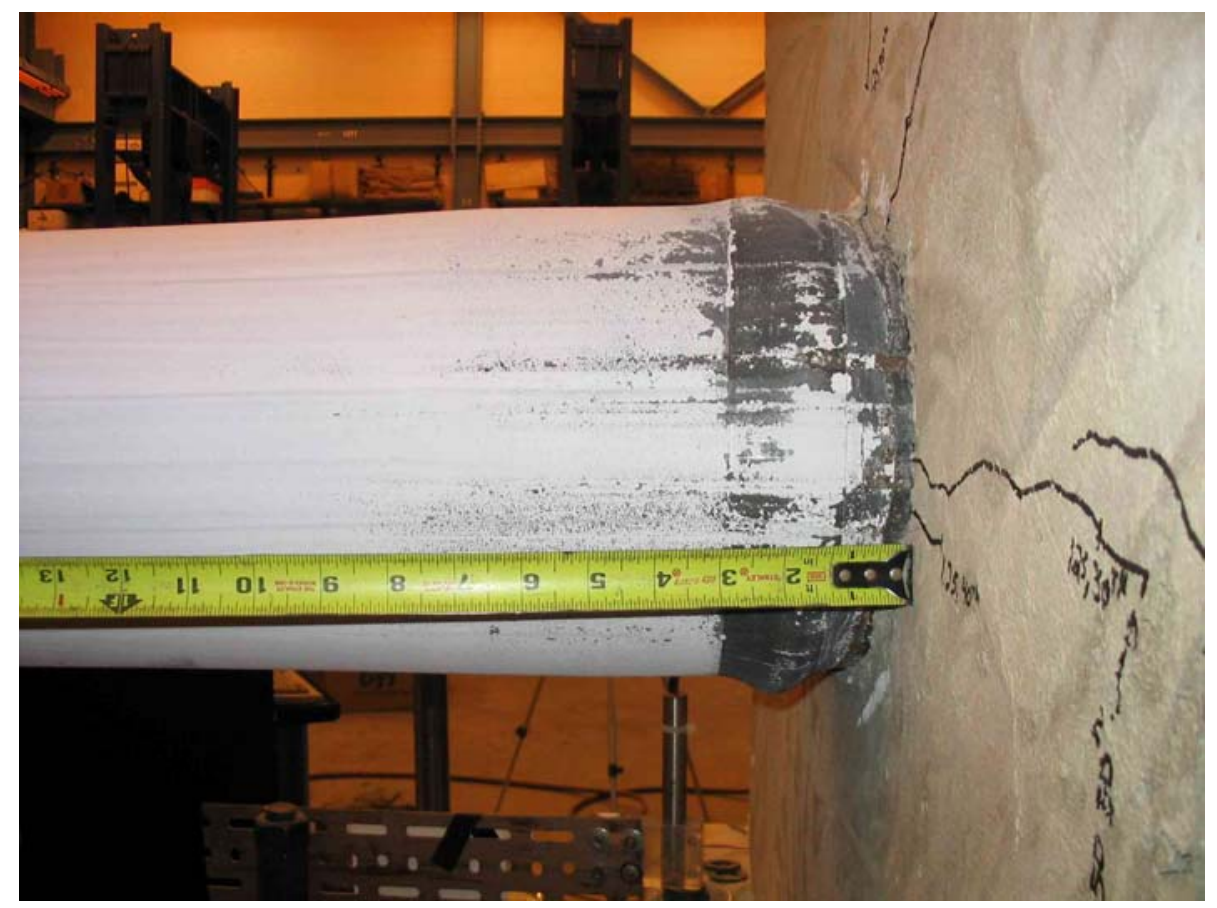

(b) East Side

Figure I.111: Specimen 8 - Pile Yielding (1.75 in., $10^{\text {th }}$ Cycle) 


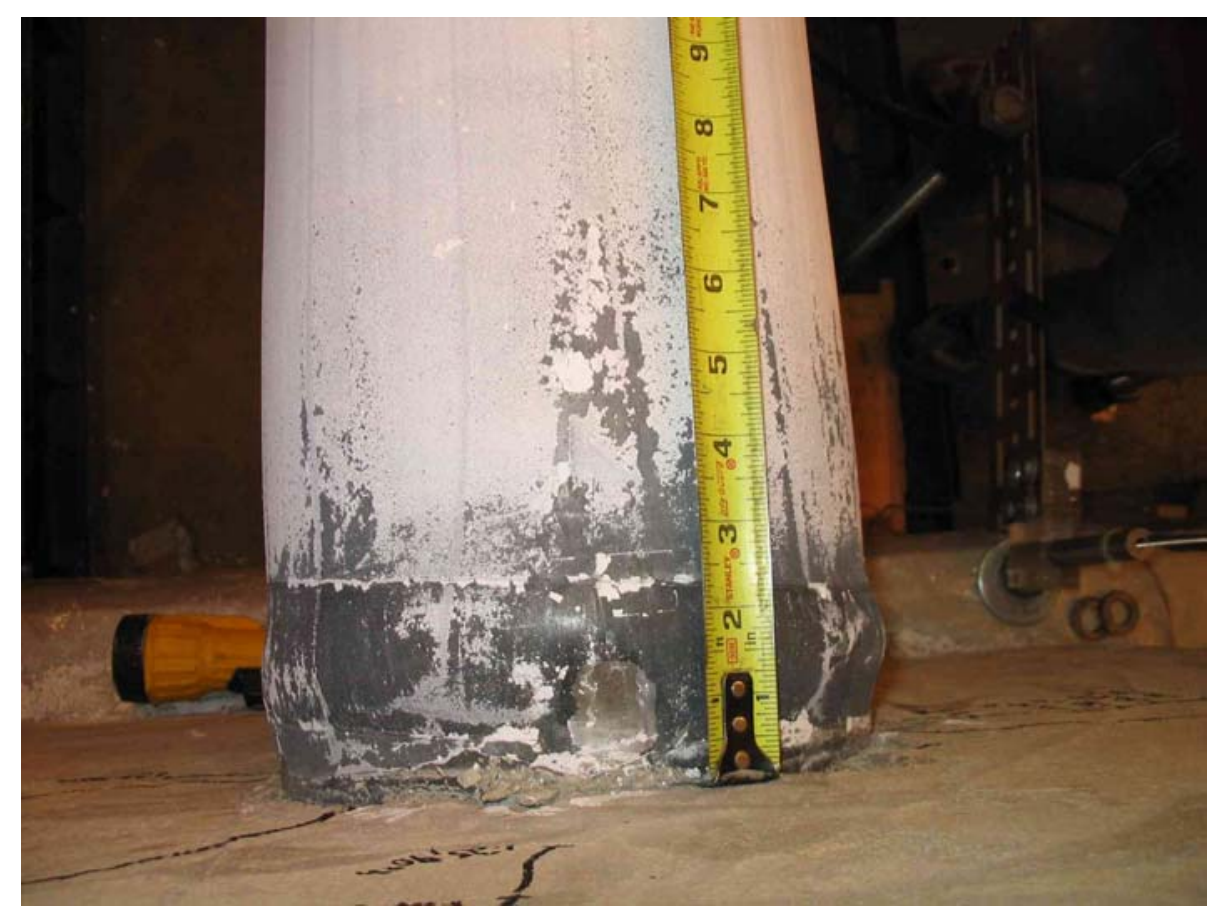

(c) Top

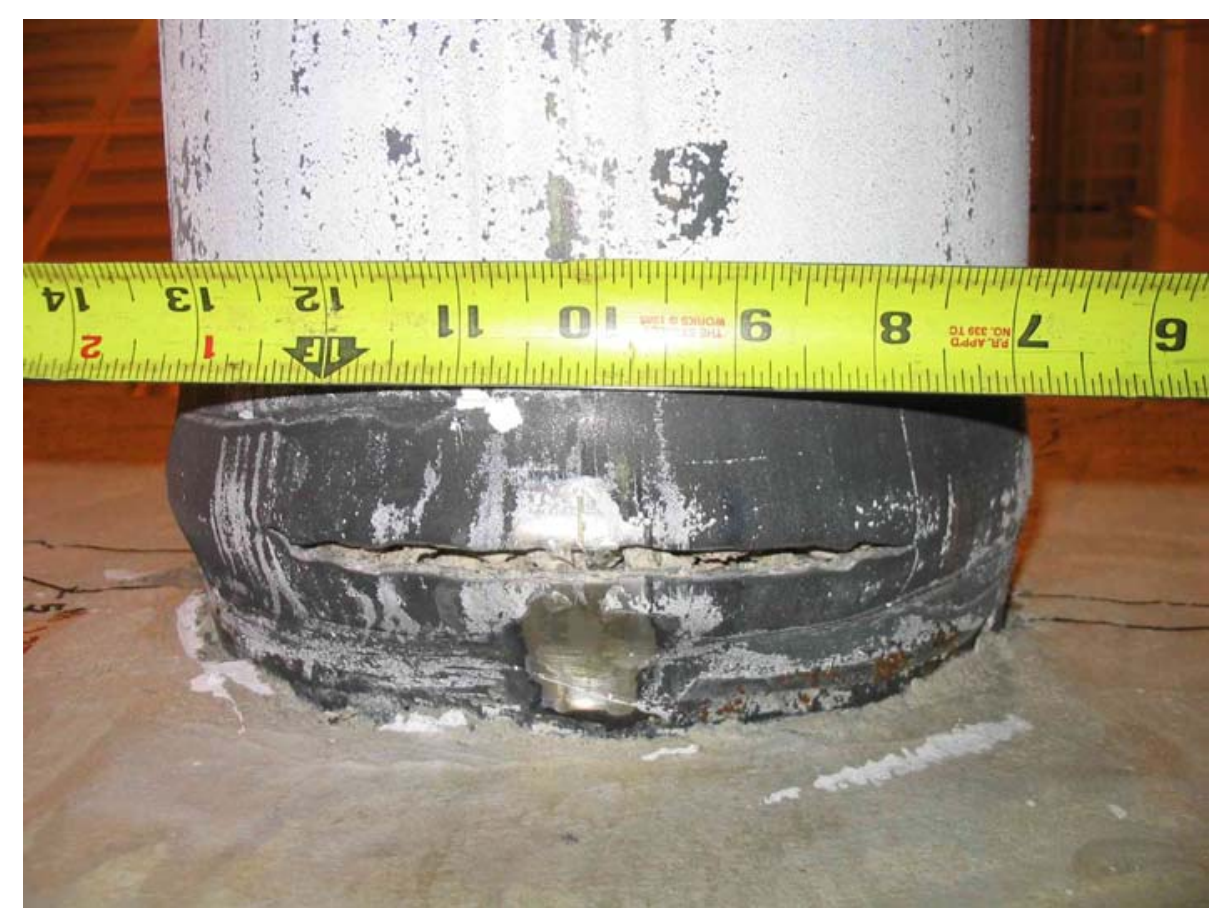

(d) Bottom

Figure I.111: Specimen 8 - Pile Yielding (1.75 in., $10^{\text {th }}$ Cycle) (Continue) 


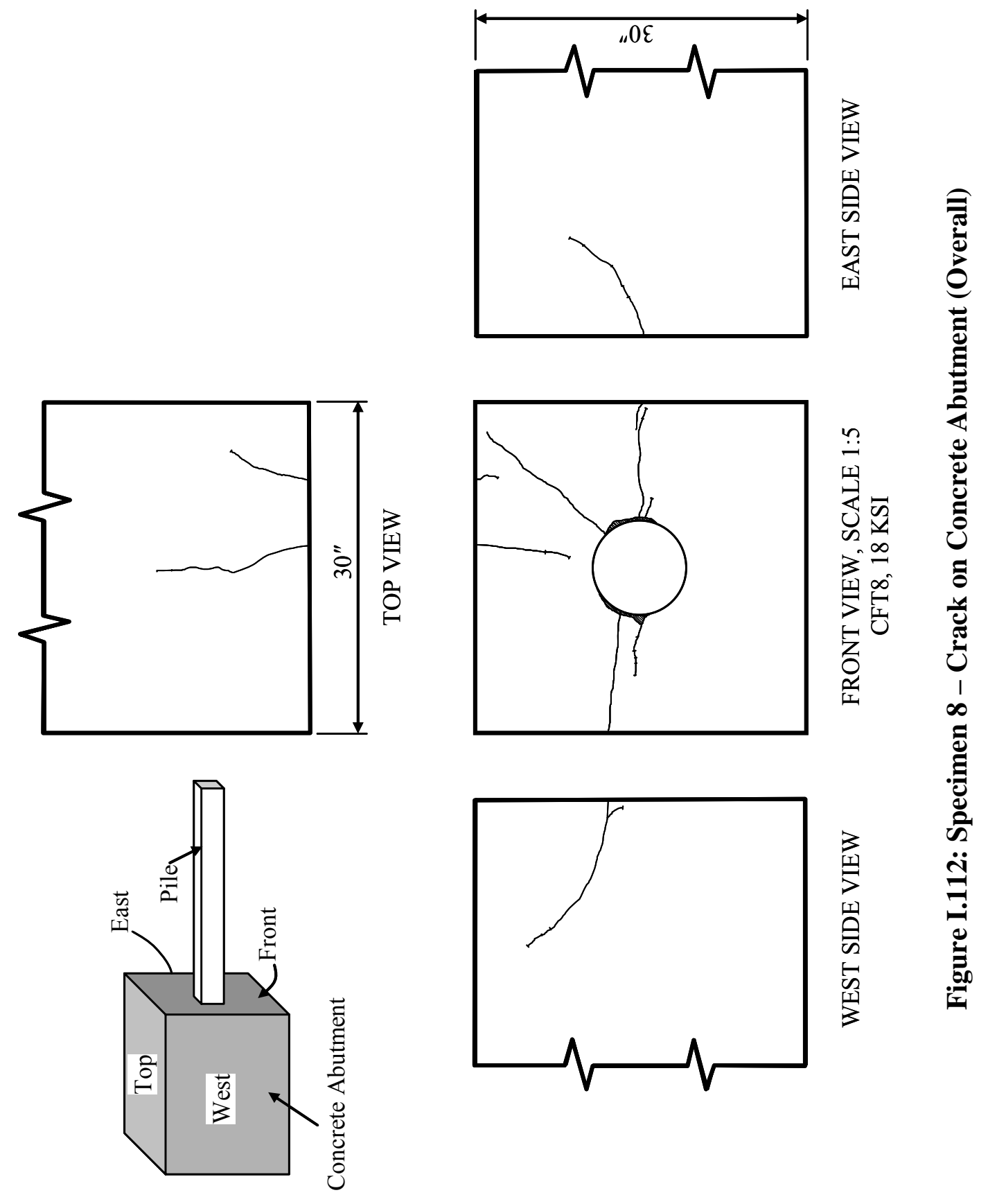




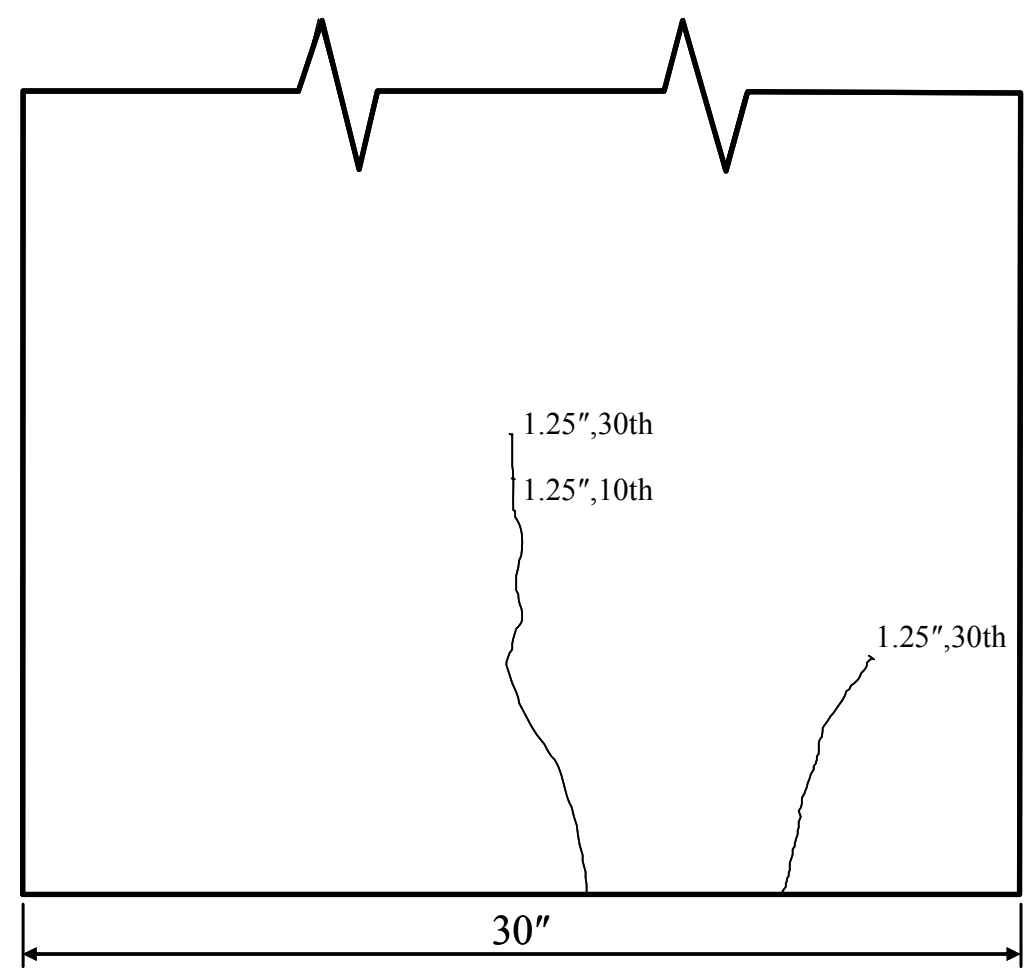

Figure I.113: Specimen 8 - Crack on Concrete Abutment (Top View)

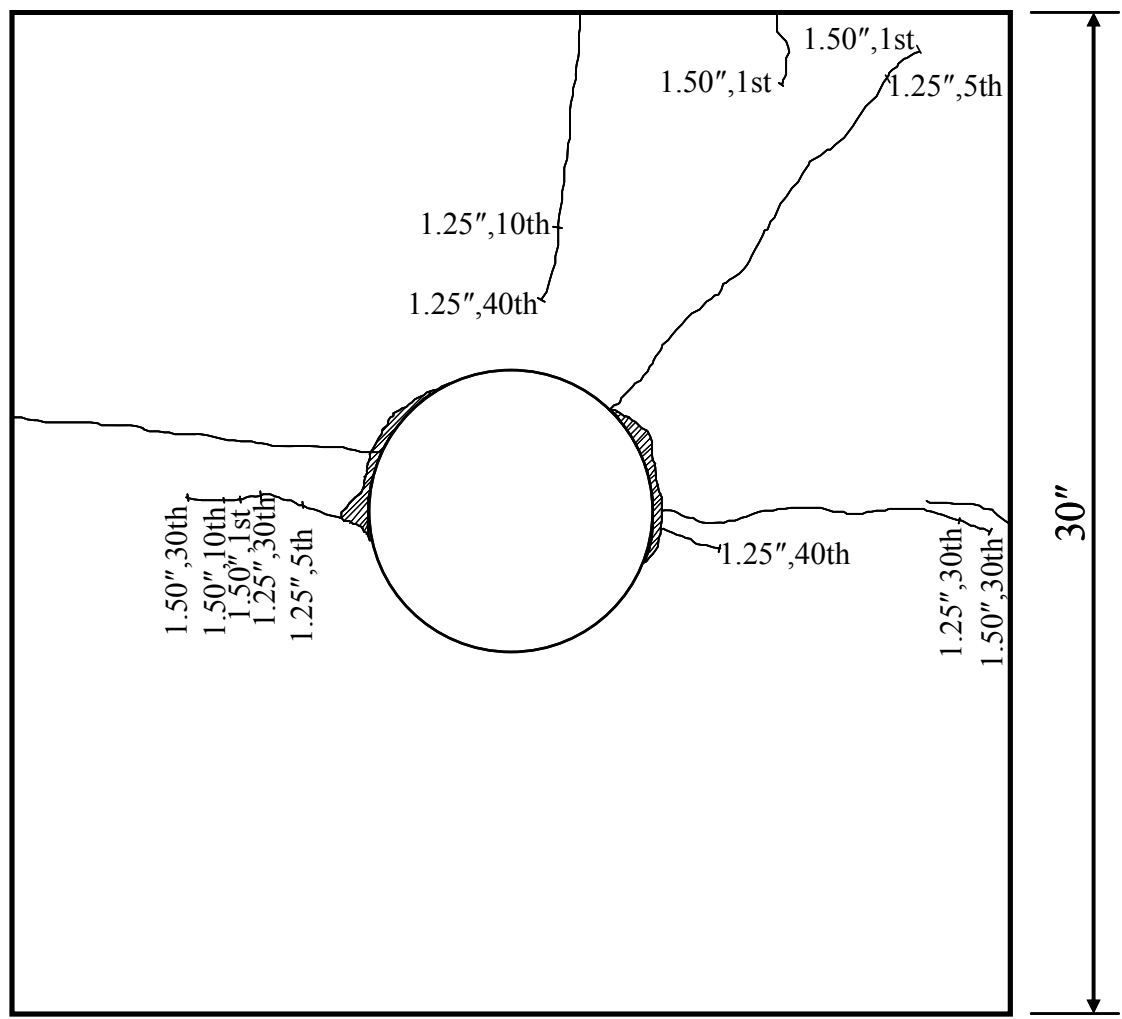

Figure I.114: Specimen 8 - Crack on Concrete Abutment (Front View) 


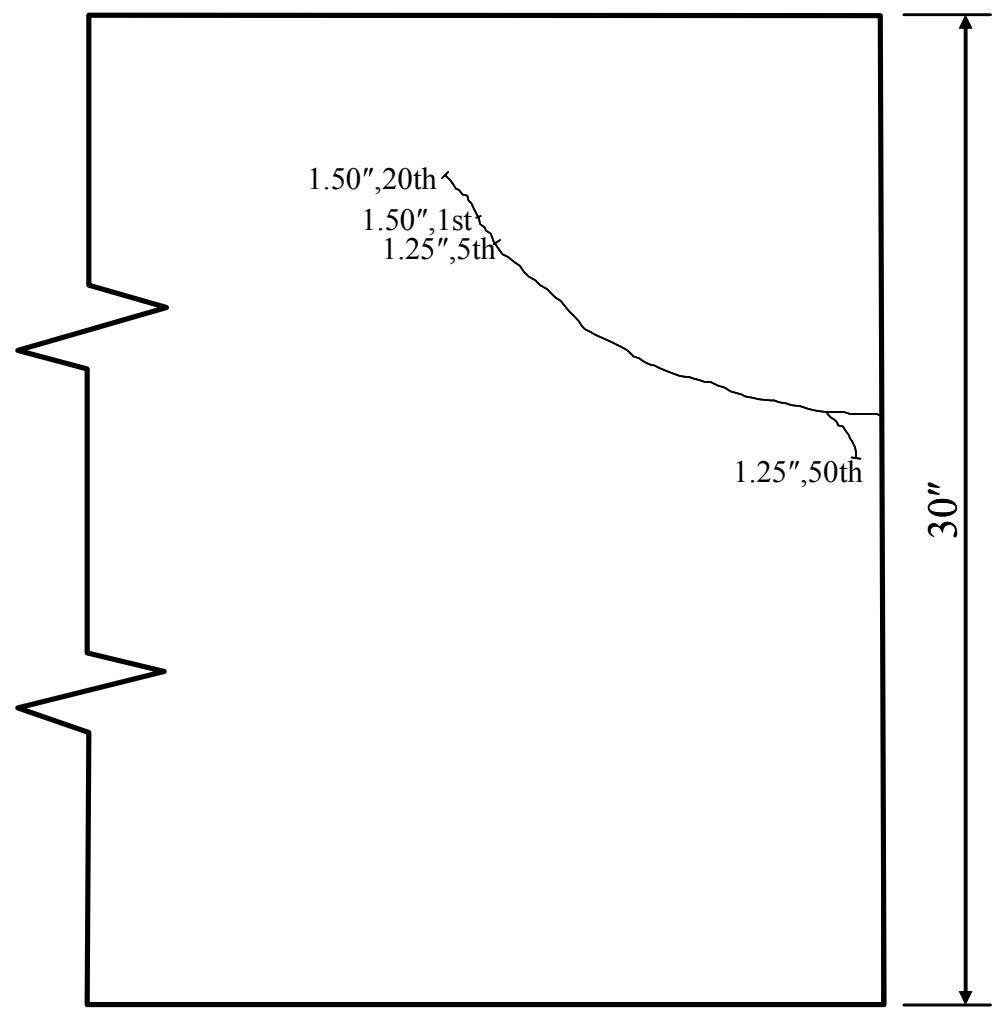

Figure I.115: Specimen 8 - Crack on Concrete Abutment (West View)

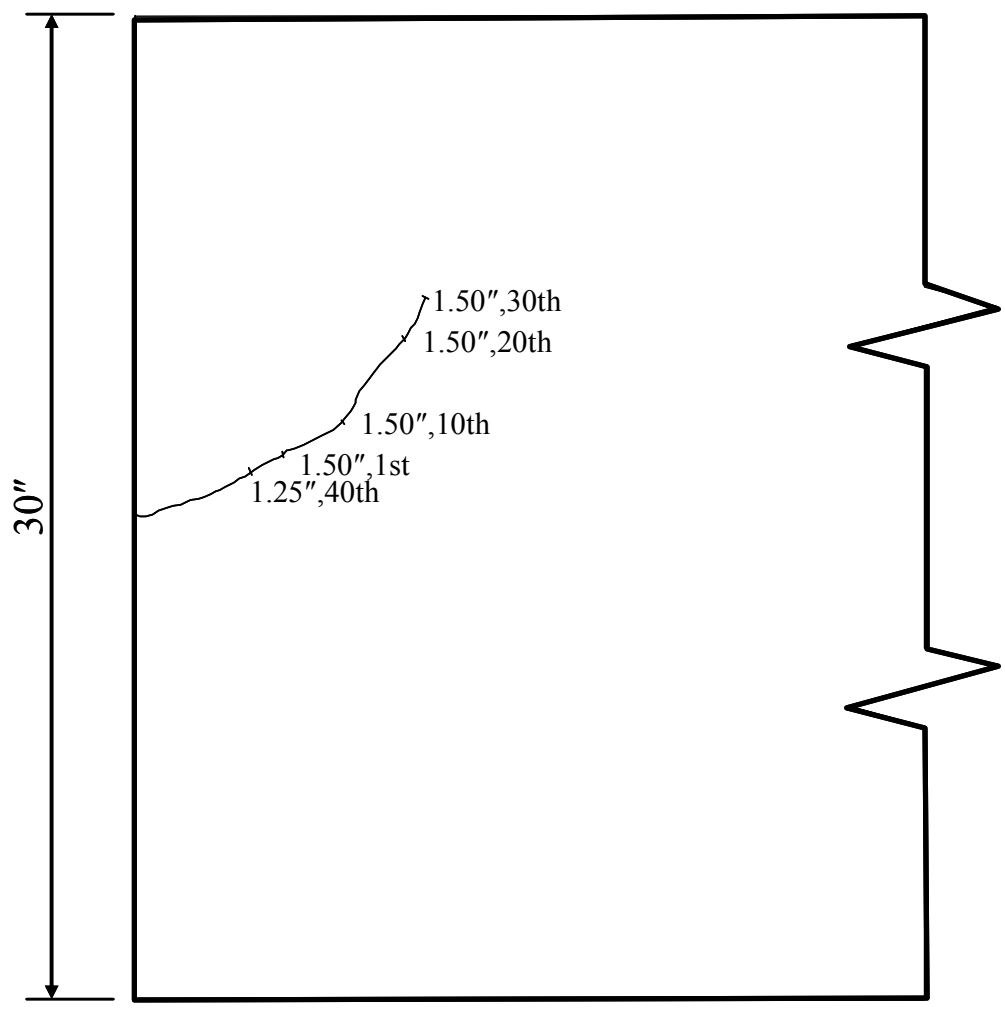

Figure I.116: Specimen 8 - Crack on Concrete Abutment (East View) 


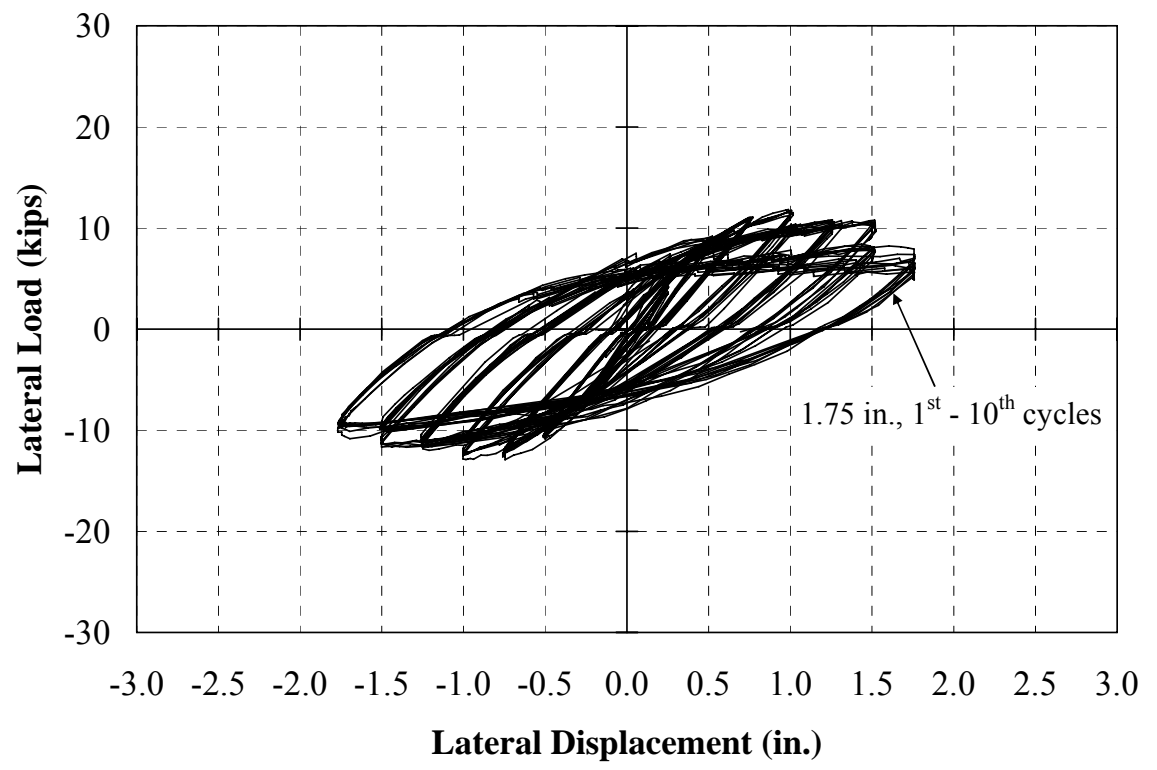

Figure I.117: Specimen 8 - Summary of Lateral Load-Deflection Curves

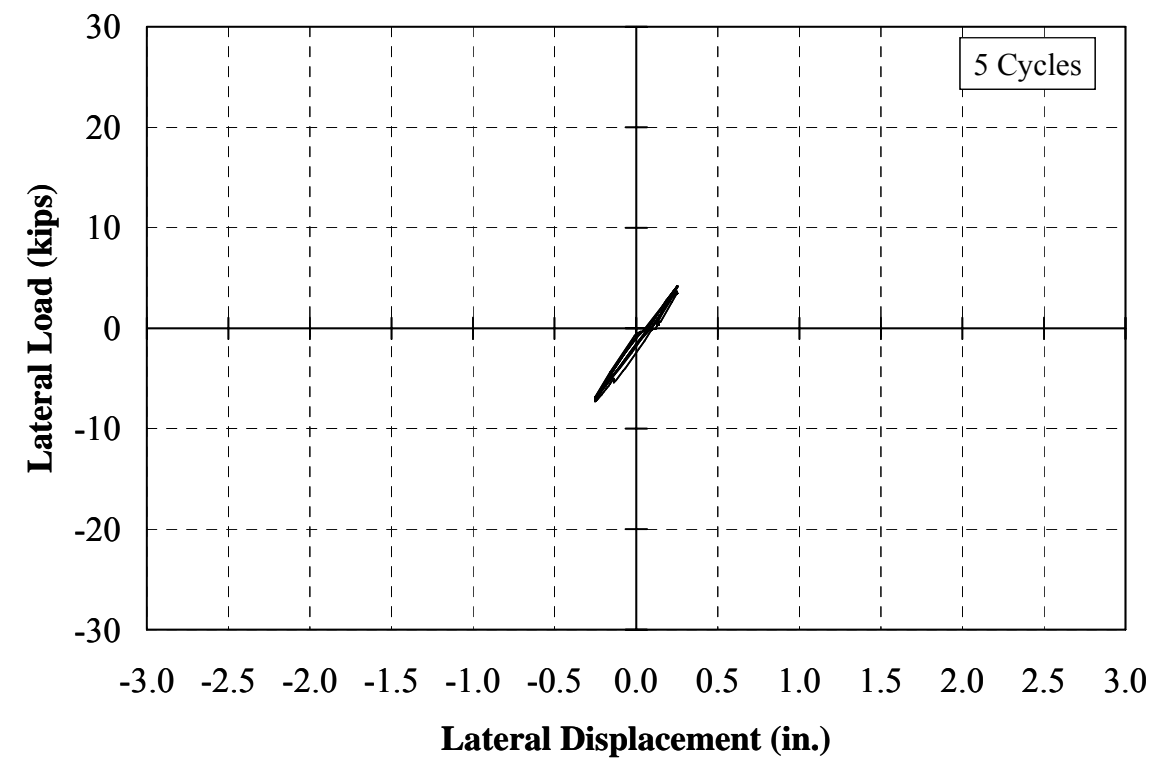

Figure I.118: Specimen 8 - Lateral Load-Deflection Response ( \pm 0.25 in.) 


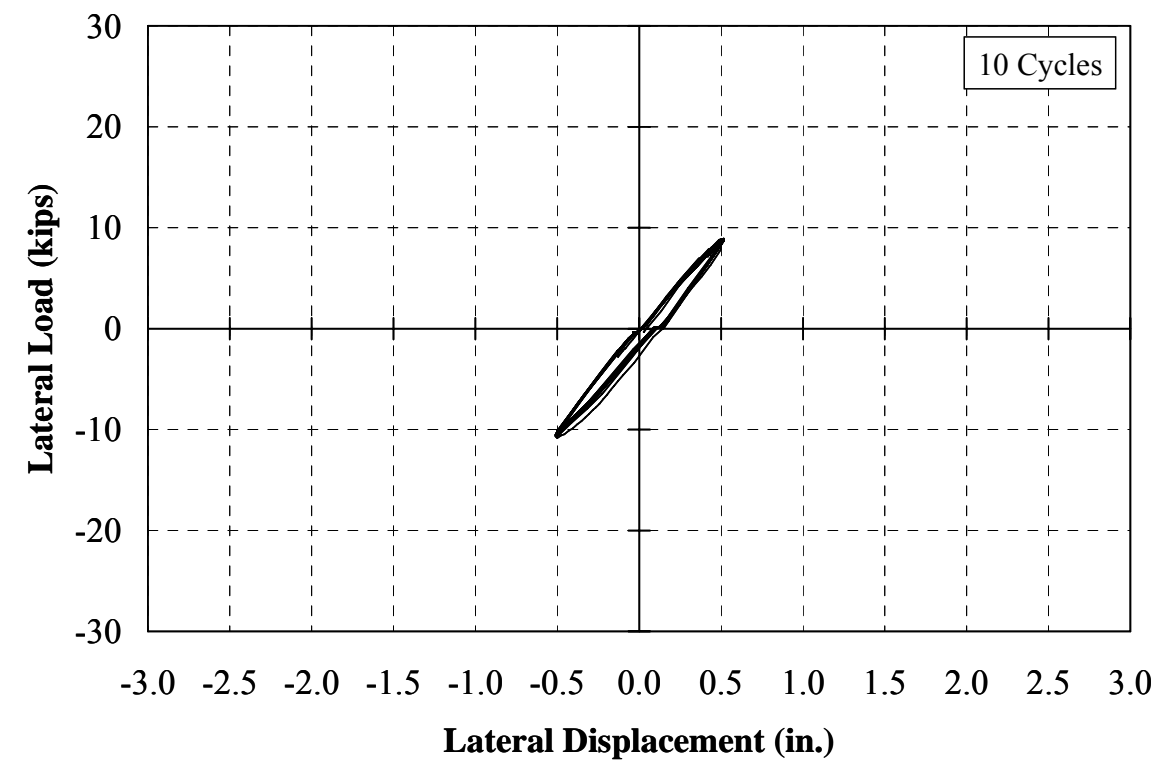

Figure I.119: Specimen 8 - Lateral Load-Deflection Response ( \pm 0.50 in.)

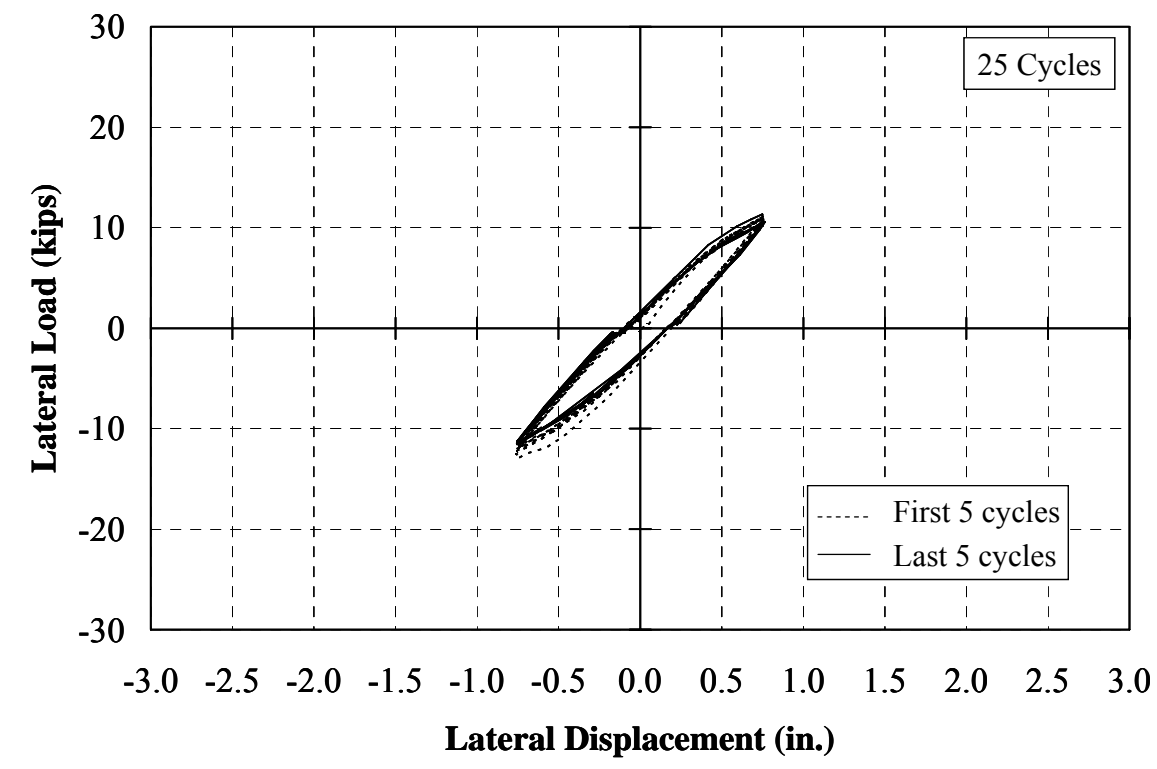

Figure I.120: Specimen 8 - Lateral Load-Deflection Response ( \pm 0.75 in.) 


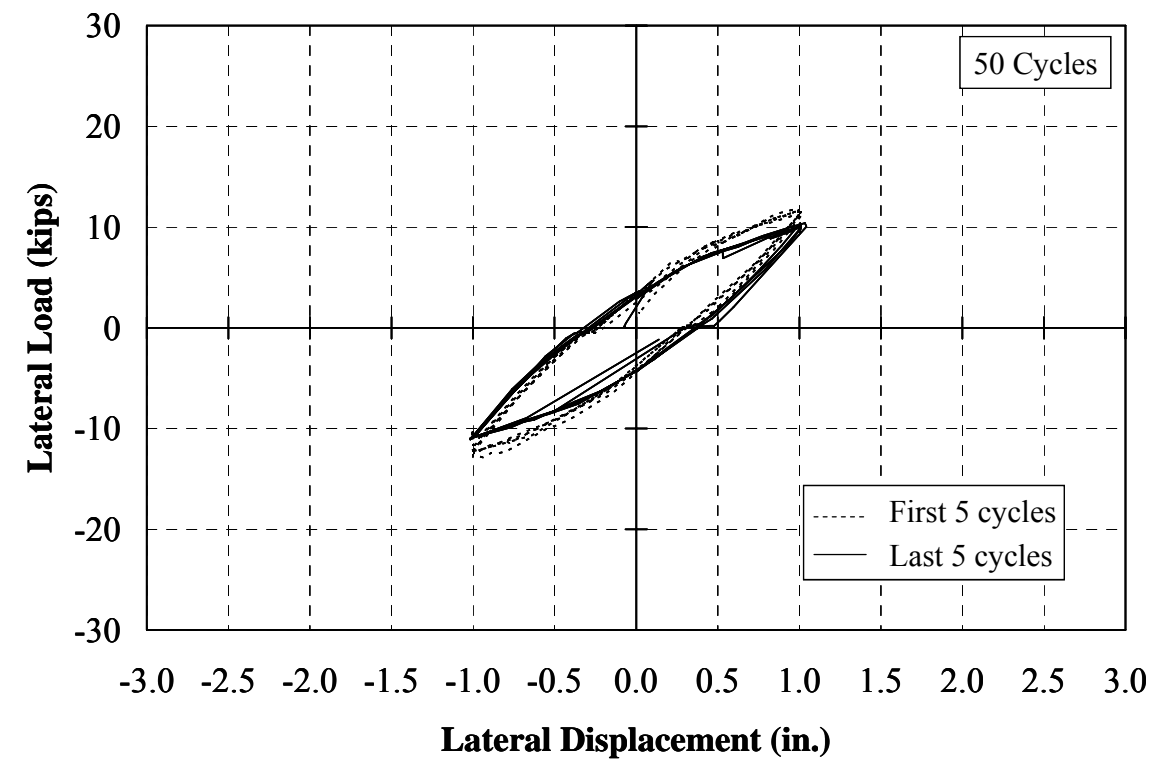

Figure I.121: Specimen 8 - Lateral Load-Deflection Response ( \pm 1.00 in.)

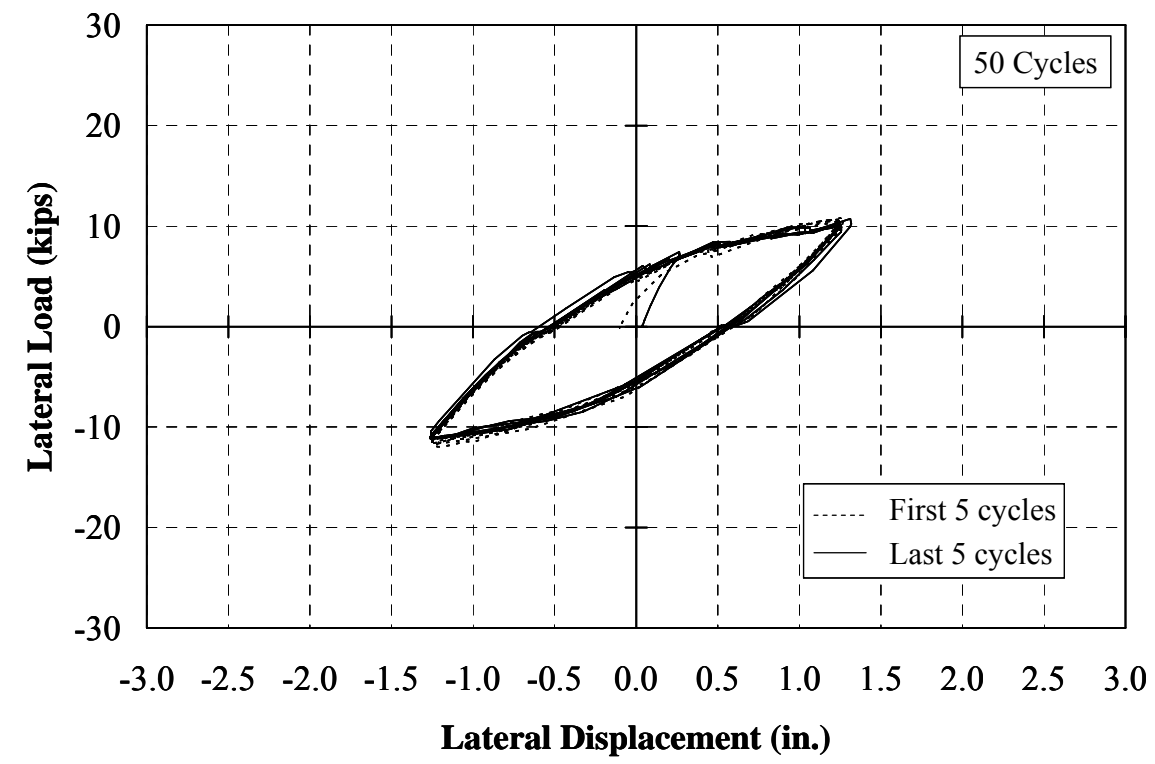

Figure I.122: Specimen 8 - Lateral Load-Deflection Response ( \pm 1.25 in.) 


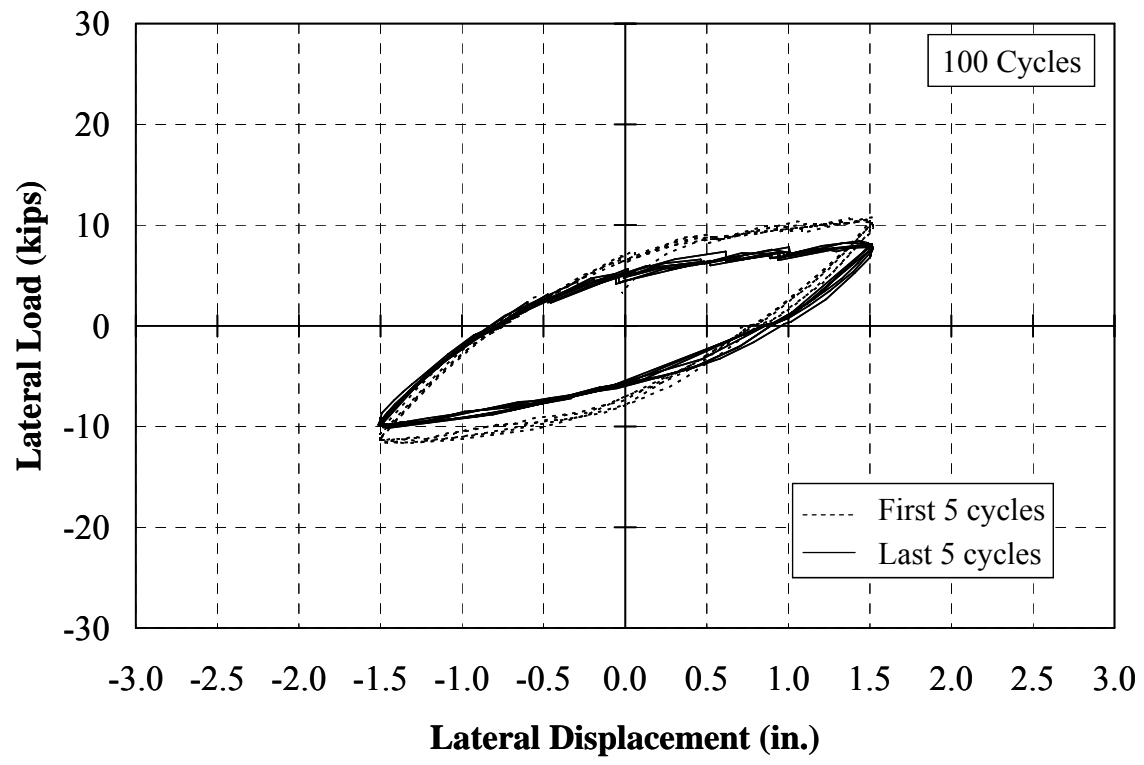

Figure I.123: Specimen 8 - Lateral Load-Deflection Response ( \pm 1.50 in.)

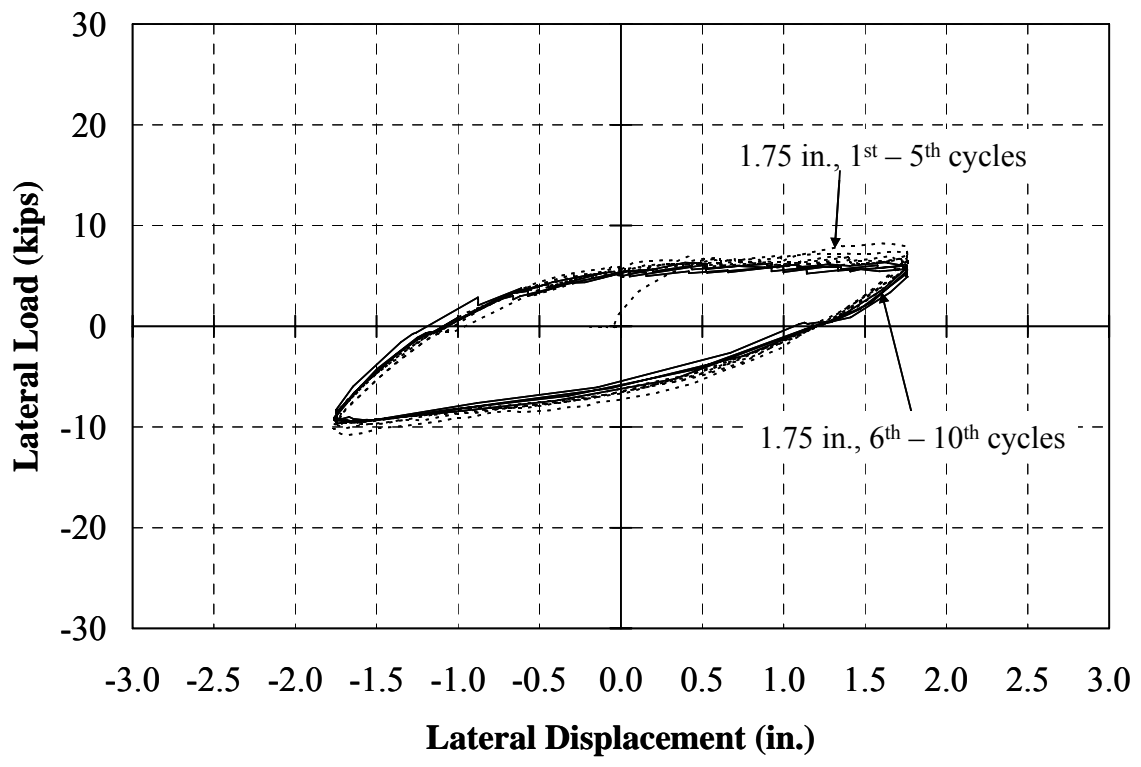

Figure I.124: Specimen 8 - Lateral Load-Deflection Response ( \pm 1.75 in.) 
Specimen 9: CFT10.75x0.250, 9 ksi

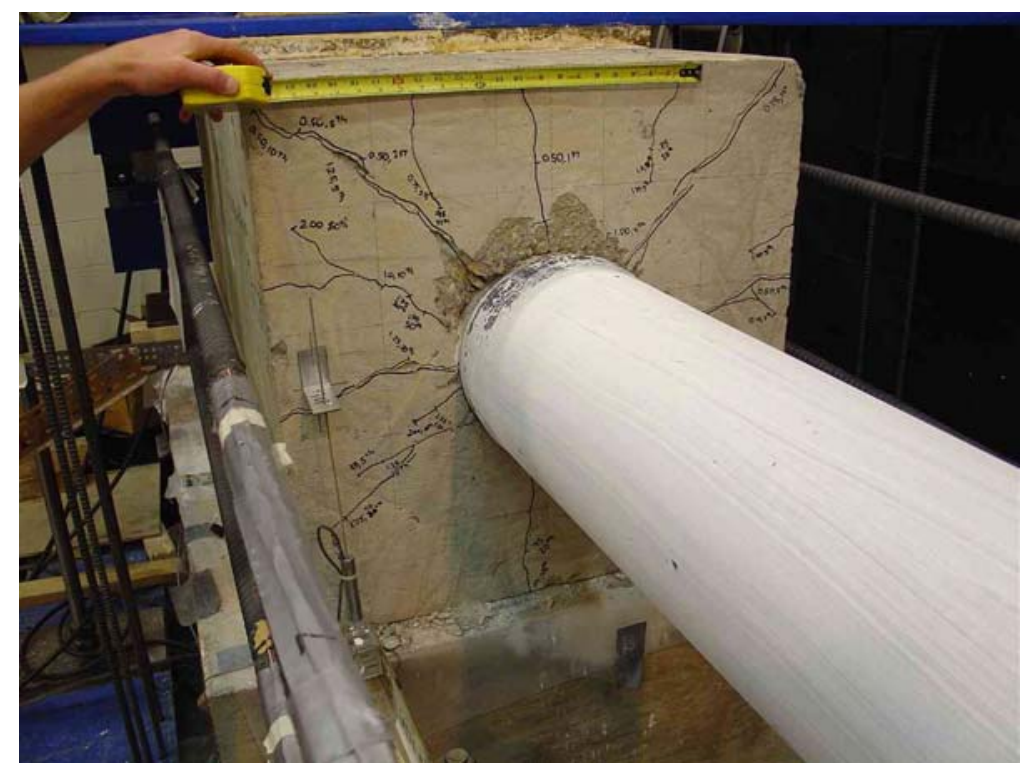

(a) West Side

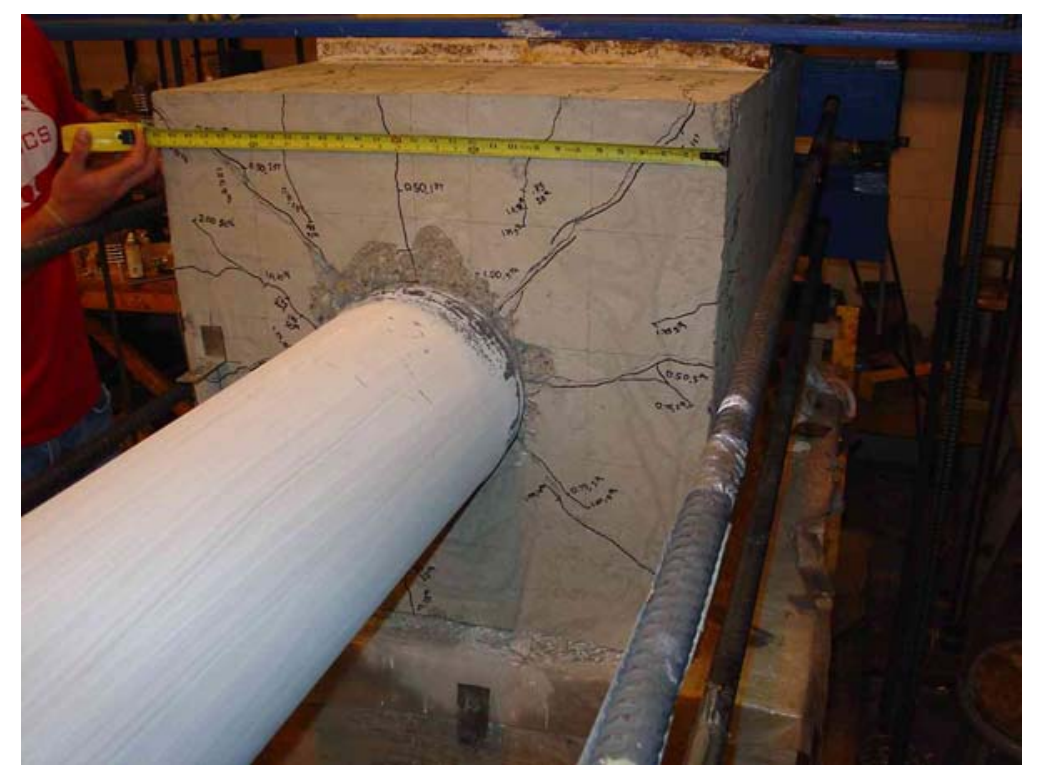

(b) East Side

Figure I.125: Specimen 9 - Cracking (2.00 in., $100^{\text {th }}$ Cycle) 


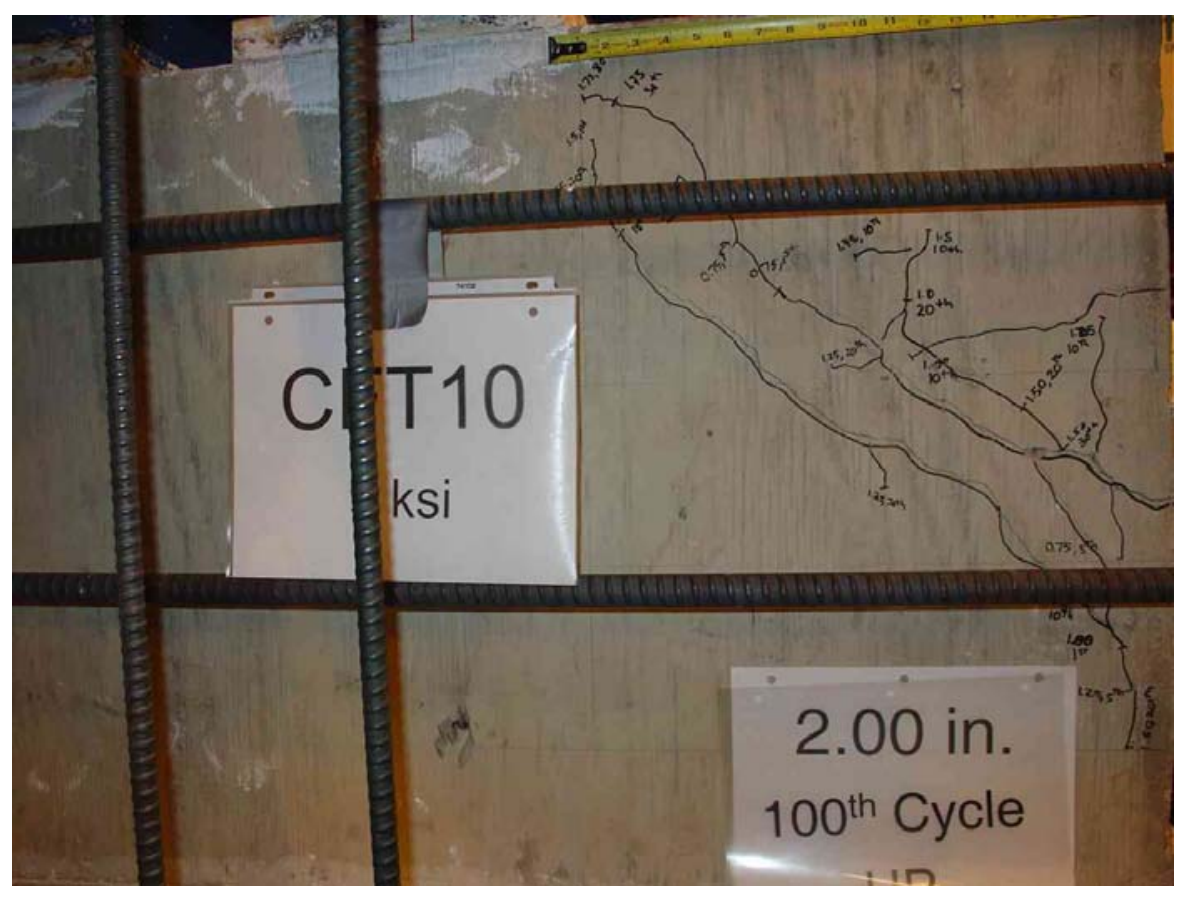

(a) West Side

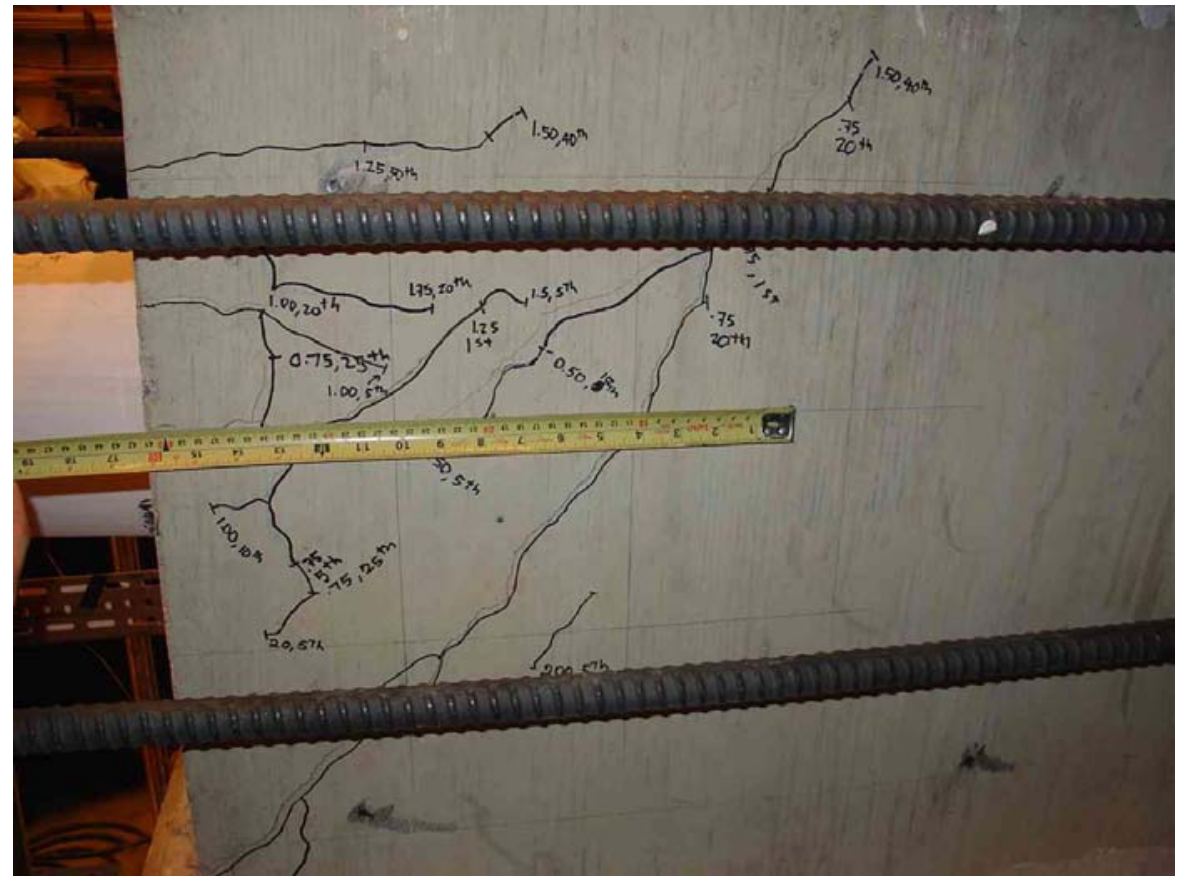

(b) East Side

Figure I.126: Specimen 9 - Crack on Concrete Abutment (2.00 in., $100^{\text {th }}$ Cycle) 


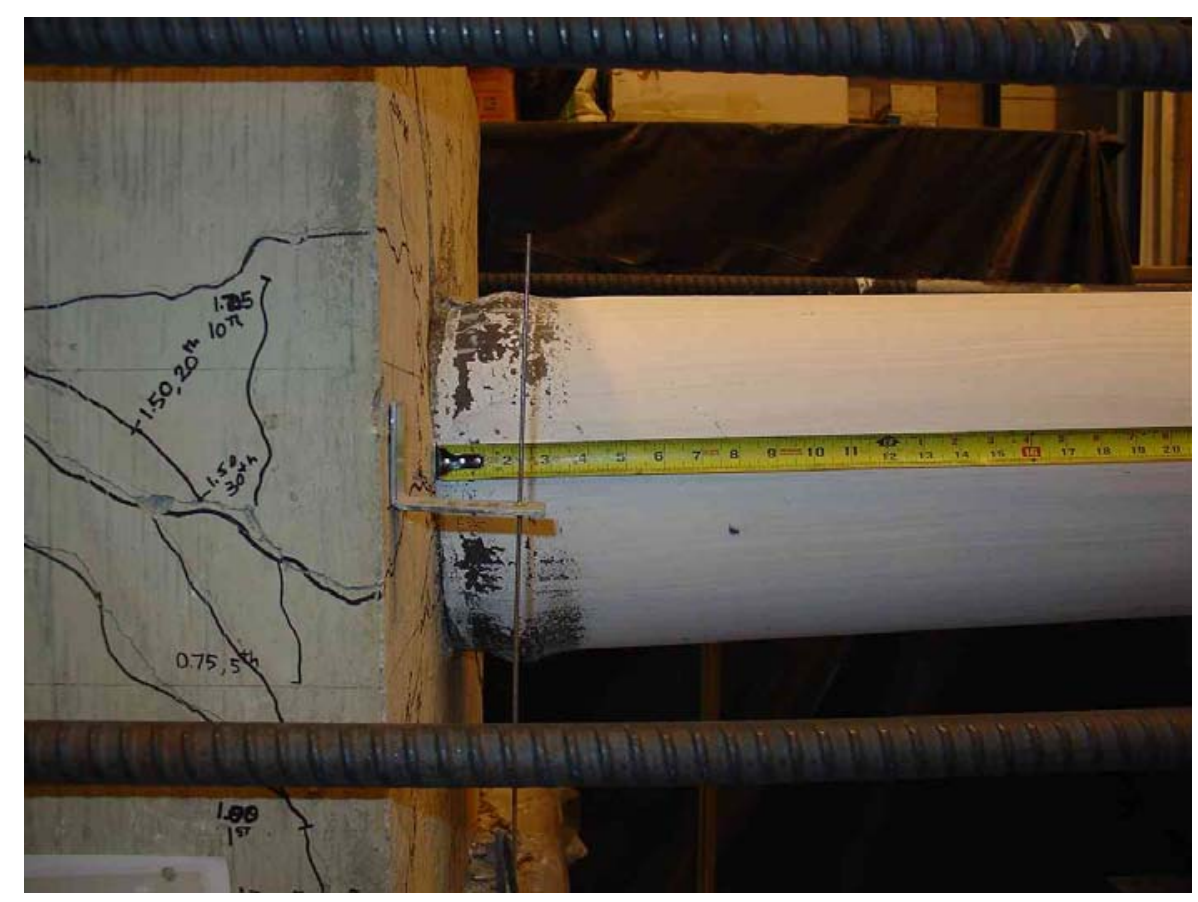

(a) West Side

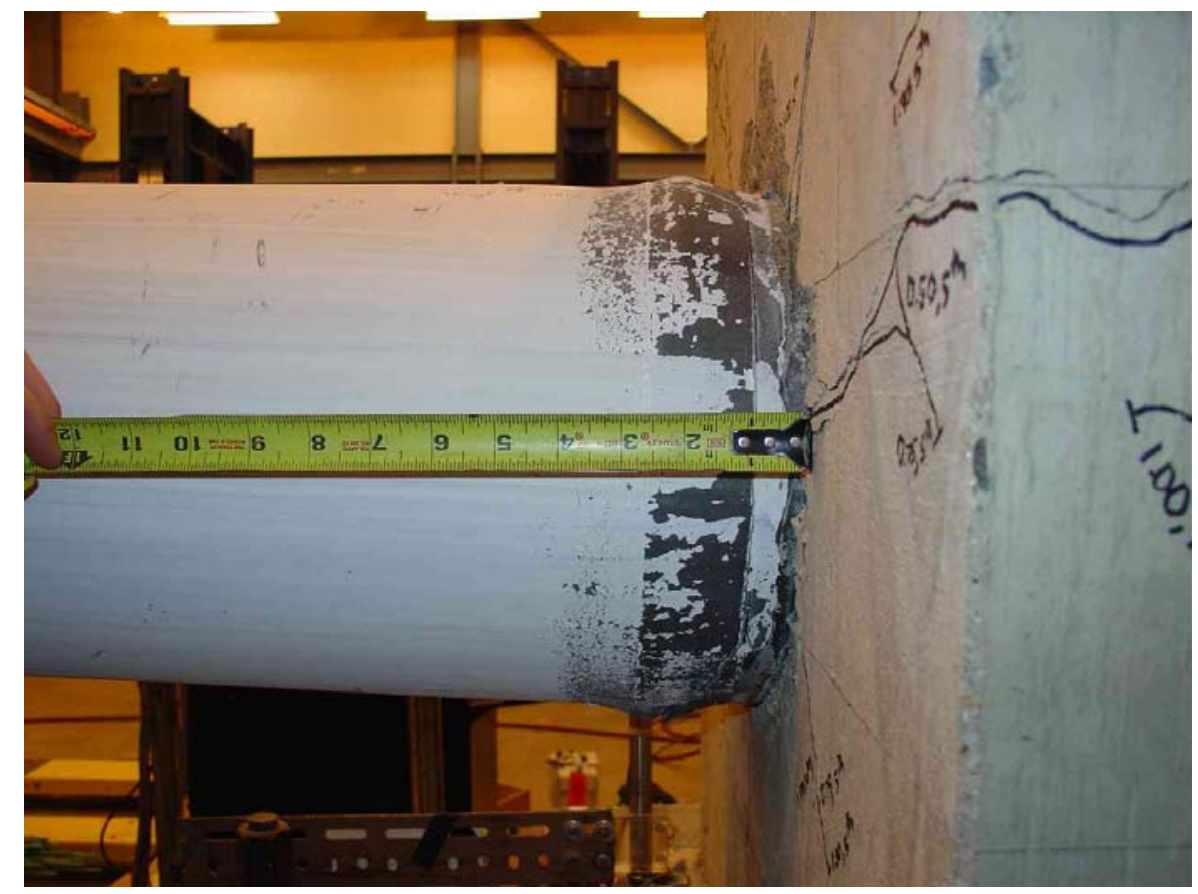

(b) East Side

Figure I.127: Specimen 9 - Pile Yielding (2.00 in., $100^{\text {th }}$ Cycle) 


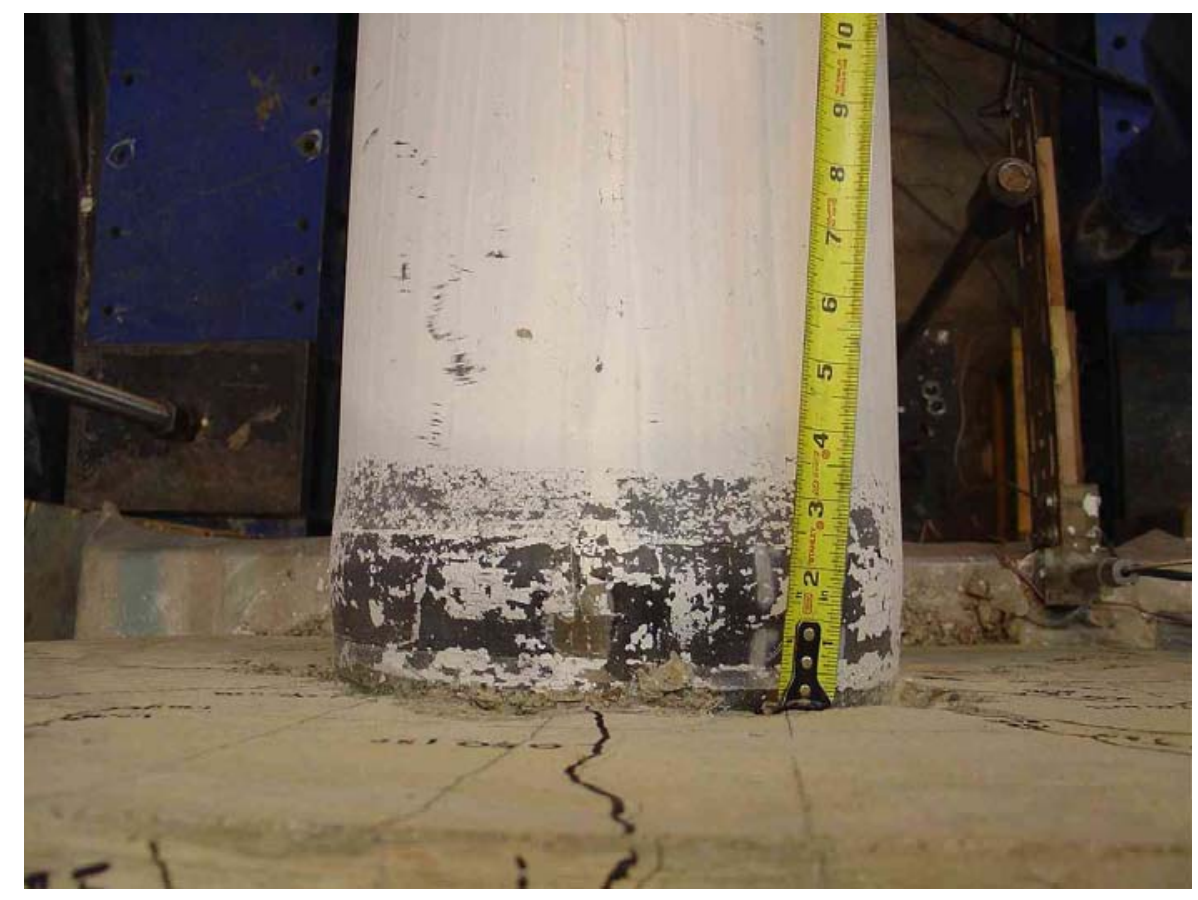

(c) Top

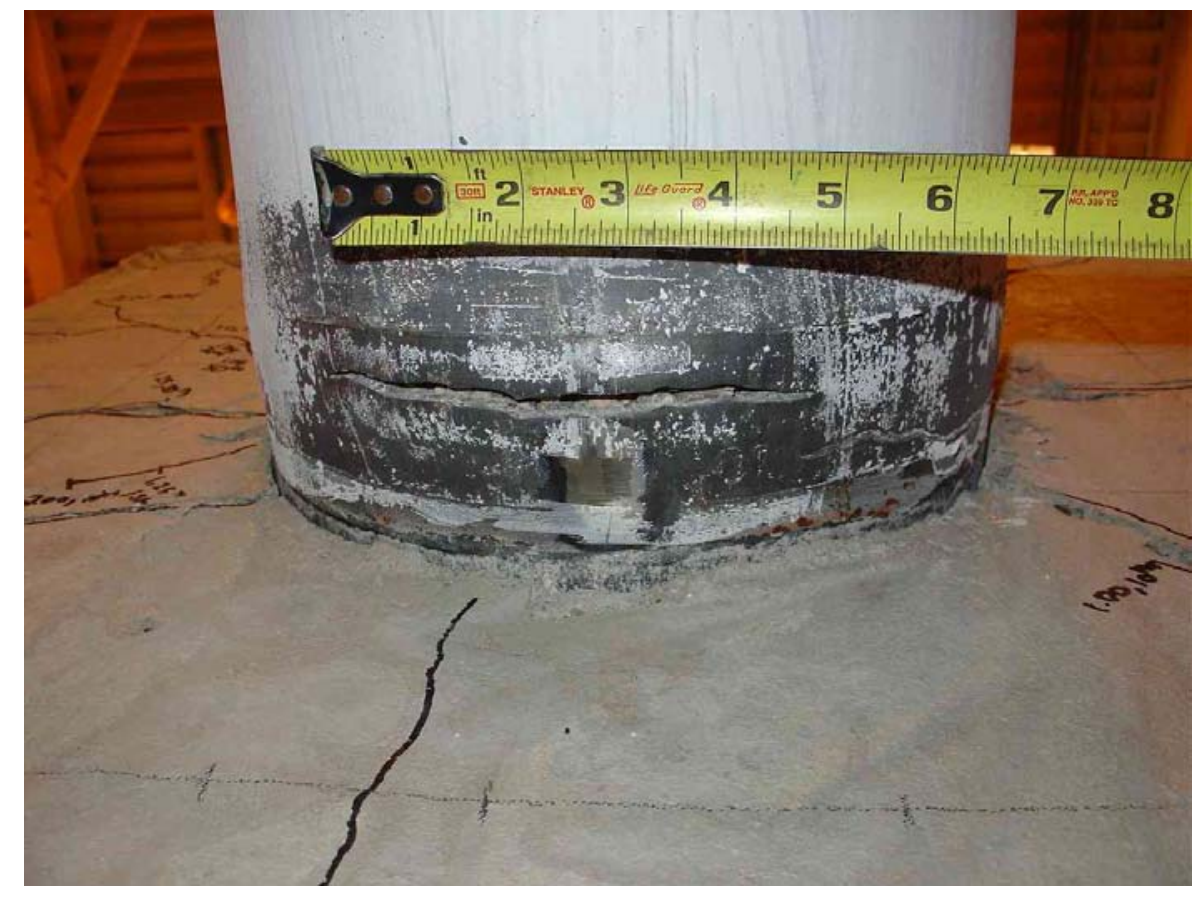

(d) Bottom

Figure I.127: Specimen 9 - Pile Yielding (2.00 in., $100^{\text {th }}$ Cycle) (Continue) 


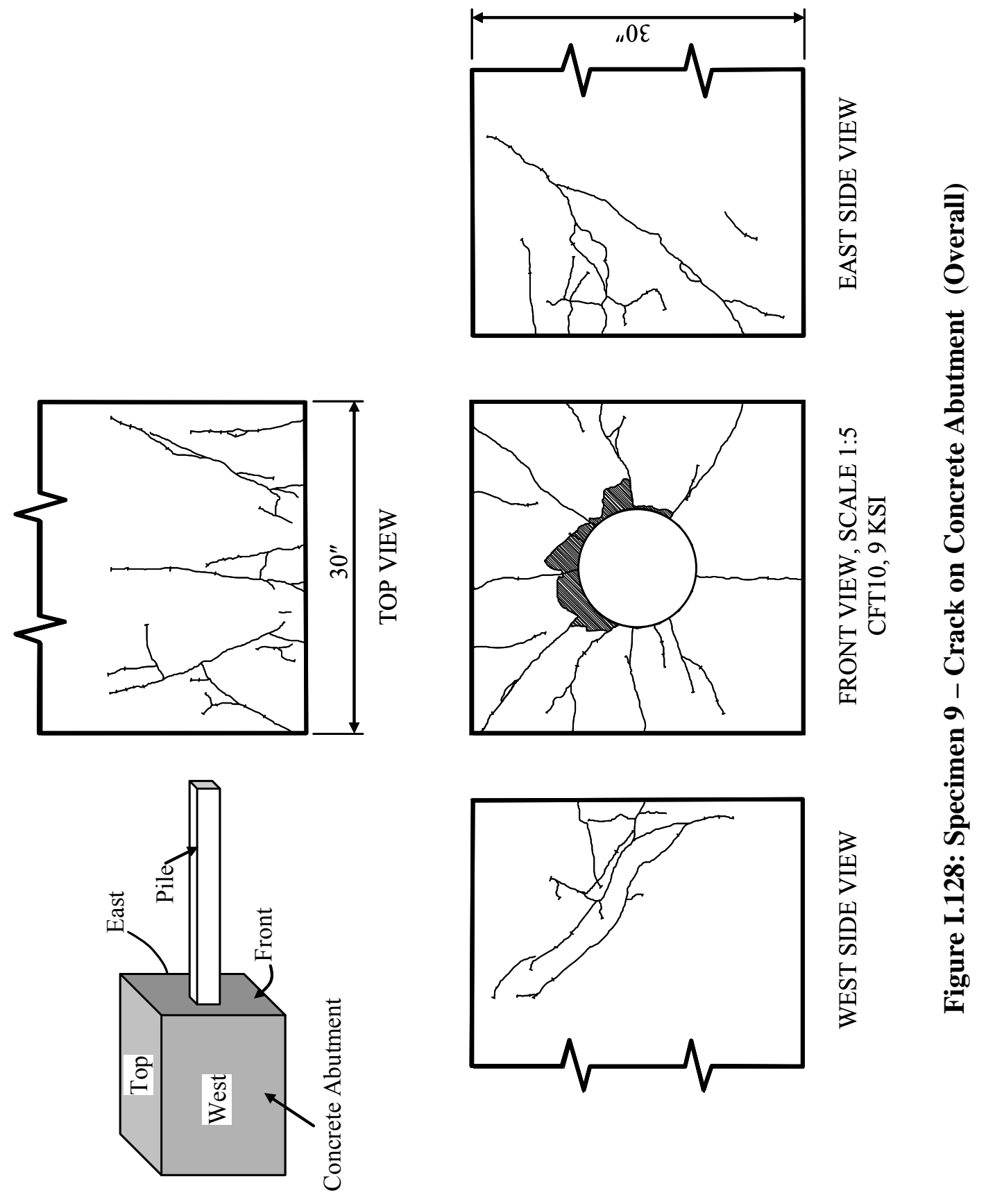




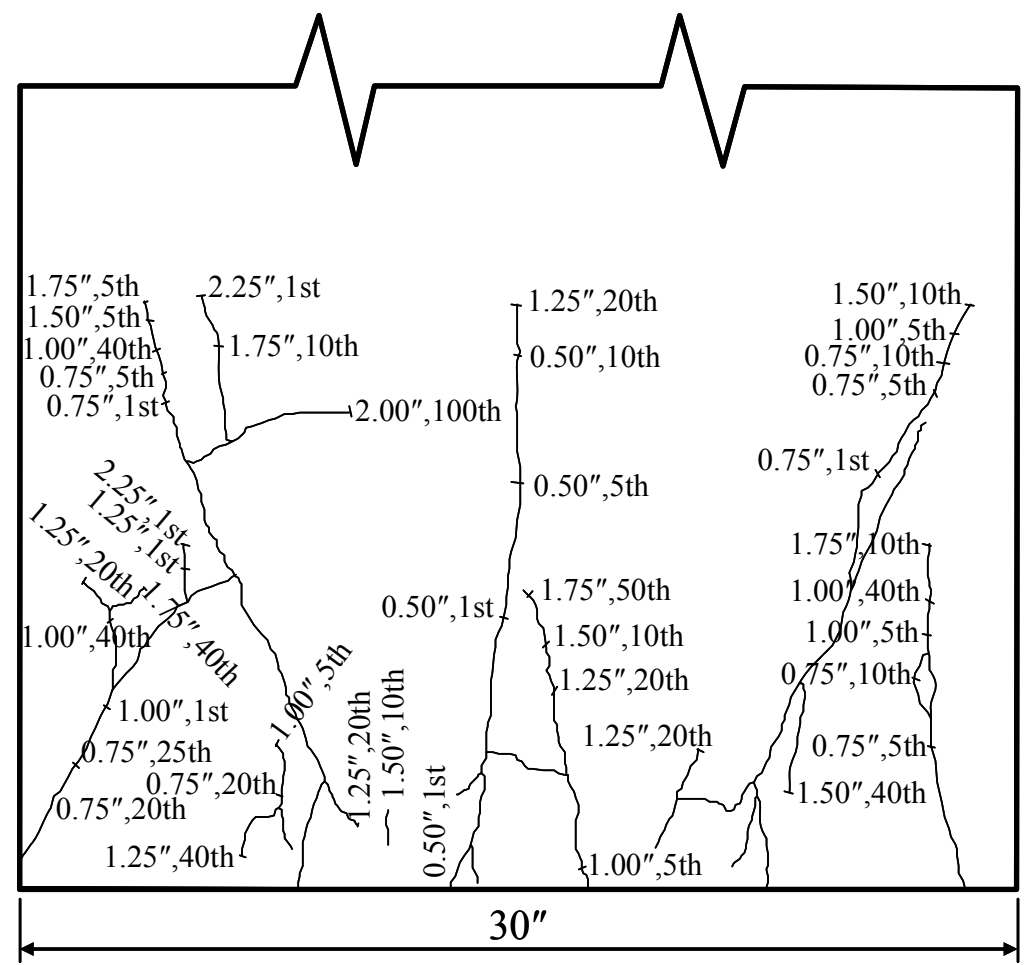

Figure I.129: Specimen 9 - Crack on Concrete Abutment (Top View)

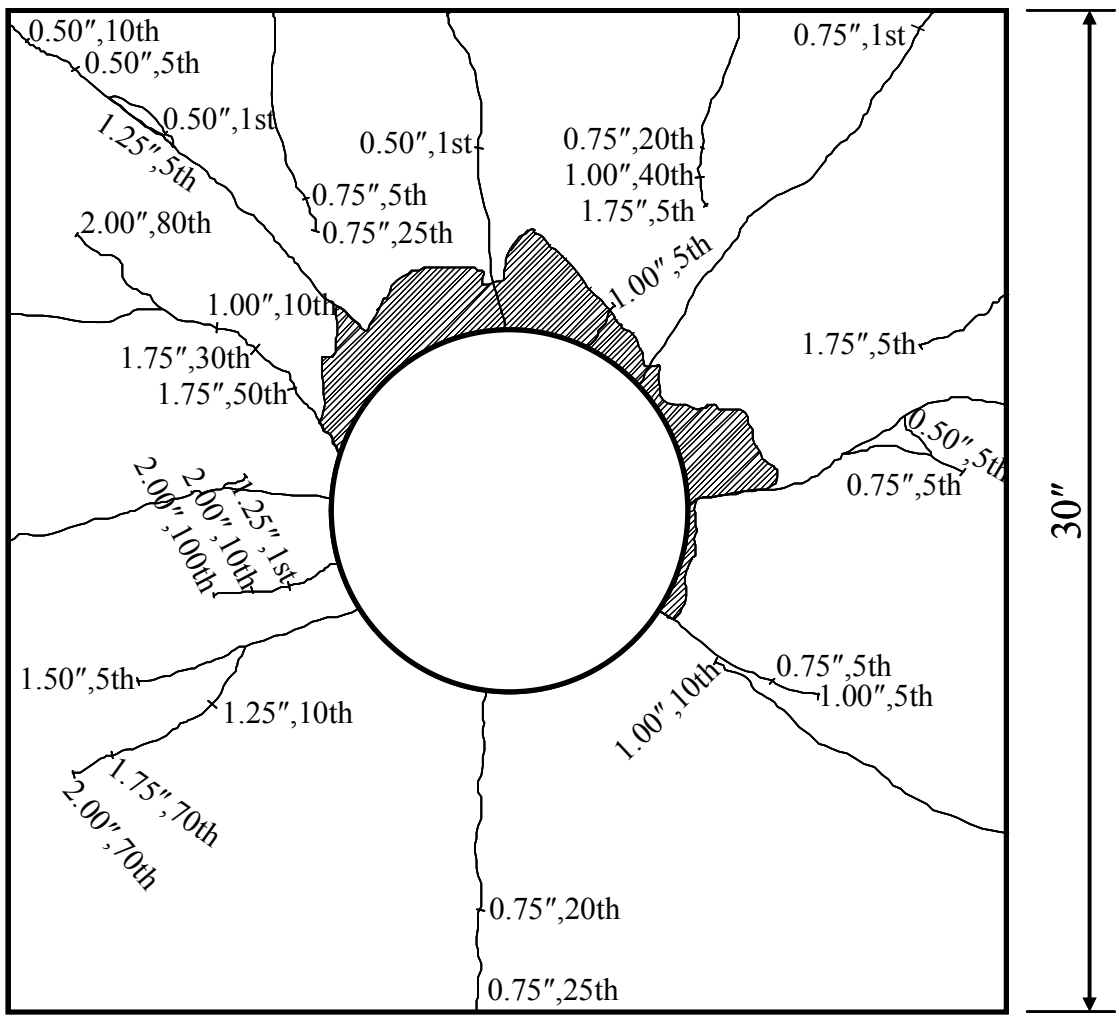

Figure I.130: Specimen 9 - Crack on Concrete Abutment (Front View) 


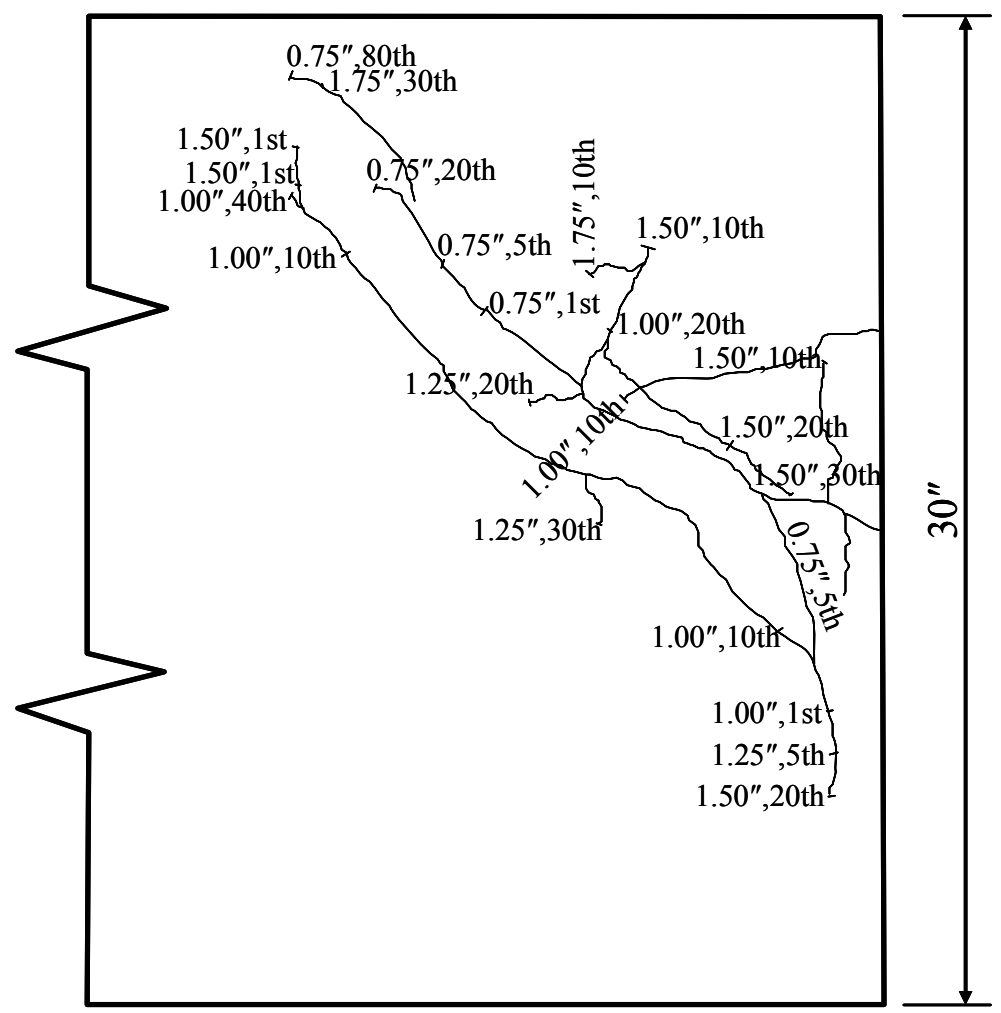

Figure I.131: Specimen 9 - Crack on Concrete Abutment (West View)

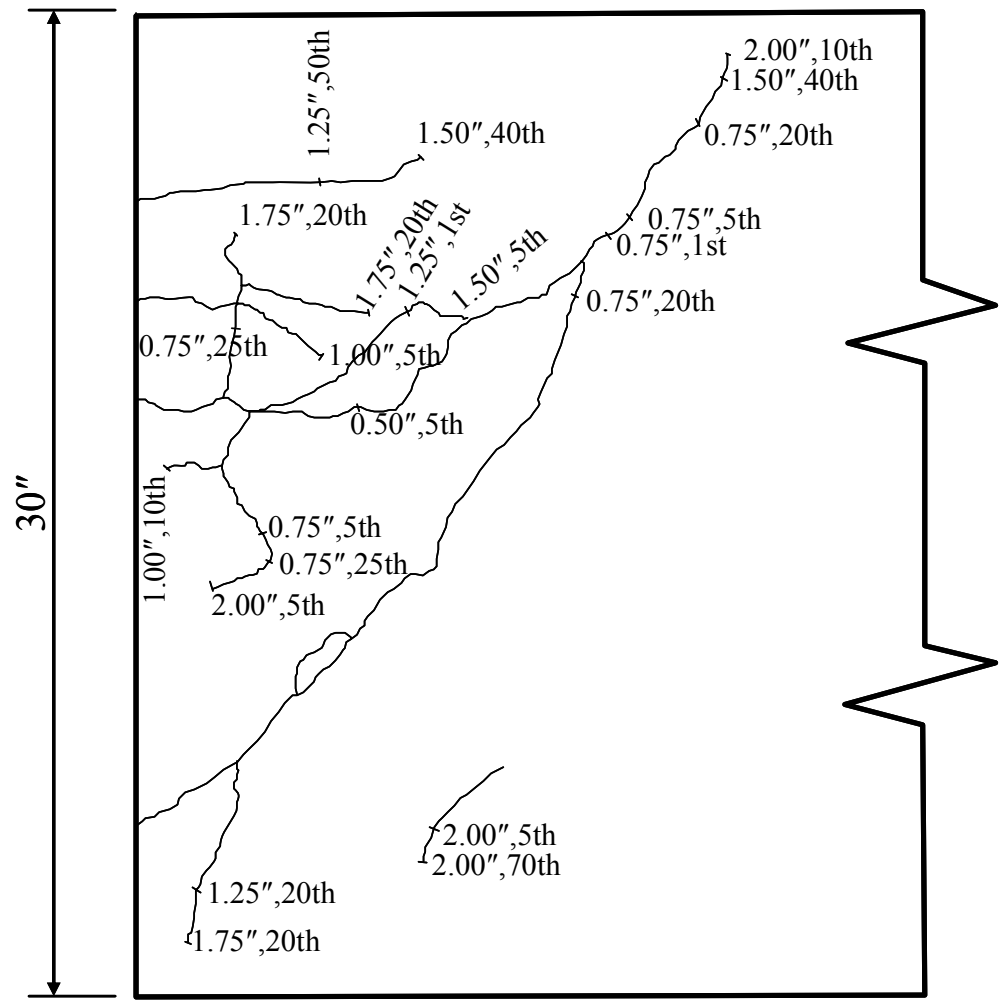

Figure I.132: Specimen 9 - Crack on Concrete Abutment (East View) 


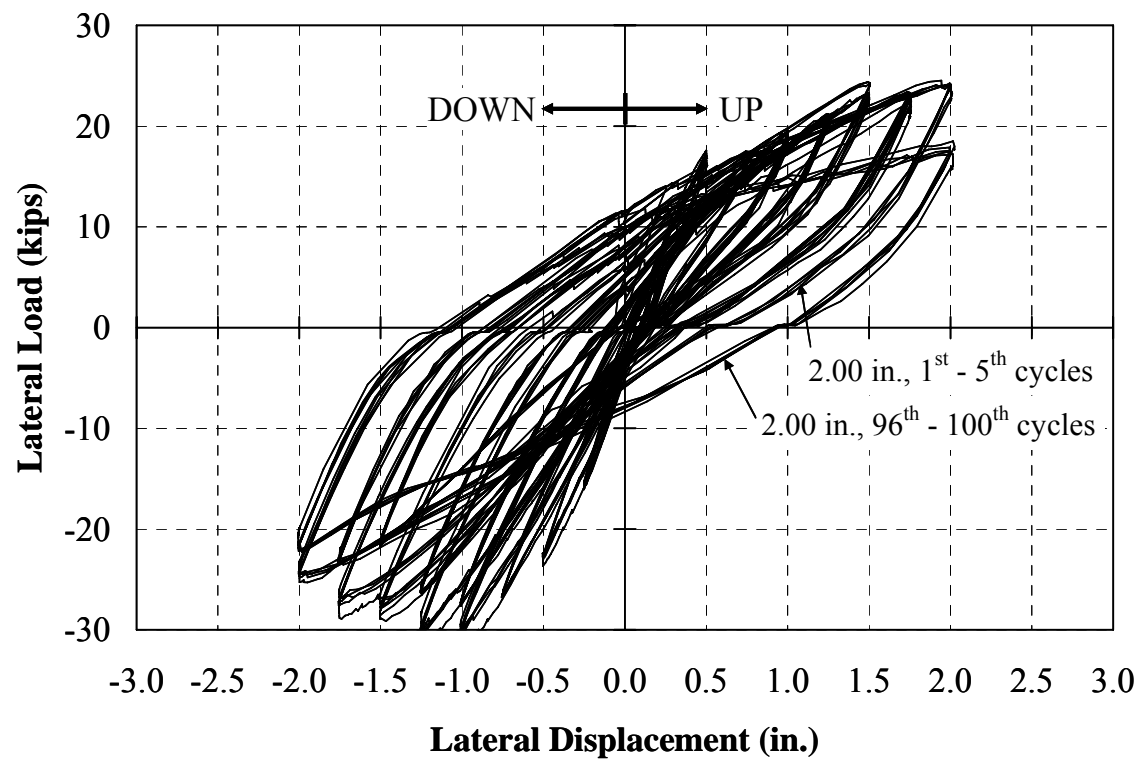

Figure I.133: Specimen 9 - Summary of Lateral Load-Deflection Curves

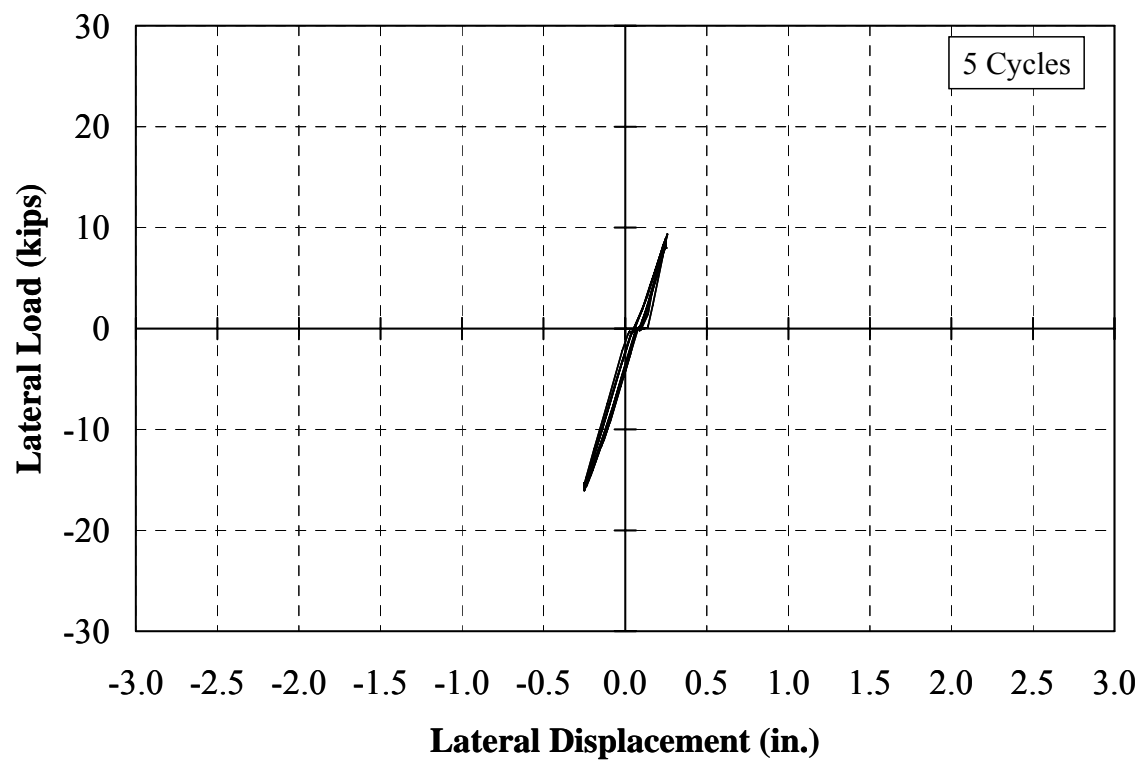

Figure I.134: Specimen 9 - Lateral Load-Deflection Response ( \pm 0.25 in.) 


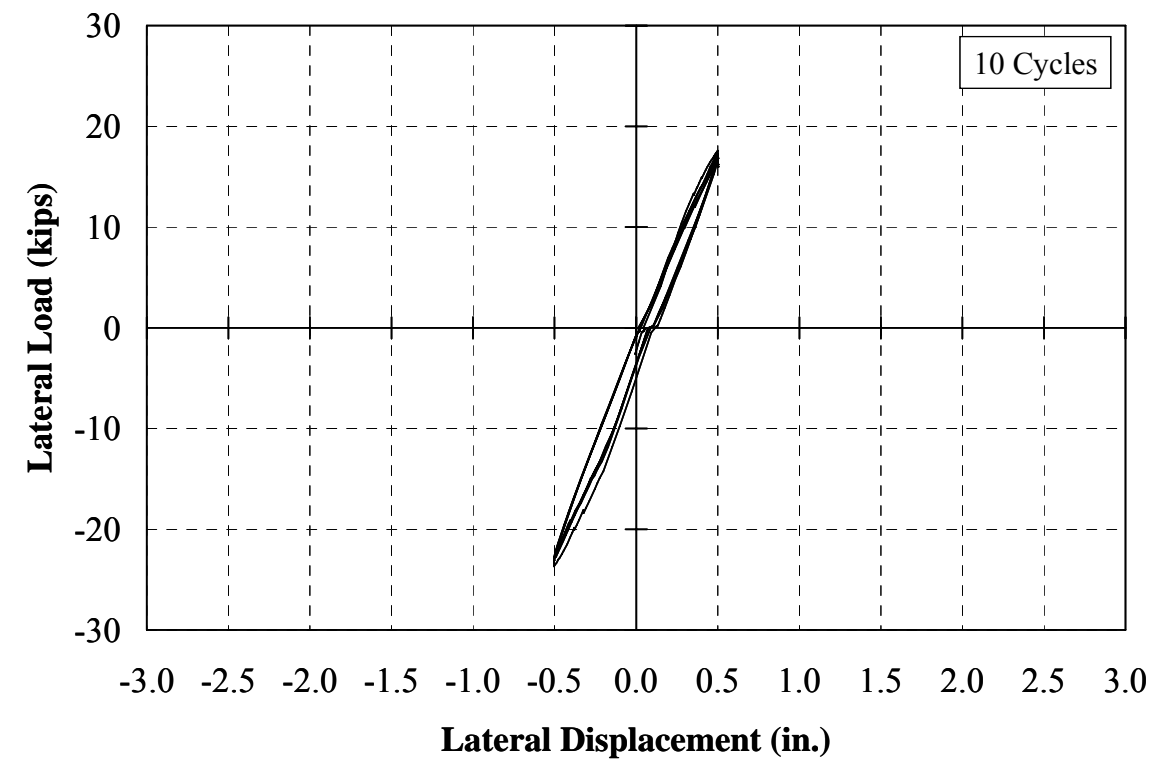

Figure I.135: Specimen 9 - Lateral Load-Deflection Response ( \pm 0.50 in.)

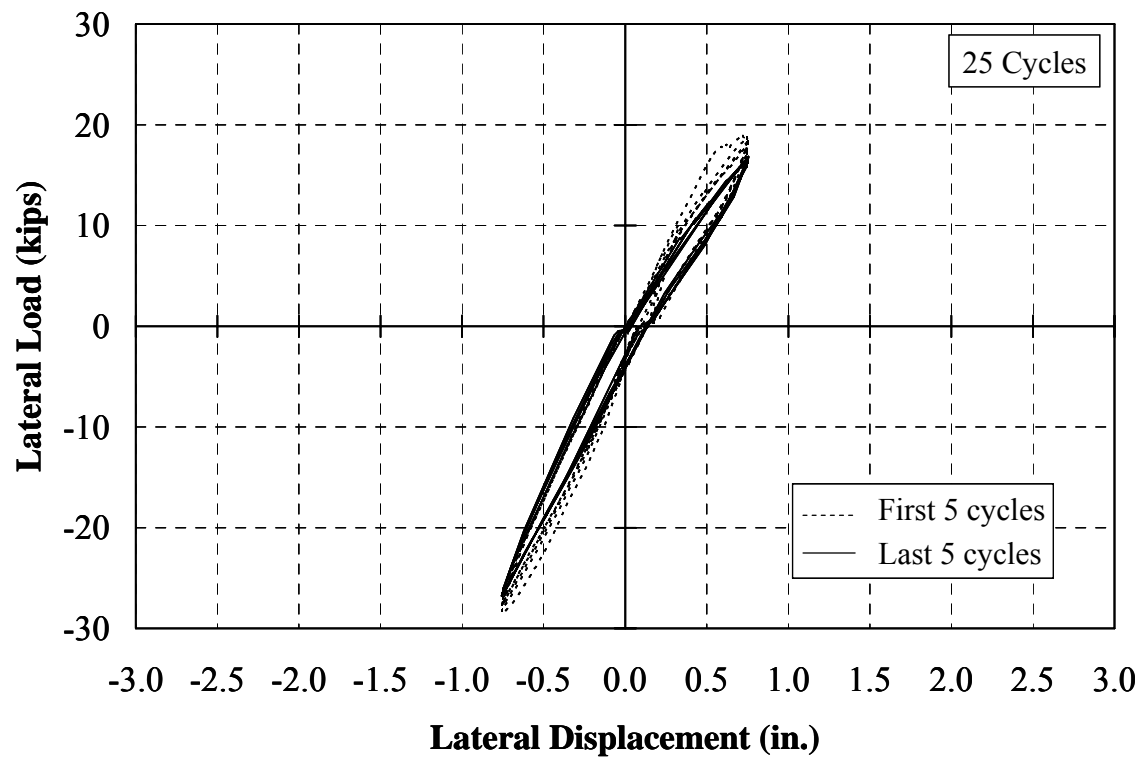

Figure I.136: Specimen 9 - Lateral Load-Deflection Response ( \pm 0.75 in.) 


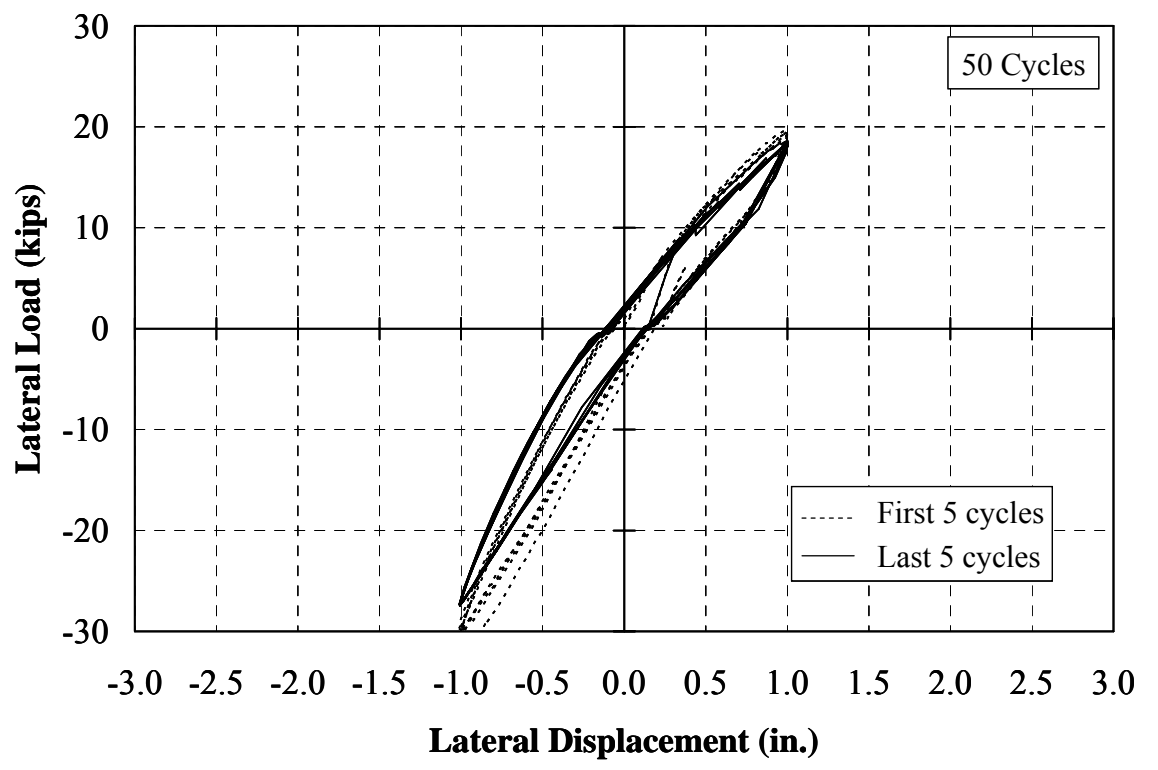

Figure I.137: Specimen 9 - Lateral Load-Deflection Response ( \pm 1.00 in.)

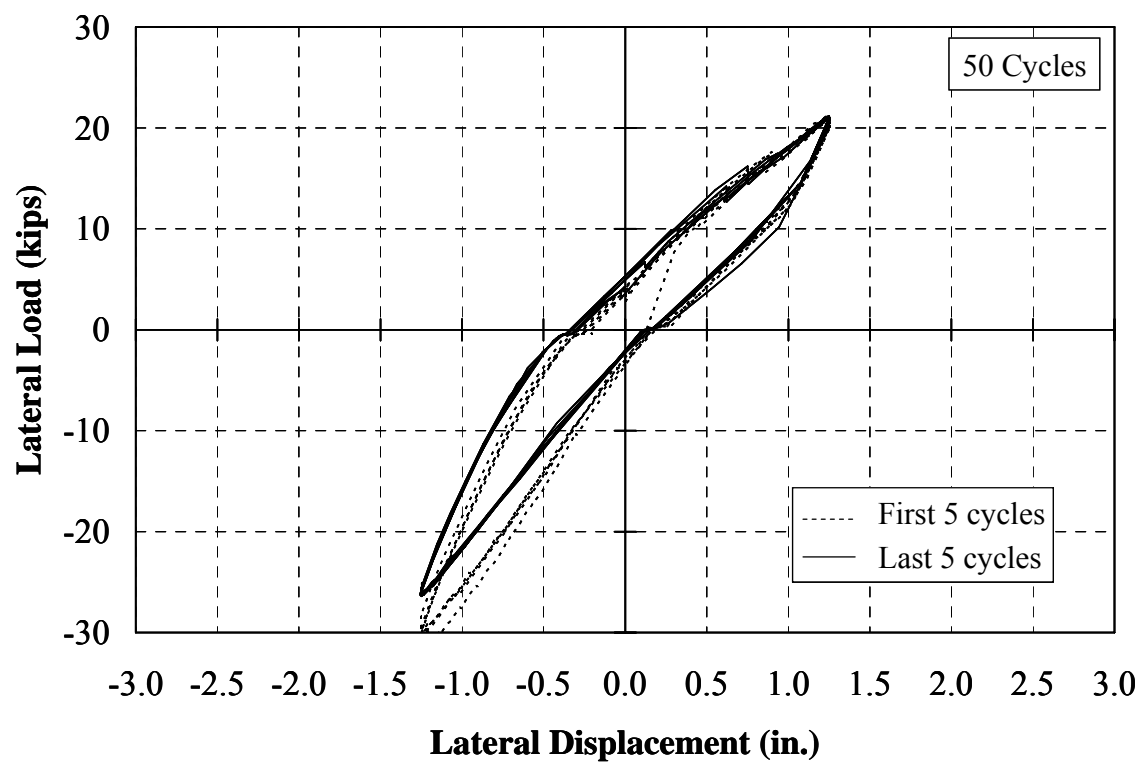

Figure I.138: Specimen 9 - Lateral Load-Deflection Response ( \pm 1.25 in.) 


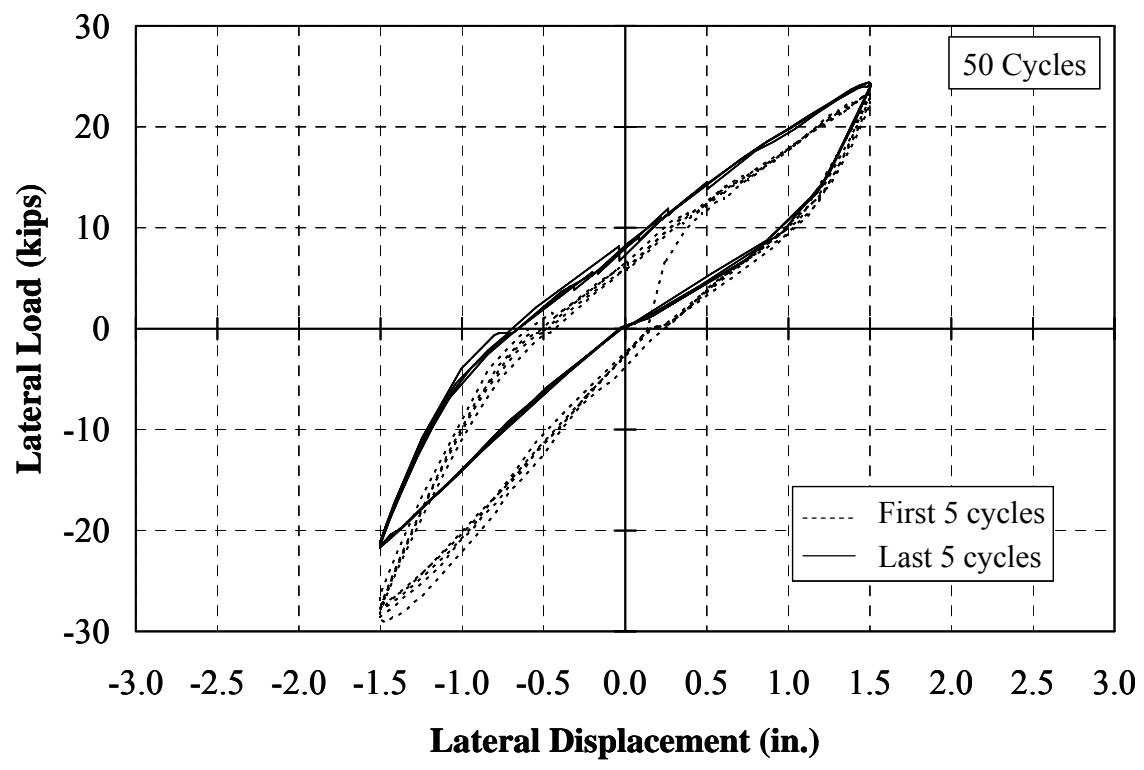

Figure I.139: Specimen 9 - Lateral Load-Deflection Response ( \pm 1.50 in.)

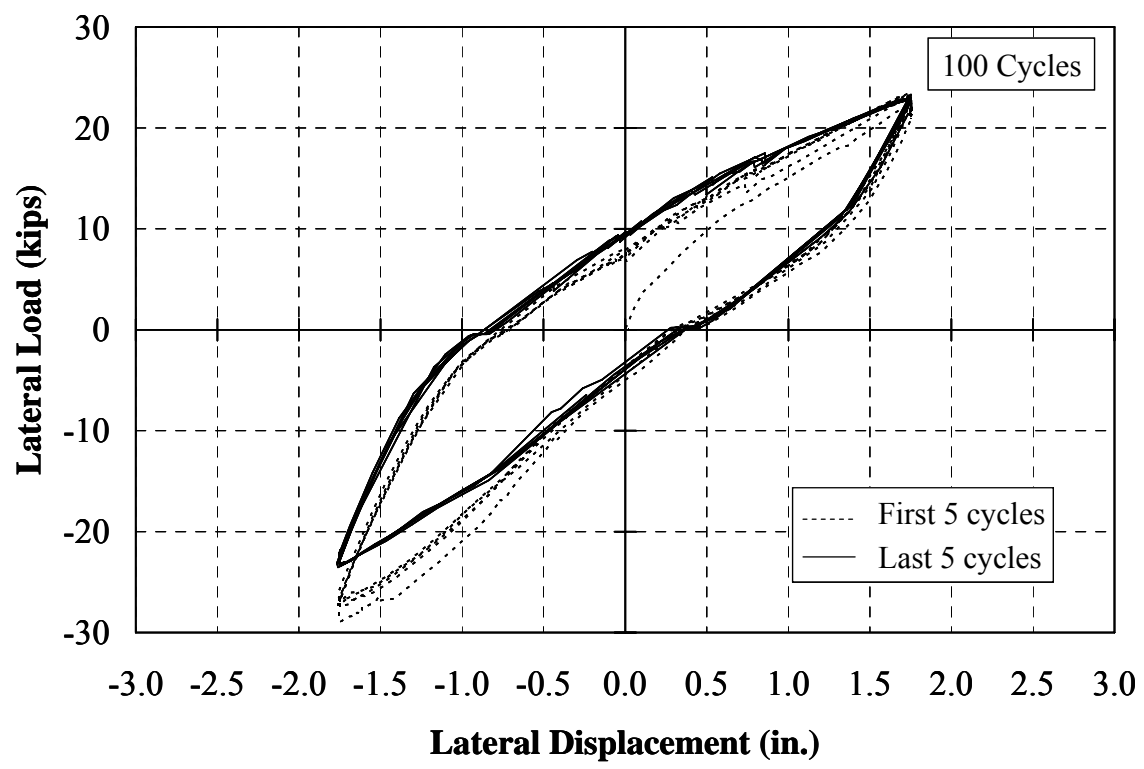

Figure I.140: Specimen 9 - Lateral Load-Deflection Response ( \pm 1.75 in.) 


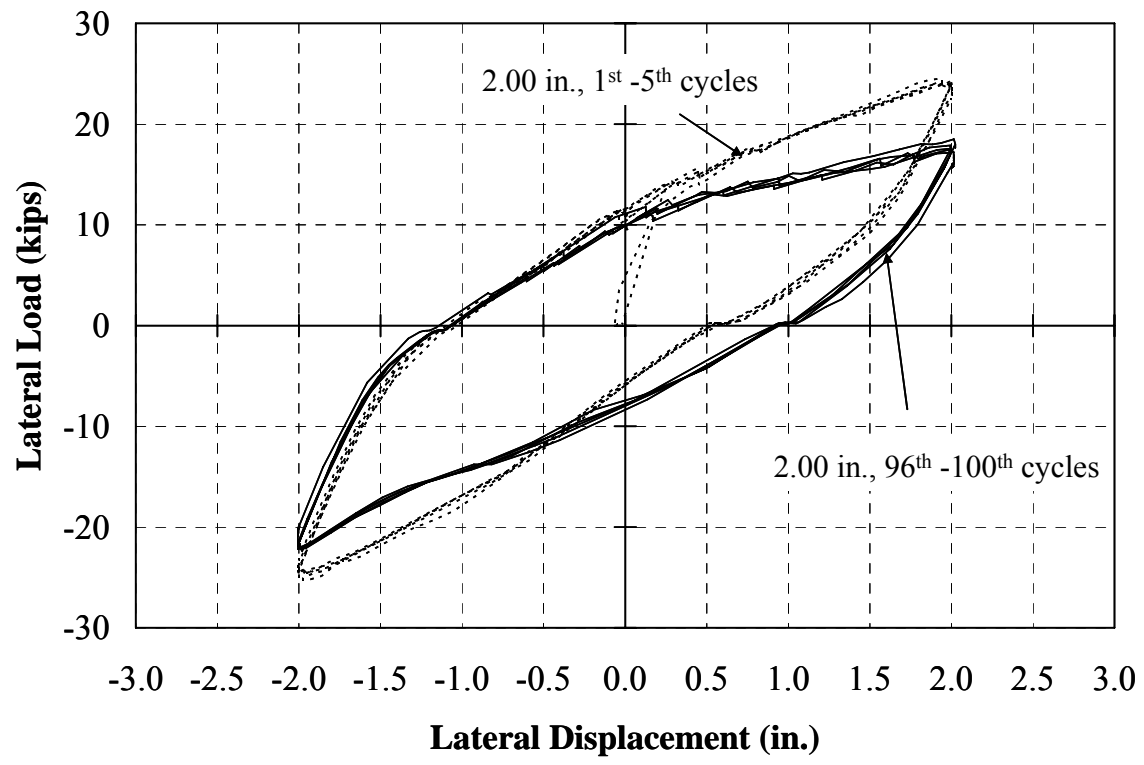

Figure I.141: Specimen 9 - Lateral Load-Deflection Response ( \pm 2.00 in.) 
APPENDIX J

MOMENT-CURVATURE ANALYSIS AND LOAD-DEFLECTION ANALYSIS 


\section{Appendix J: Moment-Curvature Analysis and Load-Deflection Analysis}

\section{Moment-Curvature Analysis}

Steel and concrete sections are divided into a numbers of slices as illustrated in

Figure J.1.

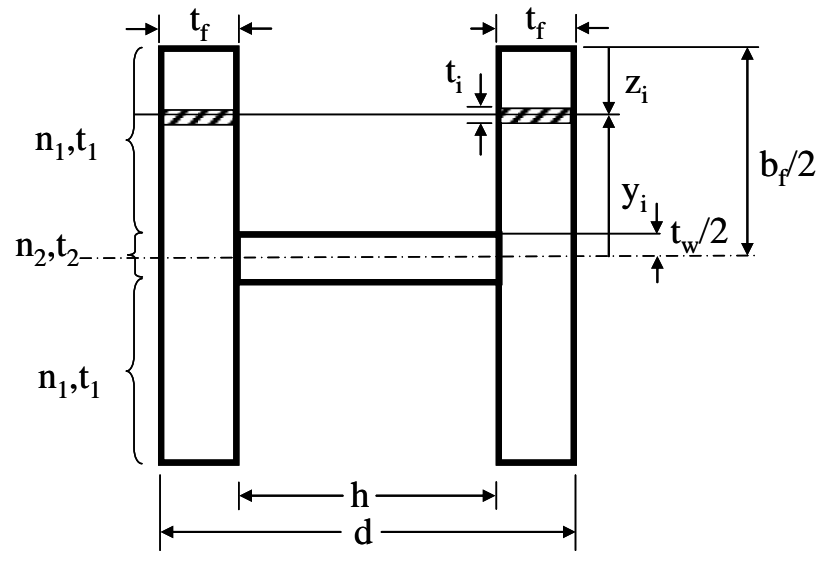

(a) H Pile, Weak Axis Bending

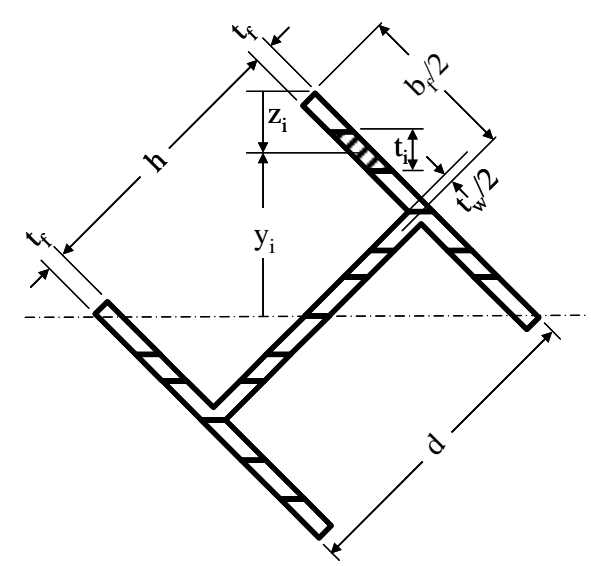

(b) $\mathrm{H}$ Pile, $45^{\circ}$ Axis Bending

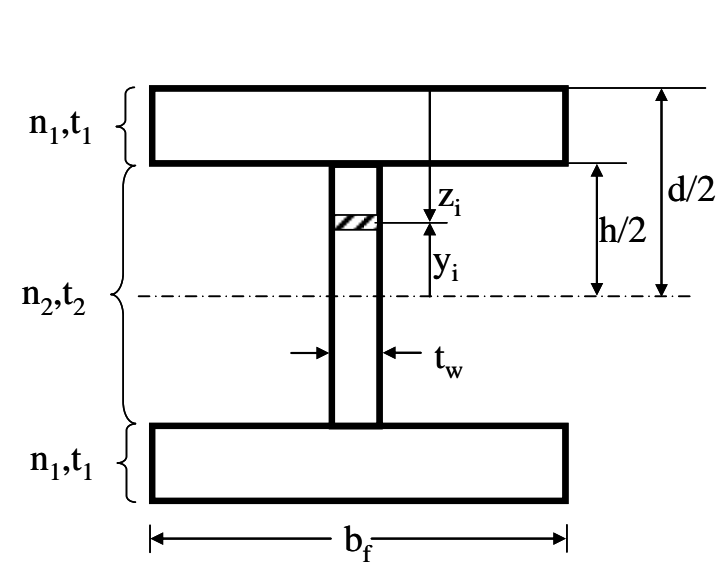

(c) H Pile, Strong Axis Bending

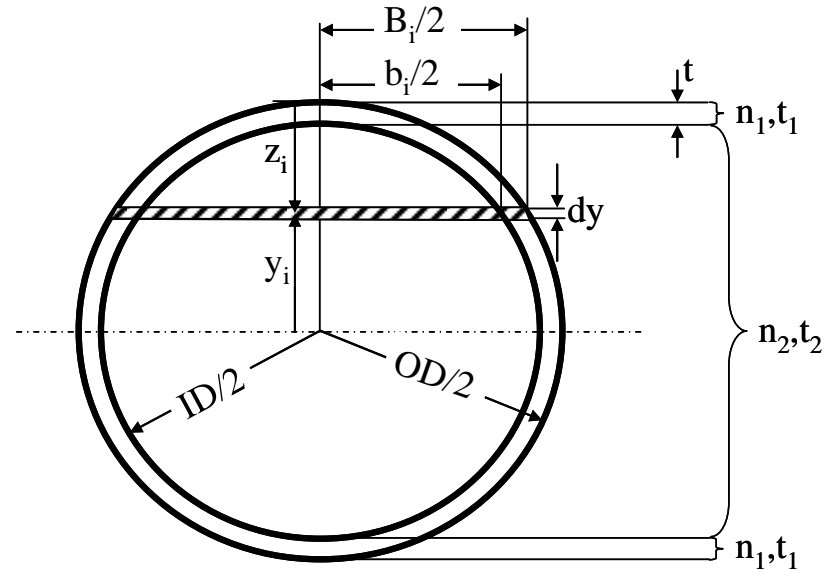

(d) CFT Pile

Figure J.1: Fiber Discretization 
where:

$$
\begin{aligned}
& \mathrm{n}_{1}, \mathrm{t}_{1}=\text { number and thickness of segment } 1 \text {, respectively. } \\
& \mathrm{n}_{2}, \mathrm{t}_{2}=\text { number thickness of segment } 2 \text {, respectively. }
\end{aligned}
$$

$$
\mathrm{n}_{1}=\left\{\begin{array}{l}
1000 ; \text { weak-axis bending pile } \\
40 ; \text { strong-axis bending pile } \\
40 ; \text { CFT pile }
\end{array}\right.
$$$$
\mathrm{n}_{2}=\left\{\begin{array}{l}
\text { 80; weak-axis bending pile } \\
\text { 2000; strong-axis bending pile } \\
\text { 2000; CFT pile }
\end{array}\right.
$$$$
\mathrm{t}_{1}=\left\{\begin{array}{l}
\frac{\left(\mathrm{b}_{\mathrm{f}}-\mathrm{t}_{\mathrm{w}}\right)}{2 \mathrm{n}_{1}} ; \text { weak-axis bending pile } \\
\frac{(\mathrm{d}-\mathrm{h})}{2 \mathrm{n}_{1}}=\frac{\mathrm{t}_{\mathrm{f}}}{\mathrm{n}_{1}} ; \text { strong-axis bending pile } \\
\frac{(\mathrm{OD}-\mathrm{ID})}{2 \mathrm{n}_{1}} ; \text { CFT pile }
\end{array}\right.
$$

$$
\mathrm{t}_{2}=\left\{\begin{array}{l}
\frac{\mathrm{t}_{\mathrm{w}}}{\mathrm{n}_{2}} ; \text { weak-axis bending pile } \\
\frac{\mathrm{h}}{\mathrm{n}_{2}} ; \text { strong-axis bending pile } \\
\frac{\mathrm{ID}}{\mathrm{n}_{2}} ; \text { CFT pile }
\end{array}\right.
$$

One can note that for $45^{\circ}$ axis pile bending, the pile was divided into 12 slices.

The area, $\mathrm{A}_{\mathrm{si}}$, and centroid, $\mathrm{y}_{\mathrm{i}}$, of each slice were determined using AutoCAD program.

$\mathrm{z}_{\mathrm{i}} \quad=$ distance measured from the top fiber to the centroid of the slice $\mathrm{i}^{\text {th }}$

$$
\mathrm{z}_{\mathrm{i}}=\left\{\begin{array}{l}
0 ; \mathrm{i}=0 \\
\frac{\mathrm{t}_{1}}{2}+(\mathrm{i}-1) \mathrm{t}_{1} ; \mathrm{i} \leq \mathrm{i} \leq \mathrm{n}_{1} \\
\mathrm{n}_{1} \mathrm{t}_{1}+\frac{\mathrm{t}_{2}}{2}+\left(\mathrm{i}-\mathrm{n}_{1}-1\right) \mathrm{t}_{2} ; \mathrm{n}_{1}<\mathrm{i} \leq \mathrm{n}_{1}+\mathrm{n}_{2} \\
\mathrm{n}_{1} \mathrm{t}_{1}+\mathrm{n}_{2} \mathrm{t}_{2}+\frac{\mathrm{t}_{1}}{2}+\left(\mathrm{i}-\mathrm{n}_{1}-\mathrm{n}_{2}-1\right) \mathrm{t}_{1} ; \mathrm{n}_{1}+\mathrm{n}_{2}<\mathrm{i} \leq 2 \mathrm{n}_{1}+\mathrm{n}_{2} \\
2 \mathrm{n}_{1} \mathrm{t}_{1}+\mathrm{n}_{2} \mathrm{t}_{2} ; \mathrm{i}=2 \mathrm{n}_{1}+\mathrm{n}_{2}+1
\end{array}\right.
$$


$\mathrm{y}_{\mathrm{i}}=$ distance measured from the centroidal axis of the section to the centroid of the $\mathrm{i}^{\text {th }}$ slice; $\mathrm{y}_{\mathrm{i}}=\mathrm{D} / 2-\mathrm{z}_{\mathrm{i}}$

$\mathrm{t}_{\mathrm{i}}=$ thickness of the $\mathrm{i}^{\text {th }}$ slice

$\mathrm{b}_{\mathrm{f}}, \mathrm{t}_{\mathrm{f}} \quad=$ flange width and thickness of $\mathrm{H}$ pile, respectively

$\mathrm{d}=$ depth of $\mathrm{H}$ pile

$\mathrm{h}, \mathrm{t}_{\mathrm{w}} \quad=$ web depth and thickness of $\mathrm{H}$ pile, respectively

ID, OD = inner diameter and outer diameter, respectively

$\mathrm{b}_{\mathrm{i}} \quad=$ width of the $\mathrm{i}^{\text {th }}$ slice

For $\mathrm{H}$ piles bending about their weak and strong axes:

For weak axis bending, $\mathrm{b}_{\mathrm{i}}=\left\{\begin{array}{l}\mathrm{d} ; 0 \leq\left|\mathrm{y}_{\mathrm{i}}\right|<\frac{\mathrm{t}_{\mathrm{w}}}{2} \\ \mathrm{zt}_{\mathrm{f}} ; \frac{\mathrm{t}_{\mathrm{w}}}{2} \leq\left|\mathrm{y}_{\mathrm{i}}\right| \leq \frac{\mathrm{b}_{\mathrm{f}}}{2}\end{array}\right.$

For strong axis bending, $\mathrm{b}_{\mathrm{i}}=\left\{\begin{array}{l}\mathrm{t}_{\mathrm{w}} ; 0 \leq\left|\mathrm{y}_{\mathrm{i}}\right|<\frac{\mathrm{h}}{2} \\ \mathrm{~b}_{\mathrm{f}} ; \frac{\mathrm{h}}{2} \leq\left|\mathrm{y}_{\mathrm{i}}\right| \leq \frac{\mathrm{d}}{2}\end{array}\right.$

For CFT piles:

$$
\begin{aligned}
& \mathrm{B}_{\mathrm{i}}=2 \sqrt{\left(\frac{\mathrm{OD}}{2}\right)^{2}-\mathrm{y}_{\mathrm{i}}^{2}} ; \mathrm{b}_{\mathrm{i}}=2 \sqrt{\left(\frac{\mathrm{ID}}{2}\right)^{2}-\mathrm{y}_{\mathrm{i}}^{2}} ; 0 \leq\left|\mathrm{y}_{\mathrm{i}}\right| \leq \frac{\mathrm{ID}}{2} \\
& \text { Steel ring width }=\left\{\begin{array}{l}
\mathrm{B}_{\mathrm{i}}-\mathrm{b}_{\mathrm{i}} ; 0 \leq\left|\mathrm{y}_{\mathrm{i}}\right|<\frac{\mathrm{ID}}{2} \\
\mathrm{~B}_{\mathrm{i}} ; \frac{\mathrm{ID}}{2} \leq\left|\mathrm{y}_{\mathrm{i}}\right| \leq \frac{\mathrm{OD}}{2}
\end{array}\right.
\end{aligned}
$$

Concrete core width $=b_{i}$

The strains of the steel slice, $\varepsilon_{\mathrm{si}}$, and of concrete slice, $\varepsilon_{\mathrm{ci}}$, can be evaluated according Equations J-1 and J-2, respectively: 


$$
\begin{gathered}
\varepsilon_{\mathrm{si}}=\left(\frac{\mathrm{c}-\frac{\mathrm{d}_{\mathrm{p}}}{2}+\mathrm{y}_{\mathrm{i}}}{\mathrm{c}}\right) \cdot \varepsilon_{\mathrm{t}} \\
\varepsilon_{\mathrm{ci}}=\left\{\begin{array}{l}
\left(\frac{\mathrm{c}-\frac{\mathrm{d}_{\mathrm{p}}}{2}+\mathrm{y}_{\mathrm{i}}}{\mathrm{c}}\right) \cdot \varepsilon_{\mathrm{t}} ; \mathrm{z}_{\mathrm{i}} \leq \mathrm{c} \\
0 ; \mathrm{z}_{\mathrm{i}}>\mathrm{c}
\end{array}\right.
\end{gathered}
$$

where:

$$
\begin{array}{ll}
\varepsilon_{\mathrm{t}} & =\text { strain at the top fiber of the section; } \\
\mathrm{c} & =\text { distance from the neutral axis to the top fiber of the section; } \\
\mathrm{d}_{\mathrm{p}} & =\text { flange width, } \mathrm{b}_{\mathrm{f}} \text {, of } \mathrm{H} \text { section bending about weak axis, or } \\
\mathrm{d}_{\mathrm{p}} & =\text { depth, } \mathrm{d} \text {, of } \mathrm{H} \text { section bending about strong axis, or } \\
\mathrm{d}_{\mathrm{p}} & =\text { outer diameter, OD, for circular pipe section }
\end{array}
$$

Hence, for a given strain profile, the stresses can be determined for each slice using the steel and concrete models in Section 7.2. The total axial load, P, and the total bending moment, $\mathrm{M}$, on the section can be calculated as follows:

$$
\begin{gathered}
P=\sum_{i=1}^{n} f_{s i} \cdot A_{s i}+\sum_{i=1}^{n} f_{c i} \cdot A_{c i} \\
M=\sum_{i=1}^{n} f_{s i} \cdot A_{s i} \cdot y_{i}+\sum_{i=1}^{n} f_{c i} \cdot A_{c i} \cdot y_{i}
\end{gathered}
$$

where:

$$
\begin{aligned}
& \mathrm{n}=\text { number of segments. } \\
& \mathrm{y}_{\mathrm{i}} \quad \text { distance measured from the centroidal axis of the section to the } \\
& \quad \text { centroid of the } \mathrm{i}^{\text {th }} \text { slice, in. } \\
& \mathrm{f}_{\mathrm{Si}} \quad=\text { stress of steel in the } \mathrm{i}^{\text {th }} \text { slice, } \mathrm{ksi} \\
& \mathrm{f}_{\mathrm{Ci}} \quad=\text { stress of concrete in the } \mathrm{i}^{\text {th }} \text { slice, } \mathrm{ksi} \\
& \mathrm{A}_{\mathrm{Si}} \quad=\text { area of steel in the } \mathrm{i}^{\text {th }} \text { slice, in. }{ }^{2} \\
& \mathrm{~A}_{\mathrm{Ci}} \quad=\text { area of concrete in the } \mathrm{i}^{\text {th }} \text { slice, } \text { in. }^{2} \\
& \mathrm{P} \quad=\text { axial load, kips. }
\end{aligned}
$$


$\mathrm{M} \quad$ = bending moment corresponding to the fixed end moment.

\section{Load -Deflection Relationship}

\section{Notations:}

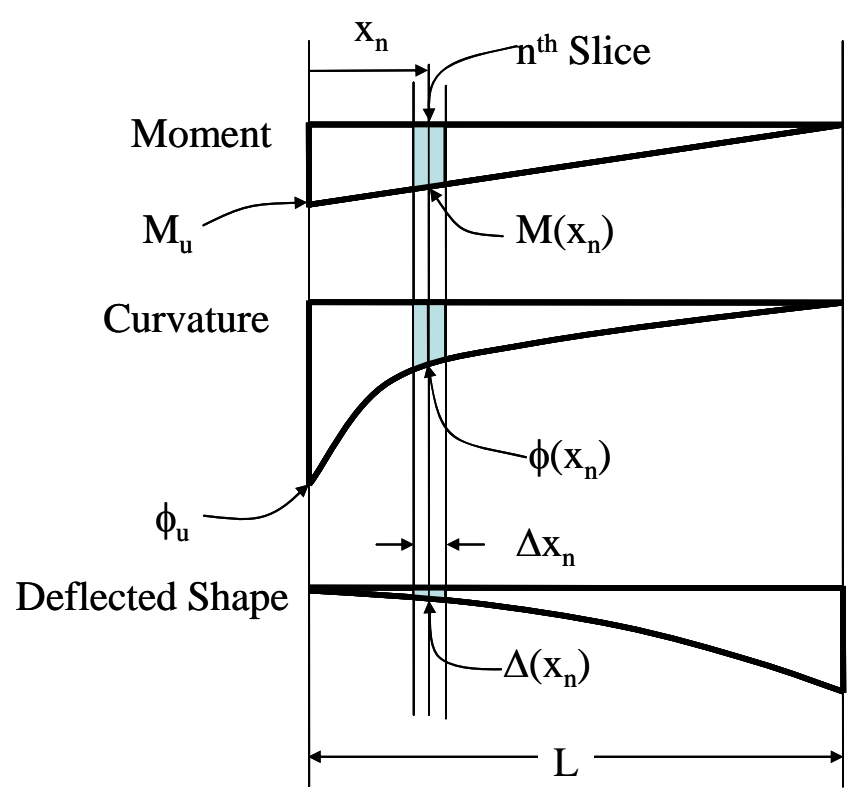

Figure J.2: Notations 
where:

$$
\begin{aligned}
& \mathrm{n} \quad=\text { number of slices (the } 0^{\text {th }} \text { slice to the } \mathrm{n}^{\text {th }} \text { slice). } \\
& \mathrm{L} \quad=\text { distance from the fixed end to the applied load, taken as } 60 \mathrm{in} \text {. } \\
& \mathrm{x}_{\mathrm{n}} \quad=\text { location of the } \mathrm{n}^{\text {th }} \text { slice, measured from the fixed end to the centroid of } \\
& \text { the slice, in. } \\
& \mathrm{H} \quad=\text { lateral load, kips. } \\
& \mathrm{P} \quad=\text { axial load, kips. } \\
& \mathrm{M}_{\mathrm{u}} \quad=\text { ultimate moment, ft-kips. } \\
& \phi_{\mathrm{u}} \quad=\text { ultimate curvature corresponding to } \mathrm{M}_{\mathrm{u}} \text {, rad/in.. } \\
& \mathrm{M}_{\mathrm{i}-1}\left(\mathrm{x}_{\mathrm{n}}\right)=\text { first-order moment at the location } \mathrm{x}_{\mathrm{n}} \text {, ft-kips. } \\
& \phi_{\mathrm{i}-1}\left(\mathrm{x}_{\mathrm{n}}\right)=\text { curvature at the location } \mathrm{x}_{\mathrm{n}}, \mathrm{rad} / \mathrm{in} \text {. } \\
& \Delta_{\mathrm{i}-1}\left(\mathrm{x}_{\mathrm{n}}\right)=\text { deflection, in. } \\
& \Delta x_{n} \quad=\text { thickness of the slice } n^{\text {th }} \text {, in. }
\end{aligned}
$$

\section{Algorithm:}

For a given moment-curvature relationship, the tip displacement can be calculated by the following algorithm:

1. Determine the ultimate moment, $\mathbf{M}_{\mathrm{u}}$, (or the plastic moment, $\mathrm{M}_{\mathrm{p}}$ ) from the given moment-curvature relationship.

2. Determine the corresponding lateral load, $\mathrm{H}=\mathrm{M}_{\mathrm{u}} / \mathrm{L}$.

3. Calculate the moment at the location $x$ from the fixed end, $M(x)$, along the pile length and define $M_{i-1}(x)=\frac{M_{u}}{L}\left(L-x_{n}\right)$ or $M_{i-1}\left(x_{n}\right)=H\left(L-x_{n}\right)$, ft-k.

4. Determine the corresponding curvature along the pile length, $\phi_{\mathrm{t}-1}(\mathrm{x})$, from a given moment-curvature relationship as illustrated in Figure J.3. 


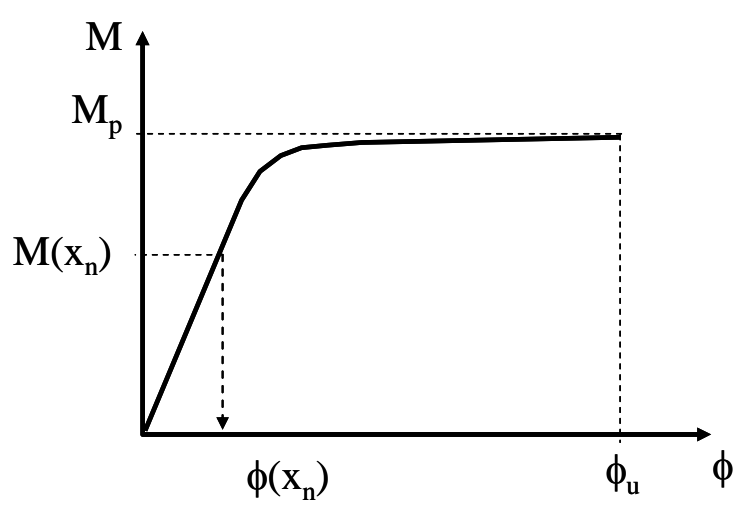

Figure J.3: Curvature Interpolation

5. Calculate the summation of the moment of area under the curvature curve; that is the lateral displacement at the pile tip. The first-order deflections,

$\Delta_{\mathrm{i}-1}\left(\mathrm{x}_{\mathrm{n}}\right)$ along the length of the cantilever pile can be calculated as follow:

First-order deflection $=($ Curvature $)($ Thickness of slice $)($ Moment arm $)$

$$
\Delta_{\mathrm{i}-1}\left(\mathrm{x}_{\mathrm{n}}\right)=\sum_{\mathrm{j}=1}^{\mathrm{n}} \phi_{\mathrm{i}-1}\left(\mathrm{x}_{\mathrm{j}}\right) \cdot \Delta \mathrm{x}_{\mathrm{j}} \cdot \mathrm{x}_{\mathrm{j}}
$$

For example, as shown in Figure J.4, the deflection at location $\mathrm{x}_{4}$ can be determined as follows:

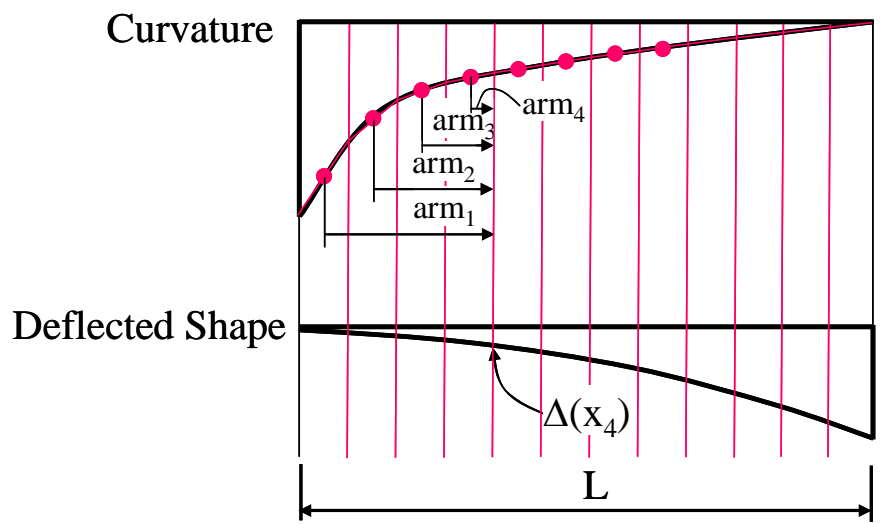

Figure J.4: Deflection Calculation Example

$$
\begin{gathered}
\Delta\left(\mathrm{x}_{4}\right)=\phi\left(\mathrm{x}_{1}\right) \Delta \mathrm{x}_{1}\left(\mathrm{x}_{1}\right)+\phi\left(\mathrm{x}_{2}\right) \Delta \mathrm{x}_{2}\left(\mathrm{x}_{2}\right)+\ldots+\phi\left(\mathrm{x}_{4}\right) \Delta \mathrm{x}_{4}\left(\mathrm{x}_{4}\right) \\
\text { and } \Delta \mathrm{x}_{1}=\Delta \mathrm{x}_{2}=\ldots=\Delta \mathrm{x}_{4}=\Delta \mathrm{x}
\end{gathered}
$$

